\title{
FLOODS IN IOWA: \\ Stage and Discharge
}

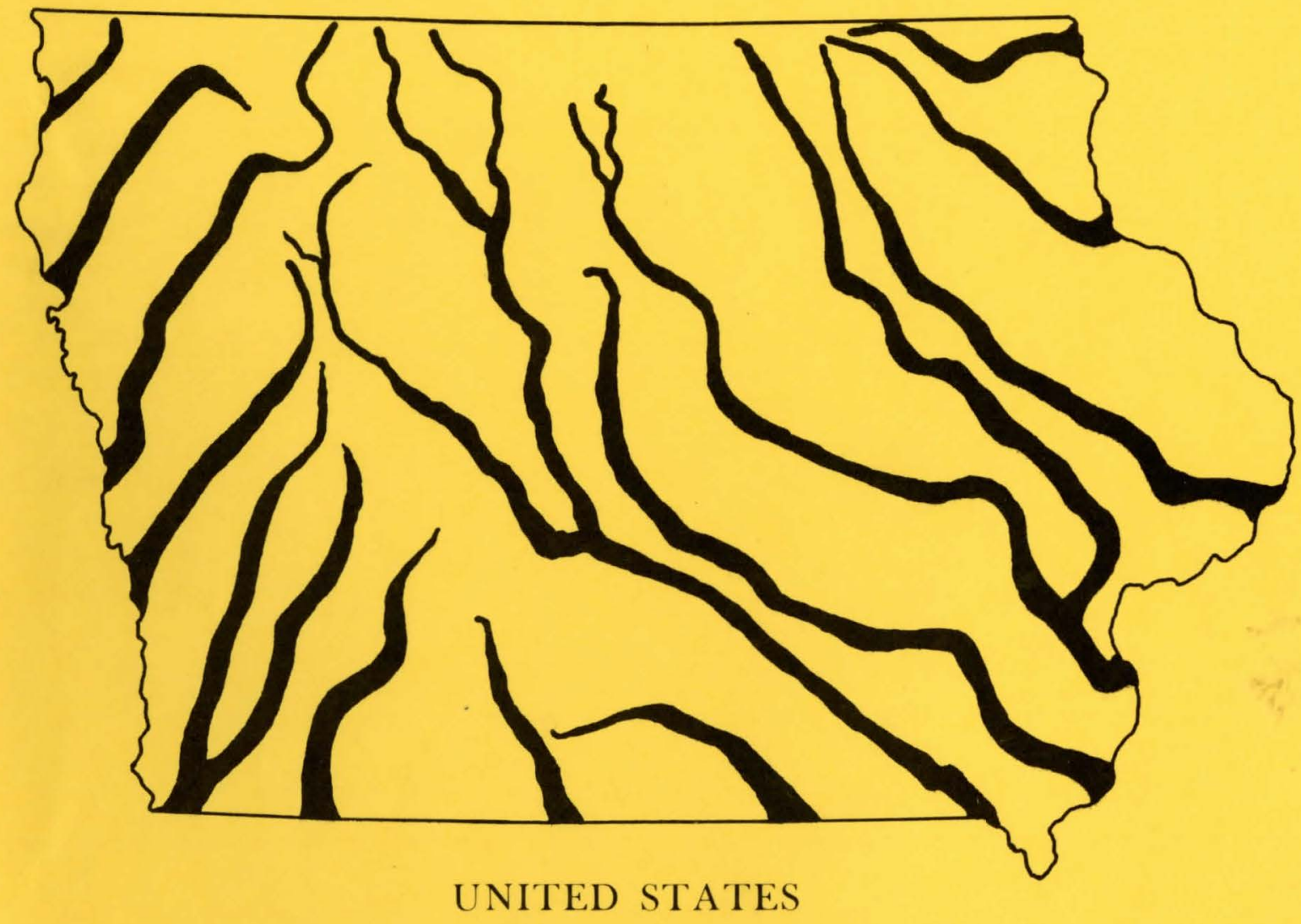

DEPARTMENT OF THE INTERIOR

GEOLOGICAL SURVEY

Prepared in cooperation with the

HIGHWAY RESEARCH BOARD

HIGHWAY DIVISION

IOWA DEPARTMENT OF TRANSPORTATION

Open-file Report

lowa City, lowa

November 1976

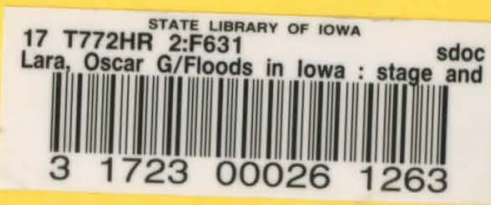





\author{
United states \\ Department of the Interior \\ Geological survey
}

\author{
FLOODS IN IOWA: \\ Stage and Discharge \\ by
}

Oscar G. Lara

\begin{abstract}
Prepared in Cooperation with the
HIGHWAY RESEARCH BOARD

HIGHWAY DIVISION

IOHA DEPARTHENT OF TRANSPORTATION
\end{abstract}

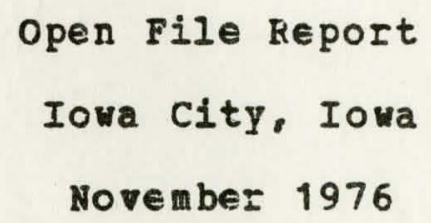

STATE LIBRARY COMMISSION OF IOWA Historical Building

DES MOINES, IOWA 50319 


$$
\begin{gathered}
\text { Department of Transportation } \\
\text { State House, Des Moines }
\end{gathered}
$$

Commissioners:

$$
\begin{aligned}
& \text { Robert R. Rigler, Chairman, New Hampton } \\
& \text { Stephen Garst, Vice Chairman, Coon Rapids } \\
& \text { Donald Gardner, Cedar Rapids } \\
& \text { Milliam F. MCGrath, Melrose } \\
& \text { Barbara Dunn, Des Moines } \\
& \text { Stanley Schoelerman, Spencer }
\end{aligned}
$$$$
\text { Allan Thoms, Dubuque }
$$

Victor Preisser, State Director of Transportation, Des Moines 


\section{CONTENTS}

Stations in downstream order,

Page

for which records are published....................... IV

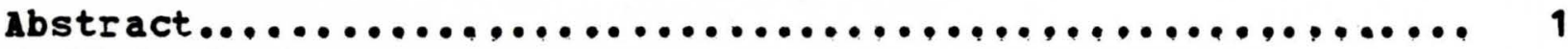

Introduction ..................................... 1

Arrangement of station Data....................... 3

Glossary of Technical Terms....................... 5

Factors for converting English onits to International

International system onits........................ 7

Index...........................................687 
STATIONS, IN DORNSTREAM ORDER,

FOR WHICH RECORDS ARE POBLISHED

\section{IISSISSIPPI_RIVER_BA}

NORTHEAST IOHA STREAMS TRIBUTARY TO MISSISSIPPI RIVER

$05-3875.00$

$05-3880.00$

$05-3884.00$

$05-3885.00$

$05-3886.00$

$05-3887.00$

$05-3890.00$

$05-3895.00$

$05-4115.30$

$05-4116.00$

$05-4116.50$

$05-4117.00$

$05-4120.00$

$05-4125.00$

$05-4143.50$

$05-4144.00$

$05-4144.50$

$05-4145.00$

$05-4146.00$

$05-4170.00$

$05-4175.00$

$05-4175.30$

$05-4175.90$

$05-4177.00$

$05-4185.00$

$05-4205.00$
Opper Iowa River at Decorah.

Opper Iowa River near Decorah.

He xford Creek near Harpers Ferry...............

Paint Creek at Waterville......................

Paint Croek near Waterville....................

Little paint Creek tributary nr Watervilie.......

Yellow River at Ion.........................

Mississippi River at McGregor.................

370

TORKEY RIVER BASIN

North Branch Turkey River near Crasco..........4 406 Turkey River at spillville................... 610 Crane Creek tributary near Saratoga............. 103 Crane Creek near Lourdes........................ 101 Turkey River at Elkader......................6 604 Turkey River at Garber....................... 605

LITTLE HAQUOKETA RIVER BASIH

Little Haquoketa River near Graf............... 289 MF Iittle Maquoketa $R$ near Rickardsville......... 342 NF Little Maquoketa $R$ near Rickardsville........4 413 Little Maquoketa River near Durango............ 285 Iittle Maquoketa River tríbutary at Dubuque....... 283

\section{MAQUOKETA RIVER BASIN}

Maquoketa River near Manchester.............. 329

Maquoketa River near Delhi.................... 328

Pl um Creek at EarIville...................... 462

kitty Creek nea = Langworthy................. 278

Bear Creek near wonmouth.................... 9

Maquoketa River near Maquoketa................ 334

Mississippi River at Clinton................ 358 
STATIONS, IN DONNSTREAM ORDER--CONTINUED

\section{MA PSIPINICON RIVER BASIN}

Page

$05-4205.60$

$05-4206.00$

Wapsipinicon River near Elma..................

633

Little Napsipinicon $R$ tributary nr Riceville..... 316

Iittle Waspipinicon River near Acme.............

Iittle Wapsipinicon River at Elma...............

$05-4206.40$

little vapsipinicon River near New Hampton........

East Fork Wapsipinicon $R$ near New Hampton........

Little apsipinicon River near oran.............

Buck Creek near Oran........................

Harter creek near Independence..................

Wa psipinicon River at Independence.............

Pine Creek tributary near Winthrop.............

Pine creek near Winthrop.....................

Pine Creek tributary No. 2 at Minthrop..........

Wapsipinicon River a.t Central City.............

Wapsipinicon River at stone City...............

Buffalo Creek above Winthrop..................

Buffalo Creek near Hinthrop...................

Wapsipinicon River near DeWitt.................

310

312

314

190

315

54

237

636

455

453

457

626

641

55

57

$05-4216.00$

$05-4220.00$

\section{IOWA RIVER BASIN}

$05-4485.00$

$05-4486.00$

$05-4487.00$

$05-4488.00$

$05-4489.00$

$05-4490.00$

$05-4495.00$

$05-4495.00$

$05-4512.00$

$05-4512.50$

$05-4513.50$

$05-4514.50$

$05-4517.00$

$05-4518.00$

$05-4519.00$

$05-4519.55$

$05-4520.00$

$05-4522.00$

$05-4525.00$

$05-4530.00$

$05-4531.00$

$05-4532.00$

$05-4536.00$

$05-4537.00$

$05-4537.50$

$05-4538.50$

$05-4539.00$
Mest Branch Iowa River near klemme............. East Branch Iowa River above Hayfield............. East Branch Iowa River near Hayfield............. East Branch Iowa River near Garner.............. East Branch Iowa River tributary nI Garner....... East Branch Iowa River neaI Klemme.............. Iowa River near Rowan.......................

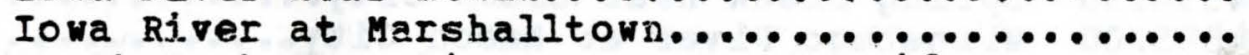
South Fork Iowa River near New Providence......... Beaver Creek near Eldora...................... Honey Creek at Bangor.......................

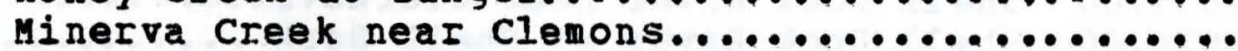
Timber Creek near Marshalltown................. Deer Creek at Toledo.......................... Richland Creek near Haven...................... stein Creek near clutier....................... Salt Creek near Elberon....................... Walnut Creek near Hartwick.................... Iowa River near Belle Plaine................... Big Bear Creek at Ladora..................... Iowa River at Marango....................... Price Creek at Amana........................ Rapid Creek below Morse........................ Rapid Creek tributary No. 4 near Oasis............ Rapid Creek southwest of Morse.................. Rapid Creek tributary No. 3 near Oasis........... Rapid Creek tributary near oasis...............
653

168

170

164

166

172

267

261

549

15

238

357

600

112

496

582

505

622

247

23

258

467

484

494

486

492

490 


\section{IOWA RIVER BASIN (CONTINOED)}

$05-4539.50$

$05-4540.00$

$05-4543.00$

$05-4545.00$

$05-4550.00$

$05-4550.10$

$05-4551.00$

$05-4551.40$

$05-4551.50$

$05-4552.00$

$05-4552.10$

$05-4552.30$

$05-4552.80$

$05-4553.00$

$05-4553.50$

$05-4555.00$

05-4555. 50

$05-4557.00$

05- 4574.40

$05-4575.00$

05- 4577.00

05-4580.00

05-4585.00

05-4585. 60

05-4585.00

$05-4590.00$

$05-4590.10$

$05-4594.90$

$05-4595.00$

05- 4601.00

05-4605.00

05-4615.00

05-4620.00

$05-4627.50$

$05-4630.00$

$05-4630.90$

$05-4635.00$

05- 4640.00

05-4641.30

05-4641.33

05-4641.37

$05-4643.18$

05-4645.00

$05-4645.60$

05-4646. 40

05-4648. 80

05- 4650.00

05-4651.50

05-4655.00
Rapid Creek tributary near Iowa City.............

Rapid Creek near Iowa City...................

Clear creek near Coralvilie....................

Iowa River at Iowa City.......................

Ralston Creek at Iowa City.....................

So uth Branch Ralston Creek at Iowa City..........

01 d Mans Creek near Iowa City...................

North English River near Montezuma..............

North English River near Montezuma...............

North English River near Guernsey...............

North English River at Guernsey.................

Deep River at Deep Rivar....................

South English River tributary nr Barnes City......

South English River near Barnes City.............

South English River trib. No. 2 near Montezuma...

English River at Kalona.....................

Bulgers Run near Riverside....................

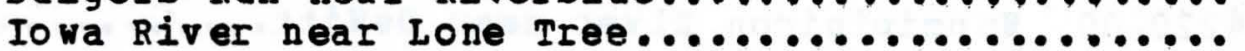

Deer Creek nr Carpenter........................

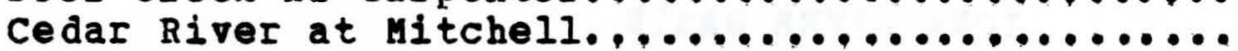

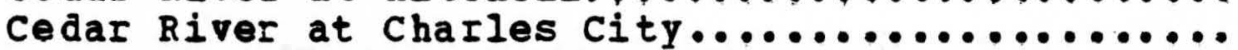

Little Cedar River near Ionia..................

Cedar River at Janesville......................

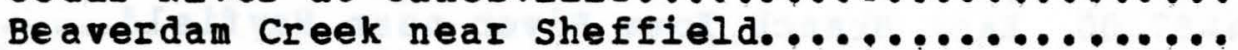

West Fork Cedar River at Finchford................

Shell Rock River neaI Northwood.................

Elk Creek at Kensett.........................

Spring Creek near Mason City...................

Hinnebago River at Mason City..................

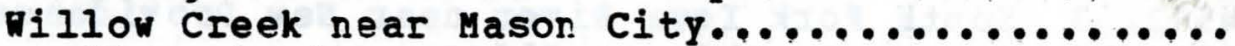

Shell Rock River at Marble Rock.................

She 11 Rock River near Clarksville...............

Shell Rock River at shell Rock...................

Beaver Creek tributary near Aplington............

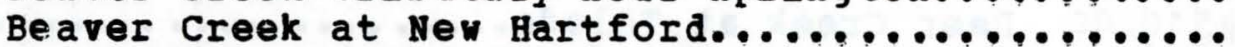

Black Hawk Creek at Grundy Center...............

Black Hawk Creek at Hudson......................

Cedar River at Waterloo......................

Fourmile Creek near Iincoln....................

Half Mile Creek near Gladbrook..................

Fourmile Creek near Traer......................

East Blue Creek at Center Point.................

Cedar River at Cedar Rapids....................

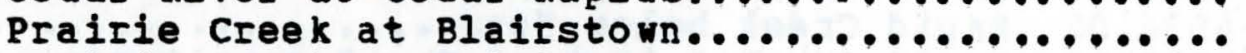

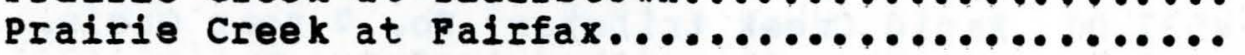

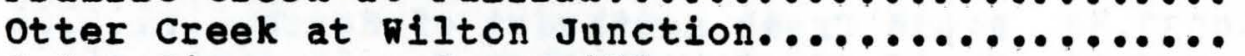

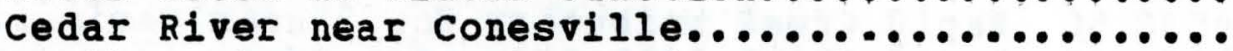

North Fork Iong Creek at Ainsworth..............

Iowa River at kapello........................
Page

488

479

97

250

474

538

431

410

411

408

407

110

543

541

545

207

58

256

111

83

69

279

77

22

655

516

205

576

681

680

513

511

519

40

84

221

230

223

163

63

463

464

439

72

415

271 
STATIONS, IN DONNSTREAM ORDER--CONTINUED

\section{SK ONK RIVER BASIN}

Page

$05-4698.60$

$05-4699.90$

$05-4700.00$

$05-4705.00$

$05-4710.00$

$05-4712.00$

$05-4715.00$

$05-4722.90$

$05-4723.90$

$05-4724.45$

$05-4725.00$

$05-4730.00$

$05-4733.00$

$05-4735.00$

$05-4740.00$

Mud Lake Drainage ditch 71 in Jewe11............

Keigley Branch near story city................

So uth skunk River near Ames...................

Squaw Creek at Ames..........................

South Skunk River below Squaw Cr. near Ames......

Indian Creek near Mingo.......................

South skunk River near oskaloosa...............

Sugar Creek near searsboro....................

Middle Creek near Lacey........................

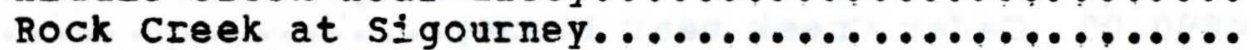

North Skunk River near Sigourney...............

Sk unk River at Coppock.......................

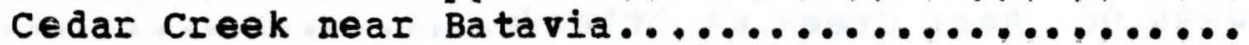

Big Creek near Mount Plea sant..................

Skunk River at Augusta....................

391

277

559

579

565

244

569

586

341

499

426

528

59

30

$05-4745.00$

Mississippi River at Keokuk.................

364

\section{DES MOINES RIVER BASIN}

$05-4765.00$

$05-4767.50$

Des Moines River at Estherville...............

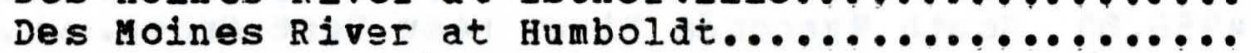

East Fork Des Moines River near Burt..............

East Fork Des Moines River at Dakota City........ Lizard Creek near clare....................... Des Moines River at Fort Dodge..................

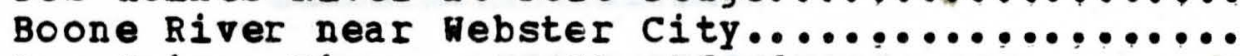

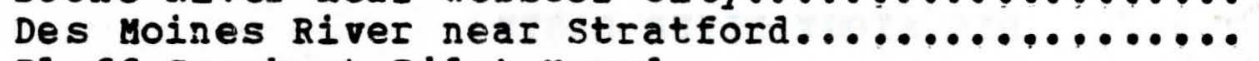

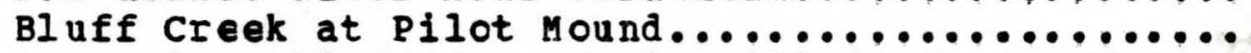
Des Moines River near Saylorvilile.............. Beaver Creek at Beaver......................

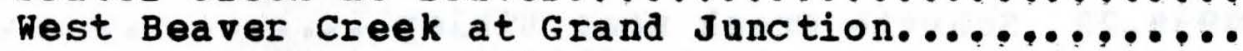
Beaver Creek near Grimes....................... Des Moines River at Des Moines.................. Big Cedar Creek near Varina.................... North Raccoon River near Sac City................ North Raccoon River near Jefferson............... Hardin Creek at Farnhamville.................. Ha ppy Run at Churdan........................ Hardin Creek near Farlin..................... East Fork Hardin Creek near Paton............... East Fork Hardin Creek near Churdan............. Middle Raccoon River at Panora................... South Raccoon River at Redfield................. Raccoon River at Van Heter...................... Malnut Creek at Des Moines....................... 123 130 175 178 318

126 44 148 43 146 15 649 16 113 28 $42 \mathrm{C}$ 416 235 231 233 . $05-4829.50$ $05-4830.00$ $05-4836.00$ $05-4840.00$ $05-4845.00$ $05-4848.00$ 05-4855.00

186

183

344

550

468

621

118 
STATIONS IN DOHNSTREAM ORDER--CONTINUED

\section{DES MOINES RIVER BASIN (CONTINOED)}

$05-4856.40$

$05-4860.00$

$05-4864.90$

$05-4874.70$

$05-4876.00$

$05-4878.00$

$05-4879.80$

$05-4880.00$

$05-4885.00$

$05-4890.00$

$05-4891.50$

$05-4893.50$

$05-4894.90$

$05-4895.00$

$05-4905.00$

$05-4910.00$

$05-4943.00$

05-4945.00

$05-4956.00$

Fourmile Creek at Des Moines....................

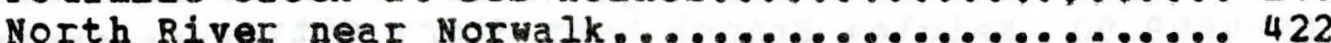

Middle River near Indianola................. 347

South River near dckworth..................... 554

South White Breast Creek near osceola........... 572

White Breast Creek at Lucas..................... 675

White Breast Creek near Dallas................ 671

White Breast Creek near Knoxville.............. 673

Des Moines River near Tracy.................... 154

Cedar Creek near Bussey...................... 60

Little Muchakinock Creek at Oskaloosa........... 291

South Avery Croek near Blakesburg............. 537

Bear Creek at ottumwa...................... 12

Des Moines River at cttumwa................... 140

Des Moines River at Keosauqua.................. 133

sugar Creek near Keokuk................... 583

FOX RIVER BASIN

Fox River at Bloomfield...................... 225

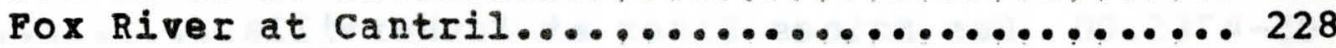

South yaconda River near west Grove.......... 574

\section{MISSOURI RIVER_BA}

\section{BIG SIOUX RIVER BASIN}

$06-4832.70$

$06-4834.10$

$06-4934.20$

$06-4835.30$

$06-4834.40$

$06-4834.50$

$06-4834.60$

$06-4835.00$

$06-4840.00$

$06-4855.00$

$06-4860.00$

$06-5998.00$

$06-5999.50$

$06-6000.00$
Rock River at Rock Rapids....................

otter Creek north of Sibley....................

Schutte Creek near sibley......................

otter Creek at sibley.........................

Dawson Creek near sibley.....................

Magner Creek near Ashton......................

Otter Creek near Ashton........................

Rock River near Rock Valley....................

Dry Creek at Hawarden........................

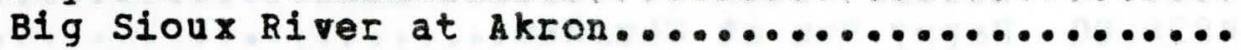

Missouri River at sioux city..................

383

\section{PERRY CREEK BASIN}

Perry Creek near Merrill.................... 447

Perry Creek near Hinton...................... 445

Perry Creek at 38th street, Sioux City......... 449 
FLOYD RIVER BASIN

Page

$06-6001.00$

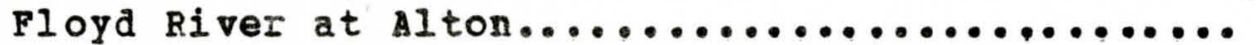

213

$06-6003.00$

West Branch Floyd River near struble.............

650

$06-6005.00$

Floyd River

215

\section{WEST FORK DITCH BASIN}

$06-6020.00$

$06-6021.90$

06-6024.00

$06-6039.20$

$06-6051.00$

$06-6053.40$

$06-6056.00$

$06-6057.50$

$06-6058.50$

$06-6058.90$

06-6066.00

06-6067.00

$06-6067.90$

06-6070.00

$06-6072.00$

$06-6073.00$

06-6075.00

$06-6085.00$

$06-6095.00$

$06-6096.00$

$06-6100.00$

$06-6105.00$

$06-6105.20$

$06-8060.00$

$06-8070.00$
West Fork ditch at Holly Springs...............659

Elliot Creek at lawton...................... 206

Monona-Harrison ditch near Turin............. 386

\section{LITTLE SIOUX EIVER EASIN}

Loon Creek near orleans.....................

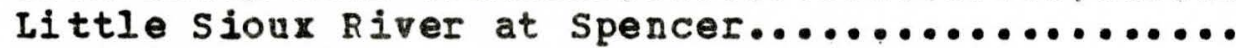

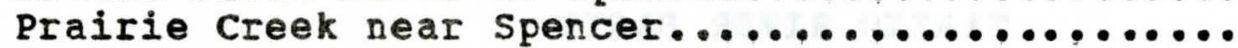
Little Sioux River at Gillett Grove..............

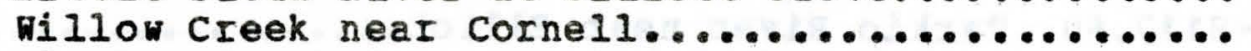
Iittle Sioux River at Iinn Grove.................

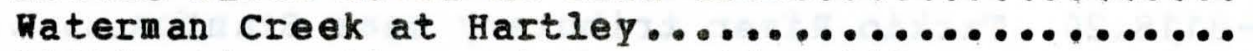
Little Sioux River at Correctionville............

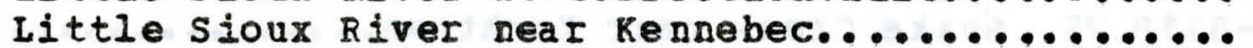
Maple Creek near Alta........................

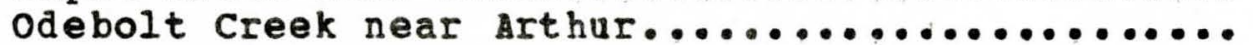

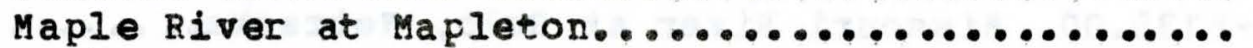
Maple River at Turin........................... Little Sioux River Dear Turin 00000000000000000000 322 306 466 299 678 305 643 294 301 323 429 324 307

SOLDIER RIVER BASIN

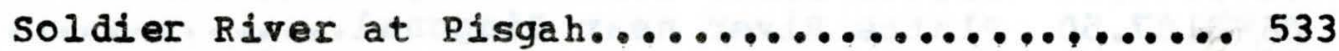
BOYER RIVER BASIN

Boyer River at Logan........................ 49 Willow Creek near logan..................... 679

Missouri River at Omaha, Nebraska............ 377 SOUTHWEST IOWA STREAMS TRIBUTARY TO THE MISSCURI RIVER

Indian Creek at Council Bluffs................ 241

Mosquito Creek near Earling.................. 389

Wa ubonsie Creek near Bartlett................ 644

Missouri River at Nebraska City, Nebraska....... 373 
STATIONS, IN DONNSTREAM ORDER--CONTINOED

NISHNABOTNA RIVER BASIN

Page

662

$06-8974 \cdot 10$

West Nishnabotna River at Hancock.............

243

$06-8074.70$

Indian Creek near Emerson.....................

351

$06-8077.20$

Middle silver Creek near Avoca................

Middle Silver Creek near Oakland..................

353

$06-8077.80$

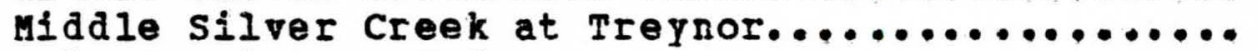

355

$06-8080.00$

Mule Creek near Malvern......................

392

$06-8082.00$

Spring Valley Creek near Tabor................

Mest Nishnabotna River at Randolph..............

577

$06-8085.00$

$06-8090.00$

Davids Creek near Hamlin.......................

665

$06-8092.10$

East Nishnabotna River near Atlartic.............

East Nishnabotna River at Red Oak...............

Nishnabotna River above Hamburg...............

105

191

$06-8095.00$

$06-8100.00$

TARKIO RIVER BASIN

$06-8117.60$

$06-8118.00$

$06-8118.20$

$06-8118.40$

$06-8118.75$

$06-8120.00$

Tarkio River near Elliot.....................

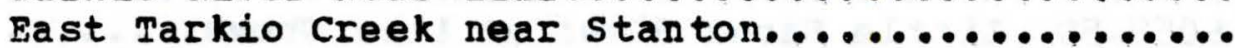

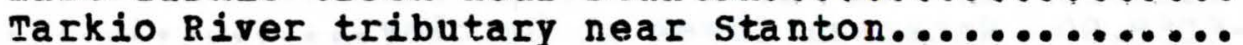

Tarkio River at stanton........................

Snake Creek near Yorktown......................

Tarkio River at Blanchard.....................

588

200

593

590

532

$06-8135.00$

Missouri River at Rulo, Nebraska.

381

NODAWAY RIVER BASIN

$06-8170.00$

$06-8185.98$

Nodaway River at Clarinda....................

Platte River near Stringtown.................

Platte River near Diagonal....................

400

$06-8187.50$

$06-8191.10$

$06-8191.90$

Middle Branch 102 River near Gravity..............

East Fork 102 River nI Bedford................

\section{GRAND RIVER BASIN}

$06-8979.50$

$06-8980.00$

Elk Creek near Decatur City..................

202

Thompson River at Davis City..................

\section{CHARITON RIVER BASIN}

$06-9034.00$

$06-9035.00$

$06-9037.00$

$06-9038.90$

$06-9039.00$

$06-9039.90$

$06-9040.00$

$06-9040.90$

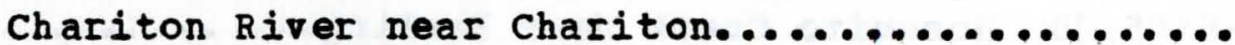

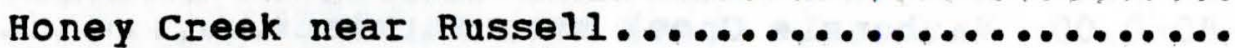

South Fork Chariton Fiver near Promise City.......

Chariton River near vdell.....................

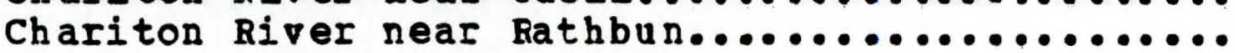

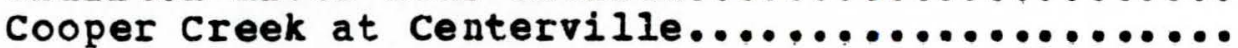

Chariton River near Centervilie................. 


\title{
FLOODS IN IONA:
}

\author{
Stage and Discharge \\ by \\ Oscar G. Lara
}

\begin{abstract}
This report presents station descriptions and tables of peak stages and discharges for 259 continuous and partial-record gaging stations all of which are located at or within the boundaries of Iowa.

Contained in this report are not only the data for the annual flood series for each gaging station but also for the partial-duration series at those stations for which they could be obtained.
\end{abstract}

\section{INT RODUCTION}

This report has been designed to present a summary of the recorded data concerning floods in Iowa.

In general, the tables of peak stages and discharges which are contained in this report have been compiled from the files of the 0.S. Geological survey. For those few instances in which other sources were used, acknowledgement of the source will be found in the "Remarks" paragraph of the station description. 
This report has been prepared in accordance with a cooperative agreement between the Highway Research Board, Highway Division, Iowa Department of Transportation and the U.S. Geological Survey. It supersedes an earlier version prepared by $\mathrm{Schwob}$ (1). Contained in this report are not only the annual flood series for each station, but also partial-duration series at those stations for which it could be obtained. To insure consistency in the compilation of these data, it has been necessary to formulate specific rules for preparing the tables of peak stages and discharges.

The more important of these rules are as follows:

1. Nithin each water year, the maximum momentary discharge must be listed, irrespective of its magnitude.

(a) In most cases the maximum gage height will occur simulaneously with the maximum discharge.

(b) Those cases in which the maximum gage height occurs as a result of an ice jam or other restricted flow condition and is presumed to be unrelated to the maximum discharge, the values are appropriately footnoted.

2. For those stations for which partial-duration series are prepared, a base discharge is determined such that it is expected to be equalled or exceeded on an average of

1. S̄chwob, H. H., 1966, Magnitude and Frequency of Iowa Floods: Iowa Highway Research Board Bull. No. 28, pt. II. 
about three to four times a year. The magnitude of this base for peaks is stated in the "Remarks" paragraph of the station description. For each complete water year of the station record, the peaks of independent floods which exceed the base, are recorded. Two flood peaks are considered independent if base flow (see glossary) is reached between them, or if they are more than 48 hours apart and the discharge of the trough between them is 25 percent or more below that of the lower peak.

Explanation of methods used in the computation of streamflow data is given in the annual reports titled "Water Resources Data for Iowa" published by the U.S. Geological survey.

\section{Arrangement of Station Data}

This report contains station descriptions and tables of peak stages and discharges for 259 continuous and partial-record gaging stations, all of which are located at or within the boundaries of Iowa.

In compliance with a request from the cooperator, the station data are arranged by station name in alphabetic order. This arrangement departs from the standard U.S. Geological survey system of presenting data by basin in a downstream order. For readers who prefer the latter, an index with the stations listed in downstream order is included in the report. For a detailed explanation of downstream order and the meaning of the station number, the reader is referred to the o.s. Geological survey annual reports titled "Water Resources Data for Iowa." 
of the data presented for the gaging stations, the station descriptions are self-explanatory. The data contained in the tables has been explained in the preceding section. statements are required, however, concerning datum of gage, bankfull and flood stage, and the arrangement of data by years.

In reference to datum of gage, the phrase "mean sea level" denotes "Sea Level Datum of $1929 "$ as used by the Topographic Division of the U.S. Geological survey, unless otherwise qualified.

Flood stage (see glossary) is listed for all stations for which it could be obtained. Bankfull stage (see glossary) is published for stations not having a flood stage available. There are a few stations for which neither of these data are available at this time. Flood stages were compiled from data supplied by the National Neather Service.

Concerning the arrangement by years, the annual flood series is composed of the highest discharge for each water year of record, water year being defined as the twelve-month pericd ending on september 30 of the stated year. In listing the flood events, each event is designated by its true calendar date, but the ovents are grouped into water-year units by inserting a blank line between the last event in one water year and the initial event in the following water year. Thus the annual flood series is obtained by selecting the highest discharge from each group rather than the highest discharge for each of the designated calendar years. 
The significance of the underlining in the tables is as follows:

1. A line under the "water year" column signifies a break or gap in the record of peaks.

2. A line beginning at the "date" column and continuing through the "discharge" column indicates a change in site and datum.

3. A line in the "date" and "discharge" columns indicates a change in site without a change in datum.

4. A line in the "gage height" column indicates a change in datum only.

No underlines are used for changes in site or datum if peaks have been adjusted to present conditions.

A glossary of selected technical terms and a table of factors for converting English units to International system Onits follows.

\section{Glossary of Technical Terms}

Base flow is the sustained or fair weather runoff. In most streams base runoff is composed largely of groundwater effluent. (Not to be confused with base for peaks).

Bannk refers to the margins of a channel. Banks are called right or left as viewed facing downstream or in the direction of flow.

Bankfull stage is the stage at which a stream first overflows the natural banks (see also flood stage). Bankfull stage is a hydraulic term, whereas flood stage implies damage).

Cubicic foot_per second $\left(\mathrm{ft}^{3} / \mathrm{s}\right)$ is the rate of discharge representing volume of 1 cubic foot passing a given point during 1 second and is equivalent to approximately 7.48 gallons per second or 448.8 gallons per minute or 0.02832 cubic metres per second.

Crest-stage gage is a device which will register the peak stage occurring between inspections of a gage. 
Discharge is the volume of water (or more broadly, total fluids) that passes a given point within a given period of time.

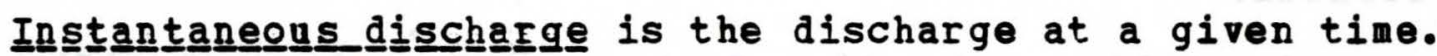

DÉainage area of a strea at a specified location is that area, measured in a horizontal plane, enclosed by a topographic divide from which direct surface runoff from precipitation normally drains by gravity into the stream above the specified point. Figures of drainage area given herein include all closed basins, or noncontributing areas, within the area unless otherwise noted.

Flood stage is the stage at which overflow of the natural banks of the stream begins to cause damage in the reach in which the elevation is measured (National Meather Service).

Gage height_(G.H.l is the water-surface elevation referred to some arbitrary gage datum. Gage height is often used interchangeably with the general term "stage", although gage height is more appropriate when used with a reading on a gage.

Gaqing station is a particular site on a stream, canal, lake, or reservoir where systematic observations of gage height and/or discharge are obtained. When used in connection with a discharge record, the term is applied only to those gaging stations where a continuous record of discharge is computed.

Partia-record station is a particular site where limited streamflow data are collected systematically over a period of years for use in hydrologic analyses.

Stage=discharge relation is the relation between gage height and the volume of water per unit of time, flowing in a channel. 


\section{Factors for converting English onits to International System (SI) Units}

The following factors may be used to convert the English units published herein to the International system of Units (SI).

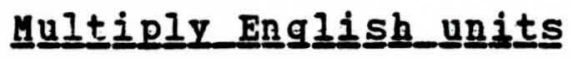

inches (in)

feet (ft)

miles (mi)
By

$-I \in n g t h-$

$$
\begin{aligned}
& 25.4 \\
& .3048 \\
& 1.609
\end{aligned}
$$

-Area -

acres

square miles (mi2)

4.047

2.590

-Volume-

gallons (gal)

cubic feet ( $\mathrm{ft}^{3}$ )

cfs-day (ft $3 / s-d a y)$

acre-feet (acre-ft)

cubic feet per second (ft $3 / s)$

-Flow-

\section{Toㅇobtain_sI units}

\author{
millimeters (mm) \\ meters (m) \\ kilometers $(\mathrm{km})$
}

square meters (m²)

square kilometers $\left(\mathrm{km}^{2}\right)$

$\begin{aligned} 0.003785 & \text { cubic meters }\left(\mathrm{m}^{3}\right) \\ .02832 & \text { cubic meters }\left(\mathrm{m}^{3}\right) \\ 2.447 & \text { cubic meters }\left(\mathrm{m}^{3}\right) \\ 1.233 & \text { cubic meters }\left(\mathrm{m}^{3}\right)\end{aligned}$

0.02832

cubic meters $p \in I$ second (m $3 / \mathrm{s})$

28.32 ubic decimeters per second $\left(d \mathrm{~m}^{3} / \mathrm{s}\right)$ 
Location.--Lat $42^{\circ 0} 2^{\prime 18 n,}$ I ong $90052 \cdot 59^{\prime \prime}$, In NE1/4 sE1/4 sec.31, T. 84 N.. R. 1 E.. Jackson County, on right bank 15 ft downstrean from briage cn county highvay. 1.6 niles upstream from Rat Run, 2.8 miles south of Monmouth, and 8.2 miles upstrean from nouth.

Drainage area.--61.3 sq ai.

Gage.-- Dater-stage recorder and concrete control. Datul of gage is 728.80 ft above mean sea level.

stage-discharge relation.--Defined by current-meter neasurements. Renarks.--Base for partial-duration series, 1,000 cfs.

Peak stáges and_dischargages

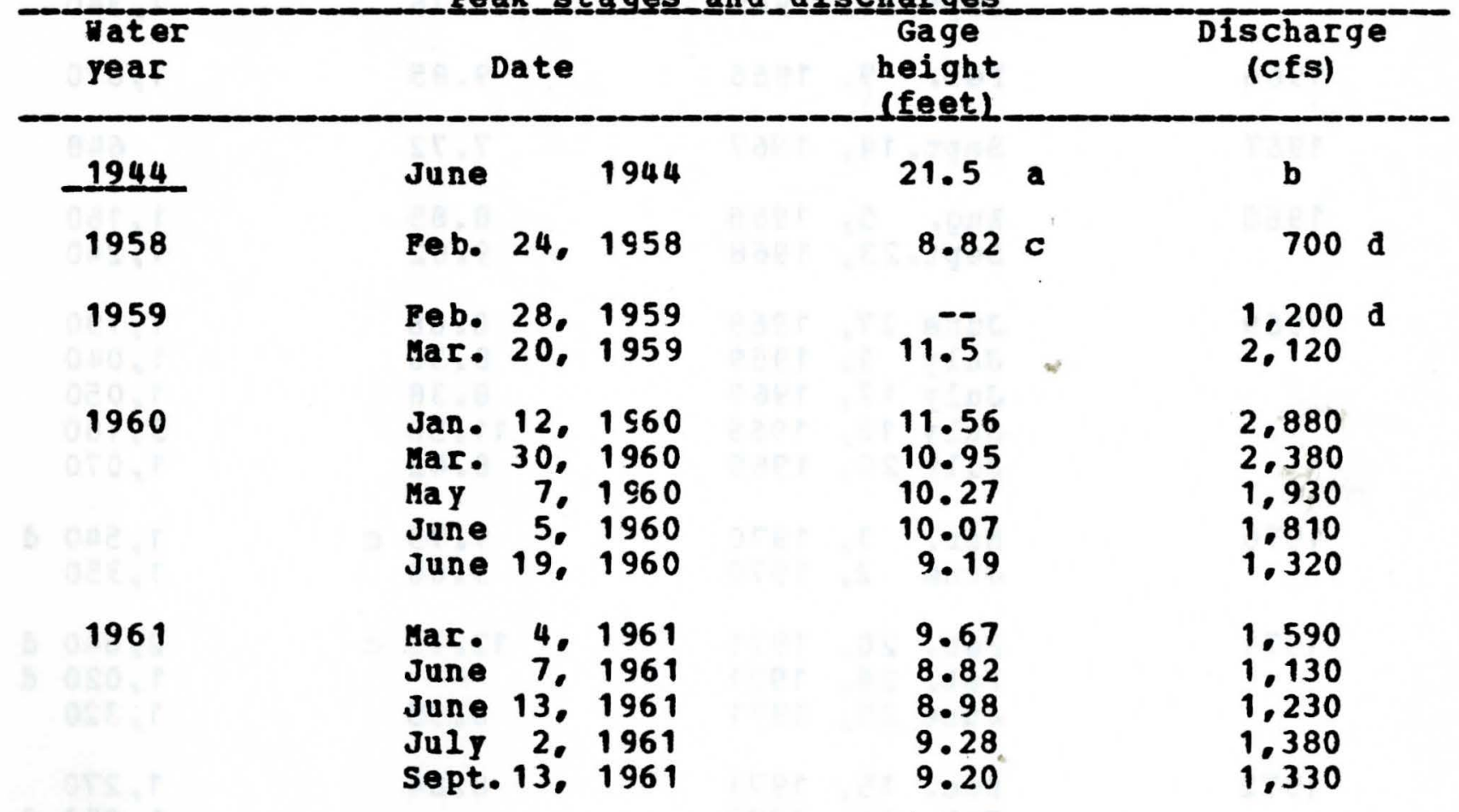

a Maximu flood known, from floodmark, from information by local residents.

b Discharge not determined.

c Affected by ice.

d About. 
05-4177.00 Bear Creek near Monmouth, Iowa--(Continued)

Pea

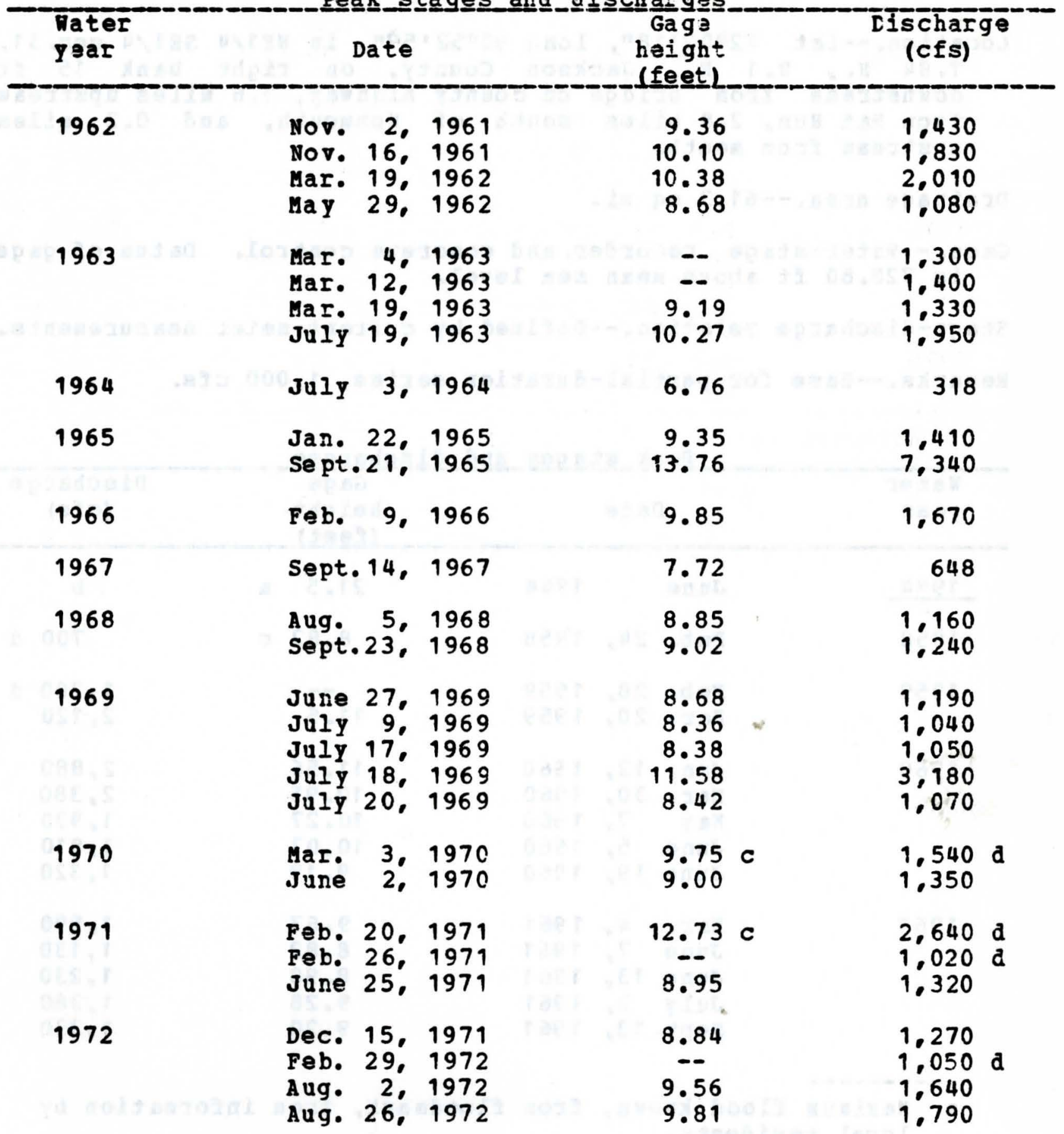

c Affected by ice.

d About. 
05-4177.00 Bear Creek near Honmouth, Iowa--(Continued)

Peak_stagges_and_di

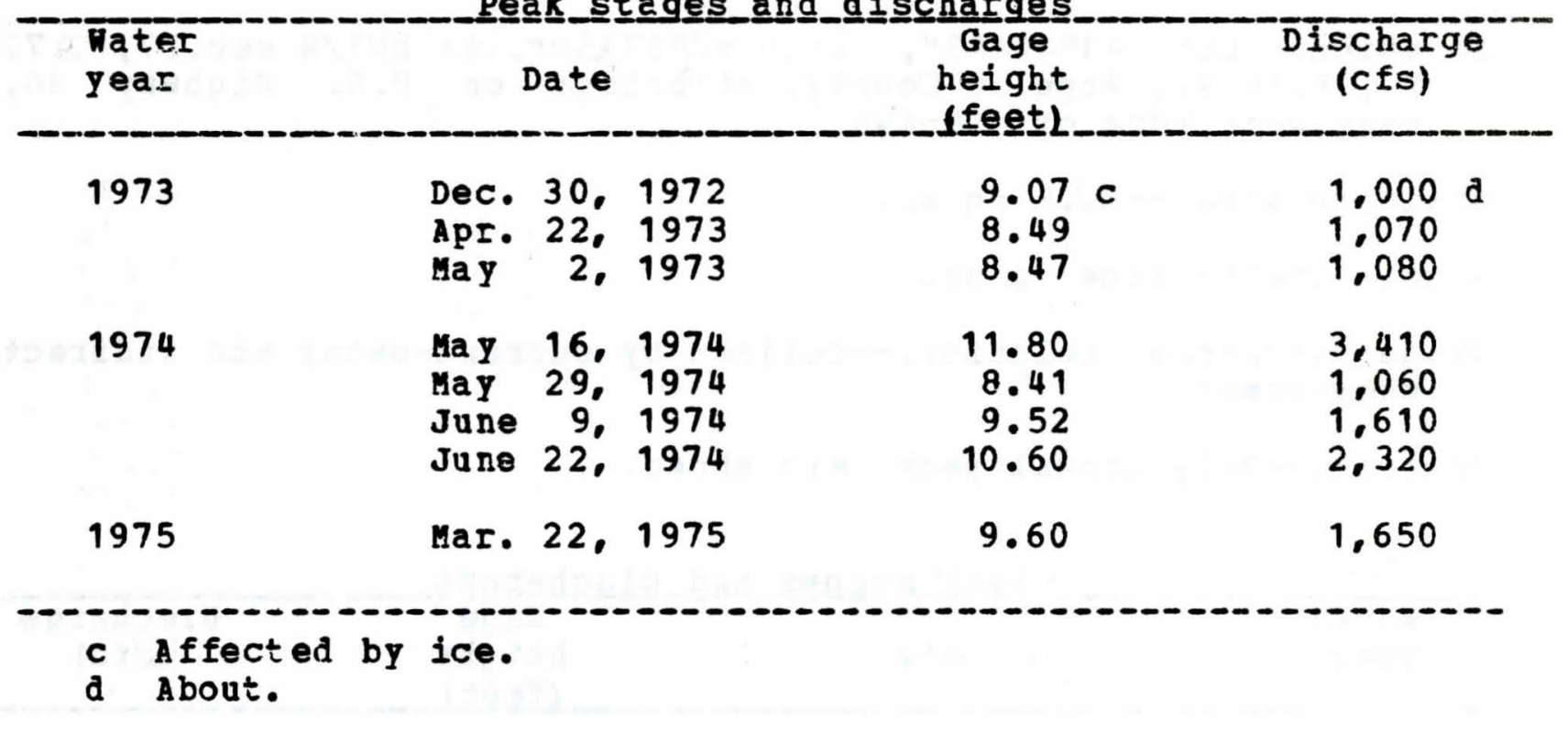




\section{5-4894.90 Bear Creek at Ottumwa, Iowa}

Location.--Iat 41000143", long 92027.54\%, in NW1/4 seC.27, T.72 N.. R.14 H., Rapello County, at bridge on J.S. Highway 34. near west edge of ottumwa.

Drainage area.--22.9 sq mi.

Gage.--Crest-stage gage.

Stage-discharge relation.--Defined by current-meter and indirect mea surements.

Remarks.--only annual peaks are shown.

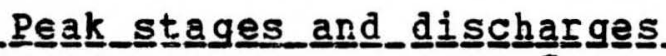

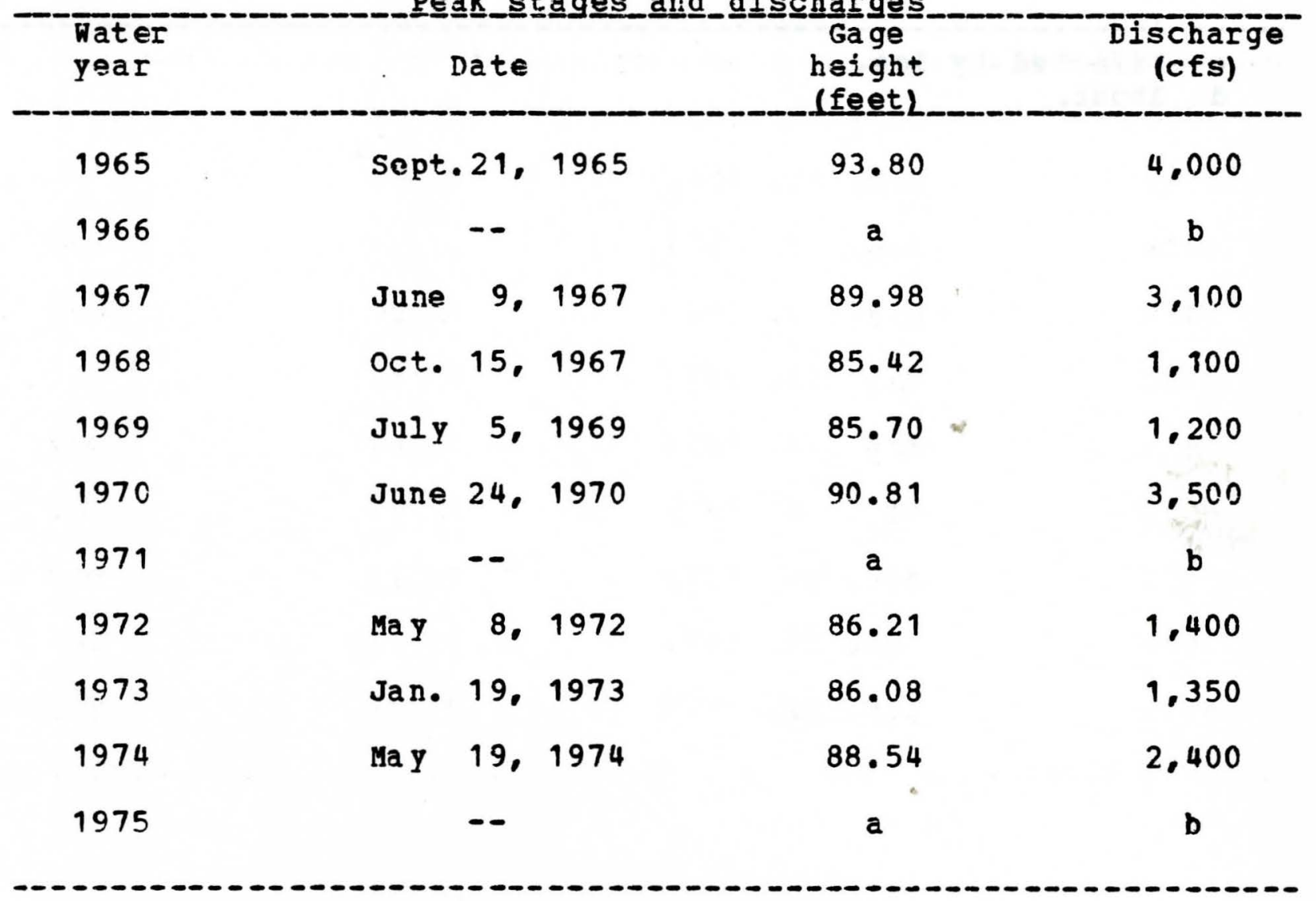

a Peak stage did not reach bottom of gage.

b Discharge not determined. 
05-4627.50 Beaver Creek tributary near Aplington, Iowa

Location.--Lat $42035^{\prime}$, long $92051^{\prime}$, in NH1/4 sec.27, T.90 N.. R. 17 M.. Butler County, at bridge on U.S. Highway 20,2 miles east of Aplington.

Drainage area.--11.6 sq mi.

Gage.--Crest-stage gage.

Stage-discharge relation.--Defined by current-meter measurements. Remarks.--only annual peaks are shown.

Peak_stages_and_discharges

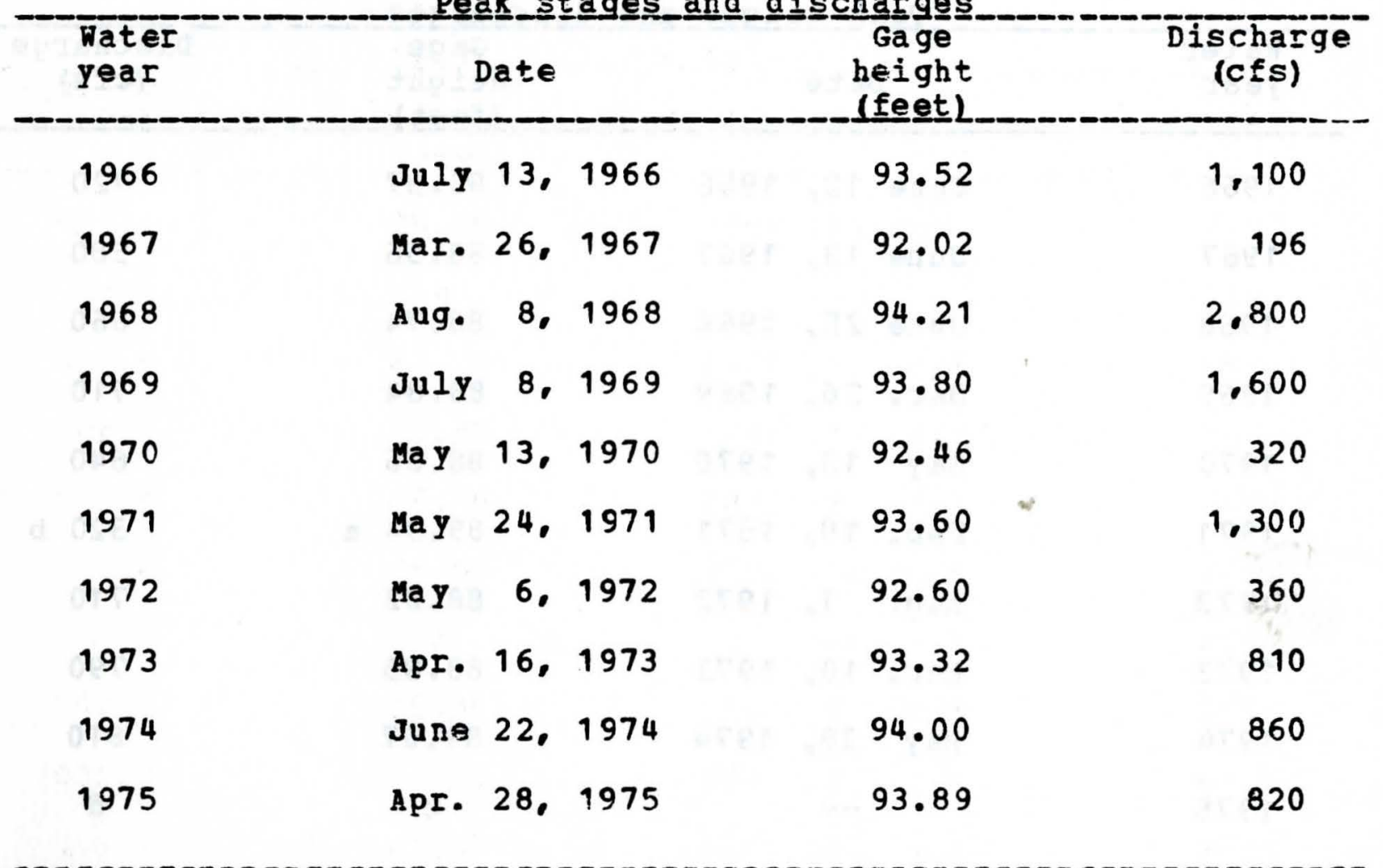




\section{5-4816.80 Beaver Creek at Beaver, Iowa}

Location.--Iat $42^{\circ} 02$, long $94009^{\prime}$, in NE1/4 sec.6, T. 83 N.. R. 28 W. Boone County, at bridge on U.S. Highway 30 , at southwest edge of Beaver.

Drainage area. $--38.5 \mathrm{sq} \mathrm{mi}$

Gage.--Crest-stage gage.

Stage-discharge relation.--Defined by current-meter measurements. Remarks.--only annual peaks are shown.

Peak_stages_and_discharges

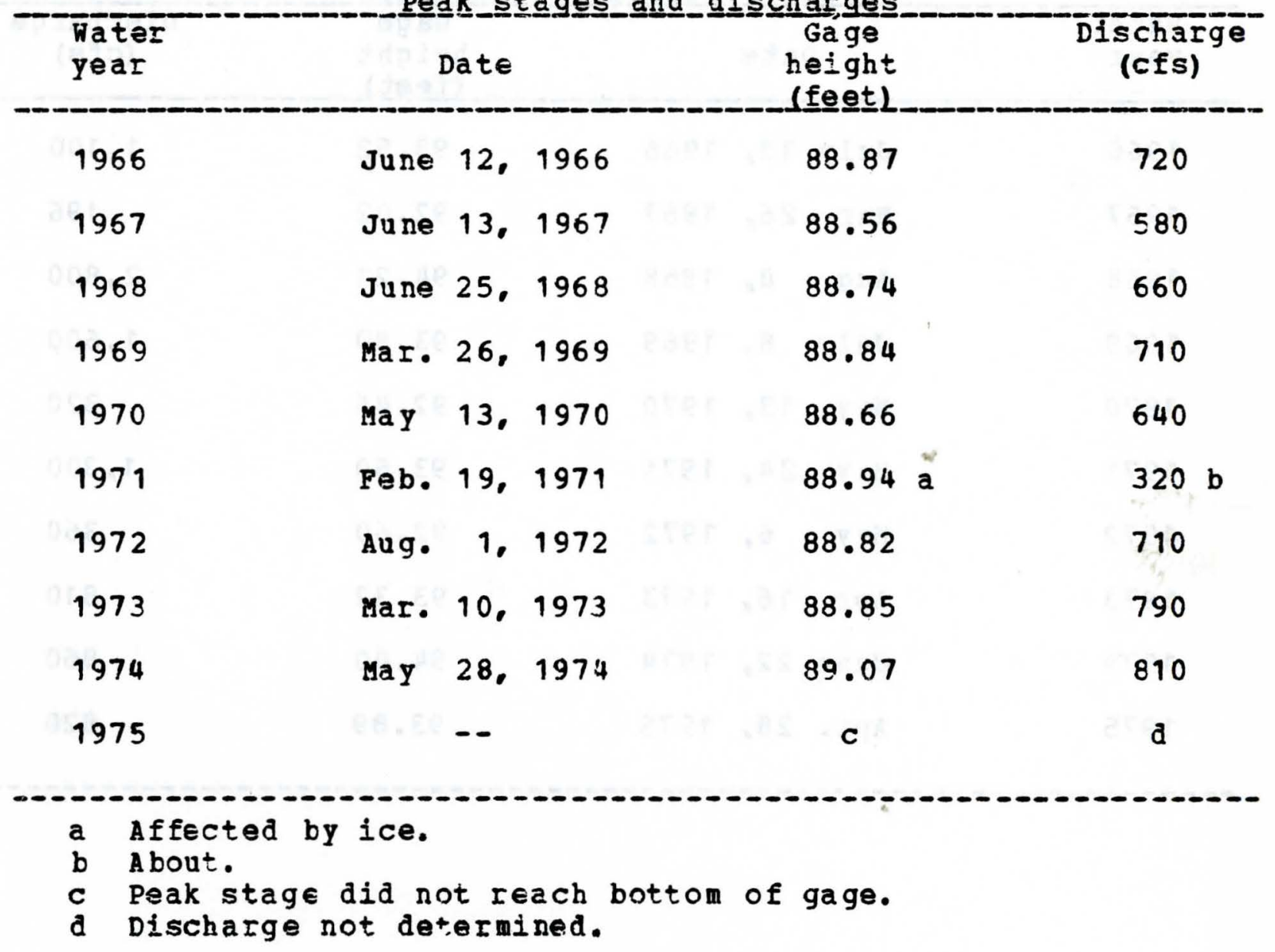




\section{5-4512.50 Beaver Creek near Eldora, Iowa}

Location.--lat $42021 \%$, long 930081 , near the center of sec.13, T. 87 N.. R. 20 H.. about a quarter of a mile south of Fldora, Iowa.

Drainage area. $--69.8 \mathrm{sg} \mathrm{mi}$.

Gage. - Nonrecording.

Stage-discharge relation.--Defined by current-meter measurements. Remarks.--Records collected by Corps of Engineers. Station is inflow forecasting station for Coralville Reservoir. Only annual peaks are shown.

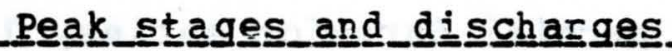

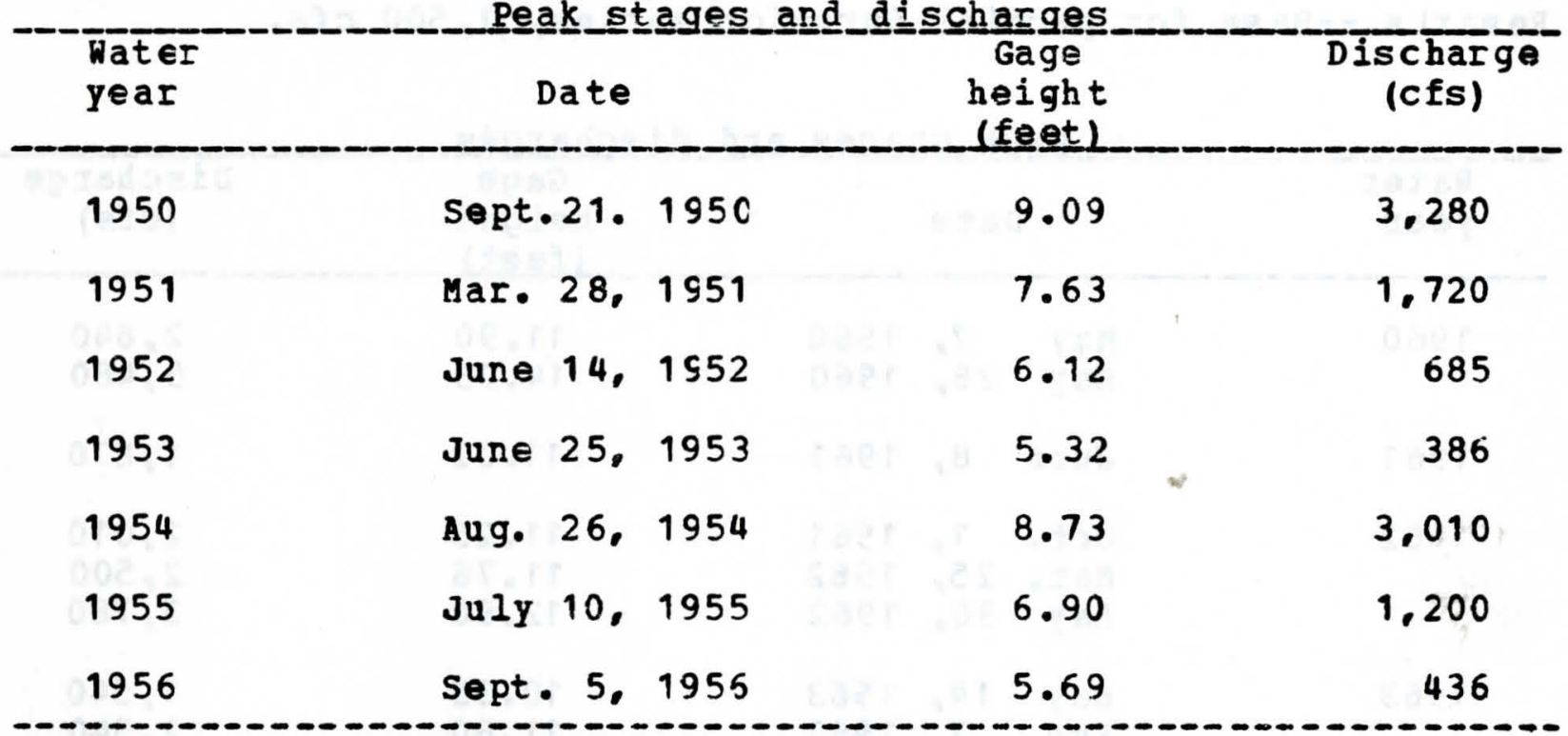




\section{5-4819.50 Beaver Creek near Grimes, Iowa}

Location.--Iat 41041'18", lcng 93044.08", 200 ft east of southwest corner of sec.35, T.80 N.., R.25 W.. Polk County, on right bank 6 ft upstream from Northwest 70 th Avenue Bridge, 0.5 mile dounstream from Little Beaver Creek, 2. 5 mile east of Grimes and 6 miles upstream from the mouth.

Drainage area. $--358 \mathrm{sq} \mathrm{mi}$.

Gage.-- Water-stage recorder and concrete and steel sheeting brcad-crested control. Datum of gage is 806.98 ft above mean sea level. Prior to Aug. 31, 1966, nonrecording gage at same site and datum.

Stage-discharge relation.--Defined by current-meter measurements.

Remarks.--Base for partial duration series, 1,500 cfs.

Peak stages and discharges

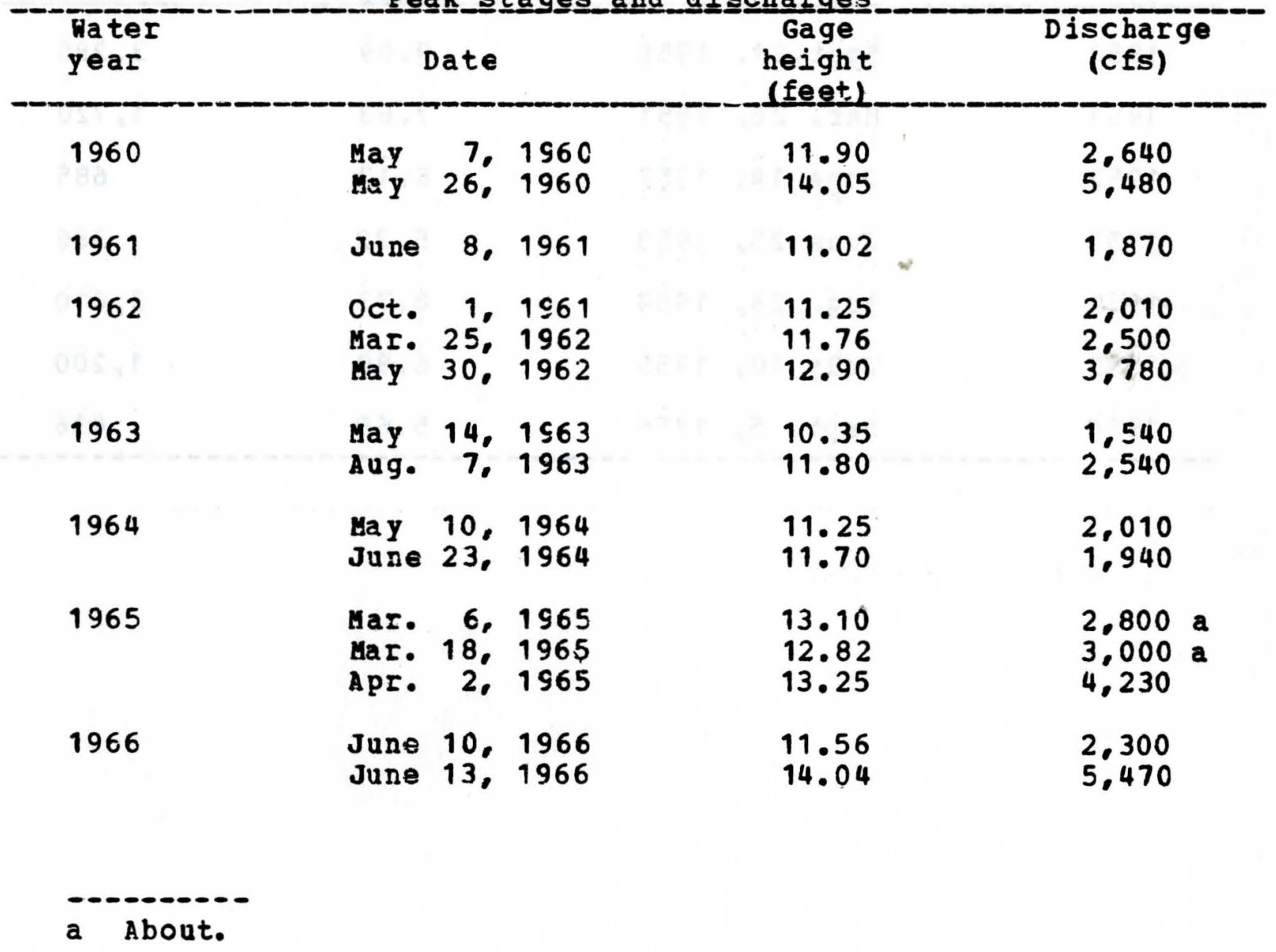


05-4819.50 Beaver Creek near Gimes, Iowa--(Continued)

Peak

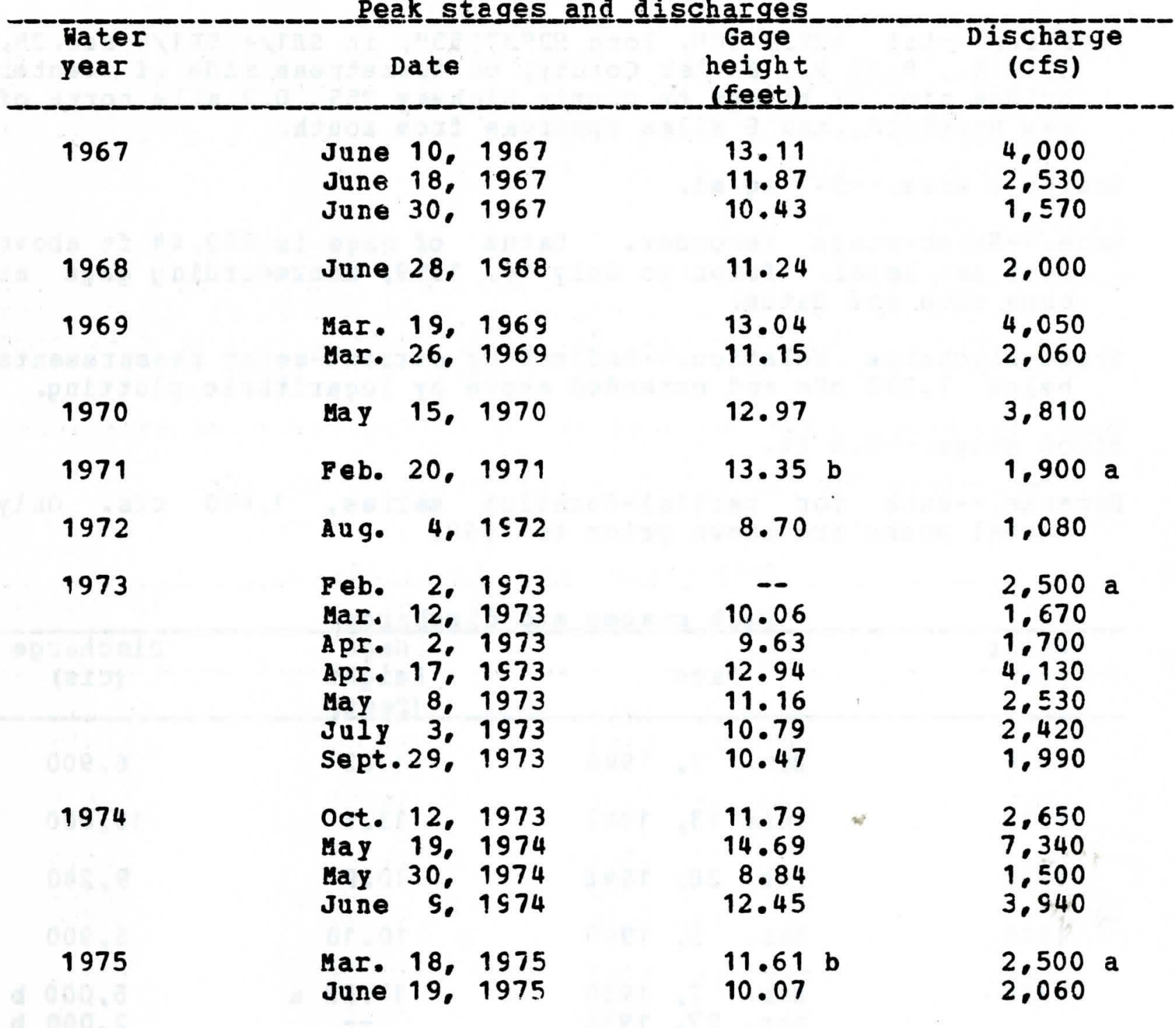

a About.

b Affected by ice. 
Locaticn.--Iat $42030 \cdot 50^{\prime \prime}$, Iong $920377^{\prime \prime}$, in SE1/4 SE1/4 sec. 28 ,

T. 90 N.. R. 15 W. Butler County, on downstream side of center bridge pier of bridge on ccunty highway T55. 0.2 mile north of New Hartford, and 8 miles upstream from mouth.

Drainage area.--347 sq mi.

Gage.-- Water-stage recorder. Datum of gage is $882.44 \mathrm{ft}$ above mean sea level. Prior to July 14, 1959, nonrecording gage at same site and datum.

Stage-discharge relation.--Defined by current-meter measurements below 7,300 cfs and extended above by logarithmic plotting.

Flood stage. $-8.5 \mathrm{ft}$.

Remarks.--Base for partial-duration series, 1.400 cfs. Only annual peaks are shown prior to 1950.

Peak sta

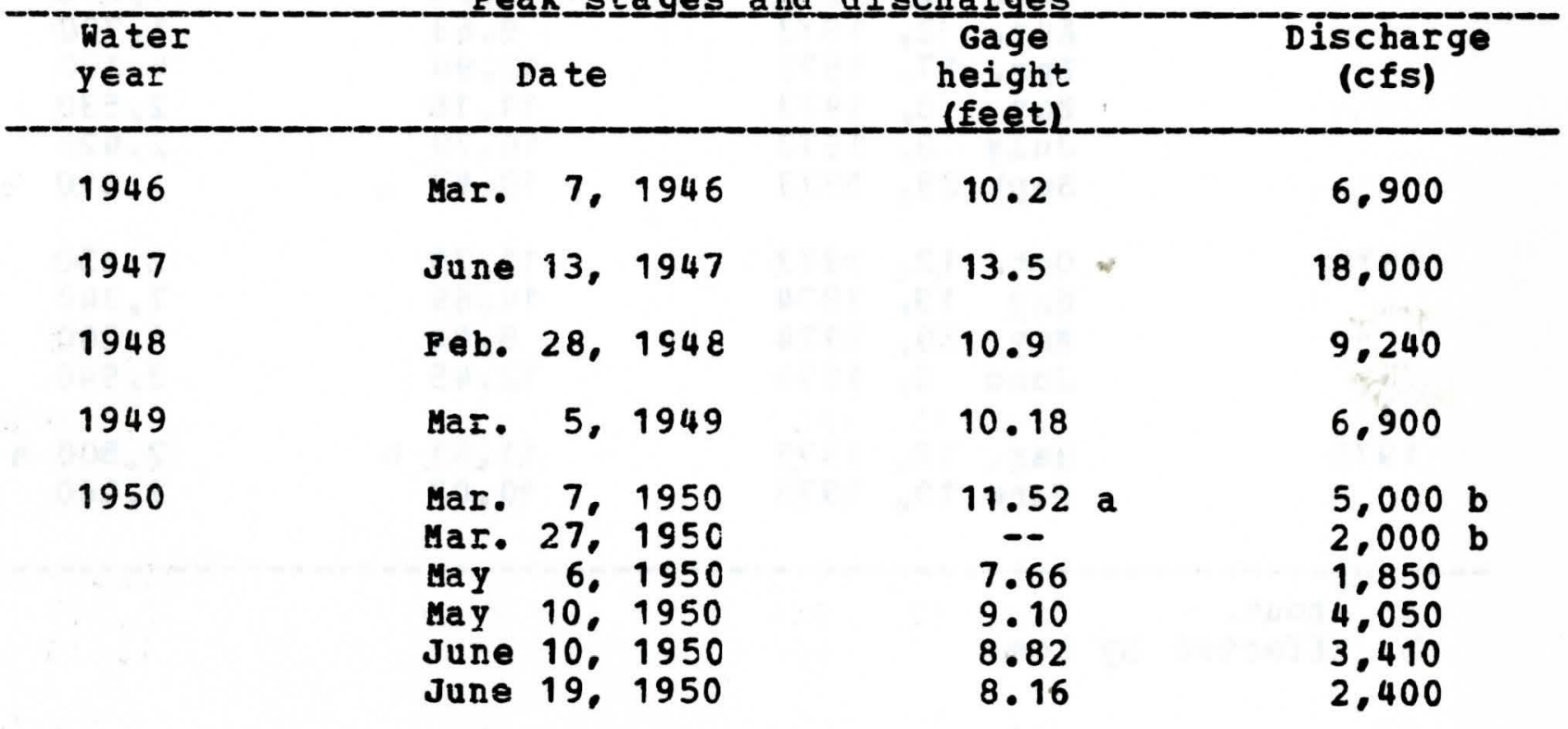

a Affected by ice.
b About. 
05-4630.00 Beaver Creek at New Hartford, Iowa--(Continued)

Feak stages and di scharges

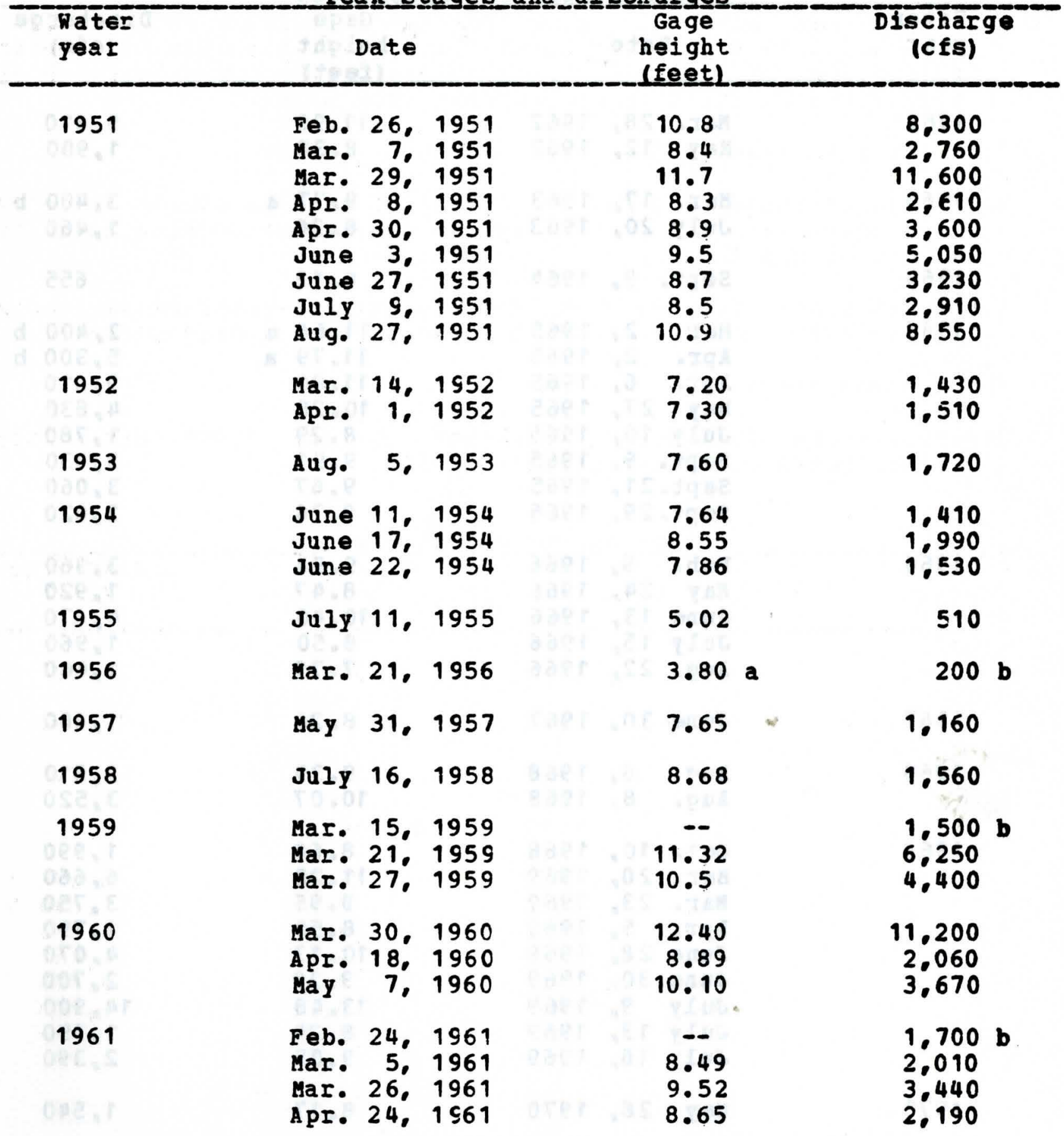

a Affected by ice.

b A bout. 
05-4630.00 Beaver Creek at New Hartford, Iowa-- (Continued)

Feak_stages and di scharges

\begin{tabular}{|c|c|c|c|}
\hline $\begin{array}{l}\text { hater } \\
\text { year }\end{array}$ & Date & $\begin{array}{l}\text { Gage } \\
\text { height } \\
\text { (feet) }\end{array}$ & $\begin{array}{l}\text { Discharge } \\
\text { (cfs) }\end{array}$ \\
\hline 1962 & 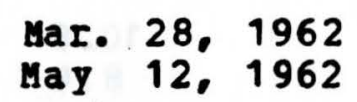 & $\begin{array}{r}11.98 \\
8.38\end{array}$ & $\begin{array}{l}9,610 \\
1,900\end{array}$ \\
\hline 1963 & $\begin{array}{l}\text { Mar, 17, } 1963 \\
\text { July 20, } 1963\end{array}$ & $\begin{array}{l}9.77 \\
8.26\end{array}$ & $\begin{array}{l}3,400 \mathrm{~b} \\
1.460\end{array}$ \\
\hline 1964 & sept. 9, 1964 & 6.12 & 655 \\
\hline 1965 & $\begin{array}{l}\text { Mar. 2, } 1965 \\
\text { Apr. 2, } 1965 \\
\text { Apr. 6, } 1965 \\
\text { May 27, } 1965 \\
\text { JuIy 10, } 1965 \\
\text { Sept. 9, } 1965 \\
\text { Sept.21, } 1965 \\
\text { Sept.29, } 1965\end{array}$ & $\begin{array}{r}11.66 \\
11.79 \\
11.80 \\
10.28 \\
8.29 \\
9.91 \\
9.67 \\
8.76\end{array}$ & $\begin{array}{l}2.400 \text { b } \\
5.300 \text { b } \\
9.610 \\
4.830 \\
1.780 \\
3.430 \\
3.060 \\
2.020\end{array}$ \\
\hline 1966 & 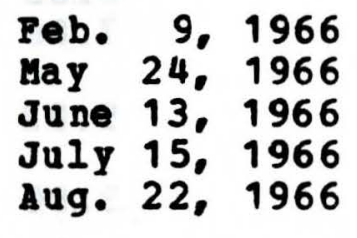 & $\begin{array}{r}9.94 \\
8.47 \\
10.40 \\
8.50 \\
7.79\end{array}$ & $\begin{array}{l}3.960 \\
1.920 \\
4.870 \\
1.960 \\
1.460\end{array}$ \\
\hline 1967 & June 30,1967 & 8.26 & 1,800 \\
\hline 1968 & $\begin{array}{lll}\text { lug. } & 6,1968 \\
\text { Aug. } & 8,1968\end{array}$ & $\begin{array}{r}9.39 \\
10.07\end{array}$ & $\begin{array}{l}2.510 \\
3.520\end{array}$ \\
\hline 1969 & $\begin{array}{lrl}\text { Oct. } & 10, & 1968 \\
\text { Mar. } & 20, & 1969 \\
\text { Mar. } & 23, & 1969 \\
\text { Apr. } & 5, & 1969 \\
\text { June } & 28, & 1969 \\
\text { June } & 30, & 1969 \\
\text { July } & 9, & 1969 \\
\text { July } & 13, & 1969 \\
\text { July } & 18, & 1969\end{array}$ & $\begin{array}{r}8.68 \\
11.28 \\
9.95 \\
8.50 \\
10.13 \\
9.29 \\
13.48 \\
8.24 \\
9.05\end{array}$ & $\begin{array}{r}1,990 \\
6,660 \\
3,750 \\
1,790 \\
4,070 \\
2,700 \\
14,900 \\
1,550 \\
2,390\end{array}$ \\
\hline 1970 & May 28,1970 & 8.17 & 1.540 \\
\hline
\end{tabular}

a Affected by ice.

b sbout. 
05-4630.00 Beaver Creek at New Hartford, Iowa--(Contin ued)

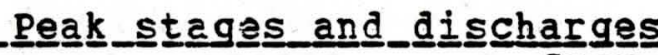

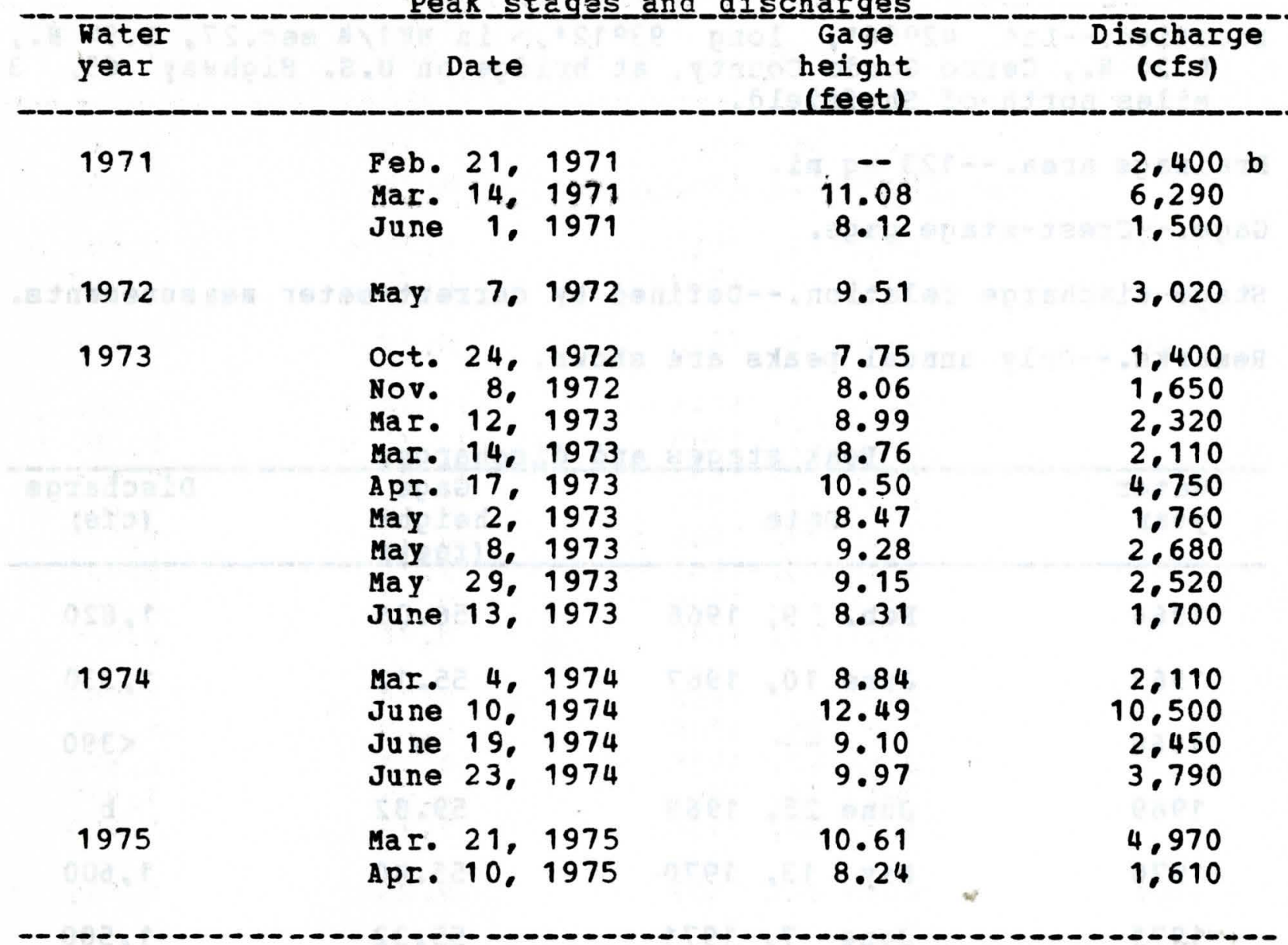

b A bout. 


\section{5-4585.60 Beaverdam Creek near Sheffield, Iowa}

Location.--Iat $42^{\circ} 56^{\prime}$, long $93012^{\circ}$, in NN1/4 sec.27, T.94 N..

R.20 W.. Cerro Gordo County. at bridge on U.S. Highway 65,3 miles north of Sheffield.

Drainage area. $--123 \mathrm{sq} \mathrm{mi}$.

Gage.--Crest-stage gage.

Stage-discharge relation.--Defined by current-meter measurements. Remarks.--only annual peaks are shown.

Peak stáge

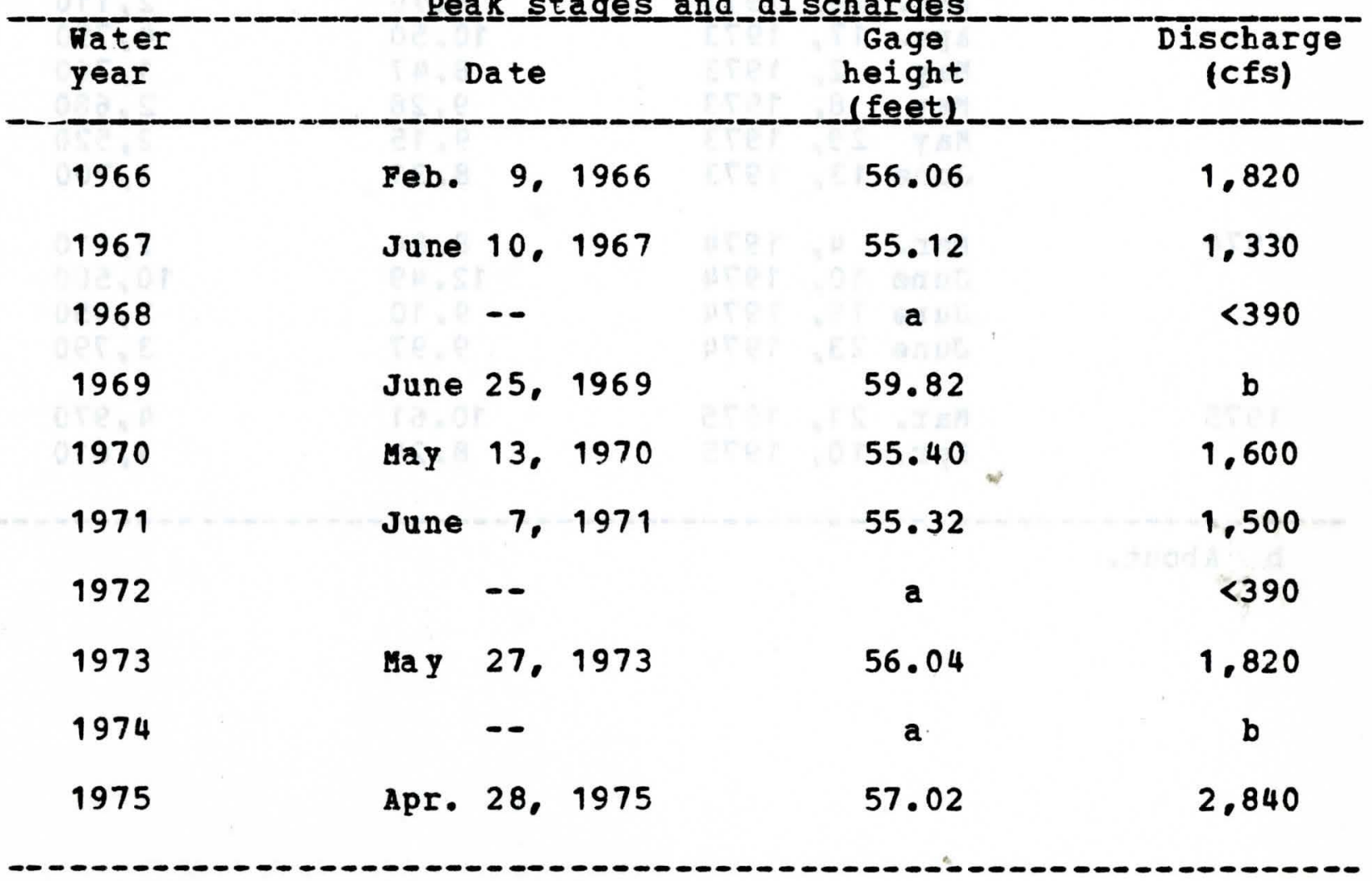

a Peak stage did not reach bottom of gage.

b Discharge not determined. 
05-4530.00 Big Bear Creek at Ladora, Iowa

(Prior to october 1966, published as Bear Creek at Iadora)

Location.--Iat 41044'58", long 92010'55", in sW1/4 sw1/4 sec.7. T. 80 N., R. 11 W.. Iowa county, on left bank $10 \mathrm{ft.} \mathrm{downstream}$ from bridge on county highway v52, 0.4 mile south of ladora, 1.2 miles downstream from Coats Creek, 2.8 miles upstream from Little Bear Creek, and 8.1 miles upstream from mouth.

Drainage area.--189 sq mi.

Gage.-Water-stage recorder. Datum of gage is $754.94 \mathrm{ft}$ above mean sea level. Prior to June 26, 1946, nonrecording gage at same site and datum.

Stage-discharge relation.--Defined by current-meter measurements.

Bankfull stage.--10 ft.

Remarks,--Base for partial-duration series, 2,000 cfs.

Peák_s_tages_and_d_isscharges

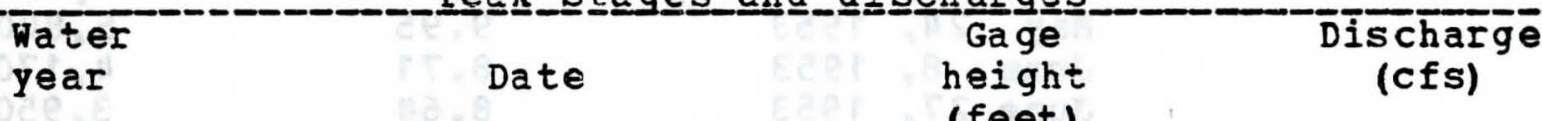

1946

Jan. 5, 1946

MaI. 6, 1946

MaI. 26, 1946

May 3, 1946

June 19, 1946

(feet)

(cfs)

sept. 22, 1946

13. 1

9.050

9.4

7.8

3.830

8.2

7.9

7.73

2,260

2.590

2.340

Apr. 5,1947

1947

ApI. 10,1947

7.42

2.200

Apr. 20,1947

June 1. 1947

June 5,1947

June 13, 1947

June 21, 1947

June 30,1947

7.68

2,260

7.36

2,570

9.45

2.200

10.90

5,360

10.00

7.610

8.67

6.650

11.35

3,830

7.060

1948

Feb. 28, 1948

Mar. 16, 1948

11.48

7,220

Mar. 19, 1948

9.60

5.630

July 21, 1948

7.70

3.250

7.72

3,270 
05-4530.00 Big Bear Creek at Ladora, Iowa--(Continued)

Peak stages and discharges

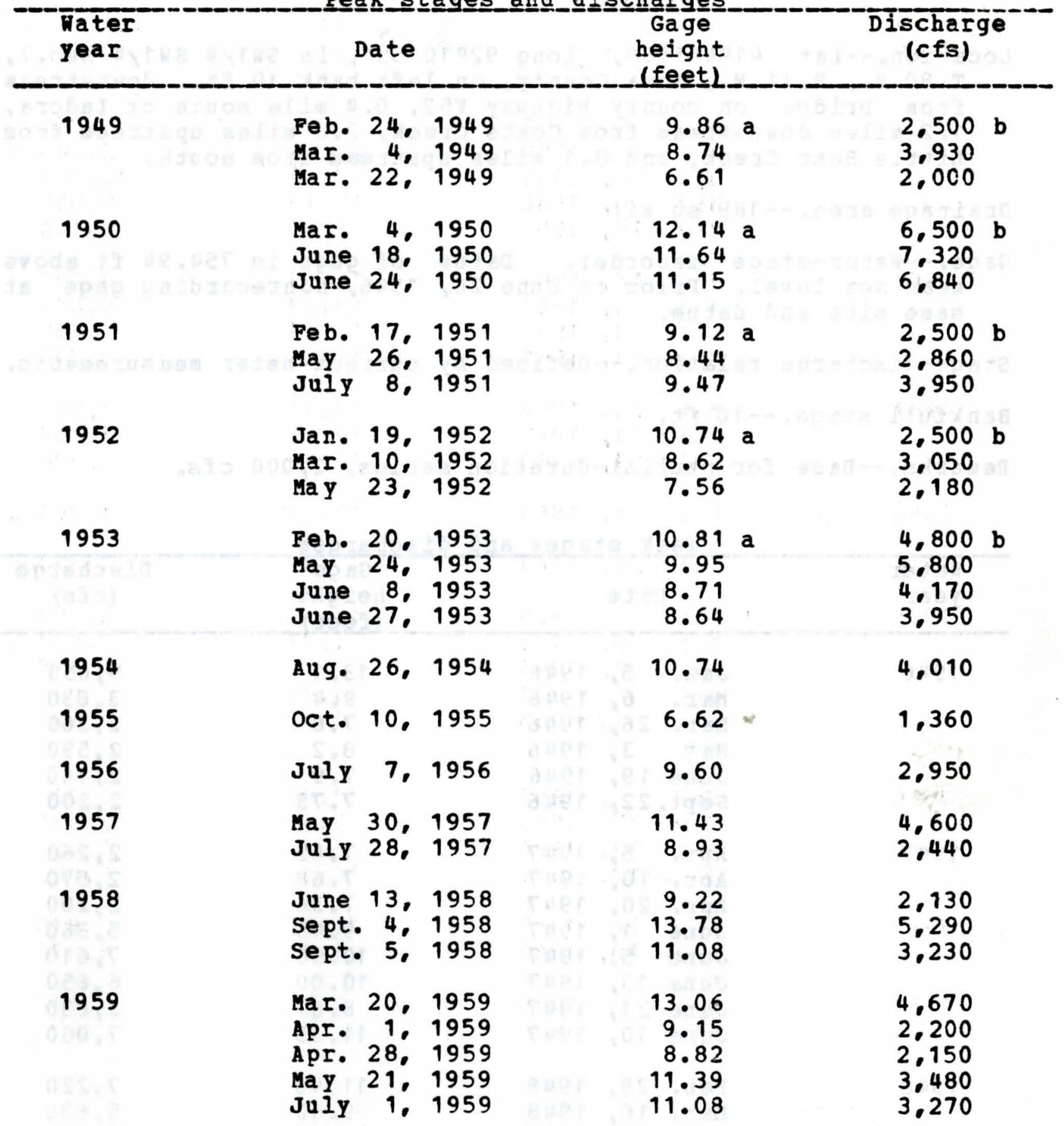

a Affected by ice.

b about. 
05-4530.00 Big Bear Creek at Ladcra, Iowa--(Continued)

Peak stages and di

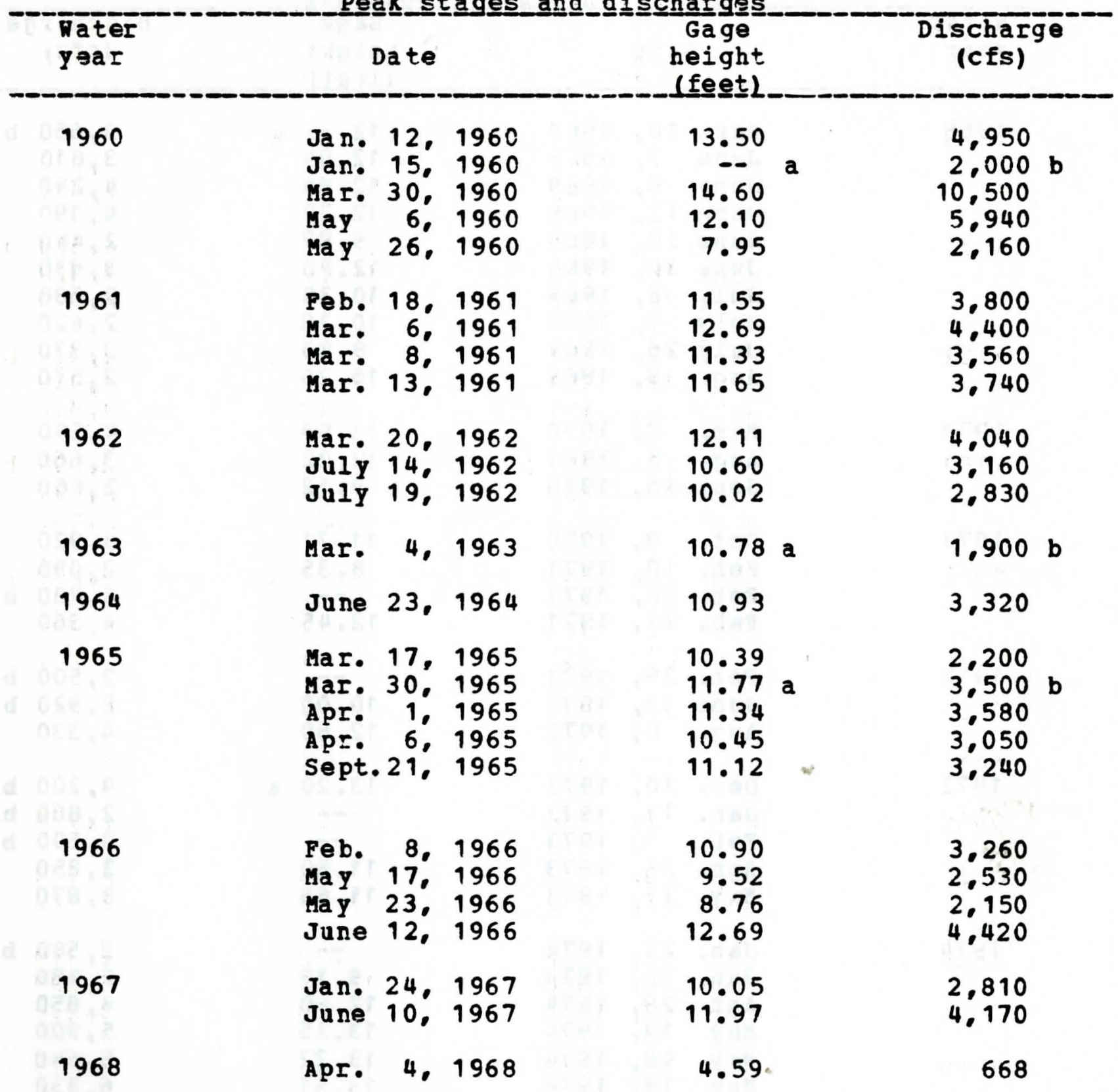

a Afecteá by ice.

b About. 
05-4530.00 Big Bear Creek at Ladora, Iowa--(Continued)

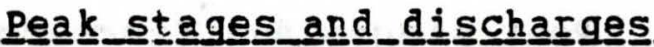

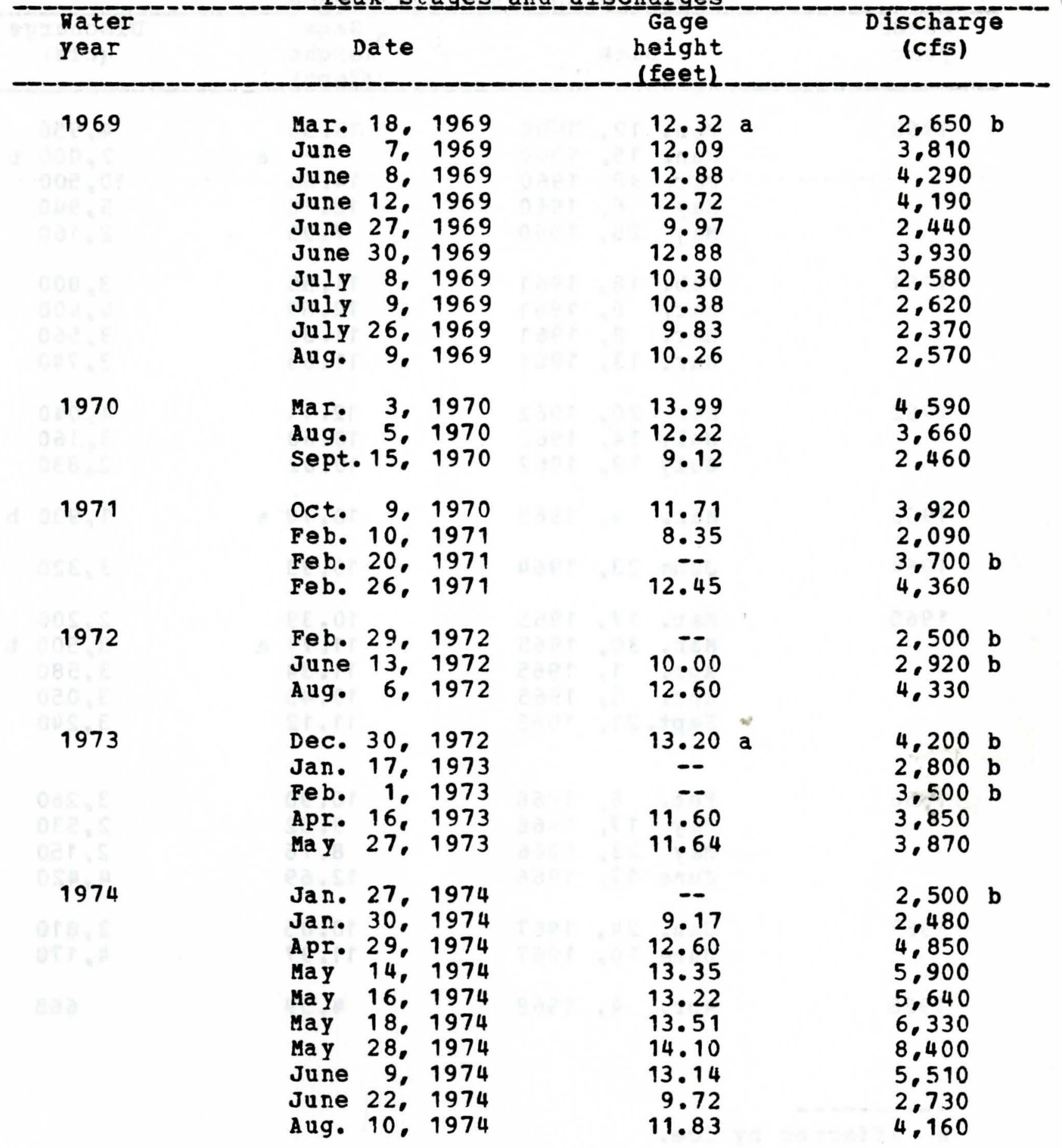

\footnotetext{
a Afected by ice.

b A bout.
} 
05-4530.00 Big Bear Creek at Ladora, Iowa--(Continued)

Peak﹎_stages_and_di $\underline{\text { schar }}$ arges

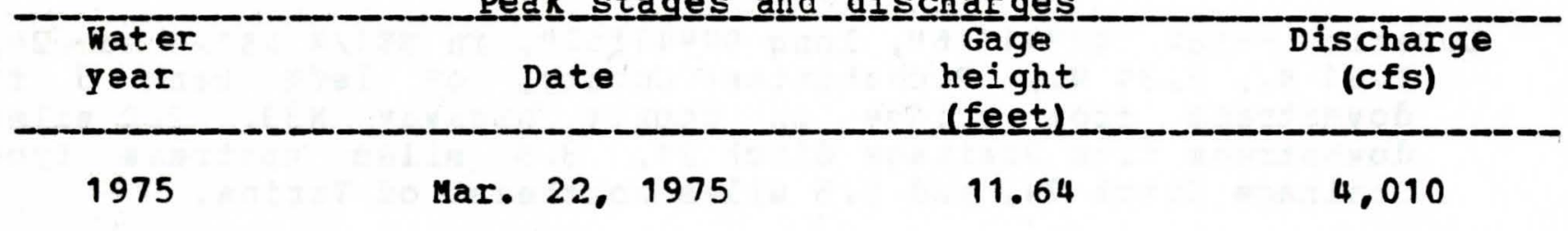




\section{5-4821.70 Big Cedar Creek near Varina, Iowa}

Location.--Iat $42041 \cdot 16 "$, long $94047 \cdot 52^{\prime \prime}$, in NE $1 / 4 \mathrm{NE} 1 / 4 \mathrm{sec} .24$, T. 91 N.. R. 34 H.. Pochahontas County, on left bank 5 ft downstream from bridge on county highway N33, 2.0 miles downstream from Drainage ditch $21,3.5$ miles upstream from Drainage ditch 74, and 5.5 miles northeast of Varina.

Drainage area. $--80.0 \mathrm{sq}$ mi.

Gage.--Water-stage recorder. Datum of gage is 1,225.12 ft above mean sea level.

Stage-discharge relation.--Defined by current-meter measurements. Remarks.--Base for partial-duration series, $400 \mathrm{cfs}$.

Feak_stagges_and_ dis

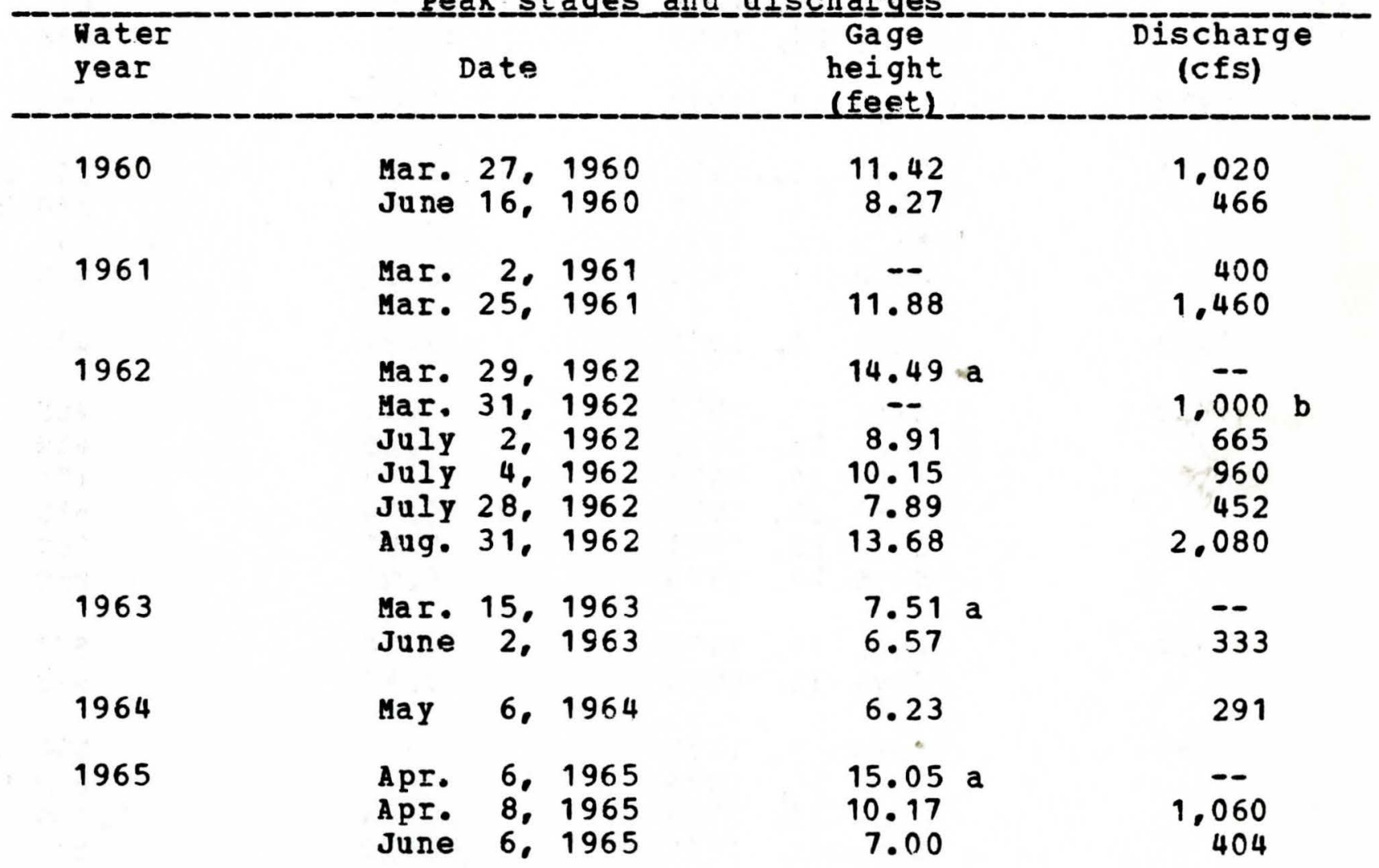

a Affected by ice.

b About. 
05-4821.70 Big Cedar Creek near Varina, Iowa--(Continued)

Peak stages and discharges

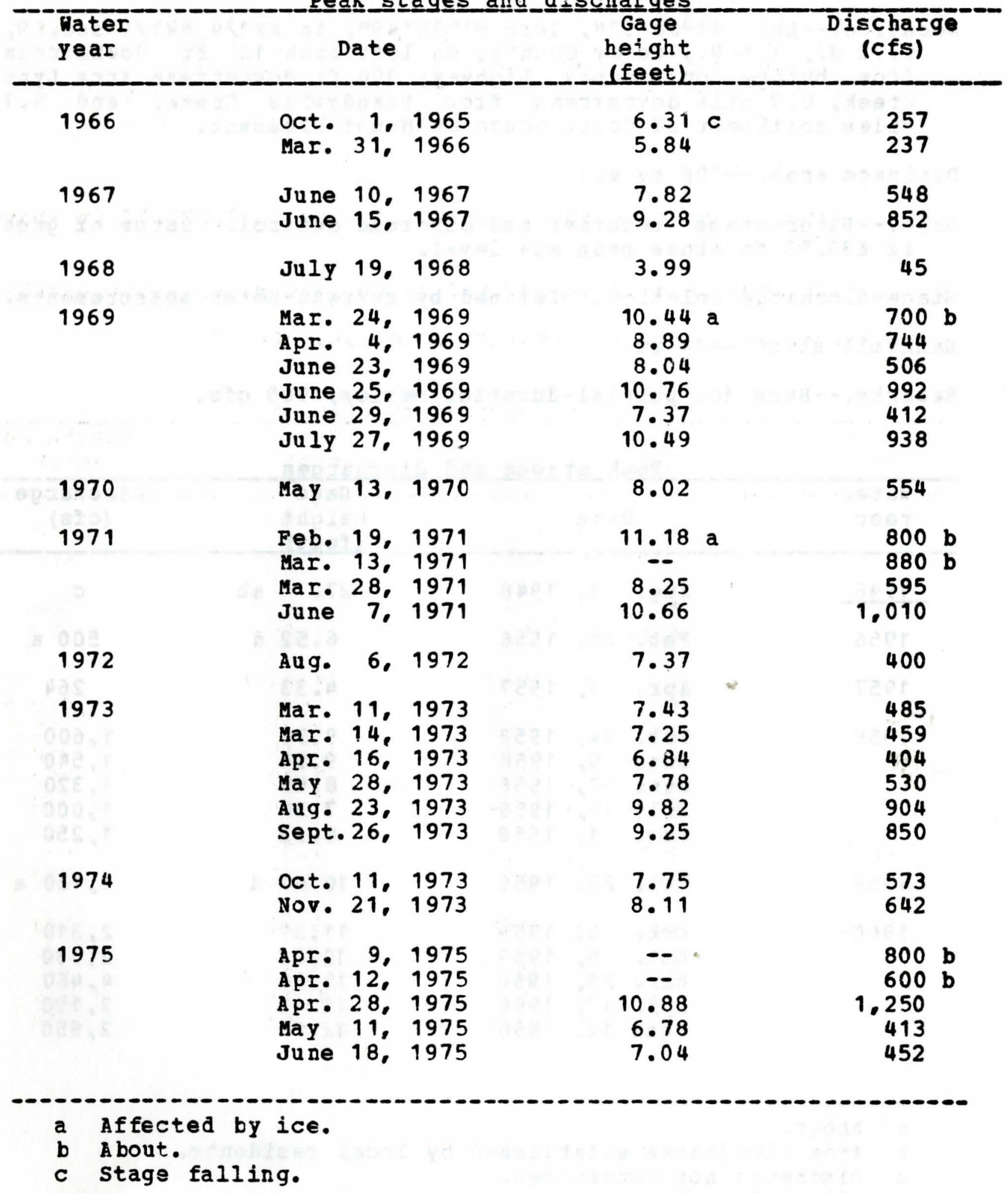




\section{5-4735.00 Big Creek near Mount Pleasant, Iowa}

Location.--Lat 41000'52", long 91034'49", in NW1/4 NN1/4 sec.29, T.72 N., R. 6 .. HenIy County, on left bank 12 ft downstream from bridge on county highway, 100 ft downstream frcm Lynn Creek, 0.7 mile downstream from Brandywine Creek, and 3.7 miles northwest of Court house at Mount Pleasant.

Drainage area. $--106 \mathrm{sq} \mathrm{mi}$

Gage.-- Water-stage recorder and concrete control. Datum of gage is $630.53 \mathrm{ft}$ above mean sea level.

Stage-discharge relation.--Defined by current-meter measurements. Bankfull stage.--14 ft.

Remarks.--Base for partial-duratior series, 900 cfs.

Peak﹎stages_and_discharges

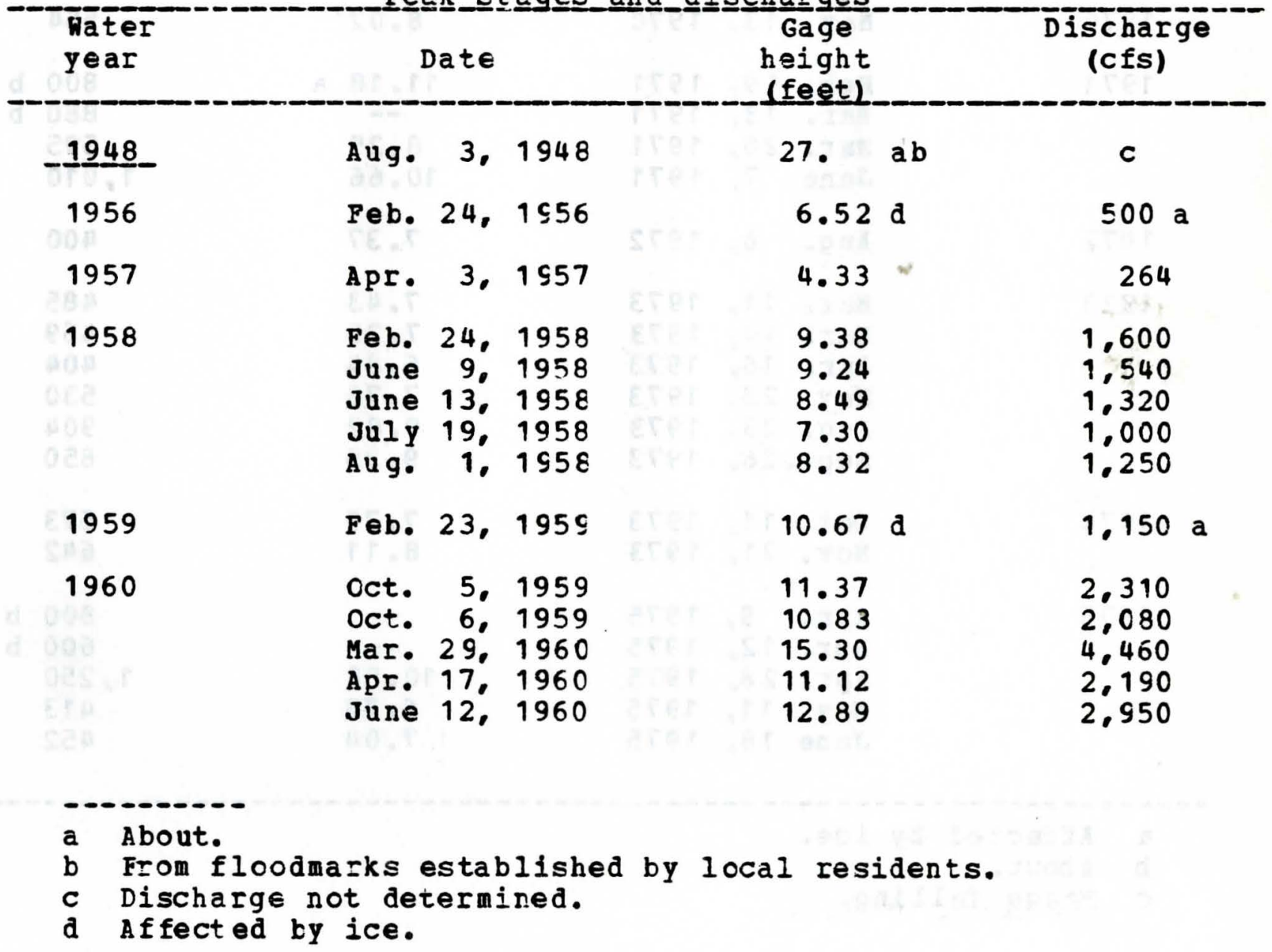


05-4735.00 Big Creek near Mcunt Pleasant, Iowa--(Continued)

Fea $\underline{k}$ stag ges_and

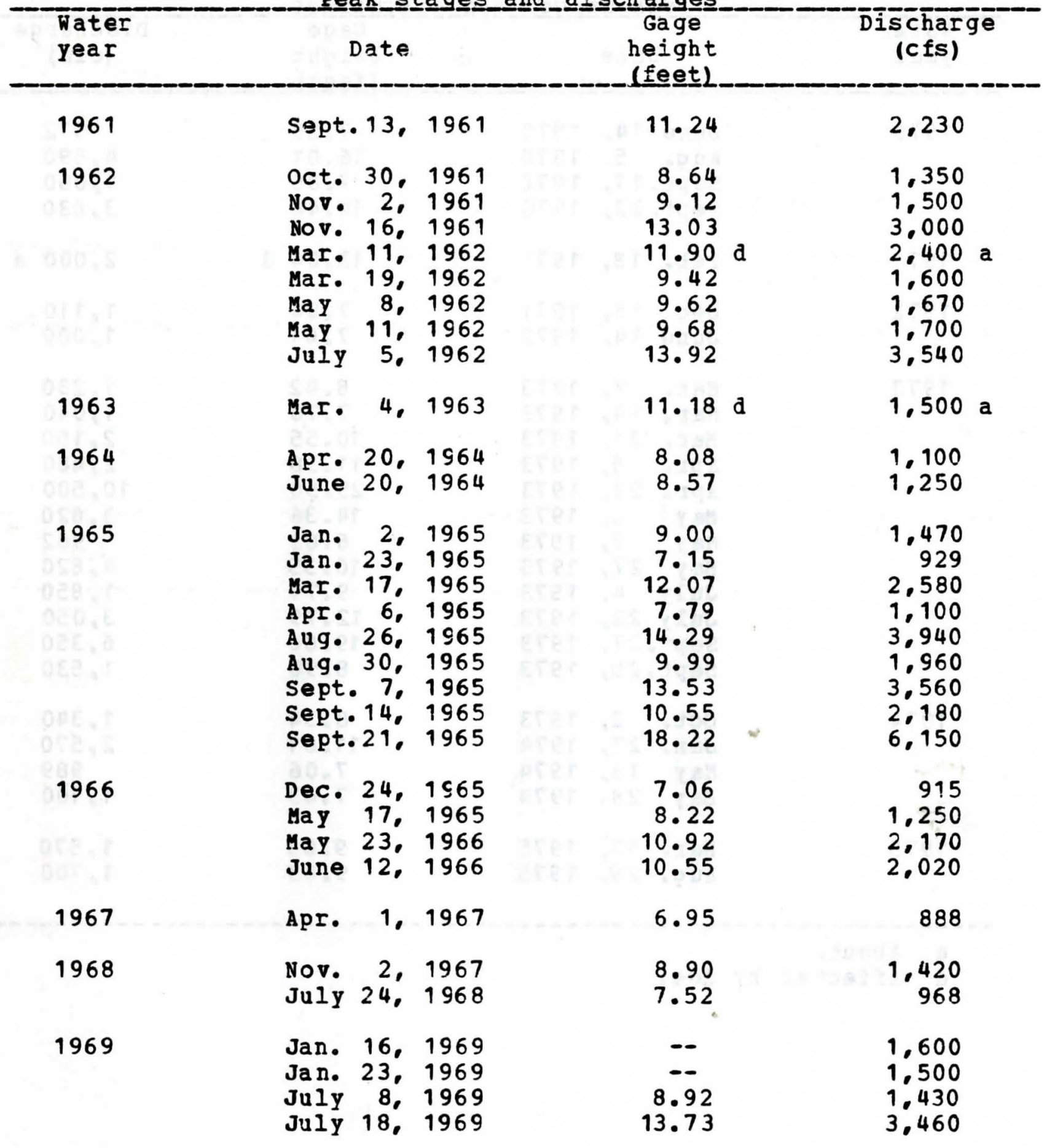

a About.

d Affected by ice. 
05-4735.00 Big Creek near Mount Pleasant, Iowa--(Continued)

Feak_stages_and_di sch arges

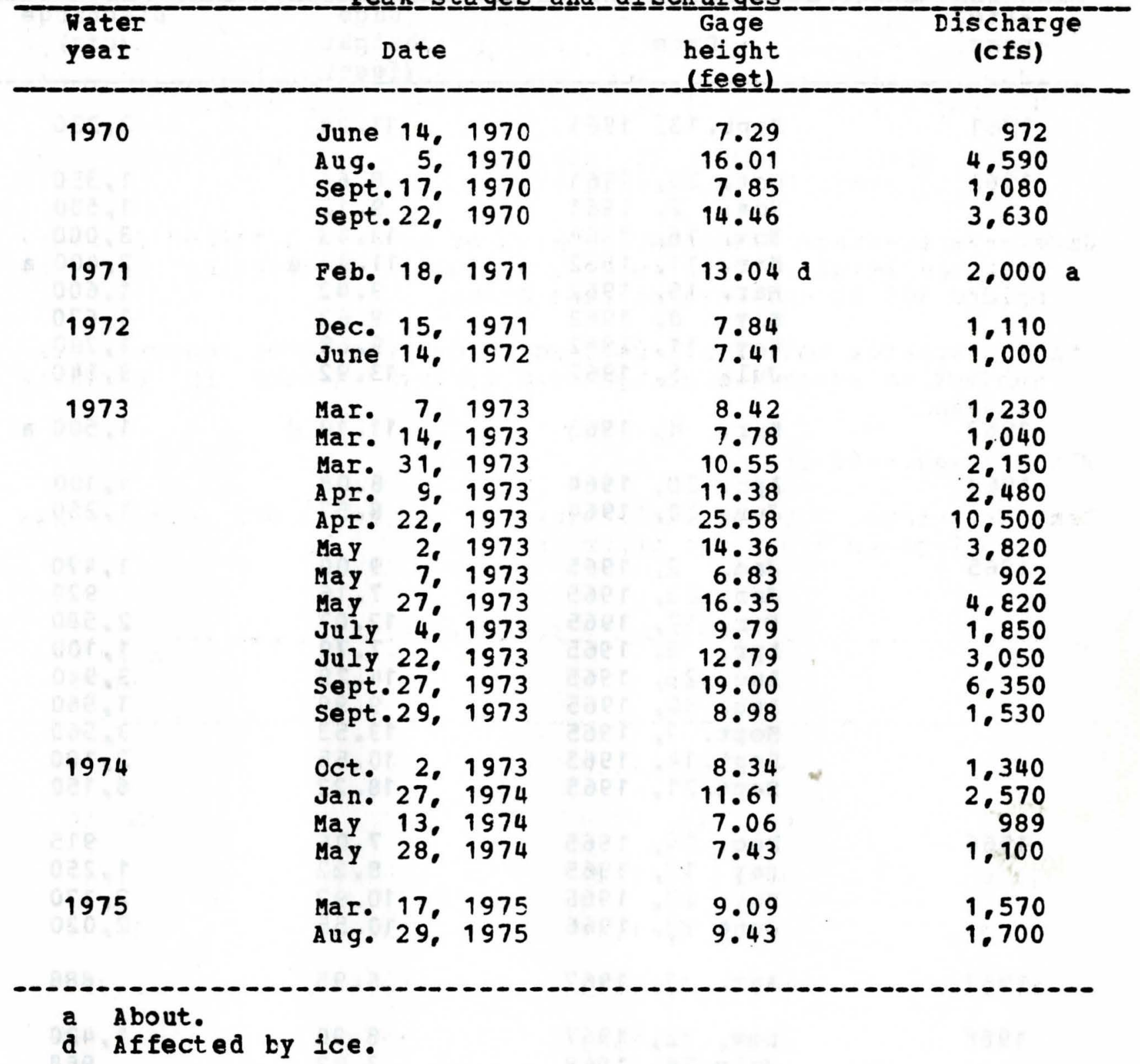


Location.--Iat $42049 \cdot 42^{\prime \prime}$, long $96033 \cdot 45^{\prime \prime}$, in NN1/4 SN1/4 sec.31, T.93 N., R. 48 W., Plymouth County, Iowa, on left bank at west edge of Akron, 0.6 mile downstream from bridge on state Highway 48, and 2.3 miles upstream from Union Creek.

Drainage area.--9,030 sq mi, approximately, of which abcut 1,970 sq $\mathrm{mi}$ is probably noncontributing.

Gage.--Water-stage recorder. Datum of gage is 1,118.90 ft above mean sea level. Prior to Dec. 3, 1934, nonrecording gage at bridge 300 ft upstream at same datum.

Stage-discharge relation.--Defined by current-meter measurements; subject to extensive changes due to levee breaks in vicinity of gage.

Flood stage. - $16 \mathrm{ft.}$

Remarks.--Base for partial-duration series 3,500 cfs. only annual peaks are shown prior to 1935.

Feak__stagges_and__di

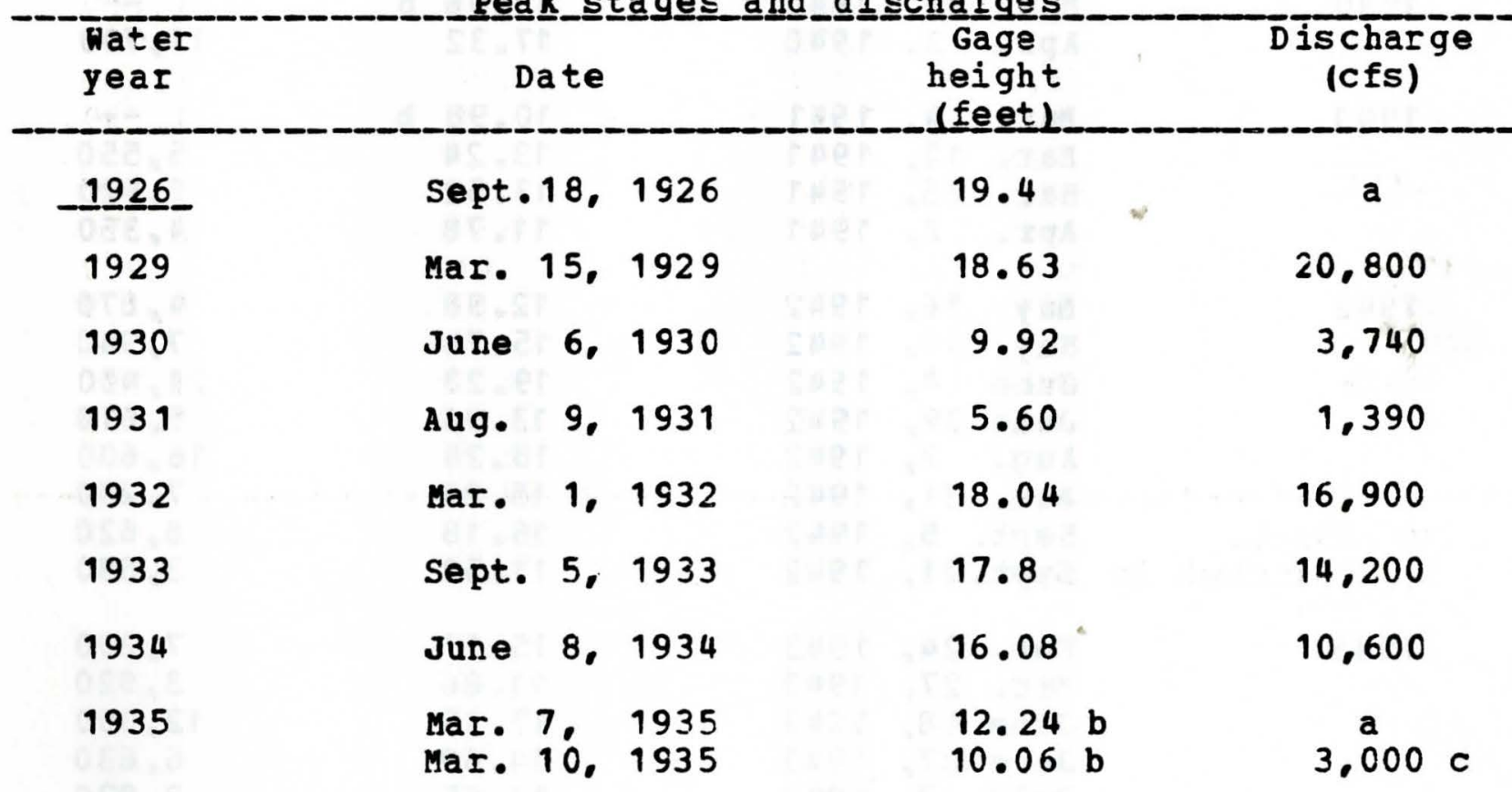

a Discharge not determined.

b Affected by ice.

c About. 
06-4855.00 Big Sioux River at Akron, Iowa--(Continued)

Peak stages and discharges

\begin{tabular}{|c|c|c|c|c|c|}
\hline $\begin{array}{l}\text { Hater } \\
\text { year }\end{array}$ & Date & & $\begin{array}{l}\text { Gage } \\
\text { height } \\
\text { (feet) }\end{array}$ & & $\begin{array}{c}\text { Discharge } \\
\text { (cfs) }\end{array}$ \\
\hline 1936 & $\begin{array}{l}\text { Mar. } 12, \\
\text { May } 26, \\
\text { Sept. } 16\end{array}$ & $\begin{array}{l}1936 \\
1936 \\
1936\end{array}$ & $\begin{array}{l}18.63 \\
11.79 \\
12.92\end{array}$ & & $\begin{array}{r}18.000 \\
5.300 \\
6.720\end{array}$ \\
\hline 1937 & $\begin{array}{l}\text { Mar. } 10, \\
\text { Apr. } 14, \\
\text { May } 26,\end{array}$ & $\begin{array}{l}1937 \\
1937 \\
1937\end{array}$ & $\begin{array}{l}12.99 \\
12.23 \\
13.14\end{array}$ & b & $\begin{array}{l}5,300 \mathrm{c} \\
4.880 \\
5,760\end{array}$ \\
\hline 1938 & $\begin{array}{l}\text { JuIy } 4, \\
\text { MaI. } 5, \\
\text { MaI. } 18, \\
\text { May } 6, \\
\text { Sept. } 12 . \\
\text { Sept. } 17 .\end{array}$ & $\begin{array}{l}1938 \\
1938 \\
1938 \\
1938 \\
1938 \\
1938\end{array}$ & $\begin{array}{l}17.5 \\
12.90 \\
17.21 \\
10.58 \\
11.03 \\
16.58\end{array}$ & b & $\begin{array}{r}12.700 \\
4.200 \mathrm{c} \\
11.200 \\
3.540 \\
3.800 \\
9.800\end{array}$ \\
\hline 1939 & $\begin{array}{l}\text { Mar. } 17 . \\
\text { Mar. } 21 .\end{array}$ & $\begin{array}{l}1939 \\
1939\end{array}$ & $\begin{array}{l}15.45 \\
11.59\end{array}$ & b & $\begin{array}{l}6.300 \mathrm{c} \\
4.370\end{array}$ \\
\hline 1940 & $\begin{array}{l}\text { Mar. 22, } \\
\text { Mpr. } 2 .\end{array}$ & $\begin{array}{l}1940 \\
1940\end{array}$ & $\begin{array}{l}11.06 \\
17.32\end{array}$ & $\mathbf{b}$ & 11.700 \\
\hline 1941 & $\begin{array}{l}\text { Mar. } 4, \\
\text { Mar. } 12, \\
\text { Mar. } 25, \\
\text { Apr. } 2,\end{array}$ & $\begin{array}{l}1941 \\
1941 \\
1941 \\
1941\end{array}$ & $\begin{array}{l}10.98 \\
13.24 \\
13.52 \\
11.78\end{array}$ & b & $\begin{array}{l}-. \\
5.550 \\
5.820 \\
4.350\end{array}$ \\
\hline 1942 & $\begin{array}{l}\text { May } 16, \\
\text { May } 30, \\
\text { June } 4, \\
\text { June } 29, \\
\text { Aug. } 2, \\
\text { Aug. } 31, \\
\text { Sept. } 5, \\
\text { Sept. } 21 .\end{array}$ & $\begin{array}{l}1942 \\
1942 \\
1942 \\
1942 \\
1942 \\
1942 \\
1942 \\
1942\end{array}$ & $\begin{array}{l}12.98 \\
15.74 \\
19.23 \\
13.96 \\
18.28 \\
15.23 \\
16.18 \\
11.52\end{array}$ & & $\begin{array}{r}4.870 \\
7.940 \\
21.400 \\
5.810 \\
16.600 \\
7.280 \\
8.620 \\
3.680\end{array}$ \\
\hline 1943 & $\begin{array}{l}\text { Feb. } 24, \\
\text { Mar. } 27, \\
\text { June } 18, \\
\text { June } 27, \\
\text { July } 7, \\
\text { Aug. } 15,\end{array}$ & $\begin{array}{l}1943 \\
1943 \\
1943 \\
1943 \\
1943 \\
1943\end{array}$ & $\begin{array}{l}15.17 \\
11.86 \\
17.35 \\
14.69 \\
11.65 \\
12.03\end{array}$ & & $\begin{array}{r}7.200 \\
3,920 \\
12,000 \\
6.630 \\
3.920 \\
4.160\end{array}$ \\
\hline
\end{tabular}

b Affected by ice.

c About. 
06-4855.00 Big Sioux River at Akron. Iowa--(Continued)

Peak stages and discharges

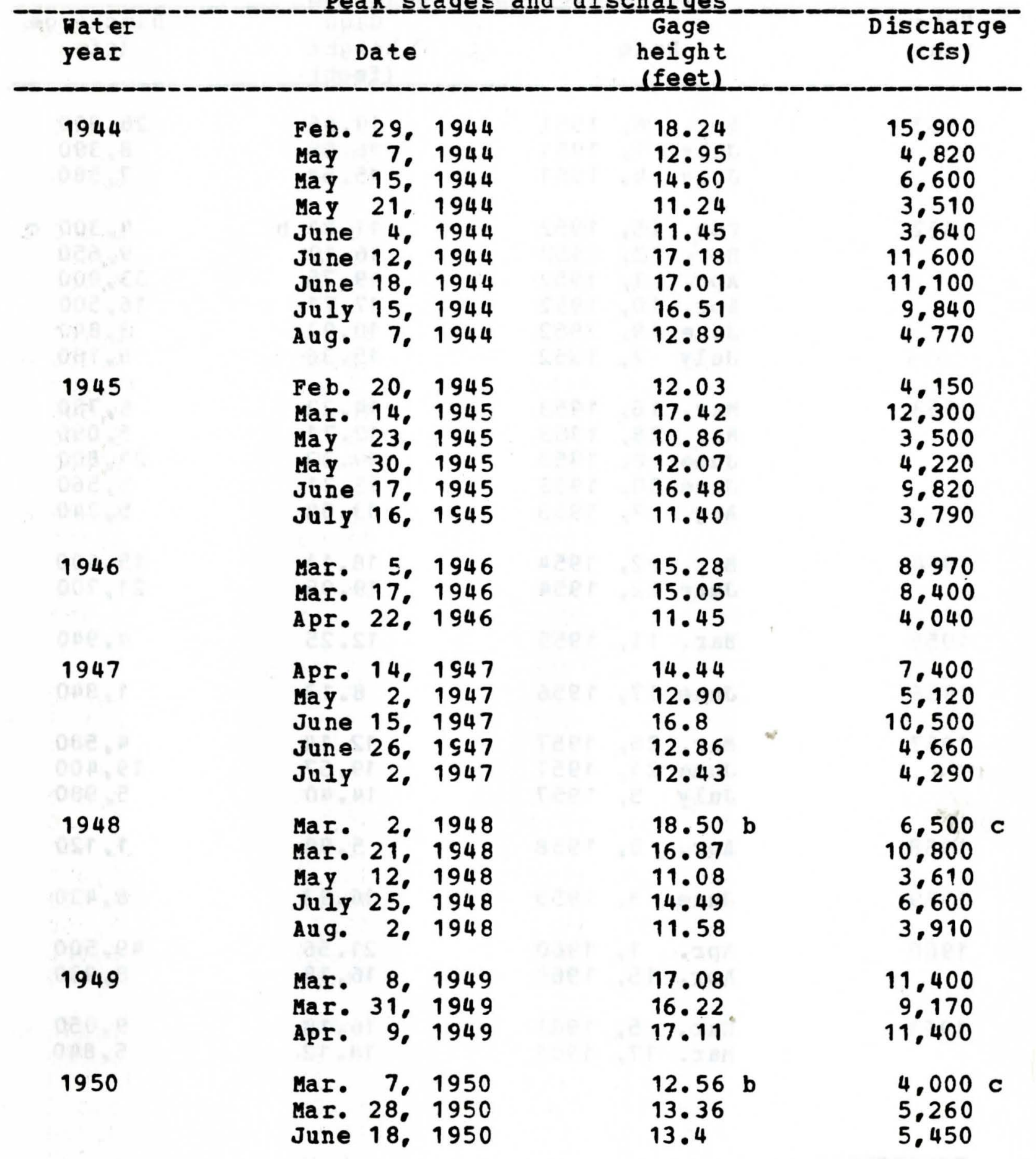

b Affected by ice.

c About. 
06-4855.00 Big Sioux River at Akron, Iowa--(Continued)

Peak stag£s_and_di scharges

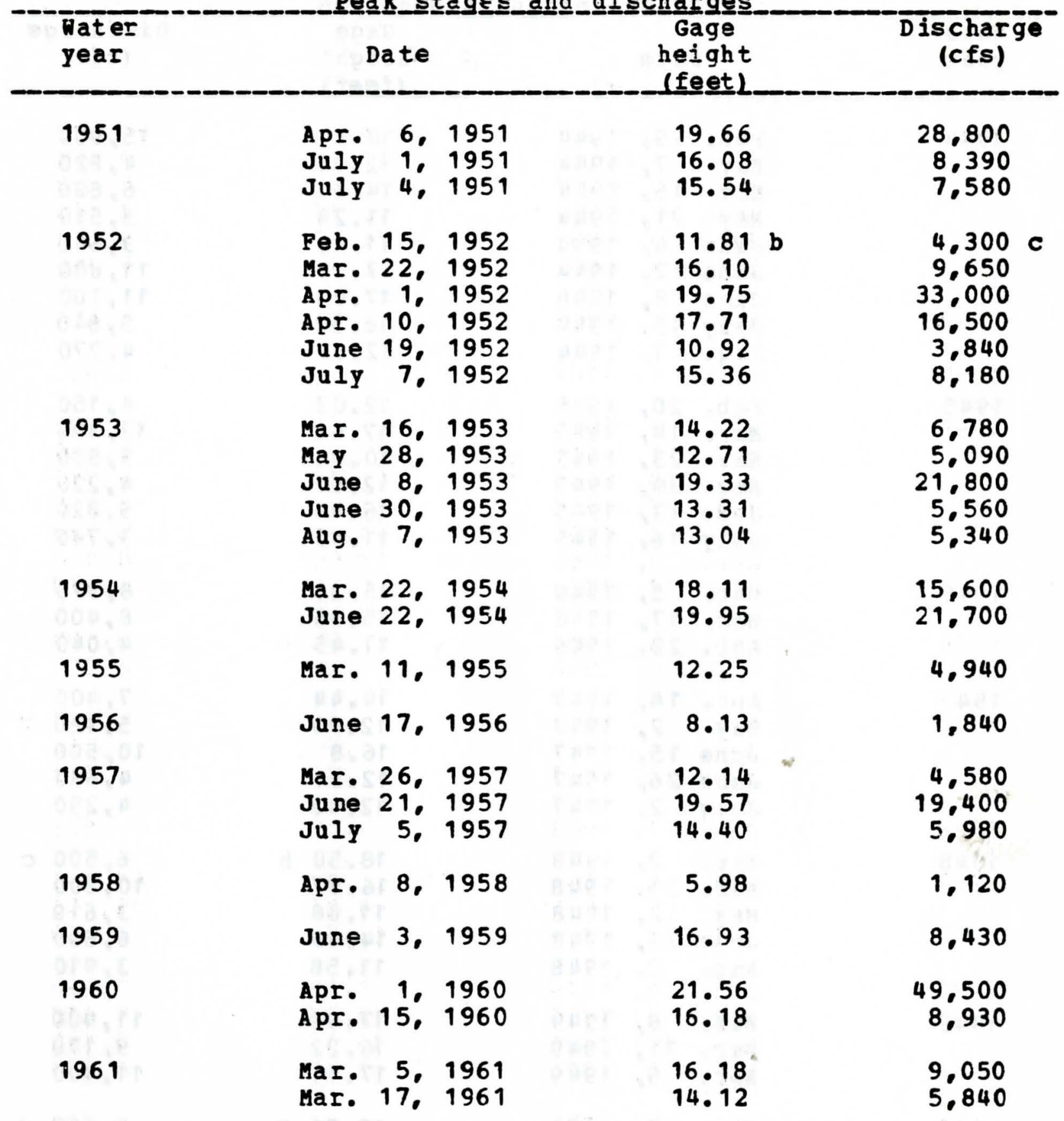

b Affected by ice.

c About. 
06-4855.00 Big Sioux River at Akron, Iowa--(Continued)

Peak_s_tages_and_di

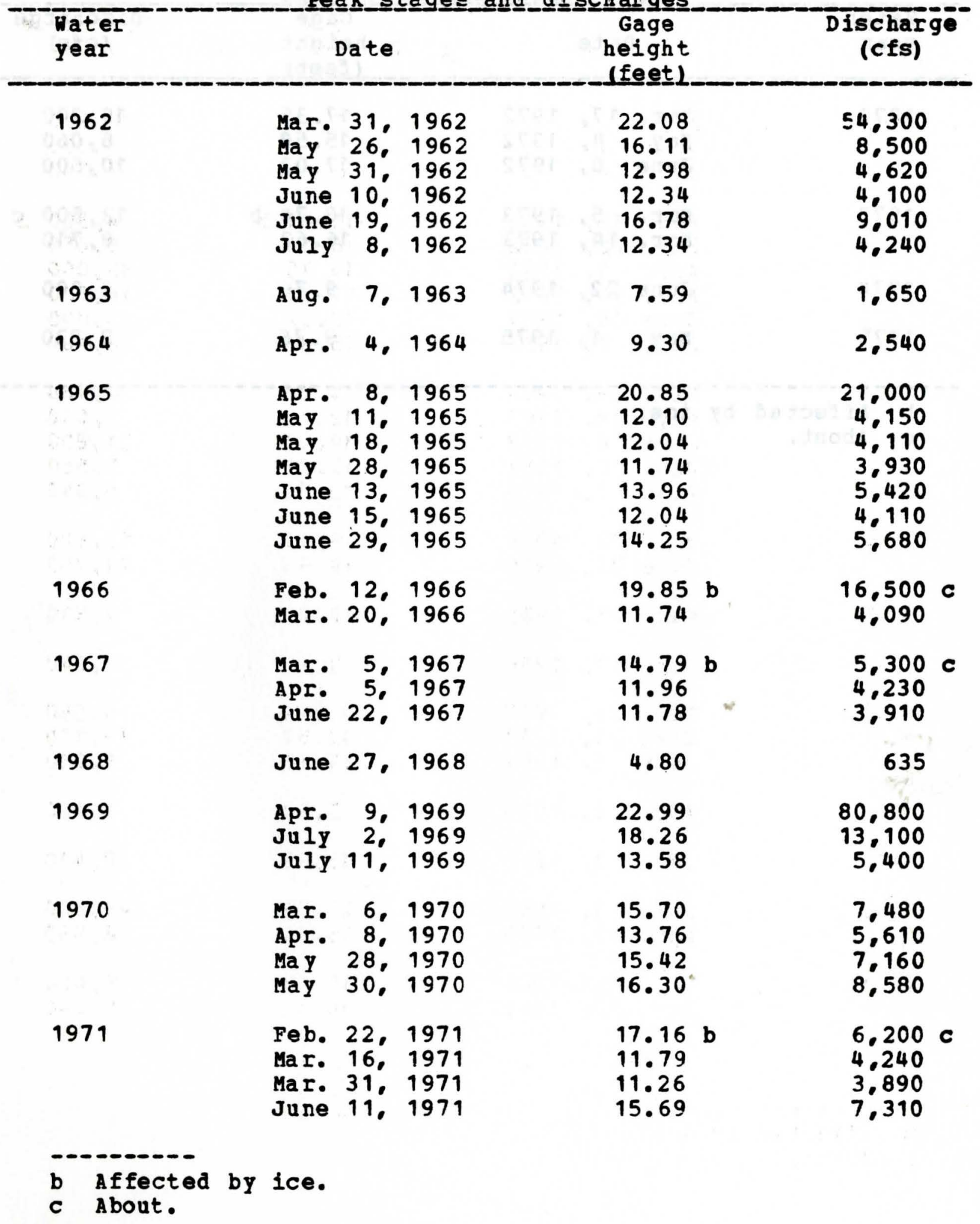


06-4855.00 Big Sioux River at Akron, Iowa--(Continued)

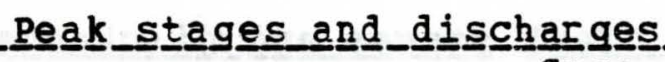

Water

year

1972

1973

1974

1975
Date

MaI. 17, 1972

May 4, 1972

June 8, 1972

Har. 5, 1973

Mar. 14, 1973

June 22, 1974

May 1, 1975
Gage height (feet)

$$
\begin{array}{r}
17.35 \\
15.58 \\
17.02
\end{array}
$$

$18.74 \mathrm{~b}$

16.62

9.76

9.76
Discharge

(cfs)

10.200

8,060

10.500

$12.500 \mathrm{C}$

8,710

3.000

2.920

b Affected by ice.

c About. 


\section{5-4630.90 Black Hawk Creek at Grundy Center, Iowa}

Location.--Iat $42022^{\circ}$, long $92046^{\circ}$, in NW1/4 sec.7, T.87 N., R. 16 1.. Grundy County, at bridge on State Highway 14, at north edge of Grundy Center.

Drainage area.--56.9 sq mi.

Gage.--Crest-stage gage.

Stage-discharge relation.--Defined by current-meter measurements. Remarks.--only annual peaks are shown.

Pea k__stages and_di

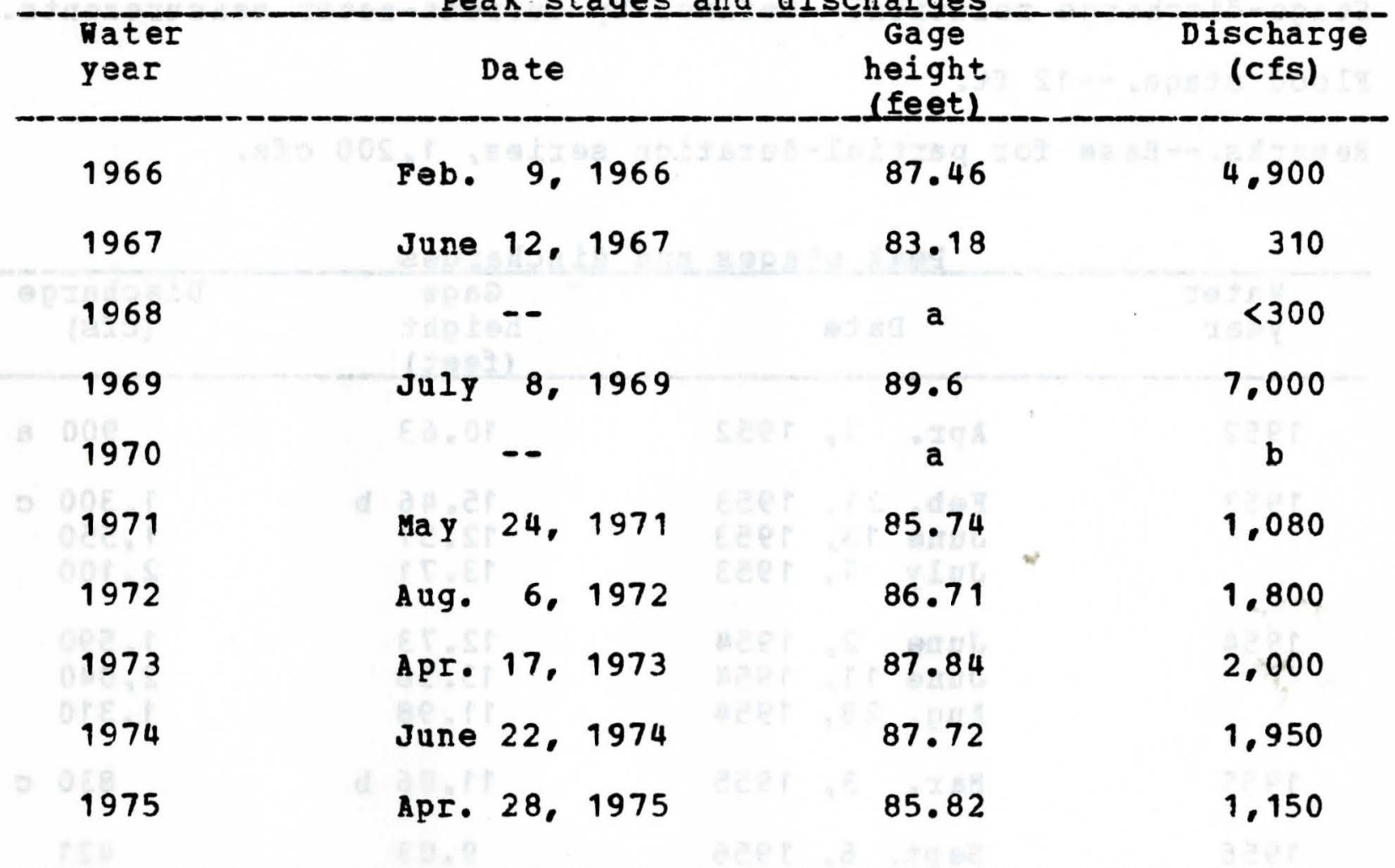

a Peak stage did not reach bottom of gage.

b Discharge not determined. 
Location.--Iat $42 \circ 24 \cdot 28$ ", Iong $92027 \cdot 47 "$, in $511 / 4$ NE1/4 sec. 27 , T. 88 N.. R. 14 N.. Black Hawk County, on left bank 35 ft downstream from bridge on State Highway $58,0.2$ mile northwest of Chicago Great Western Railway tracks at the west edge of Hudson, 4.5 miles upstream from Prescotts Creek, and 9.6 miles upstream from mouth.

Drainage area.--303 sq mi.

Gage.--Water-stage recorder. Datum of gage is $865.03 \mathrm{ft}$ above mean sea level.

Stage-discharge relation.--Defined by current-meter measurements. Flood stage. $-12 \mathrm{ft}$.

Remarks.--Base for partial-duration series, 1,200 cfs.

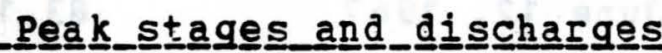

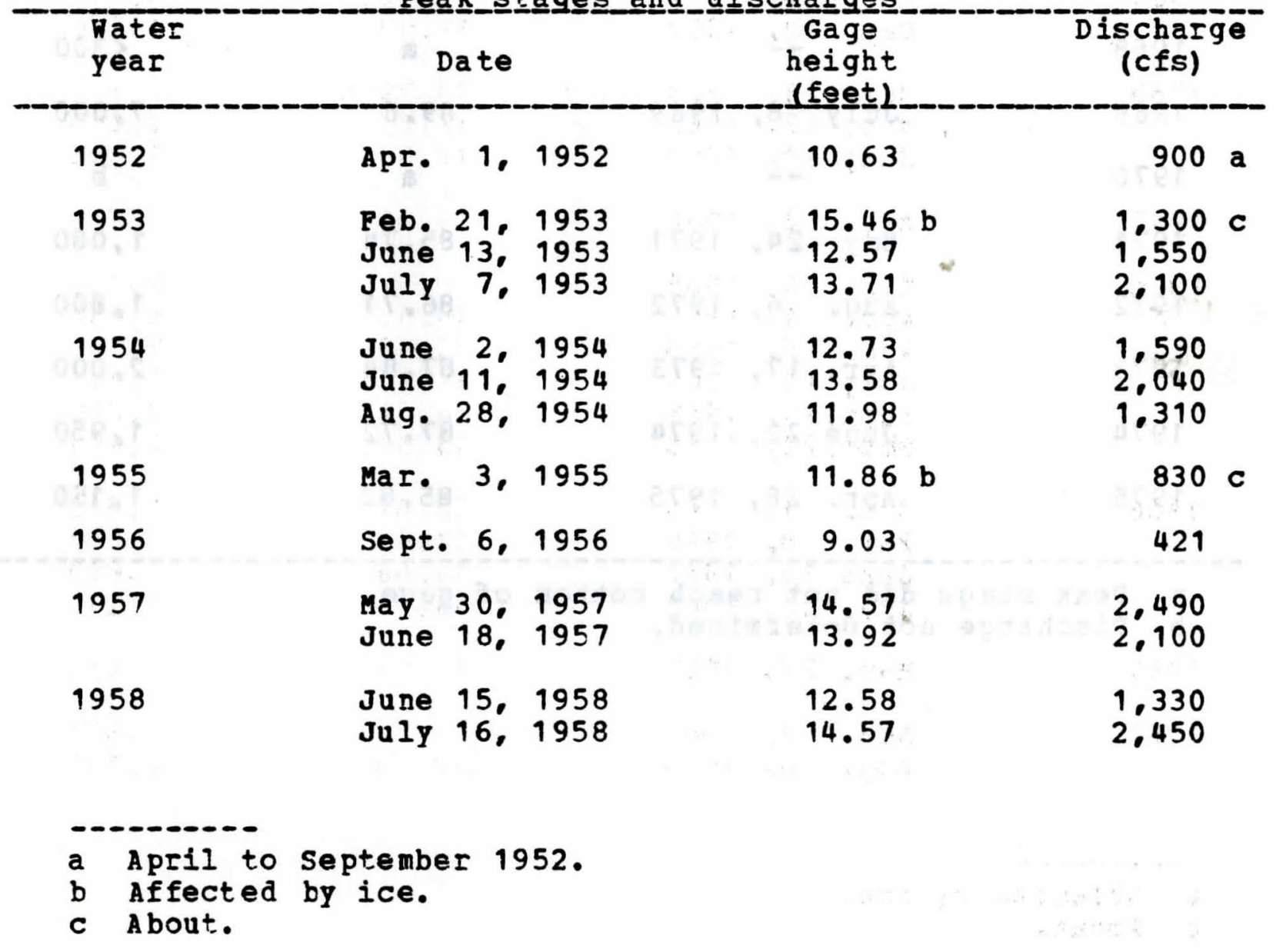


05-4635.00 Black Hawk Creek at Hudson. Iowa--(Continued)

Peak_stages_and di scharges

\begin{tabular}{|c|c|c|c|c|c|}
\hline $\begin{array}{l}\text { Bater } \\
\text { year }\end{array}$ & Date & & $\begin{array}{l}\text { Gage } \\
\text { height } \\
\text { leet) }\end{array}$ & & $\begin{array}{c}\text { Discharg } \\
\text { (cfs) }\end{array}$ \\
\hline 1959 & $\begin{array}{l}\operatorname{Mar.} 20, \\
\operatorname{Mar} .24, \\
\operatorname{Mar} .27\end{array}$ & $\begin{array}{l}1959 \\
1959 \\
1959\end{array}$ & $\begin{array}{l}16.56 \\
14.69 \\
16.48\end{array}$ & b & $\begin{array}{l}7.250 \\
2.580 \\
8.750\end{array}$ \\
\hline 1960 & $\begin{array}{l}\text { Jan. } 14, \\
\text { Mar. } 31, \\
\text { Apr. } 18, \\
\text { May } 8 .\end{array}$ & $\begin{array}{l}1960 \\
1960 \\
1960 \\
1960\end{array}$ & $\begin{array}{l}12.77 \\
16.93 \\
14.97 \\
14.75\end{array}$ & b & $\begin{array}{l}1,520 \\
9,000 \\
2,960 \\
2,710\end{array}$ \\
\hline 1961 & $\begin{array}{l}\text { Feb. } 20, \\
\text { Feb. } 23, \\
\operatorname{Mar.} 7, \\
\operatorname{Mar.} 15, \\
\operatorname{Mar} .26,\end{array}$ & $\begin{array}{l}1961 \\
1961 \\
1961 \\
1961 \\
1961\end{array}$ & $\begin{array}{l}13.52 \\
14.93 \\
14.09 \\
12.35 \\
11.88\end{array}$ & $\mathbf{b}$ & $\begin{array}{l}1.400 \\
2.950 \\
2.310 \\
1.480 \\
1.320\end{array}$ \\
\hline 1962 & $\begin{array}{ll}\text { Mar. } & 28 \\
\text { May } 12,\end{array}$ & $\begin{array}{l}1962 \\
1962\end{array}$ & $\begin{array}{l}15.70 \\
11.99\end{array}$ & & $\begin{array}{l}5.400 \\
1.360\end{array}$ \\
\hline 1963 & $\begin{array}{l}\text { Mar. } 16, \\
\text { Mar. } 17 \% \\
\text { July } 20 .\end{array}$ & $\begin{array}{l}1963 \\
1963 \\
1963\end{array}$ & $\begin{array}{l}13.79 \\
13.69 \\
12.00\end{array}$ & b & $\begin{array}{l}2.080 \\
1.360\end{array}$ \\
\hline 1964 & Lay & 1964 & 9.61 & & 825 \\
\hline 1965 & $\begin{array}{l}\text { Har. } 1, \\
\text { Apr. } 1 \% \\
\text { Apr. } 6, \\
\text { JuIy } 10, \\
\text { Sept. } 10, \\
\text { Sept. 22. }\end{array}$ & $\begin{array}{l}1965 \\
1965 \\
1965 \\
1965 \\
1965 \\
1965\end{array}$ & $\begin{array}{c}-- \\
16.01 \\
16.35 \\
14.01 \\
14.32 \\
13.84\end{array}$ & $*$ & $\begin{array}{l}2.000 \\
5.640 \\
7.500 \\
2.140 \\
2.440 \\
2.150\end{array}$ \\
\hline 1966 & $\begin{array}{l}\text { oct. 1. } \\
\text { Feb. 9, } \\
\text { June 13, } \\
\text { Aug. } 22,\end{array}$ & $\begin{array}{l}1965 \\
1966 \\
1966 \\
1966\end{array}$ & $\begin{array}{l}12.67 \\
14.82 \\
14.68 \\
13.98\end{array}$ & & $\begin{array}{l}1.580 \\
3.080 \\
3.030 \\
2.240\end{array}$ \\
\hline 1967 & Mar. 27. & 1967 & 10.11 & & 852 \\
\hline 1968 & $\begin{array}{ll}\text { Aug. } & 6 \\
\text { Aug. } & 8,\end{array}$ & $\begin{array}{l}1968 \\
1968\end{array}$ & $\begin{array}{l}15.26 \\
13.88\end{array}$ & & $\begin{array}{l}3.470 \\
2.180\end{array}$ \\
\hline
\end{tabular}


05-4635.00 Black Hawk Creek at Hudson. Iowa--(Continued)

Peak_stages and di

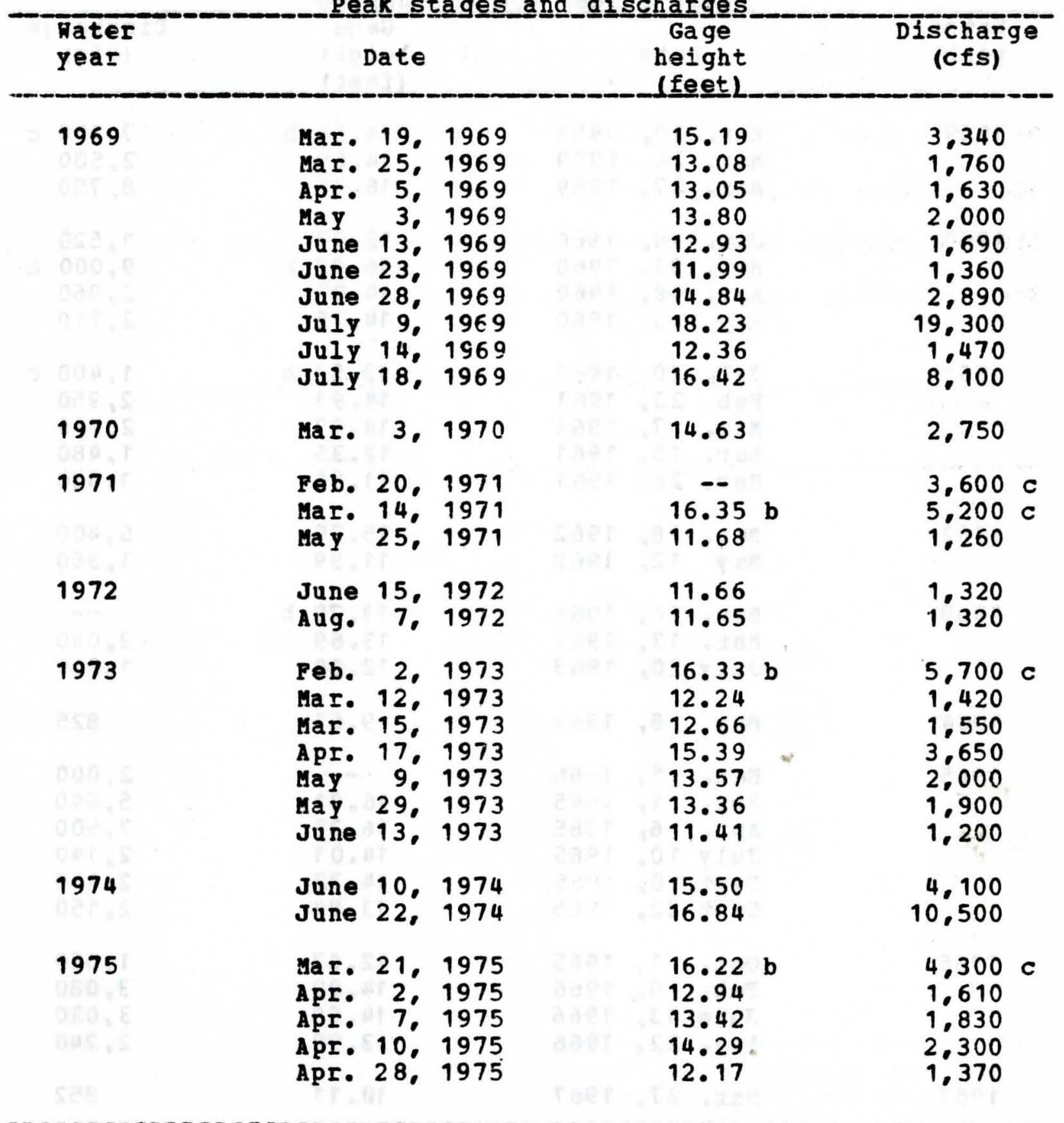

b Affected by ice.

c About. 


\section{5-4815.10 Bluff Creek at Pilot Mound. Iowa}

Location.--Iat $42010^{\prime}$, long $94001^{\circ}$, in NN1/4 seC.20, T.85 N., R. 27 W., Boone County, at bridge on State Highway 329 , at northwest edge of Pilot Mound.

Drainage area.- $-23.5 \mathrm{sq} \mathrm{mi}$.

Gage.--Crest-stage gage.

Stage-discharge relation.--Defined by current-meter measurements. Remarks.--only annual peaks are shown.

Peak_stages and_discharges

\begin{tabular}{|c|c|c|c|}
\hline $\begin{array}{l}\text { Hater } \\
\text { year }\end{array}$ & Date & $\begin{array}{l}\text { Gage } \\
\text { height } \\
\text { (feet) }\end{array}$ & $\begin{array}{c}\text { Discharge } \\
\text { (cfs) }\end{array}$ \\
\hline 1966 & - & a & b \\
\hline 1967 & -- & a & t \\
\hline 1968 & - & a & b \\
\hline 1969 & Mar. 19, 1969 & 84.55 & 325 \\
\hline 1970 & -- & a & $\mathrm{b}$ \\
\hline 1971 & Feb. 18, 1971 & $85.55 c^{2}$ & 195 \\
\hline 1972 & -- & a & b \\
\hline 1973 & Sept.26, 1973 & 85.46 & 610 \\
\hline 1974 & -- & a & $\mathbf{b}$ \\
\hline 1975 & Apr. 8,1975 & 84.26 & $\mathbf{b}$ \\
\hline
\end{tabular}

a Peak stage did not reach bottom of gage.

b Discharge not determined.

c Affected by ice. 
Location.--Lat $42^{\circ} 26^{\circ} 01 "$ " long $93048^{\prime} 12^{\prime \prime}$, in NH1/4 SE1/4 sec. 18 , T. 88 N.. R. 25 W.. Hamilton County, on right bank 100 ft upstream from bridge on State Highway 17, 2.5 miles southeast of junction of U.S. Highway 20 and State Highway 17 in Webster City, and 3.2 miles downstream from Brewers Creek.

Drainage area. $--844 \mathrm{sg} \mathrm{mi}$.

Gage.--Water-stage recorder and concrete control. Datum cf gage is $989.57 \mathrm{ft}$ above mean sea level. Prior to June 26, 1940 . nonrecording gage at same site and datum.

Stage-discharge relation.--Defined by current-meter measurements. Flood stage. $--10 \mathrm{ft}$.

Remarks.--Base for partial-duration series. 2.200 cfs. Base was 2,500 prior to 1961 .

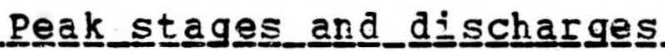

\begin{tabular}{|c|c|c|c|c|c|c|}
\hline $\begin{array}{l}\text { Water } \\
\text { year }\end{array}$ & & Date & & $\begin{array}{l}\text { Ga ge } \\
\text { height } \\
\text { feet. }\end{array}$ & & $\begin{array}{c}\text { (cfs) } \\
\text { (cfser }\end{array}$ \\
\hline 1918 & June & 10. & 1918 & $19.1 \mathrm{a}$ & & $21.500 \mathrm{~b}$ \\
\hline 1932 & June & 18 & 1932 & 16.0 & $*$ & 15,000 \\
\hline 1940 & Aug. & 15 & 1940 & 4.40 & & $740 \mathrm{c}$ \\
\hline 1941 & June & 3. & 1941 & 5.4 & & 1.500 \\
\hline 1942 & $\begin{array}{l}\text { June } \\
\text { June }\end{array}$ & 30 & $\begin{array}{l}1942 \\
1942\end{array}$ & $\begin{array}{l}6.7 \\
7.52\end{array}$ & & $\begin{array}{l}2.620 \\
3.060\end{array}$ \\
\hline 1943 & Mar. & 16 & 1943 & 6.71 & & 2,410 \\
\hline 1944 & $\begin{array}{l}\text { May } \\
\text { June }\end{array}$ & 20, & $\begin{array}{l}1944 \\
1944\end{array}$ & $\begin{array}{l}11.4 \\
13.70\end{array}$ & & $\begin{array}{r}7.090 \\
10.200\end{array}$ \\
\hline
\end{tabular}

a Maximum stage known since 1896, from floodmarks, from information by local resident.

b About.

c Maximum for period March to september 1940. 
05-4810.00 Boone River near Hebster City. Iowa.--(Continued)

Peak stages and discharges

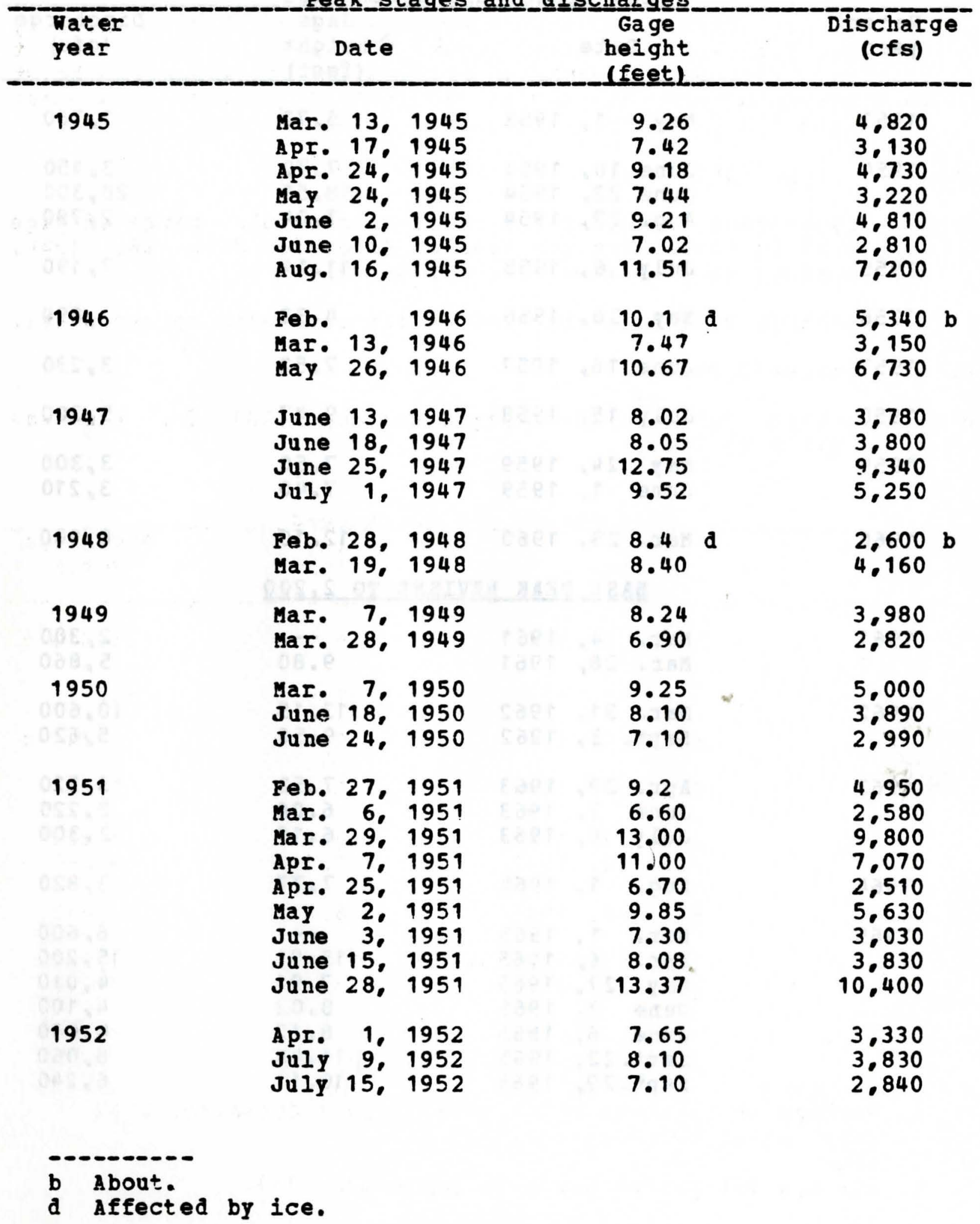


05-4810.00 Boone River near Webster City, Iowa.--(Continued)

Peak﹎stages_and_di scharges

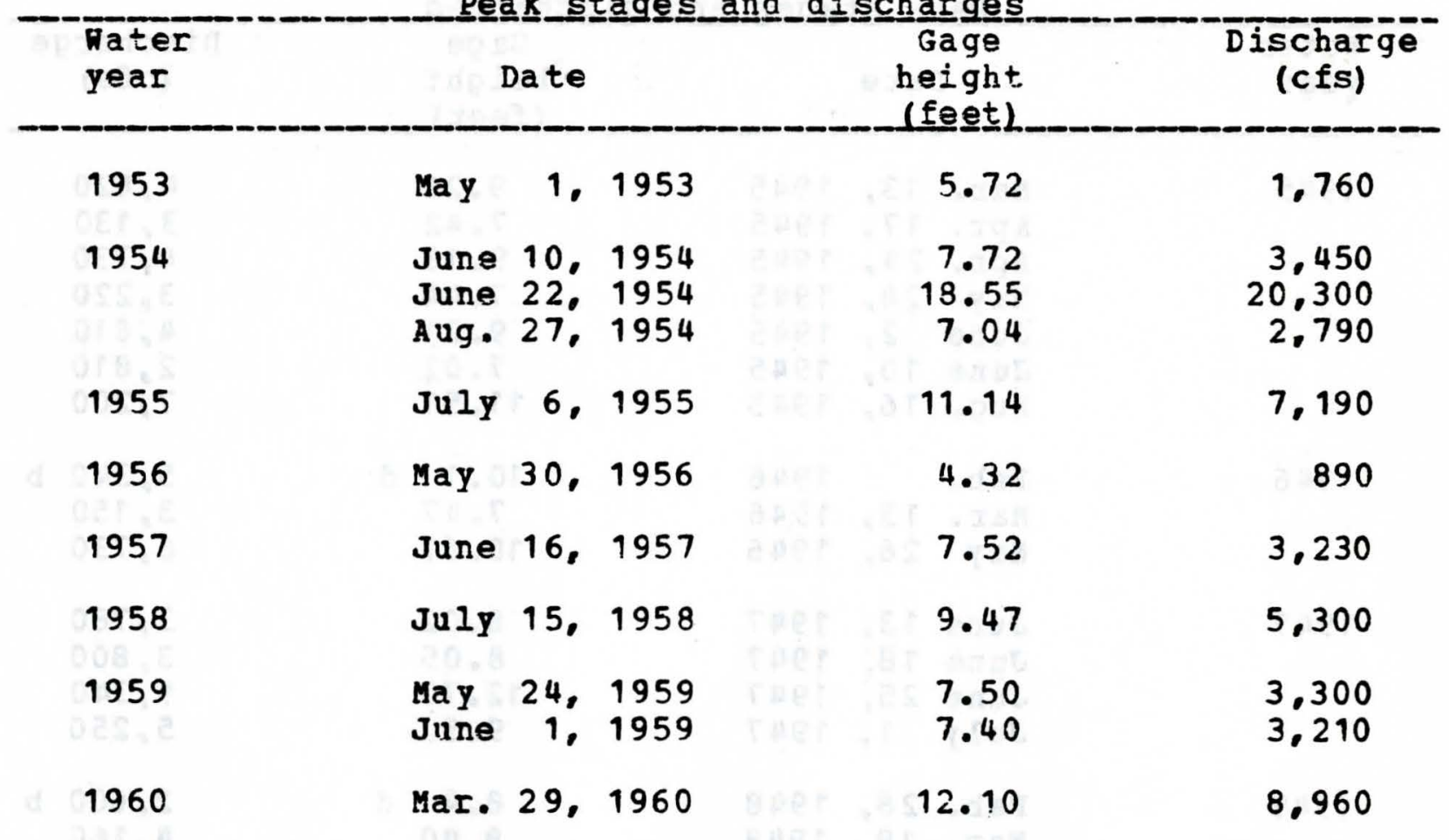

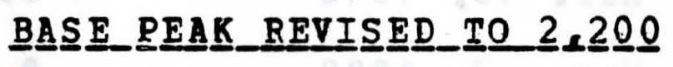

1961

MaI. 4,1961

Mar. 28, 1961

9.80

2.300

Mar. 31, 1962

se pt. 3, 1962

13.15

9.56

10.600

5.620

1963

Apr. 29, 1963

June 7, 1963

7.52

6.06

July 6, 1963

6.19

3.520

Aug. 1, 1964

7.77

2,220

1964

$--$

15. 91

7.91

8.02

8.12

11.48

10. 11

2.300

MaI. 1. 1965

Apr. 6, 1965

May 27, 1965

June 3, 1965

June 6, 1965

Se pt.22, 1965

Sept.29, 1965

3,820

6.600

15,200

4,010

4.100

4.060

8.060

6.240 
55-4810.00 Boone River near Hebster City, Iowa.--(Continued)

Peak_stages_and di scharges

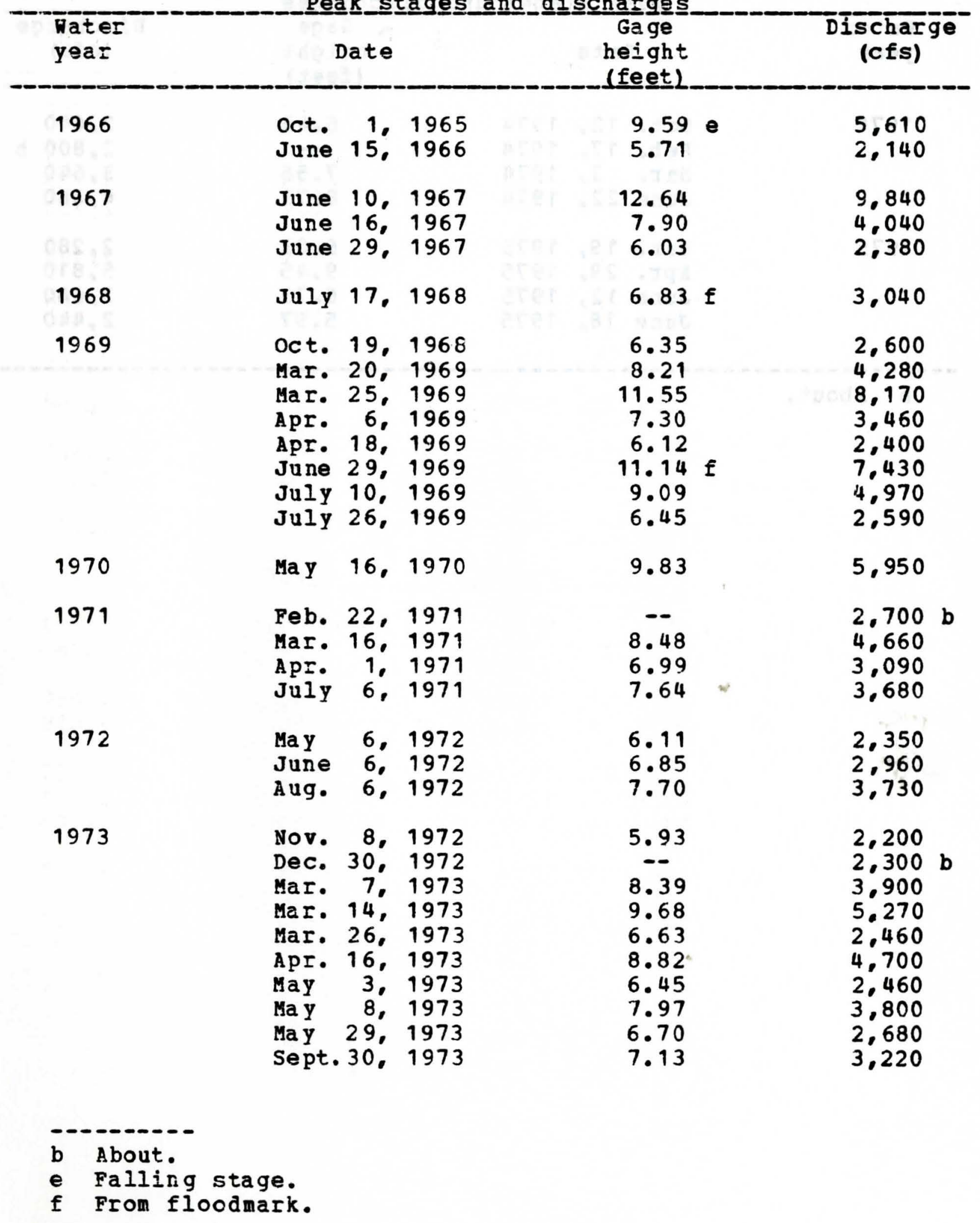


05-4810.00 Boone River near Webster City, Iowa.--(Continued)

Peak _stages_and_discharges

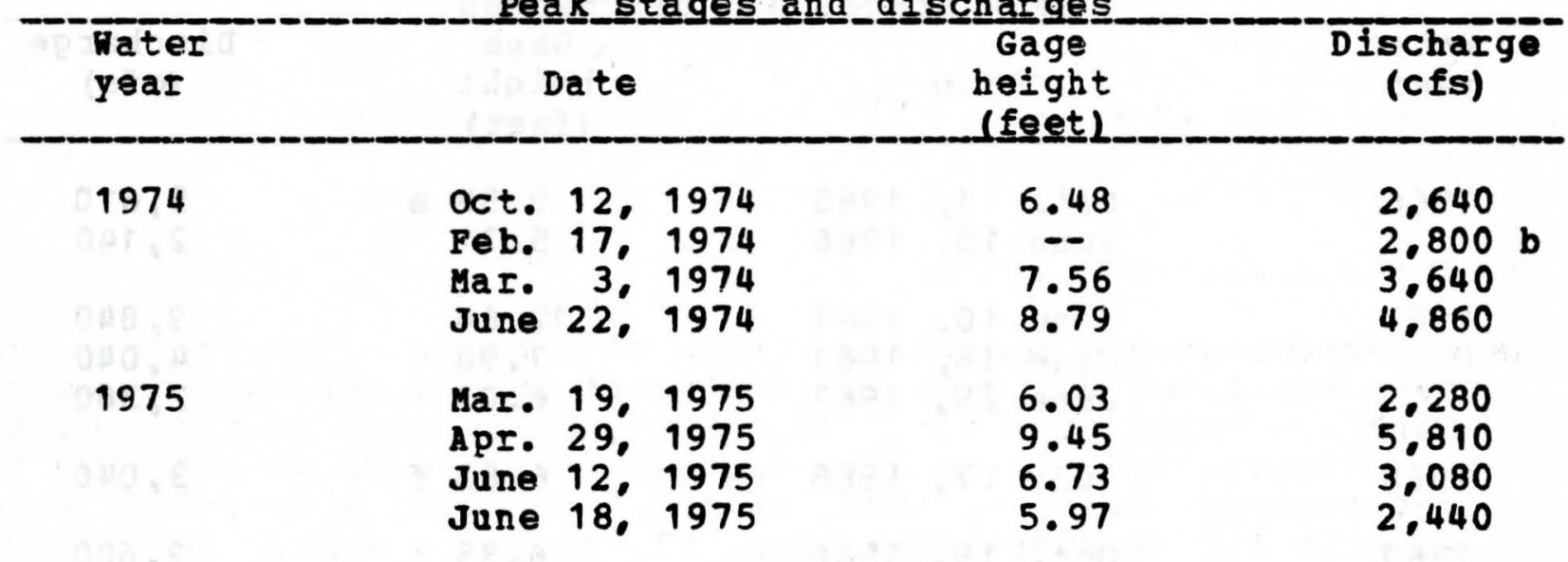

b About. 
Location.--Lat 41038133", long 95046.57", in SE1/4 NW1/4 sec.19, T.79 N.. R.42 W., Harrison County, on left bank $9 \mathrm{ft}$ downstream from Illincis Central Railroad bridge at Logan, 0.4 mile dowrstream from Elk Grove Creek, 10.5 miles upstream from willow Creek, and 15.8 miles upstream from mouth.

Drainage area.--871 sq mi.

Gage.--Hater-stage recorder. Latum of gage is 1,009.38 ft above mean sea level (Chicago and Northwestern Railway Company bench mark). Prior to A Pr. 17, 1925, chain gage at site $300 \mathrm{ft}$ downstream; Apr. 17 to July 1, 1925, chain gage at site $600 \mathrm{ft}$ downstream; Nov. 4, 1937, tc Mar. 16, 1952, wire-weight gage at site 300 ft downstream; Mar. 17, 1952, to Sept. 30, 1957. wire-weight gage $100 \mathrm{ft}$ upstream on bridge on U.S. Highway 30; all at same datum. oct. 1, 1957, to oct. 18, 1960, wireweight gage at site $300 \mathrm{ft}$ downstream. Supplementary waterstage recorder operating above $4.8 \mathrm{ft}$ gage height cct. 22 . 1946, to 0ct. 7, 1954, at site $100 \mathrm{ft}$ upstream and cct. 8, 1954, to oct. 18, 1960, supplementary water-stage reccrder at present site, both at same datum.

Ficod stage. - $19 \mathrm{ft}$.

Stage-discharge relation.--Defined by current-meter measurements. Remarks.--Base for partial-duration series, 6,000 cfs.

Peak_stag ges and_di

\begin{tabular}{|c|c|c|c|c|}
\hline $\begin{array}{l}\text { Water } \\
\text { year }\end{array}$ & Date & & $\begin{array}{l}\text { Gage } \\
\text { height } \\
\text { (feest }\end{array}$ & $\begin{array}{c}\text { Discharge } \\
\text { (cfs) }\end{array}$ \\
\hline $1 \underline{8} \underline{8} 1$ & May & 1881 & 25. a & -- \\
\hline 1918 & June 5 . & 1918 & 17.9 & 8,710 \\
\hline 1919 & $\begin{array}{l}\text { Apr. } 23, \\
\text { June } 11, \\
\text { June } 21, \\
\text { July } 13,\end{array}$ & $\begin{array}{l}1919 \\
1919 \\
1919 \\
1919\end{array}$ & $\begin{array}{l}17.8 \\
16.7 \\
16.0 \\
16.5\end{array}$ & $\begin{array}{l}8.620 \\
7.640 \\
7.040 \\
7.470\end{array}$ \\
\hline 1920 & Aug. 20 . & 1920 & 10.7 & 3,210 \\
\hline 1921 & sept. 10. & 1921 & 13.5 & 6,890 \\
\hline
\end{tabular}


06-6095.00 Boyer River at Iogan. Iowa--(Continued)

Peak s_tages and_di

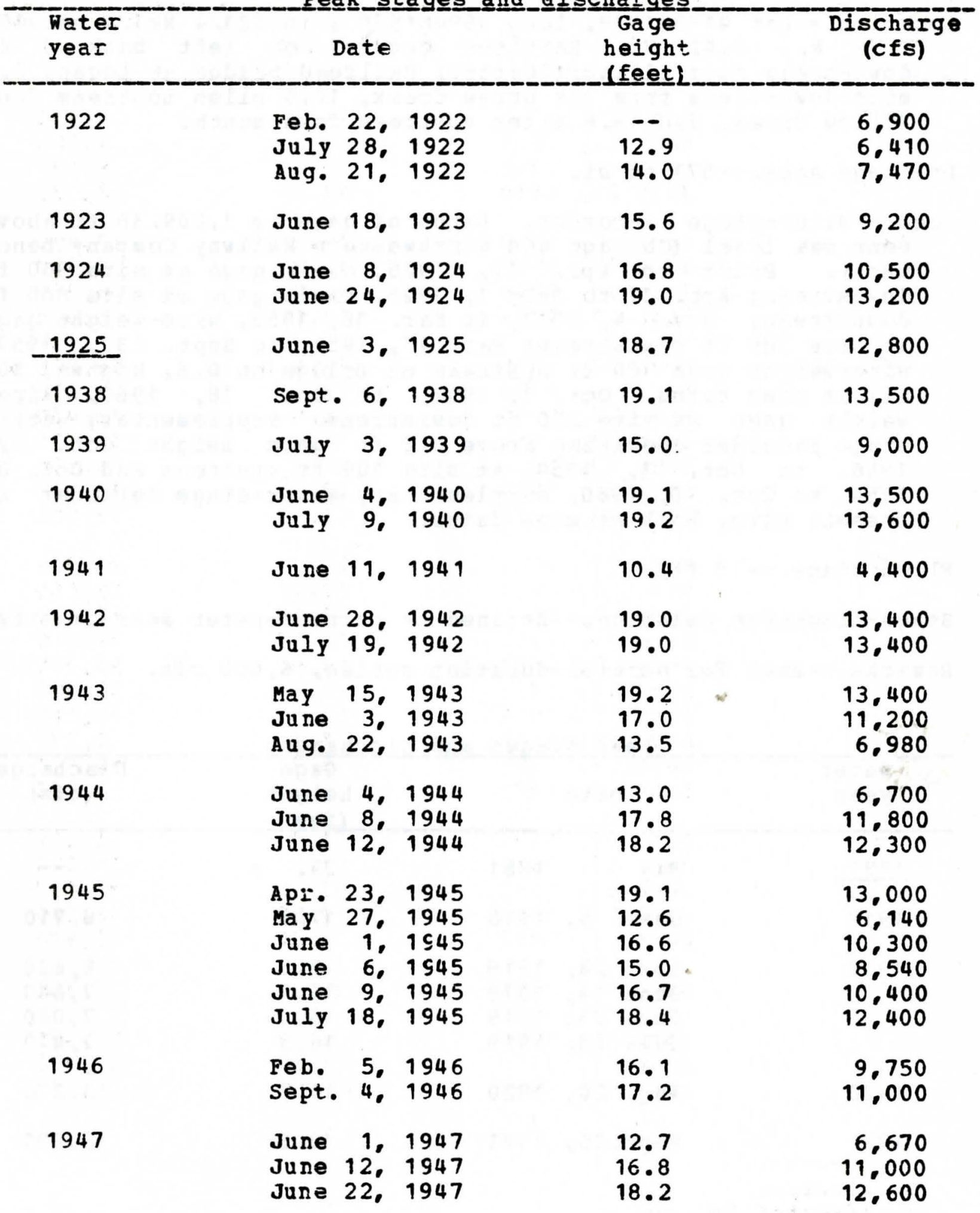


06-6095.00 Boyer River at Logan. Iowa--(Continued)

Feak stages and_discharges

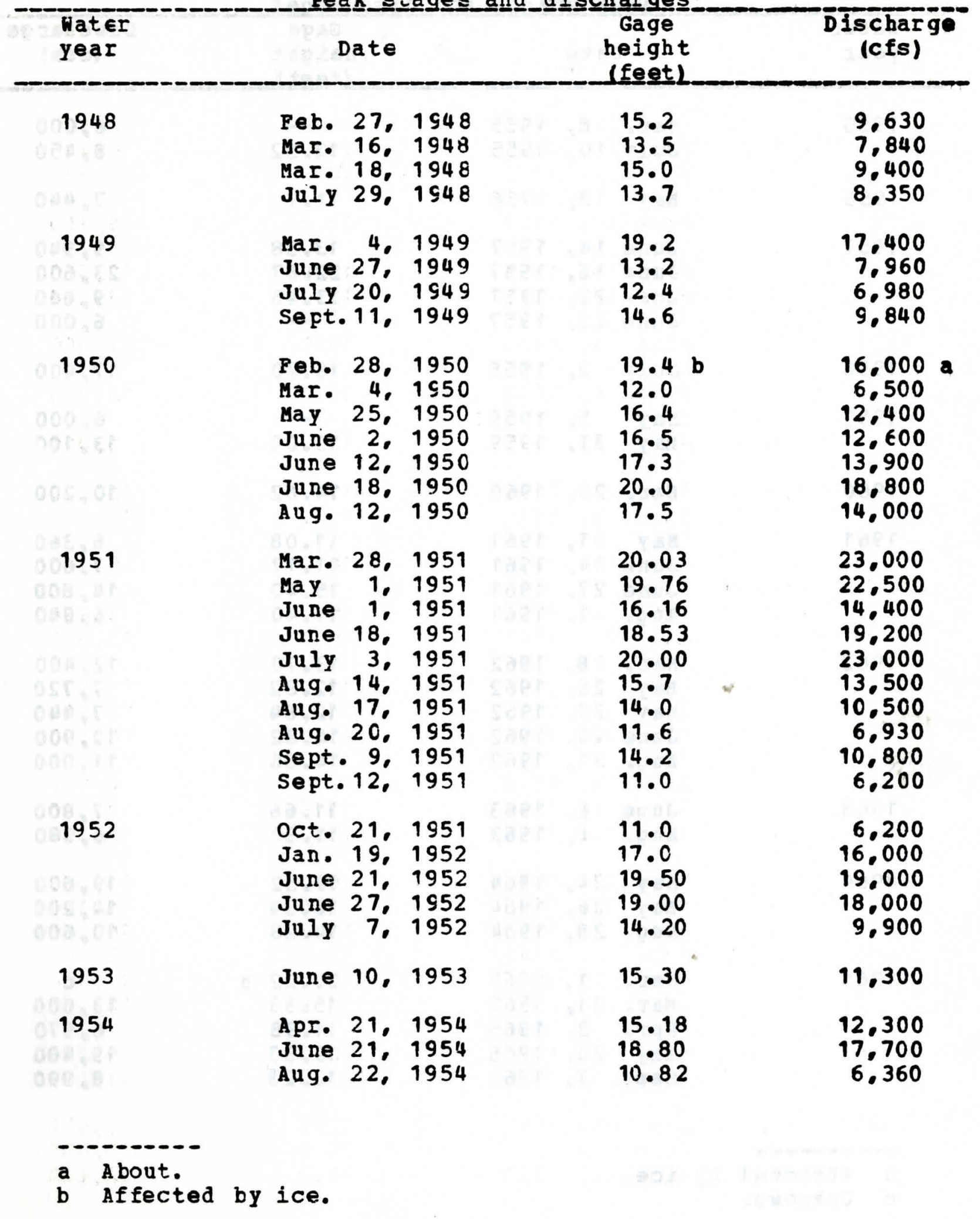


06-6095.00 Boyer River at Logan, Iowa--(Continued)

Peak_stages and_dí scharges

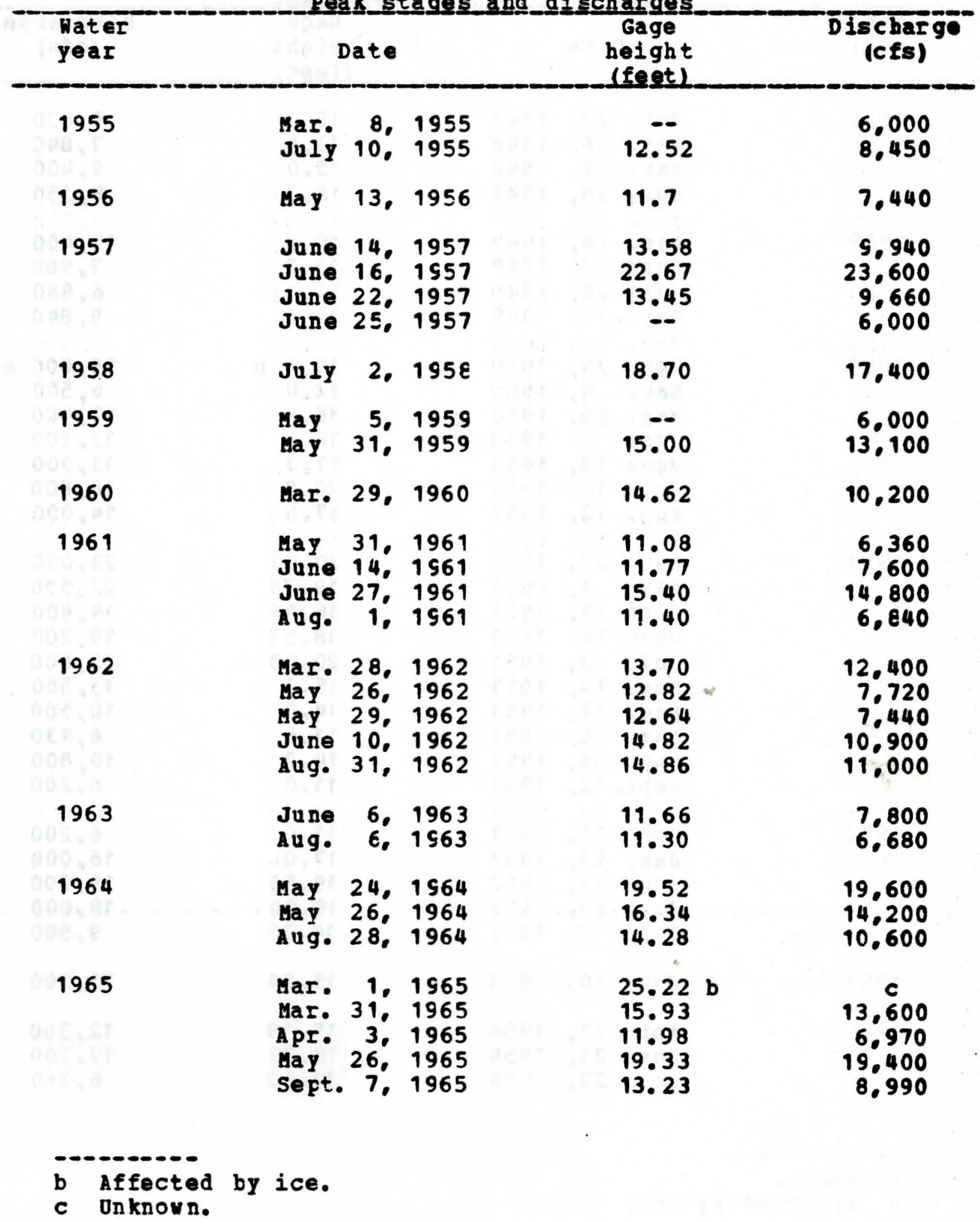


06-6095.00 Boyer River at Logan. Iowa--(Continued)

Peak_s_tagges_and di discharges

Water

year
Date
Gage height

(feet)

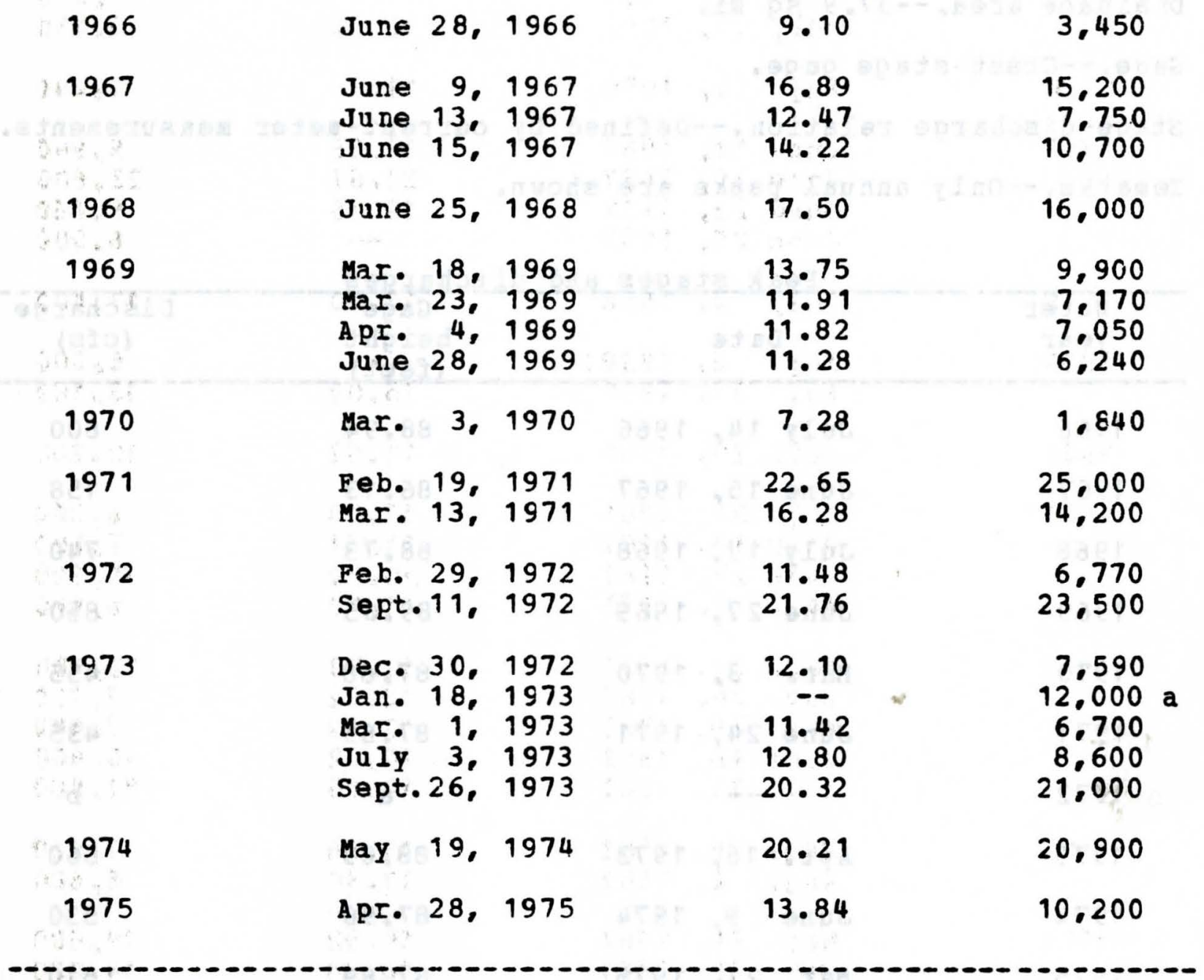

a About. 


\section{5-4208.55 Buck Creek near Oran, Iowa}

Location.--Lat $42043 \%$, long $92008 \%$ in NE1/4 sec.10, T.91 N.. R. 11 \%.. Bremer County. at bridge on state Highway 3, 2.5 miles northwest of oran. State Highway $3,2.5$ miles northwest of Oran.

Drainage area.--37.9 sq mi.

Gage.--Crest-stage gage.

Stage-discharge relation.--Defined by current-meter measurements. Remarks.--only annual peaks are shown.

Peak

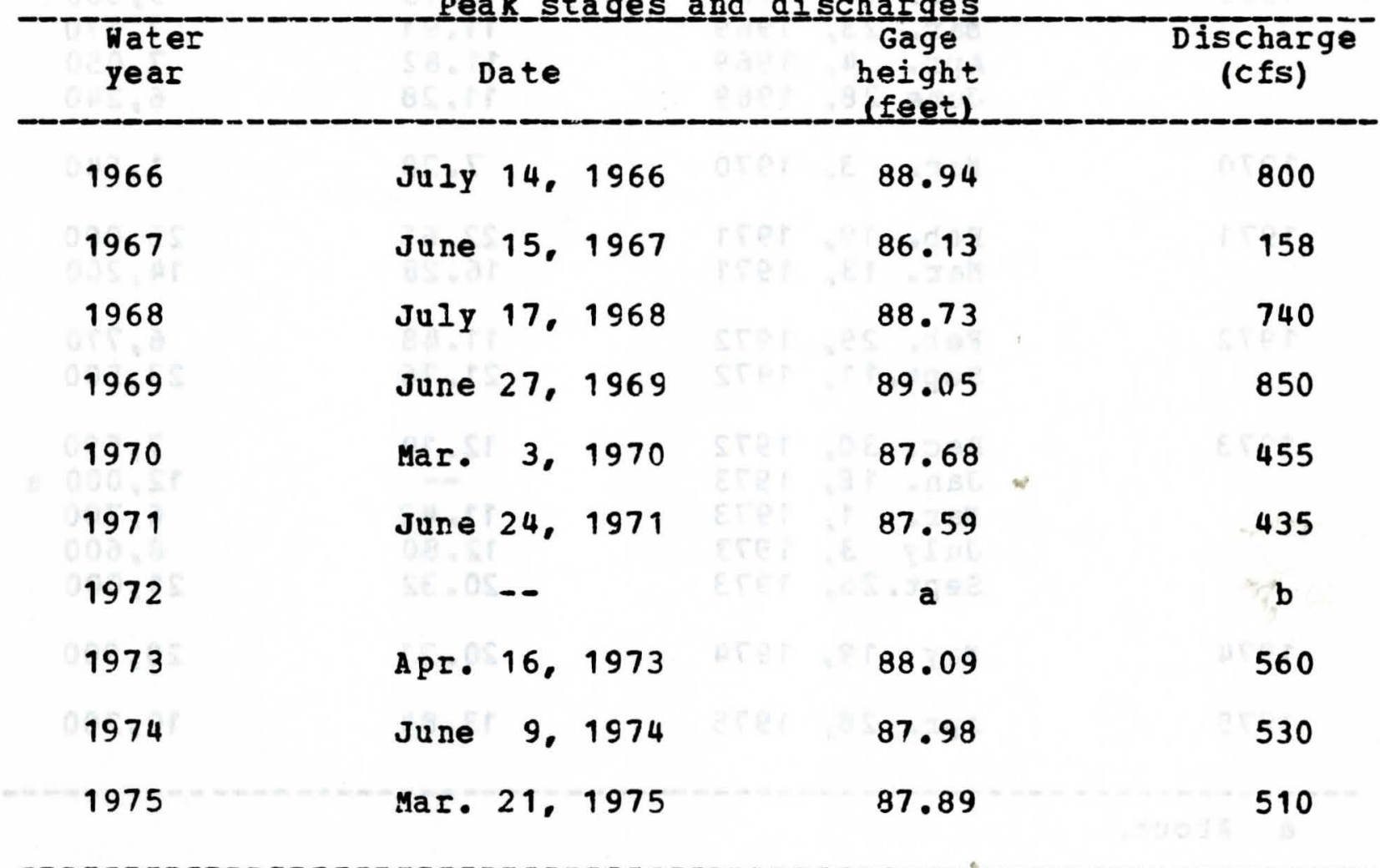

a Peak stage did not reach bottom of gage.

b Discharge not determined. 


\section{5-4215.50 Buffalo Creek above Winthrop, Iowa}

Location.--Iat 42030\%, long 91044', near NE corner sec.25. T.89 N. R.8 W.. Buchanan County, at bridge, 1.5 miles northeast of Winthrop.

Drainage area. $--68.2 \mathrm{sg} \mathrm{mi}$. At site prior to $1957,71.2 \mathrm{sq} \mathrm{mi}$. Gage.--Crest-stage gage. Datum is arbitrary. Prior tc 1957 at site 2 miles downstream at different datum.

Stage-discharge relaticn.--Defined by discharge measuremerts below and extended above 2,000 cfs by logarithmic plotting.

Remarks.--only annual peaks are shown.

Peak﹎. stages_and_di

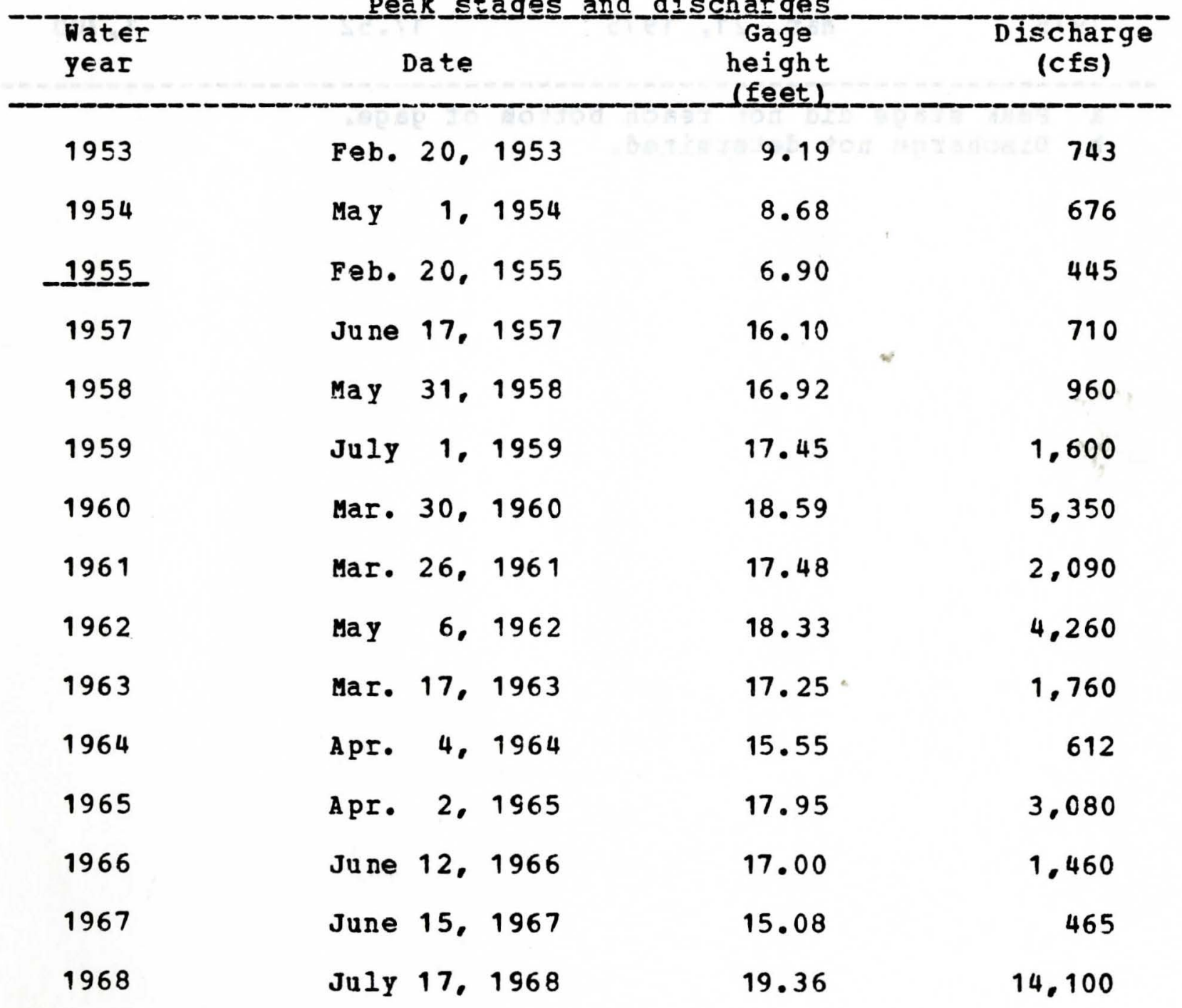


05-4215.50 Buffalo Creek above Winthrop, Iowa--(Continued)

Pea

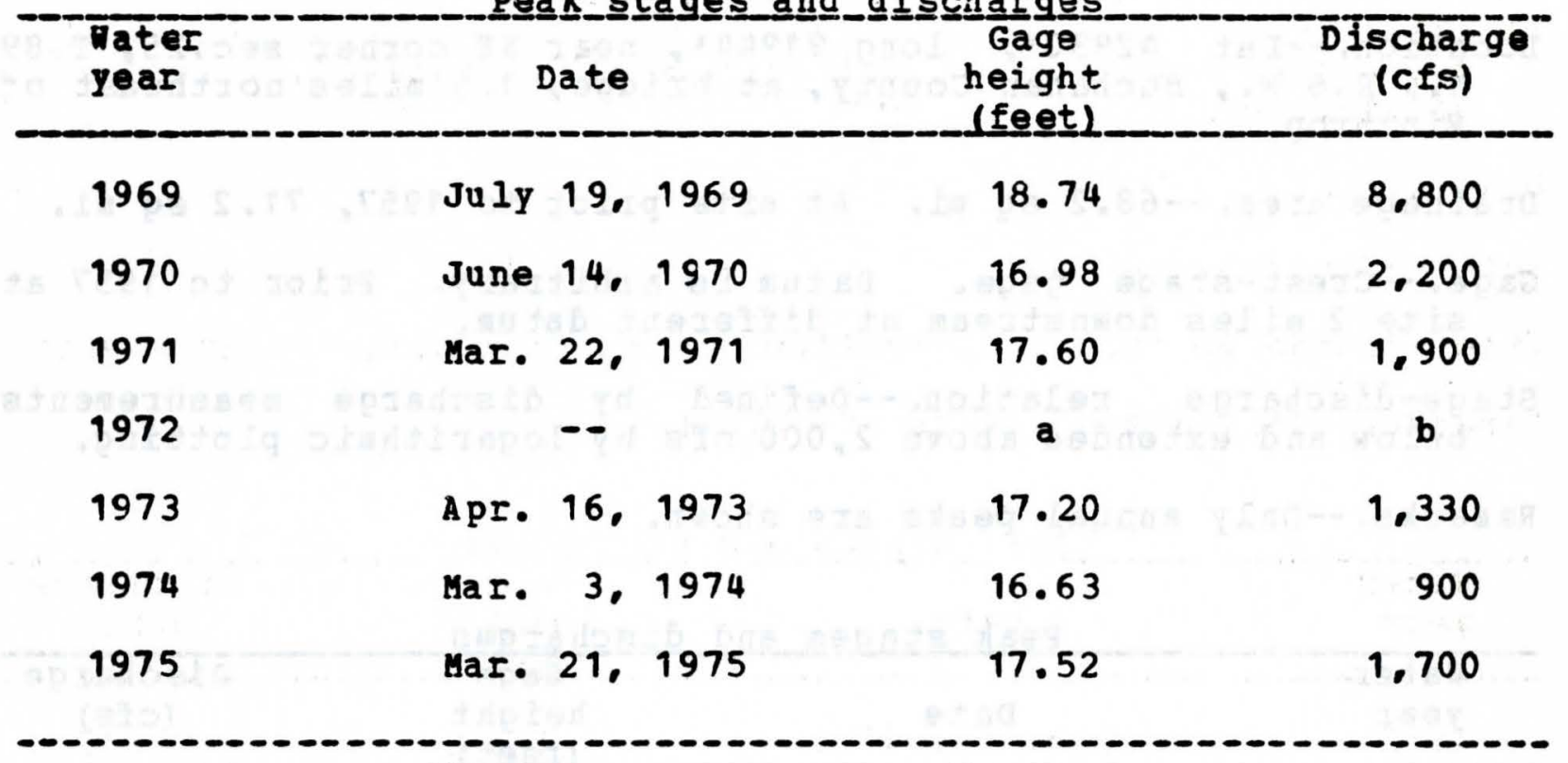

a Peak stage did not reach bottom of gage.

b Discharge not determined. 
Location.--Iat $42023^{\circ}$, long $91043^{\circ}$, in NE1/4 sec.1, T.88 N.. R.8

W. Buchanan County, at bridge on U.S. Highway 20, 1 mile east of Winthrop.

Drainage area. $--71.4 \mathrm{sq} \mathrm{mi}$

Gage.--Crest-stage gage.

Stage-discharge relation.--Defined by current-meter measurements. Remarks.--only annual peaks are shown.

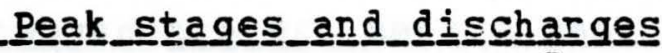

\begin{tabular}{|c|c|c|c|c|c|}
\hline $\begin{array}{l}\text { Hater } \\
\text { year }\end{array}$ & & Date & & $\begin{array}{c}\text { Ga ge } \\
\text { height } \\
\text { (feetㄴ. }\end{array}$ & $\begin{array}{c}\text { Discharge } \\
\text { (cfs) }\end{array}$ \\
\hline 1953 & $F \in b$. & 20. & 1953 & 9.19 & 743 \\
\hline 1954 & May & 1. & 1954 & 8.68 & 676 \\
\hline 1955 & Feb. & 20. & 1955 & 6.90 & 445 \\
\hline 1966 & June & 12. & 1966 & 88.64 & 1.500 \\
\hline 1967 & & $\ldots$ & & a & b \\
\hline 1968 & July & 17. & 1968 & 91.38 & 14,800 \\
\hline 1969 & JuIy & 18. & 1969 & 90.36 & 8.800 \\
\hline 1970 & June & 14. & 1970 & 87.61 & 2.200 \\
\hline 1971 & Mar. & 22. & 1971 & 88.19 & 1,600 \\
\hline 1972 & & $\ldots$ & & a & b \\
\hline 1973 & Apr. & 16. & 1973 & 88.24 & 1,700 \\
\hline 1974 & June & 22. & 1974 & 88.45 & 1,900 \\
\hline 1975 & Mar. & 21. & 1975 & 88.86 & 2,600 \\
\hline
\end{tabular}


Location.--Iat $41029^{\prime}$, long $91038^{\prime}$, in SE1/4 sec.11, T. 77 N.. R.? W. Washington County, at bridge on State Highway 22. 2.5 miles west of Riverside.

Drainage area.--6.31 sq mi.

Gage.--Crest-stage gage.

Stage-discharge relation.--Defined by current-meter measurements. Remarks.--only annual peaks are shown.

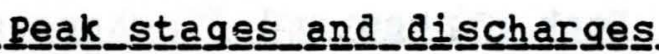

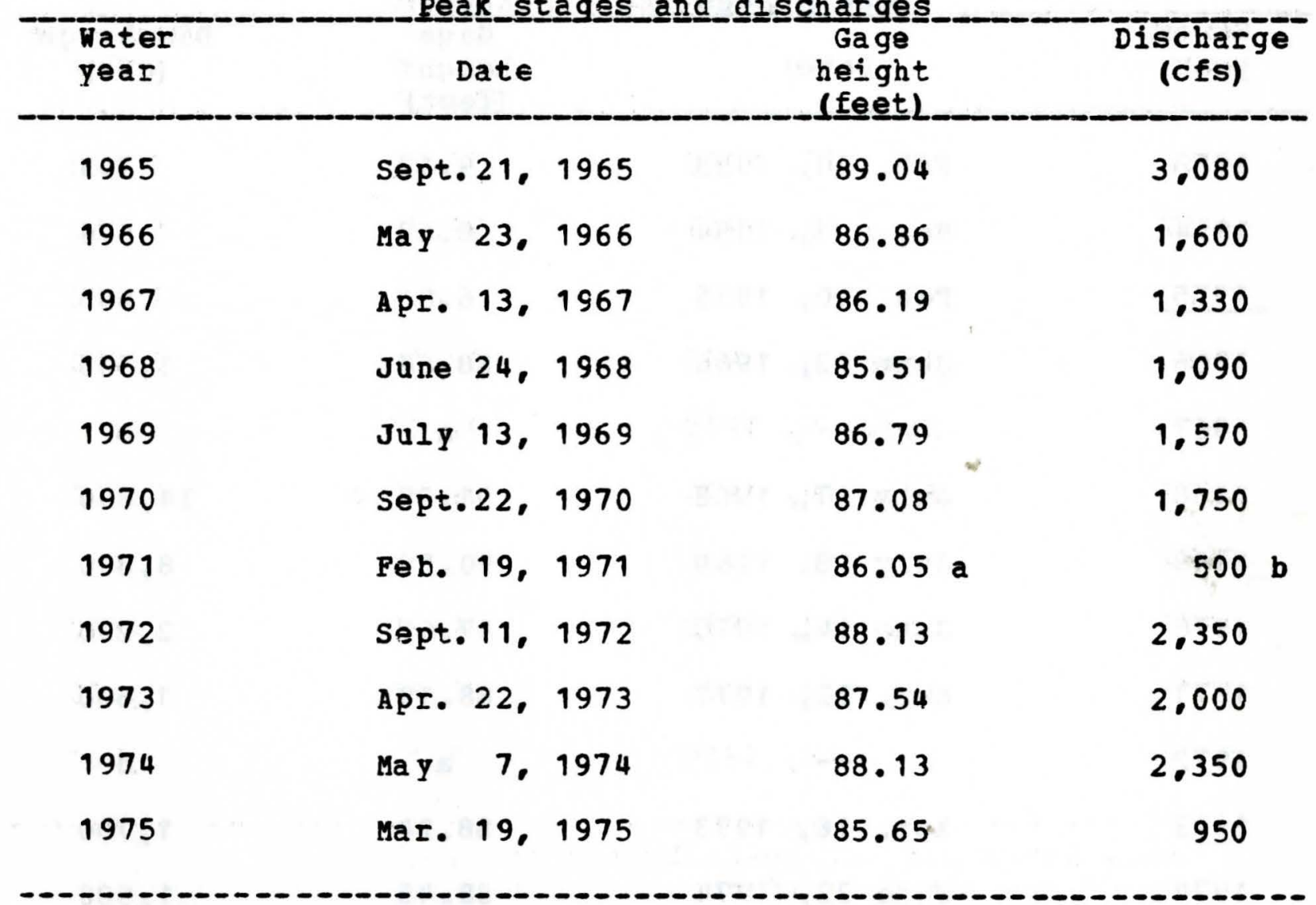

a Affected by ice.

b About. 
Location.--lat $41001 \%$, long $92007^{\circ}$, in SW1/4 sec.27, T.72 N.. R. 11 \%.. Jefferson County. at bridge on 0.5 . Highway $34,2.5$ miles northeast of Batavia.

Drainage area.--252 $\mathrm{sg} \mathrm{mi.}$

Gage.--Crest-stage gage.

stage-discharge relation.--Defined by current-meter measurements. Remarks.--only annual peaks are shown.

Feak_stages_and dischargarges

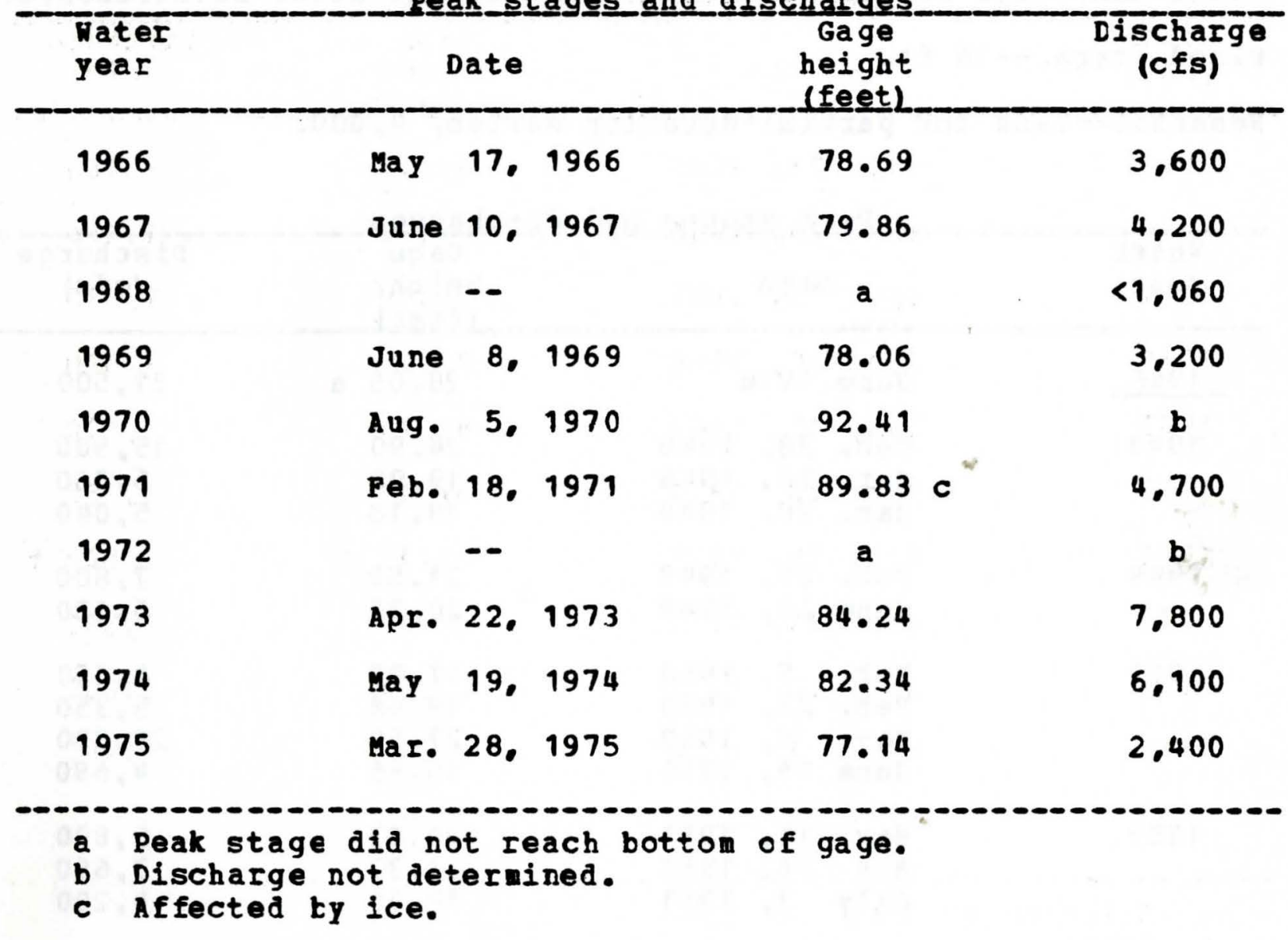


Location.--lat 41013'09", long 92054'38", at SW corner sec.11, T.74 N.. R.18 N.. Marion County, on left bank $10 \mathrm{ft}$ downstream from bridge on state Highway 156, 0.8 mile downstream from North Cedar Creek, 1.6 miles northwest of Bussey. 3.0 miles upstream from Honey Creek, and 8.9 miles upstream from mouth.

Drainage area. $--374 \mathrm{sq} \mathrm{mi}$.

Gage.-Water-stage recorder. Datum of gage is $682.15 \mathrm{ft}$ above mean sea level (levels by Corps of Engineers). Prior to Feb. 21. 1949, nonrecording gage at same site and datum.

Stage-discharge relation.--Defined by current-meter measurements. Flood stage.--16 ft.

Remarks.--Base for partial-duration series, 4,000.

Peak__stages__and_di

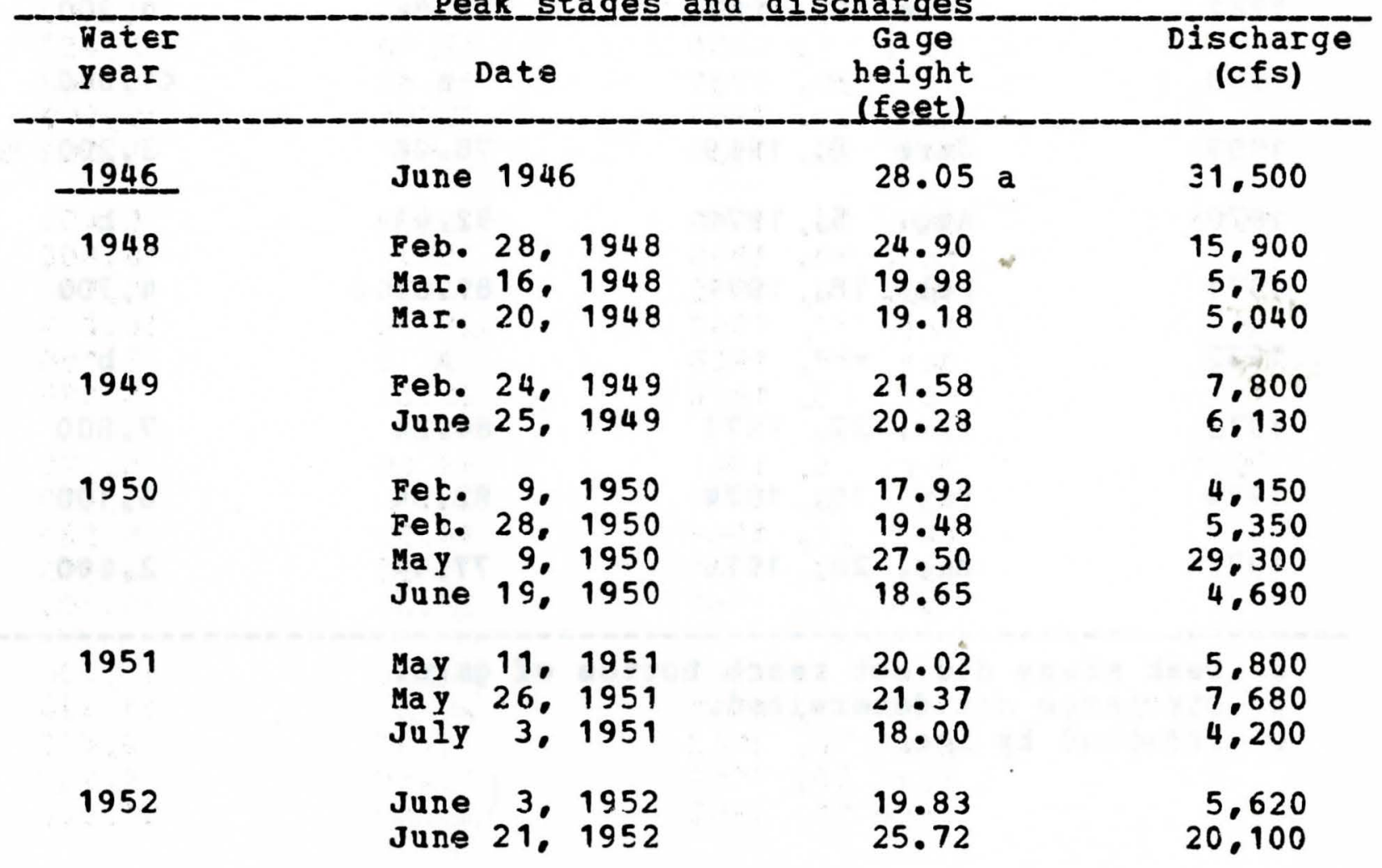

a Gage height $28.45 \mathrm{ft}$ on upstream side of bridge; from levels tc floodmarks by Corps of Engineers. 
05-4890.00 Cedar Creek near Bussey. Iowa-- (Continued)

Peak stages and discharges

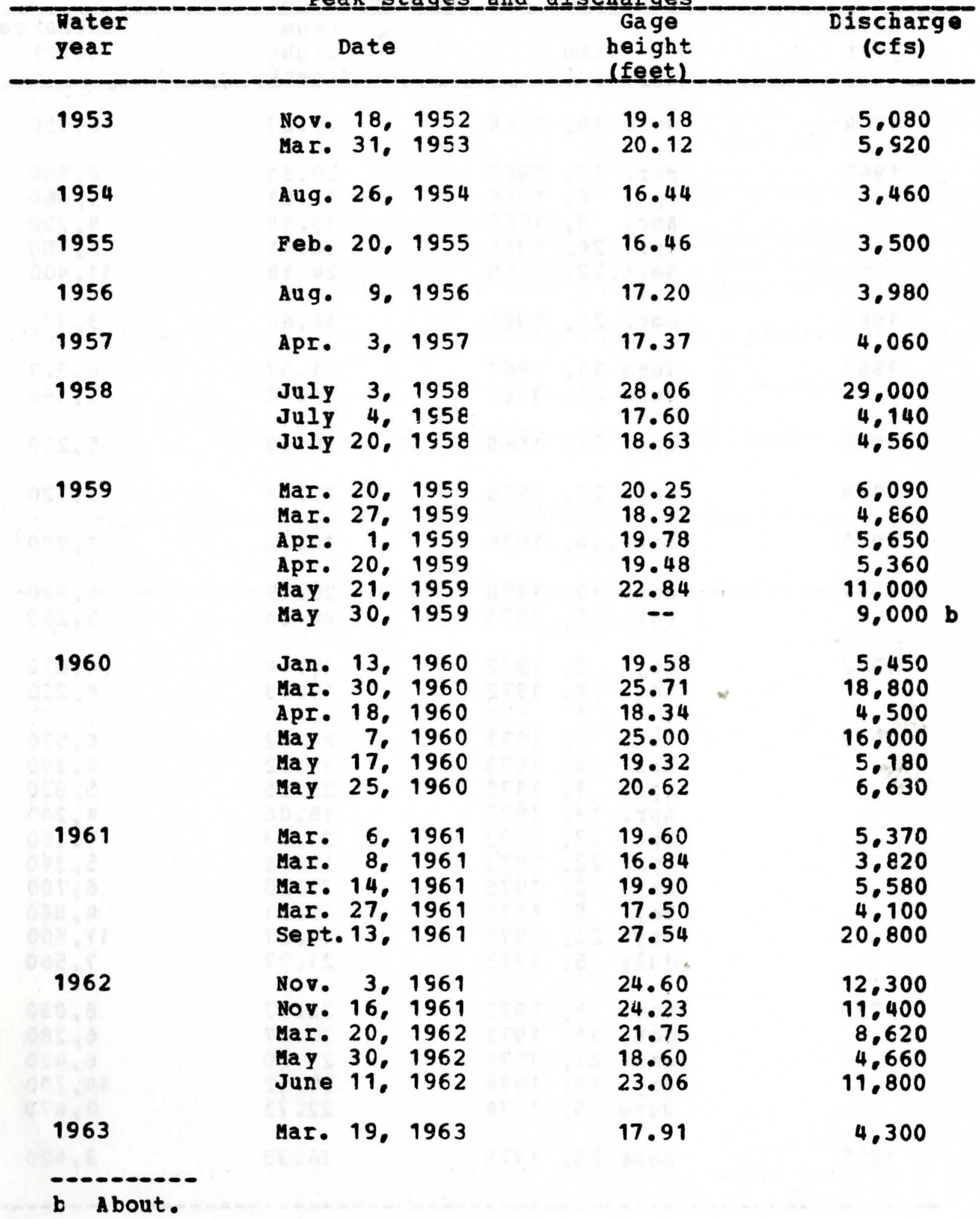


05-4890.00 Cedar Creek near Bussey. Iowa-- (Continued)

Peak_stages_and__dischargesges

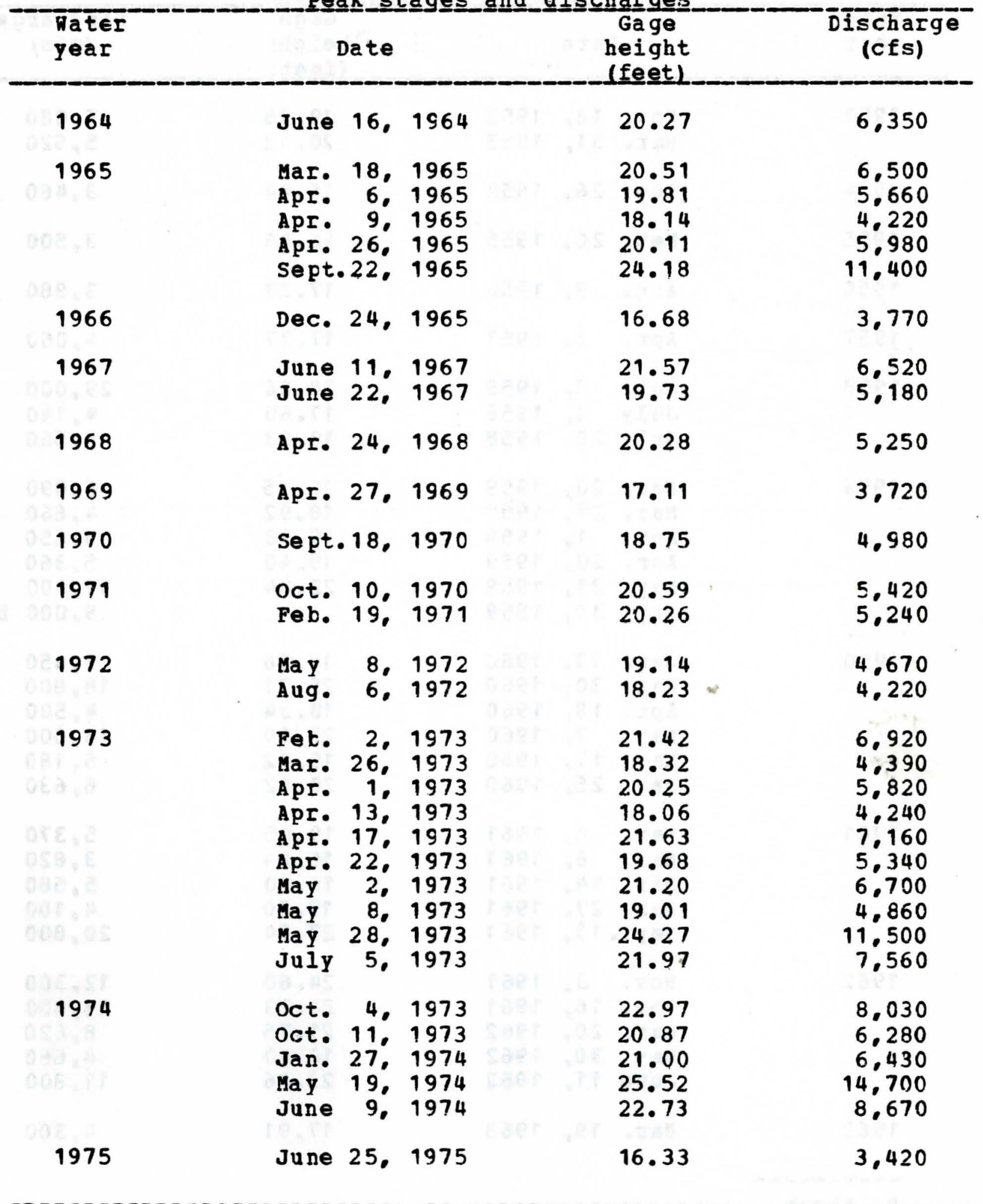


Location.--Lat $41058 \cdot 14 "$, long $91040 \cdot 01 "$ " in SE1/4 NA1/4 sec. 28, T.83 N.. R. 7 W.. Iinn County. on right bank 400 ft upstream from bridge on Eighth Avenue in Cedar Rapids, 2.7 miles upstream from Prairie Creek, and at mile 112.7 upstream from mouth of Iowa River.

Drainage area.--6,510 sq mi.

Gage.- Hater-stage recorder. Latum of gage is $700.47 \mathrm{ft}$ above mean sea level. Prior to Aug. 20, 1920, nonrecording gage at same site and datum.

Stage-discharge relation.--Defined by current-meter measurements.

Flood stage. --13 ft.

Remarks.--Base for partial-duration series, 12,000 cfs. Base was 15,000 prior to 1962 .

Feak_stages_and discharges

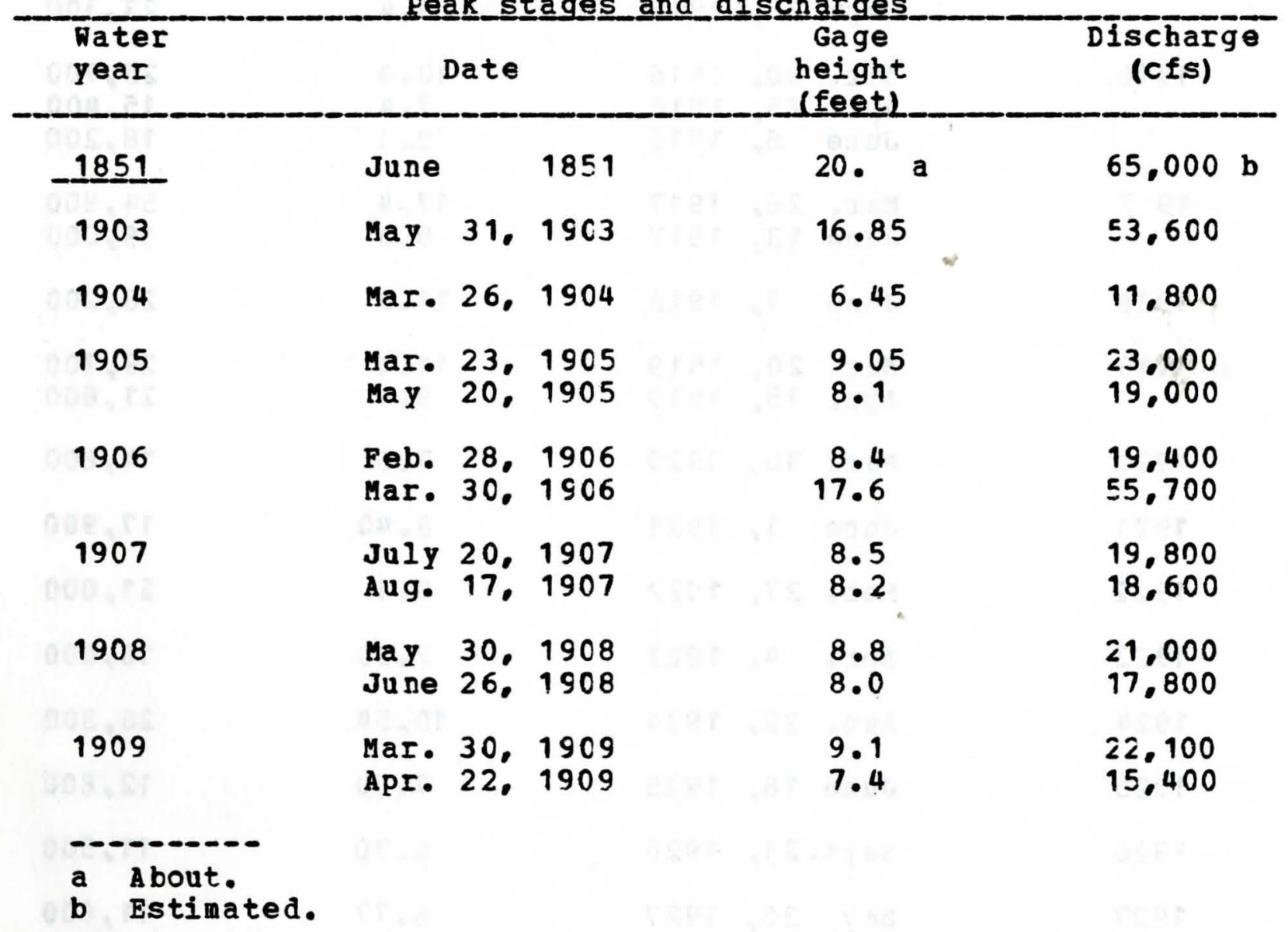


05-4645.00 Cedar River at Cedar Rapids, Iowa--(Continued)

Peak stages and di scharges

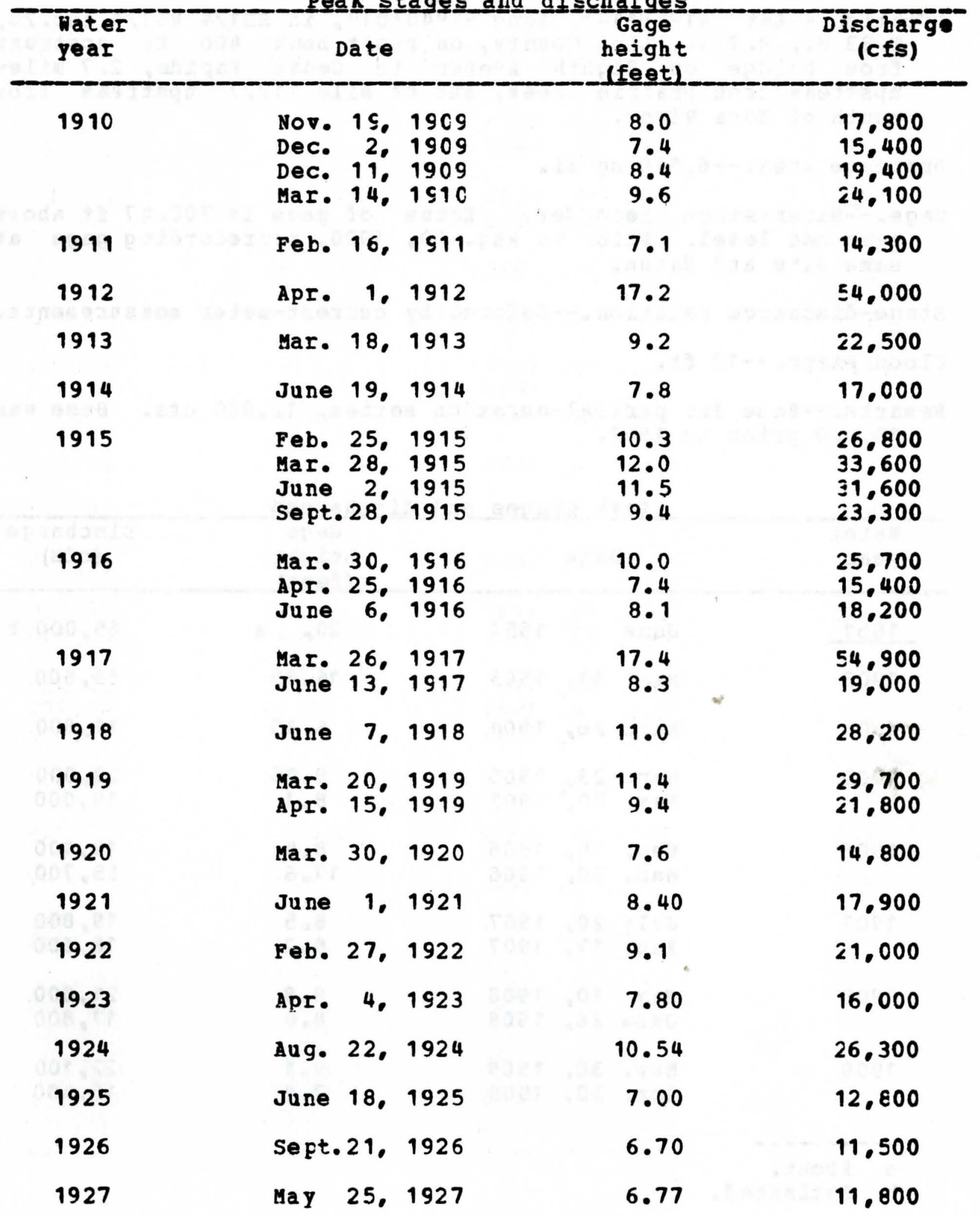


05-4645.00 Cedar River at Cedar Rapids, Iowa--(Continued)

Feak stages and discharges

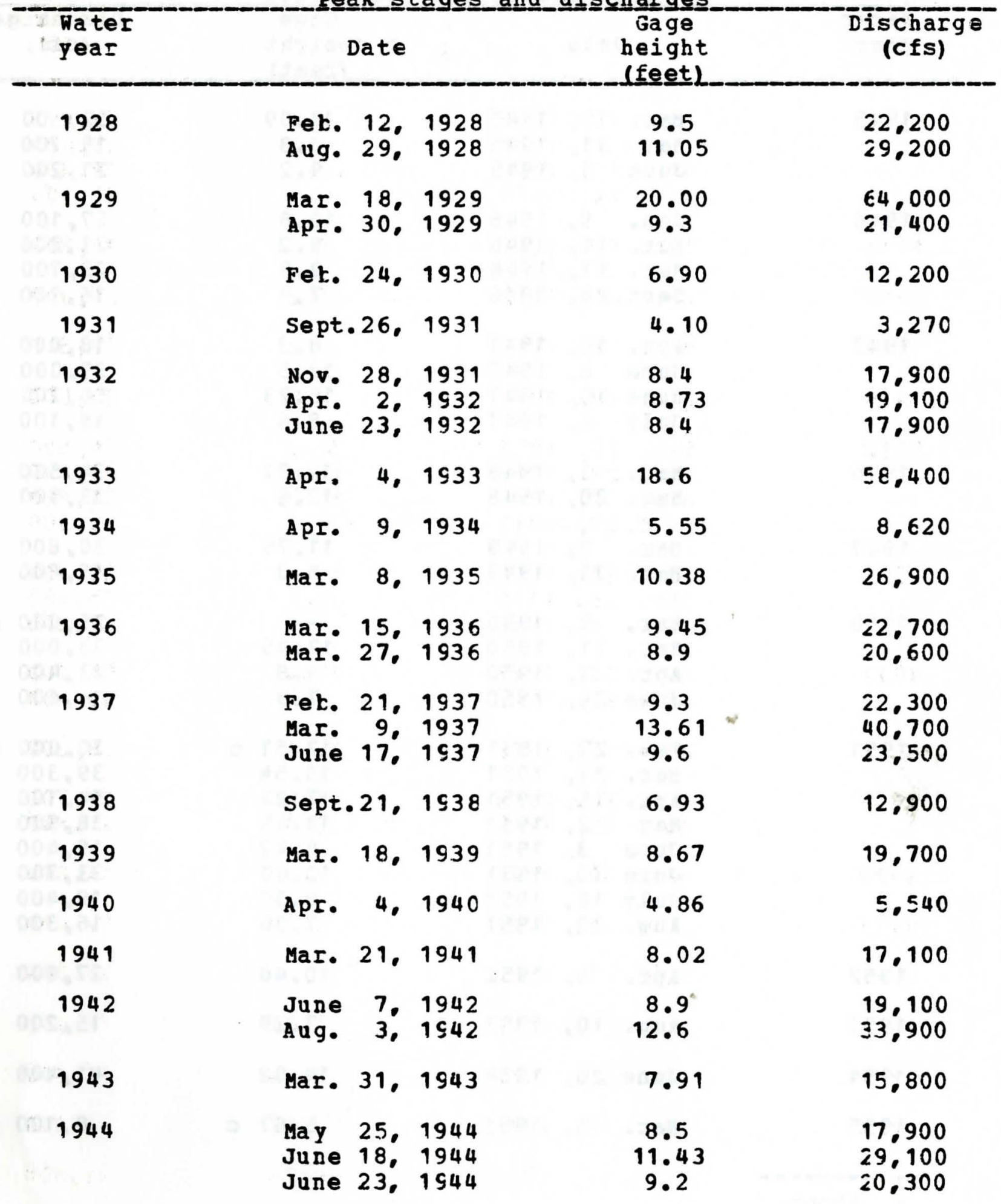


05-4645.00 Cedar River at Cedar Rapids, Iowa--(Continued)

Feak stages and discharges

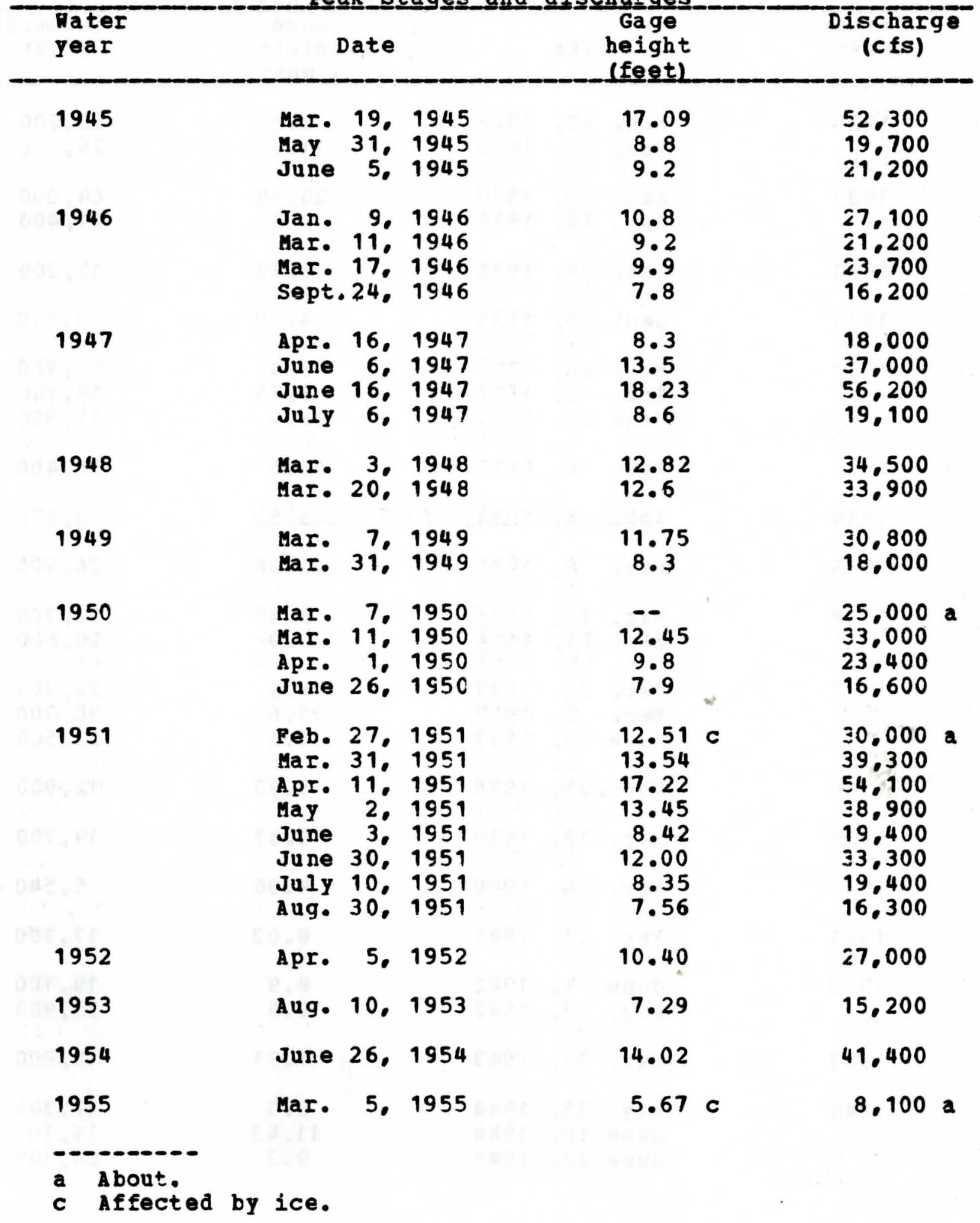


05-4645.00 Cedar River at Cedar Rapids, Iowa--(Continued)

Peak stages and di scharges

\begin{tabular}{|c|c|c|c|}
\hline $\begin{array}{l}\text { Hater } \\
\text { year }\end{array}$ & Date & $\begin{array}{l}\text { Gage } \\
\text { height } \\
\text { (feet) }\end{array}$ & $\begin{array}{c}\text { Discharge } \\
\text { (cfs) }\end{array}$ \\
\hline 1956 & ApI. 6. 1956 & 4.69 & 5.400 \\
\hline 1957 & June 20, 1957 & 6.00 & 9.900 \\
\hline 1958 & June 13. 195\& & 4.58 & 5.240 \\
\hline 1959 & $\begin{array}{l}\text { Mar. 21. } 1959 \\
\text { MaI. 30, } 1959\end{array}$ & $\begin{array}{l}8.75 \\
9.77\end{array}$ & $\begin{array}{l}21.000 \\
25.800\end{array}$ \\
\hline 1960 & $\begin{array}{lr}\text { Jan. } & 13,1960 \\
\text { Apr. } & 2,1960 \\
\text { May } & 7,1960\end{array}$ & $\begin{array}{r}8.60 \\
16.75 \\
11.59\end{array}$ & $\begin{array}{l}20.400 \\
55.100 \\
32.400\end{array}$ \\
\hline 1961 & $\begin{array}{l}\text { Mar. } 8.1961 \\
\operatorname{Mar} 31.1961\end{array}$ & $\begin{array}{r}7.62 \\
19.66\end{array}$ & $\begin{array}{l}17.600 \\
73.000\end{array}$ \\
\hline & PEAK_BASEE_REV & 12.000 & \\
\hline 1962 & $\begin{array}{ll}\text { Apr. 2. } 1962 \\
\text { Sept. 7. } 1962\end{array}$ & $\begin{array}{r}15 \cdot 15 \\
8 \cdot 11\end{array}$ & $\begin{array}{l}50.000 \\
18.900\end{array}$ \\
\hline 1963 & $\begin{array}{lll}\text { Mar. } & 19,1963 \\
\operatorname{May} & 15,1963\end{array}$ & $\begin{array}{l}7.26 \\
6.68\end{array}$ & $\begin{array}{l}15,600 \\
13.100\end{array}$ \\
\hline 1964 & 8. 1964 & 4.43 & 4.270 \\
\hline 1965 & $\begin{array}{l}\text { Mar. 6, } 1965 \\
\text { Apr. 10, } 1965 \\
\text { Sept.26, } 1965\end{array}$ & $\begin{array}{l}11.19 \\
18.51 \\
10.04\end{array}$ & $\begin{array}{l}32,100 \\
66,800 \\
27,200\end{array}$ \\
\hline 1966 & $\begin{array}{lr}\text { oct. } 5,1965 \\
\text { Feb. 12, } 1966 \\
\text { June 16, } 1966 \\
\text { July 19, } 1966\end{array}$ & $\begin{array}{c}10.51 \\
-.0 \\
7.09 \\
6.47\end{array}$ & $\begin{array}{l}29,200 \\
24,000 a \\
14.700 \\
12.100\end{array}$ \\
\hline 1967 & June 16,1967 & 7.41 & 16.000 \\
\hline 1968 & $\begin{array}{lrl}\text { July } & 20 . & 1968 \\
\text { Aug. } & 7 . & 1968\end{array}$ & $\begin{array}{l}7.27 \\
8.79\end{array}$ & $\begin{array}{l}15.400 \\
22.200\end{array}$ \\
\hline
\end{tabular}

a About. 
05-4645.00 Cedar River at Cedar Rapids. Iowa--(Continued)

Peak__stages_and_di scharges

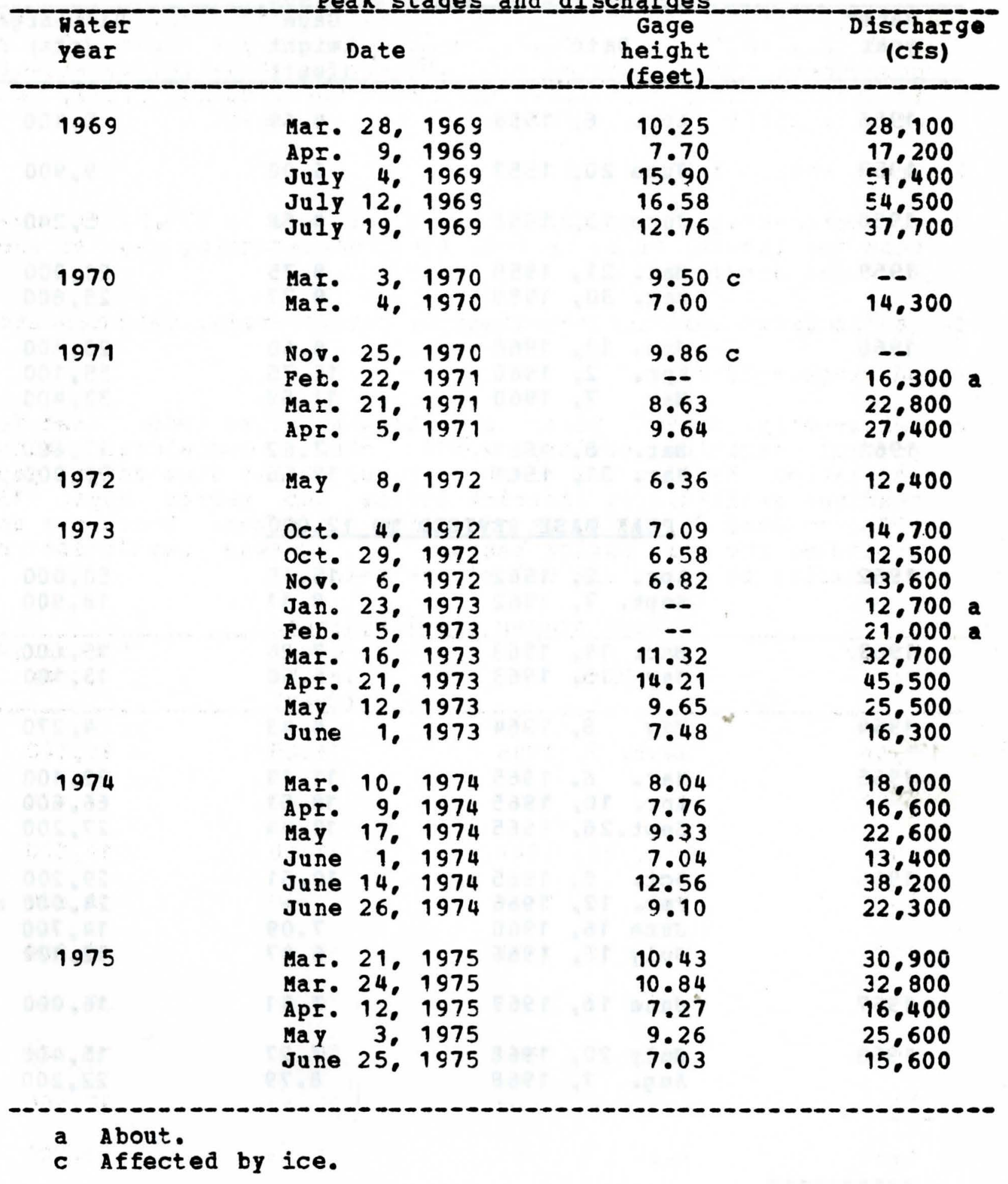




$$
\text { 05-4577.00 Cedar River at Charles City. Iowa }
$$

Location.--Iat $43003^{\circ} 4^{\prime \prime}$. long $92^{\circ} 40 \cdot 23^{\prime \prime}$, in SE1/4 NE1/4, sec.12, T.95 N.. R.16 W.. Floyd county. on right bank 800 ft downstream from bridge on $0 . S$. Highway 18 (Brantinghan street) in Charles City, 10.6 miles upstrean from Gizzard Creek, and at mile 252.9 upstream from mouth of Iowa River.

Drainage area.--1,054 sq mi.

Gage.-- Mater-stage recorder. Datum of gage is $973.02 \mathrm{ft}$ above mean sea level. Prior to oct. 1964, non recording gage at same site and datum.

Stage-discharge relation.--Defined by current-meter neasurements. Plood stage.--12 ft.

Remarks.--Only annual peaks are shown prior to 1965. Base for partial duration series. 2,500 cfs. Occasional minor regulation by dam 0.2 mi above gage. Daily wire-weight gage readings available in district office for period sept. 13. 1945, to June 30, 1954, at same site and datum. Discharge not published for this pericd because of extreme regulation of streamflow by power dam 0.2 i upstroam.

Peak_stages and díscharges

\begin{tabular}{|c|c|c|c|}
\hline $\begin{array}{l}\text { Water } \\
\text { year }\end{array}$ & Date & $\begin{array}{l}\text { Gage } \\
\text { height } \\
\text { (feet) }\end{array}$ & $\begin{array}{c}\text { Discharge } \\
\text { (cfs) }\end{array}$ \\
\hline 1946 & Sept. 7. 1946 & 16.05 & 15.100 \\
\hline 1947 & Apr. 11, 1947 & 10.44 & 7.470 \\
\hline 1948 & $\mathrm{Feb}, 28,1948$ & 17.00 & 16,500 \\
\hline 1949 & Mar. 6. 1949 & 13.00 & 10,800 \\
\hline 1950 & Mar. 28, 1950 & 18.3 & 20,000 \\
\hline 1951 & Apr. $\quad 8,1951$ & 18.9 & 21.400 \\
\hline 1952 & Apr. $\quad 1,1952$ & 14.6 & 12.600 \\
\hline 1953 & Aug. 4. 1953 & 14.35 & 12,300 \\
\hline 1961 & Mar. 27, 1961 & $21.53 a$ & 29.200 \\
\hline
\end{tabular}


05-4577.00 Cedar River at Charles City. Iowa--(Continued)

Peak_stages and discharges

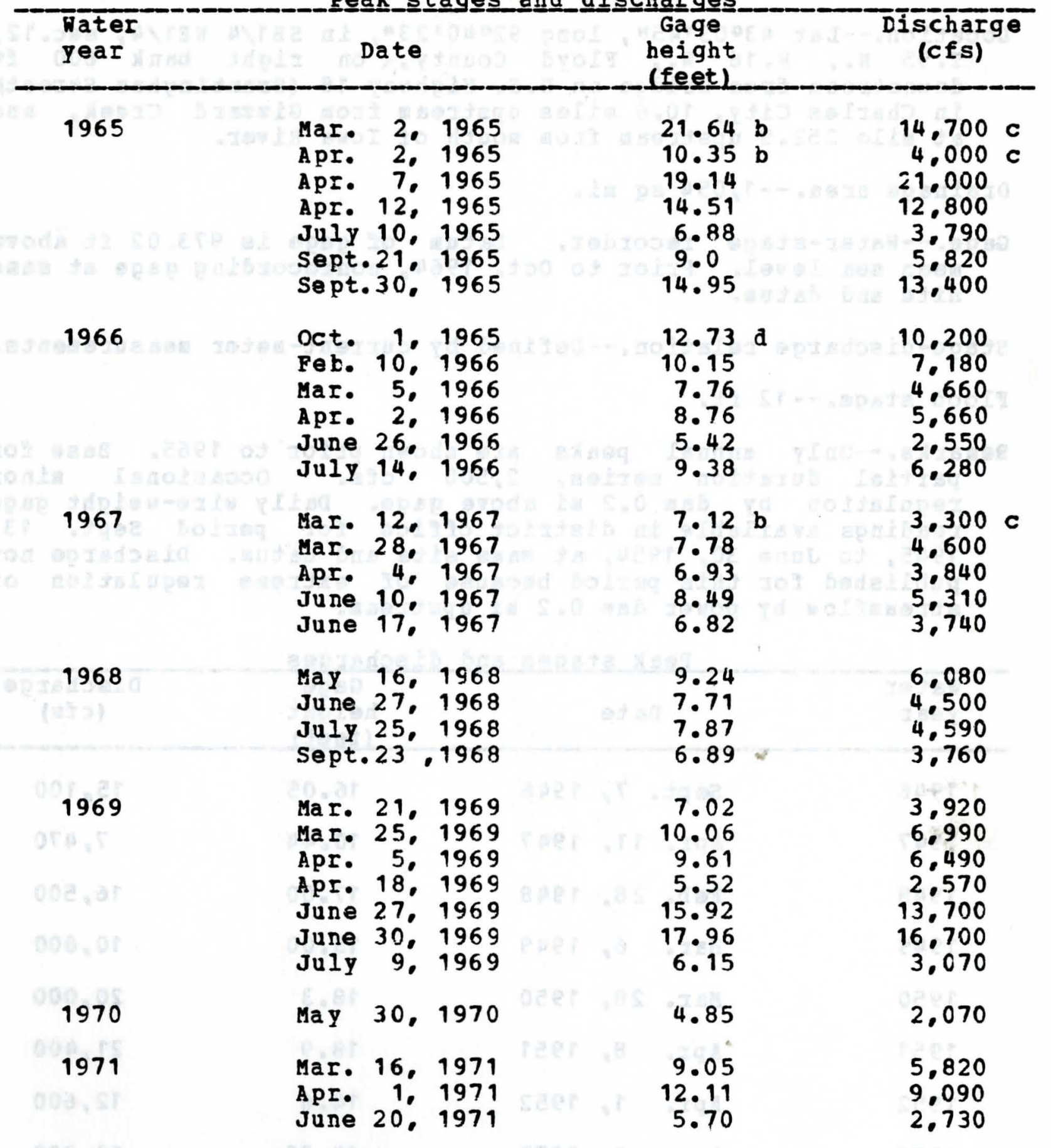

\footnotetext{
a From flocdmarks.

c About.

d Stage falling.
} 
05-4577.00 Cedar River at Charles City. Iowa--(Continued)

Peak_stages and discharges

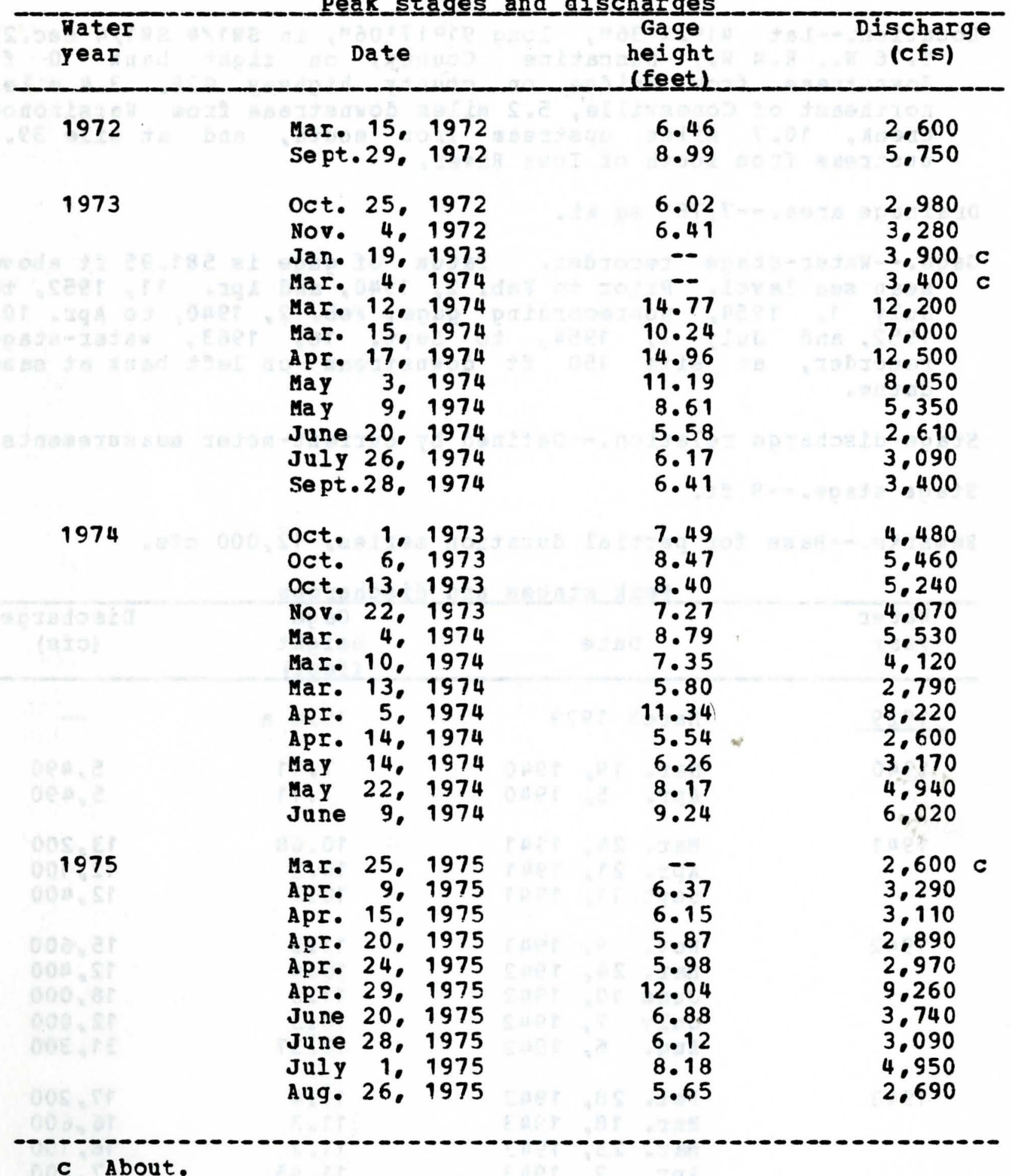


Location.--Lat $41024 \cdot 36 \%$, long $91017 \cdot 06 \%$, in 5 . $1 / 4 \mathrm{SH1/4}$ sec. 2 . T.76 N.. R.4 H.. Muscatine County. on right bank $10 \mathrm{ft}$ downstream from bridge on county highway G28, 3.4 miles northeast of Conesville, 5.2 miles downstream from Wafsinonoc creek, 10.7 miles upstream from mouth, and at mile 39.8 upstream from mouth of Iowa River.

Drainage area.--7,785 sq mi.

Gage.--Hater-stage recorder. Datum of gage is $581.95 \mathrm{ft}$ above mean sea level. Prior to Feb. 2, 1940, and Apr. 11.1952, to July 1, 1954, nonrecording gage, Feb. 2, 1940, to Apr. 10. 1952, and July 2, 1954, to sept. 16, 1963, water-stage recorder, at site 150 ft downstream on left bank at same datum.

Stage-discharge relation.--Defined by current-meter measurements. Stage stage. $-9 \mathrm{ft}$.

Remarks.--Base for partial duration series, 12,000 cfs.

Peak stages and discharges

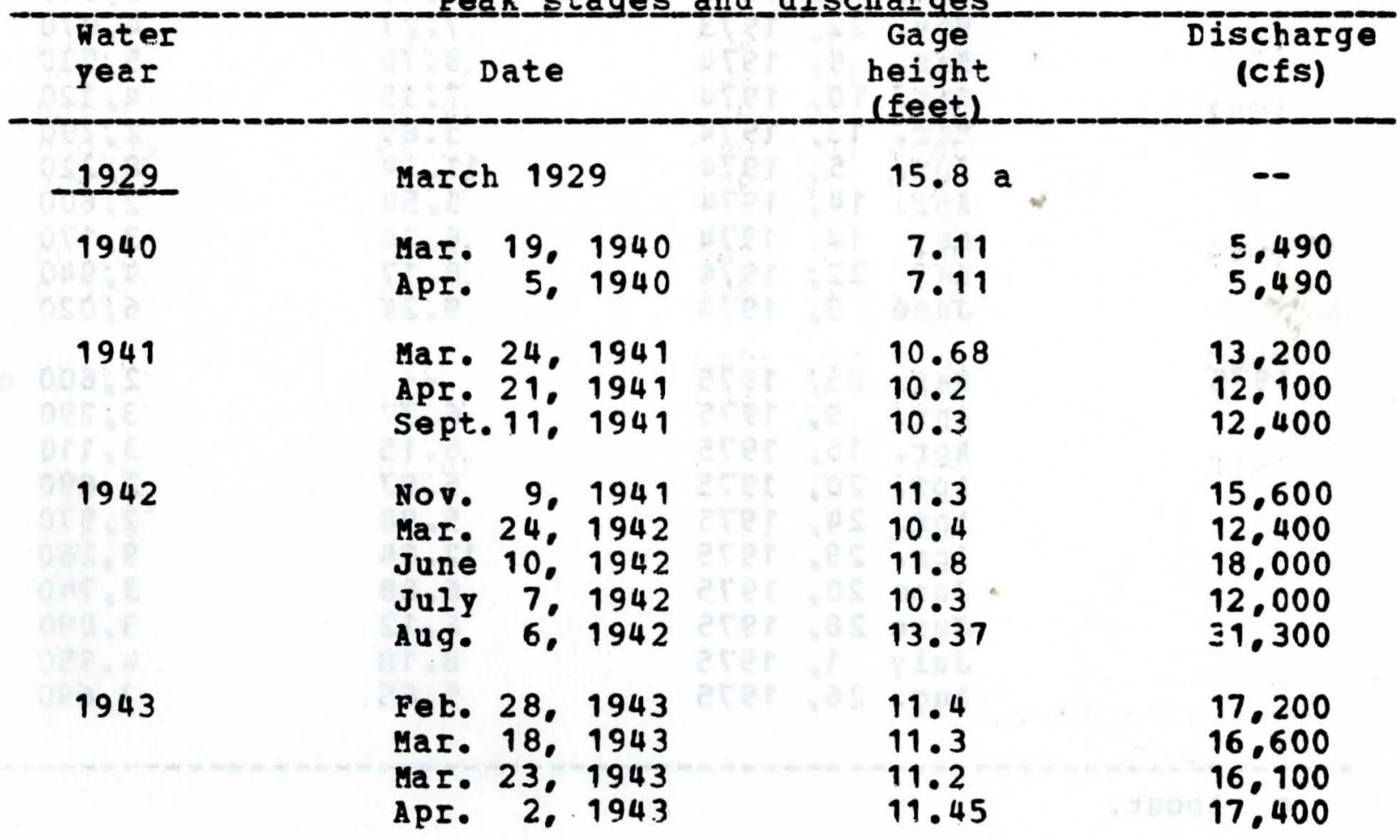

a From information by local resident to corps of Engineers. 
05-4650.00 Cedar River near Conesville, Iowa--(Continued)

Peak stages and discharges

\begin{tabular}{|c|c|c|c|}
\hline $\begin{array}{l}\text { Hater } \\
\text { year }\end{array}$ & Date & $\begin{array}{l}\text { Gage } \\
\text { height } \\
\text { (feet) }\end{array}$ & $\begin{array}{c}\text { Discharge } \\
\text { (cfs) }\end{array}$ \\
\hline 1944 & $\begin{array}{lll}\text { Apr. } 24,1944 \\
\text { May } & 12,1944 \\
\text { May } & 27, & 1944 \\
\text { June } 20, & 1944 \\
\text { June } 27, & 1944\end{array}$ & $\begin{array}{l}10.3 \\
10.6 \\
12.5 \\
13.1 \\
13.93\end{array}$ & $\begin{array}{l}12,400 \\
13,300 \\
23,500 \\
29,600 \\
44,500\end{array}$ \\
\hline 1945 & $\begin{array}{l}\text { Mar. 21, } 1945 \\
\text { Apr. 20; } 1945 \\
\text { May 1; } 1945 \\
\text { June 2: } 1945 \\
\text { June 8: } 1945 \\
\text { June 17, } 1945\end{array}$ & $\begin{array}{l}14.45 \\
11.1 \\
10.4 \\
12.3 \\
12.4 \\
10.4\end{array}$ & $\begin{array}{l}50,900 \\
14.600 \\
12.400 \\
22.200 \\
23.000 \\
12.400\end{array}$ \\
\hline 1946 & $\begin{array}{l}\text { Jan. 10, } 1946 \\
\text { Mar. 13, } 1946 \\
\text { Mar. 19, } 1946 \\
\text { July. 3, } 1946 \\
\text { Sept.26, } 1946\end{array}$ & $\begin{array}{l}14.62 \\
12.2 \\
12.8 \\
10.1 \\
10.7\end{array}$ & $\begin{array}{l}32,000 \mathrm{c} \\
21.500 \\
25,900 \\
12.200 \\
13.300\end{array}$ \\
\hline $\begin{array}{l}1947 \\
1947\end{array}$ & $\begin{array}{l}\text { Apr. } 7,1947 \\
\text { Apr. } 18,1947 \\
\text { June } 8,1947 \\
\text { June 18, } 1947 \\
\text { July } 7,1947\end{array}$ & $\begin{array}{l}10.8 \\
12.2 \\
14.2 \\
15.35 \\
12.4\end{array}$ & $\begin{array}{l}13,500 \\
19,200 \\
37,200 \\
60,000 \\
20,300\end{array}$ \\
\hline 1948 & $\begin{array}{lr}\text { Mar. } 5, & 1948 \\
\text { MaI. } 22, & 1948\end{array}$ & $\begin{array}{l}14.0 \\
13.65\end{array}$ & $\begin{array}{l}42.600 \\
37,000\end{array}$ \\
\hline 1949 & $\begin{array}{l}\text { Mar. } 10,1949 \\
\text { Apr. } 3,1949\end{array}$ & $\begin{array}{l}13.69 \\
12.1\end{array}$ & $\begin{array}{l}28.700 \\
17.700\end{array}$ \\
\hline 1950 & $\begin{array}{l}\text { Mar. 13, } 1950 \\
\text { Apr. 3, } 1950 \\
\text { June 28, } 1950\end{array}$ & $\begin{array}{l}14.10 \\
12.8 \\
11.5\end{array}$ & $\begin{array}{l}34.100 \\
21.000 \\
14.100\end{array}$ \\
\hline
\end{tabular}

b Affected by ice.

c About. 
Peak stages_and discharges

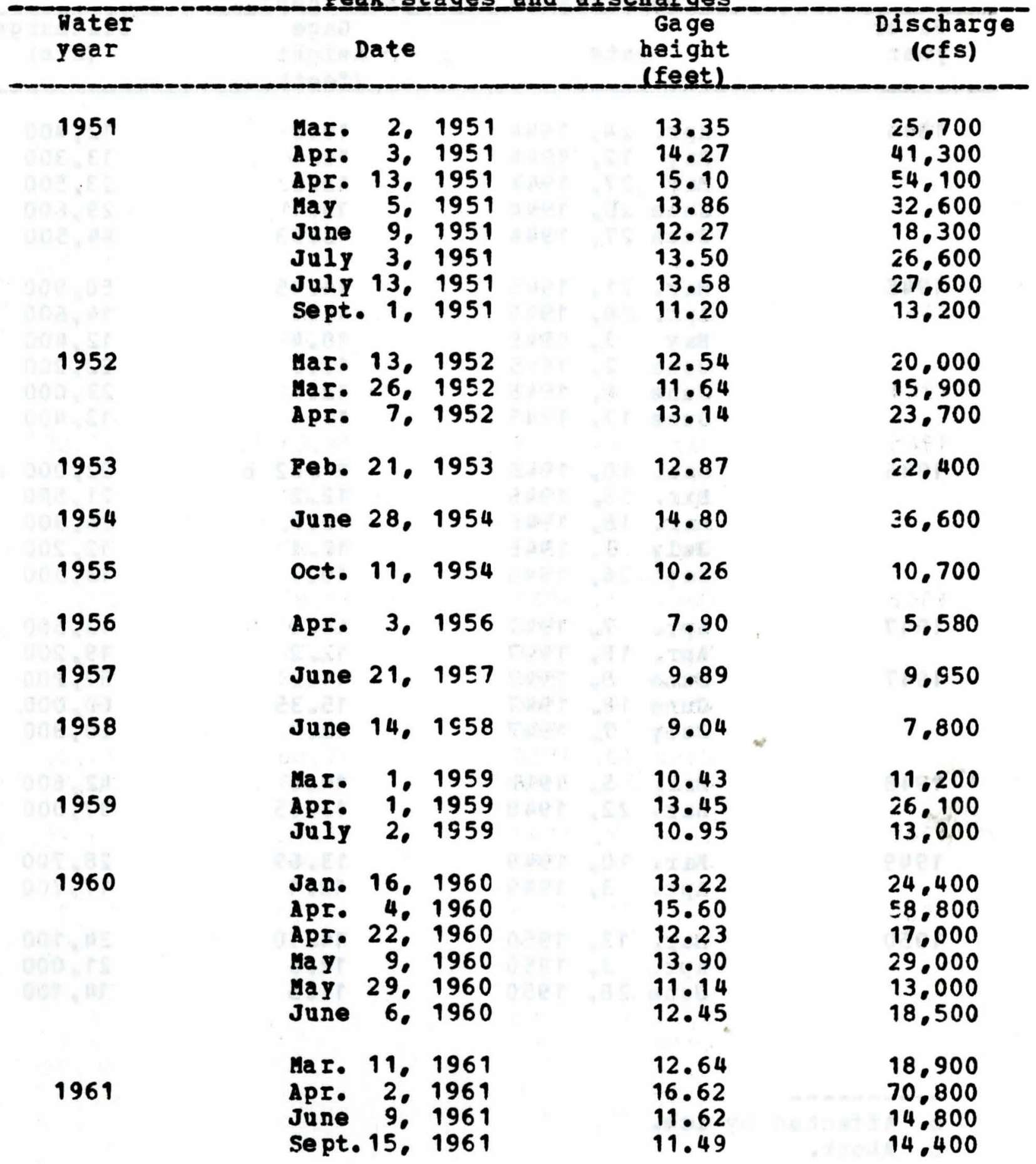


05-4650.00 Cedar River near Conesville, Iowa--(Continued)

Peak_stages_and discharges

\begin{tabular}{|c|c|c|c|}
\hline $\begin{array}{l}\text { Dater } \\
\text { year }\end{array}$ & Date & $\begin{array}{l}\text { Gage } \\
\text { height } \\
\text { (feet) }\end{array}$ & $\begin{array}{l}\text { Discharge } \\
\text { (cfs) }\end{array}$ \\
\hline 1962 & $\begin{array}{lr}\text { Nov. } & 4,1961 \\
\text { Nov. 17, } 1961 \\
\text { Mar. 21, } 1962 \\
\text { Apr. 5, } 1962 \\
\text { July 15, } 1962 \\
\text { Sept. 9, } 1962\end{array}$ & $\begin{array}{l}12.30 \\
12.96 \\
13.30 \\
15.34 \\
12.98 \\
12.26\end{array}$ & $\begin{array}{l}17.500 \\
21.500 \\
24.100 \\
47.700 \\
21.500 \\
17.500\end{array}$ \\
\hline 1963 & 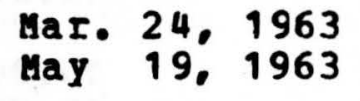 & $\begin{array}{l}11.82 \\
11.07\end{array}$ & $\begin{array}{l}15,500 \\
13,100\end{array}$ \\
\hline 1964 & June 24,1964 & 8.42 & 6.440 \\
\hline 1965 & $\begin{array}{l}\text { Mar. 8, } 1965 \\
\text { Apr. 12, } 1965 \\
\text { Apr. 24, } 1965 \\
\text { Sept. 22, } 1965 \\
\text { Sept.28, } 1965\end{array}$ & $\begin{array}{l}14.67 \\
16.85 \\
12.80 \\
14.10 \\
13.82\end{array}$ & $\begin{array}{l}37,000 \\
68,100 \\
19,100 \\
29,000 \\
26,200\end{array}$ \\
\hline 1966 & $\begin{array}{l}\text { Oct. } 7,1965 \\
\text { Feb. 16, } 1966 \\
\text { Mar. 23, } 1966 \\
\text { Apr. } 7,1966 \\
\text { May } 24,1966 \\
\text { June 18, } 1966 \\
\text { June 30, } 1966 \\
\text { July 20, } 1966\end{array}$ & $\begin{array}{l}13.95 \\
14.10 \quad b \\
10.77 \\
11.03 \\
12.66 \\
12.18 \\
11.56 \\
10.83\end{array}$ & $\begin{array}{l}27.000 \\
27.000 \mathrm{c} \\
12.100 \\
12.900 \\
19.200 \\
16.500 \\
14.300 \\
12.300\end{array}$ \\
\hline 1967 & $\begin{array}{l}\text { June } 7,1967 \\
\text { June } 18,1967\end{array}$ & $\begin{array}{l}13.92 \\
12.46\end{array}$ & $\begin{array}{l}29.200 \\
17.600\end{array}$ \\
\hline 1968 & 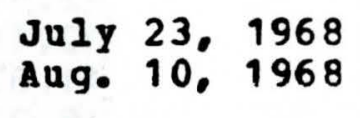 & $\begin{array}{l}11.72 \\
13.21\end{array}$ & $\begin{array}{l}14.200 \\
21.000\end{array}$ \\
\hline 1969 & $\begin{array}{lrr}\text { Mar. } & 31, & 1969 \\
\text { Apr. } & 11: & 1969 \\
\text { June } 9, & 1969 \\
\text { June } & 14, & 1969 \\
\text { July } & 60 & 1969 \\
\text { July } & 15, & 1969\end{array}$ & $\begin{array}{l}13.80 \\
12.72 \\
11.77 \\
11.75 \\
15.93 \\
16.05\end{array}$ & $\begin{array}{l}28,000 \\
19,500 \\
16,100 \\
16,000 \\
55.000 \\
55,200\end{array}$ \\
\hline
\end{tabular}

b affected by ice.

c About. 
05-4650.00 Cedar River near Conesville, Iowa--(Continued)

Peak

\begin{tabular}{|c|c|c|c|c|c|c|}
\hline $\begin{array}{l}\text { rater } \\
\text { year }\end{array}$ & & Date & & $\begin{array}{l}\text { Gage } \\
\text { height } \\
\text { (feet) }\end{array}$ & $\begin{array}{c}\text { Discharg } \\
\text { (cfs) }\end{array}$ & $\overline{g e}$ \\
\hline 1970 & $\begin{array}{l}\text { Mar. } \\
\text { May } \\
\text { June }\end{array}$ & $\begin{array}{r}5 . \\
15 \\
2 .\end{array}$ & $\begin{array}{l}1970 \\
1970 \\
1970\end{array}$ & $\begin{array}{l}12.83 \\
12.42 \\
10.98\end{array}$ & $\begin{array}{l}20,200 \\
17.900 \\
12.600\end{array}$ & \\
\hline 1971 & $\begin{array}{l}\text { Feb. } \\
\text { Mar. } \\
\text { Apr. }\end{array}$ & $\begin{array}{r}22 . \\
23 . \\
7 .\end{array}$ & $\begin{array}{l}1971 \\
1971 \\
1971\end{array}$ & $\begin{array}{c}-- \\
13.17 \\
13.56\end{array}$ & $\begin{array}{l}20,000 \\
21.600 \\
25.100\end{array}$ & c \\
\hline 1972 & $\begin{array}{l}\text { Dec. } \\
\text { Mar. } \\
\text { May } \\
\text { July } \\
\text { Aug. }\end{array}$ & $\begin{array}{r}16 . \\
1 . \\
9 . \\
18 . \\
8 .\end{array}$ & $\begin{array}{l}1971 \\
1972 \\
1972 \\
1972 \\
1972\end{array}$ & $\begin{array}{l}10.80 \\
10.84 \\
12.14 \\
12.87 \\
10.95\end{array}$ & $\begin{array}{l}12.200 \\
12.300 \\
16.800 \\
20.400 \\
12.600\end{array}$ & \\
\hline 1973 & $\begin{array}{l}\text { Oct. } \\
\text { Oct. } \\
\text { Nov. } \\
\text { Jan. } \\
\text { Jan. } \\
\text { Fab. } \\
\text { Mar. } \\
\text { Apr. } \\
\text { Apr. } \\
\text { Apr. } \\
\text { May } \\
\text { May } \\
\text { June }\end{array}$ & 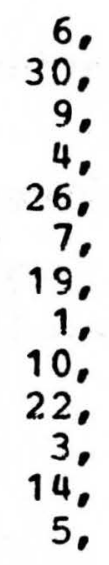 & $\begin{array}{l}1972 \\
1972 \\
1972 \\
1973 \\
1973 \\
1973 \\
1973 \\
1973 \\
1973 \\
1973 \\
1973 \\
1973 \\
1973\end{array}$ & $\begin{array}{c}11.61 \\
11.05 \\
11.61 \\
-- \\
-- \\
12.97 \\
14.04 \\
11.61 \\
11.34 \\
16.02 \\
13.39 \\
13.74 \\
12.78\end{array}$ & $\begin{array}{l}14.700 \\
12.400 \\
14.000 \\
16.000 \\
18.000 \\
21.000 \\
30.400 \\
14.700 \\
13.800 \\
54.800 \\
24.000 \\
26.900 \\
18.400\end{array}$ & $\begin{array}{l}c \\
c\end{array}$ \\
\hline 1974 & $\begin{array}{l}\text { Jan. } \\
\text { Mar. } \\
\text { Apr. } \\
\text { Apr. } \\
\text { May } \\
\text { May } \\
\text { June } \\
\text { June }\end{array}$ & $\begin{array}{l}28, \\
12 \circ \\
11 \% \\
30 \\
18 \\
30 \\
16 \\
28\end{array}$ & $\begin{array}{l}1974 \\
1974 \\
1974 \\
1974 \\
1974 \\
1974 \\
1974 \\
1974\end{array}$ & $\begin{array}{c}-- \\
12.59 \\
12.14 \\
11.52 \\
15.21 \\
12.71 \\
14.26 \\
13.18\end{array}$ & $\begin{array}{l}13.000 \\
18.800 \\
16.800 \\
14.400 \\
43.500 \\
18.900 \\
30.300 \\
20.600\end{array}$ & C \\
\hline 1975 & $\begin{array}{l}\text { Mar. } \\
\text { Apr. } \\
\text { May } \\
\text { June }\end{array}$ & $\begin{array}{r}26 \\
14 \\
5 \% \\
27\end{array}$ & $\begin{array}{l}1975 \\
1975 \\
1975 \\
1975\end{array}$ & $\begin{array}{l}13.88 \\
12.16 \\
13.11 \\
11.65\end{array}$ & $\begin{array}{l}31.600 \\
15.900 \\
22.100 \\
14.900\end{array}$ & \\
\hline
\end{tabular}


Location.--Lat $42038.54 "$, long $92027 \cdot 54^{\prime \prime}$, in NE1/4 SH1/4 sec.35, T.91 N.. R.14 W.. Bremer county, on loft bank $300 \mathrm{ft}$ downstrean from bridge on county highway at Janesville, 3.6 miles upstream frcm West PCrk Cedar River, and at mile 207.7 upstream from mouth of Iowa River.

Drainage area. $--1,661 \mathrm{sq} \mathrm{mi}$.

Gage.--Nater-stage recorder. Datum of gage is $868.26 \mathrm{ft}$ above mean sea level. Prior to July 26, 1919, nonrecording gage at site 1.000 ft downstream at datum 4.0 ft lover. July 26. 1919, to Sept. 30, 1927, Nov. 14, 1932, to sept. 30. 1942, and Apr. 26, 1946, to Nov. 10, 1949, nonrecording gage at county bridge $300 \mathrm{ft}$ upstream at same datum.

Stage-discharge relation.--Defined by current-meter measurements. Plood stage.--11 ft.

Renarks.--Base for partial-duration series, 4,000 cfs.

Peak

\begin{tabular}{|c|c|c|c|c|}
\hline $\begin{array}{l}\text { Mater } \\
\text { year }\end{array}$ & Date & $\begin{array}{l}\text { Gage } \\
\text { height } \\
\text { (feet) }\end{array}$ & & $\begin{array}{c}\text { Discharge } \\
\text { (cfs) }\end{array}$ \\
\hline 1905 & May 17,1905 & 7.1 & $\approx$ & 5.840 \\
\hline 1906 & Mar. 27, 1906 & 14.2 & & 27.100 \\
\hline 1915 & May 31, 1915 & 8.9 & & 7,220 \\
\hline 1916 & $\begin{array}{lr}\text { Mar. } 16,1916 \\
\text { Mar. 27, } 1916 \\
\text { Apr. 22, } 1916 \\
\text { June 2, } 1916\end{array}$ & $\begin{array}{r}8.9 \\
10.4 \\
10.4 \\
11.0\end{array}$ & & $\begin{array}{r}7.220 \\
10.400 \\
10.400 \\
12.100\end{array}$ \\
\hline 1917 & $\begin{array}{l}\text { Mar. 24, } 1917 \\
\text { June 25, } 1917\end{array}$ & $\begin{array}{l}13.8 \\
12.6\end{array}$ & & $\begin{array}{l}21,900 \\
17,300\end{array}$ \\
\hline 1918 & Mar. 20,1918 & 9.0 & & 7.400 \\
\hline 1919 & $\begin{array}{l}\text { Apr. 10, } 1919 \\
\text { Apre_18\&_1919 }\end{array}$ & $\begin{array}{l}8.7 \\
7.5 \\
\end{array}$ & & $\begin{array}{r}6.870 \\
5.130 \\
\end{array}$ \\
\hline 1920 & $\begin{array}{l}\text { Mar. } 19,1920 \\
\text { Mar. } 28,1920\end{array}$ & $\begin{array}{l}6.8 \\
7.3\end{array}$ & & $\begin{array}{l}5,410 \\
6,190\end{array}$ \\
\hline
\end{tabular}


05-4585.00 Cedar River at Janesville. Iowa--(Continued)

Peak_stages_and_di

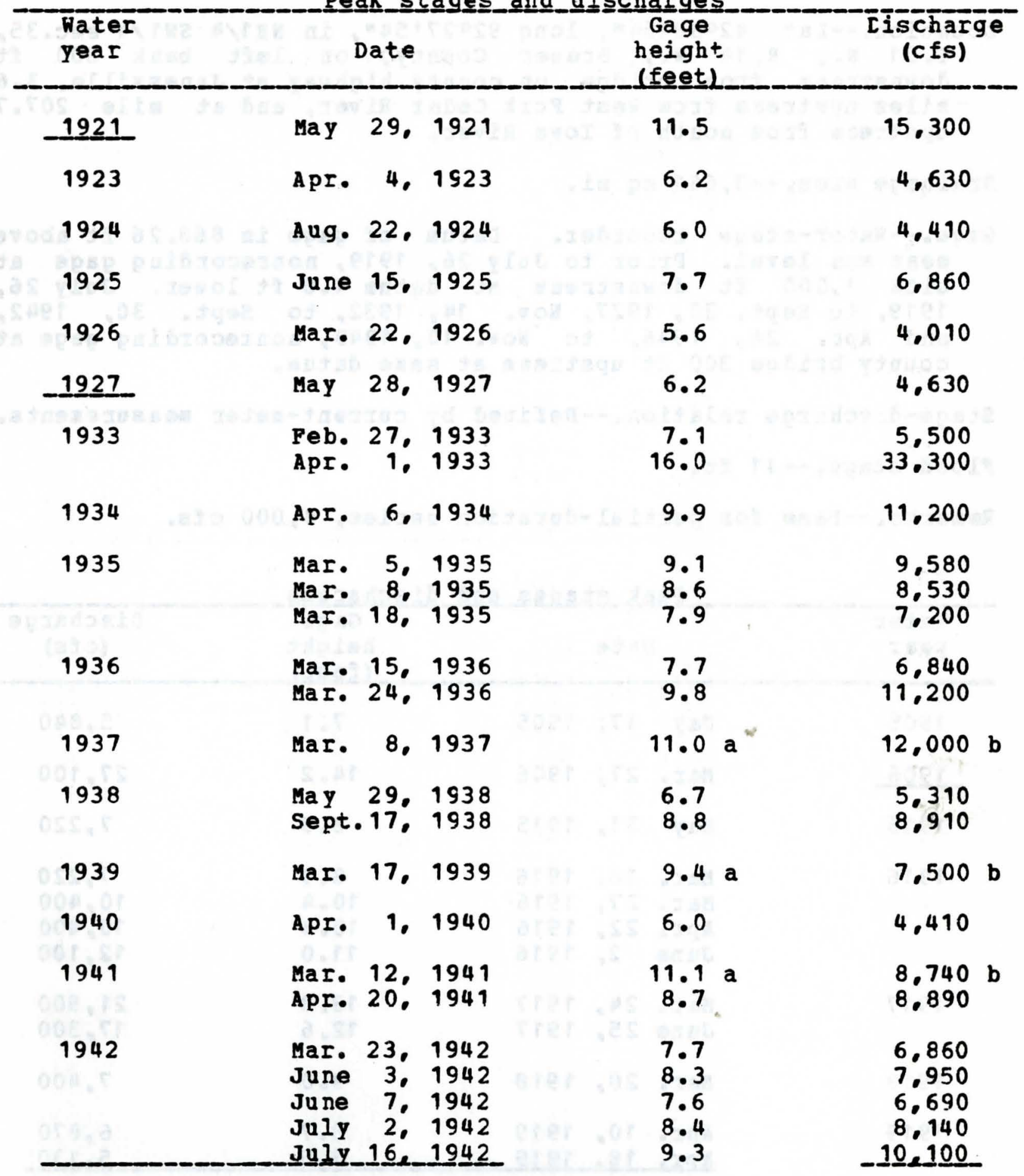

a Affected by ice.

b about. 
05-4585.00 Cedar River at Janesville, Iowa--(Continued)

Peak stages and discharges

\begin{tabular}{|c|c|c|c|}
\hline $\begin{array}{l}\text { Water } \\
\text { year }\end{array}$ & Date & $\begin{array}{l}\text { Gage } \\
\text { height } \\
\text { (feet) }\end{array}$ & $\begin{array}{c}\text { Discharge } \\
\text { (cfs) }\end{array}$ \\
\hline 1945 & 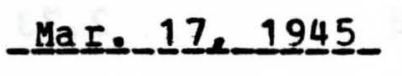 & 16.2 & $-34,200$ \\
\hline 1946 & Sept. 9, 1946 & 11.3 & 14.700 \\
\hline 1947 & $\begin{array}{l}\text { Apr. } 8,1947 \\
\text { Apr. 13, } 1947 \\
\text { June 13, } 1947 \\
\text { June 18, } 1947\end{array}$ & $\begin{array}{c}8 \cdot 1 \\
9 \cdot 3 \\
10 \cdot 14 \\
7.5\end{array}$ & $\begin{array}{r}7.650 \\
9.820 \\
12.200 \\
6.520\end{array}$ \\
\hline 1948 & $\begin{array}{l}\text { Mar. 1, } 1948 \\
\text { Mar. 19, } 1948\end{array}$ & $\begin{array}{r}14.1 \\
8.7\end{array}$ & $\begin{array}{r}25,100 \\
9.330\end{array}$ \\
\hline 1949 & $\begin{array}{l}\text { Mar. } 7,1949 \\
\operatorname{Mar} .27,1949 \\
\operatorname{Mar} .29,1949 \\
\text { Apr. } 201949\end{array}$ & $\begin{array}{c}11.4 a \\
-- \\
8.5 \\
8.0 \\
\end{array}$ & $\begin{array}{c}14.000 \mathrm{~b} \\
7.570 \\
8.850 \\
7.930 \\
\end{array}$ \\
\hline 1950 & $\begin{array}{l}\text { Mar. 9, } 1950 \\
\text { Mar. 28, } 1950\end{array}$ & $12 . \overline{7}$ & $\begin{array}{l}11.600 \mathrm{~b} \\
20.200\end{array}$ \\
\hline 1951 & $\begin{array}{l}\text { Mar. 1, } 1951 \\
\text { Mar. } 30,1951 \\
\text { Apr. 9, } 1951 \\
\text { Apr. 29: } 1951 \\
\text { June 5: } 1951 \\
\text { June 27, } 1951\end{array}$ & $\begin{array}{r}6.67 \\
6.37 \\
14.05 \\
12.43 \\
6.16 \\
7.77\end{array}$ & $\begin{array}{r}6.440 \\
5.200 \quad b \\
25.000 \\
19.300 \\
5.650 \\
8.360\end{array}$ \\
\hline 1952 & $\begin{array}{lr}\text { Mar. 21, } 1952 \\
\text { Apr. } 2,1952\end{array}$ & $\begin{array}{r}6 \cdot 30 \\
10.74\end{array}$ & $\begin{array}{r}5.800 \\
14.700\end{array}$ \\
\hline 1953 & $\begin{array}{l}\text { Feb. } 21,1953 \\
\text { June 16, } 1953 \\
\text { Aug. } 6,1953\end{array}$ & $\begin{array}{r}-- \\
8.36 \\
10.80\end{array}$ & $\begin{array}{r}4.000 \quad b \\
9.500 \\
15.000\end{array}$ \\
\hline 1954 & June 22, 1954 & 12.08 & 18,400 \\
\hline 1955 & Mar. 14, 1955 & 5.16 & 4.430 \\
\hline 1956 & Apr. $\quad 5,1956$ & 4.46 & 3.530 \\
\hline 1957 & May 31, 1957 & 3.10 & 1.890 \\
\hline
\end{tabular}

a Affected by ice.

b A bout. 
05-4585.00 Cedar River at Janesville. Iowa--(Continued)

Peak_stages and discharges

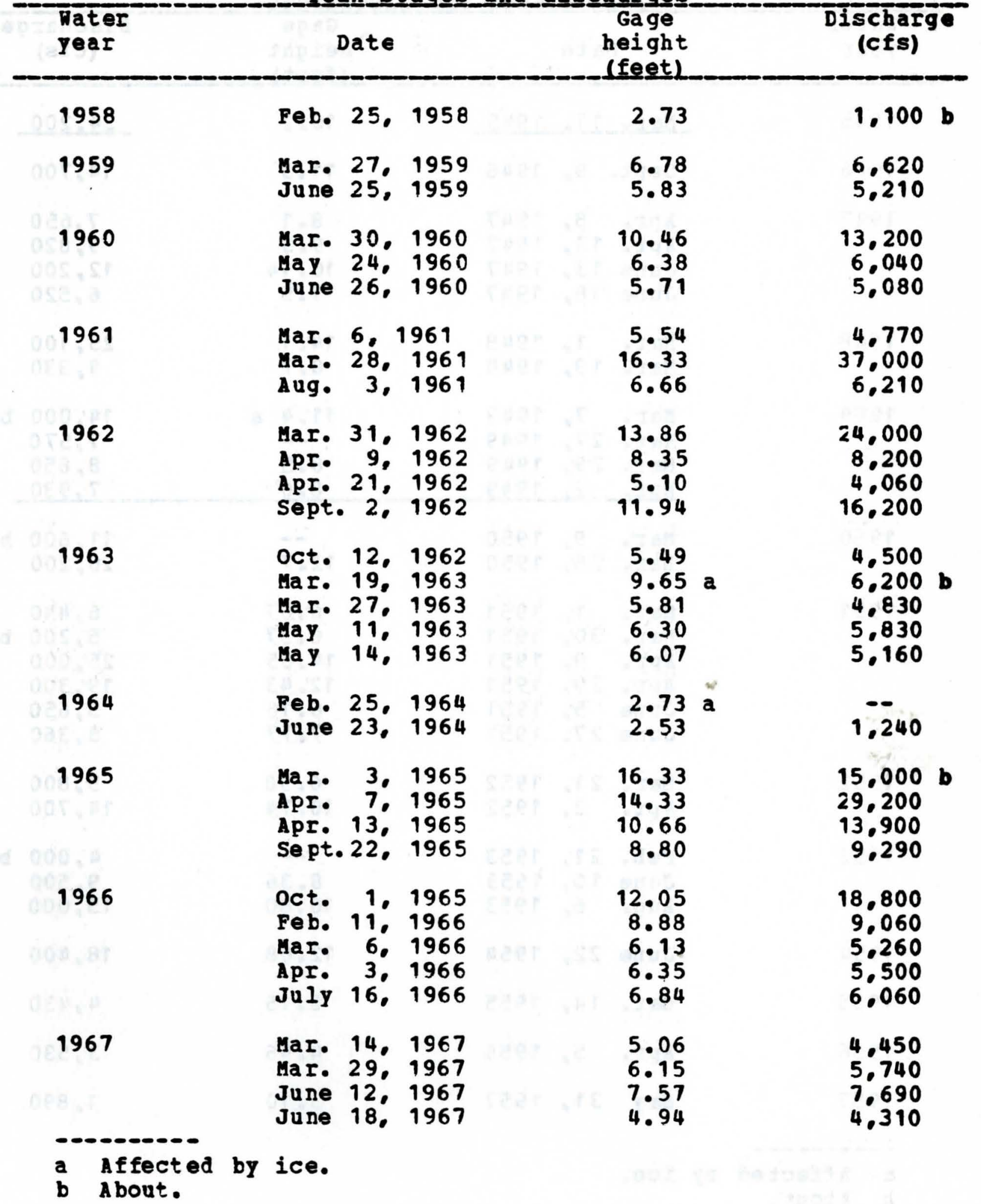


05-4585.00 Cedar River at Janesville. Iowa--(Continued)

Peak stages and discharges

\begin{tabular}{|c|c|c|c|c|c|}
\hline $\begin{array}{l}\text { nater } \\
\text { year }\end{array}$ & & Date & & $\begin{array}{l}\text { Gage } \\
\text { height } \\
\text { (feet) }\end{array}$ & $\begin{array}{c}\text { Discharge } \\
\text { (cfs) }\end{array}$ \\
\hline 1968 & $\begin{array}{l}\text { May } \\
\text { June } \\
\text { JuIy } \\
\text { July } \\
\text { July } \\
\text { Aug. }\end{array}$ & $\begin{array}{r}18, \\
29 \\
17 \\
23 \\
26 \\
8 .\end{array}$ & $\begin{array}{l}1968 \\
1968 \\
1968 \\
1968 \\
1968 \\
1968\end{array}$ & $\begin{array}{r}4.67 \\
5.44 \\
12.79 \\
6.41 \\
5.79 \\
4.68\end{array}$ & $\begin{array}{r}4.150 \\
4.970 \\
21.700 \\
6.130 \\
5.390 \\
4.080\end{array}$ \\
\hline 1969 & $\begin{array}{l}\text { Mar. } \\
\text { Apr. } \\
\text { July } \\
\text { July }\end{array}$ & $\begin{array}{r}25 \\
7 \\
1 \% \\
9\end{array}$ & $\begin{array}{l}1969 \\
1969 \\
1969 \\
1969\end{array}$ & $\begin{array}{r}8.58 \\
7.32 \\
13.74 \\
7.15\end{array}$ & $\begin{array}{r}9.260 \\
7.310 \\
23.500 \\
7.140\end{array}$ \\
\hline 1970 & Mar. & 4. & 1970 & 4.85 & $3.400 \mathrm{~b}$ \\
\hline 1971 & $\begin{array}{l}\text { MaI. } \\
\text { ApI. }\end{array}$ & $\begin{array}{r}18 . \\
2 .\end{array}$ & $\begin{array}{l}1971 \\
1971\end{array}$ & $\begin{array}{l}7.97 \\
9.59\end{array}$ & $\begin{array}{r}8.270 \\
11.400\end{array}$ \\
\hline 1972 & $\begin{array}{l}\text { Mar. } \\
\text { Sept. }\end{array}$ & $\begin{array}{l}16 . \\
.27 .\end{array}$ & $\begin{array}{l}1972 \\
1972\end{array}$ & 5.42 & $\begin{array}{l}4.300 \quad b \\
5.060\end{array}$ \\
\hline 1973 & $\begin{array}{l}\text { Oct. } \\
\text { Oct. } \\
\text { Nov. } \\
\text { MaI. } \\
\text { Mar. } \\
\text { Apr. } \\
\text { May } \\
\text { May }\end{array}$ & $\begin{array}{r}1 \% \\
26 \% \\
5 \% \\
14 \% \\
18 \% \\
4 \%\end{array}$ & $\begin{array}{l}1972 \\
1972 \\
1972 \\
1973 \\
1973 \\
1973 \\
1973 \\
1973\end{array}$ & $\begin{array}{r}8.22 \\
5.35 \\
5.11 \\
6.93 \\
11.08 \\
11.67 \\
8.63 \\
8.02\end{array}$ & $\begin{array}{r}8.830 \\
4.980 \\
4.690 \\
6.820 \\
14.700 \\
16.500 \\
9.360 \\
8.350\end{array}$ \\
\hline 1974 & $\begin{array}{l}\text { Oct. } \\
\text { Oct. } \\
\text { Oct. } \\
\text { Nov. } \\
\text { Mar. } \\
\text { ApI. } \\
\text { May } \\
\text { May } \\
\text { June } \\
\text { June }\end{array}$ & $\begin{array}{r}3 . \\
7 \% \\
15 \% \\
17 \% \\
7 \% \\
6 \% \\
23 . \\
6 \% \\
11 .\end{array}$ & $\begin{array}{l}1973 \\
1973 \\
1973 \\
1973 \\
1974 \\
1974 \\
1974 \\
1974 \\
1974 \\
1974\end{array}$ & $\begin{array}{l}5.10 \\
5.76 \\
6.01 \\
5.09 \\
7.20 \\
8.69 \\
5.28 \\
5.43 \\
6.43 \\
9.33\end{array}$ & $\begin{array}{r}4.500 \\
5.290 \\
5.650 \\
4.550 \\
7.140 \\
9.480 \\
4.780 \\
4.960 \\
6.160 \\
10.800\end{array}$ \\
\hline
\end{tabular}

\footnotetext{
a Affected by ice.

b About.
} 
05-4585.00 Cedar River at Janesville, Iowa--(Continued)

Peak_stages and discharges

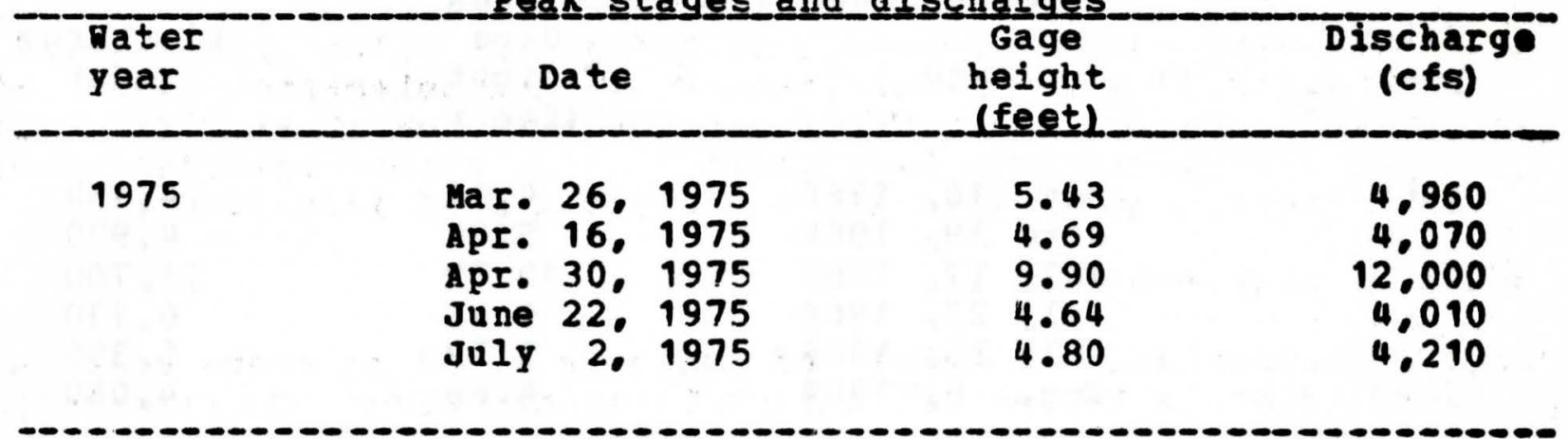




\section{5-4575.00 Cedar River at Mitchell, Iova}

Location.--lat $43018 \cdot 55^{\prime \prime}$, long $92^{\circ} 52 \cdot 45^{\circ}$, in ME1/4 $5 N 1 / 4$ sec.8. T.98 N.. R. $17 \mathrm{~N}$. . in taflrace of hydroelectric plant of Central states power and Iight corporation at Hitchell. 7.1 miles downstream from Deer Creek, 11.3 miles upstream from Rock Creek, and at mile 282.0 above nouth of Iowa River.

Drainage area.--826 sq mi.

Gage.--Nonrecording. Datum of gage is $1.000 \mathrm{ft}$ above mean sea level (levels by Central states power and light Corfcration). Stage-discharge relation.--Defined by current-neter measurementa. Remarks.--only annual peaks are shown.

Peak stages and discharges

\begin{tabular}{|c|c|c|c|c|}
\hline $\begin{array}{l}\text { Water } \\
\text { year }\end{array}$ & Date & $\begin{array}{c}\text { Gage } \\
\text { height } \\
\text { (feet) }\end{array}$ & & $\begin{array}{l}\text { Discharge } \\
\text { (cfs) }\end{array}$ \\
\hline 1933 & July 2, 1933 & 84.0 & & 1.520 \\
\hline 1934 & Apr. 4, 1934 & 89.7 & & 13.000 \\
\hline 1935 & MaI. 16,1935 & 88.3 & & 9,400 \\
\hline 1936 & Mar. 17, 1936 & 88.0 & * & 8.680 \\
\hline 1937 & Mar. 7. 1937 & $\cdots$ & & 9,000 \\
\hline 1938 & Sept.14, 1938 & 88.6 & & 10.200 \\
\hline 1939 & Mar. 14, 1939 & 87.7 & & 7.990 \\
\hline 1940 & Mar. 30,1940 & 85.7 & & 4.130 \\
\hline 1941 & Apr. 18, 1941 & 89.1 & & 11,300 \\
\hline 1942 & June 29,1942 & 89.1 & & 11.400 \\
\hline 1961 & Mar. 26, 1961 & 98.5 & & 20.500 \\
\hline 1962 & Mar. 30, 1962 & 91.9 & & 19.000 \\
\hline
\end{tabular}

a Maximum for period July 1 to sept. $30,1933$. 


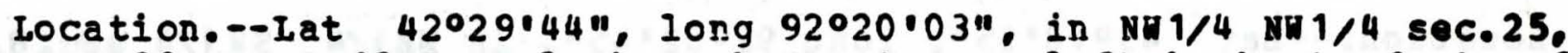
T. 89 N.. R. $13 \%$. Black Hawk County, on left bank at foot of East Seventh street, 0.3 mile upstream from Eleventh avenue Bridge in Nater100, 1.1 mile downstream from Black Hawk Creek. and at mile 187.9 above mouth of Iowa River.

Drainage area. $--5,146 \mathrm{sg} \mathrm{mi}$

Gage.- Water-stage recorder. Latum of gage is $824.14 \mathrm{ft}$ above mean sea level.

Stage-discharge relation.--Defined by current-meter measurements. Flood stage.--15 ft.

Remarks.--Base for partial-duration series. 13,000 cfs.

Peak s_tages_and_di scharges

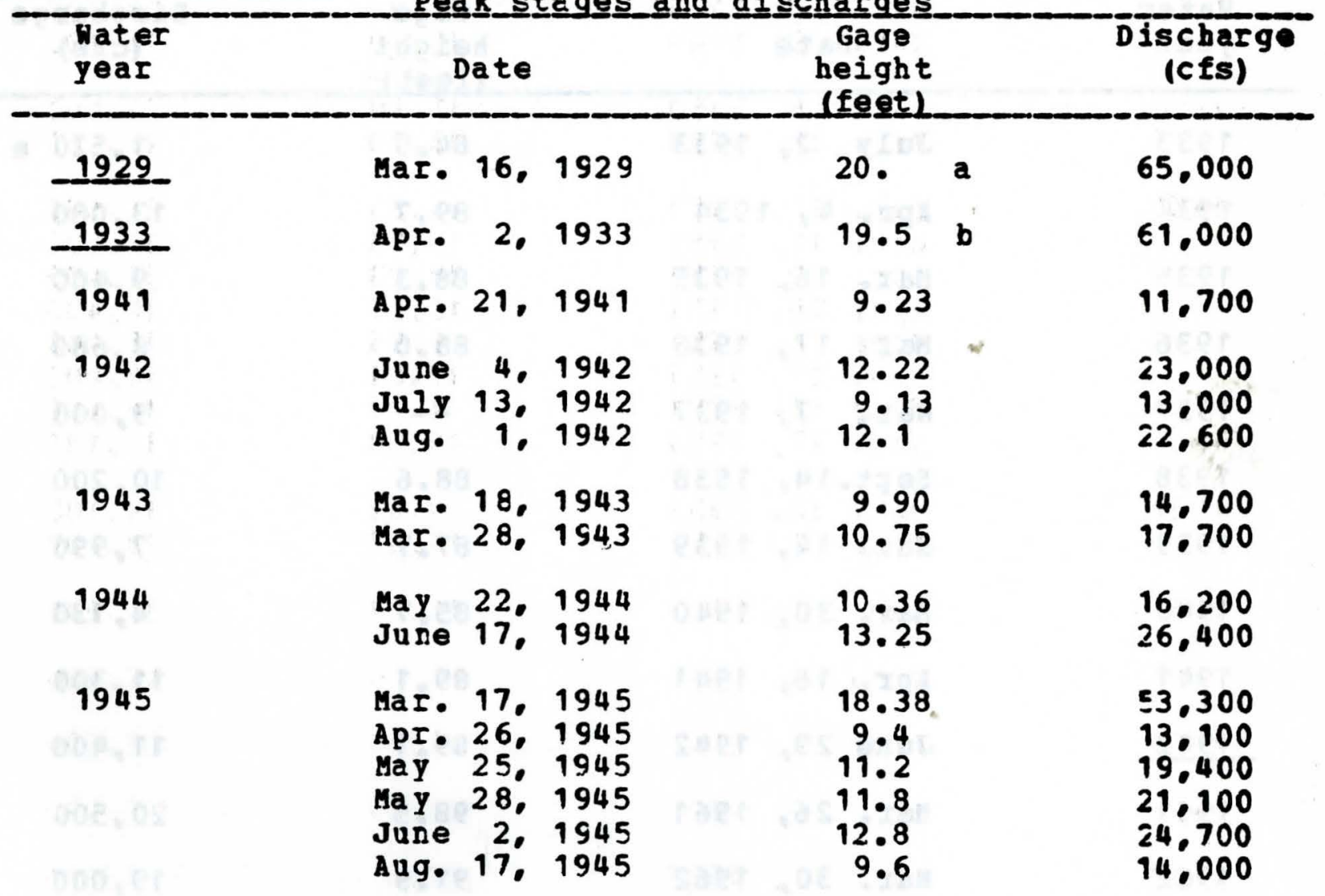

a About, determined by corps of Engineers, from infcration by City of Naterloc.

b About, from information by city of Haterloo. 
05-4640.00 Cedar River at Naterloo, Iowa-- (Continued)

Peak stages_and_di scharges

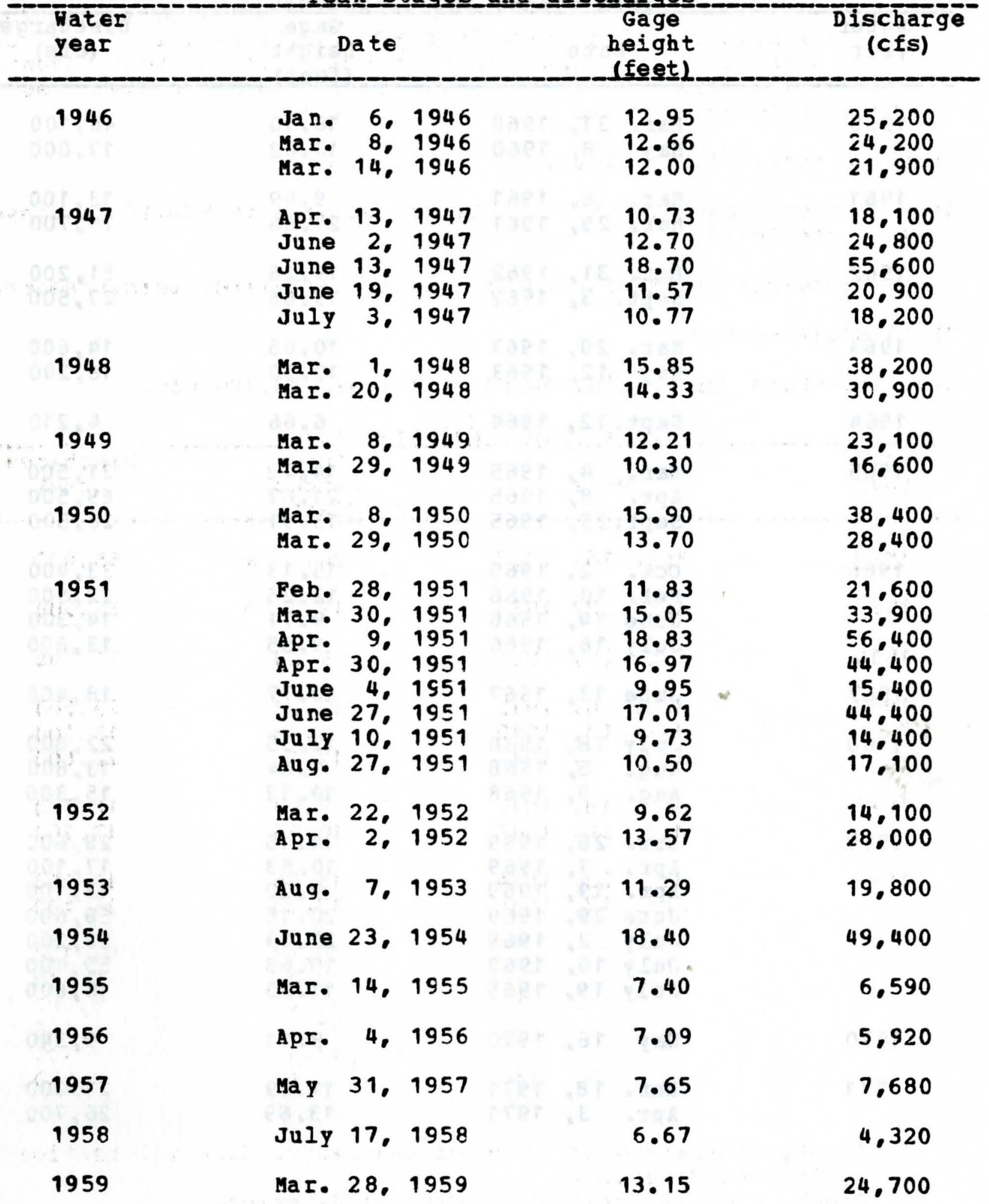


05-4640.00 Cedar River at Naterloo, Iowa--(Continued)

Peak stages and discharges

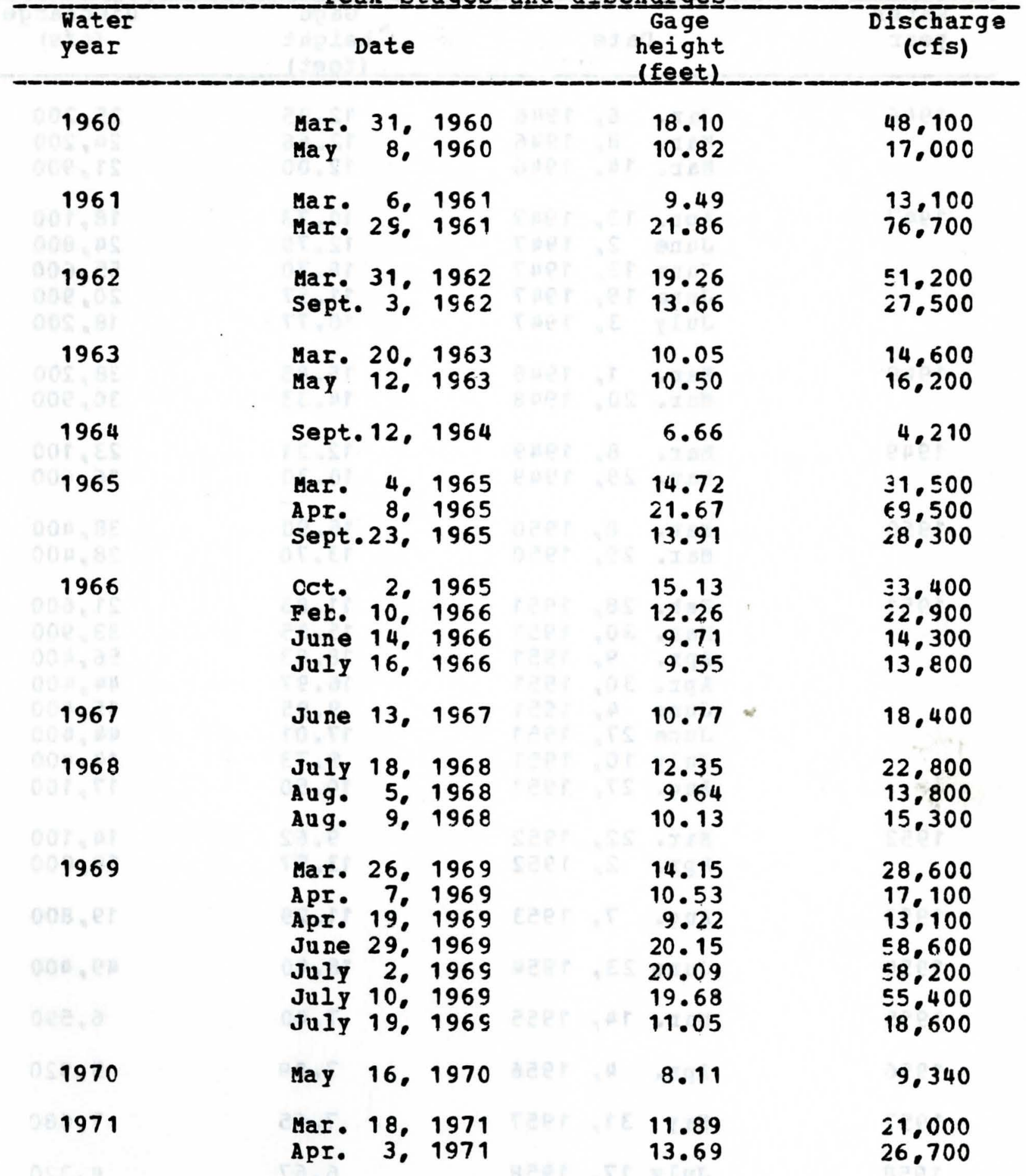


05-4640.00 Cedar River at Naterloo, Iowa-- (Continued)

Peak

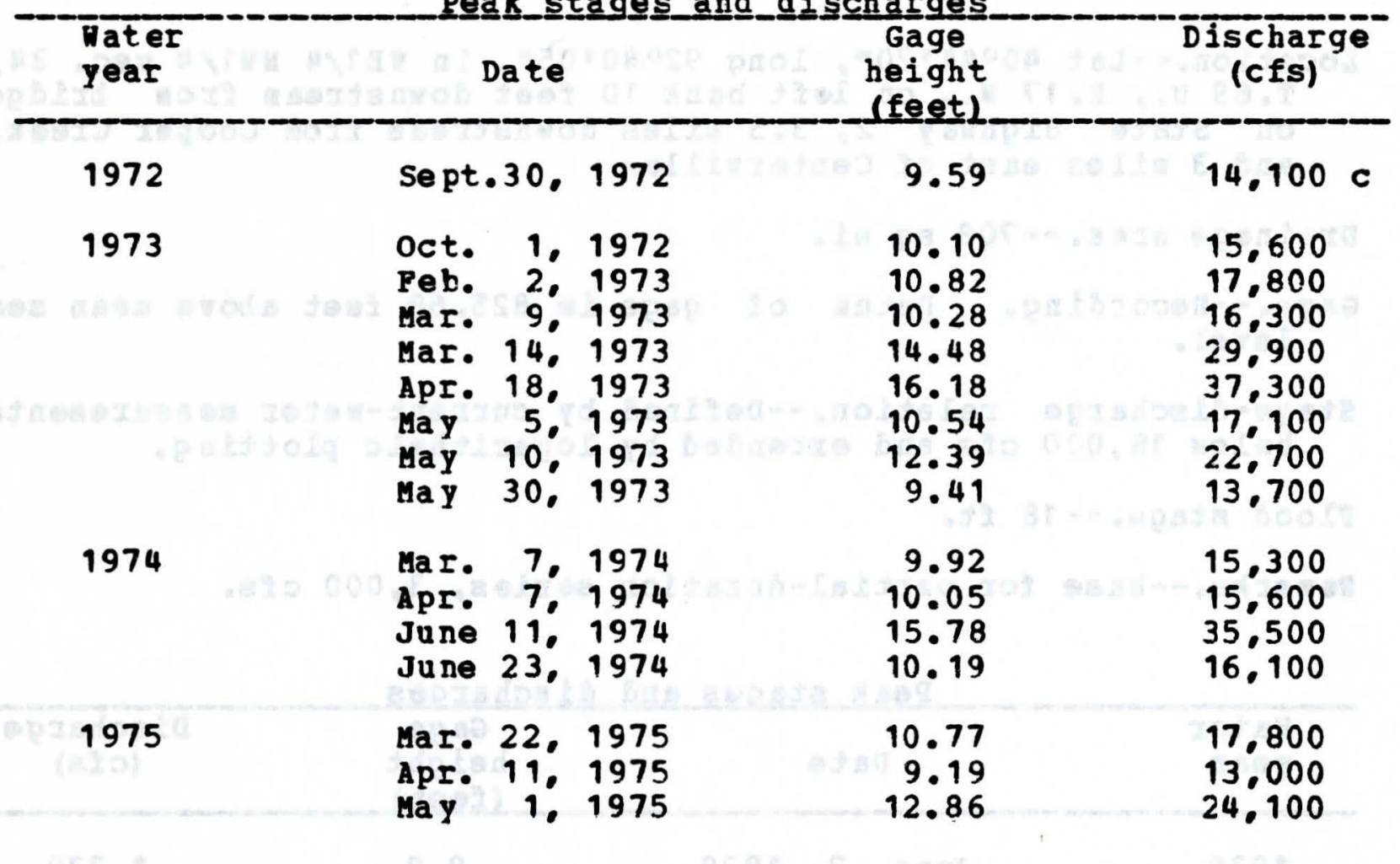

C Stage rising, peak cccurred oct. 1, 1972. 


\section{6-9040.00 Chariton River near Centerville. Iowa}

(Discontinued sept. 30, 1959)

location,-- Lat $40044^{\prime} 20^{\prime \prime}$, long $920488^{\circ} 05^{\prime \prime}$, in NE1/4 NN1/4 sec. 34 , T.69 H.. R. $17 \mathrm{M}$.. on left bank 10 feet downstrean frcm bridge on state Highway 2, 3.5 miles downstrean from Coofer Creek. and 3 miles east cf Centerville.

Drainage area.--708 sq $\mathrm{mi}$.

Gage.--Recording. Datum of gage is 825.68 feet above mean sea level.

Stage-discharge relation.--Defined by current-meter measurements below 18,000 cfs and extended by logarithmic plotting.

Flood stage.-- $18 \mathrm{ft}$.

Remarks.--Base for partial-duration series, 3,000 cfs.

Peak stages and discharges

\begin{tabular}{|c|c|c|c|c|c|c|}
\hline $\begin{array}{l}\text { Dater } \\
\text { year }\end{array}$ & I & Date & & $\begin{array}{l}\text { Gage } \\
\text { height } \\
\text { (feet) }\end{array}$ & & $\begin{array}{c}\text { Discharge } \\
\text { (cfs) }\end{array}$ \\
\hline 1938 & June & 2. & 1938 & 9.8 & & 1.730 \\
\hline 1939 & $\begin{array}{l}\text { Mar. } \\
\text { Apr. } \\
\text { aug. }\end{array}$ & $\begin{array}{l}13 . \\
16 . \\
11 .\end{array}$ & $\begin{array}{l}1939 \\
1939 \\
1939\end{array}$ & $\begin{array}{l}23.4 \\
16.2 \\
14.8\end{array}$ & w & $\begin{array}{r}16,500 \\
4.680 \\
3,900\end{array}$ \\
\hline 1940 & Hay & 10 & 1940 & 10.5 & & 2.150 \\
\hline 1941 & $\begin{array}{l}\text { June } \\
\text { June }\end{array}$ & 3. & $\begin{array}{l}1941 \\
1941\end{array}$ & $\begin{array}{l}13.9 \\
15.2\end{array}$ & & $\begin{array}{l}3.380 \\
4.080\end{array}$ \\
\hline 1942 & $\begin{array}{l}\text { Nov. } \\
\text { June }\end{array}$ & 23 & $\begin{array}{l}1541 \\
1942\end{array}$ & $\begin{array}{l}13.9 \\
15.4\end{array}$ & & $\begin{array}{l}3.530 \\
4.140\end{array}$ \\
\hline 1943 & $\begin{array}{l}\text { Dec. } \\
\text { May } \\
\text { June }\end{array}$ & $\begin{array}{l}27 . \\
17 . \\
13 .\end{array}$ & $\begin{array}{l}1942 \\
1943 \\
1943\end{array}$ & $\begin{array}{l}14.5 \\
21.9 \\
19.8\end{array}$ & & $\begin{array}{l}4.060 \\
9.610 \\
7.100\end{array}$ \\
\hline 1944 & $\begin{array}{l}\text { Apr. } \\
\text { Apr. } \\
\text { May } \\
\text { Hay } \\
\text { June }\end{array}$ & $\begin{array}{r}15 \circ \\
24 \% \\
3 \% \\
5 \% \\
11 \%\end{array}$ & $\begin{array}{l}1944 \\
1 \text { C44 } \\
1944 \\
1944 \\
1944\end{array}$ & $\begin{array}{l}14.5 \\
22.6 \\
14.1 \\
16.2 \\
21.2\end{array}$ & & $\begin{array}{r}3.980 \\
13.000 \\
3.790 \\
4.930 \\
8.410\end{array}$ \\
\hline
\end{tabular}


06-9040.00 Chariton River near Centerville, Iowa-- (Continued)

Peak_stages and discharges

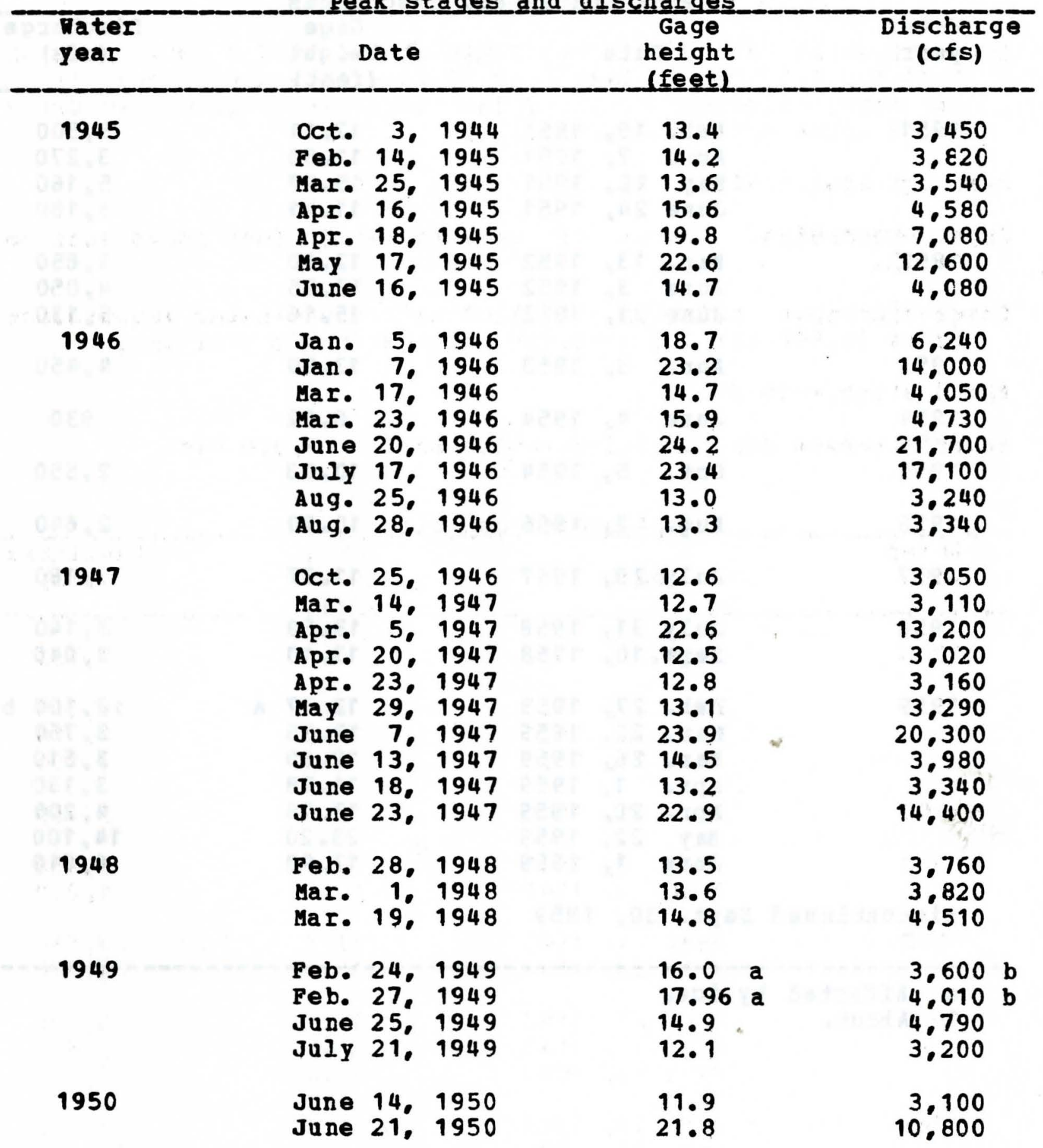

a Afected by ice.

b About. 
06-9040.00 Chariton River near Centerville. Iowa-- (Continued)

Peak_stages and discharges

\begin{tabular}{|c|c|c|c|c|}
\hline $\begin{array}{l}\text { Water } \\
\text { year }\end{array}$ & Date & & $\begin{array}{l}\text { Gage } \\
\text { height } \\
\text { (feet) }\end{array}$ & $\begin{array}{c}\text { Discharge } \\
\text { (cfs) }\end{array}$ \\
\hline 1951 & $\begin{array}{l}\text { Feb. 19, } \\
\text { Apr. } 7 . \\
\text { May 12, } \\
\text { June } 24 .\end{array}$ & $\begin{array}{l}1951 \\
1951 \\
1951 \\
1951\end{array}$ & $\begin{array}{l}12.11 \\
11.60 \\
15.27 \\
11.41\end{array}$ & $\begin{array}{l}3.500 \\
3.270 \\
5.160 \\
3.180\end{array}$ \\
\hline 1952 & $\begin{array}{l}\text { Mar. } 13, \\
\text { June } 3, \\
\text { June } 21 .\end{array}$ & $\begin{array}{l}1952 \\
1952 \\
1952\end{array}$ & $\begin{array}{l}12.80 \\
13.25 \\
15.16\end{array}$ & $\begin{array}{l}3.850 \\
4.050 \\
5.110\end{array}$ \\
\hline 1953 & Apr. & 1953 & 13.99 & 4.450 \\
\hline 1954 & June & 1954 & 6.02 & 930 \\
\hline 1955 & oct. & 1954 & 10.03 & 2.550 \\
\hline 1956 & Aug. & 1956 & 10.20 & 2.640 \\
\hline 1957 & July 29. & 1957 & 11.37 & 3.180 \\
\hline 1958 & $\begin{array}{l}\text { July } 31 . \\
\text { Sept. } 10 .\end{array}$ & $\begin{array}{l}1958 \\
1958\end{array}$ & $\begin{array}{l}13 \cdot 50 \\
13 \cdot 10\end{array}$ & $\begin{array}{l}3.140 \\
3.040\end{array}$ \\
\hline 1959 & $\begin{array}{l}\text { Feb. } 27^{\circ} \\
\text { Mar. } 22^{\circ} \\
\text { Mar. } 26_{\circ} \\
\text { Apr. } 1 . \\
\text { Apr. } 20_{\circ} \\
\text { May } 22^{\circ} \\
\text { June } 1 .\end{array}$ & $\begin{array}{l}1959 \\
1955 \\
1959 \\
1959 \\
1959 \\
1959 \\
1959\end{array}$ & $\begin{array}{l}12.77 \\
13.06 \\
12.59 \\
11.78 \\
13.99 \\
23.20 \\
17.90\end{array}$ & $\begin{array}{r}3.100 \quad b \\
3.750 \\
3.510 \\
3.130 \\
4.200 \\
14.100 \\
6.810\end{array}$ \\
\hline
\end{tabular}

Discontinued sept. 30,1959 
Location.--Iat 40057'12". ICng 93015'27", in SW1/4 NE1/4 sec.15, T.71 N.. R. 21 W.. Lucas County, or Iight bank 15 ft jewnstream from bridge on county highway $543,0.4$ mile downstream from Dolf Creek, and 5.0 miles scutheast of Chariton.

Drainage area.--182 sq mi.

Gage.- Water-stage recorder. Catum of gage is $917.96 \mathrm{ft}$ above mean sea level (levels by Natioral Heather Service ficm Corps of Engineers berch mark).

Stage-discharge relation.--Defined by current-meter measurements. Plocd stage. - - $18 \mathrm{ft.}$

Remarks.--Base for partial-duration series. 1,200 cfs.

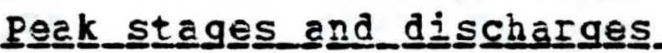

\begin{tabular}{|c|c|c|c|c|}
\hline $\begin{array}{l}\text { Hater } \\
\text { year }\end{array}$ & Date & & $\begin{array}{c}\text { Gage } \\
\text { height } \\
\text { (feet) }\end{array}$ & $\begin{array}{c}\text { ischarge } \\
\text { (cfs) }\end{array}$ \\
\hline-1947 & June 5 . & 1947 & 21.65 & 11.000 \\
\hline 1960 & March & 1960 & 23.0 & $15.000 \mathrm{~b}$ \\
\hline 1966 & Fet. 9. & 1966 & 15.90 & 1.360 \\
\hline 1967 & $\begin{array}{l}\text { June } 10 . \\
\text { June } 14, \\
\text { June } 21 .\end{array}$ & $\begin{array}{l}1967 \\
1967 \\
1967\end{array}$ & $\begin{array}{l}16.82 \\
18.08 \\
19.53\end{array}$ & $\begin{array}{l}1.670 \\
2.820 \\
4.930\end{array}$ \\
\hline 1968 & Apr. 23. & 1968 & 19.90 & 5.660 \\
\hline 1969 & $\begin{array}{ll}\text { Apr. } & 27, \\
\text { JuIy } & 10, \\
\text { July } & 13 . \\
\text { July } & 21 .\end{array}$ & $\begin{array}{l}1969 \\
1969 \\
1969 \\
1969\end{array}$ & $\begin{array}{l}16.26 \\
16.21 \\
16.77 \\
16.32\end{array}$ & $\begin{array}{l}1.360 \\
1.340 \\
1.640 \\
1.390\end{array}$ \\
\hline 1970 & $\begin{array}{l}\text { Apr. 19, } \\
\text { May 15, } \\
\text { Aug. } 8 . \\
\text { Sept. } 17 .\end{array}$ & $\begin{array}{l}1970 \\
1970 \\
1970 \\
1970\end{array}$ & $\begin{array}{l}16.61 \\
17.44 \\
20.15 \\
18.29\end{array}$ & $\begin{array}{l}1.550 \\
2.120 \\
6.320 \\
3.230\end{array}$ \\
\hline
\end{tabular}


06-9034.00 Chariton River near Chariton, Iowa--(Continutd)

Paak_stages_and discharges

\begin{tabular}{|c|c|c|c|}
\hline $\begin{array}{l}\text { Water } \\
\text { year }\end{array}$ & Date & $\begin{array}{l}\text { Gage } \\
\text { height } \\
\text { (feet). }\end{array}$ & $\begin{array}{l}\text { Discharge } \\
\text { (cfs) }\end{array}$ \\
\hline 1971 & oct. 9.1970 & 17.28 & 2.080 \\
\hline 1972 & $\begin{array}{l}\text { May, 8, } 1972 \\
\text { Sept. 13, } 1972 \\
\text { Sept. 14, } 1972\end{array}$ & $\begin{array}{l}16.32 \\
17.29 \\
18.08\end{array}$ & $\begin{array}{l}1.390 \\
1.990 \\
2.820\end{array}$ \\
\hline 1973 & 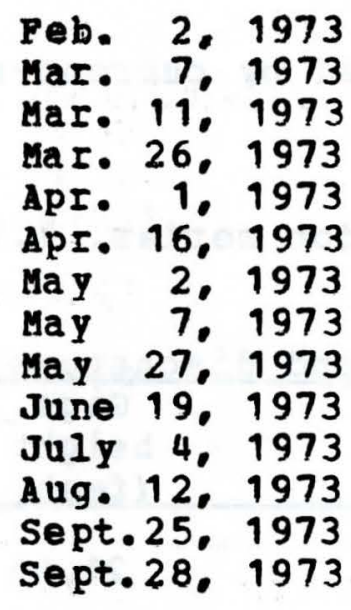 & $\begin{array}{l}17.63 \\
16.20 \\
16.49 \\
16.89 \\
17.22 \\
18.02 \\
17.01 \\
16.44 \\
17.30 \\
17.58 \\
16.12 \\
16.46 \\
16.81 \\
16.03\end{array}$ & $\begin{array}{l}2.290 \\
1.330 \\
1.470 \\
1.710 \\
1.940 \\
2.740 \\
1.790 \\
1.470 \\
2.080 \\
2.240 \\
1.290 \\
1.460 \\
1.670 \\
1.250\end{array}$ \\
\hline 1974 & $\begin{array}{l}\text { Oct. 3, } 1973 \\
\text { Oct. 12, } 1973 \\
\text { Dec. 5, } 1973 \\
\text { Jan. 27, } 1974 \\
\text { Apr. 21, } 1974 \\
\text { May 18, } 1974 \\
\text { June 9, } 1974 \\
\text { June 13, } 1974\end{array}$ & $\begin{array}{l}15.98 \\
20.20 \\
15.95 \\
17.55 \\
16.85 \\
16.03 \\
17.89 \\
16.82\end{array}$ & $\begin{array}{l}1.230 \\
6.300 \\
1.220 \\
2.220 \\
1.750 \\
1.250 \\
2.590 \\
1.770\end{array}$ \\
\hline 1975 & $\begin{array}{l}\text { Mar. 18, } 1975 \\
\text { June 28, } 1975\end{array}$ & $\begin{array}{l}16.27 \\
16.82\end{array}$ & $\begin{array}{l}1.360 \\
1.670\end{array}$ \\
\hline
\end{tabular}




$$
\text { 06-9040.40 Chariton River at Coal City. Iowa }
$$

bocation.--lat $40035 \cdot 35^{\prime \prime}$, long $92042 \cdot 40^{\prime \prime}$, in NE1/4 seC.20. T.67 N.. R.16 M. Appanoose County. at bridge in Coal City.

Drafnage area.--816 sq $\mathbf{m i}$.

Gage.--Crest-stage gage.

stage-discharge relation.--Defined by current-meter measurements. Rearks.--Only annual peaks are shcwn.

Peak_stages_and_discharges

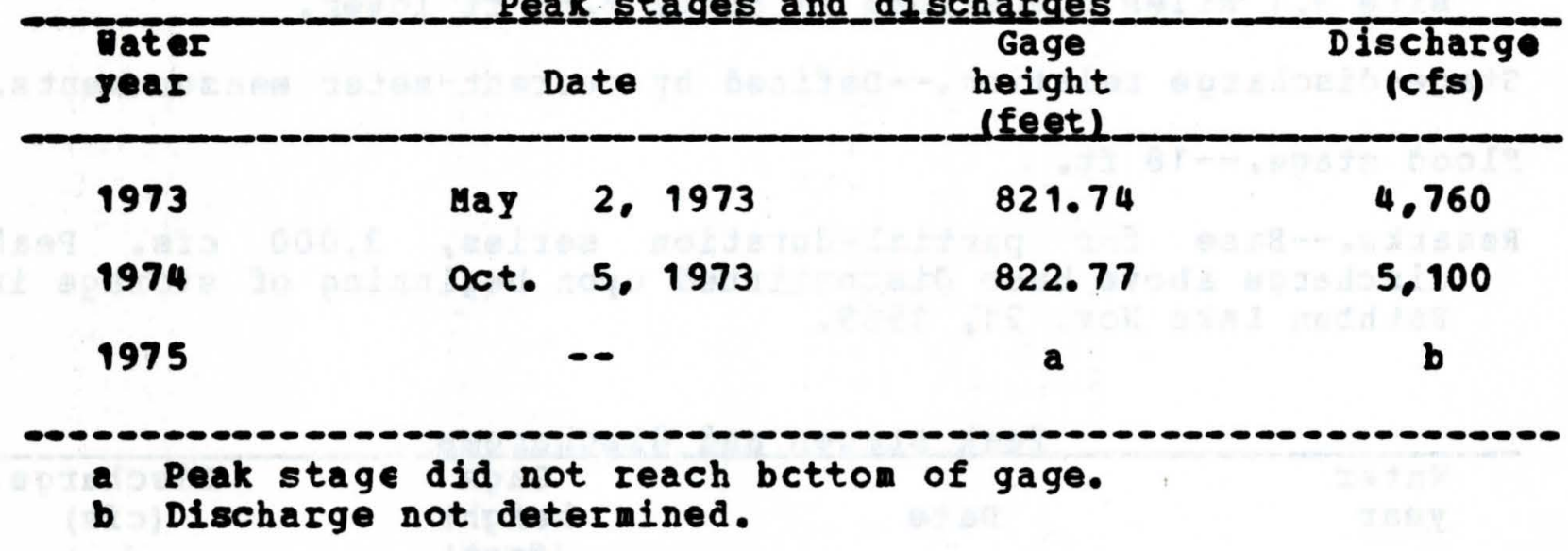


Location.--Lat $40049 \cdot 22^{\prime \prime}$, long $92053^{\circ} 22^{\prime \prime}$, in SE1/4 NE1/4 sec. 35 , T.70 N.. R. 18 \%.. Appanoose County. on left bank 600 ft downstream from outlet of Rathbun Dam, 1.8 miles north of Rathbun and 3.7 miles upstream from Walnut Creak and at mile 142.1 .

Drainage area.--549 sq mi.

Gage.--Hater-stage recorder. Datum of gage is 847.92 ft above mean sea level. Prior to Nov. 16. 1960, nonrecording gage and Nov. 17. 1960, to sept. 30, 1969, water-stage raccrder, at site 3.1 miles downstream at datum $4.65 \mathrm{ft}$ lower.

Stage-discharge relation.--Defined by current-meter measurements. Plood stage. $-18 \mathrm{ft}$.

Remarks.--Base for partial-duration series, 3,000 cfs. Peak discharge above base discontinued upon beginning of storage in Rathbun Lake Nov. 21. 1969.

Peak stages and discharges

\begin{tabular}{|c|c|c|c|}
\hline $\begin{array}{l}\text { Dater } \\
\text { year }\end{array}$ & Date & $\begin{array}{l}\text { Gage } \\
\text { height } \\
\text { lfeetl }\end{array}$ & $\begin{array}{c}\text { Discharge } \\
\text { (cfs) }\end{array}$ \\
\hline 1957 & Apr. 5. 1957 & 13.72 & 1,500 \\
\hline 1958 & Aug. 4. 1958 & 17.3 & 2.070 \\
\hline 1959 & $\begin{array}{lll}\text { Mar. } & 21, & 1959 \\
\text { Apr. } & 3, & 1959 \\
\text { Apr. } & 22, & 1959 \\
\text { May } & 22, & 1959 \\
\text { May } & 31, & 1959\end{array}$ & $\begin{array}{l}19.51 \\
18.9 \\
19.72 \\
24.0 \\
21.1\end{array}$ & $\begin{array}{r}4.100 \\
3.160 \\
4.420 \\
16.600 \\
7.100\end{array}$ \\
\hline 1960 & $\begin{array}{l}\text { Jan. } 15,1960 \\
\text { Mar. } 31,1960 \\
\text { Apr. 19, } 1960 \\
\text { May } 7,1960\end{array}$ & $\begin{array}{l}20.0 \\
25.3 \\
19.6 \\
19.0\end{array}$ & $\begin{array}{r}4.900 \\
21.800 \\
4.260 \\
3.300\end{array}$ \\
\hline 1961 & $\begin{array}{l}\text { Mar. 9, } 1961 \\
\text { Mar. 15, } 1961 \\
\text { Sept. 15, } 1961\end{array}$ & $\begin{array}{l}19.18 \\
19.80 \\
23.09\end{array}$ & $\begin{array}{r}3,620 \\
4.580 \\
13.000\end{array}$ \\
\hline
\end{tabular}

a From floodmark, site and datum then in use. 
06-9039.00 Chariton River near Rathbun, Iowa--(Continued)

Peak stages_and discharges

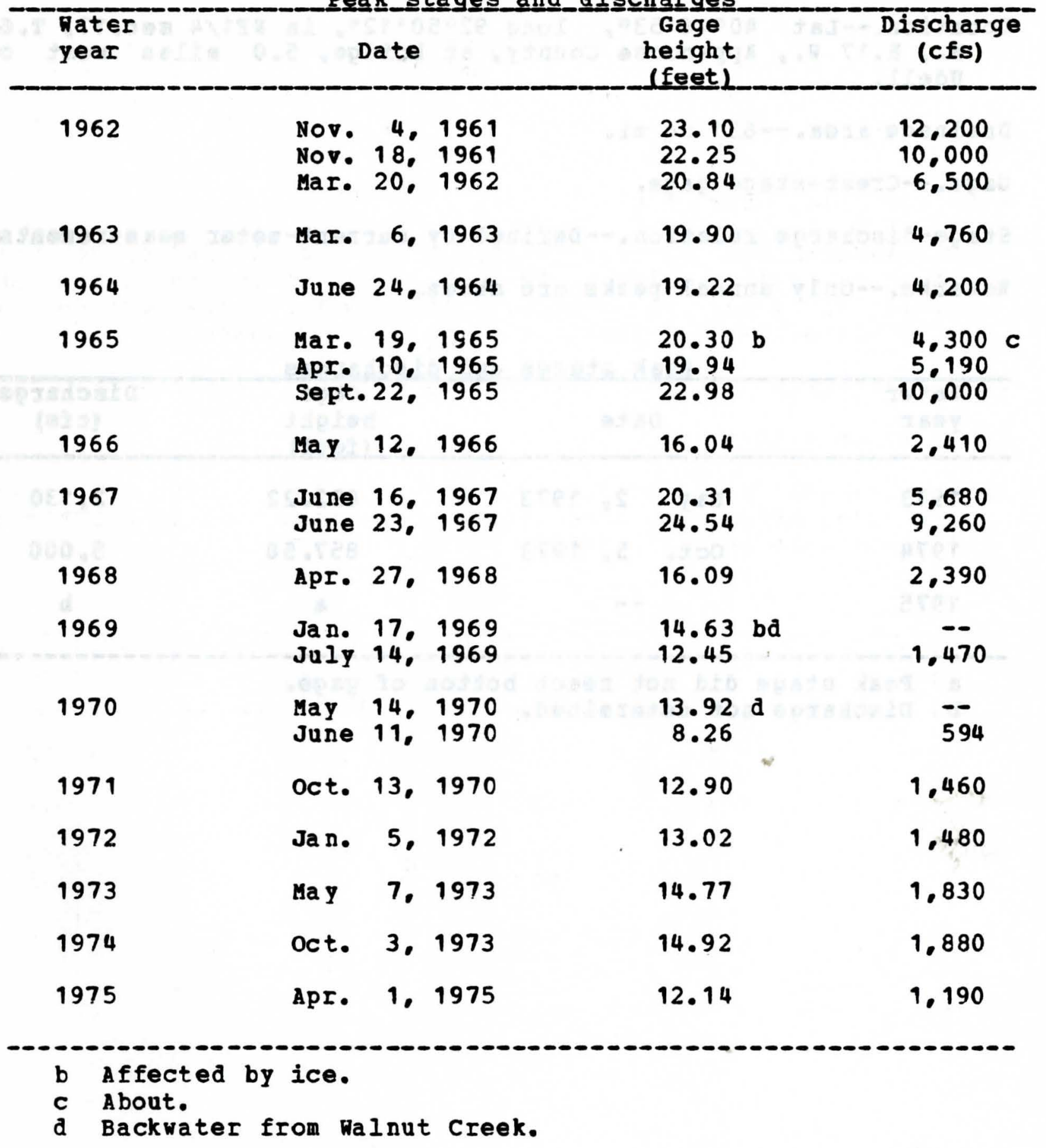




$$
\text { 06-9039.80 Chariton River near vdell, Iowa }
$$

Location.--Lat $40046 \cdot 53 n$, long $92050 \cdot 12 n$, in NE1/4 sec.17. T.69 H.. R.17 H., Appanoose County, at bridge, 5.0 miles west of odell.

Drainage area. $--631 \mathrm{sg} \mathrm{ml}$.

Gage.--Crest-stage gage.

Stage-discharge relation.--Defined by current-meter measurenents. Remarks.--only annual peaks are shcwn.

Peak_stages and discharges

\begin{tabular}{ccccc}
\hline $\begin{array}{l}\text { Mater } \\
\text { Year }\end{array}$ & \multicolumn{2}{c}{ Date } & $\begin{array}{c}\text { Gage } \\
\text { height } \\
\text { ffeetL }\end{array}$ & $\begin{array}{c}\text { Discharge } \\
\text { (Cfs) }\end{array}$ \\
\hline 1973 & May & 2.1973 & 852.22 & 2.130 \\
1974 & Oct. & 5,1973 & 857.58 & 5.000 \\
1975 & & - & a & b
\end{tabular}

a Peak stage did not reach bottom of gage.

b Discharge not determined. 
Location.--Iat $41040 \cdot 36 "$. Iong 91035'55", in NE1/4 SE1/4 sec. 1.

T.79 N.. R.7 M.. Johnson County. on left bank about 50 ft upstream from bridge on county highway. 1.1 miles west of post office in Coralville, 1.5 miles downstream from Deer Creek and 2.7 miles upstream frcm mouth.

Drainage area.--98.1 sq mi.

Gage.--Nater-stage recorder. Datum of gage is $648.43 \mathrm{ft}$ above mean sea level (levels by Corps of Engineers). Prior to Jan. 7. 1957. nonrecording gage at same site and datum.

Stage-discharge relation.--Defined by current-meter measurements. Bankfull stage.--11 ft.

Remarks.--Base for partial-duration series, 1,000 cfs.

Peak_stages_and discharges

\begin{tabular}{|c|c|c|c|}
\hline $\begin{array}{l}\text { Water } \\
\text { year }\end{array}$ & Date & $\begin{array}{l}\text { Gage } \\
\text { height } \\
\text { dfeetl }\end{array}$ & $\begin{array}{l}\text { Discharge } \\
\text { (cfs) }\end{array}$ \\
\hline 1953 & $\begin{array}{l}\text { Feb. } 20,1953 \\
\text { May } 25,1953\end{array}$ & $\begin{array}{l}11.18 \\
9.3\end{array}$ & $\begin{array}{l}1.800 \mathrm{~b} \\
1.010\end{array}$ \\
\hline 1954 & Aug. 26,1954 & 8.10 & 730 \\
\hline 1955 & Feb. 21, 1955 & 9.70 & $850 \mathrm{~b}$ \\
\hline 1956 & Aug. 30, 1956 & 9.52 & 900 \\
\hline 1957 & Jan. 22, 1957 & 6.28 & $300 \mathrm{~b}$ \\
\hline 1958 & Seft. 5. 1958 & 9.69 & 1.020 \\
\hline 1959 & $\begin{array}{l}\text { Feb. 27, } 1959 \\
\text { Mar. 20, } 1959 \\
\text { Mar. 26, } 1959 \\
\text { Apr. 28, } 1959\end{array}$ & $\begin{array}{l}11.34 \\
11.68 \\
10.22 \\
10.25\end{array}$ & $\begin{array}{l}1.500 \quad b \\
2.880 \\
1.040 \\
1.040\end{array}$ \\
\hline
\end{tabular}


05-4543.00 Clear Creek near Coralville. Iowa--(Continued)

Eeak stiages and discharges

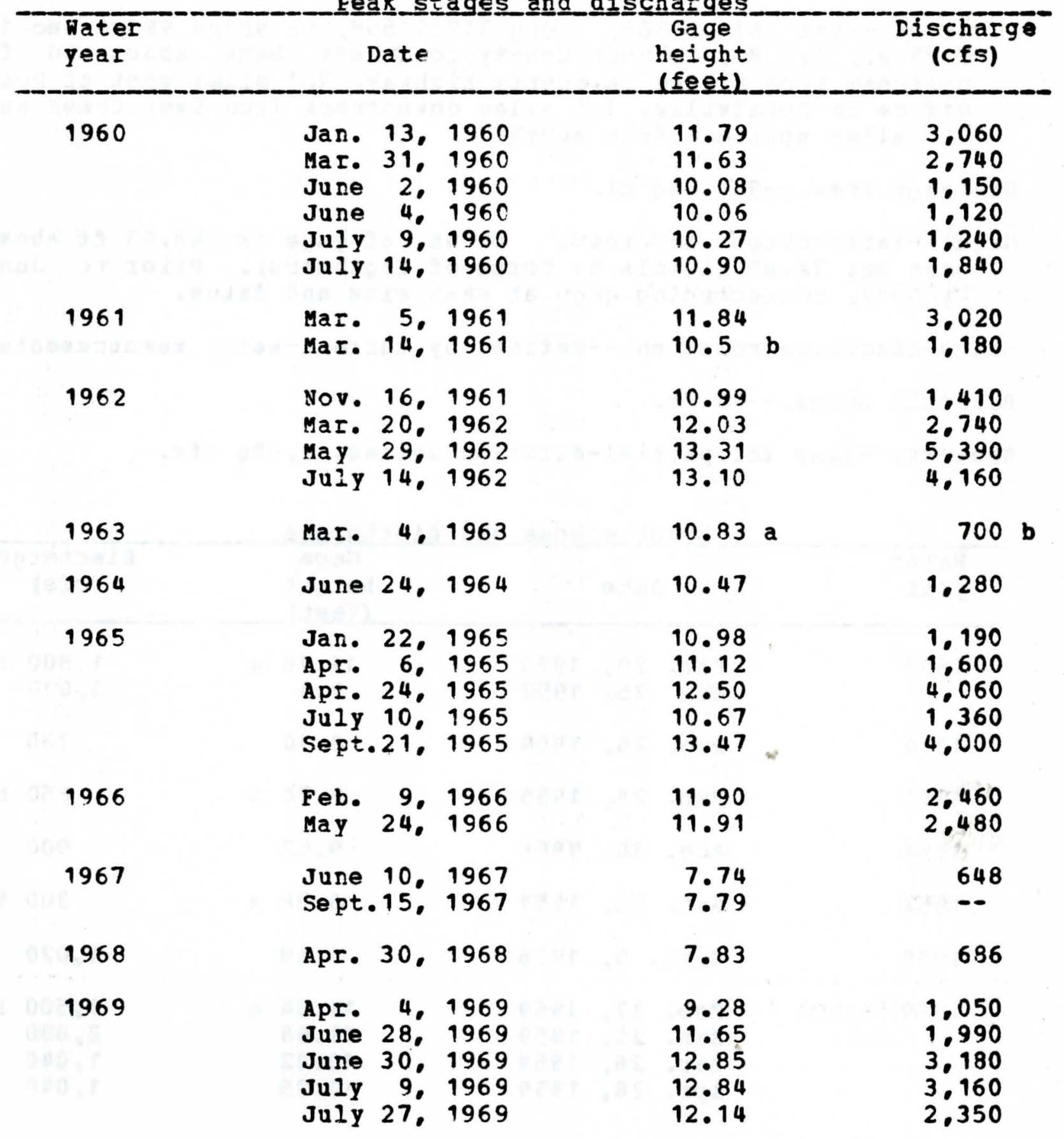

a Affected by ice.

b About. 
05-4543.00 Clear Creek near Coralville, Iowa--(Continued)

Peak_stages_and discharges

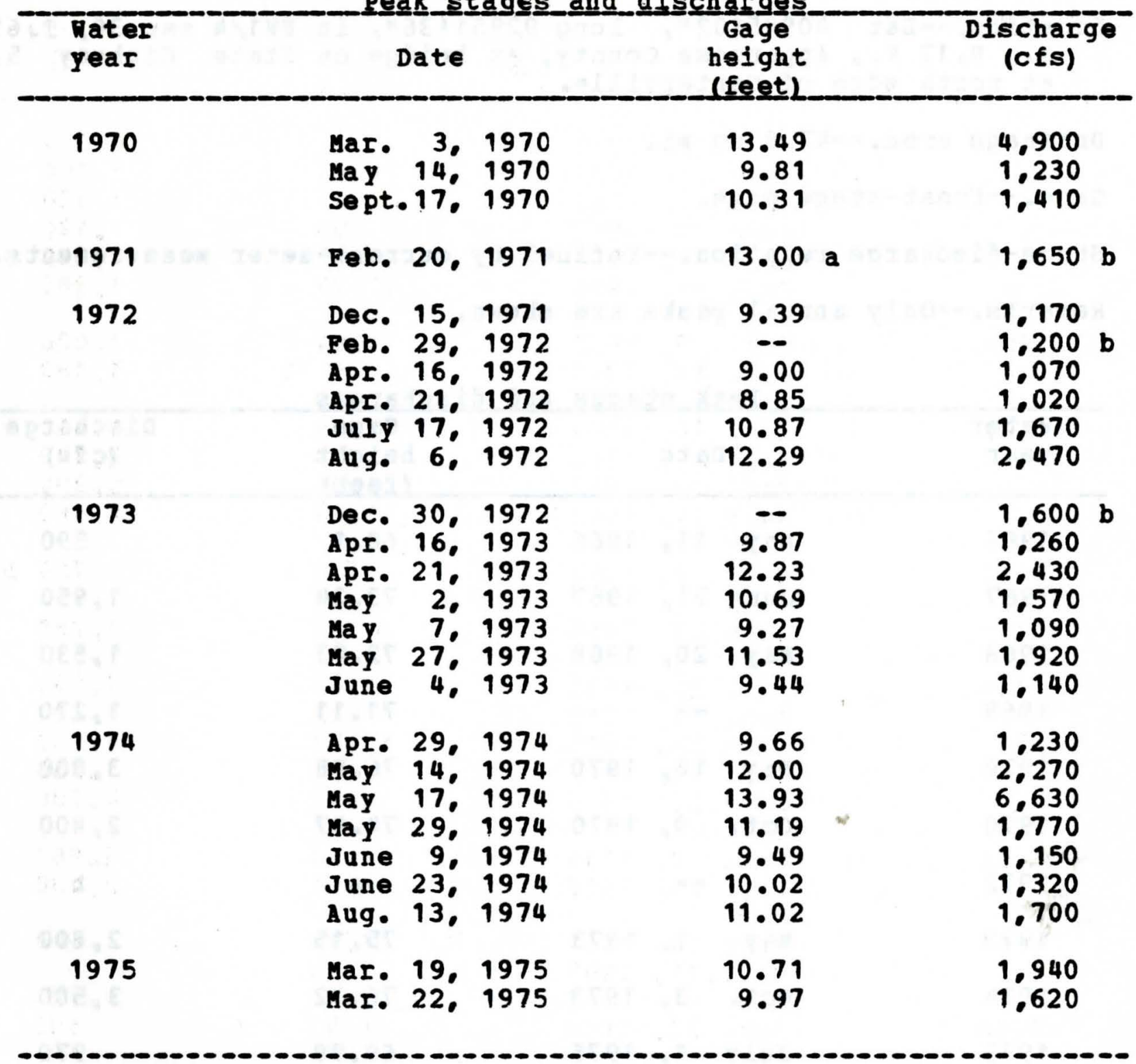

a Affected by ice.

b About. 


$$
\text { 06-9039.90 Cooper Creek at Centerville, Iowa }
$$

Location.--Iat $40045 \cdot 02^{\prime \prime}$, long $92051 \cdot 36^{\prime \prime}$, in NN1/4 sec.30, T.69 N.. R.17 N.. Appanoose County, at bridge on State Highway 5. at north edge of Centervilie.

Drainage area.--47.8 sq mi.

Gage.--Crest-stage gage.

Stage-discharge relation.--Defined by current-meter measurenents. Remarks.--only annual peaks are shown.

Peakk_stages_and_discharges

Hater

year

1966

1967

1968

1969

1970

1970

1972

1973

1974

1975
Date

Gage

height

(feet)

68.1

73.24

72.03

71.11

76.88

74.47

a

75.15

76.32

69.98
Discharge

(cfs)

590

1.950

1.530

1.270

3. 800

2.400

t

2.800

3.500

970

a Peak stage did not reach bottom of gage.

b Discharge not determined. 
Location.--lat $43015^{\circ}$, long $92019 \circ$, in 1 H1/4 sec.6. T. 97 H.. R.12 H. Howard County, at bridge on state Highway 272, 1 mile southrest of Lourdes.

Drainage area.--75.8 sq $\mathrm{si}$

Gage.--Crest-stage gage.

Stage-discharge relation.--Defined by current-meter and indirect mea surements.

Remarks.--Only annual peaks are shown.

Peak_stages_and discharges

\begin{tabular}{|c|c|c|c|c|c|c|}
\hline $\begin{array}{l}\text { Dater } \\
\text { year }\end{array}$ & D & Date & & $\begin{array}{r}\text { Gage } \\
\text { height } \\
\text { (feet) }\end{array}$ & & $\begin{array}{c}\text { E1scharge } \\
\text { (cfs) }\end{array}$ \\
\hline 1953 & June & 13 & 1953 & 12.00 & & 3.200 \\
\hline 1954 & June & 21 & 1954 & 10.61 & & 2.620 \\
\hline 1955 & Mar. & 15. & 1955 & 9.35 & & 1.430 \\
\hline 1956 & Apr. & 1. & 1956 & 9.23 & & 1.330 \\
\hline 1957 & Mar. & 24 & 1957 & 7.60 & $\approx$ & 580 \\
\hline 1958 & Apr. & 7. & 1958 & 6.39 & & 336 \\
\hline 1959 & Mar. & 31. & 1959 & 9.28 & & 1.370 \\
\hline 1960 & June & 23 & 1960 & 12.13 & & 5.960 \\
\hline 1961 & MaI. & 26. & 1961 & 11.12 & & 3.890 \\
\hline 1962 & Aug. & 31. & 1962 & 15.70 & & 11.900 \\
\hline 1963 & May & 13. & 1963 & 9.20 & & 1.310 \\
\hline 1964 & ApI. & 3. & 1964 & 8.00 & & 710 \\
\hline 1965 & Se pt. & 30 & 1965 & 11.69 & & 4.360 \\
\hline 1966 & July & 14. & 1966 & 9.19 & & 1.300 \\
\hline 1967 & June & 10. & 1967 & 11.38 & & 3.850 \\
\hline
\end{tabular}


05-4117.00 Crane Creek near Lourdes, Iowa--(Continued)

Peak__stages_and_di schargarges

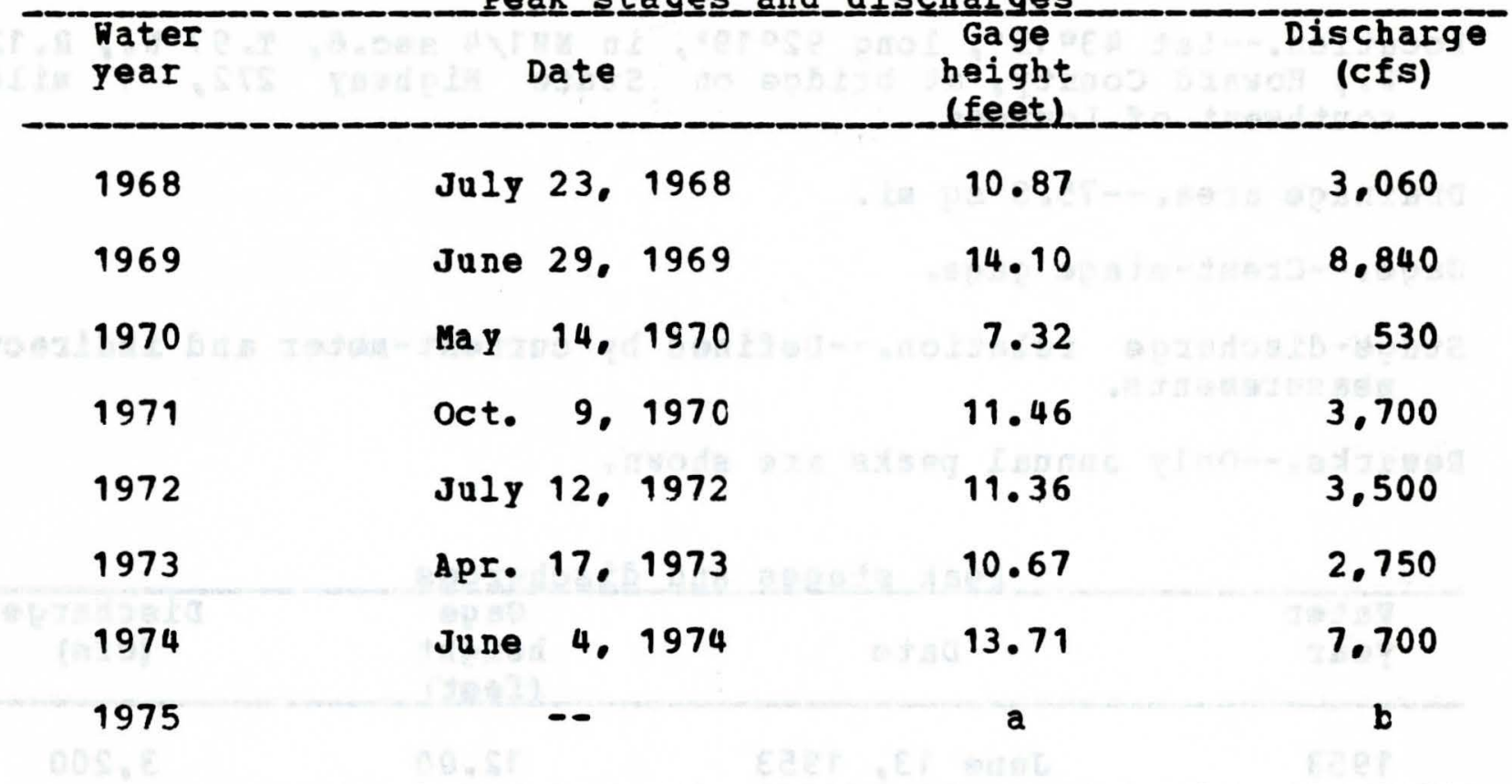

a Peak stage did not reach bottom of gage.

b Discharge not determined. 
Location.--Lat $43022^{\prime}$. long 92023\%. near SE corner of sec.21. T. 99 N.. R. 13 M.. Howard County, at bridge on State Highway 9,

1 mile east of Saratoga.

Drainage area.- $-4.06 \mathrm{sq} \mathrm{mi}$.

Gage.--Crest-stage gage.

Stage-discharge relation.--Defined by current-meter and indirect measurements.

Remarks.--only annual peaks are shown.

Peak_s_tages_and_dis

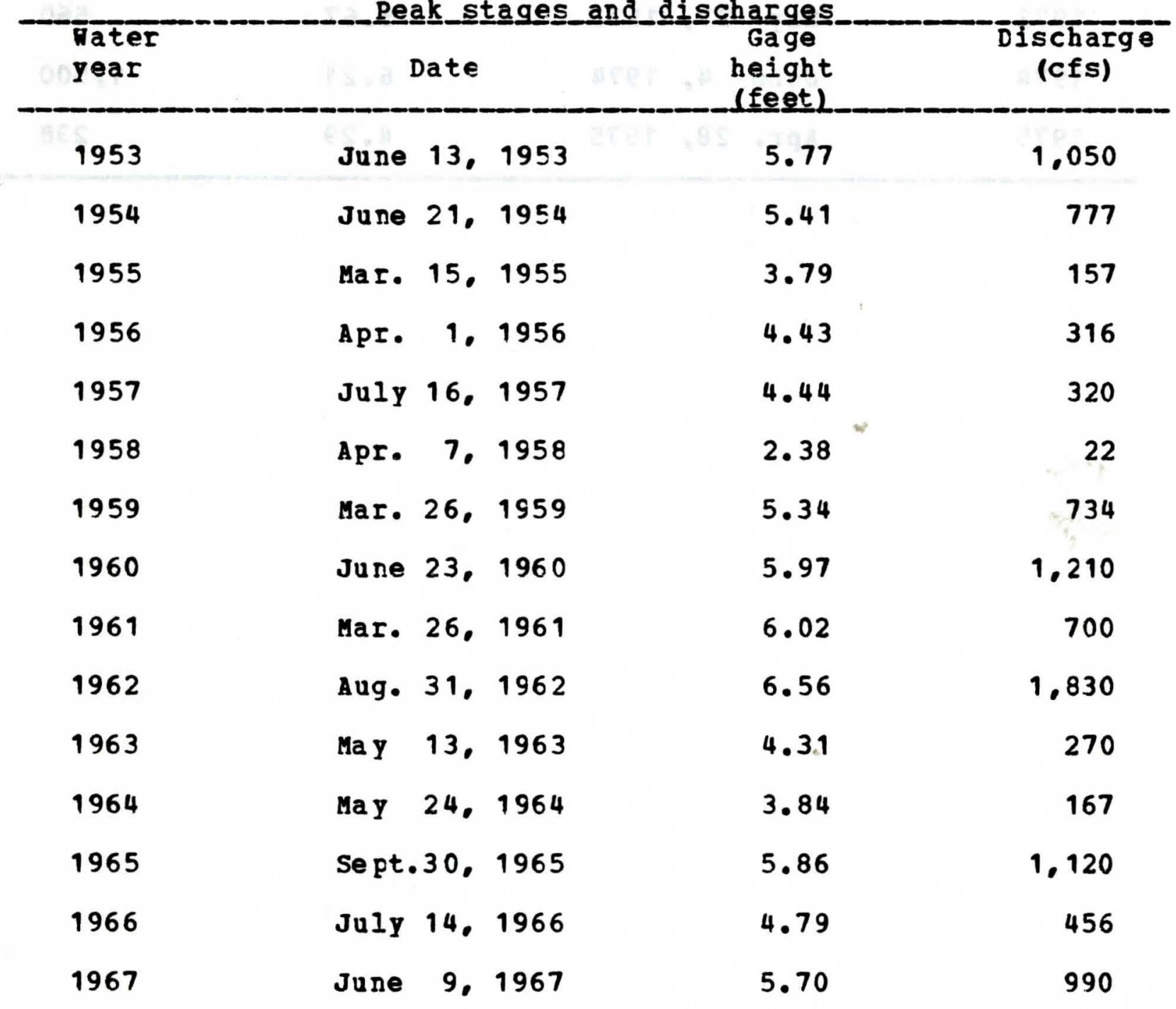


05-4116.50 Crane Creek tributary near Saratoga, Iowa-- (Continued)

Peak stages_and discharges

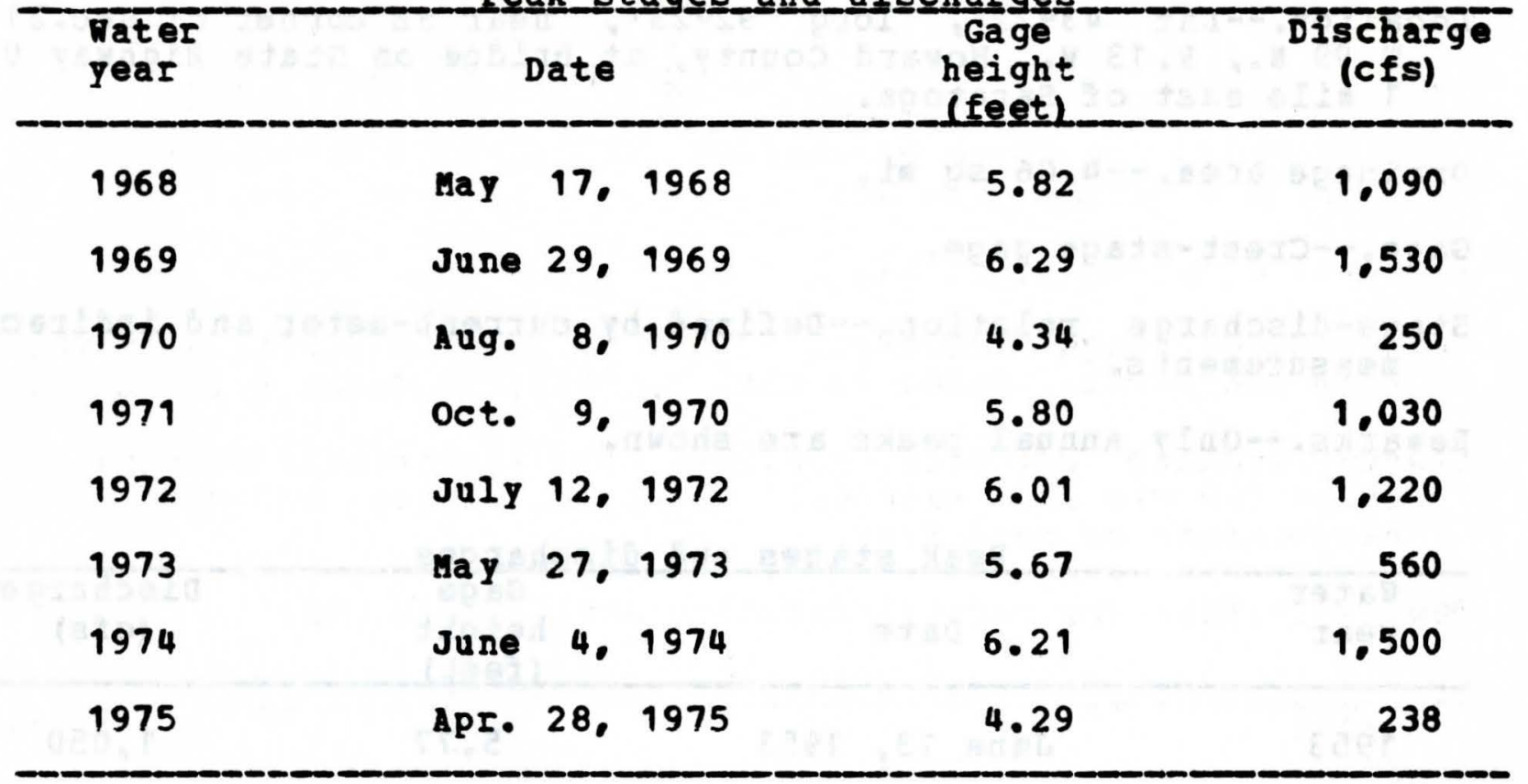


Location.--Lat $41040 \cdot 25^{\prime \prime}$, Icng $94048 \cdot 20^{\prime \prime}$, in NE1/4 NE1/4 sec.9. T.79. R.34 W. Audubon County. on left bank 20 ft dcwnstream from bridge on State Highway $64,5.2$ miles east of Hamlin, and 8 miles upstream from mouth.

Drainage area.--26.0 sq mi.

Gage.--Nater-stage recorder. Datum of gage is 1,266.54 ft above mean sea level. Prior tc oct. 1. 1972, at datum 5 ft higher.

Stage-discharge relation.--Defined by current-meter measurements below 500 cfs and extended above on bases of slcpe area measurement of peak flow.

Remarks.--Base for partial-duration series, 400 cfs.

Peak stages and discharges

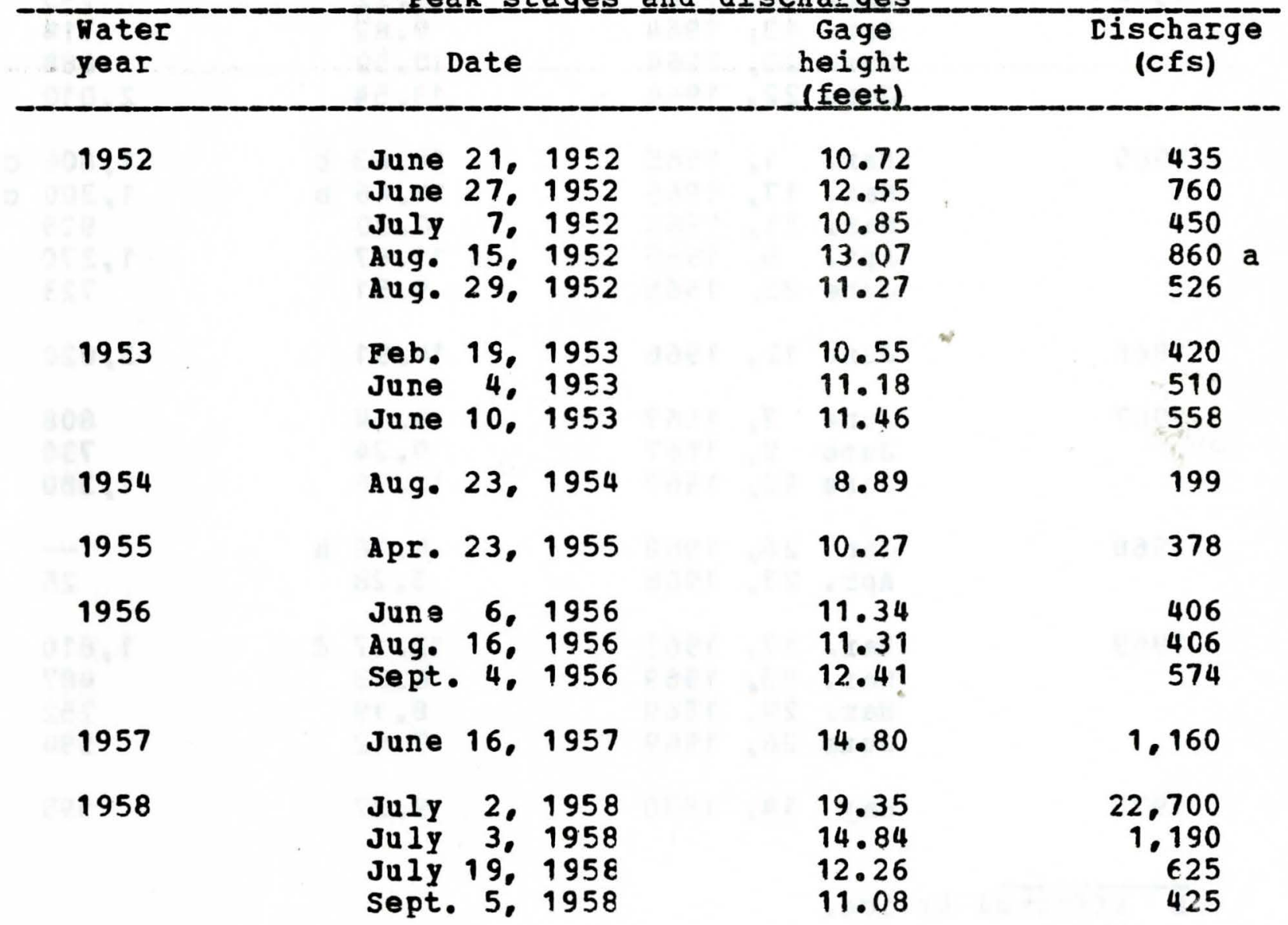

a Maximūm during period June to september 1952. 
06-8090.00 Davids Creek near Hamlin, Iowa--(Continued)

Feak stages and discharges

\begin{tabular}{|c|c|c|c|}
\hline $\begin{array}{l}\text { Hater } \\
\text { year }\end{array}$ & Date & $\begin{array}{c}\text { Gage } \\
\text { height } \\
\text { (feet) }\end{array}$ & $\begin{array}{l}\text { Discharge } \\
\text { (cfs) }\end{array}$ \\
\hline 1959 & May 29,1959 & 9.66 & 240 \\
\hline 1960 & $\begin{array}{l}\text { Mar. } 29,1960 \\
\text { Aug. } 7,1960\end{array}$ & $\begin{array}{l}12.94 \\
10.70\end{array}$ & $\begin{array}{l}900 \mathrm{C} \\
580\end{array}$ \\
\hline 1961 & $\begin{array}{l}\text { Peb. 22, } 1961 \\
\text { Sept. } 30,1961\end{array}$ & $\begin{array}{l}10 \cdot 90 \\
10.32\end{array}$ & $\begin{array}{l}620 \\
510\end{array}$ \\
\hline 1962 & $\begin{array}{l}\text { June } 8,1962 \\
\text { June } 19,1962\end{array}$ & $\begin{array}{l}13.62 \\
10.43\end{array}$ & $\begin{array}{r}1.550 \\
529\end{array}$ \\
\hline 1963 & May 4. 1963 & 8.91 & 322 \\
\hline 1964 & $\begin{array}{l}\text { Apr. 2, } 1964 \\
\text { Apr. 13, } 1964 \\
\text { June 20, } 1964 \\
\text { June } 22,1964\end{array}$ & $\begin{array}{r}10.22 \\
9.82 \\
10.59 \\
13.54\end{array}$ & $\begin{array}{r}795 \\
714 \\
888 \\
2.010\end{array}$ \\
\hline 1965 & $\begin{array}{l}\text { Mar. 1, } 1965 \\
\text { Mar. 17\% } 1965 \\
\text { Mar. 31; } 1965 \\
\text { Apr. 5, } 1965 \\
\text { June 22, } 1965\end{array}$ & $\begin{array}{c}14.63 \mathrm{~b} \\
14.46 \mathrm{~b} \\
10.30 \\
11.87 \\
9.51\end{array}$ & $\begin{array}{r}1.800 \mathrm{c} \\
1.300 \mathrm{c} \\
928 \\
1.370 \\
723\end{array}$ \\
\hline 1966 & June 12,1966 & 14.91 & 3,020 \\
\hline 1967 & $\begin{array}{l}\text { June } 7,1967 \\
\text { June } 9.1967 \\
\text { June } 12,1967\end{array}$ & $\begin{array}{r}9.54 \\
9.24 \\
10.96\end{array}$ & $\begin{array}{r}808 \\
730 \\
1,380\end{array}$ \\
\hline 1968 & $\begin{array}{ll}\text { Jan. 26, } 1968 \\
\text { Apr. } 23,1968\end{array}$ & $\begin{array}{l}4.18 \mathrm{~b} \\
3.28\end{array}$ & 25 \\
\hline 1969 & $\begin{array}{l}\text { Mar. 17, } 1969 \\
\text { Mar. 19, } 1969 \\
\text { Mar. 24, } 1969 \\
\text { June 28, } 1969\end{array}$ & $\begin{array}{c}12.17 \mathrm{~d} \\
6.83 \\
8.19 \\
7.42\end{array}$ & $\begin{array}{r}1.810 \\
487 \\
752 \\
594\end{array}$ \\
\hline 1970 & May 14,1970 & 9.27 & 995 \\
\hline
\end{tabular}

b Affected by ice.

c About.

d Maximum gage height for year, $12.85 \mathrm{ft}$ Mar. 17, 1569 (backwater from ice). 
06-8090.00 Davids Creek near Hamlin, Iowa--(Continued)

Peak﹎.stages_and_discharges

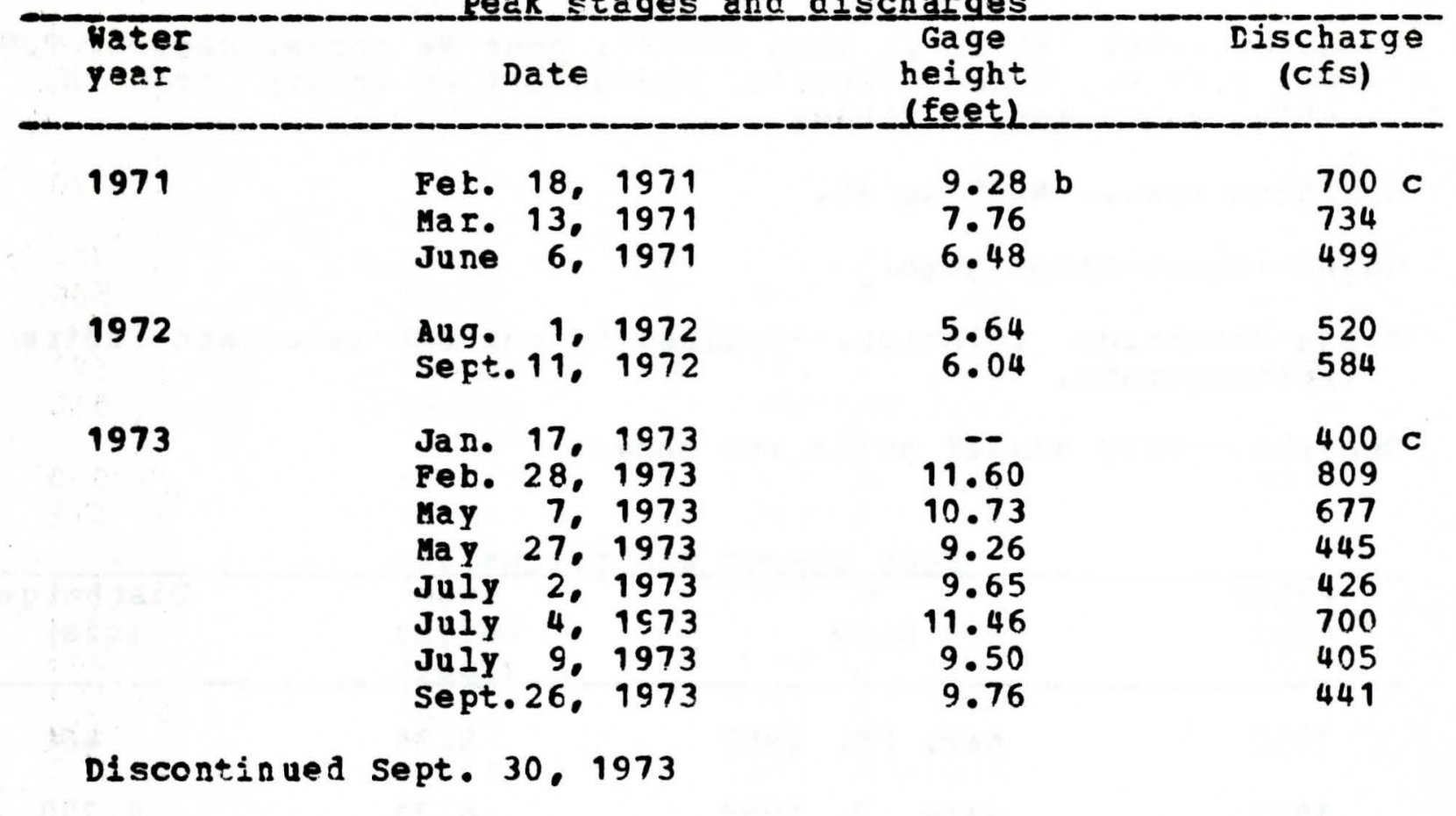

b affected by ice.

c About 


\section{6-4834.40 Dawson Creek near Sibley. Iowa}

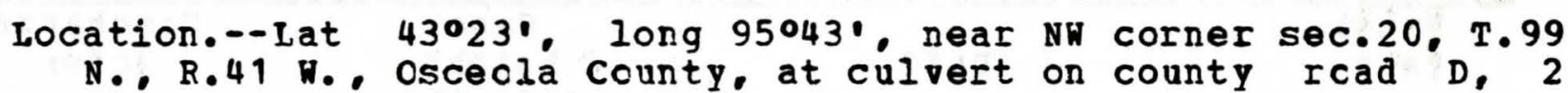

miles southeast of Sibley.

Drainage area.- $-4.35 \mathrm{sq} \mathrm{mi}$.

Gage.--Crest-stage gage.

Stage-discharge relation.--Defined by current-meter and indirect measurements.

Remarks.--only annual peaks are shown.

Peak__stages_and_discharges

\begin{tabular}{|c|c|c|c|}
\hline $\begin{array}{l}\text { Water } \\
\text { year }\end{array}$ & Date & $\begin{array}{l}\text { Gage } \\
\text { height } \\
\text { (feet) }\end{array}$ & $\begin{array}{c}\text { Discharge } \\
\text { (cfs) }\end{array}$ \\
\hline 1952 & Mar. 29, 1952 & 5.31 & 460 \\
\hline 1953 & June 7.1953 & 6.21 & 4.290 \\
\hline 1954 & June 20,1954 & 5.25 & 400 \\
\hline 1955 & Apr. 23, 1955 & 4.71 & 110 \\
\hline 1956 & Aug. 13, 1956 & 4.06 & 52 \\
\hline 1957 & July 3,1957 & 4.81 & 140 \\
\hline 1958 & June 4,1958 & 4.81 & 140 \\
\hline 1959 & May 30.1959 & 5.73 & 1.290 \\
\hline 1960 & Mar. 30,1960 & 5.27 & 440 \\
\hline 1961 & Mar. 27. 1961 & 4.67 & 110 \\
\hline 1962 & July 5,1962 & 4.66 & 113 \\
\hline 1963 & July 24, 1963 & 5.16 & 328 \\
\hline 1964 & $\operatorname{May} 12,1964$ & 4.47 & 72 \\
\hline 1965 & Aug. 21, 1965 & 4.66 & 108 \\
\hline 1966 & June 2,1966 & 5.04 & 247 \\
\hline
\end{tabular}


06-4834.40 Dawson Creek near Sibley, Iowa--(Continued)

Peak_stages and discharges

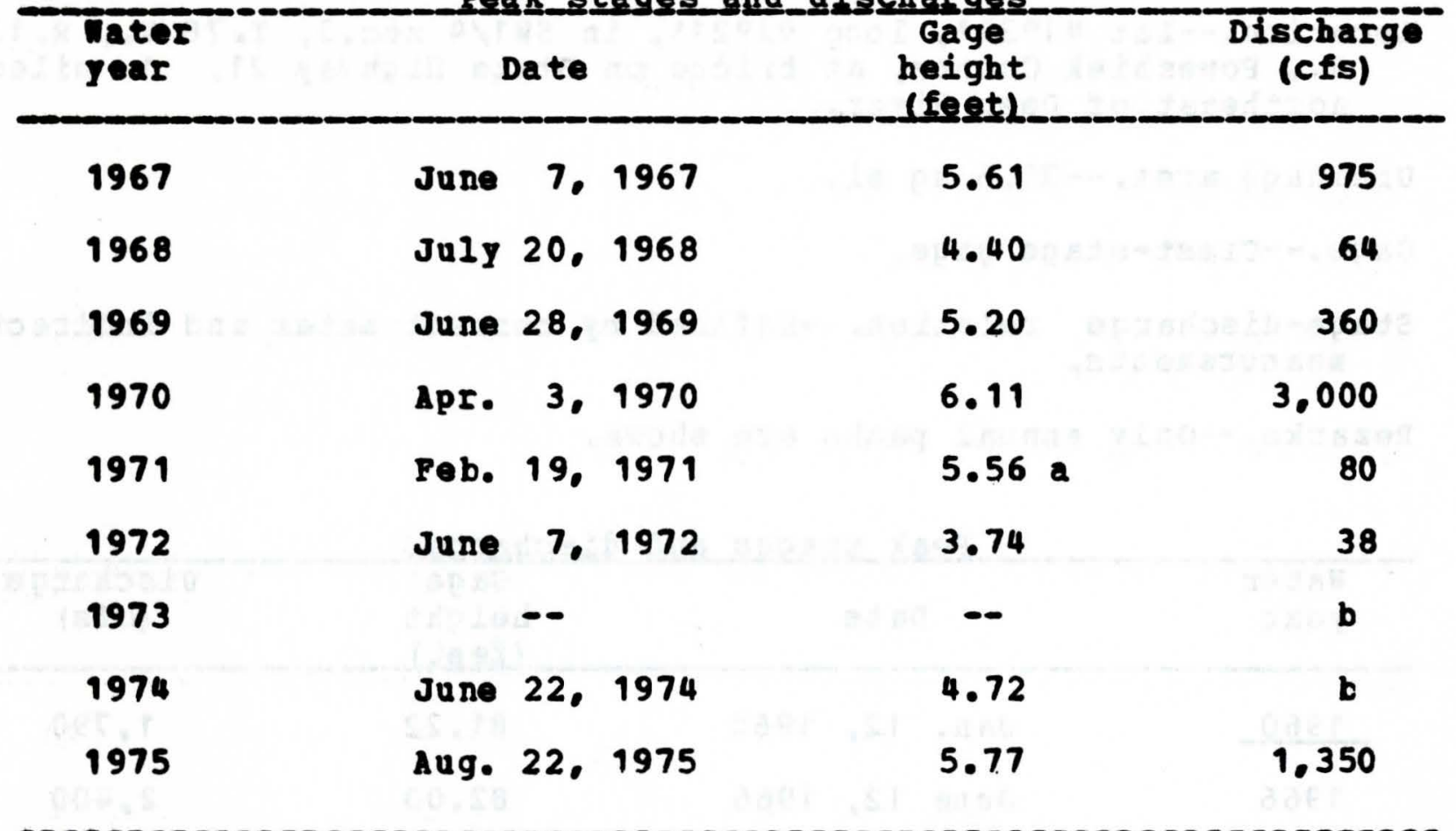

a nffected by ice.

b Discharge not determined. 


\section{5-4552.30 Deep River at Deep River, Iowa}

Location.--Lat $41035^{\circ}$. Iong $92021^{\prime}$, in S\$1/4 sec.3. T. 78 N.. R. 13 W.. Poweshiek County, at bridge on state Highway 21, 1 miles northeast of Deep River.

Drainage area.-- $-30.5 \mathrm{sq} \mathrm{mi.}$

Gage.--Crest-stage gage.

stage-discharge relation.--Defined by current-meter and indirect mea surements.

Remarks.--only annual peaks are shown.

Peak stages and di scharges

\begin{tabular}{|c|c|c|c|c|c|}
\hline $\begin{array}{l}\text { Water } \\
\text { year }\end{array}$ & & Date & & $\begin{array}{l}\text { Gage } \\
\text { height } \\
\text { deet. }\end{array}$ & $\begin{array}{c}\text { Discharge } \\
\text { (cfs) }\end{array}$ \\
\hline 1960 & Jan. & 12. & 1960 & 81.22 & 1.790 \\
\hline 1966 & June & 12 & 1966 & 82.03 & 2.400 \\
\hline 1967 & & -- & & a & $<660$ \\
\hline 1968 & & $-\infty$ & & $a$ & $<660$ \\
\hline 1969 & JuIy & 8. & 1969 & 80.88 & 1.240 \\
\hline 1970 & May & 20 & 1970 & 83.85 & 6.200 \\
\hline 1971 & Feb. & 19. & 1971 & 80.06 & 600 \\
\hline 1972 & Aug. & 6. & 1972 & 80.78 & 1.220 \\
\hline 1973 & & - & & $\mathbf{a}$ & $<450$ \\
\hline 1974 & Apr. & 29. & 1974 & 83.28 & 5.000 \\
\hline 1975 & Mar. & 18 & 1975 & 80.83 & 1.250 \\
\hline
\end{tabular}

a Peak stage did not reach bcttom of gage.

b Affected by ice. 
Location.--Lat $43025^{\circ}$, Iong $92059^{\prime}$, in NE1/4 sec.8, T. 99 N.. R. 18 W. Mitchell County, at bridge on State Highway 105, 1.5 miles east of Carpenter.

Drainage area.--91.6 sq mi.

Gage.--Crest-stage gage.

Stage-discharge relation.--Defined by current-meter measurements. Remarks.--only annual peaks are shown.

Peak_stages_and_discharges

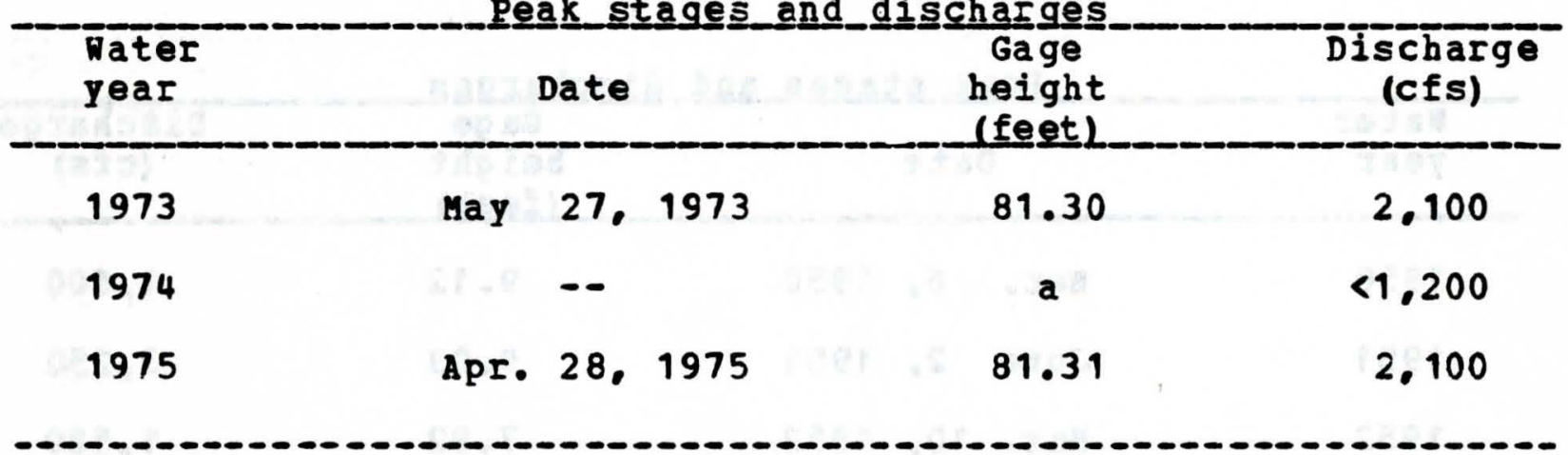

a Peak stage did not reach bottom of gage. 


$$
\text { 05-4518.00 Deer Creek at Toledo, Iowa }
$$

Location.--Lat $42000 \%$, long $92036 \%$, near west guarter ccrner of sec.15. T.83 \$.. R.15 Toledo, Iowa.

Drainage area.--76.4 sq ai.

Gage.--Monrecording.

Stage-discharge relation.--Defined by current-neter neasurenents. Remarks.--Records collected by Corps of Engineers. Station is inflow forecasting station for coralville Reservolr. Only annual peaks are shown.

Peak_stages and_discharges

\begin{tabular}{|c|c|c|c|}
\hline $\begin{array}{l}\text { Tater } \\
\text { year }\end{array}$ & Date & $\begin{array}{l}\text { Gage } \\
\text { height } \\
\text { (feet) }\end{array}$ & $\begin{array}{c}\text { DIschargo } \\
\text { (cfs) }\end{array}$ \\
\hline 1950 & Har. 6, 1950 & 9.12 & 1.600 \\
\hline 1951 & June 2, 1951 & 9.03 & 3.250 \\
\hline 1952 & Mar. 10, 1952 & 7.82 & 1,580 \\
\hline 1953 & Feb. 20,1953 & 9.51 & 2.000 \\
\hline 1954 & aug. 26, 1954 & 6.08 & 1.030 \\
\hline 1955 & Feb. 19, 1955 & 5.77 & 911 \\
\hline
\end{tabular}




\section{5-4820.00 Des Moines River at Des Moines, Iowa (Discontinued sept. 30, 1961)}

Location.--Lat $41036 \cdot 45^{\prime \prime}$. Iong $9303715^{\prime \prime}$, in NE1/4 NE1/4 sec.34. T.79 N.. R. $24 \mathrm{~W} .$. on right bank $5 \mathrm{ft}$ upstream frcul Second Avenue bridge in Des Moines, 1.8 miles upstream frcm 3enter Street dam, 2.8 miles upstream from Raccoon River, 4.5 miles downstream from Beaver Creek, and at mile 204.3 upstream from mouth.

Drainage area. $--6,245 \mathrm{sq} \mathrm{mi}$

Gage.--Water-stage recorder and concrete multiple-arch control dam. Datum of gage is $773.68 \mathrm{ft}$ above mean sea level and at city datum. Prior to Aug. 21, 1941, nonrecording or recording gages at several sites within 3 miles cf the present site and at various datums.

Stage-discharge relation.--Defined by current-meter measurements for present gage location. Discharge for certain peaks prior to 1933 computed from study of backwater effects available for those peaks only: other peak discharges could not be computed.

Flood stage. $-23 \mathrm{ft}$.

Remarks.--Base for partial-duration series. 10,000 cfs. Gage heights shown pricr to 1934 are from various gages below Center Street Dam, all of which were at about the same datum but slightly different locations. Gage heights 1936-41 computed for present gage frcm gage readings at Center street Dam. Backwater effect of $1.0 \mathrm{ft}$ included in peak cfs. Only annual peaks are shown pricr to 1944.

Peak stages and discharges

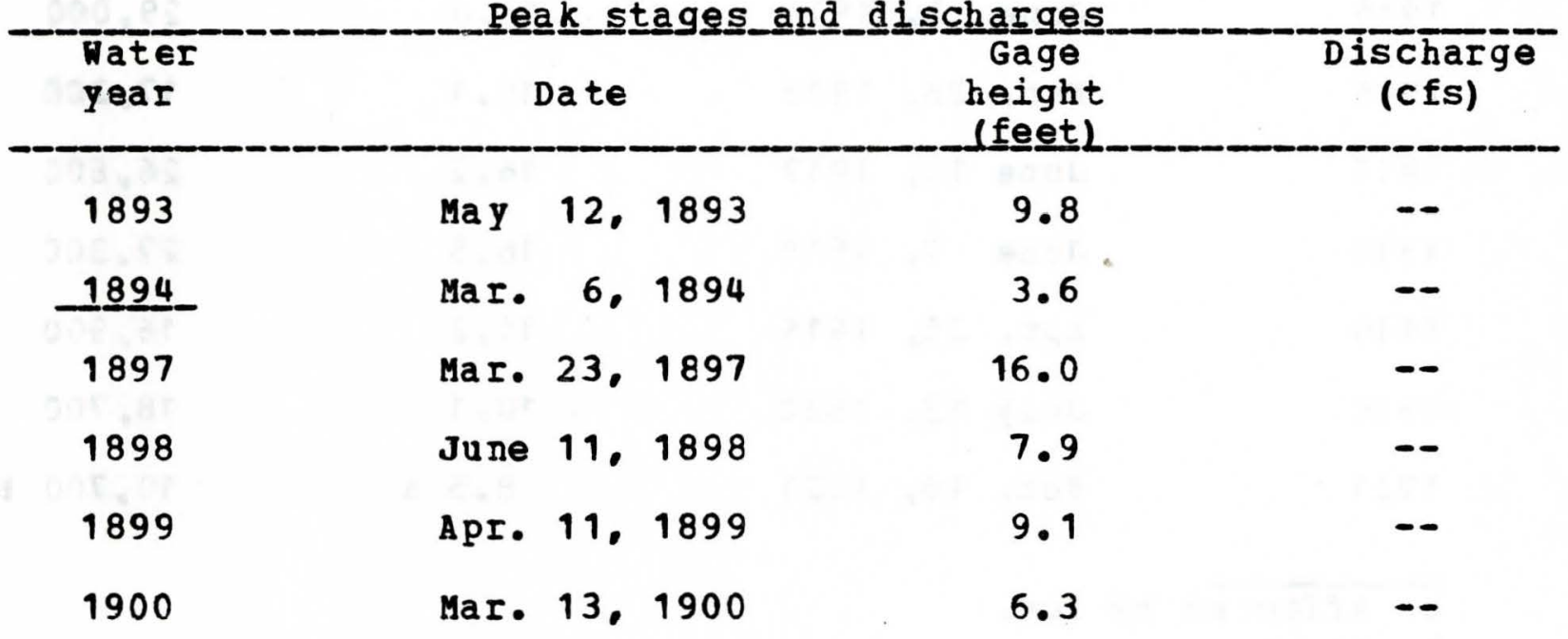


05-4820.00 Des Moines River at Des Moines, Iowa--(Continued)

Peak_stages_and discharges

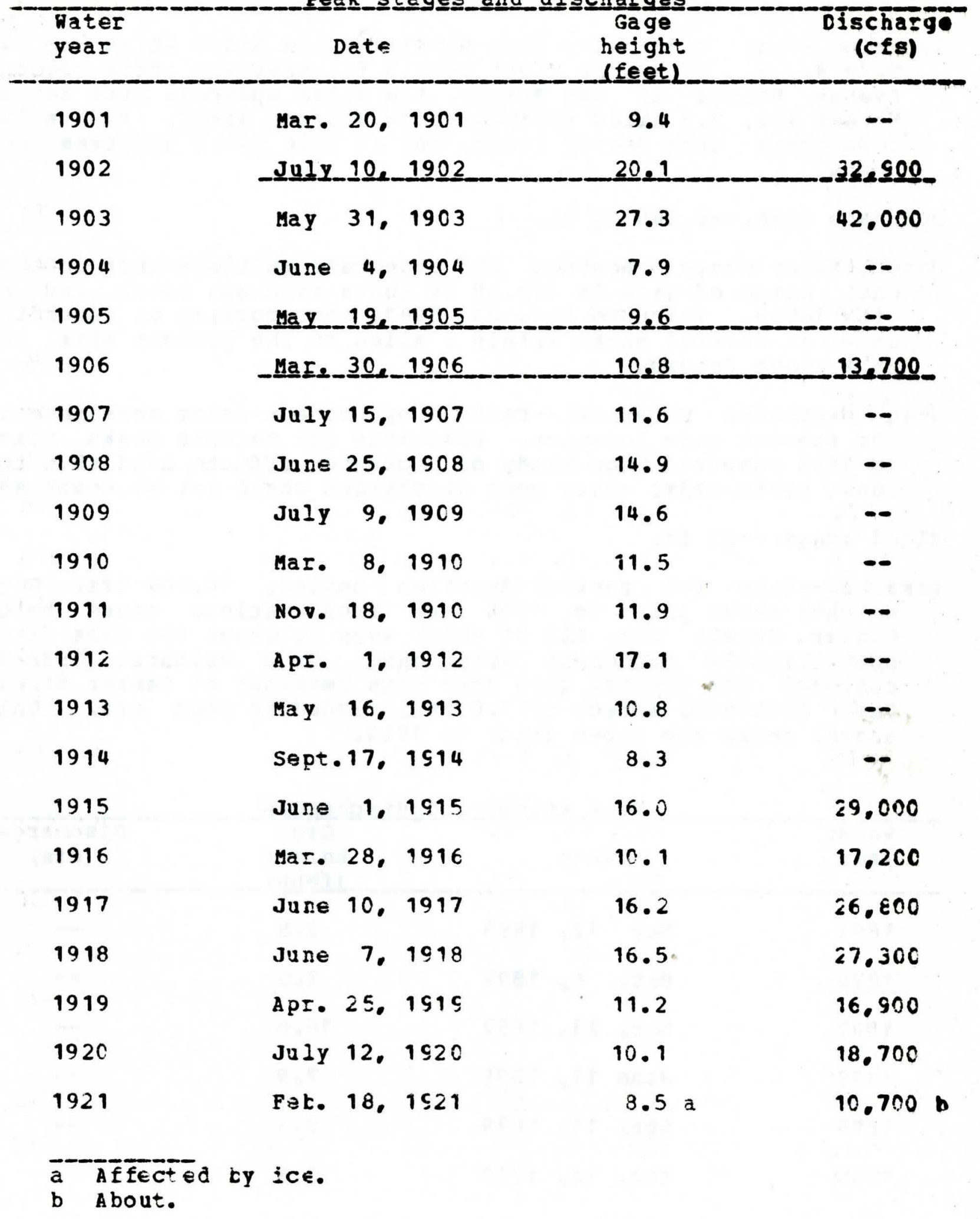


05-4820.00 Des Moines River at Des Mcines, Iowa--(Continued)

Feak_stages and_discharges

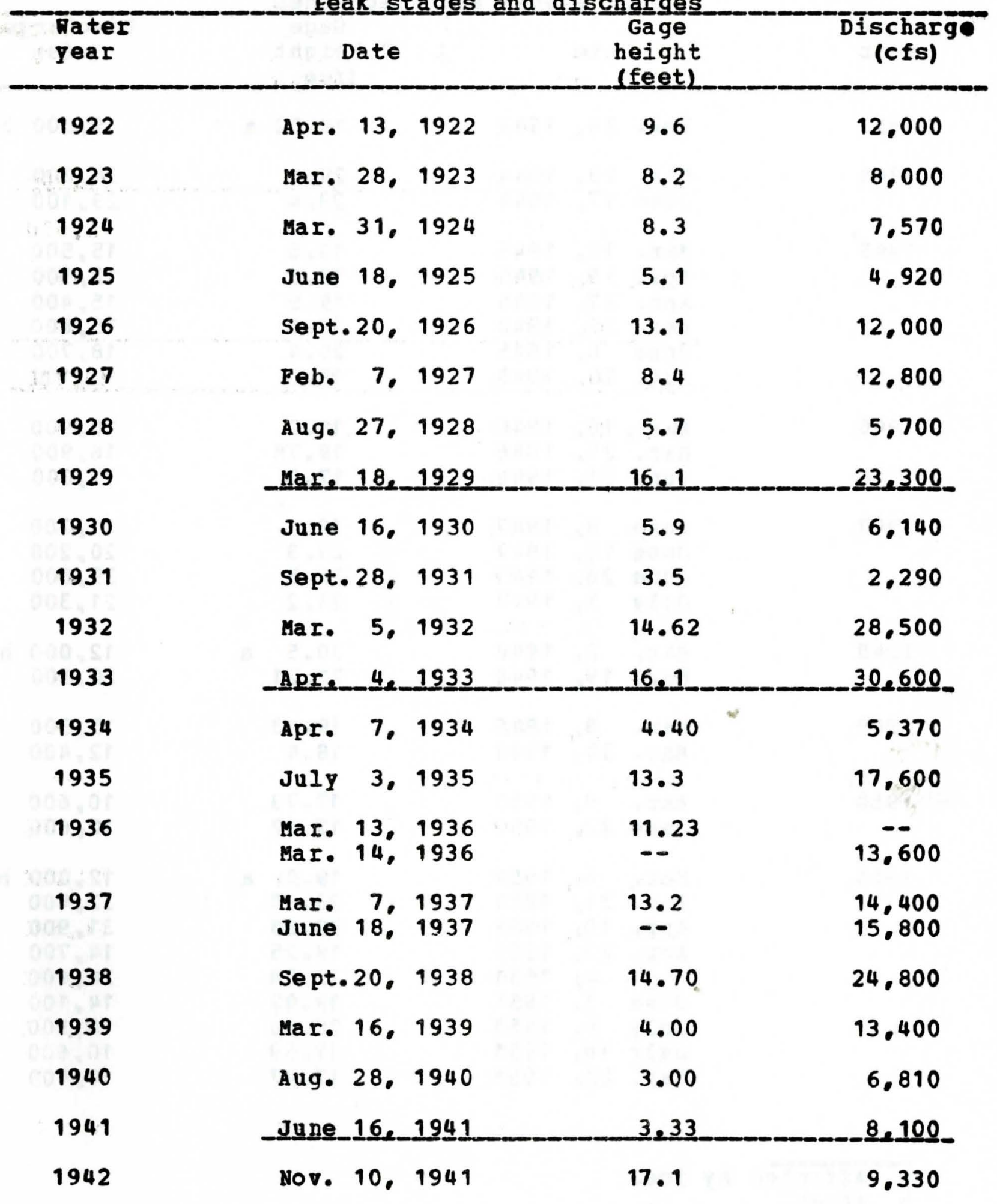


05-4820.00 Des Moines River at Des Moines, Iowa--(Continued)

Peak_stages and discharges

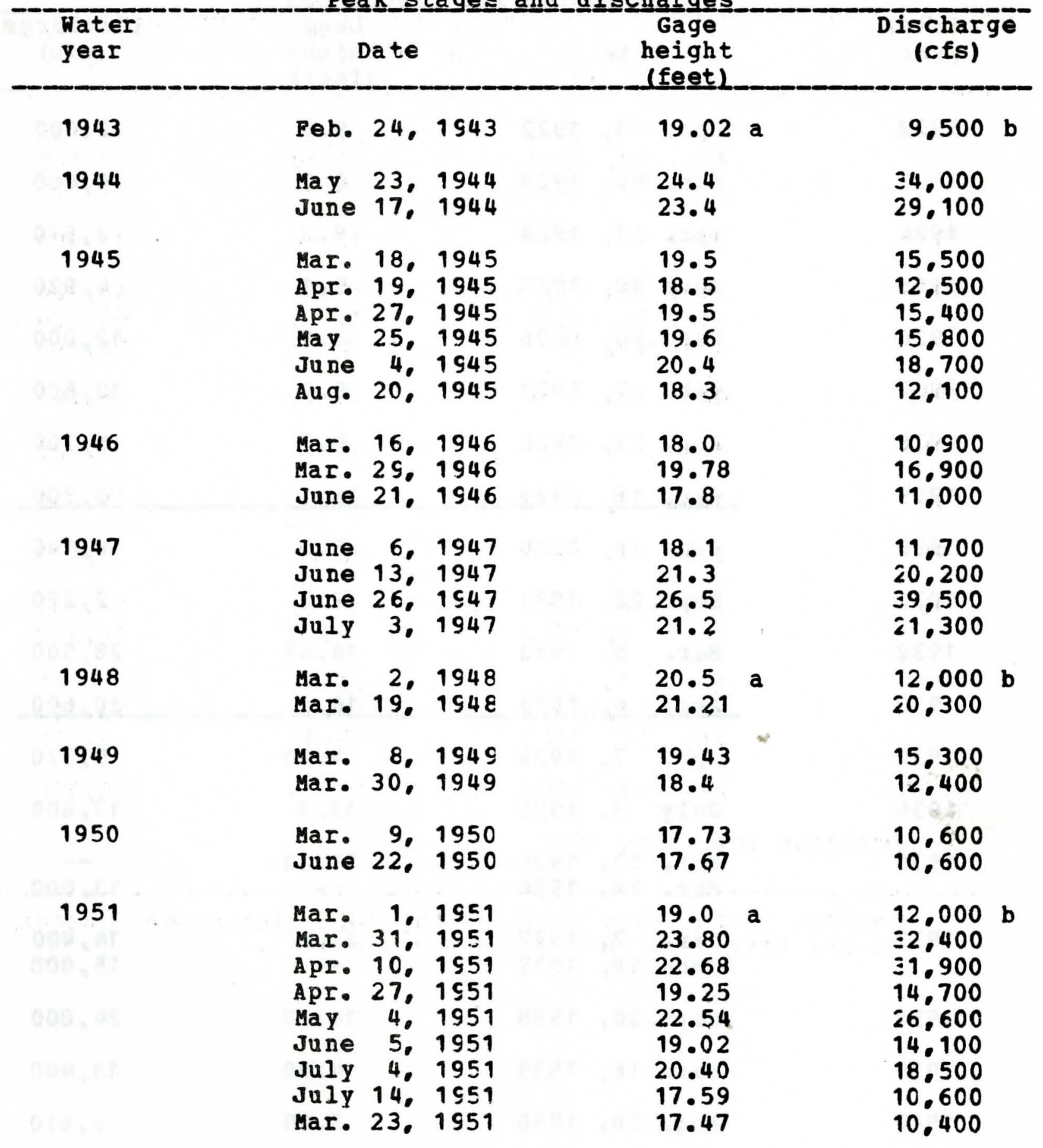

a Affectéd by ice.

b A bout. 
05-4820.00 Des Hoines River at Les Moines, Iowa--(Continued)

Peak_stages and_discharges

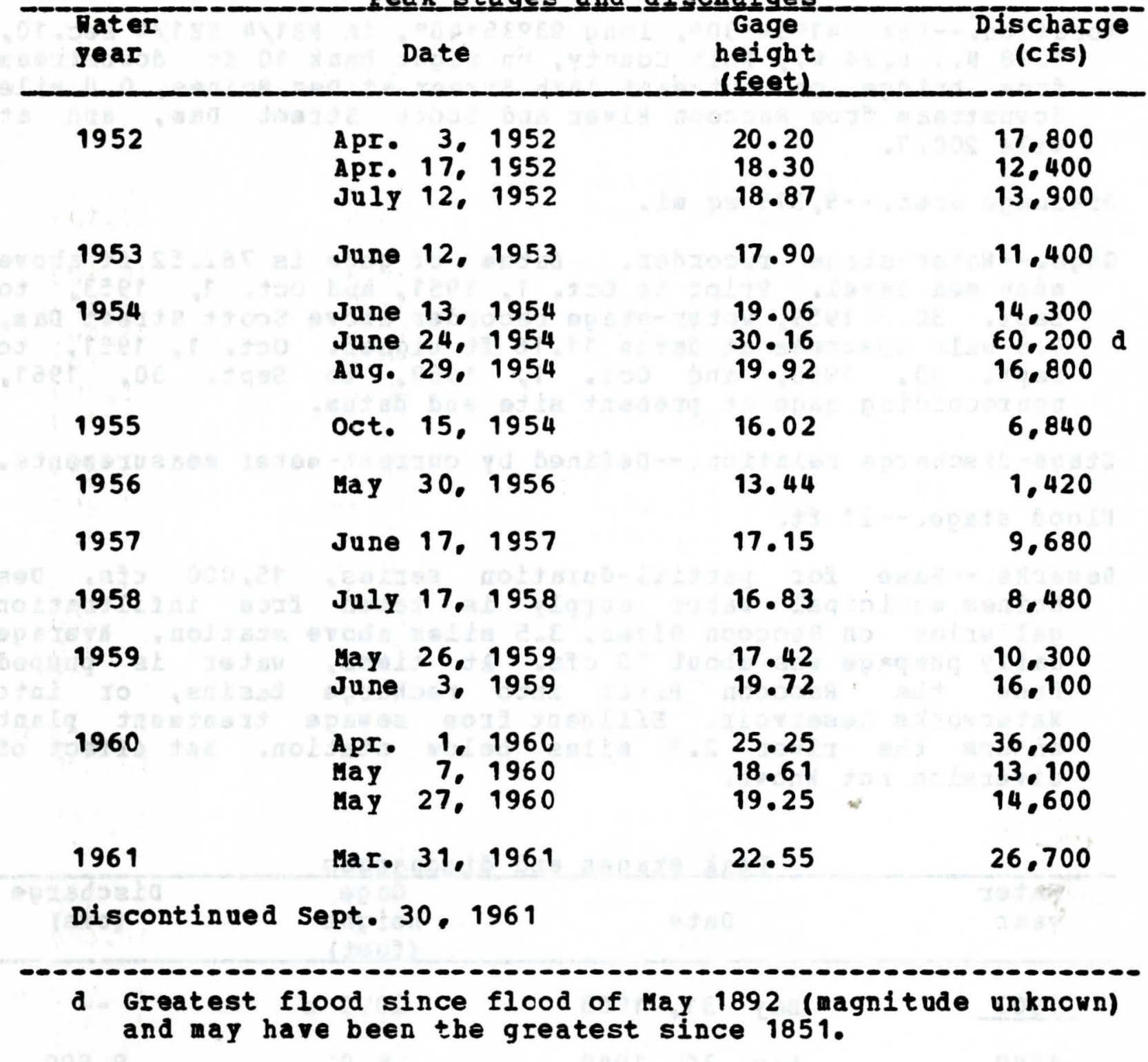


05-4855.00 Des Moines River below Raccoon River, at Des Moines, Iowa

Location.--Iat $41034 \cdot 30$ ", long $93035 \cdot 48^{\prime \prime}$, in NE1/4 SE1/4 sec.10, T.78 N.. R. $24 \mathrm{H..}$ Polk County, on right bank $10 \mathrm{ft}$ dewnstream from bridge on southeast 14 th 5 treet at Des Moines. 0.8 mile downstream from Raccoon River and Scott street Dam, and at mile 200.7.

Drainage area.--9,879 sq mi.

Gage.--Nater-stage recorder. Datum of gage is $762.52 \mathrm{ft}$ above mean sea level. prior tc cct. 1, 1951, and oct. 1, 1953, to Sept. 30 . 1959, water-stage recorder above scott street Dam, 0.8 mile upstream at datum $11.16 \mathrm{ft}$ higher. Oct. 1. 1951, to sept. 30, 1953, and Oct. 1, 1959, to sept. 30, 1961. nonrecording gage at present site and datum.

Stage-discharge relation.--Defined by current-meter measurements.

Flood stage. $-21 \mathrm{ft.}$

Remarks.--Base for partial-duration series, 15,000 cfs. Des Moines municipal water supply is taken from infiltration galleries on Raccoon River, 3.5 miles above station. Average daily pumpage was about 50 cfs. At times, water is pumped from the Raccoon River into recharge basins, or into Waterworks Reservcir. Effluent from sewage treatment plant enters the river 2.3 miles below station. Net $\in f$ fect of diversion not known.

Peak stages and discharges

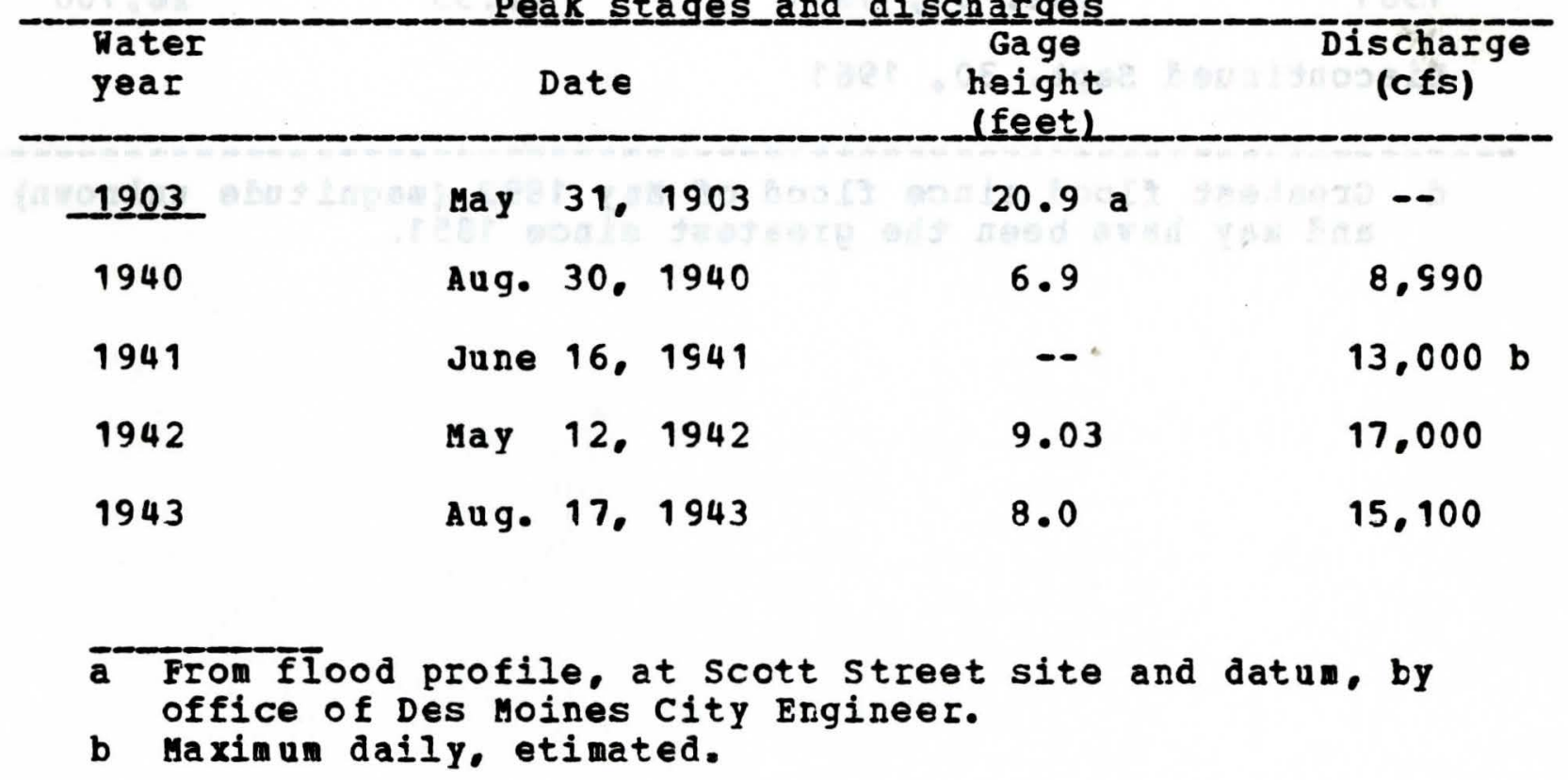


05-4855.00 Des Moines River below Raccoon River, at Des Moines, Iowa--(Continued)

Peak stages and discharges

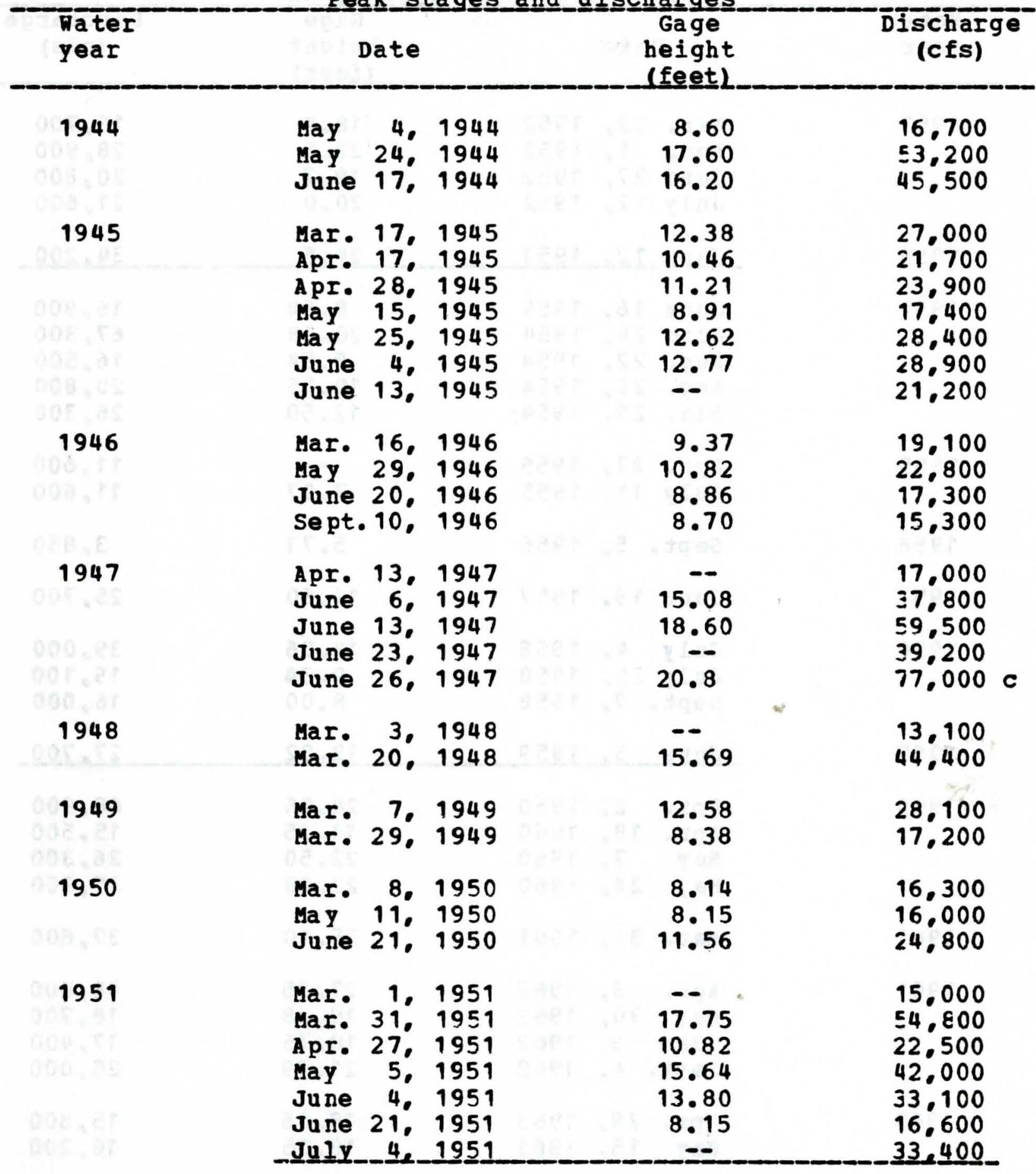

c Maximún stage known since at least 1893, site and datum then in use. 
05-4855.00 Des Moines River below Raccoon River, at Des Moines, Iowa-- (Continued)

Peak_stages_and di

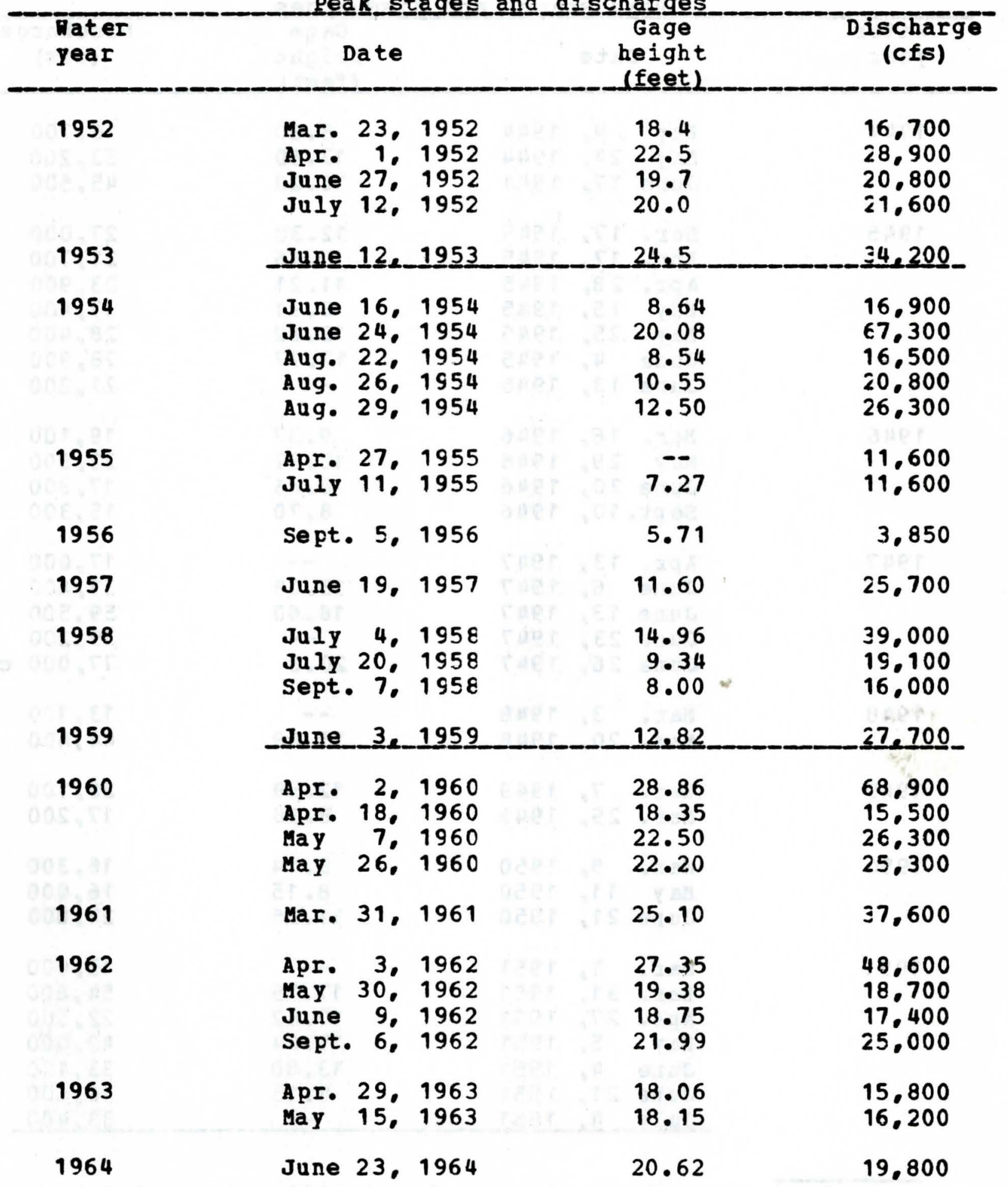


05-4855.00 Des Moines River below Raccoon River, at Des Mcines, Iowa-- (Continued)

Feak stages and discharges

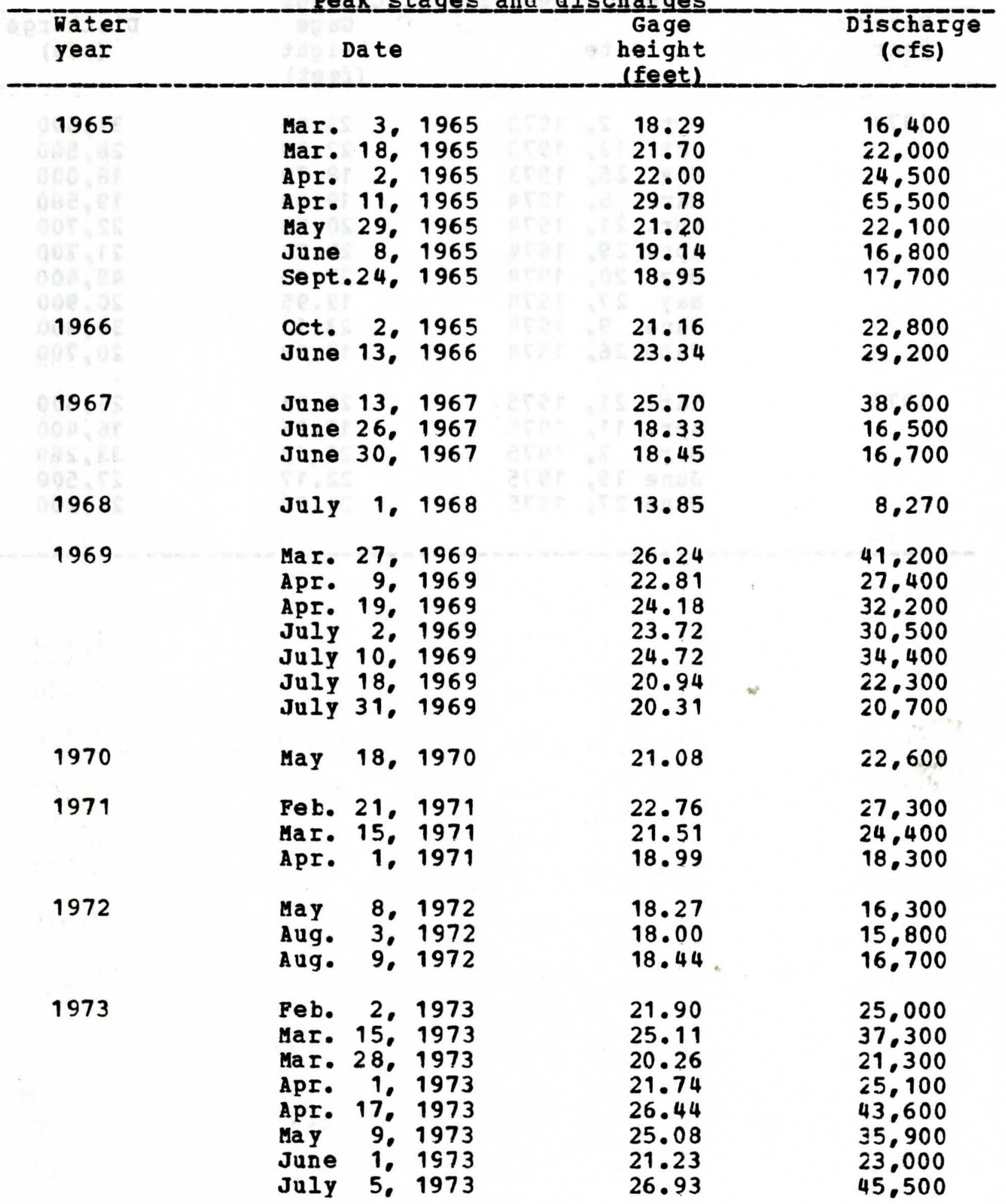


05-4855.00 Des Moines River below Raccoon River, at Des Hcines. Iowa-- (Continued)

Feak_stages_and_discharges

\begin{tabular}{|c|c|c|c|c|}
\hline $\begin{array}{l}\text { Dater } \\
\text { year }\end{array}$ & Date & & $\begin{array}{c}\text { Gage } \\
\text { height } \\
\text { (feet) }\end{array}$ & $\begin{array}{c}\text { Discharge } \\
\text { (cfs) }\end{array}$ \\
\hline 1974 & $\begin{array}{lr}\text { Oct. } 2 . \\
\text { Oct. } 12 . \\
\text { Mov. } 25 . \\
\text { Mar. } 5 . \\
\text { Apr. } 21 . \\
\text { Apr. 29, } \\
\text { May 20. } \\
\text { May } 27 . \\
\text { June } 9 . \\
\text { June } 26 .\end{array}$ & $\begin{array}{l}1973 \\
1973 \\
1973 \\
1974 \\
1974 \\
1974 \\
1974 \\
1974 \\
1974 \\
1974\end{array}$ & $\begin{array}{l}23.40 \\
22.49 \\
18.79 \\
19.40 \\
20.58 \\
20.24 \\
27.15 \\
19.95 \\
23.11 \\
19.88\end{array}$ & $\begin{array}{l}31.600 \\
28.500 \\
18.000 \\
19.500 \\
22.700 \\
21.700 \\
48.400 \\
20.900 \\
30.400 \\
20.700\end{array}$ \\
\hline 1975 & $\begin{array}{l}\text { Mar. } 21 . \\
\text { Apr. } 11 . \\
\text { May } 2 . \\
\text { June } 19 . \\
\text { June } 27^{\circ}\end{array}$ & $\begin{array}{l}1975 \\
1975 \\
1975 \\
1975 \\
1975\end{array}$ & $\begin{array}{l}20.01 \\
17.96 \\
23.61 \\
22.17 \\
21.93\end{array}$ & $\begin{array}{l}21.600 \\
16.400 \\
33.200 \\
27.500 \\
26.200\end{array}$ \\
\hline
\end{tabular}


05-4765.00 Des Moines River at Estherville. Iowa (Prior to 1971 published as

West Fork Des Moines River at Estherville, Iowa)

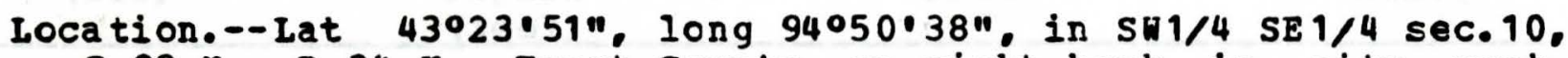
I. 99 N.. R. 34 H.. Emmet County, on right bank in city park. 1.200 ft downstream frcm bridge on state Highway 9 at Estherville. 0.1 mile upstream from school Creek, 2.3 miles upstream from Brown Creek, and at mile 404.2.

Drainage area.--1,372 sq mi.

Gage.-- Nater-stage recorder and concrete control. Datun cf gage is $1.247 .55 \mathrm{ft}$ above mean sea level.

Stage-discharge relation.--Defined by current-meter measurements. Flood stage.-- $7 \mathrm{ft}$.

Remarks.--Base for partial-duration series, 1.500 cfs. Diurnal fluctuation at low flow caused by powerplant 0.3 mile above station which discharges an average daily flow of abcut 0.5 cfs into river from subterranean wells. Base was 2,000 prior to 1961.

Peak

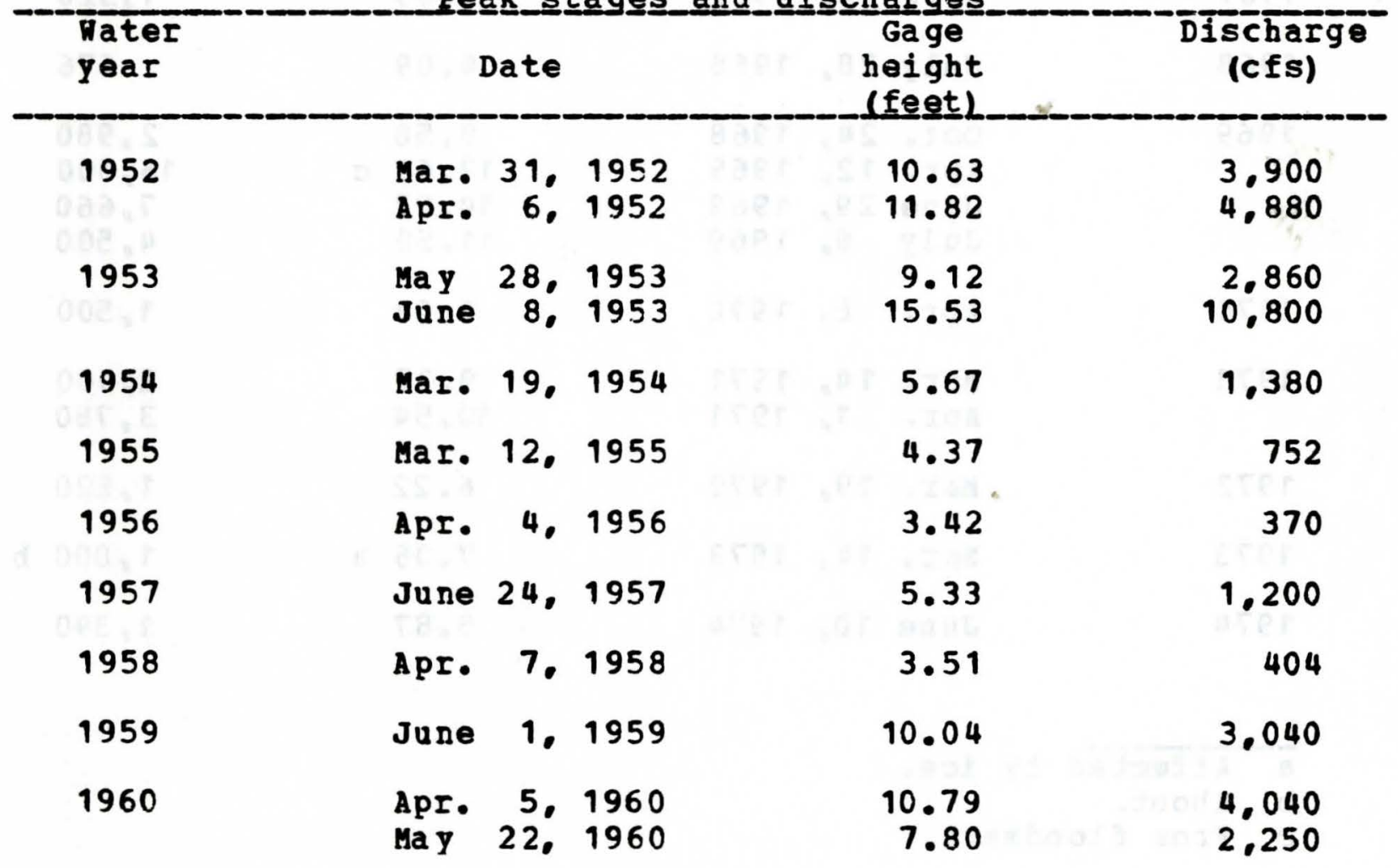


05-4765.00 Des Moines River at Estherville, Iowa-- (Continued)

Peak__stages_and__discharges

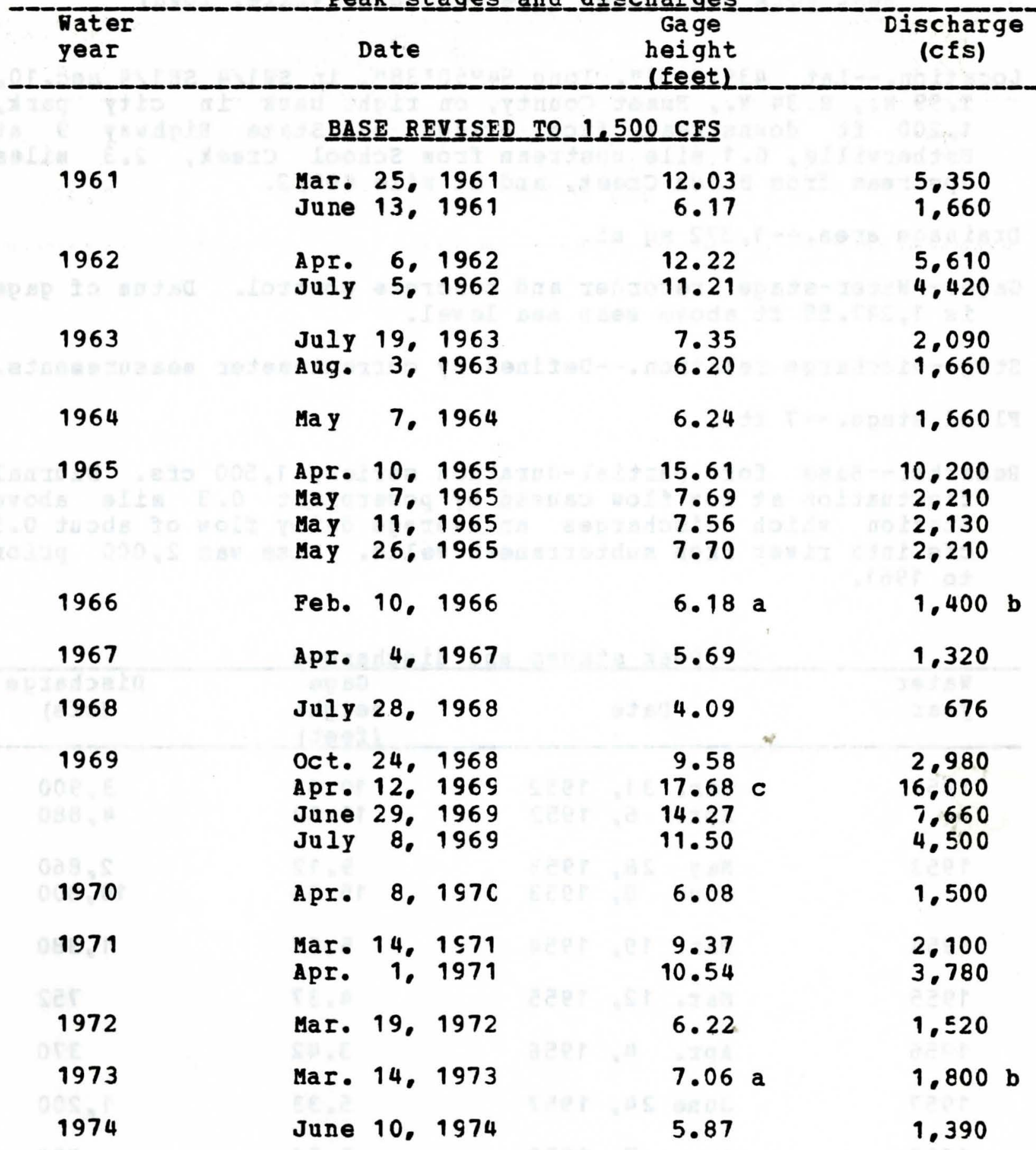

àfectéd by ice.

b About.

c From floodmark. 
05-4765.00 Des Moines River at Estherville, Iowa--(Continued)

Peak stagese and discharges

\begin{tabular}{|c|c|c|c|}
\hline $\begin{array}{l}\text { Dater } \\
\text { year }\end{array}$ & Date & $\begin{array}{l}\text { Gage } \\
\text { height } \\
\text { (feet) }\end{array}$ & $\begin{array}{c}\text { Discharge } \\
\text { (cfs) }\end{array}$ \\
\hline 1975 & $\begin{array}{l}\text { Apr. 26, } 1975 \\
\text { Apr. 28, } 1975 \\
\text { June 22, } 1975\end{array}$ & $\begin{array}{l}8.01 \\
7.73 \\
6.25\end{array}$ & $\begin{array}{l}2.320 \\
2.200 \\
1.540\end{array}$ \\
\hline
\end{tabular}


05-4805.00 Des Moines River at Fort Dodge, Iowa

Location.--Iat $42030 \cdot 22 "$, Iong $94012 \cdot 04$ ", in NH1/4 SW $1 / 4$ seC. 19 , T.89 N.. R. 28 N. Webster County, on right bank $400 \mathrm{ft}$ upstream from soldier Creek, 1,800 ft downstream from Illinois Central Railraod bridge in Fort Dodge, 2,000 ft dcwnstream from Lizard Creek, and at mile 314.6 .

Drainage area. $--4,190 \mathrm{sq} \mathrm{mi}$

Gage.--Mater-stage recorder. Datum of gage is $969.38 \mathrm{ft}$ above mean sea level. Apr. 22, 1905, to July 19, 1906, nonrecording at bridge 3,000 ft downstream at different datum. oct. 18 , 1913. to oct. 20, 1921. Jure 20 to sept. 30.1927. non recording, and oct. 21, 1921, to June 19, 1927, recording, at site 7 miles downstream at kalo, at different datum. oct. 1. 1946, to Dec. 7, 1949, nonrecording at bridge 1,800 ft upstream from present site, at present datum.

Stage-discharge relation.--Defined by current-meter measurements. Flood stage. $--10 \mathrm{ft}$.

Remarks.--Base for partial-duration series, 6,0CO cfs. occasional minor regulation caused by dam 0.8 mile upstream from gage. Base was 8,000 cfs prior to 1961.

Peak__stages_and_disch

\begin{tabular}{|c|c|c|c|}
\hline $\begin{array}{l}\text { pater } \\
\text { year }\end{array}$ & Date & $\begin{array}{l}\text { Gage } \\
\text { height } \\
\text { feet). }\end{array}$ & $\begin{array}{c}\text { Discharge } \\
\text { (cfs) }\end{array}$ \\
\hline 1905 & May 17. 18, 1905 & 7.0 & $6.460 \mathrm{a}$ \\
\hline 1906 & ㅂaI﹎_26 1906 & $\underline{9} .9$ & 12,000 \\
\hline 1914 & June 20,1914 & 7.4 & 6.530 \\
\hline 1915 & $\begin{array}{lll}\text { Mar. } 22,1915 \\
\text { Mar. 26, } 1915 \\
\text { May } 30,1915\end{array}$ & $\begin{array}{r}8.6 \\
9.1 \\
14.0\end{array}$ & $\begin{array}{r}9.120 \\
9.970 \\
18.500\end{array}$ \\
\hline 1916 & MaI. 29, 1916 & $10 \cdot 2$ & 11.900 \\
\hline 1917 & $\begin{array}{lrr}\text { MaI. } & 22,1917 \\
\text { June } & 8,1917\end{array}$ & $\begin{array}{r}12.9 \\
9.8\end{array}$ & $\begin{array}{l}17.100 \\
11.200\end{array}$ \\
\hline
\end{tabular}

a Maximún for period May to September 1905.

b Maximun for period October. November 1905 and April to June 1906. 
05-4805.00 Des Moines River at Fort Dodge, Iowa-- (Continued)

Peak_stages_and discharges

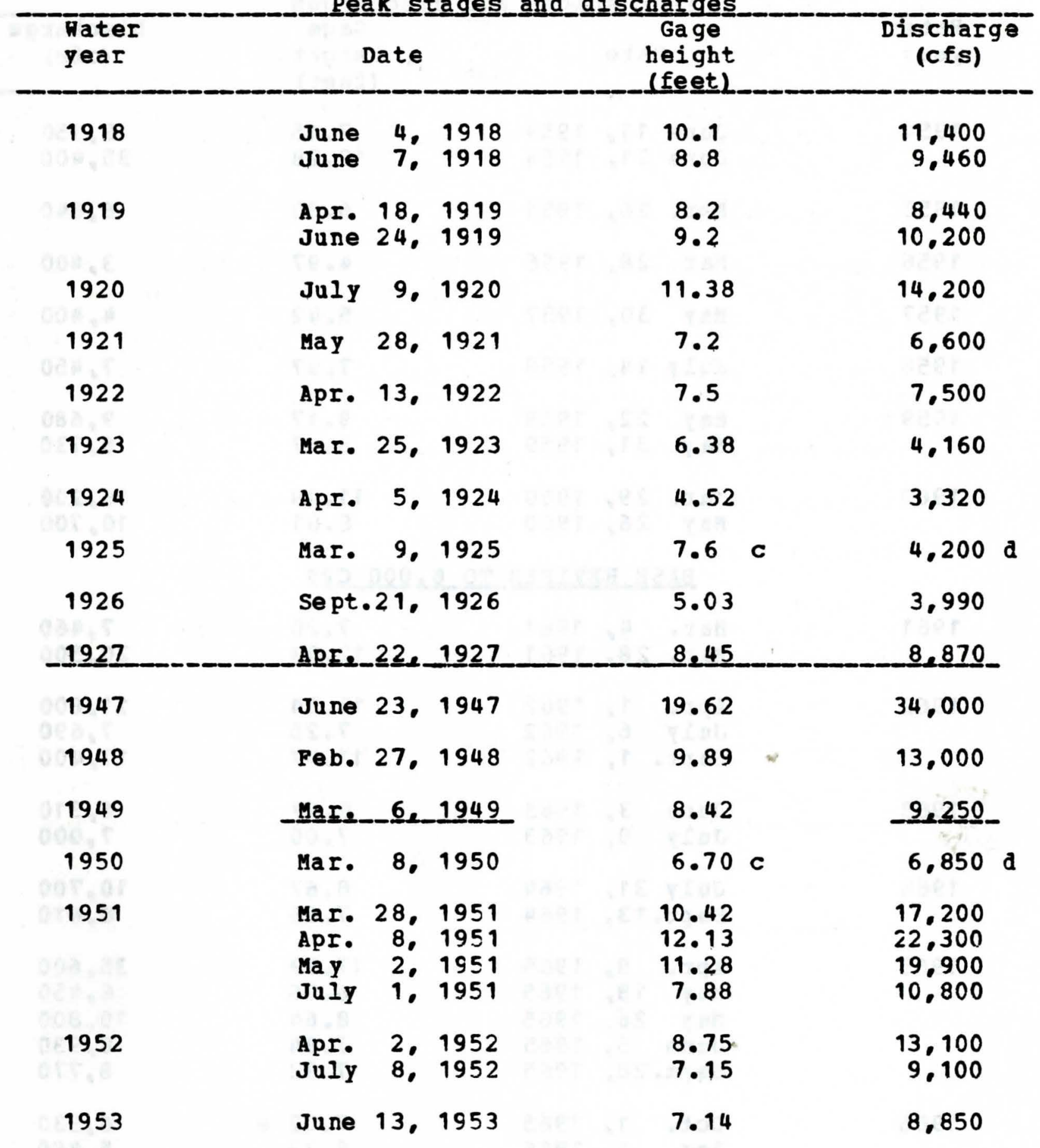

c Affected by ice.

d About. 
05-4805.00 Des Moines River at Fort Dodge, Iowa--(Continued)

Feak_stages and discharges

\begin{tabular}{|c|c|c|c|c|c|}
\hline $\begin{array}{l}\text { Water } \\
\text { year }\end{array}$ & Date & & $\begin{array}{l}\text { Gage } \\
\text { height } \\
\text { (feet) }\end{array}$ & & $\begin{array}{c}\text { Dischargo } \\
\text { (cfs) }\end{array}$ \\
\hline 1954 & $\begin{array}{l}\text { June } 11 . \\
\text { June } 21 .\end{array}$ & $\begin{array}{l}1954 \\
1954\end{array}$ & $\begin{array}{r}7.15 \\
19.28\end{array}$ & & $\begin{array}{r}9.150 \\
35.400\end{array}$ \\
\hline 1955 & Apr. 26 & 1955 & 6.30 & & 6.840 \\
\hline 1956 & Mar. 28 & 1956 & 4.97 & & 3,400 \\
\hline 1957 & May 30. & 1957 & 5.42 & & 4.400 \\
\hline 1958 & July 14 & 1958 & 7.97 & & 7.450 \\
\hline 1959 & $\begin{array}{ll}\text { May } & 22, \\
\operatorname{May} & 31 .\end{array}$ & $\begin{array}{l}1959 \\
1959\end{array}$ & $\begin{array}{l}9.17 \\
8.67\end{array}$ & & $\begin{array}{l}9.680 \\
8.730\end{array}$ \\
\hline 1960 & $\begin{array}{l}\text { MaI. } 29 . \\
\text { May } 26 .\end{array}$ & $\begin{array}{l}1960 \\
1960\end{array}$ & $\begin{array}{r}11.28 \\
8.81\end{array}$ & & $\begin{array}{l}16.200 \\
10.700\end{array}$ \\
\hline \multicolumn{6}{|c|}{ BASE_REVISED_TO_6,000 CES } \\
\hline 1961 & $\begin{array}{l}\text { Mar. } 4 . \\
\text { Mar. } 28,\end{array}$ & $\begin{array}{l}1961 \\
1961\end{array}$ & $\begin{array}{r}7.20 \\
12.83\end{array}$ & & $\begin{array}{r}7.460 \\
20.500\end{array}$ \\
\hline 1962 & $\begin{array}{ll}\text { Apr. } & 1 . \\
\text { JuIy } & 6 . \\
\text { Sept. } & 1 .\end{array}$ & $\begin{array}{l}1962 \\
1962 \\
1962\end{array}$ & $\begin{array}{r}13.34 \\
7.25 \\
11.47\end{array}$ & $*$ & $\begin{array}{r}21.800 \\
7.690 \\
17.400\end{array}$ \\
\hline 1963 & $\begin{array}{ll}\text { June } & 3 . \\
\text { July } & 9 .\end{array}$ & $\begin{array}{l}1963 \\
1963\end{array}$ & $\begin{array}{l}6.67 \\
7.00\end{array}$ & & $\begin{array}{l}6.310 \\
7.000\end{array}$ \\
\hline 1964 & $\begin{array}{l}\text { July } 31 . \\
\text { sept. } 13 .\end{array}$ & $\begin{array}{l}1964 \\
1964\end{array}$ & $\begin{array}{l}8.67 \\
7.66\end{array}$ & & $\begin{array}{r}10.700 \\
8.610\end{array}$ \\
\hline 1965 & $\begin{array}{lr}\text { Apr. } & 8 \\
\text { May } & 18, \\
\text { May } 26, \\
\text { June } 5, \\
\text { Sept. } 28,\end{array}$ & $\begin{array}{l}1965 \\
1965 \\
1965 \\
1965 \\
1965\end{array}$ & $\begin{array}{r}17.79 \\
6.76 \\
8.64 \\
7.84 \\
7.82\end{array}$ & & $\begin{array}{r}35.600 \\
6.450 \\
10.800 \\
8.930 \\
8.770\end{array}$ \\
\hline 1966 & $\begin{array}{l}\text { Oct. } 1 . \\
\text { Apr. } 1 .\end{array}$ & $\begin{array}{l}1965 \\
1966\end{array}$ & $\begin{array}{l}7.02 \\
6.33\end{array}$ & e & $\begin{array}{l}6.930 \\
5.490\end{array}$ \\
\hline 1967 & June 16 & 1967 & 9.47 & & 12.600 \\
\hline
\end{tabular}

e Stage falling. 
05-4805.00 Des Moines River at Fort Dodge, Iowa--(Continued)

Peak_stages and discharges

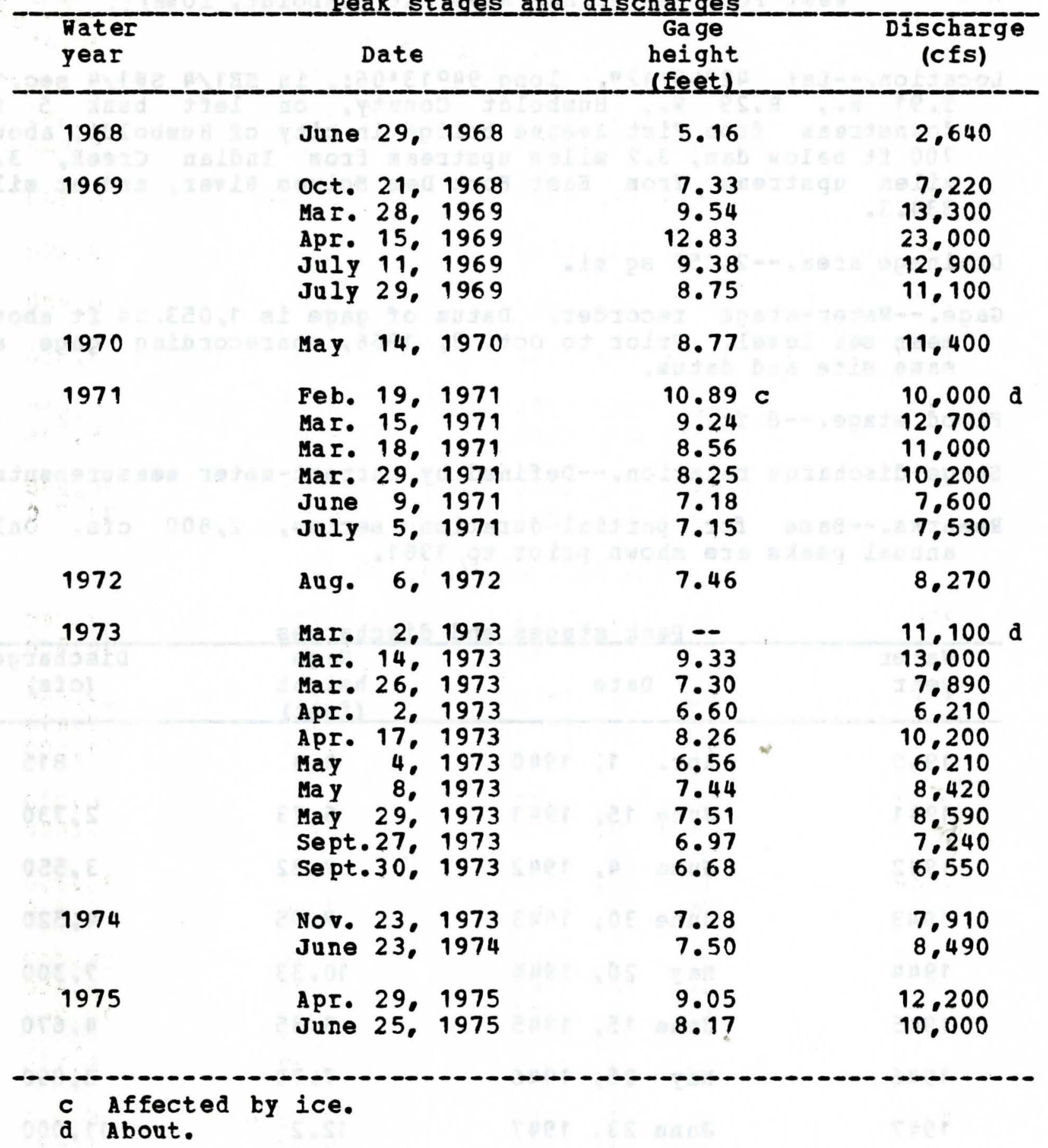




\section{5-4767.50 Des Moines River at Humboldt, Iowa (Prior to October 1970 published as \\ Mest Fork Des Moines River at Humboldt, Iowa)}

Location,--lat 42043112", long 94013106:, in SE1/4 SH1/4 sec.1.

T.91 N.. R.29 N.. Humboldt County. on left bank 5 ft downstream from Fist avenue bridge in city of Humboldt, about $700 \mathrm{ft}$ below dam. 3.2 miles upstream from Indian Creek, 3.9 miles upstream from East Fork Des Moines River, and at mile 334.3 .

Drainage area. $--2,256 \mathrm{sq} \mathrm{mi}$.

Gage.--Water-stage recorder. Datum of gage is $1.053 .54 \mathrm{ft}$ above mean sea level. Prior to oct. 3, 1966, nonrecording gage at same site and datum.

Flood stage. $--8 \mathrm{ft}$.

Stage-discharge relation.--Defined by current-meter measurements.

Remarks.--Base for partial-duration series, 2,800 cfs. only annual peaks are shown prior to 1961.

Peak__stages_and_discharges

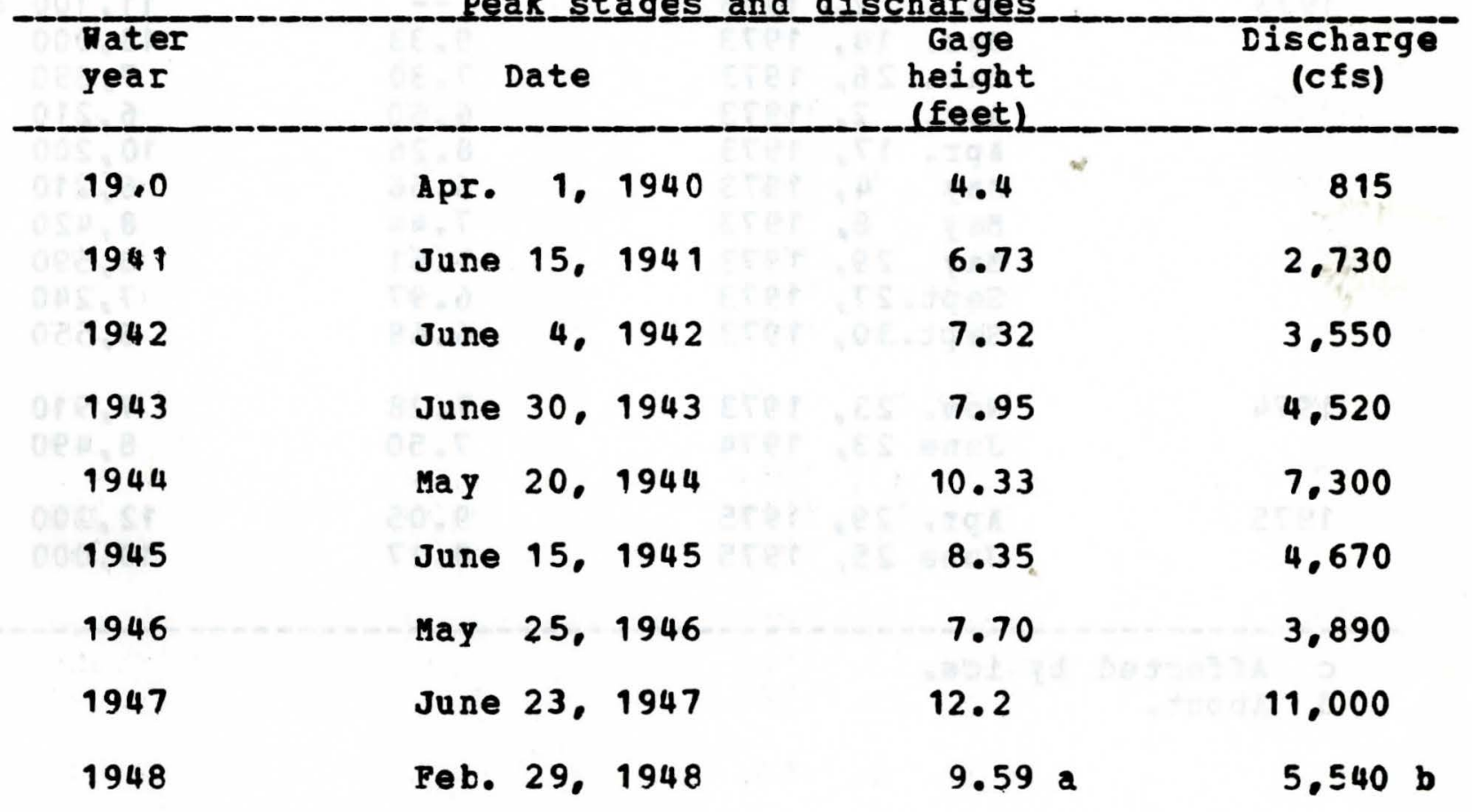

a Affectéd by ice.

b about. 
05-4767.50 Des Moines River at Humboldt, Iowa--(Continued)

Peak_stages_and di scharges

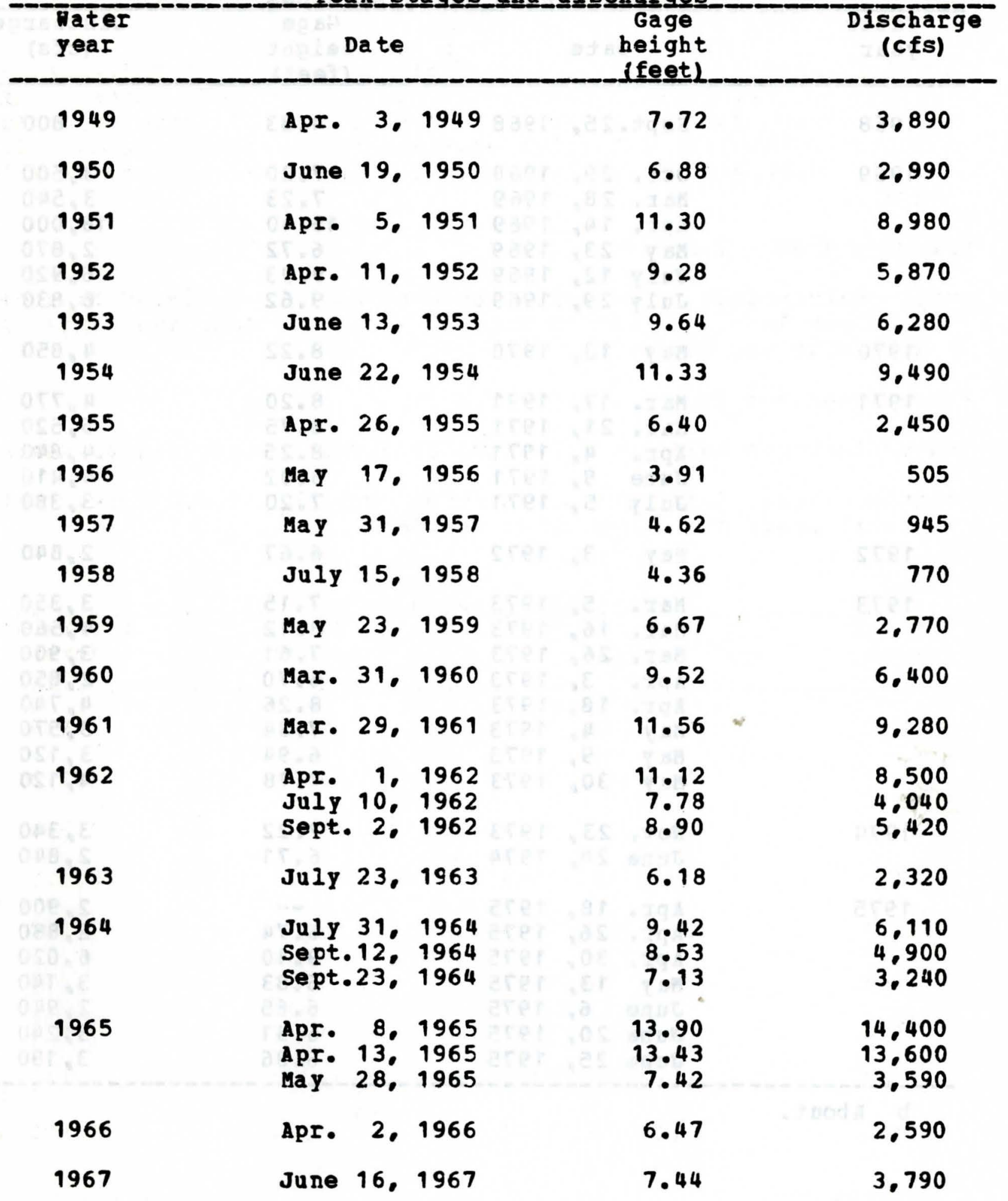


05-4767.50 Des Moines River at Humboldt, Iowa--(Continued)

Feak_stages_and_discharges

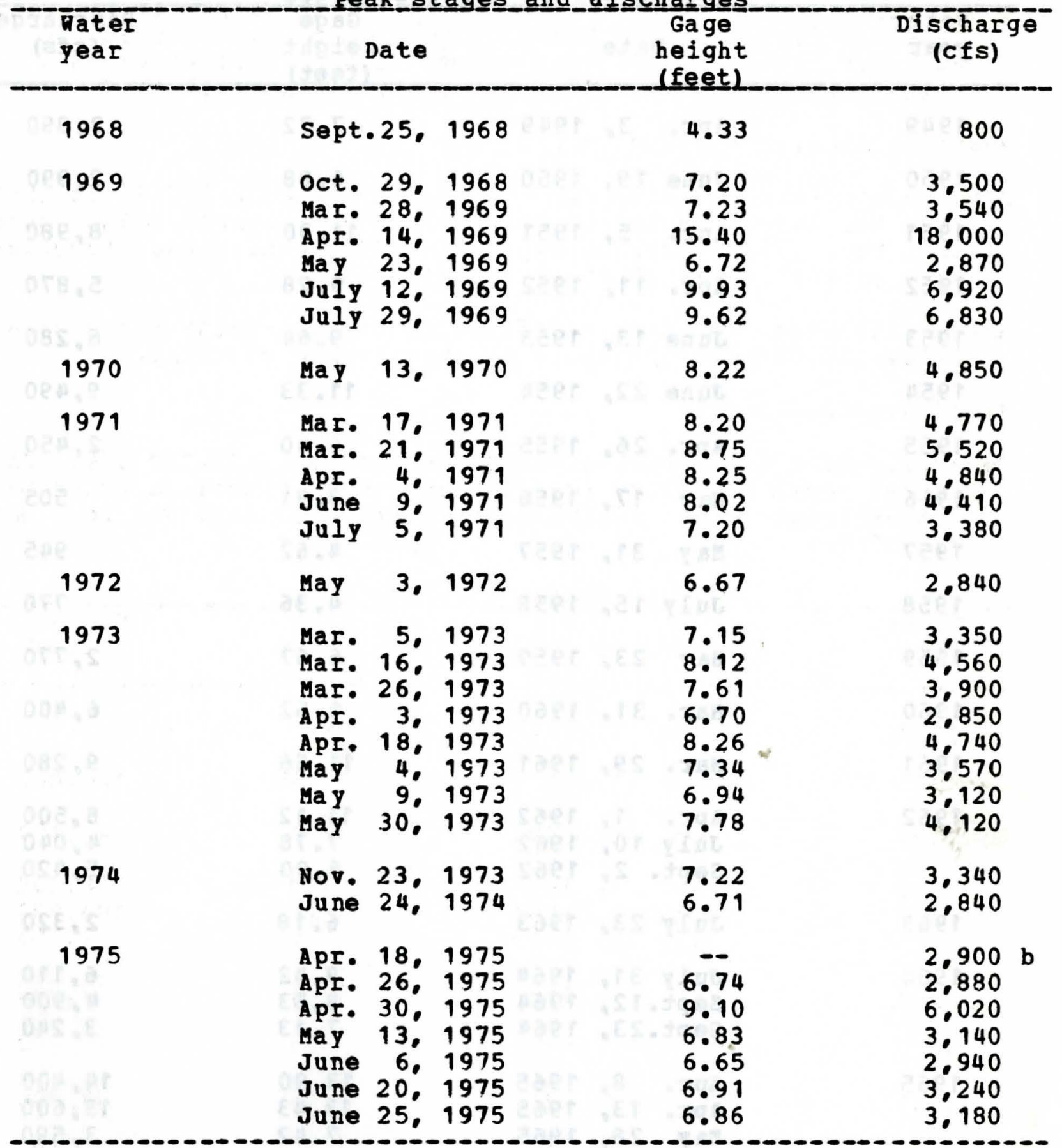

b A bout. 


$$
\text { 05-4905.00 Des Moines River at Keosauqua, Iowa }
$$

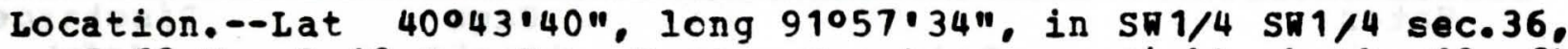
T. 69 N.. R. 10 W.. Van Buren County. on right bank 10 ft upstream from bridge on state Highway 1 at Keosaugua, 4.0 miles downstream from chequest creek, and at mile 51.3.

Drainage area.-- $-14,038 \mathrm{sq} \mathrm{mi}$

Gage.--Nater-stage recorder. Datum of gage is $547.36 \mathrm{ft}$ above mean sea level. Prior to Dec. 24, 1933, nonrecording gage. and Dec. 25, 1933, to sept. 30, 1972, water-stage recorder. same site at datum $10.00 \mathrm{ft}$ higher.

Stage-discharge relation.--Defined by current-meter measurements below 125,000 cfs and above by logarithmic plotting.

Flood stage. $-25 \mathrm{ft}$.

Remarks.--Base for partial-duration series, 25,000 cfs. Only annual peaks are shown for 1912-15. Peak discharge arove base discontinued upon beginning of storage in Lake Red rock Mar. 12. 1969.

Peak__stages_and_di

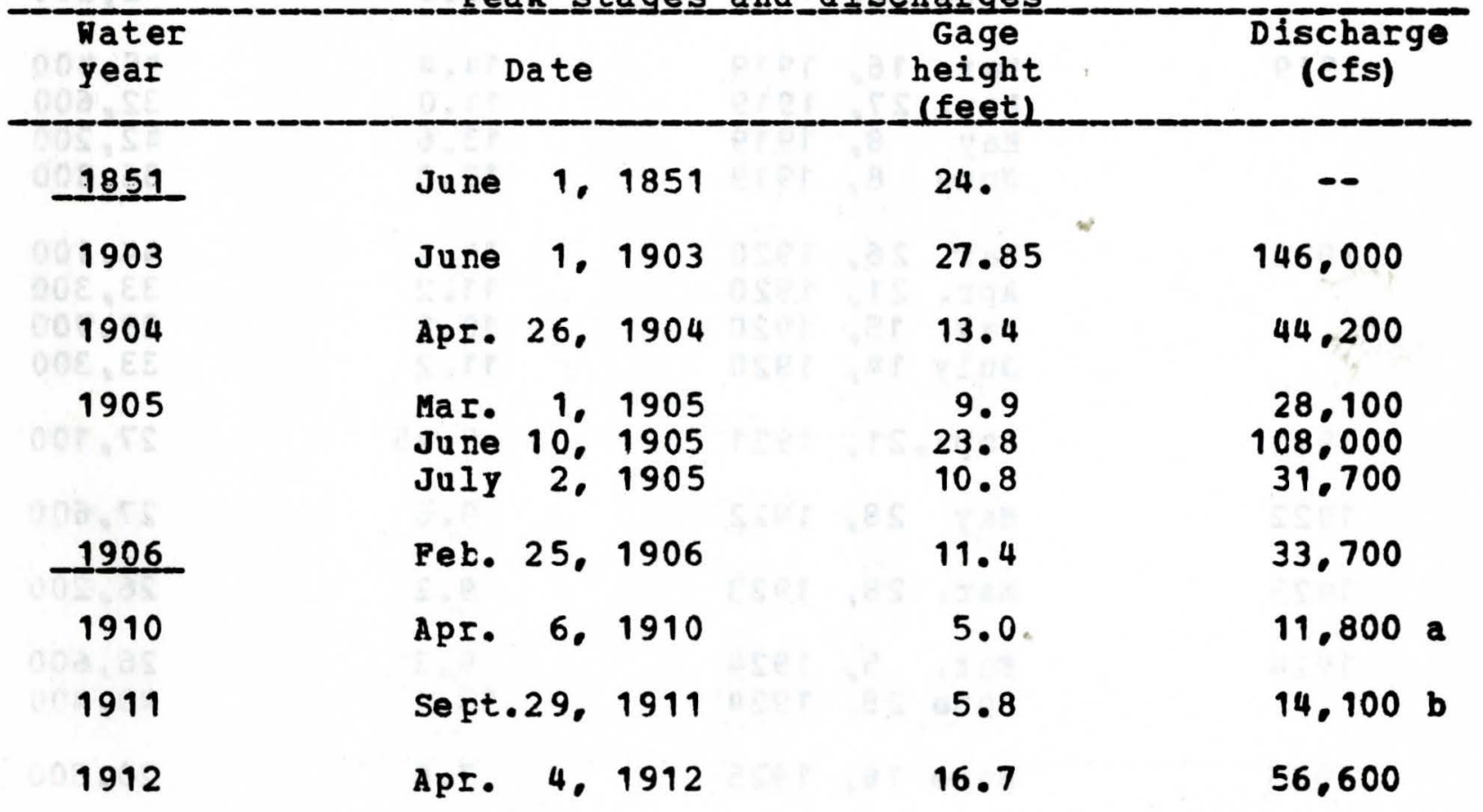

a Maximū for period April to september 1910.

b Maximum for period October to December 1910 and August September 1911. 
05-4905.00 Des Moines River at Keosauqua, Iowa--(Continued)

Pea

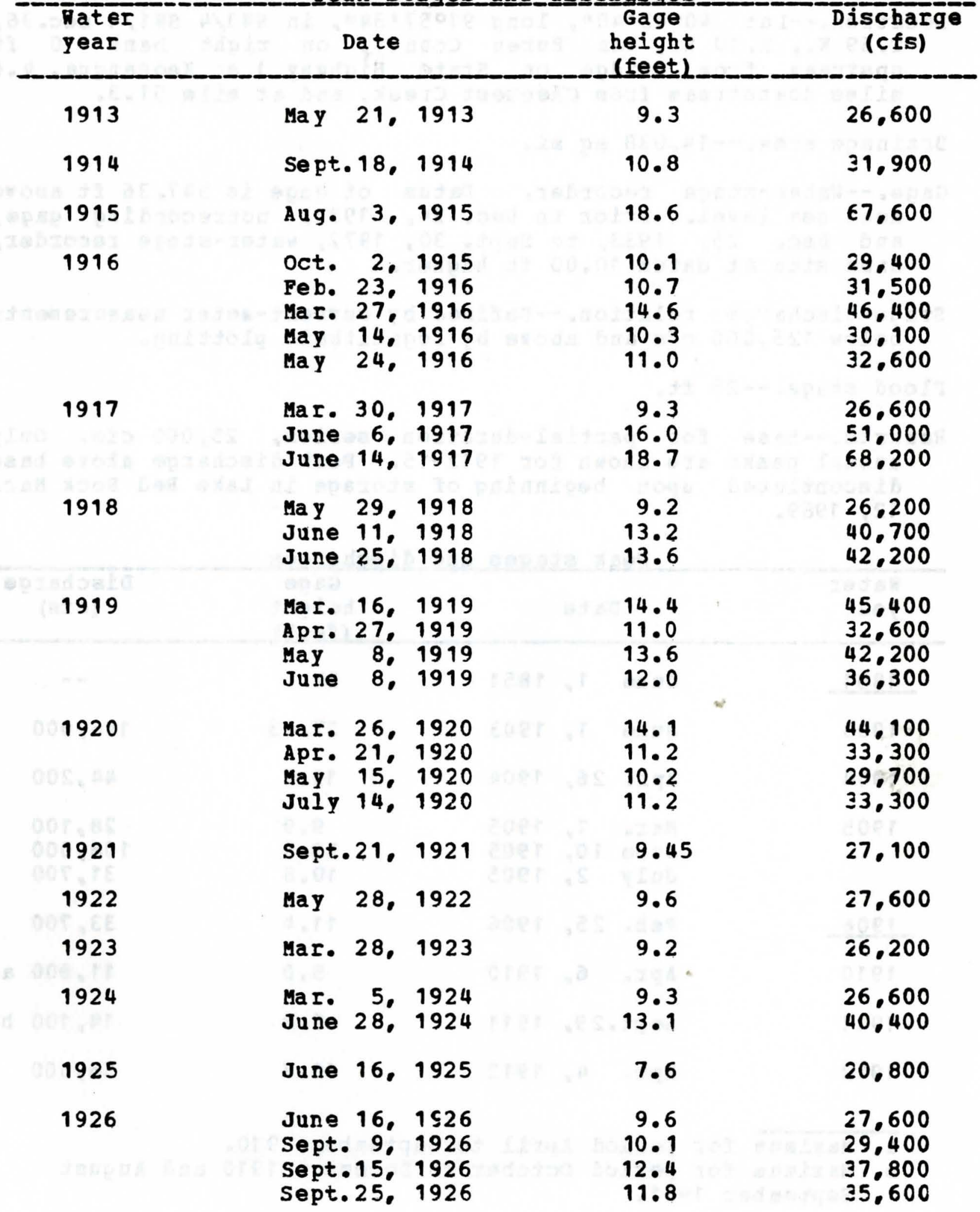


05-4905.00 Des Moines River at Keosauqua, Iowa--(Continued)

Peak﹎stages_and_discharges

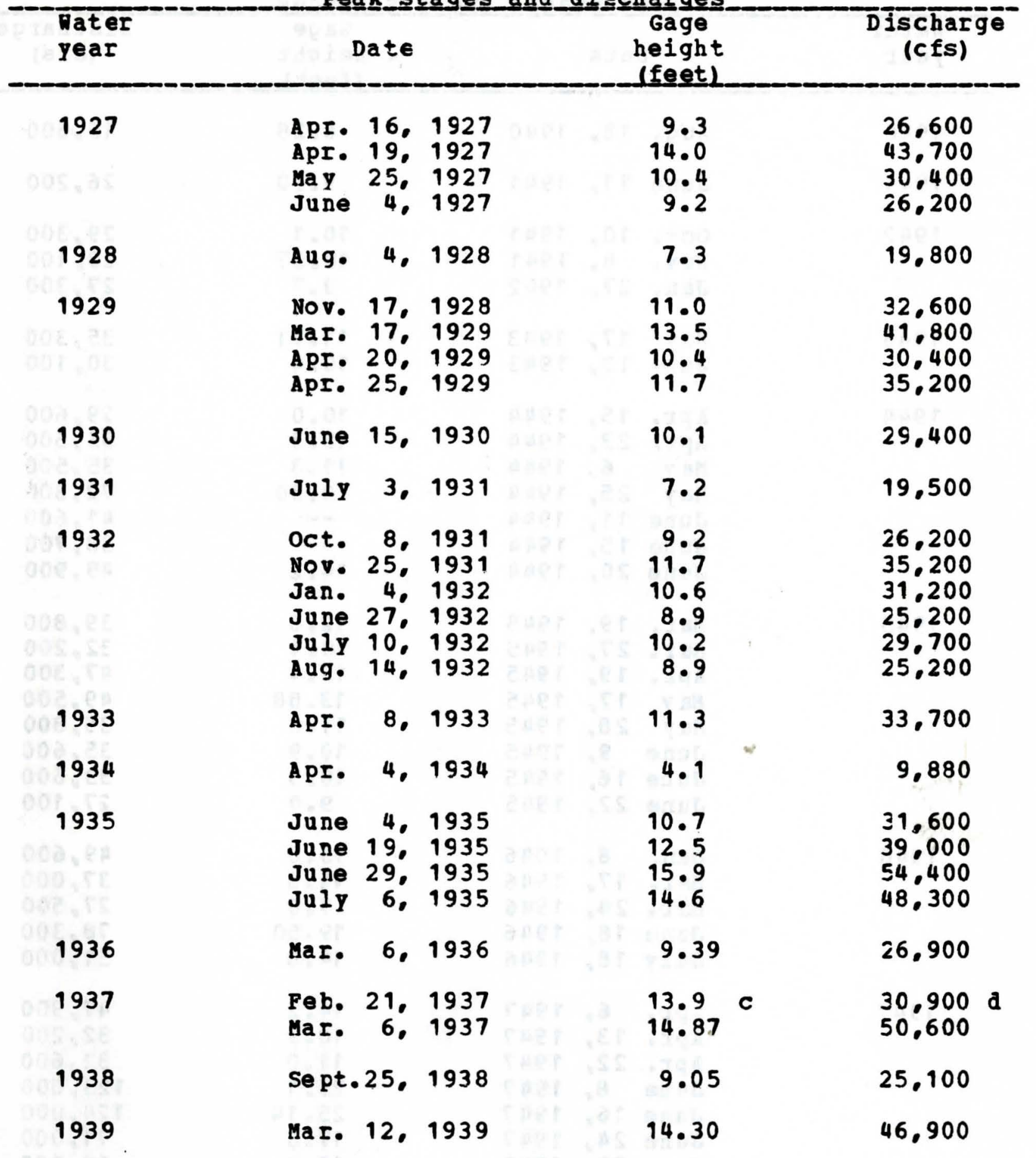

c Affectéd by ice.

d About. 
05-4905.00 Des Moines River at Keosauqua, Iowa--(Continued)

Peak stages and discharges

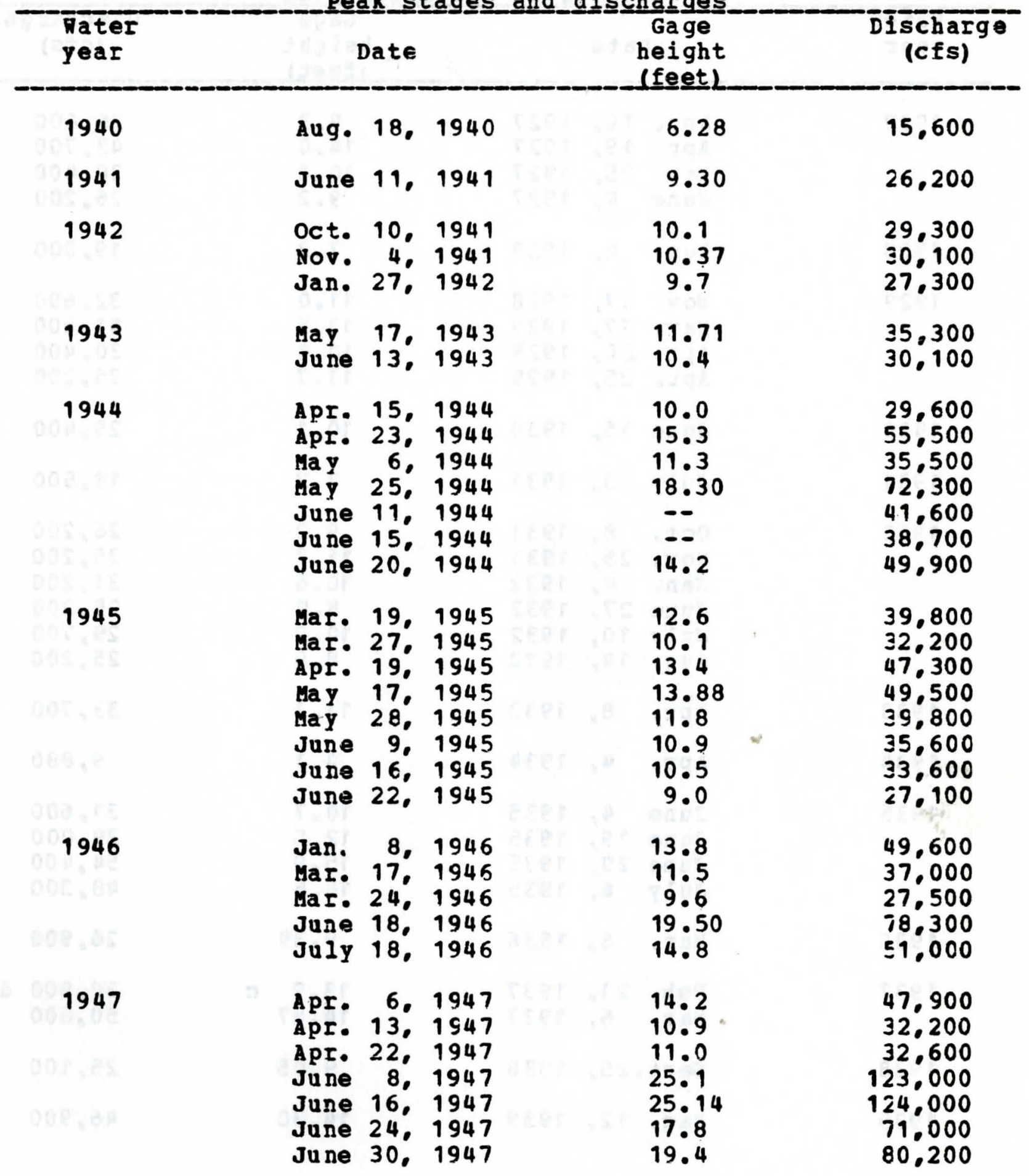


05-4905.00 Des Moines River at Keosauqua, Iowa--(Continued)

Peak stages_and_discharges

\begin{tabular}{|c|c|c|c|c|c|}
\hline $\begin{array}{l}\text { Hater } \\
\text { year }\end{array}$ & & Date & & $\begin{array}{r}\text { Gage } \\
\text { height } \\
\text { (feet) }\end{array}$ & $\begin{array}{c}\text { Discharge } \\
\text { (cfs) }\end{array}$ \\
\hline 1948 & & $\begin{array}{l}\text { Feb. } 28, \\
\text { Mar. } 17 . \\
\text { MaI. } 19 . \\
\text { Mar. } 23 .\end{array}$ & $\begin{array}{l}1948 \\
1948 \\
1948 \\
1948\end{array}$ & $\begin{array}{c}9.7 \\
8.8 \\
13.1 \\
14.38\end{array}$ & $\begin{array}{l}30.000 \\
26.400 \\
46.200 \\
52.800\end{array}$ \\
\hline 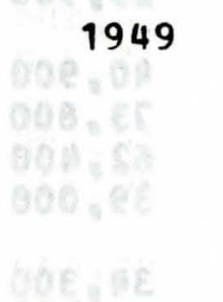 & & $\begin{array}{l}\text { Feb. } 27 . \\
\text { Mar. } 6, \\
\text { MaI. } 11, \\
\text { MaI. } 27 . \\
\text { Mar. } 31 . \\
\text { June } 24,\end{array}$ & $\begin{array}{l}1949 \\
1949 \\
1949 \\
1949 \\
1949 \\
1949\end{array}$ & $\begin{array}{l}8.4 \\
9.1 \\
9.9 \\
9.2 \\
9.97 \\
9.1\end{array}$ & $\begin{array}{l}25.000 \\
27.900 \\
31.300 \\
28.300 \\
31.700 \\
27.000\end{array}$ \\
\hline 1950 & & $\begin{array}{lr}\text { Mar. } & 2, \\
\text { May } 11, \\
\text { June } 19 .\end{array}$ & $\begin{array}{l}1950 \\
1950 \\
1950\end{array}$ & $\begin{array}{c}8.9 \\
10.6 \\
11.40\end{array}$ & $\begin{array}{l}27.000 \\
34.400 \\
38.100\end{array}$ \\
\hline 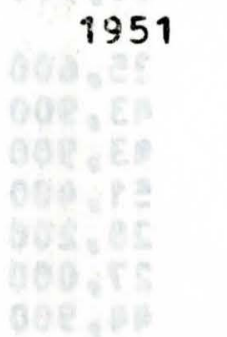 & & $\begin{array}{lr}\text { Apr. } & 4, \\
\text { Apr. } & 28, \\
\text { May } 10 ; \\
\text { May } 28, \\
\text { June } 8, \\
\text { June } 22, \\
\text { July } 5,\end{array}$ & $\begin{array}{l}1951 \\
1951 \\
1951 \\
1951 \\
1951 \\
1951 \\
1951\end{array}$ & $\begin{array}{l}14.38 \\
10.07 \\
16.45 \\
10.72 \\
12.26 \\
10.01 \\
12.14\end{array}$ & $\begin{array}{l}53,000 \\
32.200 \\
63,500 \\
34.900 \\
42.400 \\
32.200 \\
49.400\end{array}$ \\
\hline 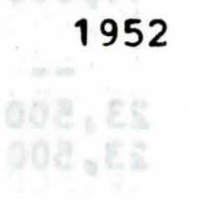 & & $\begin{array}{l}\text { Mar. } 13, \\
\text { Mar. 20, } \\
\text { Apr. } 6 \% \\
\text { June } 24,\end{array}$ & $\begin{array}{l}1952 \\
1952 \\
1952 \\
1952\end{array}$ & $\begin{array}{r}11.57 \\
8.69 \\
9.63 \\
12.45\end{array}$ & $\begin{array}{l}39,000 \\
26,200 \\
30,000 \\
42,900\end{array}$ \\
\hline 1953 & & $\begin{array}{l}\text { Apr. } 1 . \\
\text { June } 15 .\end{array}$ & $\begin{array}{l}1953 \\
1953\end{array}$ & $\begin{array}{r}9.95 \\
9.71\end{array}$ & $\begin{array}{l}31,600 \\
30,300\end{array}$ \\
\hline 1954 & & $\begin{array}{l}\text { June } 29 \\
\text { Sept. } 2\end{array}$ & $\begin{array}{l}1954 \\
1954\end{array}$ & $\begin{array}{r}16.14 \\
8.66\end{array}$ & $\begin{array}{l}60.800 \\
25.800\end{array}$ \\
\hline 1955 & & oct. 10 & 1954 & 7.57 & 22.100 \\
\hline 1956 & & Aug. 10 & 1956 & 4.46 & 11,600 \\
\hline 1957 & & June 21 . & 1957 & 7.44 & 21.300 \\
\hline 1958 & & July 5 . & 1958 & 10.50 & 33.800 \\
\hline
\end{tabular}


05-4905.00 Des Moines River at Keosauqua, Iowa--(Continued)

Peak stages and discharges

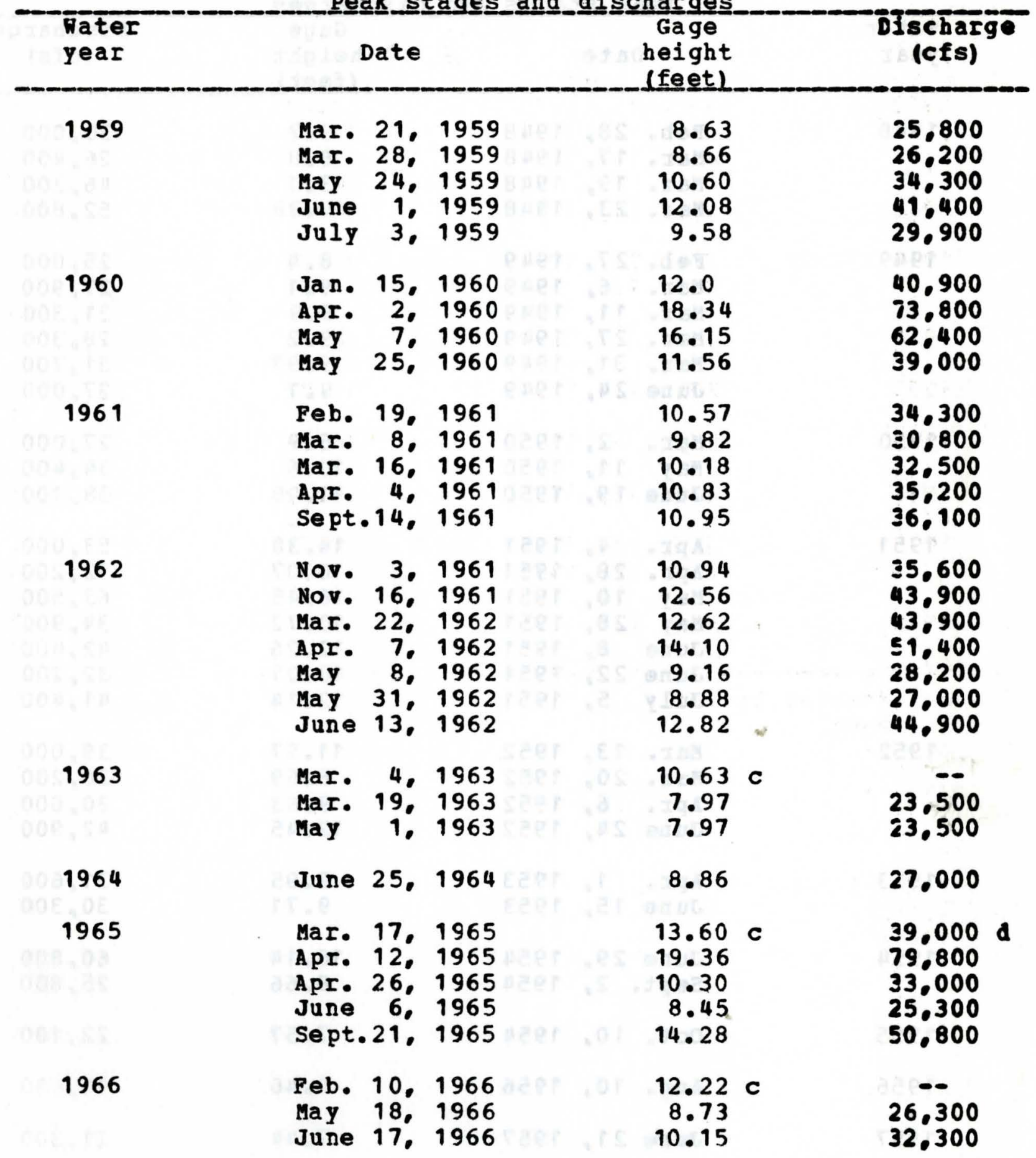

c Affected by ice.

d About. 
05-4905.00 Des Hoines River at Keosaugua, Iowa--(Continued)

Peak_stages_and_discharges

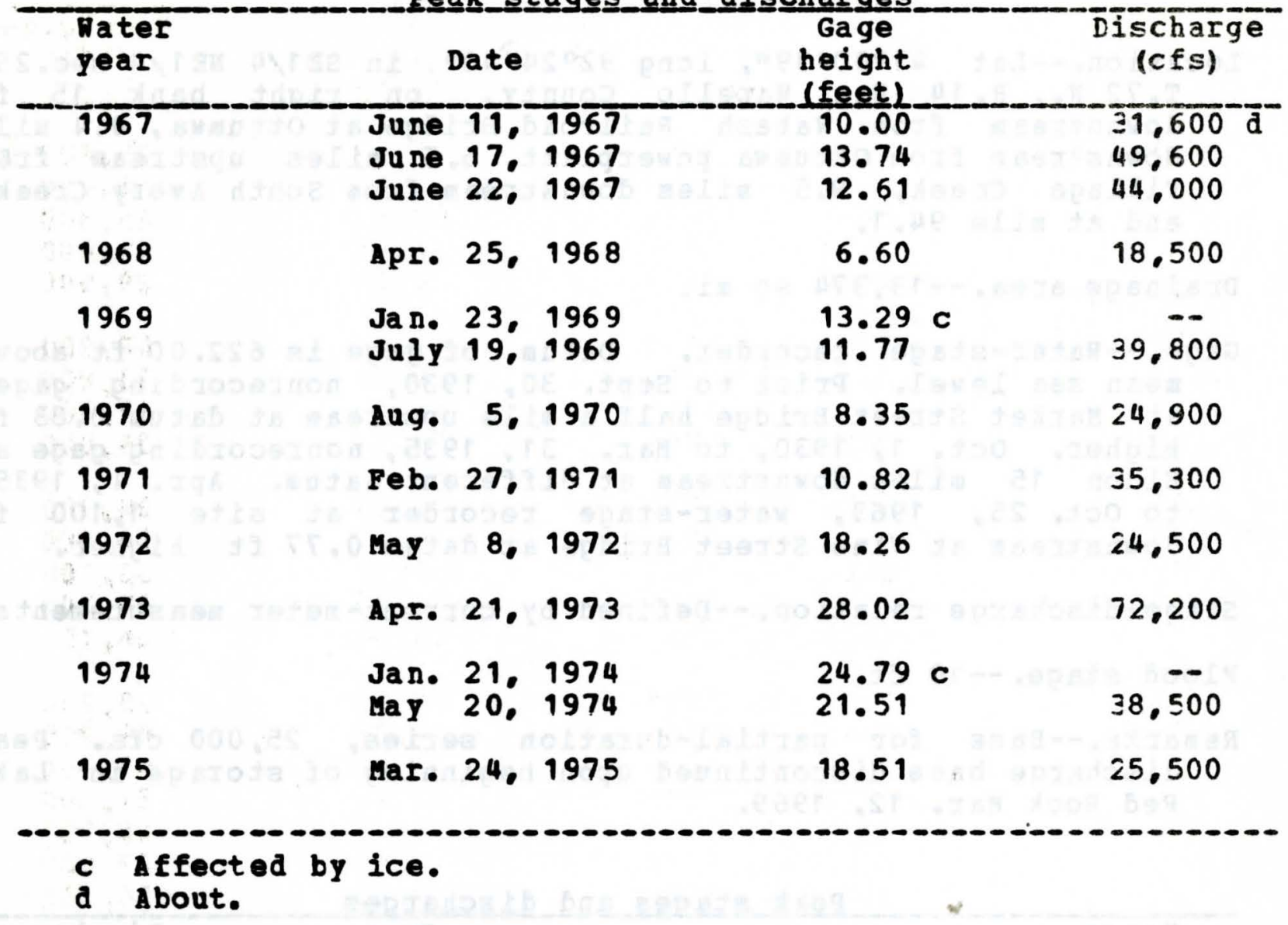


05-4895.00 Des Moines River at Ottumwa, Iowa

(Published as "at Eldon", 1930-35)

Location.--Lat 41000139". long 92024'40", in SE1/4 NE1/4 sec.25, T.72 N.. R.14 W.. Napello County. on right bank 15 ft downstream from Wabash Railroad Bridge at ottumwa, 0.4 mile downstream from ottumwa powerplant. 6.5 miles upsiream fr6m village Creek, 9.5 miles dcwnstream from South Avery Creek, and at mile 94.1 .

Drainage area.--13,374 sq $\mathrm{mi}$.

Gage.--Mater-stage recorder. Datum of gage is $622.00 \mathrm{ft}$ above mean sea level. prior to sept. 30, 1930, nonrecording gages at Market Street Bridge half a mile upstream at datum $0.83 \mathrm{ft}$ higher. Oct. 1, 1930, to Mar. 31, 1935, nonrecording gage at Eldon 15 miles downstream at different datum. Apr. 1, 1935. to oct. 25, 1963, water-stage recorder at site $1,100 \mathrm{ft}$ downstream at vine street Bridge at datum $0.77 \mathrm{ft}$ higher.

Stage-discharge relation.--Defined by current-meter measurements.

Plood stage.-- $10 \mathrm{ft.}$

Remarks.--Base for partial-duration series. 25,000 cfs. Peak discharge base discontinued upon beginning of storage in Lake Red Rock MaI. 12, 1969.

Peak stages and di

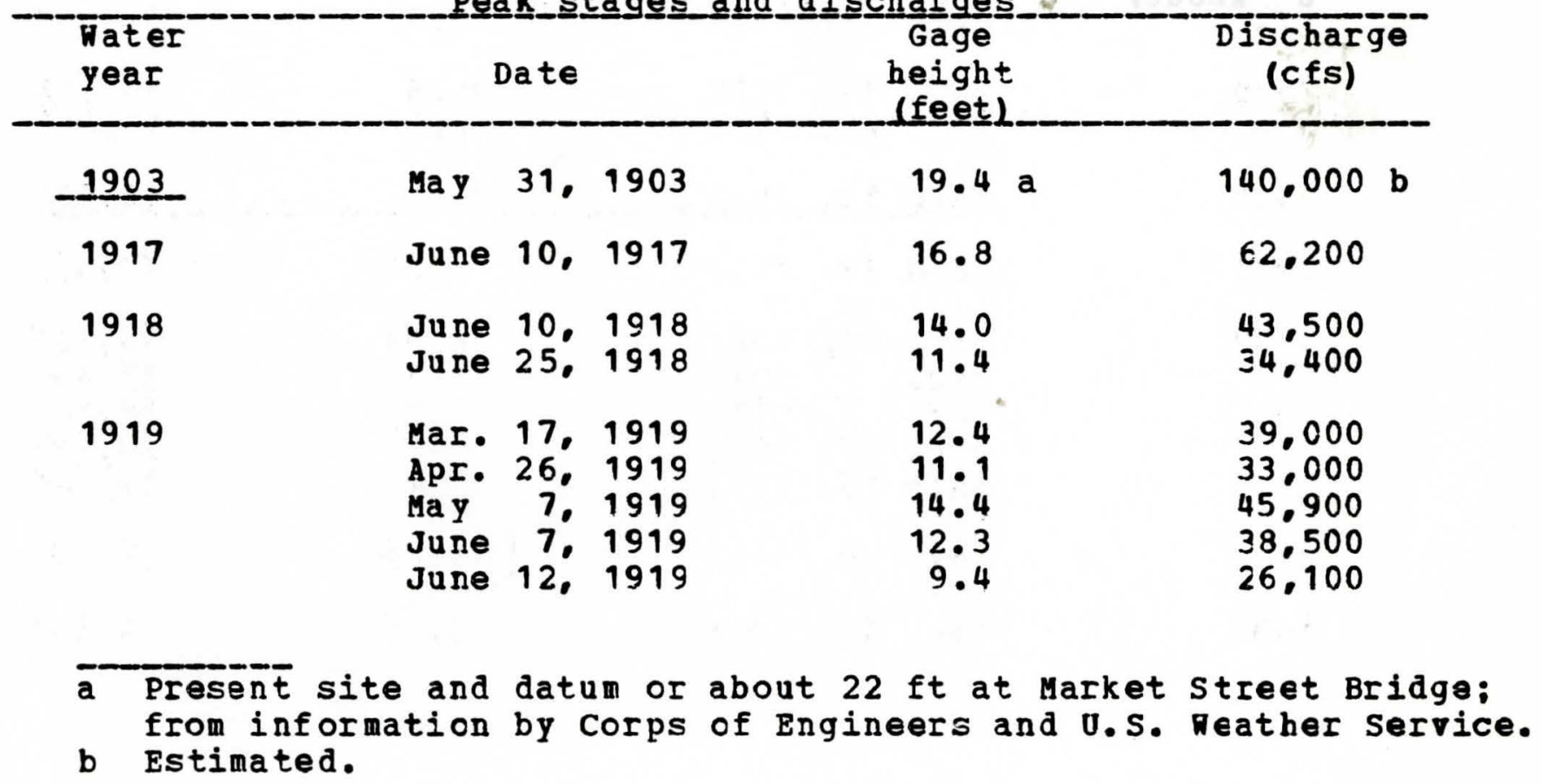


05-4895.00 Des Moines River at Cttumwa, Iowa--(Continued)

Peak stages and discharges

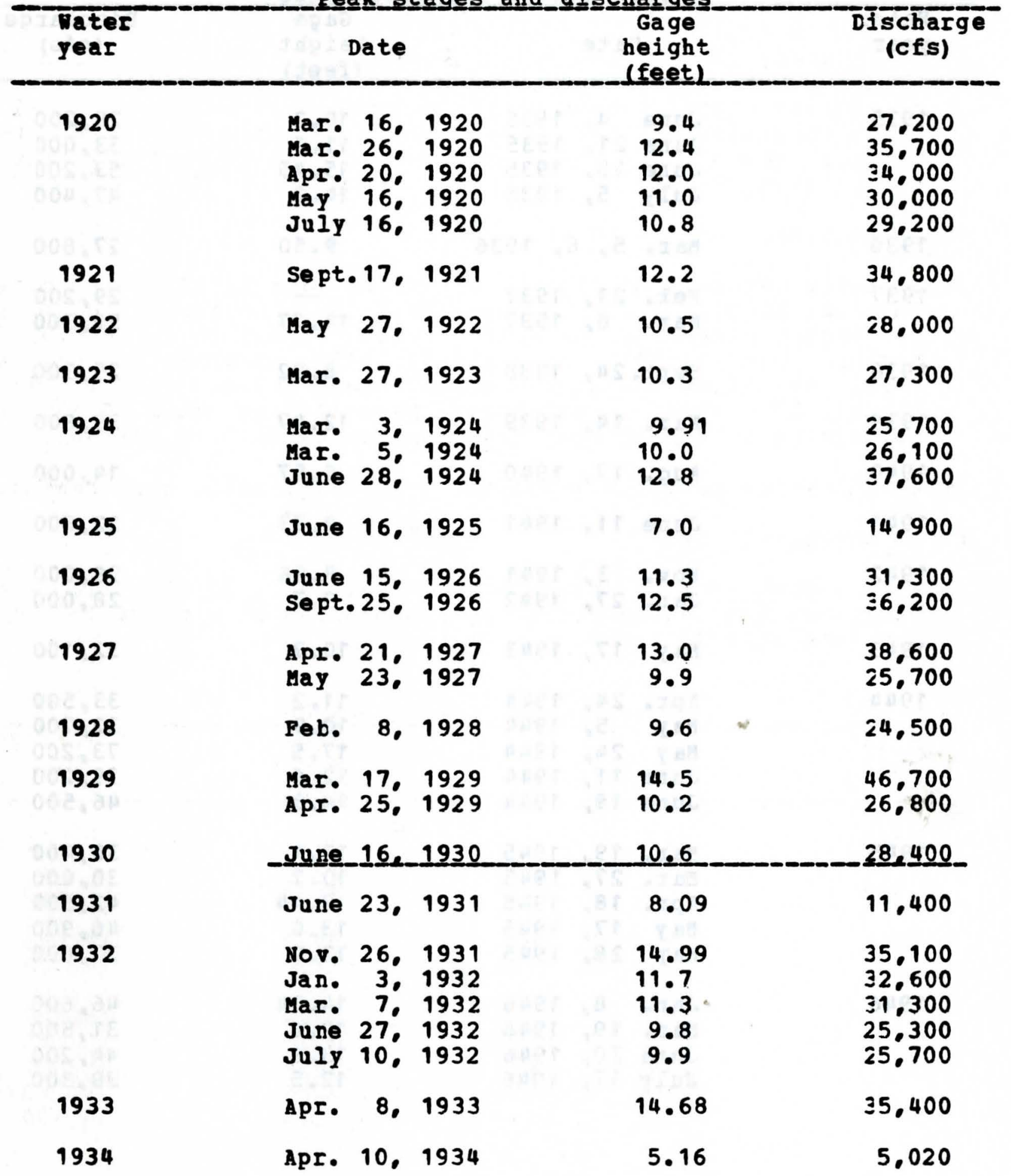


05-4895.00 Des Hoines River at Ottumwa, Iowa--(Continued)

Peak stages and discharges

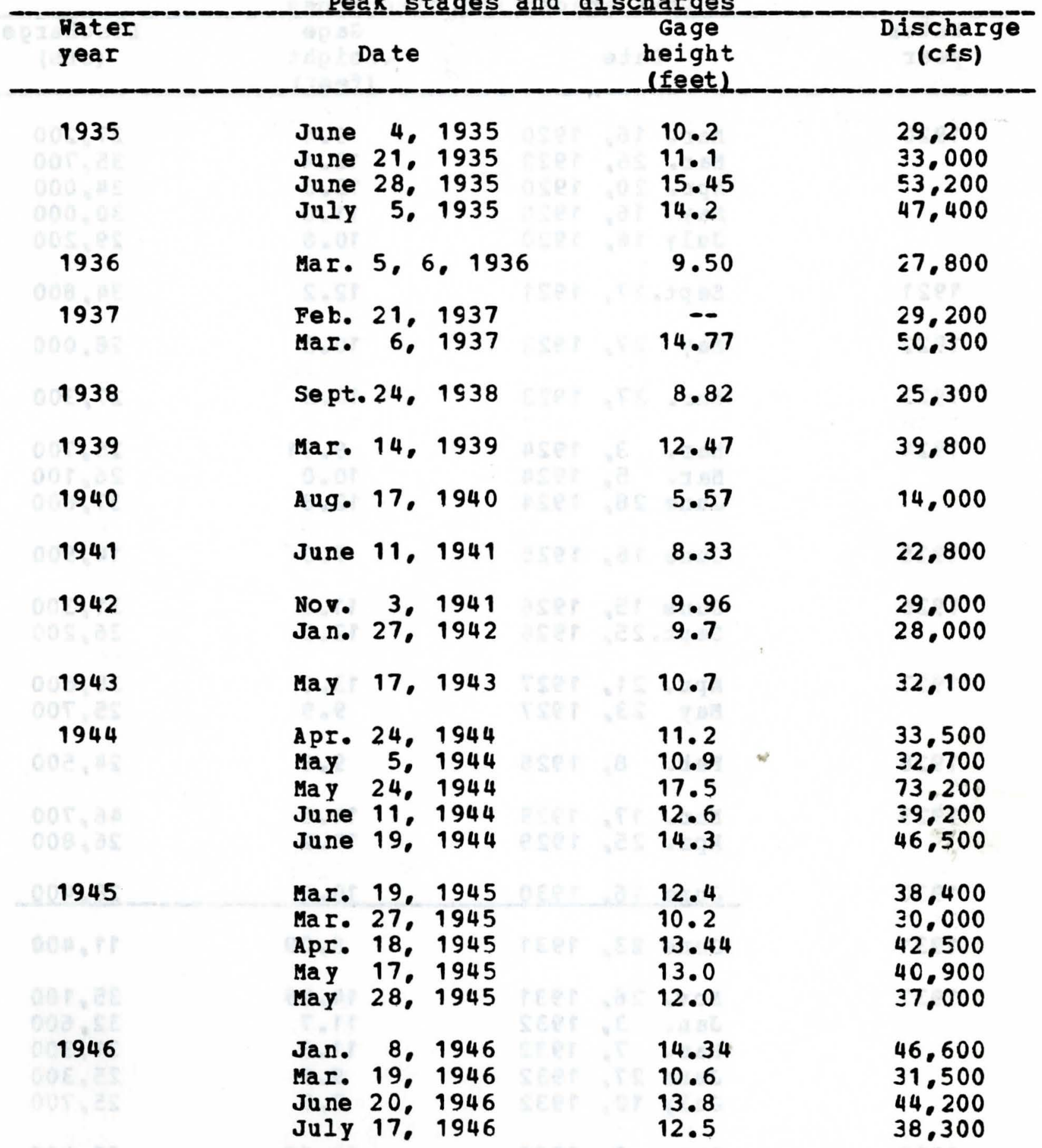


05-4895.00 Des Moines River at Ottumwa. Iowa--(Continued)

Peak stages and discharges

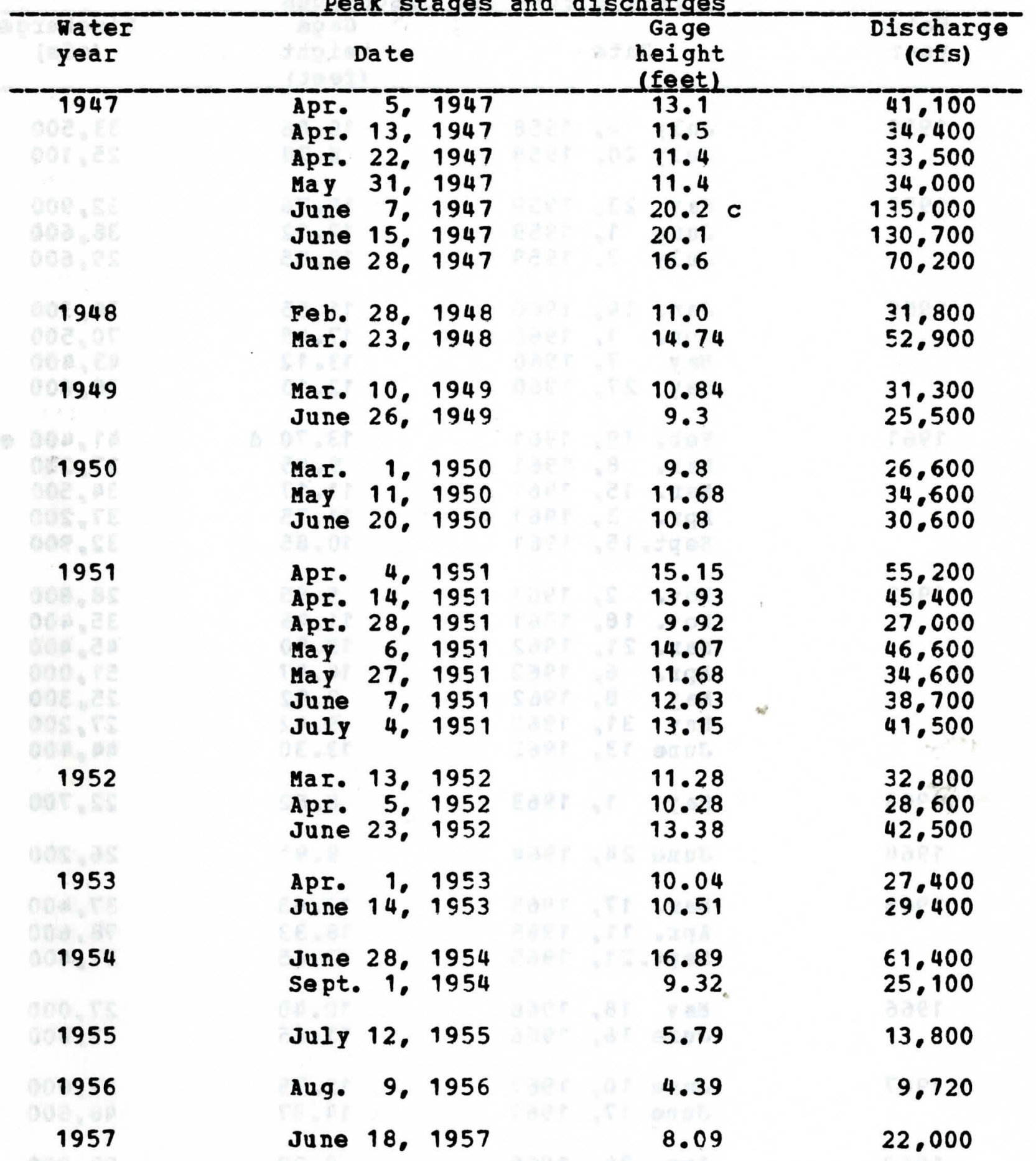

$\bar{C}$ Maximū stage known since at least 1850. 
05-4895.00 Des Moines River at Ottumwa, Iowa--(Continued)

Peak_stages_and discharges

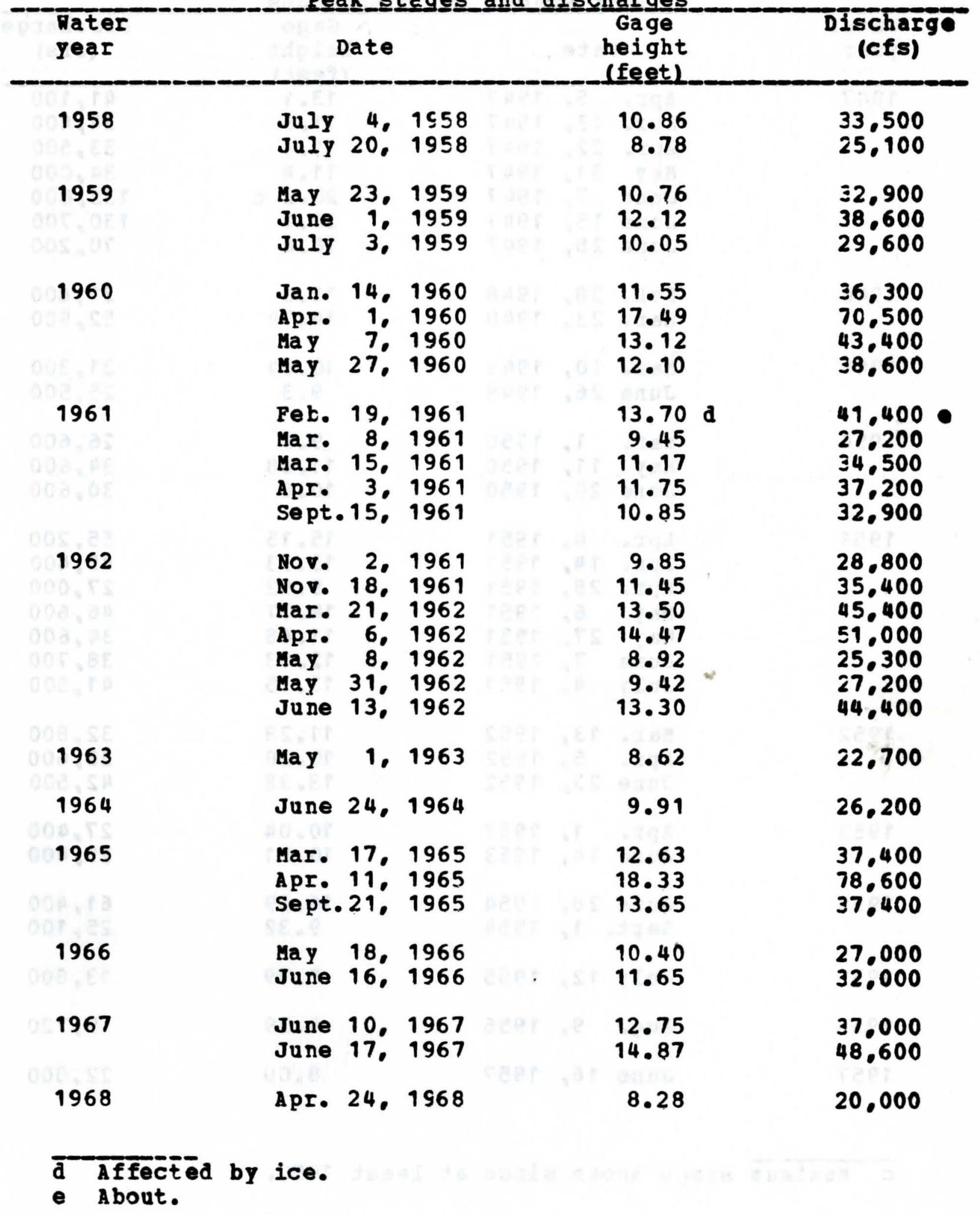


05-4895.00 Des Moines River at Cttumwa, Iowa--(Continued)

Peak_stages_and__is

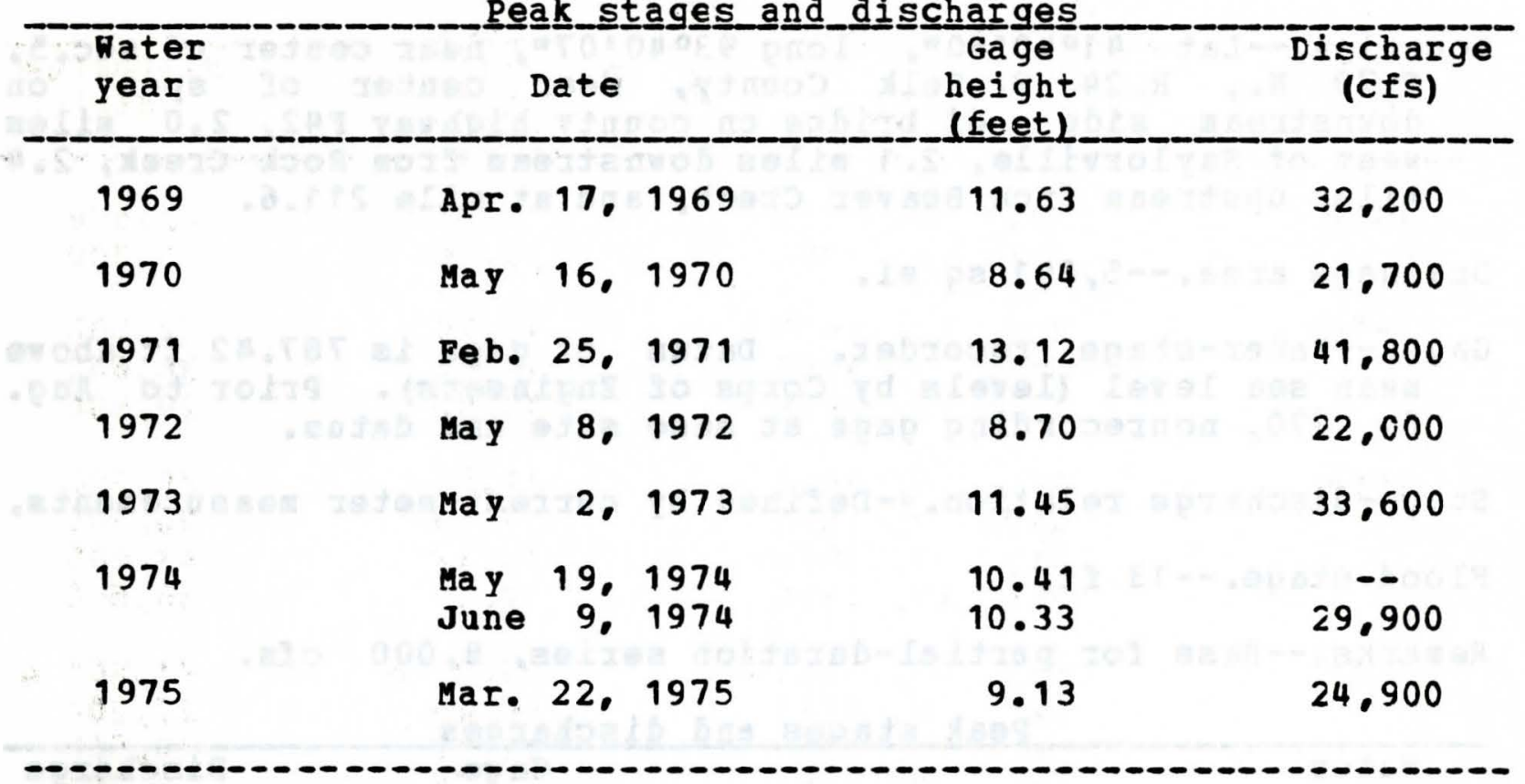




\section{5-4816.50 Des Moines River near Saylorville. Iowa}

Location.--lat $41040050 \%$, long $93040007 \%$, near center cf sec. 5. T.79 N.. R. 24 W. Poik County. near center of span on downstream side of bridge cn county highway F42, 2.0 miles west of Saylorville. 2.1 miles downstream from Rock Creek. 2.4 miles upstrean frcm Beaver Creek, and at mile 211.6.

Drainage area.- $-5,841 \mathrm{sq} \mathrm{mi}$

Gage.--Water-stage recorder. Datum of gage is $787.42 \mathrm{ft}$ above mean sea level (levels by Corps of Engineers). Prior to Aug. 6. 1970, nonrecording gage at same site and datum.

Stage-discharge relation.--Defined by current-meter measurements. Flood stage.--13 ft.

Remarks.--Base for partial-duration series, 8,000 cfs.

Peak_stages_and discharges

\begin{tabular}{|c|c|c|c|c|}
\hline $\begin{array}{l}\text { Water } \\
\text { year }\end{array}$ & Date & & $\begin{array}{l}\text { Gage } \\
\text { height } \\
\text { (feet) }\end{array}$ & $\begin{array}{c}\text { Discharge } \\
\text { (cfs) }\end{array}$ \\
\hline 1954 & June 24 . & 1554 & $24.5 \mathrm{a}$ & 60.000 \\
\hline 1962 & $\begin{array}{ll}\text { Apr. } & 3, \\
\text { July } & 8 \\
\text { July } & 15, \\
\text { Sept. } & 5 .\end{array}$ & $\begin{array}{l}1962 \\
1962 \\
1962 \\
1962\end{array}$ & $\begin{array}{l}21.10 \\
14.25 \\
13.56 \\
19.10\end{array}$ & $\begin{array}{r}31.000 \\
9.690 \\
8.720 \\
21.800\end{array}$ \\
\hline 1963 & $\operatorname{May}$ & 1963 & 13.20 & 8.100 \\
\hline 1964 & se ft. 15. & 1965 & 13.31 & 8.250 \\
\hline 1965 & $\begin{array}{l}\text { Apr. 10, } \\
\text { May 29, } \\
\text { June 5, } \\
\text { Sept. } 24,\end{array}$ & $\begin{array}{l}1965 \\
1965 \\
1965 \\
1965\end{array}$ & $\begin{array}{l}24.02 \\
18.00 \\
16.66 \\
16.48\end{array}$ & $\begin{array}{l}47.400 \\
19.100 \\
15.200 \\
14,800\end{array}$ \\
\hline 1966 & $\begin{array}{l}\text { Oct. } \\
\text { June } 12 .\end{array}$ & $\begin{array}{l}1965 \\
1966\end{array}$ & $\begin{array}{l}17 \cdot 35 \\
16.79\end{array}$ & $\begin{array}{l}17.200 \\
15.900\end{array}$ \\
\hline 1967 & $\begin{array}{l}\text { June } 13 . \\
\text { June } 19 .\end{array}$ & $\begin{array}{l}1967 \\
1967\end{array}$ & $\begin{array}{l}18.70 \\
18.50\end{array}$ & $\begin{array}{l}21.000 \\
19.600\end{array}$ \\
\hline 1968 & June 30 . & 1968 & 10.04 & 4.550 \\
\hline
\end{tabular}

$\bar{a}$ Maximum stage known since at least 1893, from flocdmarks. 
05-4816.50 Des Moines River near Saylorville, Iowa--(Continued)

Peak_stages and discharges

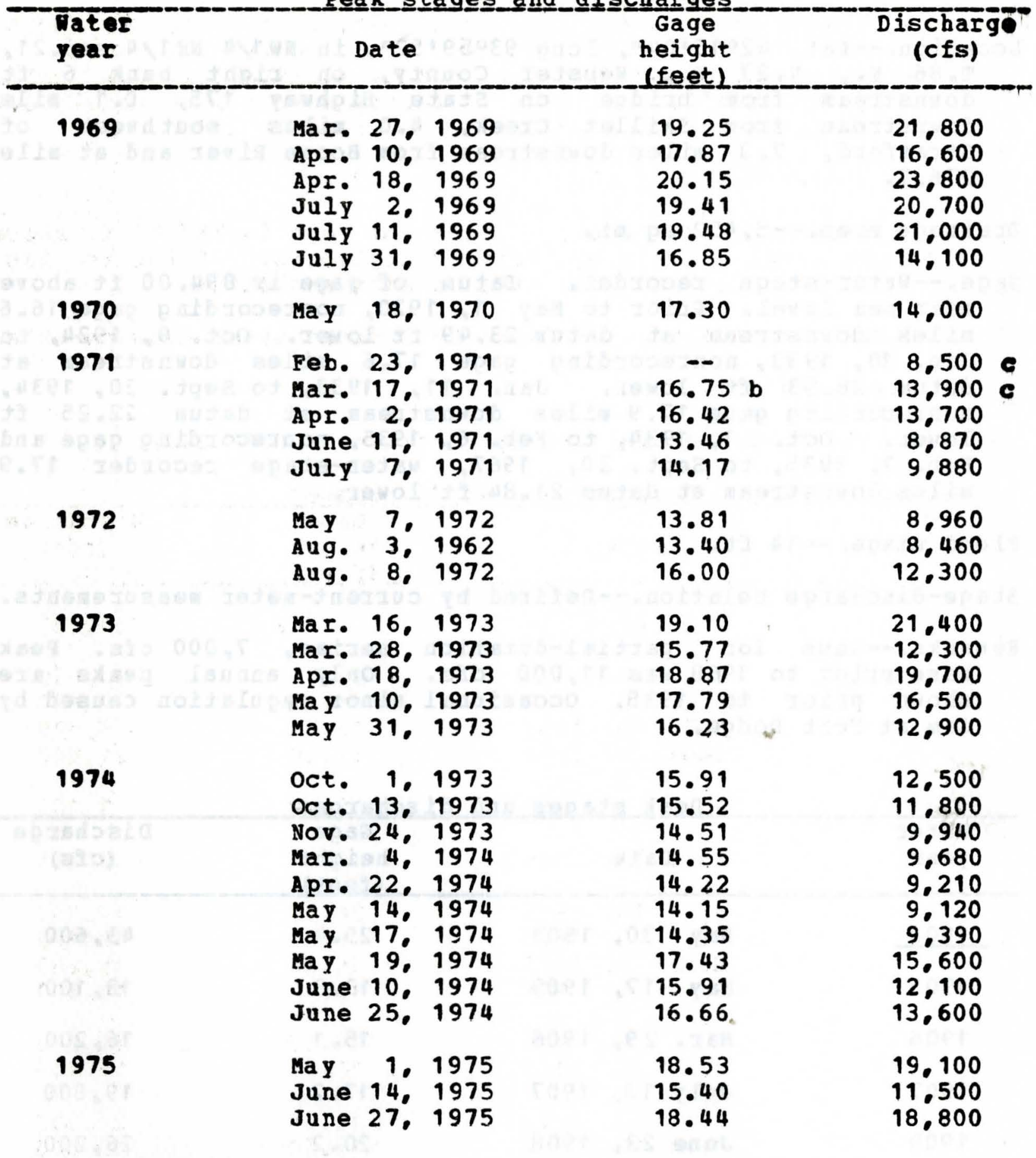

b affected by ice.

c about. 
05-4813.00 Des Moines River near Stratford. Iowa

(published as $05-4815.00$ Des Moines River near Boone, Icwa, 1920-67)

Location.--Iat $42015^{\prime 04}$ " Icng 93059'52". in N⿴1/4 NE1/4 sec.21. T.86 N., R.27 W.. Hebster County, on right bank 6 ft downstream from bridge on State Highway 175, C.1 mile downstream from skillet creek. 4.0 miles southwest of stratford, 7.3 miles downstream from Boone River and at mile 276.7 .

Drainage area.--5,452 sq mi。

Gage--Water-stage recorder. Datum of gage is $894.00 \mathrm{ft}$ above mean sea level. Frior to May 1, 1920, nonrecording gage 16.6 miles downstream at datum $23.49 \mathrm{ft} 10$ wer. oct. 9. 1924, to Jan. 10, 1933, nonrecording gage $\mathbf{1 7 . 6}$ miles downstream at datur 28.53 ft lower. Jan. 11, 1933, to sept. 00.1934 . nonrecording gage 17.9 miles downstream at datum 22.25 ft lower. oct. 1, 1934, to Feb. 6, 1935, nonrecording gage and Feb. 7. 1935, to sept. 30, 1967. water-stage recorder 17.9 miles downstream at datum 21.84 ft lower.

Flood stage. $--14 \mathrm{ft.}$

Stage-discharge relation.--Defined by current-meter measurements.

Remarkse-Base for partial-duration series. 7,000 cfs. Peak base prior to 1968 was 11,000 cfs. only annual feaks are shown prior to 1935. Occasional minor regulation caused by dar at Fort Dodge.

Peak_stages and discharges

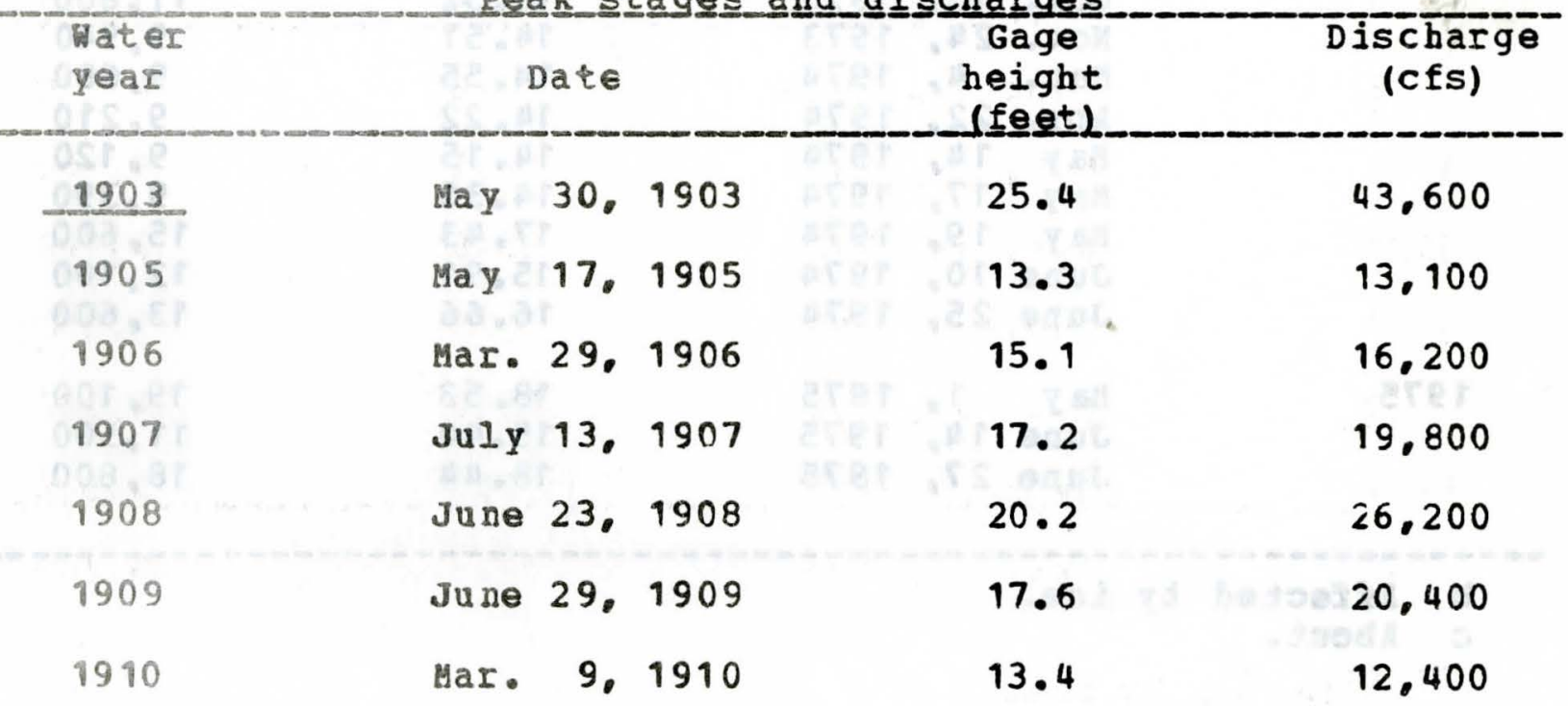


05-4813.00 Des Moines River near Stratford. Iowa-- (Continued)

Eeak_stages_and dis

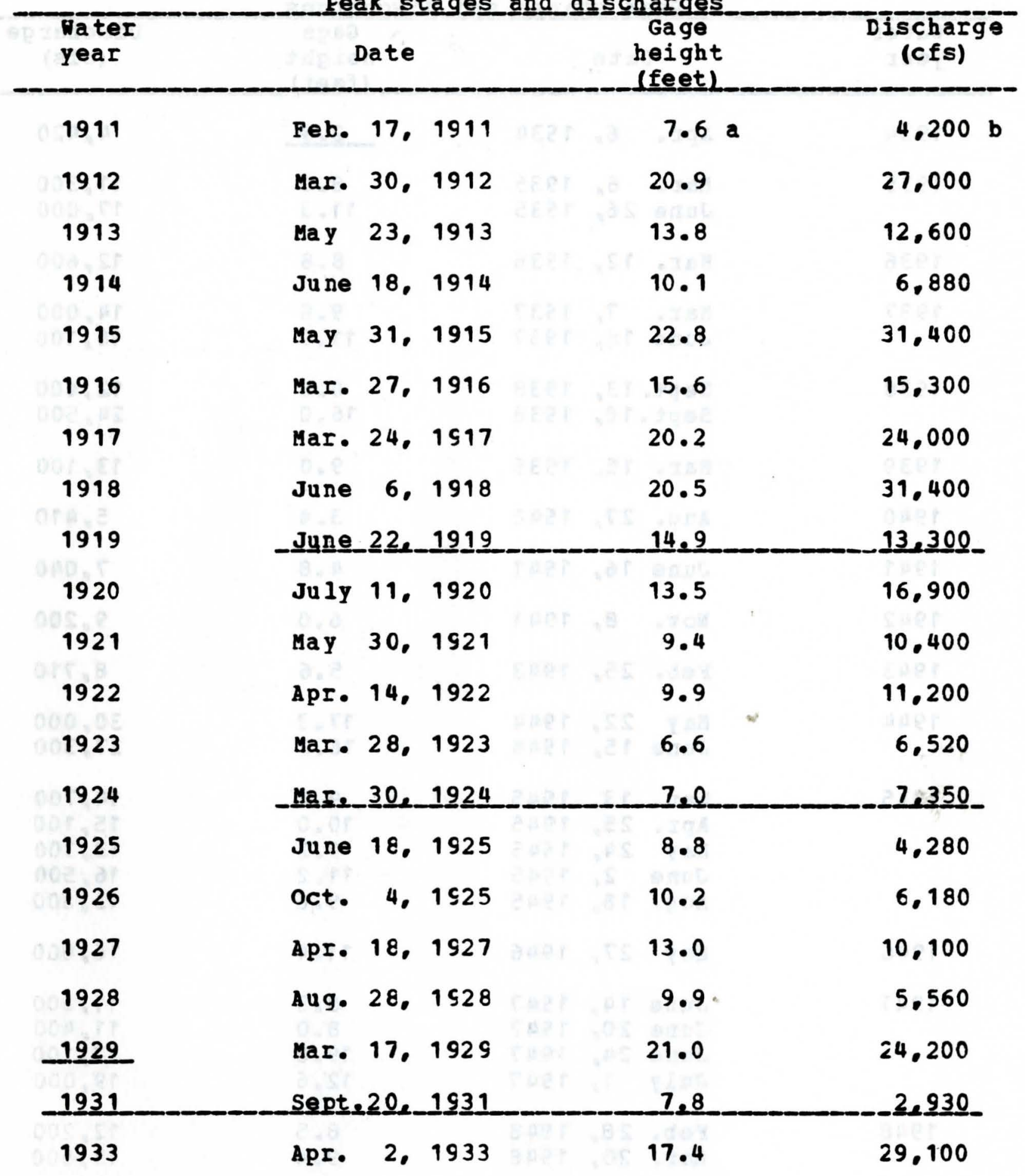

a Afected by ice.

b A bout. 
05-4813.00 Des Moines River near Stratford. Iowa-- (Continued)

Peak stages and discharges

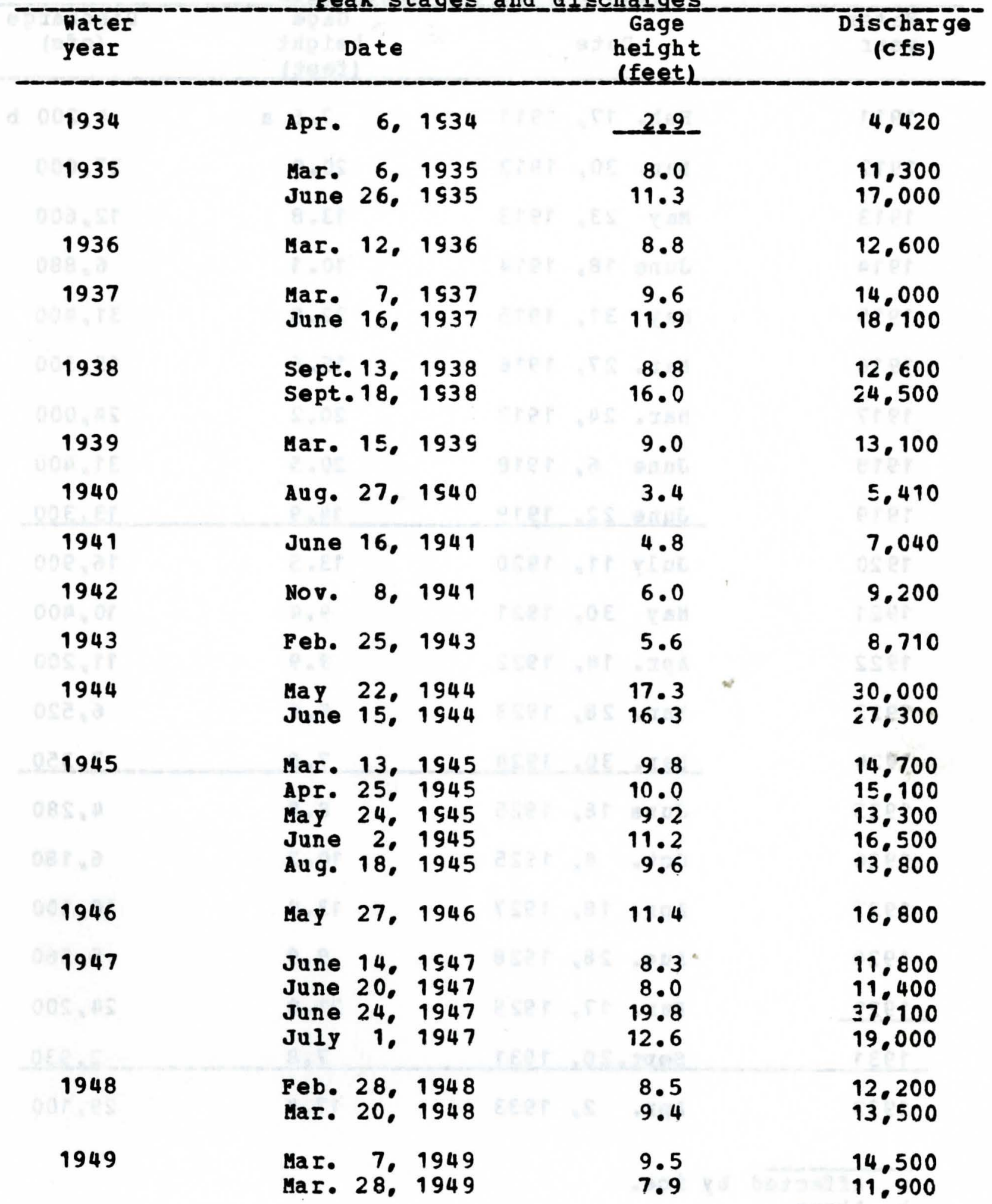


05-4813.00 Des Moines River near Stratford. Iowa-- (Continued)

Feak stages and discharges

\begin{tabular}{|c|c|c|c|c|}
\hline $\begin{array}{l}\text { Hater } \\
\text { year }\end{array}$ & Date & & $\begin{array}{l}\text { Gage } \\
\text { height } \\
\text { (feet) }\end{array}$ & $\begin{array}{c}\text { ischarge } \\
\text { (cfs) }\end{array}$ \\
\hline 1950 & Mar. 7. & 1950 & $7.5 \mathrm{a}$ & $9.800 \mathrm{~b}$ \\
\hline 1951 & $\begin{array}{lr}\text { Mar. } 30, \\
\text { Apr. } \\
\text { Hay } & 3 \circ \\
\text { June } 4 . \\
\text { June } 29 .\end{array}$ & $\begin{array}{l}1951 \\
1951 \\
1951 \\
1951 \\
1951\end{array}$ & $\begin{array}{r}16.82 \\
16.44 \\
13.82 \\
7.52 \\
11.00\end{array}$ & $\begin{array}{l}28.200 \\
27.200 \\
21.800 \\
11.300 \\
16.900\end{array}$ \\
\hline 1952 & $\begin{array}{lr}\text { Apr. } & 2, \\
\text { Apr. } 15, \\
\text { July } 10,\end{array}$ & $\begin{array}{l}1952 \\
1952 \\
1952\end{array}$ & $\begin{array}{r}10.78 \\
7.44 \\
8.68\end{array}$ & $\begin{array}{l}16.600 \\
11.100 \\
13.200\end{array}$ \\
\hline 1953 & June 15 & 1953 & 6.03 & 9.080 \\
\hline 1954 & $\begin{array}{l}\text { June } 11 . \\
\text { June } 22, \\
\text { Aug. } 27 .\end{array}$ & $\begin{array}{l}1954 \\
1954 \\
1954\end{array}$ & $\begin{array}{r}10.50 \\
25.35 \\
8.97\end{array}$ & $\begin{array}{l}16.200 \\
57.400 \\
13.800\end{array}$ \\
\hline 1955 & JuIy 10. & 1955 & 4.10 & 6.390 \\
\hline 1956 & May 31. & 1956 & 1.11 & 1.550 \\
\hline 1957 & June 16 & 1957 & 5.35 & 8.300 \\
\hline 1958 & July 16 . & 1958 & 6.22 & 9.500 \\
\hline 1959 & June 1 . & 1959 & 8.91 & 13.200 \\
\hline 1960 & $\begin{array}{l}\text { Mar. } 31 . \\
\operatorname{May} 27_{0}\end{array}$ & $\begin{array}{l}1960 \\
1960\end{array}$ & $\begin{array}{r}17.08 \\
8.00\end{array}$ & $\begin{array}{l}29.800 \\
11.800\end{array}$ \\
\hline 1961 & MaI. 29. & 1961 & 15.47 & 26.200 \\
\hline 1962 & $\begin{array}{l}\text { Apr. } 2_{0} \\
\text { Sept. } 3 .\end{array}$ & $\begin{array}{l}1962 \\
1962\end{array}$ & $\begin{array}{l}17.04 \\
13.52\end{array}$ & $\begin{array}{l}30.000 \\
21.600\end{array}$ \\
\hline 1963 & Apr. 30. & 1963 & 5.12 & 7.530 \\
\hline 1964 & Aug. & 1564 & 6.18 & 8,980 \\
\hline
\end{tabular}

a Afected by ice.

b About. 
05-4813.00 Des Moines River near Stratford, Iowa-- (Continued)

Peak_stages_and_discharges

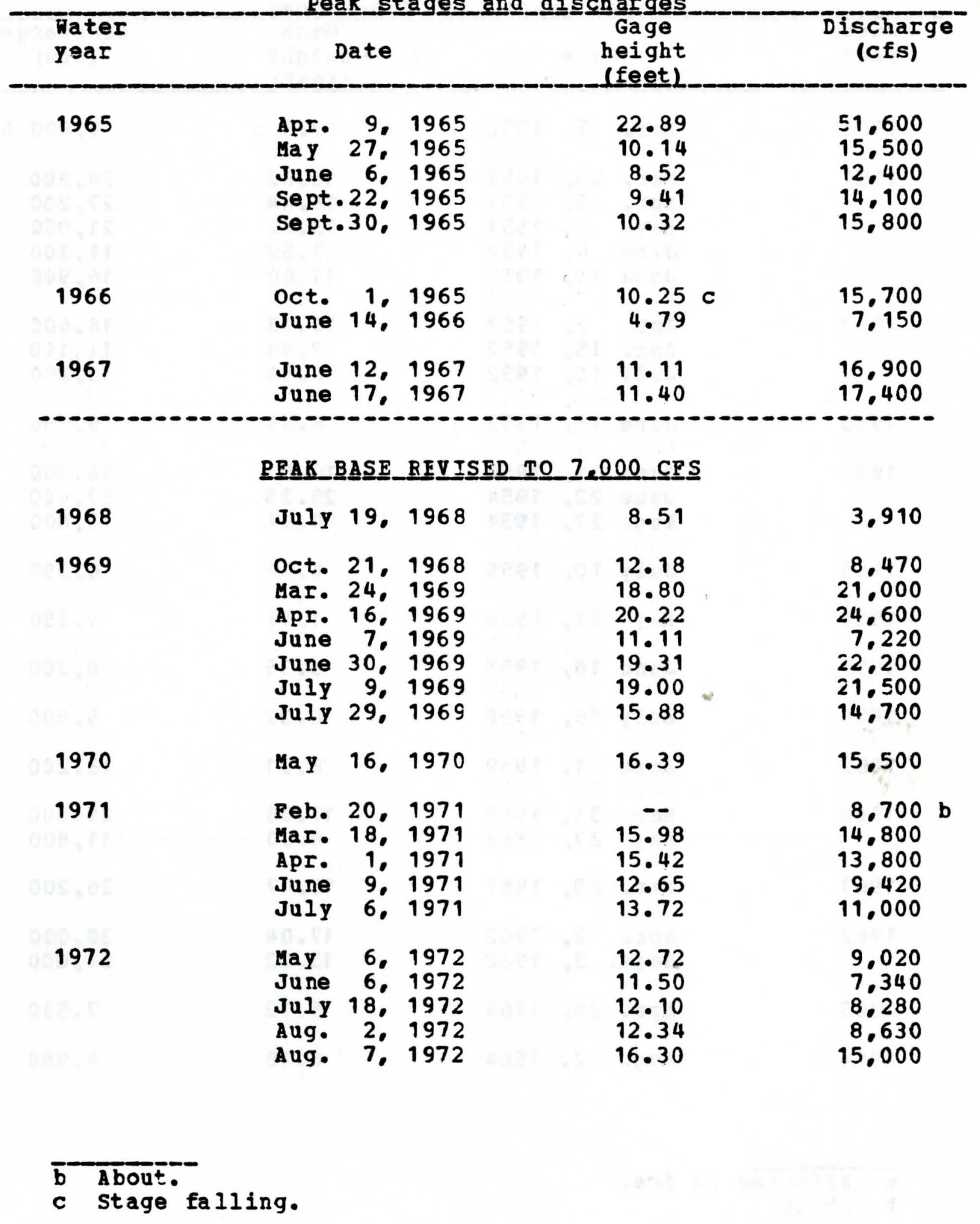


05-4813.00 Des Moines River near Stratford, Iowa--(Continued)

Peak stages and dis scharges

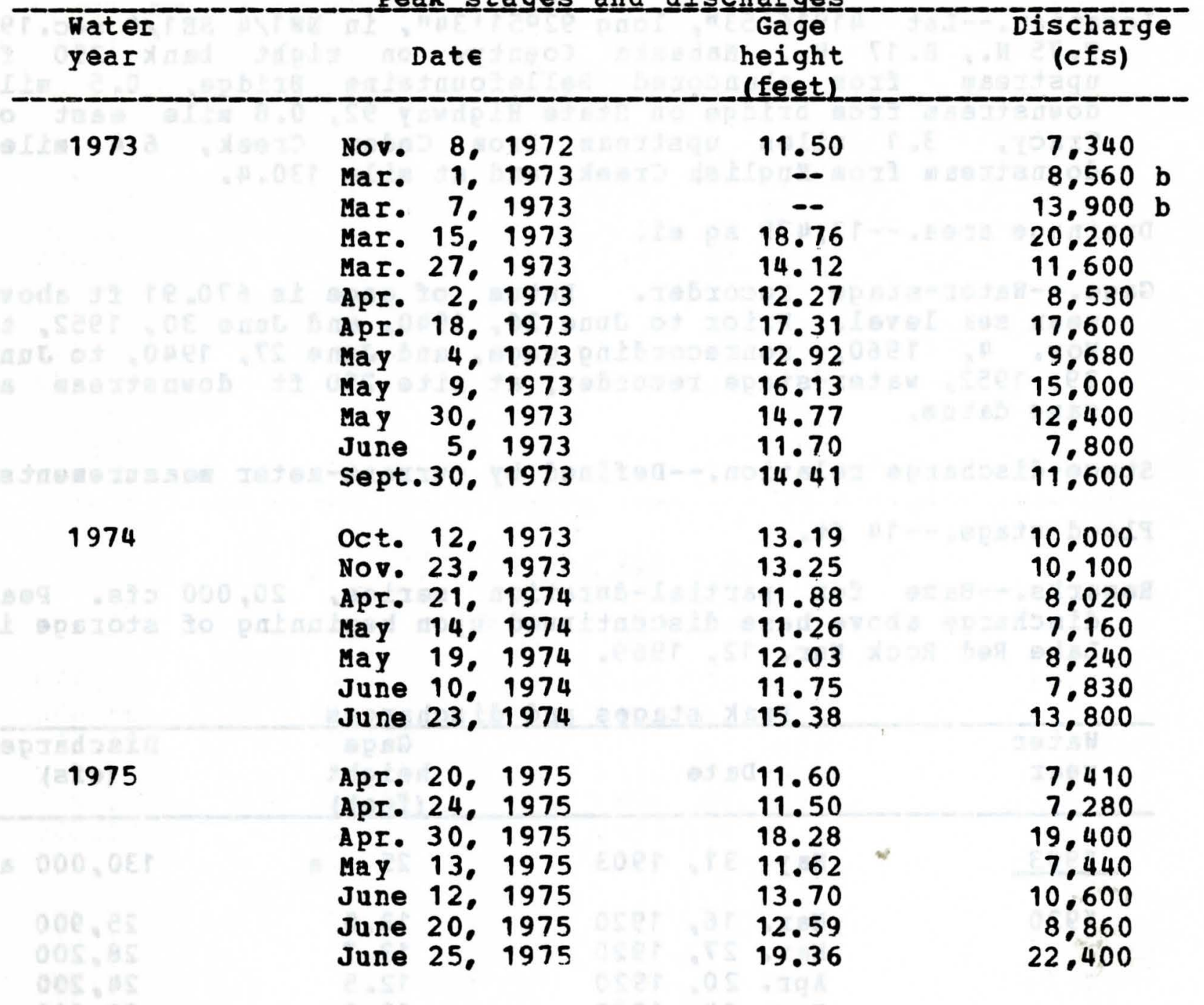

b about. 
Location.--Iat $41016 \cdot 53^{\prime \prime}$, long $92051 \cdot 34^{\prime \prime}$, in NN1/4 SE1/4 sec.19, T.75 N.. R. 17 N.. Mahaska County. on right bank 250 ft upstream from abandoned Bellefountaine Bridge, 0.5 mile downstream frcm bridge on State Highway 92, 0.8 mile east of Tracy. 3. 1 miles upstream from Cedar Creek, 6.4 miles downstrea from English Creek, and at mile 130.4 .

Drainage area. $--12,479 \mathrm{sq}$ mi.

Gage.-- Nater-stage recorder. Datum of gage is $670.91 \mathrm{ft}$ above mean sea level. Prior to June 26, 1940, and June 30,1952, to Nov. 4, 1960, nonrecording gage, and June 27, 1940, to June 29. 1952. water-stage reccrder, at site $250 \mathrm{ft}$ downstream at same datum.

Stage-discharge relation.--Defined by current-meter measurements. Flood stage. - - $14 \mathrm{ft}$.

Remarks.--Base for partial-duration series, 20,000 cfs. Peak discharge above base disccntinued upon beginning of storage in Lake Red Rock Mar. 12, 1969.

Peak stages and discharges

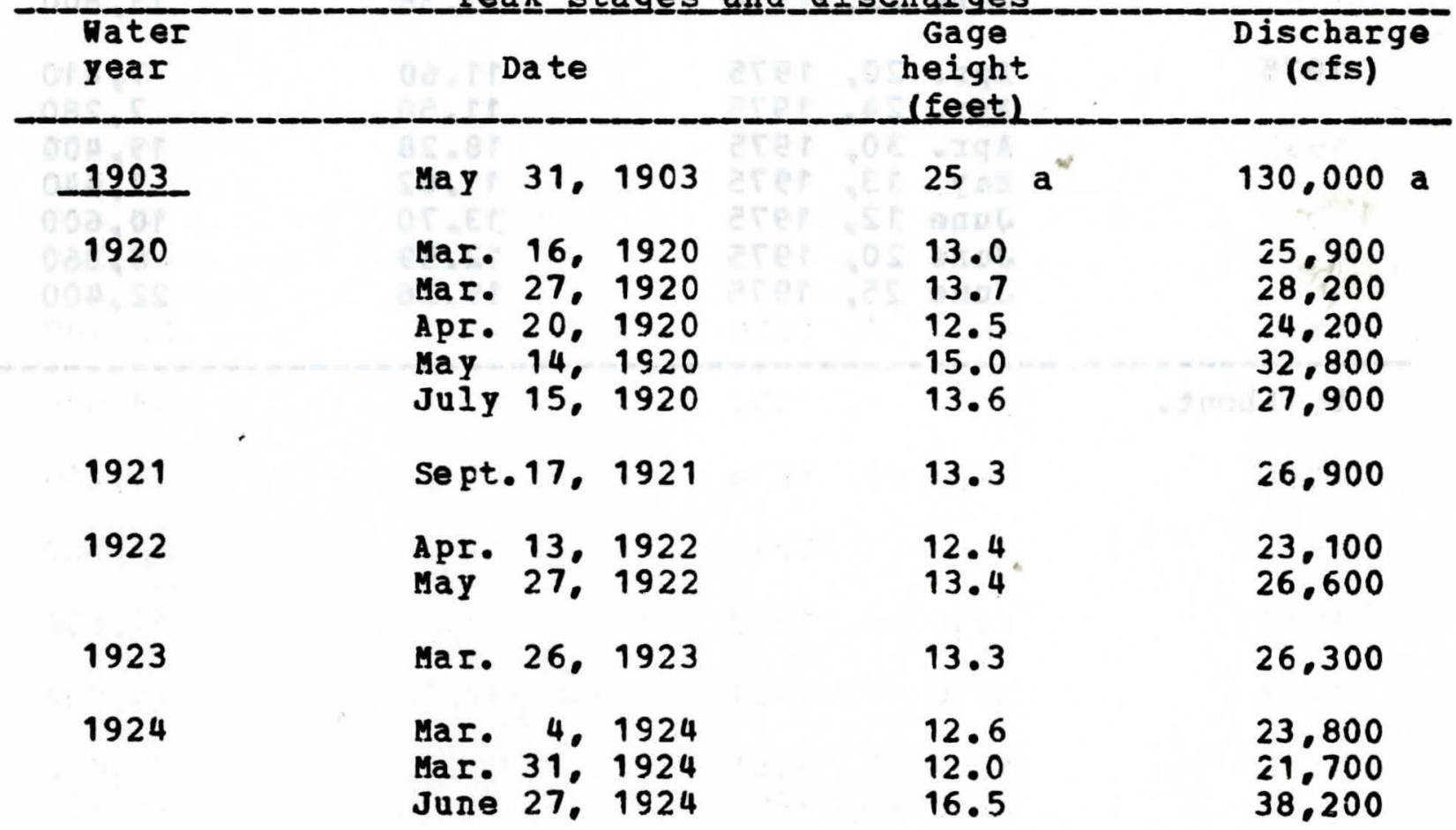

a About. 
05-4885.00 Des Moines River near Tracy. Iowa--(Continued)

Peak stages and discharges

\begin{tabular}{|c|c|c|c|c|c|c|c|}
\hline $\begin{array}{l}\text { Dater } \\
\text { year }\end{array}$ & & Date & & & $\begin{array}{l}\text { Gage } \\
\text { height } \\
\text { (feet) }\end{array}$ & & $\begin{array}{c}\text { Discharge } \\
\text { (cfs) }\end{array}$ \\
\hline 1925 & June & 23 & 1925 & & 8.7 & & 11.500 \\
\hline 1926 & $\begin{array}{l}\text { June } \\
\text { Sept. }\end{array}$ & $\begin{array}{l}15 . \\
24 .\end{array}$ & $\begin{array}{l}1926 \\
1926\end{array}$ & & $\begin{array}{l}13 \cdot 0 \\
16.3\end{array}$ & & $\begin{array}{l}25,200 \\
37,500\end{array}$ \\
\hline 1927 & $\begin{array}{l}\text { ApI. } \\
\text { ApI. } \\
\text { Hay }\end{array}$ & $\begin{array}{l}20 . \\
30 . \\
24 .\end{array}$ & $\begin{array}{l}1927 \\
1927 \\
1927\end{array}$ & & $\begin{array}{r}15.8 \\
11.7 \\
11.9\end{array}$ & & $\begin{array}{l}35,500 \\
20.700 \\
21.400\end{array}$ \\
\hline 1.928 & Aug. & 4. & 1928 & & 11.4 & & 19.700 \\
\hline 1929 & MaI. & 16 & 1929 & & 18.6 & & 45.500 \\
\hline 1930 & June & 17. & 1930 & & 16.4 & & 33.500 \\
\hline 1931 & June & 22 & 1931 & & 9.0 & & 11.800 \\
\hline 1932 & Nov. & 26. & 1931 & & 16.5 & & 34,000 \\
\hline 1933 & Apr. & 7. & 1933 & & 16.7 & & 35.000 \\
\hline 1934 & Apr. & 9. & 1934 & & 5.5 & & 4.950 \\
\hline 1935 & $\begin{array}{l}\text { June } \\
\text { June } \\
\text { June } \\
\text { July }\end{array}$ & $\begin{array}{l}3 . \\
20 \\
28 \\
4 \%\end{array}$ & $\begin{array}{l}1935 \\
1935 \\
1935 \\
1935\end{array}$ & & $\begin{array}{l}15.4 \\
15.7 \\
20.2 \\
18.6\end{array}$ & 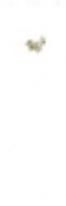 & $\begin{array}{l}26,900 \\
28,000 \\
54.600 \\
43.300\end{array}$ \\
\hline 1936 & MaI. & 5. & 1936 & & 14.2 & & 23,100 \\
\hline 1937 & MaI. & 5. & 1937 & & 17.9 & & 38.900 \\
\hline 1938 & sept. & 23 & 1938 & & 15.2 & & 26.200 \\
\hline 1939 & Mar. & 13. & 1939 & & 17.5 & & 36.600 \\
\hline 1940 & Aug. & 15. & 1940 & & 9.3 & & 11.600 \\
\hline 1941 & June & 11. & 1941 & & 13.8 & & 21.500 \\
\hline 1942 & $\begin{array}{l}\text { Nov. } \\
\text { Jan. } \\
\text { May } \\
\text { JuIy } \\
\text { July }\end{array}$ & $\begin{array}{l}20^{\circ} \\
26 \circ \\
14 \circ \\
15 \circ \\
20 .\end{array}$ & $\begin{array}{l}1941 \\
1942 \\
1942 \\
1942 \\
1942\end{array}$ & & $\begin{array}{l}15.7 \\
13.4 \\
14.4 \\
13.2 \\
13.2\end{array}$ & & $\begin{array}{l}28.000 \\
20.900 \\
23.700 \\
20.400 \\
20.400\end{array}$ \\
\hline
\end{tabular}


05-4885.00 Des Moines River near Tracy. Iowa--(Continued)

Peak stages and discharges

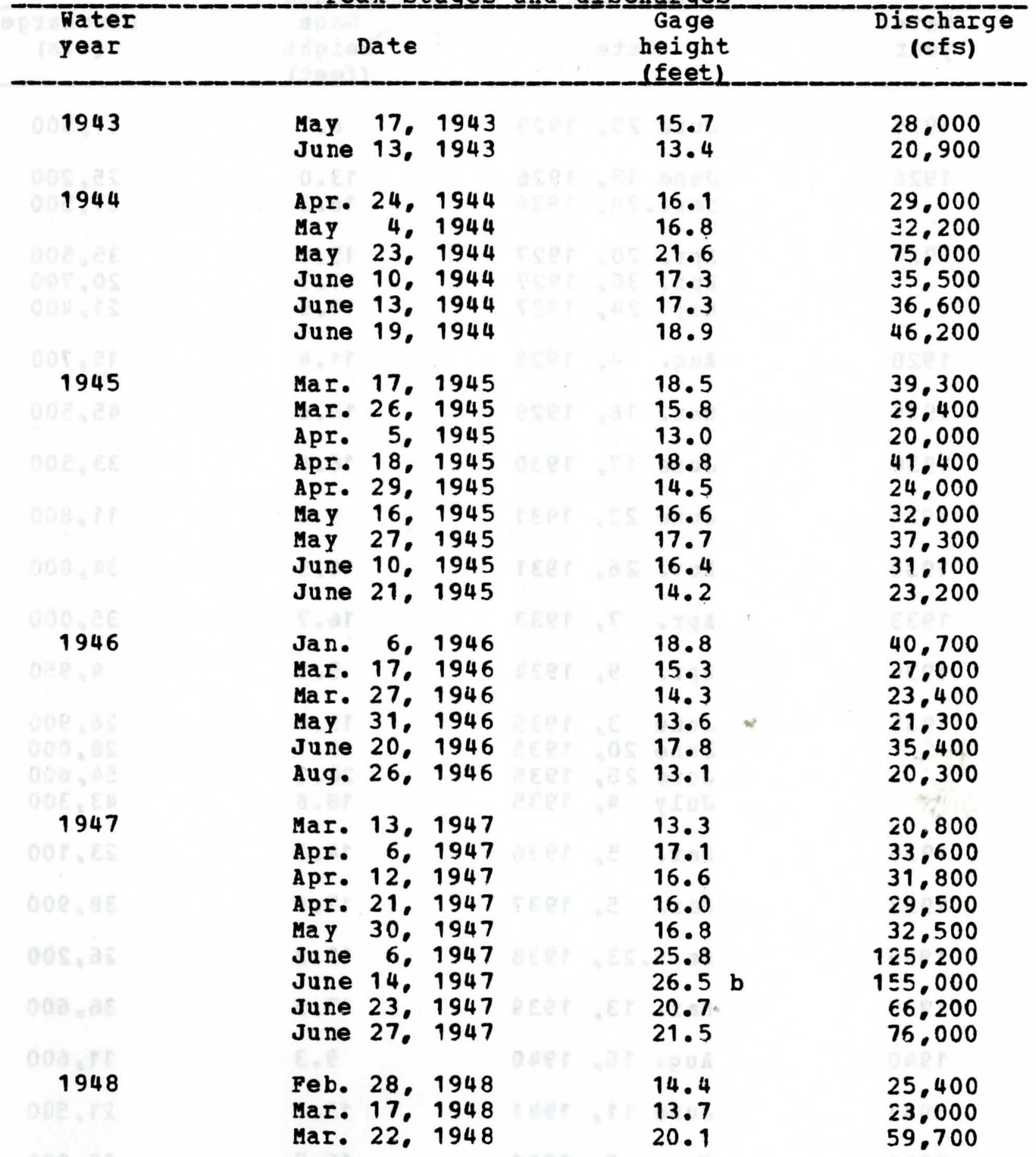

$\bar{b}$ Maximūim stage known since 1851 . 
05-4885.00 Des Moines River near Tracy, Iowa--(Continued)

Feak_stages_and_discharges

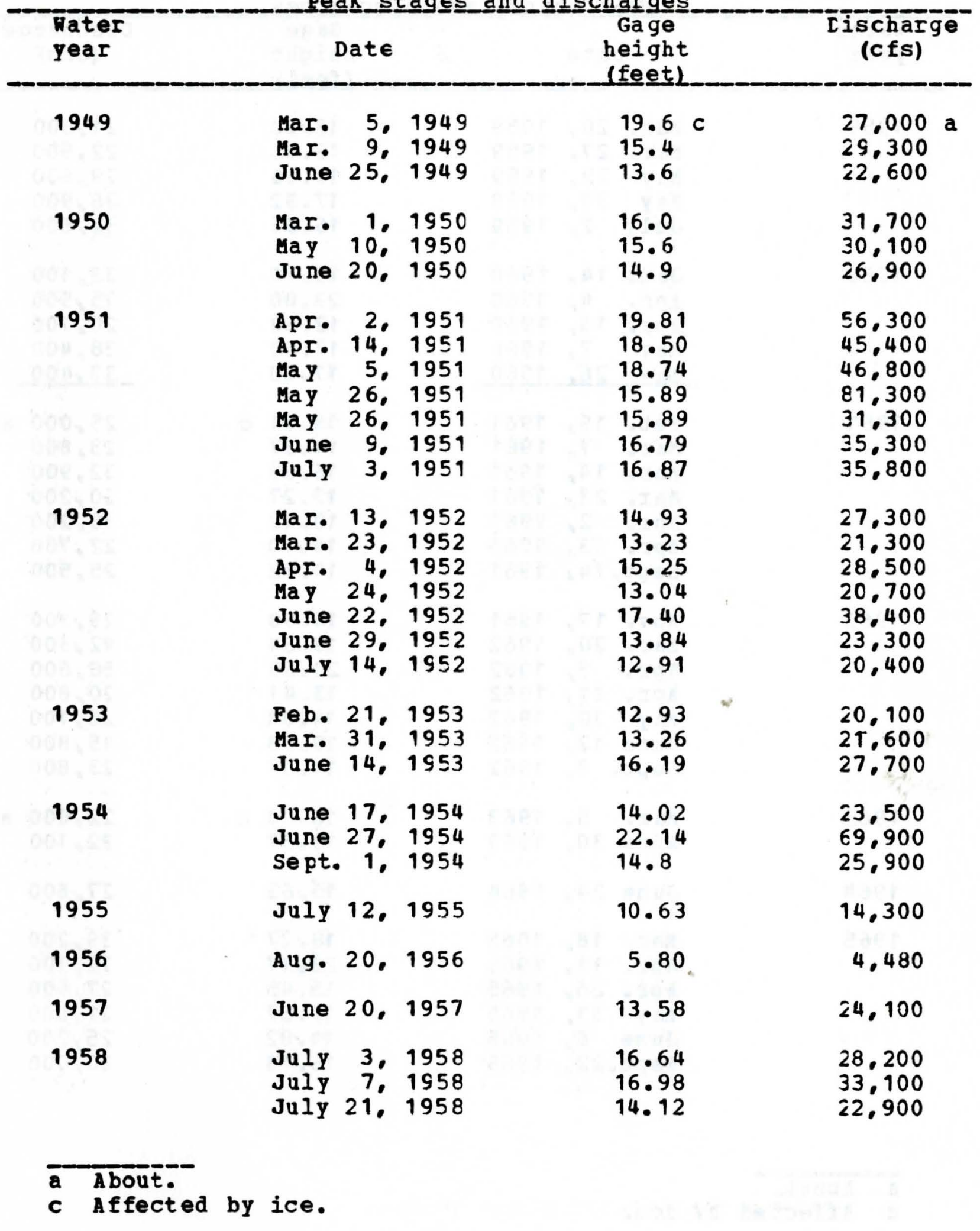


05-4885.00 Des Moines River near Tracy. Iowa--(Continued)

Peak_stages and discharges

\begin{tabular}{|c|c|c|c|c|c|}
\hline $\begin{array}{l}\text { Mater } \\
\text { year }\end{array}$ & Date & & $\begin{array}{l}\text { Gage } \\
\text { height } \\
\text { (feet) }\end{array}$ & & $\begin{array}{c}\text { Discharg } \\
\text { (cfs) }\end{array}$ \\
\hline 1959 & $\begin{array}{ll}\operatorname{Mar} & 20 . \\
\operatorname{Mar} . & 27^{\circ} \\
\operatorname{May} & 22^{\circ} \\
\operatorname{May} & 31 . \\
\mathrm{JuIy} & 2 .\end{array}$ & $\begin{array}{l}1959 \\
1959 \\
1959 \\
1959 \\
1959\end{array}$ & $\begin{array}{l}13.20 \\
13.85 \\
17.00 \\
17.92 \\
16.65\end{array}$ & & $\begin{array}{l}21.300 \\
22.900 \\
29.600 \\
38.900 \\
32.600\end{array}$ \\
\hline 1960 & $\begin{array}{l}\text { Jan. } 14, \\
\text { ApI. } 4{ }^{\circ} \\
\text { Apr. } 18^{\circ} \\
\text { May } 7 . \\
\text { ay_26. }\end{array}$ & $\begin{array}{l}1960 \\
1960 \\
1960 \\
1960 \\
1960 \\
\end{array}$ & $\begin{array}{l}16.70 \\
23.00 \\
12.50 \\
17.80 \\
17.60\end{array}$ & & $\begin{array}{r}33.100 \\
75.500 \\
20.700 \\
38.400 \\
-37.400 \\
\end{array}$ \\
\hline 1961 & $\begin{array}{l}\text { Feb. } 19 . \\
\text { Mar. } 70^{\circ} \\
\text { Mar. 14, } \\
\text { Mar. } 23^{\circ} \\
\text { Apr. } 20^{\circ} \\
\text { Apr. 13. } \\
\text { Sept. } 14^{\circ}\end{array}$ & $\begin{array}{l}1961 \\
1961 \\
1961 \\
1961 \\
1961 \\
1961 \\
1961\end{array}$ & $\begin{array}{l}15.81 \\
14.37 \\
16.89 \\
13.27 \\
18.12 \\
14.10 \\
14.92\end{array}$ & c & $\begin{array}{l}25.000 \\
23.800 \\
32.900 \\
20.200 \\
38.200 \\
22.700 \\
25.500\end{array}$ \\
\hline 1962 & $\begin{array}{l}\text { Nov. } 17 . \\
\text { Mar. } 20, \\
\text { Apr. } 5, \\
\text { Apr. } 21 . \\
\text { May } 30, \\
\text { June 12. } \\
\text { Sept. } 8 .\end{array}$ & $\begin{array}{l}1961 \\
1962 \\
1962 \\
1962 \\
1962 \\
1962 \\
1962\end{array}$ & $\begin{array}{l}16.98 \\
19.34 \\
20.69 \\
13.47 \\
14.81 \\
19.68 \\
14.07\end{array}$ & $w$ & $\begin{array}{l}29.300 \\
42.300 \\
50.600 \\
20.800 \\
25.100 \\
45.800 \\
23.800\end{array}$ \\
\hline 1963 & $\begin{array}{l}\text { Mar. } 5 . \\
\text { Apr. } 30 .\end{array}$ & $\begin{array}{l}1963 \\
1963\end{array}$ & $\begin{array}{l}16.00 \\
13.87\end{array}$ & c & $\begin{array}{l}22,000 \\
22.100\end{array}$ \\
\hline 1964 & June 24 & 1964 & 15.63 & & 27,600 \\
\hline 1965 & $\begin{array}{l}\text { Mar. } 18 . \\
\text { Apr. } 11 . \\
\text { Apr. } 26 . \\
\text { May } 31 . \\
\text { June } 6 . \\
\text { Sept. } 22^{\circ}\end{array}$ & $\begin{array}{l}1965 \\
1965 \\
1965 \\
1965 \\
1965 \\
1965\end{array}$ & $\begin{array}{l}18.27 \\
23.17 \\
15.45 \\
13.57 \\
14.82 \\
16.18\end{array}$ & & $\begin{array}{l}39.200 \\
77.300 \\
27.400 \\
21.000 \\
25.200 \\
30.000\end{array}$ \\
\hline
\end{tabular}

about.
c Affected by ice. 
05-4885.00 Des Hoines River near Tracy. Iowa--(Continued)

Peak_stages_and_di

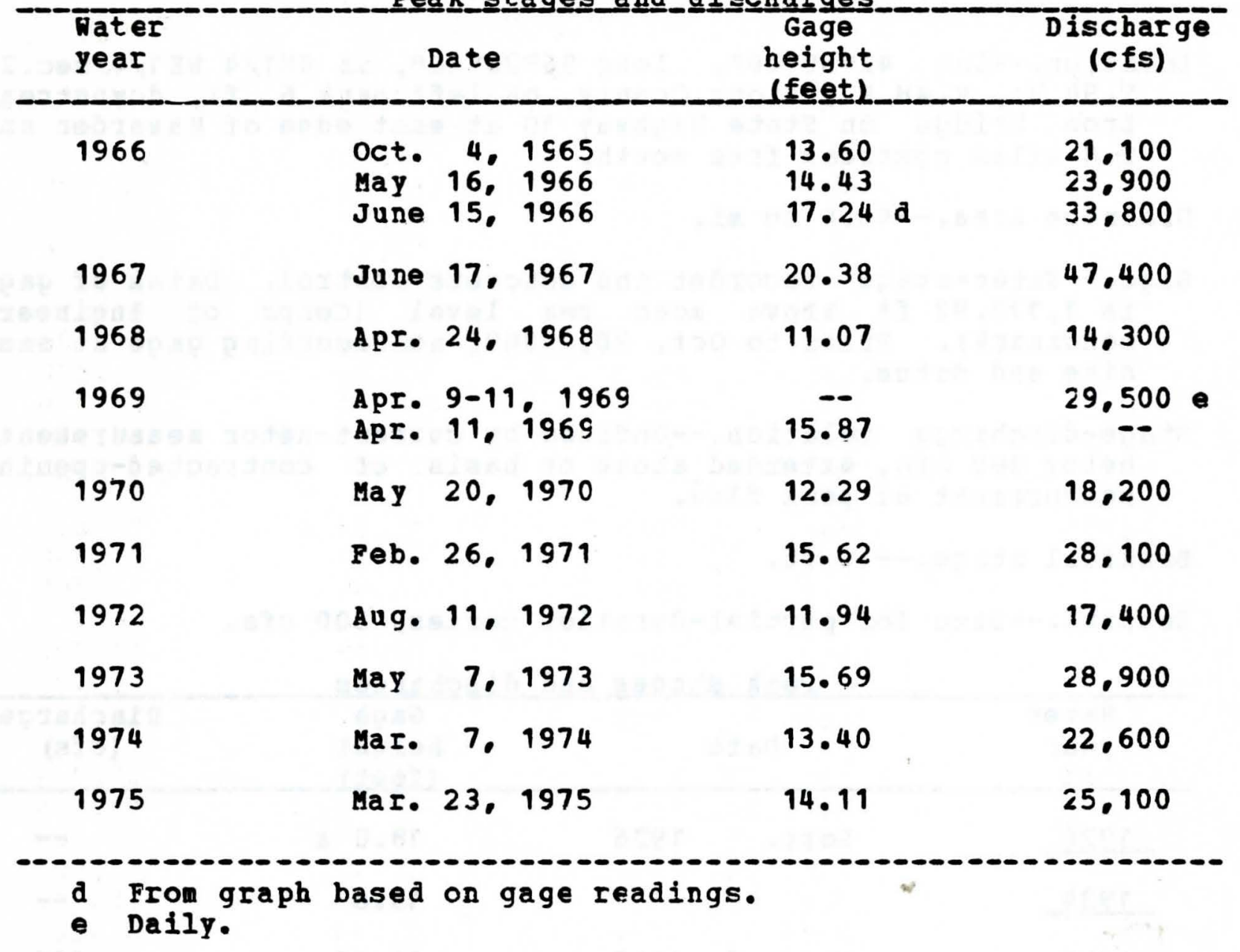




\section{6-4840.00 Dry Creek at Hawarden, Iowa (Discontinued september 1969)}

Location.--Lat $42059 \cdot 48^{\prime \prime}$, long $96028 \cdot 10^{\prime \prime}$, in NE1/4 NE1/4 sec.2. T. 94 N.. R.48 H.. Sioux County. on left bank 6 ft downstream from bridge on state Highway 10 at east edge of Hawarden and 2.0 miles upstream frcm mouth.

Drainage area.--48.4 sq mi.

Gage.-- Water-stage recorder and concrete control. Datum of gage is $1.170 .42 \mathrm{ft}$ above mean sea level (Corps of Engineers benchmark). Prior to oct. 30, 1949, nonrecording gage at sane site and datum.

Stage-discharge relation.--Defined by current-meter measurements below 860 cfs, extended above or basis of contracted-opening measurement of peak flow.

Bankfull stage.--10 ft.

Remarks.--Base for partial-duration series, 300 cfs.

Peak_stages_and_di scharges

\begin{tabular}{|c|c|c|c|c|}
\hline $\begin{array}{l}\text { Pater } \\
\text { year }\end{array}$ & \multicolumn{2}{|c|}{ Date } & $\begin{array}{l}\text { Gage } \\
\text { height } \\
\text { (feet) }\end{array}$ & $\begin{array}{c}\text { Discharge } \\
\text { (cfs) }\end{array}$ \\
\hline 1926 & Se pt. & 1926 & 18.0 a & $-\infty$ \\
\hline 1934 & \multicolumn{2}{|c|}{--} & 15.8 & - \\
\hline 1949 & Mar. & 1949 & 13.10 & 686 \\
\hline 1950 & Mar. & 1950 & $13.5 \mathrm{~b}$ & $500 \mathrm{C}$ \\
\hline 1951 & $\begin{array}{l}\text { Mar. } \\
\text { Mar. } \\
\text { Apr. } \\
\text { June } \\
\text { July }\end{array}$ & $\begin{array}{l}1951 \\
1951 \\
1951 \\
1951 \\
1951\end{array}$ & $\begin{array}{r}13.83 \\
13.29 \\
9.92 \\
11.41 \\
13.28\end{array}$ & $\begin{array}{c}950 \\
b \\
319 \\
509 \\
850\end{array}$ \\
\hline 1952 & $\begin{array}{l}\text { Mar. } \\
\text { Mar. } \\
\text { JuIy } \\
\text { Aug. }\end{array}$ & $\begin{array}{l}1952 \\
1952 \\
1952 \\
1952\end{array}$ & $\begin{array}{l}11.0 \\
14.14 \\
12.59 \\
11.74\end{array}$ & $\begin{array}{r}451 \\
1.020 \\
714 \\
556\end{array}$ \\
\hline
\end{tabular}

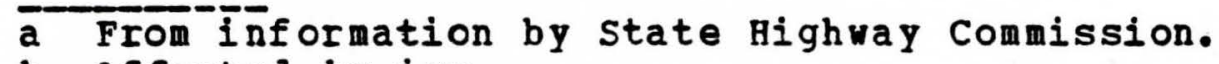

b Affected by ice.

c About. 
06-4840.00 Dry Creek at Hawarden. Iowa--(Continued)

Feak_stages_and_discharges

\begin{tabular}{|c|c|c|c|c|c|c|c|}
\hline $\begin{array}{l}\text { Mater } \\
\text { year }\end{array}$ & I & Date & & & $\begin{array}{c}\text { Gage } \\
\text { height } \\
\text { (feet) }\end{array}$ & & $\begin{array}{c}\text { Discharge } \\
\text { (cfs) }\end{array}$ \\
\hline 1953 & June & 7. & 1953 & & 17.57 & & 10,900 \\
\hline 1954 & $\begin{array}{l}\text { Mar. } \\
\text { June } \\
\text { June }\end{array}$ & $\begin{array}{l}16 . \\
10 \\
19\end{array}$ & $\begin{array}{l}1954 \\
1954 \\
1954\end{array}$ & & $\begin{array}{l}11.24 \\
11.76 \\
12.14\end{array}$ & & $\begin{array}{l}479 \\
566 \\
630\end{array}$ \\
\hline 1955 & $\begin{array}{l}\operatorname{Mar.} \\
\operatorname{Mar} .\end{array}$ & $\begin{array}{l}2 . \\
9 .\end{array}$ & $\begin{array}{l}1955 \\
1955\end{array}$ & & $\begin{array}{l}8.68 \\
6.96\end{array}$ & b & 81 \\
\hline 1956 & July & 31. & 1956 & & 8.09 & & 152 \\
\hline 1957 & July & 4. & 1957 & & 12.00 & & 606 \\
\hline 1958 & Apr. & 6. & 1958 & & 5.92 & & 17 \\
\hline 1959 & $\begin{array}{l}\text { May } \\
\text { May }\end{array}$ & $\begin{array}{l}28 . \\
31 .\end{array}$ & $\begin{array}{l}1959 \\
1959\end{array}$ & & $\begin{array}{l}11.18 \\
14.75\end{array}$ & & $\begin{array}{r}376 \\
1.000\end{array}$ \\
\hline 1960 & $\begin{array}{l}\text { Mar. } \\
\text { Apr. } \\
\text { Apr. }\end{array}$ & $\begin{array}{r}28 \\
2 \\
12\end{array}$ & $\begin{array}{l}1960 \\
1960 \\
1960\end{array}$ & & $\begin{array}{l}15.10 \\
15.36 \\
10.32\end{array}$ & & $\begin{array}{r}2.430 \\
3.000 \\
388\end{array}$ \\
\hline 1961 & $\begin{array}{l}\text { Feb. } \\
\text { Mar. }\end{array}$ & $\begin{array}{l}23 . \\
14 .\end{array}$ & $\begin{array}{l}1961 \\
1961\end{array}$ & & $\begin{array}{l}13.04 \\
10.66\end{array}$ & $\mathbf{b}$ & $\begin{array}{l}500 \mathrm{C} \\
425\end{array}$ \\
\hline 1962 & $\begin{array}{l}\text { Mar. } \\
\text { June } \\
\text { Aug. }\end{array}$ & $\begin{array}{l}28 . \\
17 \% \\
30\end{array}$ & $\begin{array}{l}1962 \\
1962 \\
1962\end{array}$ & & $\begin{array}{r}15.88 \\
11.33 \\
9.07\end{array}$ & $w$ & $\begin{array}{r}2.330 \\
730 \\
360\end{array}$ \\
\hline 1963 & $\begin{array}{l}\text { Feb. } \\
\text { July }\end{array}$ & 7. & $\begin{array}{l}1963 \\
1963\end{array}$ & & $\begin{array}{l}6.83 \\
6.77\end{array}$ & $\mathbf{b}$ & 150 \\
\hline 1964 & May & 24 & 1964 & & 6.99 & & 217 \\
\hline 1965 & $\begin{array}{l}\text { Apr. } \\
\text { Apr. } \\
\text { June } \\
\text { June }\end{array}$ & $\begin{array}{r}1 . \\
6 \% \\
12 \% \\
29\end{array}$ & $\begin{array}{l}1965 \\
1965 \\
1965 \\
1965\end{array}$ & & $\begin{array}{l}8.80 \\
8.94 \\
7.58 \\
7.92\end{array}$ & & $\begin{array}{r}1.760 \\
2.000 \\
542 \\
810\end{array}$ \\
\hline 1966 & Fet. & 9. & 1966 & & 9.67 & $\mathbf{b}$ & $2.000 \mathrm{c}$ \\
\hline
\end{tabular}

b Affectéd by ice.

c About. 
06-4840.00 DIy Creek at Hawarden, Iowa--(Continued)

Peak_stages_and_discharges

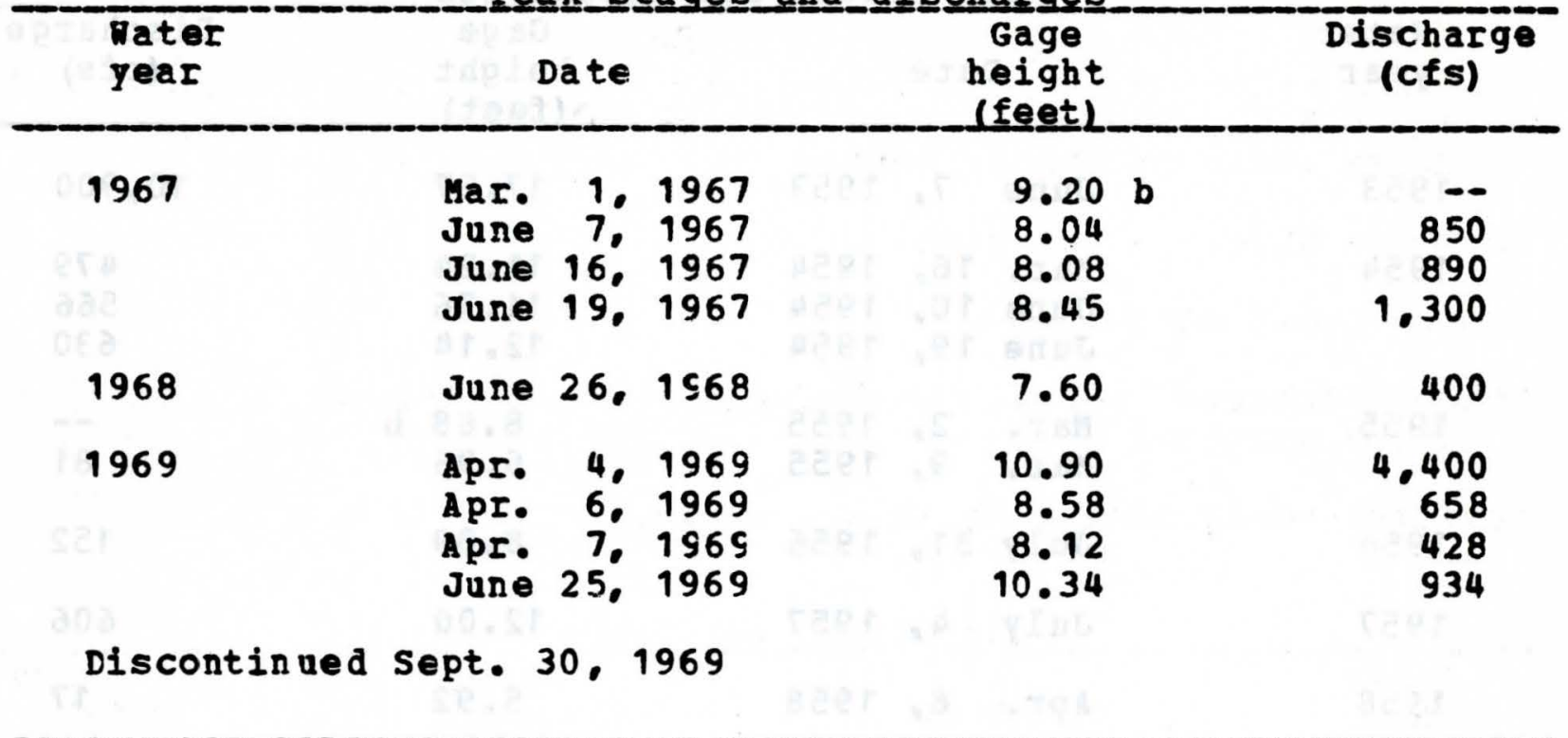

b Affected by ice. 


\section{5-4643.18 East Blue Creek at Center Point, Iowa}

Location.--Iat $42012 \cdot 44 n$, long $91047 \cdot 21 "$, in SN1/4 sec.33, T. 86

N. R.8 H.. Iinn County, at bridge on state Highway 150. 1.5 miles north of Center point.

Drainage area.--17.6 sq mi.

Gage.--Crest-stage gage.

Stage-discharge relation.--Defined by current-neter and indirect measurements.

Remarks.--only annual peaks are shown.

Eeak﹎stages_and_di schargegs

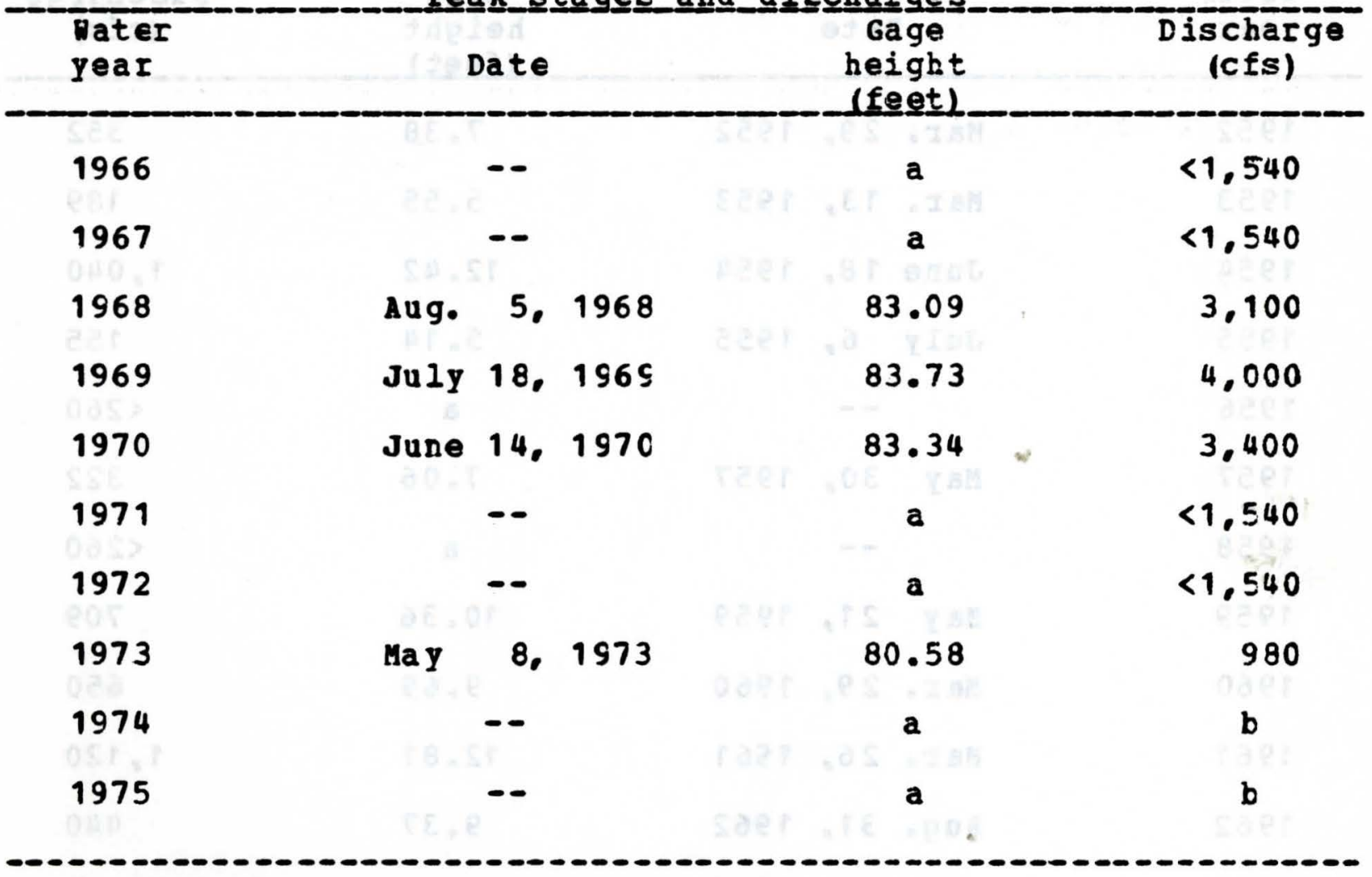

a Peak stage did not reach bottom of gage.

b Discharge not determined. 
05-4488.00 East Branch Iowa River near Garner. Iowa

Location.--Lat $43006 \%$ long $93037^{\circ}$, near center sec. 25, T.96 N.. R. 24 \%.. Hancock County. at bridge on U.S. Highway 18, 1.2, miles west of Garner.

Drainage area.- $-45.1 \mathrm{sq} \mathrm{mi}$

Gage.--Crest-stage gage.

stage-discharge relation.--Defined by current-meter measurements. Remarks.--Only annual peaks are shown.

Peak_stages_and_di sccharges

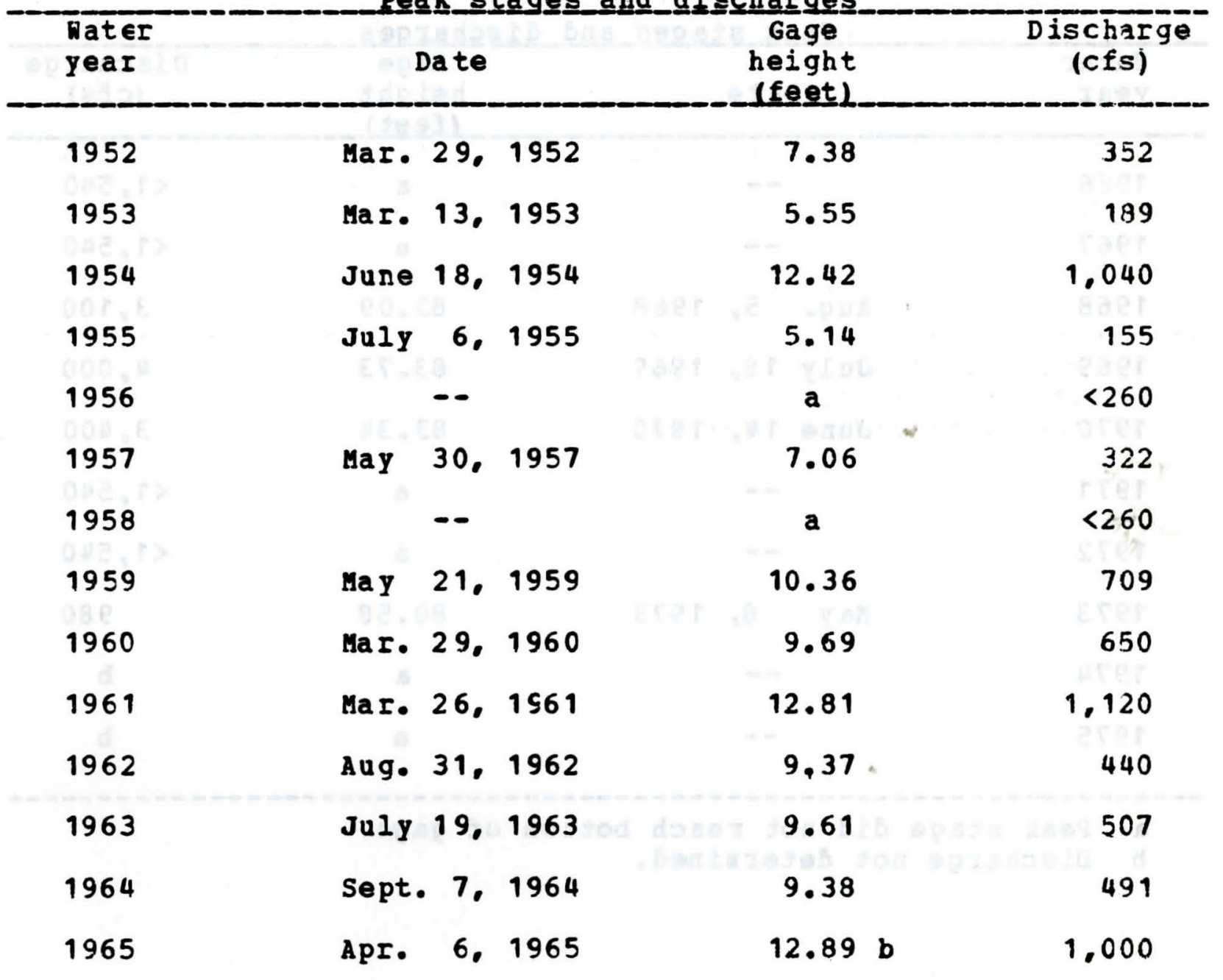

a Peak stage did not reach bottom of gage.

b Affected by ice. 
05-4488.00 East Branch Iowa River near Garner, Iowa-- (Continued)

Peak

\begin{tabular}{|c|c|c|c|c|c|}
\hline $\begin{array}{l}\text { Water } \\
\text { year }\end{array}$ & & Date & & $\begin{array}{l}\text { Gage } \\
\text { height }\end{array}$ & $\begin{array}{c}\text { Discharge } \\
\text { (cfs) }\end{array}$ \\
\hline 1966 & Feb. & s. $_{0}$ & 1966 & 9.46 & 300 \\
\hline 1967 & & - & & $\mathbf{a}$ & $<260$ \\
\hline 1968 & & -- & & a & $<260$ \\
\hline 1969 & June & 29. & 1969 & 11.67 & $\$ 50$ \\
\hline 1970 & & - & & a & $c$ \\
\hline 1971 & Mar. & 31. & 1971 & 9.93 & 330 \\
\hline 1972 & June & 9. & 1972 & 10.94 & 730 \\
\hline 1973 & MaI. & 10. & 1973 & 9.20 & 575 \\
\hline 1974 & & - & & $\mathbf{a}$ & C \\
\hline 1975 & Apr. & 28 & 1975 & $10 \cdot 12$ & 550 \\
\hline
\end{tabular}

a Peak stage did not reach bottom of gage.

b Affected by ice.

c Discharge not determined. 
05-4489.00 East Branch Iowa River tributary near Garner. Iowa Location.--Lat $43006^{\circ}$. long $93040^{\circ}$, near center sec.27, T.96 N.. R. 24 .. Hancock County. at culvert on 0.S. Highway 18. 2.1 miles west of Garner.

Drainage area. $--5.98 \mathrm{sq}$ mi.

Gage.--Crest-stage gage. Gage removed July 21,1958 and reestablished May $21,1959$.

Stage-discharge relation.--Defined by current-meter measurements. Remarks.--only annual peaks are shown.

Peak stages and discharges

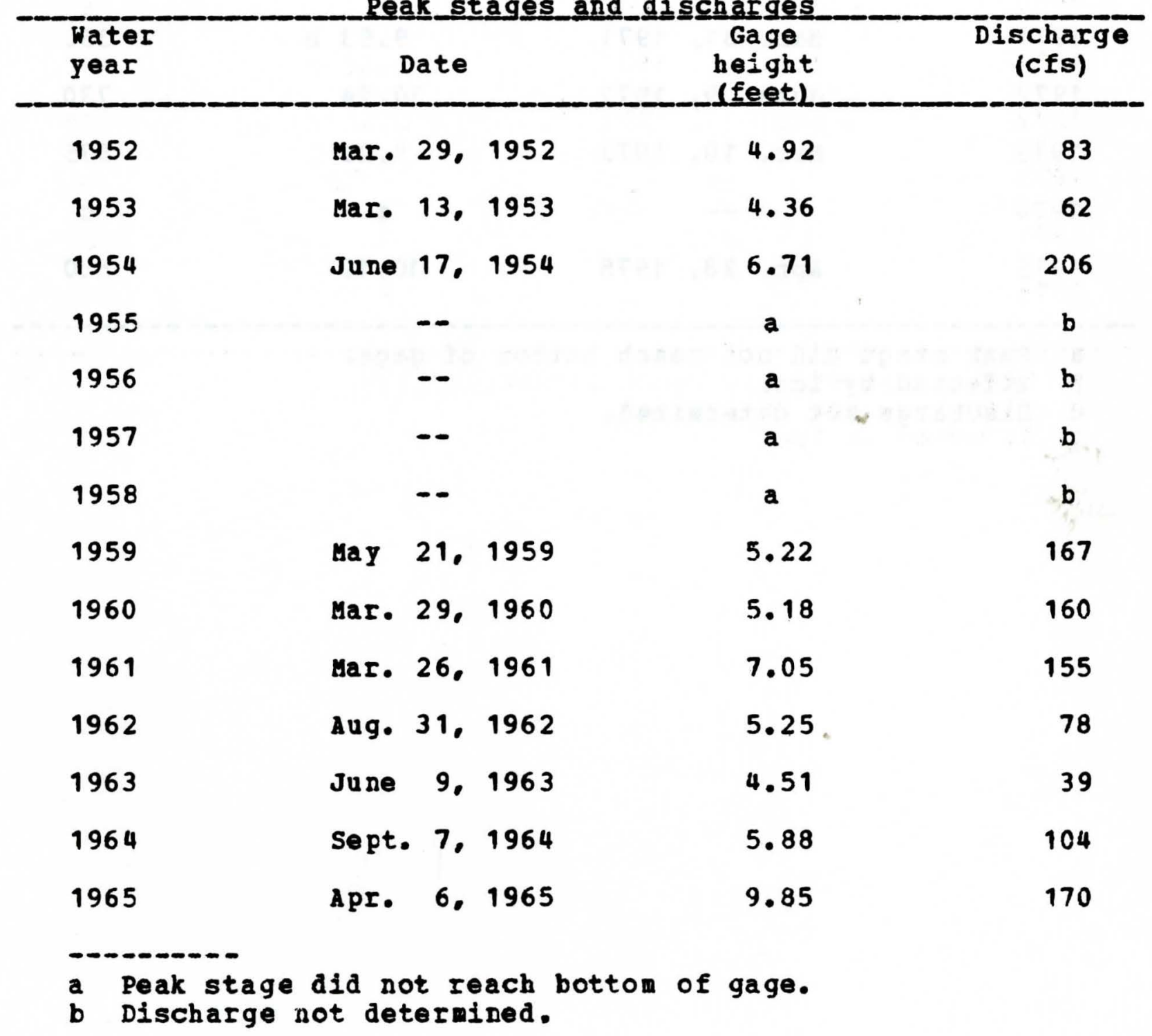


05-4489.00 East Branch Iowa River tributary near Garner, Ioxa -- (Continued)

Reak_stages and di scharges

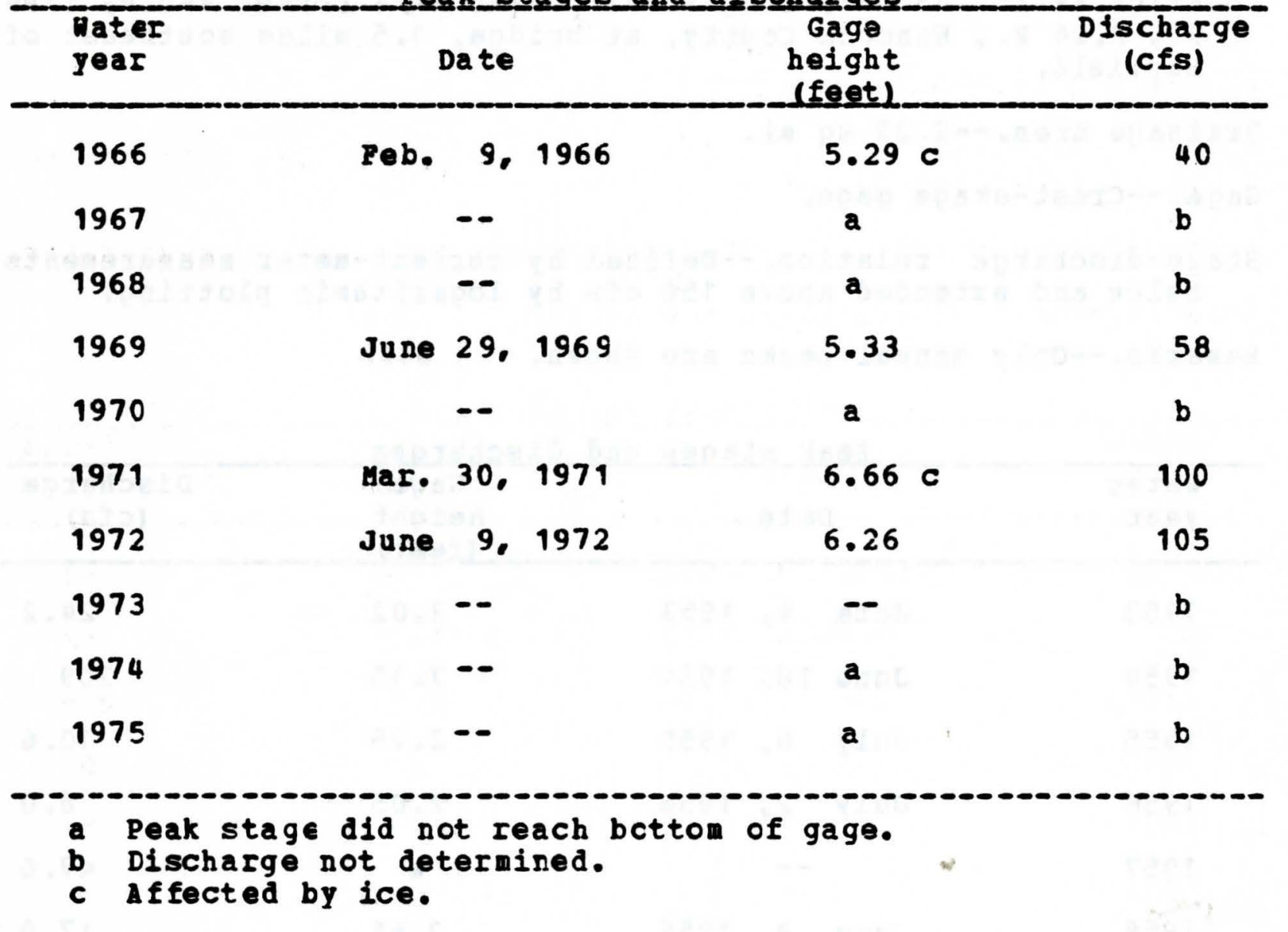


05-4486.00 East Branch Icwa River above Hayfield, Iowa

Location.--Iat $4300 \mathrm{~g}$, long 93041 , near S1/4 corner sec.4, T. 96 N.. R.24 M. Harcock County, at bridge, 1.5 miles southeast of Hayfield.

Drainage area.--2.23 sq mi.

Gage.--CIest-stage gage.

Stage-discharge relation.--Defined by current-meter measurements below and extended above 150 cfs by logarithmic plotting. Remarks.--only annual peaks are shown.

Feak_stages_and discharges

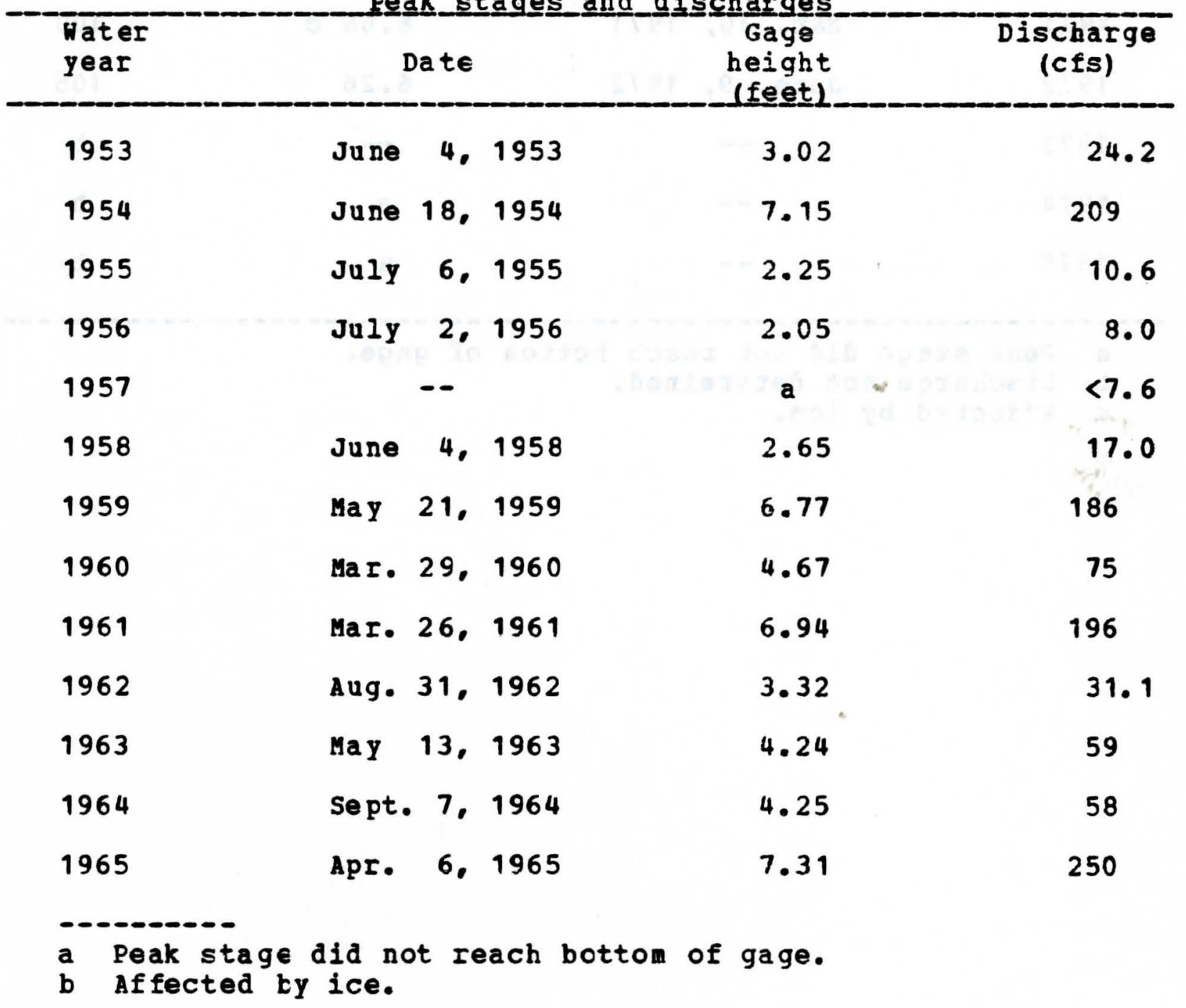


05-4486.00 East Branch Iowa River above Hayfield, Iowam (Continued)

Peak stages and di scharges

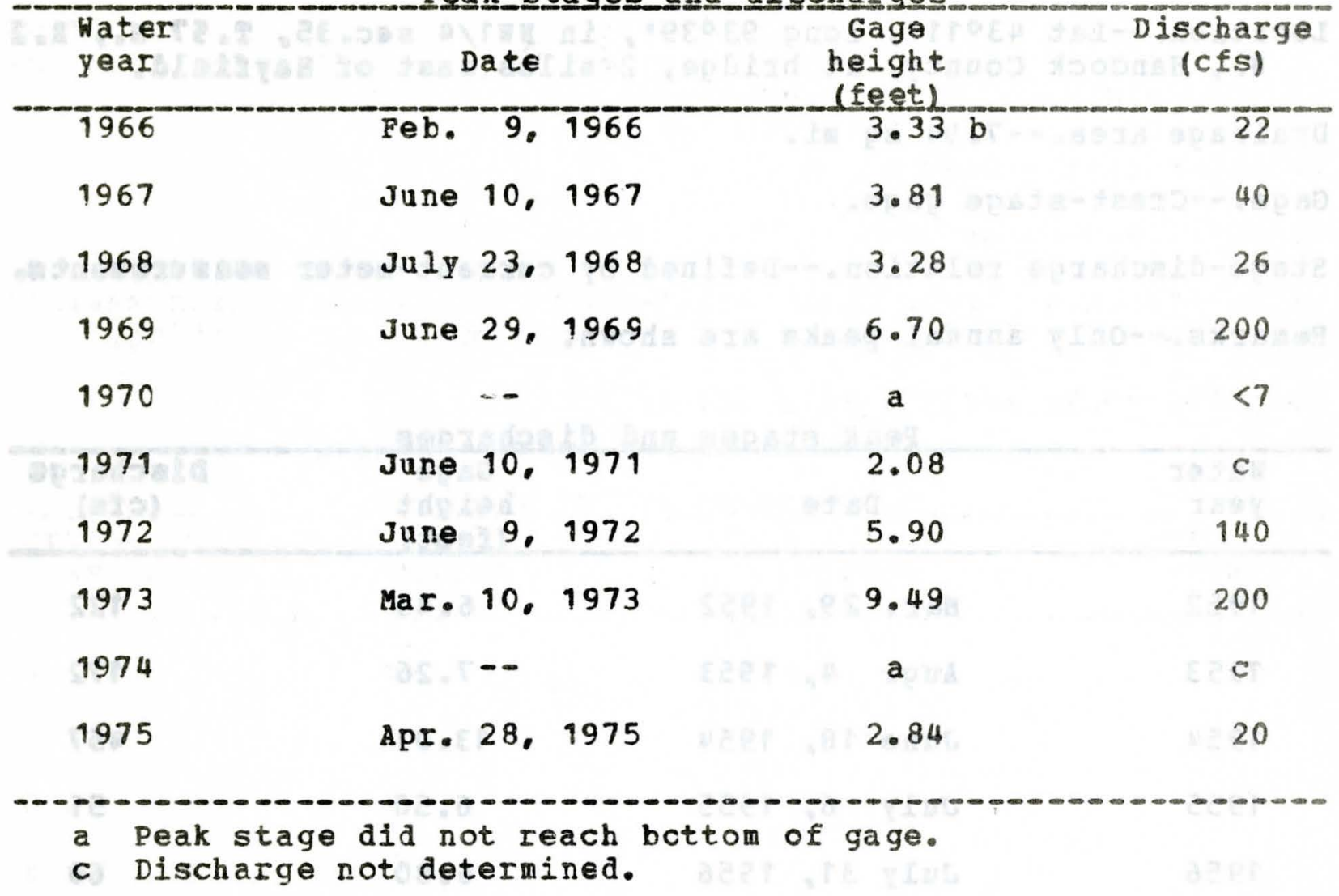


05-4487.00 East Branch Icwa River near Hayfield. Iova

Location.--Lat $43011^{\prime}$, long $930399^{\circ}$, in NH1/4 sec.35. T.57 H.. R.2

w. Hancock County, at bridge, 2 miles east of Hayeleld.

Drainage area.--7.94 sq mi.

Gage.--Crest-stage gage.

Stage-discharge relation.--Defined by current-meter neasurenentno Remarks.--Only annual peaks are shown.

Peak stages and discharges

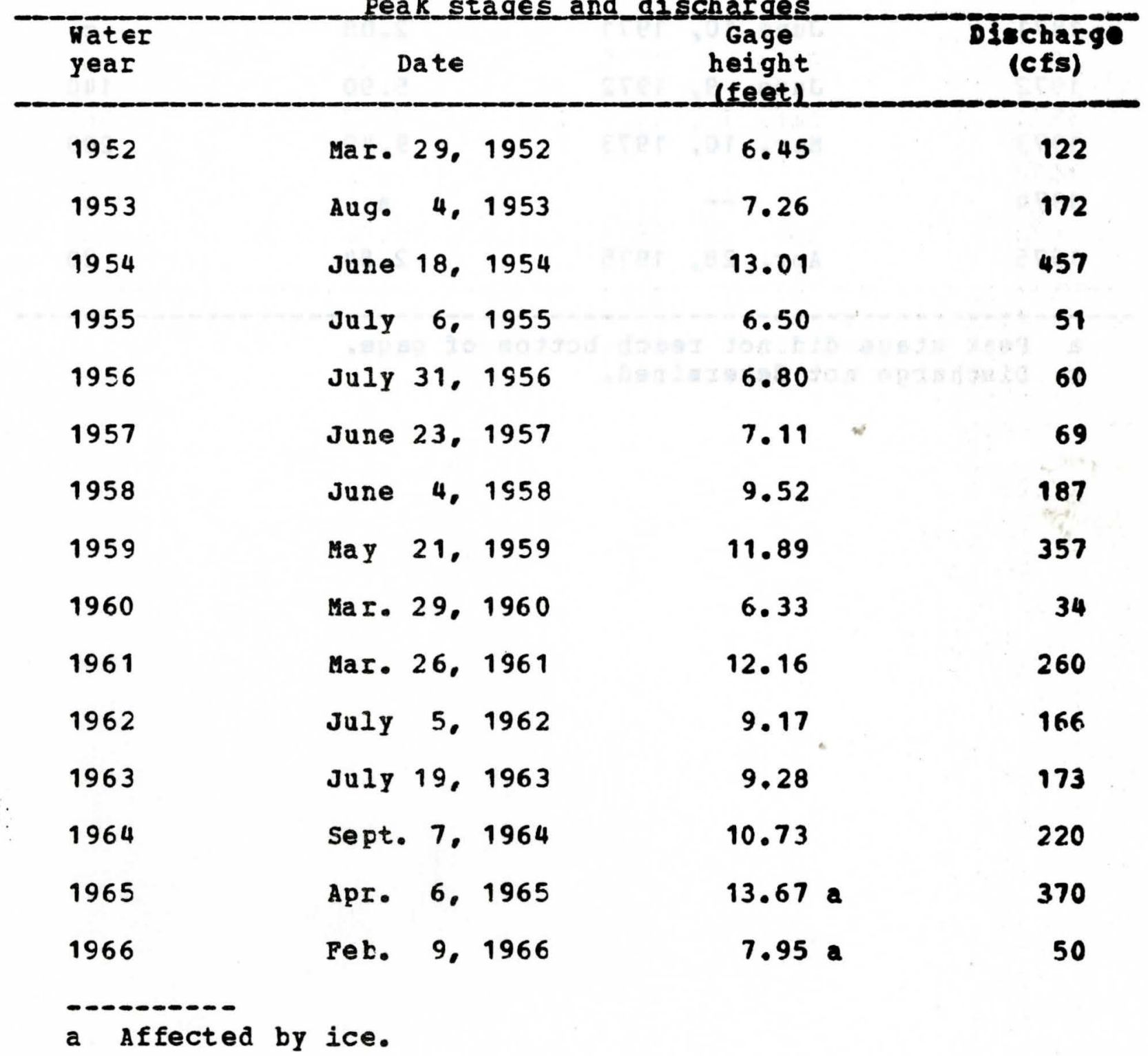


05-4487.00 East Branch Iowa River near Hayfield, Iowa--(Continued)

Peak_stages_and_di scharges

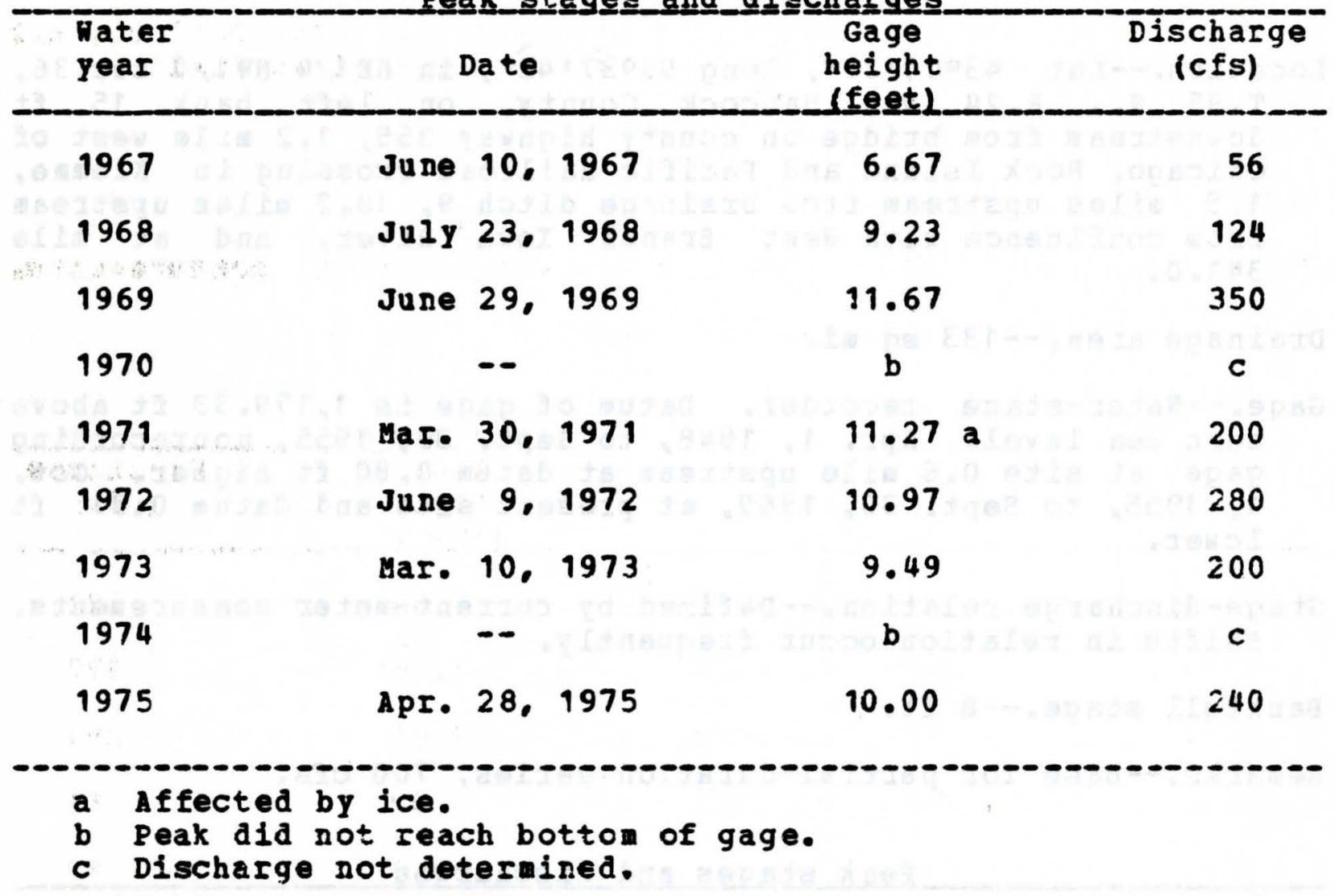


05-4490.00 East Branch Iowa River near Klemme, Iowa (Published as "East Fork Iowa River near Klemme", 194E-58)

Location.--Lat $43000 \cdot 31^{\prime \prime}$, long $93037 \cdot 42^{\prime \prime}$, in NE1/4 NH1/4 seç.36, T.95 N.. R.24 W., Hancock county, on left bank $15 \mathrm{ft}$ downstream from bridge on county highway B55. 1.2 mile west of Chicago, Rock Island and Pacific Railroad crossing in Klemme. 1.5 miles upstream from Drainage ditch 9.18 .2 miles upstream from confluence with Hest Branch Iowa River, and at mile 341.0 .

Drainage area.--133 sq mi.

Gage.--Water-stage recorder. Datum of gage is $1,179.33$ ft above mean sea level. Apr. 1, 1948, to sept. 30,1955, nonrecording gage at site 0.6 mile upstream at datum $0.80 \mathrm{ft}$ higher. Oct. 1. 1955, to Sept. 30, 1969, at present site and datum 0.31 ft lower.

Stage-discharge relation.--Defined by current-meter measurements. Shifts in relation occur frequently.

Bankfull stage. $--8 \mathrm{ft}$.

Remarks.--Base for partial-duration series, 700 cfs.

Pea

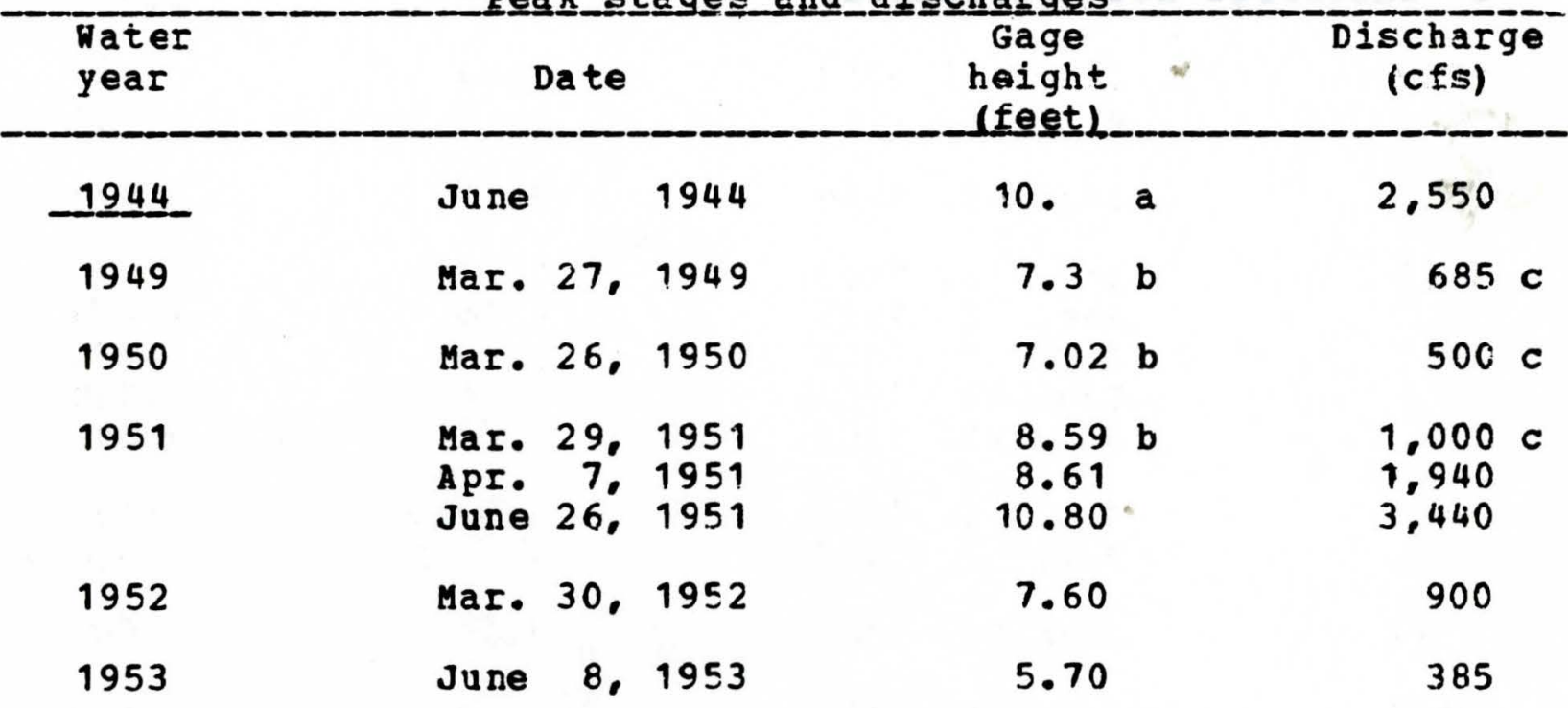


05-4490.00 East Branch Iowa River near Klemme, Iowa-- (Ccntinued)

Peak_stages_and discharges

\begin{tabular}{|c|c|c|c|}
\hline $\begin{array}{l}\text { Water } \\
\text { year }\end{array}$ & Date & $\begin{array}{l}\text { Gage } \\
\text { height } \\
\text { (feet) }\end{array}$ & $\begin{array}{c}\text { Discharge } \\
\text { (cfs) }\end{array}$ \\
\hline 1954 & $\begin{array}{l}\text { June } 19,1954 \\
\text { June } 21,1954\end{array}$ & $\begin{array}{l}11.2 \\
10.74\end{array}$ & $\begin{array}{l}5,960 \\
4,820\end{array}$ \\
\hline 1955 & Juy﹎_5_1955 & 5.47 & 348 \\
\hline 1956 & Mar. 26, 1956 & $4.91 \mathrm{~b}$ & $\uparrow 50 \mathrm{C}$ \\
\hline 1957 & June 23,1957 & 4.75 & 176 \\
\hline 1958 & June 4,1558 & 6.08 & 355 \\
\hline 1959 & $\begin{array}{lll}\text { May } & 21, & 1959 \\
\text { May } & 31, & 1959\end{array}$ & $\begin{array}{l}8.25 \\
8.12\end{array}$ & $\begin{array}{l}1,100 \\
1,020\end{array}$ \\
\hline 1960 & Mar. 28,1960 & 8.25 & 1.100 \\
\hline 1961 & Mar. 26,1961 & 9.40 & 3.250 \\
\hline 1962 & $\begin{array}{lr}\text { Mar. } 30, & 1962 \\
\text { July } 5, & 1962 \\
\text { July } 20, & 1962 \\
\text { Aug. } 31, & 1962\end{array}$ & $\begin{array}{l}9.05 \mathrm{~b} \\
8.53 \\
8.20 \\
8.84\end{array}$ & $\begin{array}{l}1.600 \mathrm{c} \\
1.420 \\
1.090 \\
1.830\end{array}$ \\
\hline 1963 & $\begin{array}{lrl}\text { July } & 6,1963 \\
\text { July } & 20, & 1963\end{array}$ & $\begin{array}{l}8.48 \\
8.44\end{array}$ & $\begin{array}{l}950 \\
922\end{array}$ \\
\hline 1964 & Seft. 9. 1964 & 8.09 & 972 \\
\hline 1965 & $\begin{array}{l}\text { Apr. 6, } 1965 \\
\text { Apr. 8, } 1965 \\
\text { June 6, } 1965 \\
\text { Sept.19, } 1965 \\
\text { Sept.29, } 1965\end{array}$ & $\begin{array}{c}10.67 \mathrm{~b} \\
9.94 \\
7.63 \\
9.39 \\
8.48\end{array}$ & $\begin{array}{l}4.090 \\
728 \\
2.080 \\
1.090\end{array}$ \\
\hline 1966 & $\begin{array}{lll}\text { Oct. } & 1,1965 \\
\text { Fek. } & 9,1966\end{array}$ & $\begin{array}{l}8.02 \mathrm{~d} \\
8.11 \mathrm{~b}\end{array}$ & $\begin{array}{l}812 \\
700 \mathrm{c}\end{array}$ \\
\hline 1967 & June 11,1967 & 7.25 & 582 \\
\hline 1968 & June 27,1968 & 6.03 & 351 \\
\hline $\begin{array}{ll}- & --- \\
b & \text { Aff } \\
\text { c } & \text { abo } \\
\text { d } & \text { Sta }\end{array}$ & $\begin{array}{l}\text { ice. } \\
\text { g. }\end{array}$ & & \\
\hline
\end{tabular}


05-4490.00 East Branch Iowa River near Klemme, Iowa-- (Contjnued)

Peak_stages and discharges

\begin{tabular}{|c|c|c|c|c|}
\hline $\begin{array}{l}\text { Hater } \\
\text { year }\end{array}$ & Date & & $\begin{array}{l}\text { Gage } \\
\text { height } \\
\text { (feet) }\end{array}$ & $\begin{array}{c}\text { ischarge } \\
\text { (cfs) }\end{array}$ \\
\hline 1969 & $\begin{array}{l}\text { Apr. } 4, \\
\text { June } 27, \\
\text { June } 29, \\
\text { July } 9 .\end{array}$ & $\begin{array}{l}1969 \\
1969 \\
1969 \\
1969\end{array}$ & $\begin{array}{l}7.86 \\
8.29 \\
9.87 \\
8.92\end{array}$ & $\begin{array}{r}806 \\
765 \\
2,770 \\
1.170\end{array}$ \\
\hline 1970 & May 14. & 1970 & 7.83 & 759 \\
\hline 1971 & Mar. 31. & 1971 & 8.22 & 1.030 \\
\hline 1972 & June 8 , & 1972 & 8.90 & 1.350 \\
\hline 1973 & $\begin{array}{lr}\text { Mar. } & 4, \\
\text { Mar. } 11, & \\
\text { Mpr. } 16, \\
\text { May } & 8, \\
\text { May } 28, \\
\text { June } 17 .\end{array}$ & $\begin{array}{l}1973 \\
1973 \\
1973 \\
1973 \\
1973 \\
1973\end{array}$ & $\begin{array}{l}-- \\
8.38 \\
7.69 \\
7.49 \\
8.05 \\
7.81\end{array}$ & $\begin{array}{r}843 c \\
1.040 \\
747 \\
687 \\
878 \\
784\end{array}$ \\
\hline 1974 & $\begin{array}{ll}\operatorname{MaI} . & 3-4 \\
\operatorname{May} & 11 .\end{array}$ & $\begin{array}{l}1974 \\
1974\end{array}$ & $\begin{array}{l}7.20 \quad b \\
6.67\end{array}$ & $=-$ \\
\hline 1975 & Apr. 28 & 1975 & 8.57 & 1,530 \\
\hline
\end{tabular}


05-4780.00 East Fork Des Hcines River near Burt, Icwa (Discontinued september 1974 )

Location.--Lat $43012 \cdot 38^{\prime \prime}$. Icng $94010 \cdot 35^{\prime \prime}$, in NN1/4 NE1/4 sec.20, T.97 N.. R.28 N.. kossuth County, on right bark $30 \mathrm{ft}$ downstream from bridge on county highway. 0.8 mile upstrean from Buffalo Creek, 2.2 miles northeast of Burt, 4.7 miles downstream from Mud Creek, and at mile 389.7 upstream from mouth of Des Moines River.

Drainage area.--462 sq mi.

Gage.-- Hater-stage recorder. Datum of gage is $1,114.42 \mathrm{ft}$ above mean sea level.

Stage-discharge relation.--Defined by current-meter measurements. Bankfull stage.--10 ft.

Remarks.--Base for partial-duration series, 500 cfs. Base was 800 cfs prior to 1962.

Feak_stages_and_discharges

\begin{tabular}{|c|c|c|c|c|c|}
\hline $\begin{array}{l}\text { Water } \\
\text { year }\end{array}$ & & Date & $\begin{array}{l}\text { Gage } \\
\text { height }\end{array}$ & 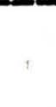 & $\begin{array}{c}\text { Discharge } \\
\text { (cfs) }\end{array}$ \\
\hline 1952 & $\begin{array}{l}\text { Mar. } \\
\text { Mar. }\end{array}$ & $\begin{array}{ll}22, & 1952 \\
31, & 1952\end{array}$ & $\begin{array}{l}10.88 \\
11.42\end{array}$ & $\approx$ & $\begin{array}{l}1.260 \\
1.680\end{array}$ \\
\hline 1953 & June & 13. 1953 & $10 \cdot 36$ & & 1,060 \\
\hline 1954 & June & $21,1 \subsetneq 54$ & 12.67 & & 3.870 \\
\hline 1955 & Apr. & 26, 1955 & 9.58 & & 670 \\
\hline 1956 & Aug. & 3,1956 & 6.71 & & 244 \\
\hline 1957 & June & 1. 1957 & 7.97 & & 392 \\
\hline 1958 & June & $4,1 \subseteq 58$ & 9.52 & & 365 \\
\hline 1959 & May & 23,1959 & $10 \cdot 13$ & & 675 \\
\hline 1960 & $\begin{array}{l}\text { Apr. } \\
\text { May }\end{array}$ & $\begin{array}{r}1.1960 \\
22.196 \mathrm{C}\end{array}$ & $\begin{array}{l}10.29 \\
11.72\end{array}$ & & $\begin{array}{r}880 \\
2.120\end{array}$ \\
\hline 1961 & Mar. & 27.1961 & 12.05 & & 2.800 \\
\hline
\end{tabular}


05-4780.00 East Fork Des Moines River near Burt, Iowa-- (Continued)

Feak_stages_and_discharges

Water

year

Date
Gage

height

(feet)
Discharge

(cfs)

\section{BASE_EEVISED_TO 500 CES}

1962

Mar. 29, 1962

Apr. 1, 1962

July 21, 1962

Sept. 1. 1962

12.51 a

11.86

11.02

11.27

2.600

1.050

1,310

1963

May 12,1963

9.30

560

June 11, 1963

10.17

July 6, 1963

11.72 a

July 22, 1963

11.67

765

$1.270 \mathrm{~b}$

1,720

1964

May 8, 1964

sept. 9, 1964

9.86

670

11.75

1,650

sept. 20 or 21.1964

--

940

1965

Apr. 6, 1965

14.21

5.000

Apr. 9, 1965

13.46

10.95

May 27, 1965

10.33

June 7,1965

10.27

4.930

1,270

892

848

1966

Apr. 2, 1966

June 29, 1966

10.39

$\varepsilon 66$

9.99

610

1967

June 16, 1967

Aug. 24, 1967

10.14

697

9.37

568

1968

June 28, 1968

9.96 a

572 b

1969

Oct. 19, 1968

Mar. 28, 196؟

11.00

Apr. 8,1969

May 23, 196 c

JuIy 1, 1965

JulY 10,1969

12.09

10.26

12.91

12.55

1.050

$740 \mathrm{~b}$

3. 280

828

3.730

3.000

1970

May 14, 1970

$9.64 a$

$635 b$

a Backwater from ice and/or Euffalo Creek.

b A bout. 
05-4780.00 East Fork Des Mcines River near Burt, Iowa--(Continued)

Feak_stages and discharges

\begin{tabular}{|c|c|c|c|c|c|c|c|c|c|c|}
\hline & $\begin{array}{l}\text { Water } \\
\text { year }\end{array}$ & & & Date & & -1 & $\begin{array}{l}\text { Gage } \\
\text { height } \\
\text { (feet) }\end{array}$ & & $\begin{array}{c}\text { Discharge } \\
\text { (cfs) }\end{array}$ & \\
\hline & 1971 & & $\begin{array}{l}\text { Fer. } \\
\text { Mar. } \\
\text { Mar. } \\
\text { June }\end{array}$ & $\begin{array}{r}22 . \\
17 . \\
31 . \\
9 .\end{array}$ & $\begin{array}{l}1971 \\
1971 \\
1971 \\
1971\end{array}$ & & $\begin{array}{l}10.69 \\
11.95 \\
11.31 \\
10.24\end{array}$ & a & $\begin{array}{r}540 \\
1,500 \\
1,740 \\
\varepsilon 55\end{array}$ & $\begin{array}{l}b \\
b\end{array}$ \\
\hline & 1972 & & May & 4. & 1972 & & 8.68 & & 481 & \\
\hline & 1973 & & $\begin{array}{l}\text { Mar. } \\
\text { Mar. } \\
\text { Apr. } \\
\text { May } \\
\text { May } \\
\text { May }\end{array}$ & $\begin{array}{l}5 . \\
26 \\
17 \\
3 \% \\
24 \\
31 .\end{array}$ & $\begin{array}{l}1973 \\
1573 \\
1973 \\
1573 \\
1573 \\
1973\end{array}$ & & $\begin{array}{r}10.95 \\
9.98 \\
10.74 \\
10.44 \\
9.29 \\
10.55\end{array}$ & 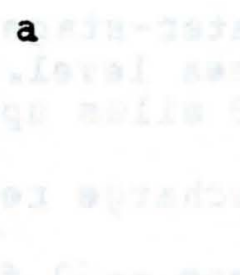 & $\begin{array}{r}1.100 \\
774 \\
1.150 \\
996 \\
582 \\
980\end{array}$ & b \\
\hline & 1974 & & $\begin{array}{l}\text { Nov. } \\
\text { Mar. } \\
\text { Apr. } \\
\text { Apr. } \\
\text { May } \\
\text { May } \\
\text { June } \\
\text { June }\end{array}$ & $\begin{array}{l}22 \\
13 \\
6 \% \\
15 \\
13 \\
23 \\
11 \\
23\end{array}$ & $\begin{array}{l}1973 \\
1574 \\
1974 \\
1574 \\
1574 \\
1974 \\
1574 \\
1974\end{array}$ & & $\begin{array}{c}10.52 \\
9.61 \\
-- \\
-- \\
\ldots \\
-- \\
9.16\end{array}$ & $\begin{array}{l}\mathrm{a} \\
\mathbf{a} \\
\mathbf{a} \\
\mathrm{a} \\
\mathrm{a}\end{array}$ & $\begin{array}{l}928 \\
663 \\
530 \mathrm{~b} \\
810 \mathrm{~b} \\
600 \mathrm{~b} \\
530 \mathrm{~b} \\
760 \mathrm{~b} \\
552\end{array}$ & $\begin{array}{l}\mathbf{b} \\
\mathbf{b} \\
\mathbf{b} \\
\mathbf{b} \\
\mathbf{b}\end{array}$ \\
\hline
\end{tabular}

Liscontinued september 1974

a Backwater fron ice andor Euffalo Creek.

b A bout. 
05-4790.00 East Fork Des Mcines River at Dakota City, Iowa (Published as "near Hardy", 1940-54)

Location.--Iat $42043 \cdot 26 "$, Icrg $94011 \cdot 30 "$, in NN1/4 SE1/4 sec.6. T.91 N.. R.28 N.. Humboldt County. on Iight bank 50 ft upstream from oid mill dam, in city park at east edge of Lakota City, $500 \mathrm{ft}$ upstrea from bridge on county highway P56. 0.6 mile dcwnstrean frcm bridge on state Highway 3. 3.4 miles upstream frcm confluence with Des Hoines River, and at mile 333.8 upstrean from nouth of Des Hoines River.

Drainage area.--1,308 sq mi.

Gage.-- later-stage recorder. Datum of gage is 1,038.71 ft above mean sea level. Prior to Oct. 1, 1954, nonrecording gage at site 8 miles upstream at different datum.

Stage-discharge relation.--Defined by current-meter measurements. Flood stage. $-20 \mathrm{ft}$.

Remarks.--Flood of June 21. 1954 reached a stage of $24.02 \mathrm{ft}$ (discharge $17,400 \mathrm{cfs}$ ) at present site. Base for partialduration series, $1,500 \mathrm{cfs}$. Base was 2,200 cfs prior to 1961.

Peak stages and discharges

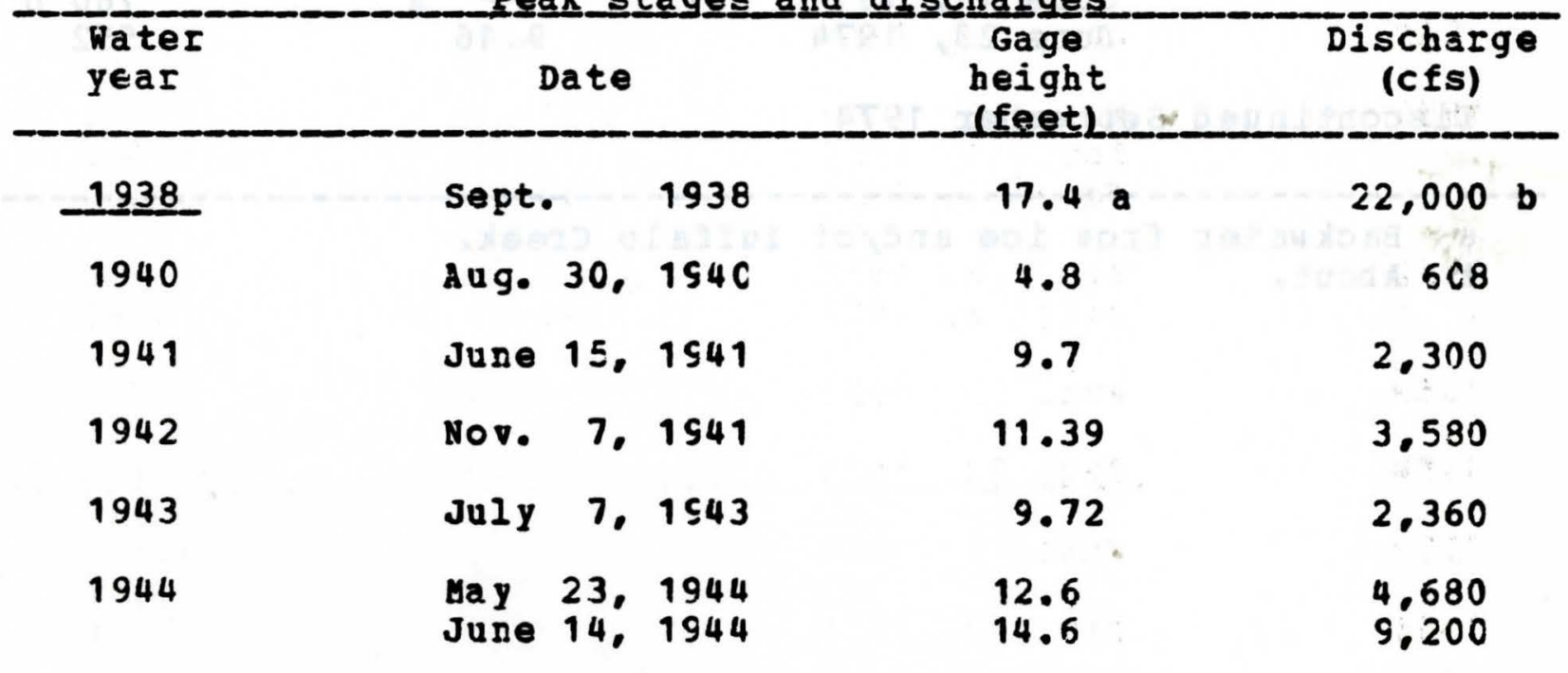

a Maximum stage known, from information by local residents.
b about. 
05-4790.00 East Fork Des Mcires River at Dakota City. ICwa-(Continued)

Peak_stages_and_dis scharges

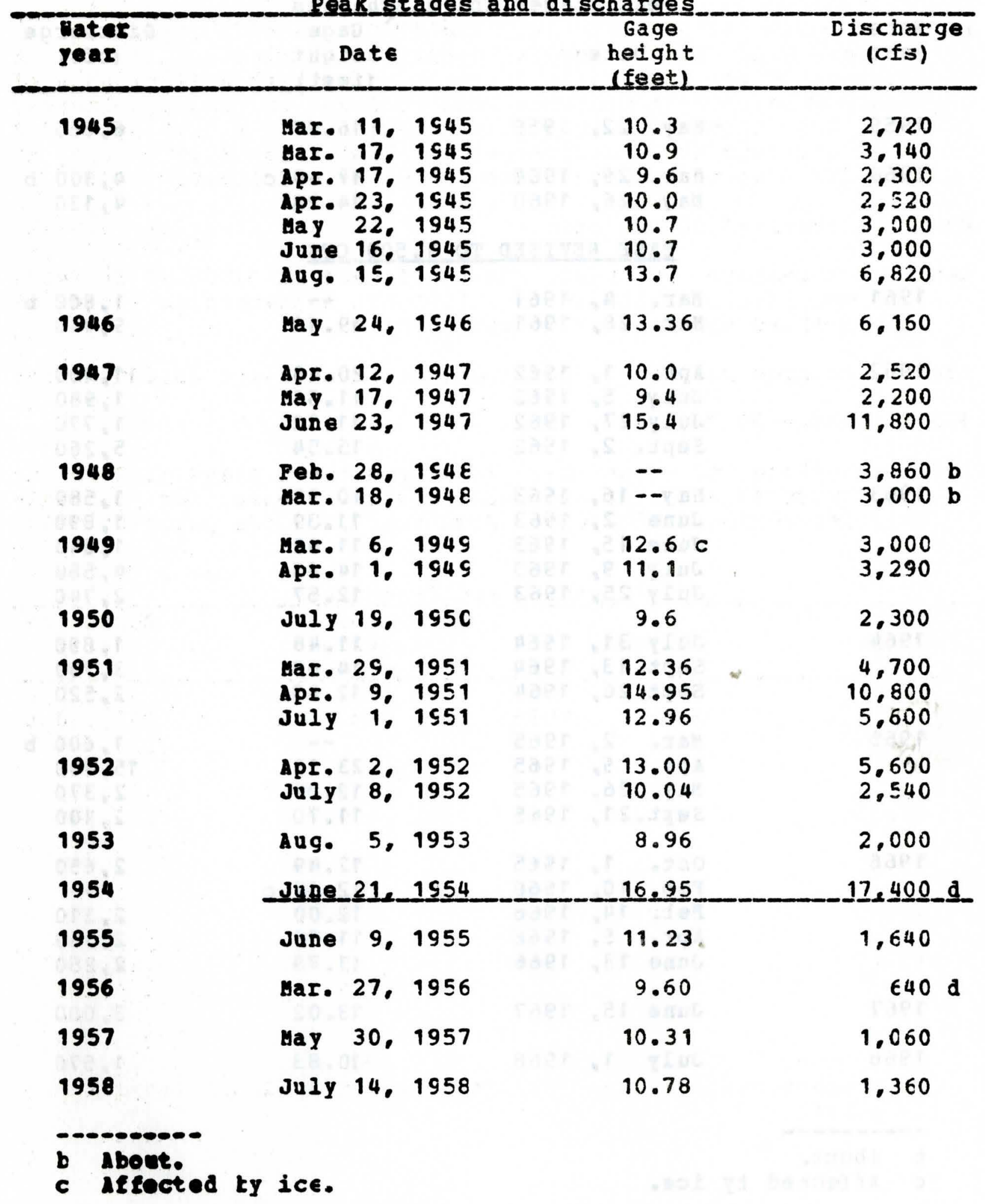


05-4790.00 East Fork Des Moines River at Dakota City, Iowa-(Continued)

Peak_stages_and discharges

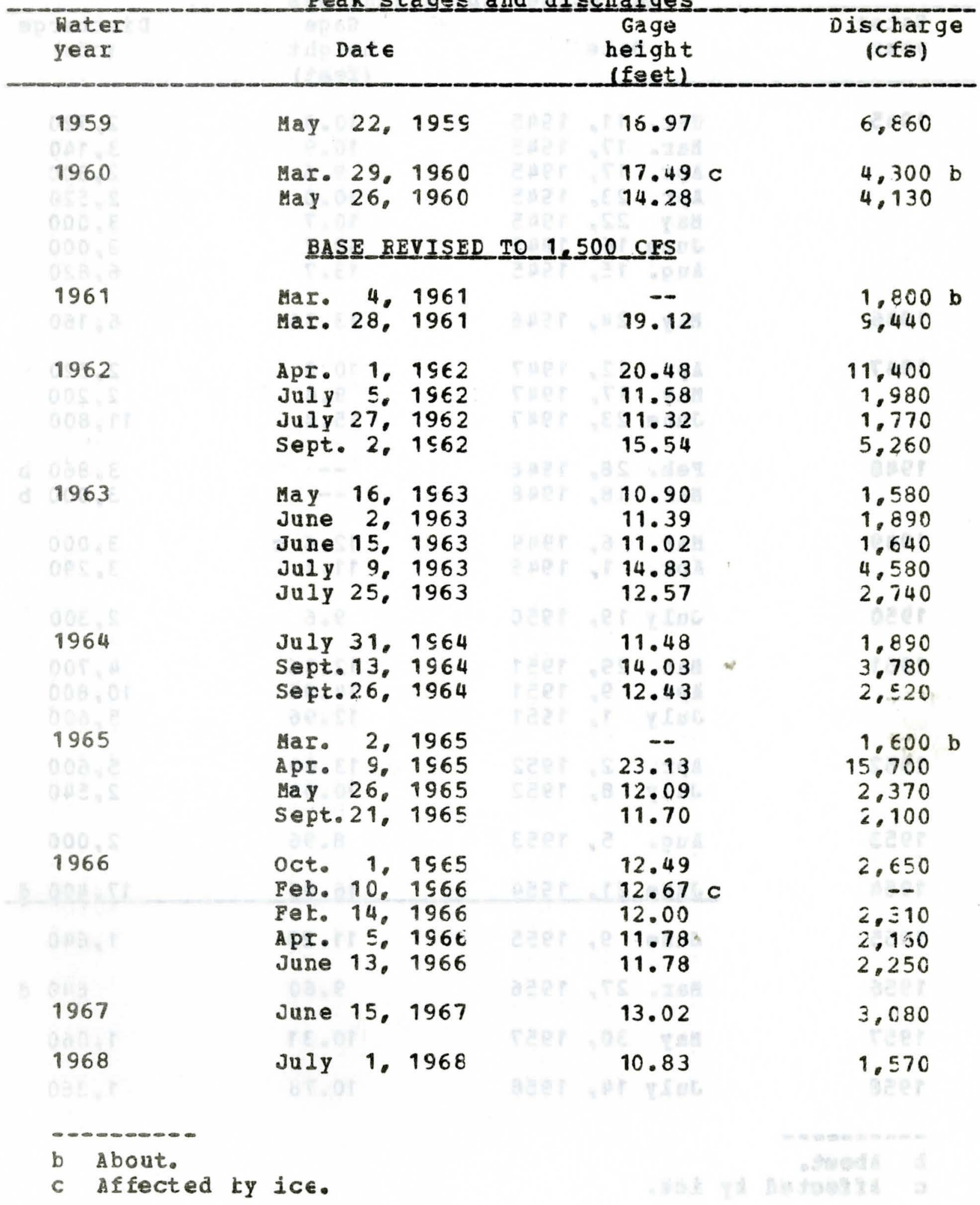


05-4790.00 East Fork Des Mcines River at Dakota City, Iowa-(Continued)

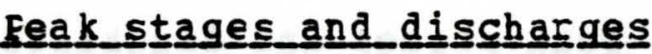

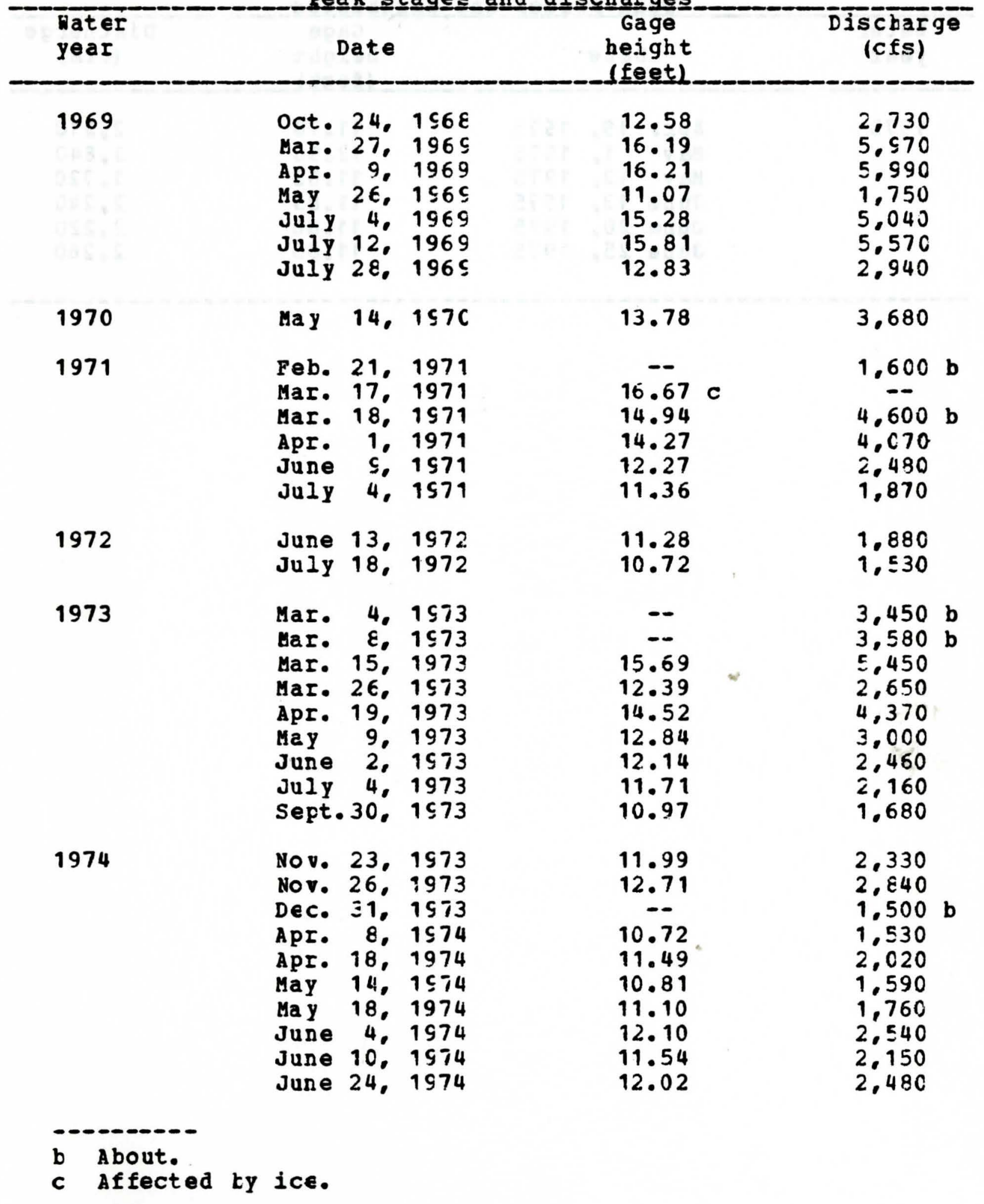


05-4790.00 East Fork Des Moines River at Dakota City. Iowa-(Continued)

Feak_stages_and discharges

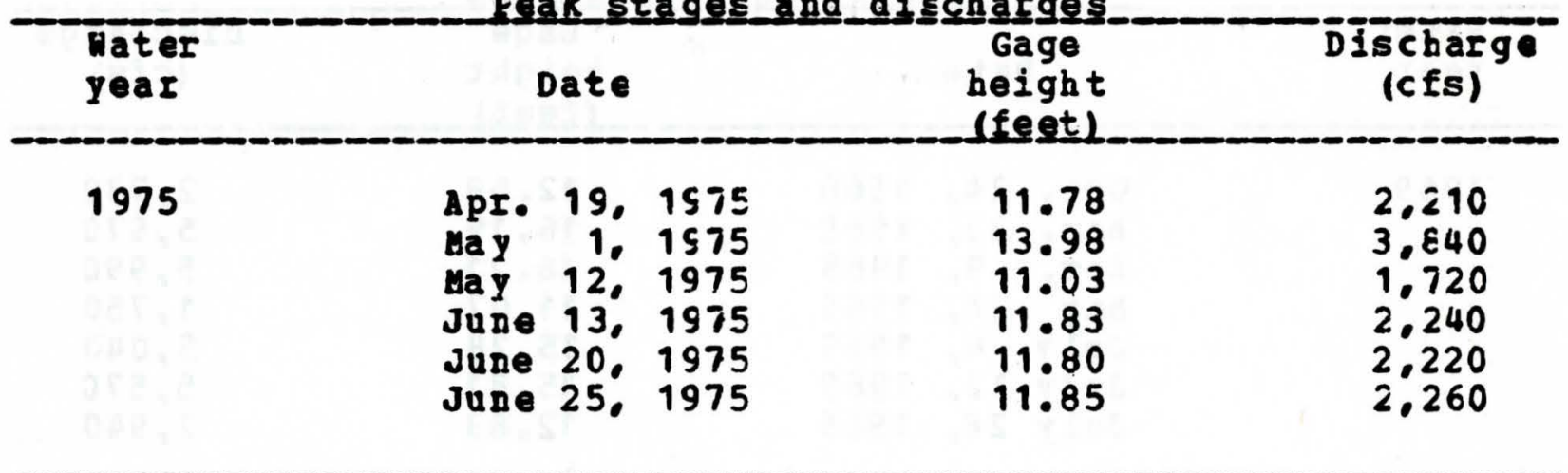


Location.--Lat $42006 \cdot 27 "$, long $94022 \cdot 12^{\prime \prime}$, in SE1/4 SN1/4 sec.5. I.84 N.. R. 30 \%., Greene County, on left bank 35 ft upstrea from bridge on county highway E26. 1.6 miles upstrea from small left-bank tributary, 4.4 miles upstrean from moutk, and 6.5 miles southeast of Churdar.

Drainage area.-- $24.0 \mathrm{sq} \mathrm{mi}$

Gage.--Hater-stage recorder. Datum of gage is $1,050,9 \mathrm{Ct}$ above mean sea level.

Stage-discharge relation.--Defined by current-meter measurements below 180 cfs and above by logarithmic plotting.

Eankfull stage.--High banks are not subject to overflow.

Remarks.--Peak base for partial-duratior series, $150 \mathrm{cfs}$. Small diversion for irrigation above station. Base was 200 cfs pricr to 1962 .

Fesk stages_and_discharges

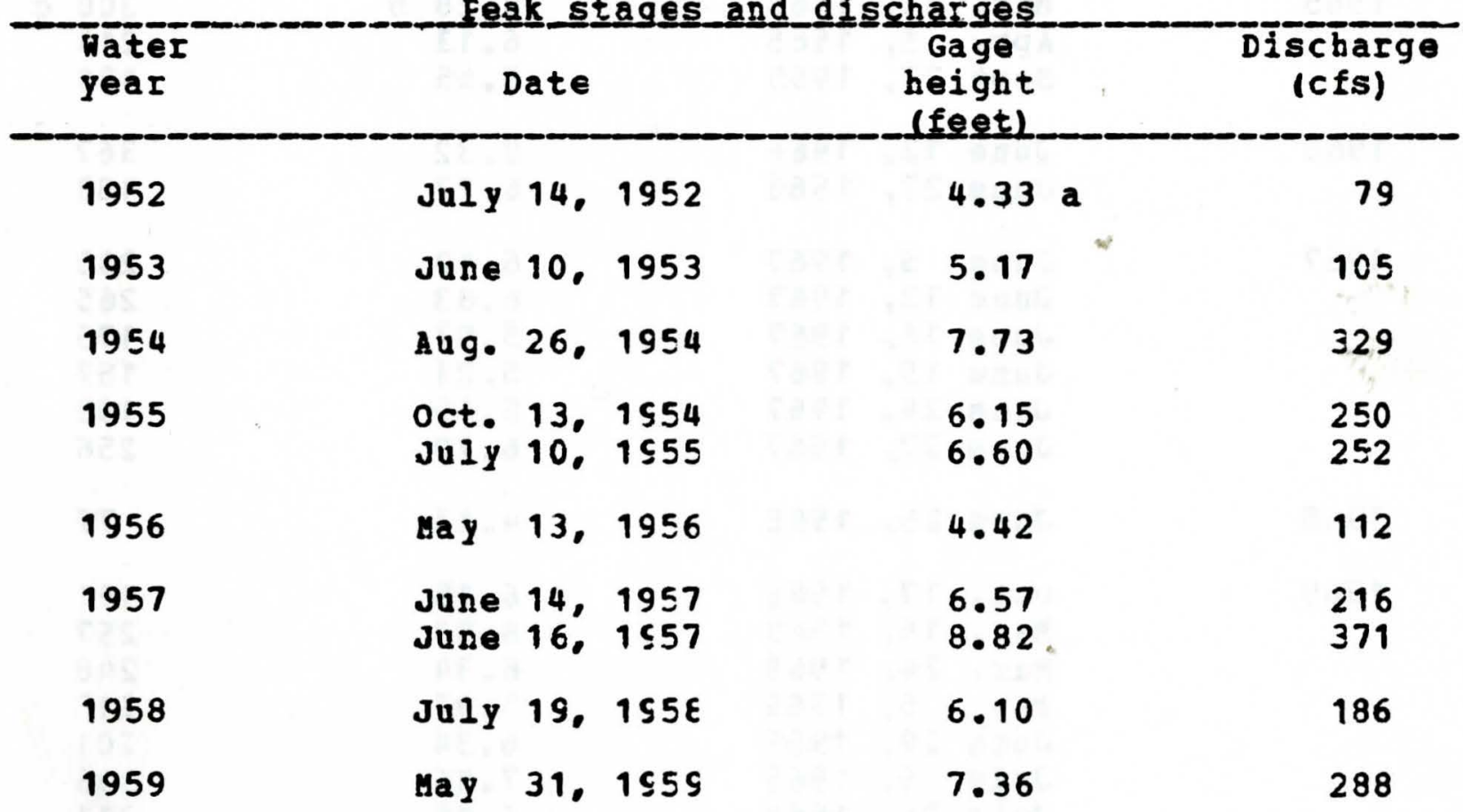

a Maximum for period July tc september 1952. 
05-4830.00 East Fork Hardin Creek near Churdan, Iowa-- (Continued)

Feak stages and discharges

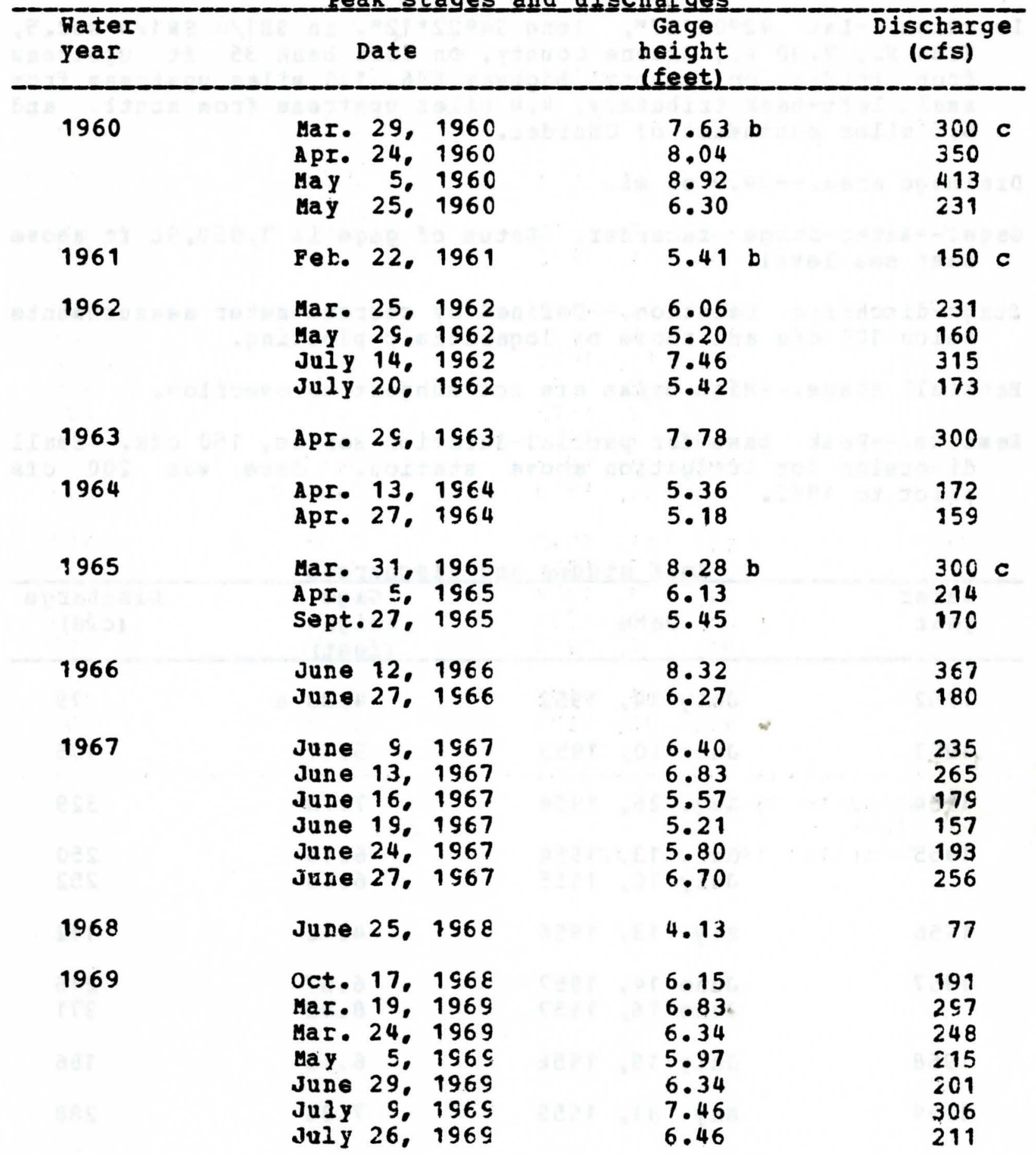

b affected by ice.

c about. 
05-4830.00 East Fork Hardin Creek near Churdan. Iowa-- (Continued)

Peaㅛ stages and di schargas

\section{Water}

year

1970

1971

1972

1973

1974

1975
Date

May 14, 157C

Feb. 19. 1571

MaI. 6. 1572

Aug. 1, 1972

Feb. 24, 1973

Mar. 1, 1573

Mar. 11, 1973

Apr. 15. 1973

vay 7, 1573

JuIy 2, 1973

Aug. 23. 1573

sept.26, 1573

Cct. 11, 1973

Feb. 17. 1974

Eay 13. 1974

May 16, 1974

way 18, 1974

Har. 18, 1975

ApI. 28. 1975
Gage

height

(fee로)
Discrarge

(cfs)

3.89

70

7.86

$200 \mathrm{c}$

$5.86 \mathrm{~b}$

5.72

$160 \mathrm{C}$

195

$157 \mathrm{C}$

$152 \mathrm{C}$

2.08

199

205

248

177

385

5.58

8.26 d

197

159

206

243

385

$6.83 \mathrm{~b}$

5.39
195

b Affected by ice.

c A bout.

d Backwater fron debris. 


\section{5-4829.50 East Fork Hardin Creek rear Paton. Iowa (Discontinued September 1955)}

Location.--Iat $42^{\circ}$, long $91^{\circ}$, near $51 / 4$ corner sec.20. T.E5 N.. R. 30 W.. at bridge on county road H. 6 miles west of Eaton.

Drainage area.--7.57 sq mi.

Gage.--Crest-stage gage.

Stage-discharge relation.--Defined by current-meter measurements. Remarks.--only annual peaks are shown.

Peak stages and di scharges

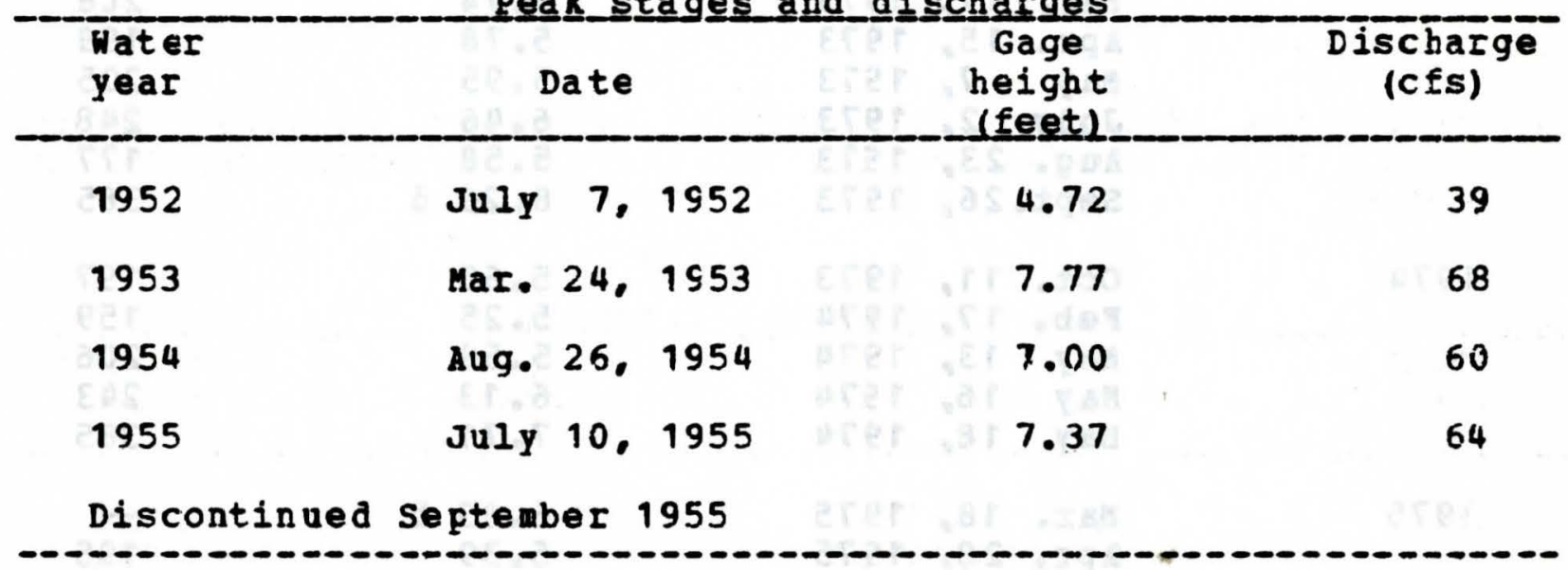


06-8191.90 East Fork one Hundred and Two River near Bedford, Iowa

Location.--Iat $400380^{\circ} 01^{\prime \prime}$, long $94044 \cdot 41^{\prime \prime}$, in NE1/4 NE1/4 sac.9, T.67 M. R. 34 \%.. Taylor County, on left bank at dcwnstream side of bridge cf county highway J55, 0.4 mile upstream from Daugherty Creek, and 2.8 miles southwest of junction of $0 . S$. Highways 2 and 148 in Bedford.

Drainage area.--92.1 sq mi.

Gage.-- Hater-stage recorder. Datum of gage is 1.057.51 ft above mean sea level (levels by Corps of Engineers). Prior to oct. 1. 1968, at datum $5.00 \mathrm{ft}$ higher.

stage-discharge relation.--Defined by current-meter measurements.

Flocd stage. --14 ft.

Remarks.--Base for partial-duration series, 2,000 cfs. \$light regulation at low flow by low dam used for water supply in Bedford.

Peak﹎_stages_and_discharges

Water

year

1960

1961

1962

1963

1964
Jan. 12, 1960

Mar. 29, 1960

June 30,1960

Aug. 25, 1960

Aug. 29, 1960

Mar. 13. 1961

MaI. 27, 1961

Oct. 12, 1961

Nov. 16, 1961

Feb. 16, 1962

Apr. 29,1963

May 8, 1964

June 21, 1964

se pt. 6, 1964
Gage height (feet)

15.95

14.50

14.29

11.11

11.81

11.00

12.20

11.04

11.29

13.20 a

9.46

9.53

11.16

11.75
Discharge

(cfs)

5.400

3,120

4,120

2,140

2,530

2.240

2.760

2.240

2.360

2.230

2.330

3,130

3,490

a Affected by ice. 
06-8191.90 East Fork One Hundred and Two River near Bedford, Iowa $--($ Continued)

Peak_stages_and_discharges

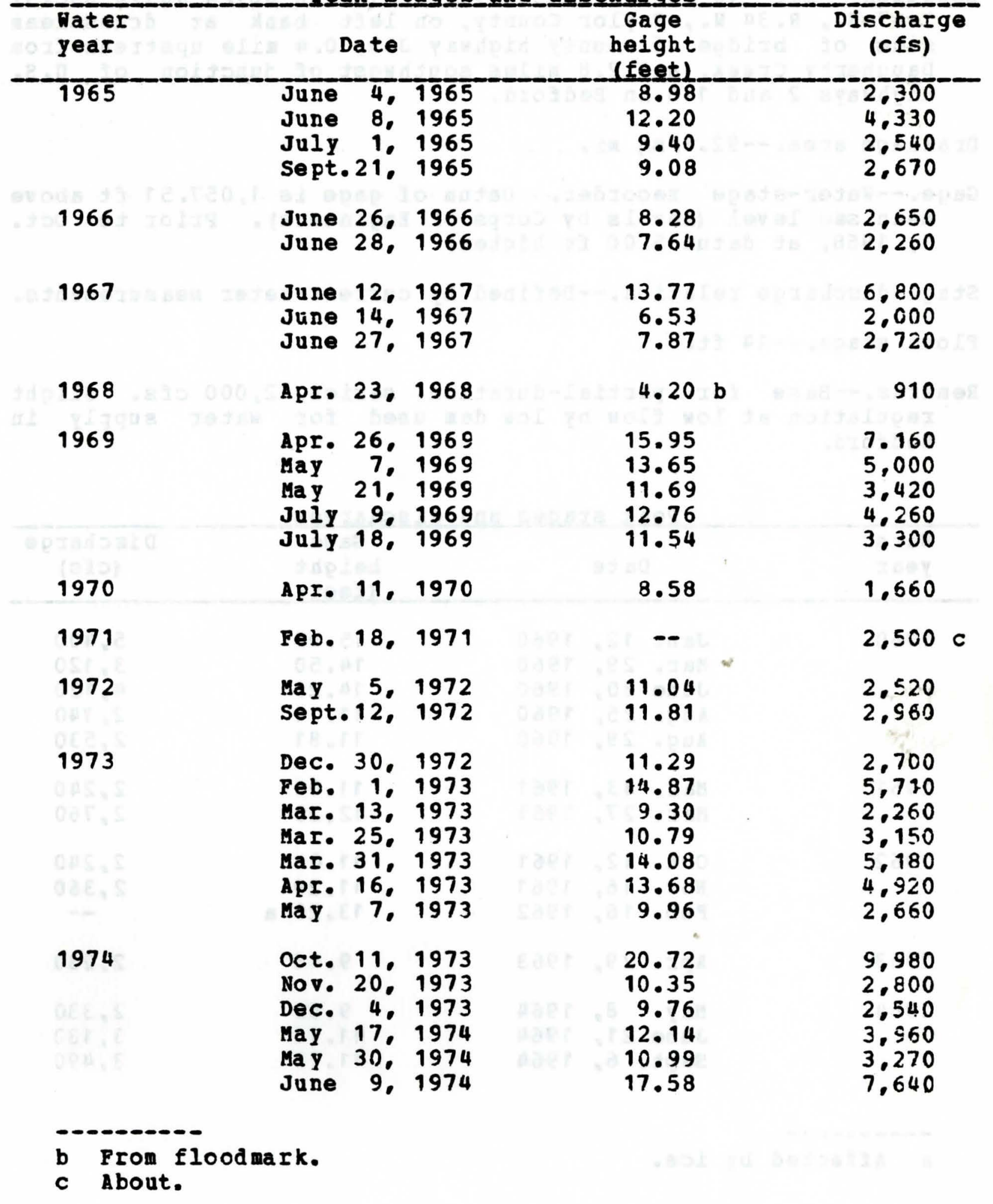


06-8191.90 East Fork One Hundred and Two 3iver near Bedford, Iowa - (Continued)

Peak stages_and discharges

\begin{tabular}{|c|c|c|c|}
\hline $\begin{array}{l}\text { Water } \\
\text { year }\end{array}$ & Date & $\begin{array}{l}\text { Gage } \\
\text { height } \\
\text { feget. }\end{array}$ & $\begin{array}{c}\text { Discharge } \\
\text { (cfs) }\end{array}$ \\
\hline 1975 & $\begin{array}{l}\text { June } 11,1975 \\
\text { June } 23,1975\end{array}$ & $\begin{array}{l}14.04 \\
10.33\end{array}$ & $\begin{array}{l}5,030 \\
2,760\end{array}$ \\
\hline
\end{tabular}


05-4206.90 East Fork Napsipinicon River near New Hamptcn, Iowa

Location.--Iat $43005^{\prime}$. long $92018 \%$ in SE1/4 sec.31. T.96 N.. R.12 W.. Chickasaw County, at bridge on U.S. Highway E3, about 2 miles north of New Hampton.

Drainage area.--30.3 sq mi.

Gage.--Crest-stage gage.

Stage-discharge relation.--Defined by current-meter and indirect measurements.

Remarks.--only annual peaks are shown.

Peak_stages_and_discharges

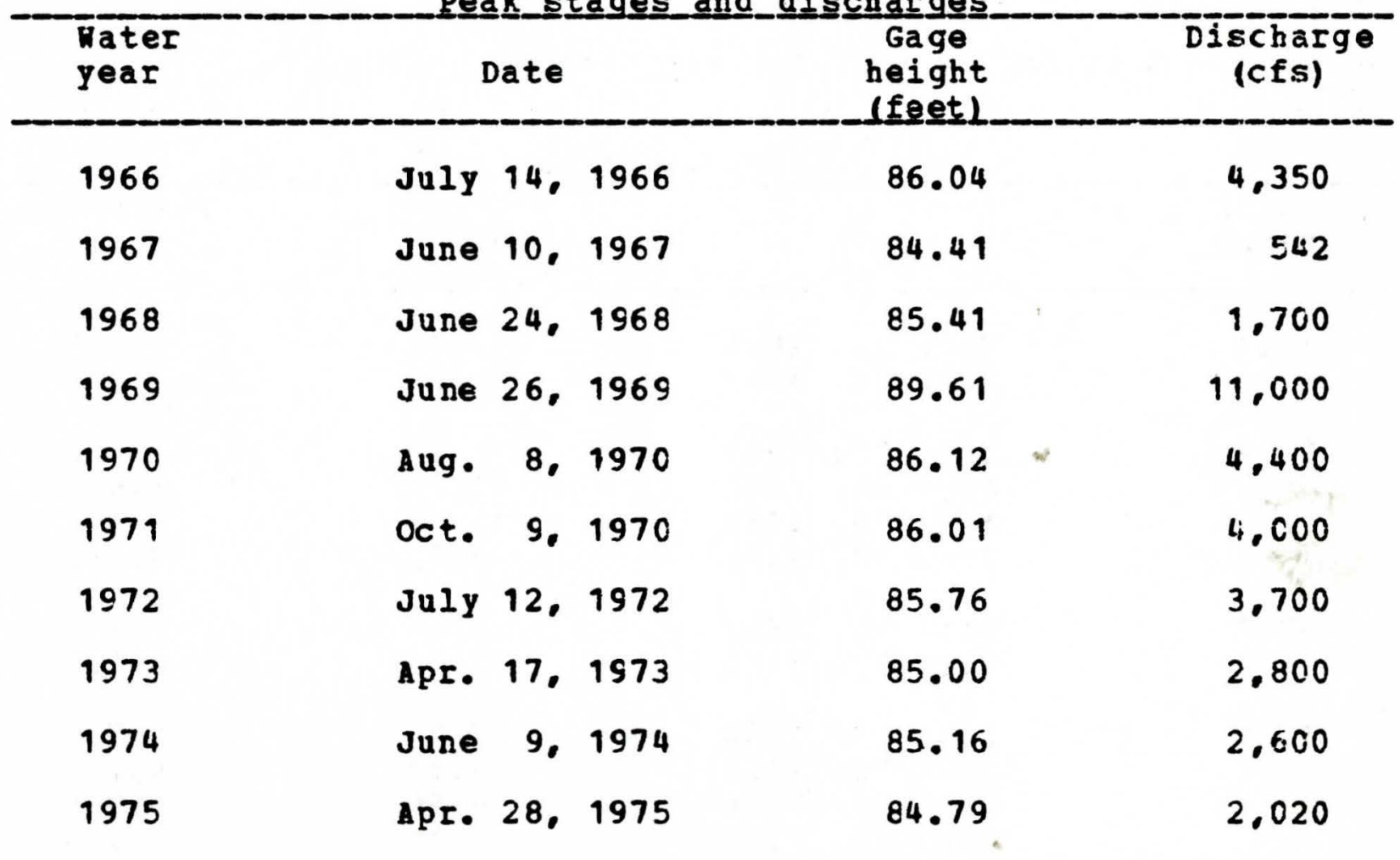


06-8092.10 East Nishnabotna River near Atlantic, Icwa

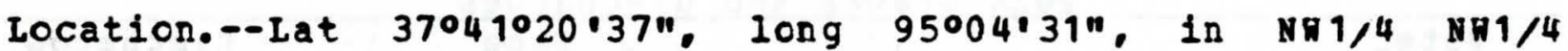
sec.35. T.76 N.. R.67 N.. Cass County. on left bank at downstream side of bridge on county highway. 1.9 miles upstream from Turkey Creek, and 5.4 miles southwest of junction of 0.S. Highway 6 and state Highway 83 in Atlartic.

Drainage area.- $-436 \mathrm{sq}$ mi.

Gage.- Hater-stage recorder. Datum of gage is 1,105.83 ft above mear sea level. Prior to oct. 1. 1970. at site 2.0 miles upstream at datum 5.00 ft higher.

Stage-discharge relation.--Defined by current-meter measurements. Flood stage. $-17 \mathrm{ft.}$

Remarks.--Base for partial-duration series, 3,000 cfs.

Peak__tages_and_discharges

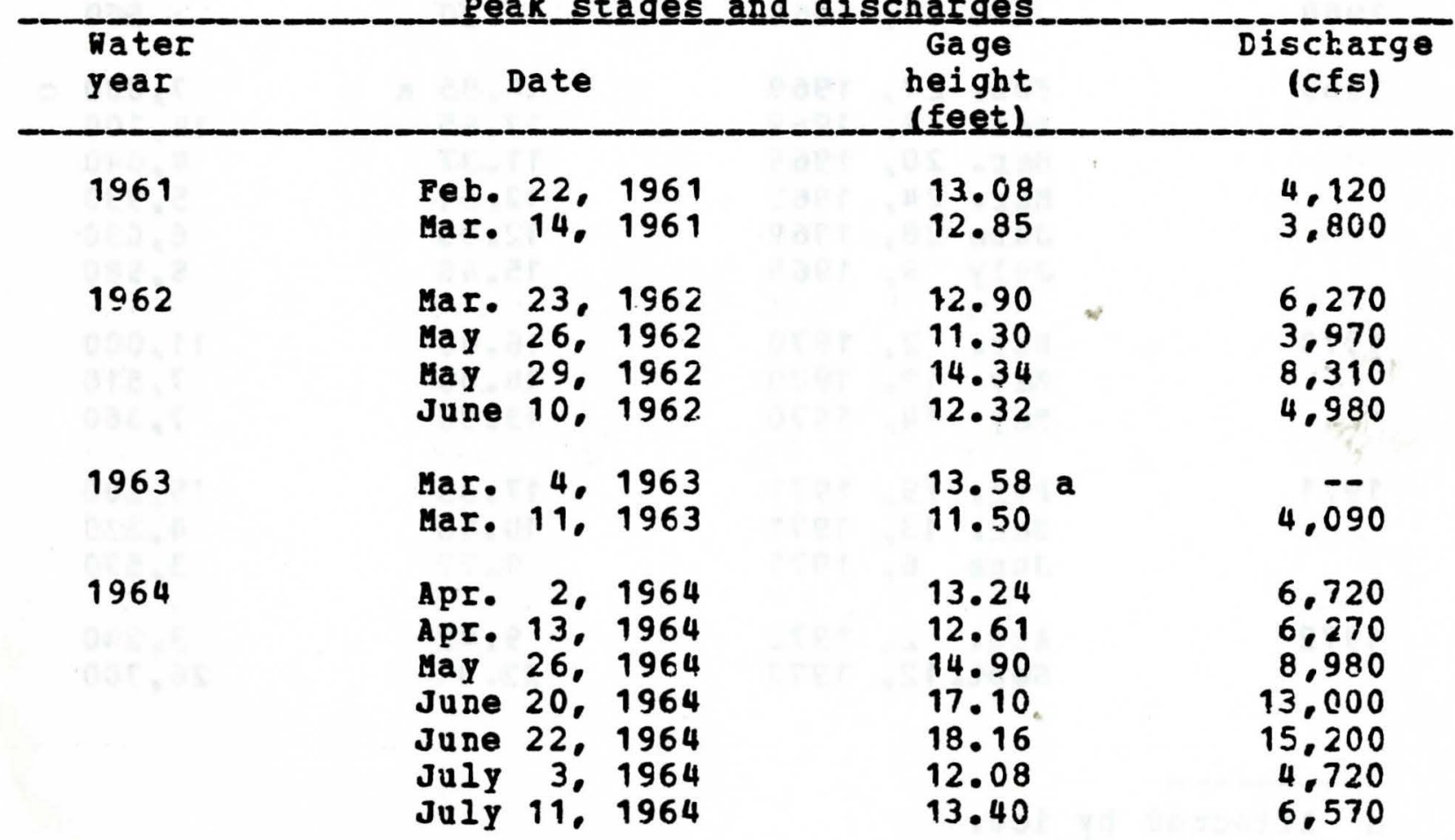

a Affected by ice. 
06-8092.10 East Nishnabotna River near Atlantic, Iowa--(Ccntinued)

Feak__stages_and discharges

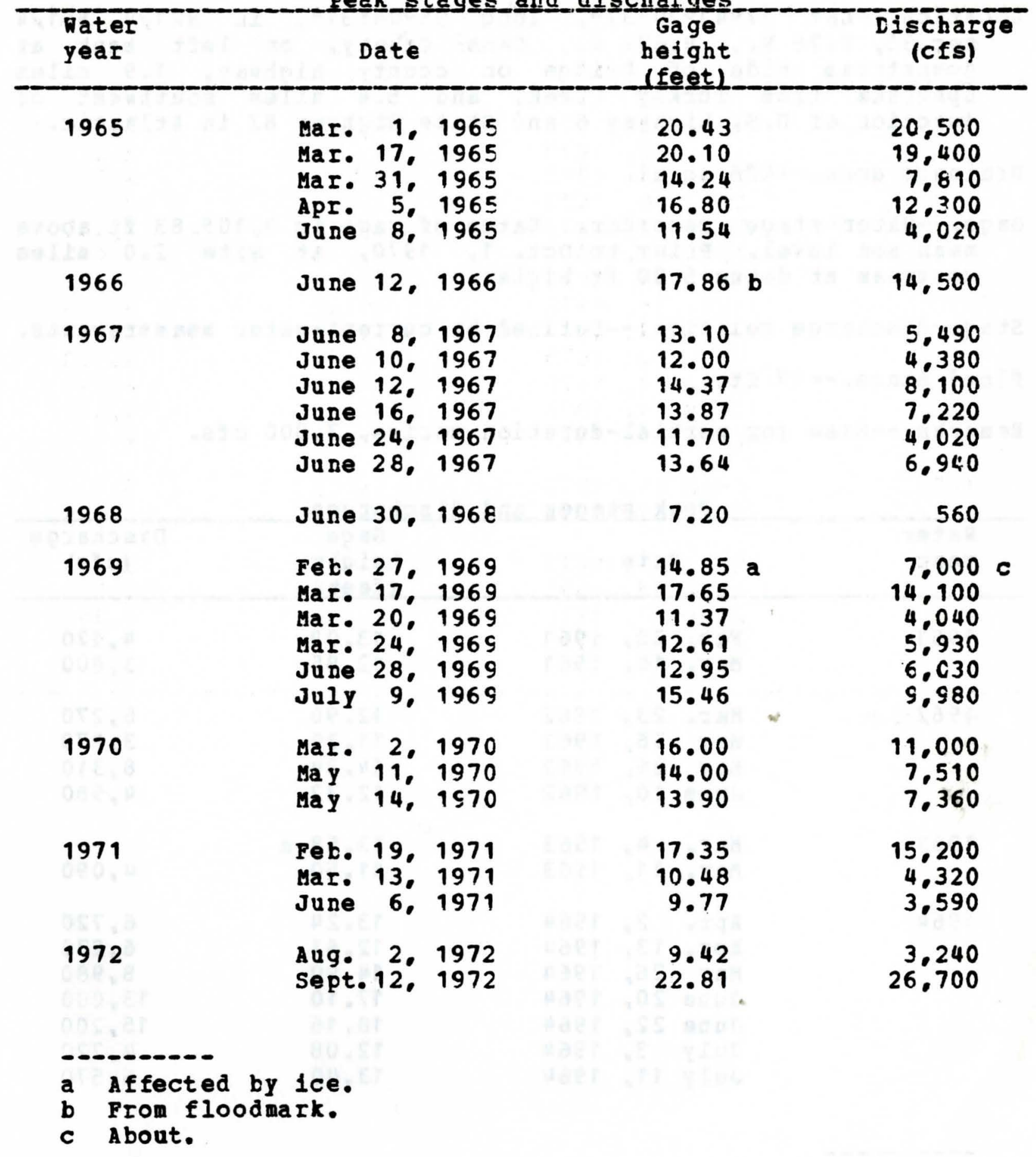


06-8092.10 East Mishnabotna River near Atlantic, Iowa--(Continued)

Peak__tagges_and discharges

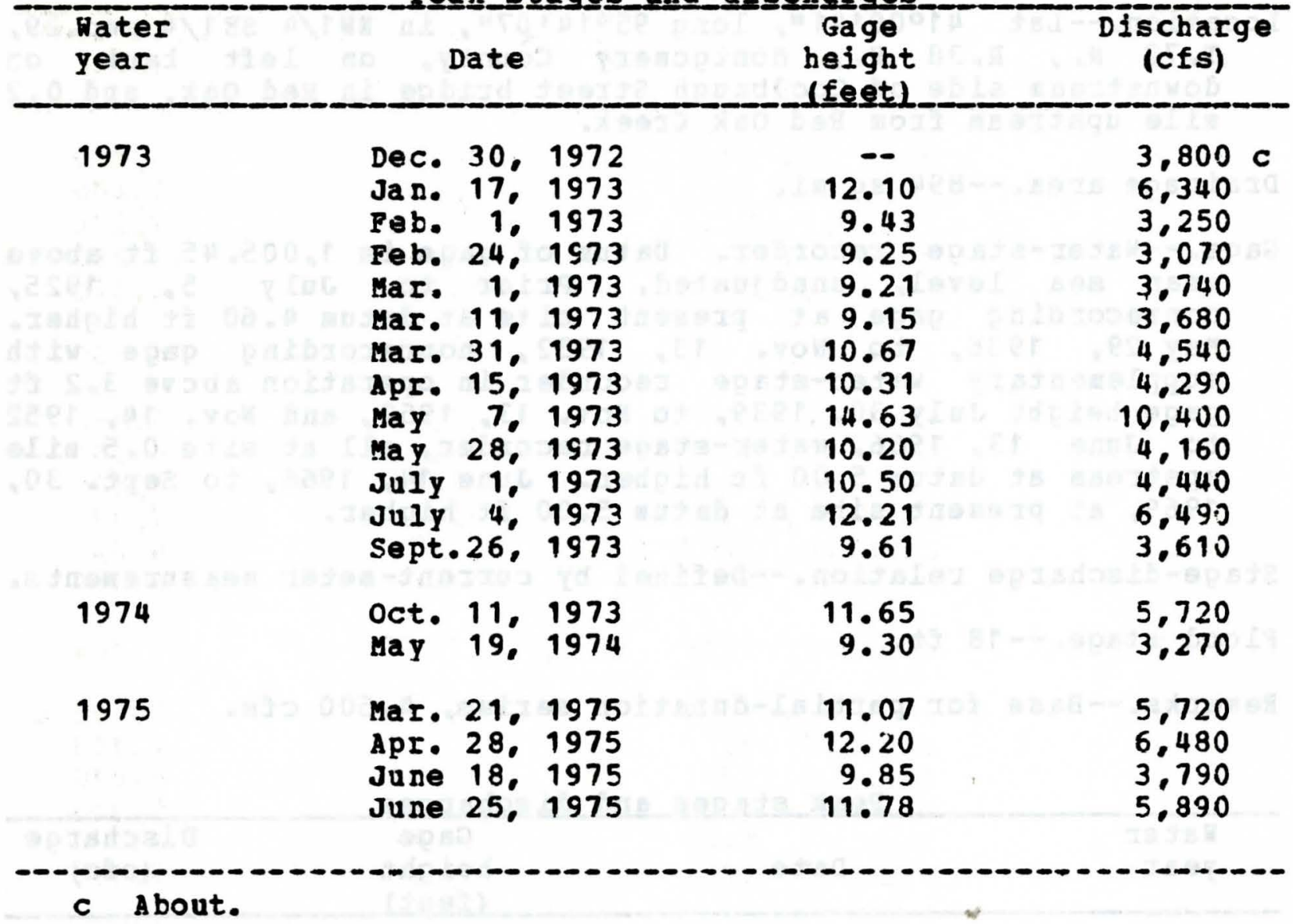


Location.--Iat $41000 \cdot 41^{\prime \prime}$, long $95^{\circ} 14 \cdot 07^{\prime \prime}$, in NW1/4 SE1/4 seC.29, T.72 N.. R.38 N.. Montgomery County. on left rank on downstream side of Coolbaugh street bridge in Red Oak, and 0.2 mile upstream from Red Oak Creek.

Drainage area.--894 sq mi.

Gage.--Water-stage recorder. Datum of gage is 1.005.45 ft above mean sea level, unadjusted. prior to July 5,1925, nonrecording gage at present site at datum $4.60 \mathrm{ft}$ higher. May 29, 1936, to Nov. 13, 1952, nonrecording gage with supplementary water-stage recorder in operation abcve $3.2 \mathrm{ft}$ gage height July 30, 1939, to Nov. 13, 1952, and Nov. 14, 1952 to June 13, 1966, water-stage recorder, all at site $0.5 \mathrm{mile}$ upstream at datum $5.00 \mathrm{ft}$ higher. June 14, 1966, to seft. 30 , 1969, at present site at datum $5.00 \mathrm{ft}$ higher.

Stage-discharge relation.--Defined by current-meter measurements. Flood stage.-- $18 \mathrm{ft.}$

Remarks.--Base for partial-duration series, 4,500 cfs.

Peak_stages_and_discharges

\begin{tabular}{|c|c|c|c|}
\hline $\begin{array}{l}\text { water } \\
\text { year }\end{array}$ & Date & $\begin{array}{l}\text { Gage } \\
\text { height } \\
\text { (feet) }\end{array}$ & $\begin{array}{c}\text { Discharge } \\
\text { (cfs) }\end{array}$ \\
\hline 1917 & June 7,1917 & 21.7 & 23,500 \\
\hline 1918 & May 29,1918 & 13.6 & 3,740 \\
\hline 1919 & June 13,1919 & 13.1 & 3,300 \\
\hline 1920 & Арг. 21. 1920 & $12 \cdot 6$ & 2.920 \\
\hline 1921 & Sept.21. 1921 & $12 \cdot 4$ & 2.800 \\
\hline 1922 & sept. 2. 1922 & 13.6 & 3.740 \\
\hline 1923 & seft.29, 1923 & $12 \cdot 2$ & 2.700 \\
\hline 1924 & $\begin{array}{lr}\text { June } 9, & 1924 \\
\text { June } 26, & 1924\end{array}$ & $\begin{array}{l}16 \cdot 5 \\
18 \cdot 2\end{array}$ & $\begin{array}{r}6.800 \\
10.000\end{array}$ \\
\hline 1925 & June 25,1925 & 10,0 & 1.850 \\
\hline 1936 & sept.16, $1 \varsigma 36$ & 14.8 & 3.800 \\
\hline
\end{tabular}


06-8095.00 East Nishnabotna River at Red Oak, Iowa--(Continued)

Feak stages and discharges

\begin{tabular}{|c|c|c|c|c|c|c|}
\hline $\begin{array}{l}\text { Hater } \\
\text { year }\end{array}$ & Date & & & $\begin{array}{l}\text { Gage } \\
\text { height } \\
\text { (feet) }\end{array}$ & & $\begin{array}{c}\text { Discharge } \\
\text { (cfs) }\end{array}$ \\
\hline 1937 & $\begin{array}{l}\text { Feb. } 19 . \\
\text { Mar. } 4 .\end{array}$ & $\begin{array}{l}1937 \\
1937\end{array}$ & & $\begin{array}{l}15.7 \\
18.6\end{array}$ & & $\begin{array}{l}4.800 \\
5.600\end{array}$ \\
\hline 1938 & Sept. 14. & 1538 & & 14.9 & & $3 . E 10$ \\
\hline 1939 & Aug. 12 & 1939 & & 18.2 & & 9.070 \\
\hline 1940 & Aug. 13 & $194 C$ & foer & 15.83 & & 5.000 \\
\hline 1941 & $\begin{array}{l}\text { June } 4, \\
\text { June } 10 \%\end{array}$ & $\begin{array}{l}1 c 41 \\
1941\end{array}$ & & $\begin{array}{l}15.5 \\
15.4\end{array}$ & & $\begin{array}{l}4.580 \\
4.550\end{array}$ \\
\hline 1942 & $\begin{array}{ll}\text { May } & 12 . \\
\text { June } & 29 . \\
\text { July } & 20\end{array}$ & $\begin{array}{l}1942 \\
1942 \\
1942\end{array}$ & & $\begin{array}{l}15.9 \\
16.1 \\
18.4\end{array}$ & & $\begin{array}{l}5.100 \\
5.300 \\
8.100\end{array}$ \\
\hline 1943 & $\begin{array}{l}\text { Feb. } \\
\operatorname{May}\end{array}$ & $\begin{array}{l}1943 \\
1943\end{array}$ & & $\begin{array}{l}17.9 \\
16.8\end{array}$ & & $\begin{array}{l}8, \in 10 \\
6,810\end{array}$ \\
\hline 1944 & $\begin{array}{ll}\text { May } & 22, \\
\text { June } & 14 . \\
\text { Aug. } & 2 .\end{array}$ & $\begin{array}{l}1944 \\
1944 \\
1944\end{array}$ & & $\begin{array}{l}17.7 \\
16.0 \\
17.9\end{array}$ & & $\begin{array}{l}8.200 \\
5.500 \\
8.500\end{array}$ \\
\hline 1945 & $\begin{array}{l}\text { Mar. } 11, \\
\text { Apr. } 24, \\
\text { May } 15, \\
\text { May } 23, \\
\text { May } 28, \\
\text { June 1, } \\
\text { June } 7, \\
\text { June } 16,\end{array}$ & $\begin{array}{l}1945 \\
1945 \\
1945 \\
1945 \\
1945 \\
1945 \\
1945 \\
1945\end{array}$ & & $\begin{array}{l}15.5 \\
16.5 \\
17.6 \\
20.5 \\
15.8 \\
17.0 \\
17.2 \\
14.5\end{array}$ & $\sim$ & $\begin{array}{r}5.400 \\
6,400 \\
8,000 \\
16.100 \\
8.000 \\
9.800 \\
10.100 \\
6.300\end{array}$ \\
\hline 1946 & $\begin{array}{lr}\text { Jan. } & 6, \\
\text { Fet. } & 6, \\
\text { Mar. } & 6, \\
\text { Mar. } & 13, \\
\text { May } & 3, \\
\text { June } & 18, \\
\text { Aug. } & 26,\end{array}$ & $\begin{array}{l}1946 \\
1946 \\
1946 \\
1946 \\
1946 \\
1946 \\
1946\end{array}$ & 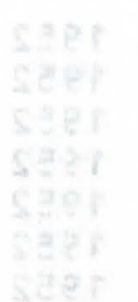 & $\begin{array}{l}16.4 a \\
18.2 \\
13.5 \\
12.9 \\
12.6 \\
14.3 \\
18.2\end{array}$ & & $\begin{array}{r}6.400 \quad b \\
12.000 \\
5.350 \\
4.850 \\
4.600 \\
6.090 \\
12.000\end{array}$ \\
\hline
\end{tabular}

a Affected by ice.

b About. 
06-8095.00 East Nishnabotna Fiver at Red Oak, Iowa--(Ccntinued)

Peak stages_and di scharges

\section{Nater \\ year}

1947

1949

1950

1951

1952

1953

1954
Date
Gage

heigh :

(feet)

14.3

16.1

12.5

19.0

18.7

23.2

12.1

19.6

15.8

18.9

12.0

10.3

17.7

9.8

9.6

9.8

10.5

11.8

11.2

11.4

14. 31

9.55

16.97

14. 1

13.7

14.9

10.9

10.56

11.58

15.53

13.54

9.95

11.28

10.22

12.58

7.77

14.08
Discharge

(cfs)

6,800

8.900

5.150

13.900

13.400

¿6.200

7.100

$15 . £ 00$

12.400

18,400

$7.00 \mathrm{C}$

5,200

15.800

4.720

4,540

4.720

6.550

8.580

7.620

7,940

10.700

4.850

15.200

10.400

9.920

11,600

6.190

5.860

7.020

12.600

9.500

5.250

6.660

5.450

8.280

3.250

10.400 
06-8095.00 East Nishnabotna River at Red Oak, Iowa--(Continued)

Feak_stag€s_and_discharges

\begin{tabular}{|c|c|c|c|c|c|}
\hline $\begin{array}{l}\text { water } \\
\text { year }\end{array}$ & Date & & $\begin{array}{l}\text { Gage } \\
\text { height } \\
\text { (feet) }\end{array}$ & & $\begin{array}{c}\text { Discharge } \\
\text { (cfs) }\end{array}$ \\
\hline 1955 & $\begin{array}{l}\text { Mar. } 3 . \\
\text { Apr. } 24 .\end{array}$ & $\begin{array}{l}1955 \\
1955\end{array}$ & $\begin{array}{l}13.58 \\
10.19\end{array}$ & & $\begin{array}{l}9.640 \\
5.450\end{array}$ \\
\hline 1956 & sept. $s_{\text {. }}$ & $1 \leqq 56$ & 12.57 & & 7,630 \\
\hline 1957 & $\begin{array}{ll}\text { May } & 30 . \\
\text { June } 17 .\end{array}$ & $\begin{array}{l}1557 \\
1957\end{array}$ & $\begin{array}{l}11.35 \\
15.12\end{array}$ & & $\begin{array}{r}6.780 \\
11.800\end{array}$ \\
\hline 1958 & $\begin{array}{l}\text { Feb. } 24, \\
\text { July } 3 . \\
\text { July } 19 . \\
\text { Aug. 1. } \\
\text { Sept. } 7 .\end{array}$ & $\begin{array}{l}1958 \\
1958 \\
1958 \\
1958 \\
1558\end{array}$ & $\begin{array}{l}12.17 \\
22 \cdot 27 \\
13.20 \\
10.30 \\
18.58\end{array}$ & $\mathbf{a}$ & $\begin{array}{r}7.710 \mathrm{~b} \\
35.600 \\
9.700 \\
5.960 \\
19.900\end{array}$ \\
\hline 1959 & $\begin{array}{lr}\text { Feb. } & 27 . \\
\text { May } & 3 \\
\text { Hay } & 29 .\end{array}$ & $\begin{array}{l}1559 \\
1959 \\
1959\end{array}$ & $\begin{array}{r}9.25 \\
10.35 \\
15.14\end{array}$ & $\mathbf{a}$ & $\begin{array}{r}4.800 \quad b \\
6 ., 800 \\
12,700\end{array}$ \\
\hline 1960 & $\begin{array}{l}\text { Mar. } 30 . \\
\operatorname{May} 25 .\end{array}$ & $\begin{array}{l}156 C \\
1960\end{array}$ & $\begin{array}{r}16.40 \\
9.25\end{array}$ & & $\begin{array}{r}15.100 \\
5.000\end{array}$ \\
\hline 1961 & $\begin{array}{l}\text { Feb. } 23 . \\
\text { Har. } 15 .\end{array}$ & $\begin{array}{l}1961 \\
1961\end{array}$ & $\begin{array}{l}10.88 \\
12.25\end{array}$ & & $\begin{array}{l}6.880 \\
8.510\end{array}$ \\
\hline 1962 & $\begin{array}{l}\text { Mar. } 23, \\
\text { May } 29, \\
\text { June } 9\end{array}$ & $\begin{array}{l}1962 \\
1962 \\
1 \subseteq \in 2\end{array}$ & $\begin{array}{l}12.00 \\
15.28 \\
11.61\end{array}$ & 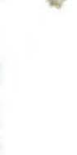 & $\begin{array}{r}9.460 \\
13.000 \\
7.730\end{array}$ \\
\hline 1963 & Mar. 11. & $19 \in 3$ & 10.90 & & 8.920 \\
\hline 1964 & $\begin{array}{lr}\text { Apr. } & 2 \% \\
\text { Apr. } & 13, \\
\text { May } 26, \\
\text { June } 20, \\
\text { June } 23, \\
\text { July } 3 . \\
\text { July } 11 .\end{array}$ & $\begin{array}{l}19 \in 4 \\
1964 \\
1964 \\
1964 \\
1964 \\
1964 \\
1964\end{array}$ & $\begin{array}{r}10.87 \\
10.38 \\
14.43 \\
15.00 \\
15.96 \\
9.33 \\
12.77\end{array}$ & & $\begin{array}{r}10.700 \\
9.700 \\
11.600 \\
13.200 \\
14.300 \\
5.000 \\
9.320\end{array}$ \\
\hline
\end{tabular}

a Affected by ice.

b a bout. 
06-8095.00 East Nishrabctna River at Red Oak, Iowa--(Ccntinued)

Feak_stages_and_discharges

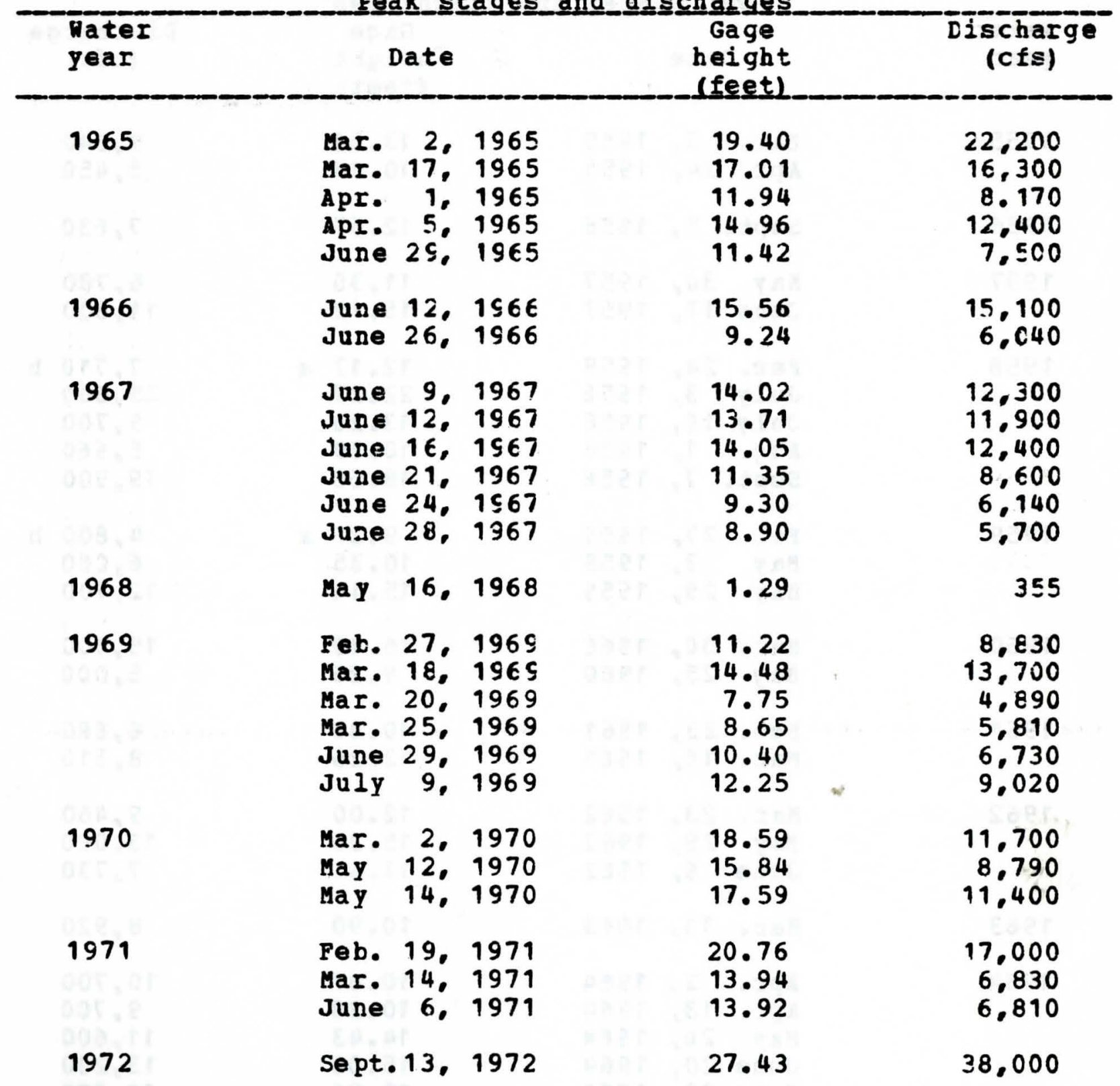


06-8095.00 East Nishnabotna River at Red Oak, Iowa--(Continued)

Peak stages and di schharges

\begin{tabular}{|c|c|c|c|c|}
\hline $\begin{array}{l}\text { Water } \\
\text { year }\end{array}$ & Date & & $\begin{array}{c}\text { Gage } \\
\text { height } \\
\text { (feet) }\end{array}$ & $\begin{array}{c}\text { Discharge } \\
\text { (cfs) }\end{array}$ \\
\hline 1973 & $\begin{array}{l}\text { Dec. } 30, \\
\text { Jan. } 17^{\circ} \\
\text { Feb. } 2, \\
\text { Mar. } 1, \\
\text { Mar. 14, } \\
\text { MaI. } 31^{\circ} \\
\text { ApI. 16, } \\
\text { May } 8, \\
\text { May } 28, \\
\text { JuIy } 4, \\
\text { Sept. } 26,\end{array}$ & $\begin{array}{l}1972 \\
1973 \\
1973 \\
1973 \\
1973 \\
1973 \\
1973 \\
1973 \\
1973 \\
1973 \\
1973\end{array}$ & $\begin{array}{l}15.47 \\
17.73 \\
14.35 \\
12.72 \\
13.25 \\
14.50 \\
14.37 \\
19.20 \\
13.40 \\
15.49 \\
13.08\end{array}$ & $\begin{array}{r}7.810 \\
10.900 \\
6.500 \\
4.810 \\
5.310 \\
6.660 \\
6.520 \\
14.500 \\
6.240 \\
8.740 \\
5.460\end{array}$ \\
\hline 1974 & $\begin{array}{l}\text { Oct. } 11 . \\
\text { MaI. } 3 .\end{array}$ & $\begin{array}{l}1973 \\
1974\end{array}$ & $\begin{array}{l}15.28 \\
12.08\end{array}$ & $\begin{array}{l}8.460 \\
4.600\end{array}$ \\
\hline 1975 & $\begin{array}{l}\text { Mar. } 21, \\
\text { Mar. } 28, \\
\text { Apr. } 28, \\
\text { June } 19 . \\
\text { June } 25 .\end{array}$ & $\begin{array}{l}1975 \\
1975 \\
1975 \\
1975 \\
1975\end{array}$ & $\begin{array}{l}15.00 \\
12.40 \\
15.84 \\
12.72 \\
14.19\end{array}$ & $\begin{array}{l}7.600 \\
4.730 \\
8.610 \\
5.050 \\
6.630\end{array}$ \\
\hline
\end{tabular}




\section{6-8118.00 East Tarkio Creek near Stanton, Iowa}

Location.--Lat $41005^{\prime}$, long $95^{\circ 006}$, in $1 / 2$ sec.34, T.73 N.. R.37

W.. Montgomery County, at bridge, 7 miles north of stanton.

Drainage area.- $-4.66 \mathrm{sq} \mathrm{mi}$.

Gage.--Crest-stage gage.

Stage-discharge relation.--Defined by current-meter measurements. Remarks.--only annual peaks are shown.

Peak s_tageges_and_discharges

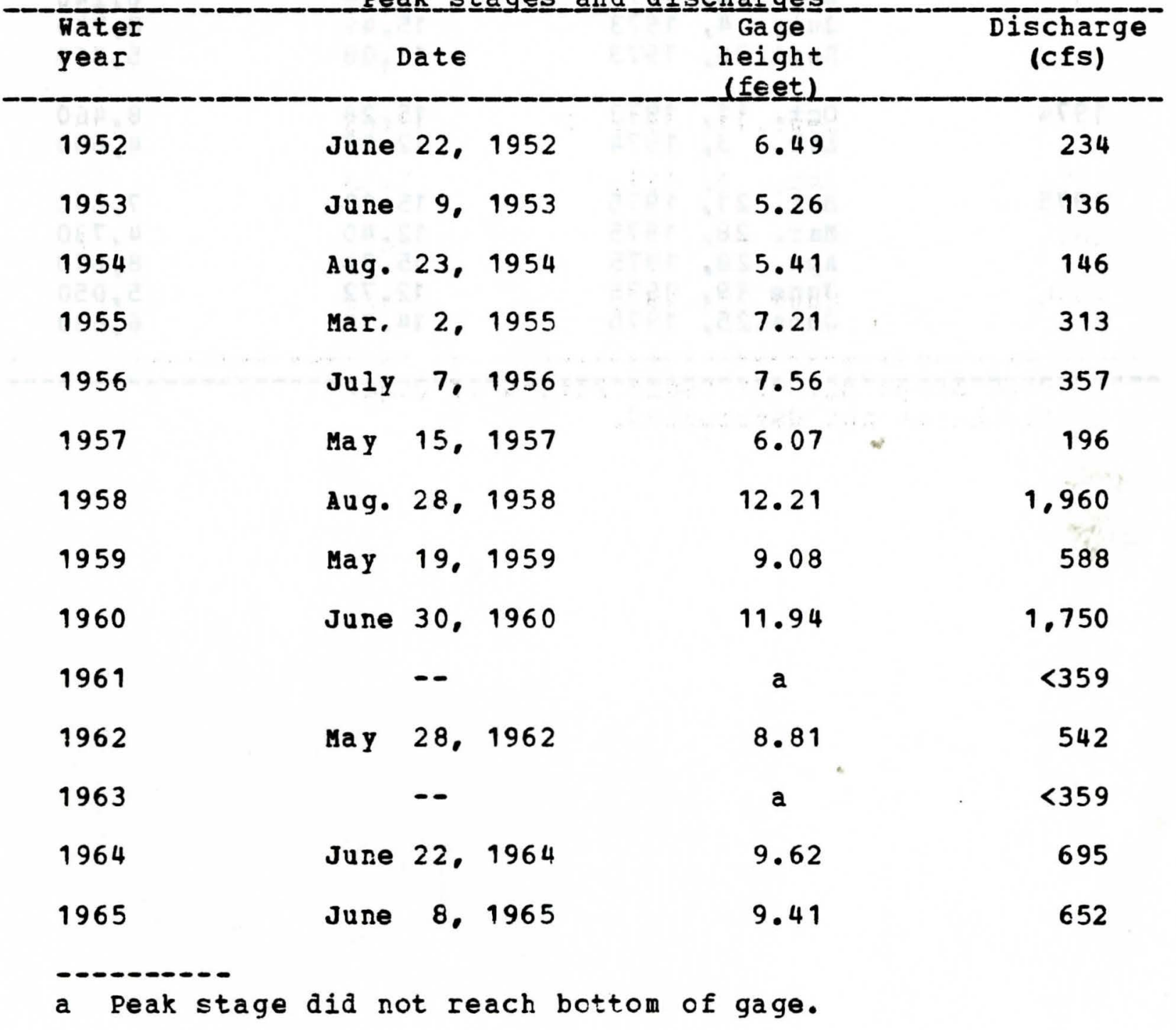


06-8118.00 East Tarkio Creek near Stanton, Iowa--(Continued)

Peak stages and discharges

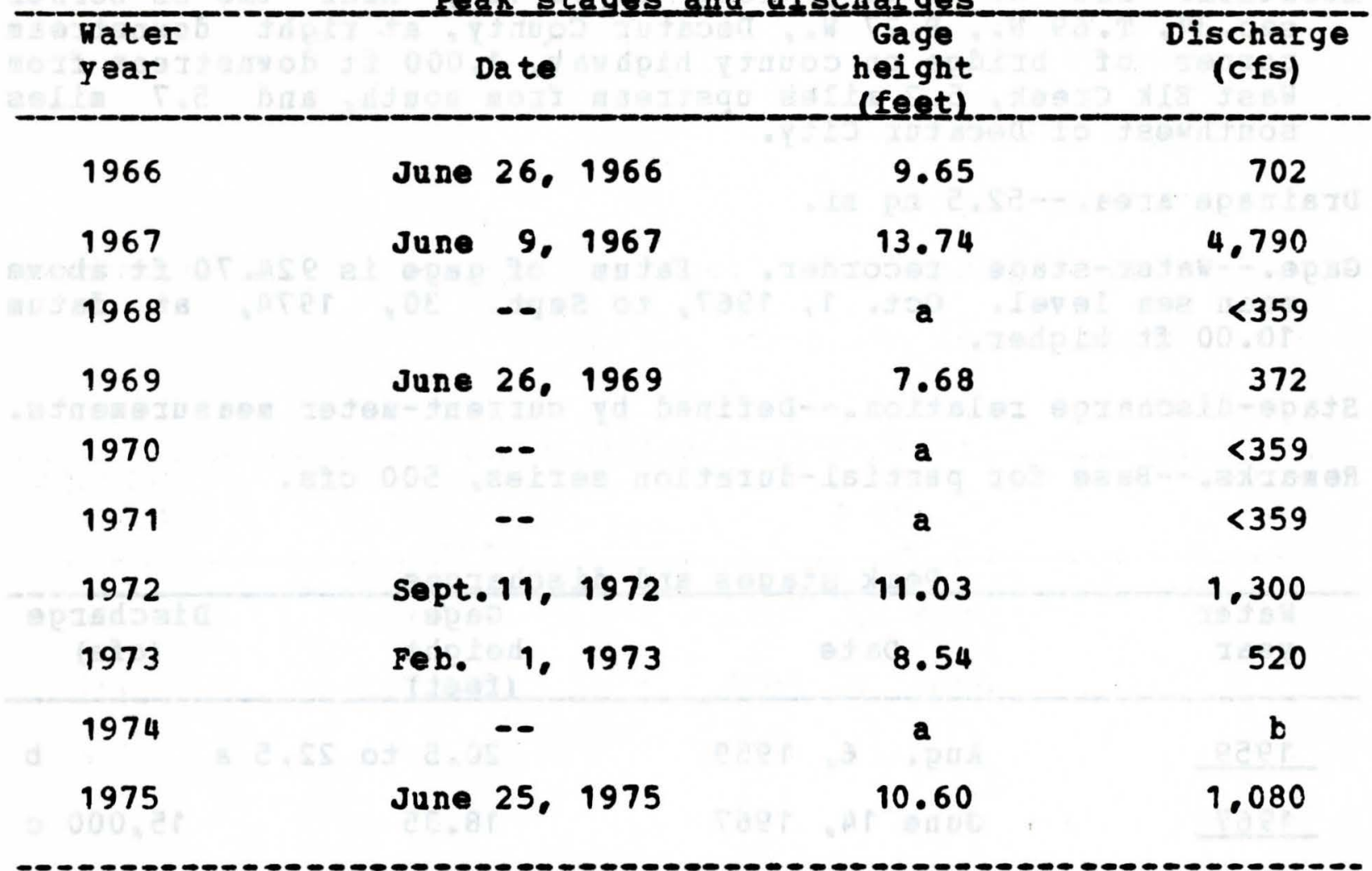

a Peak stage did not reach botton of gage.

b Discharge not deternined. 


\section{6-8979.50 Elk Creek near Decatur City. Iowa}

Location.--Lat $40043118 "$, long 93056'12". near the SE corner sec.34. T.69 N.. R. 27 H.. Decatur County, at right downstream corner of bridge on county highway, 1,000 ft downstream from West Elk Creek, 5.2 miles upstream from mouth, and 5.7 miles southwest of Decatur City.

Drainage area.--52.5 sq mi.

Gage.-- Mater-stage recorder. Latum of gage is $924.70 \mathrm{ft}$ above mean sea level. Oct. 1, 1967, to sept. 30, 1974, at datum $10.00 \mathrm{ft}$ higher.

Stage-discharge relation.--Defined by current-meter measurements. Remarks.--Base for partial-duration series, 500 cfs.

Pea $\underline{k}$ stages and di $\underline{i}$ scharges

\begin{tabular}{|c|c|c|c|c|}
\hline $\begin{array}{l}\text { Water } \\
\text { year }\end{array}$ & Date & & $\begin{array}{r}\text { Gage } \\
\text { height } \\
\text { (feet) }\end{array}$ & $\begin{array}{c}\text { Discharge } \\
\text { (cfs) }\end{array}$ \\
\hline $19 \underline{59}$ & Aug. 6. & 1959 & 20.5 to $22.5 \mathrm{a}$ & b \\
\hline 1967 & June 14 & 1967 & 18.35 & $15,000 \mathrm{c}$ \\
\hline 1968 & $\begin{array}{l}\text { ApI. } 23, \\
\text { July } 23, \\
\text { Aug. } 4 .\end{array}$ & $\begin{array}{l}1968 \\
1968 \\
1968\end{array}$ & $\begin{array}{r}10.50 \\
8.14 \\
9.75\end{array}$ & $\begin{array}{l}2.900 \\
1.540 \\
2.450\end{array}$ \\
\hline 1969 & $\begin{array}{lr}\text { Apr. } & 4, \\
\text { Apr. } & 17, \\
\text { Apr. } & 26, \\
\text { May } & 7, \\
\text { May } 21, \\
\text { June } 12, \\
\text { June } 28, \\
\text { June } 30, \\
\text { July } 9, \\
\text { July } 18,\end{array}$ & $\begin{array}{l}1969 \\
1969 \\
1969 \\
1969 \\
1969 \\
1969 \\
1969 \\
1969 \\
1969 \\
1969\end{array}$ & $\begin{array}{r}6.11 \\
7.55 \\
11.39 \\
10.44 \\
11.32 \\
8.47 \\
10.27 \\
10.40 \\
15.23 \\
8.69\end{array}$ & $\begin{array}{r}654 \\
1.300 \\
3.490 \\
2.930 \\
3.440 \\
1.700 \\
2.760 \\
2.840 \\
7.710 \\
1.820\end{array}$ \\
\hline
\end{tabular}

a From information by assistant county engineer, $300 \mathrm{ft}$ downstream.

b Discharge not determined.

c Estimated from rating curve extended above $5,300 \mathrm{cfs}$ on basis of step-backwater computation, datum in use prior to oct. 1. 1974. 
06-8979.50 Elk Creek near Decatur City, Iowa--(Continued)

Peak

\begin{tabular}{|c|c|c|c|}
\hline $\begin{array}{l}\text { Water } \\
\text { year }\end{array}$ & Date & $\begin{array}{l}\text { Gage } \\
\text { height } \\
\text { (feet) }\end{array}$ & $\begin{array}{c}\text { Discharge } \\
\text { (cfs) }\end{array}$ \\
\hline 1970 & $\begin{array}{l}\text { Apr. 18, } 1970 \\
\text { May 12, } 1970 \\
\text { Aug. 3, } 1970 \\
\text { Sept.15, } 1970 \\
\text { Sept.17, } 1970 \\
\text { Sept.22, } 1970\end{array}$ & $\begin{array}{r}8.98 \\
13.59 \\
5.77 \\
6.72 \\
5.93 \\
6.79\end{array}$ & $\begin{array}{r}1.990 \\
5.310 \\
500 \\
848 \\
556 \\
876\end{array}$ \\
\hline 1971 & 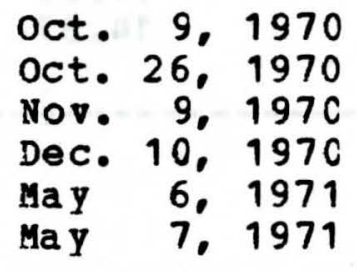 & $\begin{array}{l}5.94 \\
6.49 \\
5.78 \\
6.49 \\
6.10 \\
6.56\end{array}$ & $\begin{array}{l}559 \\
756 \\
503 \\
756 \\
636 \\
784\end{array}$ \\
\hline 1972 & $\begin{array}{lrr}\text { May } & 7, & 1972 \\
\text { May } & 12, & 1972 \\
\text { June } & 17, & 1972 \\
\text { July } & 19, & 1972 \\
\text { July } 26, & 1972 \\
\text { Sept.12, } & 1972\end{array}$ & $\begin{array}{r}11.46 \\
7.42 \\
9.64 \\
7.76 \\
9.71 \\
15.41 \mathrm{~d}\end{array}$ & $\begin{array}{l}3,480 \\
1,220 \\
2,400 \\
1,360 \\
2,470 \\
8.130\end{array}$ \\
\hline 1973 & $\begin{array}{l}\text { Nov. 13, } 1972 \\
\text { Dec. } 29,1972 \\
\text { Jan. 16, } 1973 \\
\text { Feb. 1, } 1973 \\
\text { Mar. 10, } 1974 \\
\text { Mar. 13, } 1974 \\
\text { Mar. 25, } 1974 \\
\text { Apr. 1, } 1973 \\
\text { Apr. 16, } 1973 \\
\text { May } 7,1973 \\
\text { Aug. 11, } 1973 \\
\text { Sept.26, } 1973\end{array}$ & $\begin{array}{c}6.21 \\
-- \\
10.07 \\
13.25 \\
7.91 \\
10.77 \\
9.65 \\
-- \\
-- \\
-- \\
8.46 \\
11.50\end{array}$ & $\begin{array}{l}654 \\
3.400 \mathrm{e} \\
2.640 \\
4.920 \\
1.420 \\
3.060 \\
2,390 \\
2,000 \mathrm{e} \\
2.200 \mathrm{e} \\
700 \mathrm{e} \\
1.700 \\
3.500\end{array}$ \\
\hline 1974 & $\begin{array}{l}\text { Cct. 11, } 1973 \\
\text { Nov. } 20,1973 \\
\text { Dec. } 4,1973 \\
\text { Jan. } 20,1974 \\
\text { Jan. } 26,1974 \\
\text { Mar. } 8,1974 \\
\text { Apr. } 21,1974 \\
\text { May } 30,1974 \\
\text { June } 9,1974\end{array}$ & $\begin{array}{r}13.60 \\
7.49 \\
9.90 \\
-- \\
-- \\
6.05 \\
12.50 \\
12.47 \\
--\end{array}$ & $\begin{array}{l}5.320 \\
1.220 \\
2.540 \\
1.000 \mathrm{e} \\
1.300 \mathrm{e} \\
598 \\
4.170 \\
4.150 \\
4.600 \mathrm{e}\end{array}$ \\
\hline
\end{tabular}


06-8979.50 Elk Creek near Decatur City, Iowa--(Continued)

Feakㅡ_stages_and_dis $\underline{\text { ch harges }}$

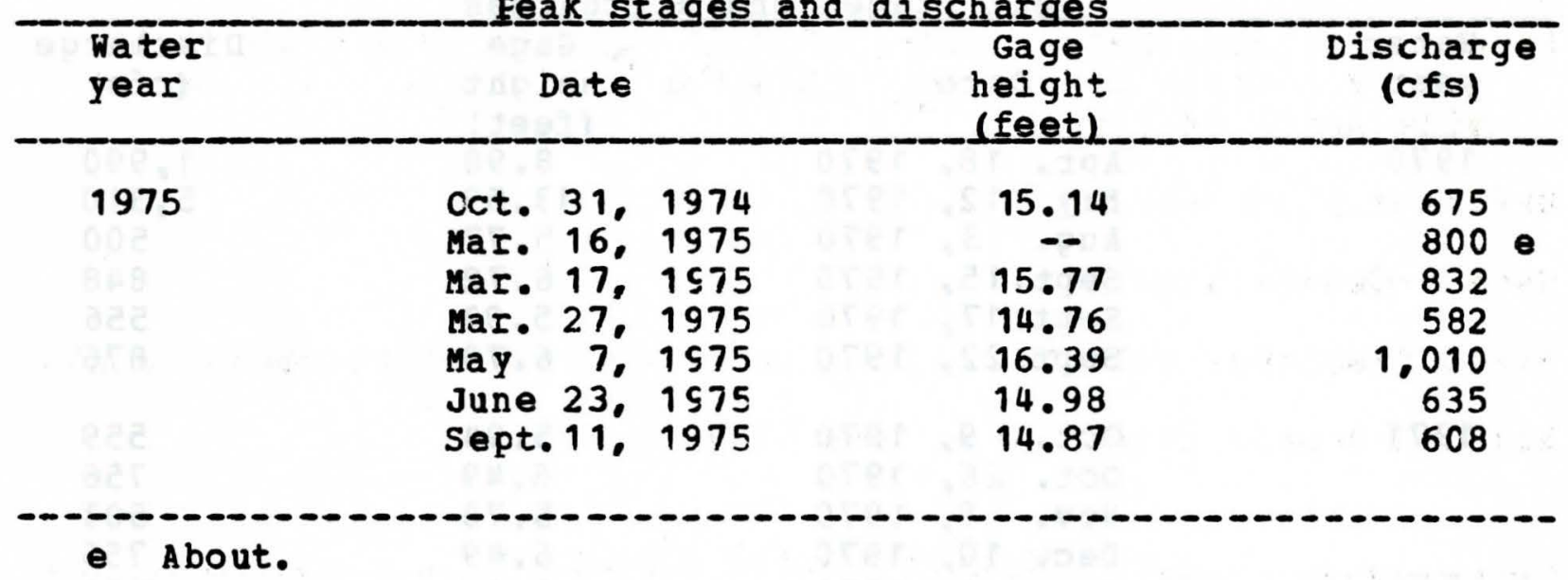




$$
\text { 05-4590.10 Elk Creek at Kensett, Iowa }
$$

Location.--Iat $43022^{\prime}$, long 930131 , in NE1/4 sec.28, I.99 N.. R. 20 \%.. Worth County, at bridge on U.S. Highway 65 , about 1 mile north of Kensett.

Drainage area. $--58.1 \mathrm{sq}$ mi.

Gage.--Crest-stage gage.

Stage-discharge relation.--Defined by current-meter measurements. Remarks.--only annual peaks are shown.

Feak_stages and di scharges

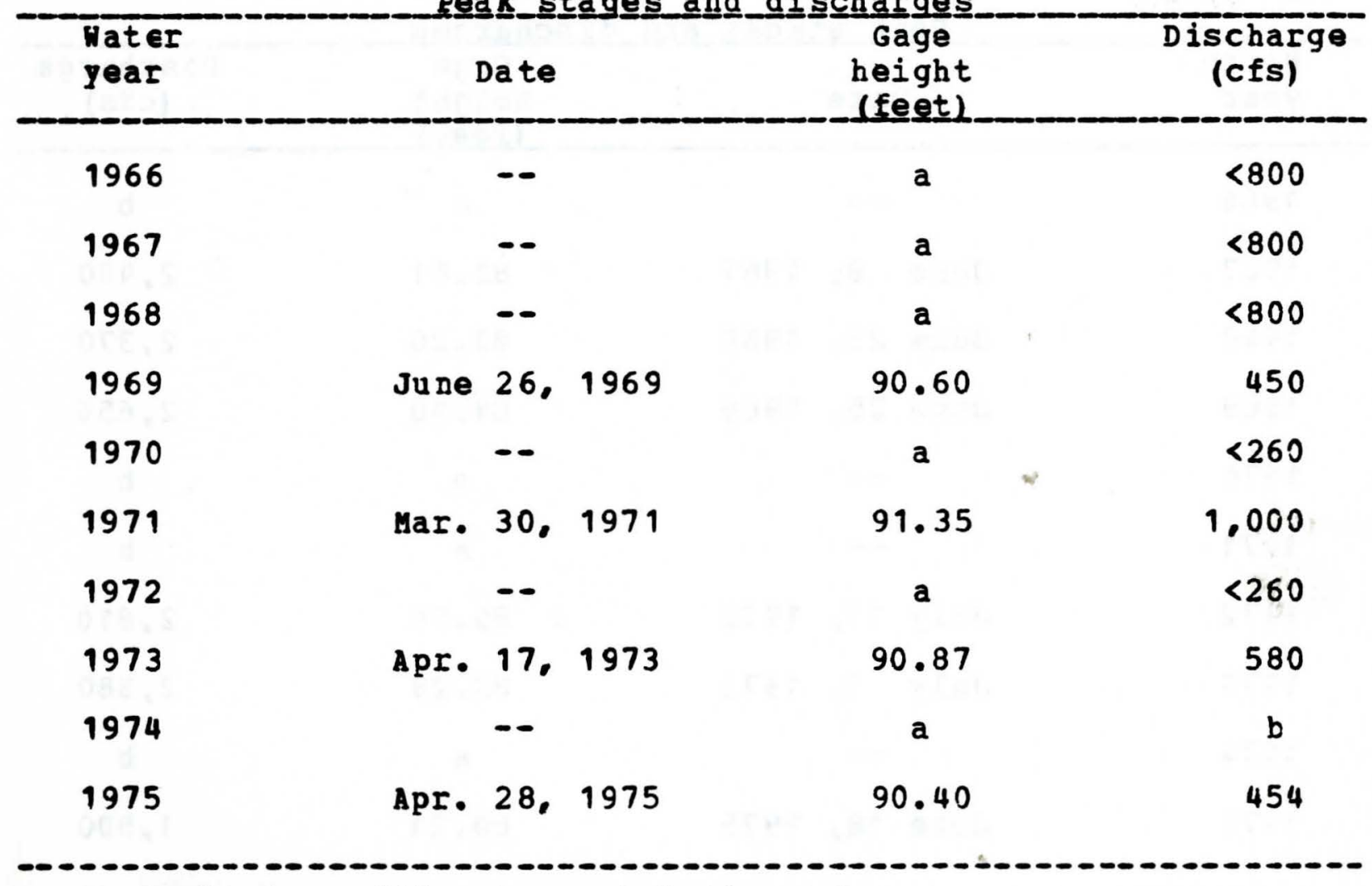

a Peak stage did not reach bottom of gage.

b Discharge not determined. 


\section{6-6021.90 Ellict Creek at Lawton, Iowa}

Location,--Iat $42028 \%$, Iong 96011 , in NW1/4 sec.3. T. 88 N., R. 46 W. Noodbury County, at bridge on 0.5 . Highway 20 , at west edge of Iawton.

Drainage area.--34.8 sq mi.

Gage.--Crest-stage gage.

Stage-discharge relation.--Defined by current-meter and indirect measurements.

Remarks.--Only annual peaks are shown.

Peak﹎.stages_and_di

\begin{tabular}{|c|c|c|c|c|c|c|}
\hline $\begin{array}{l}\text { Water } \\
\text { year }\end{array}$ & & Date & & $\begin{array}{c}\text { Gage } \\
\text { height } \\
\text { (feet) }\end{array}$ & & $\begin{array}{c}\text { Discharge } \\
\text { (cfs) }\end{array}$ \\
\hline 1966 & & -- & & $a$ & & $b$ \\
\hline 1967 & June & 8. & 1967 & 83.61 & & 2.450 \\
\hline 1968 & June & 25. & 1968 & $83 \cdot 26$ & & 2.370 \\
\hline 1969 & June & 25. & 1969 & 84.40 & & 2.650 \\
\hline 1970 & & $\cdots$ & & a & $*$ & b \\
\hline 1971 & & -- & & $a$ & & b \\
\hline 1972 & Ju Iy & 17. & 1972 & 85.09 & & 2.810 \\
\hline 1973 & JuIY & 9. & 1973 & 83.28 & & 2.380 \\
\hline 1974 & & -- & & $a$ & & $\mathbf{b}$ \\
\hline 1975 & June & 18. & 1975 & 80.21 & & 1.500 \\
\hline
\end{tabular}

a Peak stage did not reach bottom of gage.

b Discharge not determined. 
Location.--Iat 410279591 , long $91042 \cdot 56 "$, in SE1/4 SE1/4 sec.13, T.77 N.. R. 8 W., Washington County, on right bank $30 \mathrm{ft}$ upstream from bridge on State Highway $1,0.8$ mile south of Kalona, 1.1 mile upstream from Camp Creek, 4.5 miles downstream from Smith Creek, and 14.5 miles upstream from mouth.

Drainage area. $--573 \mathrm{sq} \mathrm{mi}$.

Gage.--Hater-stage recorder. Datum of gage is $633.45 \mathrm{ft}$ above mean sea level (levels by Ccrps of Engineers). Prior to Dec. 27. 1939. nonrecording gage $30 \mathrm{ft}$ downstream at same datum.

Stage-discharge relation.--Defined by current-meter measurements. Flood stage. $-14 \mathrm{ft}$.

Remarks.--Base for partial-duration series, 4,000 cfs. Base was 2,800 prior to 1966 .

Pea

\begin{tabular}{|c|c|c|c|}
\hline $\begin{array}{l}\text { Water } \\
\text { year }\end{array}$ & Date & $\begin{array}{c}\text { Gage } \\
\text { height } \\
\text { (feet) }\end{array}$ & $\begin{array}{c}\text { Discharge } \\
\text { (cfs) }\end{array}$ \\
\hline 1930 & June 30,1930 & $19.9 \mathrm{a}$ & 18,500 \\
\hline 1940 & Mar. 19, 1940 & 7.35 & 1.400 \\
\hline 1941 & July 2, 1941 & 10.0 & 2.490 \\
\hline 1942 & Nov. 2, 1941 & 11.8 & 3.340 \\
\hline 1943 & $\begin{array}{lr}\text { Feb. } & 5,1943 \\
\text { May } 1,1943 \\
\text { May 17, } 1943 \\
\text { Aug. } & 5,1943\end{array}$ & $\begin{array}{l}13.8 \mathrm{~b} \\
11.1 \\
12.8 \\
18.11\end{array}$ & $\begin{array}{r}3,960 \mathrm{c} \\
3,000 \\
4,030 \\
10,700\end{array}$ \\
\hline 1944 & $\begin{array}{l}\text { Apr. } 16,1944 \\
\text { Apr. } 23,1944 \\
\text { May } 22,1944 \\
\text { May } 27,1944 \\
\text { June } 17,1944\end{array}$ & $\begin{array}{l}11.9 \\
15.3 \\
15.9 \\
13.8 \\
13.2\end{array}$ & $\begin{array}{l}3.660 \\
6.670 \\
6.810 \\
4.730 \\
4.290\end{array}$ \\
\hline
\end{tabular}

a Fom floodmark, from infcrmation by local resident.
c Affected by ice.
About. 
05-4555.00 English River at Kalona, Iowa-- (Continued)

Peak_stages_and_discharges

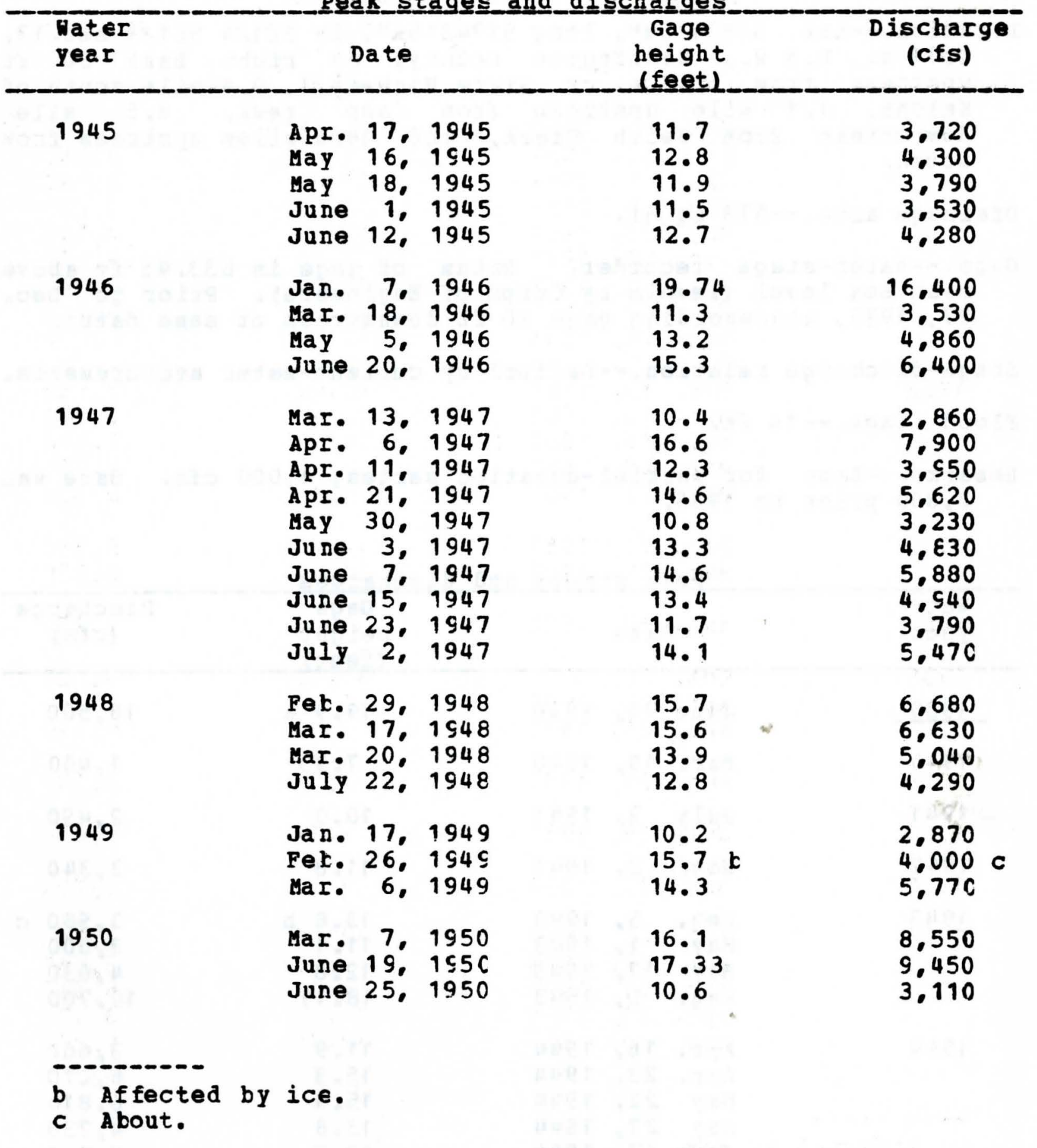


05-4555.00 English River at Kalona. Iowa--(Continued)

Peak stages and di scharges

\begin{tabular}{|c|c|c|c|c|c|c|}
\hline $\begin{array}{l}\text { Water } \\
\text { year }\end{array}$ & & Date & & $\begin{array}{l}\text { Gage } \\
\text { height } \\
\text { (feet) }\end{array}$ & & $\begin{array}{c}\text { Discharge } \\
\text { (cfs) }\end{array}$ \\
\hline 1951 & $\begin{array}{l}\text { Feb. } \\
\text { Mar. } \\
\text { Apr. } \\
\text { May } \\
\text { May } \\
\text { June } \\
\text { JuIy } \\
\text { July } \\
\text { Aug. }\end{array}$ & $\begin{array}{r}19, \\
30 \\
8, \\
11 . \\
27 . \\
26, \\
4 \% \\
10 \\
26\end{array}$ & $\begin{array}{l}1951 \\
1951 \\
1951 \\
1951 \\
1951 \\
1951 \\
1951 \\
1951 \\
1951\end{array}$ & $\begin{array}{l}12.26 \\
11.84 \\
11.61 \\
10.46 \\
12.70 \\
11.24 \\
10.82 \\
11.06 \\
14.74\end{array}$ & b & $\begin{array}{l}3.700 \mathrm{c} \\
3.860 \\
3.740 \\
3.080 \\
4.490 \\
3.500 \\
3.260 \\
3.440 \\
6.130\end{array}$ \\
\hline 1952 & $\begin{array}{l}\text { Nov. } \\
\text { MaI. } \\
\text { MaI. } \\
\text { May } \\
\text { June }\end{array}$ & $\begin{array}{l}13 . \\
12 . \\
19 . \\
24 . \\
21 .\end{array}$ & $\begin{array}{l}1951 \\
1952 \\
1952 \\
1952 \\
1952\end{array}$ & $\begin{array}{l}12.09 \\
15.47 \\
10.12 \\
11.02 \\
10.18\end{array}$ & & $\begin{array}{l}3.930 \\
6.840 \\
2.870 \\
3.380 \\
2.920\end{array}$ \\
\hline 1953 & $\begin{array}{l}\text { Feb. } \\
\text { Mar. }\end{array}$ & $\begin{array}{l}21 . \\
31 .\end{array}$ & $\begin{array}{l}1953 \\
1953\end{array}$ & $\begin{array}{l}14.43 \\
10.27\end{array}$ & & $\begin{array}{l}5.860 \\
2.970\end{array}$ \\
\hline 1954 & Aug. & 27. & $1 \subseteq 54$ & 8.90 & & 2.270 \\
\hline 1955 & $\begin{array}{l}\text { Oct. } \\
\text { Apr. } \\
\text { Apr. }\end{array}$ & $\begin{array}{l}10 \\
20 \\
25\end{array}$ & $\begin{array}{l}1954 \\
1955 \\
1955\end{array}$ & $\begin{array}{l}11.35 \\
10.83 \\
13.4\end{array}$ & 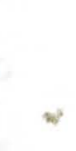 & $\begin{array}{l}3.620 \\
3.260 \\
5.020\end{array}$ \\
\hline 1956 & Aug. & 31. & 1956 & 10.78 & & 2.730 \\
\hline 1957 & July & 15. & 1957 & 9.17 & & 2.000 \\
\hline 1958 & May & 31, & 1958 & 9.75 & & 2,200 \\
\hline 1959 & $\begin{array}{l}\text { Fer. } \\
\text { Feb. } \\
\text { Mar. } \\
\text { Apr. } \\
\text { tay }\end{array}$ & $\begin{array}{l}23 \\
25 \\
21 \\
29 \\
30\end{array}$ & $\begin{array}{l}1959 \\
1959 \\
1959 \\
1959 \\
1959\end{array}$ & $\begin{array}{l}12.80 \\
12.23 \\
17.12 \\
11.19 \\
12.54\end{array}$ & b & $\begin{array}{l}3.300 \mathrm{c} \\
3.590 \\
8.960 \\
3.170 \\
4.000\end{array}$ \\
\hline
\end{tabular}

b Affected by ice.

c About. 
05-4555.00 English River at Kalona, Iowa-- (Continued)

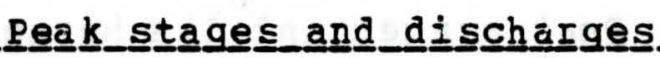

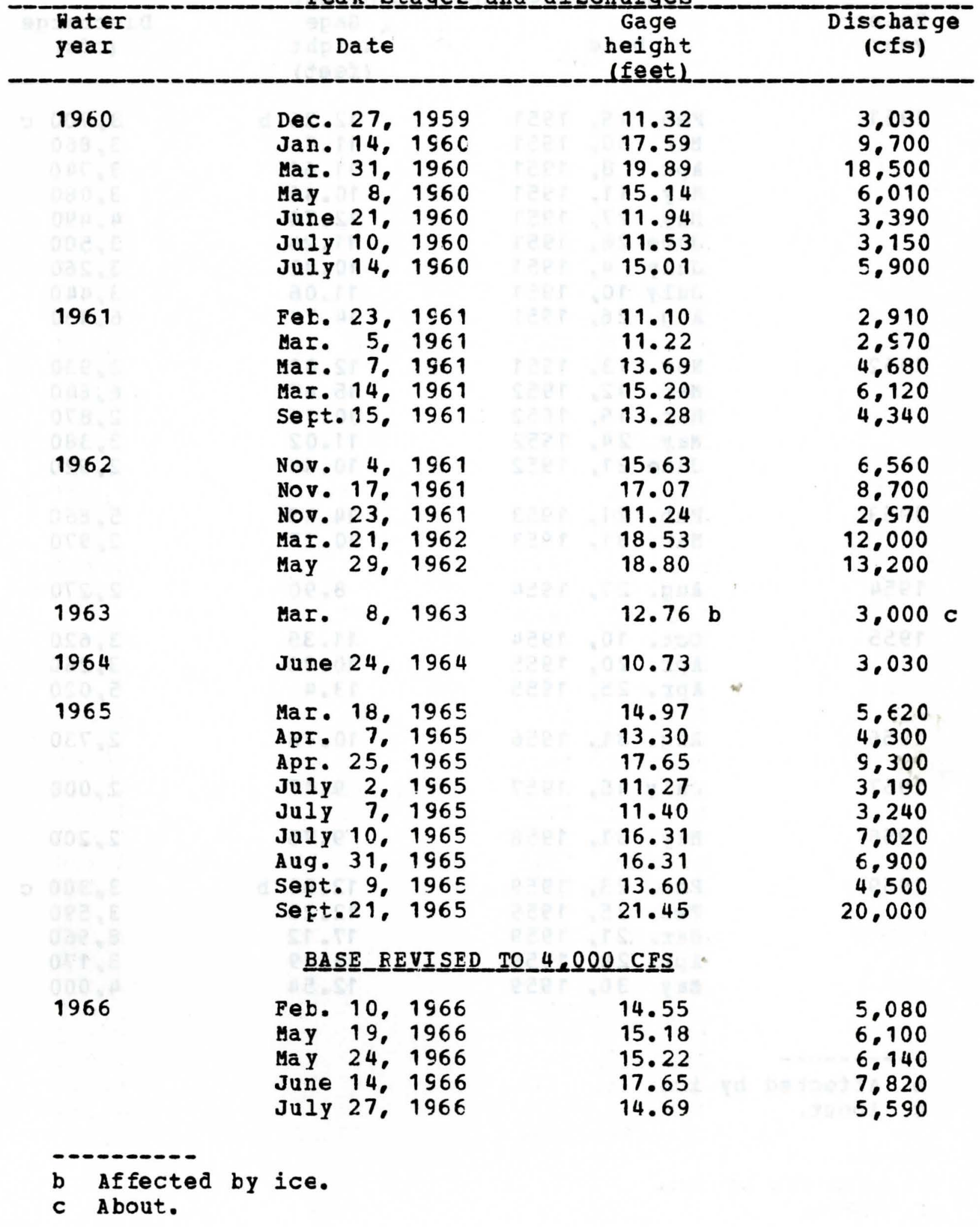


05-4555.00 English River at Kalona. Iowa--(Continued)

Peak staqes and discharges

\begin{tabular}{|c|c|c|c|c|c|c|c|}
\hline $\begin{array}{l}\text { Hater } \\
\text { year }\end{array}$ & 1 & Date & & $\begin{array}{l}\text { Gage } \\
\text { height } \\
\text { (feet) }\end{array}$ & & $\begin{array}{c}\text { Discharg } \\
\text { (cfs) }\end{array}$ & \\
\hline 1967 & June & 10 & 1967 & 14.47 & & 5,370 & \\
\hline 1968 & Nov. & 29. & 1967 & 7.93 & & 1.590 & \\
\hline 1969 & $\begin{array}{l}\text { June } \\
\text { June } \\
\text { June } \\
\text { July } \\
\text { July } \\
\text { Aug. }\end{array}$ & $\begin{array}{l}10 \\
27 \\
30 \\
10 \\
20 \\
11\end{array}$ & $\begin{array}{l}1969 \\
1969 \\
1969 \\
1969 \\
1969 \\
1969\end{array}$ & $\begin{array}{l}12.73 \\
13.24 \\
12.93 \\
15.91 \\
14.33 \\
16.04\end{array}$ & & $\begin{array}{l}4.010 \\
4.340 \\
4.150 \\
6.900 \\
5.250 \\
7.060\end{array}$ & \\
\hline 1970 & $\begin{array}{l}\text { Mar. } \\
\text { Aug. } \\
\text { Sept. }\end{array}$ & $\begin{array}{r}4 . \\
7 \% \\
17 \%\end{array}$ & $\begin{array}{l}1970 \\
1970 \\
1970\end{array}$ & $\begin{array}{l}18.79 \\
18.77 \\
16.77\end{array}$ & & $\begin{array}{r}13.200 \\
13.100 \\
8.160\end{array}$ & \\
\hline 1971 & $\begin{array}{l}\text { Feb. } \\
\text { July }\end{array}$ & $\begin{array}{l}20 \\
11 .\end{array}$ & $\begin{array}{l}1971 \\
1971\end{array}$ & $\begin{array}{l}18.44 \\
13.57\end{array}$ & b & $\begin{array}{l}5.300 \\
4.560\end{array}$ & $c$ \\
\hline 1972 & $\begin{array}{l}\text { Dec. } \\
\text { Mar. } \\
\text { Apr. } \\
\text { May } \\
\text { Aug. }\end{array}$ & $\begin{array}{r}15, \\
1 \% \\
2 \% \\
9 \\
8\end{array}$ & $\begin{array}{l}1971 \\
1972 \\
1972 \\
1972 \\
1972\end{array}$ & $\begin{array}{c}14.23 \\
-- \\
14.55 \\
13.94 \\
15.81\end{array}$ & & $\begin{array}{l}5.160 \\
4.100 \\
5.450 \\
4.900 \\
6.790\end{array}$ & C \\
\hline 1973 & $\begin{array}{l}\text { Jan. } \\
\text { Jan. } \\
\text { Feb. } \\
\text { Apr. } \\
\text { Apr. } \\
\text { May } \\
\text { May } \\
\text { June }\end{array}$ & $\begin{array}{r}1 \% \\
19 \% \\
2 \% \\
17 \% \\
21 \% \\
6 \% \\
6 \%\end{array}$ & $\begin{array}{l}1973 \\
1973 \\
1973 \\
1973 \\
1973 \\
1973 \\
1973 \\
1973\end{array}$ & $\begin{array}{c}-- \\
-- \\
12.80 \\
16.17 \\
16.62 \\
15.17 \\
17.74 \\
12.98\end{array}$ & $*$ & $\begin{array}{l}4.200 \\
4.600 \\
4.100 \\
7.260 \\
7.930 \\
6.030 \\
9.980 \\
4.190\end{array}$ & $\begin{array}{l}c \\
c\end{array}$ \\
\hline 1974 & $\begin{array}{l}\text { Jan. } \\
\text { Jan. } \\
\text { Apr. } \\
\text { May } \\
\text { May } \\
\text { June } \\
\text { June } \\
\text { June } \\
\text { July }\end{array}$ & $\begin{array}{l}28, \\
31 \% \\
30 \% \\
18, \\
29 \% \\
7 \% \\
21 \% \\
23 \% \\
11 \%\end{array}$ & $\begin{array}{l}1974 \\
1974 \\
1974 \\
1974 \\
1974 \\
1974 \\
1974 \\
1974 \\
1974\end{array}$ & $\begin{array}{l}13.71 \\
13.58 \\
19.97 \\
20.17 \\
17.80 \\
13.73 \\
14.13 \\
14.42 \\
14.23\end{array}$ & & $\begin{array}{r}4.680 \\
4.570 \\
17.000 \\
18.400 \\
8.600 \\
4.060 \\
4.340 \\
4.540 \\
4.410\end{array}$ & \\
\hline
\end{tabular}


05-4555.00 English River at Kalona, Iowa-- (Continued)

Peak_stages and_discharges

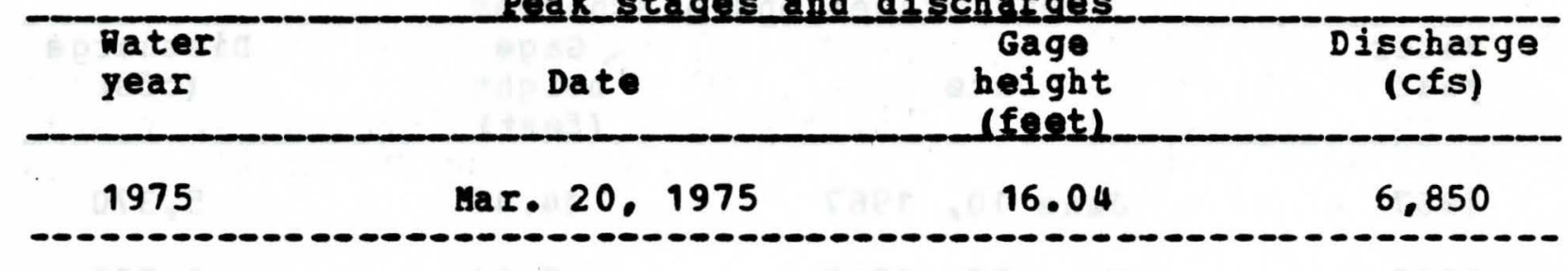


Location.--Iat 42058'55", long 96000'03", in NE1/4 NE1/4 sec.11. T. 94 N.. R. 44 W.. Sioux county, on left bank at dcwnstream side of Chicago and Northwestern Railway Company rridge at east edge of Alton. 34.3 miles upstream from West Branch Floyd River at mile 58.1.

Drainage area.--265 sq mi.

Gage.-Water-stage recorder. Datum of gage is 1,269.55 ft above mean sea level.

Flood stage. $-12 \mathrm{ft}$.

Stage-discharge relation.--Defined by current-meter measurements. Remarks.--Base for partial-duration series, 800 cfs.

Peak_stagges_and_dis

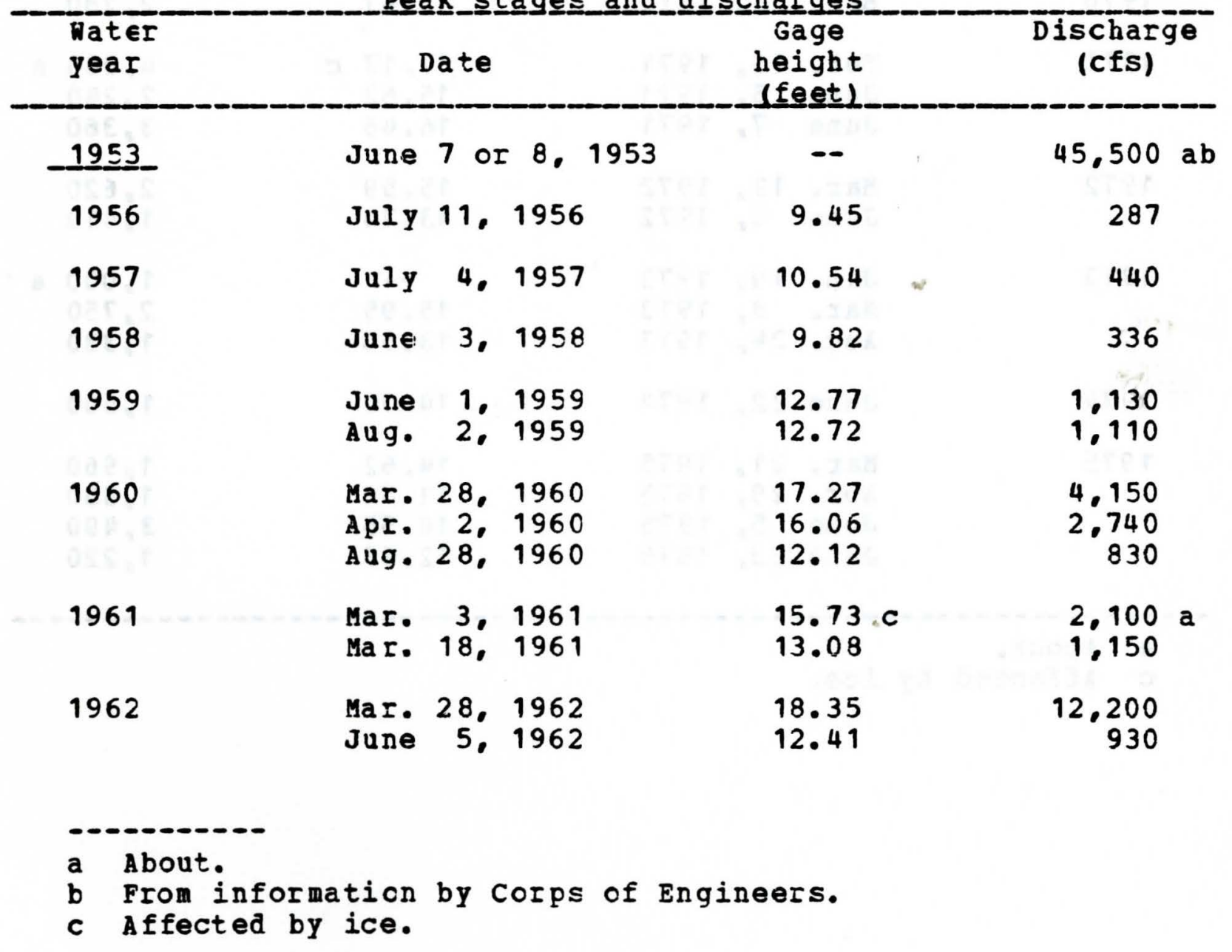


06-6001.00 Floyd River at Alton. Iowa--(Continued)

Feak stages and discharges

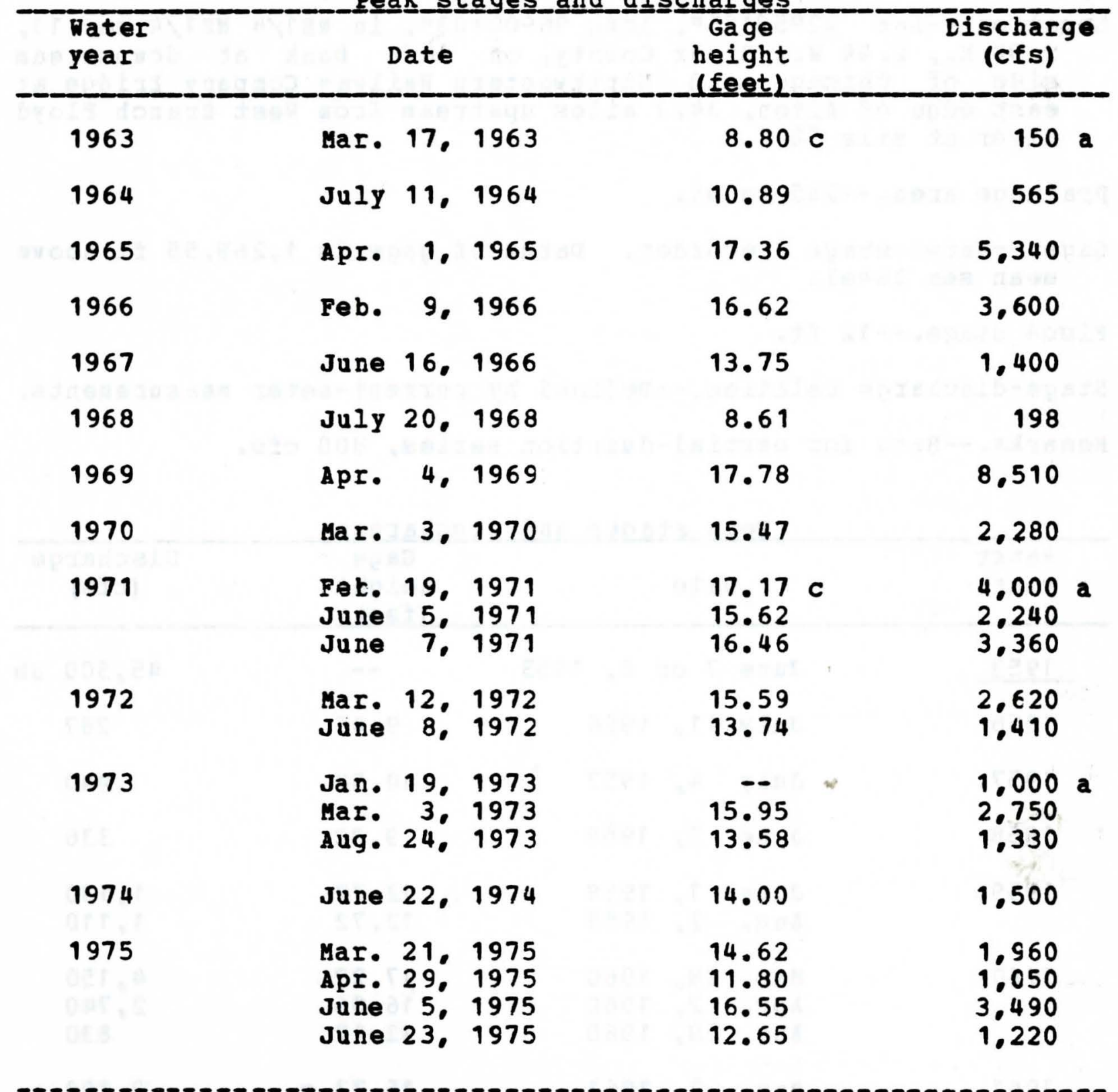

a A bout.

c Affected by ice. 


\section{6-6005.00 Floyd River at James, Iowa}

Location.--Iat $42034 \cdot 36^{\prime \prime}$, long $96018 \cdot 43^{\prime \prime}$, in SE1/4 SE1/4 sec.30. T.90 N.. R.46 W.. Plymouth County, on right bank at dewnstream side of bridge on county highway c70, 0.2 mile east of James, 14.3 miles downstream from West Branch Floyd River, and at mile 9.5 .

Drainage area.--882 sq $\mathrm{mi}$.

Gage.-- Nater-stage recorder. Datum of gage is 1,092.59 ft above mean sea level. Prior tc Sept. 11, 1938. June 9 to Nov. 5 , 1953, and Oct. 1, 1955, to May 22, 1957, nonrecording gage and lly 23, 1957, to Sept. 30, 1970, water-stage recorder at same site at datum 10.C ft higher.

Flocd stage. $--26 \mathrm{ft}$.

Stage-discharge relation.--Defined by current-meter measurements below 16,000 cfs and extended above on basis of contractedopening of flow-over-embankment measurement of peak flow.

Remarks.--Base for partial-duration series, 2,500 cfs.

Peak stages and discharges

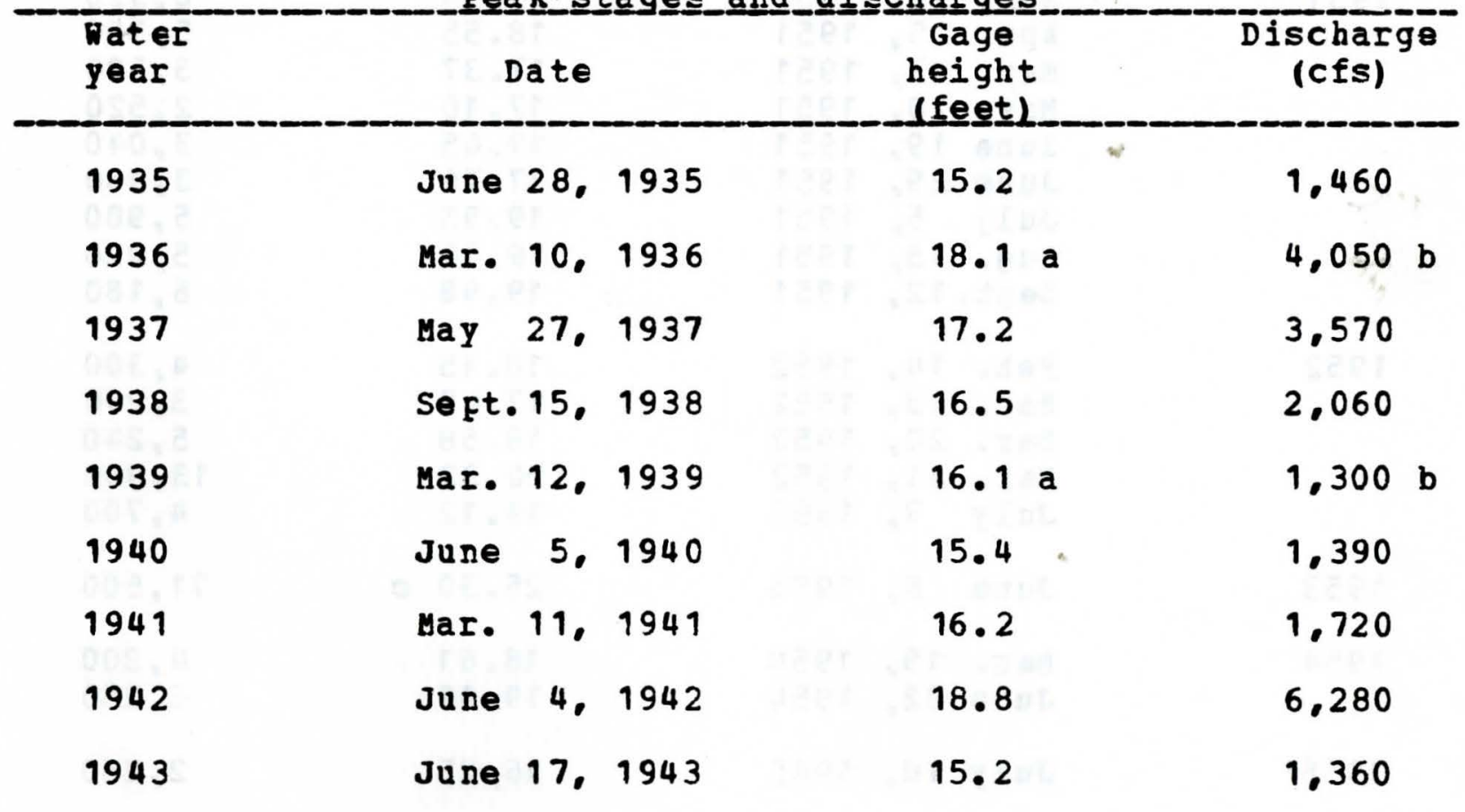

a Affected by ice.

b A bout. 
06-6005.00 Floyd River at James, Iowa--(Continued)

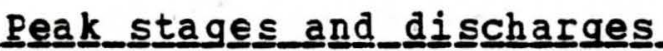

\begin{tabular}{|c|c|c|c|c|c|}
\hline $\begin{array}{l}\text { Water } \\
\text { year }\end{array}$ & Date & 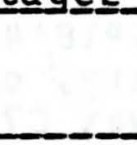 & $\begin{array}{c}\text { Gage } \\
\text { height } \\
\text { (feet) }\end{array}$ & & $\begin{array}{c}\text { Discharge } \\
\text { (cfs) }\end{array}$ \\
\hline 1944 & $\begin{array}{lr}\text { Feb. } & 27, \\
\text { May } & 13, \\
\text { June } & 13, \\
\text { July } & 7 \\
\text { July } & 12,\end{array}$ & $\begin{array}{l}1944 \\
1944 \\
1944 \\
1944 \\
1944\end{array}$ & $\begin{array}{l}17.4 \\
18.8 \\
18 \cdot 1 \\
17.7 \\
17.2\end{array}$ & & $\begin{array}{l}3.600 \\
7.440 \\
5.150 \\
4.350 \\
3.320\end{array}$ \\
\hline 1945 & MaI. 12. & 1945 & $18 \cdot 4$ & & 5,320 \\
\hline 1946 & MaI. 1. & 1946 & $15 \cdot 3$ & & 1.400 \\
\hline 1947 & June 25 & 1947 & 17.8 & & 3.240 \\
\hline 1948 & MaI. 17. & 1948 & 17.1 & & 2.710 \\
\hline 1949 & $\begin{array}{l}\text { Mar. } 5 . \\
\text { Sept. } 12,\end{array}$ & $\begin{array}{l}1949 \\
1949\end{array}$ & $\begin{array}{l}18.1 \\
18.1\end{array}$ & & $\begin{array}{l}4.520 \\
2.720\end{array}$ \\
\hline 1950 & June 19 & 1950 & 19.2 & & 4.840 \\
\hline 1951 & $\begin{array}{lr}\text { Mar. } & 28, \\
\text { Apr. } & 5, \\
\text { May } & 3, \\
\text { May } & 20, \\
\text { June } & 19, \\
\text { June } & 29, \\
\text { July } & 5, \\
\text { Aug. } & 15, \\
\text { Sept. } & 12 .\end{array}$ & $\begin{array}{l}1951 \\
1951 \\
1951 \\
1951 \\
1951 \\
1951 \\
1951 \\
1951 \\
1951\end{array}$ & $\begin{array}{l}19.94 \\
18.55 \\
17.37 \\
17.10 \\
17.65 \\
17.76 \\
19.95 \\
19.35 \\
19.98\end{array}$ & $w$ & $\begin{array}{l}8.320 \\
5.380 \\
3.520 \\
2.520 \\
3.040 \\
3.160 \\
5.980 \\
5.020 \\
6.180\end{array}$ \\
\hline 1952 & $\begin{array}{l}\text { Feb. } 14, \\
\text { Mar. } 13, \\
\text { Mar. } 20, \\
\text { Mar. } 31 . \\
\text { July } 7 .\end{array}$ & $\begin{array}{l}1952 \\
1952 \\
1952 \\
1952 \\
1952\end{array}$ & $\begin{array}{l}18.15 \\
17.49 \\
18.58 \\
20.32 \\
19.12\end{array}$ & & $\begin{array}{r}4.300 \\
3.290 \\
5.240 \\
13.900 \\
4.700\end{array}$ \\
\hline 1953 & June 8 , & 1953 & 25.30 & c & 11.500 \\
\hline 1954 & $\begin{array}{l}\text { MaI. } 19, \\
\text { June } 22,\end{array}$ & $\begin{array}{l}1954 \\
1954\end{array}$ & $\begin{array}{l}18.61 \\
19.88\end{array}$ & & $\begin{array}{l}4.800 \\
6.250\end{array}$ \\
\hline 1955 & July 10. & 1955 & 16.25 & & 2.260 \\
\hline
\end{tabular}

c From floodmark. 
06-6005.00 Floyd River at James, Iowa--(Continued)

Feak stages and discharges

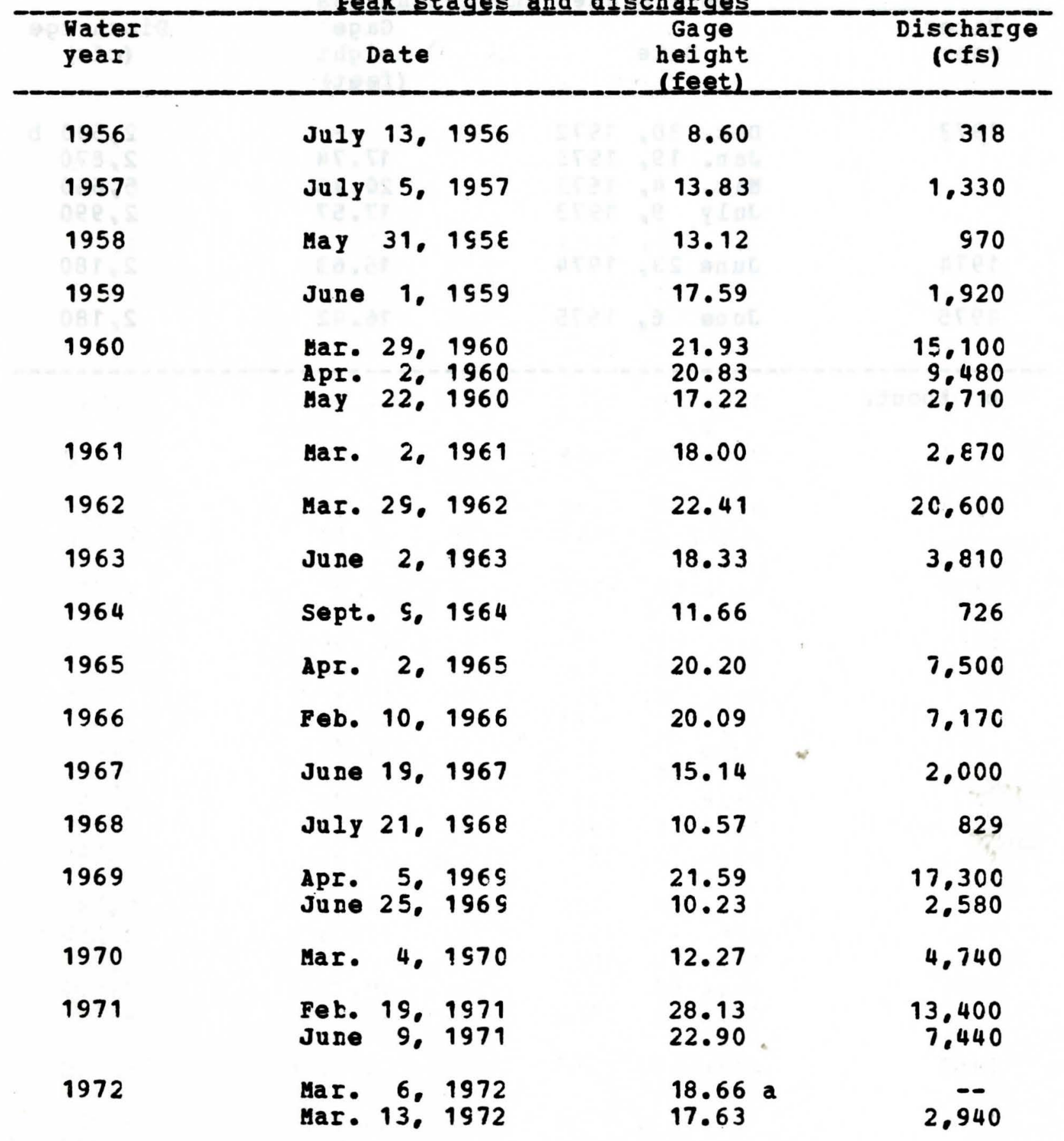

a Affected by ice. 
06-6005.00 Floyd River at James, Iowa--(Continued)

Feak stages and discharges

\begin{tabular}{|c|c|c|c|}
\hline $\begin{array}{l}\text { Water } \\
\text { year }\end{array}$ & Date & $\begin{array}{c}\text { Gage } \\
\text { height } \\
\text { (feeet) }\end{array}$ & $\begin{array}{l}\text { Discharge } \\
\text { (cfs) }\end{array}$ \\
\hline 1973 & $\begin{array}{ll}\text { Dec. } & 30,1972 \\
\text { Jan. } 19,1973 \\
\text { Mar. } & 4,1973 \\
\text { July } & 9,1973\end{array}$ & $\begin{array}{l}17 . \overline{74} \\
20.46 \\
17.57\end{array}$ & $\begin{array}{l}2.500 \quad b \\
2.870 \\
5.660 \\
2.990\end{array}$ \\
\hline 1974 & June 23,1974 & 16.63 & 2,180 \\
\hline 1975 & June $\epsilon, 1975$ & 16.42 & 2,180 \\
\hline
\end{tabular}

b About. 
Location.--Lat $410360^{\circ} 0^{\prime \prime}$, lcng $93^{\circ} 32^{\prime} 4^{\prime \prime}$, in NE1/4 NE1/4 sec.32, T.79 N., R. 23 W.. Polk Ccunty, on right bank 20 ft dcwnstream from bridge on Easton Blvd.. 4.4 miles downstream from Muchikinock Creek and 5.0 miles upstream from Des Moines River.

Drainage area. $--92.7 \mathrm{sq} \mathrm{mi}$.

Gage.--Water-stage recorder. Datum of gage is $795.87 \mathrm{ft}$ above mean sea level.

Stage-discharge relation.--Defined by current-meter measurements. Remarks.--Base for partial-duration series, 500 cfs.

Feak_s

\begin{tabular}{|c|c|c|c|c|c|c|}
\hline $\begin{array}{l}\text { Water } \\
\text { year }\end{array}$ & Date & & $\begin{array}{l}\text { Gage } \\
\text { height } \\
\text { (feet) }\end{array}$ & & $\begin{array}{c}\text { Discharg } \\
\text { (cfs) }\end{array}$ & $9 e$ \\
\hline 1972 & June 20. & 1972 & 9.54 & & 1.440 & \\
\hline 1973 & 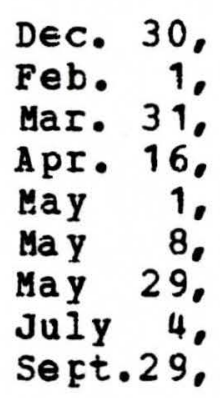 & $\begin{array}{l}1972 \\
1973 \\
1973 \\
1973 \\
1973 \\
1973 \\
1973 \\
1973 \\
1973\end{array}$ & $\begin{array}{c}-- \\
12.71 \\
7.75 \\
10.30 \\
-- \\
-- \\
-- \\
9.67 \\
9.75\end{array}$ & $*$ & $\begin{array}{r}1.000 \\
2.600 \\
702 \\
1.470 \\
600 \\
1.200 \\
500 \\
1.240 \\
1.310\end{array}$ & $\begin{array}{l}a \\
a \\
a\end{array}$ \\
\hline 1974 & 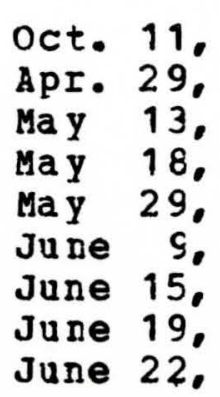 & $\begin{array}{l}1973 \\
1974 \\
1974 \\
1974 \\
1974 \\
1974 \\
1974 \\
1974 \\
1974\end{array}$ & $\begin{array}{r}9.77 \\
10.89 \\
10.05 \\
14.61 \\
7.95 \\
14.84 \\
8.89 \\
14.28 \\
9.40\end{array}$ & & $\begin{array}{r}1,270 \\
1.620 \\
1,280 \\
5.010 \\
655 \\
5.340 \\
914 \\
4.550 \\
1.190\end{array}$ & \\
\hline
\end{tabular}

a About. 
05-4856.40 Fourmile Creek at Des Moines. Iowa-- (Continued)

Feak_stages_and discharges.

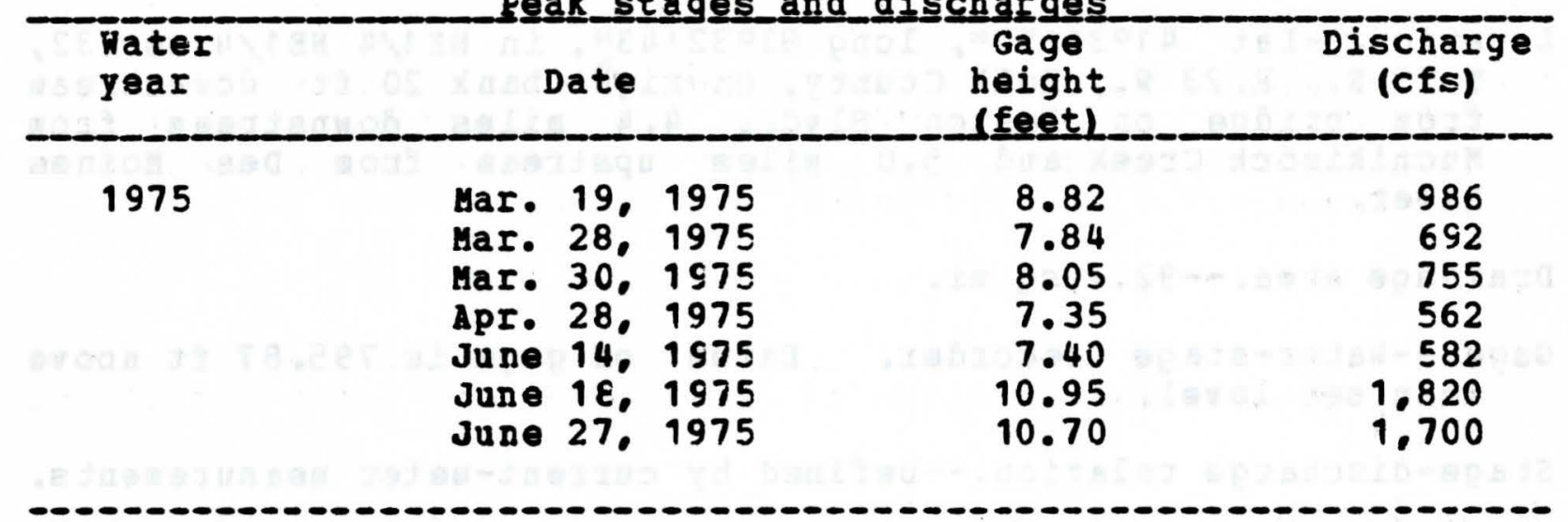




\section{5-4641.30 Fourmile Creek near Iincoln. Iowa (Discontinued september 1974)}

Location.--Iat $42013 \cdot 32 "$ " long $92036 \cdot 39 "$, in SW $1 / 4 \mathrm{SH1} 4 \mathrm{seC.28,}$ T.86 N.. R. 15 W.. Tama County, on left bank 10 ft dcwnstream from bridge on ccunty highway, 1 mile upstream from Half Mile Creek and 4.7 miles southeast of Iinccln.

Drainage area.--13.78 sq mi.

Gage.--Nater-stage recorder and concrete control witb $v$-notch sharp-crested weir. Datum cf gage is $931.26 \mathrm{ft}$ above mean sea lovel.

Stage-discharge relation.--Defined by current-meter measurements. Remarks.--Base for partial-duration series, 400 cfs.

Peak_stages_and_di scharges

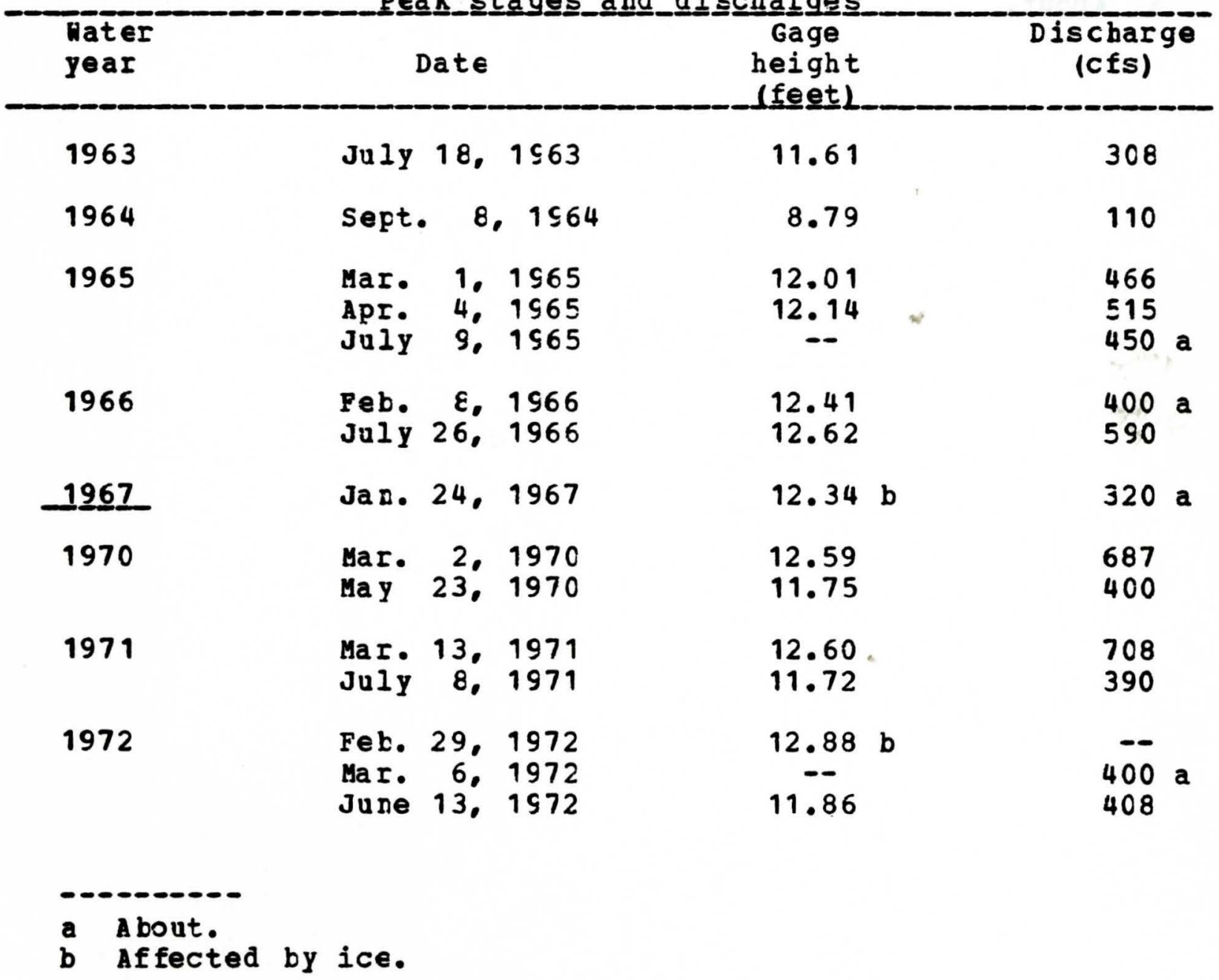


05-4641.30 Fourmile Creek near Iincoln. Iowa--(Continued)

Peak stages and discharges

\begin{tabular}{|c|c|c|c|}
\hline $\begin{array}{l}\text { Water } \\
\text { year }\end{array}$ & Date & $\begin{array}{l}\text { Gage } \\
\text { height } \\
\text { (feet). }\end{array}$ & $\begin{array}{c}\text { Discharge } \\
\text { (cfs) }\end{array}$ \\
\hline 1973 & $\begin{array}{l}\text { Dec. } 30,1973 \\
\text { Feb. 1. } 1973 \\
\text { ApI. 16, } 1973 \\
\text { July 4, } 1973\end{array}$ & $\begin{array}{c}-- \\
12.07 \\
12.96\end{array}$ & $\begin{array}{l}630 a \\
460 a \\
494 \\
859\end{array}$ \\
\hline 1974 & 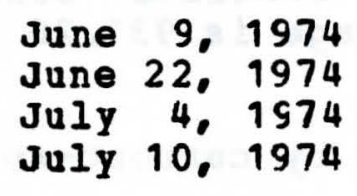 & $\begin{array}{l}13.59 \\
13.98 \\
11.77 \\
11.93\end{array}$ & $\begin{array}{r}1.210 \\
1.450 \\
405 \\
456\end{array}$ \\
\hline Discol & eptember 1974 & & \\
\hline
\end{tabular}

a about. 


\section{5-4641.37 Fourmile Creek near Traer, Iowa}

(Discontinued september 1974)

Location.--Iat $42012 \cdot 07^{\prime \prime}$, Icng $92033.44^{\prime \prime}$, near center cf sec.2. T.85 N.. R. 15 W.. Tama County, on left bank 10 ft dcwistream from bridge on county highway T69, 2.0 miles upstream from mouth, and 5.0 miles northwest of Traer.

Drainage area.--19.51 sq mi.

Gage.--Water-stage recorder and $\nabla$-notch sharp-crested weir. Datum of gage is $905.87 \mathrm{ft}$ abcre mean sea level.

Stage-discharge relation.--Defined by current-meter measurements. Flood stage. - $11 \mathrm{ft.}$

Remarks.--Base for partial-duration series, 400 cfs.

Peak stages and di scharges

\begin{tabular}{|c|c|c|c|c|c|}
\hline $\begin{array}{l}\text { water } \\
\text { year }\end{array}$ & Date & & $\begin{array}{l}\text { Gage } \\
\text { height } \\
\text { (feet) }\end{array}$ & & $\begin{array}{c}\text { Discharge } \\
\text { (cfs) }\end{array}$ \\
\hline 1963 & $\begin{array}{l}\text { MaI. } 13 . \\
\text { JuIy } 18,\end{array}$ & $\begin{array}{l}1963 \\
1963\end{array}$ & $\begin{array}{l}11.50 \\
11.24\end{array}$ & a & 287 \\
\hline 1964 & $\begin{array}{l}\text { Apr. } \\
\text { Sept. } \\
8 .\end{array}$ & $\begin{array}{l}1964 \\
1964\end{array}$ & $\begin{array}{l}9.48 \\
9.49\end{array}$ & $w$ & $\begin{array}{r}157 \\
--\end{array}$ \\
\hline 1965 & $\begin{array}{l}\text { Mar. } 1, \\
\text { Mar. } 31, \\
\text { Apr. 5, } \\
\text { July } \text { f. }^{2}\end{array}$ & $\begin{array}{l}1965 \\
1965 \\
1965 \\
1965\end{array}$ & $\begin{array}{l}11.91 \\
12.30 \\
11.82 \\
11.59\end{array}$ & $\mathbf{a}$ & $\begin{array}{r}600 \\
-- \\
555 \\
456\end{array}$ \\
\hline 1966 & July 26 . & 1966 & 12.00 & & 453 \\
\hline 1967 & Jan. 24 & 1967 & 12.50 & $\mathbf{a}$ & $340 \mathrm{~b}$ \\
\hline 1968 & $\begin{array}{l}\text { Jan. } \\
\text { Mar. }\end{array}$ & $\begin{array}{l}1968 \\
1968\end{array}$ & $\begin{array}{l}11.65 \\
10.70\end{array}$ & $\mathbf{a}$ & 221 \\
\hline 1969 & $\begin{array}{lr}\text { Mar. } & 17 . \\
\text { July } & 8 . \\
\text { July } 18 .\end{array}$ & $\begin{array}{l}196 \mathrm{C} \\
1969 \\
1965\end{array}$ & $\begin{array}{l}12 \cdot 39 \\
12.12 \\
12.32\end{array}$ & & $\begin{array}{l}628 \\
468 \\
536\end{array}$ \\
\hline
\end{tabular}

a Affected by ice.

b About. 
05-4641.37 Fourmile creek near Traer, Iowa--(Continued)

Peak stages and dis

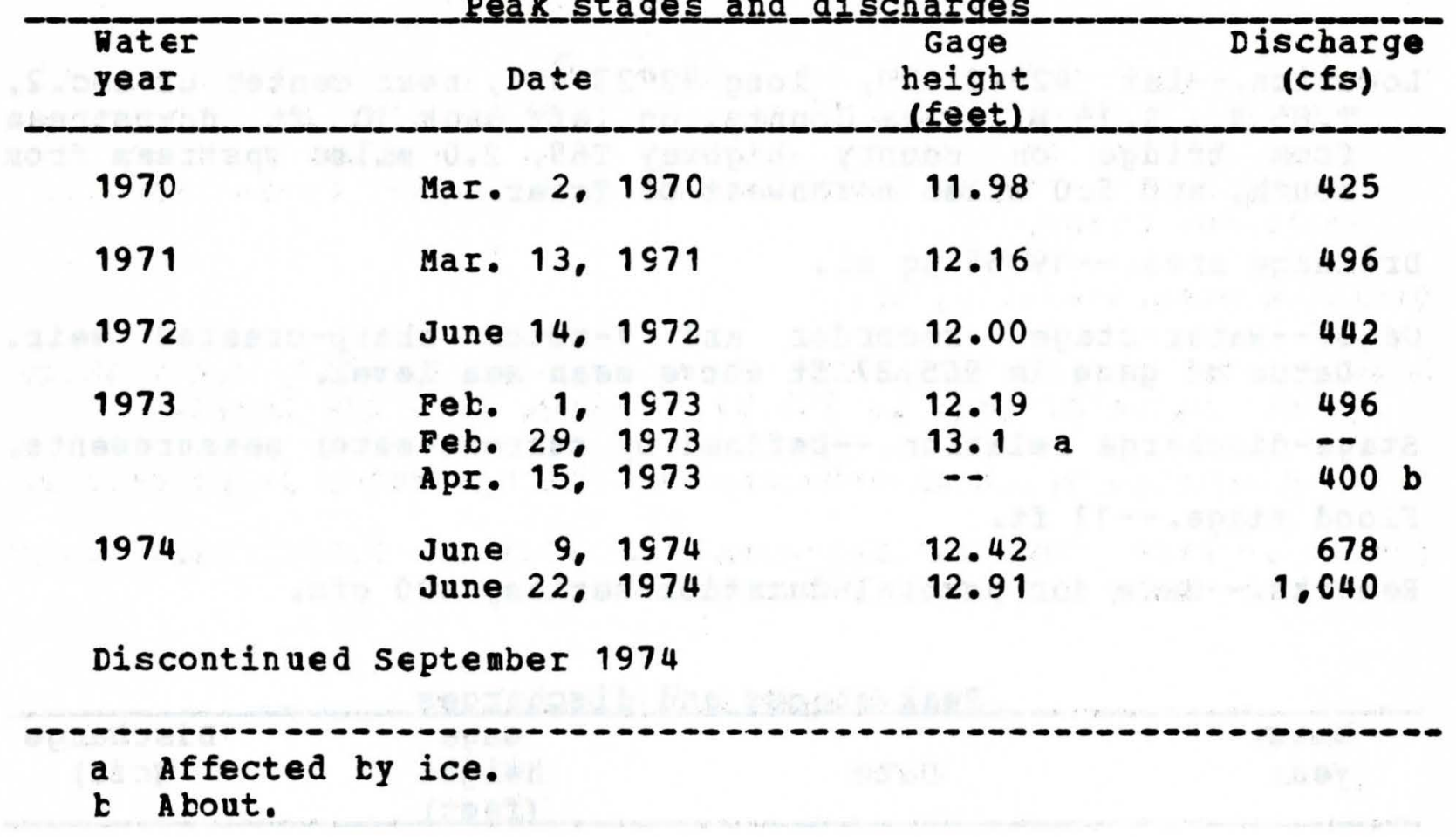




\section{5-4943.00 Fox River at Bloomfield. Iowa}

(Discontinued september 1973)

Locaticn.--Iat $40046 \cdot 10^{\prime \prime}$, Iong 92025'05", in sw1/4 SE1/4 sec.13, I.69 N.. R. 14 H.. Davis County, on left bank 15 ft dewnstream from bridge on county highway v20.1.3 miles northwest of county courthouse at Bloomfield, and 8.6 miles downstream from North Fox Creek.

Drainage area.--87.7 sq mi.

Gage.--Nater-stage recorder. Prior to oct. 1. 1957, crest-stage gage. Datum of gage is $755.57 \mathrm{ft}$ above mean sea level.

Stage-discharge relation.--Defined by current-meter measurements.

Remarks.--Base for partial-duration series, 2.000 cfs. Only annual peaks are shown pricr to 1958.

Peak_stages_and discharges

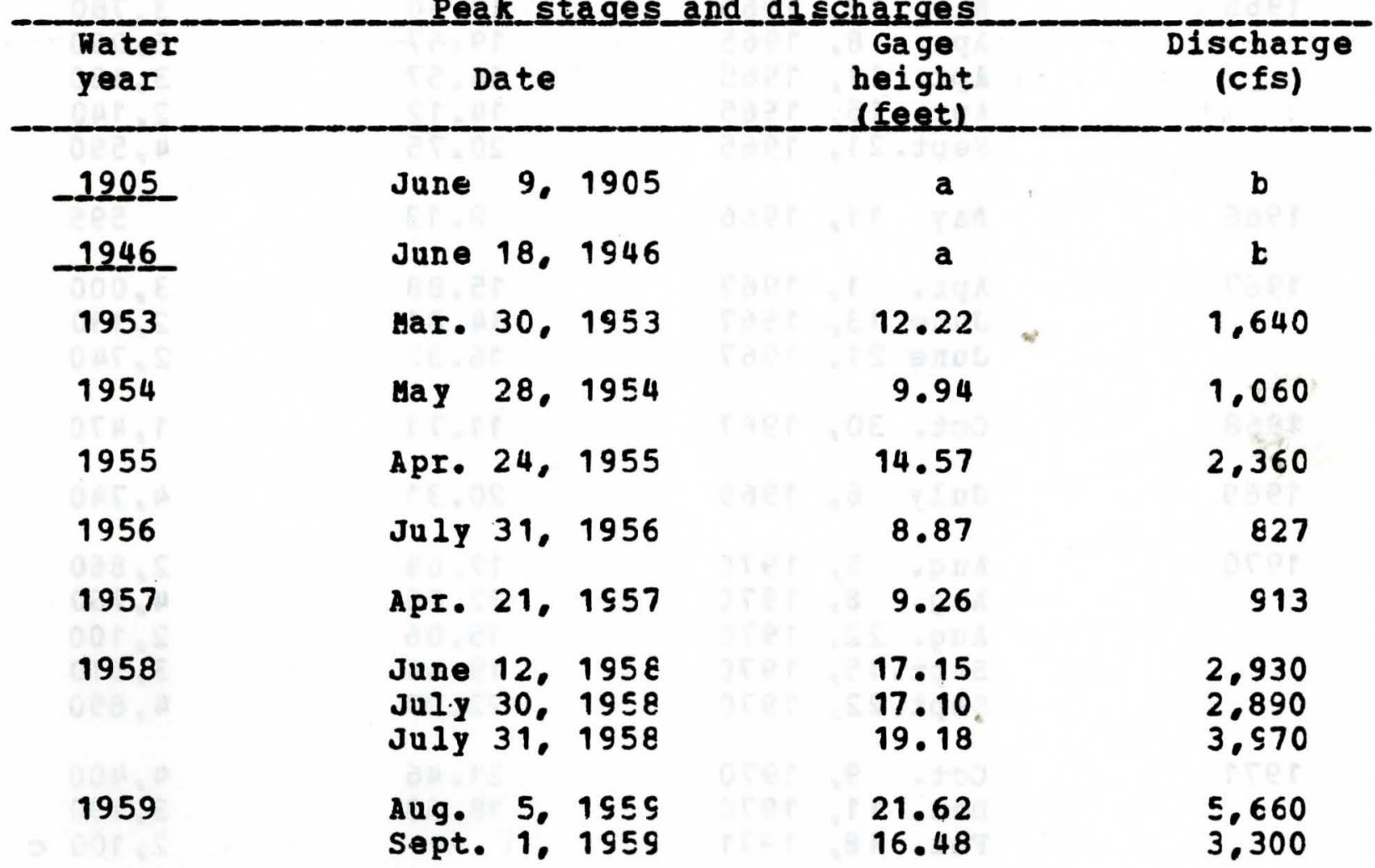

a Exceeded all other kncwn flocds at this location.

b Discharge not determined. 
05-4943.00 Fox River near at Eloomfield, Iowa--(Continued)

Peak staoes and discharges

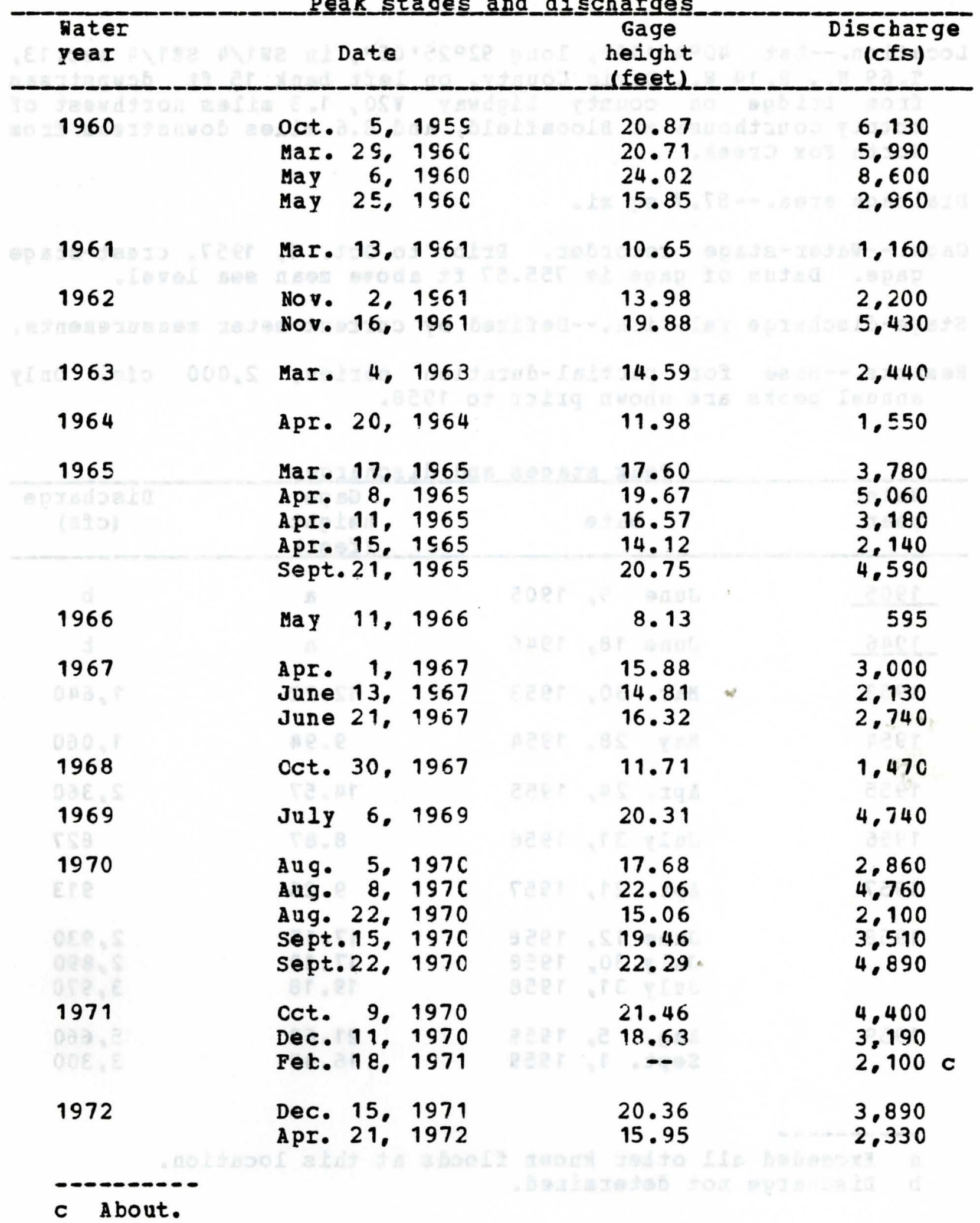


05-4943.00 Fox River near at Elcomfield, Iowa--(Continued)

Peak_stages_and_disch charges

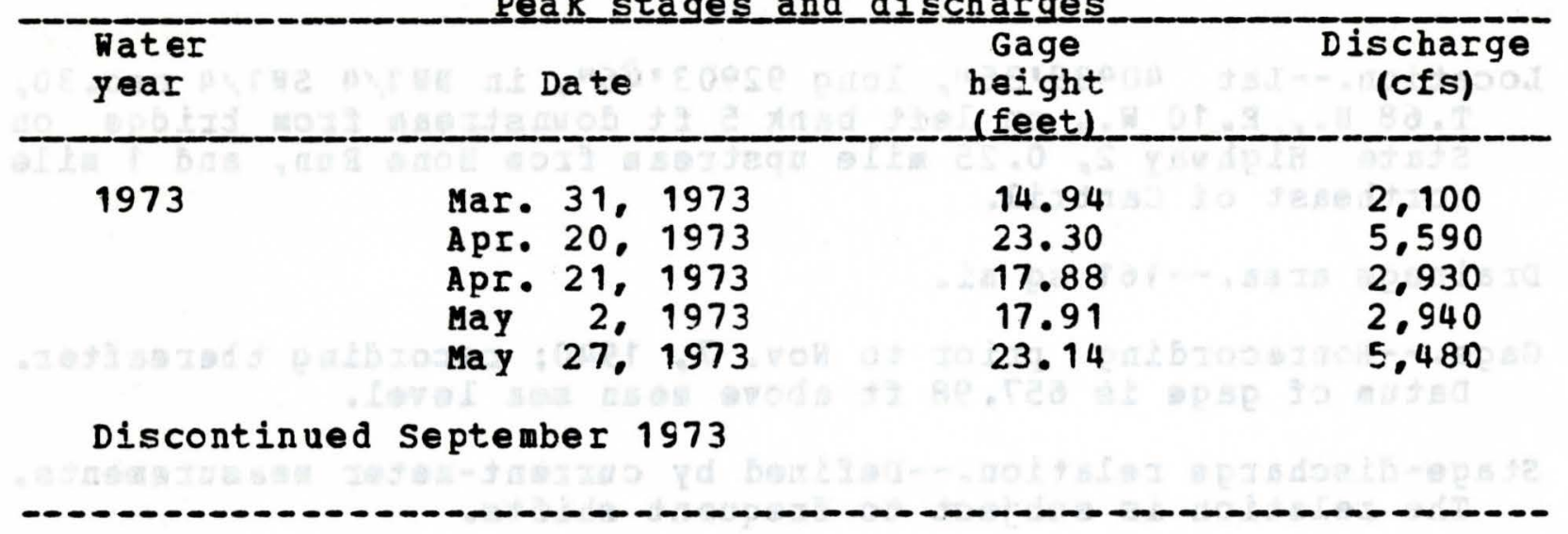




\section{5-4945.00 Fox River at Cantril. Iowa \\ (Discontinued September 1951)}

Location.--Iat $400393^{\prime \prime}$, long $92^{\circ 0} 3^{\circ} 46^{\prime \prime}$, in NN1/4 SW1/4 sec.30, T. $68 \mathrm{~N}$. . R. $10 \mathrm{M}$. , on left bank 5 ft downstream from tridge on State Highway 2. 0.25 mile upstream ficm Bone Run, and 1 mile northeast of Cantril.

Drainage area.--161 sq mi.

Gage.--Nonrecording prior to Nov. 7. 1940: recording thereafter. Datum of gage is $657.98 \mathrm{ft}$ above mean sea level.

Stage-discharge relation.--Defined by current-meter measurements. The relation is subject to frequent shifts.

Remarks.--Base for partial-duration series, 4,000 cfs.

Feak stages_and discharges

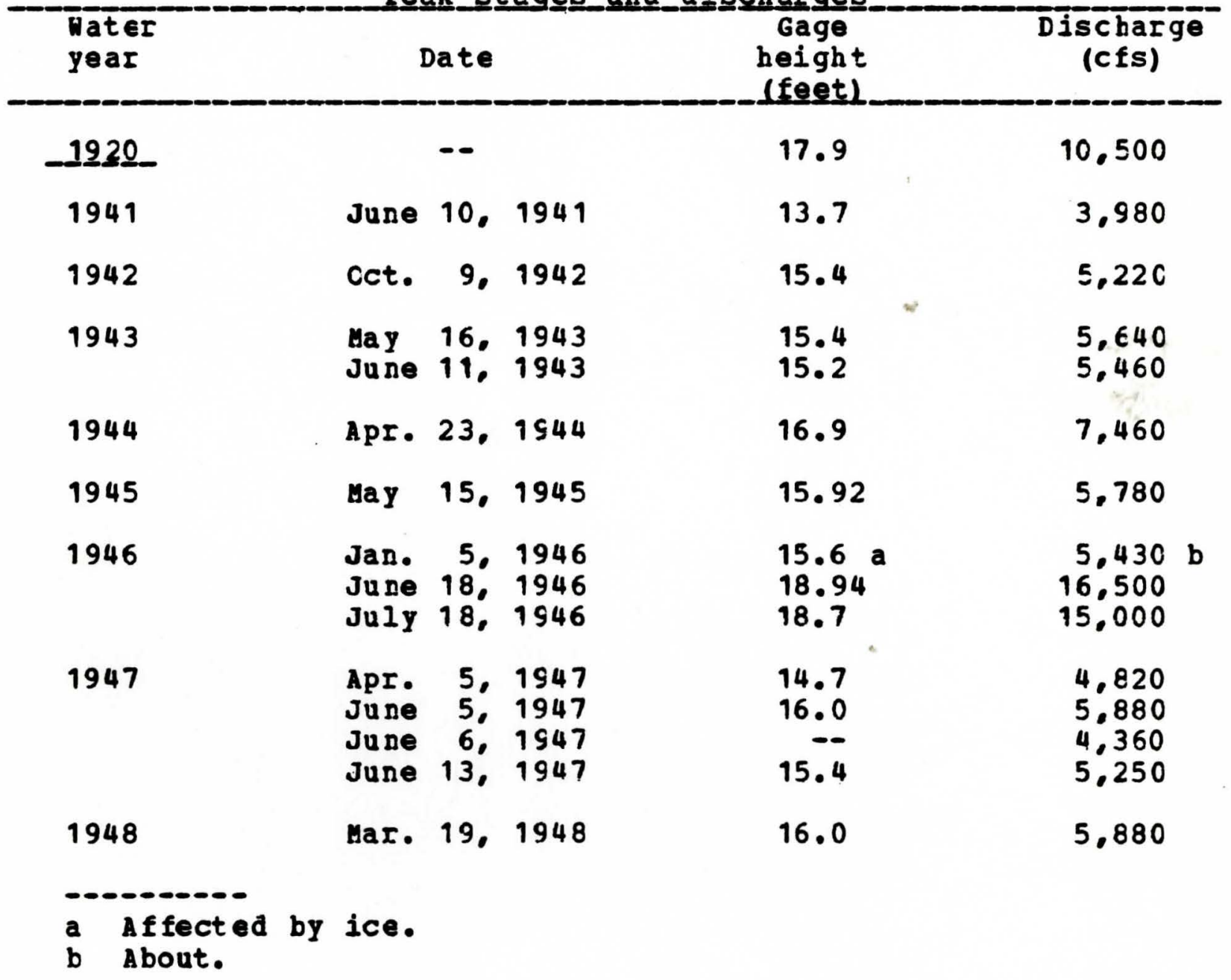


05-4945.00 Fox River at Cantril, Iowa--(Continued)

Peak_stages_and discharges

\begin{tabular}{|c|c|c|c|}
\hline $\begin{array}{l}\text { Water } \\
\text { year }\end{array}$ & Date & $\begin{array}{l}\text { Gage } \\
\text { height } \\
\text { (feet) }\end{array}$ & $\begin{array}{l}\text { Discharge } \\
\text { (cfs) }\end{array}$ \\
\hline 1949 & June 24,1949 & 11.45 & 3.270 \\
\hline 1950 & $\begin{array}{ll}\text { June } 15, & 1950 \\
\text { June } 19, & 1950\end{array}$ & $\begin{array}{l}17.4 \\
15.5\end{array}$ & $\begin{array}{r}10,000 \\
6,380\end{array}$ \\
\hline 1951 & $\begin{array}{lll}\text { June } & 25, & 1951 \\
\text { July } & 20, & 1951 \\
\text { JuIY } & 22, & 1951\end{array}$ & $\begin{array}{l}14.93 \\
15.82 \\
14.28\end{array}$ & $\begin{array}{l}5,780 \\
6,500 \\
5,160\end{array}$ \\
\hline Disce & $t \in m b e r ~ 1951$ & & \\
\hline
\end{tabular}




\section{5-4641.33 Half Mile Creek near Gladbrook, Iowa (Discontinued september 1974)}

Location.--Iat $42012 \cdot 40^{\prime \prime}$, long $92036 \cdot 39 "$, in sw1/4 sw1/4 sec.33. T.86 N., R. 15 W.. Tama County, on right bank $10 \mathrm{ft}$ dcwnstream from bridge on county highway, 0.8 mile upstream frcm mouth, and 5.3 miles northeast of Gladbrook.

Drainage area.--1.33 sq mi.

Gage.--Water-stage recorder and v-notch sharp-crested weir. Datum of gage is $948.16 \mathrm{ft}$ above mean sea level.

Stage-discharge relation.--Defined by current-meter measurements. Remarks.--Base for partial-duration series, 90 cfs.

Feak_stages_and discharges

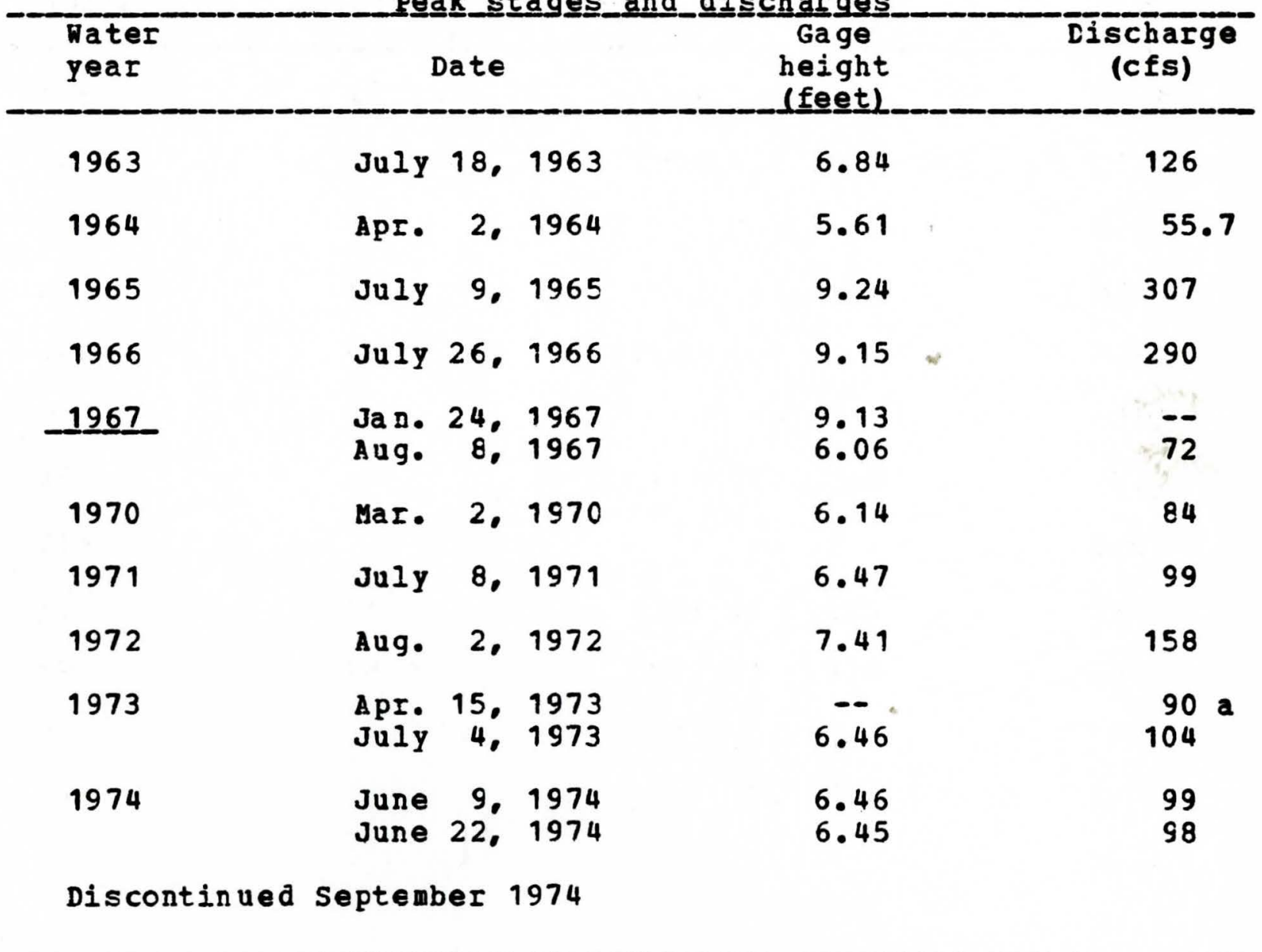

a About. 


\section{5-4828.00 Happy Run at Churdan, Iowa}

Location.--Iat $42010^{\circ}$. lcng $94030^{\circ}$, near SW corner sec.17. T.85 N.. R. 31 W. Greene County, at bridge near west city limits of Churdan.

Drainage area. $--7.58 \mathrm{sg}$ mi.

Gage.--Crest-stage gage.

stage-discharge relation.--Defined by current-meter measurements and logarithic extension above $100 \mathrm{cfs}$.

Remarks.--Only annual peaks are shown.

Peak_stages_and di scharges

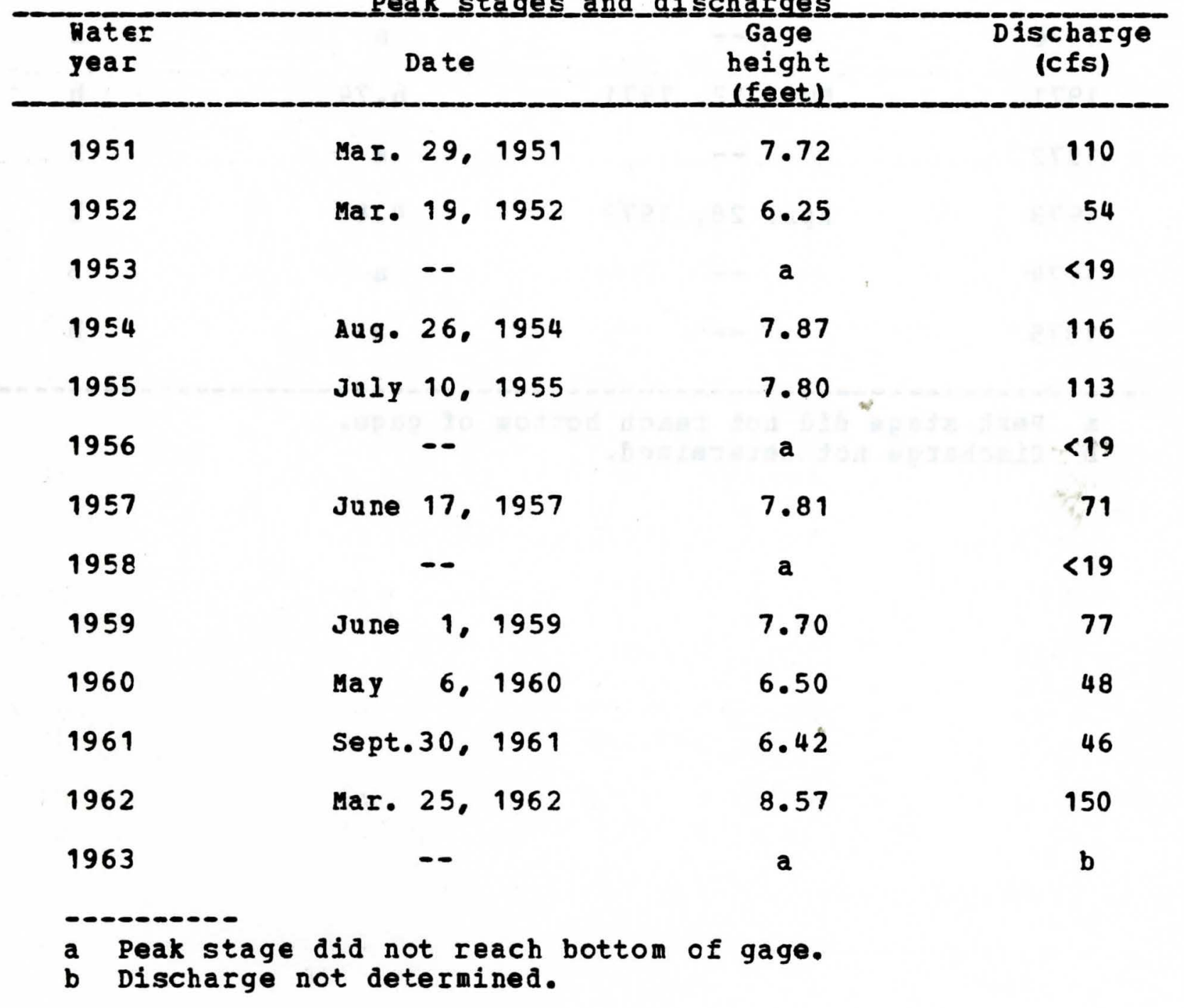


05-4828.00 Happy Run at Churdan. Iowa--(Continued)

Peak_stages and discharges

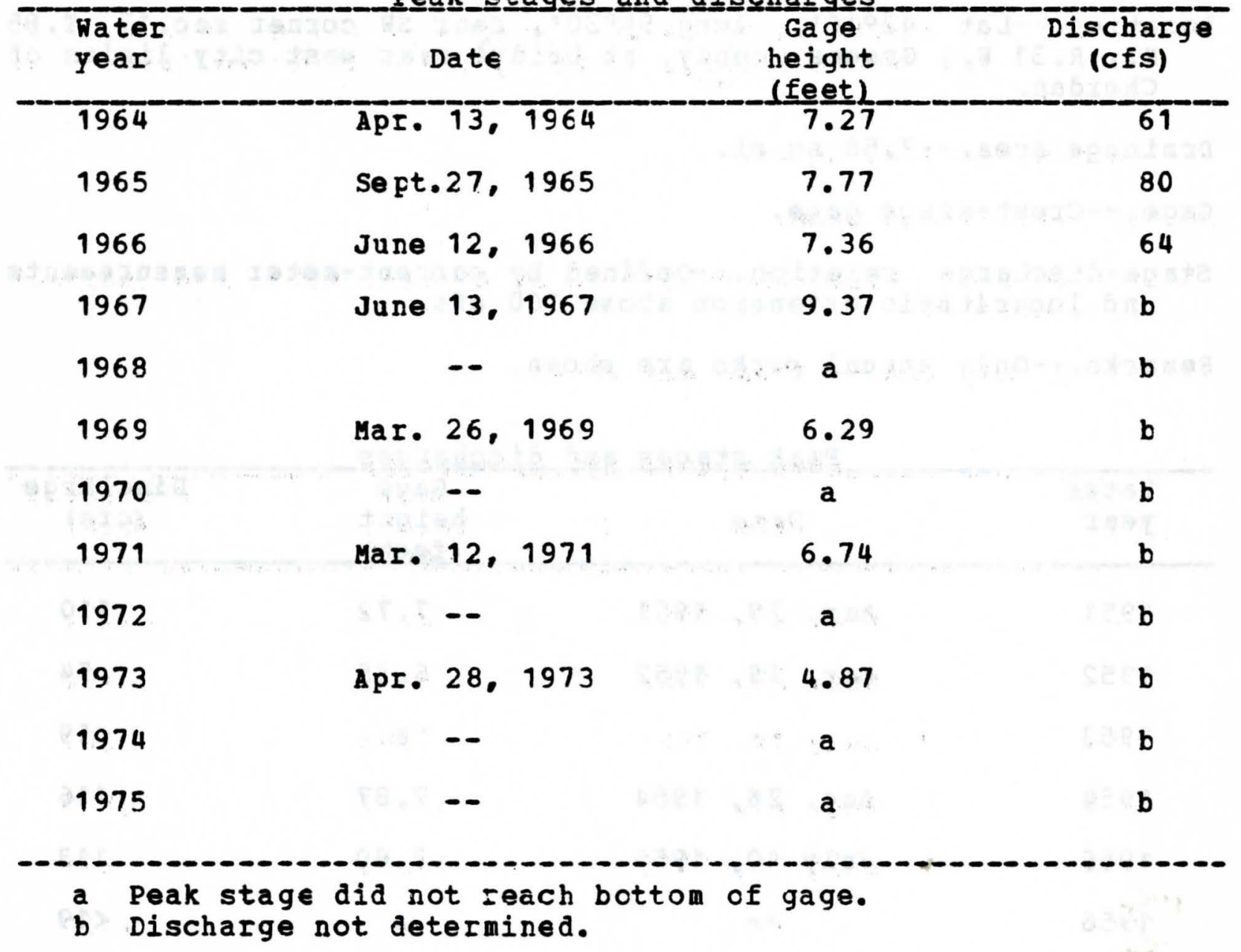




\section{5-4829.00 Hardin Creek near Farlin. Iowa}

Location.--Iat $42006 \%$. long $94026 \circ$, near N1/4 corner sec.14, T. 84 N.. R.31 H.. Greene Connty. at bridge. 1.5 niles northeast of Farlin.

Drainage area.--101 $\mathrm{sg} \mathrm{ni.}$

Gage.--Crest-stage gage.

Stage-discharge relation.--Defined by current-neter and indirect measurements.

Remarks.--OnIy annual peaks are shown.

Peak_stages_and_aischarges

\begin{tabular}{|c|c|c|c|c|}
\hline $\begin{array}{l}\text { Hater } \\
\text { year }\end{array}$ & & Date & $\begin{array}{c}\text { Gage } \\
\text { height } \\
\text { (feet) }\end{array}$ & $\begin{array}{c}\text { B1scharge } \\
\text { (cfs) }\end{array}$ \\
\hline 1951 & Har. & 29, 1951 & 12.97 & 2.270 \\
\hline 1952 & Mar. & 29. 1952 & 9.11 & 472 \\
\hline 1953 & July & 14,1953 & 7.96 & 300 \\
\hline 1954 & Aug. & 27. 1954 & 12.57 & 1.810 \\
\hline 1955 & July & 10.1955 & 10.03 & 631 \\
\hline 1956 & & $-\infty$ & $\mathbf{a}$ & $<120$ \\
\hline 1957 & June & 17. 1557 & 10.59 & 743 \\
\hline 1958 & & $\cdots$ & $\mathbf{a}$ & $<120$ \\
\hline 1959 & June & 1. 1959 & 11.40 & 980 \\
\hline 1960 & Mar. & 29. 1960 & 13.32 & 1.960 \\
\hline 1961 & Mar. & 27. 1961 & 8.82 & 324 \\
\hline 1962 & MaI. & 26. 1962 & 12.48 & 2.000 \\
\hline 1963 & May & 13. 1963 & 10.87 & 930 \\
\hline 1964 & ApI. & 13,1964 & 9.39 & 615 \\
\hline
\end{tabular}

a Peak stage did not reach botton of gage. 
05-4829.00 Hardin Creek near Farlin. Iowa--(Continued)

Peak_stages_and discharges

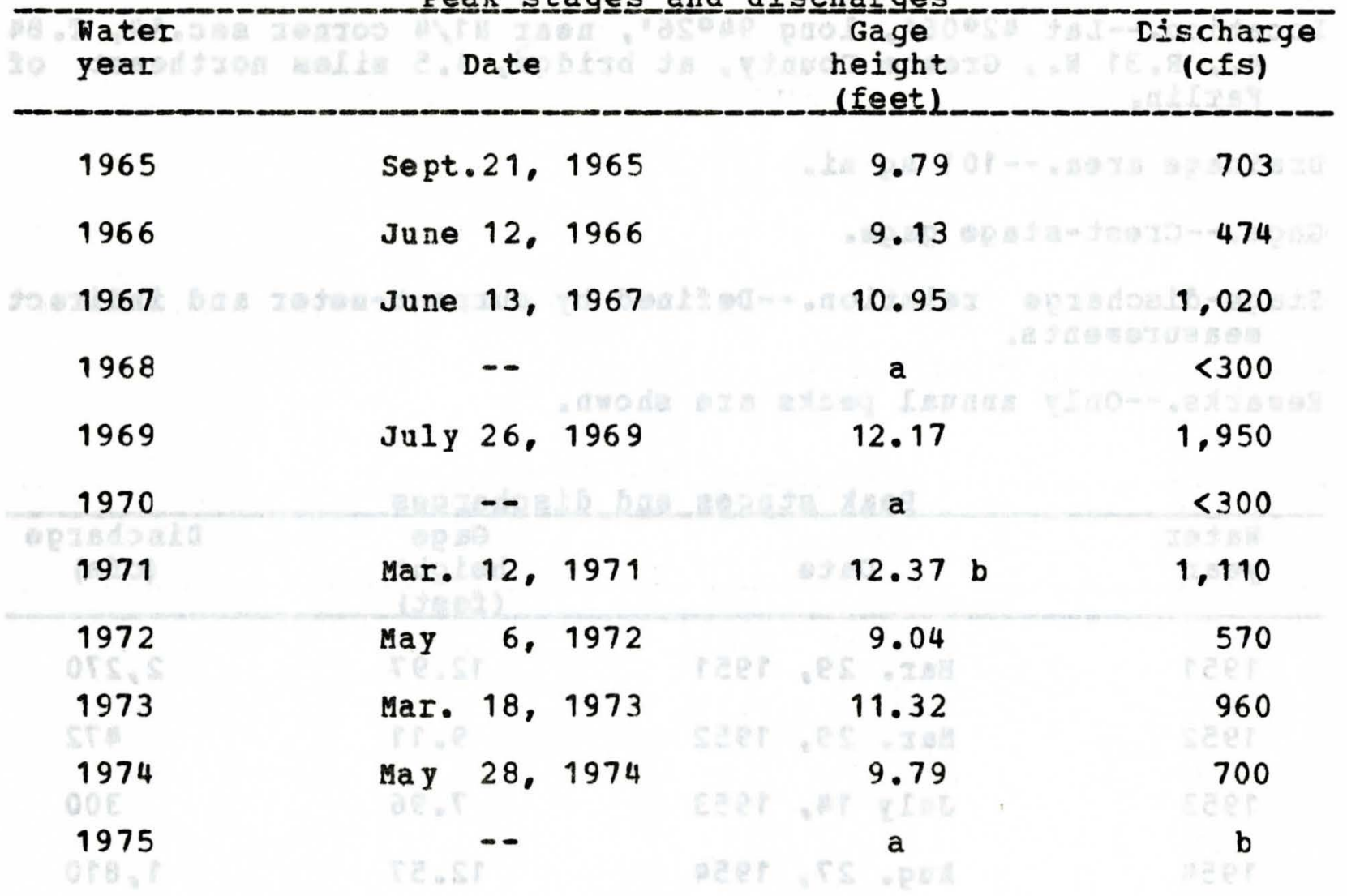

a Peak stage did not reach bottom cf gage.

b Affected by ice. 
Location.--Iat $42016 \cdot 01 "$ " long $94025 \cdot 10^{\prime \prime}$, near NE corner sec. 14, T.86 N.. R.31 N.. Calhoun county at bridge on state Highway 175. near west city limits cf Farnhamvilie.

Drainage area.- -43.7 sq mi.

Gage.--Crest-stage gage.

Stage-discharge relation.--Defined by current-meter measurements. Remarks.--only annual peaks are shown.

Peak__stages_and_discharges

\begin{tabular}{|c|c|c|c|c|c|}
\hline $\begin{array}{l}\text { Water } \\
\text { year }\end{array}$ & & Date & & $\begin{array}{r}\text { Gage } \\
\text { height } \\
\text { (feet) }\end{array}$ & $\begin{array}{c}\text { Discharge } \\
\text { (cfs) }\end{array}$ \\
\hline 1952 & Mar. & 29 & 1952 & 8.09 & 318 \\
\hline 1953 & July & 14. & 1953 & 8.44 & 429 \\
\hline 1954 & Aug. & 26 & 1954 & 10.48 & 2.000 \\
\hline 1955 & MaI. & 11. & 1955 & 8.76 & 557 \\
\hline 1956 & Mar. & 21 & 1956 & 6.78 & 118 \\
\hline 1957 & June & 16 & 1957 & 7.90 & 270 \\
\hline 1958 & June & 7. & 1958 & 7.69 & 225 \\
\hline 1959 & June & 1. & 1959 & 9.06 & 700 \\
\hline 1960 & Mar. & 29. & 1960 & 9.75 & 840 \\
\hline 1961 & Sept. & .30. & 1961 & 7.91 & 272 \\
\hline 1962 & July & 14 & 1962 & 9.20 & 812 \\
\hline 1963 & $\operatorname{May}$ & 13. & 1963 & 9.55 & 995 \\
\hline 1964 & ApI. & 13. & 1964 & 8.54 & 466 \\
\hline 1965 & $\operatorname{May}$ & 26 & 1965 & 9.78 & 1.110 \\
\hline 1966 & May & 23 & 1966 & 7.93 & 277 \\
\hline 1967 & June & 13 & 1967 & 9.34 & 854 \\
\hline
\end{tabular}


05-4826.00 Hardin Creek at Farnhamville, Iowa--(Continued)

Peak_stages_and_discharges

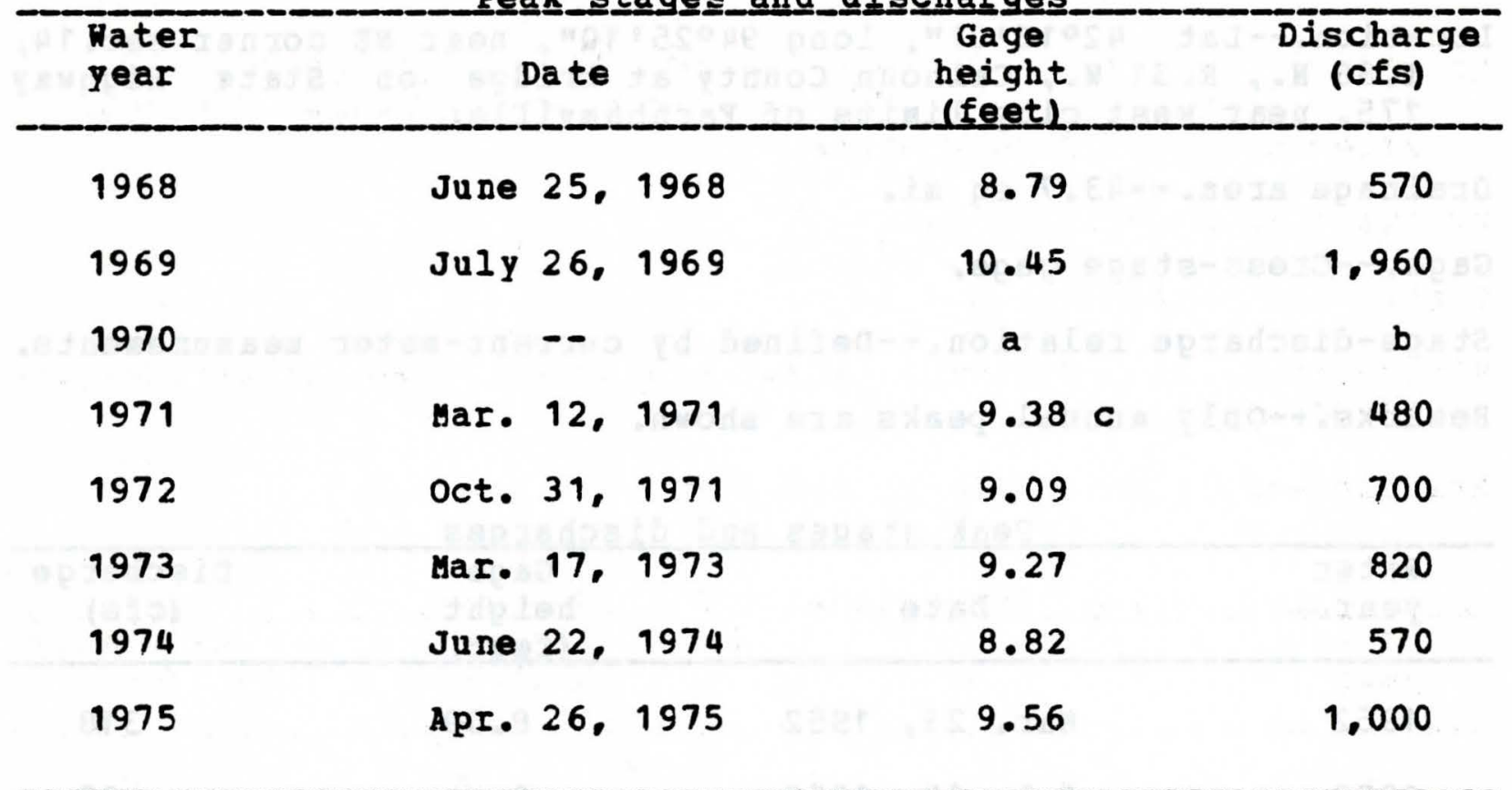

a Peak stage did not reach bottom cf gago.

b Discharge not determined.

c Affected by ice. 


\section{5-4209.60 Harter Creek near Independence, Iowa (Discontinued sept. 30, 1969)}

Location.--Iat 420 , long $91^{\circ}$, near SW1/4 corner sec.27, I.89 N.. R.9 M. at bridge 0.2 mile west of state Highway 150 and 2 miles north of Independence.

Drainage area.--6.17 sq mi.

Gage.--Crest-stage gage.

Stage-discharge relation.--Defined by current meter and indirect measurements.

Remarks.--only annual peaks are shown.

Peak stages_and_dischharges

\begin{tabular}{|c|c|c|c|c|c|}
\hline $\begin{array}{l}\text { Water } \\
\text { year }\end{array}$ & - & Date & & $\begin{array}{c}\text { Gage } \\
\text { height } \\
\text { (feet) }\end{array}$ & $\begin{array}{c}\text { Discharge } \\
\text { (cfs) }\end{array}$ \\
\hline 1952 & MaI. & 10 & 1952 & 6.31 & 162 \\
\hline 1953 & $\mathrm{Feb}$. & 20 & 1953 & 7.43 & 420 \\
\hline 1954 & Apr. & 30 & 1954 & 6.74 & 238 \\
\hline 1955 & $\mathrm{Feb}$. & 20 & 1955 & 5.67 & 90 \\
\hline 1956 & & -- & & a & $<72$ \\
\hline 1957 & June & 17. & 1957 & 8.18 & 750 \\
\hline 1958 & Feb. & 28 & 1958 & 5.51 & 77 \\
\hline 1959 & Mar. & 26 & 1959 & 9.17 & 1.450 \\
\hline 1960 & May & 7. & 1960 & 8.35 & 842 \\
\hline 1961 & Aug. & 7. & 1961 & 8.07 & 695 \\
\hline 1962 & May & 5. & 1962 & 9.96 & 2.280 \\
\hline 1963 & Ma I. & 18 & 1963 & 6.92 & 275 \\
\hline Discontin ued & sept. & 30 & 1963 & & \\
\hline
\end{tabular}

a Peak stage did not reach bottom of gage. 


\section{5-4513.50 Honey Creek at Bangor, Iowa}

Location.--Iat $42010 \%$ long $93005 \%$ near west quarter corner seC.16, T.85 N.. R.19 $\mathrm{H.}$. at county road "L" briage over Honey Creek, about 1.0 miles east of Bangor, Iowa.

Drainage area.--95.6 sq mi.

Gage.--Nonrecording.

Stage-discharge relation.--Defined by current-meter measurements. Remarks.--Records collected by Corps of Engineers. Station is inflow forecasting station for Coralvilla Reservoir. only annual peaks are shown.

Peak stages and dis $\underline{\text { charges }}$

\begin{tabular}{|c|c|c|c|}
\hline $\begin{array}{l}\text { Water } \\
\text { year }\end{array}$ & Date & $\begin{array}{c}\text { Gage } \\
\text { height } \\
\text { (feet) }\end{array}$ & $\begin{array}{l}\text { Discharge } \\
\text { (cfs) }\end{array}$ \\
\hline 1950 & Mar. 7. 1950 & 8.25 & 1.480 \\
\hline 1951 & Mar. 28, 1951 & 9.01 & 2.230 \\
\hline 1952 & Mar. 11, 1952 & 6.53 & 1.400 \\
\hline 1953 & Fer. 21. 1953 & 6.92 & 1.640 \\
\hline 1954 & June 11, 1954 & 9.60 & 3.350 \\
\hline 1955 & Feb. 19, 1955 & 5.54 & 744 \\
\hline 1956 & se pt. 5. 1956 & 5.58 & 757 \\
\hline
\end{tabular}




\section{6-9035.00 Honey Creek near Russell, Iowa \\ (Discontirued Sept. 30, 1962)}

Location.--Lat $40055^{\circ} 25^{\prime \prime}$, ICng $93007 \cdot 55^{\prime \prime}$, in SH1/4 NW1/4 sGC.26. T.71 N., R. 20 W.. on left bank 15 ft downstream from highway bridge, 0.7 mile upstream from Chariton River, and 5.5 miles southeast of Russell.

Drainage area.--13.2 sq mi.

Gage.--Recording. Datum of gage is $901.73 \mathrm{ft}$ above mean sea level (levels by scil conservation Service).

Stage-discharge relation.- Defined by current meter measurements below 640 cfs and extended above on basis of contractedopening and flow-over-road measurement of peak flow.

Remarks.--Base for partial-duration series, 250 cfs.

Peak stages and discharges

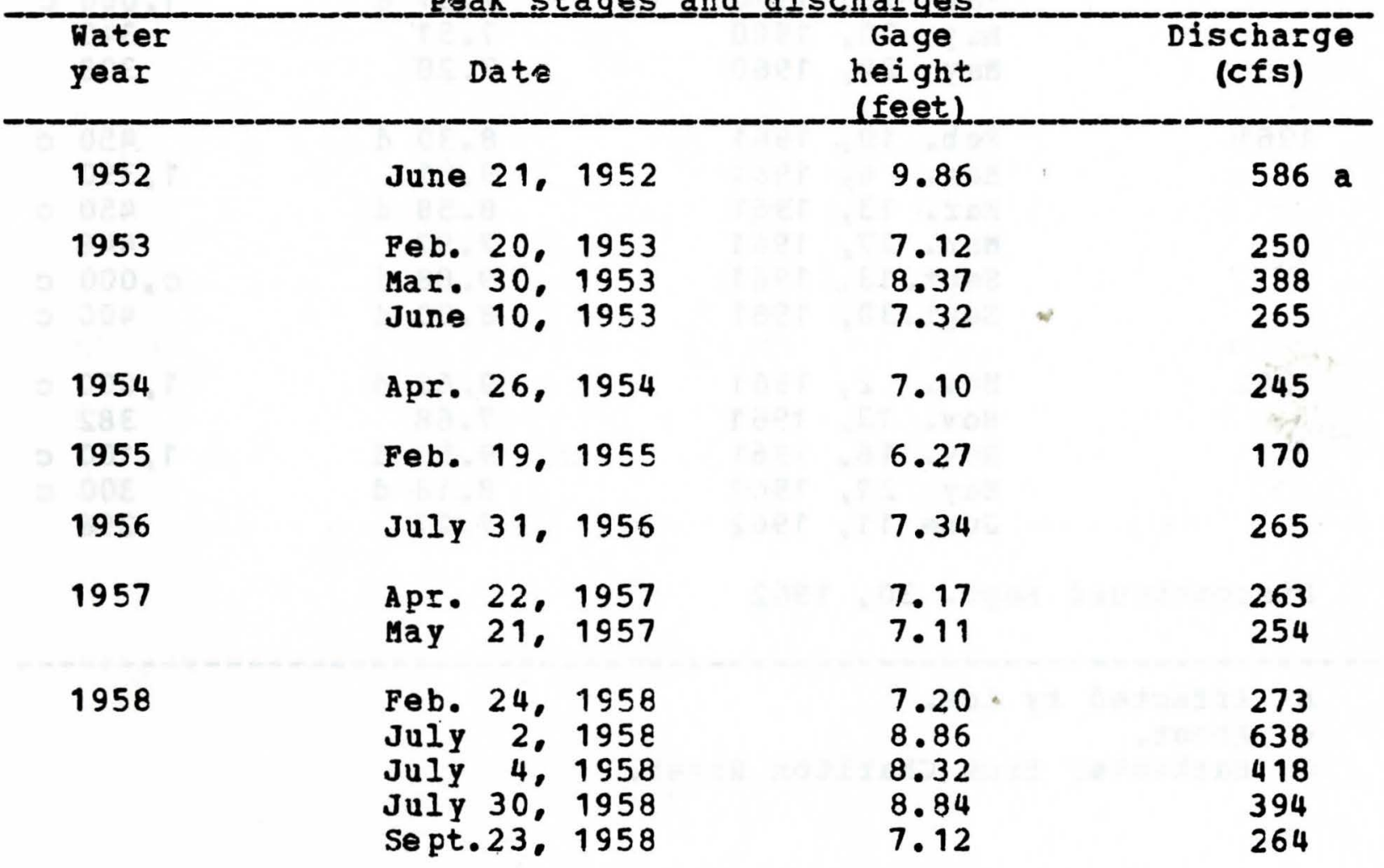

a Maximum for period June to september. 
06-9035.CJ Honey Creek near Russell, Iowa--(Continued)

Peak_stages_and_discharges

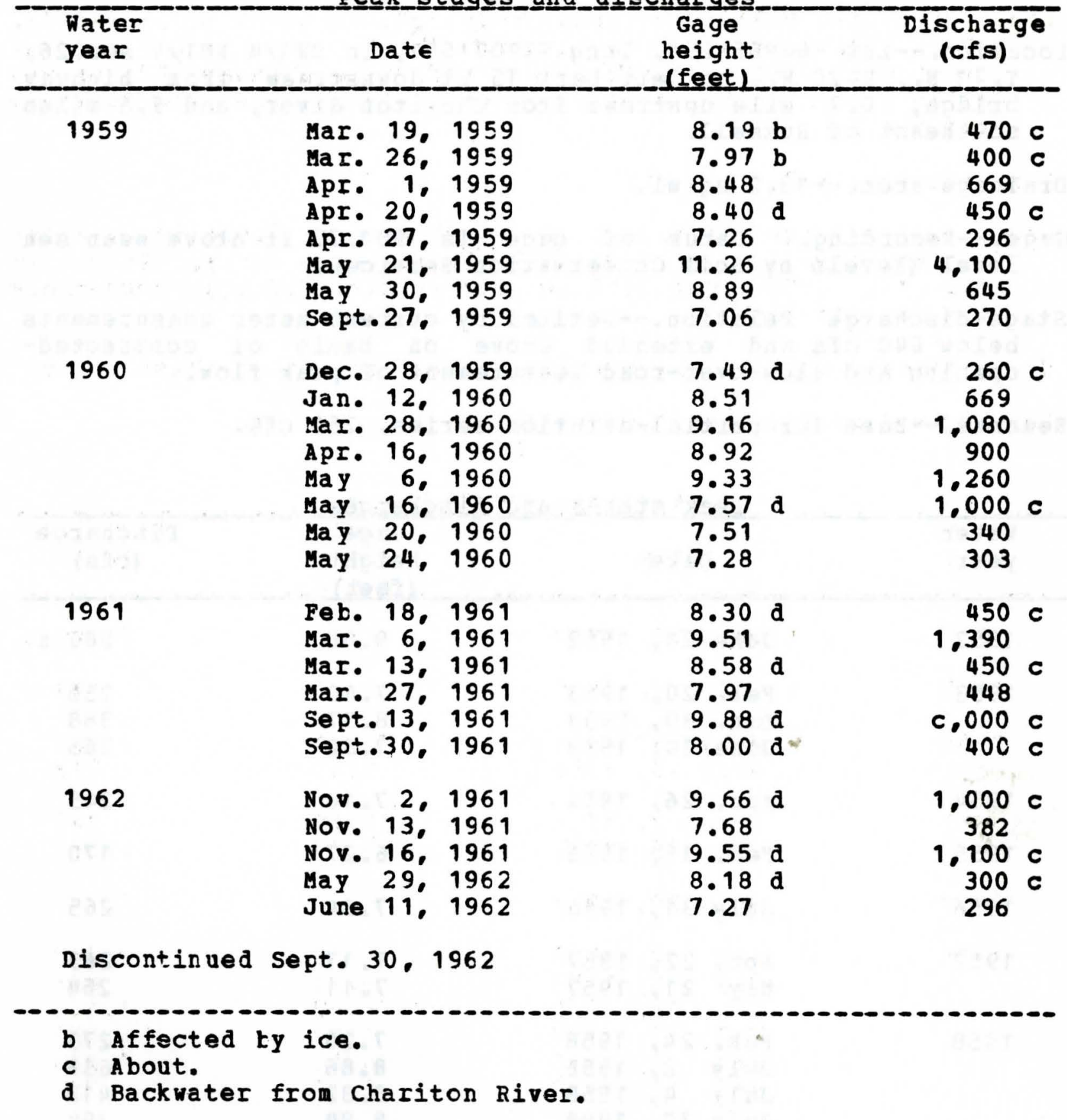


Location.--Lat $41017 \cdot 40^{\prime \prime}$. long $95049 \cdot 55^{\prime \prime}$. in NW1/4 SE1/4 sec. 18. T. 75 N.. R.43 W.. Pottawattamie County, on left bank at downstream side of first bridge off State Highway 183, on Mud Hollow Road at north edge of Council Bluffs, 8.8 mile upstream from mouth.

Drainage area.--7.99 sq mi.

Gage.--Water-stage recorder. Datum of gage is $1.038 .81 \mathrm{ft}$ above mean sea level (City of Council Bluffs bench mark). Prior to Apr. 12, 1955, nonrecording gage at site 0.2 mile dcwnstream at different datum.

Stage-discharge relation.--Defined by current-meter measurements. Remarks.--Base for partial-duration series, 700 cfs.

Peak﹎.stagges_and

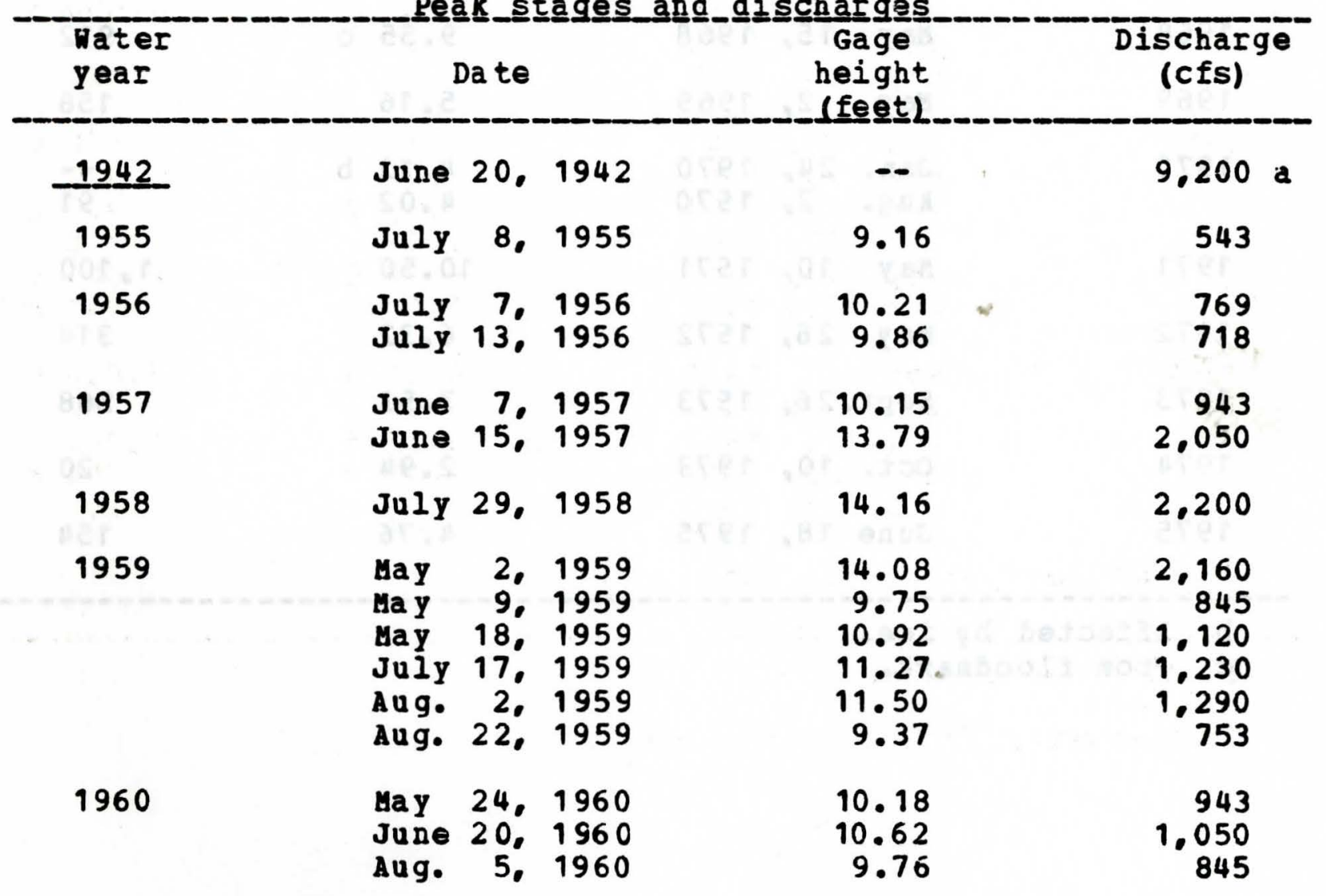

a From information by Corps of Engineers. 
06-6105.00 Indian Creek at Council Bluffs, Iowa--(Continued)

Peakㅡ_s

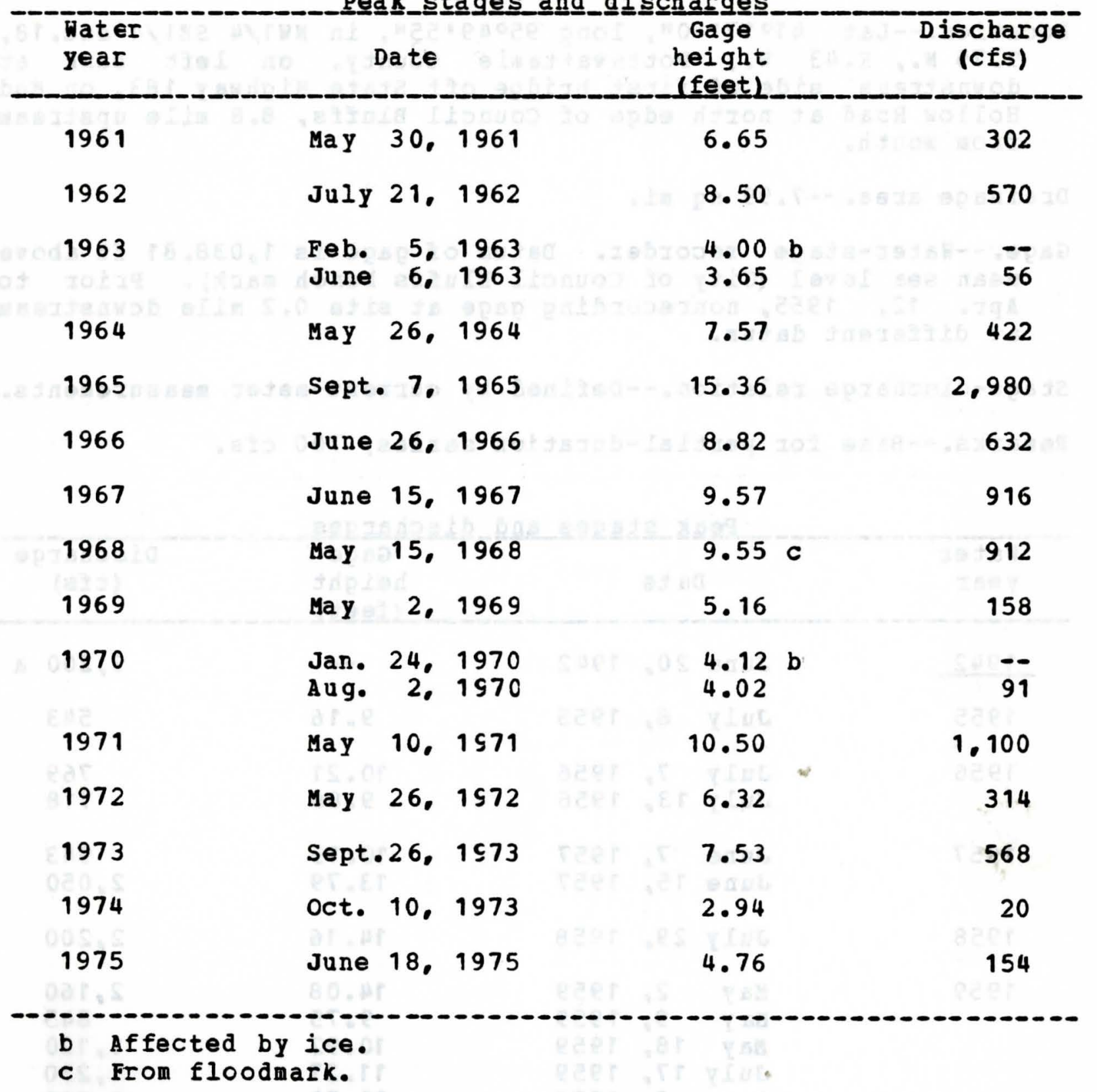




\section{6-8074.7C Indian Creek near Emerson, Iowa}

Location.--lat $41002 \%$ long $95023 \%$ in NW1/4 sec.19. T.72 N.,

R.39 H. Montgomery Courty, at bridge on U.S. Highway 34, 1 mile east of Emerson.

Drainage area.--37.3 sq mi.

Gage.--Crest-stage gage.

Stage-discharge relation.--Defined by current-meter measurements. Remarks.--only annual peaks are shown.

Fea $\underline{\text { k }}$ stages and di $\underline{\text { scharges }}$

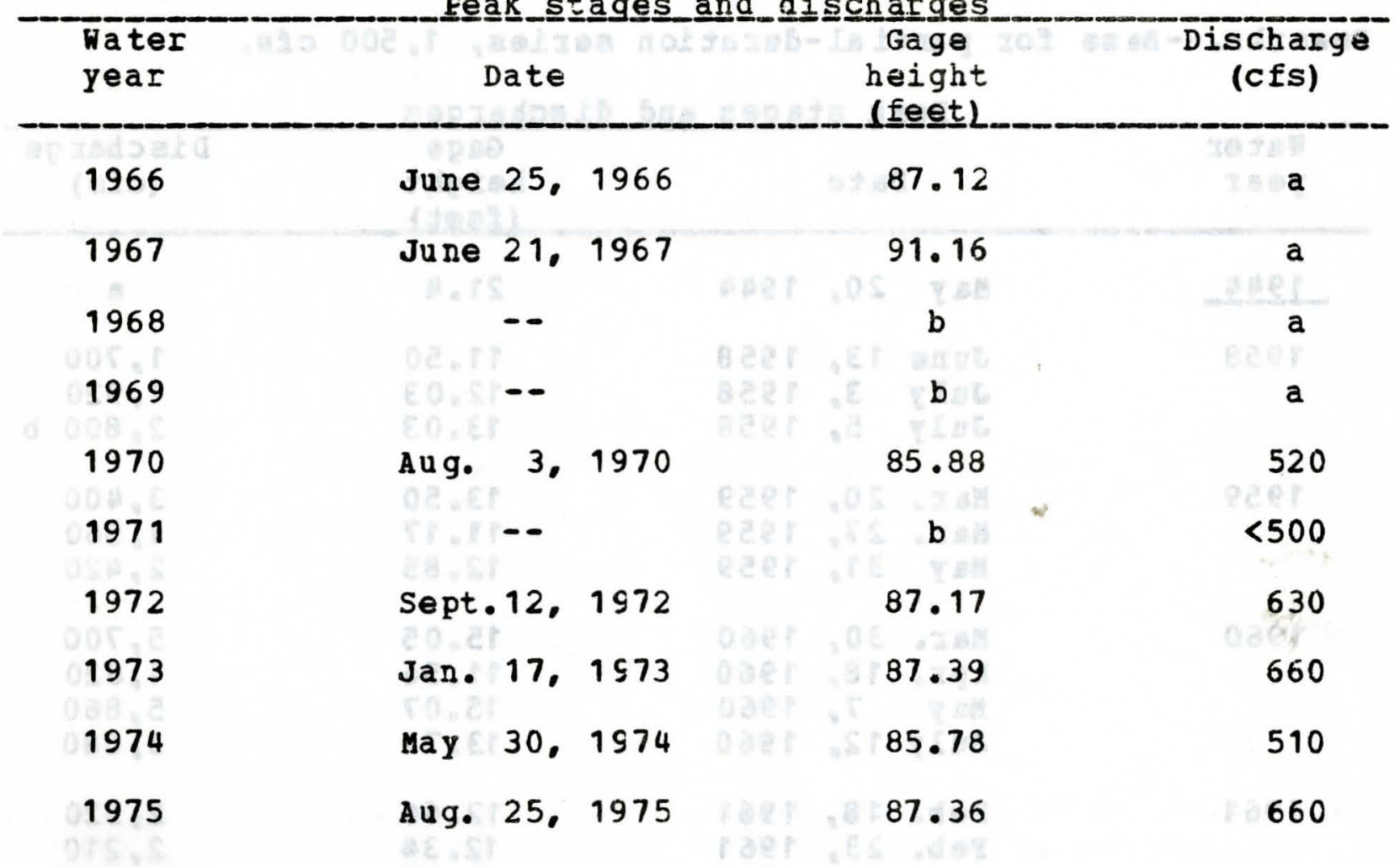

a Discharge not determined.

b Peak stage did not $r \in a c h$ bottom of gage. 


\section{5-4712.00 Indian Creek near Mingo. Iowa (Discontinued septenber 1975)}

Location.--lat $41048 \cdot 17 n$. long $93018 \cdot 26 \mathrm{~W}$, in $191 / 4$ NW1/4 sec.28, T.81 M.. R.21 ".. Jasper County. on right bank 30 ft dounstrean fron bridge on state Highway 117, C.7 mile downstrean fron Wolf Creek. 2.9 niles northwest of Hingo, and 3.3 ailes upstrean from Clear Creek.

Drainage area. --276 sq $m i$.

Gage.--llater-stage recorder. Datun of gage is $810.47 \mathrm{ft}$ above mean sea level.

Stage-discharge relation.--Defined by current-neter neasurements. Renarks.--Base for partial-duration series, $1,500 \mathrm{cfs}$.

Peak_stages_and_discharges

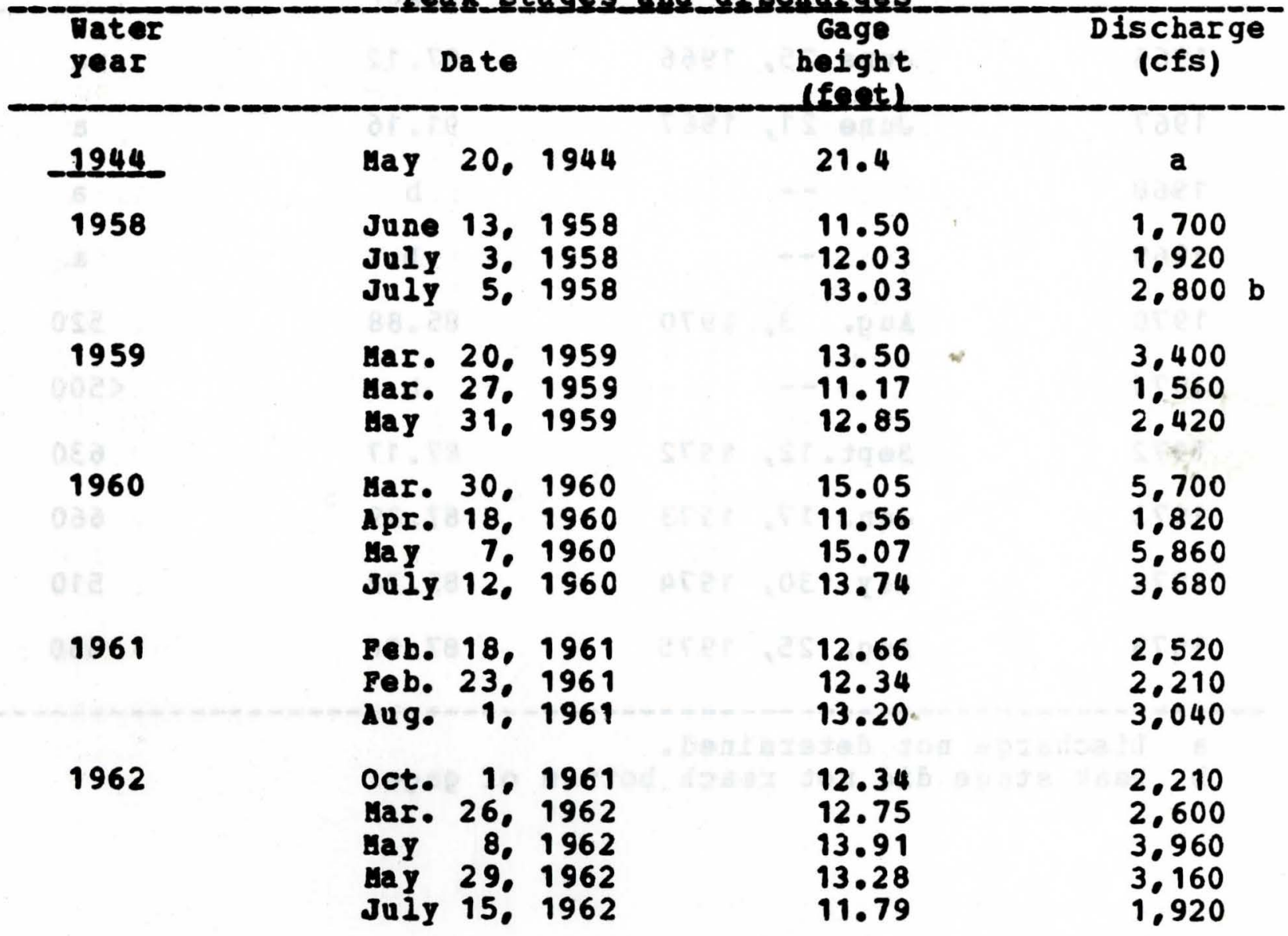

a Discharge not determined.

b Haxinun for period llay to Septenber 1958. 
05-4712.00 Indian Creek near Mingo, Icwa--(Continued)

Peak_stages_and_discharges

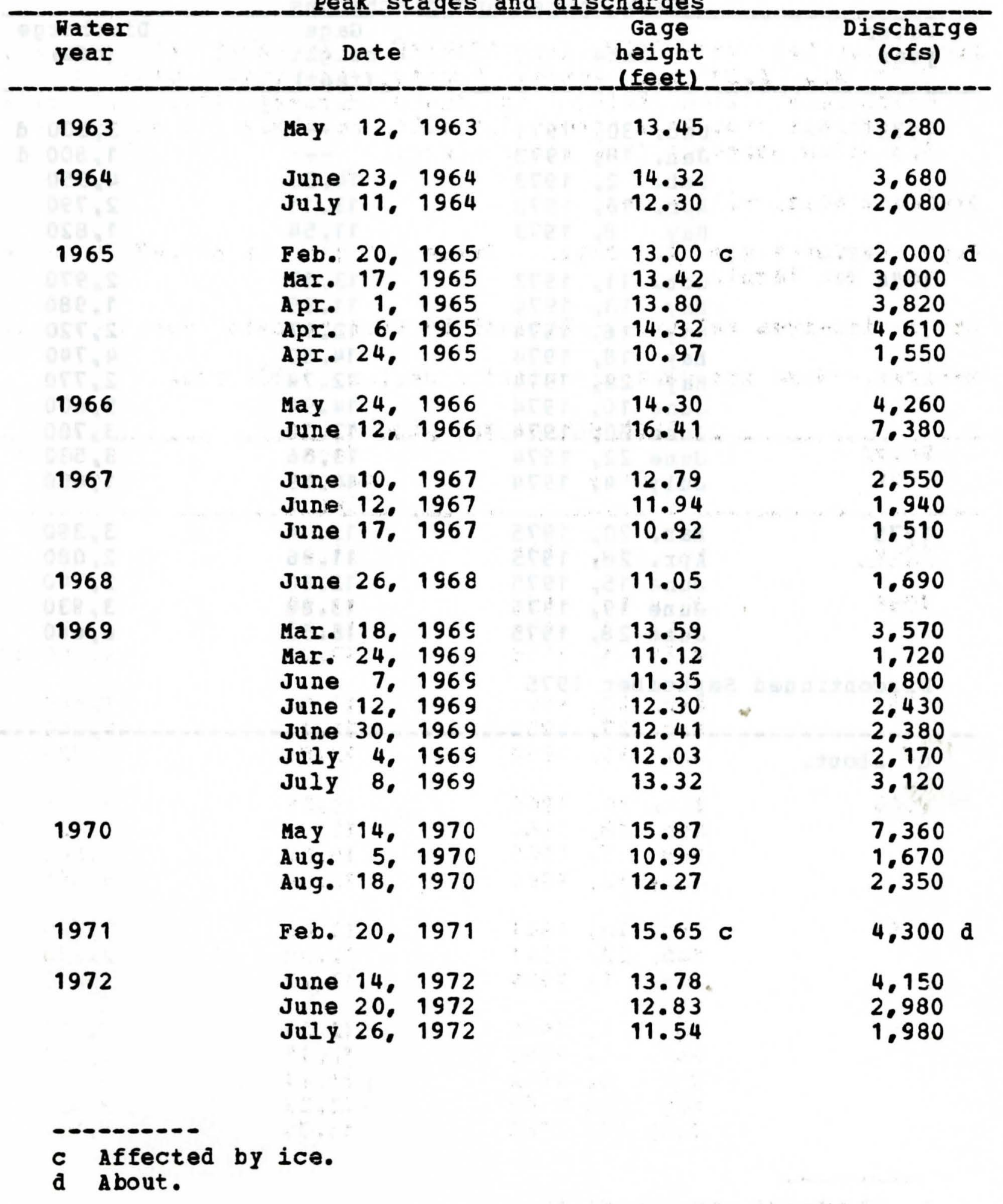


05-4712.00 Indian Creek near Mingo, Iowa-- (Continued)

Peak stages and discharges

\begin{tabular}{|c|c|c|c|c|}
\hline $\begin{array}{l}\text { Water } \\
\text { year }\end{array}$ & & Date & $\begin{array}{c}\text { Gage } \\
\text { height } \\
\text { feetl }\end{array}$ & $\begin{array}{l}\text { Discharge } \\
\text { (cfs) }\end{array}$ \\
\hline 1973 & $\begin{array}{l}\text { Dec. } \\
\text { Jan. } \\
\text { Peb. } \\
\text { Apr. } \\
\text { May }\end{array}$ & $\begin{array}{rr}30, & 1971 \\
18, & 1973 \\
2, & 1973 \\
16, & 1973 \\
8, & 1973\end{array}$ & $\begin{array}{c}-- \\
-\overline{-} \\
14.53 \\
13.11 \\
11.54\end{array}$ & $\begin{array}{l}3.500 \mathrm{~d} \\
1.800 \mathrm{~d} \\
4.950 \\
2.790 \\
1.820\end{array}$ \\
\hline 1974 & $\begin{array}{l}\text { Oct. } \\
\text { May } \\
\text { May } \\
\text { May } \\
\text { May } \\
\text { June } \\
\text { June } \\
\text { June } \\
\text { July }\end{array}$ & $\begin{aligned} 11, & 1973 \\
13, & 1974 \\
16, & 1974 \\
18, & 1974 \\
28, & 1974 \\
10, & 1974 \\
20, & 1974 \\
22, & 1974 \\
4, & 1974\end{aligned}$ & $\begin{array}{l}13.17 \\
11.85 \\
12.97 \\
14.50 \\
12.74 \\
14.94 \\
13.70 \\
13.56 \\
10.69\end{array}$ & $\begin{array}{l}2.970 \\
1.980 \\
2.720 \\
4.740 \\
2.770 \\
5.600 \\
3.700 \\
3.530 \\
1.600\end{array}$ \\
\hline 1975 & $\begin{array}{l}\text { Jar. } \\
\text { Apr. } \\
\text { June } \\
\text { June } \\
\text { June }\end{array}$ & $\begin{array}{ll}20, & 1975 \\
28, & 1975 \\
15, & 1975 \\
19, & 1975 \\
28, & 1975\end{array}$ & $\begin{array}{l}13.44 \\
11.86 \\
12.80 \\
13.88 \\
15.52\end{array}$ & $\begin{array}{l}3.390 \\
2.080 \\
2.740 \\
3.930 \\
6.660\end{array}$ \\
\hline
\end{tabular}

Discontinued September 1975

d about. 


$$
\begin{gathered}
\text { 05-4525.00 Iowa River near Belle plaine. Iowa } \\
\text { (Discontinued sept. 30, 1959) }
\end{gathered}
$$

Location.--lat 41051'20", long $92014 \cdot 201$, in NW1/4 sEC.5. T.81 N.. R. 12 W.. on right bank 5 ft downstream from state Highway 212 bridge, 0.5 mile downstream from Walnut Creek, 2.7 miles south of Belle Plaine and at mile 159.0.

Drainage area.--2,455 sq mi.

Gage.--Nonrecording prior to Mar. 13, 1940; recording thereafter. Datum of gage is 749.82 ft abcre mean sea level.

Stage-discharge relation.--Defined by current-meter measurements. Bankfull stage.--13 ft.

Renarks.--Base for partial-duration series, 5,000 cfs.

\begin{tabular}{|c|c|c|c|c|c|c|}
\hline $\begin{array}{l}\text { Water } \\
\text { year }\end{array}$ & & ate & & $\begin{array}{l}\text { Gage } \\
\text { height }\end{array}$ & & $\begin{array}{l}\text { Discharge } \\
\text { (cfs) }\end{array}$ \\
\hline 1918 & June & 5. & 1918 & 17.86 & $\mathrm{a}$ & 43,000 \\
\hline 1940 & Mar. & 19. & 1940 & 9.46 & $\mathbf{b}$ & $2.430 \mathrm{c}$ \\
\hline 1941 & Mar. & 22. & 1941 & 12.40 & $\mathbf{b}=$ & $4.280 \mathrm{c}$ \\
\hline 1942 & $\begin{array}{l}\text { Nov. } \\
\text { June } \\
\text { June } \\
\text { June }\end{array}$ & $\begin{array}{l}2 . \\
6 \% \\
11 \%\end{array}$ & $\begin{array}{l}1941 \\
1942 \\
1942 \\
1942\end{array}$ & $\begin{array}{l}13.0 \\
14.4 \\
13.2 \\
12.5\end{array}$ & & $\begin{array}{l}5.620 \\
9.450 \\
6.200 \\
5.100\end{array}$ \\
\hline 1943 & $\begin{array}{l}\text { Feb. } \\
\text { Mar. } \\
\text { May } \\
\text { Aug. }\end{array}$ & $\begin{array}{l}24, \\
16 \% \\
16 . \\
4 .\end{array}$ & $\begin{array}{l}1943 \\
1943 \\
1943 \\
1943\end{array}$ & $\begin{array}{l}12.8 \\
13.7 \\
12.8 \\
12.7\end{array}$ & & $\begin{array}{l}5.580 \\
6.890 \\
5.680 \\
5.540\end{array}$ \\
\hline 1944 & $\begin{array}{l}\text { May } \\
\text { May } \\
\text { June }\end{array}$ & $\begin{array}{l}7 \% \\
21 \%\end{array}$ & $\begin{array}{l}1944 \\
1944 \\
1944\end{array}$ & $\begin{array}{l}13.0 \\
16.9 \\
16.8\end{array}$ & & $\begin{array}{r}5,990 \\
31.800 \\
31.600\end{array}$ \\
\hline
\end{tabular}

Peak stages and discharges

\footnotetext{
a From information by Corps of Engineers.

b affected by ice.

c about.
} 
05-4525.00 Iowa River near Belle Plaine, Iowa--(Continued)

Feak stages and discharges

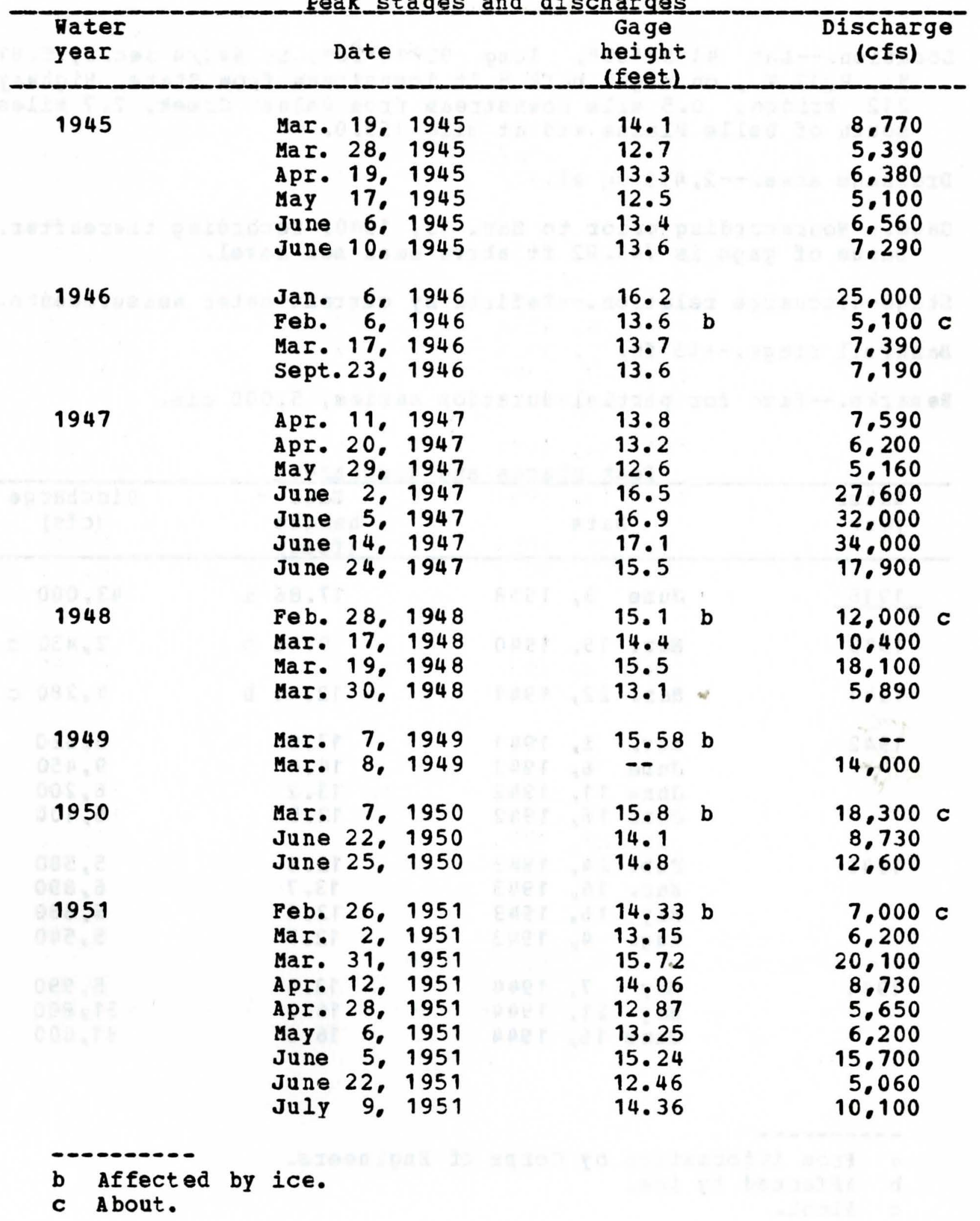


05-4525.00 Iowa River near Belle Plaine, Iowa--(Continued)

Peak stages and discharges

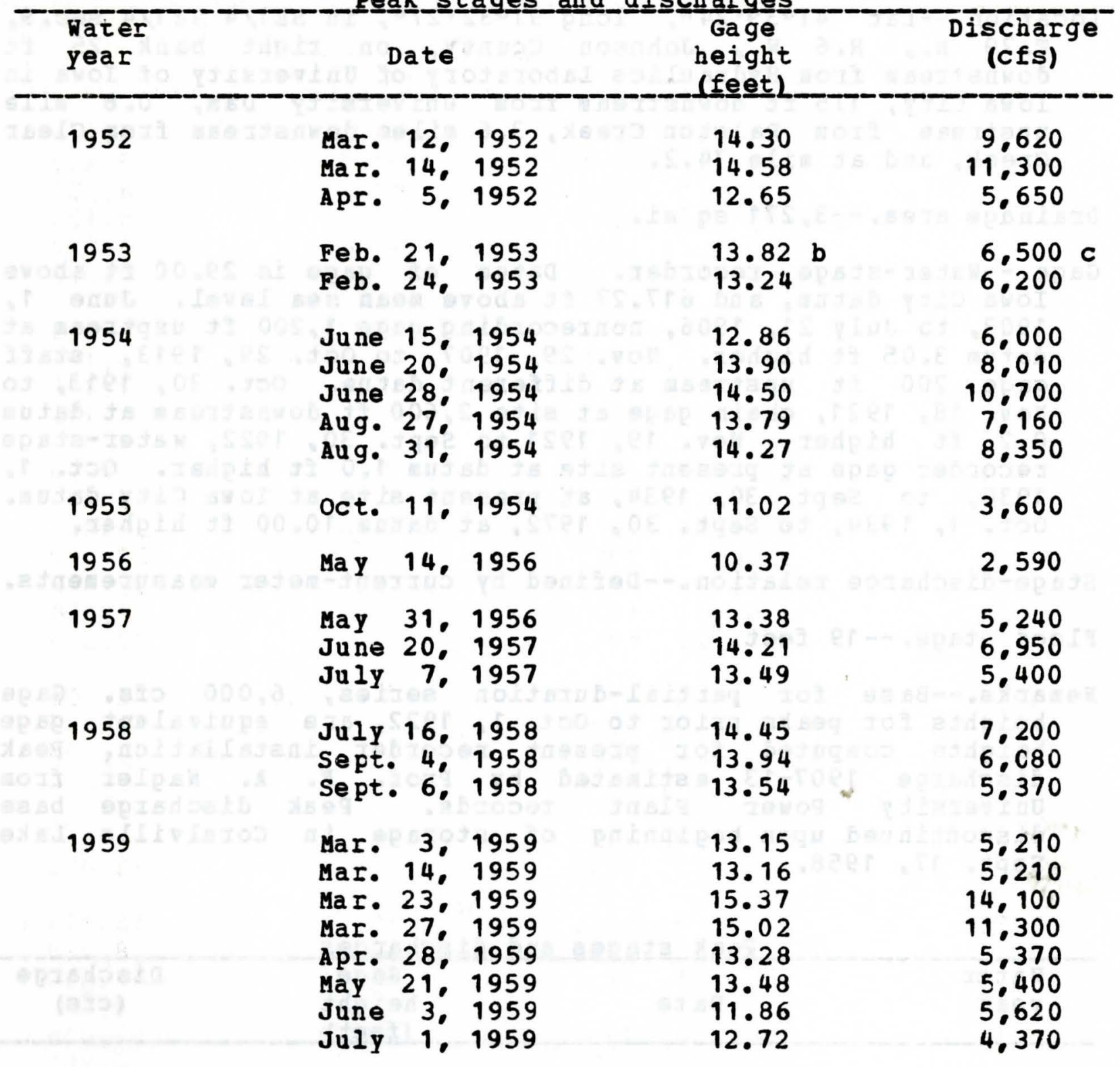

Discontinued sept. 30,1959

b Affected by ice.

c About. 
Location.--Lat $41039 \cdot 24 "$, long $91032 \cdot 27 "$, in SE1/4 SE1/4 sec.9, T.79 N.. R. 6 W.. Johnson County, on right bank $25 \mathrm{ft}$ downstream from Hydraulics Laboratory of University of Iowa in Iowa City. $175 \mathrm{ft}$ downstream from University Dam, 0.8 mile upstream from Ralston Creek. 3.6 miles downstream from Clear Creek, and at mile 74.2 .

Drainage area.--3,271 sq mi.

Gage.--Water-stage recorder. Datum of gage is $29.00 \mathrm{ft}$ above Iowa City datum, and $617.27 \mathrm{ft}$ above mean sea level. June 1 . 1903, to July 21, 1906, nonrecording gage 1.200 ft usptream at datum $3.05 \mathrm{ft}$ higher. Nov. 29, 1907, to oct. 29, 1913, staff gage 200 ft upstream at different datum. oct. 30, 1913, to Nov. 18, 1921, chain gage at site 2,600 ft downstream at datum 0.2 ft higher. Nov. 19, 1921 to Sept. 30, 1922, water-stage recorder gage at present site at datum $1.0 \mathrm{ft}$ higher. oct. 1 , 1930. to Sept. 30, 1934, at present site at Iowa City datum. oct. 1, 1934, to sept. 30, 1972, at datum 10.00 ft higher.

Stage-discharge relation.--Defined by current-meter measurements. Flood stage.--19 feet.

Remarks.--Base for partial-duration series, 6,000 cfs. Gage heights for peaks prior to Oct. 1. 1922, are equivalent gage heights computed for present recorder installaticn. Peak discharge 1907-13 estimated by Prof. F. A. Nagler from University power plant records. peak discharge base discontinued upon beginning of storage in coralville lake sept. 17. 1958 .

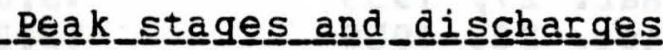

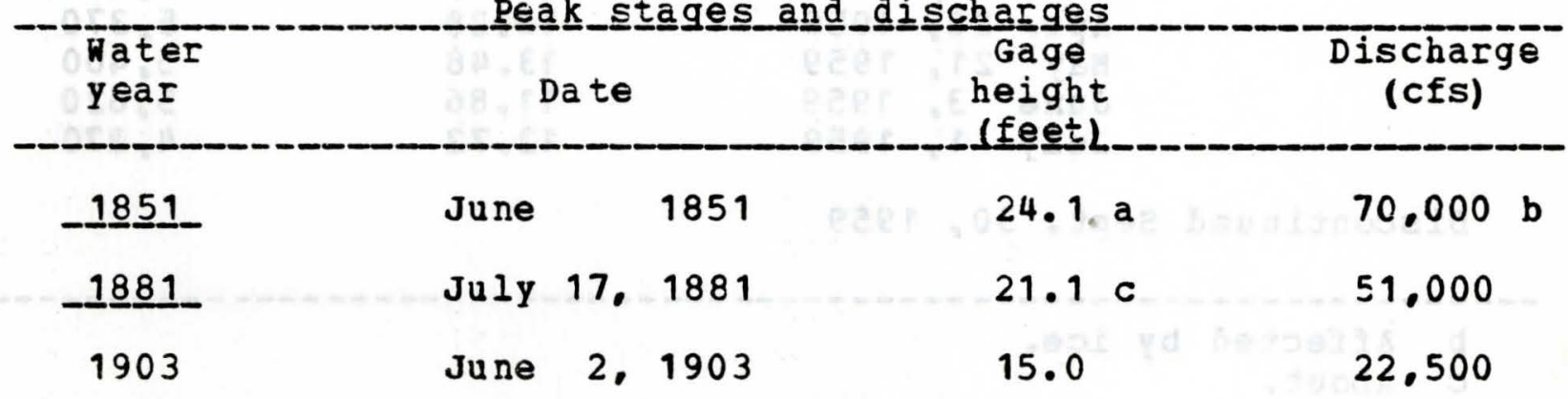

a About; maximum known since at least 1850 .

b Estimated.

c From floodmark (site and datum in use 1913-1931); frcm information by local resident. 
05-4545.00 Iowa River at Iowa City. Iowa-- (Continued)

Peak_s stagges and_di

\begin{tabular}{|c|c|c|c|c|c|c|c|}
\hline $\begin{array}{l}\text { Water } \\
\text { year }\end{array}$ & & Date & & & $\begin{array}{c}\text { Gage } \\
\text { height } \\
\text { (feet) }\end{array}$ & & $\begin{array}{c}\text { Discharge } \\
\text { (cfs) }\end{array}$ \\
\hline 1904 & Mar. & 25. & 1904 & & 8.3 & & 9.880 \\
\hline 1905 & $\begin{array}{l}\text { Mar. } \\
\text { May } \\
\text { June }\end{array}$ & $\begin{array}{l}24, \\
24 . \\
10 .\end{array}$ & $\begin{array}{l}1905 \\
1905 \\
1905\end{array}$ & & $\begin{array}{l}6.7 \\
8.0 \\
8.8\end{array}$ & & $\begin{array}{l}6.830 \\
8.490 \\
9.740\end{array}$ \\
\hline 1906 & $\begin{array}{l}\text { Mar. } \\
\text { Apr. }\end{array}$ & 2. & $\begin{array}{l}1906 \\
1906\end{array}$ & & $\begin{array}{r}10.2 \\
7.6\end{array}$ & & $\begin{array}{r}11.900 \\
7.960\end{array}$ \\
\hline 1907 & JuIy & 15. & 1907 & & - & & $13.000 \quad 0$ \\
\hline 1908 & June & 3. & 1908 & & - & & $6.000 \mathrm{a}$ \\
\hline 1909 & July & 7. & 1909 & & - & & $12.500 \mathrm{~d}$ \\
\hline 1910 & MaI. & 9. & 1910 & & - & & $12.600 \mathrm{~d}$ \\
\hline 1911 & Feb. & 17. & 1911 & & - & & $17.200 \mathrm{~d}$ \\
\hline 1912 & Apr. & 4. & 1912 & & - & & $20.000 d$ \\
\hline 1913 & Mar. & 24. & 1913 & & - & & $7.030 \mathrm{a}$ \\
\hline 1914 & sept & .15. & 1914 & & 10.6 & $*$ & 9.620 \\
\hline 1915 & $\begin{array}{l}\text { Feb. } \\
\text { Feb. } \\
\text { June } \\
\text { July } \\
\text { Aug. } \\
\text { Sept. }\end{array}$ & $\begin{array}{r}18 . \\
25 . \\
4 \% \\
28 \\
2 . \\
29\end{array}$ & $\begin{array}{l}1915 \\
1915 \\
1915 \\
1915 \\
1915 \\
1915\end{array}$ & & $\begin{array}{r}-- \\
10.9 \\
11.0 \\
10.8 \\
12.5\end{array}$ & & $\begin{array}{r}20.000 \\
20.000 \\
9.470 \\
9.600 \\
9.340 \\
10.600\end{array}$ \\
\hline 1916 & Mar. & 26. & 1916 & & 13.5 & & 16,100 \\
\hline 1917 & $\begin{array}{l}\text { Mar. } \\
\text { June }\end{array}$ & $\begin{array}{l}29 . \\
16 .\end{array}$ & $\begin{array}{l}1917 \\
1917\end{array}$ & & - & & $\begin{array}{l}17.500 \\
17.500\end{array}$ \\
\hline 1918 & $\begin{array}{l}\text { May } \\
\text { June } \\
\text { July }\end{array}$ & $\begin{array}{r}27 \\
8 \\
7\end{array}$ & $\begin{array}{l}1918 \\
1918 \\
1918\end{array}$ & & $\begin{array}{r}12.7 \\
19.6 \\
8.7\end{array}$ & & $\begin{array}{r}14.200 \\
42.500 \\
7.220\end{array}$ \\
\hline
\end{tabular}

d About. 
05-4545.00 Iowa River at Iowa City, Iowa--(Continued)

Peak stages and discharges

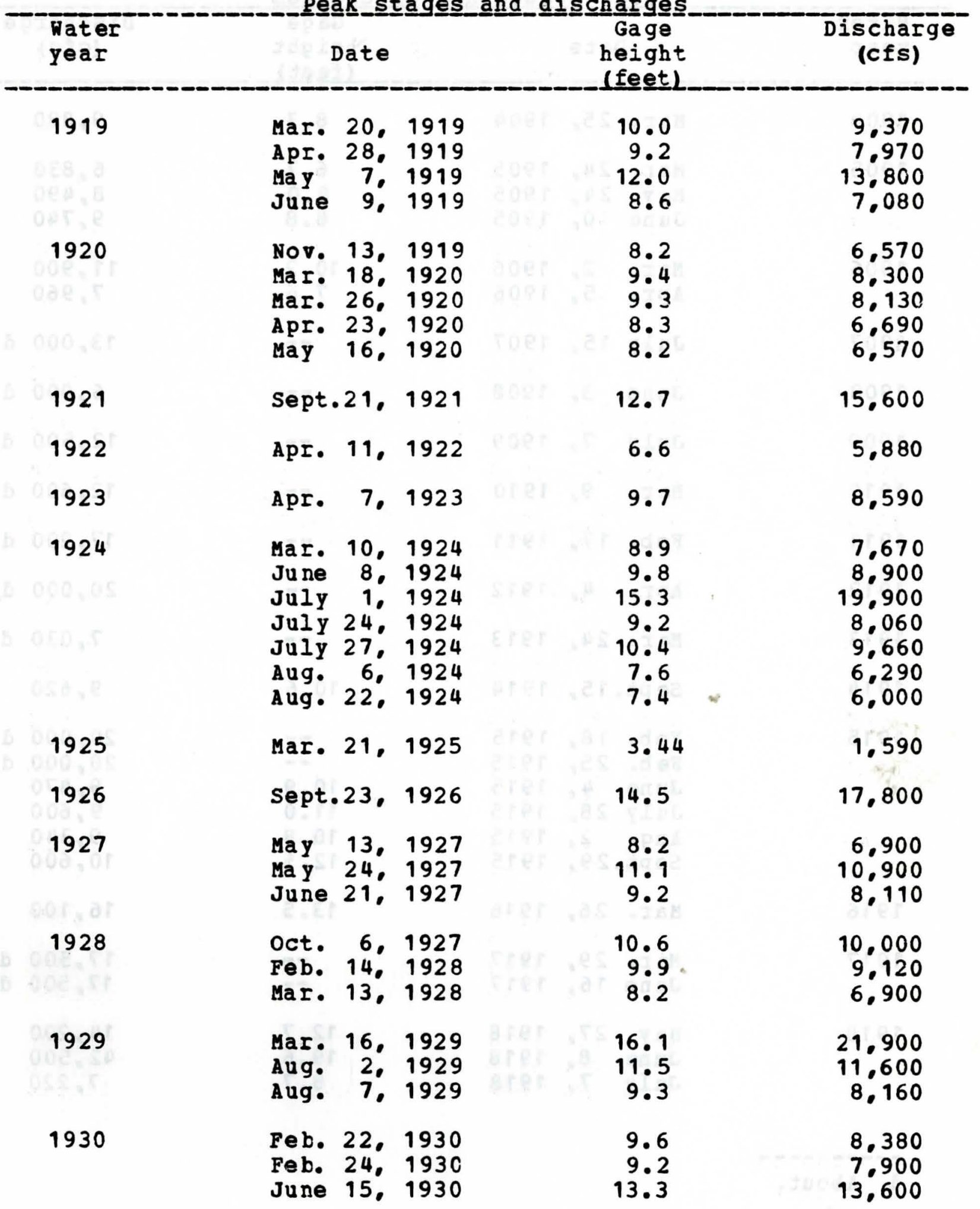


05-4545.00 Iowa River at Iowa City. Iowa--(Continued)

Peak_stages_and_di scharges

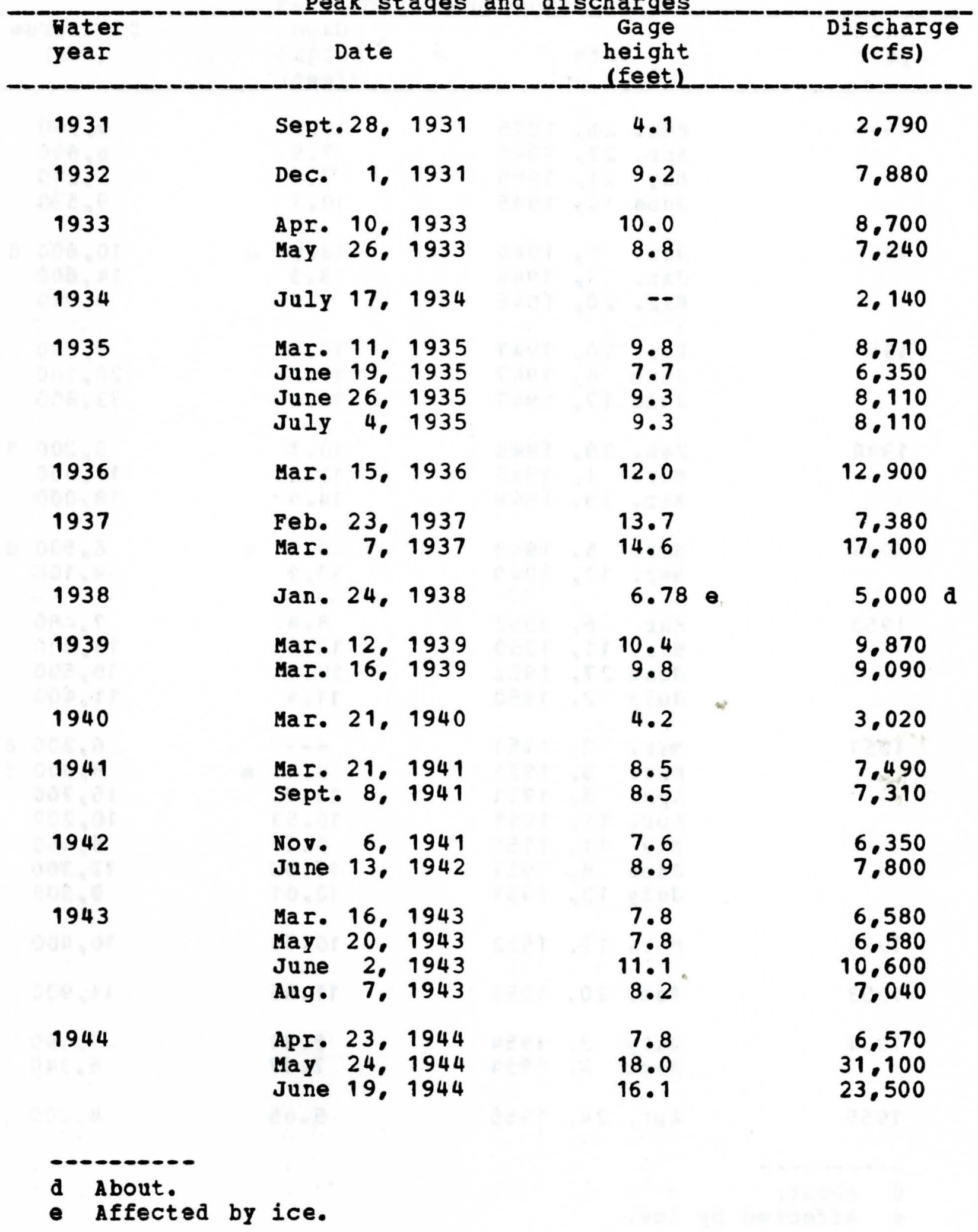


05-4545.00 Iowa River at Iowa City, Iowa-- (Continued)

Peak﹎.stages and d dis

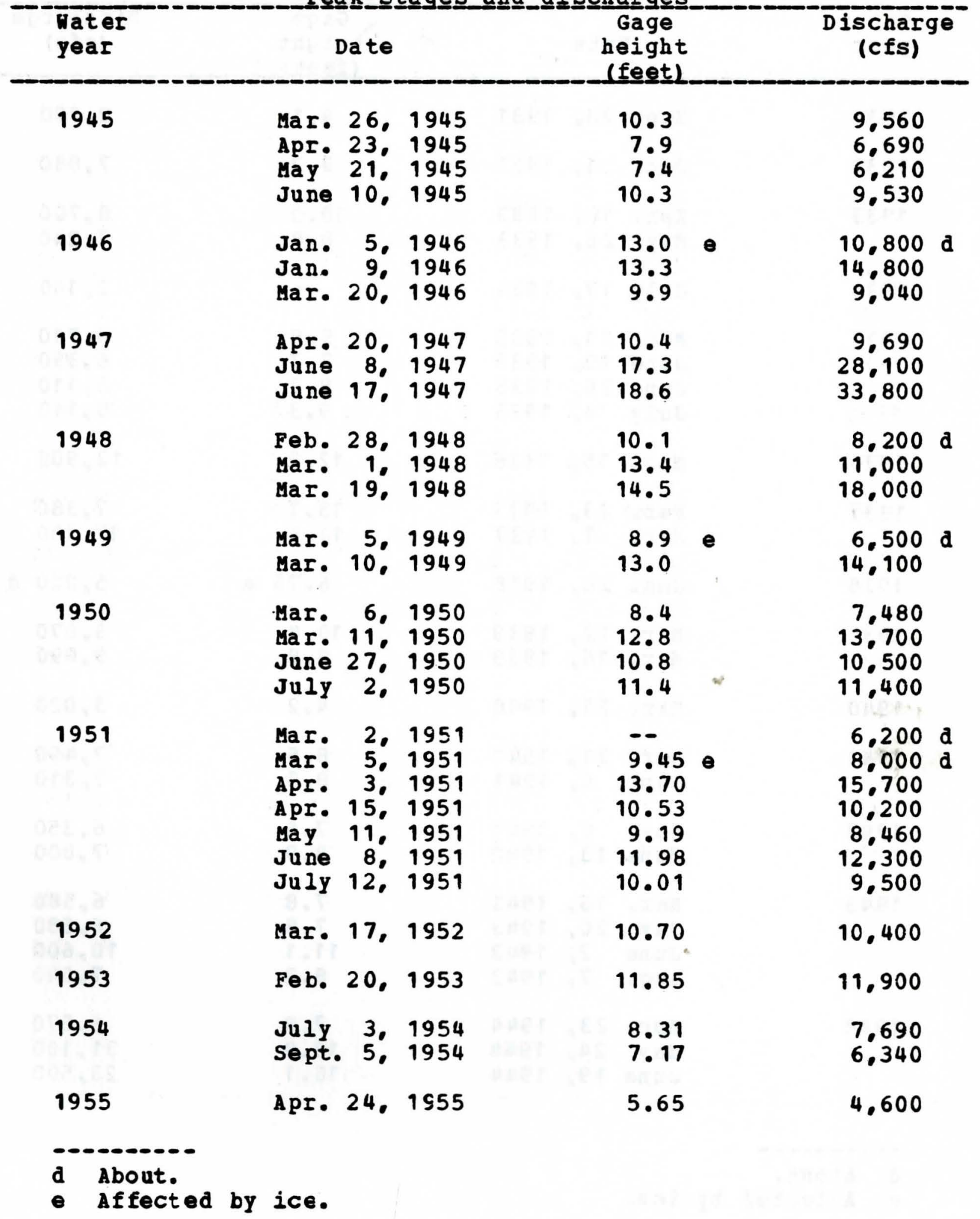


05-4545.00 Iowa River at Iowa City. Iowa-- (Continued)

Feak_stages_and_discharges

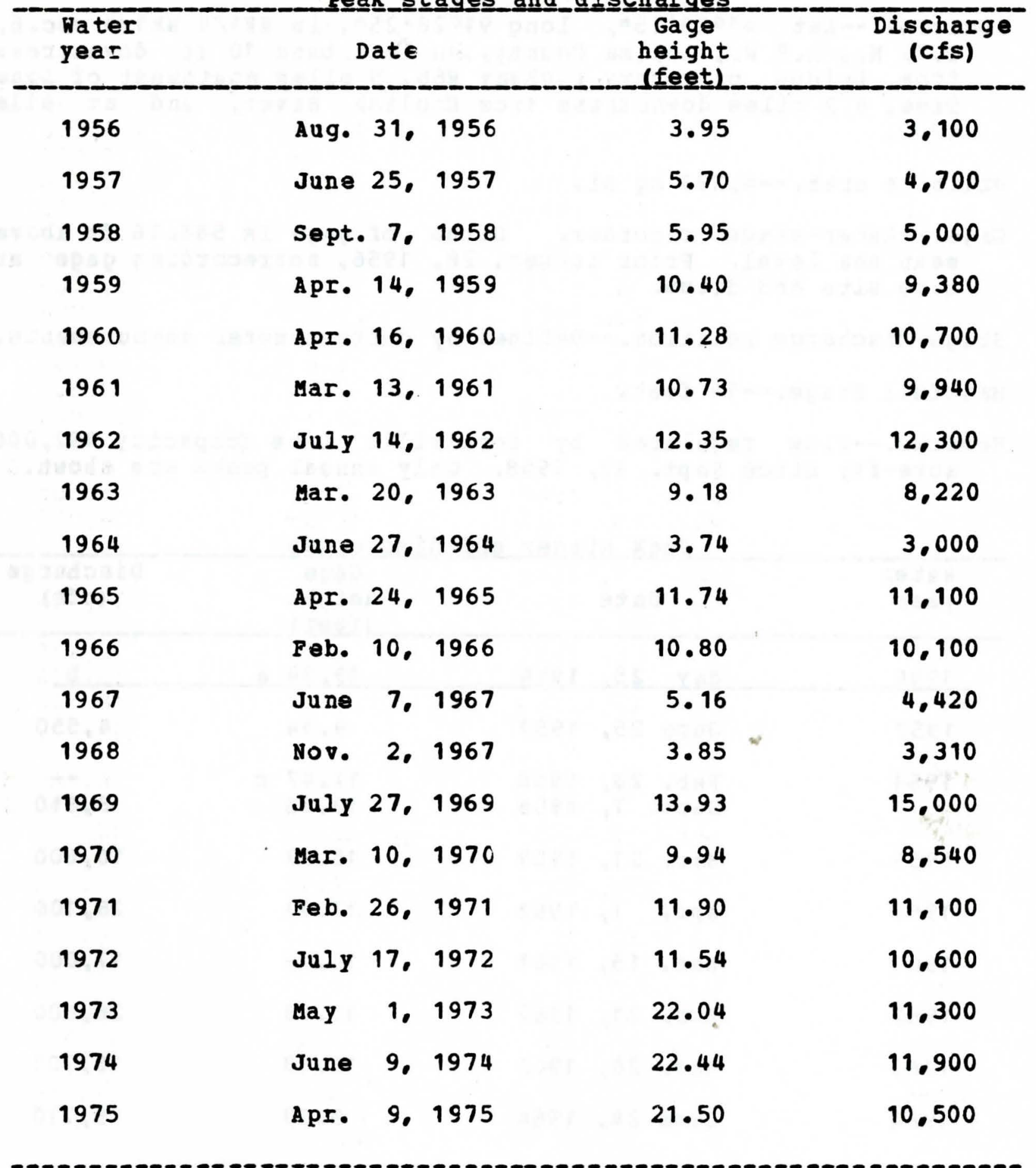




\section{5-4557.0C I owa River near Lone Tree, Iowa}

Location.--Lat $41025 \cdot 15 "$, long $91028 \cdot 25 "$, in NW1/4 NE1/4 sec.6. T.76 N.. R.5 W. . Louisa County, on left bank $10 \mathrm{ft}$ downstream from bridge on county highway $\mathbf{6 6}, 5$ miles southwest of lone Tree, 6.2 miles downstream from English River, and at mile 47.2 .

Drainage area. $--4,293 \mathrm{sq} \mathrm{mi}$.

Gage.--Water-stage recorder. Datum of gage is $588.16 \mathrm{ft}$ above mean sea level. Prior to Dec. 28, 1956, nonrecording gage at same site and datum.

Stage-discharge relation.--Defined by current-meter measurements. Bankfull stage.--14 feet.

Remarks.--Flow regulated by Coralville Lake (capacity 492,000 acre-ft) since sept. 17, 1958. Only annual peaks are shown.

Pea $\underline{k}$ sttagges_and_di $\underline{\text { scharges }}$

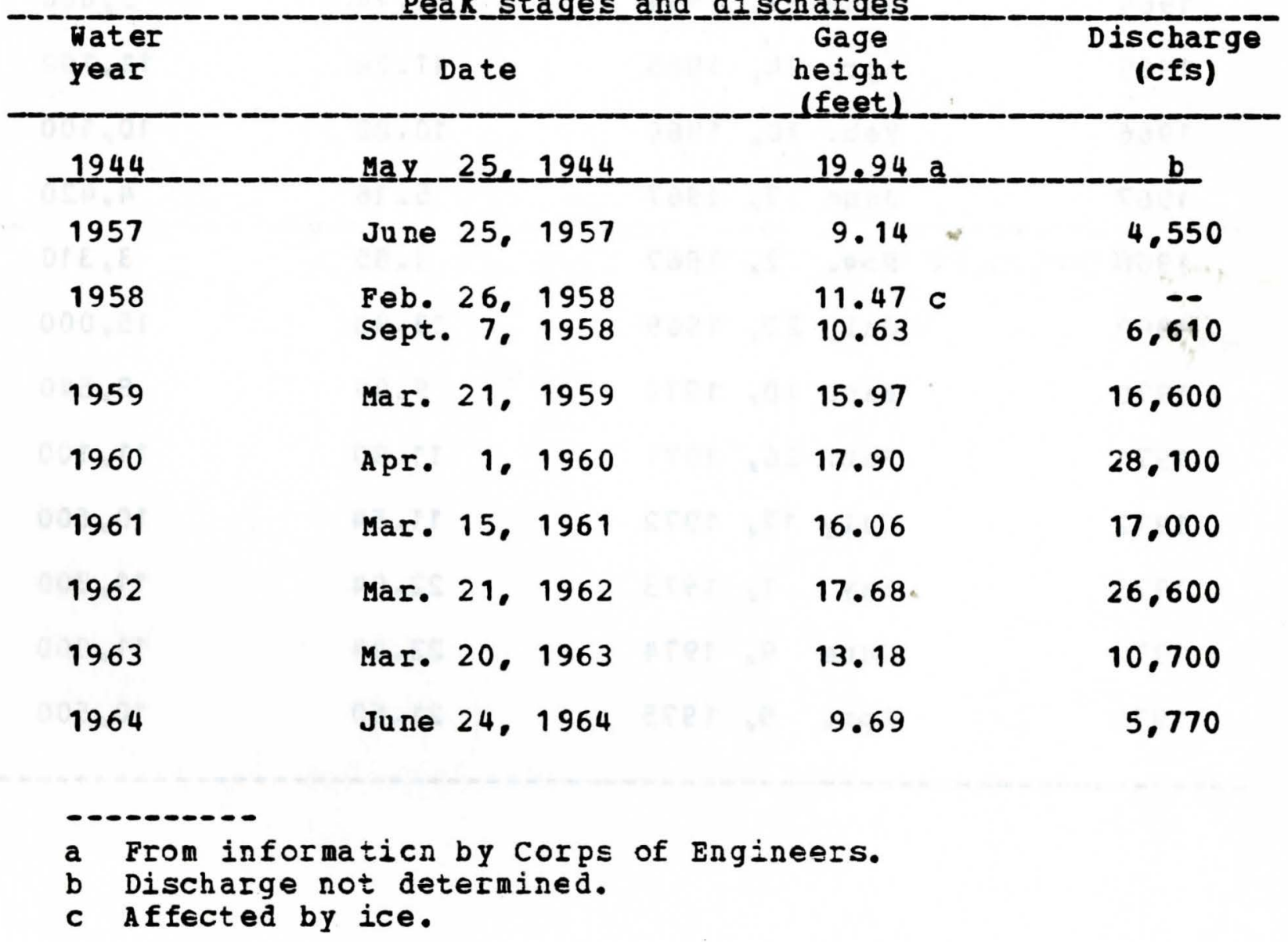


05-4557.00 Iowa River near Lone Tree. Iowa--(Continued)

Feak__sitag토_and

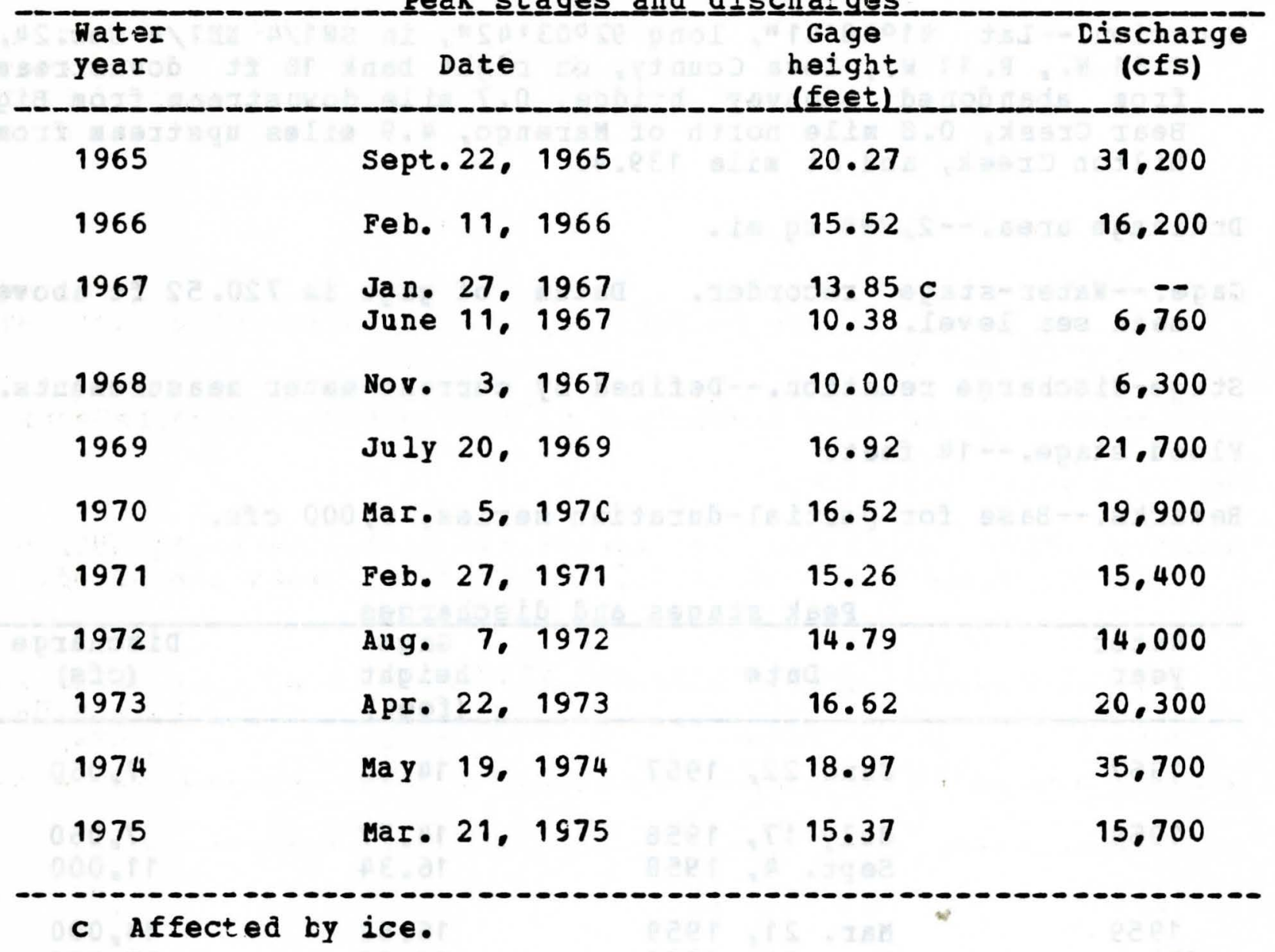




\section{5-4531.00 Iowa River at Marengo. Iowa}

Location.--Lat $41048 \cdot 41 "$, long $92003 \cdot 42^{\prime \prime}$, in Sw1/4 NE1/4 sec. 24 , T. 81 N.. R. 11 W.. Iowa County, on right bank $10 \mathrm{ft}$ downstream from abandoned highway bridge, 0.7 mile downstream from Big Bear Creek, 0.8 mile north of Marengo, 4.9 miles upstream from Hilton Creek, and at mile 139.4 .

Drainage area.--2,794 sq mi.

Gage.--Water-stage recorder. Datum of gage is 720.52 ft above mean sea level.

Stago-discharge relation.--Defined by current-meter measurements. Flood stage.--14 feet.

Remarks.--Base for partial-duration series, 6.000 cfs.

Peak

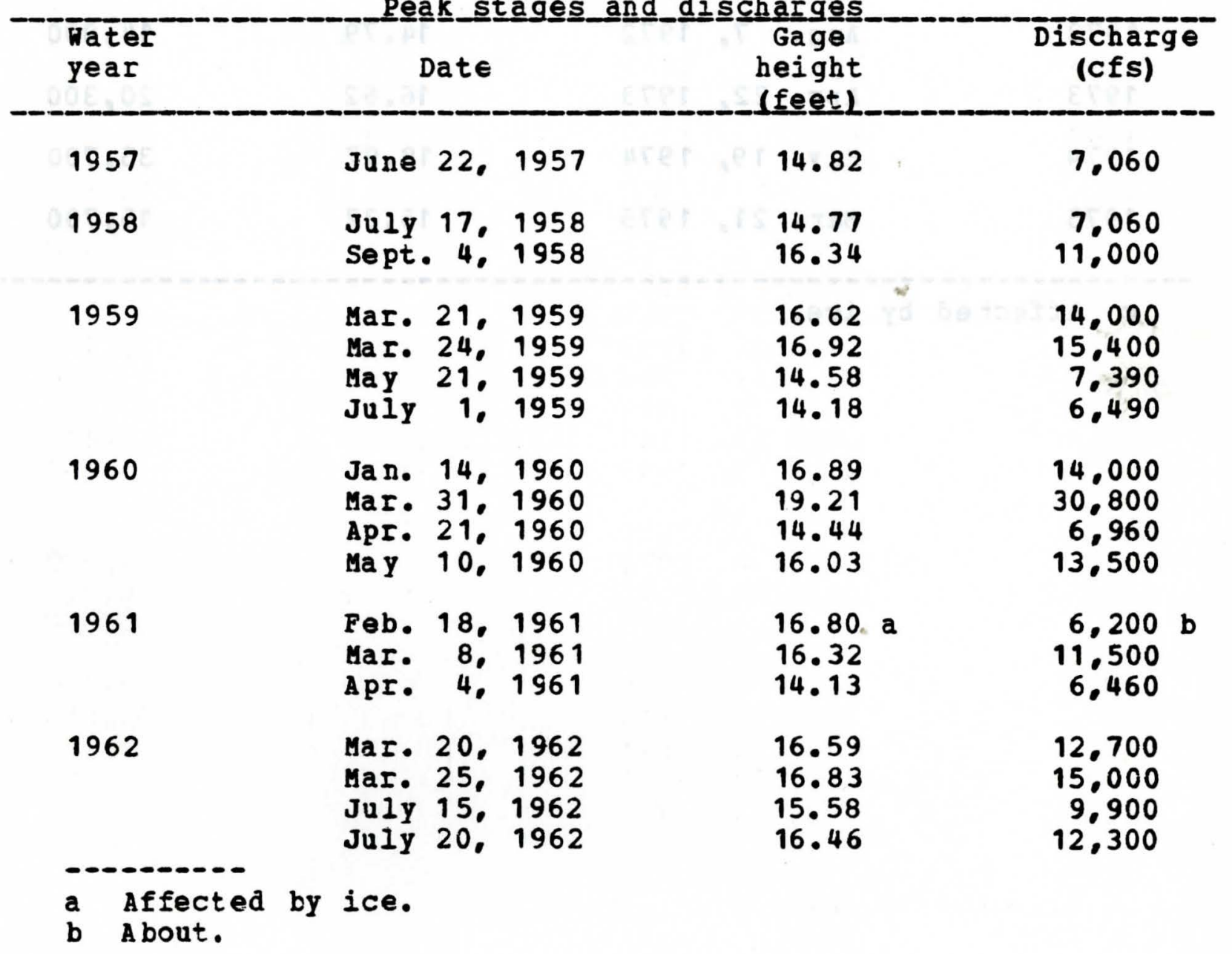


05-4531.00 Iowa River at Marengo, Iowa-- (Continued)

Peak_stages_and discharges

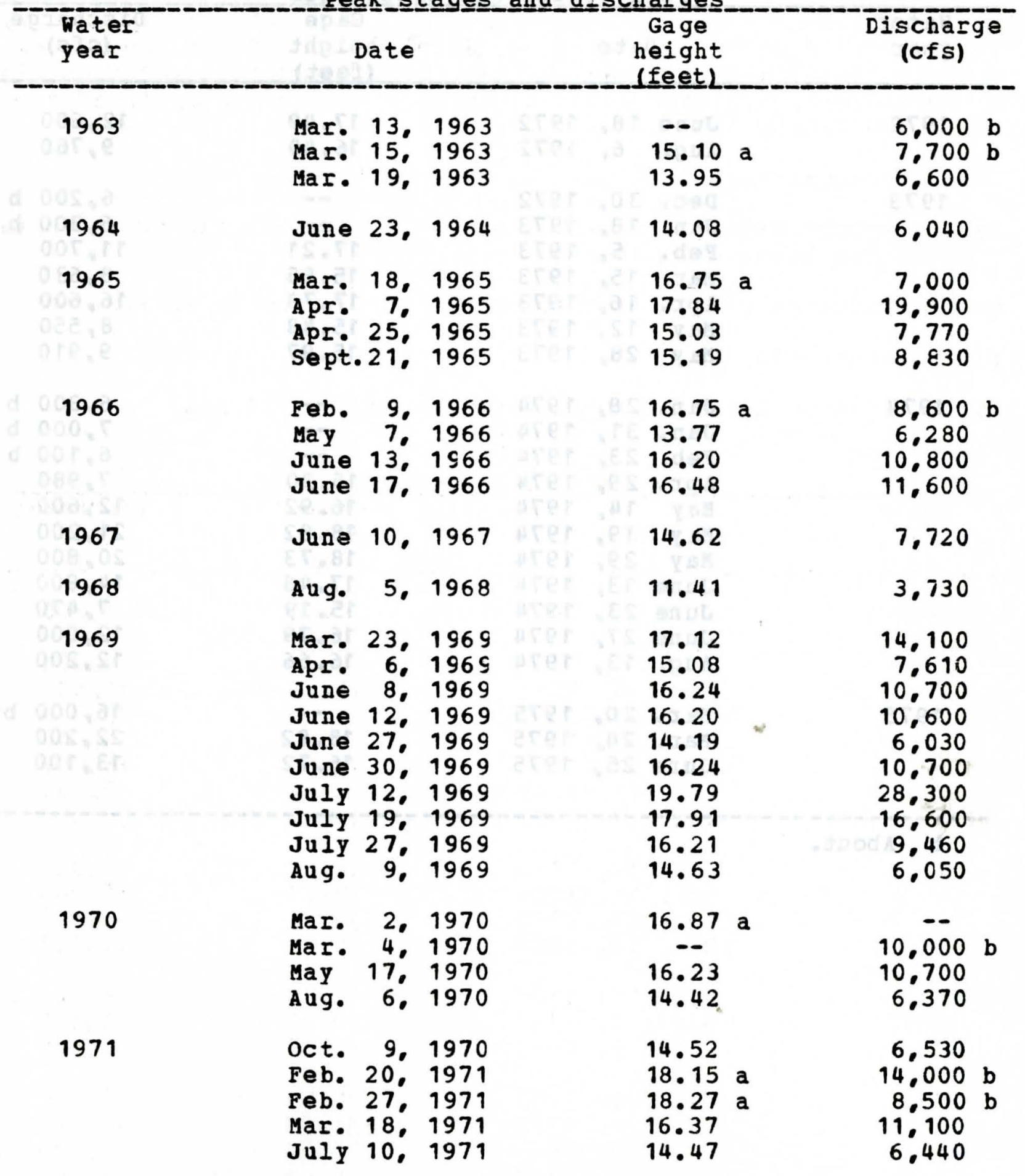

a Affected by ice.

b about. 
05-4531.00 Iowa River at Marengo, Iowa-- (Continued)

Pea $\underline{k}$ _stages_and_di

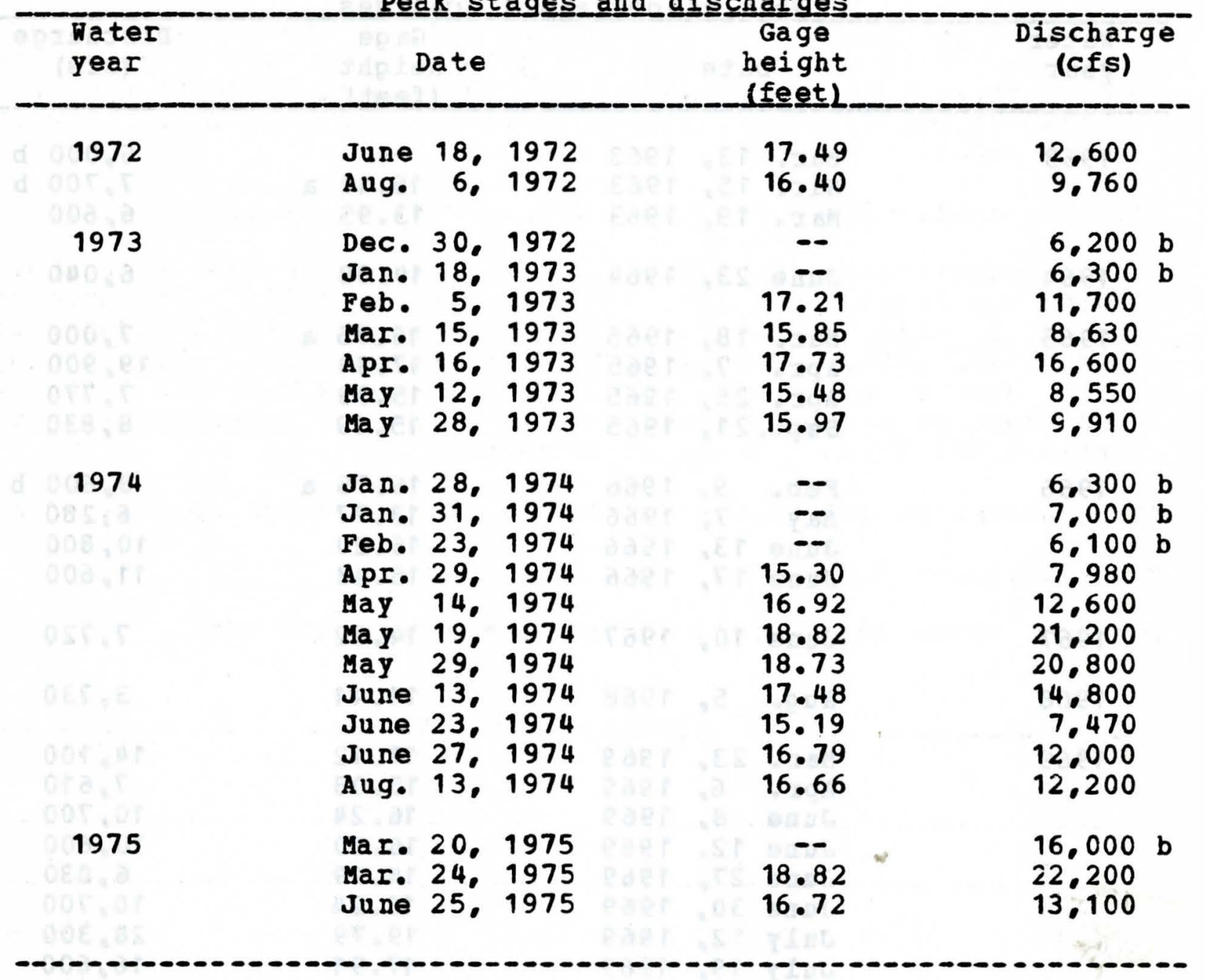

b About. 


\section{5-4515.00 Iowa River at Marshalltown. Iowa}

Location.--Iat 42003'57", long 92054'27", in SE1/4 SE1/4 sec.23, T.84 N.. R. 18 W.. Marshall County, on right bank $10 \mathrm{ft}$ downstream from State Highway 14 bridge, 1,500 ft upstream from Burnett Creek, 2.2 miles upstream from Linn Creek, and at mile 222.8.

Drainage area.-- 1,564 sq mi, including that of Burnett Creek.

Gage.-- Water-stage recorder. Datum of gage is $853.10 \mathrm{ft}$ above mean sea level. Oct. 25, 1902, to Aug. 8, 1903, staff gage at site 1 mile upstream at different datum. May 21, 1915, to Sept. 30, 1927, and Feb. 1, 1933, to May 8, 1934, chain gage, and May 9 to Sept. 1, 1934, staff gage, at site 1.000 ft upstream at present datum. Sept. 2-20, 1934, staff gage at site 1,000 ft downstream at different datum.

Stage-discharge relation.--Defined by current-meter measurements. Flood stage. - 13 feet.

Remarks.--Base for partial-duration series, $5,000 \mathrm{cfs}$.

Peak_stages_and di $\underline{\text { s. }}$ ch

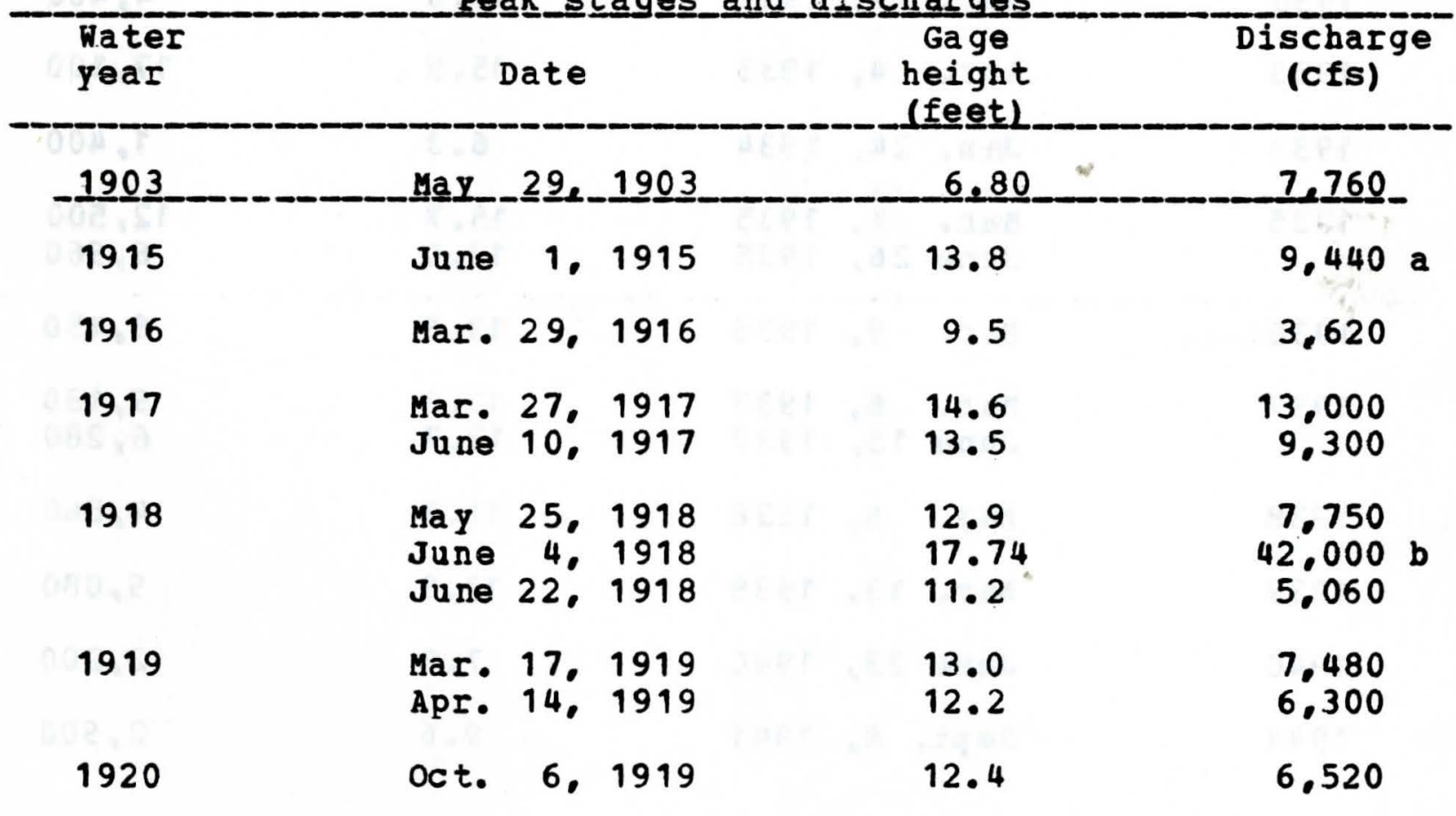

a Maximum during period May to september 1915.

b From floodmark. 
05-4515.00 Iowa River at Marshalltown, Iowa--(Continued)

Peak﹎.stagges_and_dis $\underline{\text { charges }}$

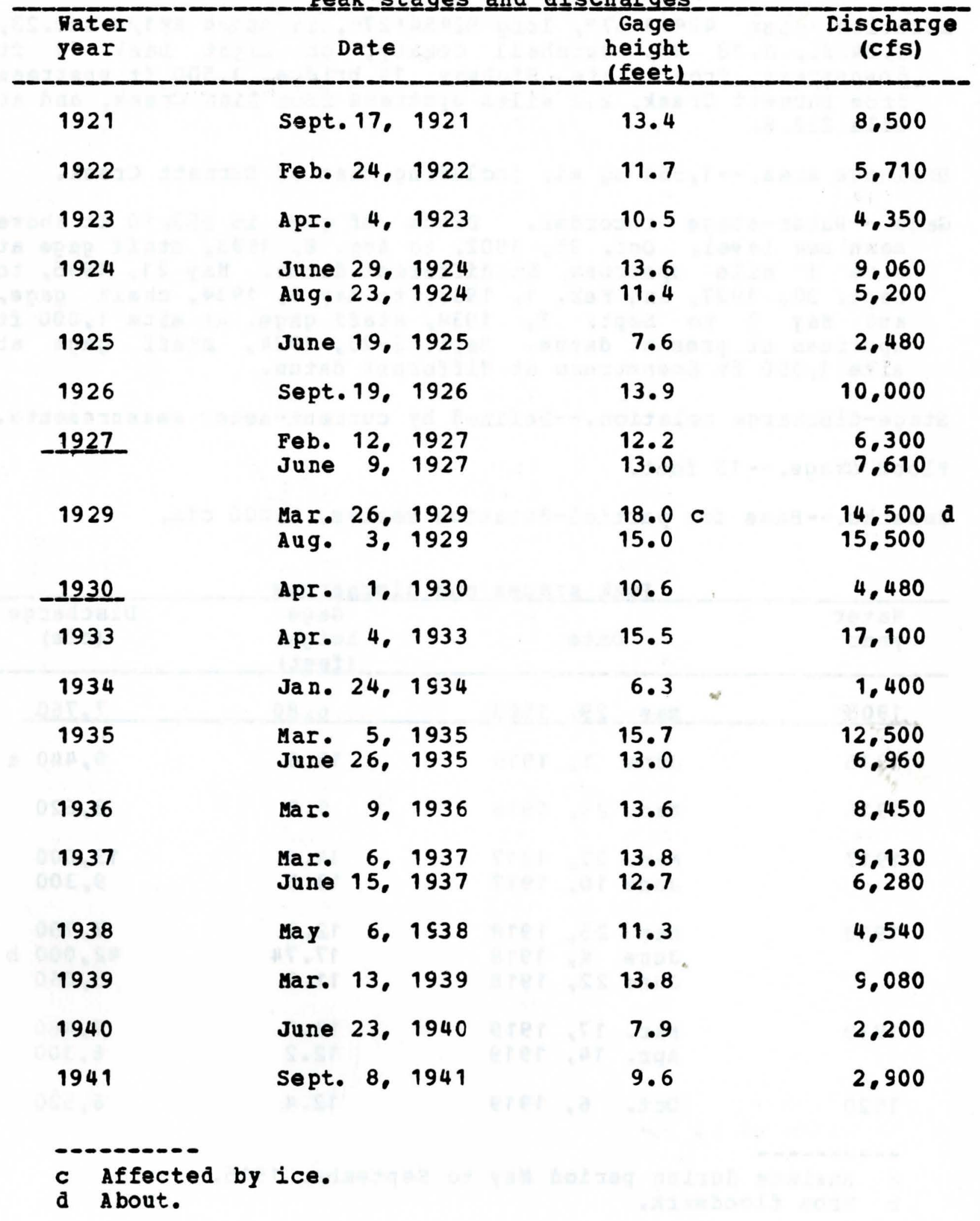


05-4515.00 Iowa River at Marshalltown. Iowa--(Continued)

Peak_stages_and discharges

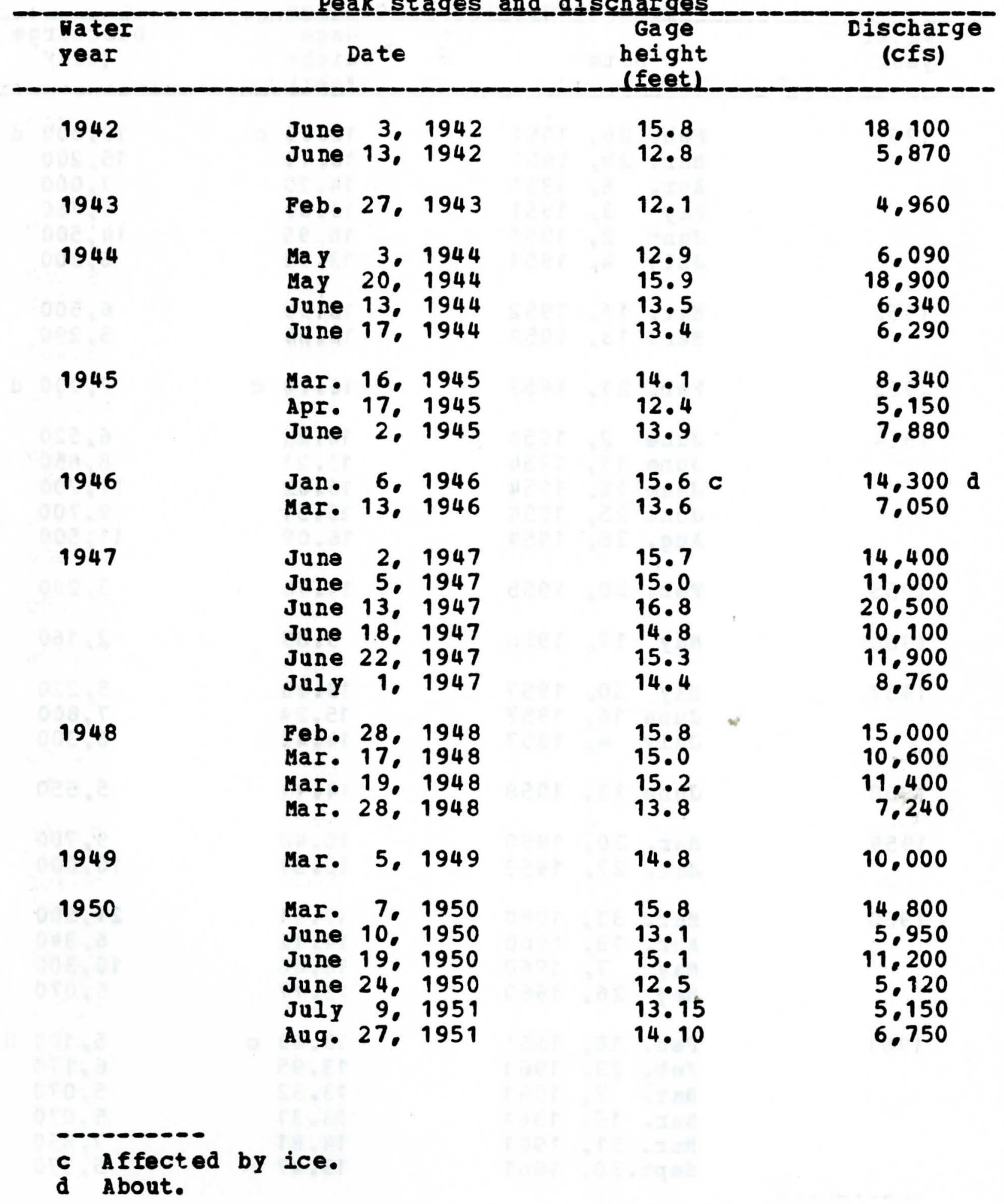


05-4515.00 Iowa River at Marshalltown, Iowa-- (Continued)

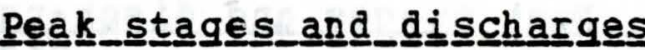

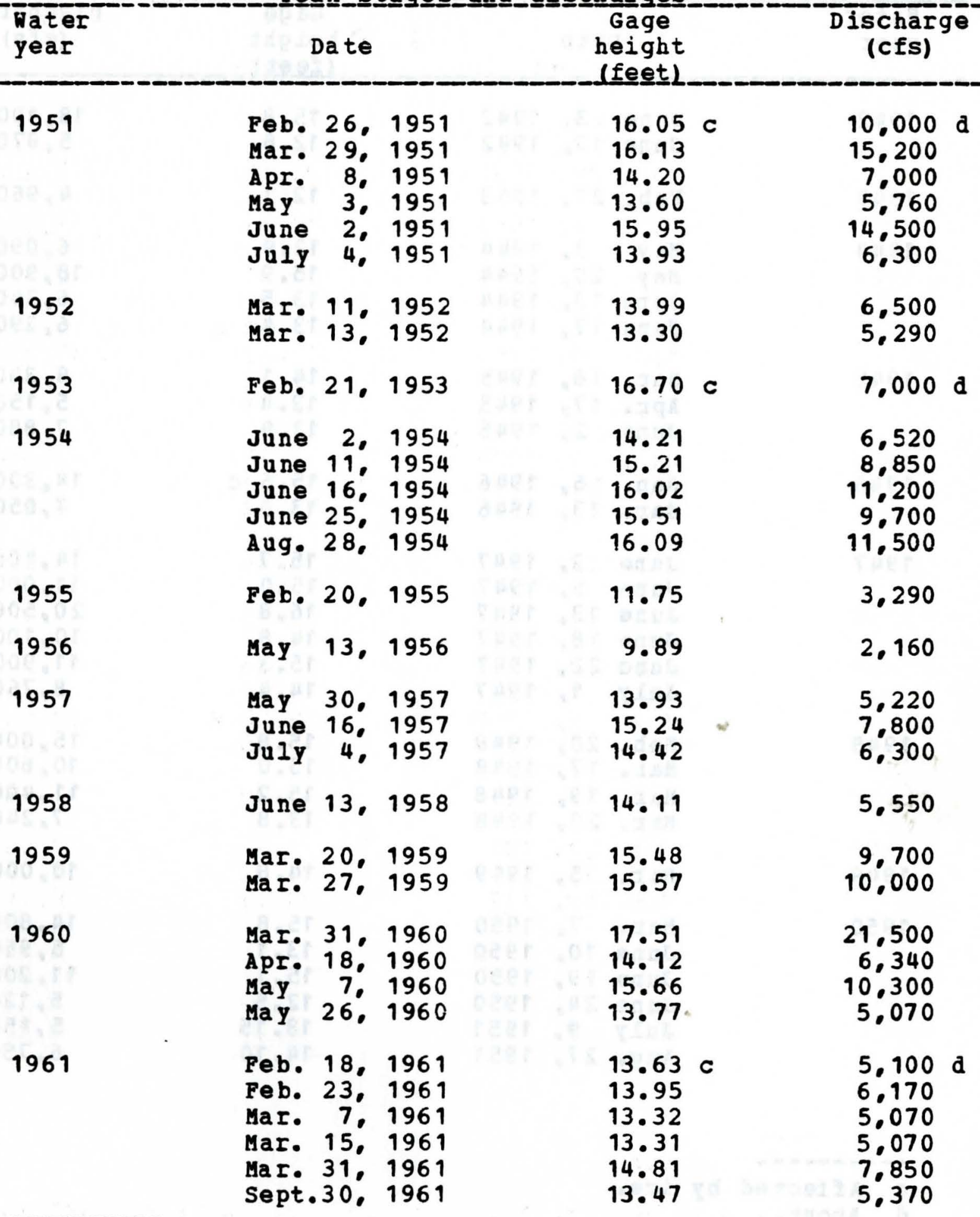

c Affected by ice.

d about. 
05-4515.00 Iowa River at Marshalltown. Iowa--(Continued)

Peak stages and discharges

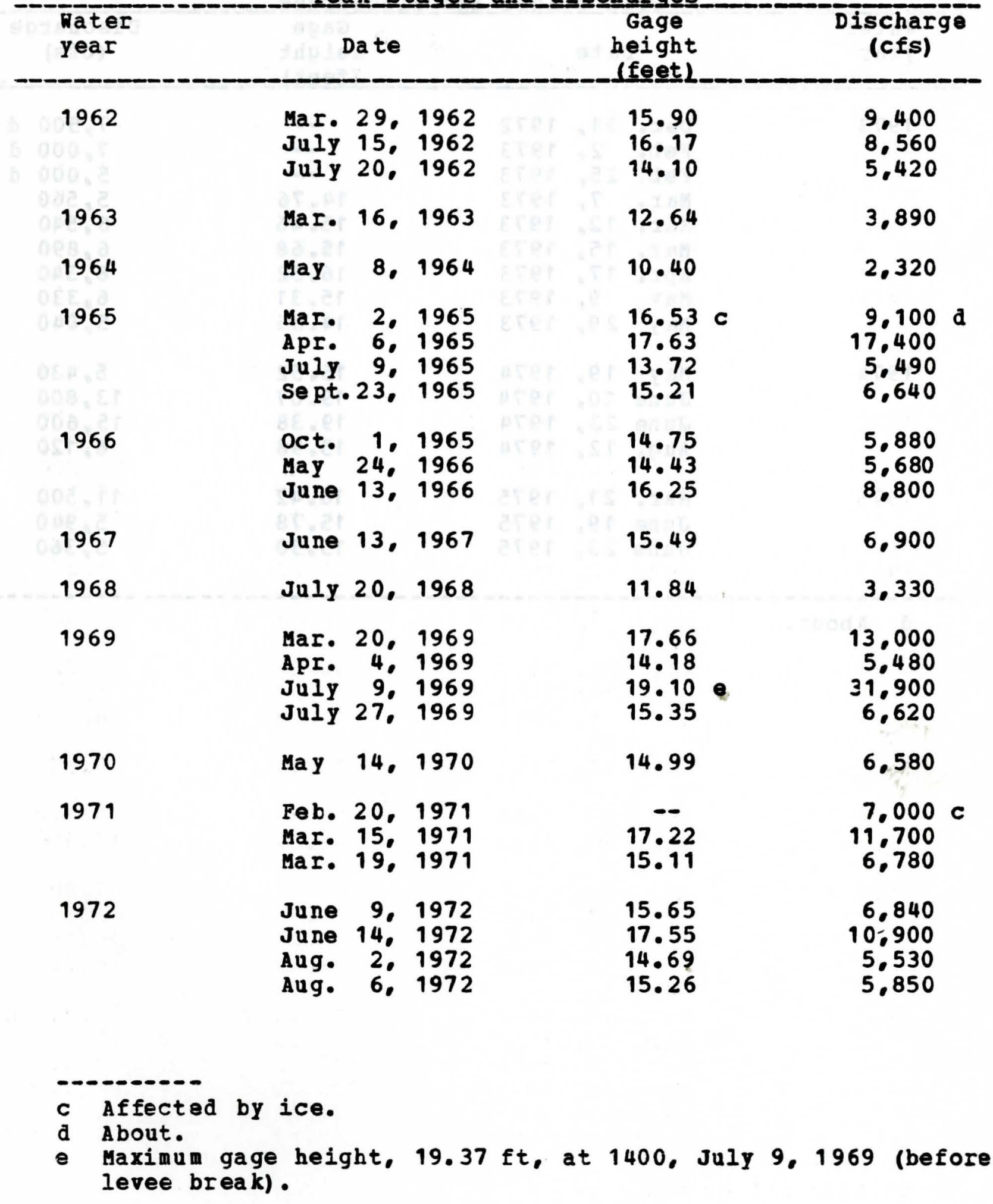


05-4515.00 Iowa River at Marshalltown, Iowa--(Continued)

Peak﹎.stagges_and_di

\begin{tabular}{|c|c|c|c|c|c|c|}
\hline $\begin{array}{l}\text { Water } \\
\text { year }\end{array}$ & 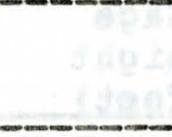 & Date & & & $\begin{array}{r}\text { Gage } \\
\text { height } \\
\text { (feet) }\end{array}$ & $\begin{array}{c}\text { Discharge } \\
\text { (cfs) }\end{array}$ \\
\hline 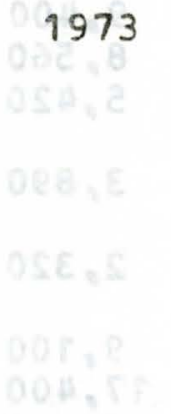 & $\begin{array}{l}\text { Dec. } \\
\text { Fab. } \\
\text { Feb. } \\
\text { Mar. } \\
\text { Mar. } \\
\text { Mar. } \\
\text { Apr. } \\
\text { May } \\
\text { May }\end{array}$ & $\begin{array}{r}31 . \\
2 \% \\
25 . \\
7 \% \\
12 \% \\
15 \% \\
9 \% \\
29 .\end{array}$ & $\begin{array}{l}1972 \\
1973 \\
1973 \\
1973 \\
1973 \\
1973 \\
1973 \\
1973 \\
1973\end{array}$ & & $\begin{array}{r}\ldots \\
-- \\
14.76 \\
15.46 \\
15.68 \\
16.52 \\
15.31 \\
14.35\end{array}$ & $\begin{array}{l}7,500 \text { d } \\
7.000 \text { d } \\
5.000 \text { d } \\
5.560 \\
6.540 \\
6.890 \\
8.340 \\
6.330 \\
5.040\end{array}$ \\
\hline 1974 & $\begin{array}{l}\text { May } \\
\text { June } \\
\text { June } \\
\text { Aug. }\end{array}$ & $\begin{array}{l}19 . \\
10 . \\
23 . \\
12 .\end{array}$ & $\begin{array}{l}1974 \\
1974 \\
1974 \\
1974\end{array}$ & & $\begin{array}{r}15.52 \\
19.07 \\
19.38 \\
15.98\end{array}$ & $\begin{array}{r}5.430 \\
13.800 \\
15.600 \\
6.120\end{array}$ \\
\hline 1975 & $\begin{array}{l}\text { Mar. } \\
\text { June } \\
\text { June }\end{array}$ & $\begin{array}{l}21 . \\
19 \\
23\end{array}$ & $\begin{array}{l}1975 \\
1975 \\
1975\end{array}$ & & $\begin{array}{r}18.42 \\
15.78 \\
15.30\end{array}$ & $\begin{array}{r}11.500 \\
5.940 \\
5.360\end{array}$ \\
\hline
\end{tabular}

d A bout. 


\section{5-4495.00 Iowa River near Rowan, Iowa}

Location.--Lat $42045 \cdot 36^{\prime \prime}$. Iong $93037 \cdot 23^{\prime \prime}$, in NN1/4 NE $1 / 4$ seC. 25 , T. 92 N.. R. 24 W.. Wright County, on left bank $10 \mathrm{ft}$ downstream from bridge on county highway C38, 0.9 mile downstream from Drainage ditch 123, 3.8 miles northwest of Rowan, 10.7 miles downstream from confluence of East and Nest Branches, and at mile 316. 4 .

Drainage area.-- $-429 \mathrm{sq} \mathrm{mi}$

Gage.- Water-stage recorder. Datum of gage is $1,143.35$ ft above mean sea level. Prior to oct. 14, 1948, nonrecording gage at same site and datum.

Stage-discharge relation.--Defined by current-meter measurements. Bankfull stage.--10 feet.

Remarks.--Base for partial-duration series, 1,200 cfs.

Peak__stagges_and__dis $\underline{\text { charges }}$

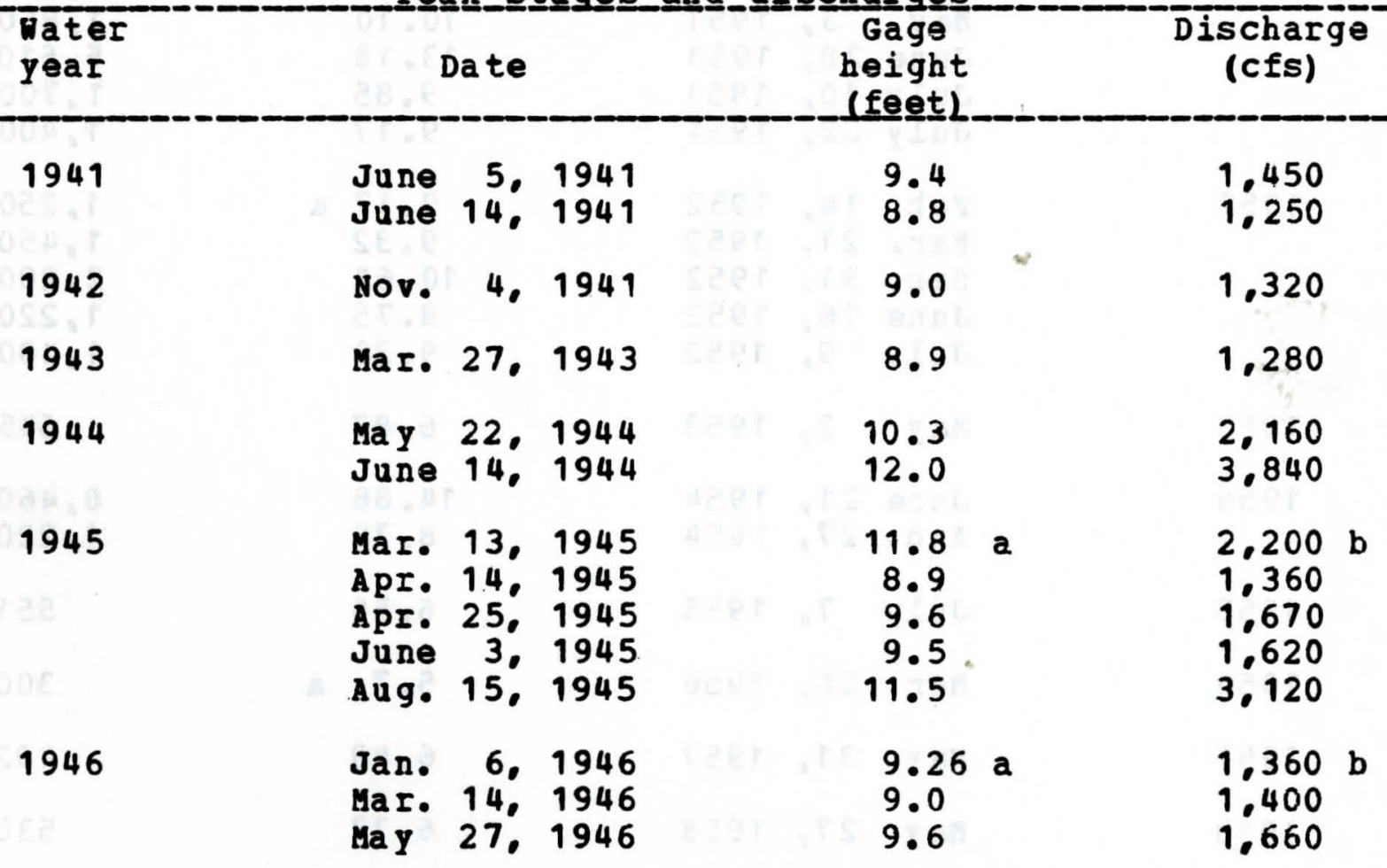

a Affected by ice.

b about. 
05-4495.00 Iowa River near Rowan, Iowa--(Continued)

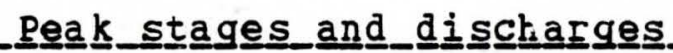

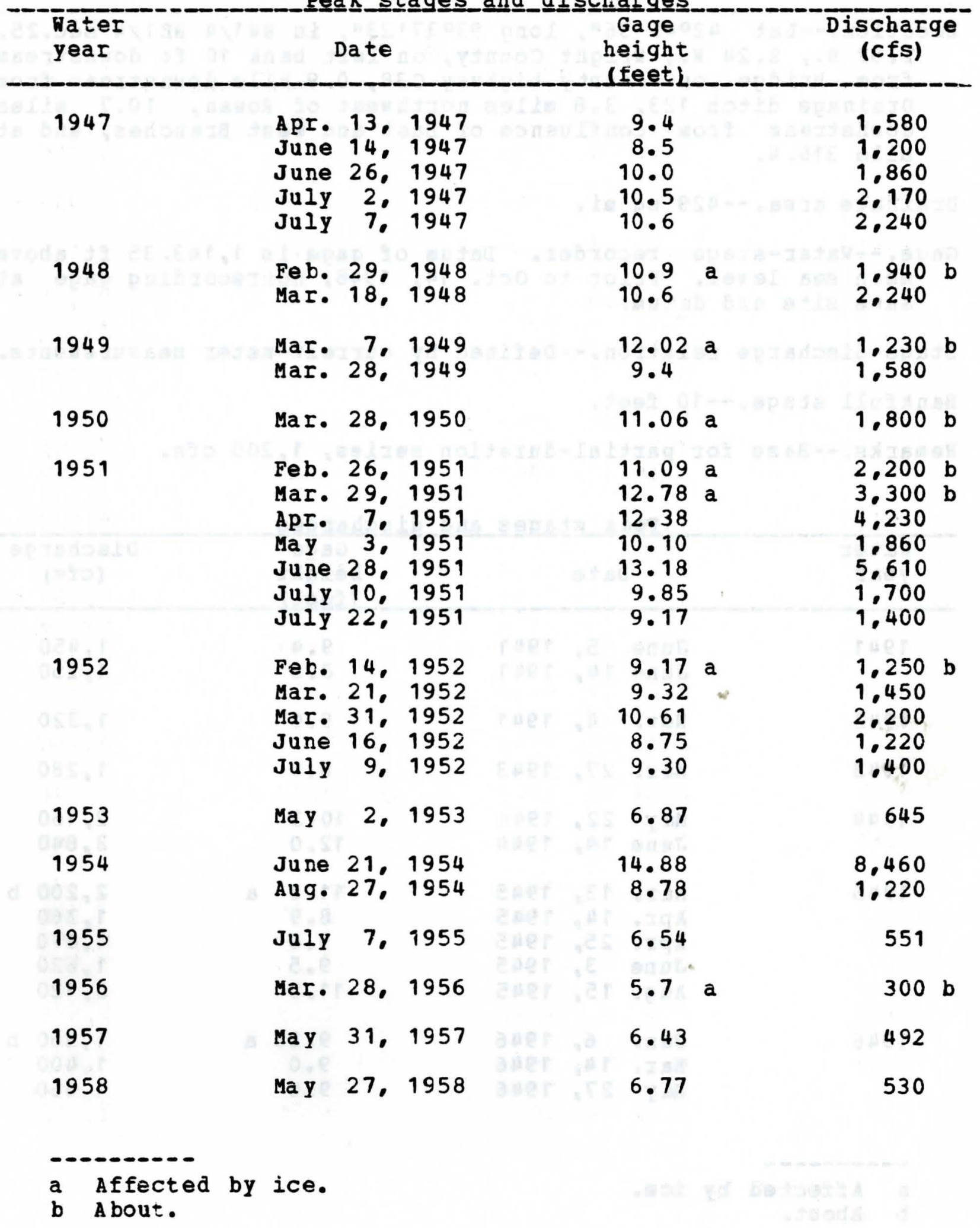


05-4495.00 Iowa River near Rowan, Iowa-- (Continued)

Feak﹎﹎ㅡㅁages_and_discharges

\begin{tabular}{|c|c|c|c|}
\hline $\begin{array}{l}\text { Water } \\
\text { year }\end{array}$ & Date & $\begin{array}{l}\text { Gage } \\
\text { height } \\
\text { lfeetl. }\end{array}$ & $\begin{array}{l}\text { Discharge } \\
\text { (cfs) }\end{array}$ \\
\hline 1959 & $\begin{array}{lrr}\text { May } & 24, & 1959 \\
\text { June } & 2, & 1959\end{array}$ & $\begin{array}{r}9.87 \\
10.07\end{array}$ & $\begin{array}{l}1,420 \\
1,540\end{array}$ \\
\hline 1960 & Mar. 30, 1960 & $12.11 \mathrm{a}$ & $2.900 \mathrm{~b}$ \\
\hline 1961 & Mar. 28, 1961 & 12.81 & 5.580 \\
\hline 1962 & $\begin{array}{l}\text { Mar. 29, } 1962 \\
\text { July } 7,1962 \\
\text { July 22, } 1962 \\
\text { Sept. 2, } 1962\end{array}$ & $\begin{array}{r}12.60 \quad a \\
9.46 \\
9.35 \\
11.21\end{array}$ & $\begin{array}{l}4.050 \quad b \\
1.530 \\
1.530 \\
3.090\end{array}$ \\
\hline 1963 & $\begin{array}{lrl}\text { Mar. } & 20, & 1963 \\
\text { July } & 8, & 1963 \\
\text { July } & 22,1963\end{array}$ & $\begin{array}{r}9.29 \\
10.22 \\
9.55\end{array}$ & $\begin{array}{l}1.260 \\
1.820 \\
1.390\end{array}$ \\
\hline 1964 & Sept. 11, 1964 & 9.82 & 1.520 \\
\hline 1965 & $\begin{array}{l}\text { Apr. 6, } 1965 \\
\text { Apr. 7, } 1 \text { 565 } \\
\text { Sept.21, } 1965 \\
\text { Sept.30, } 1965\end{array}$ & $\begin{array}{l}14.62 \\
11.86 \\
10.98\end{array}$ & $\begin{array}{l}6.700 \mathrm{~b} \\
4.100 \\
2.750\end{array}$ \\
\hline 1966 & $\begin{array}{l}\text { Feb. 11, } 1966 \\
\text { Apr. } 2,1966 \\
\text { June } 13,1966\end{array}$ & $\begin{array}{r}10.21 \\
9.19 \\
9.03\end{array}$ & $\begin{array}{l}1.910 \\
1.320 \\
1.260\end{array}$ \\
\hline 1967 & June 10,1967 & 10.13 & 1.640 \\
\hline 1968 & July 18,1968 & 9.88 & 1.640 \\
\hline 1969 & $\begin{array}{lr}\text { Mar. } 25,1969 \\
\text { Apr. } & 6,1969 \\
\text { July } 1,1969 \\
\text { July } 10,1969\end{array}$ & $\begin{array}{l}10.58 \\
10.27 \\
12.36 \\
11.26\end{array}$ & $\begin{array}{l}2.170 \\
1.940 \\
4.250 \\
2.770\end{array}$ \\
\hline 1970 & May $14,157 C$ & 10.98 & 2.560 \\
\hline 1971 & $\begin{array}{lrl}\text { Mar. } & 16,1571 \\
\text { Apr. } & 101971 \\
\text { June } & 9,1571\end{array}$ & $\begin{array}{r}--- \\
10.67 \\
9.50\end{array}$ & $\begin{array}{l}1.530 \mathrm{~b} \\
2.410 \\
1.510\end{array}$ \\
\hline
\end{tabular}

a Affected by ice.

b About. 
05-4495.00 Iowa River near Fowan. Iowa--(Continued)

Peek_stages_and__di sçharges

\begin{tabular}{|c|c|c|c|c|}
\hline $\begin{array}{l}\text { Water } \\
\text { year }\end{array}$ & Date & & $\begin{array}{l}\text { Gage } \\
\text { height } \\
\text { (feet) }\end{array}$ & $\begin{array}{c}\text { Discharge } \\
\text { (cfs) }\end{array}$ \\
\hline 1972 & June 10 & 1572 & 11.25 & 2.790 \\
\hline 1973 & $\begin{array}{lr}\text { Mar. } & 4, \\
\text { Mar. } 12, & \\
\text { Apr. 17, } \\
\text { May } 9, \\
\text { May } 30, \\
\text { June 19, }\end{array}$ & $\begin{array}{l}1973 \\
1973 \\
1973 \\
1973 \\
1973 \\
1973\end{array}$ & $\begin{array}{r}-- \\
10.96 \\
10.64 \\
9.77 \\
10.33 \\
9.58\end{array}$ & $\begin{array}{l}2.230 \quad b \\
2.740 \\
2.480 \\
1.770 \\
2.210 \\
1.680\end{array}$ \\
\hline 1974 & June 10. & 1974 & 9.04 & 1.400 \\
\hline 1975 & $\begin{array}{l}\text { Apr. } 30 . \\
\text { June } 13 .\end{array}$ & $\begin{array}{l}1975 \\
1975\end{array}$ & $\begin{array}{r}11.10 \\
9.05\end{array}$ & $\begin{array}{l}3.270 \\
1.410\end{array}$ \\
\hline
\end{tabular}

b About. 


$$
\text { 05-4655.00 Iowa River at Wape110. Iowa }
$$

Location.--Iat $41010 \cdot 48 "$, long $91010 \cdot 57 "$, in NW1/4 SE1/4 sec.27. T. 74 N., R. 3 W.. Louisa county, on right bank 30 ft dcunstream from bridge on State Highway 99 at east edge of Wape110, 13.0 miles downstream from Cedar River, and at mile 16.0.

Drainage area.--12,499 sq mi.

Gage.-- Water-stage recorder. Datum of gage is $538.98 \mathrm{ft}$ above mean sea level, adjustment cf 1912; oct. 1, 1914. to Apr. 15. 1934. nonrecording gage and Apr. 16, 1934, to sept. 30, 1972. water-stage recorder at datum $10 \mathrm{ft}$ higher.

Stage-discharge relation.--Defined by current-meter measurements. Flood stage.-- 20 feet. Levees frotect lowland.

Remarks.--Peak daily discharge for 1903-1914 was estimated by Corps of Engineers from Mississippi River records. Since peak discharge at this station rarely exceeds the peak daily discharge by more than five percent, these estimates are listed as annual flocd peaks. Peak discharge base discontinued upon beginning of storage in Coralvilie lake sept. 17. 1958.

Peak stag

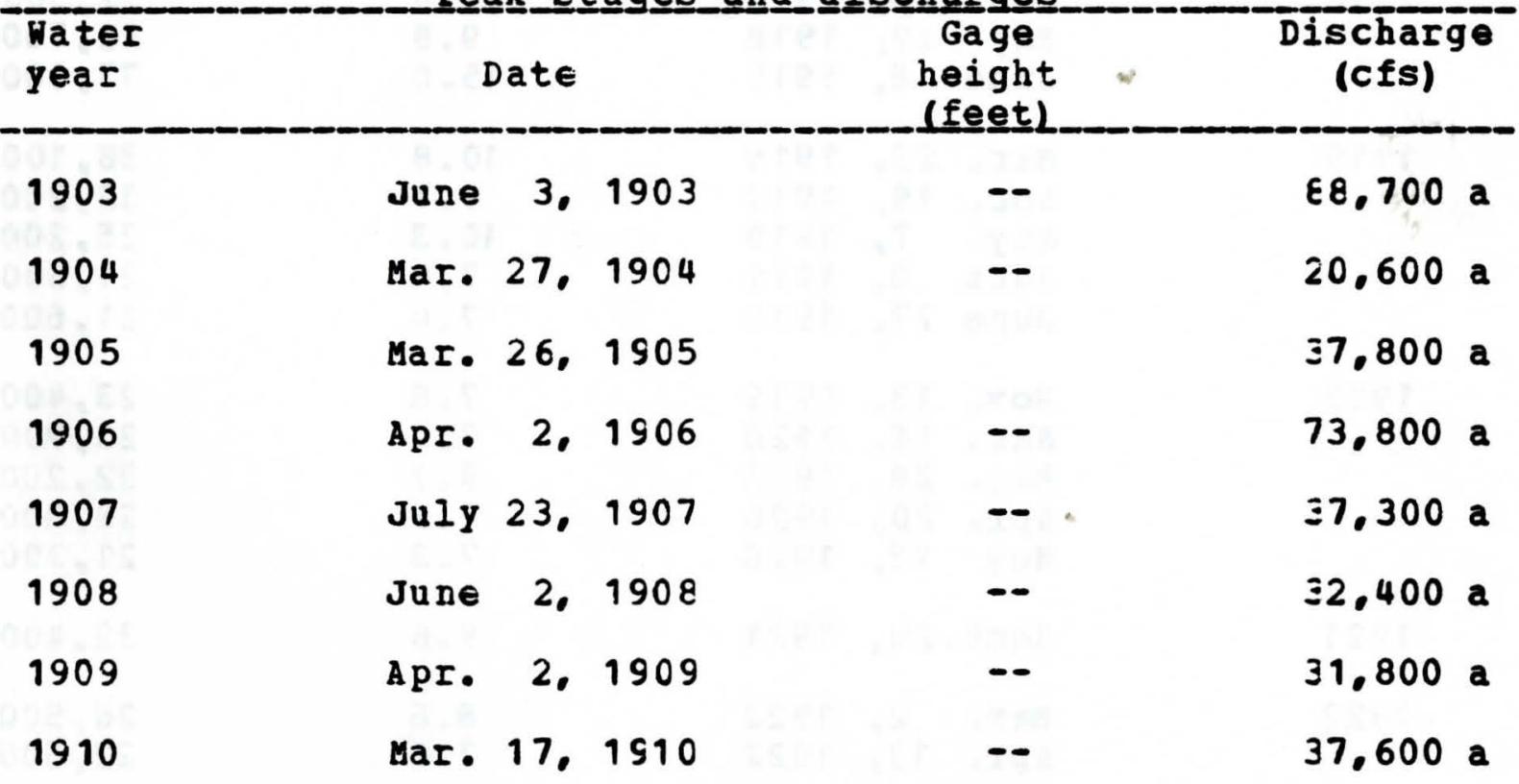

a About. 
05-4655.00 Iowa River at Wapellc. Iowa--(Continued)

Eeak_stageses_and_di

\begin{tabular}{|c|c|c|c|c|}
\hline $\begin{array}{l}\text { Water } \\
\text { year }\end{array}$ & Date & & $\begin{array}{l}\text { Gage } \\
\text { height } \\
\text { (feet) }\end{array}$ & $\begin{array}{c}\text { Discharg } \\
\text { (cfs) }\end{array}$ \\
\hline 1911 & Feb. 19. & 1911 & - & 29.400 \\
\hline 1912 & Apr. 3. & 1912 & 14.3 & 58.000 \\
\hline 1913 & MaI. 21. & 1913 & $\cdots$ & 35.000 \\
\hline 1914 & June 22 & 1914 & - & 27.000 \\
\hline 1915 & $\begin{array}{l}\text { Feb. } 26, \\
\text { Apr. 1. } \\
\text { June } 6, \\
\text { July } 31 .\end{array}$ & $\begin{array}{l}1915 \\
1915 \\
1915 \\
1915\end{array}$ & $\begin{array}{r}11.5 \\
10.3 \\
10.6 \\
7.7\end{array}$ & $\begin{array}{l}41.800 \\
35.300 \\
\equiv 6.800 \\
22.600\end{array}$ \\
\hline 1916 & $\begin{array}{l}\text { Oct. } 2, \\
\text { Jan. } 28, \\
\text { Mar. } 28, \\
\text { June } 10,\end{array}$ & $\begin{array}{l}1915 \\
1916 \\
1916 \\
1916\end{array}$ & $\begin{array}{r}10.6 \\
8.4 \\
12.7 \\
7.5\end{array}$ & $\begin{array}{l}36.800 \\
25.800 \\
48.900 \\
22.100\end{array}$ \\
\hline 1917 & $\begin{array}{l}\text { Mar. } 29 . \\
\text { June } 15 .\end{array}$ & $\begin{array}{l}1917 \\
1917\end{array}$ & $\begin{array}{l}13.2 \\
11.9\end{array}$ & $\begin{array}{l}52.000 \\
44.100\end{array}$ \\
\hline 1918 & $\begin{array}{ll}\text { Feb. } 14, \\
\text { May } 29 \\
\text { June } 8\end{array}$ & $\begin{array}{l}1918 \\
1918 \\
1918\end{array}$ & $\begin{array}{r}7.6 \\
9.8 \\
15.0\end{array}$ & $\begin{array}{l}22.500 \\
32.700 \\
77.000\end{array}$ \\
\hline 1919 & $\begin{array}{l}\text { Mar. } 23 . \\
\text { Apr. 19. } \\
\text { May } 7 . \\
\text { June } 8 . \\
\text { June 27. }\end{array}$ & $\begin{array}{l}1919 \\
1919 \\
1919 \\
1919 \\
1919\end{array}$ & $\begin{array}{r}10.8 \\
9.7 \\
10.3 \\
7.4 \\
7.4\end{array}$ & $\begin{array}{l}38.100 \\
32.200 \\
35.200 \\
21.600 \\
21.600\end{array}$ \\
\hline 1920 & $\begin{array}{l}\text { Nov. } 13, \\
\text { Mar. } 18, \\
\text { Mar. } 29, \\
\text { Apr. } 20, \\
\text { May } 15,\end{array}$ & $\begin{array}{l}1919 \\
1920 \\
1920 \\
1920 \\
1920\end{array}$ & $\begin{array}{l}7.8 \\
7.2 \\
9.7 \\
7.9 \\
7.3\end{array}$ & $\begin{array}{l}23.400 \\
20.900 \\
32.200 \\
23.800 \\
21.300\end{array}$ \\
\hline 1921 & sept. 24. & 1921 & 9.6 & 32.400 \\
\hline 1922 & $\begin{array}{l}\text { Mar. } \\
\text { Apr. }\end{array}$ & $\begin{array}{l}1922 \\
1922\end{array}$ & $\begin{array}{l}8.6 \\
7.6\end{array}$ & $\begin{array}{l}26.500 \\
22.500\end{array}$ \\
\hline
\end{tabular}

a About. 
05-4655.00 Iowa River at Wapello, Iowa--(Continued)

Pea $\underline{k}$ stages and

\begin{tabular}{|c|c|c|c|}
\hline $\begin{array}{l}\text { Water } \\
\text { year }\end{array}$ & Date & $\begin{array}{c}\text { Gage } \\
\text { height } \\
\text { Jfeetl. }\end{array}$ & $\begin{array}{c}\text { Discharge } \\
\text { (cfs) }\end{array}$ \\
\hline 1923 & Apr. 7. 1923 & 9.6 & 31.700 \\
\hline 1924 & $\begin{array}{lll}\text { June } & 28, & 1924 \\
\text { July } & 24, & 1924 \\
\text { Aug. } & 23, & 1924\end{array}$ & $\begin{array}{r}11.3 \\
8.6 \\
10.4\end{array}$ & $\begin{array}{l}40,700 \\
26,900 \\
35,500\end{array}$ \\
\hline 1925 & June 21,1925 & 5.2 & 12,900 \\
\hline 1926 & Sept.25, 1926 & 11.8 & 43.500 \\
\hline 1927 & $\begin{array}{l}\text { Feb. } 5,1927 \\
\text { Apr. 20, } 1927 \\
\text { May } 26,1927 \\
\text { June 22, } 1927\end{array}$ & $\begin{array}{r}7.6 \\
9 \cdot 7 \\
10 \cdot 1 \\
8.3\end{array}$ & $\begin{array}{l}22.500 \\
32.200 \\
34.200 \\
25.600\end{array}$ \\
\hline 1928 & $\begin{array}{l}\text { Oct. } 9,1927 \\
\text { Feb. 16, } 1928 \\
\text { Mar. 15, } 1928 \\
\text { Sept. 3, } 1928\end{array}$ & $\begin{array}{l}9.1 \\
9.2 \\
8.0 \\
9.0\end{array}$ & $\begin{array}{l}29.200 \\
28,800 \\
24.200 \\
28.800\end{array}$ \\
\hline 1929 & $\begin{array}{l}\text { Nov. 20, } 1928 \\
\text { Mar. 21, } 1929 \\
\text { Apr. 13, } 1929 \\
\text { Apr. 21, } 1929 \\
\text { Apr. 26, } 1929 \\
\text { May 4. } 1929\end{array}$ & $\begin{array}{r}8.8 \\
14.6 \\
8.1 \\
8.8 \\
8.6 \\
9.4\end{array}$ & $\begin{array}{l}27.800 \\
72.200 \\
24.600 \\
27.800 \\
26.900 \\
30.700\end{array}$ \\
\hline 1930 & $\begin{array}{ll}\text { Feb. } 27, & 1930 \\
\text { June } 17, & 1930\end{array}$ & $\begin{array}{r}8.5 \\
13.5\end{array}$ & $\begin{array}{l}26,500 \\
52,200\end{array}$ \\
\hline 1931 & Sept.27, 1931 & 3.1 & 6,740 \\
\hline 1932 & $\begin{array}{lrl}\text { Dec. } & 2,1931 \\
\text { ApI. } & 5, & 1932 \\
\text { June } & 27, & 1932\end{array}$ & $\begin{array}{l}8.8 \\
8.3 \\
8.0\end{array}$ & $\begin{array}{l}27.800 \\
25.600 \\
24.200\end{array}$ \\
\hline 1933 & $\begin{array}{l}\text { Apr. } 7,1933 \\
\text { May } 24,1933\end{array}$ & $\begin{array}{r}15.4 \\
9.2\end{array}$ & $\begin{array}{l}62.000 \\
28.600\end{array}$ \\
\hline 1934 & Apr. 11, 1934 & 3.3 & 7.230 \\
\hline 1935 & $\begin{array}{l}\text { Mar. } 12,1935 \\
\text { June 21, } 1935 \\
\text { June 29, } 1935\end{array}$ & $\begin{array}{r}11.0 \\
8.0 \\
8.1\end{array}$ & $\begin{array}{l}35,500 \\
21,600 \\
22,100\end{array}$ \\
\hline
\end{tabular}


05-4655.00 Iowa River at wapel10. Iowa--(Continued)

Pea

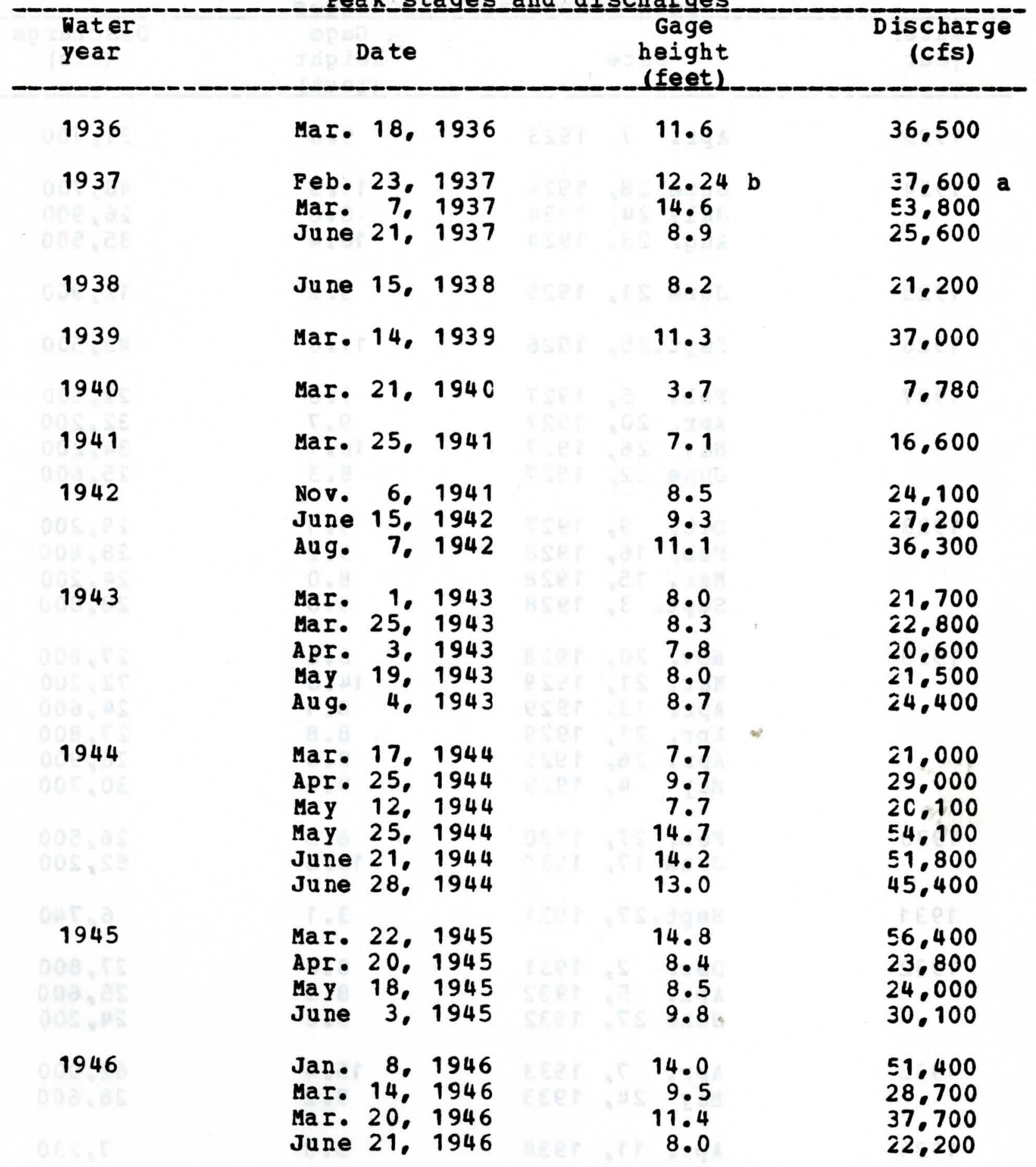

a A bout.

b Affected by ice. 
05-4655.00 Iowa River at Wapello, Iowa-- (Continued)

Peak

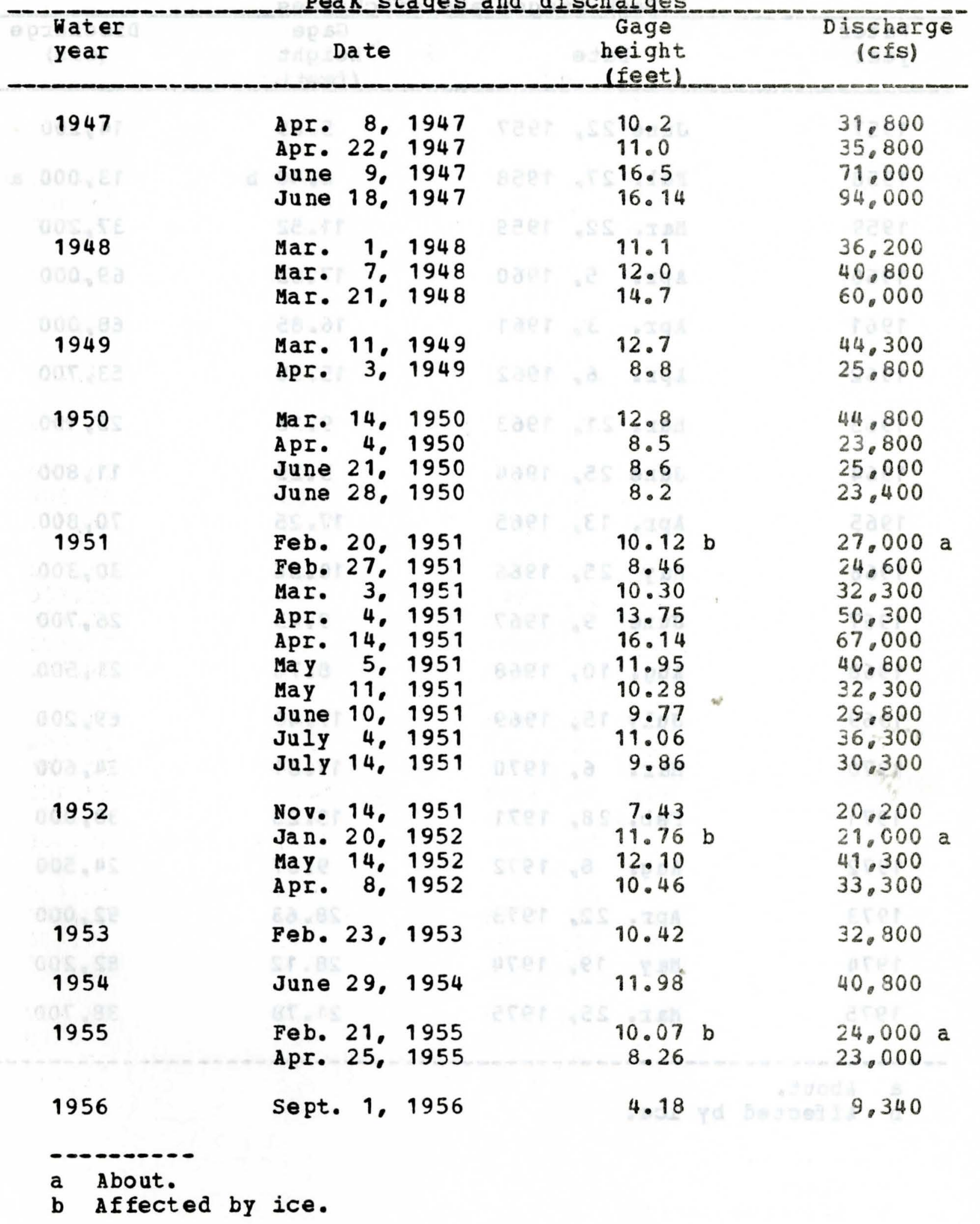


05-4655.00 Iowa River at Wapellc. Iowa--(Continued)

Peak stages_and discharges

\begin{tabular}{|c|c|c|c|c|c|}
\hline $\begin{array}{l}\text { Hater } \\
\text { year }\end{array}$ & & Date & & $\begin{array}{c}\text { Gage } \\
\text { height } \\
\text { (feet) }\end{array}$ & $\begin{array}{c}\text { Discharge } \\
\text { (cfs) }\end{array}$ \\
\hline 1957 & June & 22. & 1957 & 5.89 & 14.200 \\
\hline 1958 & $\mathrm{Feb}$ & 27 & 1958 & $6.48 \mathrm{~b}$ & $13,000 \mathrm{a}$ \\
\hline 1959 & MaI. & 22 & 1959 & 11.52 & 37.200 \\
\hline 1960 & Apr. & 5. & 1960 & 17.02 & 69.000 \\
\hline 1961 & Apr. & 3. & 1961 & 16.85 & 68.000 \\
\hline 1962 & Apr. & 6. & 1962 & $15 \cdot 38$ & 53,700 \\
\hline 1963 & Mar. & 21. & 1963 & 9.16 & 25.100 \\
\hline 1964 & June & 25 & 1964 & 5.25 & 11.800 \\
\hline 1965 & Apr. & 13. & 1965 & 17.25 & 70,800 \\
\hline 1966 & May & 25 & 1966 & 10.36 & 30.300 \\
\hline 1967 & June & 9. & 1967 & 9.43 & 26.700 \\
\hline 1968 & Aug. & 10 & 1968 & 8.70 & 21.500 \\
\hline 1969 & JuIY & 15. & 1969 & 17.40 & $\in 9,200$ \\
\hline 1970 & MaI. & 6. & 1970 & 11.81 & 34,600 \\
\hline 1971 & Feb. & 28 & 1971 & 13.23 & 38.000 \\
\hline 1972 & Aug. & 8. & 1972 & 9.37 & 24,500 \\
\hline 1973 & Apr. & 22 & 1973 & 28.63 & 92.000 \\
\hline 1974 & May & 19. & 1974 & 28.12 & 82.200 \\
\hline 1975 & MaI. & 25 & 1975 & 21.78 & 38,700 \\
\hline
\end{tabular}

a About.

b Affected by ice. 


\section{5-4699.90 Keigley Branch near Story City, Iowa}

Location.--Lat 420099 , long $93037 \%$ in NW1/4 sec.26, T.85 N.. R. 24 \%. . Story County, at bridge on U.S. Highway 69, about 3 miles south of Story City.

Drainage area.--31.0 sq mi.

Gage.--Crest-stage gage.

Stage-discharge relation.--Defined by current-meter measurements. Remarks.--only annual peaks are shown.

Peak_stsages_and_dis

\begin{tabular}{|c|c|c|c|}
\hline $\begin{array}{l}\text { Water } \\
\text { year }\end{array}$ & Date & $\begin{array}{l}\text { Gage } \\
\text { height } \\
\text { lfeetl }\end{array}$ & $\begin{array}{c}\text { Discharge } \\
\text { (cfs) }\end{array}$ \\
\hline 1966 & June 12, 1966 & 86.78 & 197 \\
\hline 1967 & June 8,1967 & 88.97 & 600 \\
\hline 1968 & June 25,1968 & 88.66 & 470 \\
\hline 1969 & July 9, 1969 & 88.51 & 420 \\
\hline 1970 & Aug. 6,1970 & 87.81 & 295 \\
\hline 1971 & Feb. 18, 1971 & $90.05 \mathrm{a}^{2}$ & 555 \\
\hline 1972 & June 6.1972 & 84.75 & 66 \\
\hline 1973 & Mar. 11. 1973 & 89.27 & 550 \\
\hline 1974 & Aug. 8,1974 & 89.06 & 610 \\
\hline 1975 & June 27, 1975 & 91.38 & b \\
\hline
\end{tabular}

a Affected by ice.

b Discharge not determined. 


\section{5-4175.90 Kitty Creek near Langworthy. Iowa}

Location.--Iat $42012^{\circ}$. long $91012^{\circ}$, in $N w 1 / 4$ sec.4. T.85 N.. R.3 W. Jones County, at bridge on 0.5 . Highway 151, about 1 nile northeast of Langworthy.

Drainage area.--14.4 sq mi.

Gage.--Crest-stage gage.

Stage-discharge relation.--Defined by current-meter and indirect measurements.

Remarks.--only annual peaks are shown.

Peak_stages_and_dischharges

\begin{tabular}{|c|c|c|c|c|c|}
\hline $\begin{array}{l}\text { Water } \\
\text { year }\end{array}$ & Date & & $\begin{array}{c}\text { Gage } \\
\text { height } \\
\text { (feet) }\end{array}$ & & $\begin{array}{c}\text { Discharge } \\
\text { (cfs) }\end{array}$ \\
\hline 1966 & Feb. 8 & 1966 & 86.49 & & 780 \\
\hline 1967 & sept. 14. & 1967 & 86.18 & & 660 \\
\hline 1968 & Aug. 5 . & 1968 & 87.27 & ' & 1.150 \\
\hline 1969 & July 19. & 1969 & 90.24 & & 3.700 \\
\hline 1970 & Mar. 2. & 1970 & 87.65 & $*$ & 1.340 \\
\hline 1971 & June 24. & 1971 & 87.33 & & 1.160 \\
\hline 1972 & Apr. 16 & 1972 & 86.90 & & 960 \\
\hline 1973 & $\mathrm{Feb} .1$ & 1973 & 86.00 & & 600 \\
\hline 1974 & May 29. & 1974 & 87.85 & & 1.500 \\
\hline 1975 & Mar. 21. & 1975 & 85.65 & & 520 \\
\hline
\end{tabular}


Location.--Iat $43002.05^{\prime \prime}$, long $92030005^{\prime \prime}$, in SN1/4 NE1/4 sec.21. T. 95 N.. R. 14 W. Chickasaw County. on left bank 12 fi downstream from bridge on ccunty highway B57, 2.4 miles west of Ionia. 6.4 miles upstream from mouth, and 7.6 miles downstream from Beaver Creek.

Drainage area.--306 sq mi.

Gage.--Hater-stage recorder. Datum of gage is $973.35 \mathrm{ft}$ above mean sea level.

Stage-dsicharge relation.--Defined by current-meter measurements. Flood stage.--9.5 ft.

Remarks.--Base for partial-duration series, 1.200 cfs.

Peak__stagges_and_dis

\begin{tabular}{|c|c|c|c|}
\hline $\begin{array}{l}\text { Water } \\
\text { year }\end{array}$ & Date & $\begin{array}{l}\text { Gage } \\
\text { height } \\
\text { (feet) }\end{array}$ & $\begin{array}{c}\text { Discharge } \\
\text { (cfs) }\end{array}$ \\
\hline 1954 & June 22, 1954 & 11.37 & $4.600 a$ \\
\hline 1955 & June $\quad 3,1955$ & 7.54 & 1,500 \\
\hline 1956 & Apr. $\quad 2,1956$ & 6.78 & 1.160 \\
\hline 1957 & July 23, 1957 & 6.19 & 890 \\
\hline 1958 & July 15, 1958 & 5.53 & 632 \\
\hline 1959 & $\begin{array}{lll}\text { Mar. 26, } 1959 \\
\text { May 20, } 1959 \\
\text { May } 31,1959\end{array}$ & $\begin{array}{l}7.63 \\
7.30 \\
7.30\end{array}$ & $\begin{array}{l}1.710 \\
1.830 \\
1.830\end{array}$ \\
\hline 1960 & $\begin{array}{l}\text { Mar. 30, } 1960 \\
\text { May } 7,1960 \\
\text { June 25, } 1960 \\
\text { Aug. } 30,1960\end{array}$ & $\begin{array}{l}8.42 \\
6.89 \\
9.19 \\
6.95\end{array}$ & $\begin{array}{l}2.650 \\
1.530 \\
2.790 \\
1.340\end{array}$ \\
\hline 1961 & $\begin{array}{l}\text { Mar. } 4,1961 \\
\text { Mar. } 27,1961 \\
\text { Aug. } 2,1961\end{array}$ & $\begin{array}{r}6.52 \\
15.58 \\
11.43\end{array}$ & $\begin{array}{r}1,370 \\
10.800 \\
5.310\end{array}$ \\
\hline
\end{tabular}

a Maximum for period June to september 1954. 
05-4580.00 Little Cedar River near Ionia, Iowa--(Continued)

Peak_stages_ard discharges

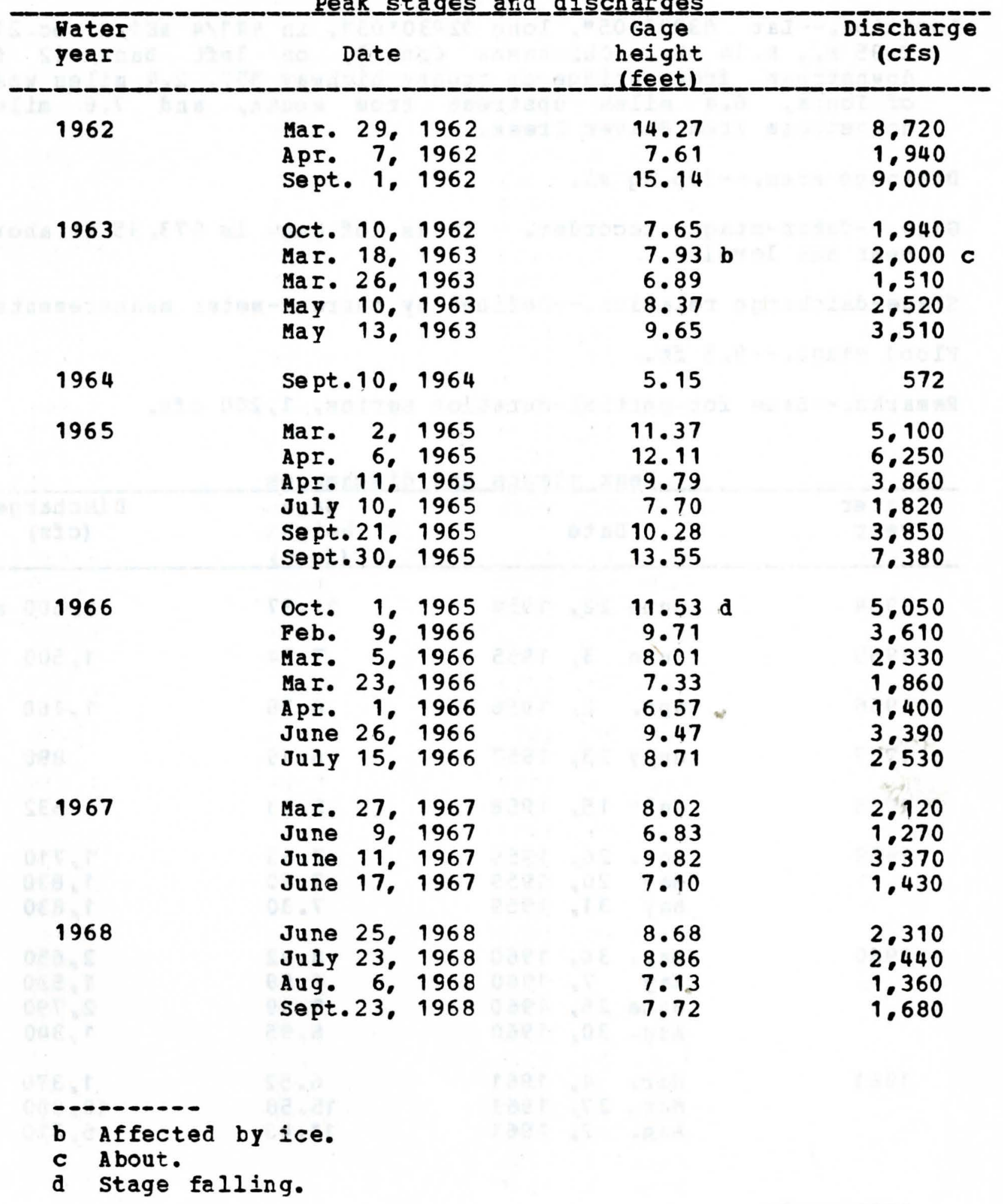


05-4580.00 Little Cedar River near Ionia, Iowa--(Continued)

Peak stages and discharges

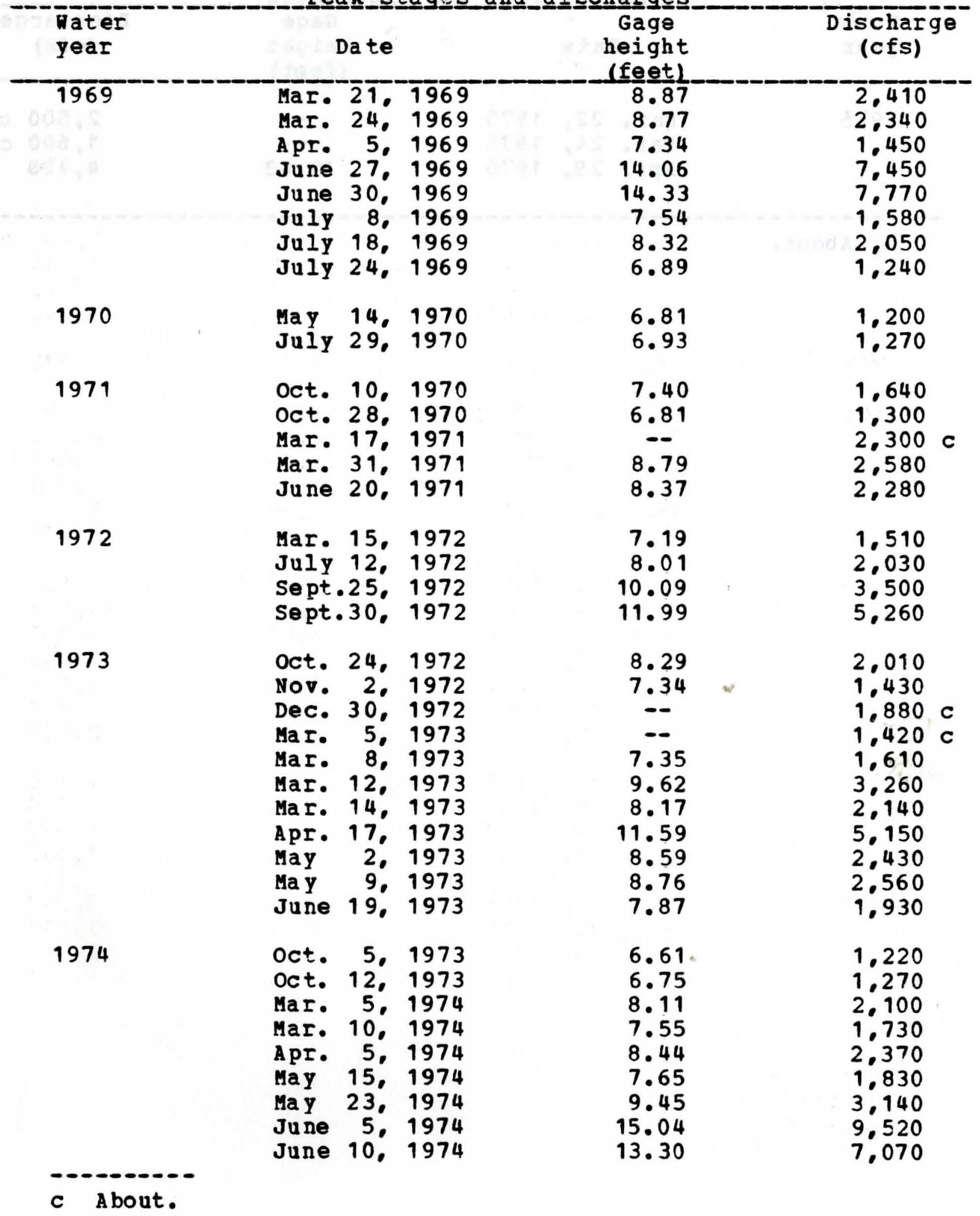


05-4580.00 Iittle Cedar River near Ionia, Iowa--(Continued)

Peakk_stage

\begin{tabular}{|c|c|c|c|}
\hline $\begin{array}{l}\text { Water } \\
\text { year }\end{array}$ & Date & $\begin{array}{c}\text { Gage } \\
\text { height } \\
\text { (feet) }\end{array}$ & $\begin{array}{c}\text { Discharge } \\
\text { (cfs) }\end{array}$ \\
\hline 1975 & $\begin{array}{ll}\text { Mar. 22, } & 1975 \\
\text { Mar. 24, } 1975 \\
\text { Apr. 29, } 1975\end{array}$ & 10.63 & $\begin{array}{l}2.500 \mathrm{C} \\
1.600 \mathrm{C} \\
4.180\end{array}$ \\
\hline
\end{tabular}


05-4146.00 Iittle Maquoketa River tributary at Dubuque. Iowa

Location.--Iat $42032 \cdot 33$ ". Iong $90041 \cdot 38$ ". near NW corner sec.11. T.89 H.. R. 2 E.. Dubuque County, at bridge on State Highway 386 near north city limits of Dubuque.

Drainage area.--1.54 sq mi.

Gage.--Crest-stage gage.

Stage-discharge relation.--Defined by current-meter, indirect measurements, and step-backwater computation.

Remarks.--orly annual peaks are shown.

Peak__stages_and_dis

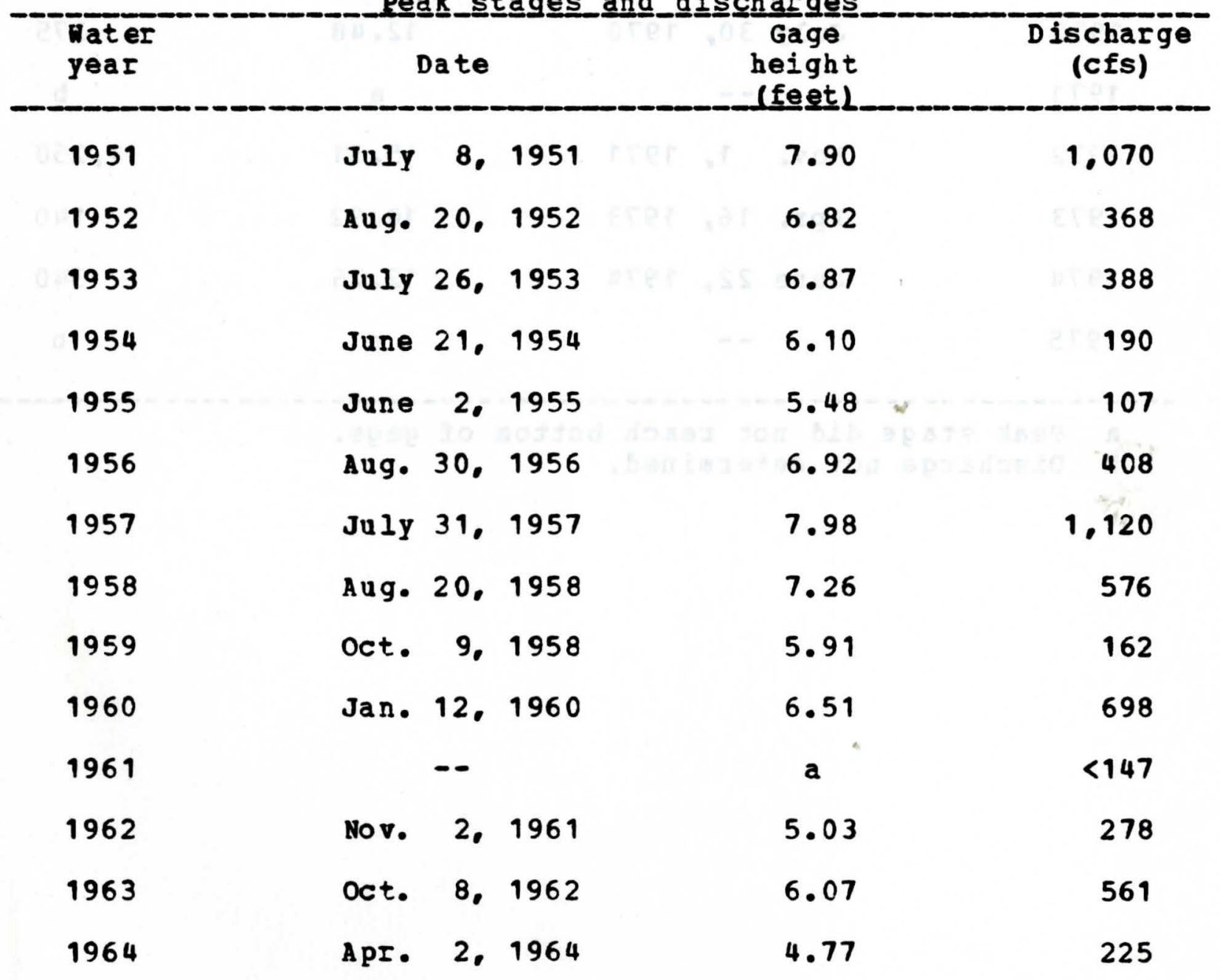

a Peak stage did not $I \in a c h$ bottom of gage. 

05-4146.00 Little Maquoketa River tributary at Dubuque. Iowa--
(Continued)

Peak

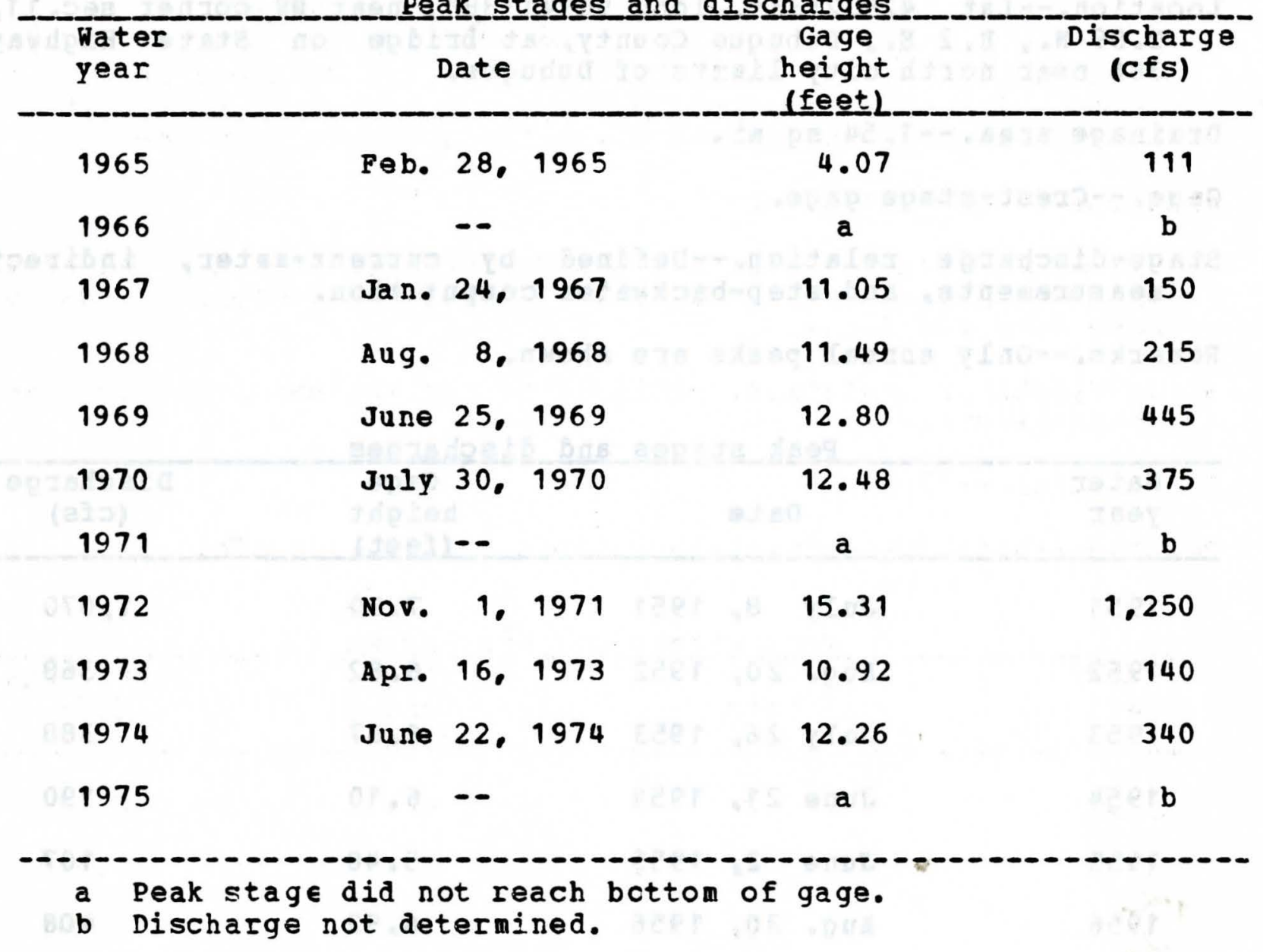


Location.--Iat $42^{\circ} 33^{\prime} 18^{\prime \prime}$. Iorg $90044 \cdot 46^{\prime \prime}$, in NW1/4 NE1/4 sec.5. T.89 N.. R.2 E.. Dubuque County, on left bank 10 ft upstream from bridge on county highway. 300 ft upstream from cloie Branch, 1.7 miles east of Durango, 5.6 miles northwest of courthouse at Dubuque, and 6.4 miles upstream from mouth.

Drainage area. --130 sq mi.

Gage.-Water-stage recorder. Datum of gage is $612.03 \mathrm{ft}$ above mean sea level. prior to Jan. 5. 1939, nonrecording gage at same site and datum.

Stage-discharge relation.--Defined by current-meter and indirect measurements.

Flood stage. $-15 \mathrm{ft}$.

Remarks.--Base for partial-duration series, 5, 100 cfs.

Peak_k_stages_and

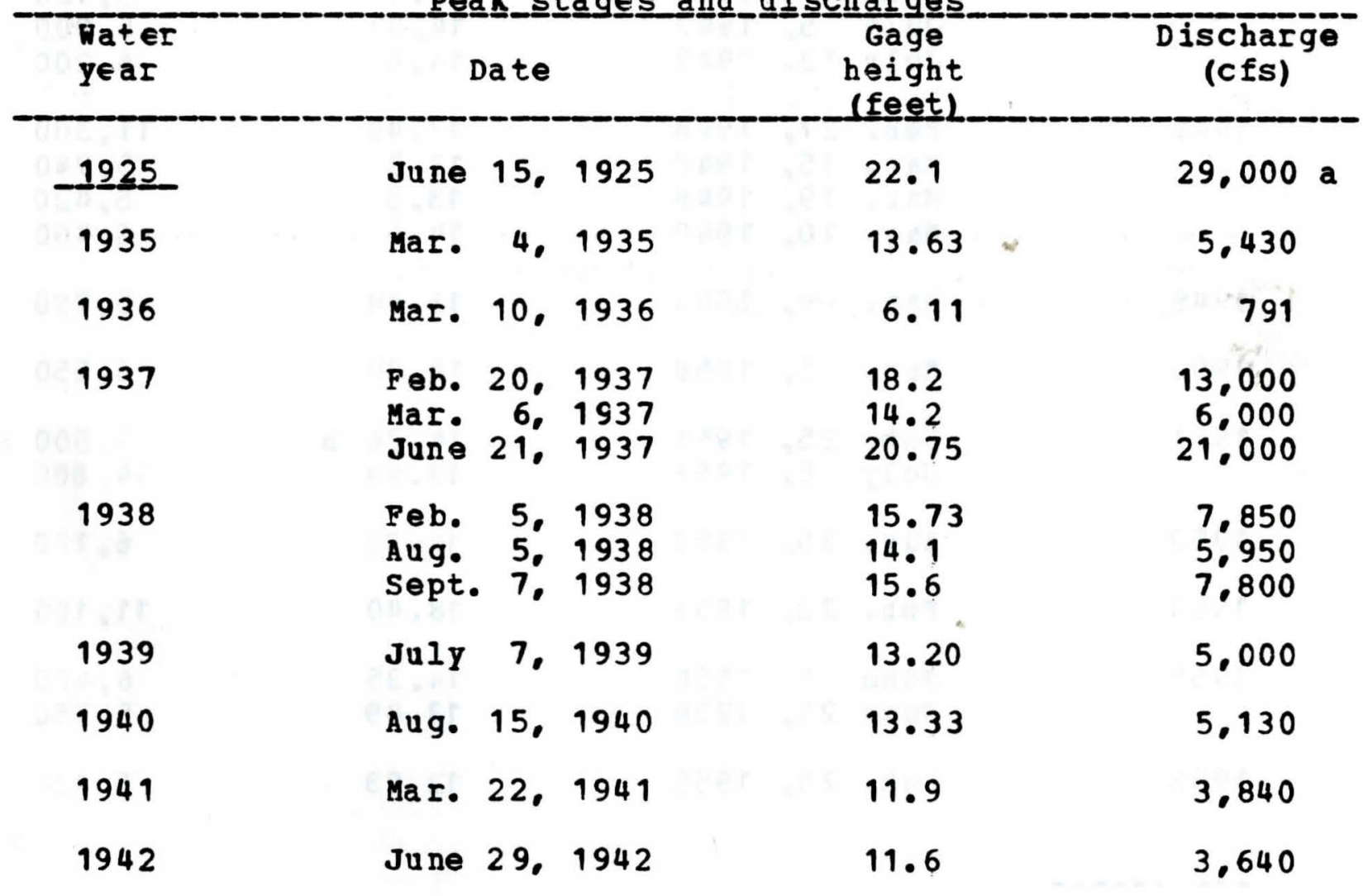

a About, computed by Corps of Engineers. 
05-4145.00 Little Maquoketa River near Durango, Iowa-- (Continued)

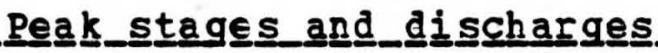

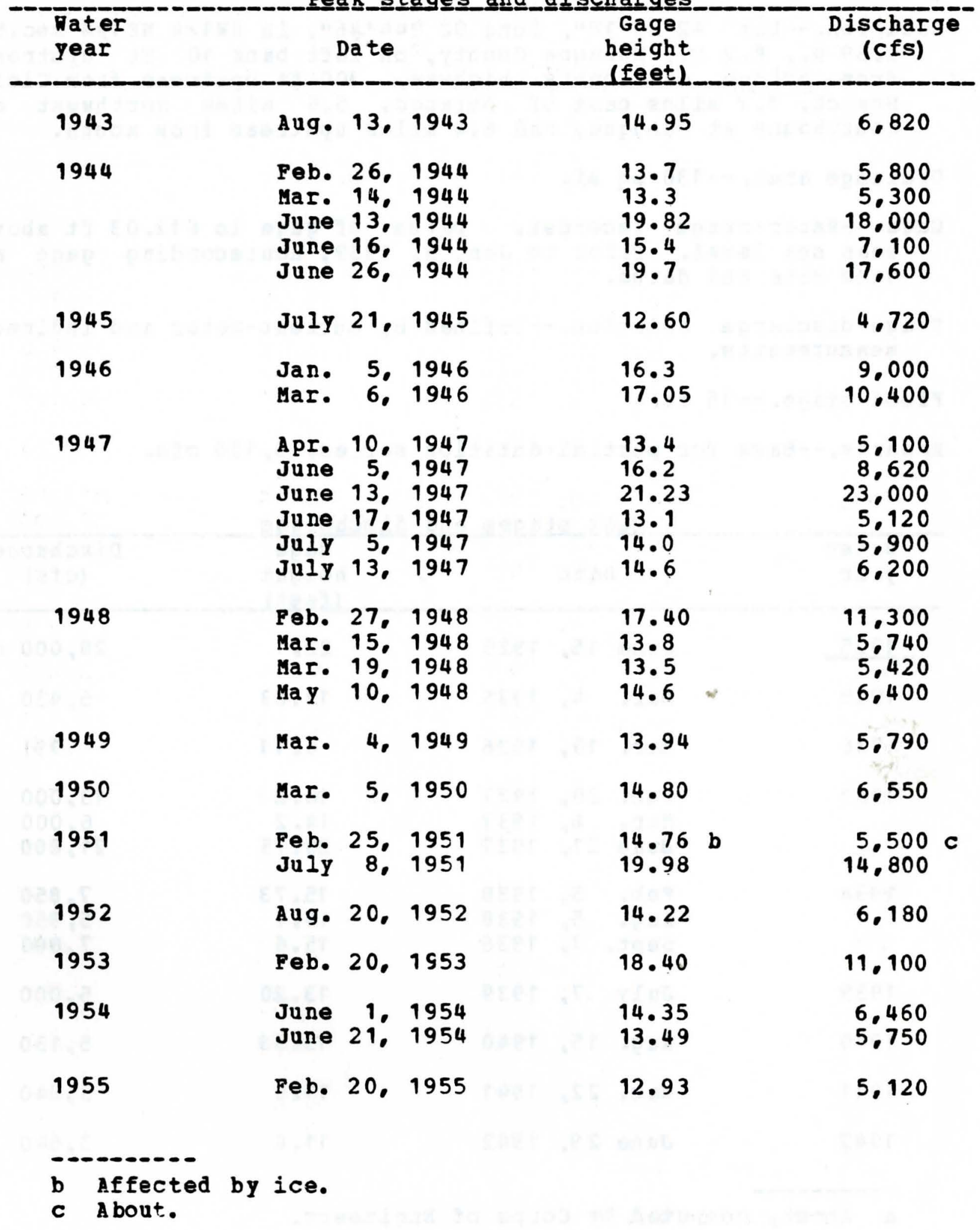


Peak_stagaes_and di scharges

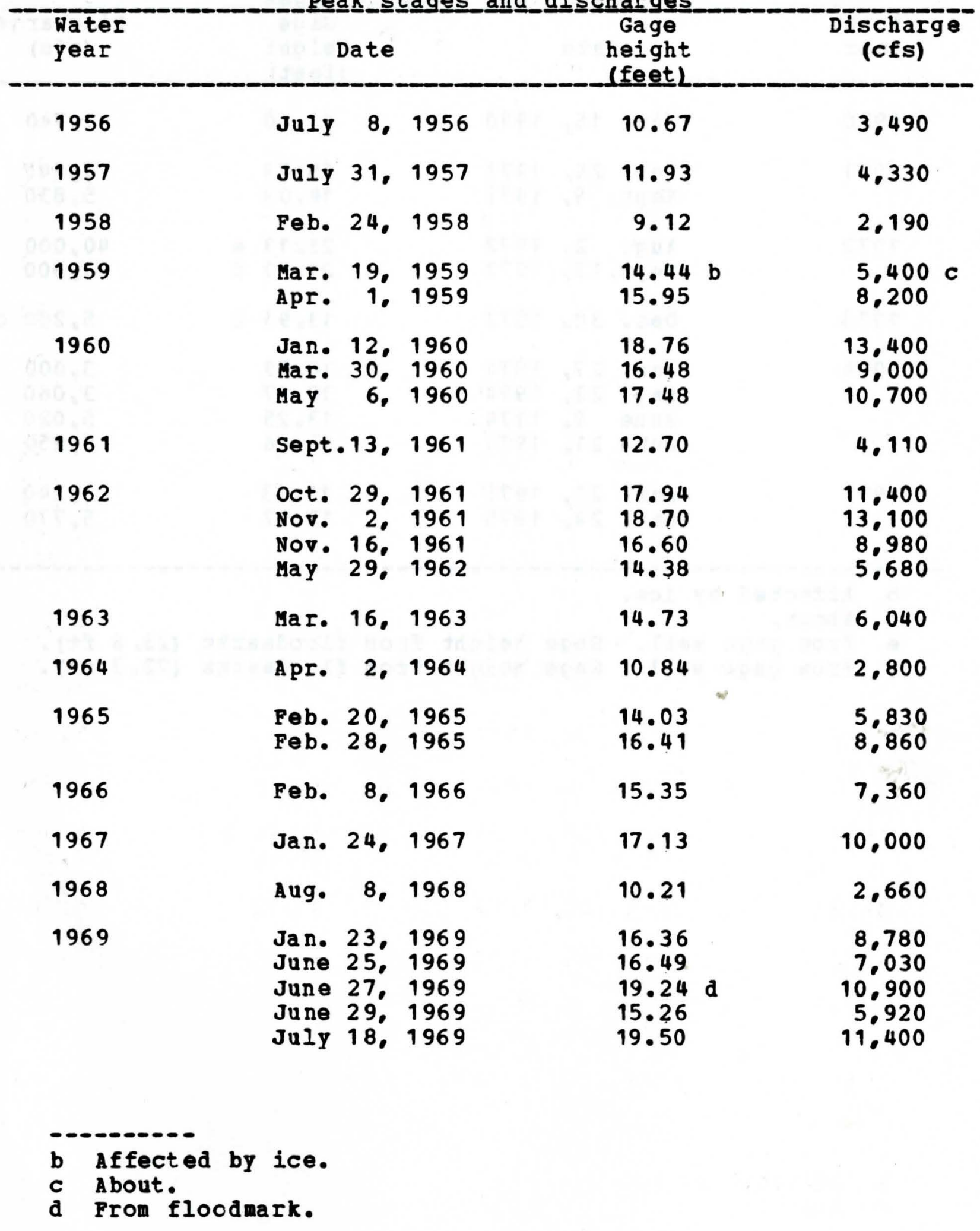


05-4145.00 Little Maquoketa River near Durango. Iowa-- (Continued)

Feak_stages and discharges

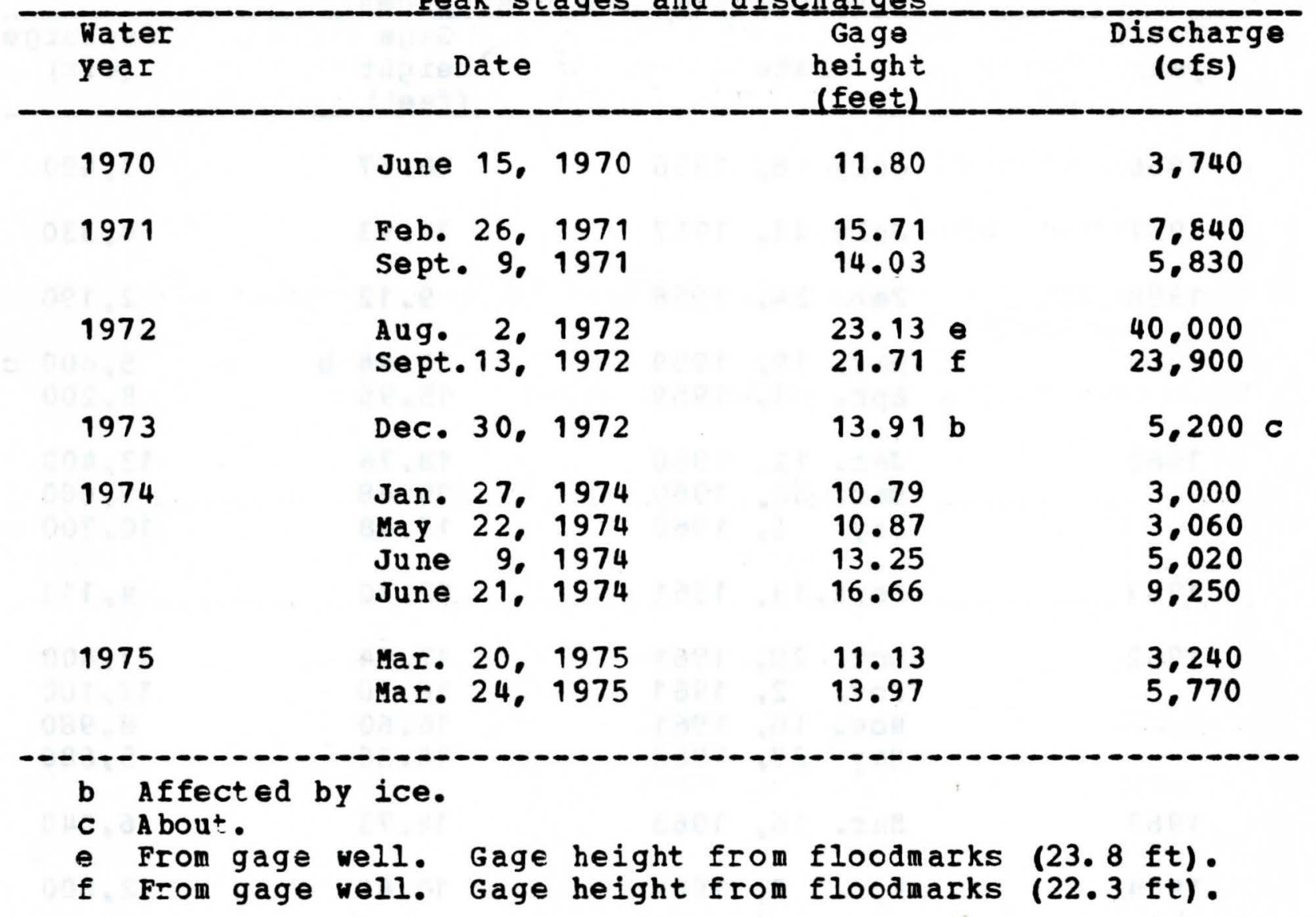


Location.--Iat $42^{\circ} 30^{\prime}$, long $90052^{\circ}$, in SE1/4 sec.20, T.89 N.. R.1 E. Dubuque County, at bridge about 300 ft downstream from Ilinois Central Railroad bridge, 0.5 mile northeast of Graf. Drainage area.--39.6 sq mi. Gage.--Crest-stage gage. Stage-discharge relation.--Defined by current-meter and indirect measurements.

Remarks.--only annual peaks are shown.

Feak__stages_and_discharges

\begin{tabular}{|c|c|c|c|c|}
\hline $\begin{array}{l}\text { Water } \\
\text { year }\end{array}$ & Date & & $\begin{array}{l}\text { Gage } \\
\text { height } \\
\text { (feet) }\end{array}$ & $\begin{array}{l}\text { Discharge } \\
\text { (cfs) }\end{array}$ \\
\hline 1951 & July 8, & 1951 & 15.78 & 7.220 \\
\hline 1952 & Aug. 20 . & 1952 & 9.30 & 1.850 \\
\hline 1953 & Feb. 20 & 1953 & 13.41 & 4.500 \\
\hline 1954 & May 31. & 1954 & 11.79 & 3.250 \\
\hline 1955 & Feb. 19. & 1955 & 9.26 & 1.830 \\
\hline 1956 & Aug. 30. & 1956 & 10.90 & 2.690 \\
\hline 1957 & Jan. 21 & 1957 & 8.57 & 1.520 \\
\hline 1958 & -- & & a & $<1,100$ \\
\hline 1959 & Apr. & 1959 & 13.10 & 4.590 \\
\hline 1960 & Jan. 12 & 1960 & 13.93 & 5.280 \\
\hline 1961 & Se pt.13. & 1961 & 8.36 & 1.560 \\
\hline 1962 & Nov. & 1961 & $13 \cdot 18$ & 4.660 \\
\hline 1963 & Mar. 18, & 1963 & 11.43 & 3.300 \\
\hline 1964 & Apr. 2 & 1964 & 10.69 & 2.810 \\
\hline
\end{tabular}

a Peak stage did not reach bottom of gage. 
05-4143.50 Iittle Maquoketa River near Graf, Iowa--(Continued)

Peak stages and di scharges

\begin{tabular}{|c|c|c|c|c|c|}
\hline $\begin{array}{l}\text { Hater } \\
\text { year }\end{array}$ & & Date & - & $\begin{array}{c}\text { Gage } \\
\text { height } \\
\text { (feet) }\end{array}$ & $\begin{array}{c}\text { Discharge } \\
\text { (cfs) }\end{array}$ \\
\hline 1965 & Feb. & 28 & 1965 & 8.16 & 1.300 \\
\hline 1966 & $F \in b$. & 8, & 1966 & 8.17 & 1.490 \\
\hline 1967 & Jan. & 24. & 1967 & 10.88 & 1.140 \\
\hline 1968 & & - & & a & $<1,100$ \\
\hline 1969 & June & 25 & 1969 & 13.63 & 5.070 \\
\hline 1970 & JuIy & 30 & 1970 & 9.18 & 1.950 \\
\hline 1971 & Feb. & 26 & 1971 & 10.09 & 2.500 \\
\hline 1972 & Aug. & 2. & 1972 & 14.59 & 6.100 \\
\hline 1973 & Jan. & 31. & 1973 & 8.56 & 1.700 \\
\hline 1974 & May & 21. & 1974 & 9.85 & 2.350 \\
\hline 1975 & Mar. & 21. & 1975 & 8.85 & 1.800 \\
\hline
\end{tabular}

a Peak stage did not reach bcttom of gage.

b Affected by ice. 
05-4891.50 Little Muchakinock Creek at Oskaloosa, Iowa

Location.--Lat $41016 \%$ long $92038^{\circ}$. in SE1/4 sec.25, T.75 N.. R. 16 \%.. Ma haska County, at bridge on State Highway 137, at south edge of Oskaloosa..

Drainage area.--9.12 sq mi.

Gage.--Crest-stage gage.

Stage-discharge relation.--Defined by current-meter measurements. Remarks.--only annual peaks are shown.

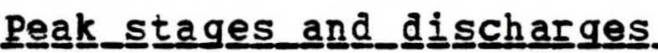

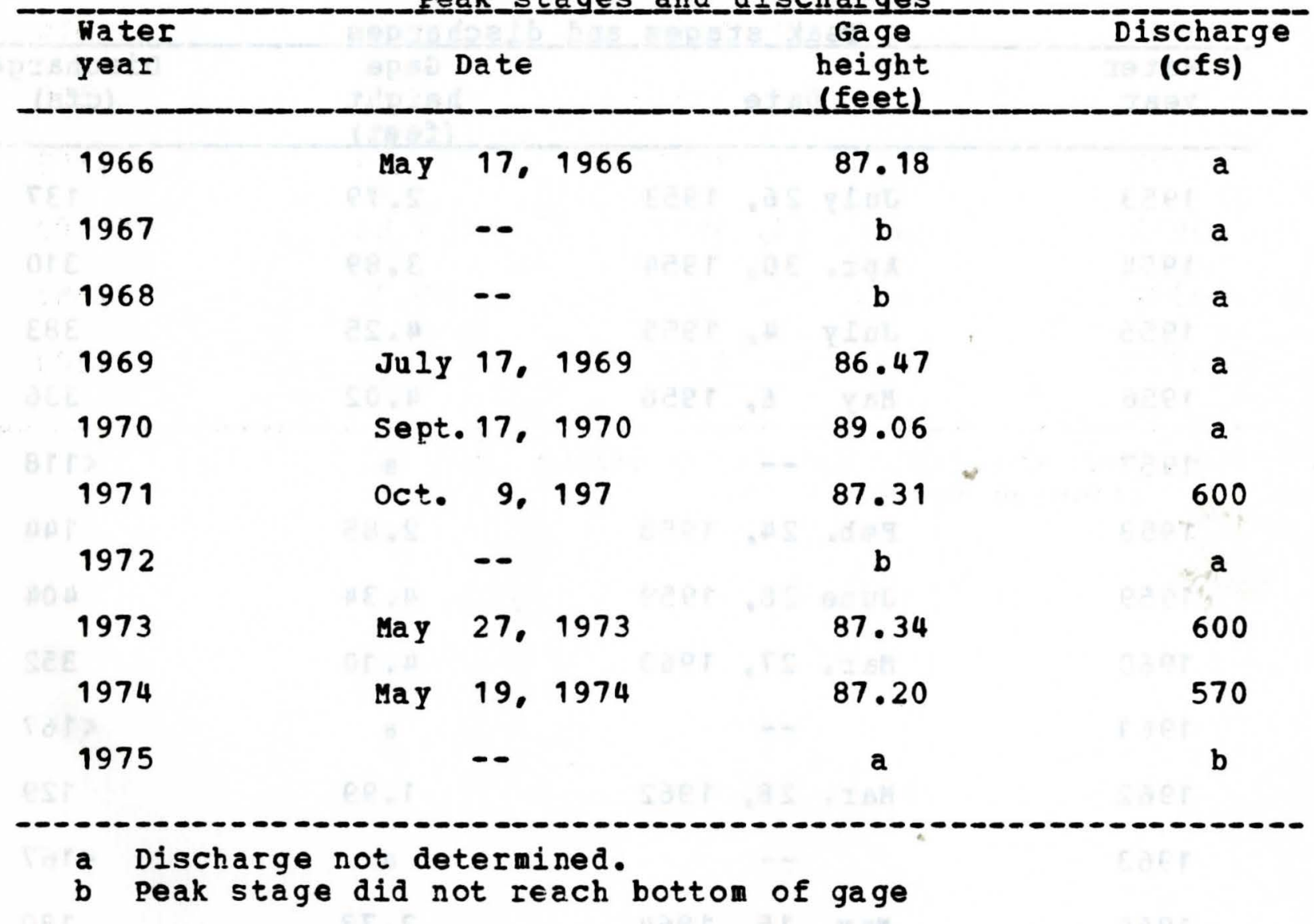


05-3887.00 Iittle Paint Creek tributary near Waterville, Iowa

Location.--Iat $43014^{\circ}$. long $91015^{\prime}$, in SE1/4 sec.1, T.97 N.. R.4 W. Allamakee County, at culvert, 3.5 miles northeast of Waterville.

Drainage area.--1.09 sq mi.

Gage.--Crest-stage gage.

Stage-discharge relation.--Defined by current-meter measurements and step-backwater computations.

Remarks.--only annual peaks are shown.

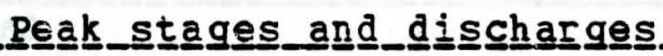

\begin{tabular}{|c|c|c|c|c|}
\hline $\begin{array}{l}\text { Water } \\
\text { year }\end{array}$ & & Date & $\begin{array}{r}\text { Gage } \\
\text { height } \\
\text { (feet) }\end{array}$ & $\begin{array}{c}\text { Discharge } \\
\text { (cfs) }\end{array}$ \\
\hline 1953 & July & 26.1953 & 2.79 & 137 \\
\hline 1954 & Apr. & 30,1954 & 3.89 & 310 \\
\hline 1955 & JuIy & 4. 1955 & 4.25 & 383 \\
\hline 1956 & May & 6. 1956 & 4.02 & 336 \\
\hline 1957 & & -- & a & $<118$ \\
\hline 1958 & Feb. & 24,1958 & 2.85 & 144 \\
\hline 1959 & June & 28,1959 & 4.34 & 404 \\
\hline 1960 & Mar. & 27,1960 & 4.10 & 352 \\
\hline 1961 & & $\cdots$ & a & $<167$ \\
\hline 1962 & Mar. & 28,1962 & 1.99 & 129 \\
\hline 1963 & & -- & a & $<167$ \\
\hline 1964 & May & 15, 1964 & 2.73 & 180 \\
\hline 1965 & & $\cdots$ & $a$ & $<167$ \\
\hline 1966 & & -- & a & $<167$ \\
\hline
\end{tabular}

a Peak stage did not $r \in a c h$ bottom of gage. 
05-3887.00 Iittle Paint creek tributary near Waterville, Iowa-(Continued)

Peak stages and di scharges

\begin{tabular}{|c|c|c|c|c|}
\hline $\begin{array}{l}\text { pater } \\
\text { year }\end{array}$ & Date & 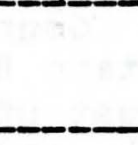 & $\begin{array}{c}\text { Gage } \\
\text { height } \\
\text { (feet) }\end{array}$ & $\begin{array}{c}\text { Discharge } \\
\text { (cfs) }\end{array}$ \\
\hline 1967 & -- & & $a$ & $<167$ \\
\hline 1968 & June 25 . & 1968 & 3.47 & 264 \\
\hline 1969 & -- & & a & $<167$ \\
\hline 1970 & -- & & $a$ & $<167$ \\
\hline 1971 & -- & & $\mathbf{a}$ & $<167$ \\
\hline 1972 & -- & & $a$ & $<167$ \\
\hline 1973 & sept. 2 & 1973 & 2.69 & 180 \\
\hline 1974 & Apr. 3. & 1974 & 3.73 & 270 \\
\hline 1975 & Mar. 21. & 1975 & 4.56 & 360 \\
\hline
\end{tabular}

a Peak stage did not reach bcttom of gage. 
06-6066.00 Little Sioux River at Correctionville. Iowa

Location.--lat $42028 \cdot 20^{\prime \prime}$, long $95047 \cdot 49 n$, in NE1/4 NN1/4 sec. 1. T. 88 N., R. 43 M.. Noodbury County. on right bank $10 \mathrm{ft}$ upstream from bridge on state Highway 31.0 .3 mile upstrean from Bacon Creek, 0.5 mile west of Correctionville, 0.8 mile downstream from Pierson Creek, and at mile 56.0.

Drainage area. $--2,500 \mathrm{sq} \mathrm{mi}$.

Gage.--llater-stage recorder. Datum of gage is 1.096.49 ft above mean sea level. May 28, 1918, to July 1, 1925, and Cct. 29, 1928. to July 15, 1929, nonrecording gage 0.2 mile dcwnstrean at datum 1.25 ft lower. July 16, 1929, to July 2, 1932, and June 15, 1936, to Nov. 7, 1938, nonrecording gage at present site and datum.

Plood stage.-- $19 \mathrm{ft}$.

Stage-discharge relation.--Defined by current-meter measurements. Remarks.--Base for partial-duration series, 4,000 cfs.

Pea $\underline{k}$ staages_and_di $\underline{\text { sqch }}$ arges

\begin{tabular}{|c|c|c|c|c|c|}
\hline $\begin{array}{l}\text { Dater } \\
\text { year }\end{array}$ & & Date & & $\begin{array}{l}\text { Gage } \\
\text { height } \\
\text { (feet) }\end{array}$ & $\begin{array}{c}\text { Discharge } \\
\text { (cfs) }\end{array}$ \\
\hline 1891_ & June & 23. & $1 \varepsilon 91$ & 29.34 & $-\infty$ \\
\hline 1919 & $\begin{array}{l}\text { Mar. } \\
\text { June } \\
\text { June } \\
\text { July }\end{array}$ & $\begin{array}{l}18 \\
12 \\
28 \\
13\end{array}$ & $\begin{array}{l}1919 \\
1919 \\
1919 \\
1919\end{array}$ & $\begin{array}{l}14.9 \\
19.6 \\
15.1 \\
17.6\end{array}$ & $\begin{array}{r}5.500 \\
10.700 \\
5.640 \\
8.350\end{array}$ \\
\hline 1920 & $\begin{array}{l}\text { Mar. } \\
\text { June } \\
\text { June }\end{array}$ & $\begin{array}{r}13 . \\
1 \% \\
7 .\end{array}$ & $\begin{array}{l}1920 \\
1920 \\
1920\end{array}$ & $\begin{array}{l}17.4 \\
14.2 \\
14.8\end{array}$ & $\begin{array}{l}8.920 \\
5.100 \\
5.440\end{array}$ \\
\hline 1921 & May & 27. & 1921 & 11.7 & 3.960 \\
\hline 1922 & Mar. & 13. & 1922 & 9.0 & 2.520 \\
\hline 1923 & $\begin{array}{l}\text { Mar. } \\
\text { Mar. }\end{array}$ & $\begin{array}{l}25 \\
26\end{array}$ & $\begin{array}{l}1923 \\
1923\end{array}$ & 11.3 & 2.000 \\
\hline
\end{tabular}

a Present datum, from levels to floodmark by soil conservation Service. 
06-6066.00 Little Sioux River at Correctionville, Iowa--(Continued)

Pea

\begin{tabular}{|c|c|c|c|}
\hline $\begin{array}{l}\text { Water } \\
\text { year }\end{array}$ & Date & $\begin{array}{l}\text { Gage } \\
\text { height } \\
\text { (feet). }\end{array}$ & $\begin{array}{l}\text { Discharge } \\
\text { (cfs) }\end{array}$ \\
\hline 1924 & 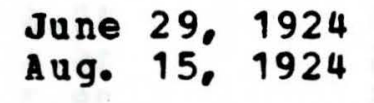 & $\begin{array}{l}13.9 \\
12.4\end{array}$ & $\begin{array}{l}4,950 \\
4,200\end{array}$ \\
\hline-1925 & June 4,1925 & 9.3 & 2.190 \\
\hline 1929 & $\begin{array}{r}\text { Mar. } 14,1929 \\
\text { Mar._18, } 1929 \\
\end{array}$ & $\begin{array}{r}16.3 \\
-15.7 \\
\end{array}$ & $\begin{array}{r}6.250 \\
6.170 \\
\end{array}$ \\
\hline 1930 & June 13,1930 & 11.2 & 2.990 \\
\hline 1931 & July 17, 1931 & 10.3 & 2.540 \\
\hline 1932 & $\begin{array}{ll}\text { Apr. } 21, & 1932 \\
\text { May } 26, & 1932\end{array}$ & $\begin{array}{l}17.7 \\
14.5\end{array}$ & $\begin{array}{l}6.560 \\
4.330\end{array}$ \\
\hline 1937 & $\begin{array}{l}\text { May } 31,1937 \\
\text { June 19, } 1937 \\
\text { Aug. 19, } 1937\end{array}$ & $\begin{array}{l}16.4 \\
17.0 \\
15.7\end{array}$ & $\begin{array}{l}5.500 \\
5,950 \\
5.030\end{array}$ \\
\hline 1938 & $\begin{array}{l}\text { Sept. 8, } 1938 \\
\text { Sept.21, } 1938\end{array}$ & $\begin{array}{l}15.4 \\
18.9\end{array}$ & $\begin{array}{l}4,380 \\
7,250\end{array}$ \\
\hline 1939 & Mar. 12, 1939 & $15.23 \mathrm{~b}$ & $2,200 \mathrm{c}$ \\
\hline 1940 & Aug. 26,1940 & 16.2 & 4.730 \\
\hline 1941 & Sept. 15. 1941 & 17.0 & 4.740 \\
\hline 1942 & June 19, 1942 & $15 \cdot 3$ & 3.800 \\
\hline 1943 & $\begin{array}{lr}\text { July } & 4,1943 \\
\text { July } & 20,1943\end{array}$ & $\begin{array}{l}18.5 \\
18.4\end{array}$ & $\begin{array}{l}6.530 \\
6.600\end{array}$ \\
\hline 1944 & $\begin{array}{lrl}\text { May } & 19, & 1944 \\
\text { June } & 12, & 1944 \\
\text { JuIy } & 7, & 1944 \\
\text { July } & 15, & 1944\end{array}$ & $\begin{array}{l}19.4 \\
21.1 \\
17.4 \\
16.6\end{array}$ & $\begin{array}{r}8.500 \\
13.000 \\
5.450 \\
4.560\end{array}$ \\
\hline
\end{tabular}

b affected by ice.

c About. 
06-6066.00 Little Sioux River at Correctionville, Iowa--(Continued)

Peak_stages_and discharges

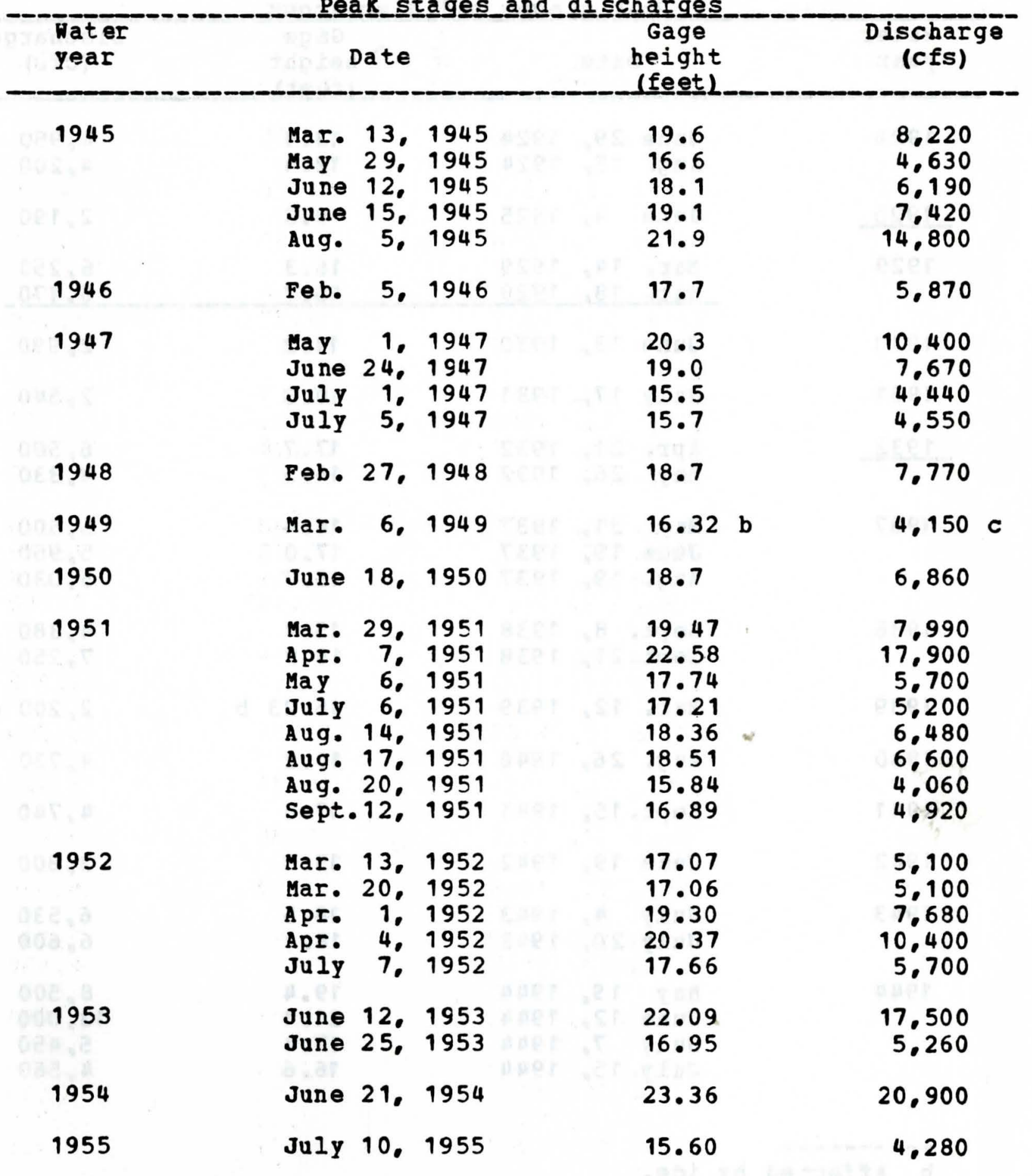

b Affected by ice.

c About. 
06-6066.00 Little Sioux River at correctionville, Iowa--(Continued)

Peak﹎.stages and di

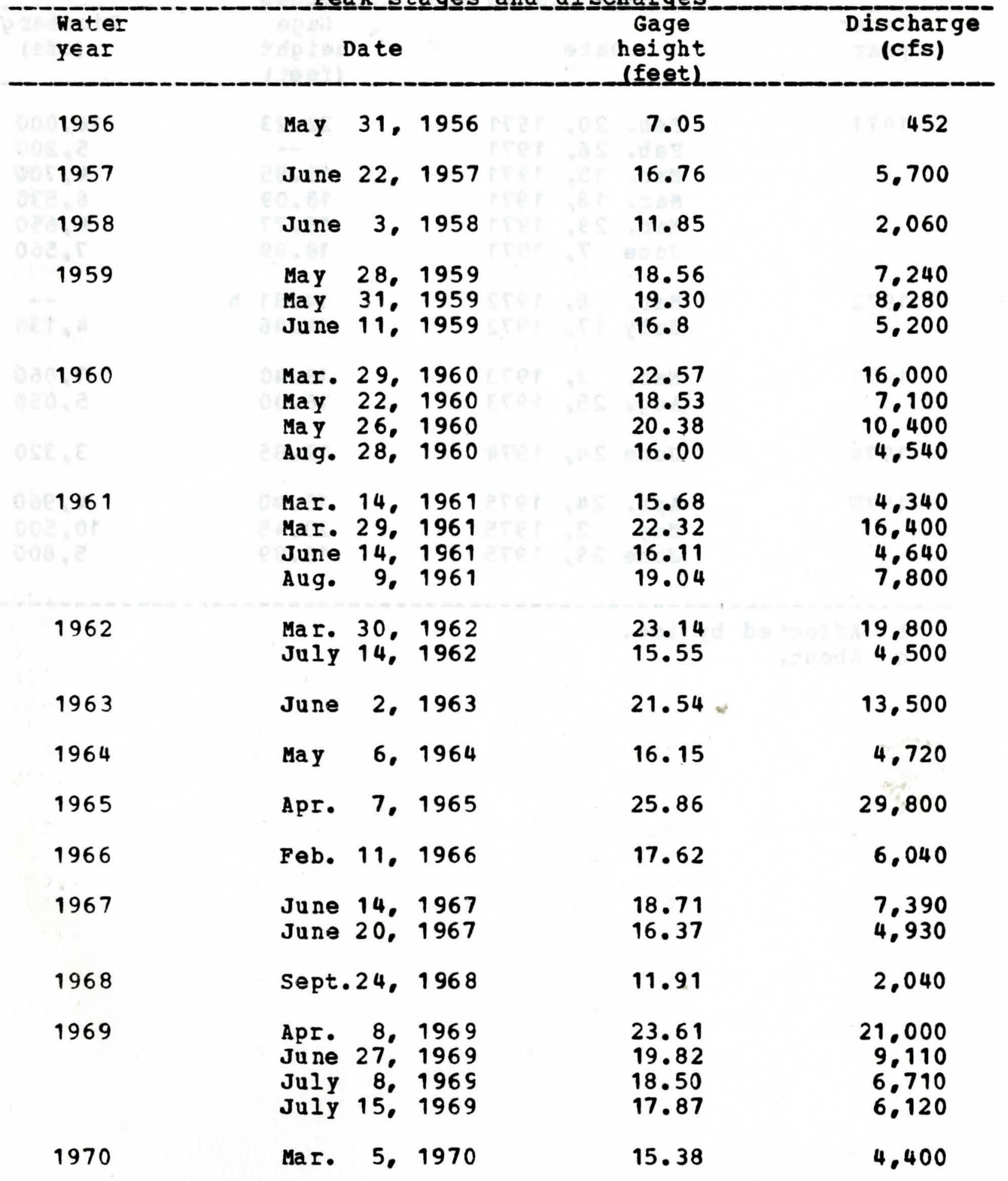


06-6066.00 Little Sioux River at Correctionville, Iowa--(Continued)

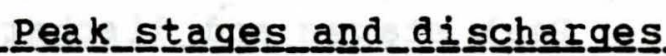

\begin{tabular}{|c|c|c|c|}
\hline $\begin{array}{l}\text { Hater } \\
\text { year }\end{array}$ & Date & $\begin{array}{r}\text { Gage } \\
\text { height } \\
\text { (feetL }\end{array}$ & $\begin{array}{c}\text { Discharge } \\
\text { (cfs) }\end{array}$ \\
\hline $\begin{array}{l}1971 \\
607 x^{2}\end{array}$ & $\begin{array}{l}\text { Feb. 20, } 1971 \\
\text { Fab. 26, } 1971 \\
\text { Mar. 15, } 1971 \\
\text { Mar. 18, } 1971 \\
\text { Mar. 29, } 1971 \\
\text { June } 7,1971\end{array}$ & $\begin{array}{l}22.23 \\
-.- \\
15.85 \\
18.09 \\
15.77 \\
18.89\end{array}$ & $\begin{array}{r}16.000 \\
5.200 \quad c \\
4.700 \\
6.530 \\
4.650 \\
7.560\end{array}$ \\
\hline 1972 & $\begin{array}{lr}\text { Mar. } 8, & 1972 \\
\text { July } 17, & 1972\end{array}$ & $\begin{array}{l}14.81 \mathrm{~b} \\
14.46\end{array}$ & $4 . \overline{130}$ \\
\hline 1973 & $\begin{array}{l}\text { Mar. 3, } 1973 \\
\text { Aug. 25, } 1973\end{array}$ & $\begin{array}{l}18.40 \\
16.00\end{array}$ & $\begin{array}{l}7.060 \\
5.050\end{array}$ \\
\hline 1974 & June 24,1974 & 12.85 & 3,320 \\
\hline 1975 & $\begin{array}{lrr}\text { Apr. } & 24, & 1975 \\
\text { May } & 2, & 1975 \\
\text { June } & 29, & 1975\end{array}$ & $\begin{array}{r}15.40 \\
20.45 \\
16.99\end{array}$ & $\begin{array}{r}4,960 \\
10.500 \\
5,800\end{array}$ \\
\hline
\end{tabular}

b Affected by ice.

c About. 
Location.--Lat 43001.06". long 95002.34", in sw1/4 NE1/4 sec.25. T. 95 N., R. 36 N.. Clay County, on left bank 5 ft dcwnstream from bridge on county highway B53, 0.4 mile northwest of Gillett Grove. 0.9 mile above Elk Creek, and at mile 146.1.

Drainage area.--1,334 sq mi.

Gage.--Hater-stage recorder. Datum of gage is 1.266 .84 ft abore mean sea level.

Flood stage. -- $12 \mathrm{ft}$.

stage-discharge relation.--Defined by current-meter measurements. Remarks.--Base for partial-duration series, 1,500 cfs.

Peak_stages_and__di schahargess

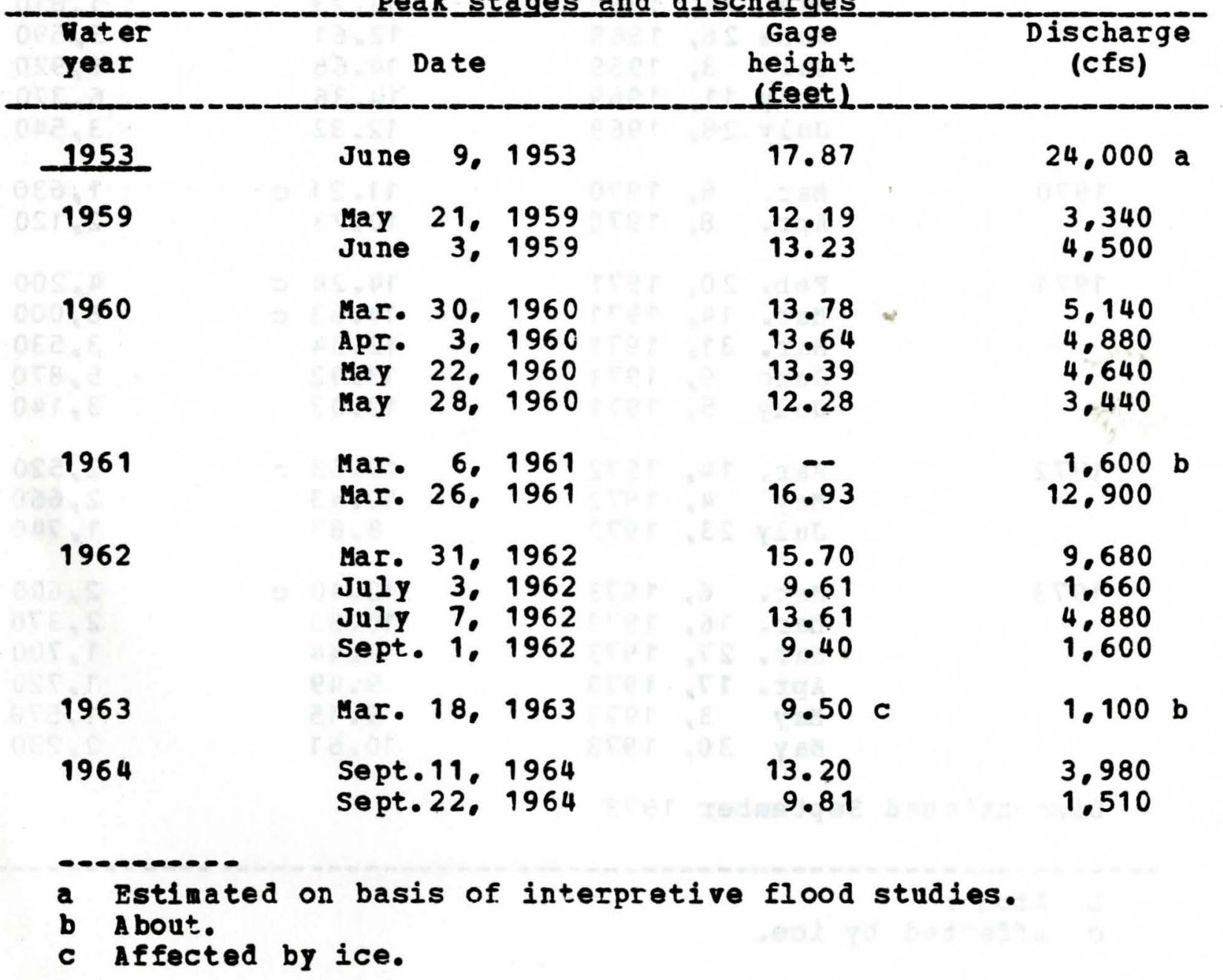


06-6056.00 Little Sioux River at Gillett Grove, Iowa--(Continued)

Pea $\underline{k}$ staquges_and﹎di

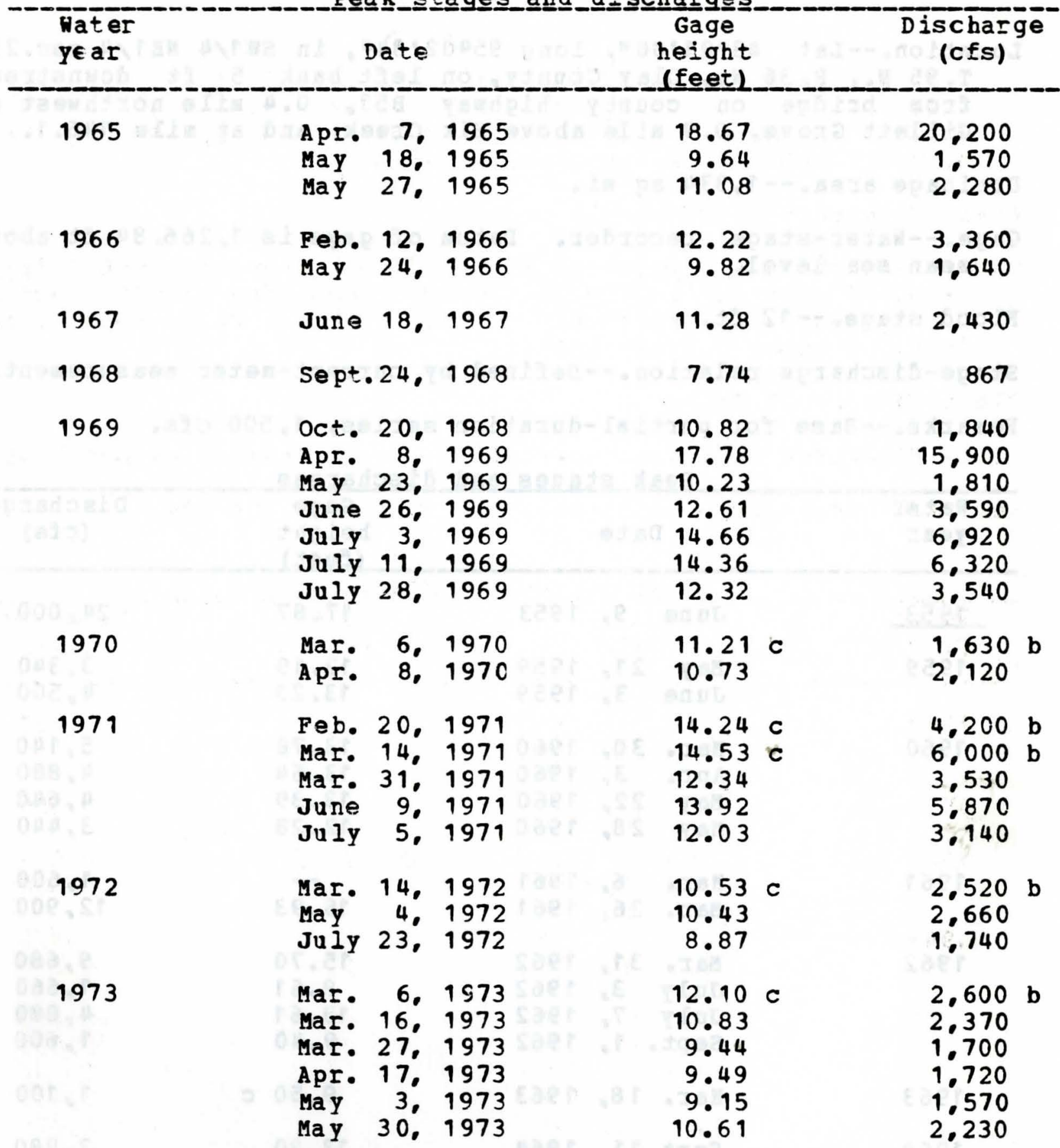

Discontinued september 1973

b a bout.

c Affected by ice. 


$$
\begin{gathered}
\text { 06-6067.00 Little Sioux River near Kennebec, Iowa } \\
\text { (Discontinued Sept. 30, 1969) }
\end{gathered}
$$

Location.--Lat 42004'55", long 96000.50", in SE1/4 SH1/4 sec.18, T.84 N.. R. 44 W.. Monona County, near left bank on downstream side of pier of bridge on Monona County Highway A, 1.1 miles south of Kennebec, 5.5 miles northeast of Onawa, and 6.0 miles upstream from Maple River and at mile 22.0

Drainage area.--2,738 sq mi.

Gage.--Nonrecording prior to May 24, 1950; recording thereafter. Datum of gage is $1.027 .02 \mathrm{ft}$ above mean sea level (Monona County Highway Department bench mark). Prior to oct. 12, 1959. at datum $0.87 \mathrm{ft}$ highar.

Flood stage. $--25 \mathrm{ft}$.

Stage-discharge relation.--Defined by current-meter measurements. Remarks.--Base for partial-duration series, 4,000 cfs.

Peak stages and discharges

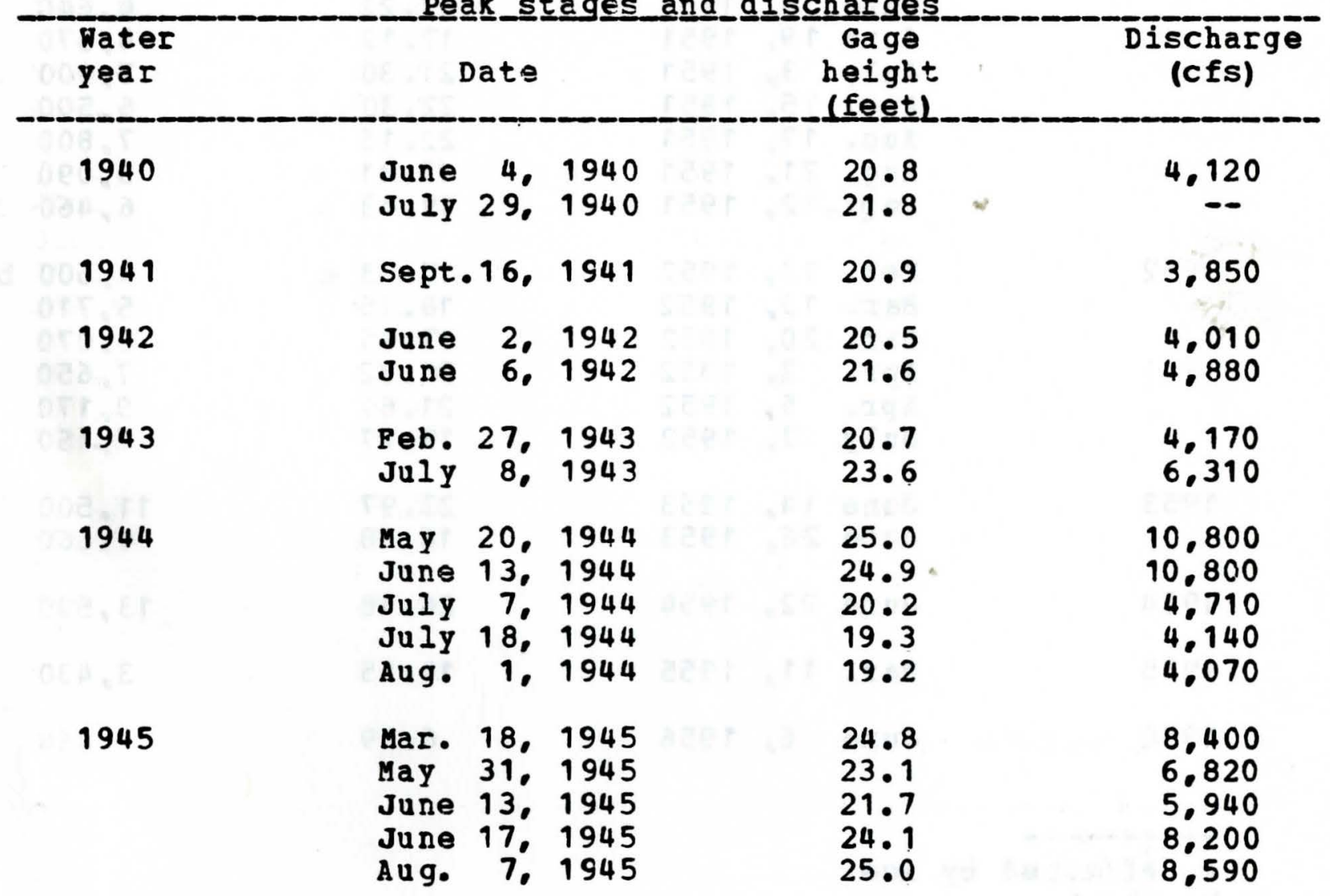


06-6067.00 Little Sioux River near Kennebec, Iowa--(Continued)

Peak_stages and

\begin{tabular}{|c|c|c|c|c|c|c|}
\hline $\begin{array}{l}\text { water } \\
\text { year }\end{array}$ & Date & & $\begin{array}{c}\text { Gage } \\
\text { height } \\
\text { (feet). }\end{array}$ & & $\begin{array}{l}\text { Discharg } \\
\text { (cfs) }\end{array}$ & \\
\hline 1946 & Feb. 6 & 1946 & 23.4 & $\mathbf{a}$ & 6.0001 & $\mathbf{b}$ \\
\hline 1947 & $\begin{array}{lr}\text { May } & 2, \\
\text { May } & 6, \\
\text { June } & 25,\end{array}$ & $\begin{array}{l}1947 \\
1947 \\
1947\end{array}$ & $\begin{array}{l}22.9 \\
18.8 \\
22.4\end{array}$ & & $\begin{array}{l}8.390 \\
4.860 \\
7.940\end{array}$ & \\
\hline 1948 & $\begin{array}{l}\text { Feb. } 28, \\
\text { Mar. } 16,\end{array}$ & $\begin{array}{l}1948 \\
1948\end{array}$ & $\begin{array}{l}24.2 \\
21.4\end{array}$ & & $\begin{array}{l}7.870 \\
5.590\end{array}$ & \\
\hline 1949 & MaI. 4. & 1949 & 24.0 & a & 5.3001 & b \\
\hline 1950 & $\begin{array}{l}\text { June } 12, \\
\text { June } 18,\end{array}$ & $\begin{array}{l}1950 \\
1950\end{array}$ & $\begin{array}{l}19.1 \\
22.4\end{array}$ & & $\begin{array}{l}4.470 \\
6.140\end{array}$ & \\
\hline 1951 & $\begin{array}{l}\text { Mar. } 28, \\
\text { ApI. } 11, \\
\text { May } 1, \\
\text { June } 8, \\
\text { June } 19, \\
\text { July } 3 . \\
\text { Aug. 15, } \\
\text { Aug. } 17 . \\
\text { Aug. } 21 . \\
\text { Sept. } 12 .\end{array}$ & $\begin{array}{l}1951 \\
1951 \\
1951 \\
1951 \\
1951 \\
1951 \\
1951 \\
1951 \\
1951 \\
1951\end{array}$ & $\begin{array}{l}24.86 \\
24.33 \\
18.92 \\
17.22 \\
17.12 \\
21.30 \\
22.30 \\
22.15 \\
17.81 \\
19.43\end{array}$ & $\sim$ & $\begin{array}{r}8.400 \\
12.000 \\
5.330 \\
4.640 \\
4.570 \\
7.000 \\
6.500 \\
7.800 \\
5.090 \\
6.460\end{array}$ & b \\
\hline 1952 & $\begin{array}{lr}\text { Feb. } 13, \\
\text { Mar. } 13, \\
\text { Mar. } 20^{\circ} \\
\text { Apr. } 2, \\
\text { Apr. } 5, \\
\text { July } \quad 7 .\end{array}$ & $\begin{array}{l}1952 \\
1952 \\
1952 \\
1952 \\
1952 \\
1952\end{array}$ & $\begin{array}{l}17.73 \\
18 \cdot 15 \\
17.35 \\
20.32 \\
21.67 \\
19.77\end{array}$ & $\mathbf{a}$ & $\begin{array}{l}4.500 \\
5.710 \\
5.070 \\
7.650 \\
9.170 \\
7.150\end{array}$ & b \\
\hline 1953 & $\begin{array}{l}\text { June } 14, \\
\text { June } 26\end{array}$ & $\begin{array}{l}1953 \\
1953\end{array}$ & $\begin{array}{l}23 \cdot 97 \\
16 \cdot 88\end{array}$ & & $\begin{array}{r}11.500 \\
4.660\end{array}$ & \\
\hline 1954 & June 22 . & 1954 & $26 \cdot 18$ & & 13.500 & \\
\hline 1955 & Mar. 11. & 1955 & $14 \cdot 15$ & & 3.430 & \\
\hline 1956 & June 6 & 1956 & 6.99 & & 464 & \\
\hline
\end{tabular}

a Affected by ice.

b A bout. 
06-6067.00 Little Sioux River near Kennebec, Iowa--(Continued)

Peak_stagges_and_di schharges

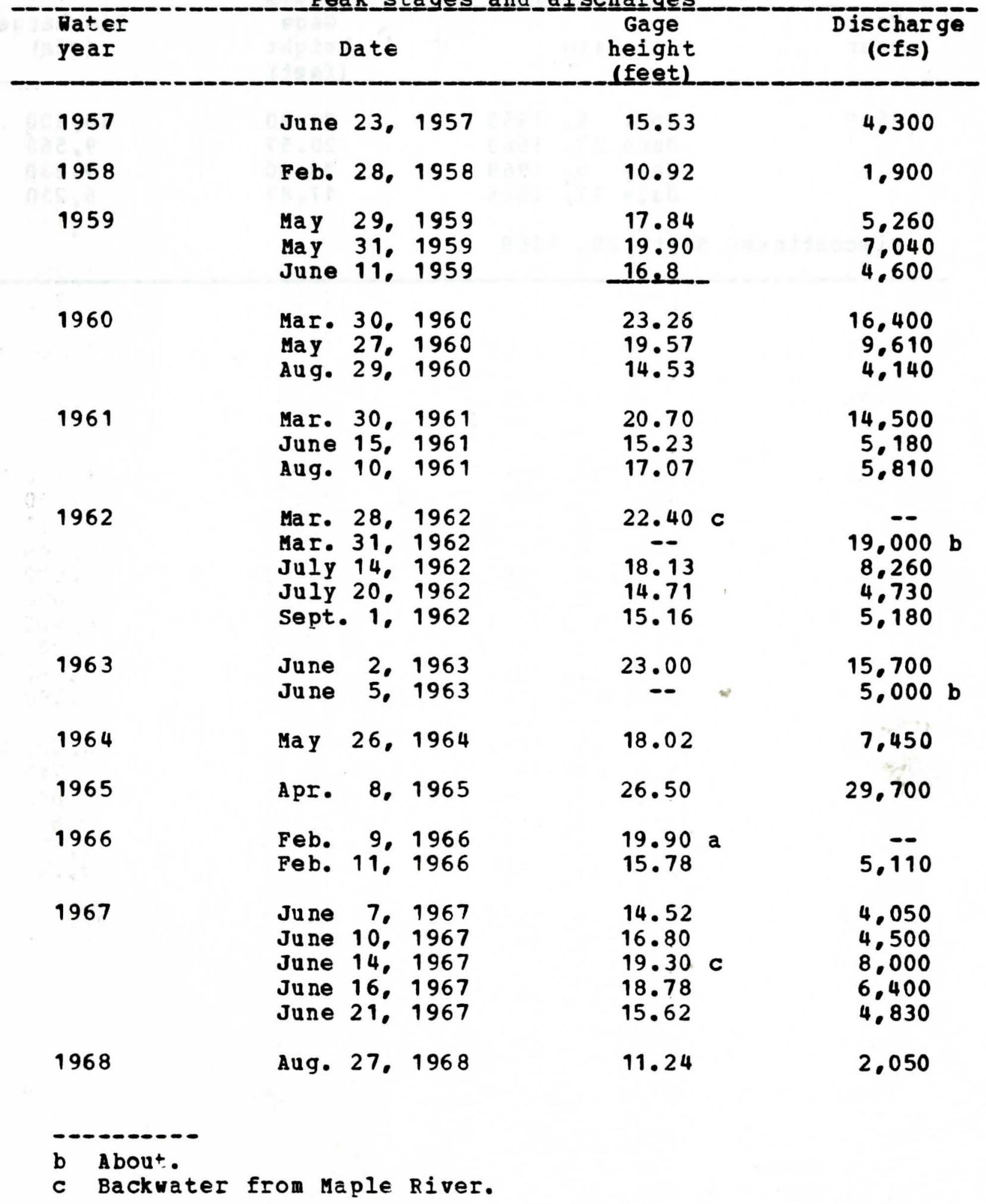


06-6067.00 Little Sioux River near Kennebec, Iowa--(Continued)

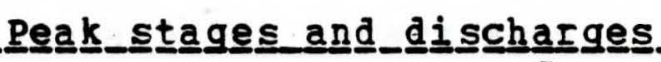

\begin{tabular}{|c|c|c|c|}
\hline $\begin{array}{l}\text { Water } \\
y \in a r\end{array}$ & Date & $\begin{array}{l}\text { Gage } \\
\text { height } \\
\text { feeet }\end{array}$ & $\begin{array}{l}\text { Discharge } \\
\text { (cfs) }\end{array}$ \\
\hline 1969 & $\begin{array}{lll}\text { Apr. } & 9, & 1969 \\
\text { June } & 27, & 1969 \\
\text { July } & 9, & 1969 \\
\text { July } & 17, & 1969\end{array}$ & $\begin{array}{l}24.90 \\
20.57 \\
18.80 \\
17.87\end{array}$ & $\begin{array}{r}18.900 \\
9.560 \\
7.230 \\
6.210\end{array}$ \\
\hline Discon & sept. 30,1969 & & \\
\hline
\end{tabular}




\section{6-6058.50 Little Sioux River at Iinn Grove, Iowa}

Location.--Lat 42053'24", long 95014'30", in sw1/4 SW1/4 sec.5. T.93 N.. R. 37 H.. Buena vista County, on right bank at downstream side of bridge on State Highway 264, in Iinn Grove, and at mile 123.7.

Drainage area.--1,548 sq $\mathrm{mi}$.

Gage.--Water-stage recorder. Datum of gage is $1,223.60 \mathrm{ft}$ above mean sea level.

Stage-discharge relation.--Defined by current meter measurements. Flood stage. --12 ft.

Remarks.--Base for partial-duration series, 2,500 cfs.

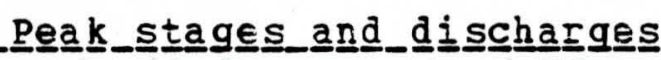

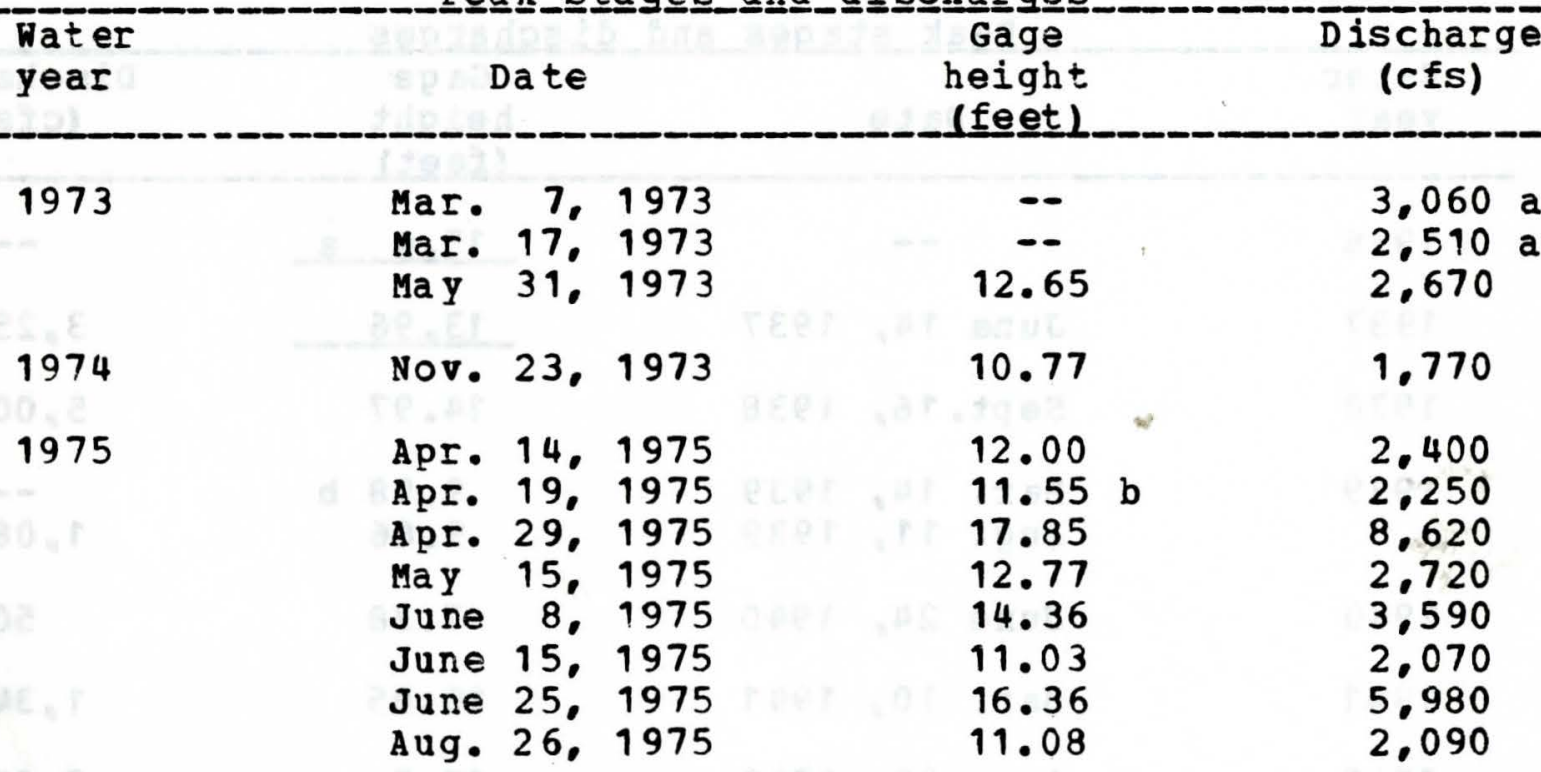

a About.

b From graph based on daily wi re-weight gage readings. 


\section{6-6051.00 Little Sioux River at Spencer, Iowa}

(Discontinued september 1942)

Location.--Lat $43008 \%$, long 95008 ', in sec.18, T.96 N.. R.36 W.. Clay County, at bridge on U.S. Highway 18 and 71 at spencer. three-quarters of a aile dcwnstream from ocheyedan River, and at mile 160.3 .

Drainage area.--1,030 sq mi.

Gage.--Nonrecording. Datum of gage is $1.294 .56 \mathrm{ft}$ above mean sea level. Prior to Sept. 17. 1937, at datum $0.40 \mathrm{ft}$ lower.

Stage-discharge relation.--Defined by current-meter measurenents. Plood stage. --10 ft.

Remarks.--only annual peaks are shown.

Peak﹎ㅗtages and di

\begin{tabular}{|c|c|c|c|}
\hline $\begin{array}{l}\text { Water } \\
\text { year }\end{array}$ & Date & $\begin{array}{c}\text { Gage } \\
\text { height } \\
\text { ffeetl }\end{array}$ & $\begin{array}{l}\text { Discharge } \\
\text { (cfs) }\end{array}$ \\
\hline 1936 & -- & 15.4 & - \\
\hline 1937 & June 14, 1937 & 13,96 & 3.250 \\
\hline 1938 & Sept. 16, 1938 & 14.97 & 5.000 \\
\hline 1939 & $\begin{array}{l}\text { Mar. } 14,1939 \\
\text { Aug. } 11,1939\end{array}$ & $\begin{array}{l}9.98 \quad b \\
9.86\end{array}$ & 1.080 \\
\hline 1940 & June 24. 1940 & 7.38 & 503 \\
\hline 1941 & Mar. 10, 1941 & 10.95 & 1.340 \\
\hline 1942 & Aug. 31,1942 & 12.3 & 2,170 \\
\hline 1953 & June 8,1953 & 20.20 & 30.000 \\
\hline 1965 & Apr. 6,1965 & 17.37 & 16.700 \\
\hline
\end{tabular}

a From floodmark, datum used is 1942.

b Backwater from ice. 
Location.--Iat $41057 \cdot 52$ ", long 95058'21", in NW1/4 NE1/4 sec.33, T.83 N.. R. 44 W.. Monona County, on left bank on dcwnstream side of bridge on county highway E54.1.0 mile east of gaging station on Monona-Harrison ditch near Turin, 2.5 miles downstream from Maple River, 3.8 miles south of Turin, 6.2 miles northeast of Blencoe, and at mile 13.5.

Drainage area.--3,526 sq mi.

Gage.-- Nater-stage recorder. Datum of gage is $1,019.85$ ft above mean sea level (Corps of Engineers bench mark).

Flood stage. $--25 \mathrm{ft}$.

Stage-discharge relation.--Defined by current-meter measurements. Remarks.--Base for partial-duratior: series, 4,500 cfs.

Pea

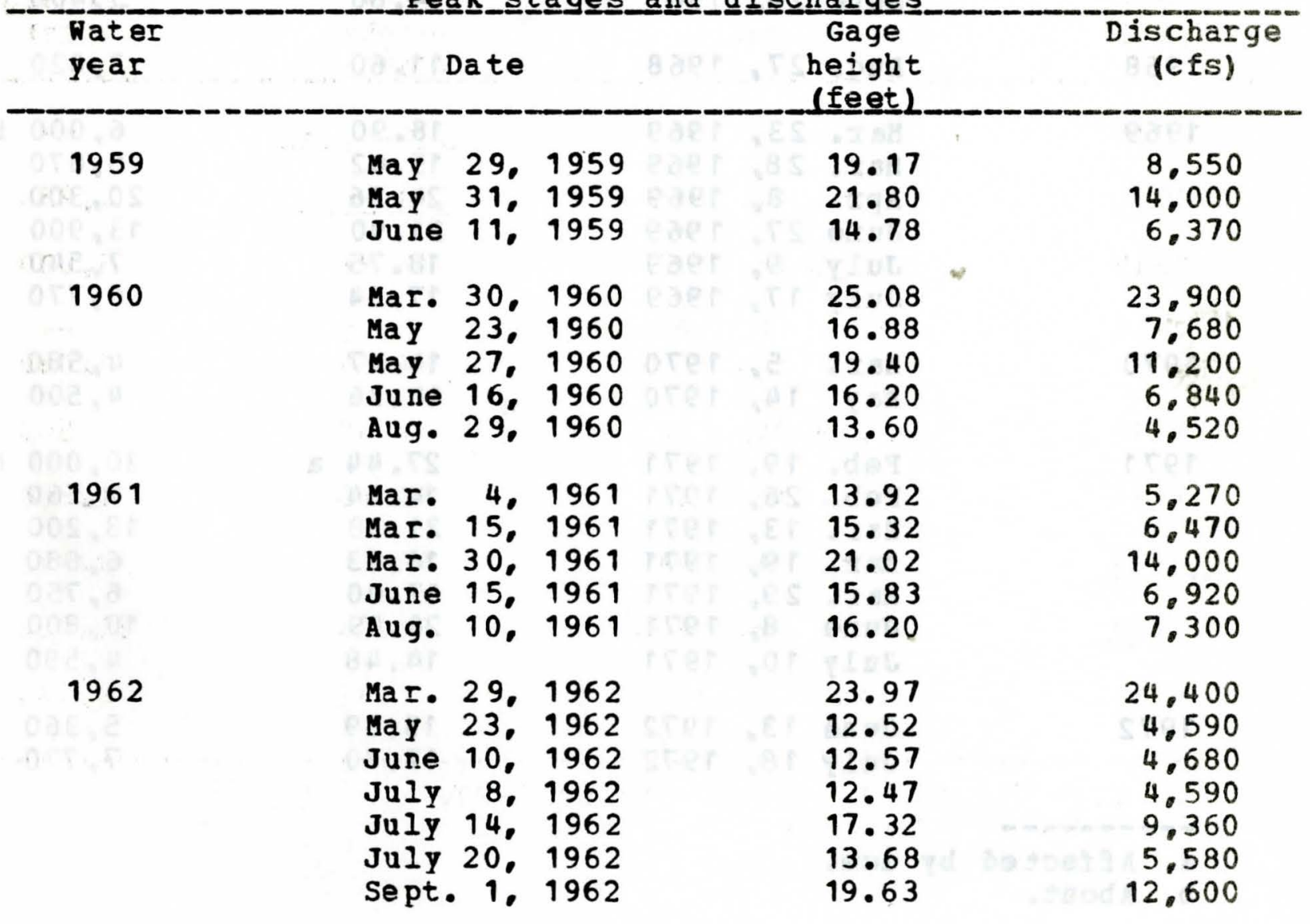


06-6075.00 Little Sioux River near Turin. Iowa--(Continued)

Peak_stagges and_discharges

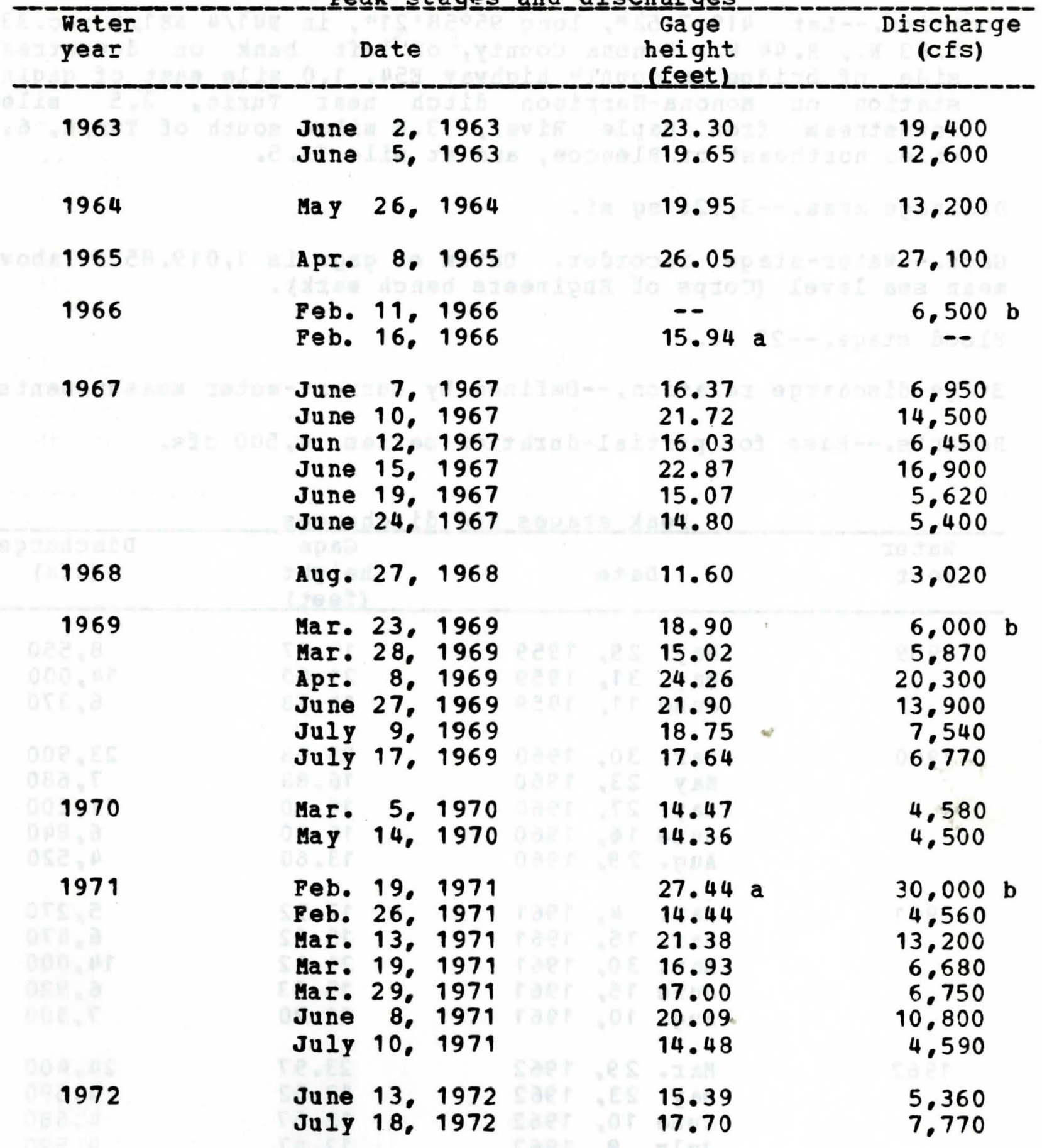

a Affected by ice.

b About. 
06-6075.00 Little Sioux River near Turin, Iowa--(Continued)

Peakk_stages and discharges

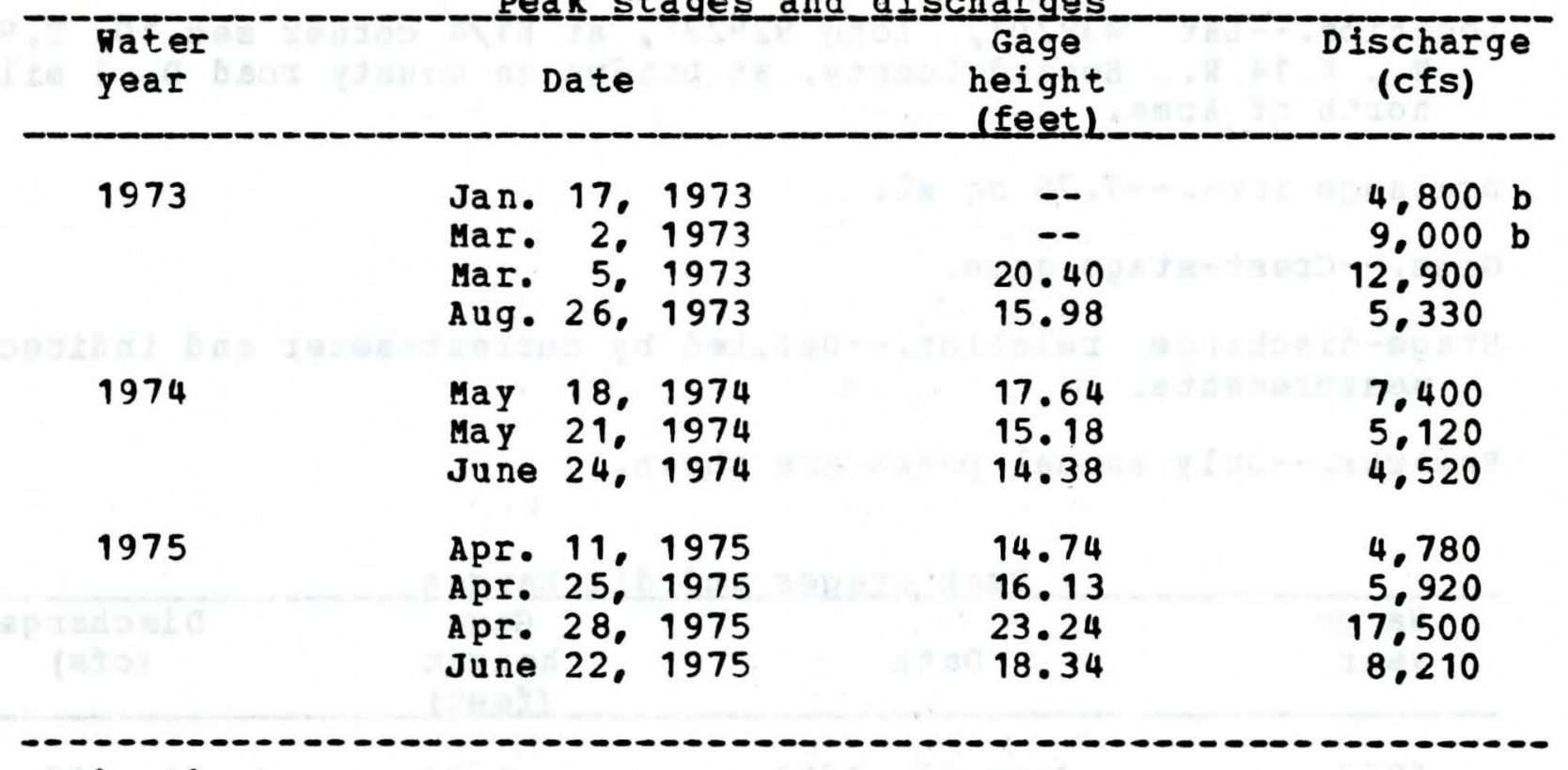

b About. 
Location.--lat $43020^{\circ}$. long $92029^{\circ}$ at N1/4 corner sec.10, T.98 N. R. 14 H. . Howard County, at bridge on county road $D_{,} 1$ mile north of Acme.

Drainage area.--7.76 sq mi.

Gage.--Crest-stage gage.

stage-discharge relation.--Defined by current-meter and indirect measurements.

Remarks.--only annual peaks are shown.

Peak_stages and_di schargares

\begin{tabular}{|c|c|c|c|c|}
\hline $\begin{array}{l}\text { Water } \\
\text { year }\end{array}$ & Date & & $\begin{array}{c}\text { Gage } \\
\text { height } \\
\text { (feet) }\end{array}$ & $\begin{array}{c}\text { Discharge } \\
\text { (cfs) }\end{array}$ \\
\hline 1953 & June 13 & 1953 & 6.74 & 668 \\
\hline 1954 & June 21 , & 1954 & 7.19 & 822 \\
\hline 1955 & Aug. 1 , & 1955 & 6.63 & 635 \\
\hline 1956 & Apr. 1 & 1956 & 5.60 & 420 \\
\hline 1957 & MaI. 24. & 1957 & 3.77 & 167 \\
\hline 1958 & Apr. 7. & 1958 & 3.66 & 155 \\
\hline 1959 & Mar. 26, & 1959 & 5.75 & 250 \\
\hline 1960 & Mar. 29. & 1960 & 6.04 & 302 \\
\hline 1961 & Mar. 27. & 1961 & 7.19 & 700 \\
\hline 1962 & Aug. 31 . & 1962 & 9.02 & 2.380 \\
\hline 1963 & Oct. 10. & 1962 & 4.68 & 285 \\
\hline 1964 & May & 1964 & 4.80 & 302 \\
\hline 1965 & Sept.30. & 1965 & 7.53 & 965 \\
\hline 1966 & July 14, & 1966 & 5.84 & 458 \\
\hline 1967 & June 9. & 1967 & 8.54 & 1.670 \\
\hline
\end{tabular}


05-4206.20 Little Mapsipinicon River near Acme, Iowa-- (Continued)

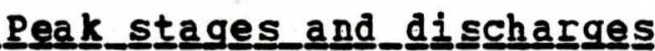

\begin{tabular}{llcr}
$\begin{array}{c}\text { Water } \\
\text { Year }\end{array}$ & \multicolumn{1}{c}{ Date } & $\begin{array}{c}\text { Gage } \\
\text { height } \\
\text { (feetL }\end{array}$ & $\begin{array}{c}\text { Discharge } \\
\text { (cfs) }\end{array}$ \\
\hline 1968 & May 17,1968 & 6.98 & 749 \\
1969 & June 26, 1969 & 8.58 & 1.720 \\
1970 & Aug. 8,1970 & 5.45 & 396 \\
1971 & Oct. 9, 1970 & 5.05 & 322 \\
1972 & Sept.12, 1972 & 3.44 & 395 \\
1973 & May 27, 1973 & 4.57 & 275 \\
1974 & June 4, 1974 & 8.83 & 1.900 \\
1975 & Apr. 28, 1975 & 5.80 & 460 \\
\hline
\end{tabular}


Location.--Iat $43014 \%$ long $92027 \%$ in NW1/4 sec.12. T.97 N.. R.14 W. . Howard County, at bridge on county road $A$ near west city limits of Elma.

Drainage area.-- $-37.3 \mathrm{sq} \mathrm{mi}$

Gage.--Crest-stage gage.

stage-discharge relation.--Defined by current-meter and indirect mea surements.

Remarks.--only annual peaks are shown.

Peak_stages_and_di

\begin{tabular}{|c|c|c|c|}
\hline $\begin{array}{l}\text { Water } \\
\text { year }\end{array}$ & Date & $\begin{array}{l}\text { Gage } \\
\text { height } \\
\text { (feet) }\end{array}$ & $\begin{array}{l}\text { Discharge } \\
\text { (cfs) }\end{array}$ \\
\hline 1953 & June 13, 1953 & 10.60 & 3.010 \\
\hline 1954 & June 21, 1954 & 10.59 & 3.000 \\
\hline 1955 & Mar. 15, 1955 & 7.00 & 450 \\
\hline 1956 & Apr. 1. 1956 & 5.91 & 259 \\
\hline 1957 & Mar. 24, 1957 & $4.21 \%$ & 88 \\
\hline 1958 & Apr. 7,1958 & 5.02 & 154 \\
\hline 1959 & Mar. 26, 1959 & 7.43 & 559 \\
\hline 1960 & June 23,1960 & 9.09 & 1,380 \\
\hline 1961 & July 31, 1961 & 10.10 & 2.400 \\
\hline 1962 & Aug. 31, 1962 & 12.53 & 5.740 \\
\hline 1963 & May 13,1963 & $8 \cdot 30$ & 890 \\
\hline 1964 & May 24. 1964 & 5.59 & 217 \\
\hline 1965 & sept.30. 1965 & 9.46 & 1.720 \\
\hline 1966 & July 14, 1966 & 9.49 & 1.750 \\
\hline 1967 & June 9, 1967 & 10.27 & 2.600 \\
\hline
\end{tabular}


05-4206.40 Little Mapsipinicon Fiver at Elma, Iowa--(Continued)

Peak_stages and_di scharges

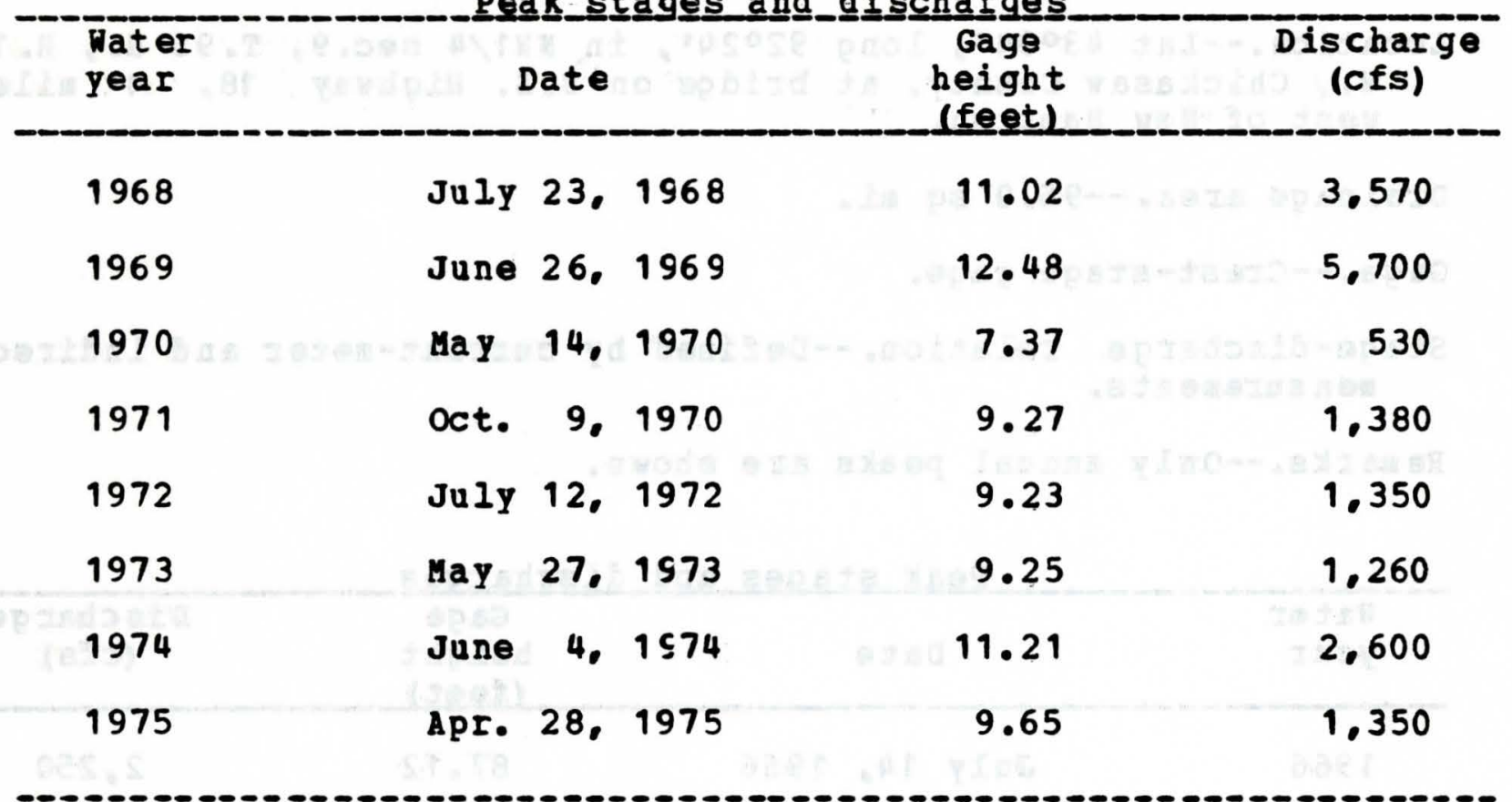


05-4206.50 Little Wapsipiniccn River near New Hampton, Iowa

Location.--Iat $43004^{\circ}$. Iong $92^{\circ} 24^{\circ}$, in Nw1/4 sec.9, T.95 N.. R. 13 W. Chickasaw County, at bridge on U.S. Highway 18, 4 miles west of New Hampton.

Drainage area.--95.0 sq mi.

Gage.--Crest-stage gage.

Stage-discharge relation.--Defined by current-meter and indirect mea surements.

Remarks.--only annual peaks are shown.

Peak stages and discharges

\begin{tabular}{|c|c|c|c|}
\hline $\begin{array}{l}\text { Water } \\
\text { year }\end{array}$ & Date & $\begin{array}{l}\text { Gage } \\
\text { height } \\
\text { (feet) }\end{array}$ & $\begin{array}{l}\text { Discharge } \\
\text { (cfs) }\end{array}$ \\
\hline 1966 & July 14, 1966 & 87.12 & 2.250 \\
\hline 1967 & June 10,1967 & 86.92 & 2.000 \\
\hline 1968 & July 25, 1968 & 86.92 & 2.000 \\
\hline 1969 & June 27, 1969 & 88.72 & 9.200 \\
\hline 1970 & Aug. 8,1970 & 87.89 & 4.100 \\
\hline 1971 & oct. 9. 1970 & 87.26 & 2.600 \\
\hline 1972 & July 12, 1972 & 86.81 & 1.800 \\
\hline 1973 & Apr. 17, 1973 & 86.74 & 2.000 \\
\hline 1974 & June 4.1974 & 88.15 & 4.800 \\
\hline 1975 & Apr. 28, 1975 & 87.12 & 2.280 \\
\hline
\end{tabular}


location.--Iat $42043 \circ$. Iong 92002 , in NE1/4 sec.8, T. 91 N.. R. 10 1. Fayette County. at briage on state Highway 3 , about 2 alies northeast of oran.

Drainage area.--94.1 sq mi.

Gage.--Crest-stage gage.

stage-discharge relation.--Defined by current-meter measurements. Renarks.--only annual peaks are shown.

Peak stages and discharges

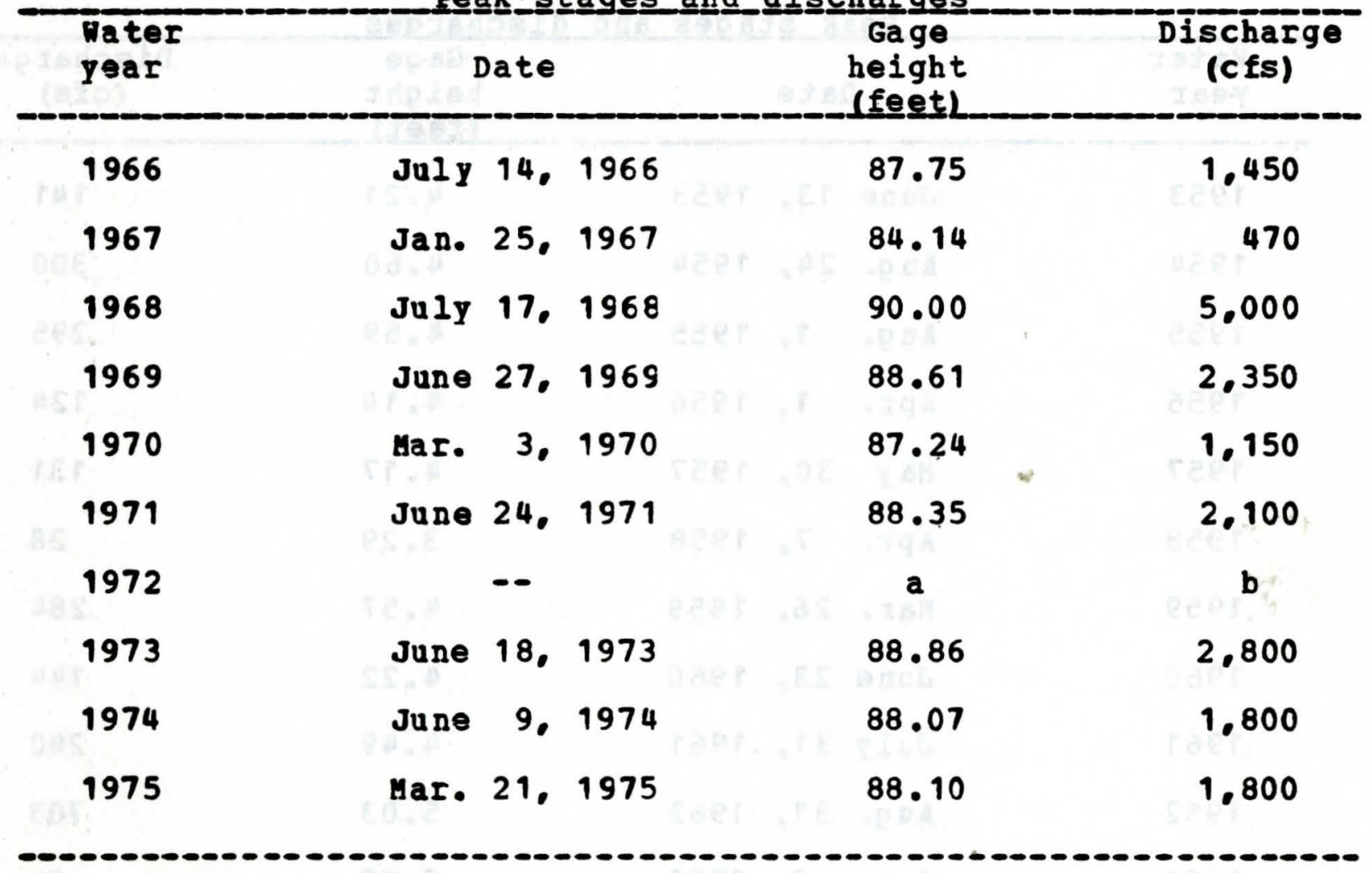

a Peak stage did not reach bctton of gage.

b Discharge not determined. 
05-4206.00 Little Mapsipinicon Fiver tributary near Riceville, Iowa

Location.--Lat 43021 , long $92029 \%$, near $51 / 4$ corner sec.27. T. 99 N.. R. 14 W.. Howard county, at culvert, 3.5 miles east of Riceville.

Drainage area. $--0.90 \mathrm{sq} \mathrm{mi}$.

Gage.--Crest-stage gage.

Stage-discharge relation.--Defined by current-meter and indirect measurements.

Remarks.--only annual peaks are shown.

Peak stages and discharges

\begin{tabular}{|c|c|c|c|}
\hline $\begin{array}{l}\text { Water } \\
\text { year }\end{array}$ & Date & $\begin{array}{c}\text { Gage } \\
\text { height } \\
\text { (feet) }\end{array}$ & $\begin{array}{l}\text { Discharge } \\
\text { (cfs) }\end{array}$ \\
\hline 1953 & June 13,1953 & 4.21 & 141 \\
\hline 1954 & Aug. 24. 1954 & 4.60 & 300 \\
\hline 1955 & Aug. 1,1955 & 4.59 & 295 \\
\hline 1956 & Apr. 1,1956 & 4.14 & 124 \\
\hline 1957 & May 30,1957 & 4.17 & 131 \\
\hline 1958 & Apr. 7. 1958 & 3.29 & 28 \\
\hline 1959 & Mar. 26. 1959 & 4.57 & 284 \\
\hline 1960 & June 23, 1960 & 4.22 & 144 \\
\hline 1961 & July 31, 1961 & 4.49 & 240 \\
\hline 1962 & Aug. 31,1962 & 5.03 & 703 \\
\hline 1963 & oct. 8, 1962 & 3.69 & 54 \\
\hline 1964 & May 24,1564 & 4.00 & 95 \\
\hline 1965 & sept. 30, 1965 & 4.72 & 382 \\
\hline 1966 & July 14, 1966 & 4.38 & 195 \\
\hline 1967 & June 9,1967 & 4.87 & 511 \\
\hline
\end{tabular}


05-4206.00 Little Mapsipinicon River tributary near Riceville, Iowa-(Continued)

Peak_stages and_di

\begin{tabular}{|c|c|c|c|c|}
\hline $\begin{array}{l}\text { Dater } \\
\text { yoar }\end{array}$ & Date & & $\begin{array}{c}\text { Gage } \\
\text { height } \\
\text { (feet) }\end{array}$ & $\begin{array}{c}\text { Discharge } \\
\text { (cfs) }\end{array}$ \\
\hline 1968 & May & 1968 & 4.82 & 463 \\
\hline 1969 & June 26 , & 1969 & 4.88 & 520 \\
\hline 1970 & Aug. & 1970 & 4.04 & 115 \\
\hline 1971 & oct. & 1970 & 3.97 & 101 \\
\hline 1972 & Sept. 12. & 1972 & 4.64 & 290 \\
\hline 1973 & Apr. 17. & 1973 & 3.28 & 28 \\
\hline 1974 & June -- & 1974 & 4.96 & 470 \\
\hline 1975 & Apr. 28 & 1975 & 4.28 & 172 \\
\hline
\end{tabular}




\section{5-4800.00 Iizard Creek near clare, Iowa}

(Published as "North Lizard Creek near Clare". 1940-54)

Location.--Iat $42032 \cdot 35^{\prime \prime}$, Iong $94020 \cdot 45^{\prime \prime}$, in NE1/4 NE1/4 sec. 11 , T.89 N.. R.30 N.. Nebster County, on right bank 20 ft downstream from bridge on county highway. 2.3 miles downstream from Drainage ditch $3,3.0$ miles south of clare, and 8.2 miles upstream from south Lizard creek.

Drainage area.--257 sq $\mathrm{mi}$

Gage.--Wacer-stage recorder and concrete control. Datun of gage is 1.079.30 ft above mean sea level. Prior to May $6,1953$. nonrecording gage at same site and datum.

Stage-discharge relation.--Defined by current-meter measurements below 4,500 cfs and by logarithmic plotting above $4,500 \mathrm{cfs}$.

Flood stage.--9 feet.

Remarks.--Base for partial-duration series, 800 cfs.

Peak_stag ges and_discharges

\begin{tabular}{|c|c|c|c|c|c|c|}
\hline $\begin{array}{l}\text { Fater } \\
\text { year }\end{array}$ & & Date & & $\begin{array}{c}\text { Gage } \\
\text { height } \\
\text { (feet) }\end{array}$ & & $\begin{array}{c}\text { Discharge } \\
\text { (cfs) }\end{array}$ \\
\hline 1940 & Aug. & 26 & 1940 & 4.8 & & 374 \\
\hline 1941 & June & 14. & 1941 & 5.1 & $\approx$ & 442 \\
\hline 1942 & June & 5. & 1942 & 6.65 & & 1.060 \\
\hline 1943 & Fob. & 22 & 1943 & 7.4 & & 1.440 \\
\hline 1944 & $\begin{array}{l}\text { May } \\
\text { June }\end{array}$ & $\begin{array}{l}20 \\
13\end{array}$ & $\begin{array}{l}1944 \\
1944\end{array}$ & $\begin{array}{c}11.11 \\
9.2\end{array}$ & & $\begin{array}{l}4.410 \\
2.640\end{array}$ \\
\hline 1945 & $\begin{array}{l}\text { Mar. } \\
\text { Apr. } \\
\text { May } \\
\text { June }\end{array}$ & $\begin{array}{l}11 . \\
24 . \\
22 . \\
1 .\end{array}$ & $\begin{array}{l}1945 \\
1945 \\
1945 \\
1945\end{array}$ & $\begin{array}{l}7.42 \\
6.7 \\
6.7 \\
6.8\end{array}$ & & $\begin{array}{l}1.570 \\
1.270 \\
1.310 \\
1.310\end{array}$ \\
\hline 1946 & May & 25 & 1946 & 9.18 & & 2.750 \\
\hline 1947 & $\begin{array}{l}\text { June } \\
\text { June } \\
\text { June }\end{array}$ & $\begin{array}{l}19 . \\
23 \\
30\end{array}$ & $\begin{array}{l}1947 \\
1947 \\
1947\end{array}$ & $\begin{array}{r}6.1 \\
16.0 \\
8.5\end{array}$ & $\mathbf{a}$ & $\begin{array}{r}1.030 \\
10.000 \\
2.170\end{array}$ \\
\hline
\end{tabular}


05-4800.00 Lizard Creek near Clare, Iowa-- (Continued)

Pea $\underline{\text { s }}$ stages and di $\underline{\text { sq }}$ charges

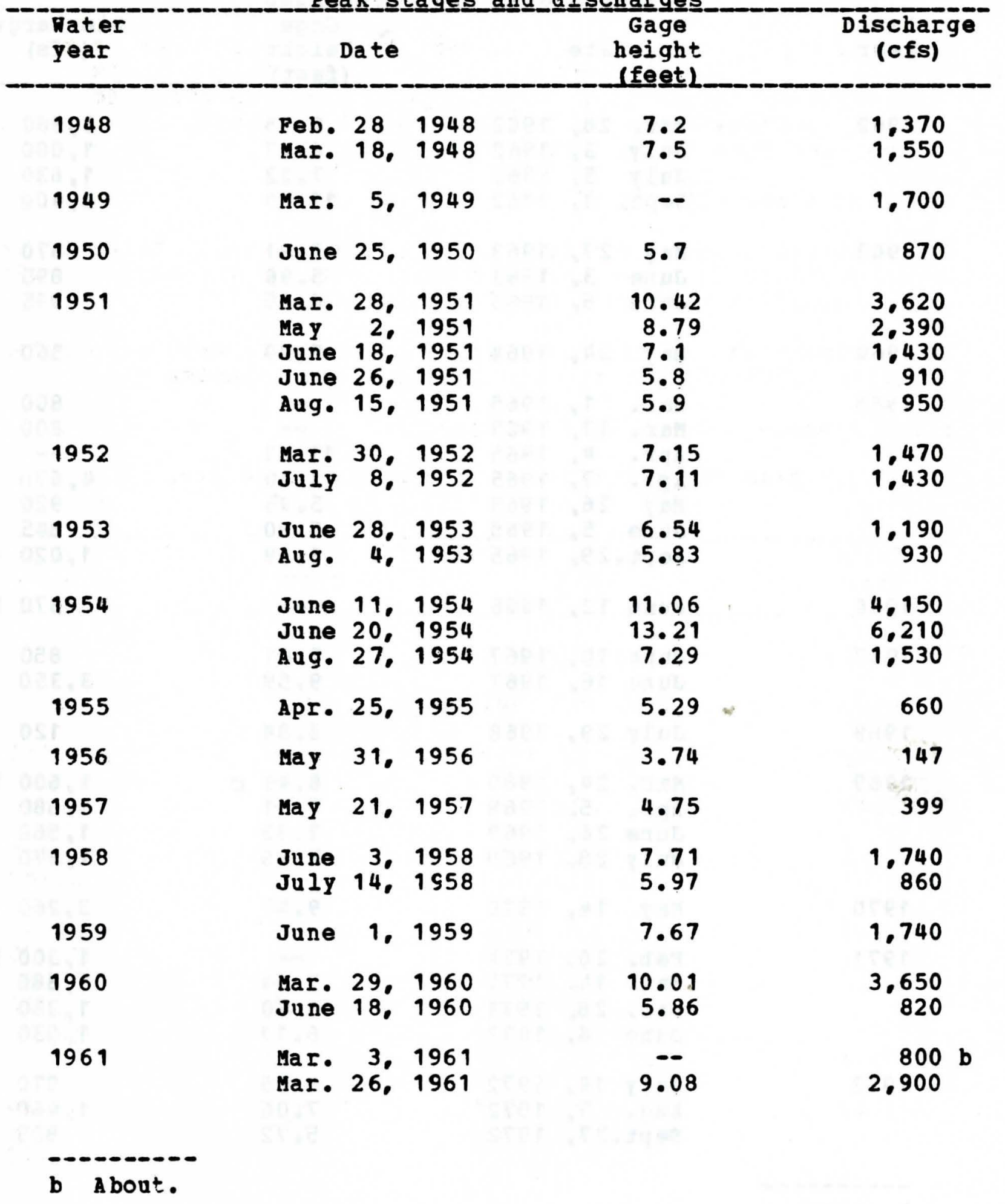


05-4800.00 Lizard Creek near Clare. Iowa--(Continued)

peakk_stages_and_di ischargarges

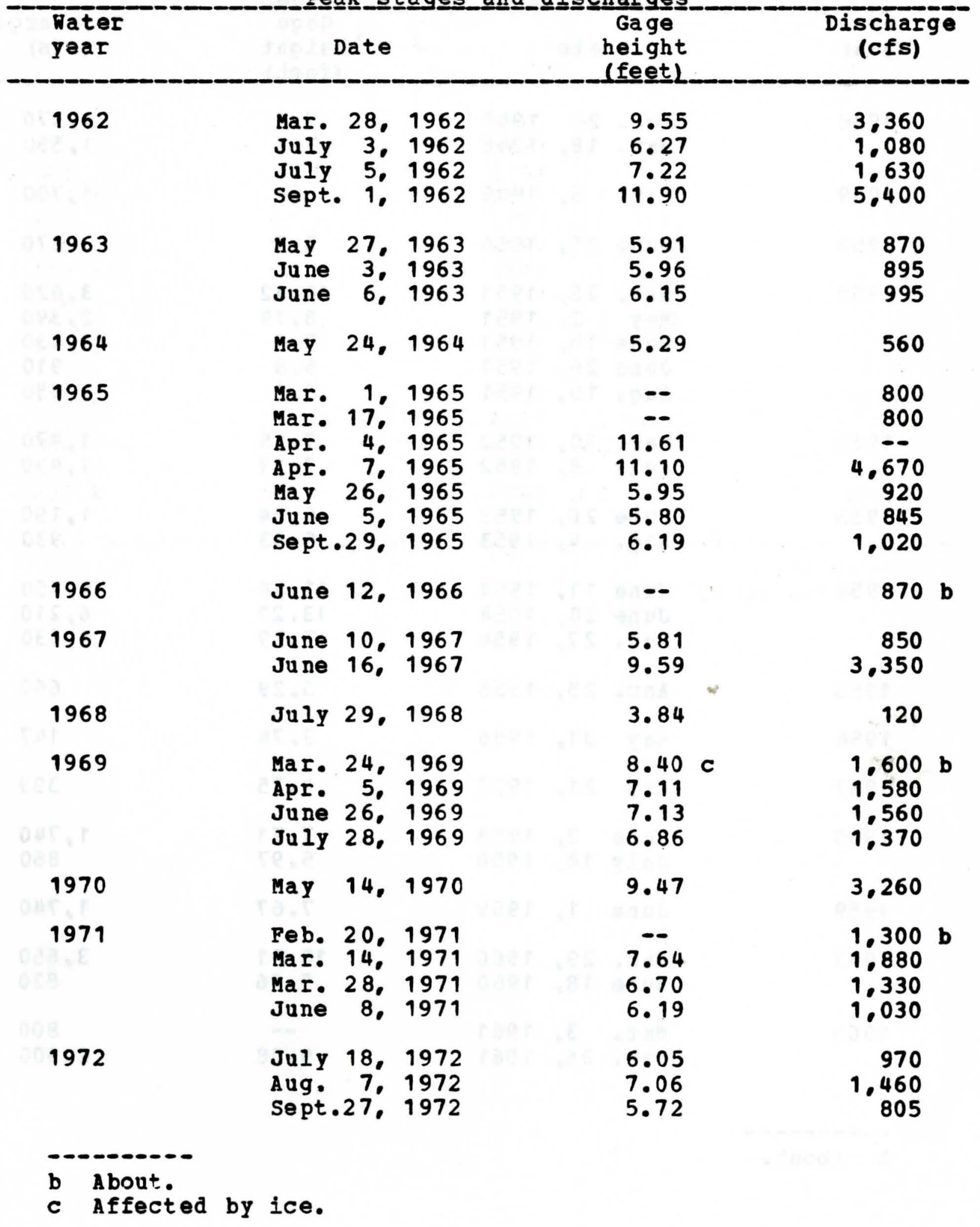


05-4800.00 Lizard Creek near Clare, Iowa-- (Continued)

Pea $\underline{k}$ stagges_and

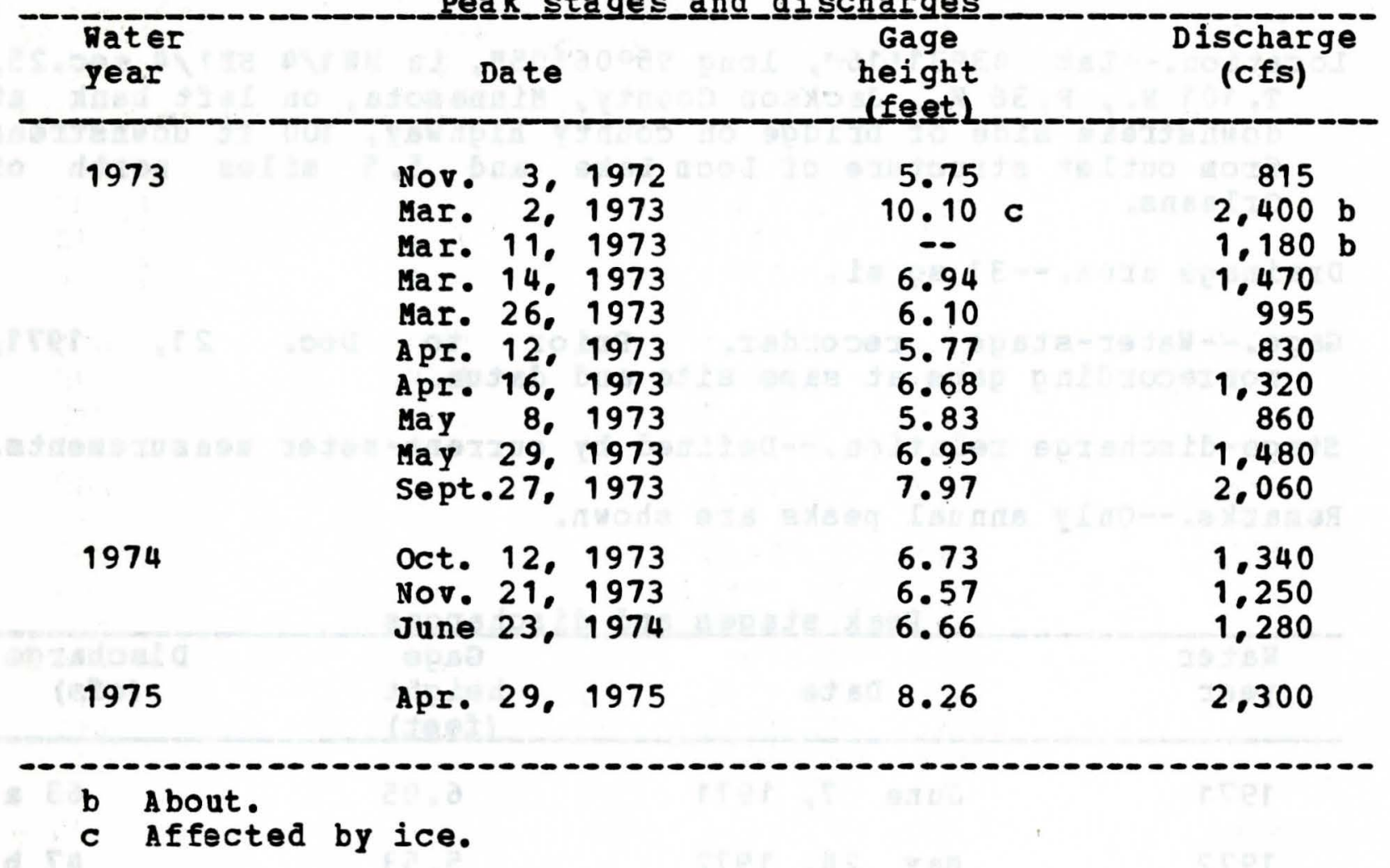




\section{6-6039.20 Loon Creek near Orleans. Iowa (Discontinued september 1974)}

Location.--Iat $43031 \cdot 16^{\prime \prime}$, long 95006'05", in NN1/4 SE1/4 sec.25. T. $101 \mathrm{~N}$. . R.36 W.. Jackson County. Minnesota, on left bank at downstream side of bridge on county highway. 100 ft dcwnstrean from outlet structure of Locn lake and 5.5 miles north of orleans.

Drainage area.--31 sq mi.

Gage.-- Nater-stage recorder. Prior to Dec. 21.1971. non recording gage at same site and datum.

Stage-discharge relation.--Defined by current-meter measurements. Remarks.--Only annual peaks are shown.

Peak_stages_and_di schargas

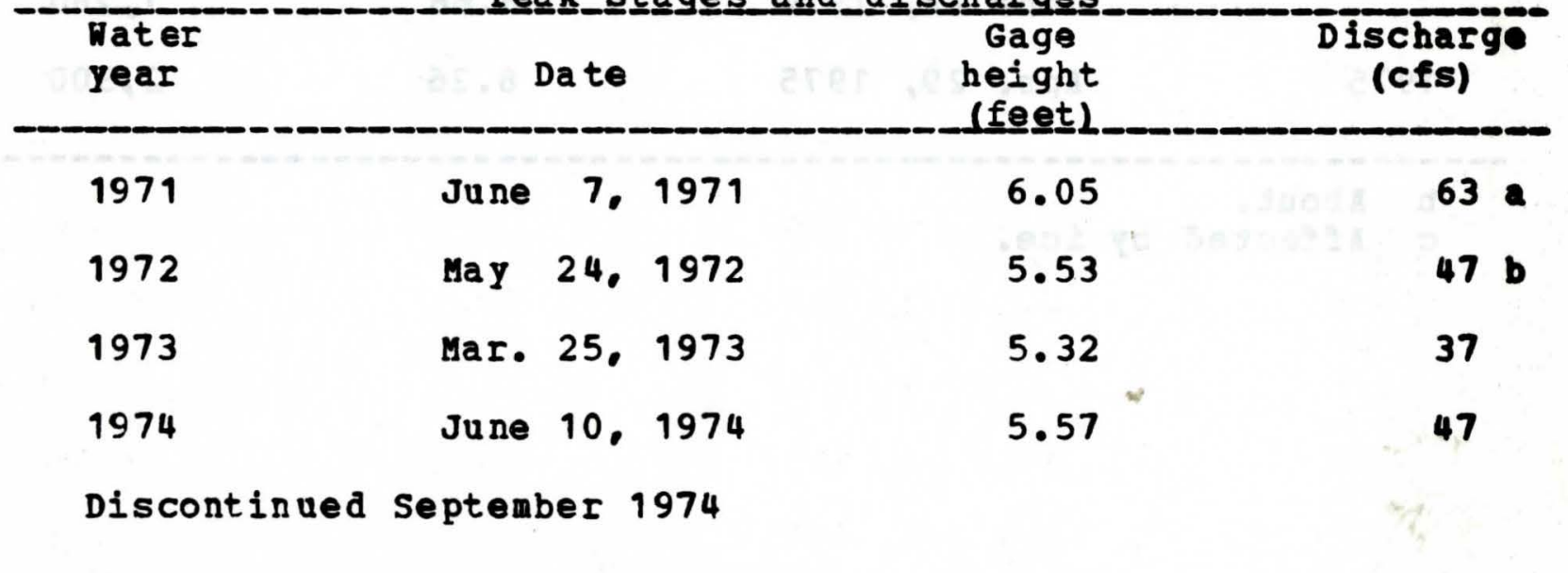

a From graph based on gage readings.

b From high-water mark. 
Location.--Lat $42045^{\prime}$. long $95^{\circ} 22^{\prime}$, in NE1/4 seC.31, T.92 N.. R.38 W., Buena vista County, at bridge on State Highway 3,6 miles northwest of Alta.

Drainage area.--15.5 sq $\mathrm{mi}$.

Gage.--Crest-stage gage.

Stage-discharge relation.--Defined by current-meter and indirect mea surements.

Remarks.--only annual peaks are shown.

Peak﹎.stages_and_di

\begin{tabular}{|c|c|c|c|c|c|}
\hline $\begin{array}{l}\text { Water } \\
\text { year }\end{array}$ & & Date & & $\begin{array}{l}\text { Gage } \\
\text { height } \\
\text { leet }\end{array}$ & $\begin{array}{c}\text { Discharge } \\
\text { (cfs) }\end{array}$ \\
\hline 1966 & & - & & a & $<60$ \\
\hline 1967 & & - & & a & $<60$ \\
\hline 1968 & June & 25. & 1968 & 87.29 & 440 \\
\hline 1969 & June & 25 & 1969 & 89.75 & 5.300 \\
\hline 1970 & & $\cdots$ & & a & $<60$ \\
\hline 1971 & June & 6. & 1971 & 88.25 & 1.150 \\
\hline 1972 & May & 1. & 1972 & 85.35 & b \\
\hline 1973 & Mar. & 6. & 1973 & 86.75 & 260 \\
\hline 1974 & June & 22. & 1974 & 86.02 & 144 \\
\hline 1975 & June & 25. & 1975 & 88.47 & 1,440 \\
\hline
\end{tabular}

a Peak stage did not reach bottom of gage.

b Discharge not determined. 
Location.--lat $42009 \cdot 28 "$. long $95^{\circ} 488^{\circ} 27^{\prime \prime}$, in SE1/4 SE1/4 sec.23, T. 85 N.. R.43 M.. Monona County, on right bank on dewnstream side of bridge on state Highway 175, 80 ft downstream from Chicago \& Northwestern Railway Company bridge, 0.5 miles southwest of Mapleton, 0.8 mile downstrean from Wilsey Creek, 2. 0 miles upstream from Mcclarey Creek, and 16 miles upstream from mouth.

Drainage area.--669 sq mi.

Gage.--Nater-stage recorder. Datum of gage is $1,085.86$ ft above mean sea level. Nonrecording prior to Aug. 20, 1952, and from June 21, 1954, to sept. 20, 1956: recording remainder of time. June 21, 1954, to sept. 6, 1955 at site 1.4 miles upstream at datum $4.05 \mathrm{ft}$ higher.

Stage-discharge relation.--Defined by current-meter measurements. Flood stage. $-18 \mathrm{ft}$.

Remarks.--only annual peaks are shown for 1942-50. Base for partial-duration series, 4,000 cfs.

Peak_stages_and discharges

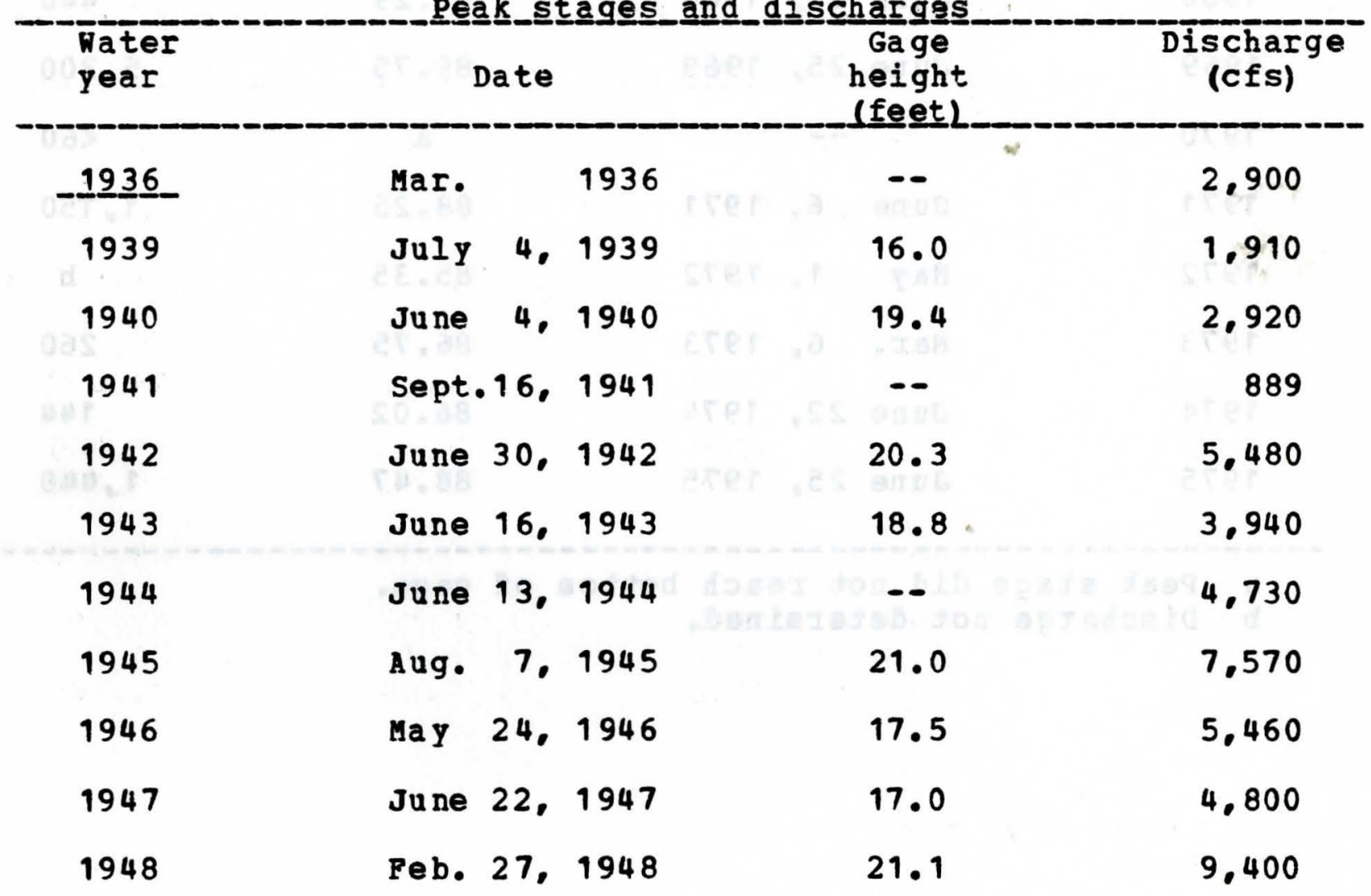


06-6072.00 Maple River at Mafleton. Iowa--(Continued)

Peak stages and discharges

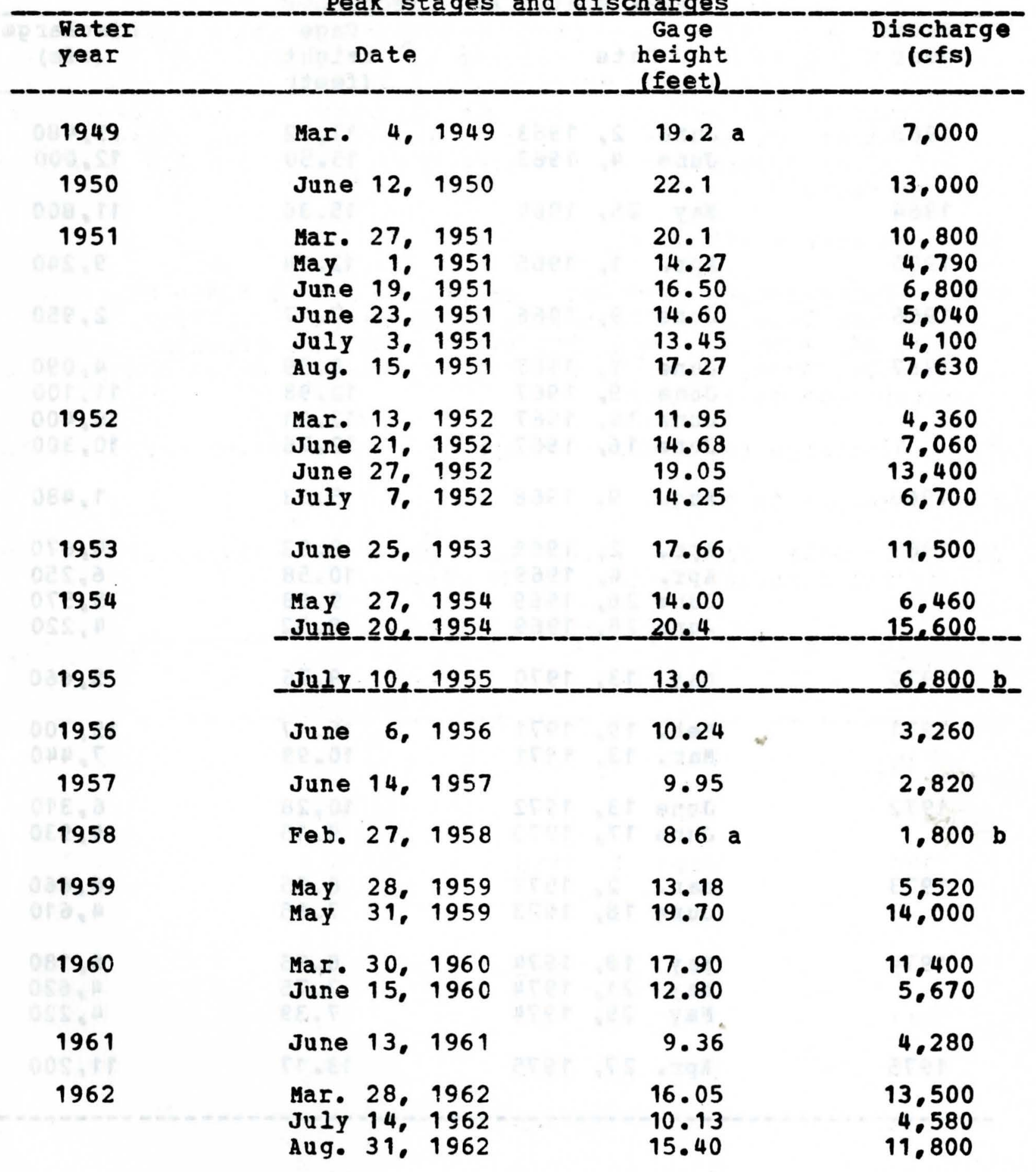

a Affected by ice.

b about. 
06-6072.00 Maple River at Mapleton. Iowa--(Continued)

Peak_stages_and_discharges

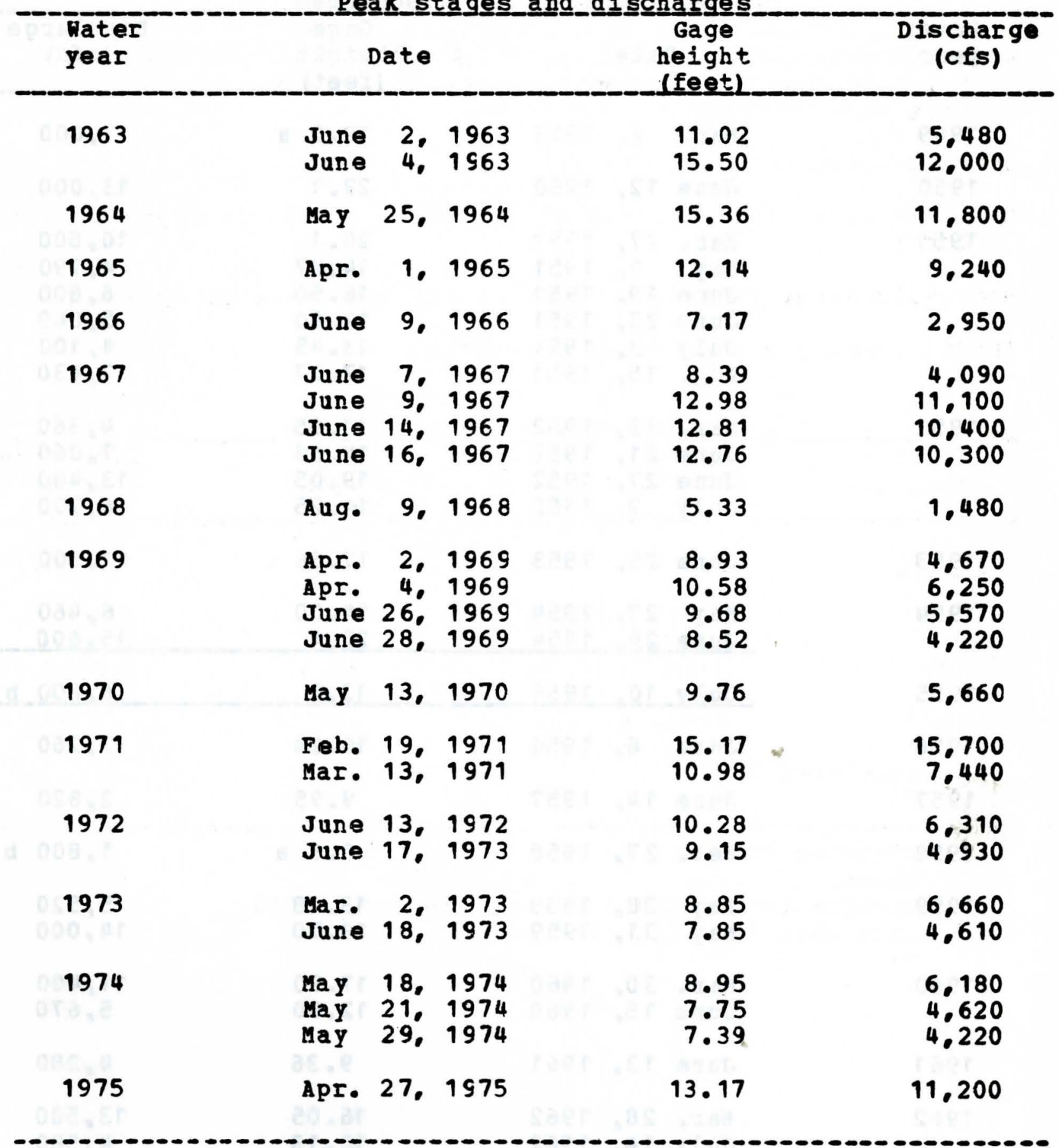




$$
\begin{gathered}
\text { 06-6073.00 Maple River at Turin. Iowa } \\
\text { (Discontinued 1941) }
\end{gathered}
$$

Location.--Iat $42001 \%$, long $95057 \%$, in SW1/4 NE1/4 sec.10, T.83 N.. R.44 W.. Monona County, at bridge on State Highway 37, 0.7 mile east of Turin.

Drainage area. $--734 \mathrm{sq}$ mi.

Gage.--Nonrecording. Datum of gage is $1.028 .45 \mathrm{ft}$ above mean sea level.

Stage-discharge relation.--Defined by current-meter measurements. Remarks.--only annual peaks are shown.

Peak_stages and discharges

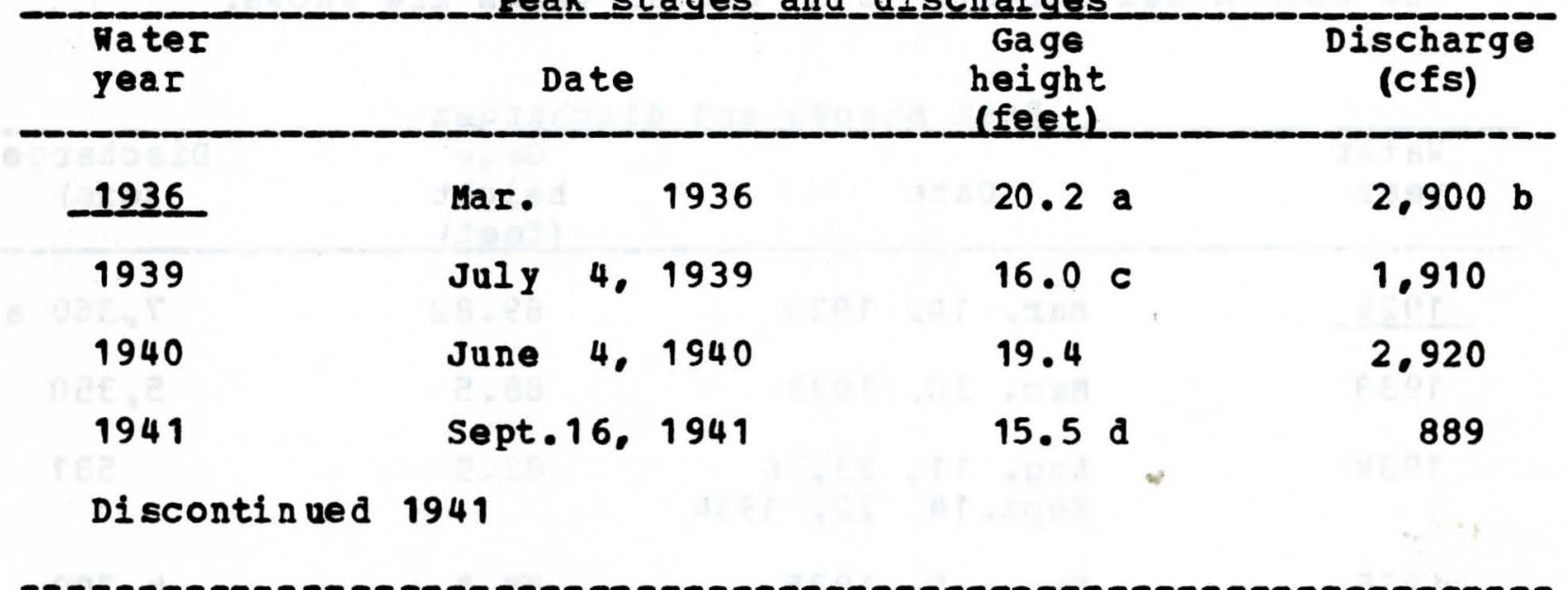

a Affected by ice.

b About.

c Maximum for period April to september 1939.

d Backwater from Little Sioux River. 


\section{5-4175.00 Maquoketa River near Delhi. Iowa (Discontinued september 1940)}

Location.--Lat $42024 \cdot 30^{\prime \prime}$, long $91020 \cdot 45^{\prime \prime}$, in SH1/4 NW 1/4 sec.29, T.88 N.. R. 4 W.. Delaware County. in tailrace of Interstate Power Company's hydroelectric plant. 1.5 miles south of Delhi. and 6 miles upstream from Plum Creek.

Drainage area. $--347 \mathrm{sq} \mathrm{mi}$

Gage.--Recording. Datum of gage is 774.32 ft above mean sea level. adjustment of 1912 .

Stage-discharge relation.--Defined by current-metar measurements. Remarks.--Flow regulated by reservoir just above station. Records furnished by Interstate power Company and reviewed by the Geological survey. Only annual peaks are shown.

Peak stages and discharges

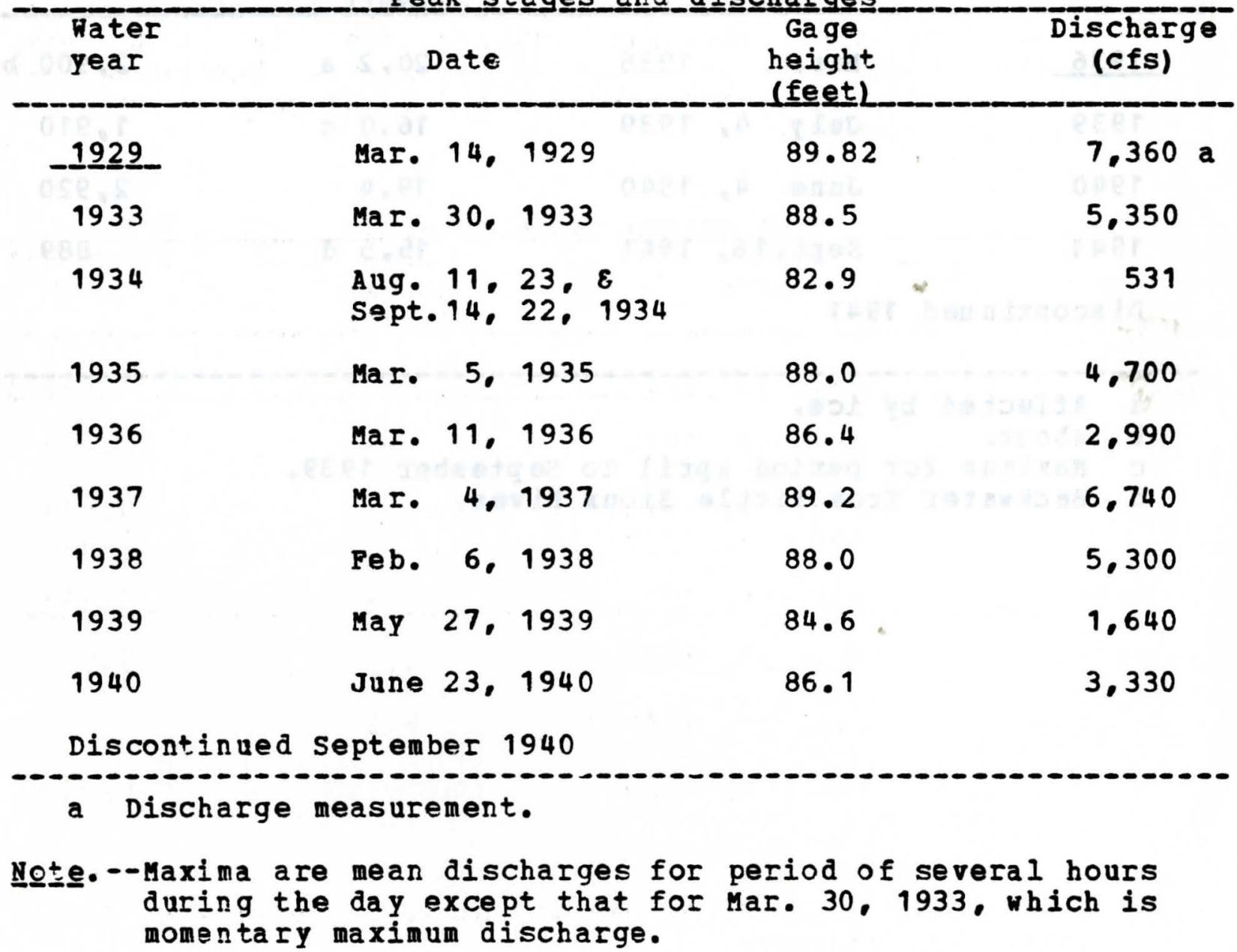




\section{5-4170.00 Maquoketa River near Manchester, Iowa (Discontinued september 1973)}

Location.--Lat $42027 \cdot 22^{\prime \prime}$, long $91025 \cdot 56 \%$, in NN1/4 NE1/4 sec.9, T.88 N.. R.5 H.. Delaware County. on left bank 0.6 miles downstream from Sand Creek, 1.5 miles upstream frcm spring Branch, 2.3 miles southeast from dam on Maquoketa River in Manchester, and at mile 100.5.

Drainage area.--305 sq mi.

Gage.-- Hater-stage rocorder. concrete control since June 1. 1935. Datum of gage is 895.06 ft above mean sea level. adjustment of 1912 .

Stage-discharge relation.--Defined by current-meter measurements below 10,000 cfs and extended above by velocity-area studies.

Bankfull stage.--Banks not subject to overflow.

Remarks.--Base for partial-duration series. 2.200 cfs. Data for 1928-30 from Iowa Electric Company dam in Manchester. discharge estimatod by Corps of Engineers. Equivalent gage heights on present gage computed for 1933-35 peaks. Base was 2,600 prior to 1966 .

Pẹak﹎_stages_and__di

\begin{tabular}{|c|c|c|c|c|}
\hline $\begin{array}{l}\text { Water } \\
\text { year }\end{array}$ & Date & 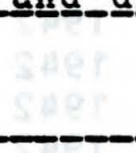 & $\begin{array}{c}\text { Gage } \\
\text { height } \\
\text { dfeetl }\end{array}$ & $\begin{array}{c}\text { Discharge } \\
\text { (cfs) }\end{array}$ \\
\hline$-192 \underline{5}$ & _Juuㅡㅇ__15,_1925 & - & $=-$ & $2 \underline{5}, 400$ a \\
\hline 1928 & Nov. 18,1927 & & -- & 2.640 \\
\hline 1929 & $\begin{array}{lrr}\text { Mar. } & 13,1929 \\
\text { Apr. } & 7, & 1929\end{array}$ & & 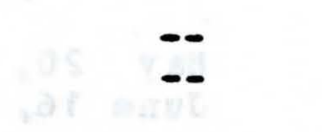 & $\begin{array}{l}5.600 \\
3.320\end{array}$ \\
\hline-1930 & -Féb._19,_1930 & & $=$ & 3.180 \\
\hline 1933 & $\operatorname{May} 20,1933$ & & 9.2 & 2.850 \\
\hline 1934 & Jan. 22, 1934 & & 6.2 & 695 \\
\hline 1935 & Mar. 5. 1935 & & 10.45 & 4.880 \\
\hline
\end{tabular}

a Computed by prof. F. A. Nagler, State University of Iowa. Maximum flood known. 
05-4170.00 Maquoketa River near Manchester, Iowa--(Continued)

Peak stages and di scharga로

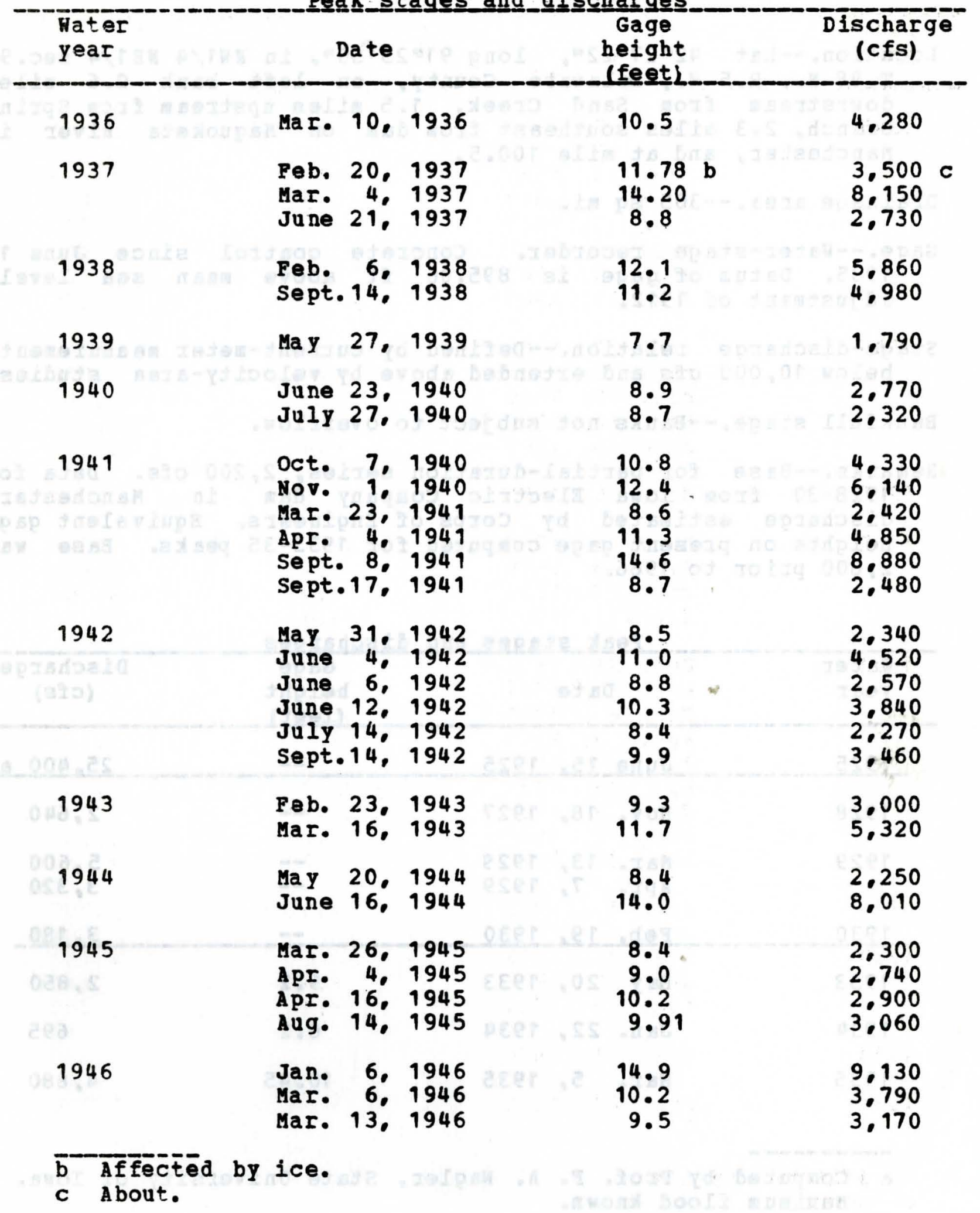


05-4170.00 Maquoketa River near Manchester, Iowa-- (Continued)

Peak__stages_and di

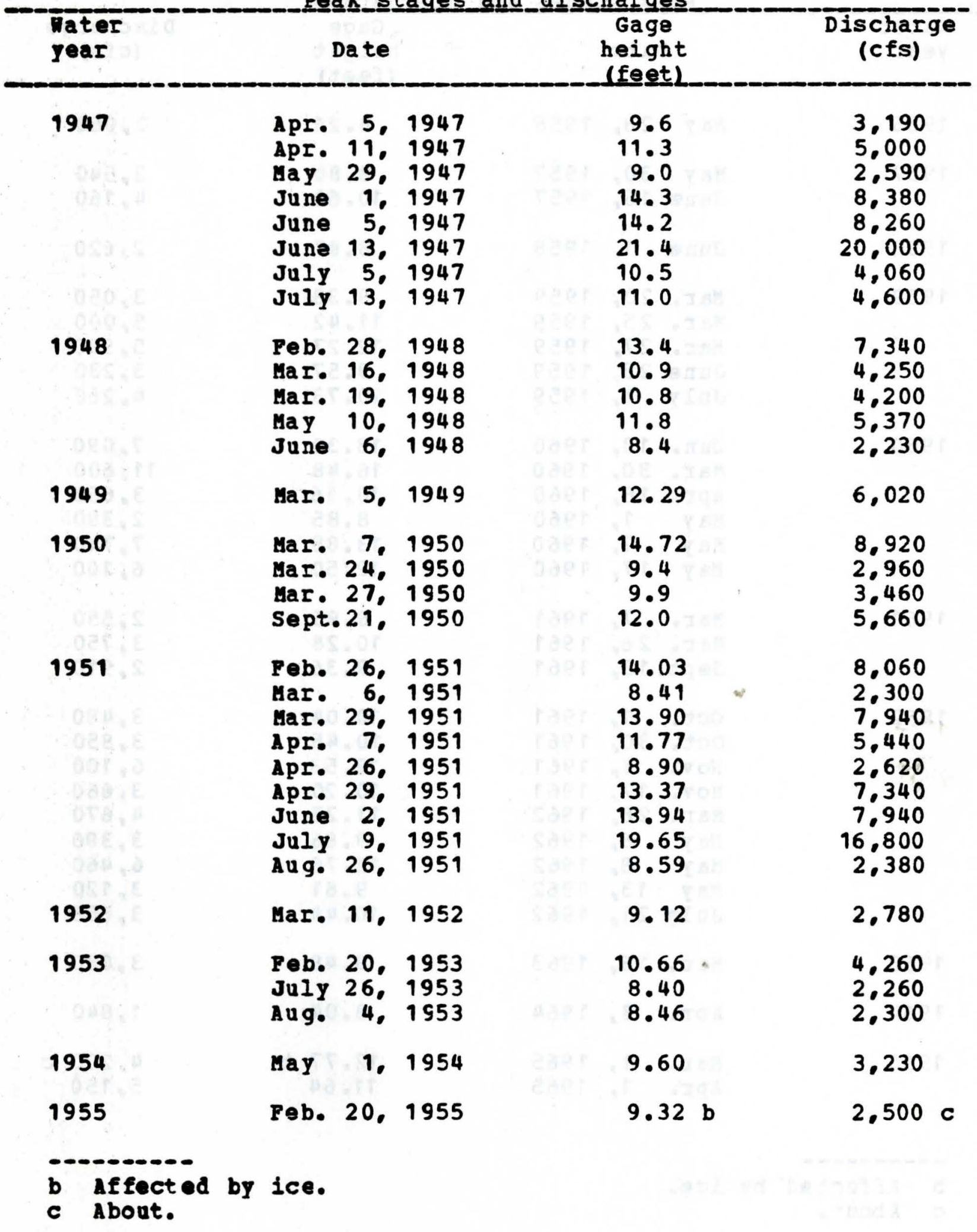


05-4170.00 Maquoketa River near Manchester, Iowa-- (Continued)

pea $\underline{k}$ stage

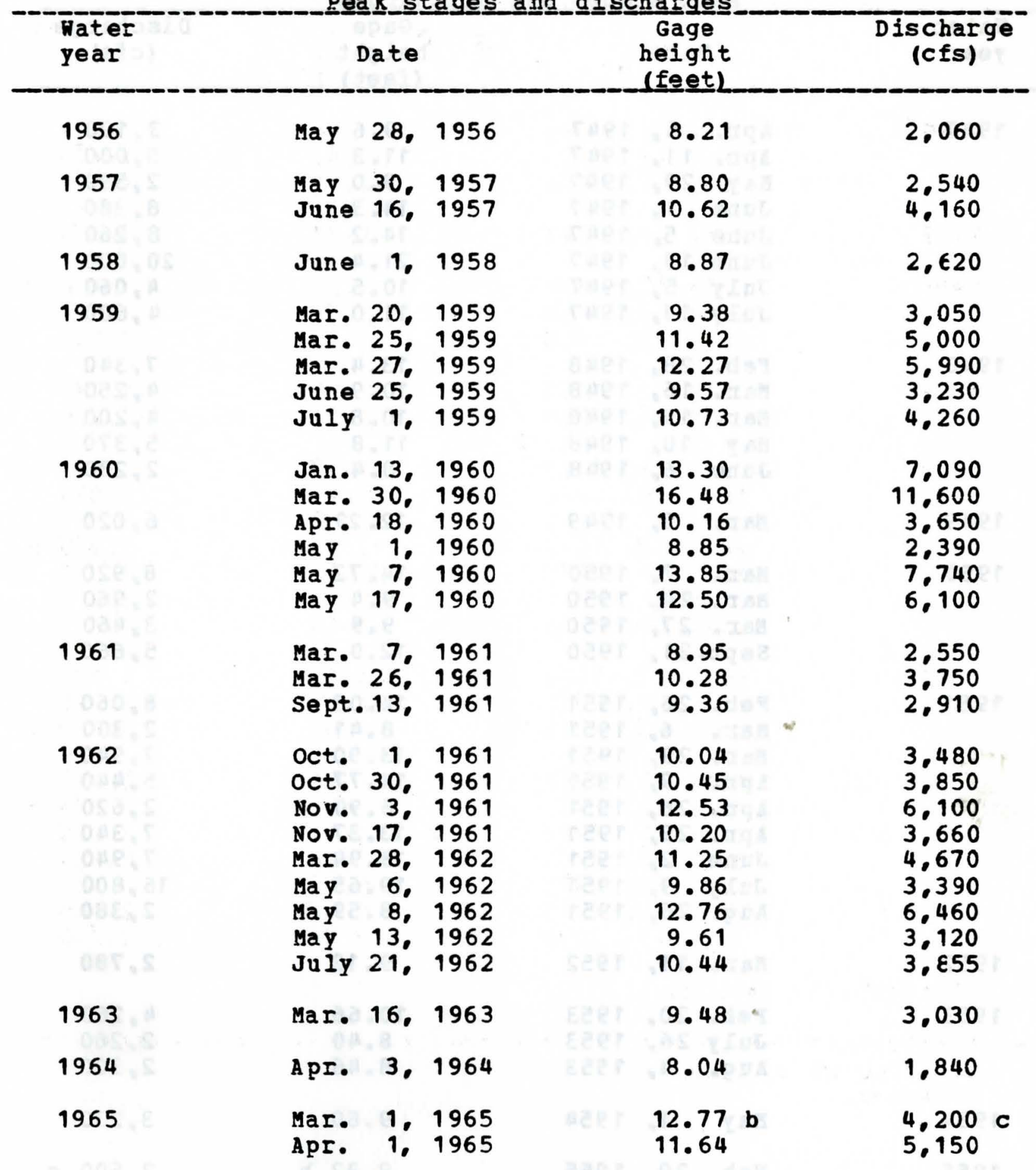

b Affected by ice.

c About. 
05-4170.00 Maquoketa River near Manchester. Iowa-- (Continued)

Feak_stages and discharges

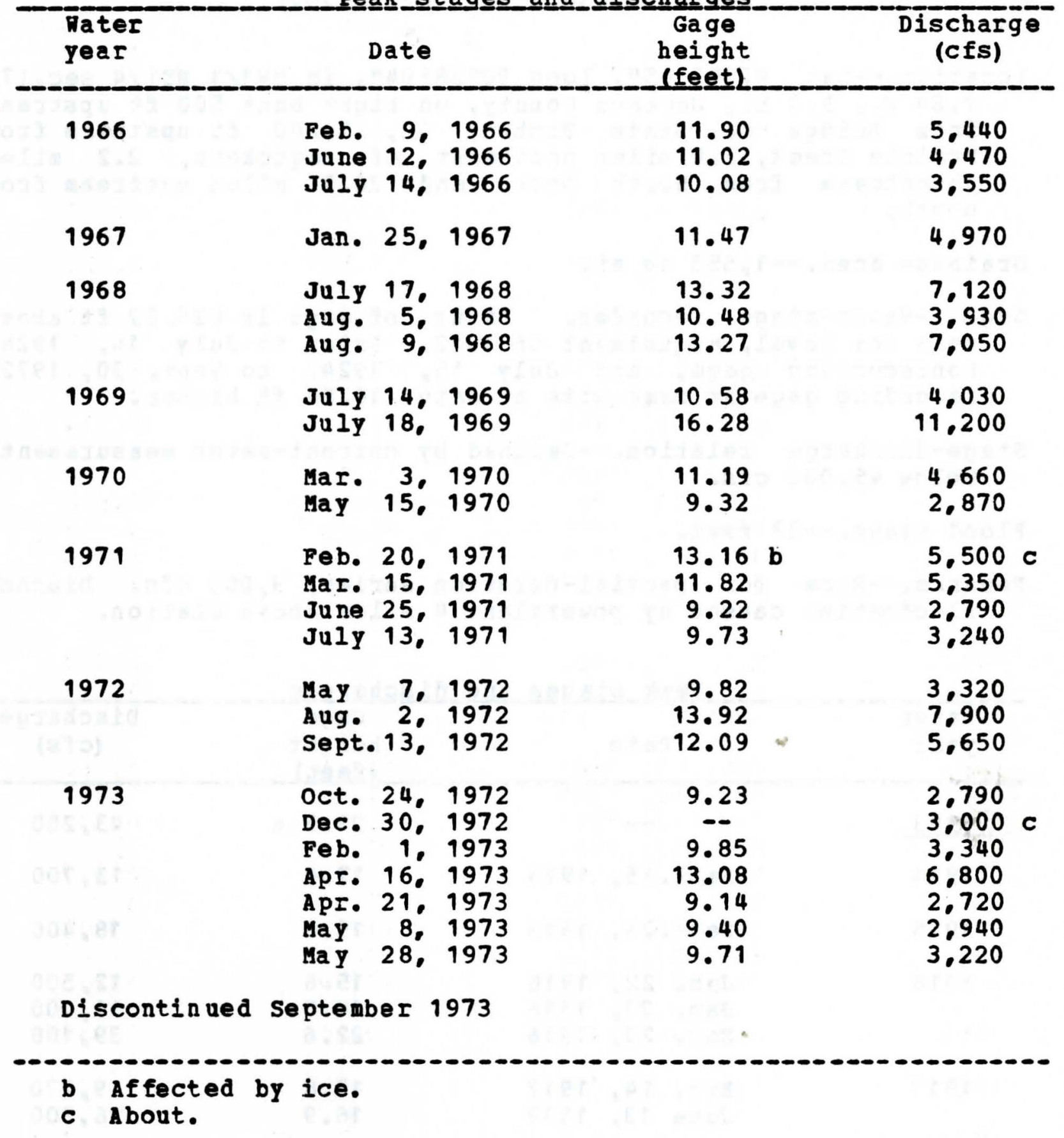


05-4185.00 Maquoketa River near Maquoketa, Iowa (Published as "below North Fork Maquoketa River near Maquoketa" prior to 1940)

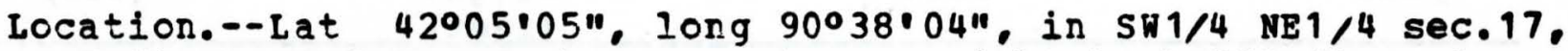
T.84 N.. R.3 E.. Jackson County, on right bank 500 ft upstream from bridge on state Highway 62.1 .200 ft upstream from Prairie creek, 2.0 miles northeast of Maquoketa, 2.2 miles downstream from North Fork, and 26.7 miles upstream from mouth.

Drainage area.--1,553 sq mi.

Gage.--Water-stage recorder. Datum of gage is $626.52 \mathrm{ft}$ above mean sea level, adjustment of 1912. Prior to July 14, 1924, nonrecording gage, and July 15, 1924, to sept. 30, 1972, recording gage at same site at datum 10.00 ft higher.

Stage-discharge relation.--Defined by current-meter measurements below 45,000 cfs.

Flood stage.--23 feet.

Remarks.--Base for partial-duration series, 9,000 cfs. Diurnal fluctuation caused by powerplant 4 miles above station.

Peak__stages_and_di

\begin{tabular}{|c|c|c|c|}
\hline $\begin{array}{l}\text { Water } \\
\text { yəaI }\end{array}$ & Date & $\begin{array}{l}\text { Gage } \\
\text { height } \\
\text { (feet) }\end{array}$ & $\begin{array}{l}\text { Discharge } \\
\text { (cfs) }\end{array}$ \\
\hline$-19 \underline{0} \underline{3}$ & -- & $23.5 \mathrm{a}$ & 43,200 \\
\hline 1914 & Se pt.15, 1914 & 17.0 & 13,700 \\
\hline 1915 & Sept.28, 1915 & 19.6 & 18,400 \\
\hline 1916 & $\begin{array}{l}\text { Jan. 22, } 1916 \\
\text { Jan. 27, } 1916 \\
\text { Mar. 27, } 1916\end{array}$ & $\begin{array}{l}15.6 \\
14.9 \\
22.6\end{array}$ & $\begin{array}{l}12,500 \\
11,000 \\
39,100\end{array}$ \\
\hline 1917 & $\begin{array}{l}\text { Mar. } 14,1917 \\
\text { June } 13,1917\end{array}$ & $\begin{array}{l}13.8 \\
16.9\end{array}$ & $\begin{array}{r}9,270 \\
16,300\end{array}$ \\
\hline 1918 & Fab. 15,1918 & 15.8 & 13.000 \\
\hline
\end{tabular}

a At dam in use prior to oct. 1, 1972. 
05-4185.00 Maquoketa Ríver near Maquoketa, Iowa--(Continued)

Peak stages and discharges

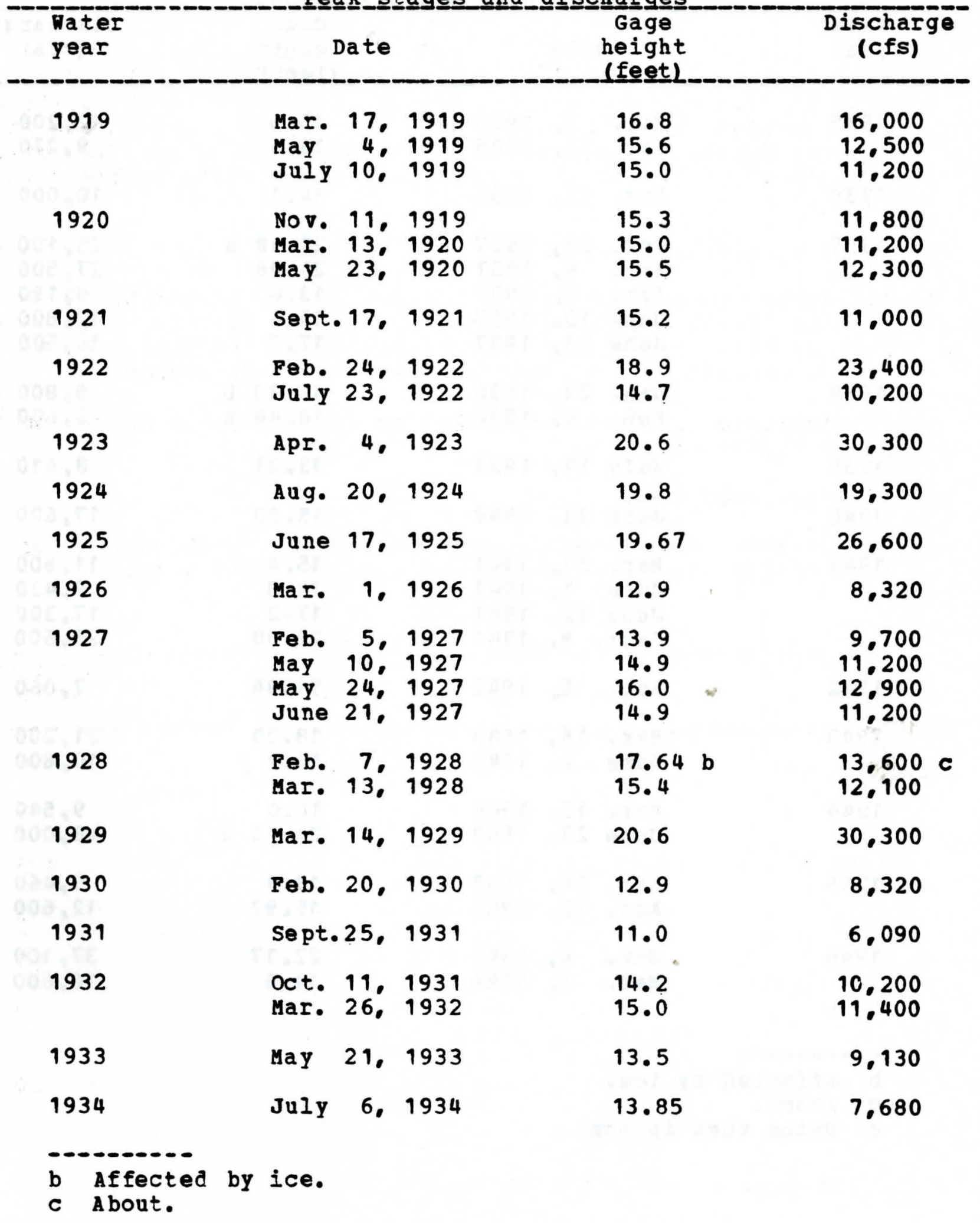


05-4185.00 Maquoketa River near Maquoketa, Iowa--(Continued)

Peak_stages_and dis

\begin{tabular}{|c|c|c|c|c|c|}
\hline $\begin{array}{l}\text { Water } \\
\text { year }\end{array}$ & Date & & $\begin{array}{l}\text { Gage } \\
\text { height } \\
\text { (feet) }\end{array}$ & & $\begin{array}{c}\text { Discharg } \\
\text { (cfs) }\end{array}$ \\
\hline 1935 & $\begin{array}{l}\text { MaI. } 5, \\
\text { MaI. } 11 .\end{array}$ & $\begin{array}{l}1935 \\
1935\end{array}$ & $\begin{array}{l}15.5 \\
13.6\end{array}$ & & $\begin{array}{r}12.200 \\
9.270\end{array}$ \\
\hline 1936 & Mar. 11. & 1936 & 14.1 & & 10.000 \\
\hline 1937 & $\begin{array}{l}\text { Feb. } 21 . \\
\text { Mar. } 6 . \\
\text { Apr. } 5 . \\
\text { June } 13 . \\
\text { June } 21 .\end{array}$ & $\begin{array}{l}1937 \\
1937 \\
1937 \\
1937 \\
1937\end{array}$ & $\begin{array}{l}22.18 \\
20.08 \\
13.6 \\
15.6 \\
17.7\end{array}$ & b & $\begin{array}{r}25.100 \\
27.500 \\
9.190 \\
12.800 \\
18.500\end{array}$ \\
\hline 1938 & $\begin{array}{l}\text { Jan. } 24 . \\
\text { Fab. } 6 .\end{array}$ & $\begin{array}{l}1938 \\
1938\end{array}$ & $\begin{array}{l}16.33 \\
18.48\end{array}$ & $\begin{array}{l}\mathbf{b} \\
\mathbf{b}\end{array}$ & $\begin{array}{r}9,800 \\
13,600\end{array}$ \\
\hline 1939 & July 17. & 1939 & 13.21 & & 8,610 \\
\hline 1940 & June 23. & 1940 & $18 \cdot 30$ & & 17.600 \\
\hline 1941 & $\begin{array}{l}\text { Mar. } 21, \\
\text { June 1, } \\
\text { June 12, } \\
\text { Sept. } 9 .\end{array}$ & $\begin{array}{l}1941 \\
1941 \\
1941 \\
1941\end{array}$ & $\begin{array}{l}15.4 \\
14.3 \\
17.2 \\
22.08\end{array}$ & & $\begin{array}{r}11.800 \\
9.430 \\
17.300 \\
25.600\end{array}$ \\
\hline 1942 & Aug. & 1942 & 11.94 & $\sim$ & 7.060 \\
\hline 1943 & $\begin{array}{l}\text { Mar. } 16, \\
\text { June } 2,\end{array}$ & $\begin{array}{l}1943 \\
1943\end{array}$ & $\begin{array}{l}18 \cdot 30 \\
15 \cdot 2\end{array}$ & & $\begin{array}{l}21.200 \\
10.800\end{array}$ \\
\hline 1944 & $\begin{array}{l}\text { Mar. } 15 . \\
\text { June } 27 .\end{array}$ & $\begin{array}{l}1944 \\
1944\end{array}$ & $\begin{array}{l}14.0 \\
24.70\end{array}$ & $\mathbf{a}$ & $\begin{array}{r}9.540 \\
48.000\end{array}$ \\
\hline 1945 & $\begin{array}{l}\text { Mar. } 26, \\
\text { Aug. } 15,\end{array}$ & $\begin{array}{l}1945 \\
1945\end{array}$ & $\begin{array}{l}13.9 \\
15.92\end{array}$ & & $\begin{array}{r}9.460 \\
12.600\end{array}$ \\
\hline 1946 & $\begin{array}{ll}\text { Jan. } & 6, \\
\operatorname{MaI} . & 6,\end{array}$ & $\begin{array}{l}1946 \\
1946\end{array}$ & $\begin{array}{l}22.17 \\
14.6\end{array}$ & & $\begin{array}{l}37.100 \\
10.600\end{array}$ \\
\hline
\end{tabular}

b Affected by ice.

c About.

d Datum then in use. 
05-4185.00 Maquoketa River near Maquoketa, Iowa--(Continued)

Peak stages and di scharges

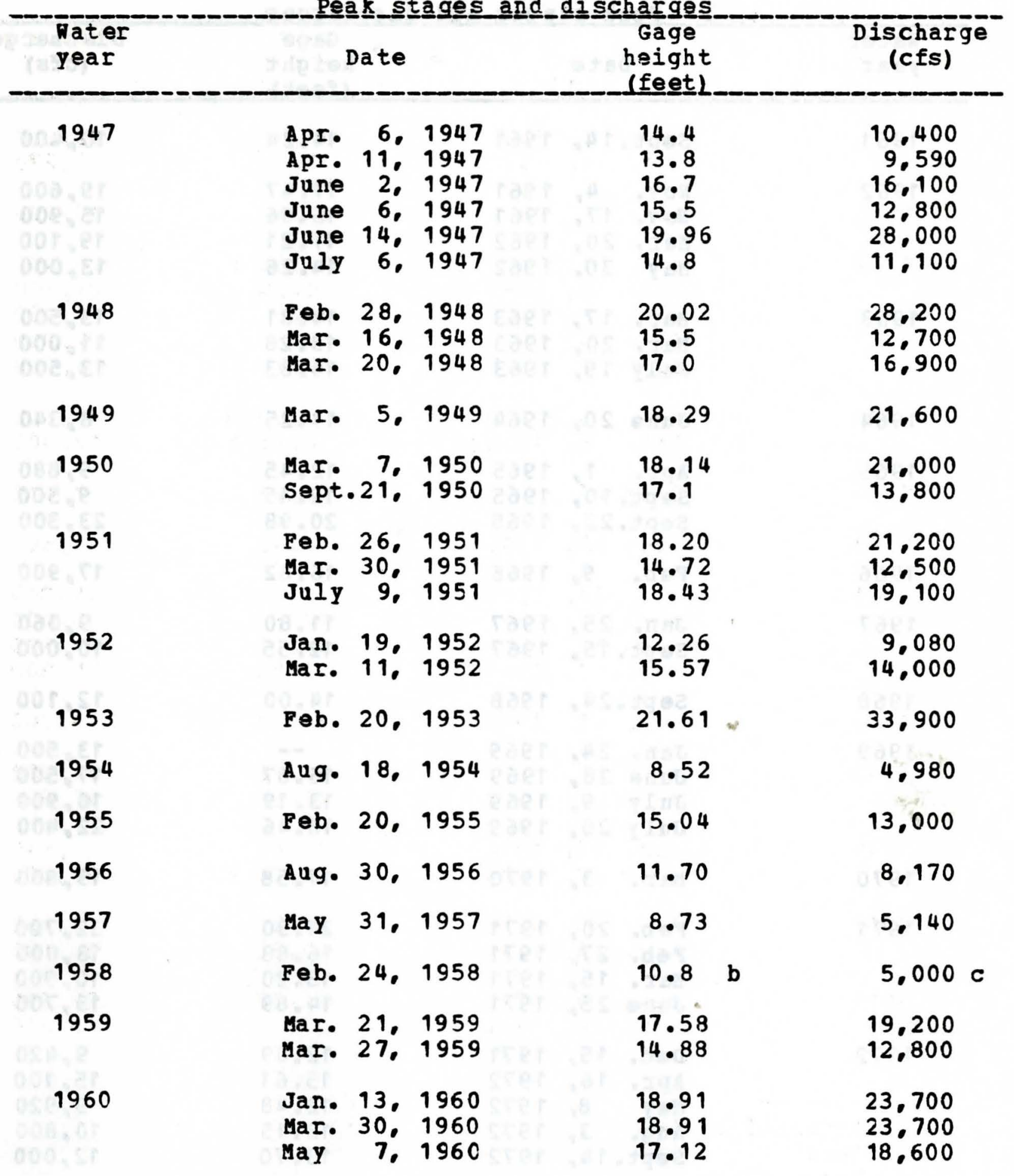

b Affected by ice.

c About. 
05-4185.00 Maquoketa River near Maquoketa, Iowa--(Continued)

Peak stages and di scharges

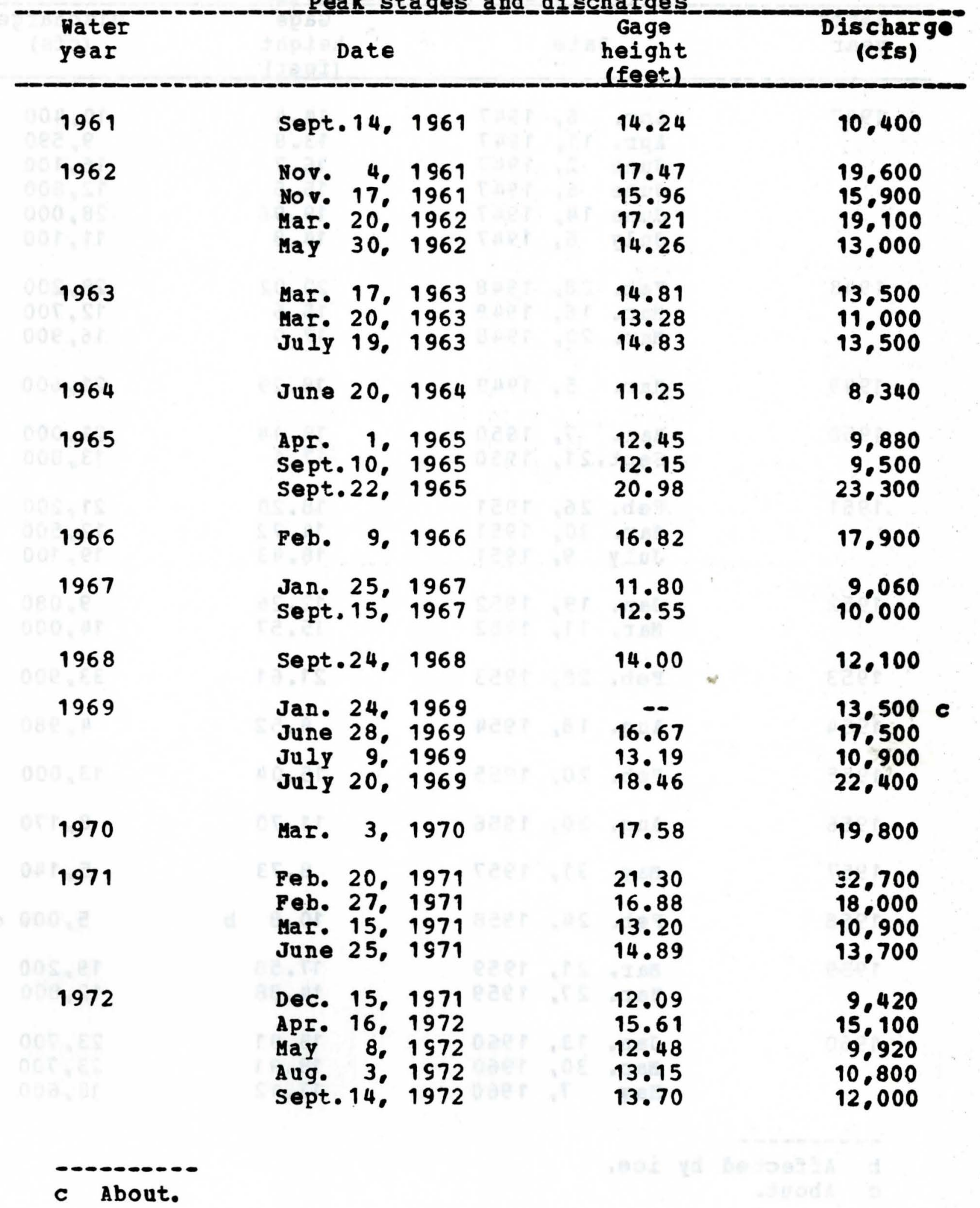


05-4185.00 Maquoketa River near Maquoketa, Iowa--(Continued)

Peak_stages and di scharges

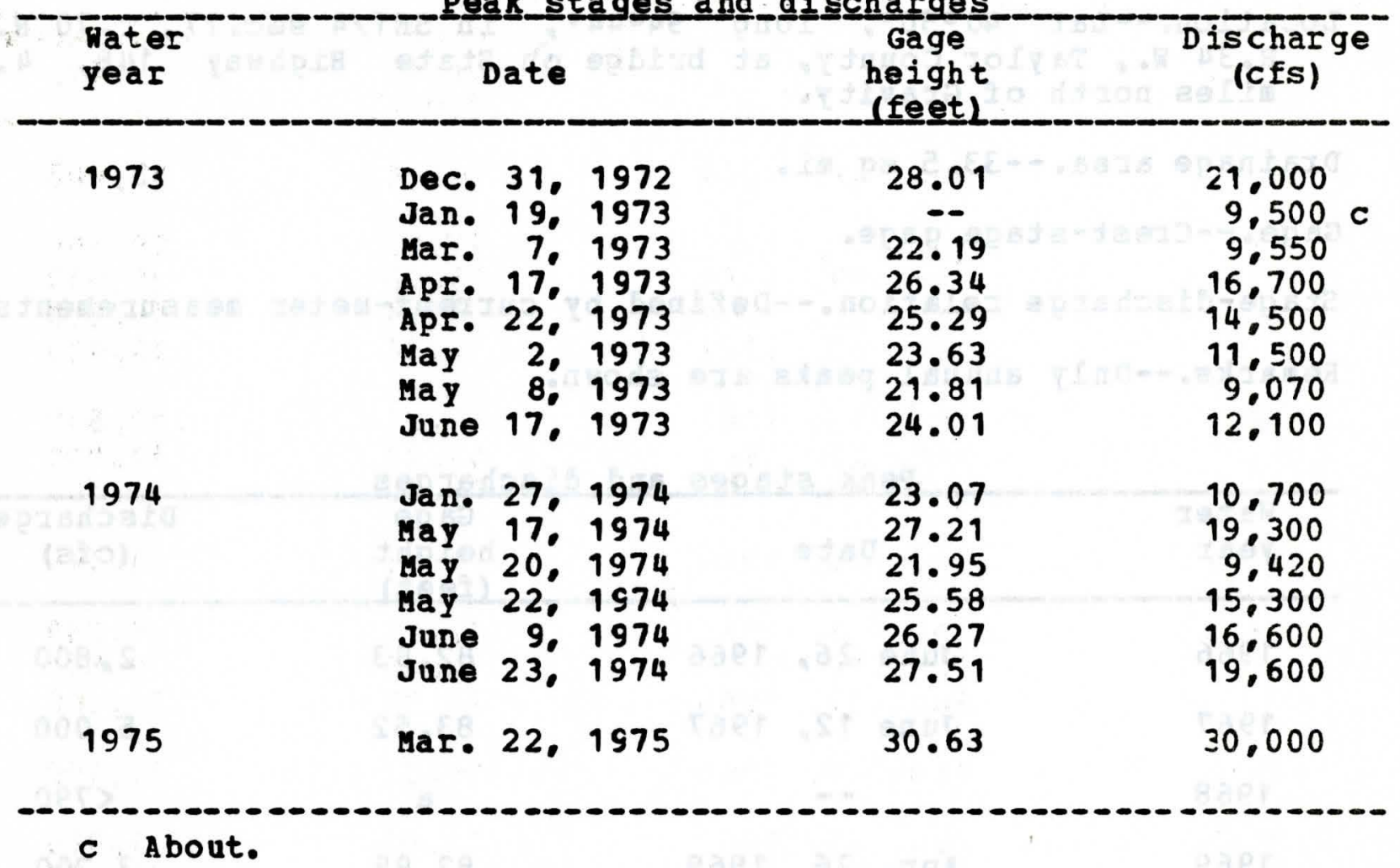


06-8191.10 Middle Branch One Hundred and Two River near Gravity. Iowa

Location.--Iat $40050 \%$ long $94044^{\circ}$, in SE1/4 sec.27, T.70 N.. R.34 W.. Taylor County, at bridge on State Highway 148, 4.8 miles north of Gravity.

Drainage area.--33.5 sq mi.

Gage.--Crest-stage gage.

Stage-discharge relation.--Defined by current-meter measurements. Remarks.--Only annual peaks are shown.

Peak_stages_and_dis charges

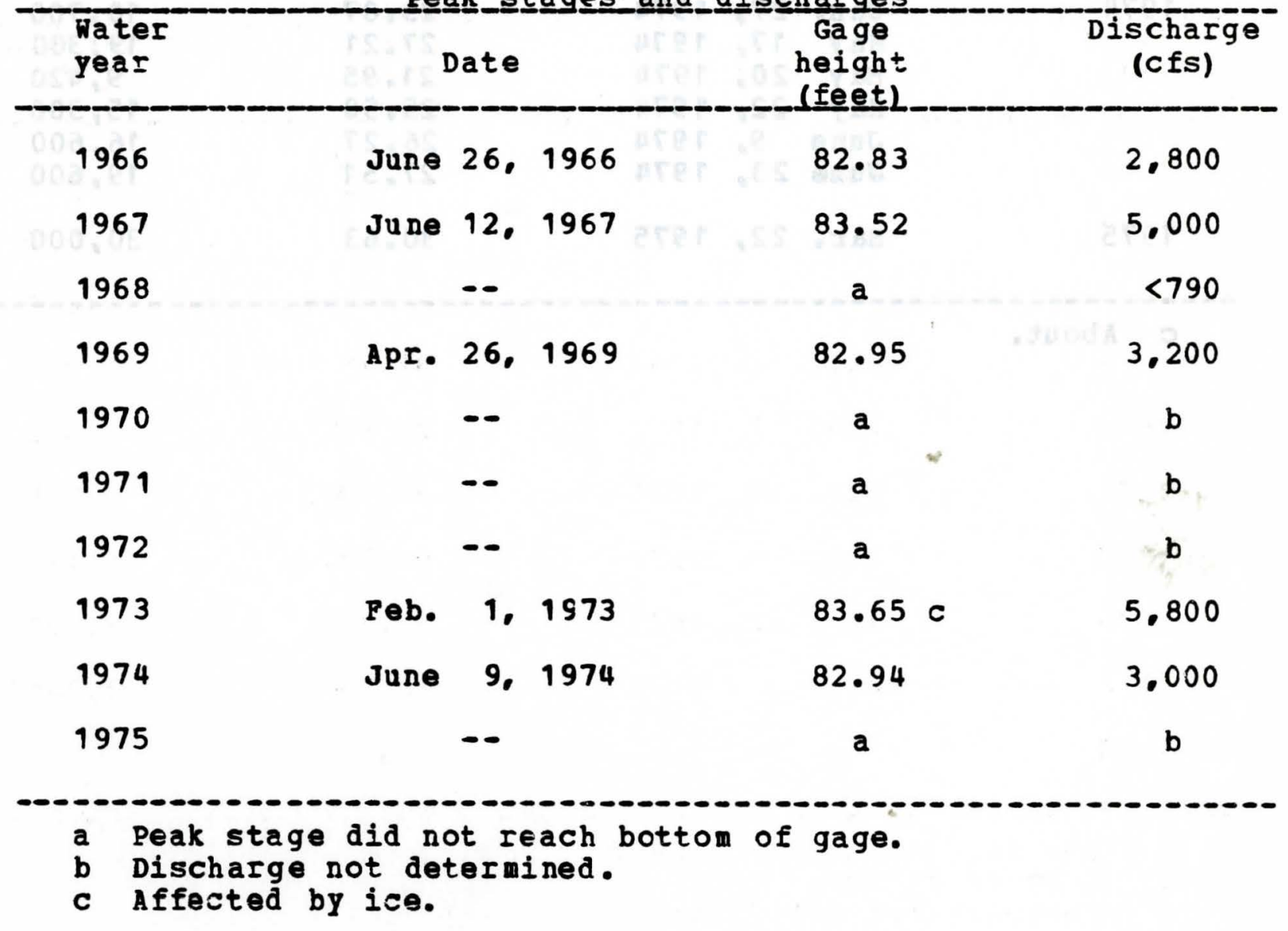




\section{5-4723.90 Middle Creek near Lacey, Iowa}

Location.--Iat 41025 , long $92039^{\circ}$, in NE1/4 seC.1. T. 76 N.. R. 16 W. Mahaska County, at bridge on 0.5 . highway 63, about 1.5 miles northwest of Lacey.

Drainage area. $--23.0 \mathrm{sq} \mathrm{mi}$.

Gage.--Crest-stage gage.

Stage-discharge relation.--Defined by current-meter measurements. Remarks.--only annual peaks are shown.

Peak

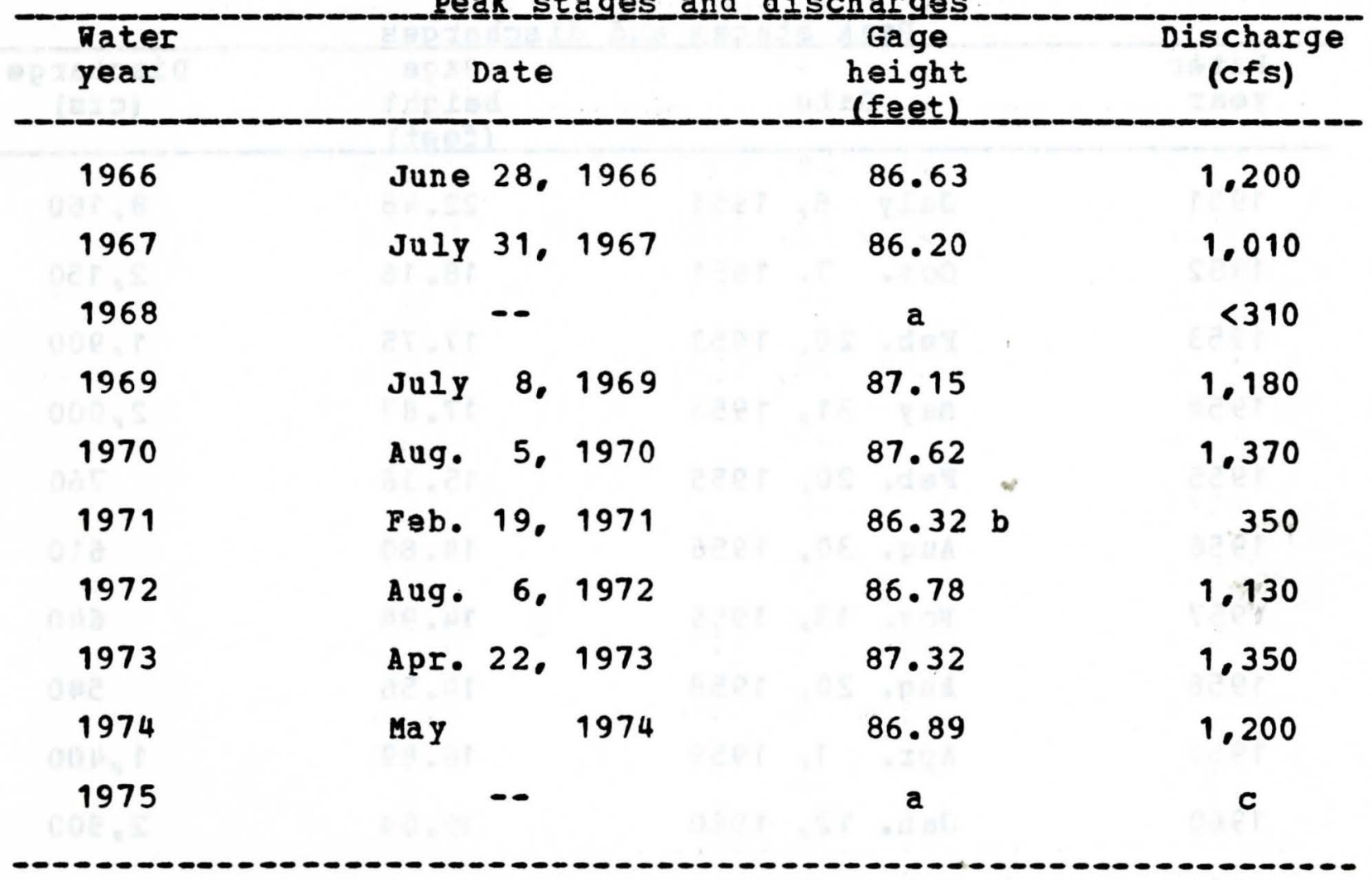

a Peak stage did not reach bottom of gage.

b Affected by ice.

c Discharge not determined. 
05-4144.00 Middle Pork Iittle Maquoketa River near Rickardsville, Iova

Location.--Iat $42033 \cdot 38^{\prime \prime}$, long $90051 \cdot 35 "$, in SE1/4 sec.32, T. 90 N.. R.1 E.. Dubuque County, at bridge, 2 miles southeast of Rickardsville.

Drainage area.-- $-30.2 \mathrm{sq} \mathrm{mi}$.

Gage.--Crest-stage gage.

Stage-discharge relation.--Defined by current-meter and indirect measurements.

Remarks.--only annual peaks are shown.

Pea $\underline{k}$ stages_and_discharges

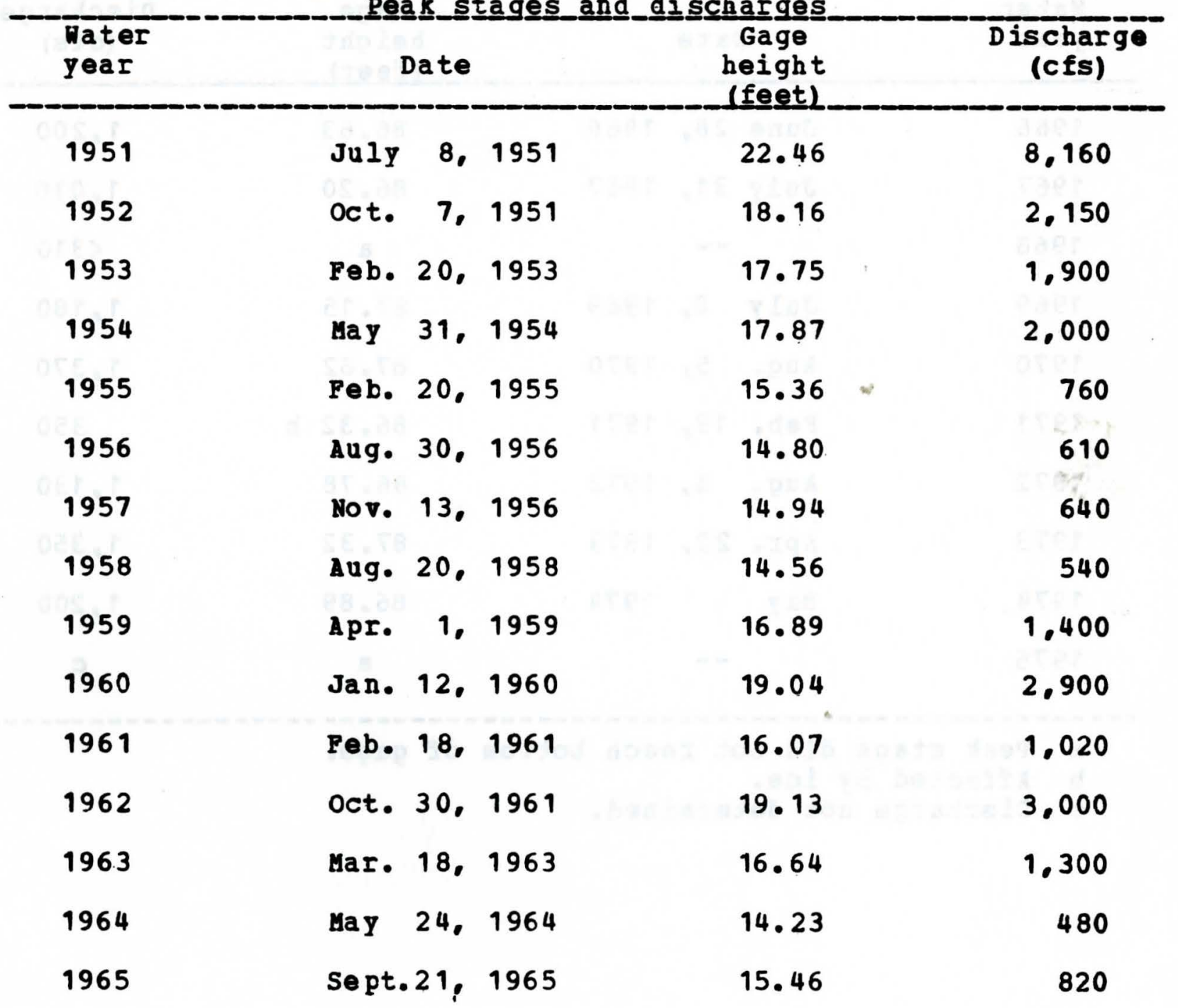


05-4144.00 Middle Fork Little Maquoketa River near Rickardsville, Iowa--(Continued)

Peak_stages_and_di scharges

\begin{tabular}{|c|c|c|c|c|}
\hline $\begin{array}{l}\text { Dater } \\
\text { year }\end{array}$ & Date & & $\begin{array}{l}\text { Gage } \\
\text { height } \\
\text { (feet) }\end{array}$ & $\begin{array}{c}\text { Discharge } \\
\text { (cfs) }\end{array}$ \\
\hline 1966 & Feb. & 1966 & 15.53 & 820 \\
\hline 1967 & sept. 14 & 1967 & 14.26 & 480 \\
\hline 1968 & Aug. 8 . & 1968 & $16 \cdot 30$ & 1.120 \\
\hline 1969 & JuIY 18 . & 1969 & 21.02 & 5.400 \\
\hline 1970 & Mar. 3. & 1970 & $15 \cdot 12$ & 690 \\
\hline 1971 & $\mathrm{Feb} .26$, & 1971 & 15.76 & 890 \\
\hline 1972 & Aug. 2 . & 1972 & 27.7 & - 23,000 \\
\hline 1973 & -- & & $\mathbf{a}$ & $\mathbf{b}$ \\
\hline 1974 & $-\infty$ & & c & -- \\
\hline 1975 & -- & & c & -- \\
\hline
\end{tabular}

a Peak stage did not reach bottom of gage.

b Discharge not determined.

c Gage removed during bridge construction. 
Location.--Lat $41041 \cdot 14 \%$, long $94022 \cdot 15^{\prime \prime}$, in NE1/4 NW1/4 sec.5, T.79 N.. R.30 H. Guthrie County, on left bank 15 ft downstream from bridge on county highway, 0.2 miles southwest of Panora, 1.5 miles upstream from Andy's Branch, and 1.7 miles downstream from Lake Panorama.

Drainage area. $--440 \mathrm{sq} \mathrm{mi.}$

Gage.-- Water-stage recorder and concrete control. Datun of gage is 991.20 ft above mean sea level.

Stage-discharge relation.--Defined by current-meter measurements below 4,500 cfs and above by logarithmic plotting.

Remarks.--Base for partial-duration series, 2,500 cfs. City of Panora diverts approximately 100 acre-ft/yI above station. Flow regulated by dam on Lake Panorama since August 1970.

Peak__stagges_and_di $\underline{\text { scharges }}$

\begin{tabular}{|c|c|c|c|}
\hline $\begin{array}{l}\text { Mater } \\
\text { year }\end{array}$ & Date & $\begin{array}{l}\text { Gage } \\
\text { height } \\
\text { ffeetl_ }\end{array}$ & $\begin{array}{l}\text { Discharge } \\
\text { (cfs) }\end{array}$ \\
\hline 1953 & June 10,1953 & $14.3 \mathrm{a}$ & $14,000 \mathrm{~b}$ \\
\hline 1958 & $\begin{array}{lrl}\text { July } & 2, & 1958 \\
\text { July } & 3, & 1958 \\
\text { July } & 19, & 1958\end{array}$ & $\begin{array}{r}11.87 \\
8.95 \\
8.07\end{array}$ & $\begin{array}{l}9.150 \quad b \\
4,200 \\
3,020\end{array}$ \\
\hline 1959 & June 1,1959 & 7.50 & 2.480 \\
\hline 1960 & $\begin{array}{lr}\text { Mar. 31, } 1960 \\
\text { May } 1960\end{array}$ & $\begin{array}{l}9.68 \\
8.33\end{array}$ & $\begin{array}{l}5,320 \\
3,740\end{array}$ \\
\hline 1961 & June 16, 1961 & 7.82 & 2.730 \\
\hline 1962 & $\begin{array}{l}\text { Mar. 26, } 1962 \\
\text { June } 10,1962\end{array}$ & $\begin{array}{l}9.29 \\
8.85\end{array}$ & $\begin{array}{l}4.620 \\
3.940\end{array}$ \\
\hline 1963 & Aug. 7. 1963 & 9.05 & 4.200 \\
\hline 1964 & June 22,1964 & 10.47 & 6,300 \\
\hline
\end{tabular}

a From floodmark.

b A bout. 
05-4836.00 Middle Raccoon River at Panora, Iowa-- (Cont inued)

Peak stages and discharges

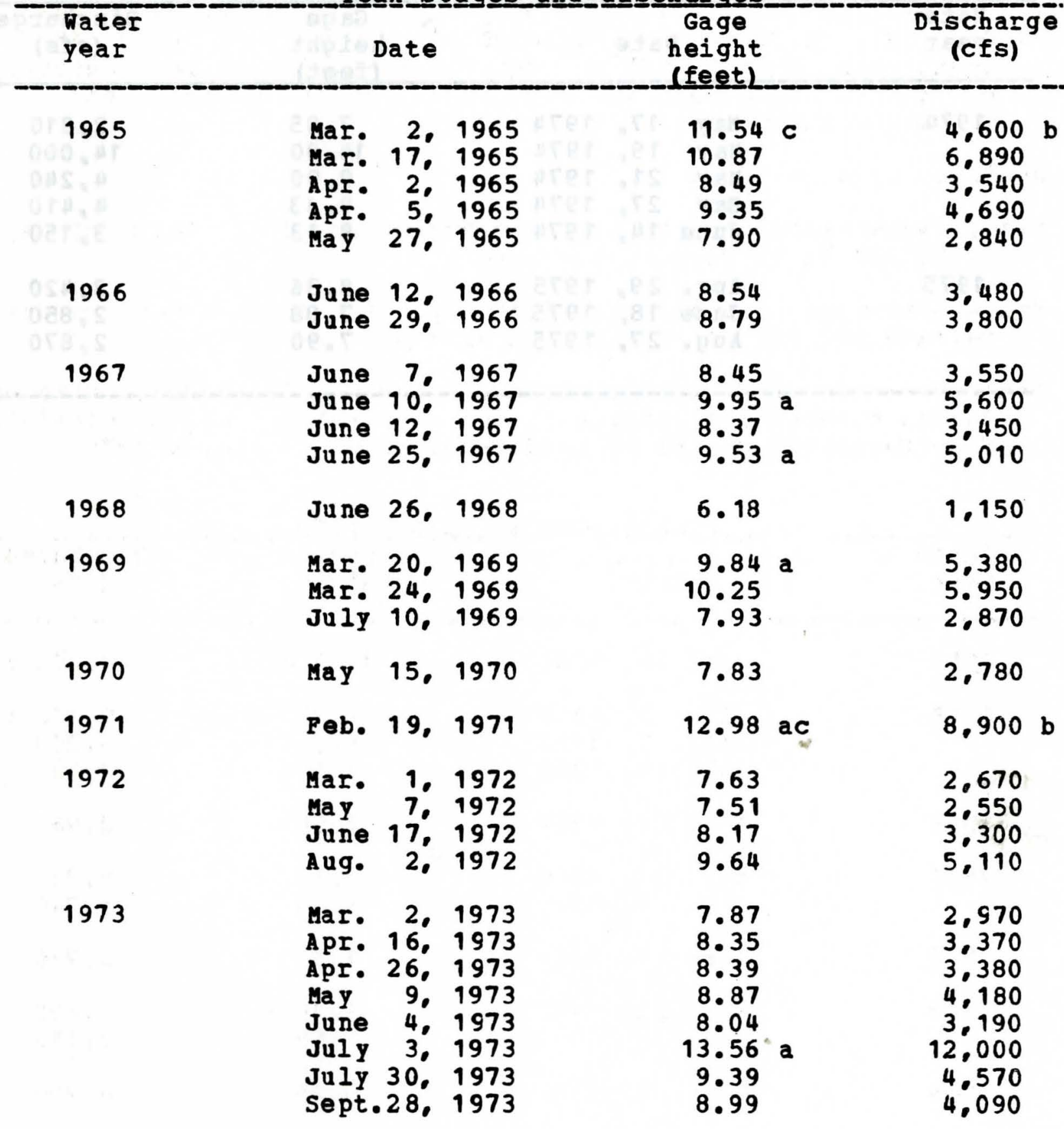

\footnotetext{
a From floodmark.

b About.

c affected by ice.
} 
05-4836.00 Middle Raccoon River at Panora, Iowa--(Continued)

Feak _. sta ges_and_discharges.

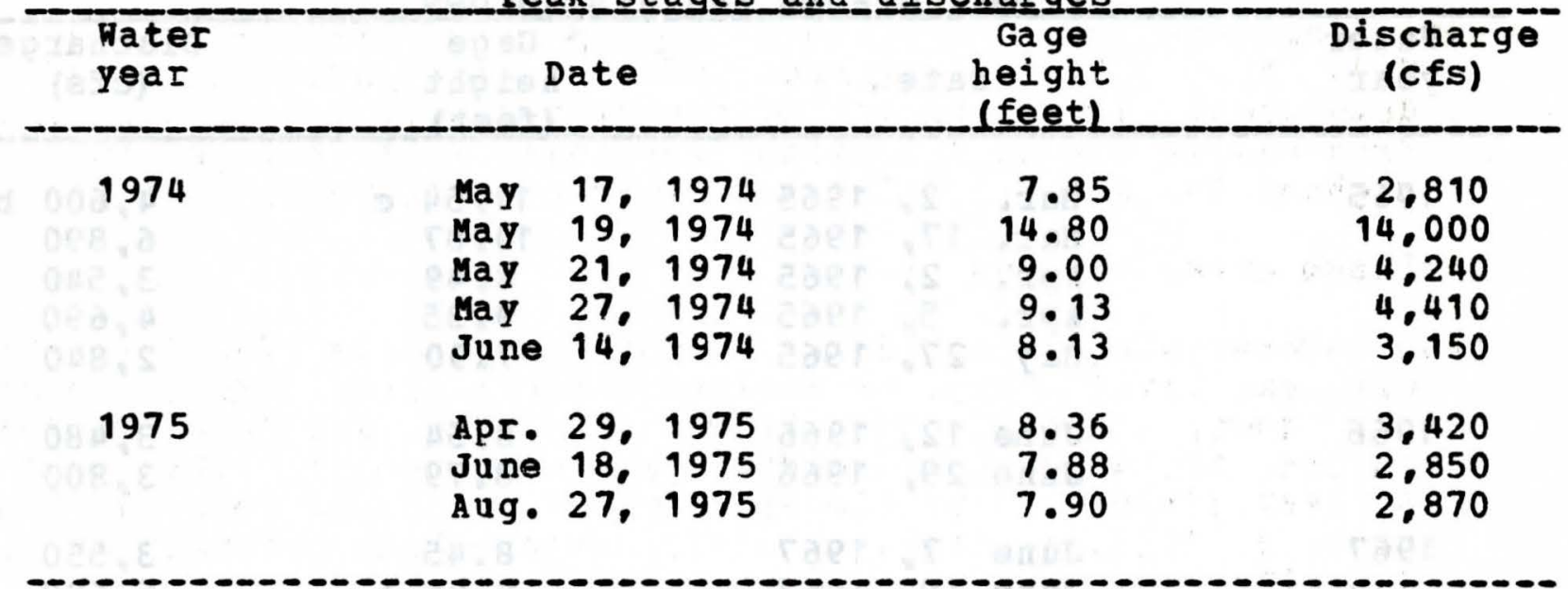


Iocation.--Iat $41025 \cdot 27 "$, Iong $93035^{\circ} 09^{\prime \prime}$. in SH1/4 SE1/4 sec.35. T.77 N.. R.24 H... Warren County, on right bank $10 \mathrm{ft}$ downstream from bridge on county highway. 0.4 mile upstrean from Cavitt Creek, 1.5 miles upstream from bridge on $0 . S$. Highway 69. and 4.6 miles northwest of Indianola.

Drainage area.--503 sq mi.

Gage.-- Water-stage recorder. Datum of gage is 776.15 ft above mean sea level (Corps of Engineers bench mark). Prior to June 11. 1946, June 9, 1947, to Nov. 23, 1948, and Sept. 8, 1951. to oct. 30, 1952, nonrecording gage and June 11, 1946, to June 8. 1947 (destroyed by flood). Nov. 24, 1948, to Sept. 7, 1951. sept. 1. 1952, to sept. 30, 1962, water-stage recorder at site 1.6 miles downstream at datum $2.81 \mathrm{ft}$ lower.

stage-discharge relation.--Defined by current-meter measurements. Flood stage.--19 feet.

Remarks.--Base for partial-duration series, 4.500 cfs.

Peak stages and discharges

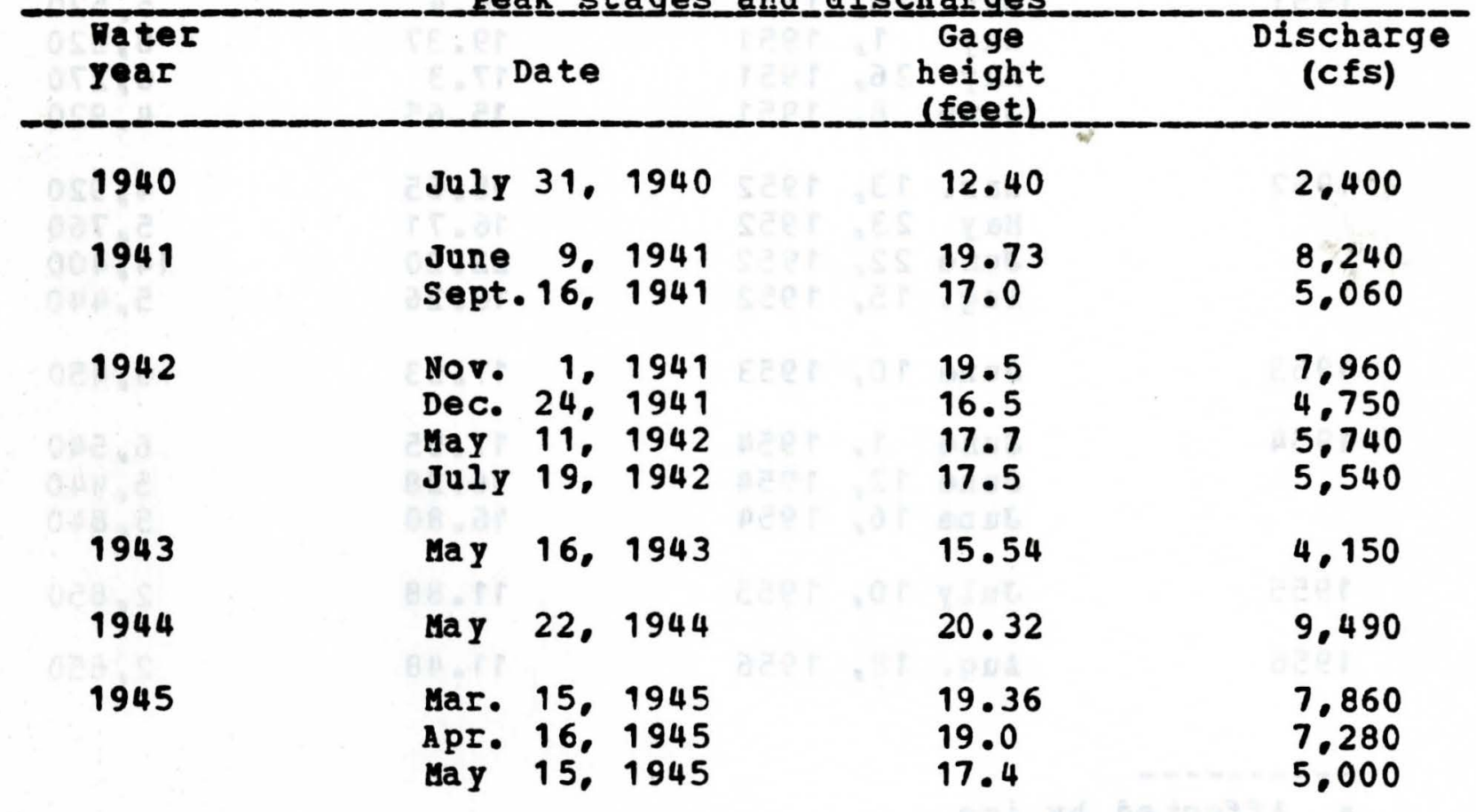


05-4864.90 Middle River near Indianola. Iowa--(Continued)

Peak stages and dis ischarges

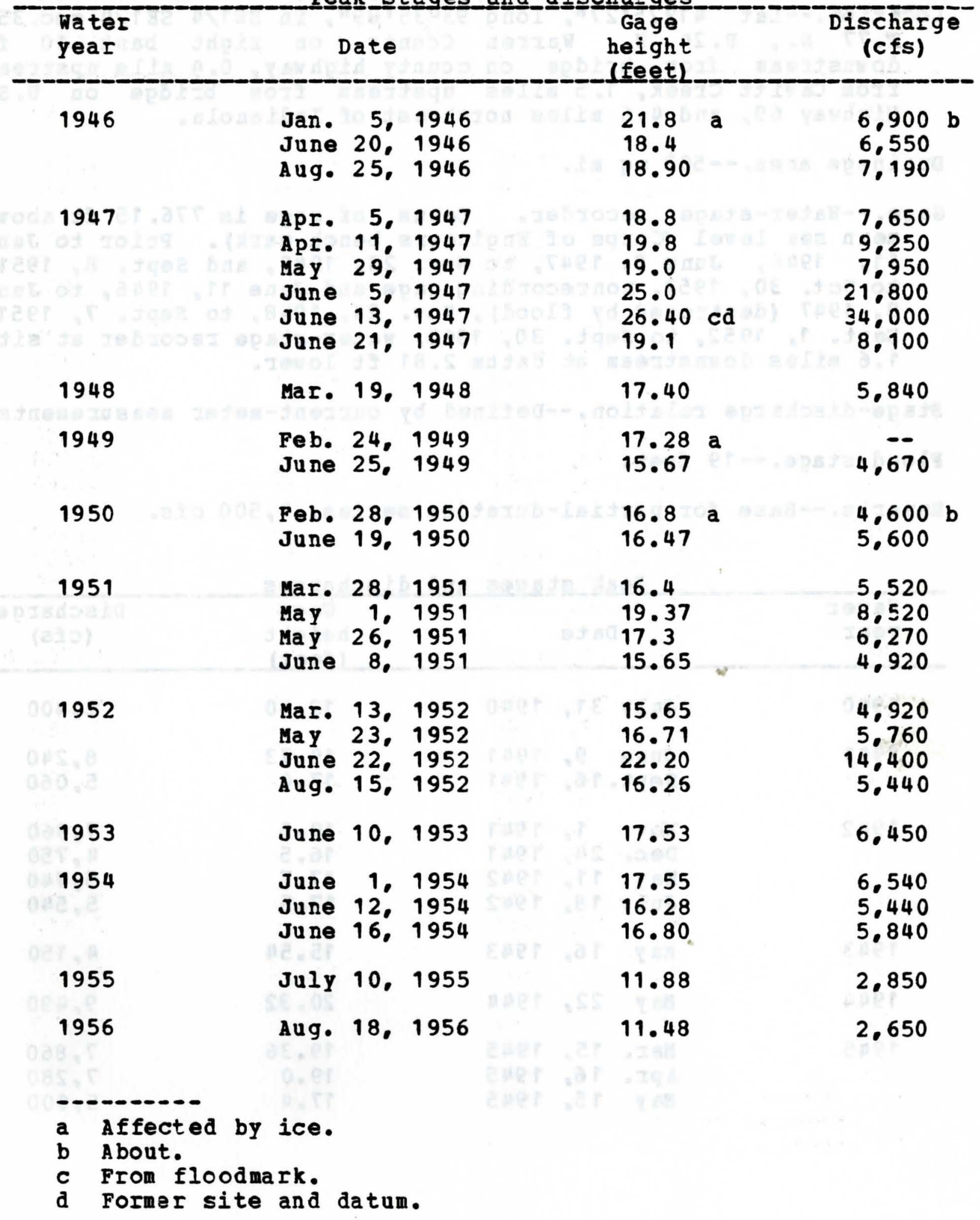


05-4864.90 Middle River near Indianola, Iowa--(Continued)

Peak﹎.stagqes_and_di scharges

\begin{tabular}{|c|c|c|c|c|c|}
\hline $\begin{array}{l}\text { Hater } \\
\text { year }\end{array}$ & Date & & $\begin{array}{l}\text { Gage } \\
\text { height } \\
\text { (feet) }\end{array}$ & & $\begin{array}{c}\text { Discharge } \\
\text { (cfs) }\end{array}$ \\
\hline 1957 & May 11 . & 1957 & 12.90 & & 3.350 \\
\hline 1958 & $\begin{array}{ll}\text { July } & 2, \\
\text { Sept. } & 8 .\end{array}$ & $\begin{array}{l}1958 \\
1958\end{array}$ & $\begin{array}{l}17 \cdot 54 \\
19 \cdot 22\end{array}$ & & $\begin{array}{l}6.090 \\
8.260\end{array}$ \\
\hline 1959 & $\begin{array}{lr}\text { May } & 21 . \\
\operatorname{May} & 30 \\
\text { JuIy } & 1 .\end{array}$ & $\begin{array}{l}1959 \\
1959 \\
1959\end{array}$ & $\begin{array}{l}17.13 \\
17.2 \\
19.52\end{array}$ & b & $\begin{array}{l}6.090 \\
6.000 \quad b \\
8.650\end{array}$ \\
\hline 1960 & $\begin{array}{l}\text { Jan. } 13 . \\
\text { MaI. } 30^{\circ} \\
\text { May } 25 .\end{array}$ & $\begin{array}{l}1960 \\
1960 \\
1960\end{array}$ & $\begin{array}{l}19.44 \\
20.43 \\
15.26\end{array}$ & & $\begin{array}{l}8.520 \\
9.900 \\
4.710\end{array}$ \\
\hline 1961 & $\begin{array}{l}\text { Feb. } 18 . \\
\text { Mar. } 13 . \\
\text { Sept. } 13 .\end{array}$ & $\begin{array}{l}1961 \\
1961 \\
1961\end{array}$ & $\begin{array}{l}18.6 \\
16.97 \\
16.76\end{array}$ & a & $\begin{array}{l}6.500 \quad b \\
5.520 \\
5.360\end{array}$ \\
\hline 1962 & $\begin{array}{l}\text { Nov. } 16, \\
\text { Mar. 20, } \\
\text { May } 29, \\
\text { June } 10^{\circ}\end{array}$ & $\begin{array}{l}1961 \\
1962 \\
1962 \\
1962\end{array}$ & $\begin{array}{l}16.27 \\
19 \cdot 42 \\
16.16 \\
15.14\end{array}$ & ' & $\begin{array}{l}5.440 \\
8.520 \\
5.360 \\
4.570\end{array}$ \\
\hline 1963 & Mar. & 1963 & 19.61 & $\mathbf{a}$ & $4.500 \mathrm{~b}$ \\
\hline 1964 & $\begin{array}{l}\text { June } 23 . \\
\text { Sept. } 7 .\end{array}$ & $\begin{array}{l}1964 \\
1964\end{array}$ & $\begin{array}{l}16 \cdot 45 \\
18 \cdot 13\end{array}$ & & $\begin{array}{l}4.810 \\
5.960\end{array}$ \\
\hline 1965 & $\begin{array}{l}\text { Mar. 17. } \\
\text { Apr. 6. } \\
\text { Apr. 9, } \\
\text { Sept. 21. }\end{array}$ & $\begin{array}{l}1965 \\
1965 \\
1965 \\
1965\end{array}$ & $\begin{array}{l}20.45 \\
21.00 \\
15.93 \\
17.33\end{array}$ & & $\begin{array}{l}9.700 \\
9.120 \\
4.570 \\
5.460\end{array}$ \\
\hline 1966 & $\begin{array}{l}\text { May } \\
\operatorname{May}\end{array}$ & $\begin{array}{l}1966 \\
1966\end{array}$ & $\begin{array}{l}17 \cdot 56 \\
17.10\end{array}$ & & $\begin{array}{l}5.770 \\
5.400\end{array}$ \\
\hline 1967 & June 12 . & 1967 & 17.69 & & 5.680 \\
\hline 1968 & Apr. 24. & 1968 & 9.96 & & 1.370 \\
\hline
\end{tabular}

a Affected by ice.

b About. 
05-4864.90 Midale River near Indianola. Iowa--(Continued)

Peak_stages_arda di

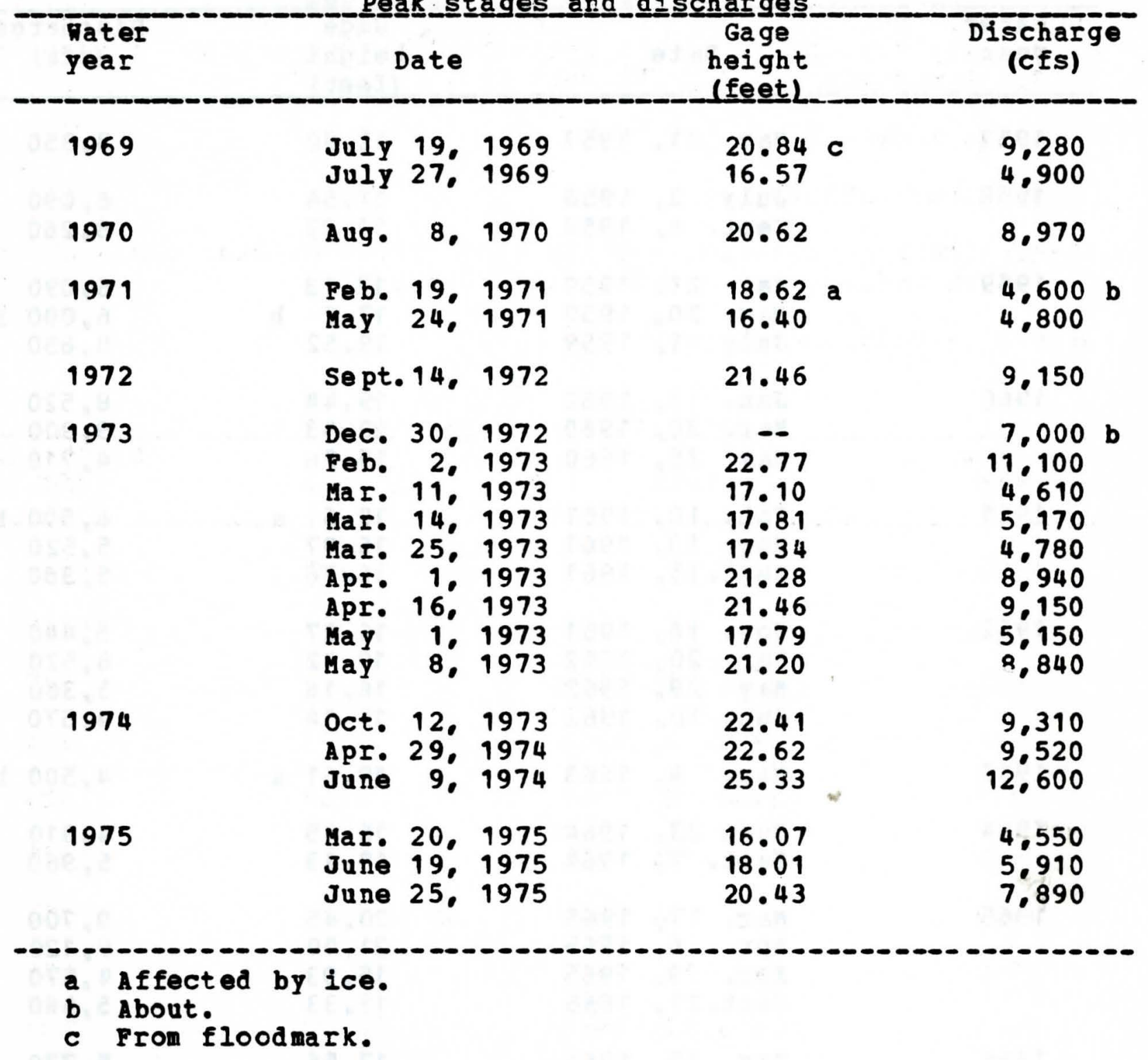




\section{6-8077.20 Middle Silver Creek near Aroca, Iowa}

Location.--lat 41028.33", long 95028.06", near $N 1 / 4$ corner sec.17. T.77 N.. R.40 W.. Pottawattamie County. at bridge on State Highway 83,7 miles west of Avoca.

Drainage area.--3.21 $\mathrm{sq} \mathrm{mi}$.

Gage.--Crest-stage gage.

Stage-discharge relation.--Defined by step-backwater comfutations and on indirect measurement at $642 \mathrm{cfs}$.

Remarks.--only annual peaks are shown.

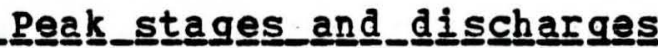

\begin{tabular}{|c|c|c|c|}
\hline $\begin{array}{l}\text { Mater } \\
\text { year }\end{array}$ & Date & $\begin{array}{l}\text { Gage } \\
\text { height } \\
\text { lfeetl }\end{array}$ & $\begin{array}{l}\text { Discharge } \\
\text { (cfs) }\end{array}$ \\
\hline 1953 & - & a & $<141$ \\
\hline 1954 & $\cdots$ & a & $<141$ \\
\hline 1955 & July 9, 1955 & 8.73 & 642 \\
\hline 1956 & Sept. 5, 1956 & 5.37 & 233 \\
\hline 1957 & June 16,1957 & 8.51 & 629 \\
\hline 1958 & Aug. 13,1958 & 9.36 & 815 \\
\hline 1959 & May 2, 1959 & 8.10 & 563 \\
\hline 1960 & May 24,1960 & 7.16 & 429 \\
\hline 1961 & June 27, 1961 & 6.83 & 387 \\
\hline 1962 & May 20,1962 & 7.00 & 408 \\
\hline 1963 & June 5,1963 & 7.79 & 516 \\
\hline 1964 & June 22, 1964 & 6.39 & 335 \\
\hline 1965 & -- & a & $<141$ \\
\hline 1966 & May 23, 1966 & 7.33 & 451 \\
\hline
\end{tabular}

a Peak stage did not reach bottom of gage. 
06-8077.20 Middle Silver Creek near Avoca, Iowa--(Continued)

Peak_stages_and_di scharges.

\begin{tabular}{|c|c|c|c|c|}
\hline $\begin{array}{l}\text { Hater } \\
\text { year }\end{array}$ & Date & & $\begin{array}{c}\text { Gage } \\
\text { height } \\
\text { (feet) }\end{array}$ & $\begin{array}{c}\text { Discharge } \\
\text { (cfs) }\end{array}$ \\
\hline 1967 & June 15 . & 1967 & 9.0 & $725 \mathrm{~b}$ \\
\hline 1968 & $\cdots$ & & $a$ & $<141$ \\
\hline 1969 & JuIy 9. & 1969 & 8.03 & 553 \\
\hline 1970 & $-\infty$ & & a & $<141$ \\
\hline 1971 & Feb. 19. & 1971 & $7.42 \mathrm{c}$ & d \\
\hline 1972 & -- & & $\mathbf{a}$ & $<141$ \\
\hline 1973 & Sept. 26 & 1973 & 10.65 & 1.040 \\
\hline 1974 & -- & & $\mathbf{a}$ & $<141$ \\
\hline 1975 & Aug. 29. & 1975 & 9.13 & 730 \\
\hline
\end{tabular}

a Peak stage did not reach bcttom of gage.

b A bout.

c Affected by ice.

d Discharge not determined. 
Location.--Lat 41019'28" long 95033'19", near E1/4 corner sec.4, T.75 N.. R. 41 H.. Pottawattamie County. at bridge, 8.5 miles northwest of oakland.

Drainage area.--25.7 sq mi.

Gage.--Crest-stage gage.

Stage-discharge relation.--Defined by current-meter and indirect measurement s.

Remarks.--only annual peaks are shown.

Peak__stagges_and_discharges

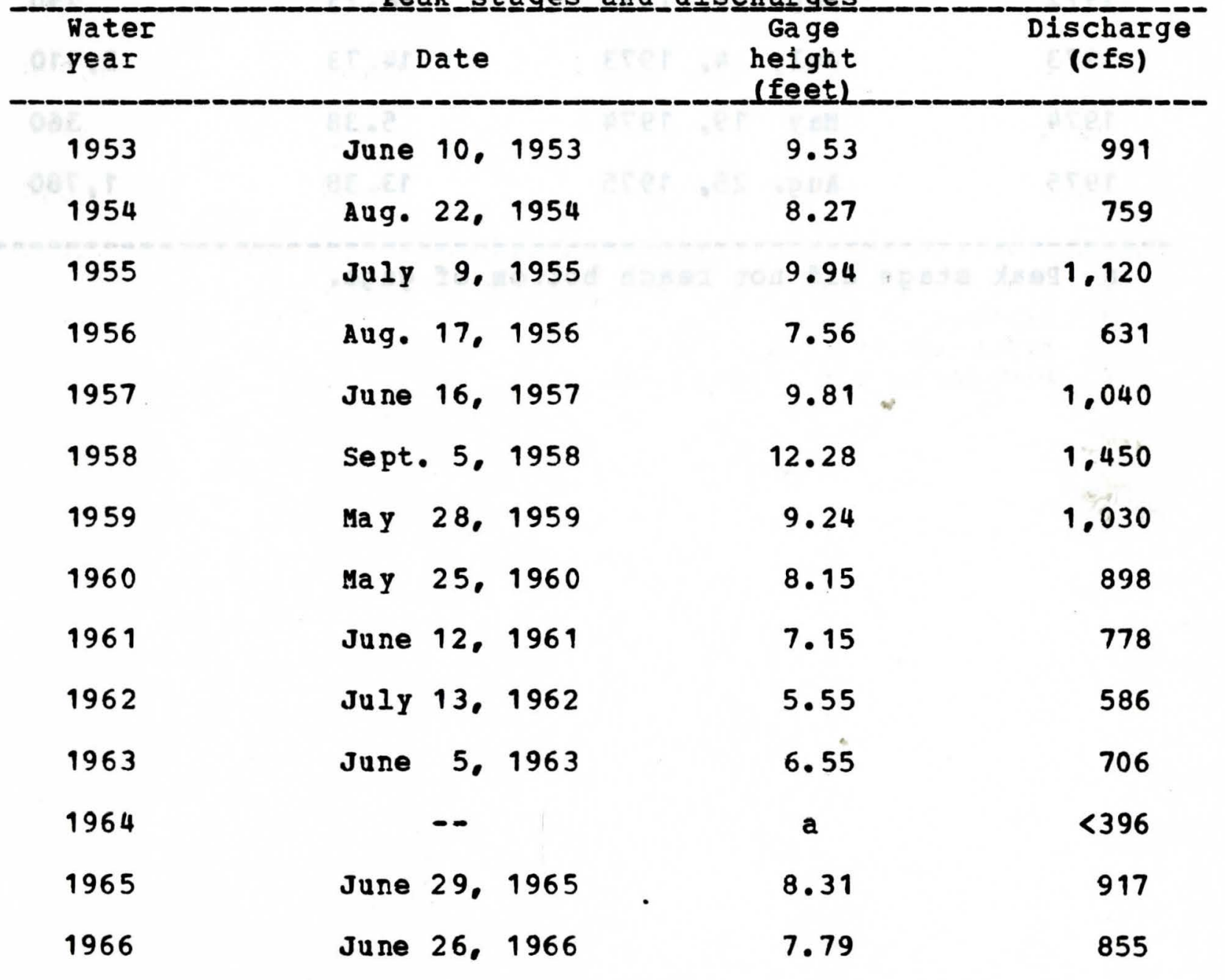

a Peak stage did not reach bottom of gage. 
06-8077.60 Middle Silver Creek near Oakland, Iowa--(Continued)

Peak_stages and di

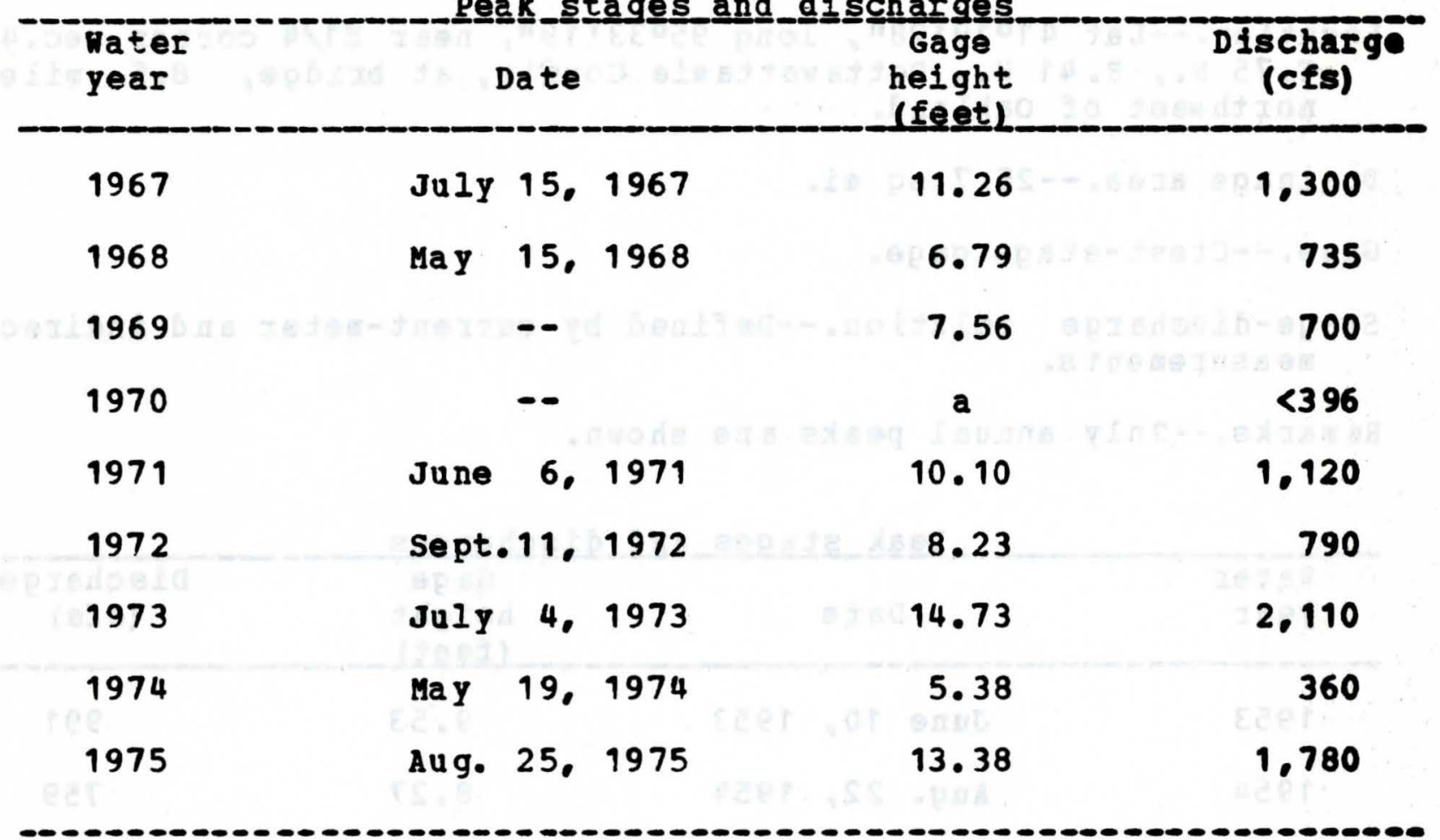

a Peak stage did not reach bottom of gage. 


\section{6-8077.80 Middle Silver Creek at Treynor. Iowa}

Location.--Lat 41014037", long 95036'53", near NE corner sec.1.

T.74 N.. R. 42 W.. Pottawattamie County, at bridge on county road $F, 1$ mile north of Treynor.

Drainage area.--42.7 sq mi.

Gage.--Crest-stage gage.

Stage-discharge Ielation.--Defined by current-meter and indirect mea surements.

Remarks.--only annual peaks are shown.

Peak_stages_and_di

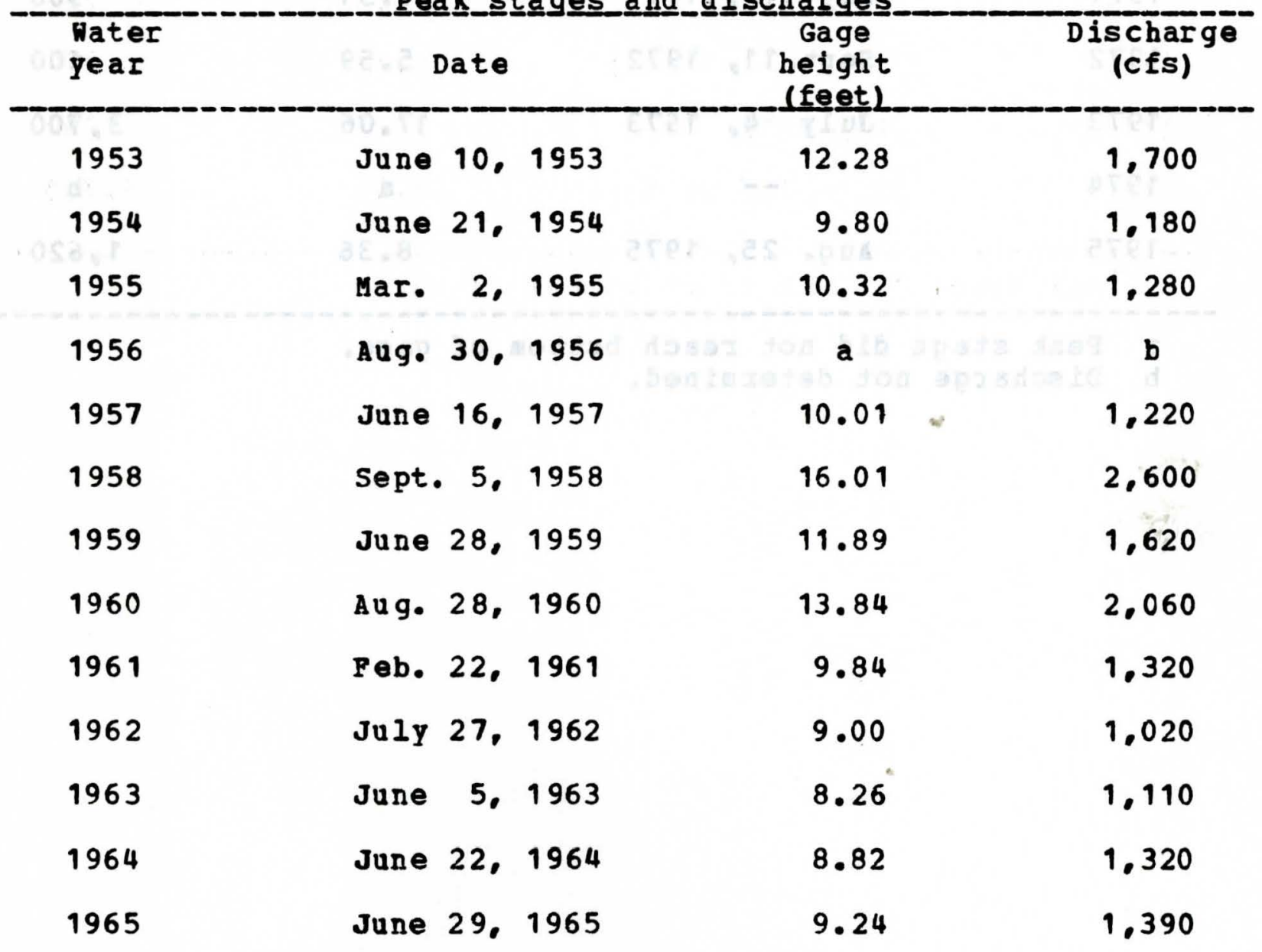

a Peak stage did not reach bcttom of gage.

b Discharge not determined. 
06-8077.80 Middle Silver Creek at Treynor, Iowa--(Continued)

Peak﹎stages and_di

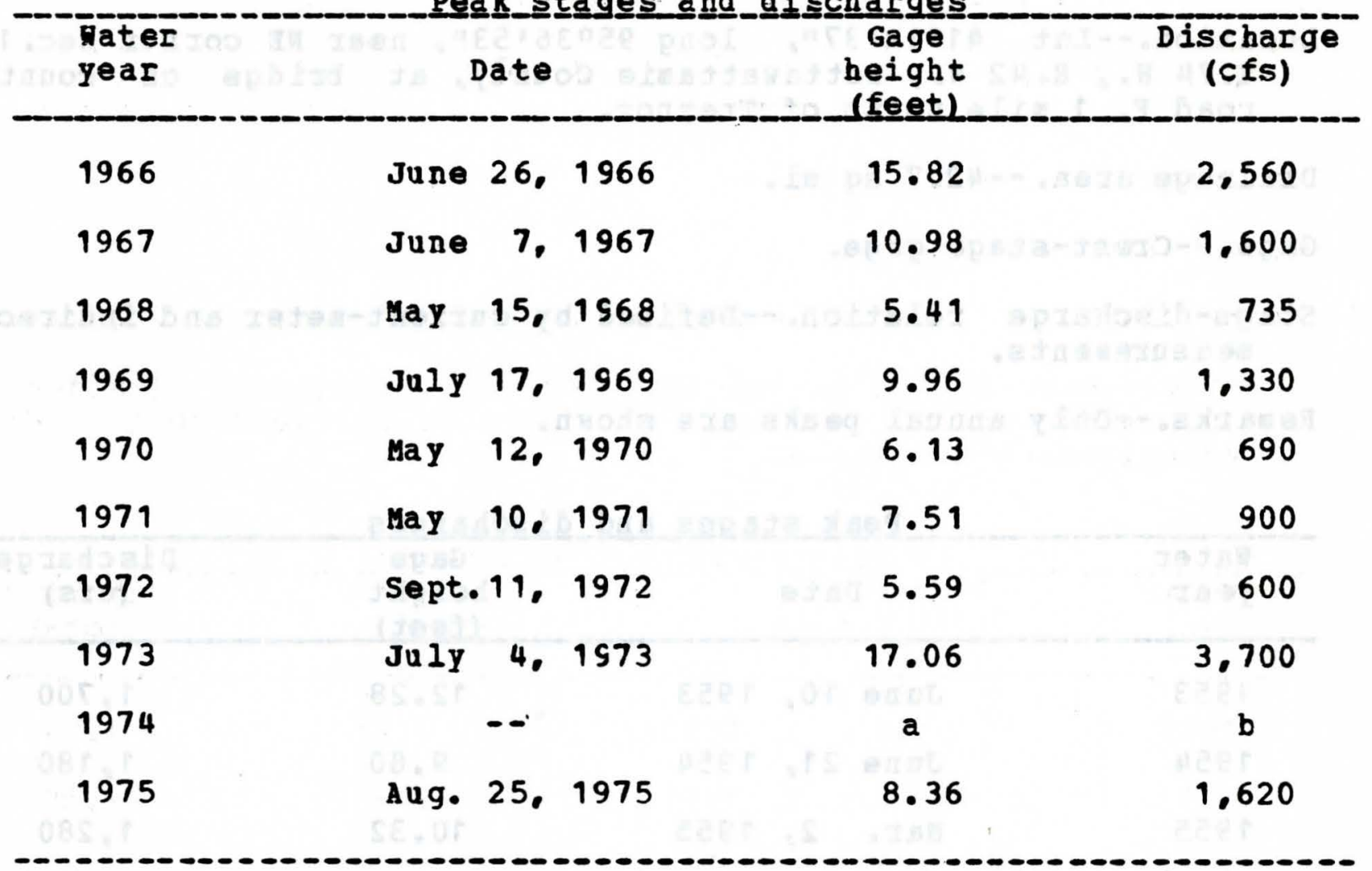

a Peak stage did not reach bctton of gage.

b Discharge not determined. 
Location.--Iat 42007\%. long 93005', near center of sec.5. T.84 N.. R.19 W. Marshall County, at county road bridge about 3.5 miles east of clemons. Iowa.

Drainage area. --148 sq mi.

Gage.--Nonrecording.

Stage-discharge relation.--Defined by current-meter measurements. Remarks.--Records collected by Corps of Engineers. Station is inflow forecasting station for Coralville Reservoir. Only annual peaks are shown.

Peak_stages_and_di

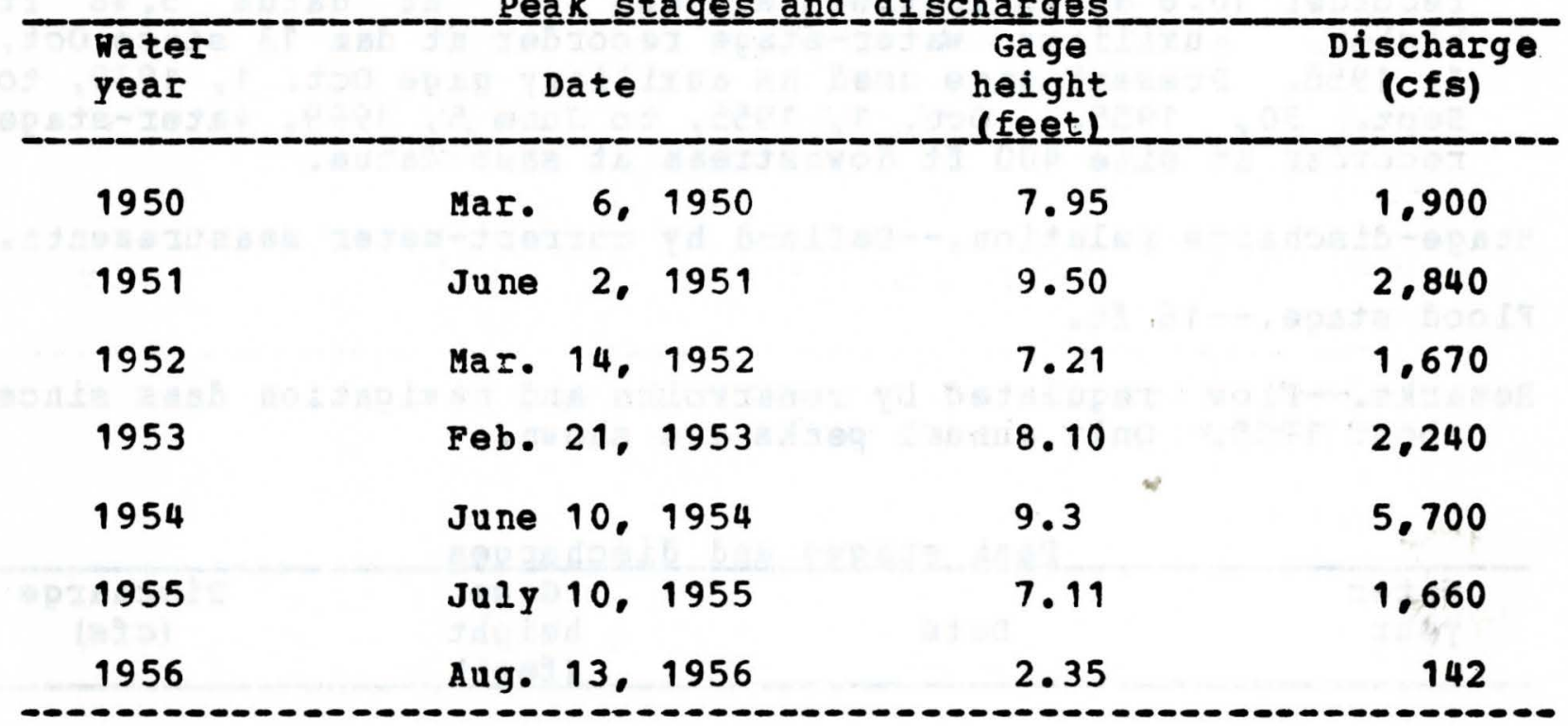


Location.--Iat 41046'53". long 90015.04", in NH1/4 sec.34, T.81 N.. R.6 W.. Clint on County, on right bank at foot of seventh Avenue in Camanche, 5.0 mi upstream from Wapsipinicon River. 6.4 mi downstream from Clinton, $10.6 \mathrm{mi}$ downstream from Dam 13. and at mile 511.8 upstream from Ohio River. Prior to June 6. 1969, at site $400 \mathrm{ft}$ downstream.

Drainage area.--85,600 sq mi , approximately, at Fulton-Iyons Bridge where discharge measurements are made.

Gage.--Nater-stage recorder. Datum of gage is $562.68 \mathrm{ft}$ above mean sea level. June 1873 to lly 31, 1934, staff gage in stone well and June 1, 1934, to Sept. 30, 1939, water-stage recorder 14.8 miles downstream at Le Claire, at datum 6.07 ft lower (revised). Oct. 1, 1939, to Sept. 30, 1955, water-stage recorder 10.6 miles upstream at dam 13, at datum $5.48 \mathrm{ft}$ higher. Auxiliary water-stage recorder at dam 13 since oct. 1. 1958. Present gage used as auxiliary gage Oct. 1, 1939, to sept. 30, 1955. Oct. 1, 1955, to June 5, 1969, water-stage recorder at site $400 \mathrm{ft}$ downstream at same datum.

Stage-discharge relation.--Defined by current-meter measurements.

Flood stage. --16 ft.

Remarks.--Flow regulated by reservoirs and navigation dams since about 1935. Only annual peaks are shown.

Peak_stagages_and_di is $\underline{\text { charges }}$

\begin{tabular}{|c|c|c|c|}
\hline $\begin{array}{l}\text { Hater } \\
\text { year }\end{array}$ & Date & $\begin{array}{l}\text { Gage } \\
\text { height } \\
\text { (feet) }\end{array}$ & $\begin{array}{l}\text { Discharge } \\
\text { (cfs) }\end{array}$ \\
\hline 1874 & May 17,1874 & -- & 98.400 \\
\hline 1875 & Apr. $29,30,1875$ & -- & 167.000 \\
\hline 1876 & $\begin{array}{l}\text { May } 7-10,30,31, \\
\text { June } 1,2,1876\end{array}$ & -- & 165.000 \\
\hline 1877 & Apr. 3, 1877 & -- & 104,000 \\
\hline 1878 & June 5,1878 & -- & 80,800 \\
\hline 1879 & June 1,1879 & -- & 96,800 \\
\hline 1880 & June 25,1880 & -- & 250,000 \\
\hline
\end{tabular}


05-4205.00 Mississippi River at Clinton, Iowa--(Continued)

Peak__stagges_and_di schargages

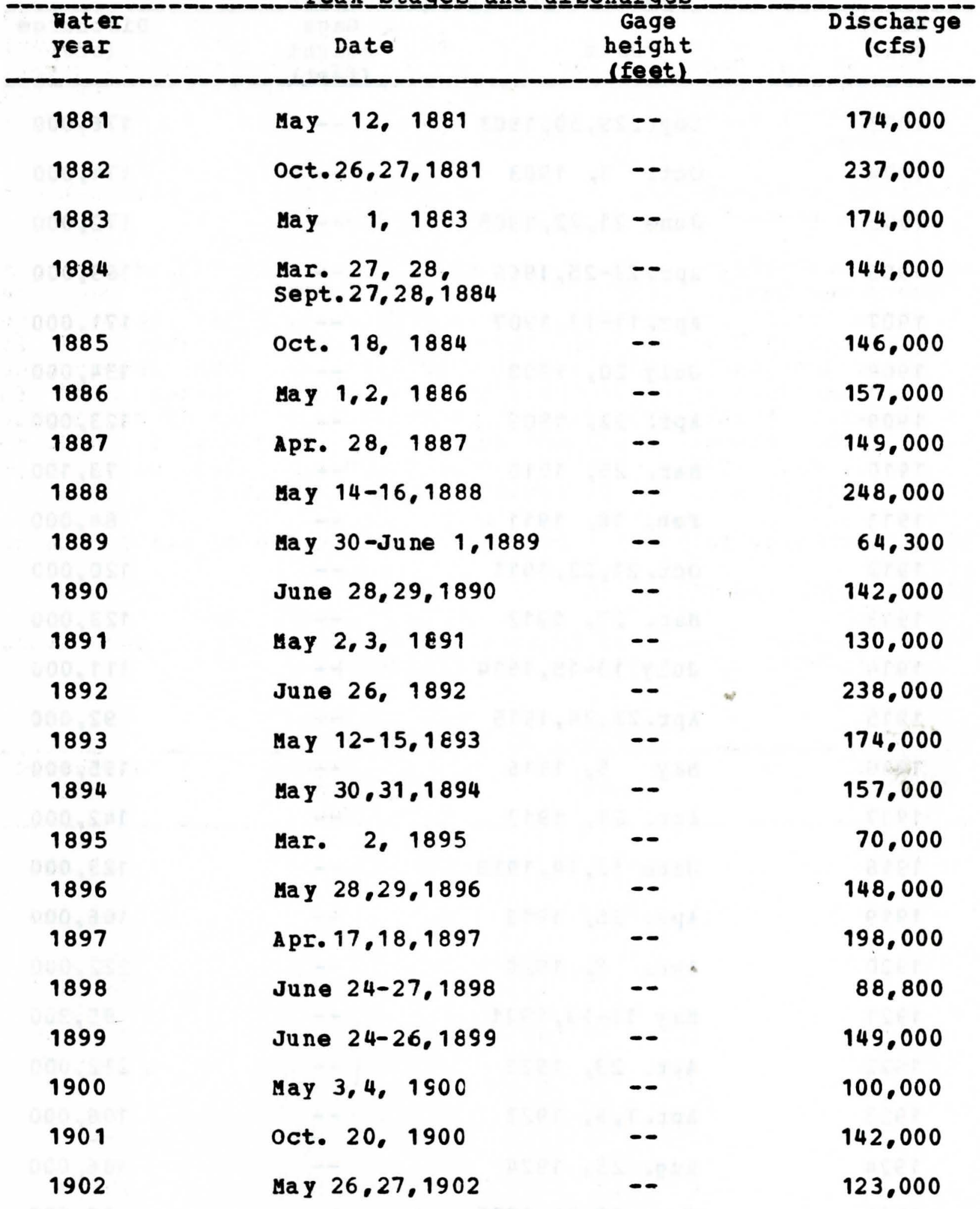


05-4205.00 Mississippi River at Clinton, Iowa--(Continued)

Peak_stages_and_discharges

\begin{tabular}{|c|c|c|c|c|}
\hline $\begin{array}{l}\text { water } \\
\text { year }\end{array}$ & Date & $\begin{array}{l}\text { Gage } \\
\text { height } \\
\text { (feet) }\end{array}$ & & $\begin{array}{c}\text { Discharge } \\
\text { (cfs) }\end{array}$ \\
\hline 1903 & Sept.29,30,1903 & -- & & 176,000 \\
\hline 1904 & oct. 1, 1903 & -- & & 174.000 \\
\hline 1905 & June $21,22,1905$ & -- & & 172.000 \\
\hline 1906 & Apr. $22-25,19 \mathrm{C} 6$ & -- & & 169.000 \\
\hline 1907 & Apr. $11-13,1907$ & -- & & 171,000 \\
\hline 1908 & July 20, 1908 & -- & & 134,000 \\
\hline 1909 & Apr. 22. 1909 & -- & & 123,000 \\
\hline 1910 & Mar. 25, 1910 & -- & & 73,100 \\
\hline 1911 & Feb. 18, 1911 & -- & & 84.000 \\
\hline 1912 & oct. $21,22,1911$ & -- & & 120,000 \\
\hline 1913 & MaI. 27, 1913 & -- & & 123,000 \\
\hline 1914 & July $13-15,1914$ & -- & ر & 111.000 \\
\hline 1915 & Apr. $23,24,1915$ & -- & & 92,000 \\
\hline 1916 & May 5, 1916 & -- & & 195.000 \\
\hline 1917 & Apr. 21,1917 & -- & & 142.000 \\
\hline 1918 & June $13,14,1918$ & -- & & 123.000 \\
\hline 1919 & Apr. 25, 1919 & -- & & 166.000 \\
\hline 1920 & Apr. $\quad 9,1920$ & -- & 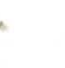 & 222.000 \\
\hline 1921 & Ma y $11-13,1921$ & $\cdots$ & & 85.300 \\
\hline 1922 & Apr. 23, 1922 & -- & & 212.000 \\
\hline 1923 & Apr.7,8, 1923 & -- & & 106,000 \\
\hline 1924 & Aug. 23,1924 & $\cdots$ & & 106,000 \\
\hline 1925 & June $19,20,1925$ & -- & & 93,900 \\
\hline
\end{tabular}


05-4205.00 Mississippi River at Clinton, Iowa-- (Continued)

Peak stagges_and dis

\begin{tabular}{|c|c|c|c|}
\hline $\begin{array}{l}\text { Water } \\
\text { year }\end{array}$ & Date & $\begin{array}{c}\text { Gage } \\
\text { height } \\
\text { (feetl }\end{array}$ & $\begin{array}{l}\text { Discharge } \\
\text { (cfs) }\end{array}$ \\
\hline 1926 & Sept. 26,27,1926 & -- & 83,600 \\
\hline 1927 & Mar. 31,Apr. 1, 1927 & -- & 133,000 \\
\hline 1928 & Apr.9.10,1928 & -- & 116,000 \\
\hline 1929 & Apr. 2, 3,19-20,1929 & -- & 146,000 \\
\hline 1930 & June 28, 1930 & -- & 83.600 \\
\hline 1931 & July $6-11,1931$ & -- & 40,700 \\
\hline 1932 & Apr. $22,23,1932$ & $2+14=$ & 97.500 \\
\hline 1933 & Apr. 8-13,1933 & $--2 a-1$ & 92,100 \\
\hline 1934 & Apr. $19,20,1934$ & -- & 81,400 \\
\hline 1935 & Apr. $\quad 7,1935$ & -- & 123,000 \\
\hline 1936 & Apr. 7, 1936 & -- & 133,000 \\
\hline 1937 & Mar. 8, 9, 1937 & -- & 95,800 \\
\hline 1938 & Sept.23, 1938 & -- & 167.400 \\
\hline 1939 & - A⿱PDI. & $=-$ & 144,900 \\
\hline 1940 & June 19, 1940 & 10.36 & 74.100 \\
\hline 1941 & Apr. 25, 1941 & 15.11 & 128,200 \\
\hline 1942 & June 13, 1942 & 18.04 & 169.600 \\
\hline 1943 & June 30,1943 & 17.30 & 158,700 \\
\hline 1944 & June 28,1944 & 18.60 & 168,500 \\
\hline 1945 & Mar. 31, 1945 & 17.69 & 164.400 \\
\hline 1946 & $\begin{array}{l}\text { Mar. 28, } 1946 \\
\text { Mar. 29, } 1946\end{array}$ & 16.48 & 144,800 \\
\hline 1947 & $\begin{array}{l}\text { June } 15,1947 \\
\text { June 16, } 1947\end{array}$ & 15.18 & 125,500 \\
\hline
\end{tabular}


05-4205.00 Mississippi River at Clinton, Iowa--(Continued)

Peak stages and di scharges

\begin{tabular}{|c|c|c|c|c|}
\hline $\begin{array}{l}\text { Hater } \\
\text { year }\end{array}$ & Date & $\begin{array}{r}\text { Gage } \\
\text { height } \\
\text { (fegt) }\end{array}$ & & $\begin{array}{c}\text { Discharge } \\
\text { (cfs) }\end{array}$ \\
\hline 1948 & Mar. 21, 1948 & 13.66 & & 108,300 \\
\hline 1949 & Apr. 7. 1949 & 11.08 & & 85.300 \\
\hline 1950 & May 22, 1950 & $15 \cdot 24$ & & 129,900 \\
\hline 1951 & Apr. 26, 1951 & 21.0 & & 221.500 \\
\hline 1952 & Apг. 27. 1952 & 21.24 & & 225.400 \\
\hline 1953 & Apr. 5, 1953 & 14.00 & & 104,100 \\
\hline 1954 & May 14,1954 & $18 \cdot 55$ & & 175,900 \\
\hline 1955 & 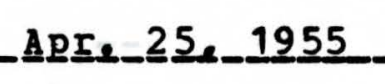 & 13.69 & & 96.900 \\
\hline 1956 & ApI. 20, 1956 & $15 \cdot 3$ & & 127,000 \\
\hline 1957 & July 14, 1957 & 13.87 & . & 103,000 \\
\hline 1958 & $\begin{array}{l}\text { Apr. } 15-17,1958 \\
\text { Apr. } 17,1958\end{array}$ & 10.78 & & 64.500 \\
\hline 1959 & Apr. 3, 1959 & 14.97 & $*$ & 112,000 \\
\hline 1960 & May 18,1960 & 17.04 & & 151.000 \\
\hline 1961 & Apr. 2, 1961 & $16 \cdot 13$ & & 143,000 \\
\hline 1962 & Apr. 21, 1962 & $15 \cdot 98$ & & 138,000 \\
\hline 1963 & Apr. 2, 1963 & 13.06 & & 90.900 \\
\hline 1964 & $\begin{array}{lc}\text { May } & 19,20,1964 \\
\text { May } & 24,1964\end{array}$ & 12.63 & & 84.000 \\
\hline 1965 & Apr. 28, 1965 & 24.65 & & 307,000 \\
\hline 1966 & Apr. 1. 1966 & 16.43 & & 143.000 \\
\hline 1967 & $\begin{array}{l}\text { Арг. 14, } 1967 \\
\text { Арг. } 15,1967\end{array}$ & $20 . \overline{16}$ & & $\begin{array}{c}207.000 \\
.-\end{array}$ \\
\hline
\end{tabular}

a Maximum stage known since at least 1828. 
05-4205.00 Hississippi River at Clinton, Iowa--(Continued)

Pea $\underline{\text { k_s }}$ tages_and

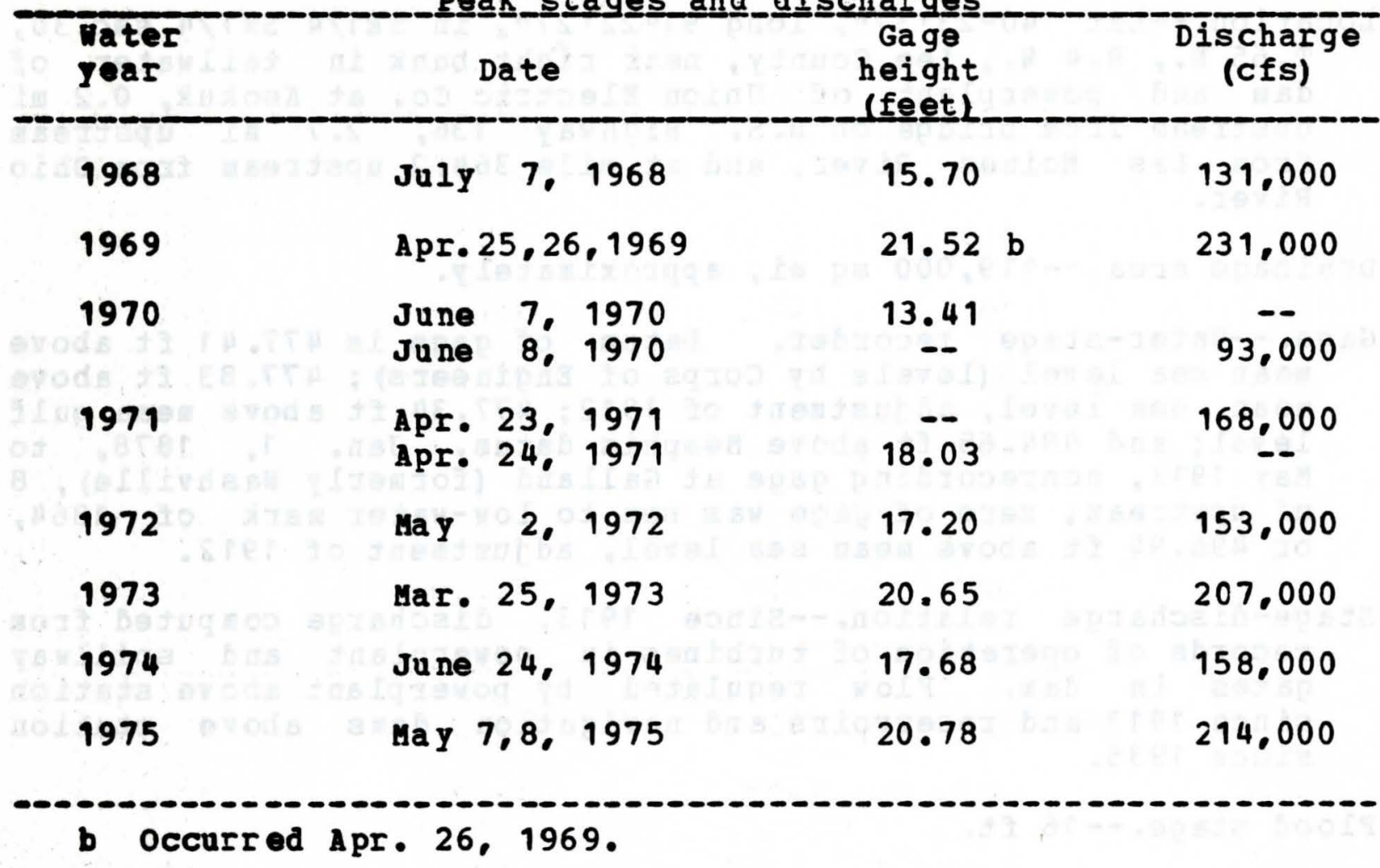


Location.--Lat $40023 \cdot 37 "$, long $91022 \cdot 27 "$, in SE1/4 SN1/4 sec. 30 , T.65 N.. R. 4 H.. Lee County, near right bank in tailwater of dam and powerplant of Union Electric Co. at Keokuk, 0.2 mi upstream from bridge on $0 . S$. Highway 136, $2.7 \mathrm{mi}$ upstream from Des Moines River, and at mile 364.2 upstream from Ohio River.

Drainage area.--119,000 sq mi, approximately•

Gage.-Water-stage recorder. Datum of gage is $477.41 \mathrm{ft}$ above mean sea level (levels by Corps of Engineers): $477.83 \mathrm{ft}$ above mean sea level, adjustment of $1912 ; 477.34 \mathrm{ft}$ above mean gulf level: and $484.65 \mathrm{ft}$ above Memphis datum. Jan. 1. 1878, to May 1913, nonrecording gage at Galland (formerly Nashville), 8 mi upstream: zero of gage was set to low-water mark of 1864 . or 496.94 ft above mean sea. level, adjustment of 1912.

Stage-discharge relation.--Since 1913, discharge computed from records of operation of turbines in powerplant and spillway gates in dam. Flow regulated by powerplant above station since 1913 and reservoirs and navigation dams above station since 1935.

Flood stage. $-16 \mathrm{ft}$.

Remarks.--Keokuk Dam completed in 1913. Records January 1878 to September 1932 from Report of Iowa state pianning; since October 1932, furnished by Union Electric Company. Records for May 1913 to september 1937 adjusted for change in contents in Keokuk Reservoir, those after september 1973 unadjusted. only annual peaks are shown.

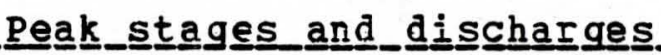

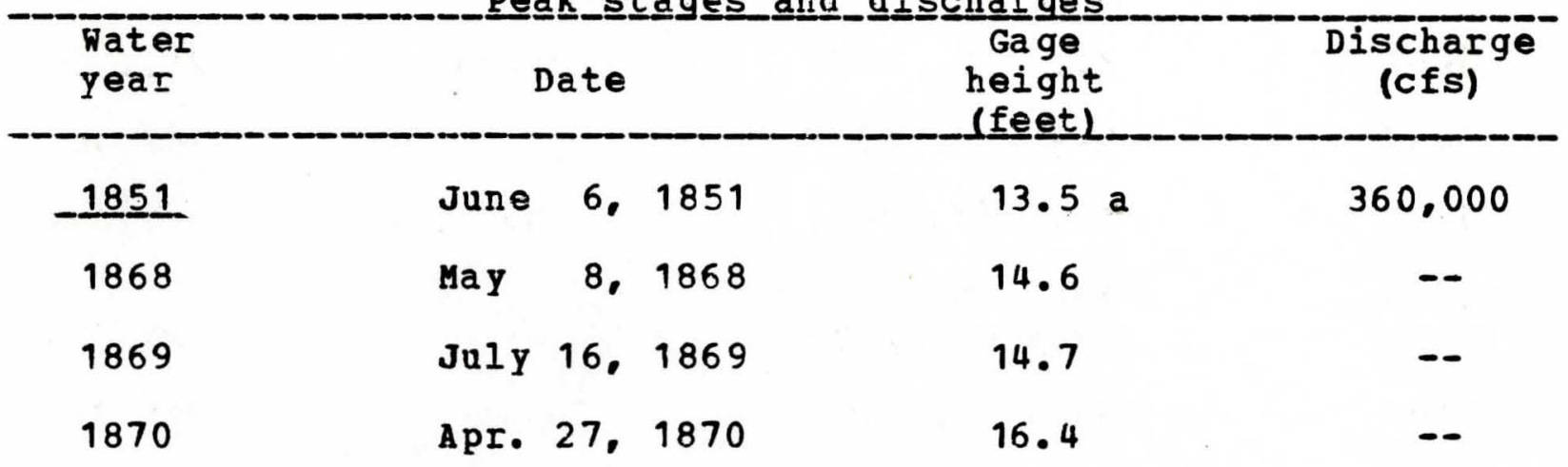

a Estimated; stage at presont site and datum, 21 feet. 
05-4745.00 Mississippi River at Keokuk, Iowa--(Continued)

Peak

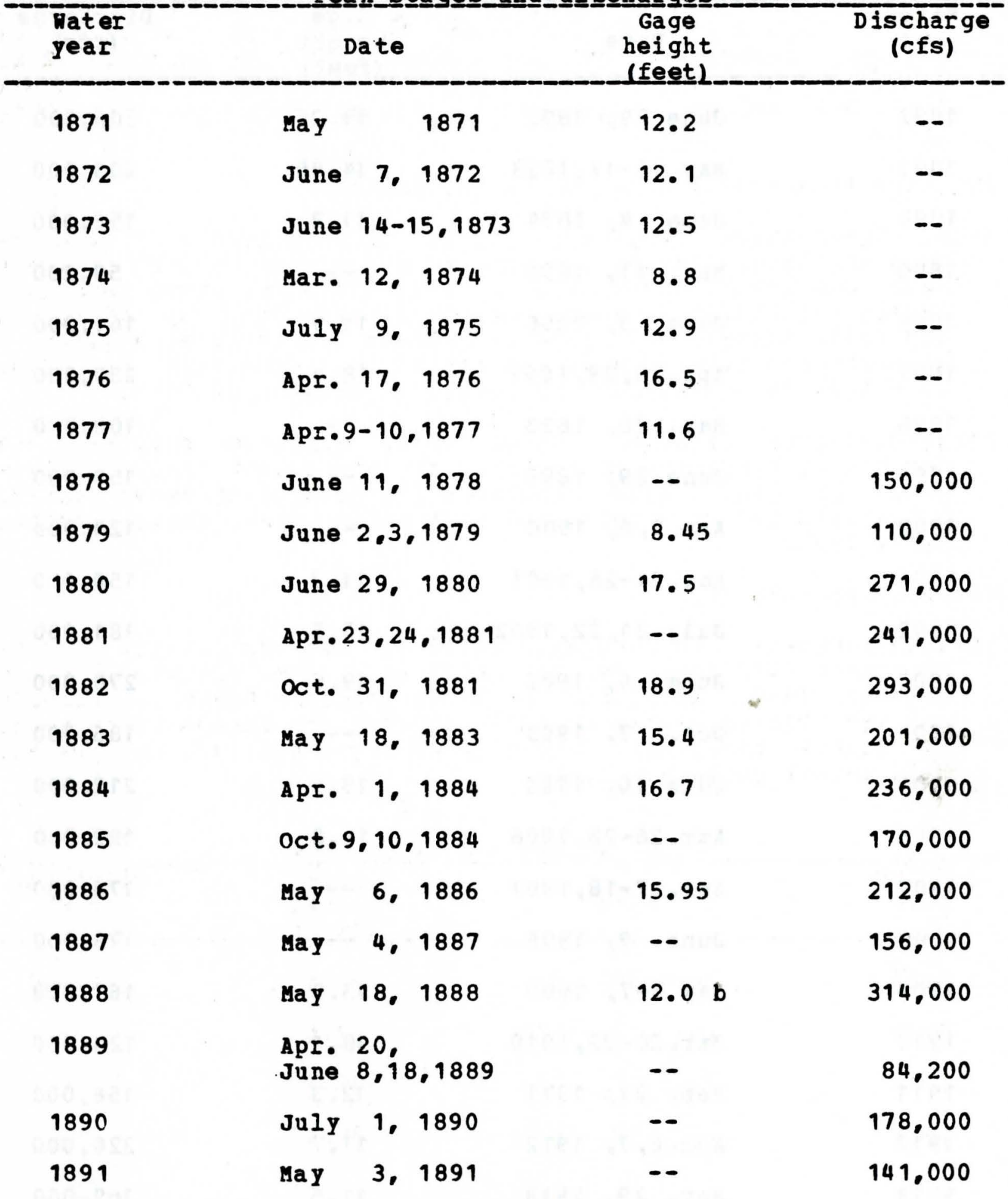

b Stage at present site and datum, 19.6 feet. 
05-4745.00 Mississippi River at Keokuk, Iowa--(Continued)

Peak﹎. stages and di

\begin{tabular}{|c|c|c|c|}
\hline $\begin{array}{l}\text { Mater } \\
\text { year }\end{array}$ & Date & $\begin{array}{c}\text { Gage } \\
\text { height } \\
\text { (feet) }\end{array}$ & $\begin{array}{l}\text { Discharge } \\
\text { (cfs) }\end{array}$ \\
\hline 1892 & June 29, 1892 & 19.25 & 306,000 \\
\hline 1893 & May $15-17,1893$ & 14.85 & 203,000 \\
\hline 1894 & June 4,1894 & 11.3 & 158,000 \\
\hline 1895 & Mar. 11, 1895 & -- & 59.200 \\
\hline 1896 & June 3,1896 & 11.9 & 161.000 \\
\hline 1897 & Apr. $28,29,1897$ & 18.4 & 230.000 \\
\hline 1898 & Mar. 20,1898 & -- & 108.000 \\
\hline 1899 & June 29, 1899 & -- & 159.000 \\
\hline 1900 & Apr.5, 6, 1900 & - & 124,000 \\
\hline 1901 & Mar. $24-26,1901$ & 11.3 & 150.000 \\
\hline 1902 & July $21,22,1902$ & 15.5 & 181,000 \\
\hline 1903 & June 6,1903 & 19.6 & 270,000 \\
\hline 1904 & oct. 7,1903 & -- & 186,000 \\
\hline 1905 & June 10,1905 & 18.5 & 212.000 \\
\hline 1906 & Apr.26-28,1906 & 14.0 & 192.000 \\
\hline 1907 & Apr.17-18,1907 & -- & 178,000 \\
\hline 1908 & June 9,1908 & -- & 178,000 \\
\hline 1909 & $\operatorname{May} 5-7,1909$ & 13.9 & 181,000 \\
\hline 1910 & Mar. $20-23,1910$ & 10.1 & 124,000 \\
\hline 1911 & Feb. 21, 1911 & 12.3 & 156.000 \\
\hline 1912 & Apr.6,7, 1912 & 17.7 & 220.000 \\
\hline 1913 & ㅂaㄹ._29, 1913 & $-13 \cdot 5$ & -169.000_ \\
\hline 1914 & June 24, 1914 & 11.2 & 122.000 \\
\hline
\end{tabular}


05-4745.00 Uississippi River at Keokuk, Iowa--(Continued)

Pea k__stages_and_di $\underline{\text { squharges }}$

\begin{tabular}{|c|c|c|c|}
\hline $\begin{array}{l}\text { Water } \\
\text { year }\end{array}$ & Date & $\begin{array}{l}\text { Gage } \\
\text { height } \\
\text { (feet) }\end{array}$ & $\begin{array}{l}\text { Discharge } \\
\text { (cfs) }\end{array}$ \\
\hline 1915 & Feb. 28, 1915 & -- & 142,000 \\
\hline 1916 & May 9,1916 & -- & 213,000 \\
\hline 1917 & June 17, 1917 & -- & 163,000 \\
\hline 1918 & June 12,1918 & 16.7 & 192.000 \\
\hline 1919 & Way 8,1919 & 17.15 & 205,000 \\
\hline 1920 & Apr. $10-11,1920$ & -- & 230,000 \\
\hline 1921 & May $12-13,1921$ & -- & 108.000 \\
\hline 1922 & Apr. $24,25,1922$ & 17.45 & 240,000 \\
\hline 1923 & Apr.9,10,1923 & 12.0 & 148,000 \\
\hline 1924 & aug. $24,25,1924$ & -- & 160,000 \\
\hline 1925 & June 23,1925 & 10.3 & 112.000 \\
\hline 1926 & Sept. 28, 1926 & -- & 146,000 \\
\hline 1927 & Apr. $\quad 3,1927$ & -- & 175,000 \\
\hline 1928 & Apr. 12, 1928 & -- & 150,000 \\
\hline 1929 & Mar. 23, 1929 & 19.3 & 247.000 \\
\hline 1930 & June 18,1930 & 13.9 & 163.000 \\
\hline 1931 & July 4, 1931 & -- & 52,500 \\
\hline 1932 & Apr. $24,25,1932$ & 10.2 & 106,000 \\
\hline 1933 & Apr. $\quad 9,1933$ & 14.5 & 160.000 \\
\hline 1934 & Apr. 22, 1934 & -- & 83.500 \\
\hline 1935 & Apr. $11,12,1935$ & -- & 138,000 \\
\hline 1936 & Apr.9, 10,1936 & 12.3 & 148,000 \\
\hline 1937 & Mar. 10,1937 & 16.1 & 190,000 \\
\hline
\end{tabular}


05-4745.00 Mississippi River at Keokuk, Iowa--(Continued)

Eeak﹎stagges and di

\begin{tabular}{|c|c|c|c|}
\hline $\begin{array}{l}\text { Water } \\
\text { year }\end{array}$ & Date & $\begin{array}{l}\text { Gage } \\
\text { height } \\
\text { (feet) }\end{array}$ & $\begin{array}{l}\text { Discharge } \\
\text { (cfs) }\end{array}$ \\
\hline 1938 & Sept. 26, 1938 & 16.4 & 193,800 \\
\hline 1939 & oct. 1,1938 & -- & 159,100 \\
\hline 1940 & Apr. 19, 1940 & 6.4 & 81,700 \\
\hline 1941 & Apr. 27, 1941 & 12.3 & 154,400 \\
\hline 1942 & June 16, 1942 & 15.80 & $20 C, 900$ \\
\hline 1943 & Apr. 18,1943 & -- & 174.000 \\
\hline 1944 & $\operatorname{May} 27,28,1944$ & 20.85 & 256.000 \\
\hline 1945 & Mar. 26, 1945 & 16.80 & 203,300 \\
\hline 1946 & $\operatorname{Jan} .11,1946$ & 16.95 & 223,300 \\
\hline 1947 & June 21, 1947 & 20.2 & 245.700 \\
\hline 1948 & Mar. 23,1948 & 18.9 & 233.600 \\
\hline 1949 & Mar. 12, 1949 & 13.3 & 150,700 \\
\hline 1950 & Apr. $25,26,1950$ & -- & 175,900 \\
\hline 1951 & Apr. 29,1951 & -- & 265.100 \\
\hline 1952 & Apr. 27,1952 & - & 253.800 \\
\hline 1953 & Apr.1,2, 1953 & 12.5 & 137,200 \\
\hline 1954 & May 17,1954 & -- & 181,400 \\
\hline 1955 & Apr. 25, 1955 & 12.7 & 156,600 \\
\hline 1956 & Apr. 22,1956 & 10.2 & 131,500 \\
\hline 1957 & July 15,1957 & 8.70 & 106.000 \\
\hline 1958 & June 13,1958 & 8.29 & 99,000 \\
\hline 1959 & Apr. $\quad 5,1959$ & 14.17 & 182.000 \\
\hline 1960 & Apr. 4, 1960 & 21.83 & 289,500 \\
\hline
\end{tabular}


05-4745.00 Mississippi River at Keokuk, Iowa--(Continued)

Peak﹎stagges_and__di

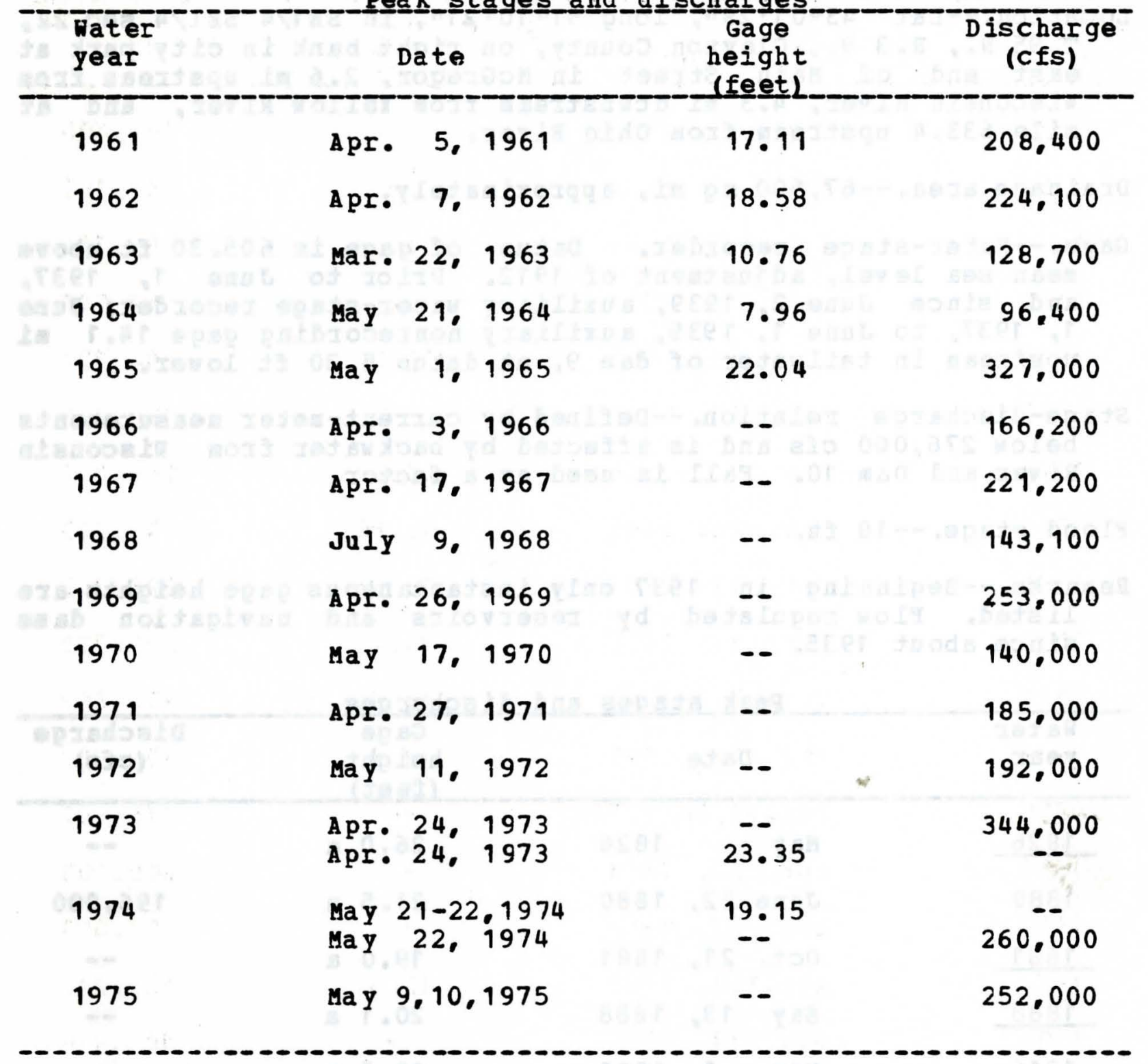




\section{5-3895.00 Mississippi River at MCGregor, Iowa}

Location.--Iat $43001 \cdot 291$, long $91010 \cdot 211$, in SE1/4 SE1/4 sec.22. T. 95 N., R. 3 W., Clayton County, on right bank in city park at east end of Main street in McGregor, $2.6 \mathrm{mi}$ upstrean fron Wisconsin River, 4.3 mi dcwnstream from Yellow River, and at mile 633.4 upstream from Ohio River.

Drainage area.--67,500 sq mi, approximately.

Gage.--Water-stage recorder. Datum of gage is $605.30 \mathrm{ft}$ above mean sea level, adjustment of 1912. Prior to June 1. 1937. and since June 2, 1939, a uxiliary water-stage recorder: June 1. 1937, to June 1, 1939, a uxiliary nonrecording gage 14.1 a upstream in tailwater of dam 9, at datum $5.30 \mathrm{ft}$ lower.

Stage-discharge relation.--Defined by current-meter neasurenents below $276,000 \mathrm{cfs}$ and is affected by backwater fron Misconsin River and Dam 10. Fall is used as a factor.

Plood stage. $--18 \mathrm{ft}$.

Remarks.--Beginning in 1937 only instantaneous gage heights are listed. Flow regulated by reservoirs and navigation dana since about 1935.

Peak﹎stages_and_discharges

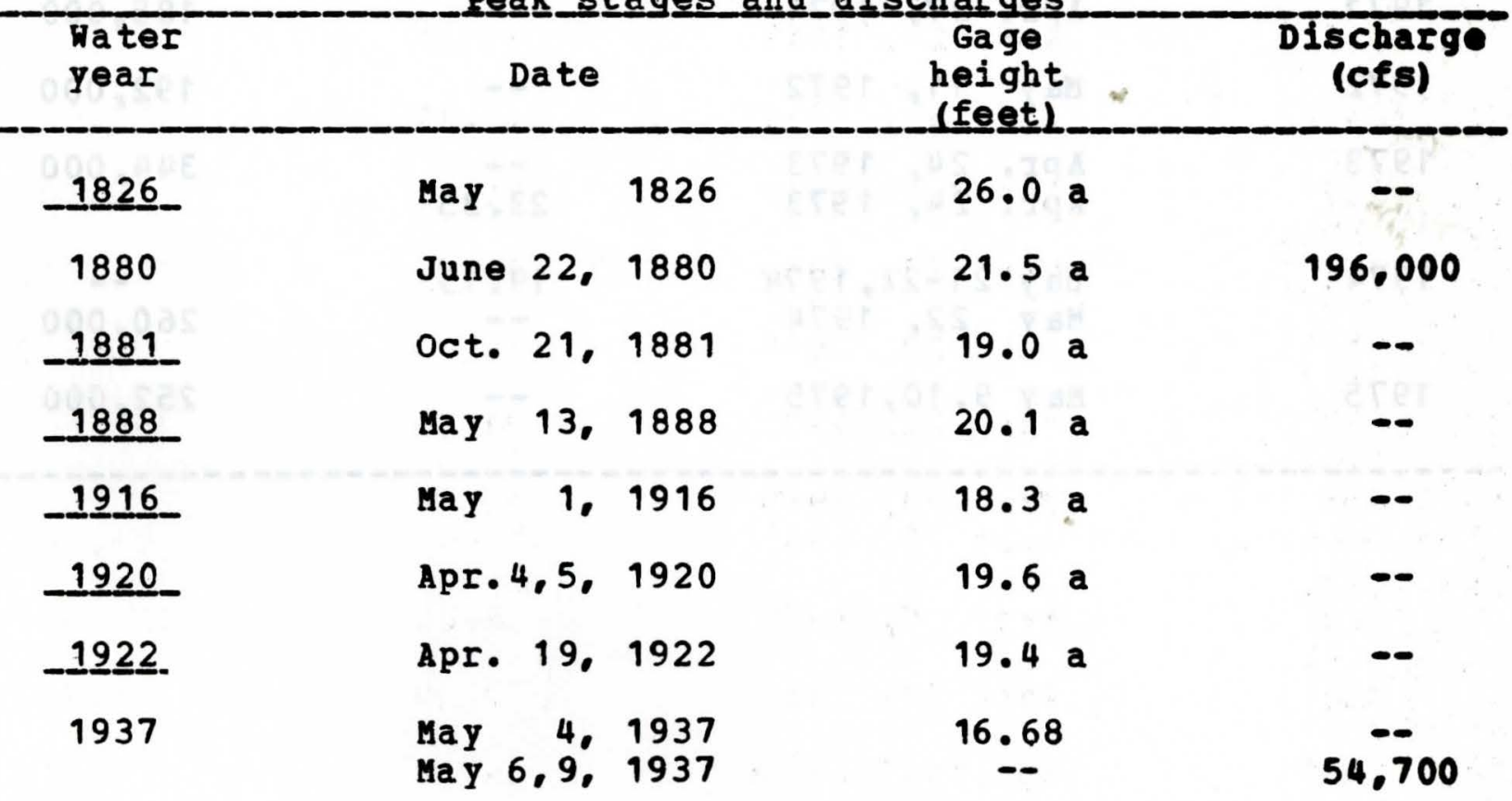

a At Prairie du Chien, Wisconsin. Zero of gage at elevation 605.4 feet above mean sea level, adjustment of 1912. 
05-3895.00 Mississippi River at McGregor, Iowa--(Continued)

Peak_stages and discharges

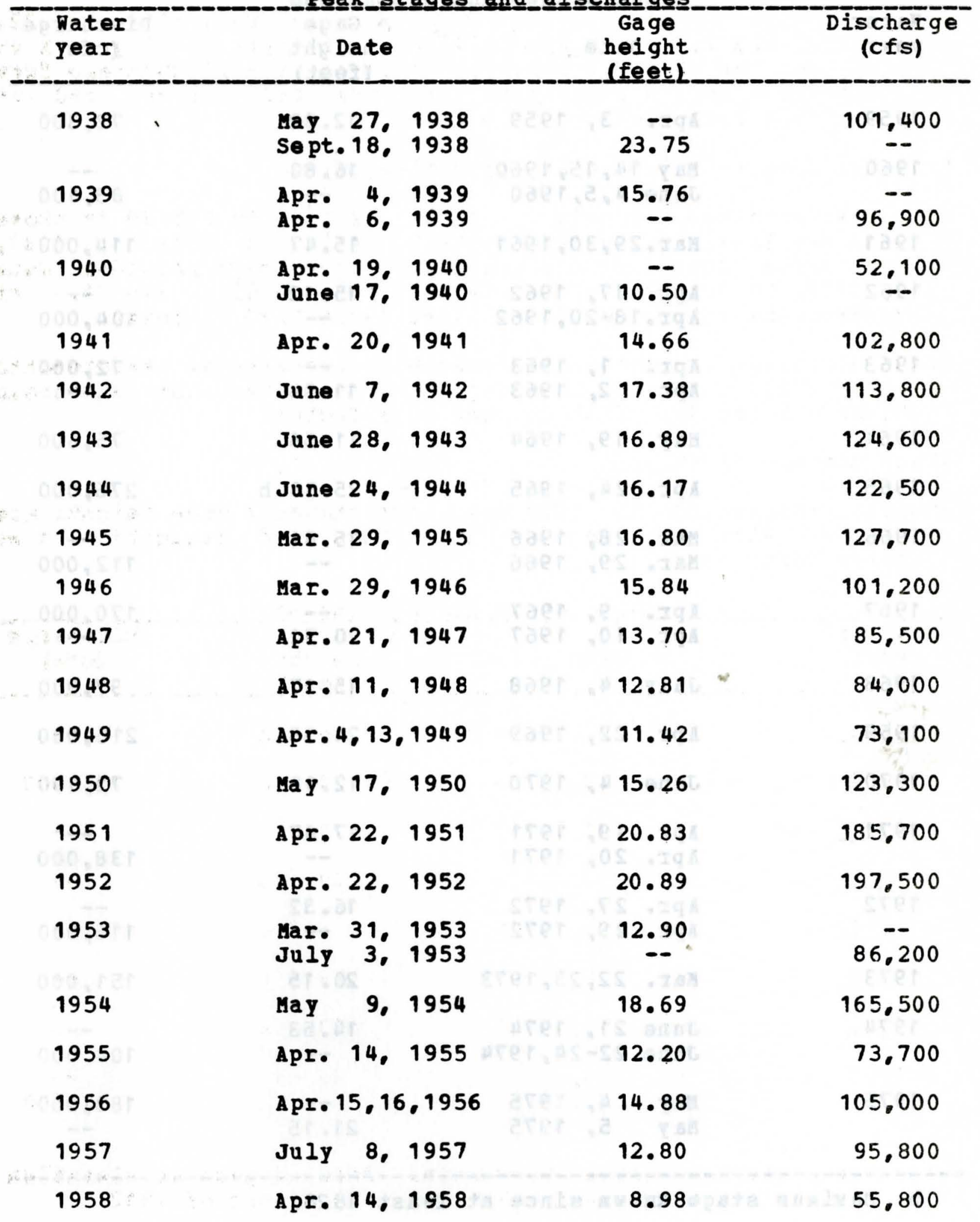


05-3895.00 Mississippi River at MCGregor, Iowa--(Continued)

Peak﹎stages and dis

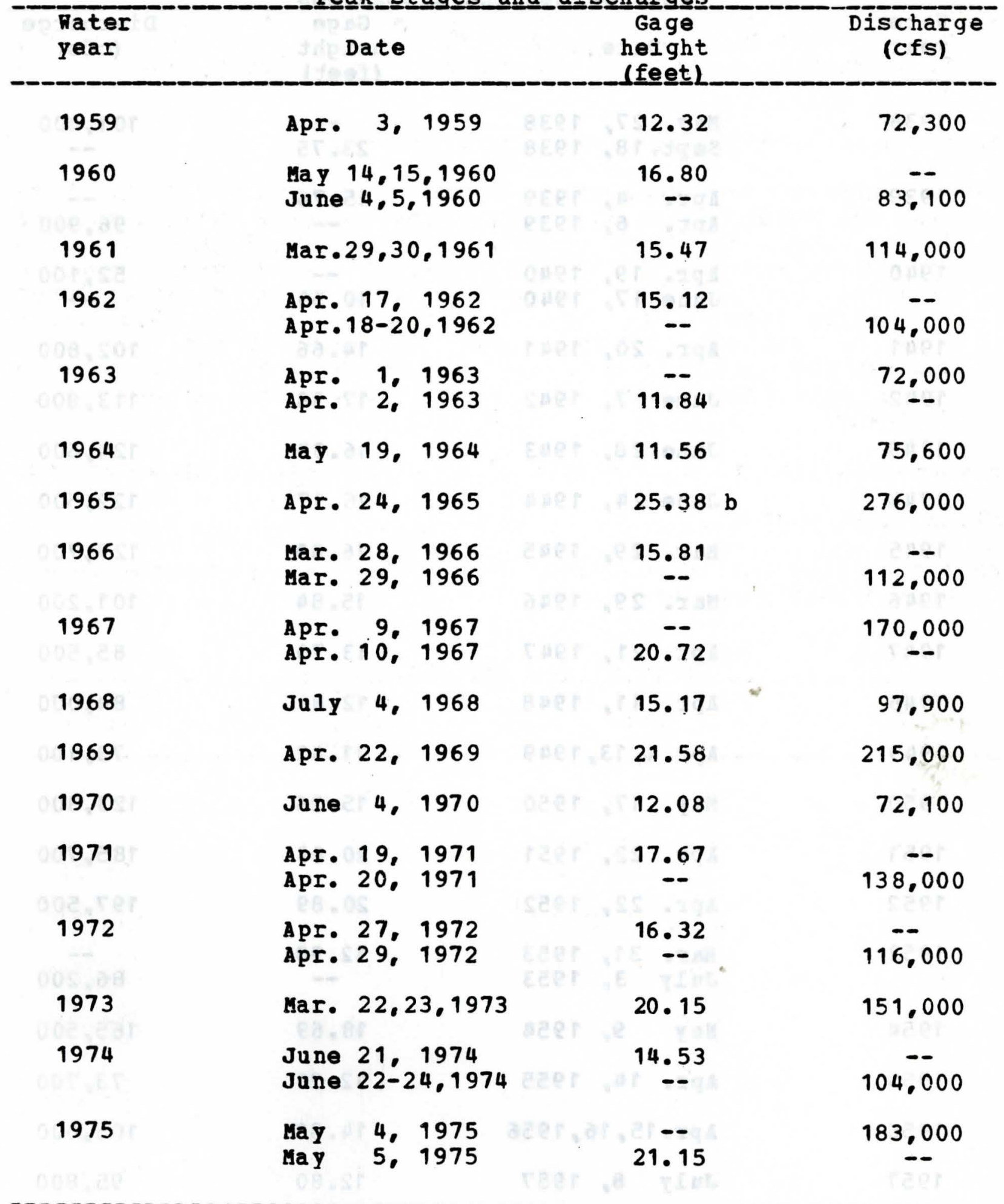

b Maximum stage known since at least 1828 . 
06-8070.00 Missouri River at Nebraska City. Nebraska

Location.--Iat 40040'55", Iong $95050148 "$, in NR1/4 NE1/4 sec.9, T. 8 N.. R. 14 E.. Oteo County, on right bank 0.7 mi upstream from Wabonsie Highway Bridge at Nebraska City, and at mile 562.6 .

Drainage area.- $-414,400 \mathrm{sq}$ mi, approximately.

Gage.-- Nater-stage recorder. Datum of gage is 905.36 ft above mean sea level, datum of 1929, supplementary adjustment of 1954. A ug. 1. 1878, to Oct. 30, 1888, staff gage 1.2 miles downstream and oct. 31, 1888, to Dec. 31, 1899, cable gage on railroad bridge 0.7 mile downstream, at datum 492.89 ft lower (St. Louis directrix). Aug. 12, 1929, to June 26, 1930, chain gage on railroad bridge, June 27,1930 , to oct. 21, 1931, wire-weight gage, and oct. 22, 1931, to Mar. 31, 1963, waterstage recorder, all at site $0.7 \mathrm{mile}$ downstream at datum 1.09 ft lower.

Stage-discharge relation.--Defined by current-meter measurements. Flood stage. $--18 \mathrm{ft}$.

Remarks.--Flow partly regulated by upstream main-stem reservoirs. only annul peaks are shown.

Peak__stąges_and_di

\begin{tabular}{|c|c|c|c|c|c|}
\hline $\begin{array}{l}\text { Water } \\
\text { year }\end{array}$ & & Date & $\begin{array}{c}\text { Gage } \\
\text { height } \\
\text { (feet) }\end{array}$ & - & $\begin{array}{c}\text { Discharge } \\
\text { (cfs) }\end{array}$ \\
\hline 1930 & $\operatorname{May}$ & 11. 1930 & 11.63 & & 95.200 \\
\hline 1931 & $\begin{array}{l}\text { Jan. } \\
\text { June }\end{array}$ & $\begin{array}{r}5,1931 \\
24,1931\end{array}$ & $\begin{array}{l}11.02 \\
10.76\end{array}$ & & 56.200 \\
\hline 1932 & June & $17-19,1932$ & 12.9 & & 138,000 \\
\hline 1933 & May & 29,1933 & 12.2 & & 112,000 \\
\hline 1934 & Mar. & 5. 1934 & 12.4 & & 138,000 \\
\hline 1935 & $\begin{array}{l}\text { Jan. } \\
\text { June }\end{array}$ & $\begin{array}{l}16,1935 \\
23,24.1935\end{array}$ & $\begin{array}{l}15.25 \\
13.9\end{array}$ & & 106,000 \\
\hline 1936 & $\begin{array}{l}\text { Mar. } \\
\text { Mar. }\end{array}$ & $\begin{array}{r}6.1936 \\
10.1936\end{array}$ & $\begin{array}{l}15.25 \\
14.05\end{array}$ & & $113, \overline{-0}$ \\
\hline 1937 & June & 25,1937 & 16.55 & & 111,000 \\
\hline
\end{tabular}


06-8070.00 Missouri River at Nebraska City. Nebraska-- (Continued)

Peak_stages and discharges

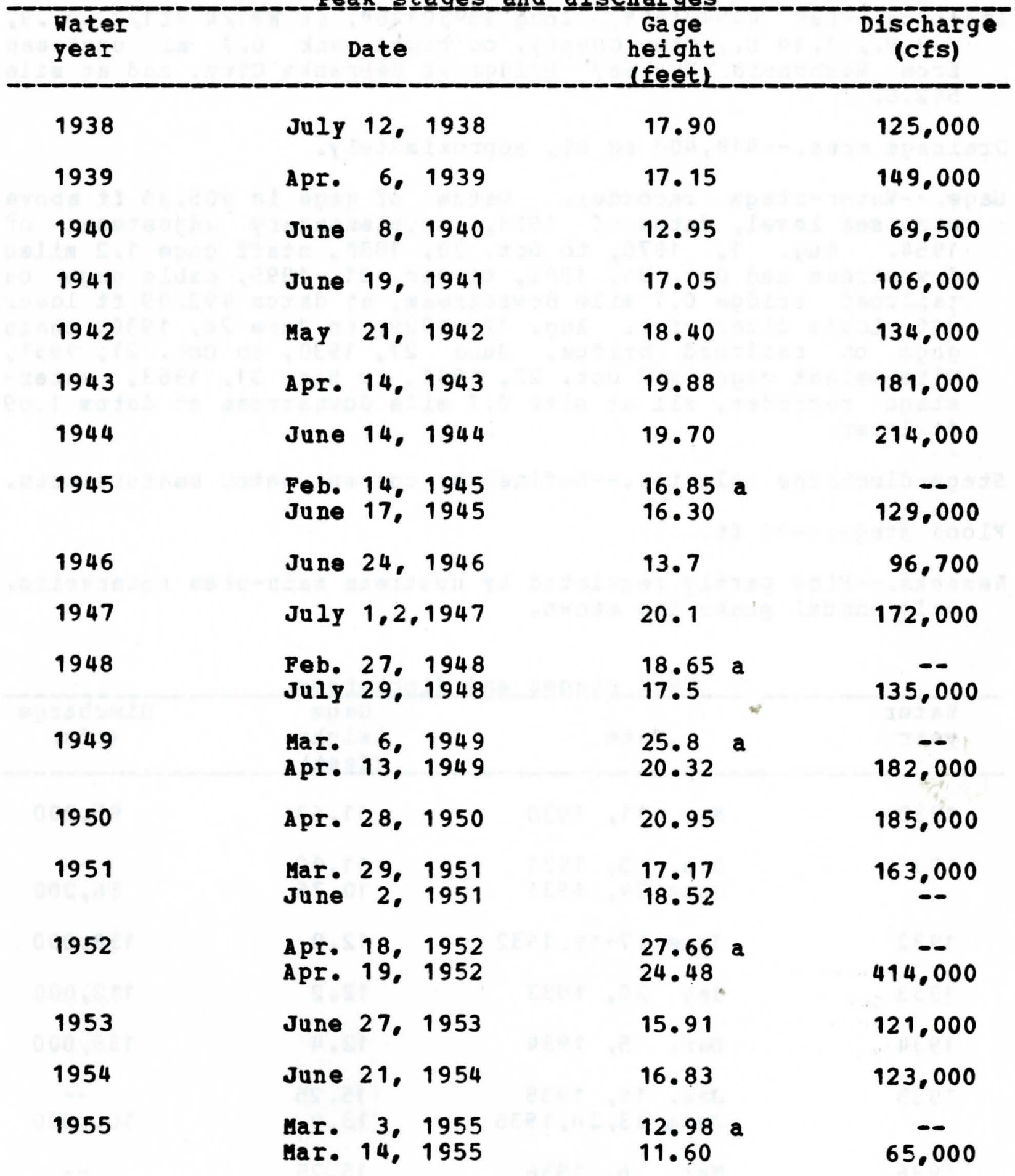

a Affected by ice. 
06-8070.00 Hissouri River at Nebraska City. Nebraska-- (Continued)

Peak_stages_and_disscharges

\begin{tabular}{|c|c|c|c|}
\hline $\begin{array}{l}\text { Water } \\
\text { year }\end{array}$ & Date & $\begin{array}{c}\text { Gage } \\
\text { height } \\
\text { (feet) }\end{array}$ & $\begin{array}{l}\text { Discharge } \\
\text { (cfs) }\end{array}$ \\
\hline 1956 & $\begin{array}{l}\text { Jan. 11, } 1956 \\
\text { Har. 19, } 1956\end{array}$ & $\begin{array}{l}12.12 \mathrm{a} \\
10.4\end{array}$ & $54 . \overline{000}$ \\
\hline 1957 & June 18, 1957 & 17.08 & 116.000 \\
\hline 1958 & sug. 6,1958 & 13.48 & 85,000 \\
\hline 1959 & $\begin{array}{lll}\text { June } & 1, & 1959 \\
\text { Aug. } & 3, & 1959\end{array}$ & $\begin{array}{l}14.92 \\
14.80\end{array}$ & $83 . \overline{-400}$ \\
\hline 1960 & Apr. $\quad 5,1960$ & 21.43 & 178,000 \\
\hline 1961 & June 15,1961 & 11.42 & 55,600 \\
\hline 1962 & Mar. 31, 1962 & 20.65 & 151,000 \\
\hline 1963 & June 25,1963 & 15.66 & 92.400 \\
\hline 1964 & June 17,1964 & 17.46 & 108,000 \\
\hline 1965 & May 26, 1965 & 15.65 & 94,200 \\
\hline 1966 & $\begin{array}{ll}\text { Oct. } & 1,1965 \\
\text { Feb. } & 8,1966\end{array}$ & $\begin{array}{l}14.50 \\
16.75 \mathrm{a}\end{array}$ & 90.100 \\
\hline 1967 & June 17,1967 & 22.95 & 166,000 \\
\hline 1968 & $\begin{array}{ll}\text { Jan. } 24,1968 \\
\text { June } 26,1968\end{array}$ & $\begin{array}{l}16.22 \text { a } \\
13.92\end{array}$ & 71.000 \\
\hline 1969 & $\begin{array}{l}\text { Feb. } 26,1969 \\
\text { Apr. 13, } 1969\end{array}$ & $\begin{array}{l}19.32 a \\
18.36\end{array}$ & 105.000 \\
\hline 1970 & $\begin{array}{lr}\text { Jan. } 22, & 1970 \\
\text { Oct. } & 7,1970\end{array}$ & $\begin{array}{l}16.06 a \\
12.78\end{array}$ & $56 . \overline{--}$ \\
\hline 1971 & $\begin{array}{l}\text { Feb. 22, } 1971 \\
\text { June 12, } 1971\end{array}$ & $\begin{array}{l}18.45 \\
18.98\end{array}$ & 114.000 \\
\hline 1972 & sept.13, 1972 & 15.82 & 86,500 \\
\hline 1973 & May 28,1973 & 16.99 & 86.800 \\
\hline
\end{tabular}

a Affected by ice. 
06-8070.00 Missouri River at Nebraska City, Nebraska--(Continued) Peak_stagges_and dis charges

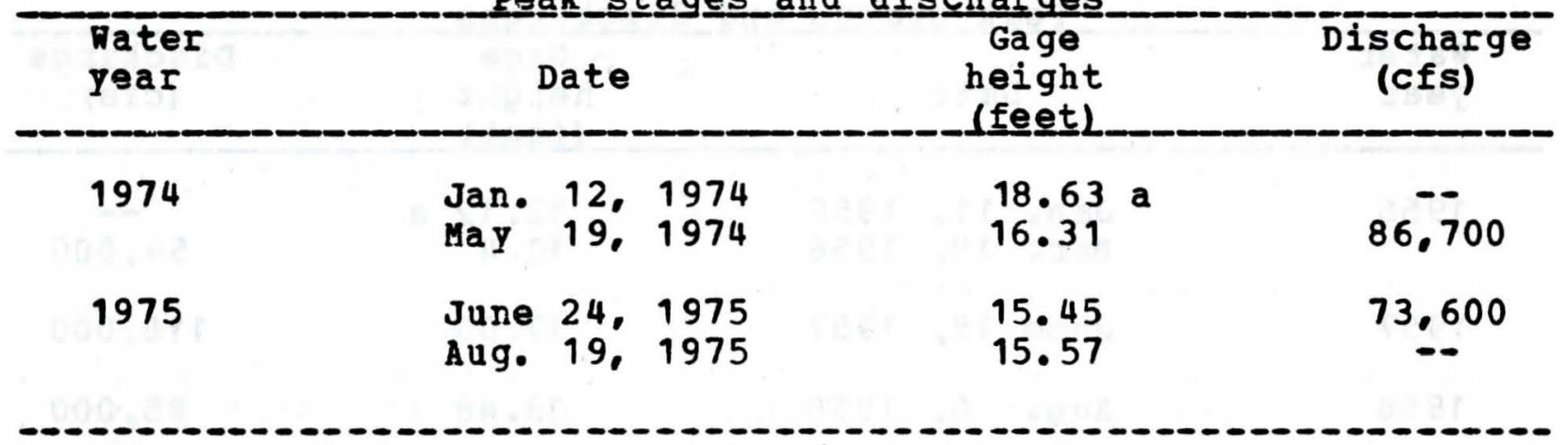

a Affected by ice. 
06-6100.00 Missouri River at Omaha, Nebraska

Location.--Iat $41015^{\circ} 32^{\prime \prime}$, long $95055^{\circ} 20^{\prime \prime}$, in SE1/4 NW1/4 sec.23, T. 15 N.. R. 13 E.. Douglas County, on right bank on left side of concrete floodwali, at foot of Douglas street, $275 \mathrm{ft}$ downstream from Interstate 480 Highway bridge in Omaha, and at 由ile 615.9.

Drainage area.--322,800 sq mi, approximately.

Gage.--Water-stage recorder. Datum of gage is $958.24 \mathrm{ft}$ above mean sea level. Apr. 10, 1872, to Aug. 31, 1928, staff, cable, and chain gages at several sites within 0.6 mile of present site not more than $0.43 \mathrm{ft}$ below present datum. Sept. 1. 1928, to Nov. 30, 1929, chain gage attached to Illinois Central Railroad bridge 2 miles upstream at datum 2.97 ft higher. Dec. 1, 1929, to May 26, 1930, chain gage and May 27, 1930, to Oct. 18, 1931, wire-weight gage, at present site and datum. oct. 19, 1931, to Sept. 30, 1936, water-stage recorder 0.4 mile downstream at present datum.

Stage-discharge relation.--Defined by current-meter measurements. Flood stage. $-19 \mathrm{ft}$.

Remarks.--Flow partly regulated by upstream main-stem reservoirs. only annual peaks are shown.

Peak

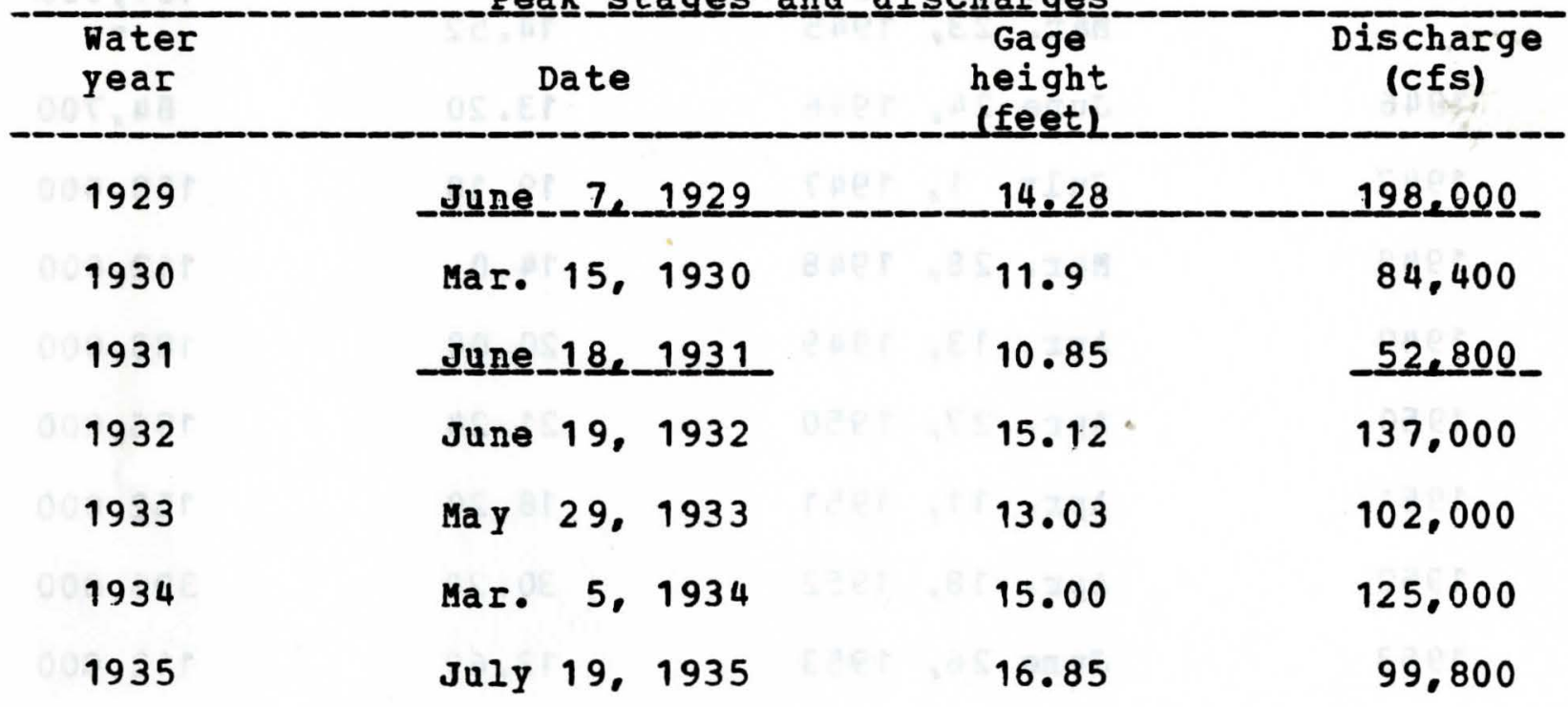


06-6100.00 Missouri River at Omaha, Nebraska--(Continued)

Peak stages and discharges

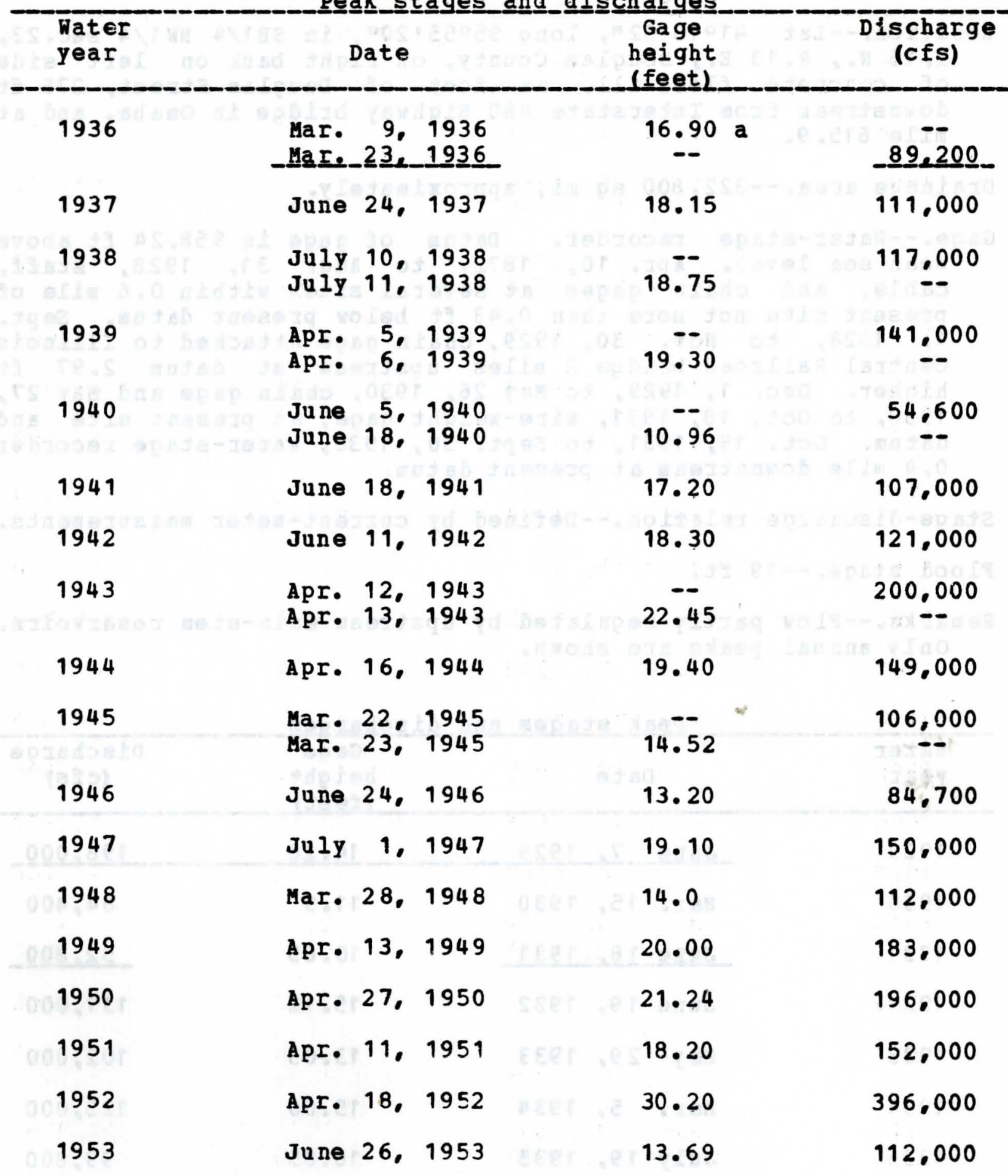

a Affected by ice. 
06-6100.00 Missouri River at Omaha, Nebraska--(Continued)

Pea $\underline{k}$ stages and dis

\begin{tabular}{|c|c|c|c|}
\hline $\begin{array}{l}\text { Mater } \\
\text { year }\end{array}$ & Date & $\begin{array}{c}\text { Gage } \\
\text { height } \\
\text { (fest) }\end{array}$ & $\begin{array}{l}\text { Discharge } \\
\text { (cfs) }\end{array}$ \\
\hline 1954 & June 21,1954 & 11.12 & 87,400 \\
\hline 1955 & $\begin{array}{lll}\text { Mar. } & 13, & 1955 \\
\text { July } 11, & 1955\end{array}$ & $7 .-\overline{36}$ & 51,500 \\
\hline 1956 & $\begin{array}{l}\text { Mar. 18, } 1956 \\
\text { July } 13,1956\end{array}$ & 7.47 & 42,600 \\
\hline 1957 & June 16,1957 & 9.25 & 59.000 \\
\hline 1958 & July 2,1958 & 8.55 & 45,400 \\
\hline 1959 & June 1,1959 & 9.77 & 57,000 \\
\hline 1960 & $\begin{array}{lll}\text { Apr. } & 1,1960 \\
\text { Apr. } & 4,1960\end{array}$ & $16 . \overline{96}$ & 120.000 \\
\hline 1961 & June 15, 1961 & 7.66 & 41,700 \\
\hline 1962 & Mar. 29, 1962 & 16.48 & 115.000 \\
\hline 1963 & June 5,1963 & 9.97 & 61.700 \\
\hline 1964 & May 26,1964 & 11.10 & 68.900 \\
\hline 1965 & Apr. $\quad 8,1965$ & 11.82 & 69,800 \\
\hline 1966 & Feb. 10,1966 & 10.69 & 61,800 \\
\hline 1967 & June 16,1967 & 14.03 & 68,400 \\
\hline 1968 & $\begin{array}{l}\text { Jan. } 19,1968 \\
\text { June } 25,1968\end{array}$ & $\begin{array}{l}13.98 \mathrm{a} \\
10.39\end{array}$ & $53, \overline{000}$ \\
\hline 1969 & Apr. 12, 1969 & 16.82 & 100,000 \\
\hline 1970 & $\begin{array}{ll}\text { Oct. } & 1,1969 \\
\text { Aug. } & 2, \\
1970\end{array}$ & $\begin{array}{r}9.88 \\
10.33\end{array}$ & 51,900 \\
\hline 1971 & $\begin{array}{l}\text { Mar. 14, } 1971 \\
\text { June 11, } 1971\end{array}$ & $\begin{array}{l}13.94 \\
14.08\end{array}$ & 91,900 \\
\hline
\end{tabular}

affected by ice. 
06-6100.00 Missouri River at Omaha, Nebraska--(Continued)

Peak_stages_and di

\begin{tabular}{|c|c|c|c|c|}
\hline $\begin{array}{l}\text { Water } \\
\text { year }\end{array}$ & Date & & $\begin{array}{c}\text { Gage } \\
\text { height } \\
\text { (feet) }\end{array}$ & $\begin{array}{c}\text { Discharge } \\
\text { (cfs) }\end{array}$ \\
\hline 1972 & $\begin{array}{l}\text { July } 18 . \\
\text { sept. } 11 .\end{array}$ & $\begin{array}{l}1972 \\
1972\end{array}$ & $\begin{array}{l}12 \cdot 64 \\
12.57\end{array}$ & 70.500 \\
\hline 1973 & $\begin{array}{l}\text { Nov. } 3 . \\
\text { Se pt. } 26 .\end{array}$ & $\begin{array}{l}1972 \\
1973\end{array}$ & $\begin{array}{r}9.28 \\
11.14\end{array}$ & 59.200 \\
\hline 1974 & 19. & 1974 & 10.86 & 52.400 \\
\hline 1975 & Aug. 18 & 1975 & 13.66 & 70.200 \\
\hline
\end{tabular}


Location.--Lat $40003 \cdot 14 "$, long $95^{\circ} 25 \cdot 12^{\prime \prime}$, in NW1/4 NN1/4 sec.17, T. 1 N.. R.18 E.. Richardson County, on downstream end of middle pier of bridge on U.S. Highway 159 at Rulc, 3.2 mi upstream from Nemaha River, and at mile 498.0 .

Drainage area. $-418,900 \mathrm{sq}$ mi, approximately.

Gage.-- Nater-stage recorder. Datum of gage is $837.23 \mathrm{ft}$ above mean sea level. Prior to sept. 13, 1950, nonrecording gage at site $80 \mathrm{ft}$ upstream at same datum.

Stage-discharge relation.--Defined by current-meter measurements. Flood stage. $-17 \mathrm{ft.}$

Bemarks.--Flow partly regulated by upstream main-stem reservoirs.

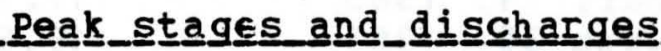

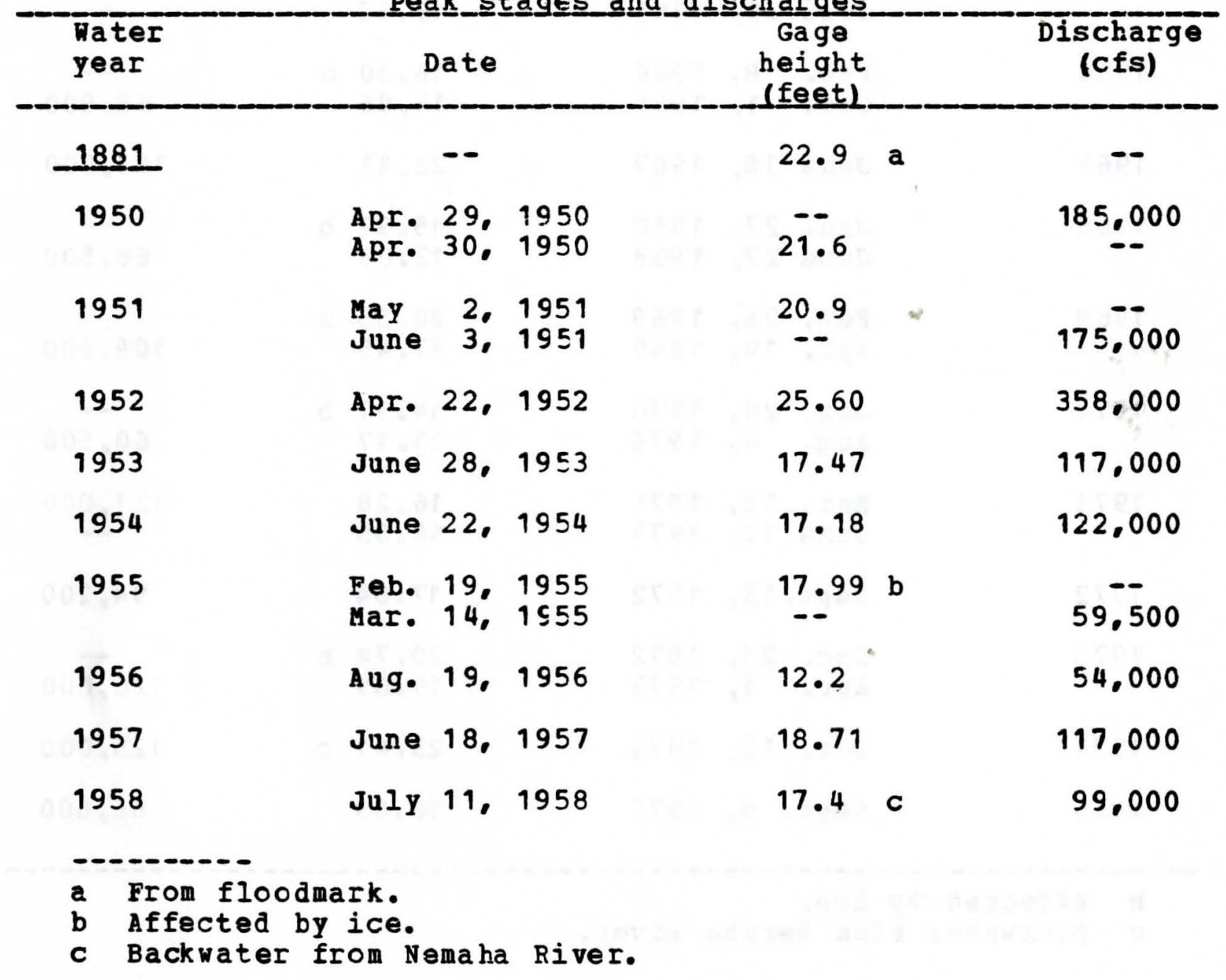


06-8135.00 Missouri River at Rulo, Nebraska-- (Continued)

Peak_stages_and di

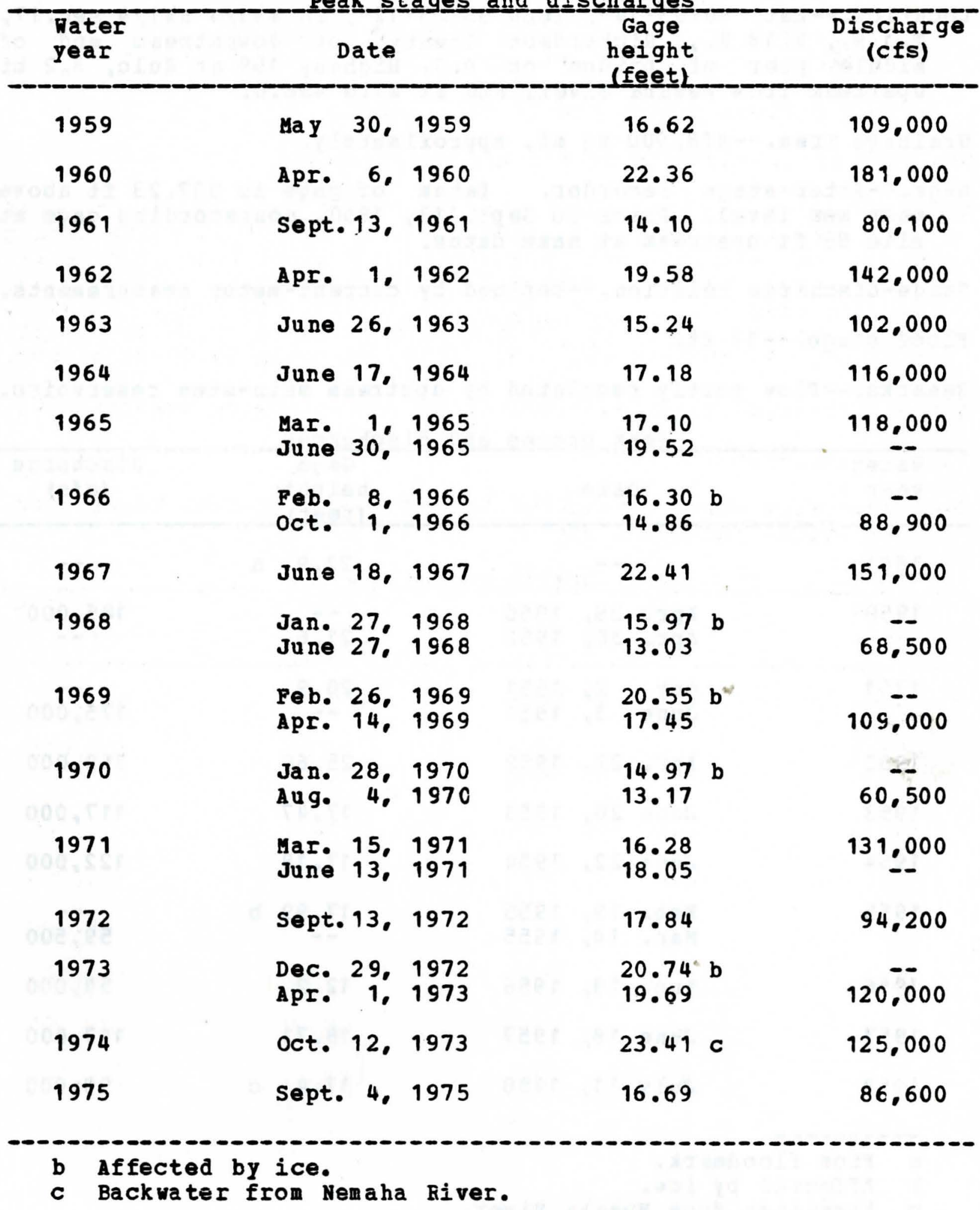




$$
\text { 06-4860.00 Missouri River at Sioux City. Iowa }
$$

Location.--Iat $422^{\circ} 9^{\prime} 10^{\prime \prime}$, long $96024 \cdot 47 "$, in NN1/4 SE1/4 sec.16, T.29 N., R.9 E., sixth principal meridian, Dakota County. Hebraska, on right bank on upstream side of bridce on $0 . S$. Highway 77 at South Sioux City, Nebraska, 2.0 mi dcwnstream from Big sioux River, and at mile 732.3.

Drainage area.--314,600 sq $\mathrm{mi}$, approximately.

Gage.--Nater-stage recorder. Datum of gage is 1,056.98 ft above mean sea level. Sept. 2, 1878, to Dec. 31, 1905, nonrecording gages at various locations within $1.7 \mathrm{mi}$ of present site and at various datums. Jan. 1, 1906, to Feb. 14, 1935, nonrecording gage, and Feb. 15, 1935, to sept. 30, 1969, water-stage recorder at present site at datum $19.98 \mathrm{ft}$ higher. and Oct. 1. 1969 to sept. 30,1970, at datum 20.00 ft higher.

Stage-discharge relation.--Defined by current-meter measurements. Flood stage. --36 ft.

Remarks.--Flow partly regulated by upstream main-stem reservoirs. only annual peaks are shown.

Peak_stages_and

\begin{tabular}{|c|c|c|c|c|}
\hline $\begin{array}{l}\text { Water } \\
\text { year }\end{array}$ & & Date & $\begin{array}{c}\text { Gage } \\
\text { height } \\
\text { (feet) }\end{array}$ & $\begin{array}{c}\text { Discharge } \\
\text { (cfs) }\end{array}$ \\
\hline 1929 & Apr. & 1. 1929 & $12.5 \mathrm{a}$ & 190,000 \\
\hline 1930 & $\begin{array}{l}\text { Mar. } \\
\text { Apr. }\end{array}$ & $\begin{array}{r}6,1930 \\
10,1930\end{array}$ & $\begin{array}{l}9.4 \\
9.8 \mathrm{a}\end{array}$ & 108,000 \\
\hline 1931 & June & 16, 1931 & 9.79 & 54.700 \\
\hline 1939 & Apr. & 3. 1939 & $14 \cdot 35$ & 168,000 \\
\hline 1940 & June & 16. 1940 & 8.90 & 55.700 \\
\hline 1941 & June & 15, 1941 & 13.0 & 121.000 \\
\hline 1942 & June & 8. 1942 & 13.77 & 127,000 \\
\hline 1943 & Apr. & 10. 1943 & 18.72 & 212,000 \\
\hline 1944 & Apr. & 12, 1944 & 15.45 & 180,300 \\
\hline
\end{tabular}

a Probably backwater from ice. 
06-4860.00 Missouri River at Sioux City, Iowa--(Continued)

Pea

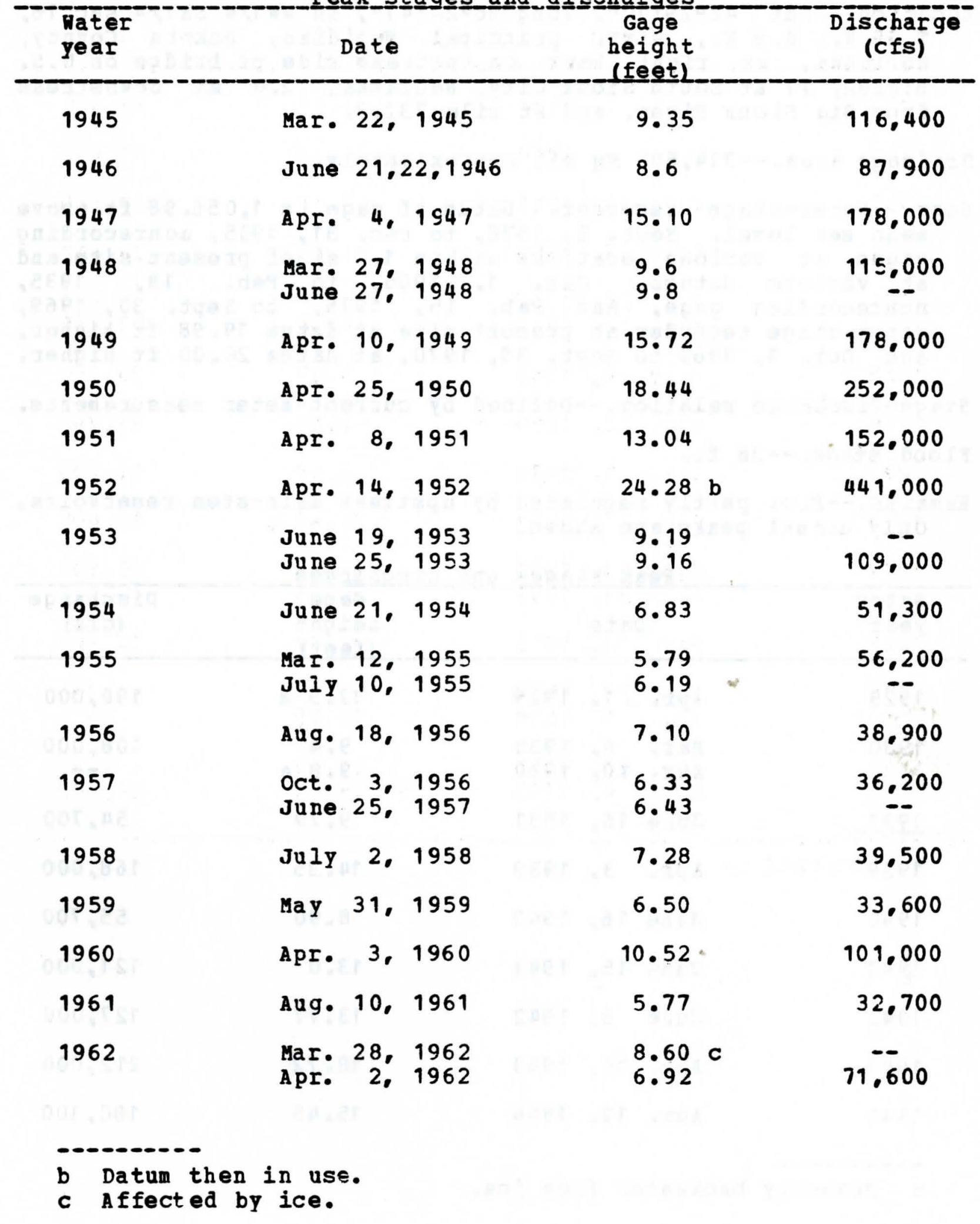


06-4860.00 Missouri River at Sioux City. Iowa-- (Continued)

Peak stages and discharges

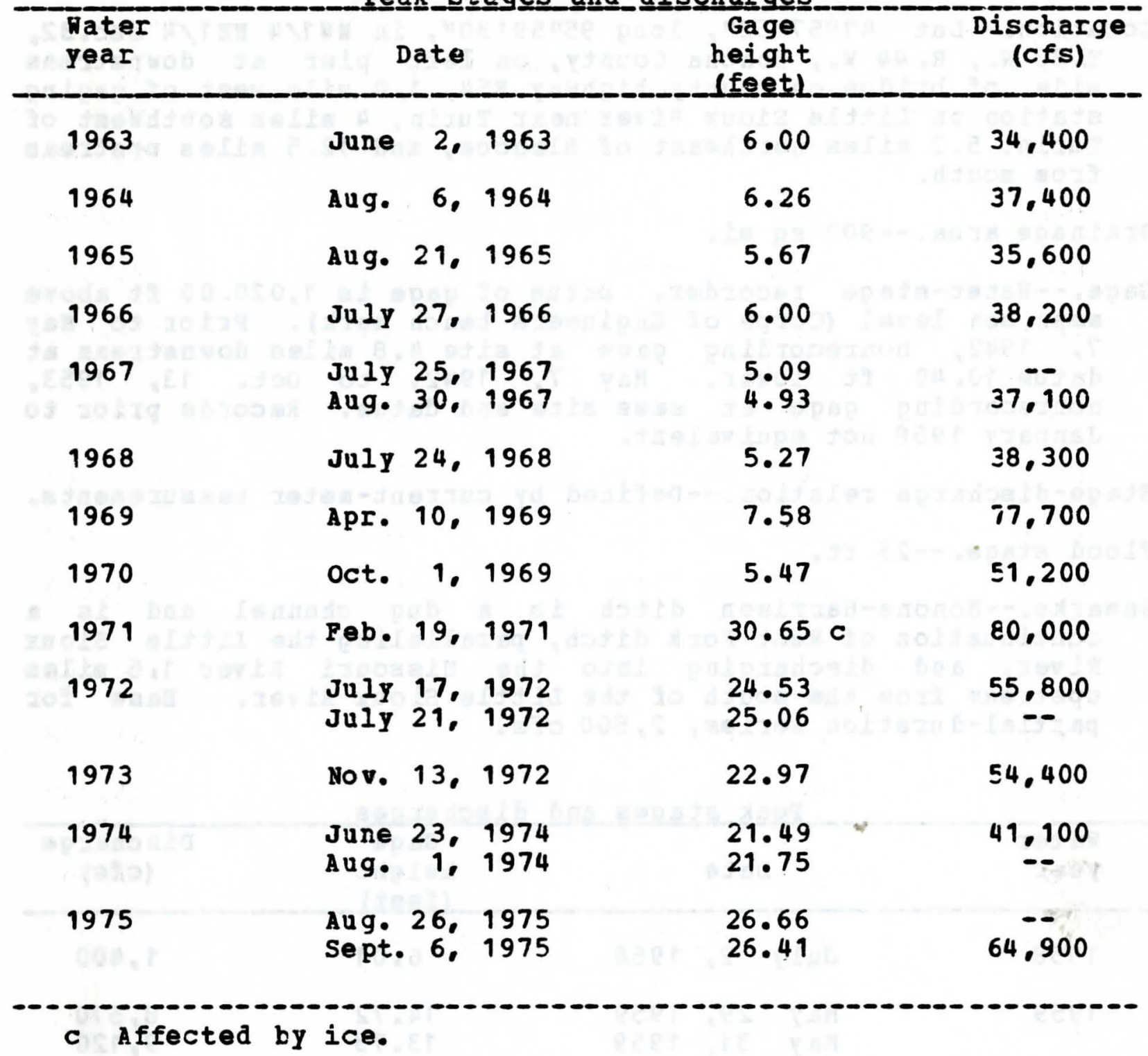




\section{6-6024.00 Monona-Harrison ditch near Turin. Iowa}

Location.--Lat 41057'52", lcng 95059'30", in NN1/4 NE1/4 sec.32, T.83 N.. R. 44 W.. Monona County, on left pier at downstrean side of bridge on county highway E54, 1.0 mile west of gaging station on little sioux River near Turin. 4 miles southwest of Turin. 5.2 miles northeast of Blencoe, and 12.5 miles upstrea from mouth.

Drainage area.--900 sq mi.

Gage.--Water-stage recorder. Datum of gage is $1.020 .00 \mathrm{ft}$ above mean sea level (Corps of Engineers bench mark). Prior to Hay 7. 1942, nonrecording gage at site 4.8 miles downstrean at datum 10.40 ft lower. May 7. 1942, to Oct. 13, 1953. nonrecording gage at same site and datum. Records prior to January 1958 not equivalent.

Stage-discharge relation.--Defined by current-meter neasurenents. Flood stage.--25 ft.

Remarks.--Monona-Harrison ditch is a dug channel and is a continuation of West Fork ditch, paralleling the Iittle sioux River, and discharging into the Missouri River 1.5 miles upstream from the mouth of the little sioux River. Base for partial-duration series, $2,500 \mathrm{cfs}$.

Peak__stages_and_discharges

\begin{tabular}{|c|c|c|c|c|}
\hline $\begin{array}{l}\text { Water } \\
\text { year }\end{array}$ & Date & & $\begin{array}{c}\text { Gage } \\
\text { height } \\
\text { (feet) }\end{array}$ & $\begin{array}{c}\text { Dischargo } \\
\text { (cfs) }\end{array}$ \\
\hline 1958 & July 2, & 1958 & 6.01 & 1.400 \\
\hline 1959 & $\begin{array}{ll}\text { May } & 29 . \\
\text { May } & 31 .\end{array}$ & $\begin{array}{l}1959 \\
1959\end{array}$ & $\begin{array}{l}14.72 \\
13.73\end{array}$ & $\begin{array}{l}8.570 \\
9.120\end{array}$ \\
\hline 1960 & $\begin{array}{lr}\text { Mar. } & 30^{\circ} \\
\text { Apr. } & 2{ }^{\circ} \\
\text { May } & 22^{\circ} \\
\text { May } & 27^{\circ} \\
\text { Aug. } & 6_{\circ}^{\circ} \\
\text { Aug. } & 29^{\circ}\end{array}$ & $\begin{array}{l}1960 \\
1960 \\
1960 \\
1960 \\
1960 \\
1960\end{array}$ & $\begin{array}{r}16.32 \\
13.95 \\
10.58 \\
10.02 \\
8.82 \\
11.96\end{array}$ & $\begin{array}{r}10.400 \\
7.800 \\
4.480 \\
4.000 \\
3.060 \\
5.700\end{array}$ \\
\hline 1961 & Mar. 15, & 1961 & $8: 13$ & 3,170 \\
\hline
\end{tabular}


06-6024.00 Monona-Harrison ditch near Turin, Iowa-- (Continued)

Peak_stages and di

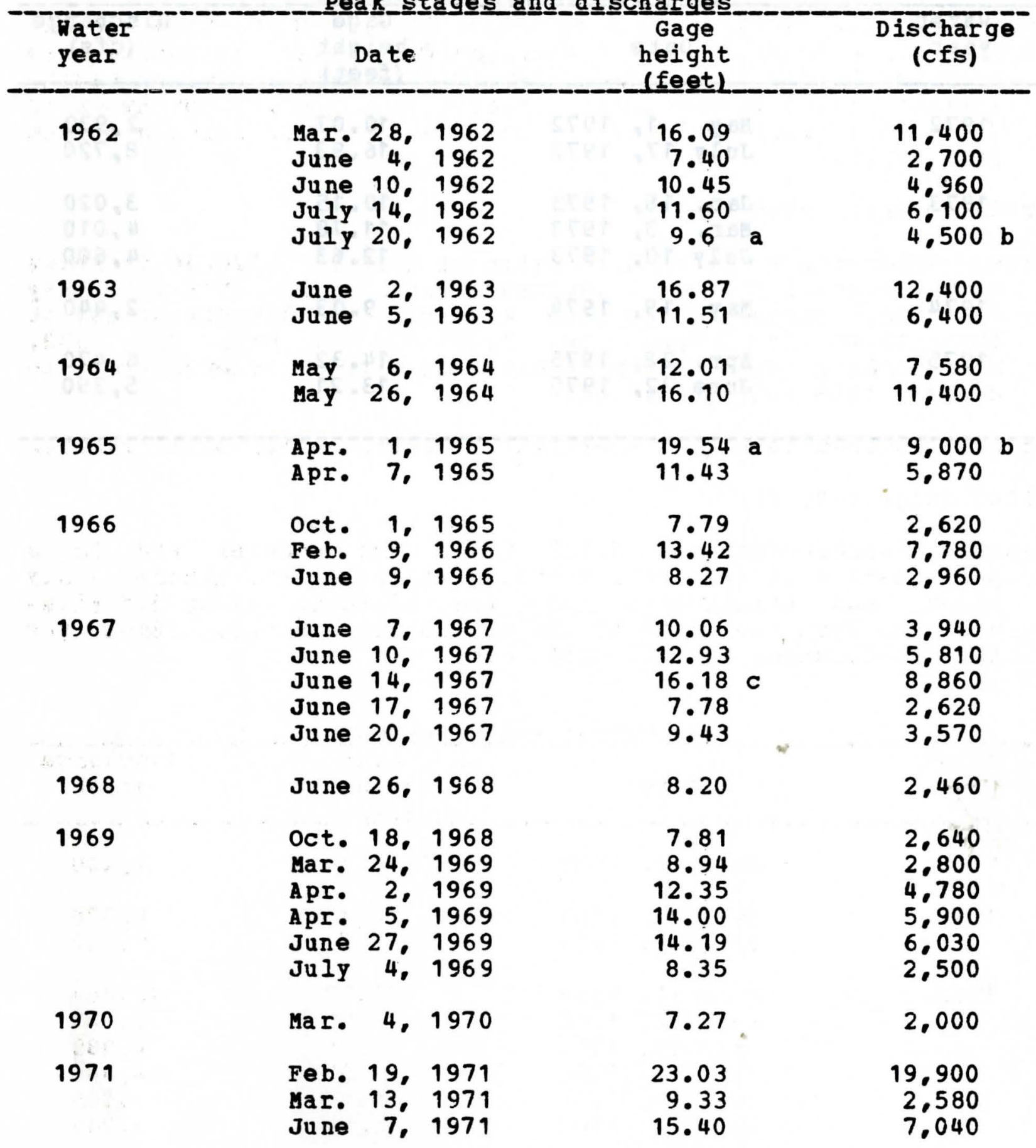

\footnotetext{
a Affected by ice.

b About.

c From floodmark.
} 
06-6024.00 Monona-Harrison ditch near Turin, Iowa-- (Continued)

Peak__stages and_di ischarges

\begin{tabular}{|c|c|c|c|c|}
\hline $\begin{array}{l}\text { Water } \\
\text { year }\end{array}$ & Date & & $\begin{array}{c}\text { Gage } \\
\text { height } \\
\text { (feet). }\end{array}$ & $\begin{array}{c}\text { Discharge } \\
\text { (cfs) }\end{array}$ \\
\hline 1972 & $\begin{array}{ll}\text { May } & 1 . \\
\text { JuIy } & 17 .\end{array}$ & $\begin{array}{l}1972 \\
1972\end{array}$ & $\begin{array}{l}10.07 \\
16.93\end{array}$ & $\begin{array}{l}2.930 \\
8.720\end{array}$ \\
\hline 1973 & $\begin{array}{l}\text { Jan. } 18, \\
\text { Mar. } \\
\text { July } 10\end{array}$ & $\begin{array}{l}1973 \\
1973 \\
1973\end{array}$ & $\begin{array}{l}10.15 \\
11.78 \\
12.63\end{array}$ & $\begin{array}{l}3.020 \\
4.010 \\
4.600\end{array}$ \\
\hline 1974 & $\operatorname{May} 19$. & 1974 & 9.03 & 2.440 \\
\hline 1975 & $\begin{array}{l}\text { Apr. } 28, \\
\text { June } 22,\end{array}$ & $\begin{array}{l}1975 \\
1975\end{array}$ & $\begin{array}{l}14 \cdot 32 \\
13 \cdot 21\end{array}$ & $\begin{array}{l}6.470 \\
5.390\end{array}$ \\
\hline
\end{tabular}




\section{6-6105.20 Mosquito Creek near Earling, Iowa}

Location.--Lat 41045'10", long 95027'50", in N1/2 SE1/4 sec.11. T. 80 N.. R. 40 W.. Shelby County, on right bank at streamstabilization structure 1,300 ft downstream from bridge on State Highway 191, 0.5 mile downstream from small left-bank tributary and 2.3 miles southwest of Earling.

Drainage area.--32.0 sq mi.

Gage.--Duplex water-stage recorder. Datum of gage is 1.222.56 ft above mean sea level. Gage heights obtained of headwater (base gage) and tailwater (supplementary gage) elevations at stream-stabilization structure. The stabilization structure is a dam approximately $16 \mathrm{ft}$ high constructed of sheet piling and derrick stone. The crest of the cut-off filing is rectangular in shape at low stages and trapezoidal at high stages.

Stage-discharge relation.--Defined by current-meter measurements.

Remarks.--Base for partial-duration series, 500 cfs. The stabilization structure is a dam approximately 16 ft high constructed of sheet piling and derrick stone. The crest of the cut-off piling is rectangular in shape at low stages and trapezoidal at high stages. Discharges computed from headwater gage readings.

Pea $\underline{k}$ stages_and dis $\underline{\text { charges }}$

\begin{tabular}{|c|c|c|c|}
\hline $\begin{array}{l}\text { Water } \\
\text { year }\end{array}$ & Date & $\begin{array}{l}\text { Gage } \\
\text { height } \\
\text { (feet). }\end{array}$ & $\begin{array}{c}\text { Discharge } \\
\text { (cfs) }\end{array}$ \\
\hline 1965 & Sept. 7,1965 & 20.82 & 589 \\
\hline 1966 & $\begin{array}{lll}\text { May } & 22,1966 \\
\text { May } & 23,1966 \\
\text { June } & 28,1966\end{array}$ & $\begin{array}{l}21 \cdot 39 \\
21 \cdot 84 \\
22 \cdot 38\end{array}$ & $\begin{array}{r}870 \\
1.120 \\
1.390\end{array}$ \\
\hline 1967 & $\begin{array}{l}\text { June } 7,1967 \\
\text { June } 9,1967 \\
\text { June 11. } 1967 \\
\text { June 15, } 1967 \\
\text { June 19, } 1967\end{array}$ & $\begin{array}{l}23.67 \\
20.65 \\
21.95 \\
24.42 \\
21.17\end{array}$ & $\begin{array}{r}2.370 \\
512 \\
1.190 \\
2.960 \\
755\end{array}$ \\
\hline
\end{tabular}

a From floodmark. 
06-6105.20 Hosquito Creek near Earling. Iowa--(Continued)

Pea $\underline{k}$ sttages_and

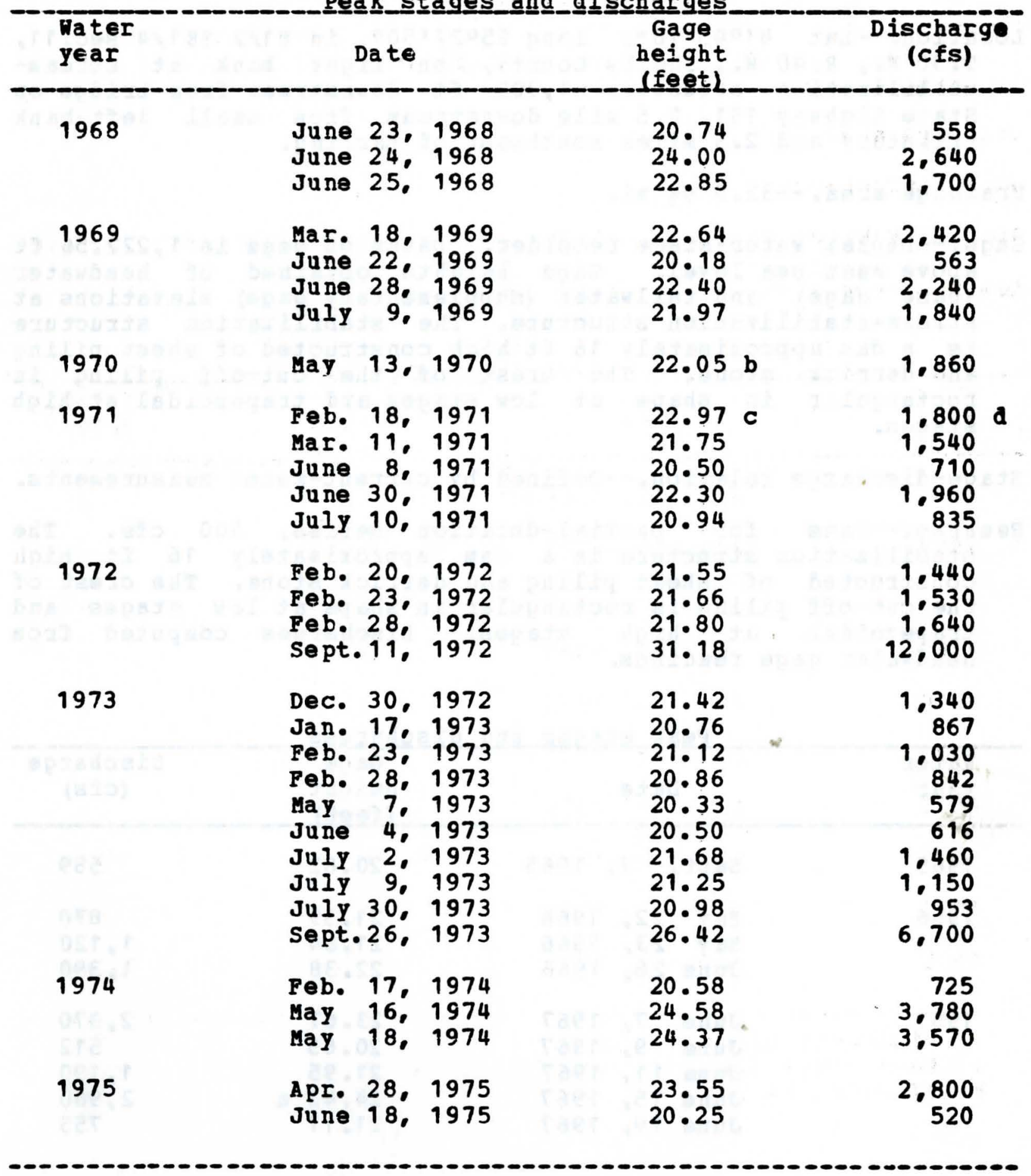

b From graph based on tailwater gage heights.

c Affected by ice.

d About. 
Location.--Iat $42019^{\prime}$, long $93038^{\circ}$, in SW1/4 seC.27. T.87 N.. R. 24 M.. Hamilton County, at bridge on U.S. Highway 69 in Jewell.

Drainage area. $--65.4 \mathrm{sq} \mathrm{mi}$.

Gage.--Crest-stage gage.

stage-discharge relation.--Defined by current-meter measurements. Renarks.--Only annual peaks are shown.

Peakㅡ_s stages and_di

\begin{tabular}{|c|c|c|c|}
\hline $\begin{array}{l}\text { pater } \\
\text { year }\end{array}$ & Date & $\begin{array}{l}\text { Gage } \\
\text { height } \\
\text { (feetl. }\end{array}$ & $\begin{array}{c}\text { Discharge } \\
\text { (cfs) }\end{array}$ \\
\hline 1966 & June 12,1966 & 84.67 & a \\
\hline 1967 & June 10,1967 & 87.91 & a \\
\hline 1968 & $-\infty$ & b & a \\
\hline 1969 & July 9, 1969 & 89.76 & $\mathbf{a}$ \\
\hline 1970 & Aug. 6,1970 & 84.45 & a \\
\hline 1971 & Feb. 18, 1971 & $90.13 \mathrm{c}^{2}$ & a \\
\hline 1972 & aug. 7,1972 & 89.02 & a \\
\hline 1973 & Nov. 8,1972 & 86.96 & 710 \\
\hline 1974 & June 9,1974 & 85.64 & 490 \\
\hline 1975 & June 27, 1975 & 90.04 & 2,300 \\
\hline
\end{tabular}

a Discharge not determined.

b Peak stage did not reach bottom of gage.

c Affected by ice. 


\section{6-8080.0C Mule Creek near Malvern. Iowa}

(Discontinued Sept. 30, 1969)

Location.--Lat $40056 \cdot 36^{\prime \prime}$, long 95035'42", in NE1/4 NE1/4 sec.19, T. 71 N.. R. 41 M.. Mills County, on right bank $170 \mathrm{ft}$ upstream from culvert on county highway $163,0.2$ mile downstream from unramed tributary, 1.8 miles upstream from mouth, and 4.3 miles south of Malvern.

Drainage area.--10.6 sq mi.

Gage.--Water-stage recorder. Datum of gage is $974.20 \mathrm{ft}$ above mean sea level (levels by soil conservation Service). Prior to oct. 1, 1964, water-stage recorder at site $180 \mathrm{ft}$ downstream. Oct. 1, 1964, to Mar. 25, 1965, nonrecording gage with supplemental water-stage recorder at site 180 feet downstream. Mar. 26 to July 13, 1965, nonrecording gages at various locations.

Stage-discharge relation.--Defined by current-meter measurements below 510 cfs and extended above on basis of slope-area measurement of peak flow.

Remarks.--Base for partial-duration series, 300 cfs.

Pea

\begin{tabular}{|c|c|c|c|c|c|}
\hline $\begin{array}{l}\text { Hater } \\
\text { year }\end{array}$ & & Date & & $\begin{array}{l}\text { Gage } \\
\text { height } \\
\text { (fe日t) }\end{array}$ & $\begin{array}{c}\text { Discharge } \\
\text { (cfs) }\end{array}$ \\
\hline 1954 & $\begin{array}{l}\text { Aug. } \\
\text { Aug. }\end{array}$ & $\begin{array}{l}21 . \\
23 .\end{array}$ & $\begin{array}{l}1954 \\
1954\end{array}$ & $\begin{array}{l}15.84 \\
14.19\end{array}$ & $\begin{array}{l}2.070 \quad a \\
1.680\end{array}$ \\
\hline 1955 & Mar. & 1. & 1955 & 7.51 & 411 \\
\hline 1956 & $\begin{array}{l}\text { July } \\
\text { July } \\
\text { Aug• }\end{array}$ & $\begin{array}{l}11, \\
15, \\
18,\end{array}$ & $\begin{array}{l}1956 \\
1956 \\
1956\end{array}$ & $\begin{array}{l}7.55 \\
15.54 \\
10.4\end{array}$ & $\begin{array}{r}398 \\
1.990 \\
867\end{array}$ \\
\hline 1957 & $\begin{array}{l}\text { May } \\
\text { June } \\
\text { June } \\
\text { June } \\
\text { July }\end{array}$ & $\begin{array}{r}29 . \\
7 \% \\
15 \% \\
17 . \\
1 .\end{array}$ & $\begin{array}{l}1957 \\
1957 \\
1957 \\
1957 \\
1957\end{array}$ & $\begin{array}{r}12.58 \\
9.80 \\
6.30 \\
7.40 \\
8.70\end{array}$ & $\begin{array}{r}1.310 \\
849 \\
334 \\
479 \\
678\end{array}$ \\
\hline 1958 & $\begin{array}{l}J u 1 y \\
\text { JuIy }\end{array}$ & $\begin{array}{l}19 . \\
30,\end{array}$ & $\begin{array}{l}1958 \\
1558\end{array}$ & $\begin{array}{r}6.92 \\
12.35\end{array}$ & $\begin{array}{r}334 \\
1.180\end{array}$ \\
\hline
\end{tabular}

a Maximum during period June to September 1954. 
06-8080.00 Mule Creek near Malvern. Iowa-- (Continued)

Feak_stages and_discharges

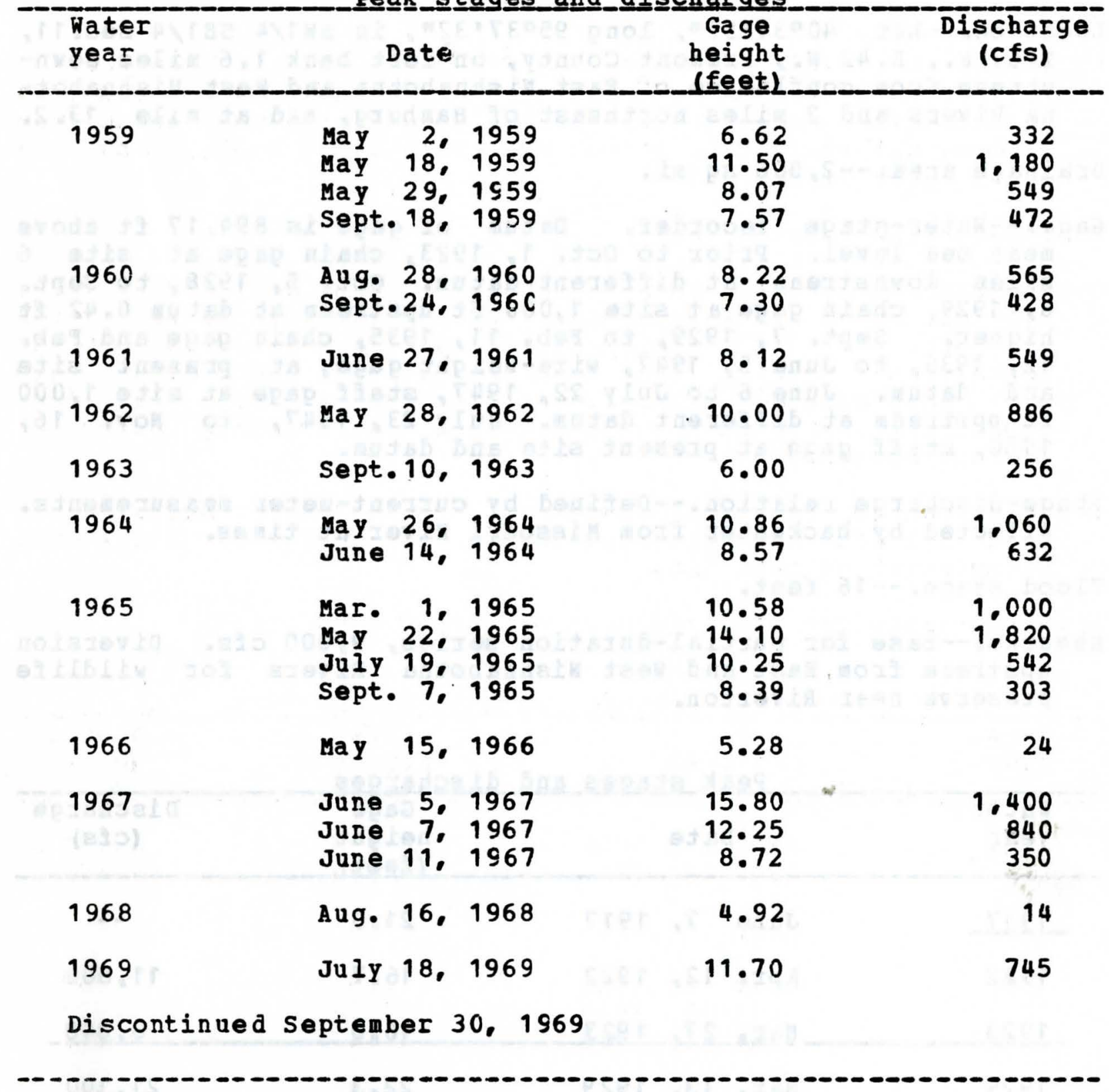


Location.--Iat $40037 \cdot 57 "$ " long $95037 \cdot 32^{\prime \prime}$. in Sw1/4 SE1/4 sec.11. T. 67 N.. R. 42 W.. Fremont County, on left bank 1.6 miles downstream from confluence of East Nishnabotna and West Nishnabotna Rivers and 2 miles northeast of Hamburg, and at mile 13.2.

Drainage area.--2,806 sq mi.

Gage.- - Water-stage recorder. Datum of gage is 894.17 ft above mean sea level. Prior to oct. 1, 1923, chain gage at site 6 miles downstream at different datum. oct. 5, 1928 , to sept. 6. 1929, chain gage at site $1.000 \mathrm{ft}$ upstream at datum $0.42 \mathrm{ft}$ higher. Sept. 7, 1929, to Feb. 11, 1935, chain gage and Feb. 12. 1935, to June 5, 1947, wire-weight gage, at present site and datum. June 6 to July 22, 1947. staff gage at site 1,000 ft upstream at different datum. July 23, 1947, to Nov. 16. 1950, staff gage at present site and datum.

Stage-discharge relation.--Defined by current-meter measurements. Affected by backwater from Missouri River at times.

Flood stage. -16 feet.

Remarks.--Base for partial-duration series, 9.000 cfs. Diversion upstream from East and West Nishnabotna Rivers for wildlife preserve near Riverton.

Pea k﹎stages and_di

\begin{tabular}{|c|c|c|c|}
\hline $\begin{array}{l}\text { Water } \\
\text { year }\end{array}$ & Date & $\begin{array}{l}\text { Gage } \\
\text { height } \\
\text { (feetl. }\end{array}$ & $\begin{array}{c}\text { Discharge } \\
\text { (cfs) }\end{array}$ \\
\hline 1917 & June 7,1917 & 21.0 & - \\
\hline 1922 & Apr. 12, 1922 & 16.7 & 11,800 \\
\hline 1923 & 브믇﹎글 1923 & 16.0 & 8.800 \\
\hline 1929 & 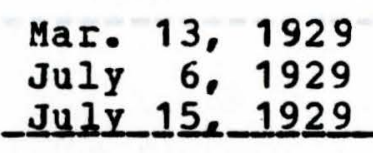 & $\begin{array}{l}22.3 \\
18.2 \\
19.1\end{array}$ & $\begin{array}{r}21,100 \\
9,500 \\
11,100 \\
\end{array}$ \\
\hline 1930 & Feb. 8,1930 & $13.8 \mathrm{a}$ & $3,020 \mathrm{~b}$ \\
\hline 1931 & June 22, 1931 & 18.1 & 9.350 \\
\hline
\end{tabular}

a Affected by ice.

b A bout. 
06-8100.00 Mishnabotna River above Hamburg, Iowa-- (Continued)

Peak_stages_and discharges

Hater
year

1932

1933

1934

1935

1936

1937

1938

1939

1940

1941

1942

1943

1944

Date

No v. 25, 1931

Aug. 16, 1932

Jan. 22, 1933

June 9, 1934

June 26, 1935

Har. 5, 1936

Har. 5, 1937

Aug. 28, 1938

sept.14, 1938

MaI. 12, 1939

Aug. 11, 1939

Aug. 8,1940

Aug. 12, 1940

Aug. 14, 1940

Aug. 17. 1940

June 9, 1941

Sept.15, 1941

oct. 22, 1941

June 20, 1942

June 25, 1942

Hay 16, 1943

June 3, 1943

June 5, 1943

aug. 3, 1943

Hay 26, 1944

June 4, 1944

June 9, 1944

June 15, 1944
Gage

height

(feet)

19. 1

19.1

17.1

14.6

17.5

22.2

21.6

17.9

18.2

23.0 a

17.9

18.4

18.9

18.2

18.4

20.4

19.1

18.8

19.2

19.2

19.1

18.6

18.6

18.9

17.9

19.5

18.8

20.8
Discharge

(cfs)

11.100

10.300

8,020

5.620

8,500

20,600

16,500

9.060

9.650

$22.100 \mathrm{~b}$

9.060

9.800

10.700

9.500

9.800

14.600

11.100

10.500

11.700

11.400

11.100

10.100

10.100

10,700

9.060
11.600
9.200
11.800 
Feak_s_tages_and_didischarges

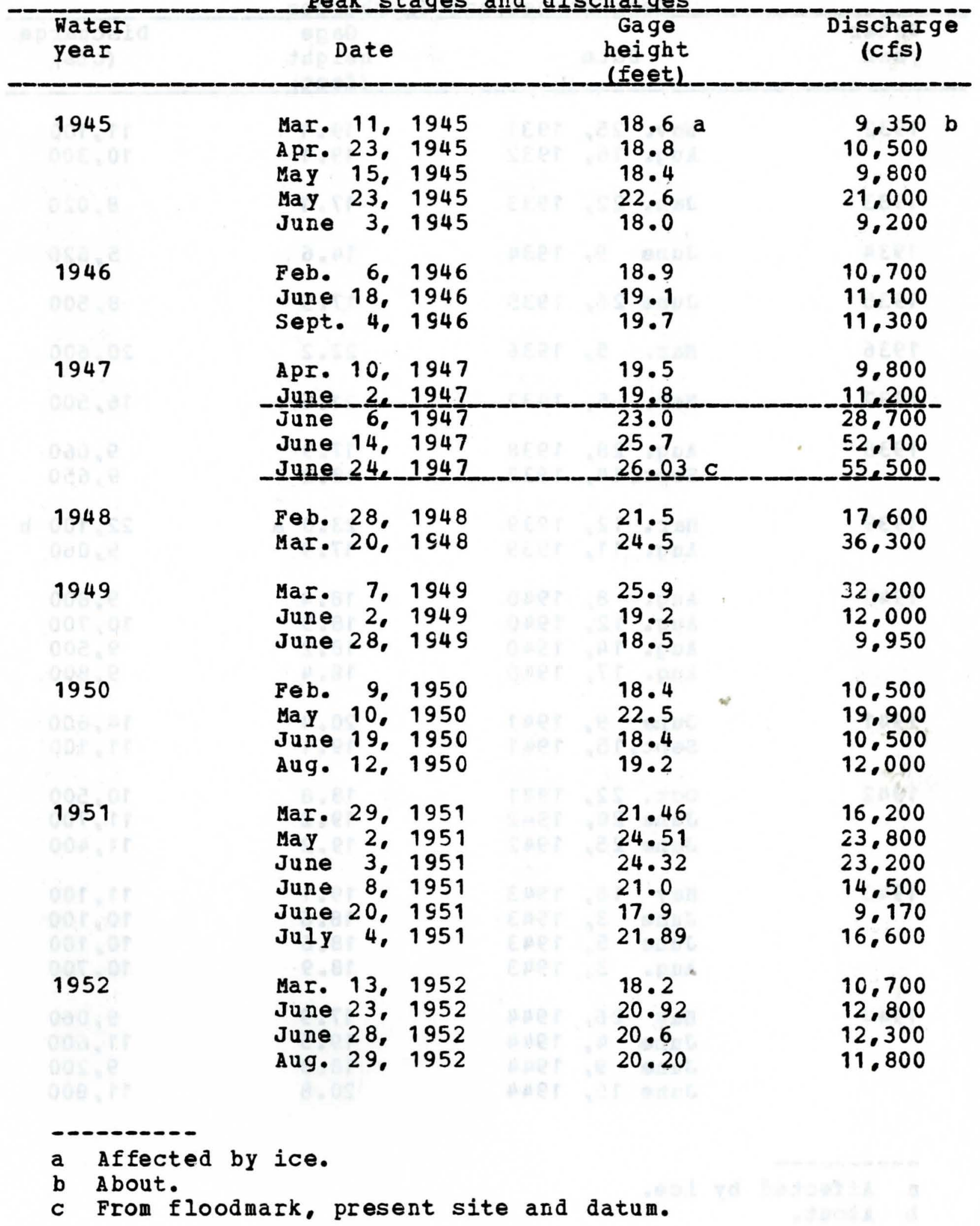


06-8100.00 Nishnabotna River above Hamburg, Iowa--(Continued)

Pea

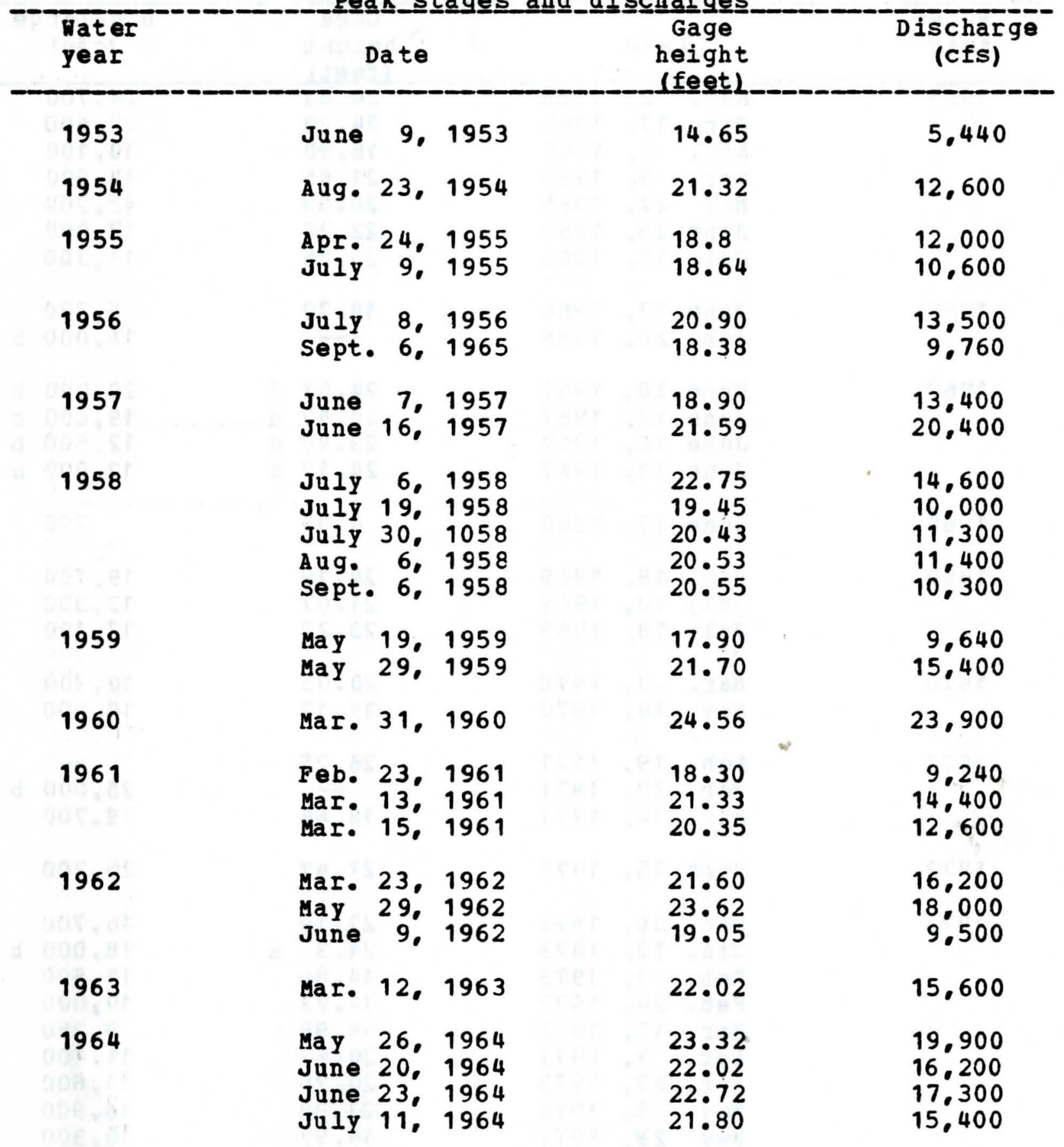


06-8100.00 Nishnabotna River above Hamburg. Iowa-- (Continued)

Peak_s stages ang

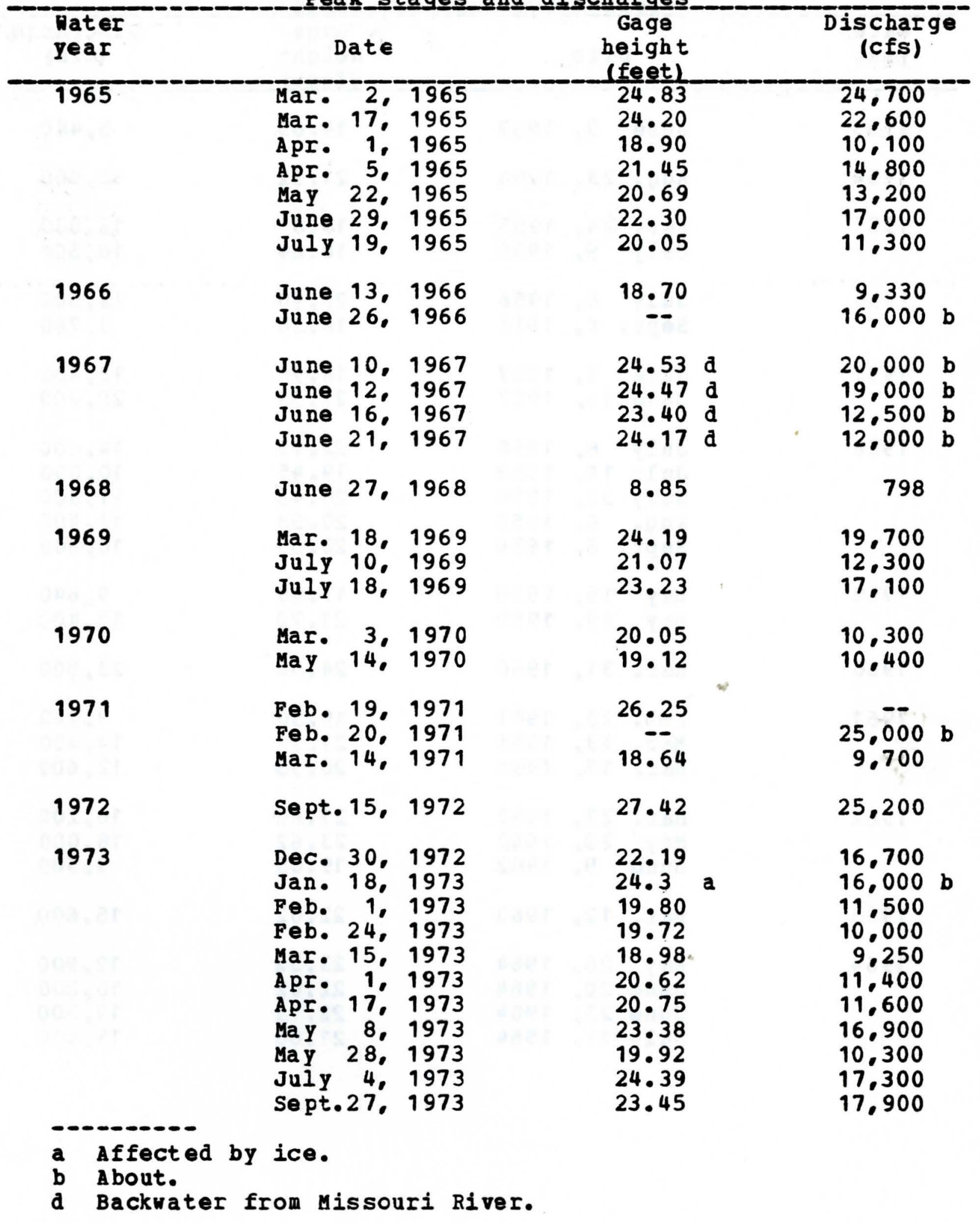


06-8100.00 Nishnabotna River above Hamburg, Iowa-- (Continued) Peak_stages_and_discharges

\begin{tabular}{llcc}
$\begin{array}{c}\text { Water } \\
\text { Year }\end{array}$ & Date & $\begin{array}{c}\text { Gage } \\
\text { height } \\
\text { (feetL }\end{array}$ & $\begin{array}{c}\text { Discharge- } \\
\text { (Cfs) }\end{array}$ \\
\hline 1974 & Oct. 12,1973 & 23.07 & 16,300 \\
1975 & Mar. 21,1975 & 18.99 & 12,600 \\
& Apr. 28,1975 & 21.63 & 13.300 \\
& June 25, 1975 & 20.75 & 11.600
\end{tabular}




\section{6-8170.00 Nodaway River at Clarinda. Iowa}

Location.--Lat $40044119 "$, long $95000 \cdot 47 "$, in SW1/4 NE1/4 sec.32. T.69 N.. R. 36 W.. Page County, on downstream side of center bridge pier on State Highway 2, 0.5 mile downstream from North Branch. 1.2 miles east of city square of clarinda, and 7.5 miles upstream from East Nodaway River.

Drainage area.--762 sq mi.

Gage.--Water-stage recorder. Latum of gage is $960.36 \mathrm{ft}$ above mean sea level. Prior to July 5, 1925, and May 28, 1936, to Mar. 26, 1957, nonrecording gage at same site and datum.

Stage-discharge relation.--Defined by current-meter measurements below 15.000 cfs and extended above on basis of an overflow profile and extended channel rating.

Flood stage.--14 feet.

Remarks.--Base for partial-duration series, 5,000 cfs.

Peak﹎stages_and di

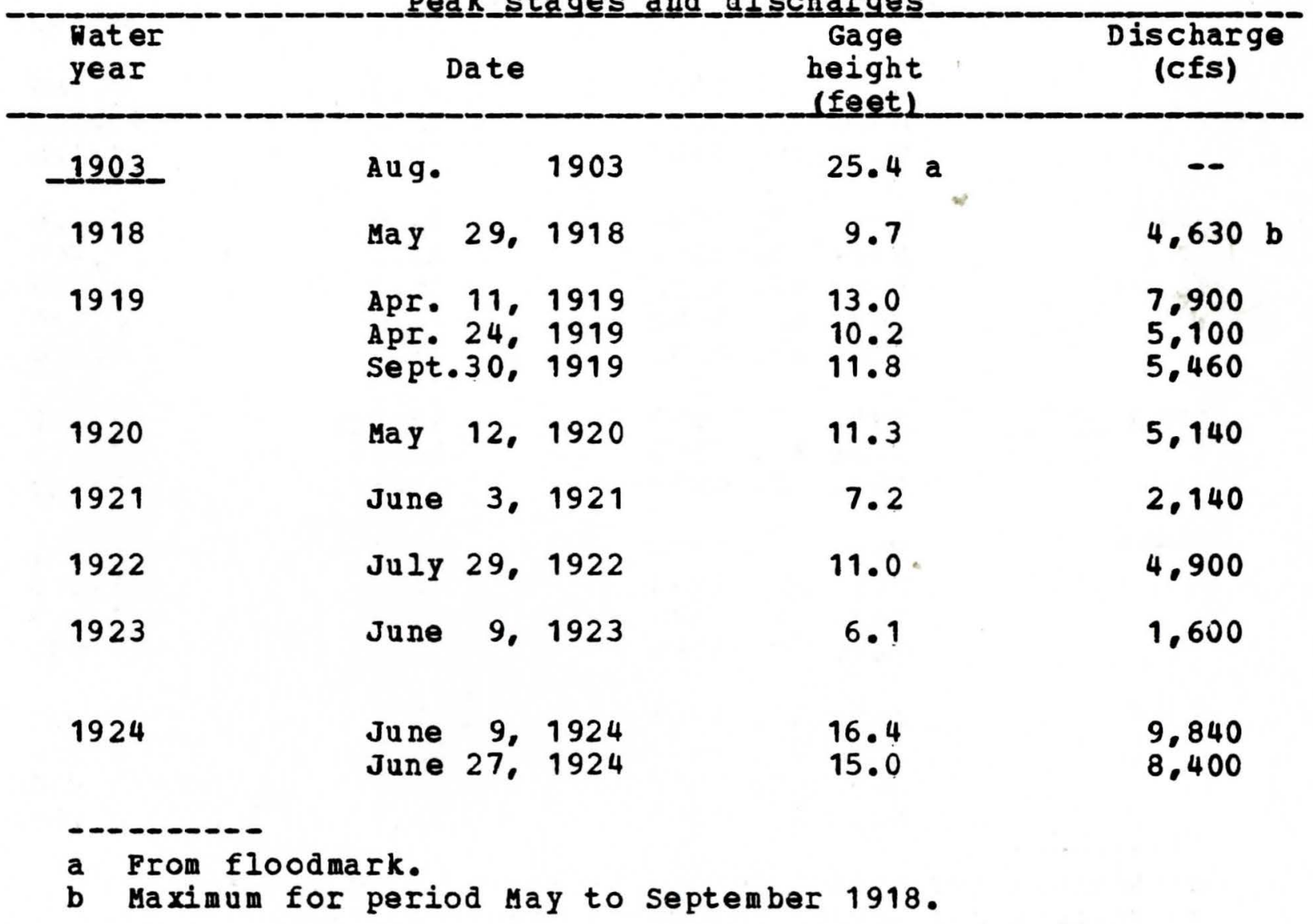


06-8170.00 Nodaway River at Clarinda, Iowa--(Continued)

Pea $\underline{k}$ s.tages_and

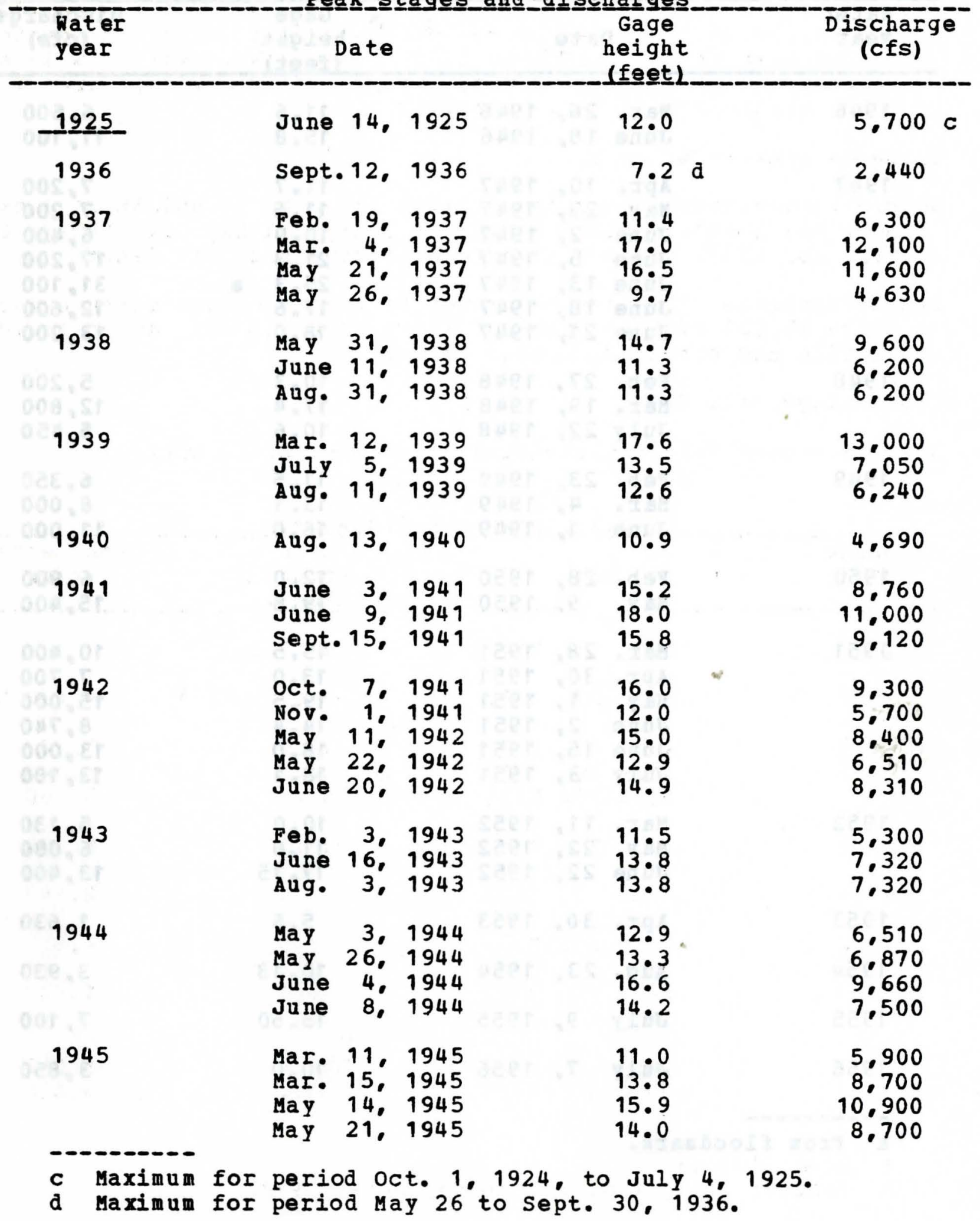


06-8170.00 Hodaway River at Clarinda, Iowa--(Continued)

Peak stages and discharges

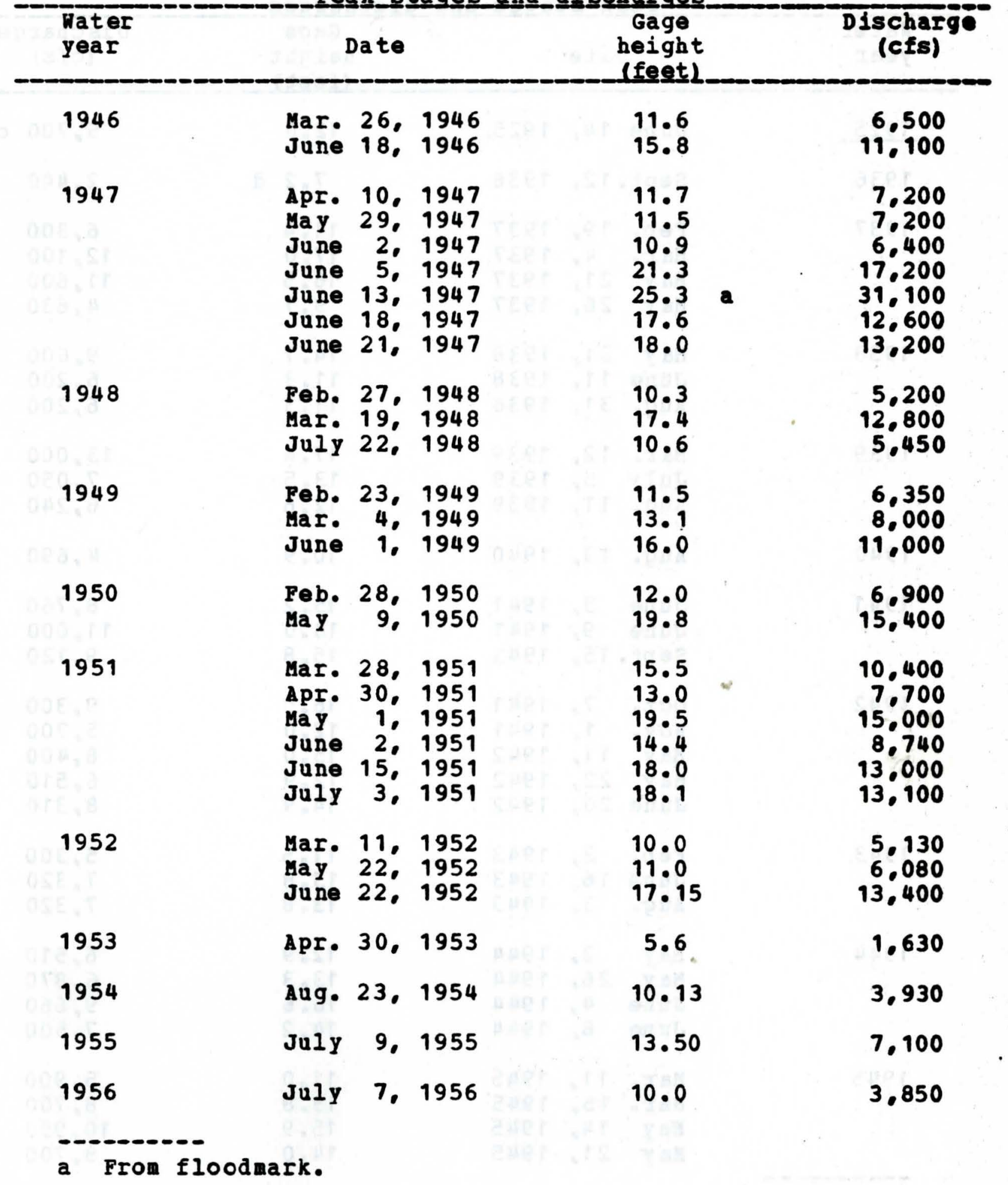


06-8170.00 Nodaway River at Clarinda, Iowa--(Continued)

Peak_stages and discharges

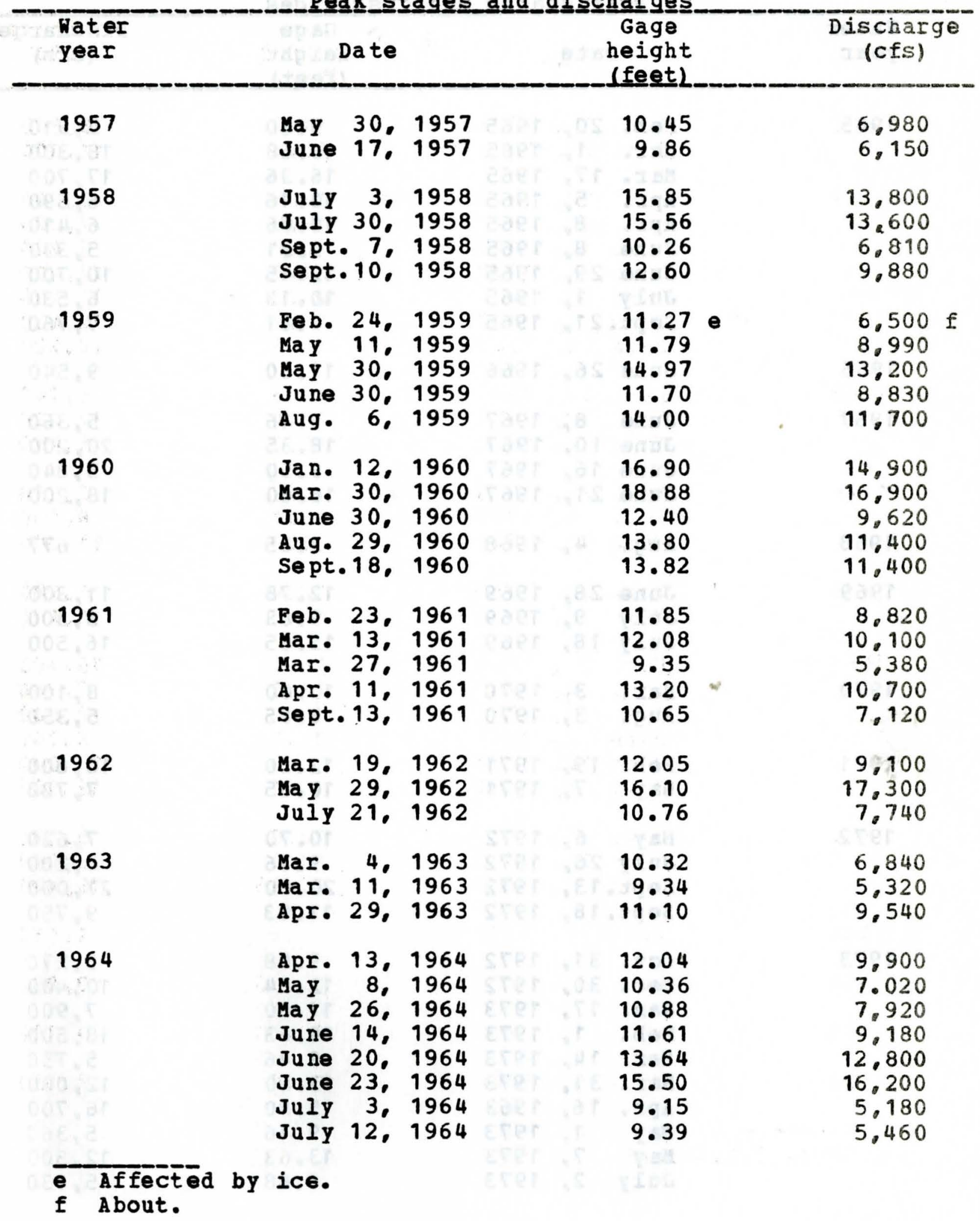


06-8170.00 Nodaway River at Clarinda, Iowa--(Continued)

Peak_stages_and_di

Water

year

1965

1966

1967

1968

1969

1970

1971

1972

1973
Feb. 20, 1965

Mar. 1. 1965

Mar. 17, 1965

Apr. 5, 1965

Apr. 8, 1965

June 8, 1965

June 29, 1965

July 1, 1965

Sept.21, 1965

June 26, 1966

June 8,1967

June 10, 1967

June 16, 1967

June 21, 1967

Aug. 4, 1968

June 28, 1969

July 9, 1969

July 18, 1969

MaI. 3, 1970

sug. 3, 1970

Feb. 19, 1971

May 7, 1971

May 6, 1972

July 26, 1972

Sept.13. 1972

Sept.18, 1972

Oct. 31, 1972

Dec. 30, 1972

Jan. 17, 1973

Feb. 1. 1973

Mar. 14, 1973

ㅂar. 31, 1973

Apr. 16, 1963

May 1, 1973

May 7, 1973

July 2。 1973
Gage

height

(feet)

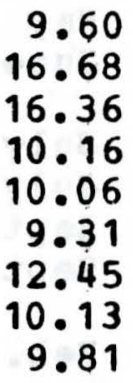

11.80

9. 16

18.35

9.50

16.60

3.85

12.78

9.83

15.65

10.00

8.85

12.50

10.65

10.70

9.76

20.00

11.03

9.08

12.54

11.00

16.63

9.46

13. 50

15.80

9.16

13.63

8.88
Discharge

(cfs)

5,910

18,300

17,700

6.590

6,410

5.330

10,700

6.530

7,760

9.540

5,360

20.200

5.840

18,200

677

11.300

6.300

16,500

8,100

5,350

10.800

7.720

7.620

6.200

27.000

9,750

5.270

10,400

7.900

18.500

5.750

12.000

16,700

5.360

12.300

5,030 
06-8170.00 Nodaway River at Clarinda, Iowa--(Continued)

Peaㅡ﹎.stages_and_di

\begin{tabular}{|c|c|c|c|c|}
\hline $\begin{array}{l}\text { Water } \\
\text { year }\end{array}$ & Date & & $\begin{array}{l}\text { Gage } \\
\text { height } \\
\text { (feet). }\end{array}$ & $\begin{array}{c}\text { Discharge } \\
\text { (cfs) }\end{array}$ \\
\hline 1974 & $\begin{array}{l}\text { Oct. } 11 . \\
\text { Nov. } 21, \\
\text { Apr. } 21 . \\
\text { ApI. } 29, \\
\text { June } 9 .\end{array}$ & $\begin{array}{l}1973 \\
1973 \\
1973 \\
1974 \\
1974\end{array}$ & $\begin{array}{r}17.74 \\
9.68 \\
11.50 \\
10.10 \\
9.00\end{array}$ & $\begin{array}{r}21.400 \\
6.670 \\
9.400 \\
7.250 \\
5.790\end{array}$ \\
\hline 1975 & $\begin{array}{l}\text { Mar. } 18, \\
\text { Mar. } 20, \\
\text { June } 25,\end{array}$ & $\begin{array}{l}1975 \\
1975 \\
1975\end{array}$ & $\begin{array}{r}8.66 \\
8.72 \\
12.68\end{array}$ & $\begin{array}{r}5.380 \\
5.450 \\
11.400\end{array}$ \\
\hline
\end{tabular}


05-4115.30 North Branch Turkey River near Cresco, Iowa

Location.--Iat $43022 \%$ long $92013 \%$ in NN1/4 sec.25, T.99 H.. R. 12 W.. Howard County, at bridge on State Highway 9 , about 5 miles west of Cresco.

Drainage area.--19.5 sq mi.

Gage.--Crest-stage gage.

Stage-discharge relation.--Defined by current-meter and indirect measurements.

Remarks.--Only annual peaks are shown.

Peak_stages_and_discharges

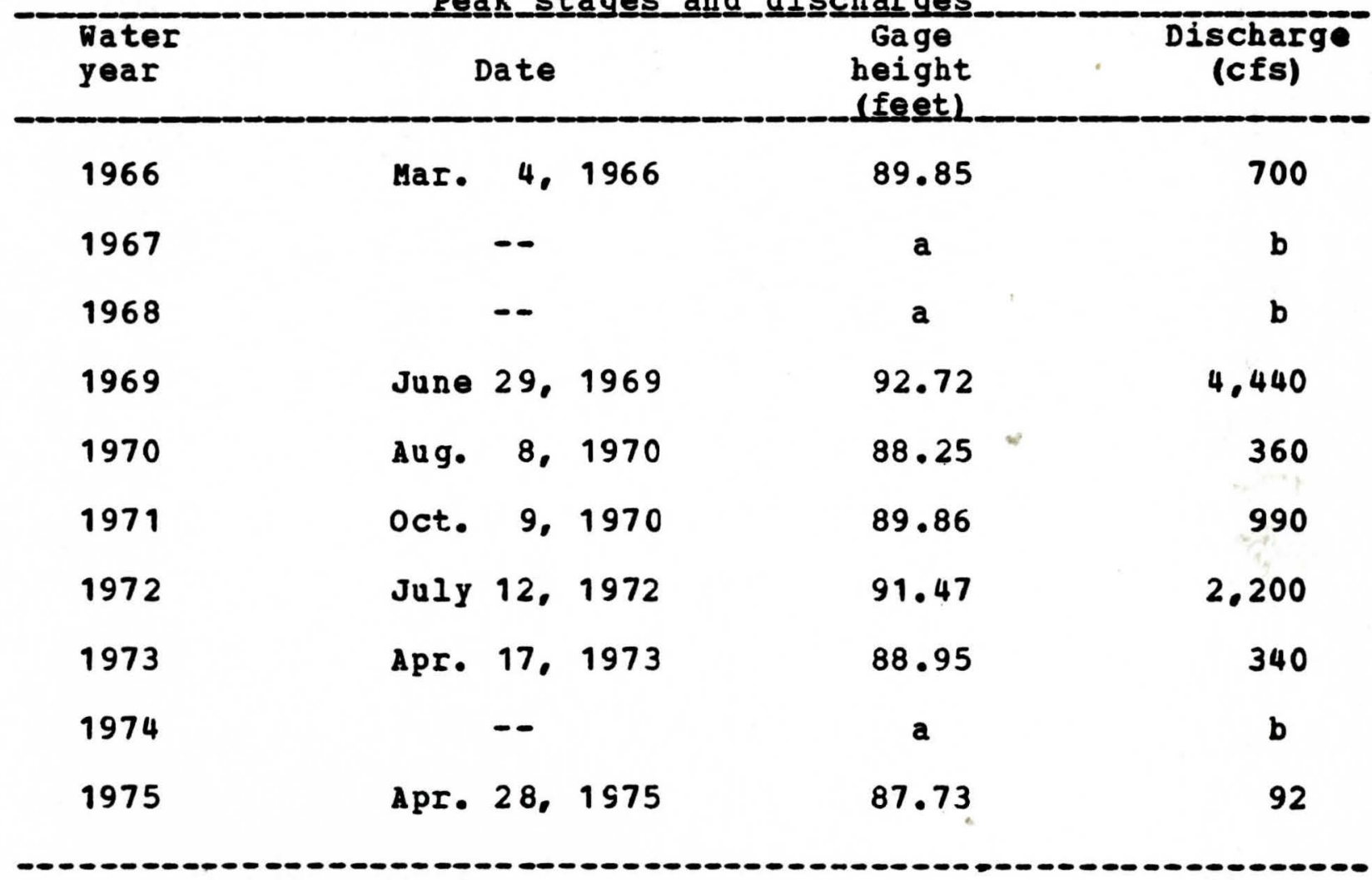

a Peak stage did not reach bcttom of gage.

b Discharge not determined. 


\section{5-4552.10 North English River at Guernsey. Iowa}

Location.--Iat 41038'. long 92021', in NW1/4 sec.22. T.79 N..

R. 13 W., Poweshiek County, at bridge on State Highway 21, 1 mile southwest of Guernsey.

Drainage area.--81.5 sq mi.

Gage.--Crest-stage gage.

stage-discharge relation.--Defined by current-meter and indirect measurements.

Remarks.--Only annual peaks are shown.

Peak stáges and discharges

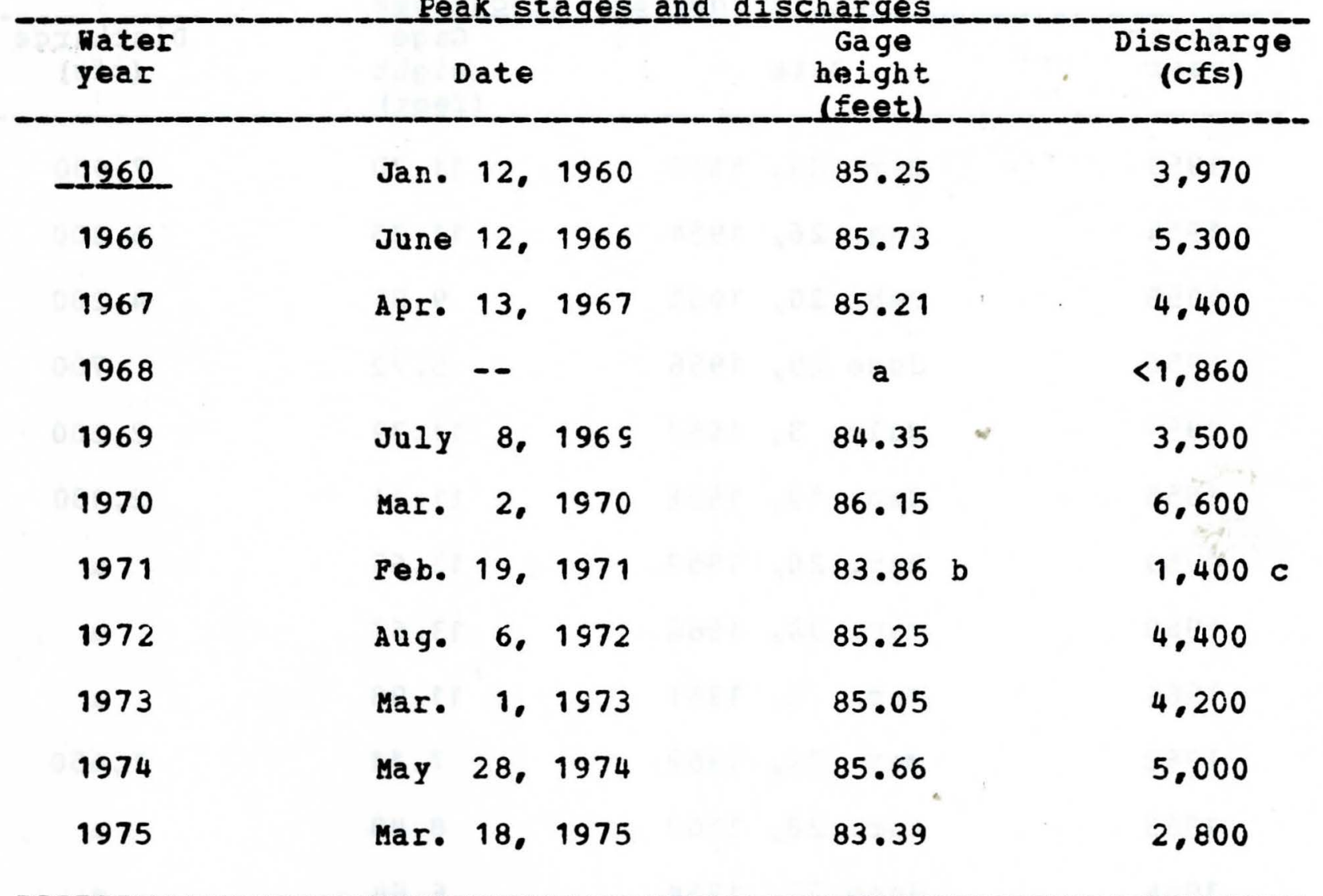

a Peak stage did not reach bottom of gaga.

b Affected by ice.

c About. 

05-4552.00 North English River near Guernsey. Iowa
(Prior to 1970 published as "North Fork English River near Guernsey")
Location.--Iat $41038^{\circ}$, long $92024^{\circ}$, near Sy corner sec.17. T.79
N.. R.13 M. . Poweshiek County, at bridge, 2.2 miles west of Guernsey.

Drainage area.--68.7 sq mi.

Gage.--Crest-stage gage.

Stage-discharge relation.--Defined by current-meter measurements. Remarks.--only annual peaks are shown.

Peak stages and discharges

\begin{tabular}{|c|c|c|c|c|c|}
\hline $\begin{array}{l}\text { Hater } \\
\text { year }\end{array}$ & Date & & $\begin{array}{c}\text { Gage } \\
\text { height } \\
\text { lfeetl }\end{array}$ & 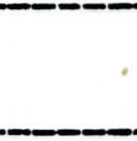 & $\begin{array}{c}\text { Discharge } \\
\text { (cfs) }\end{array}$ \\
\hline 1953 & $\operatorname{May} 24$ & 1953 & 11.70 & & 7,000 \\
\hline 1954 & Aug. 26 & 1954 & 11.35 & & 6.300 \\
\hline 1955 & Feb. 20 & 1955 & 9.86 & & 4.280 \\
\hline 1956 & June 20 . & 1956 & 5.72 & & 700 \\
\hline 1957 & July 3 & 1957 & 11.39 & $*$ & 2.200 \\
\hline 1958 & sept. 10, & $1 \varsigma 5 \varepsilon$ & 11.21 & & 2.130 \\
\hline 1959 & MaI. 20. & 1959 & 12.65 & & a \\
\hline 1960 & Mar. 30, & 1960 & 13.63 & & a \\
\hline 1961 & Mar. 6. & 1961 & 11.98 & & $\mathbf{a}$ \\
\hline 1962 & $\operatorname{May} 29$. & 1962 & 7.11 & & 1.650 \\
\hline 1963 & Aрг. 28 , & 1963 & 8.48 & & $a$ \\
\hline 1964 & June 22 , & 1964 & 6.64 & & a \\
\hline 1965 & Sept. 21 . & 1965 & 8.65 & & a \\
\hline 1966 & June 12 & 1966 & 13.47 & & 4.450 \\
\hline
\end{tabular}

a Discharge not determined. 
05-4552.00 North English River nea: Guernsey, Iowa--(Continued)

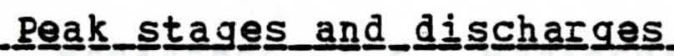

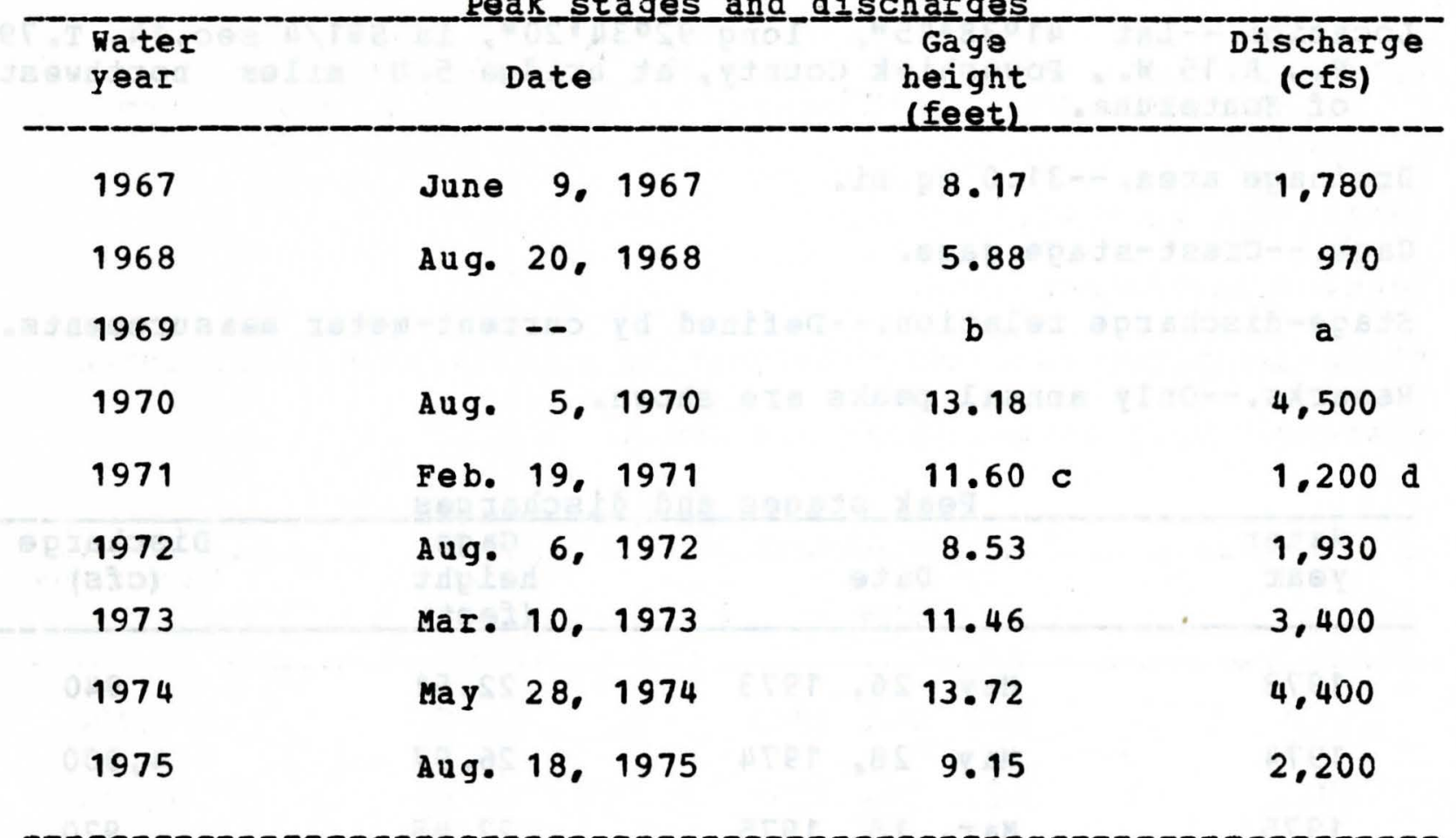

a Discharge not determined.

b Peak stage did not reach bottom of gage.

c Affected by ice.

d About. 
Location.--Iat 41038.45", long $92034 \cdot 20 "$ " in SW1/4 sec.14, T. 79 N.. R.15 W.. Poweshiek County. at bridge 5.0 miles northwest of Montezuma.

Drainage area. $--31.0 \mathrm{sq} \mathrm{mi}$.

Gage.--Crest-stage gage.

Stage-discharge relation.--Defined by current-meter measuremants. Remarks.--Only annual peaks are shown.

Peakㅡ_stage

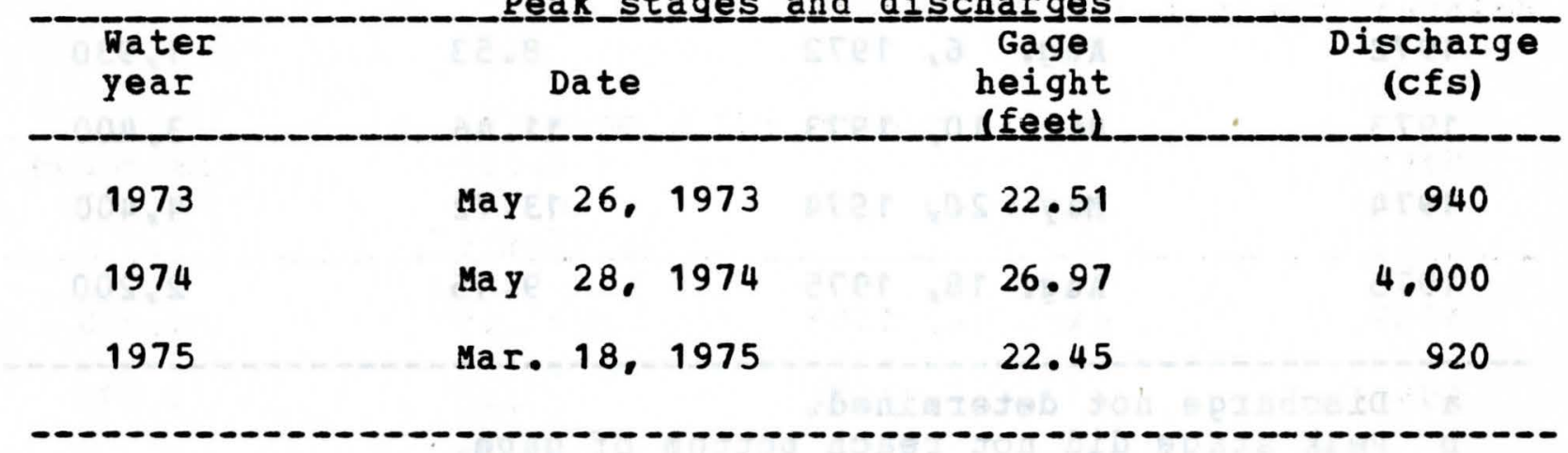


05-4551.50 North English River near Montezuma, Iowa

(Prior to 1970 published as North Fork English River near Montezuma. Iowa) (Discontinued 1973)

Location.--Iat $41039^{\circ}$, long $92033^{\circ}$, in SN1/4 sec.13. T.79 N.. R. 15 W.. Poweshiek County. at bridge on U.S. Highway 63,5 miles north west of Montezuma.

Drainage area.--34.0 sq mi.

Gage.--Crest-stage gage.

stage-discharge relation.--Defined by current-meter and indirect mea surements.

Bemarks.--Only annual peaks are shown.

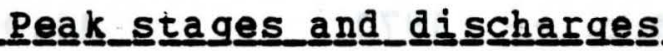

\begin{tabular}{cccc}
$\begin{array}{c}\text { Water } \\
\text { Year }\end{array}$ & Date & $\begin{array}{c}\text { Peak_stages_and_discharges } \\
\text { Gage } \\
\text { height } \\
\text { (feet) }\end{array}$ & $\begin{array}{c}\text { Discharge } \\
\text { (cfs) }\end{array}$ \\
\hline 1953 & 24,1953 & 13.25 & 4,240 \\
1954 & Aug. 26,1954 & 7.47 & 1,270 \\
1955 & -- & a & $<450$ \\
1956 & June 20,1956 & 7.08 & 1,120 \\
1957 & July 28,1957 & 12.22 & 3,700 \\
1958 & May 31,1958 & 9.13 & 1,940 \\
1959 & Mar. 20,1959 & 13.18 & 4,190 \\
1960 & Mar. 30,1960 & 11.60 & 2,000 \\
1961 & Mar. 13,1961 & 12.95 & 3,400 \\
1962 & -- & a & b \\
1963 & Apr. 28,1963 & 8.03 & 990 \\
1964 & -- & a & b
\end{tabular}

a Peak stage did not reach bottom of gage.

b Discharge not determined. 
05-4551.50 North English River near Montezuma, Iowa-- (Continued)

Peak_stages and_ dischharges

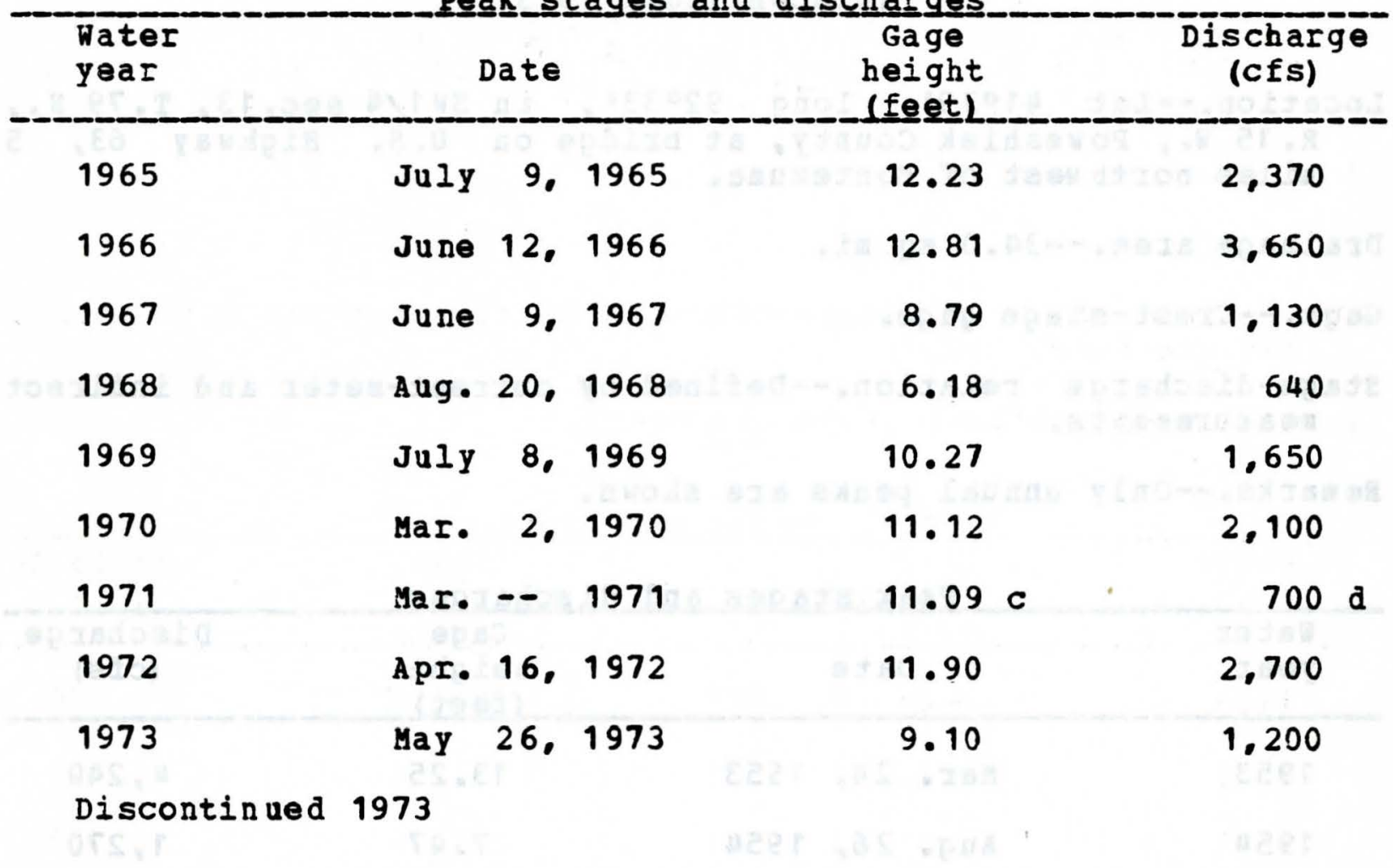

c Affected by ice.

d About. 
05-4144.50 North Fork Little Maguoketa River near Rickardsville, Iowa

Location.--Lat 42035109", long 90051'20", near NW corner sec.28, T. 90 N.. R. 1 E.. Dubuque County, at bridge, 1 mile northeast of Rickardsville.

Drainage area.--21.6 sq $\mathrm{mi}$.

Gage.--Crest-stage gage.

Stage-discharge relation.--Defined by current-meter and indiract mea surements.

Remarks.--only annual peaks are shown.

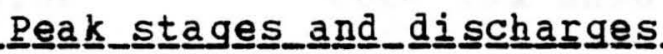

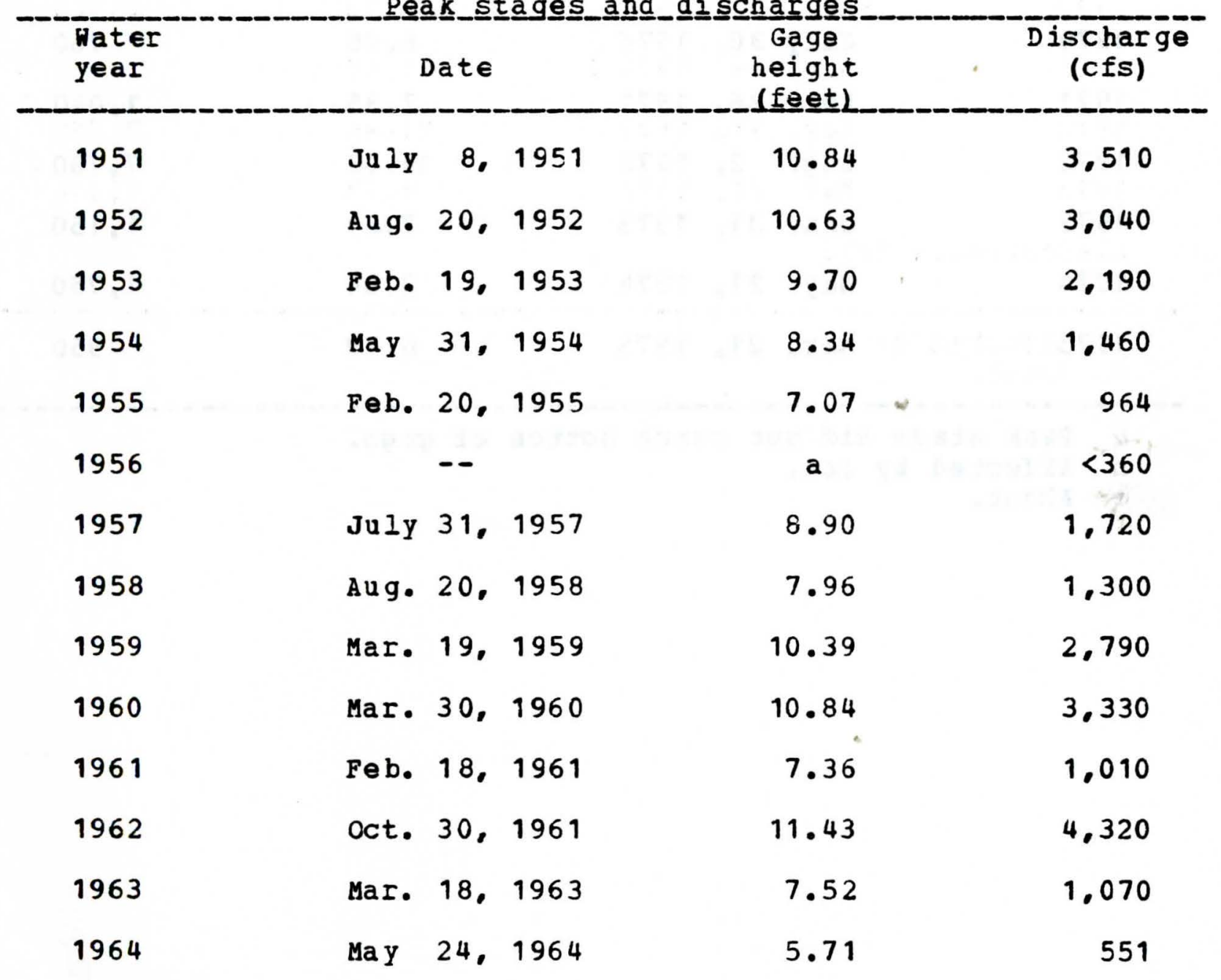

a Stage did not reach bottom of gage. 

05-4144.50 North Fork Little Maquoketa River near Rickardsville,
Iowa--(Continued)

Peak_stages_and discharges

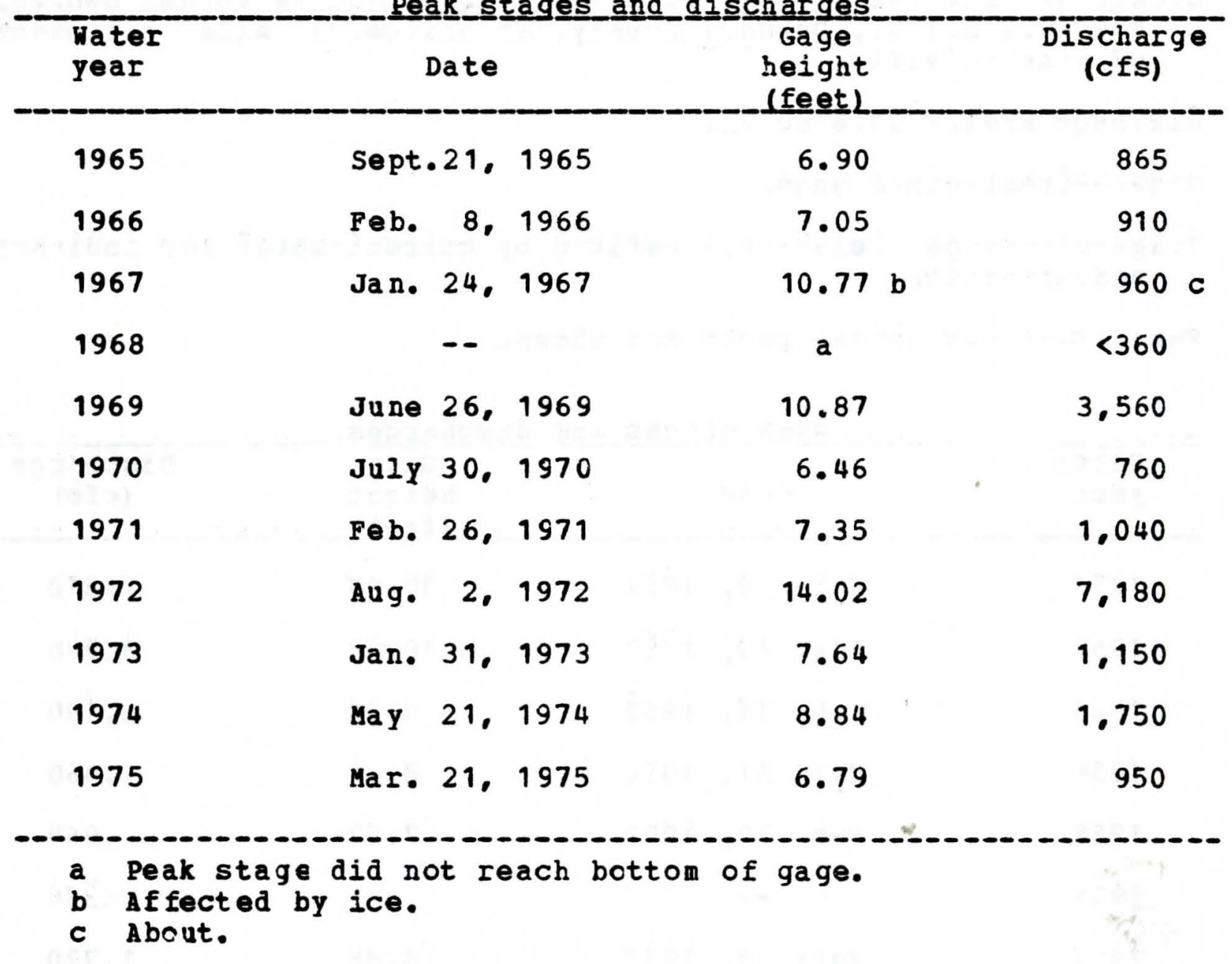


Location.--Iat $41017^{\prime}$, long $91032^{\circ}$, in SW1/4 sec.22, T. 75 N.. R.6 W.. Washington County, at bridge on U.S. Highway 218, 1 mile southeast of Ainsworth.

Drainage area.--30.2 sq mi.

Gage.--Crest-stage gage.

stage-discharge relation.--Defined by current-meter and indirect measurements.

Remarks.--only annual peaks are shown.

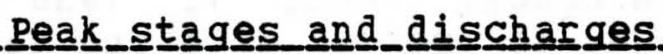

\begin{tabular}{|c|c|c|c|c|c|}
\hline $\begin{array}{l}\text { Water } \\
\text { year }\end{array}$ & Date & & $\begin{array}{c}\text { Gage } \\
\text { height } \\
\text { (feet). }\end{array}$ & 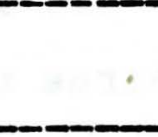 & $\begin{array}{c}\text { Discharge } \\
\text { (cfs) }\end{array}$ \\
\hline 1965 & Sept.21. & 1965 & 89.78 & & 2,560 \\
\hline 1966 & May 23, & 1966 & 88.55 & & 1,880 \\
\hline 1967 & June 13. & 1967 & 88.77 & & 770 \\
\hline 1968 & -- & & $\mathbf{a}$ & & $<160$ \\
\hline 1969 & July & 1969 & $87 \cdot 30$ & $\sim$ & 450 \\
\hline 1970 & Mar. 3, & 19.70 & 87.43 & & 560 \\
\hline 1971 & Mar. 3. & 1971 & 87.05 & & 430 \\
\hline 1972 & $\operatorname{May}$ & 1972 & 87.57 & & 600 \\
\hline 1973 & May 29. & 1973 & 88.43 & & 1.550 \\
\hline 1974 & Apr. 30. & 1974 & 88.31 & & 650 \\
\hline 1975 & Mar. 19, & 1975 & 87.70 & & 490 \\
\hline
\end{tabular}

a Peak stage did not reach bcttom of gage. 
05-4825.00 North Raccoon River near Jefferson, Iowa (Published as "Racccon River near Jefferson", 1940-55)

Location.--Iat 41059117", long $94^{\circ} 22 \cdot 36 "$, in SW1/4 NH1/4 sec. 20 . T. 83 N., R. 30 W.. Greene County, on right bank 5 ft dcwnstream from bridge on State Highway 4 , 0.1 mile downstream from Drainage ditches 33 , and $40,1.9$ miles south of Jefferson, and 4.2 miles upstream from Hardin Creek.

Drainage area.--1,619 sq mi.

Gage.-Water-stage recorder. Latum of gage is $967.09 \mathrm{ft}$ above mean sea level. Prior tc Afr. 22, 1946, nonrecording gage at site 4 miles upstream at different datum. Apr. 22 to June 25, 1946, non recording gage, June 26, 1946 to Sept. 30, 1955, water-stage recorder, Oct. 1, 1955 to Apr. 30, 1958, nonrecording gage, at present site and datum.

Stage-discharge relation.--Defined by current-meter measurements. Flood stage.-- 10 feet.

Remarks.--Base for partial-duration series, 4,000 cfs.

Peak_s_tages_and di

\begin{tabular}{|c|c|c|c|c|c|}
\hline $\begin{array}{l}\text { Water } \\
\text { year }\end{array}$ & & Date & & $\begin{array}{c}\text { Gage } \\
\text { height } \\
\text { (feet) }\end{array}$ & $\begin{array}{c}\text { Discharge } \\
\text { (cfs) }\end{array}$ \\
\hline 1940 & Aug. & 28, & 1940 & 10.9 & 4.030 \\
\hline 1941 & June & 14 & 1941 & 9.1 & 2,420 \\
\hline 1942 & JuIy & 15. & 1942 & 10.5 & 3,590 \\
\hline 1943 & Aug. & 13. & 1943 & $15 \cdot 5$ & 9.480 \\
\hline 1944 & $\begin{array}{l}\text { May } \\
\text { June }\end{array}$ & $\begin{array}{l}22 . \\
14 .\end{array}$ & $\begin{array}{l}1944 \\
1544\end{array}$ & $\begin{array}{l}15.4 \\
16.2\end{array}$ & $\begin{array}{r}9.860 \\
11.900\end{array}$ \\
\hline 1945 & $\begin{array}{l}\text { Mar. } \\
\text { Apr. } \\
\text { ApI. } \\
\text { May } \\
\text { June } \\
\text { June } \\
\text { Aug. }\end{array}$ & $\begin{array}{r}12, \\
18 \\
25 \\
24 \\
30 \\
10 \\
8\end{array}$ & $\begin{array}{l}1945 \\
1945 \\
1945 \\
1945 \\
1945 \\
1945 \\
1945\end{array}$ & $\begin{array}{l}12.9 \\
10.6 \\
14.2 \\
13.1 \\
14.3 \\
13.5 \\
10.7\end{array}$ & $\begin{array}{l}6.880 \\
4.130 \\
8.700 \\
7.120 \\
8.780 \\
7.630 \\
4.230\end{array}$ \\
\hline
\end{tabular}


05-4825.00 North Raccoon River near Jefferson, Iowa-- (Continued)

Peak stages and discharges

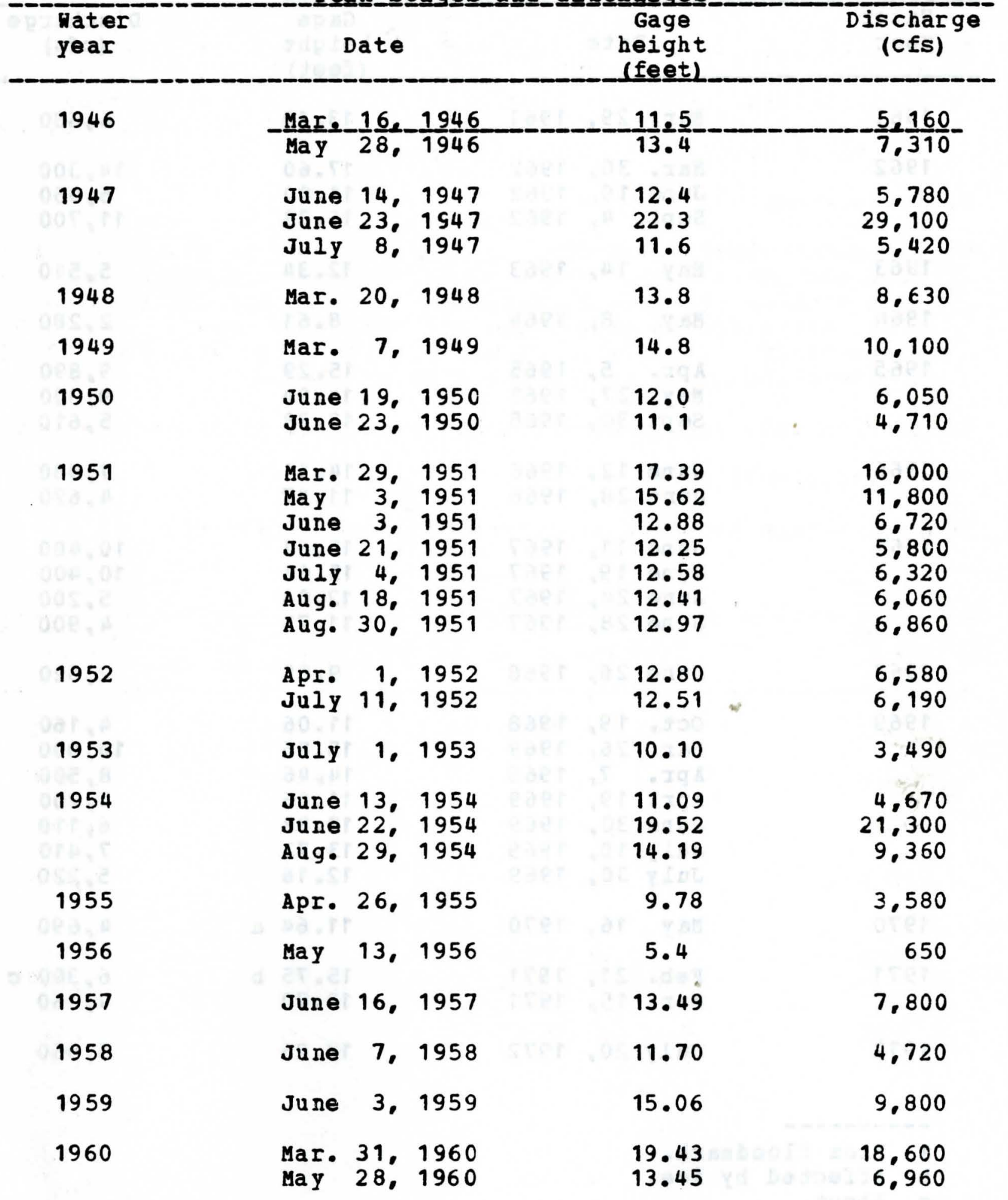


05-4825.00 North Raccoon River near Jefferson, Iowa--(Continued)

Peak_stages and discharges

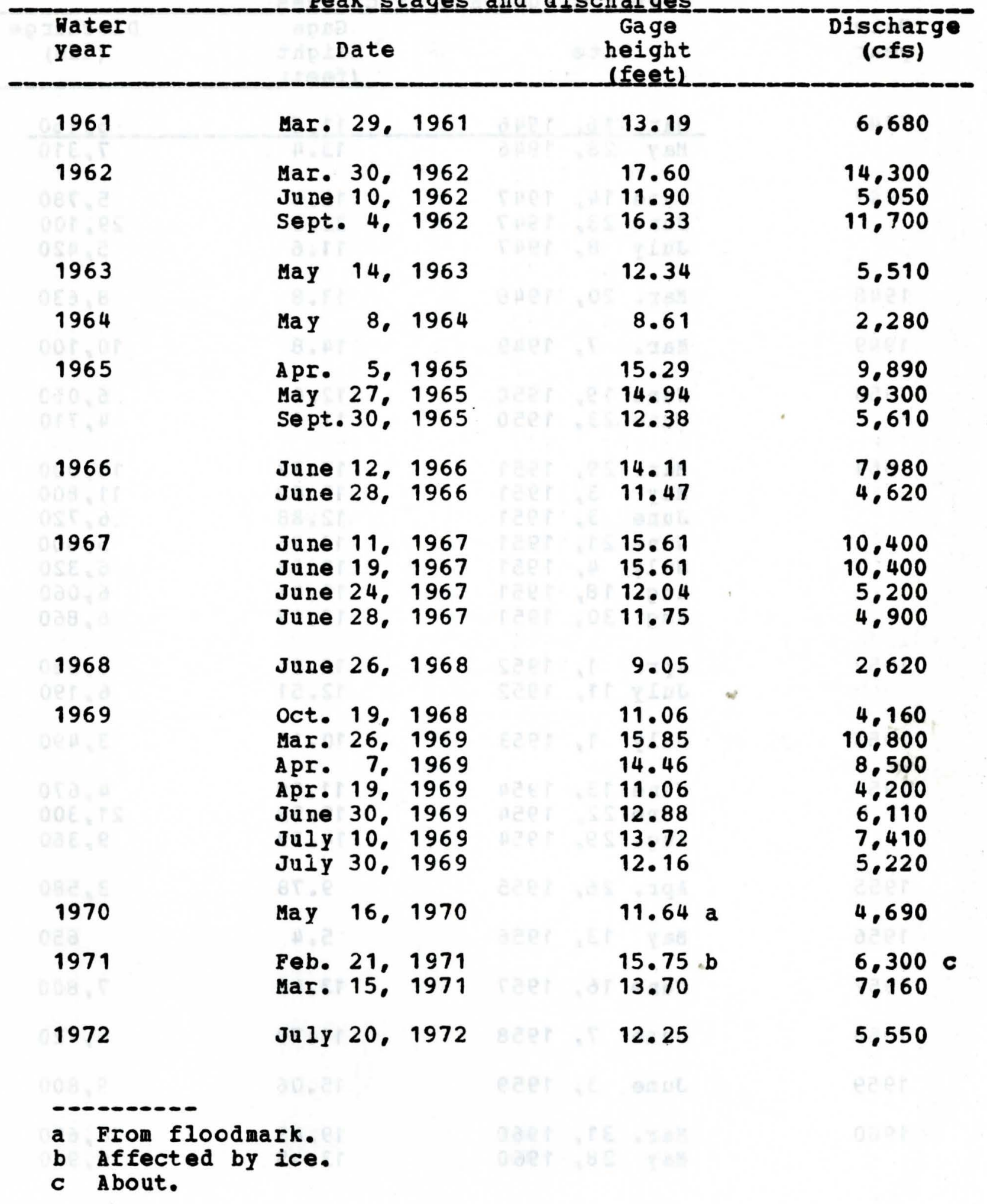


05-4825.00 North Raccoon River near Jefferson, Iowa-- (Continued)

Peak stages and discharges

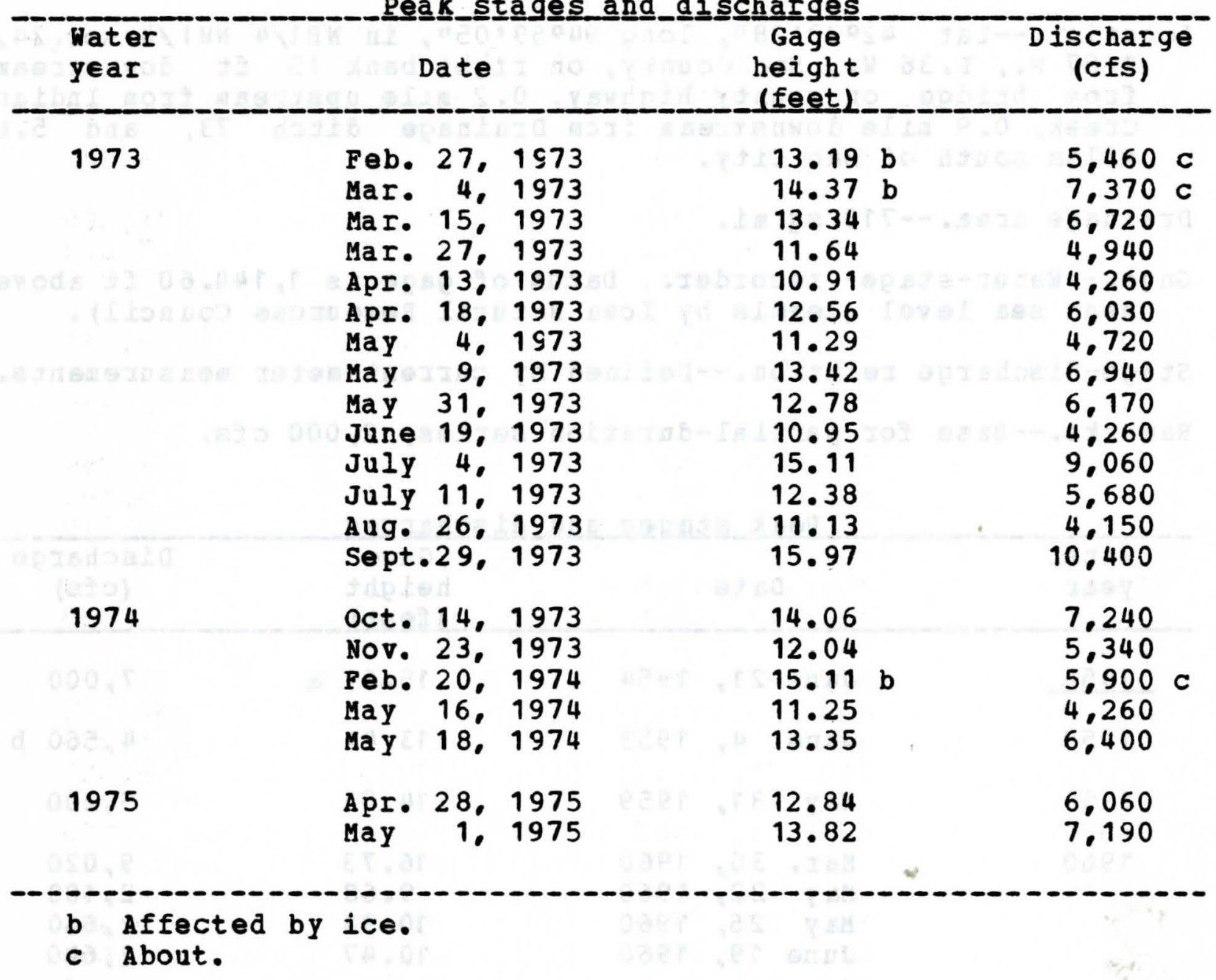


Location.--Iat $420202^{\prime \prime}$ ". long $94059^{\circ} 05^{\prime \prime}$, in NE1/4 NN1/4 sec.24, T.87 N., R.36 W.. Sac County, on right bank 15 ft dowrstream from bridge on county highway, 0.2 mile upstream from Indian Creek, 0.9 mile downstream frcm Drainage ditch 73 , and 5.6 miles south of Sac City.

Drainage area.--713 sq mi.

Gage.--Water-stage recorder. Datum of gage is $1.144 .60 \mathrm{ft}$ above mean sea level (levels by I cwa Natural Resources Council).

Stage-discharge relation.--Defined by current-meter measurements. Remarks.--Base for partial-duration series, 2,000 cfs.

Peak_s stages and d di

\begin{tabular}{|c|c|c|c|}
\hline $\begin{array}{l}\text { Water } \\
\text { year }\end{array}$ & Date & $\begin{array}{l}\text { Gage } \\
\text { height } \\
\text { (feet) }\end{array}$ & $\begin{array}{l}\text { Discharge } \\
\text { (cfs) }\end{array}$ \\
\hline 1954 & June 21, 1954 & $15.61 \mathrm{a}$ & 7.000 \\
\hline 1958 & June 4, 1953 & 13.44 & $4.560 \mathrm{~b}$ \\
\hline 1959 & May 31, 1959 & 14.51 & 5,200 \\
\hline 1960 & $\begin{array}{lll}\text { Mar. } & 30, & 1960 \\
\text { May } & 22, & 1960 \\
\text { May } & 26, & 1960 \\
\text { June } & 19, & 1960\end{array}$ & $\begin{array}{r}16.73 \\
9.68 \\
10.94 \\
10.47\end{array}$ & $\begin{array}{l}9.020 \\
2,100 \\
2.840 \\
2.640\end{array}$ \\
\hline 1961 & Mar. 28, 1961 & 13.16 & 4,420 \\
\hline 1962 & $\begin{array}{lrl}\text { Mar. } & 29, & 1962 \\
\text { June } & 9, & 1962 \\
\text { JuIy } & 5, & 1962 \\
\text { Sept. } & 1, & 1962\end{array}$ & $\begin{array}{r}15.83 \\
9.96 \\
10.32 \\
18.12\end{array}$ & $\begin{array}{r}7,730 \\
2,010 \\
2,160 \\
10,800\end{array}$ \\
\hline 1963 & June 3,1963 & 9.32 & 1,910 \\
\hline 1964 & May 7,1964 & 7.47 & 1,100 \\
\hline 1965 & $\begin{array}{l}\text { Apr. } 6,1965 \\
\text { Sept.2 8, } 1965\end{array}$ & $\begin{array}{r}15.59 \\
9.82\end{array}$ & $\begin{array}{l}6,960 \\
2,020\end{array}$ \\
\hline
\end{tabular}


05-4823.00 NoIth Raccoon River near Sac City, Iowa--(Continued)

Peak_stages and_discharges

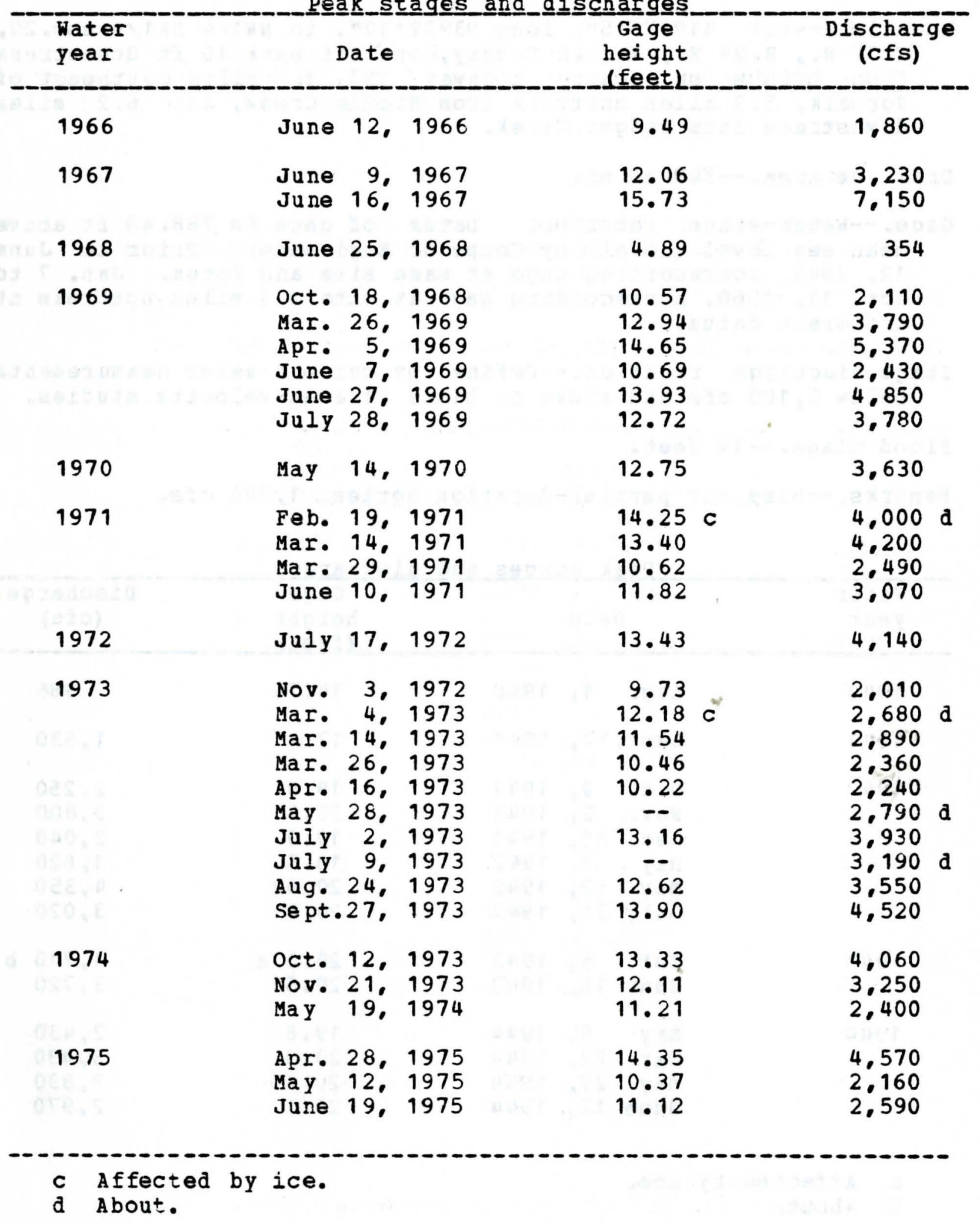


Location.--Iat 41027'25". long 93039'10", in NH1/4 SH1/4 sec.20. T. 77 N.. R. 24 W.. Narren County, on left bank 10 ft dcwnstrean from bridge on county highway R57, 1.7 miles southeast of Norwalk, 5.2 miles upstream from Middle Creek, and 6.2 miles downstream from Badger Creek.

Drainage area.--349 sq mi.

Gage.-Hater-stage recorder. Datum of gage is $788.45 \mathrm{ft}$ above mean sea level (levels by Corps of Engineers). Prior to June 12. 1946, nonrecording gage at same site and datum. Jan. 7 to oct. 11. 1960, nonrecording gage at site 2.1 miles upstream at different datum.

Stage-discharge relation.--Defined by current-meter measurements below 9,100 cfs and above on basis of area-velocity studies.

Flood stage.--14 feet.

Remarks.--Base for partial-duration series, 1,700 cfs.

Peak_s_taages_and_di

\begin{tabular}{|c|c|c|c|c|c|}
\hline $\begin{array}{l}\text { Water } \\
\text { year }\end{array}$ & Date & & $\begin{array}{l}\text { Gage } \\
\text { height } \\
\text { (feet) }\end{array}$ & & $\begin{array}{c}\text { Discharge } \\
\text { (cfs) }\end{array}$ \\
\hline 1940 & Aug. 1. & 1940 & 14.74 & & 986 \\
\hline 1941 & Sept. 17. & 1941 & $17 \cdot 4$ & & 1.530 \\
\hline 1942 & $\begin{array}{lr}\text { Oct. } & 9, \\
\text { Nov. } & 2{ }^{\circ} \\
\text { Dec. } & 25^{\circ} \\
\text { May } & 7^{\circ} \\
\text { May } & 12^{\circ} \\
\text { July } & 21^{\circ}\end{array}$ & $\begin{array}{l}1941 \\
1941 \\
1941 \\
1942 \\
1942 \\
1942\end{array}$ & $\begin{array}{l}19.8 \\
20.4 \\
19.0 \\
18.5 \\
20.62 \\
20.0\end{array}$ & & $\begin{array}{l}2.250 \\
3.800 \\
2.040 \\
1.820 \\
4.350 \\
3.020\end{array}$ \\
\hline 1943 & $\begin{array}{l}\text { Feb. } 5 . \\
\text { June } 18 .\end{array}$ & $\begin{array}{l}1943 \\
1943\end{array}$ & $\begin{array}{l}20.0 \quad a \\
20.51\end{array}$ & & $\begin{array}{l}1.710 \mathrm{~b} \\
3.720\end{array}$ \\
\hline 1944 & $\begin{array}{lr}\text { May } & 5, \\
\text { May } & 22, \\
\text { May } & 27, \\
\text { June } & 12,\end{array}$ & $\begin{array}{l}1944 \\
1944 \\
1944 \\
1944\end{array}$ & $\begin{array}{l}19.8 \\
20.3 \\
20.45 \\
20.1\end{array}$ & & $\begin{array}{l}2.430 \\
3,430 \\
3.830 \\
2.970\end{array}$ \\
\hline
\end{tabular}

a Affected by ice.
b About. 
05-4860.00 North $\mathrm{River}$ near Norwalk. Iowa--(Continued)

Peak stagaes and discharges

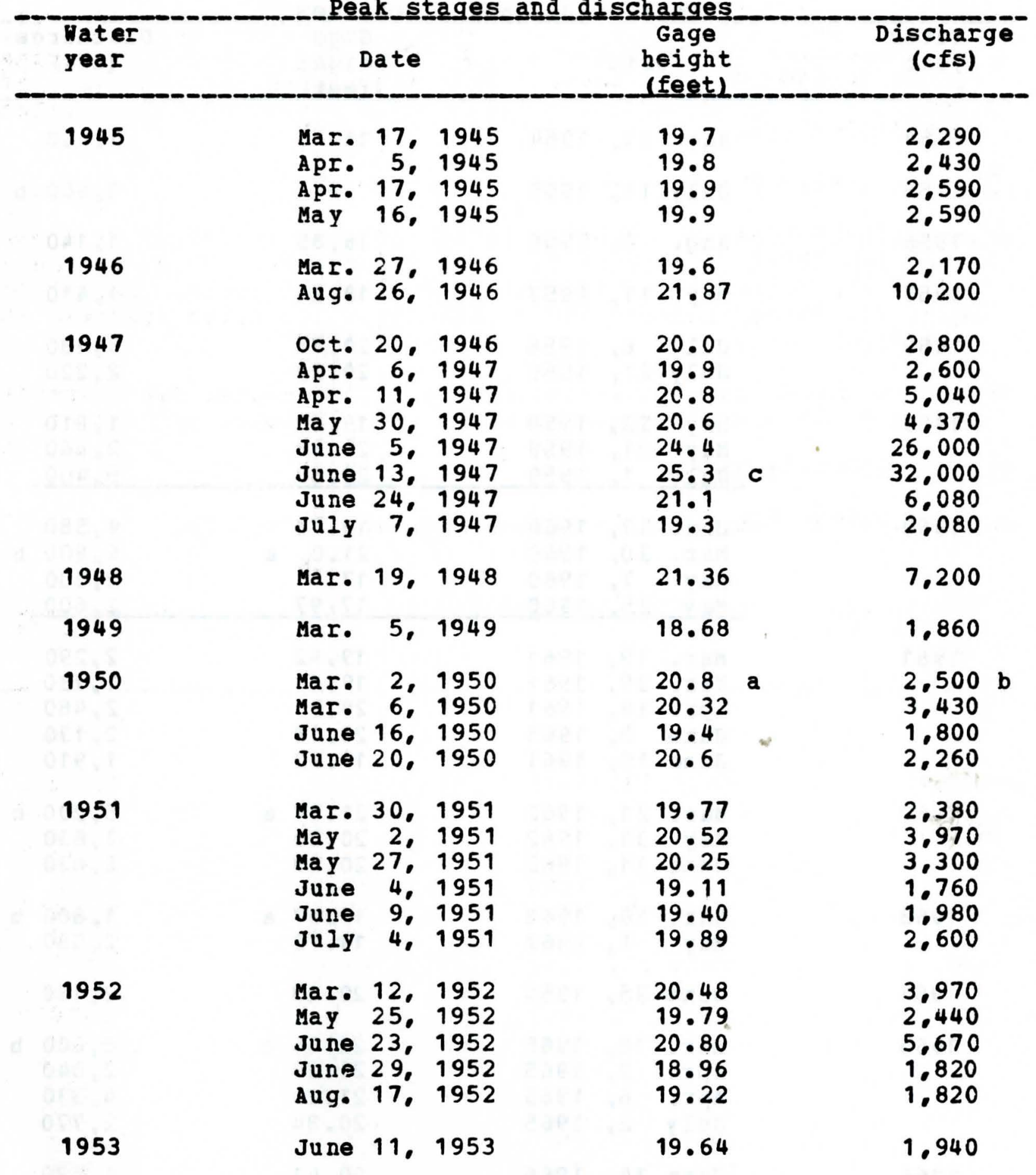

\footnotetext{
a Affected by ice.

b about.

c From floodmark.
} 
05-4860.00 North River near Norwalk, Iowa--(Continued)

Peak﹎_stages_anda_di

\begin{tabular}{|c|c|c|c|c|c|c|}
\hline $\begin{array}{l}\text { Water } \\
\text { year }\end{array}$ & & Date & $\begin{array}{l}\text { Gage } \\
\text { height } \\
\text { (feet). }\end{array}$ & & $\begin{array}{c}\text { Discharge } \\
\text { (cfs) }\end{array}$ & \\
\hline 1954 & May & 31.1954 & 18.45 & & 1.600 & \\
\hline 1955 & July & 11,1955 & -- & & $1.400 \mathrm{~b}$ & $b$ \\
\hline 1956 & Aug. & 8, 1956 & 16.85 & & 1.140 & \\
\hline 1957 & May & 11.1957 & 18.26 & & 1.410 & \\
\hline 1958 & $\begin{array}{l}\text { JuIy } \\
\text { JuIy }\end{array}$ & $\begin{array}{r}6,1958 \\
21,1958\end{array}$ & $\begin{array}{l}20 \cdot 77 \\
20 \cdot 20\end{array}$ & & $\begin{array}{l}3.180 \\
2.220\end{array}$ & \\
\hline 1959 & $\begin{array}{l}\text { May } \\
\text { May } \\
\text { Juuy․ }\end{array}$ & $\begin{array}{r}22,1959 \\
31,1959 \\
1,1959\end{array}$ & $\begin{array}{r}19 \cdot 63 \\
20.33 \\
22.60 \\
\end{array}$ & & $\begin{array}{l}1.810 \\
2.660 \\
9.460 \\
\end{array}$ & \\
\hline 1960 & $\begin{array}{l}\text { Jan. } \\
\text { Mar. } \\
\text { May } \\
\text { Mazy. }\end{array}$ & $\begin{array}{r}13,1960 \\
30,1960 \\
7 ; \\
25,1960 \\
\end{array}$ & $\begin{array}{l}19.76 \\
21.0 \\
17.8 \\
17.97\end{array}$ & $a$ & $\begin{array}{l}4.580 \\
6.800 \\
2.500 \\
2.600 \\
\end{array}$ & b \\
\hline 1961 & $\begin{array}{l}\text { Mar. } \\
\text { Mar. } \\
\text { Apr. } \\
\text { June } \\
\text { June }\end{array}$ & 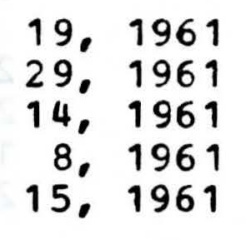 & $\begin{array}{l}19 \cdot 92 \\
19.19 \\
20.05 \\
20.18 \\
19.90\end{array}$ & $\approx$ & $\begin{array}{l}2.290 \\
1.730 \\
2.480 \\
2.130 \\
1.910\end{array}$ & \\
\hline 1962 & $\begin{array}{l}\text { Mar. } \\
\text { May } \\
\text { June }\end{array}$ & $\begin{array}{l}21,1962 \\
31 ; 1962 \\
11 ; 1962\end{array}$ & $\begin{array}{l}21.87 \\
20.30 \\
20.29\end{array}$ & $a$ & $\begin{array}{l}5.200 \\
2.830 \\
2.830\end{array}$ & b \\
\hline 1963 & $\begin{array}{l}\text { Mar. } \\
\text { May }\end{array}$ & $\begin{array}{r}13,1963 \\
1.1963\end{array}$ & $\begin{array}{l}19.97 \\
19.72\end{array}$ & $a$ & $\begin{array}{l}1.800 \\
2.080\end{array}$ & b \\
\hline 1964 & June & 25,1964 & 20.23 & & 2.130 & \\
\hline 1965 & $\begin{array}{l}\text { Mar. } \\
\text { Apr. } \\
\text { ApI. } \\
\text { JuIy }\end{array}$ & $\begin{array}{rr}18, & 1965 \\
2, & 1965 \\
6, & 1965 \\
2, & 1965\end{array}$ & $\begin{array}{l}22.86 \\
20.23 \\
21.20 \\
20.84\end{array}$ & $a$ & $\begin{array}{l}8.000 \\
2.040 \\
4.330 \\
2.770\end{array}$ & b \\
\hline 1966 & June & 14.1966 & 20.41 & & 1.580 & \\
\hline
\end{tabular}

a Affected by ice.

b A bout. 
05-4860.00 North River neaI Norwalk. Iowa--(Continued)

Peak__stages and_di

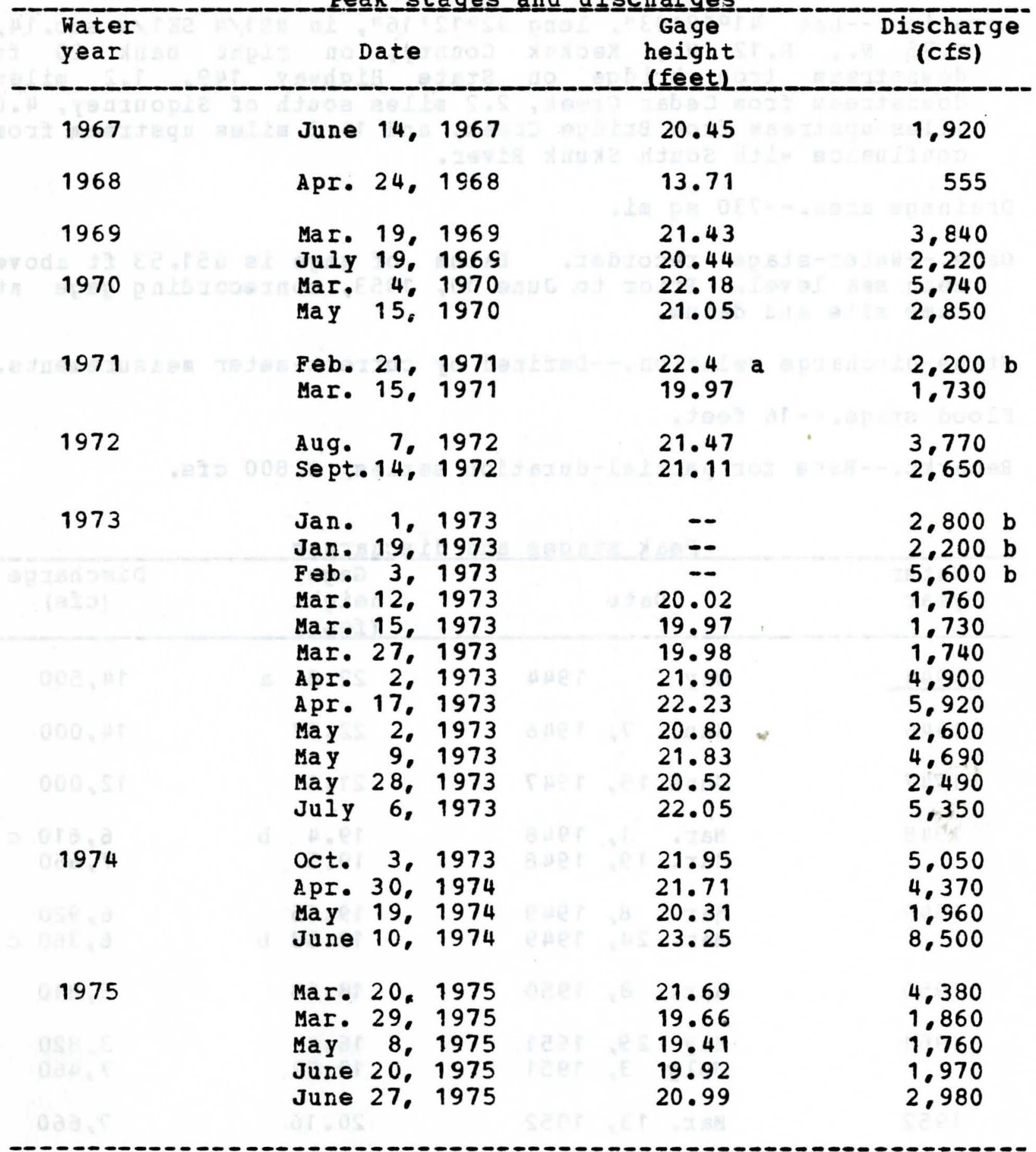

a Affected by ice.

b About. 
Location,--Lat $41018^{\circ} 03^{\prime \prime}$, long $92^{\circ} 12^{\prime} 16^{\prime \prime}$, in NE1/4 SE1/4 sec. 14 , T.75 N.. R.12 N.. Keokuk County. on right bank 20 ft downstream from bridge on state Highway 149, 1.2 miles downstream from Cedar Creek, 2.2 miles south of sigourney. 4.0 miles upstream from Bridge Creek, and 16.2 miles upstream from confluence with South skunk River.

Drainage area. $--730 \mathrm{sq} \mathrm{mi}$

Gage.--Water-stage recorder. Datum of gage is $651.53 \mathrm{ft}$ above mean sea level. Prior to June 10, 1953, nonrecording gage at same site and datum.

Stage-discharge relation.--Defined by current-meter measurements. Flood stage.--16 feet.

Remarks.--Base for partial-duration series, 3,800 cfs.

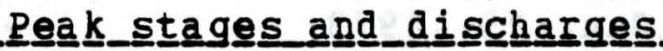

\begin{tabular}{|c|c|c|c|c|c|c|}
\hline $\begin{array}{l}\text { Water } \\
\text { year }\end{array}$ & Date & & $2 x$ & $\begin{array}{r}\text { Gage } \\
\text { height } \\
\text { (feet) }\end{array}$ & & $\begin{array}{c}\text { Discharge } \\
\text { (cfs) }\end{array}$ \\
\hline-1944 & May & 1944 & & 22.8 & a & 14,500 \\
\hline 1946 & Jan. 7 , & 1946 & & 22.57 & $\approx$ & 14,000 \\
\hline 1947 & June 15 & 1947 & & 21.8 & & 12,000 \\
\hline 1948 & $\begin{array}{l}\text { Mar. 1, } \\
\text { Mar. 19, }\end{array}$ & $\begin{array}{l}1948 \\
1948\end{array}$ & & $\begin{array}{l}19.4 \\
19.5\end{array}$ & b & $\begin{array}{l}6.610 \\
7.660\end{array}$ \\
\hline 1949 & $\begin{array}{l}\text { Mar. } 8, \\
\text { Mar. } 24 .\end{array}$ & $\begin{array}{l}1949 \\
1949\end{array}$ & & $\begin{array}{r}19.65 \\
19.53\end{array}$ & b & $\begin{array}{l}6,920 \\
6,760\end{array}$ \\
\hline 1950 & Mar. 8, & 1950 & & 18.84 & & 5,810 \\
\hline 1951 & $\begin{array}{lr}\text { May } & 29 \\
\text { JuIy } & 3,\end{array}$ & $\begin{array}{l}1 \subsetneq 51 \\
1951\end{array}$ & & $\begin{array}{l}16.4 \\
19.92\end{array}$ & $a$ & $\begin{array}{l}3.820 \\
7.460\end{array}$ \\
\hline 1952 & $\operatorname{Mar.} 13$. & 1952 & & 20.16 & & 7,660 \\
\hline $\begin{array}{ll}\mathrm{a} & \mathrm{Fr} \\
\mathrm{b} & \mathrm{Af} \\
\mathrm{c} & \mathrm{Ab}\end{array}$ & $\begin{array}{l}\text { ark. } \\
\text { ice. }\end{array}$ & & & & & 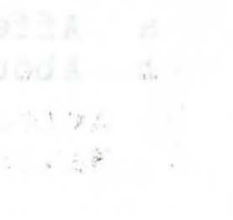 \\
\hline
\end{tabular}


05-4725.00 Worth Skunk River near Sigourney, Iowa--(Continued)

Peak_stages_and_discharges

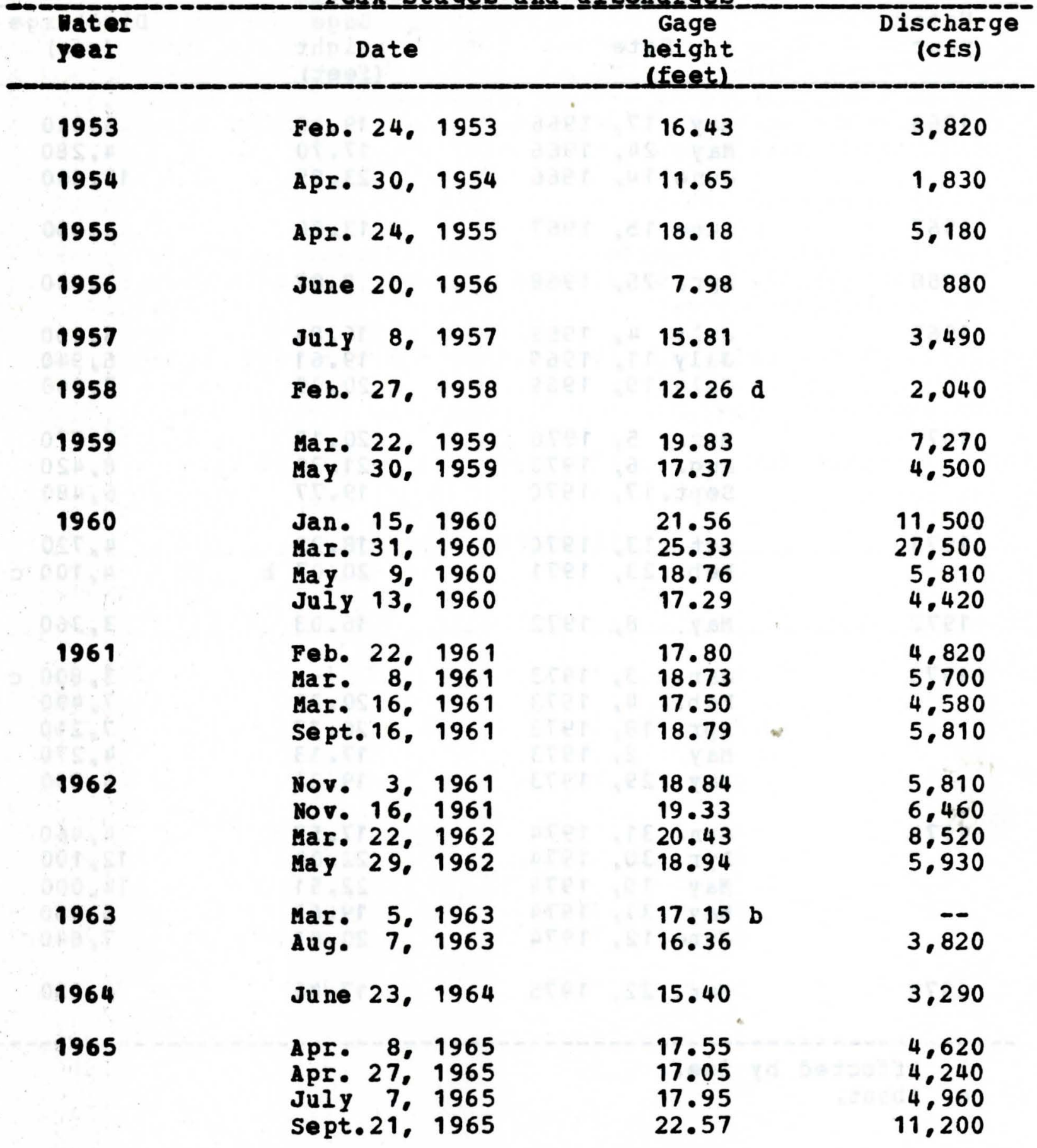

b affected by ice.

d Haxinum gage height, $13.60 \mathrm{ft}$. 
05-4725.00 North Skunk River near Sigourney. Iowa--(Continued)

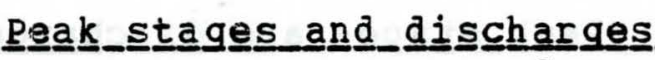

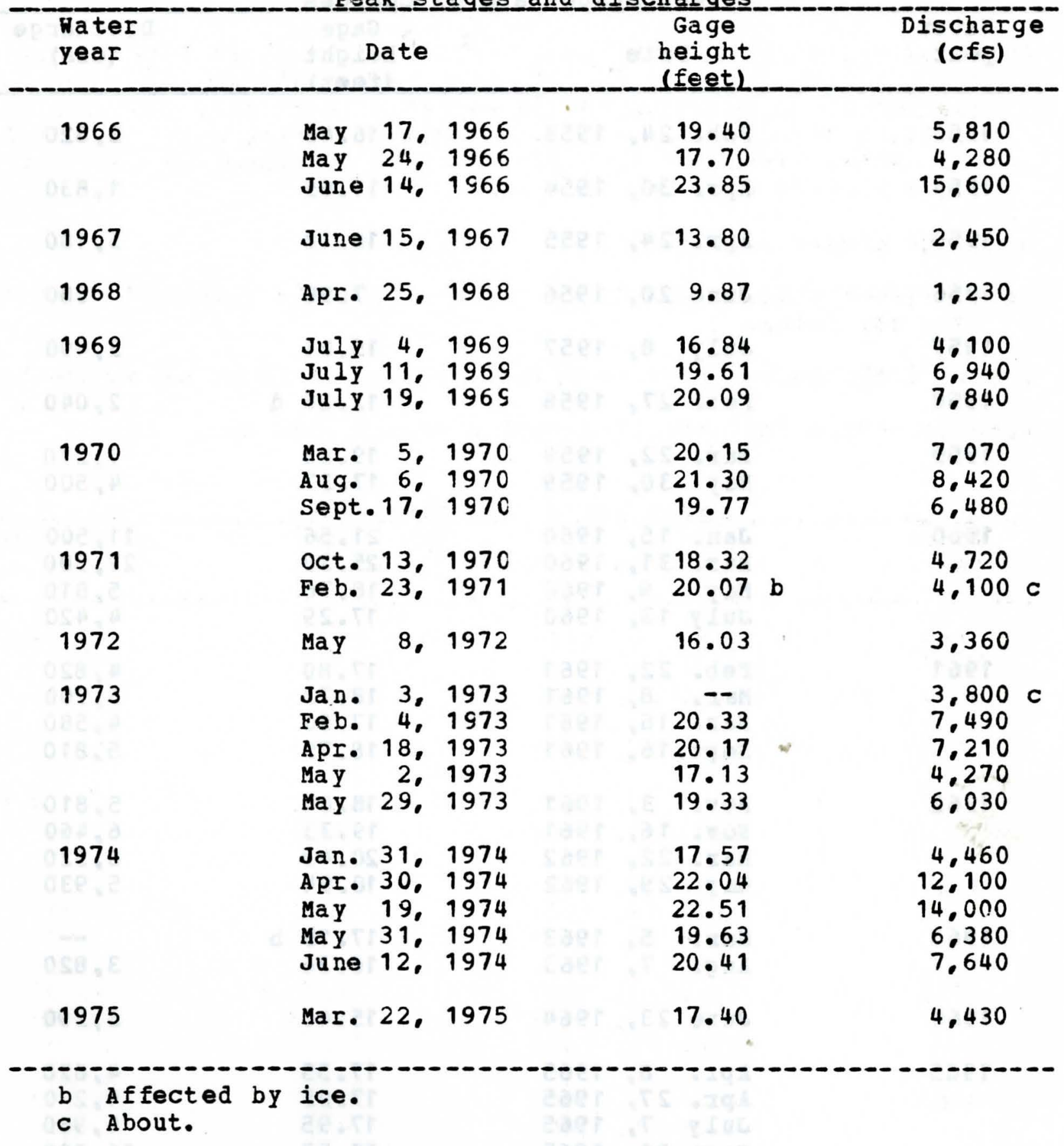




\section{6-6070.00 odebolt Creek near Arthur, Iowa (Discontinued September 1975)}

Location.--Lat $42^{\circ} 20^{\prime} 10^{\prime \prime}$, long $95^{\circ} 22^{\prime} 52^{\prime \prime}$, in SE $1 / 4 \mathrm{NE} 1 / 4$ sec. 21 , T.87 N.. R.39 \%.. Ida County. near center of span on downstream side of bridge on county highway M27, 700 ft south of State Highway 175, 1.0 mile downstream from Hoskins Creek, 1.8 miles west of Arthur, 4.6 miles southeast of Ida Grove, and 6.5 miles upstream from mouth.

Drainage area.--39.3 sq mi.

Gage.--Hater-stage recorder. Datum of gage is 1.258.57 ft above moan sea level.

Stage-discharge relation.--Defined by current-meter measurements. Remarks.--Base for partial-duration series, 500 cfs.

Peak_s_stages_and di

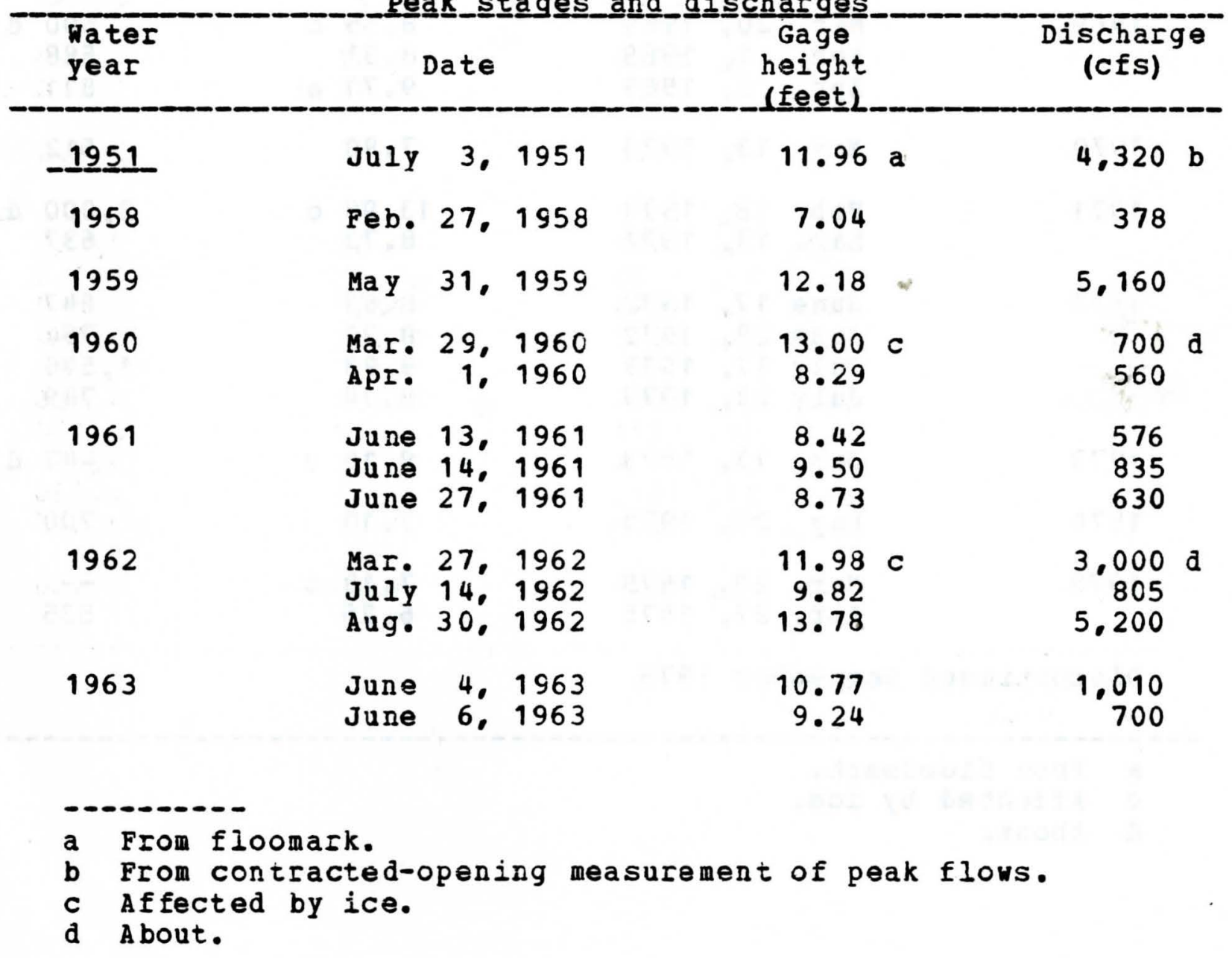


06-6070.00 0debolt Creek near AIthuI, Iowa--(Continued)

Peak

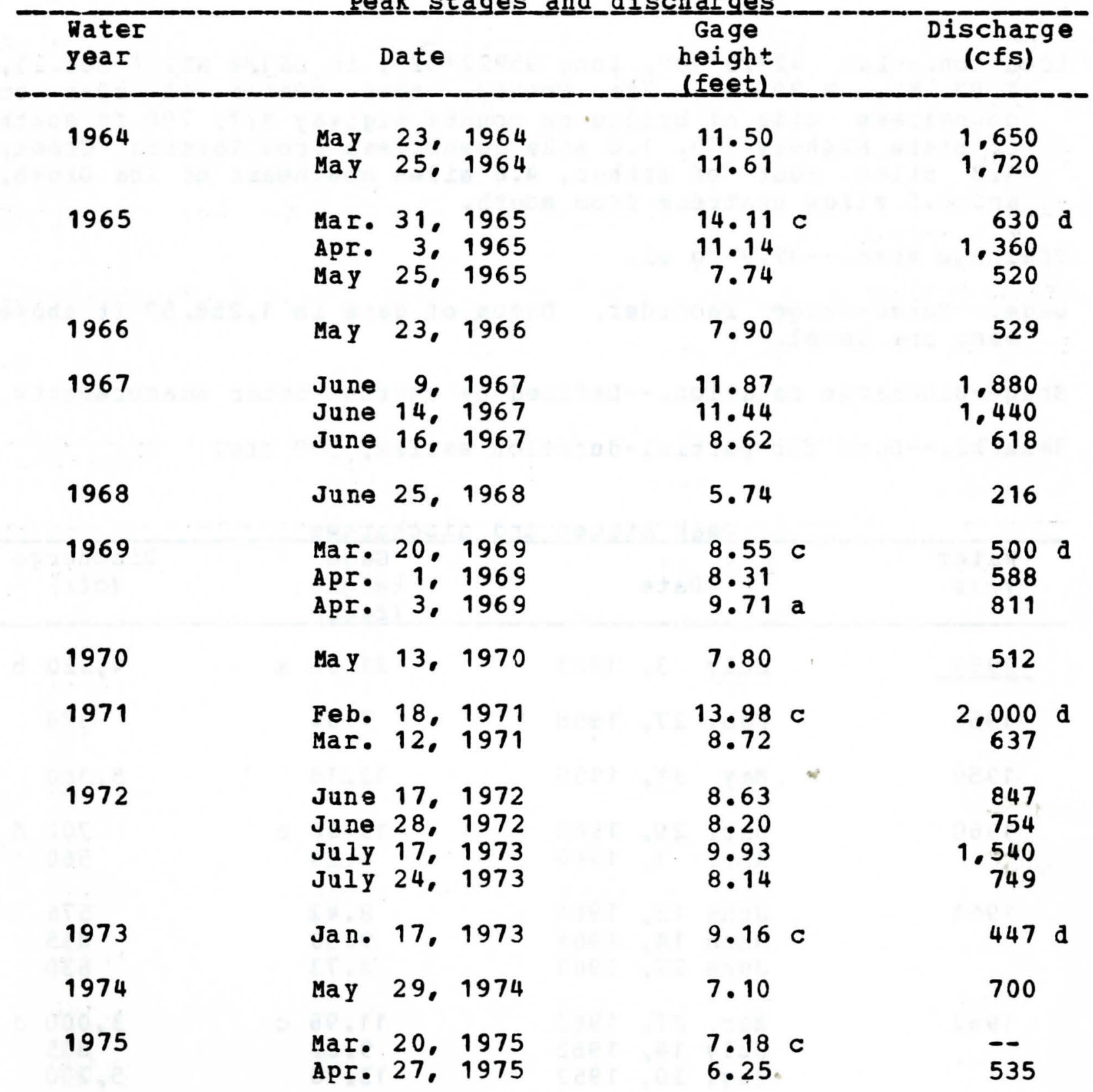

Discontinued September 1975

a From floodmark.

c Affected by ice.

d About. 


$$
\text { 05-4551.00 old Mans Creek near Iowa City. Iowa }
$$

Location.--Lat 41036'23", long $91036 \cdot 56^{\prime \prime}$, in Nw1/4 sec.36, T.79

N.. R.7 W.. Johnson County, at bridge, 3 miles southwest of Iowa City.

Drainage area.--201 sq mi.

Gage.-Nonrecording. Altitude of gage is $645 \mathrm{ft}$ (from topographic map).

Stage-discharge relation.--Defined by current-meter measurements. Remarks.--only annual peaks are shown.

Peakㅡ_stages_and di scharges

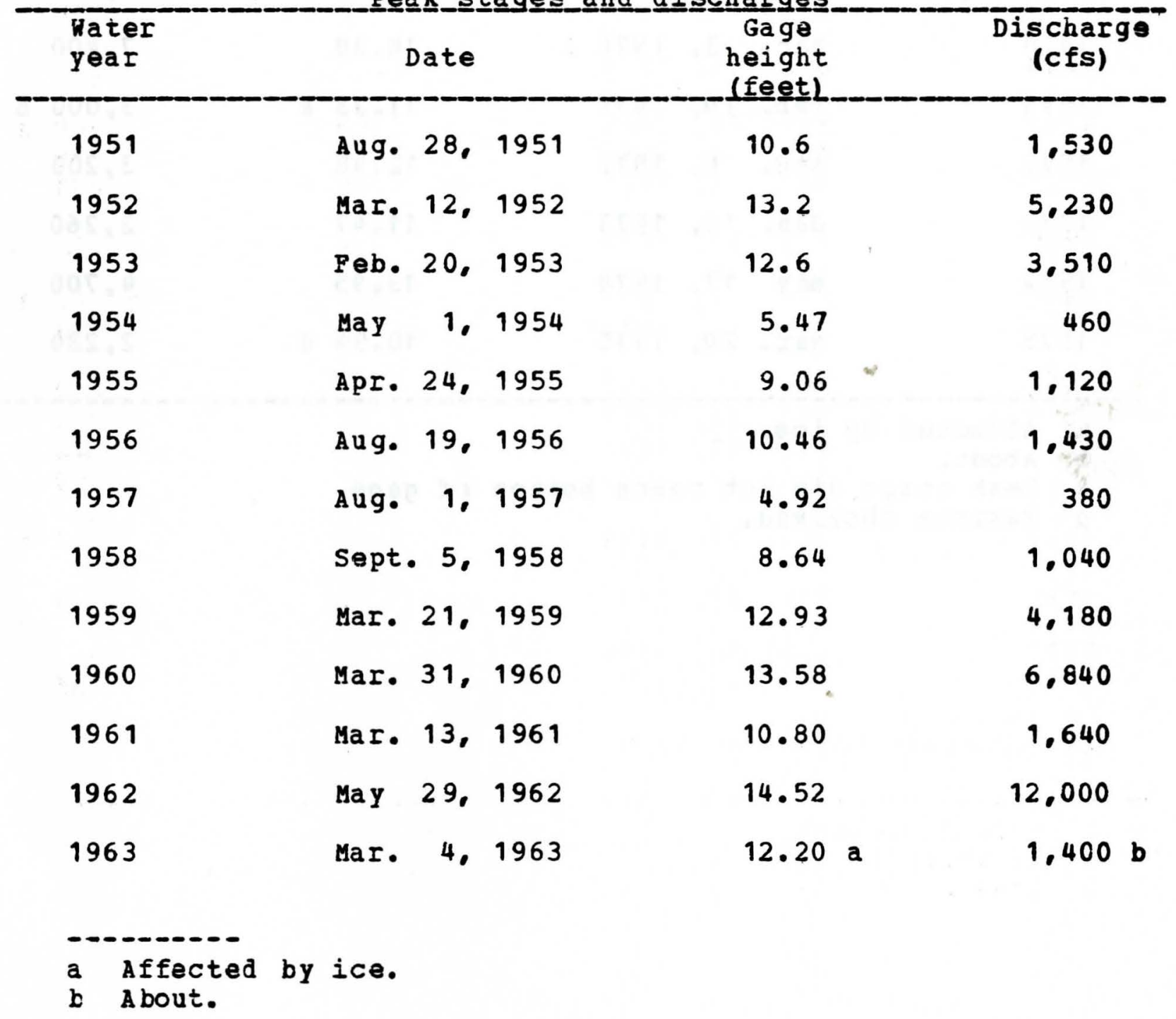


05-4551.00 old Mans Creek near Iowa City. Iowa--(Continued)

Peak﹎.stages_and_di

\begin{tabular}{|c|c|c|c|c|}
\hline $\begin{array}{l}\text { Water } \\
\text { year }\end{array}$ & Date & 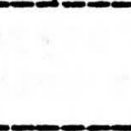 & $\begin{array}{l}\text { Gage } \\
\text { height } \\
\text { (feet) }\end{array}$ & $\begin{array}{c}\text { Discharge } \\
\text { (cfs) }\end{array}$ \\
\hline 1964 & June 20 & 1964 & $10 \cdot 42$ & 1.480 \\
\hline 1965 & sept. 21. & 1965 & 15.55 & 7.750 \\
\hline 1966 & 24. & 1966 & 13.00 & 3.400 \\
\hline 1967 & Ju $1 Y$ & 1967 & 9.33 & 1.200 \\
\hline 1968 & -- & & c & $<1,180$ \\
\hline 1969 & JuIy & 1969 & 12.73 & 2,570 \\
\hline 1970 & Mar. & $197 C$ & $14 \cdot 38$ & 7.400 \\
\hline 1971 & Feb. 19. & 1971 & $11.33 \mathrm{a}$ & $3.000 \mathrm{~b}$ \\
\hline 1972 & Aug. $\quad 6$, & 1972 & $12 \cdot 98$ & 3.200 \\
\hline 1973 & Jan. 18, & 1973 & 11.47 & 2.260 \\
\hline 1974 & 17. & 1974 & 13.95 & 4.700 \\
\hline 1975 & Mar. 20 & 1975 & $10.94 \mathrm{~d}$ & 2.230 \\
\hline
\end{tabular}

a Affected by ice.

b A bout.

c Peak stage did not reach bottom of gage.

d Maximum observed. 


$$
\text { 06-4834.60 Otter Creek near Ashton. Iowa }
$$

Location.--Lat $43020^{\circ}$, Iong $95046^{\prime}$, in SE1/4 sec.2, T.98 N., R. 42

W. Osceola County, at bridge, 2 miles northeast of Ashton.

Drainage area.--88.0 sq mi.

Gage.--Crest-stage gage.

Stage-discharge relation. Defined by current-meter and indirect mea surements.

Remarks.--only annual peaks are shown.

Peak

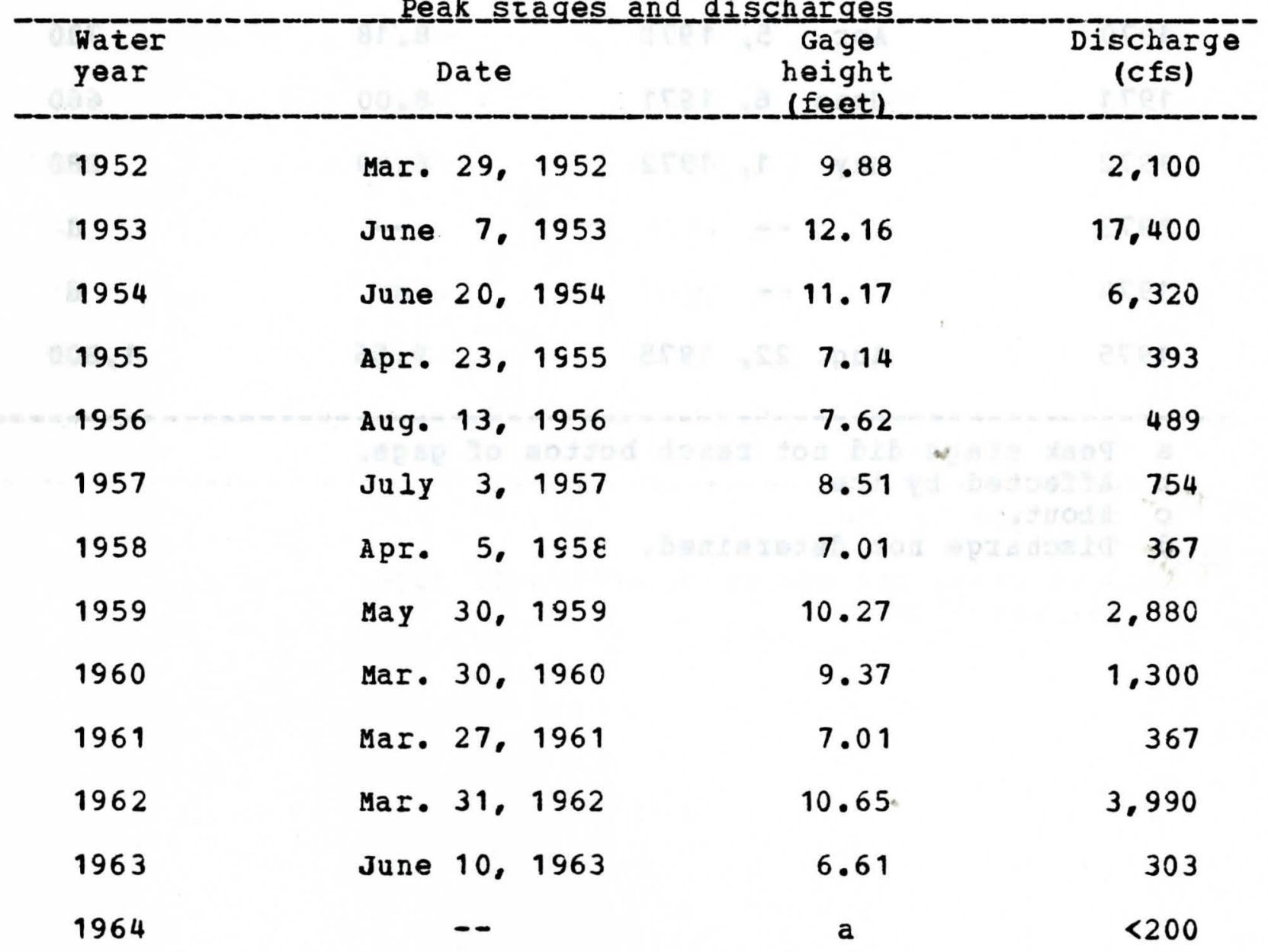

a Peak stage did not reach bottom of gage. 
06-4834.60 otter Creek near Ashton, Iowa--(Continued)

Peak stages and discharges

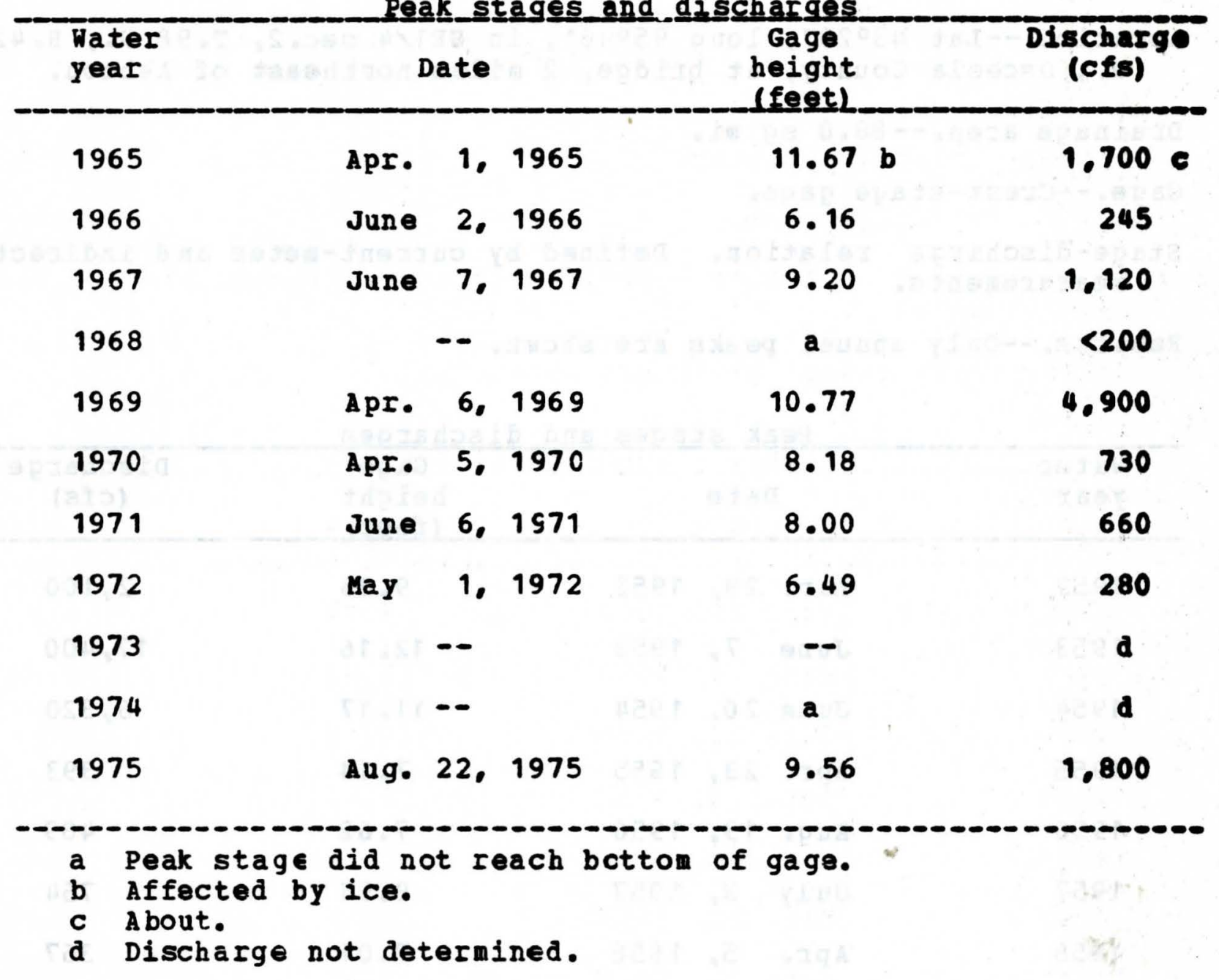




\section{6-4834.30 Otter Creek at Sibley. Iowa}

Location.--Lat $43024^{\prime}$, long 95046', near N1/4 corner sec.14, T.99 N.. R.42 W., Osceola County, at bridge, 1 mile northwest of Sibley.

Drainage area.--29.9 sq mi.

Gage.--Crest-stage gage.

Stage-discharge relation.--Defined by current-meter and indirect measurements.

Remarks.--only annual peaks are shown.

Peakk_stages and_discharges

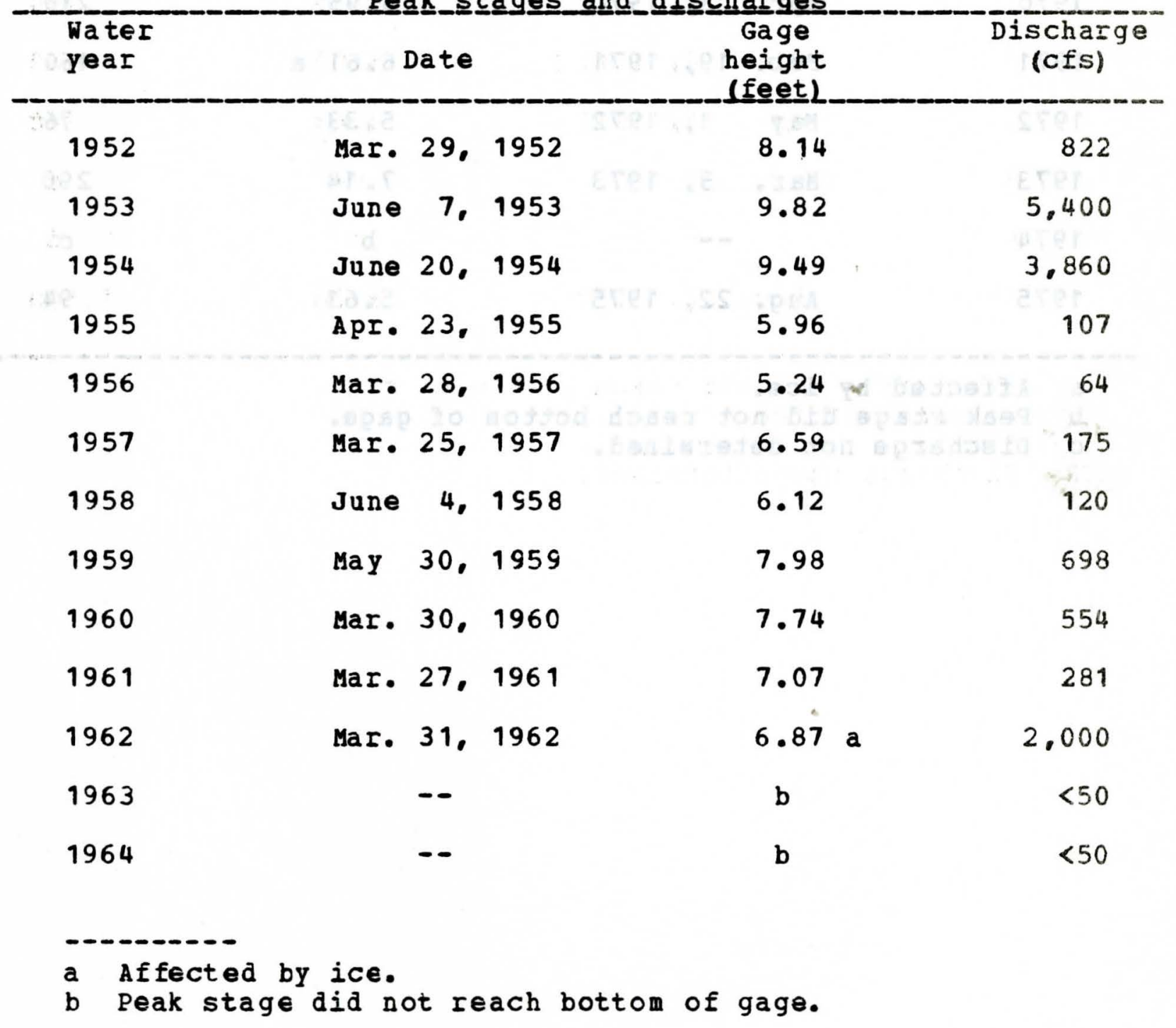


06-4834.30 otter Creek at Sibley. Iowa--(Continued)

Pea $\underline{k}$ stag ges_and_di

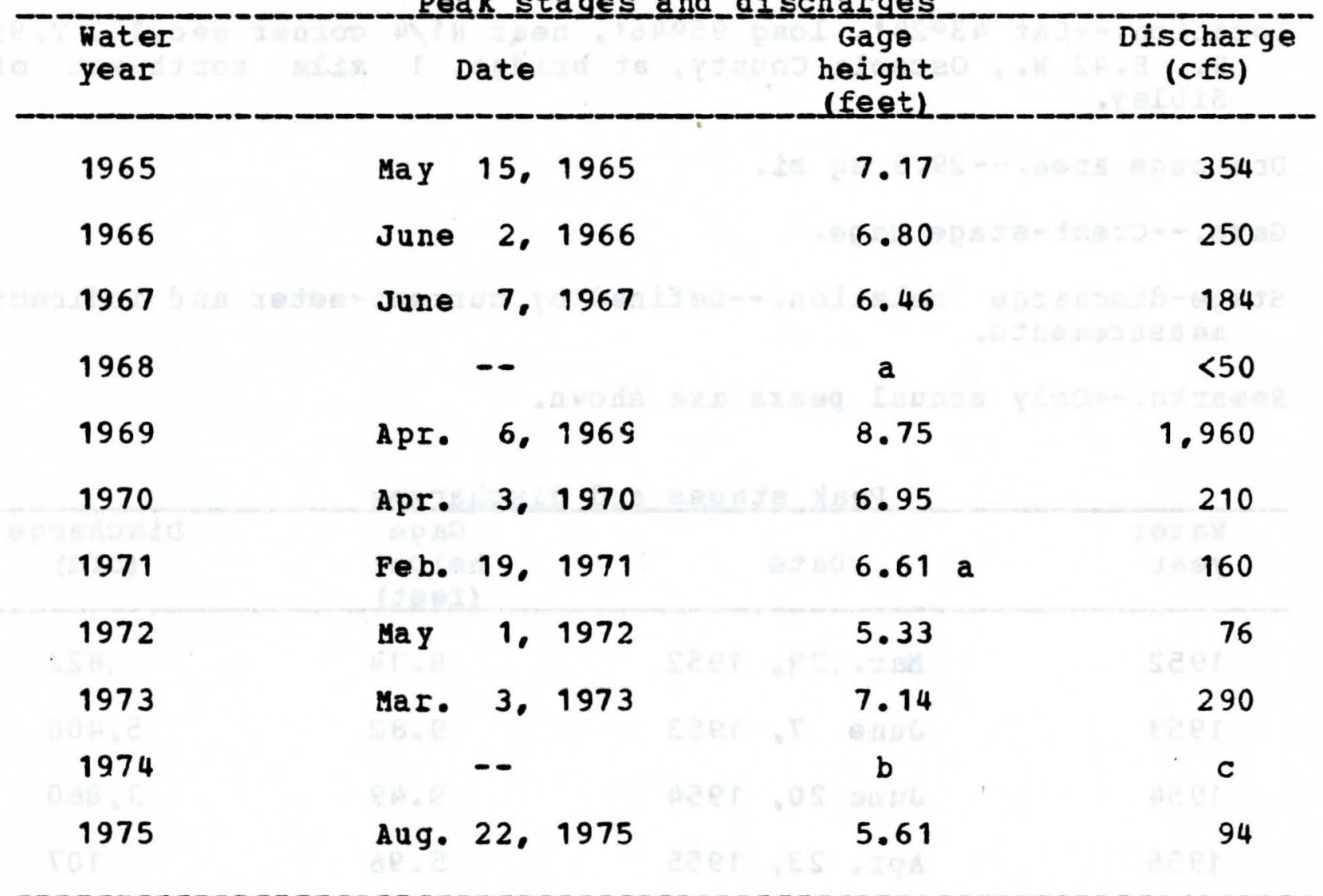

a Affected by ice.

b Peak stage did not reach bottom of gage.

c Discharge not determined. 


\section{6-4834.10 0tter Creek north of Sibley. Iowa}

Location.--Lat 430281 , long 95044', at NE corner s8c.25. T. 100 N.. R.42 W., Osceola county, at bridge on county road $H, 4$ miles north of sibley.

Drainage area.--11.9 sq mi.

Gage.--Crest-stage gage.

Stage-discharge relation.--Defined by current-meter and indirect measurements.

Remarks.--only annual peaks are shown.

Peak_stag ges and

\begin{tabular}{|c|c|c|c|c|c|}
\hline $\begin{array}{l}\text { Water } \\
\text { year }\end{array}$ & & Date & & $\begin{array}{l}\text { Gage } \\
\text { height } \\
\text { (feet) }\end{array}$ & $\begin{array}{c}\text { Discharge } \\
\text { (cfs) }\end{array}$ \\
\hline 1952 & Mar. & 29. & 1952 & 6.95 & 300 \\
\hline 1953 & June & 7. & 1953 & 8.06 & 982 \\
\hline 1954 & June & 20 & 1954 & 7.73 & 751 \\
\hline 1955 & Apr. & 23. & 1955 & 4.56 & 52 \\
\hline 1956 & Mar. & 28 & 1956 & $4 \cdot 12$ & 45 \\
\hline 1957 & & -- & & $a$ & b \\
\hline 1958 & & -- & & a & b \\
\hline 1959 & May & 30. & 1959 & 7.62 & 674 \\
\hline 1960 & Mar. & 30. & 1960 & 6.60 & 229 \\
\hline 1961 & Mar. & 27 & 1961 & $a$ & $<68$ \\
\hline 1962 & Mar. & 31. & 1962 & 8.49 & 1.410 \\
\hline 1963 & & -- & & $a$ & $<68$ \\
\hline 1964 & & -- & & $a$ & $<68$ \\
\hline
\end{tabular}

a Peak stage did not reach bottom of gage.

b Discharge not determined. 
06-4834.10 otter Creek north of Sibley. Iowa--(Continued)

Peak

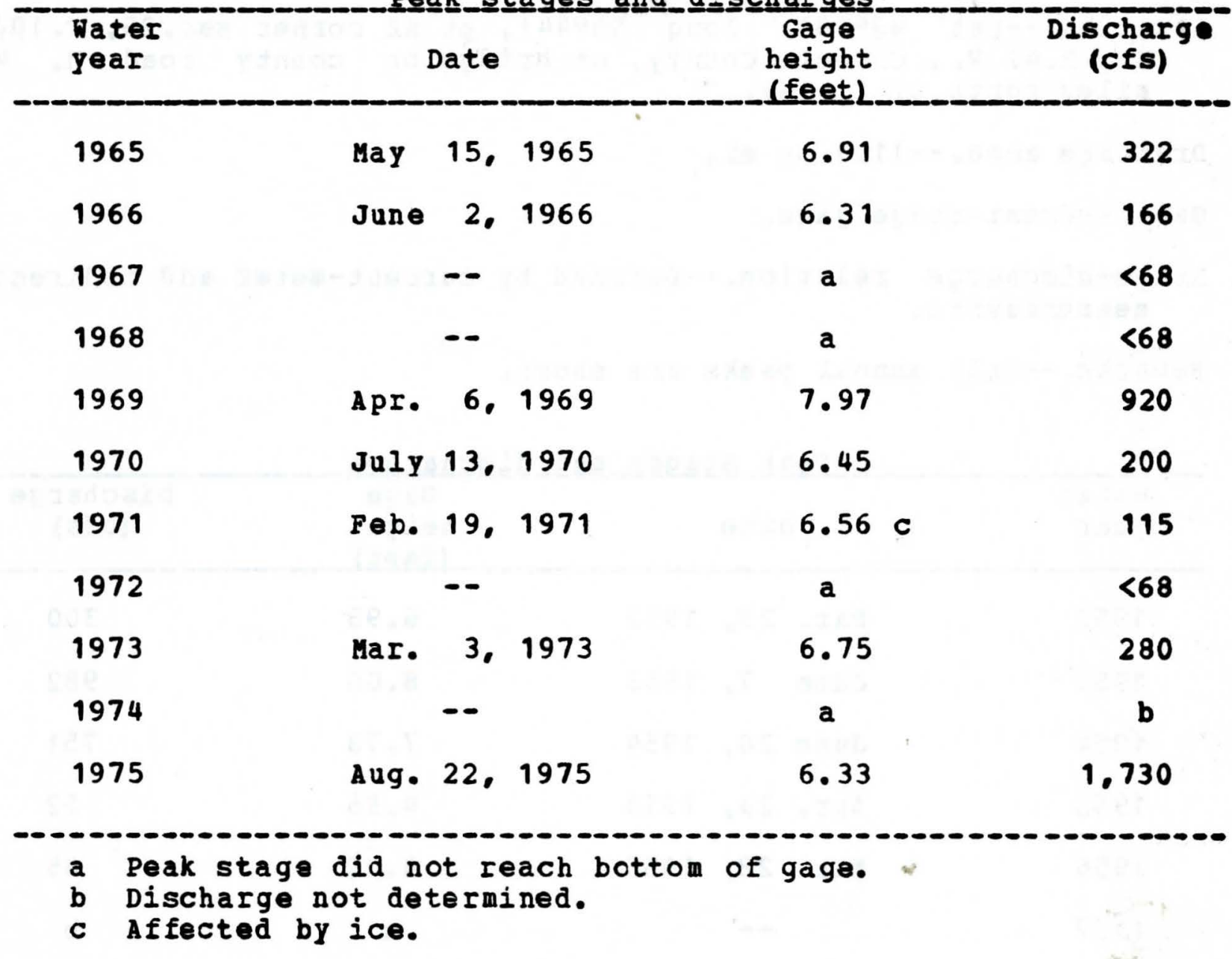




\section{5-4648.80 Otter Creek at Wilton. Iowa}

Location.--Lat $41036 \cdot 17 "$. long $91002 \cdot 08 "$, in NE1/4 seC.35. T.79 N.. R.2 W.. CedaI County, at bridge on State Highway 38, about 1.5 miles northwest of Wilton.

Drainage area.--10.7 sq mi.

Gage.--Crest-stage gage.

Stage-discharge relation.--Defined by current-meter measurements. Remarks.--only annual peaks are shown.

Peakㅡ_stagges and di schargeges

\begin{tabular}{|c|c|c|c|c|c|}
\hline $\begin{array}{l}\text { Water } \\
\text { year }\end{array}$ & & Date & & $\begin{array}{c}\text { Gage } \\
\text { height } \\
\text { lfeetl. }\end{array}$ & $\begin{array}{c}\text { Discharge } \\
\text { (cfs) }\end{array}$ \\
\hline 1966 & May & 23. & 1966 & 86.71 & 1.650 \\
\hline 1967 & Mar. & & 1967 & 87.00 & 2.200 \\
\hline 1968 & & - & & $\mathbf{a}$ & b \\
\hline 1969 & July & 9. & 1969 & $86 \cdot 78$ & 1.700 \\
\hline 1970 & May & 14. & 1970 & 86.47 & 1.250 \\
\hline 1971 & June & 20. & 1971 & 86.46 & 1.240 \\
\hline 1972 & JuIy & 18 & 1972 & 84.57 & 520 \\
\hline 1973 & Apr. & 16 & 1973 & 85.37 & 690 \\
\hline 1974 & May & 5. & 1974 & 87.22 & 1.900 \\
\hline 1975 & Mar. & 21. & 1975 & 84.55 & 520 \\
\hline
\end{tabular}

a Peak stage did not reach bctrom of gage.

b Discharge not determined. 


\section{5-3885.00 Paint Creek at Waterville, Iowa}

(Discontinued September 1973)

Location.--Lat $43012 \cdot 37 "$, long $91018 \cdot 21 "$, in NW1/4 NW1/4 sec. 22 , T.97 N.. R.4 W.. Alamakee County, on right bank $100 \mathrm{ft}$ downstream from bridge on county highway X32. 0.5 mile northwest of Waterville and 10 miles upstream from mouth.

Drainage area.--42.8 sq $\mathrm{mi}$

Gage.--Water-stage recorder.

Stage-discharge relation.--Defined by current-meter measurements. Bankfull stage.--11 feet.

Remarks.--Base for partial-duration series, 500 cfs.

Peak﹎.

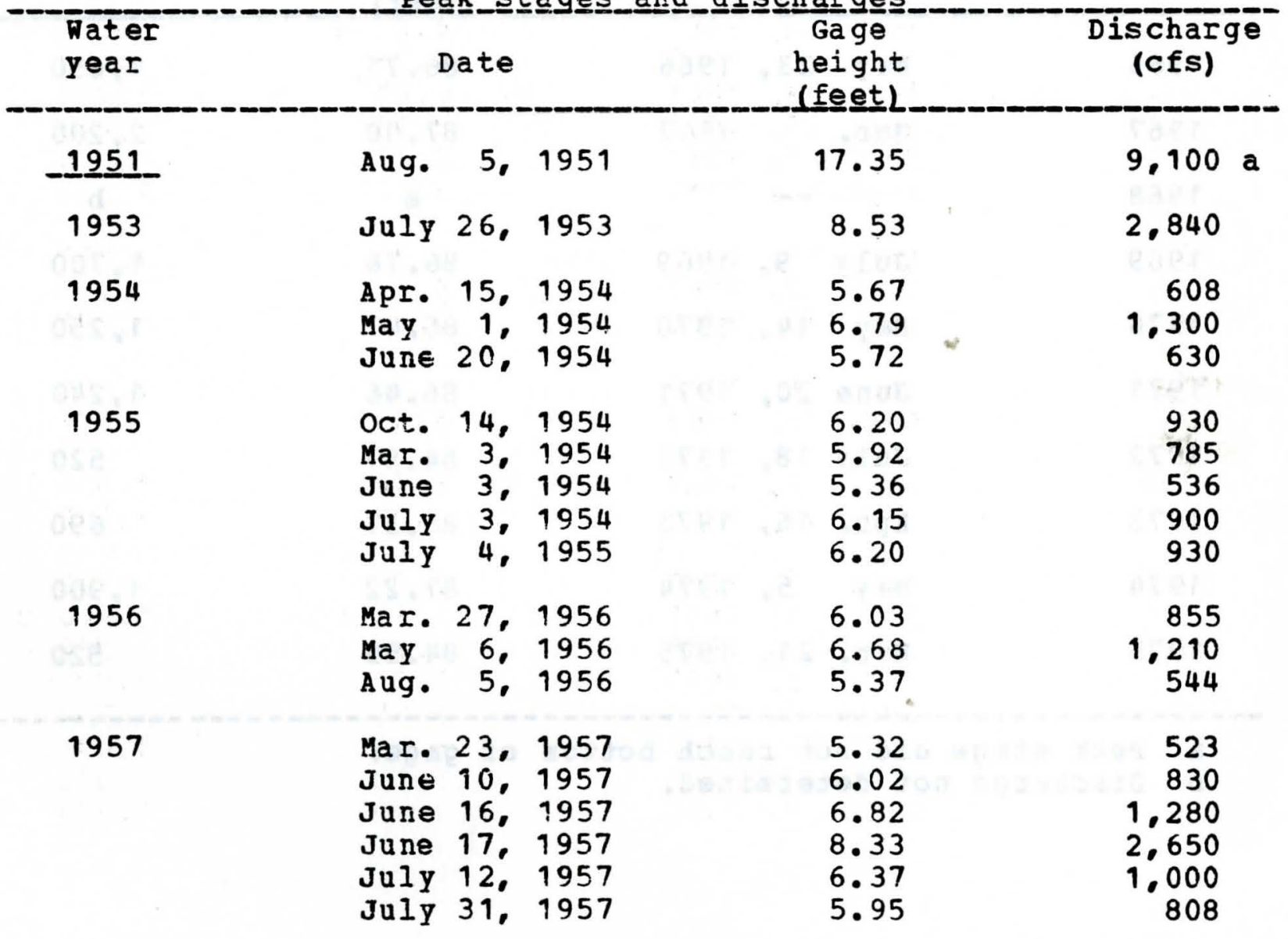

a From $\bar{i}$ nformation by local resident on floodmarks in vicinity of gage. A higher stage may have occurred during the spring of 1949 . 
05-3885.00 Paint Creek at Waterville, Iowa--(Continued)

Pㅌakk_stages_and_di scharges

\begin{tabular}{|c|c|c|c|c|c|}
\hline $\begin{array}{l}\text { Water } \\
\text { year }\end{array}$ & Date & & $\begin{array}{l}\text { Gage } \\
\text { height } \\
\text { (feet) }\end{array}$ & & $\begin{array}{c}\text { Discharg } \\
\text { (cfs) }\end{array}$ \\
\hline 1958 & Feb. 24 , & 1958 & 6.40 & & 1.030 \\
\hline 1959 & $\begin{array}{l}\text { Mar. } 24, \\
\text { Mar. } 31, \\
\text { May 20, } \\
\text { May } 31, \\
\text { June 28, } \\
\text { Aug. 3, } \\
\text { Sept. } 26,\end{array}$ & $\begin{array}{l}1959 \\
1959 \\
1959 \\
1959 \\
1959 \\
1959 \\
1959\end{array}$ & $\begin{array}{l}6.38 \\
6.62 \\
5.58 \\
5.77 \\
8.40 \\
5.29 \\
7.48\end{array}$ & & $\begin{array}{r}1.030 \\
1.150 \\
650 \\
718 \\
2.710 \\
523 \\
1.790\end{array}$ \\
\hline 1960 & $\begin{array}{l}\text { Mar. } 27, \\
\text { JuIy } 2,\end{array}$ & $\begin{array}{l}1960 \\
1960\end{array}$ & $\begin{array}{l}8.39 \\
5.35\end{array}$ & & $\begin{array}{r}2.710 \\
544\end{array}$ \\
\hline 1961 & $\begin{array}{l}\text { Feb. } 22, \\
\text { Mar. } 4, \\
\text { Mar. } 24, \\
\text { Mar. } 25^{\circ} \\
\text { Sopt. 1, } \\
\text { Sept. } 30^{\circ}\end{array}$ & $\begin{array}{l}1961 \\
1961 \\
1961 \\
1961 \\
1961 \\
1961\end{array}$ & $\begin{array}{l}8.07 \\
6.24 \\
6.88 \\
8.96 \\
6.67 \\
7.60\end{array}$ & b & $\begin{array}{r}1.800 \\
930 \\
1.340 \\
3.420 \\
1.180 \\
1.870\end{array}$ \\
\hline 1962 & $\begin{array}{lr}\text { Mar. } 28, \\
\text { July } 2, \\
\text { Aug. } 30\end{array}$ & $\begin{array}{l}1962 \\
1962 \\
1962\end{array}$ & $\begin{array}{l}8.46 \\
5.42 \\
7.32\end{array}$ & 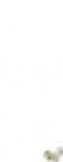 & $\begin{array}{r}3.250 \\
755 \\
1.900\end{array}$ \\
\hline 1963 & $\begin{array}{l}\text { MaI. } 16, \\
\text { MaI. } 25,\end{array}$ & $\begin{array}{l}1963 \\
1963\end{array}$ & $\begin{array}{l}7.00 \\
5.86\end{array}$ & & $\begin{array}{r}1.600 \\
832\end{array}$ \\
\hline 1964 & $\begin{array}{l}\text { Apr. } 2, \\
\text { May } 16,\end{array}$ & $\begin{array}{l}1964 \\
1964\end{array}$ & $\begin{array}{l}6.94 \\
8.32\end{array}$ & & $\begin{array}{l}1.550 \\
3.010\end{array}$ \\
\hline 1965 & $\begin{array}{l}\text { Feb. } 7, \\
\text { Mar. } 1, \\
\text { Mar. } 31 . \\
\text { Apr. } 3, \\
\text { Apr. } 6, \\
\text { May } 26, \\
\text { June } 20, \\
\text { Sept. } 7 .\end{array}$ & $\begin{array}{l}1965 \\
1965 \\
1965 \\
1965 \\
1965 \\
1965 \\
1965 \\
1965\end{array}$ & $\begin{array}{l}5.95 \\
7.60 \\
5.86 \\
7.32 \\
5.40 \\
6.79 \\
5.53 \\
7.18\end{array}$ & b & $\begin{array}{r}845 \\
1.900 \\
964 \\
1.920 \\
744 \\
1.440 \\
835 \\
1.790\end{array}$ \\
\hline
\end{tabular}

b Affected by ice.
c About. 
05-3885.00 Paint Creek at Waterville, Iowa--(Continued)

Peak

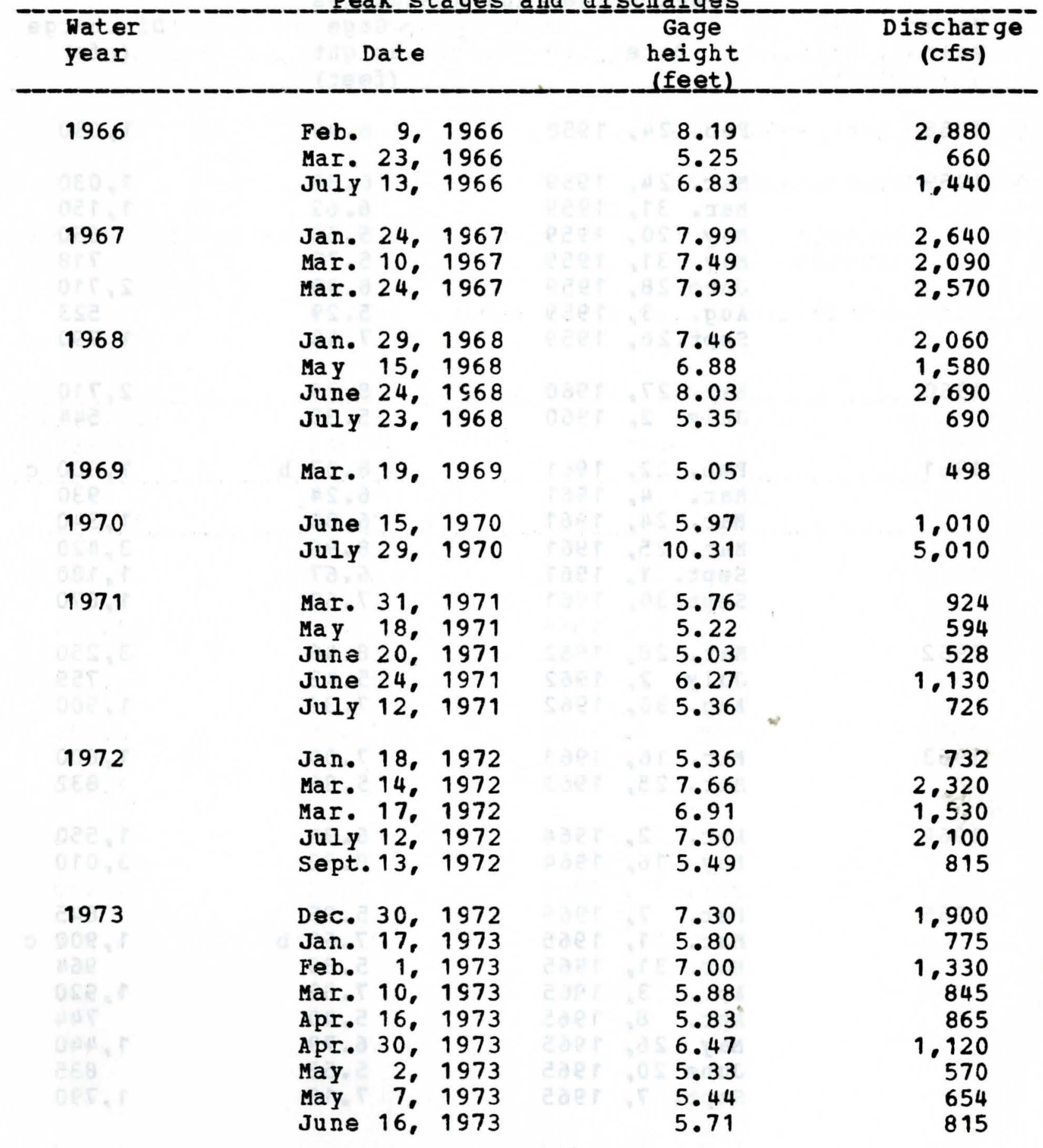

Discontinued september 1973 


\section{5-3886.00 Paint Creek near Naterville, Iowa}

Location.--Iat $43011^{\prime}$, long 91016 , near center sec.36, T.97 N.. R. 4 W.. Allamakee county, at bridge, 3 miles southeast of Waterville.

Drainage area.- $-56.0 \mathrm{sq} \mathrm{mi}$.

Gage.--Crest-stage gage.

Stage-discharge relation.--Defined by current-meter and indirect measurements.

Remarks.--only annual peaks are shown.

Peak__stages_and_di ischargarges

\begin{tabular}{|c|c|c|c|c|c|c|}
\hline $\begin{array}{l}\text { Water } \\
\text { year }\end{array}$ & & Date & & $\begin{array}{l}\text { Gage } \\
\text { height } \\
\text { (feet). }\end{array}$ & & $\begin{array}{c}\text { Discharge } \\
\text { (cfs) }\end{array}$ \\
\hline $19 \underline{51}$ & 소므. & $--\underline{5}$ & 1951 & 17.00 & & 10.800 \\
\hline 1953 & Ju $1 Y$ & 26 & 1953 & 12.89 & & 3.900 \\
\hline 1954 & Apr. & 30. & 1954 & 9.83 & & 1.920 \\
\hline 1955 & July & 4. & 1955 & 11.25 & & 2.720 \\
\hline 1956 & May & 6 & 1956 & 11.06 & 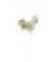 & 2,590 \\
\hline 1957 & July & 31. & 1957 & 9.33 & & 1.850 \\
\hline 1958 & $\mathrm{Fab}$. & 24 & 1958 & 7.25 & & 760 \\
\hline 1959 & Mar. & 24. & 1959 & 8.71 & & 1.470 \\
\hline 1960 & Mar. & 27. & 1960 & 13.81 & & 4.870 \\
\hline 1961 & Mar. & 25 & 1961 & 13.53 & & 4.540 \\
\hline 1962 & Mar. & 28 & 1962 & $12 \cdot 68$ & & 3.710 \\
\hline 1963 & & - & & a & & $<425$ \\
\hline 1964 & May & 15. & 1964 & 11.98 & & 3.040 \\
\hline 1965 & Apr. & 3. & 1965 & 10.35 & & 2,190 \\
\hline
\end{tabular}

a Peak stage did not reach bcttom of gage. 
05-3886.00 Paint Creek near Waterville. Iowa--(Continued)

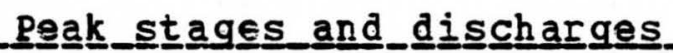

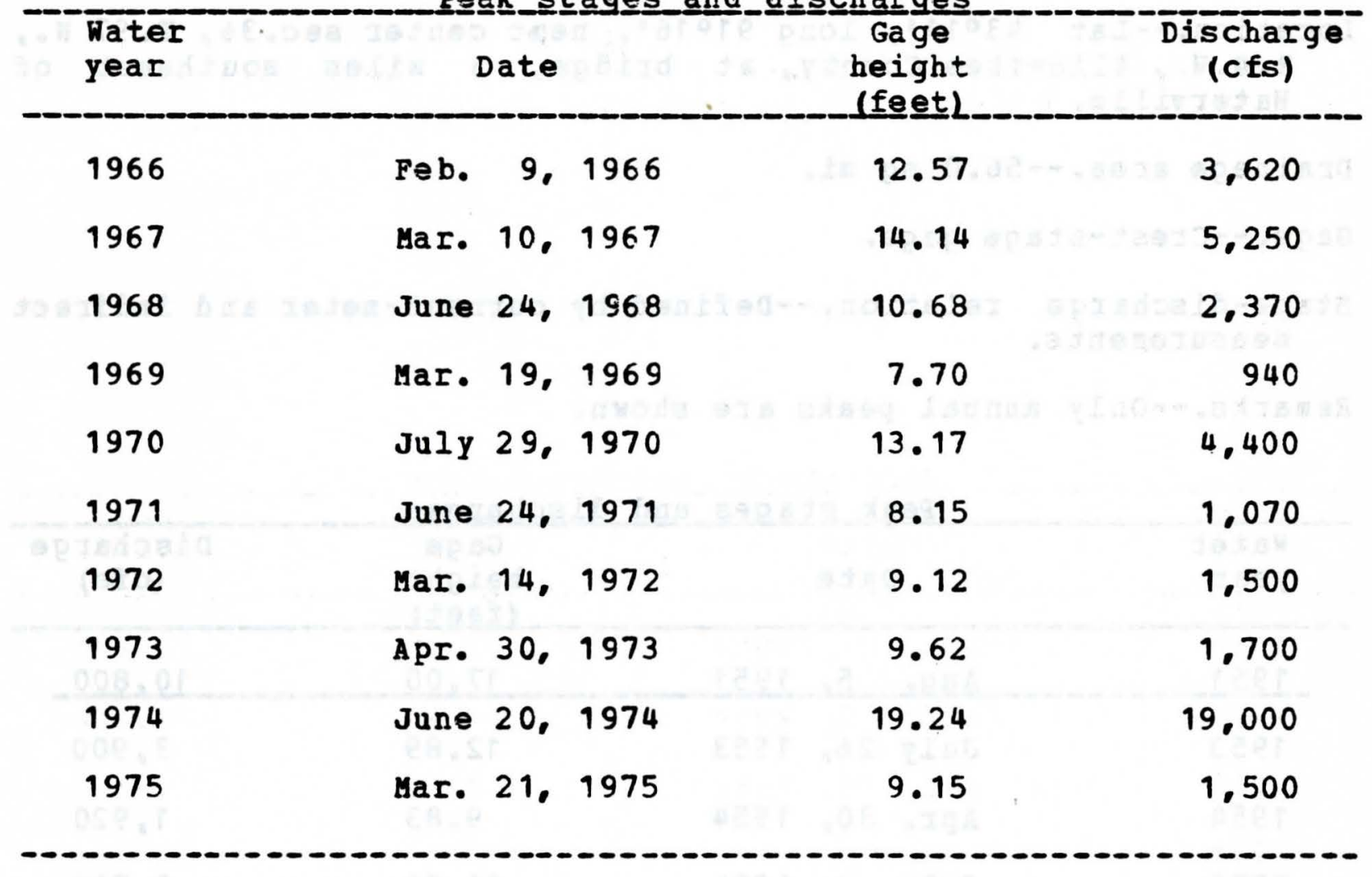




\section{6-5999.50 Perry Creek near Hinton. Iowa}

Location.--Lat 42037'57", long 96022'13", near $\$ 1 / 4$ corner sec.11, T. 90 N.. R.47 W.. Plymouth County, at bridge on State Highway 7,4 miles west of Hinton.

Drainage area.-- $-30.8 \mathrm{sq} \mathrm{mi}$.

Gage.--Crest-stage gage.

Stage-discharge relation.--Defined by current-meter and irdirect measurements.

Remarks.--only annual peaks are shown.

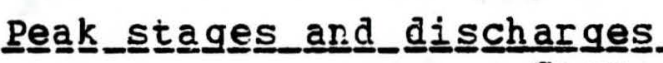

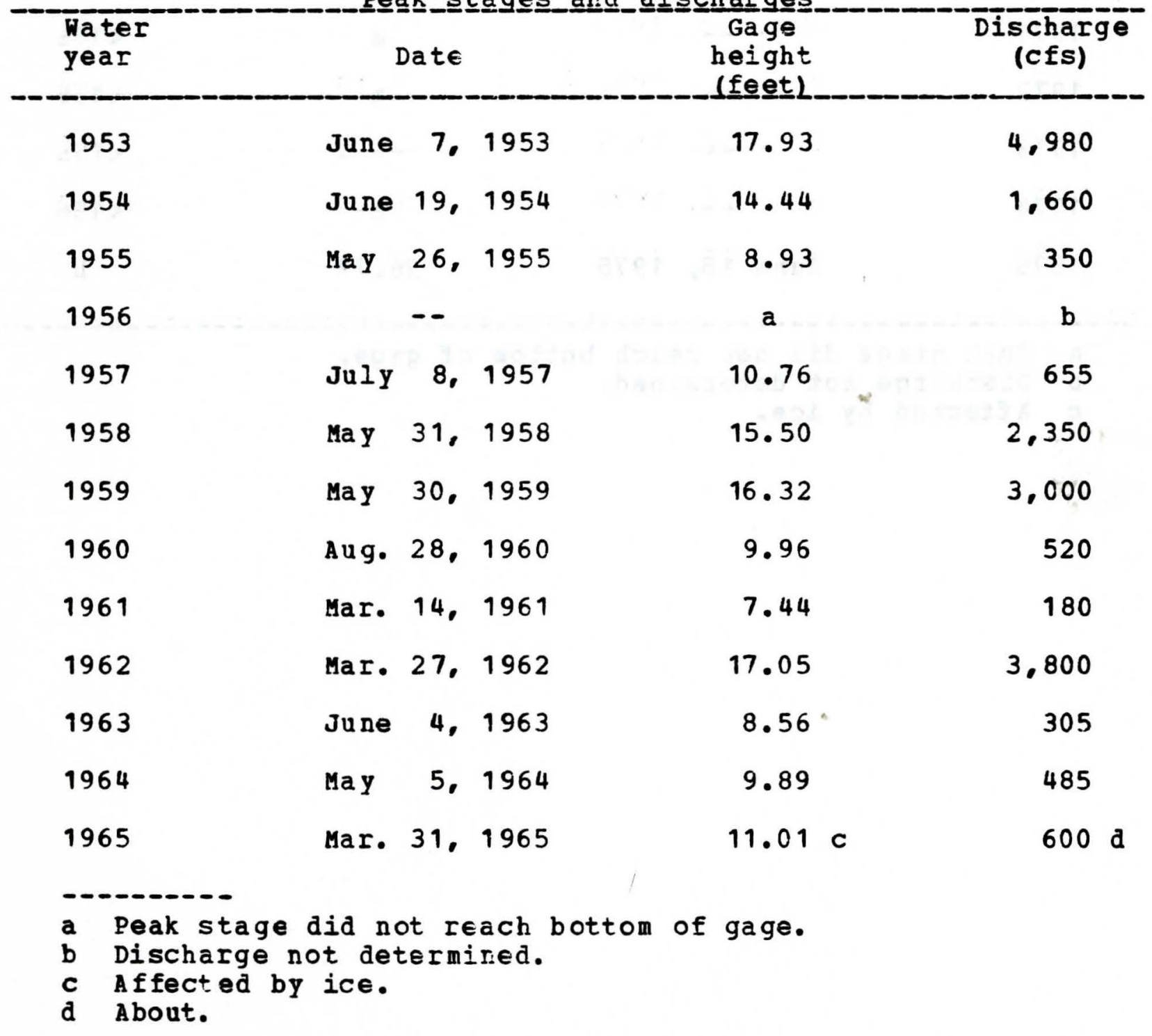


06-5999.50 PerIy Creek near Hinton. Iowa-- (Continued)

Peak﹎ stagges and_di

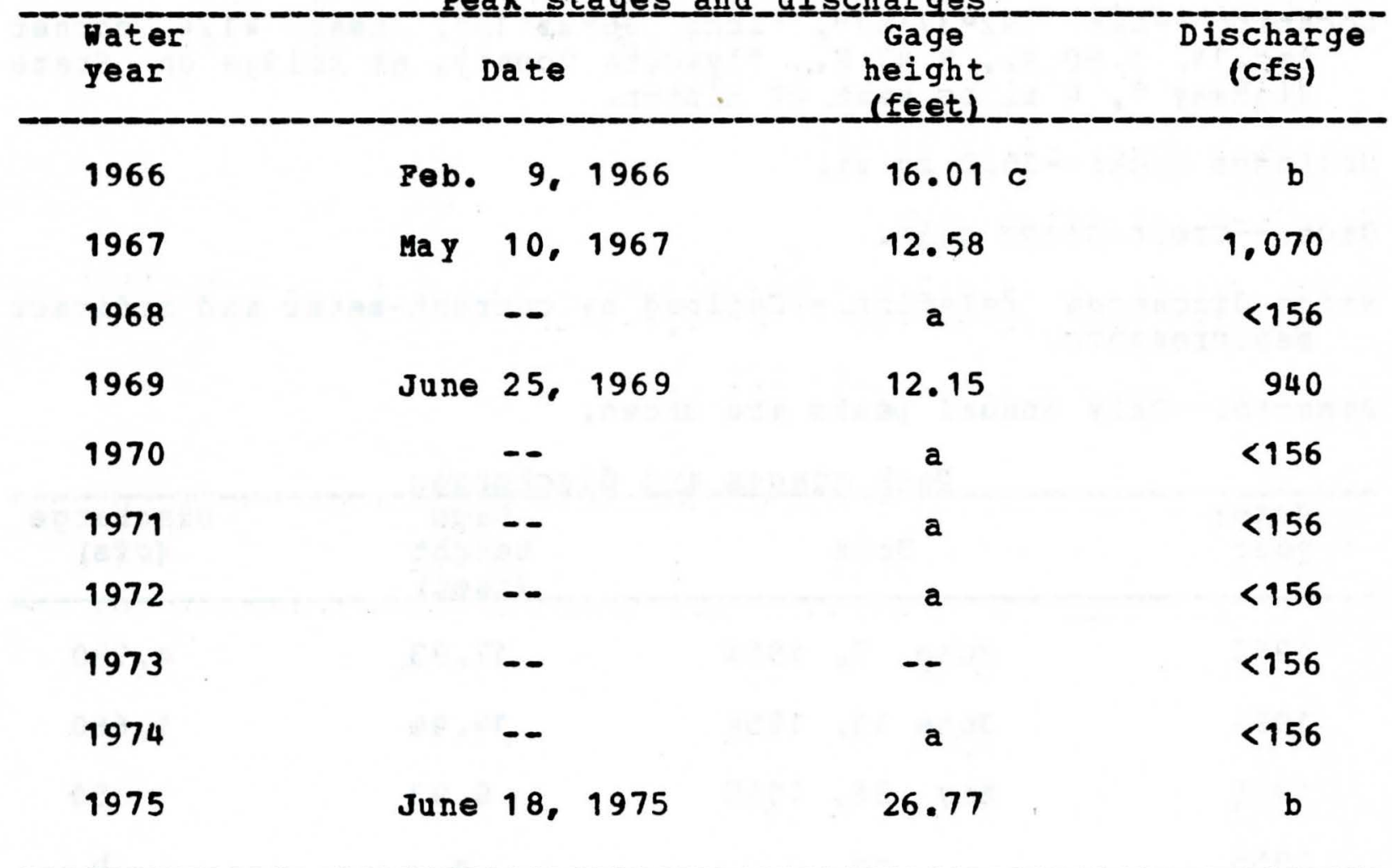

a Peak stage did not reach bottom of gage.

b Discharge not determined.

c Affected by ice. 
Location.--Iat $42043 \cdot 16 "$, long $96020 \cdot 33^{\prime \prime}$, in NN1/4 sec.12, T.91

N.. R.47 N.. Plymouth County, at bridge on county road M. 5 miles west of Merrill.

Drainage area.--8.17 sq mi.

Gage.--Crest-stage gage.

Stage-discharge relation.--Defined by step-backwater computations and indirect measurements at 2,540 cfs.

Remarks.--only annual peaks are shown.

Pea $\underline{\text { _ }}$ sta

\begin{tabular}{|c|c|c|c|}
\hline $\begin{array}{l}\text { Water } \\
\text { Year }\end{array}$ & Date & $\begin{array}{c}\text { Gage } \\
\text { height } \\
\text { (feet) }\end{array}$ & $\begin{array}{l}\text { Discharge } \\
\text { (cfs) }\end{array}$ \\
\hline 1953 & June 7,1953 & 9.51 & 2.540 \\
\hline 1954 & June 19,1954 & 5.84 & 169 \\
\hline 1955 & May 26,1955 & 3.60 & 37 \\
\hline 1956 & Mar. 1, 1956 & 4.10 & 54 \\
\hline 1957 & May 11,1957 & 5.66 & 151 \\
\hline 1958 & May 31,1958 & 8.73 & 857 \\
\hline 1959 & May 30,1959 & 8.81 & 932 \\
\hline 1960 & June 20,1960 & 5.02 & 69 \\
\hline 1961 & $\operatorname{Mar} .26,1961$ & 7.44 & 428 \\
\hline 1962 & Mar. 27, 1962 & $12.22 \mathrm{a}$ & $2.000 \mathrm{~b}$ \\
\hline 1963 & -- & c & $<20$ \\
\hline 1965 & Mar. 31, 1965 & $9.39 \mathrm{a}$ & $300 \mathrm{~b}$ \\
\hline 1964 & July 10,1964 & 7.09 & 358 \\
\hline \multicolumn{4}{|c|}{$\begin{array}{l}\text { affected by ice. } \\
\text { b About. } \\
\text { c Peak stage did not }\end{array}$} \\
\hline
\end{tabular}


06-5998.00 Perry Creek near Merrill, Iowa--(Continued)

Peakㅡ_stage

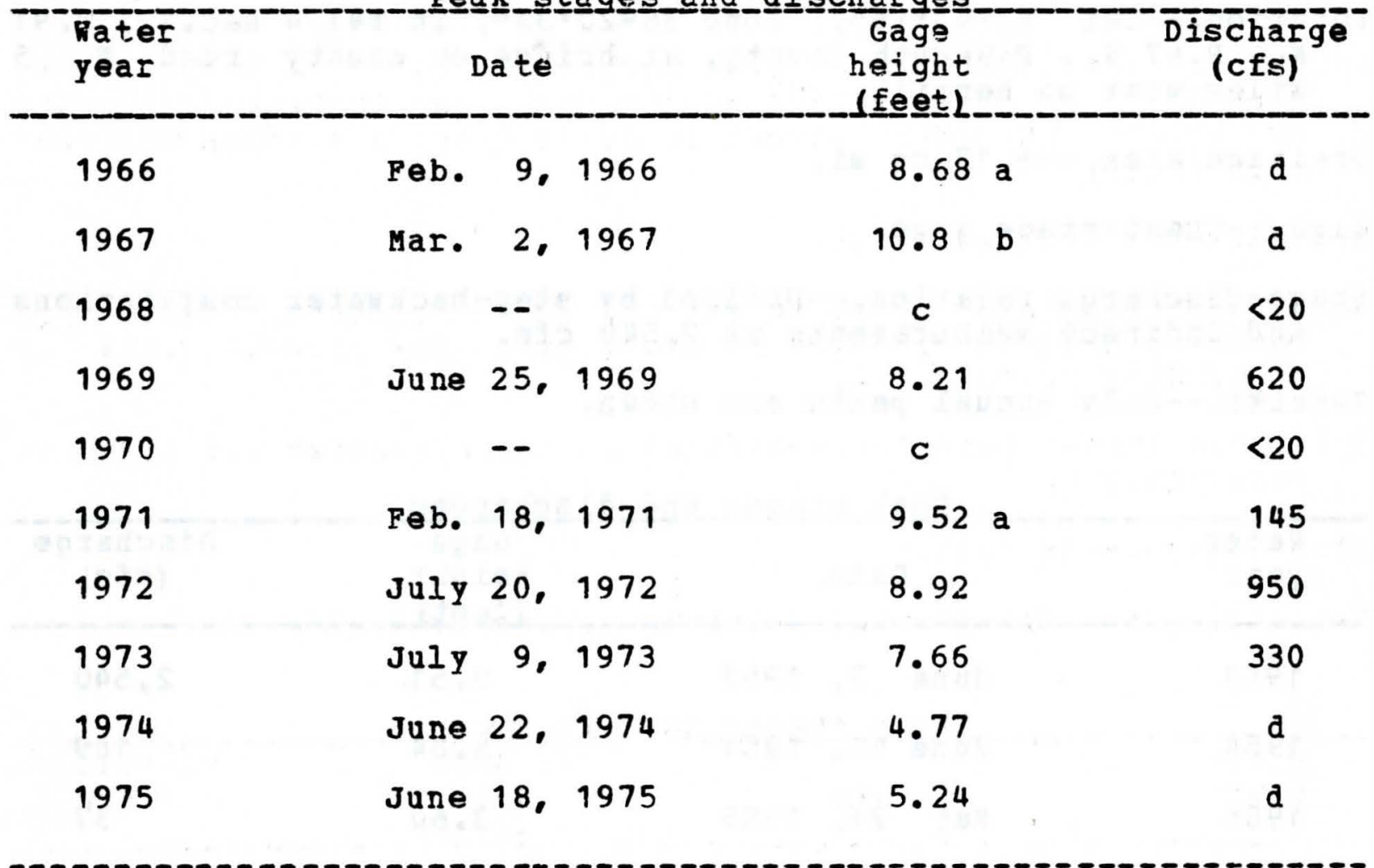

a Affected by ice.

b About.

C Peak stage did not reach bottom of gage.

d Discharge not determired. 
06-6000.00 Perry Creek at 38th Street, Sioux City. Iowa (Discontinued sept. 30, 1969)

Location.--Lat $42032 \cdot 05^{\prime \prime}$, long $96024 \cdot 35^{\prime \prime}$, in SE1/4 SE1/4 sec. 8 , T. 89 N., R. 47 W. Woodbury County, on right upstream abutment of briage on 38 th street in Sioux City, 3.6 miles upstream from mouth.

Drainage area.--65.1 sq mi.

Gage.--Non-recording pri or to May 20, 1954; recording thereafter. Datum of gage is $1,117.04 \mathrm{ft}$ above mean sea level (City of Sioux City bench mark).

Stage-discharge relation.--Defined by current-meter and indirect measurements.

Flood stage.--19 feet.

Remarks.--Base for partial-duration series, 800 cfs.

Peakㅏ.stages and di

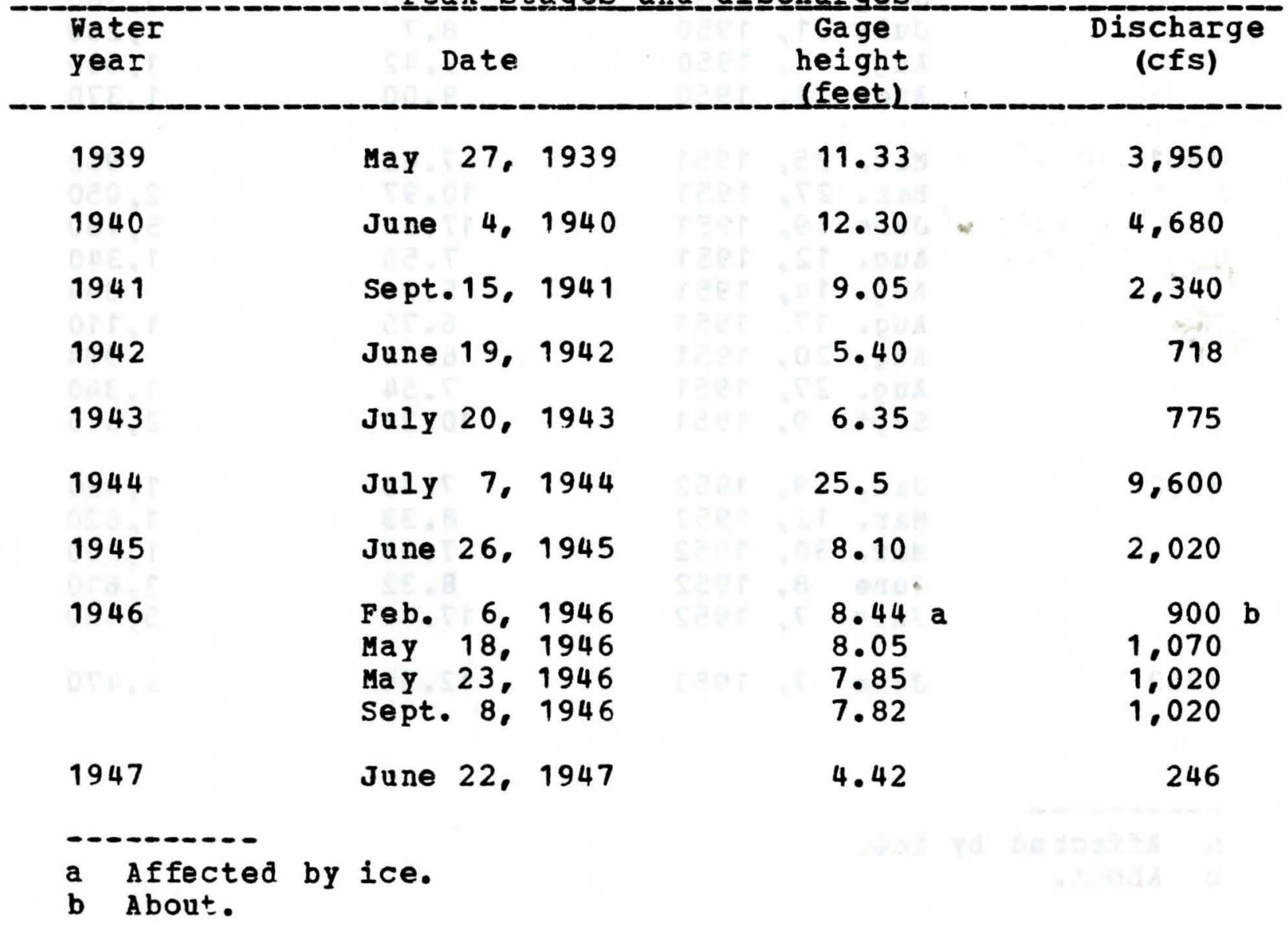


06-6000.00 Perry Creek at 38th Street, Sioux City, Iowa--(Continued)

Peak__stages_and_discharges

\begin{tabular}{|c|c|c|c|c|}
\hline $\begin{array}{l}\text { Water } \\
\text { year }\end{array}$ & Date & 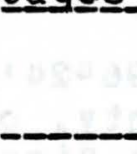 & $\begin{array}{r}\text { Gage } \\
\text { height } \\
\text { (feet) }\end{array}$ & $\begin{array}{l}\text { Discharge } \\
\text { (cfs) }\end{array}$ \\
\hline 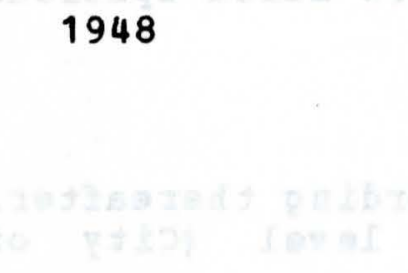 & $\begin{array}{l}\text { Feb. 16, } \\
\text { Feb. 17, } \\
\text { Feb. 27, } \\
\text { June 22, } \\
\text { July 29, } \\
\text { Aug. 14, }\end{array}$ & $\begin{array}{l}1948 \\
1948 \\
1948 \\
1948 \\
1948 \\
1948\end{array}$ & $\begin{array}{r}7.53 \\
7.30 \\
9.34 \\
10.40 \\
9.54 \\
14.12\end{array}$ & $\begin{array}{r}935 \\
881 \\
1,470 \\
1,840 \\
1,540 \\
3,350\end{array}$ \\
\hline 1949 & $\begin{array}{l}\text { Mar. } 4, \\
\text { Mar. 24, } \\
\text { JuIy 27, } \\
\text { Aug. 13, } \\
\text { Sept. 3, } \\
\text { Sept. 10, }\end{array}$ & $\begin{array}{l}1949 \\
1949 \\
1949 \\
1949 \\
1949 \\
1949\end{array}$ & $\begin{array}{r}7.77 \\
7.11 \\
12.32 \\
17.28 \\
19.85 \\
21.80\end{array}$ & $\begin{array}{r}900 \\
827 \\
2.570 \\
5.080 \\
6.580 \\
7.780\end{array}$ \\
\hline 1950 & $\begin{array}{l}\text { Mar. } 4, \\
\text { June } 17, \\
\text { July } 12, \\
\text { July } 21, \\
\text { Aug. } 7, \\
\text { Aug. 11, }\end{array}$ & $\begin{array}{l}1950 \\
1950 \\
1950 \\
1950 \\
1950 \\
1950\end{array}$ & $\begin{array}{c}10.5 \\
12.47 \\
17.75 \\
8.7 \\
9.42 \\
9.00\end{array}$ & $\begin{array}{l}1.600 \quad b \\
2.650 \\
5.380 \\
1.280 \\
1.500 \\
1.370\end{array}$ \\
\hline 1951 & $\begin{array}{l}\text { Mar. 25, } \\
\text { Mar. 27,, } \\
\text { June 19, } \\
\text { Aug. 12, } \\
\text { Aug. 14, } \\
\text { Aug. 17, } \\
\text { Aug. 20, } \\
\text { Aug. 27, } \\
\text { Sept. 9, }\end{array}$ & $\begin{array}{l}1951 \\
1951 \\
1951 \\
1951 \\
1951 \\
1951 \\
1951 \\
1951 \\
1951\end{array}$ & $\begin{array}{r}7.62 \\
10.97 \\
17.38 \\
7.53 \\
5.96 \\
6.75 \\
6.43 \\
7.54 \\
10.21\end{array}$ & $\begin{array}{r}962 \\
2.050 \\
5,480 \\
1.340 \\
844 \\
1.110 \\
984 \\
1.340 \\
2.310\end{array}$ \\
\hline 1952 & $\begin{array}{l}\text { Jan. } 19, \\
\text { Mar. 12, } \\
\text { Mar. 30, } \\
\text { June 8, } \\
\text { JuIy } 7,\end{array}$ & $\begin{array}{l}1952 \\
1952 \\
1952 \\
1952 \\
1952\end{array}$ & $\begin{array}{r}7.75 \\
8.33 \\
7.08 \\
8.32 \\
17.40\end{array}$ & $\begin{array}{l}1.430 \\
1.620 \\
1.200 \\
1.610 \\
5.480\end{array}$ \\
\hline 1953 & June 7. & 1953 & 12.56 & 3,470 \\
\hline
\end{tabular}

a Affected by ice.

b about. 
06-6000.00 Perry Creek at 38th Street, Sioux City, Iowa--(Continued)

Peak_stagges_and_discharges

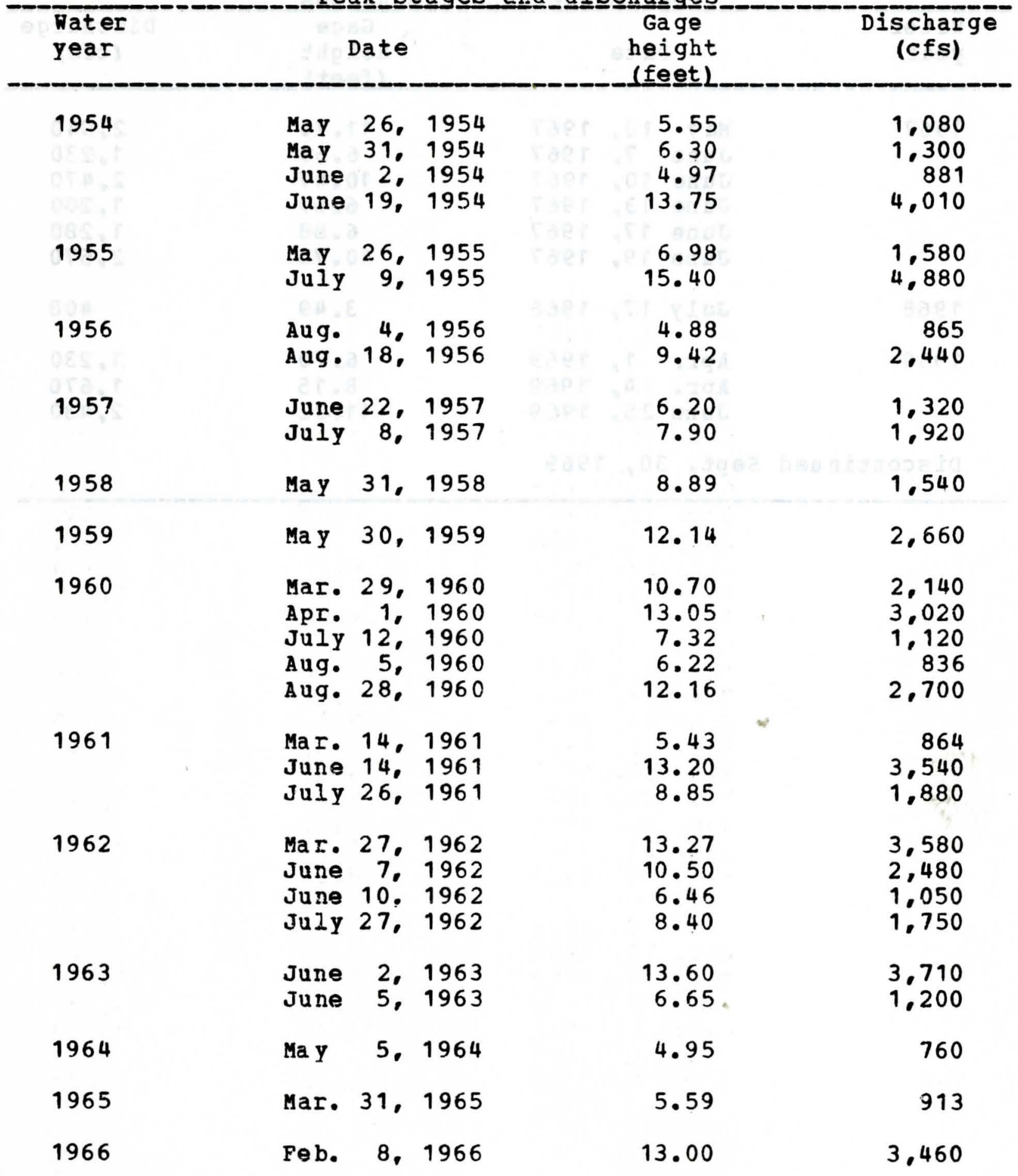


06-6000.00 Perry Creek at 38th Street, Sioux City, Iowa--(Continued)

Pegak___stages_and__di $\underline{\text { s }}$ chharges

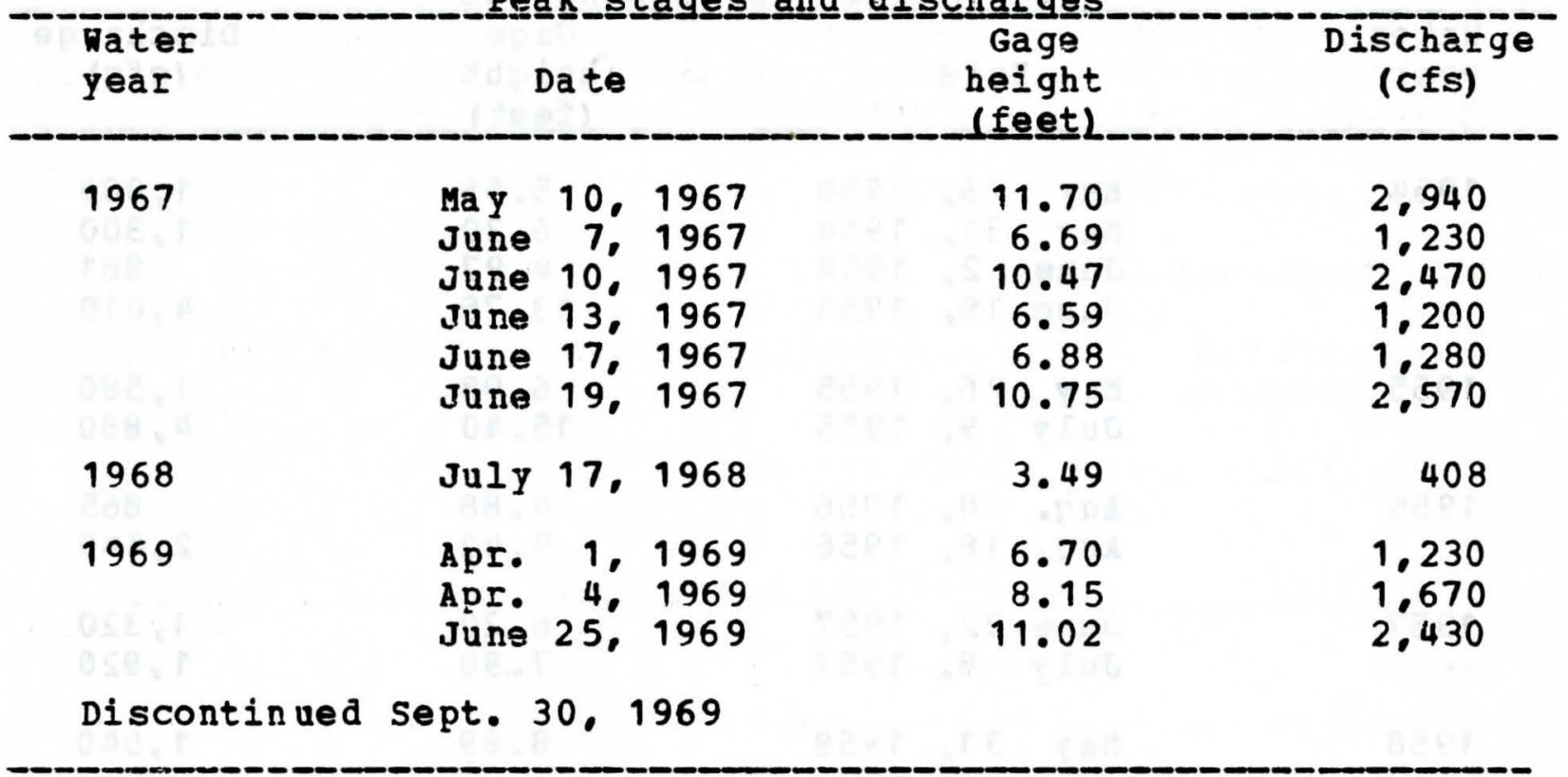




\section{5-4212.00 Pine Creek near Winthrop. Iowa}

Location.--Iat 42028 , Iong 91047 , in SW1/4 sec. 34 , T. 89 N., R. 8

W. Buchanan County at railroad bridge 500 ft above 0.S.

Highway 20 and 2.5 miles northwest of winthrop.

Drainage area.- $-28.3 \mathrm{sq} \mathrm{mi}$.

Gage.--Crest-stage gage.

Stage-discharge relation.--Defined by current-meter and indirect measurements.

Remarks.--only annual peaks are shown.

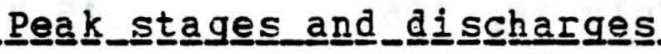

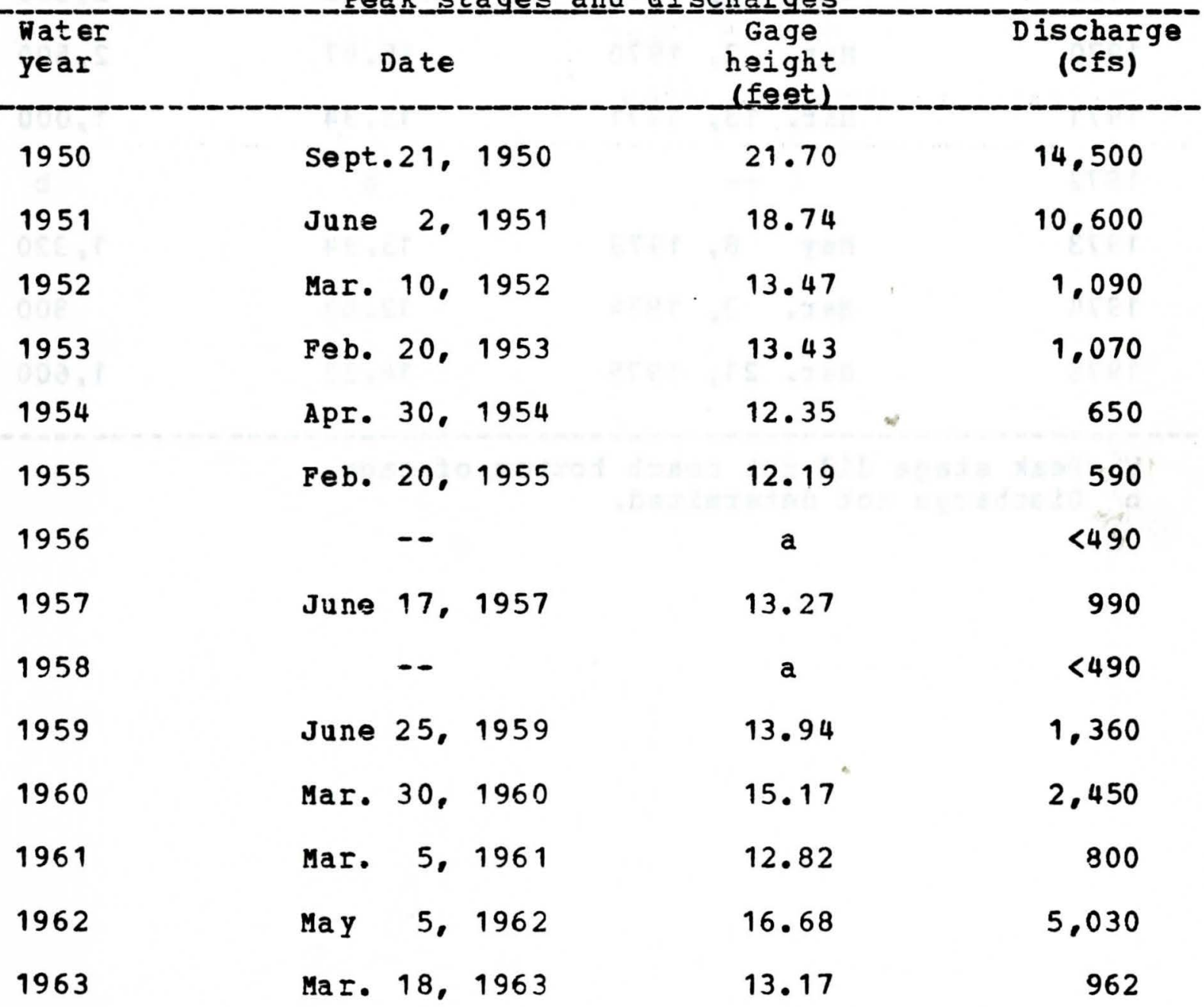

a Peak stage did not reach bottom of gage. 
05-4212.00 Pine Creek near Winthrop, Iowa--(Continued)

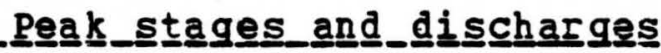

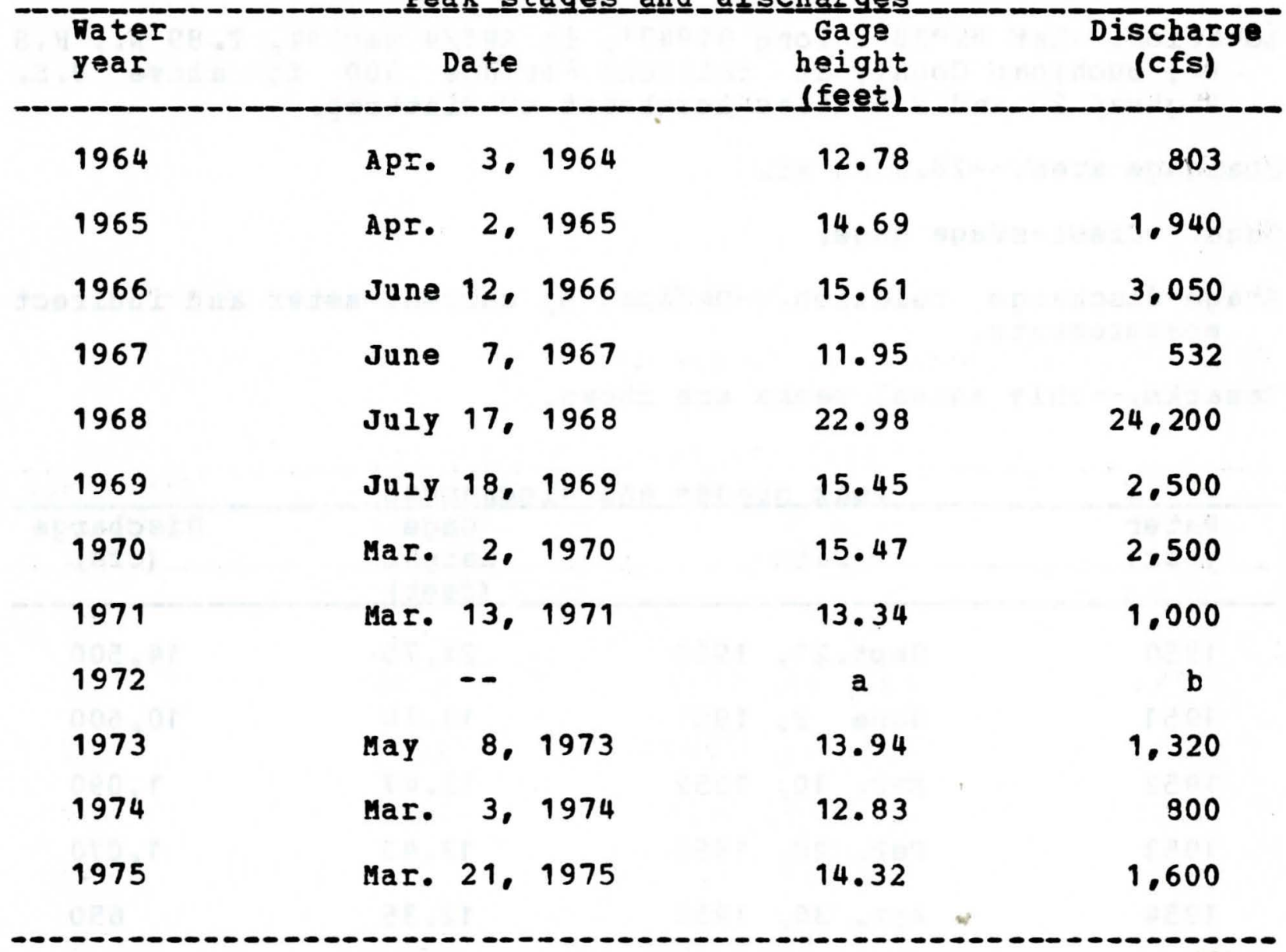

a Peak stage did not reach bottom of gage.

b Discharge not determined. 


\section{5-4211.00 Pine Creek tributary near Minthrop. Iowa}

Location.--Iat 420291 , long 91047 , in S\$1/4 sec.27, T.89 N.. R.8

N. Buchanan County, at culvert, 1.4 miles north of 0.5 .

Highway 20 and 2.5 miles northwest of Winthrop.

Drainage area.--0.334 sq mi.

Gage.--Crest-stage gage.

Stage-discharge relation.--Defined by indirect measurenents.

Remarks.--Only annual peaks are shown.

P브므_s

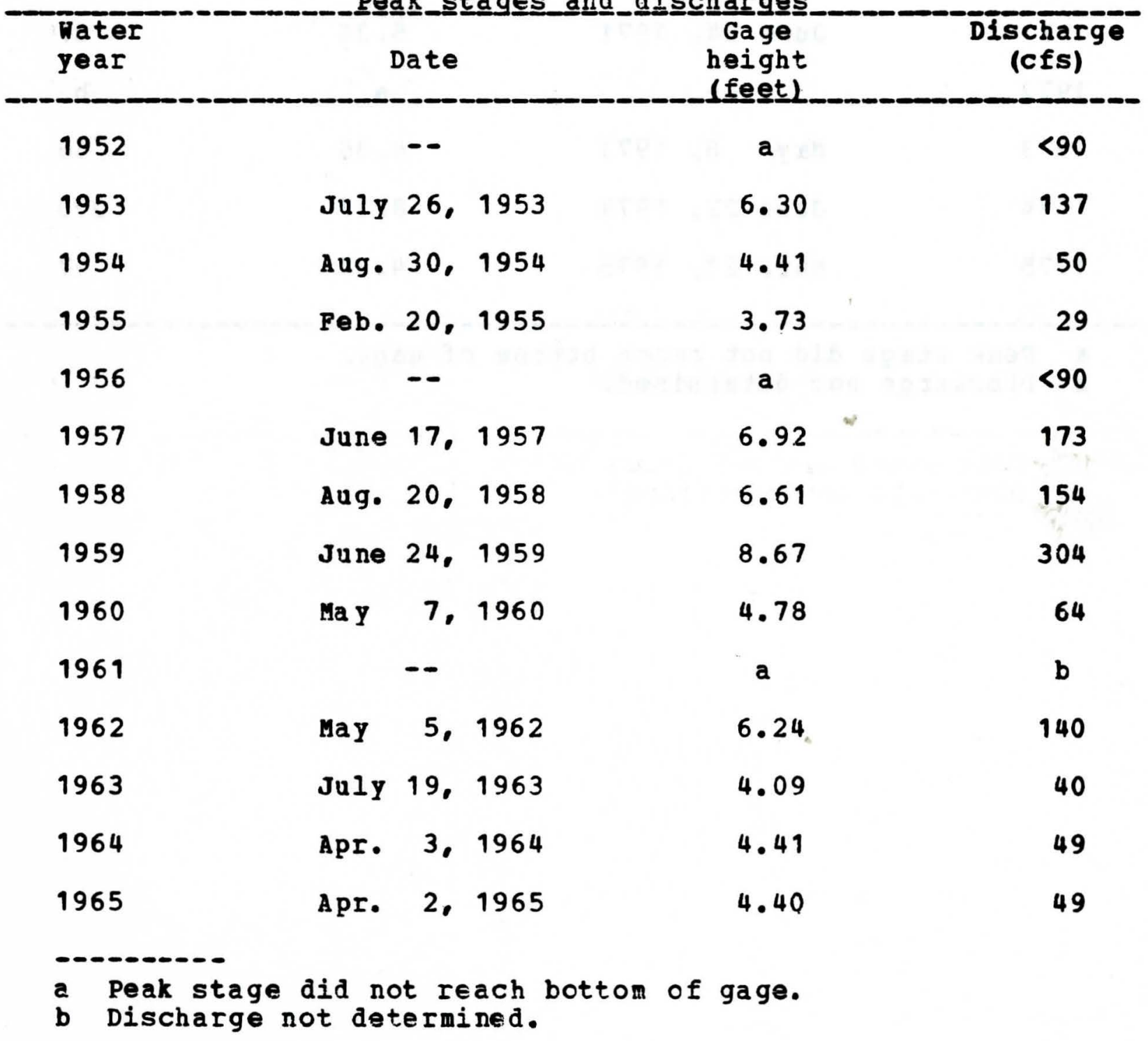


05-4211.00 Pine Creek tributary near Winthrop, Iowa--(Continued)

Peak﹎.stagges_and_di

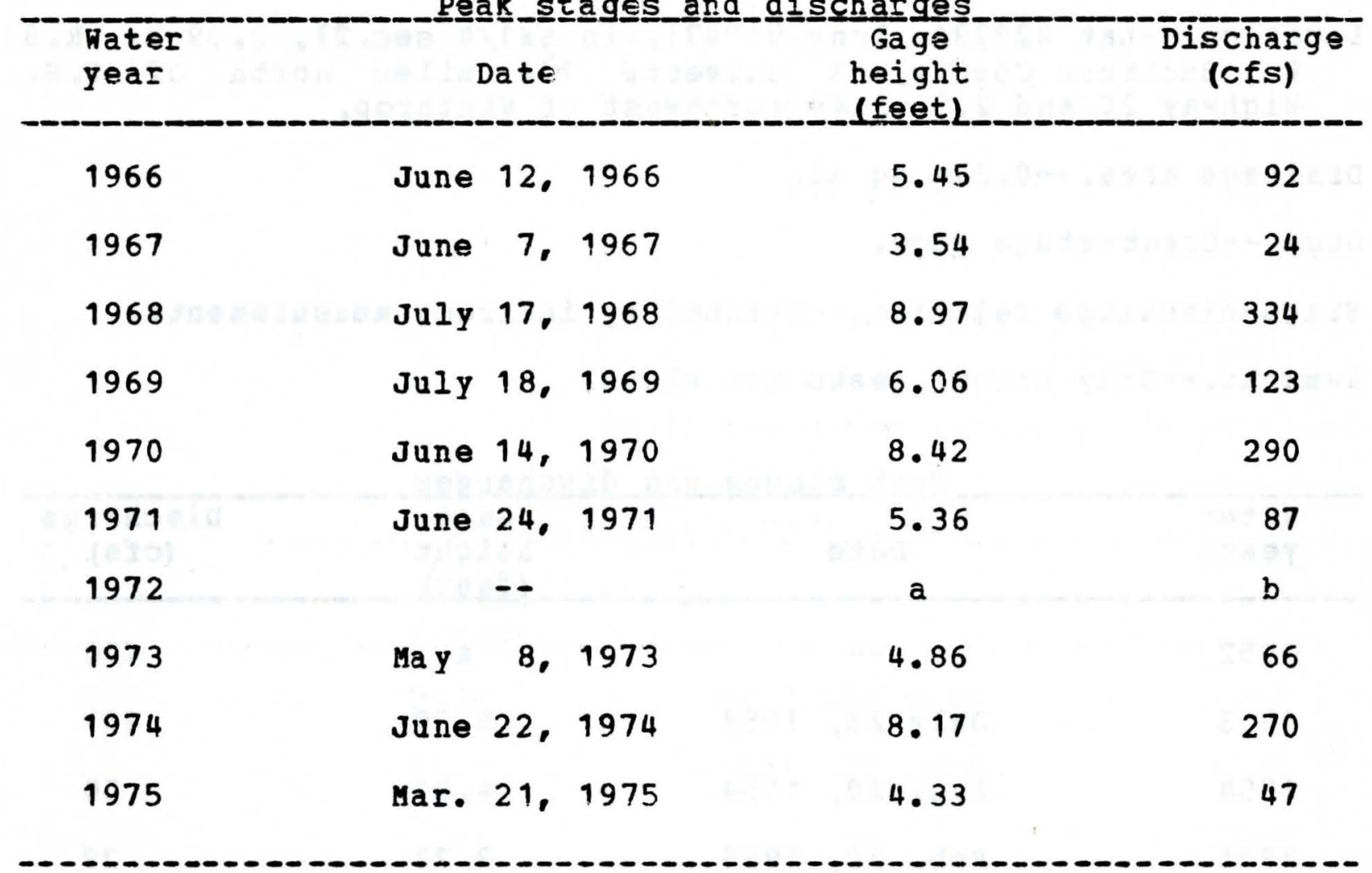

a Peak stage did not reach bottom of gage.

b Discharge not determined. 
Location.--Lat $42028^{\circ}$, Iorg $91044^{\circ}$, at N1/4 corner sec.2. T. 88 N.. R.8 W.. Buchanan Courty, at culvert on U.S. Highway 20 near west city limits of winthrop.

Drainage area. $--0.704 \mathrm{sq} \mathrm{mi}$.

Gage.--Crest-stage gage.

Stage-discharge relation.--Defined by current-meter and indirect measurements.

Remarks.--only annual peaks are shown.

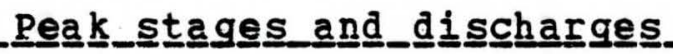

\begin{tabular}{|c|c|c|c|c|}
\hline $\begin{array}{l}\text { Water } \\
\text { year }\end{array}$ & 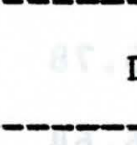 & Date & $\begin{array}{r}\text { Gage } \\
\text { height } \\
\text { (feet) }\end{array}$ & $\begin{array}{l}\text { Discharge } \\
\text { (cfs) }\end{array}$ \\
\hline 1953 & July & 26,1953 & 5.78 & 27 \\
\hline 1954 & Aug. & 30,1954 & 5.90 & 36 \\
\hline 1955 & & -- & a & $<1.4$ \\
\hline 1956 & May & 29,1956 & 6.28 & 87 \\
\hline 1957 & June & 17,1957 & 6.50 & 135 \\
\hline 1958 & Aug. & 20,1958 & 6.04 & 51 \\
\hline 1959 & June & 24,1959 & 7.12 & 443 \\
\hline 1960 & Mar. & 30,1960 & 7.05 & 390 \\
\hline 1961 & Mar. & 5,1961 & 5.30 & 7.1 \\
\hline 1962 & May & 29.1962 & 6.37 & 104 \\
\hline 1963 & & -- & a & $<1.4$ \\
\hline 1964 & Apr. & 3. 1964 & 5.89 & 35 \\
\hline 1965 & Mar. & 5. 1965 & 5.50 & 13 \\
\hline 1966 & June & 12,1966 & 6.61 & 168 \\
\hline
\end{tabular}

a Peak stage did not reach bottom of gage. 
05-4213.00 Pine Creek tributary No. 2 at Ninthrop, Iowa-- (Continued)

Peak__stagges_and_disscharges

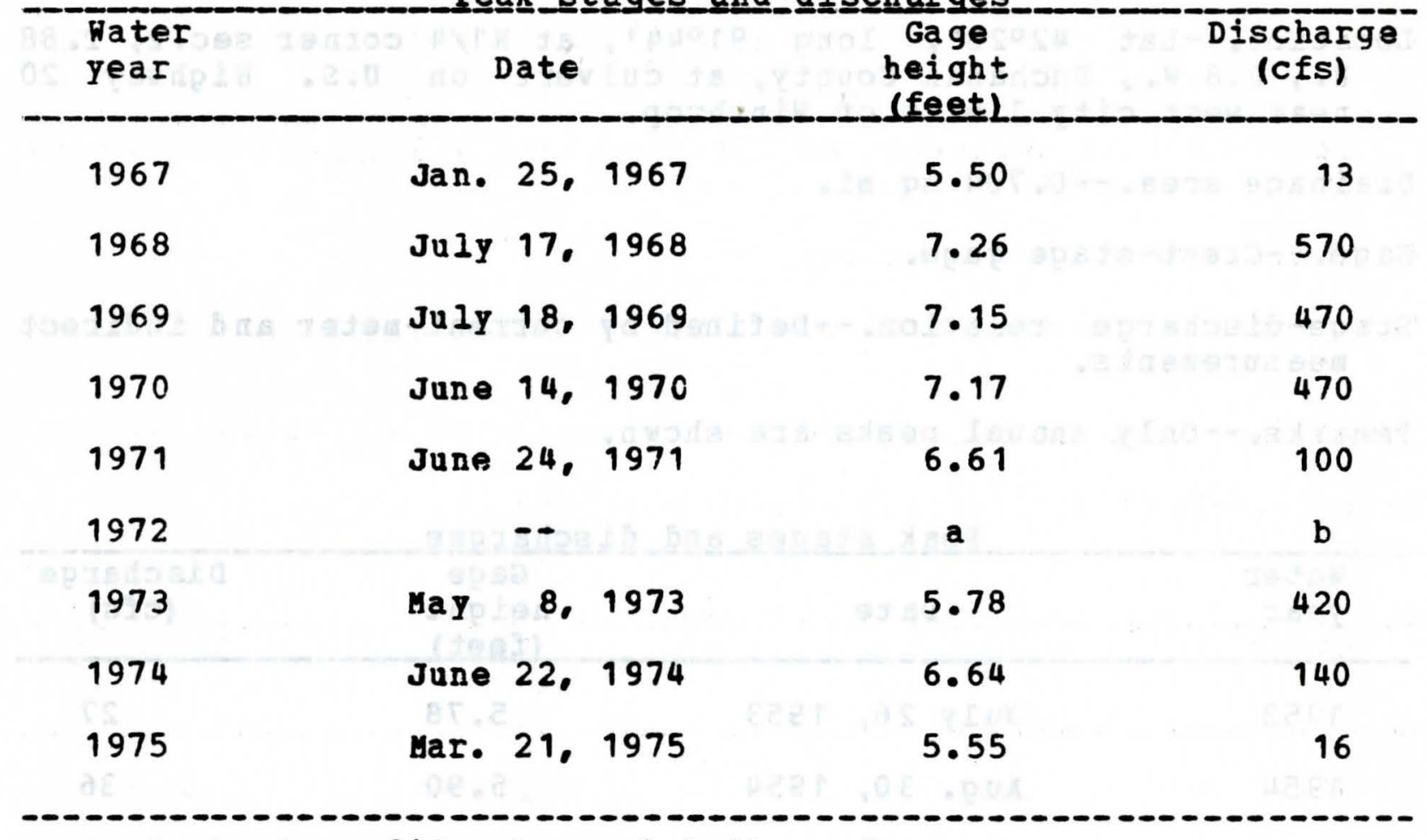

a Peak stage did not reach bottom of gage.

b Discharge not determined. 
Location.--Iat 40046002 ", long $94024 \cdot 46^{\prime \prime}$, in NE1/4 NN1/4 sec.22. T. 69 N.. R. 31 W., Ringgold County, on left bank at dcwnstream side of bridge on county highway, 2.2 mi upstream from Turkey Creek, $4.6 \mathrm{mi}$ southwest of Diagonal, and 4.9 miles downstream from Gard Creek.

Drainage area.--217 sq miles.

Gage.--Nater-stage recorder. Datum of gage is 1.095 .27 ft above mean sea level.

Stage-discharge relation.--Defined by current-meter measurements. Remarks.--Base for partial-duration series, 1,200.

Peak_stages_and_di scharges

\begin{tabular}{|c|c|c|c|c|c|c|}
\hline $\begin{array}{l}\text { Water } \\
\text { year }\end{array}$ & & Date & & $\begin{array}{l}\text { Gage } \\
\text { height } \\
\text { (feet) }\end{array}$ & & $\begin{array}{c}\text { Discharge } \\
\text { (cfs) }\end{array}$ \\
\hline 1967 & June & & 1967 & 23.16 & a & 6,360 \\
\hline 1968 & $\begin{array}{l}\text { Apr. } \\
\text { Aug. }\end{array}$ & $\begin{array}{r}23 . \\
4 .\end{array}$ & $\begin{array}{l}1968 \\
1968\end{array}$ & $\begin{array}{l}15.11 \\
11.57\end{array}$ & & $\begin{array}{l}2.440 \mathrm{~b} \\
1.310 \mathrm{~b}\end{array}$ \\
\hline 1969 & $\begin{array}{l}\text { Apr. } \\
\text { May } \\
\text { May } \\
\text { June } \\
\text { June } \\
\text { July } \\
\text { July }\end{array}$ & $\begin{array}{r}27 . \\
8, \\
22, \\
12, \\
29 . \\
9, \\
18 .\end{array}$ & $\begin{array}{l}1969 \\
1969 \\
1969 \\
1969 \\
1969 \\
1969 \\
1969\end{array}$ & $\begin{array}{l}19.13 \\
19.32 \\
12.24 \\
14.71 \\
12.72 \\
20.73 \\
22.76\end{array}$ & $*$ & $\begin{array}{l}4.120 \\
4.210 \\
1.530 \\
2.300 \\
1.660 \\
4.920 \\
6.110\end{array}$ \\
\hline 1970 & May & 13. & 1969 & $17 \cdot 30$ & & 3.120 \\
\hline 1971 & $\begin{array}{l}\text { Nov. } \\
\text { Feb. } \\
\text { Feb. } \\
\text { May } \\
\text { May }\end{array}$ & $\begin{array}{r}9 . \\
19, \\
26, \\
8 \%\end{array}$ & $\begin{array}{l}1971 \\
1971 \\
1971 \\
1971 \\
1971\end{array}$ & $\begin{array}{l}16.23 \\
20.66 \\
12.47 \\
15.61 \\
22.24\end{array}$ & $\begin{array}{l}c \\
c\end{array}$ & $\begin{array}{l}2.850 \\
3,900 \mathrm{~d} \\
1.400 \mathrm{~d} \\
2.570 \\
6.070\end{array}$ \\
\hline
\end{tabular}

a From floodmark by local resident.

b For period April through september 1968.

c Affected by ice.

d About. 
06-8187.50 Platte River near Diagonal, Iowa--(Continued)

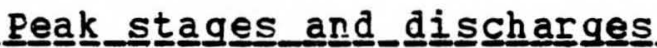

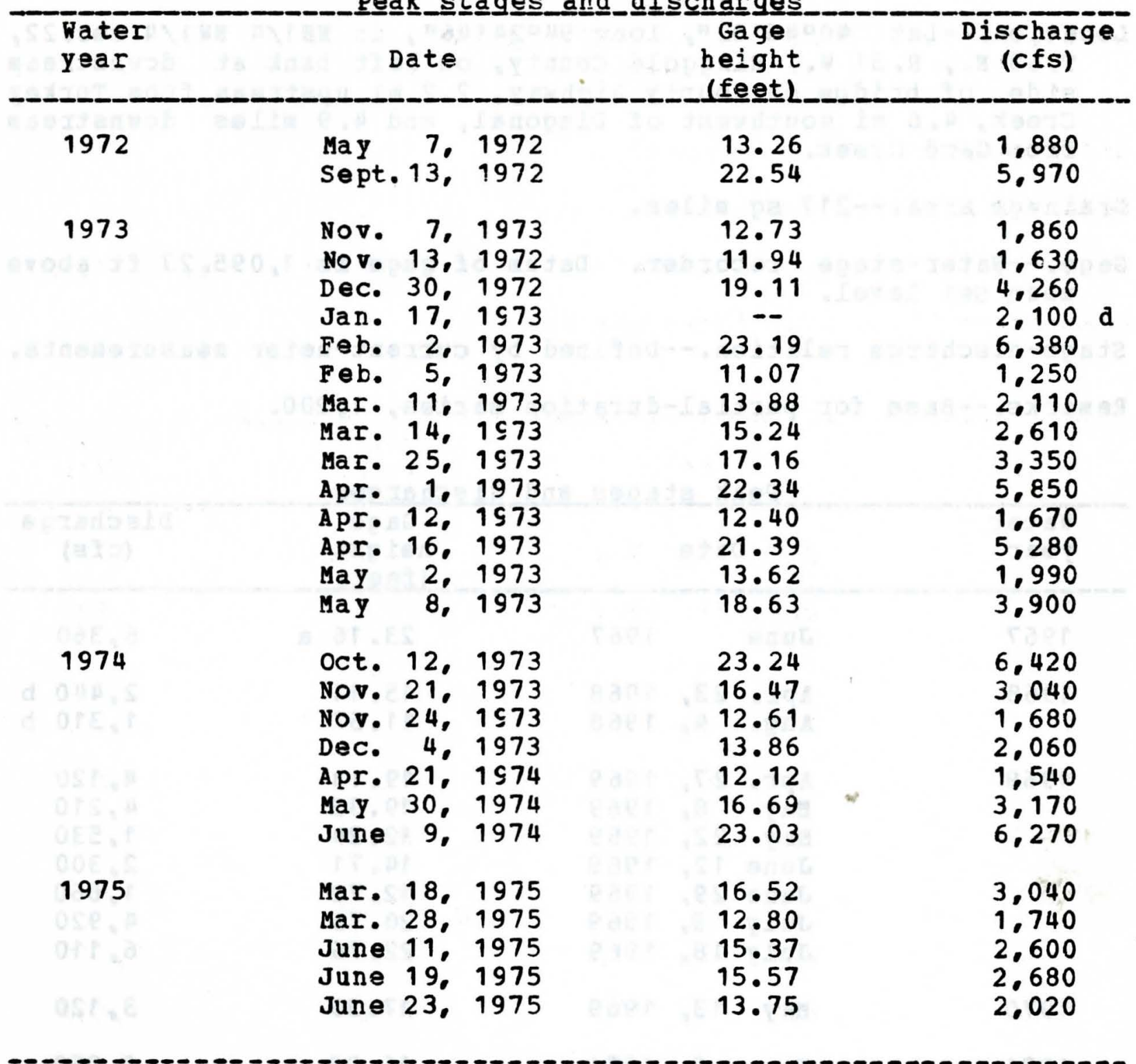

d About. 
Location.--Lat $40059^{\prime}$, Iong $94030^{\circ}$, in SE1/4 sec.2, T.71 N.. R. 32 1. Adams County, at bridge on U.S. Highway $34,3.8$ miles east of Stringtown.

Drainage area. $--51.7 \mathrm{sq} \mathrm{mi}$

Gage.--Crest-stage gage.

Stage-discharge relation.--Defined by current-meter measurements. Remarks.--only annual peaks are shown.

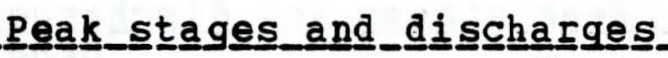

\begin{tabular}{|c|c|c|c|c|}
\hline $\begin{array}{l}\text { water } \\
y \in a r\end{array}$ & & Date & $\begin{array}{l}\text { Gage } \\
\text { height } \\
\text { (feet) }\end{array}$ & $\begin{array}{c}\text { Discharge } \\
\text { (cfs) }\end{array}$ \\
\hline 1966 & May & 15,1966 & 89.59 & 710 \\
\hline 1967 & June & 21,1967 & 91.05 & 2.600 \\
\hline 1968 & & $\cdots$ & a & b \\
\hline 1969 & July & $10,196 \mathrm{c}$ & 90.37 & 1,450 \\
\hline 1970 & & -- & a & b \\
\hline 1971 & May & 23,1971 & 91.59 & b \\
\hline 1972 & & -- & 89.03 & b \\
\hline 1973 & $F \in b$. & 1, 1973 & 91.91 & 3,300 \\
\hline 1974 & oct. & 11. 1973 & 92.09 & 3,800 \\
\hline 1975 & June & 24,1975 & 90.61 & 1,330 \\
\hline
\end{tabular}

a Peak stage did not reach bottom of gage.

b Discharge not determined. 


\section{5-4175. 30 Plum Creek at Earlville, Iowa}

Location.--Lat $42028 \cdot 13^{\prime \prime}$, long $91014 \cdot 53 "$, in NE $1 / 4$ seC. 1. T. 88 N.. R.4 W.. Delaware County, at bridge on U.S. Highway 20 , about 1.5 miles southeast cf Earlville.

Drainage area.- $-41.1 \mathrm{sq} \mathrm{mi}$

Gage.--Crest-stage gage.

Stage-discharge relation.--Defined by current-meter measurements. Remarks.--only annual peaks are shown.

Peak_stáges_and_discharges

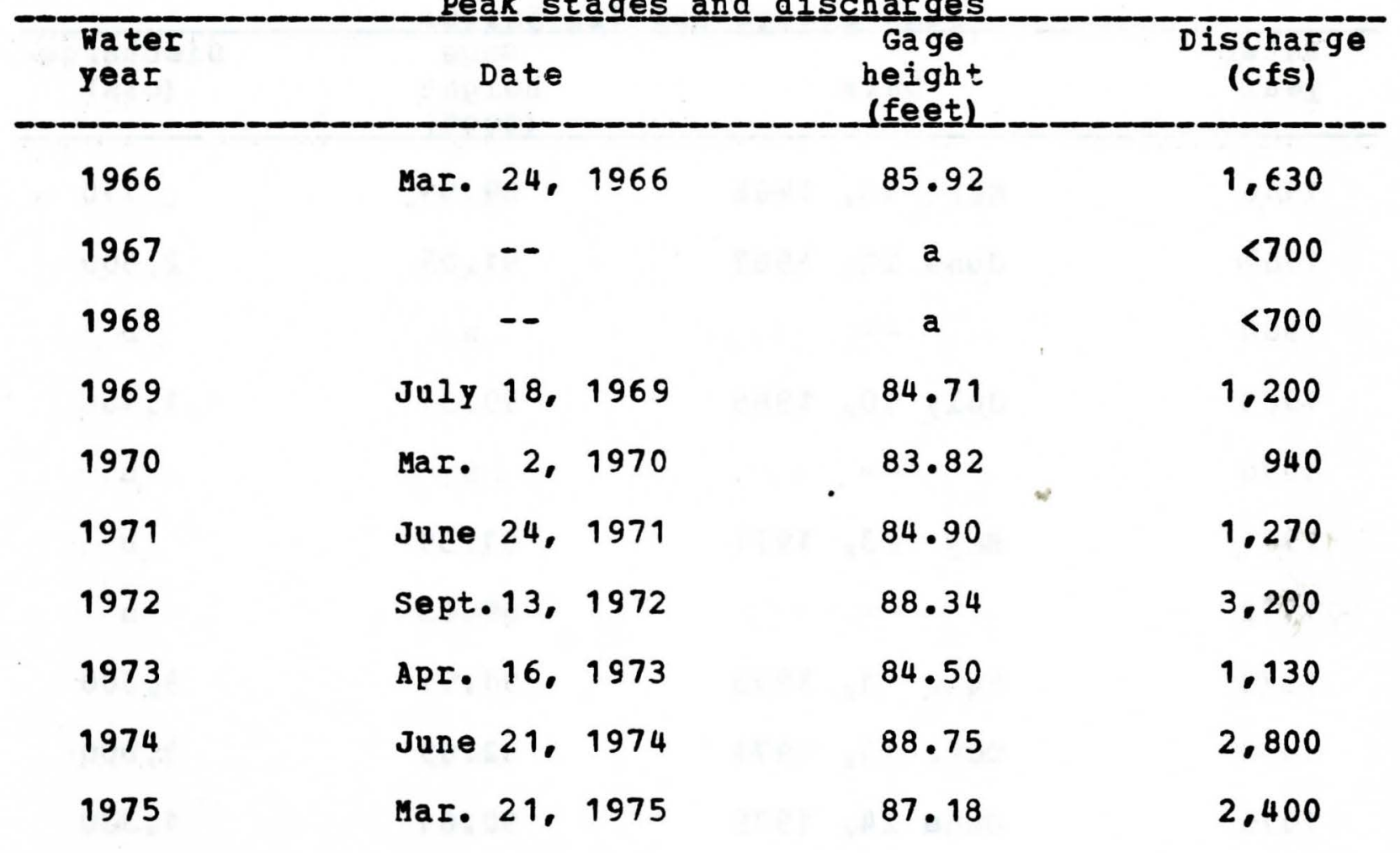

a Peak stage did not reach bottom of gage. 


\section{5-4645.60 Prairie Creek at Blairstown, Iowa}

Location.-- Lat $41054 \cdot 42^{\prime \prime}$, long 92005'03", in Sw1/4 sec.13, T.82 N.. R.11 M. . Benton County, at bridge on State Highway 82, at north edge of Blairstown.

Drainage area.--87.0 sq mi.

Gage.--Crest-stage gage.

Stage-discharge relation.--Defined by current-meter measurements. Remarks.--only annual peaks are shown.

Peak

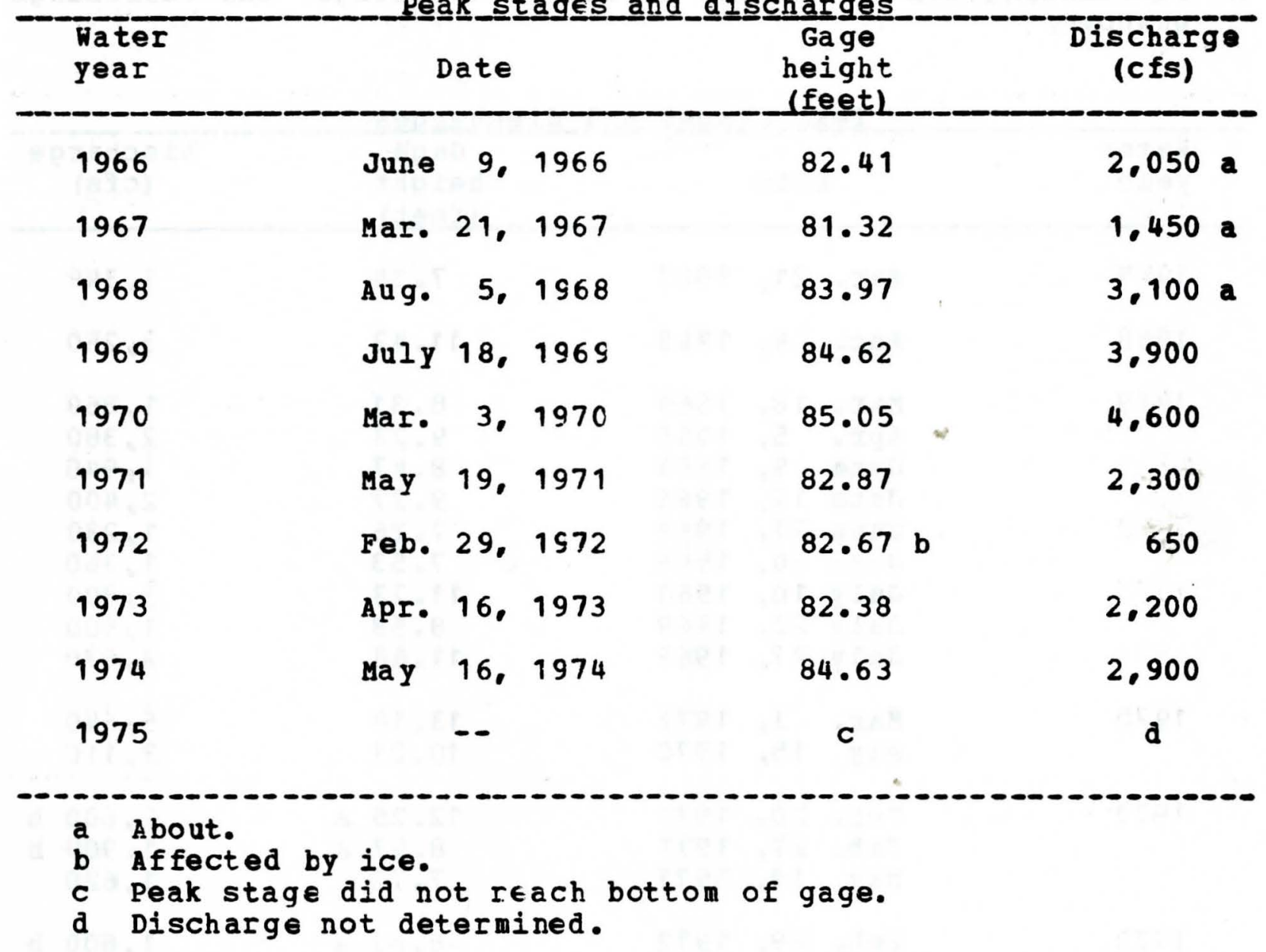




\section{5-4646.40 Prairie Creek at Fairfax, Iowa}

Location.--Lat 41055'22", long 91047'02", in SE1/4 SW1/4 sec.9, T.82 N., R. 8 W.. Iinn County. on right bank 20 ft upstream from bridge on State Highway 149 at west side of Pairfax, and 10.7 mi upstream from mouth.

Drainage area.--178 sq mi.

Gage.-- Water-stage recorder. Datum of gage is $737.00 \mathrm{ft}$ above mean sea level.

Stage-discharge relation.--Defined by current-meter measurements.

Remarks.--Base for partial-duration series, 1,200 cfs. An outstanding flood occurred in June 1944, stage and discharge unknown.

Peak

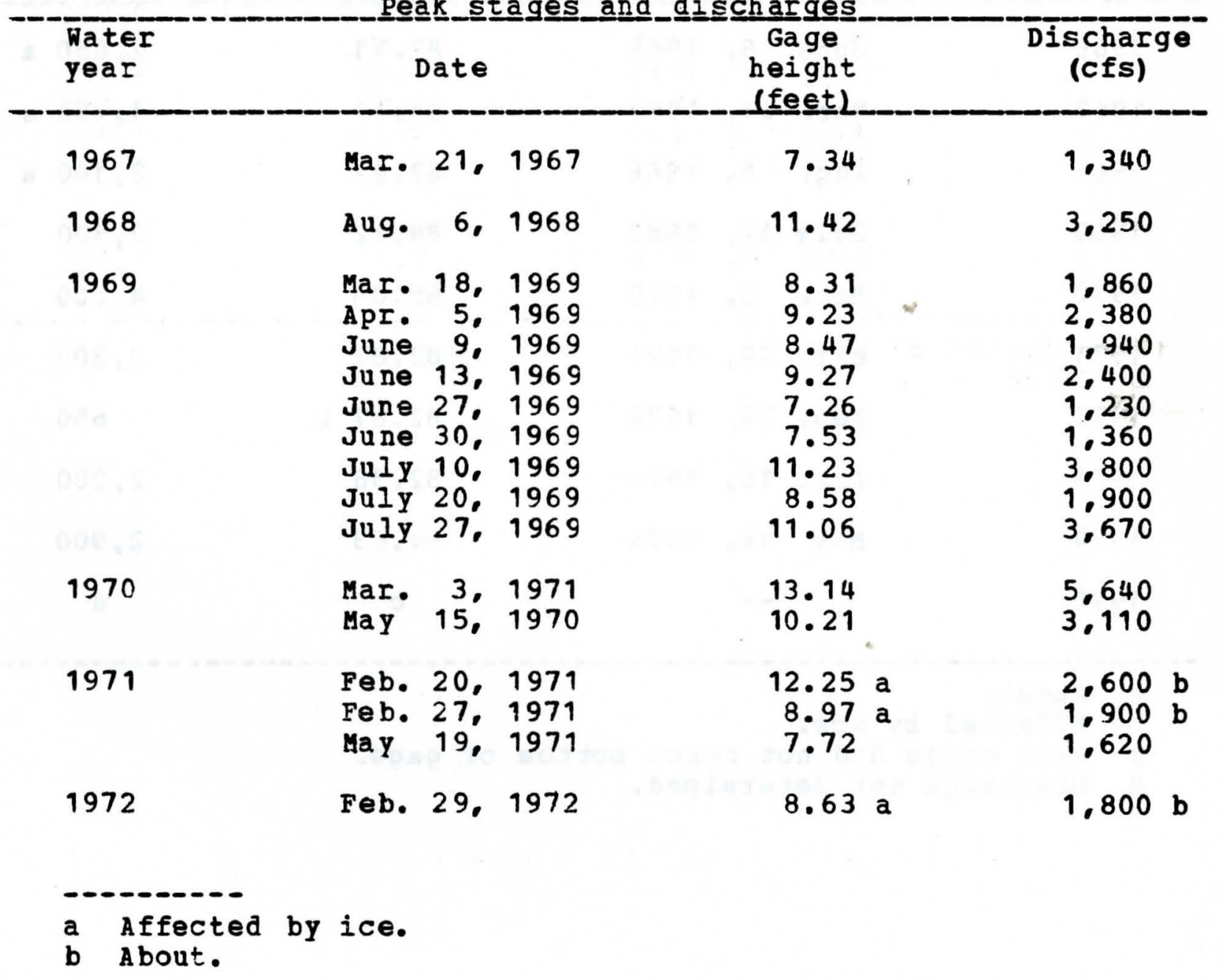


05-4646.40 Prairie Creek at Fairfax, Iowa--(Continued)

Pea $\underline{k}$ stages and di $\underline{\text { tascharges }}$

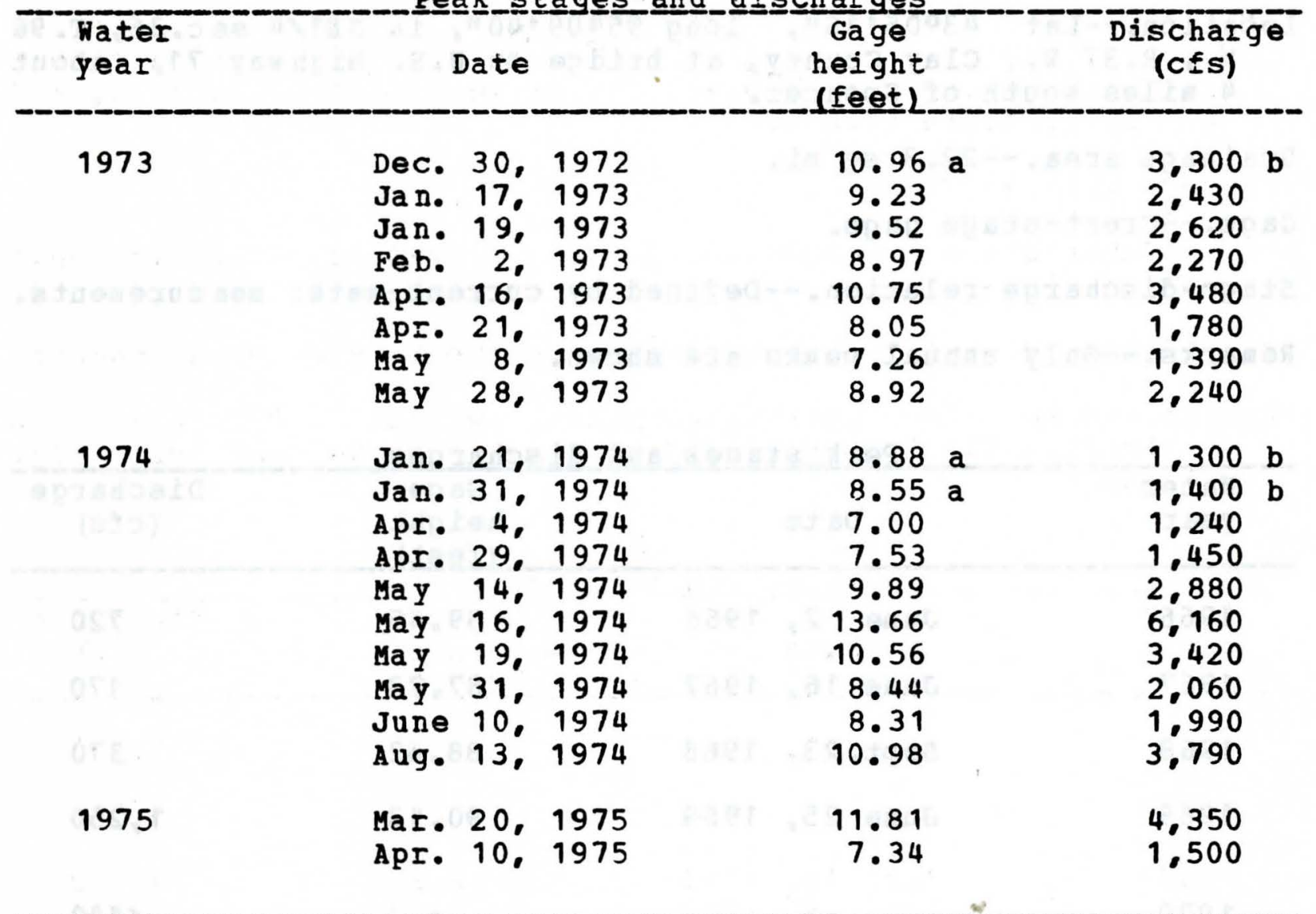

a Affected by ice.

b About. 


$$
\text { 06-6053.40 Prairie Creek near Spencer, Iowa }
$$

Location,--Lat 43005'16", long 95009.40", in SE1/4 sec.36, T. 96 N., R.37 W., Clay County, at bridge on U.S. Highway 71, about 4 miles south of spencer.

Drajnage area.--22.3 sq mi.

Gage.--Crest-stage gage.

Stage-discharge relation.--Defined by current-meter measurements. Remarks.--Only annual peaks are shown.

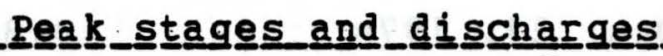

\begin{tabular}{|c|c|c|c|}
\hline $\begin{array}{l}\text { water } \\
\text { year }\end{array}$ & Date & $\begin{array}{l}\text { Gage } \\
\text { height } \\
\text { dfeetl }\end{array}$ & $\begin{array}{c}\text { Discharge } \\
\text { (cfs) }\end{array}$ \\
\hline 1966 & June 2,1966 & 89.45 & 720 \\
\hline 1967 & June 16,1967 & 87.73 & 170 \\
\hline 1968 & Sept. 23, 1968 & 88.62 & 370 \\
\hline 1969 & June 25, 1969 & 90.13 & 1.250 \\
\hline 1970 & -- & a & $<110$ \\
\hline 1971 & July 4, 1971 & 90.77 & 2.200 \\
\hline 1972 & June 27, 1972 & 88.13 & 225 \\
\hline 1973 & Mar. 6. 1973 & 88.79 & 380 \\
\hline 1974 & -- & a & b \\
\hline 1975 & Apr. 28, 1975 & 88.89 & 430 \\
\hline
\end{tabular}

a Peak stage did not reach bottom of gage.

b Discharge not determined. 


\section{5-4532.00 Price Creek at Amana. Iowa}

Location.--Lat $41048 \%$. Iong $91053^{\circ}$, in SE1/4 sec.22, T. 81 N.. R.9 W. Iowa County, at briage on state Highway 149, near north edge of Amana.

Drainage area.--29.1 sq mi.

Gage.--Crest-stage gage.

Stage-discharge relation.--Defined by current-meter measurements. Remarks.--Only annual peaks are shown.

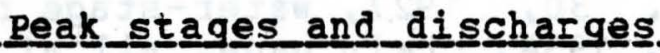

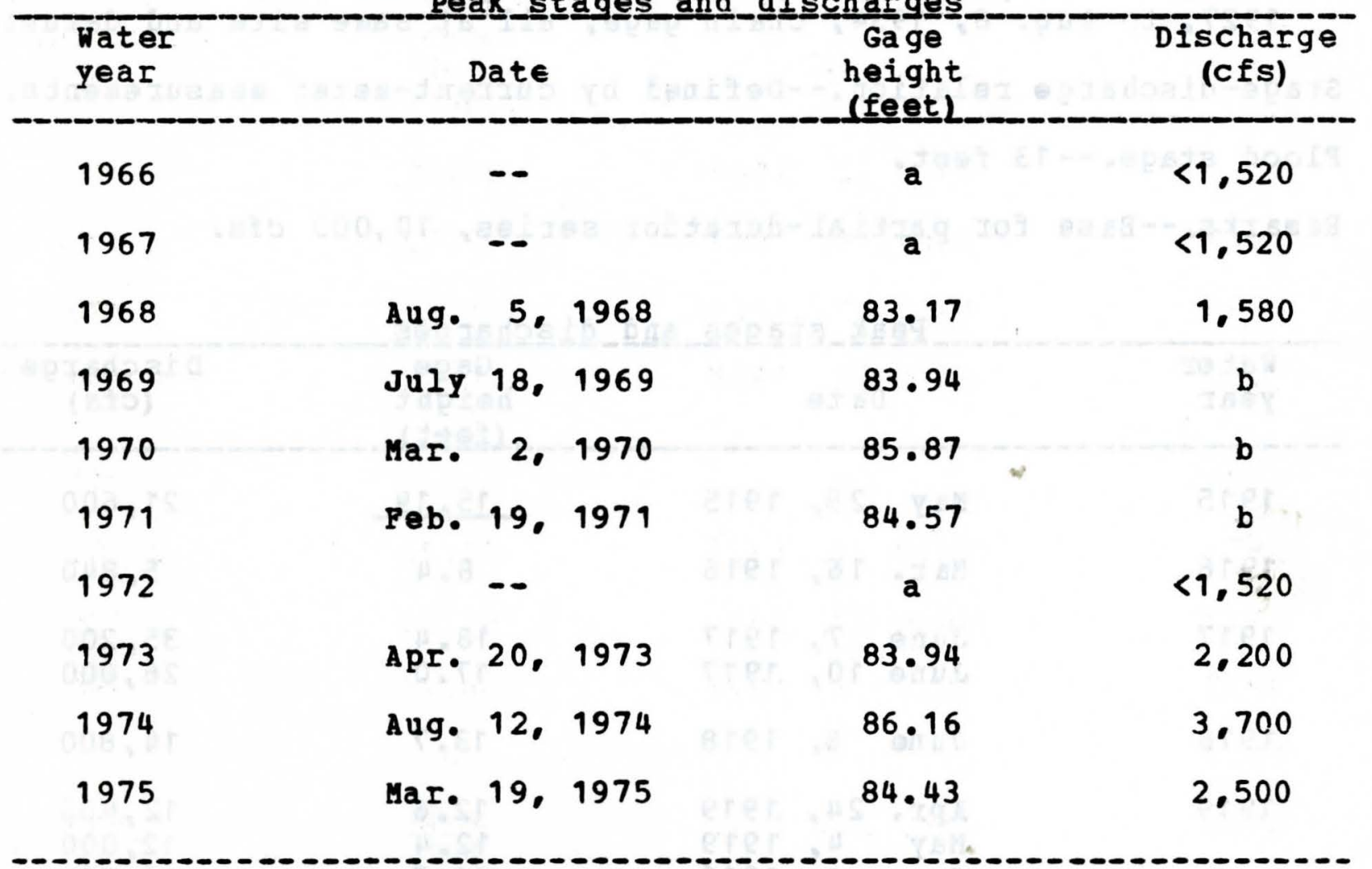

a Peak stage did not $r \in a c h$ bottom of gage.

b Discharge not determined. 
Location.-- Lat $41032 \cdot 02 "$, long $93056 \cdot 59 "$. in SW1/4 SW1/4 seC.22, T.78 N., R.27 W.. Dallas County, on right bank $100 \mathrm{ft}$ downstream from bridge on county highway R16, 0.3 mile northeast of Van Meter. 0.7 mile upstream from small left bank tributary. 1.2 miles downstream from confluence of North and South Raccoon River, and 30 miles upstream from mouth.

Drainage area. $--3,441 \mathrm{sq}$ mi.

Gage.--Water-stage recorder at present site after Aug. 9, 1934. Datum of gage is 841.16 ft above mean sea level. prior to oct. 1. 1915, chain gage at same site and at datum $2 \mathrm{ft}$ higher. Oct. 1, 1915, to May 30, 1923, chain gage, May 31, 1923. to sept. 30, 1927, water-stage recorder, and oct. 1, 1927, to Aug. 8, 1934, chain gage, all at same site and datum.

Stage-discharge relation.--Defined by current-meter measurements. Flood stage.--13 feet.

Remarks.--Base for partial-duration series, $10.000 \mathrm{cfs}$.

Peak_t_t.ages__and

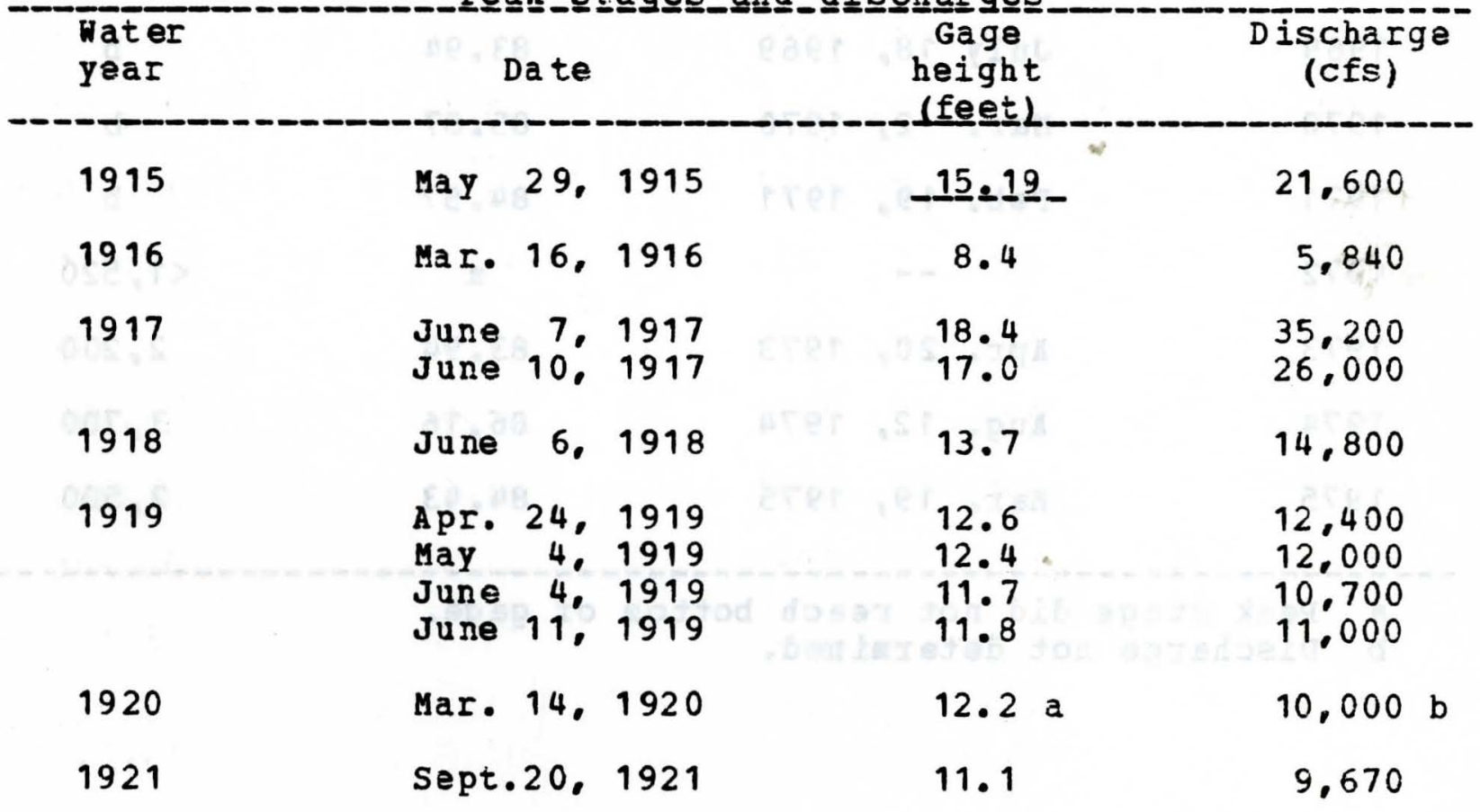

a Affected by ice.

b About. 
05-4845.00 Raccoon River at Van Meter. Iowa--(Continued)

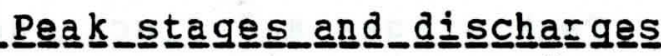

\begin{tabular}{|c|c|c|c|c|c|}
\hline $\begin{array}{l}\text { Water } \\
\text { year }\end{array}$ & Date & . & $\begin{array}{l}\text { Gage } \\
\text { height } \\
\text { lfeetL }\end{array}$ & & $\begin{array}{c}\text { Discharge } \\
\text { (cis) }\end{array}$ \\
\hline 1922 & Apr. 11. & 1922 & 12.1 & & 11,400 \\
\hline 1923 & Mar. 27. & 1923 & 11.6 & & 10.300 \\
\hline 1924 & $\begin{array}{ll}\text { Oct. } & 3 \\
\text { June } & 8 \\
\text { June } & 25\end{array}$ & $\begin{array}{l}1923 \\
1924 \\
1924\end{array}$ & $\begin{array}{l}11 \cdot 2 \\
12 \cdot 3 \\
15 \cdot 2\end{array}$ & & $\begin{array}{l}10.000 \\
12.400 \\
20.100\end{array}$ \\
\hline 1925 & Aug. & 1925 & $10 \cdot 1$ & & 8,060 \\
\hline 1926 & Sept. 20 & 1926 & 19.0 & & 32.000 \\
\hline 1927 & $F \otimes b$. & 1927 & 9.7 & & 6.880 \\
\hline 1928 & Aug. 27 & 1928 & $10 \cdot 8$ & & 8,480 \\
\hline 1929 & Mar. 14, & 1929 & $16 \cdot 2$ & & 19,400 \\
\hline 1930 & May & 1930 & 8.8 & & 5.870 \\
\hline 1931 & June 21 & 1931 & 8.3 & & 5.270 \\
\hline 1932 & $\begin{array}{ll}\text { Nov. } & 24, \\
\text { Jan. } & 1, \\
\operatorname{Mar}{ }_{0} & 4,\end{array}$ & $\begin{array}{l}1931 \\
1932 \\
1932\end{array}$ & $\begin{array}{l}14 \cdot 6 \\
12 \cdot 5 \\
14 \cdot 2\end{array}$ & $\approx$ & $\begin{array}{l}15.200 \\
11.400 \\
14.200\end{array}$ \\
\hline 1933 & Apr. & 1933 & 10.1 & & 7.550 \\
\hline 1934 & Apr. & 1934 & 5.0 & & 2.020 \\
\hline 1935 & Mar. & 1935 & 13.1 & & 11.000 \\
\hline 1936 & Mar. & 1936 & 13.9 & & 12.200 \\
\hline 1937 & Mar. & 1937 & 13.9 & & 12,200 \\
\hline 1938 & June & 1938 & 11.6 & & 8.590 \\
\hline 1939 & $\begin{array}{l}\text { Mar. } 12, \\
\operatorname{Mar.~} 16,\end{array}$ & $\begin{array}{l}1939 \\
1939\end{array}$ & $\begin{array}{l}17.85 \\
13.0\end{array}$ & a & $\begin{array}{l}14.000 \mathrm{~b} \\
10,600\end{array}$ \\
\hline
\end{tabular}

a Affezted by ice.

b About. 
05-4845.00 Raccoon River at Van Meter, Iowa--(Continued)

Peak__stages_and_di

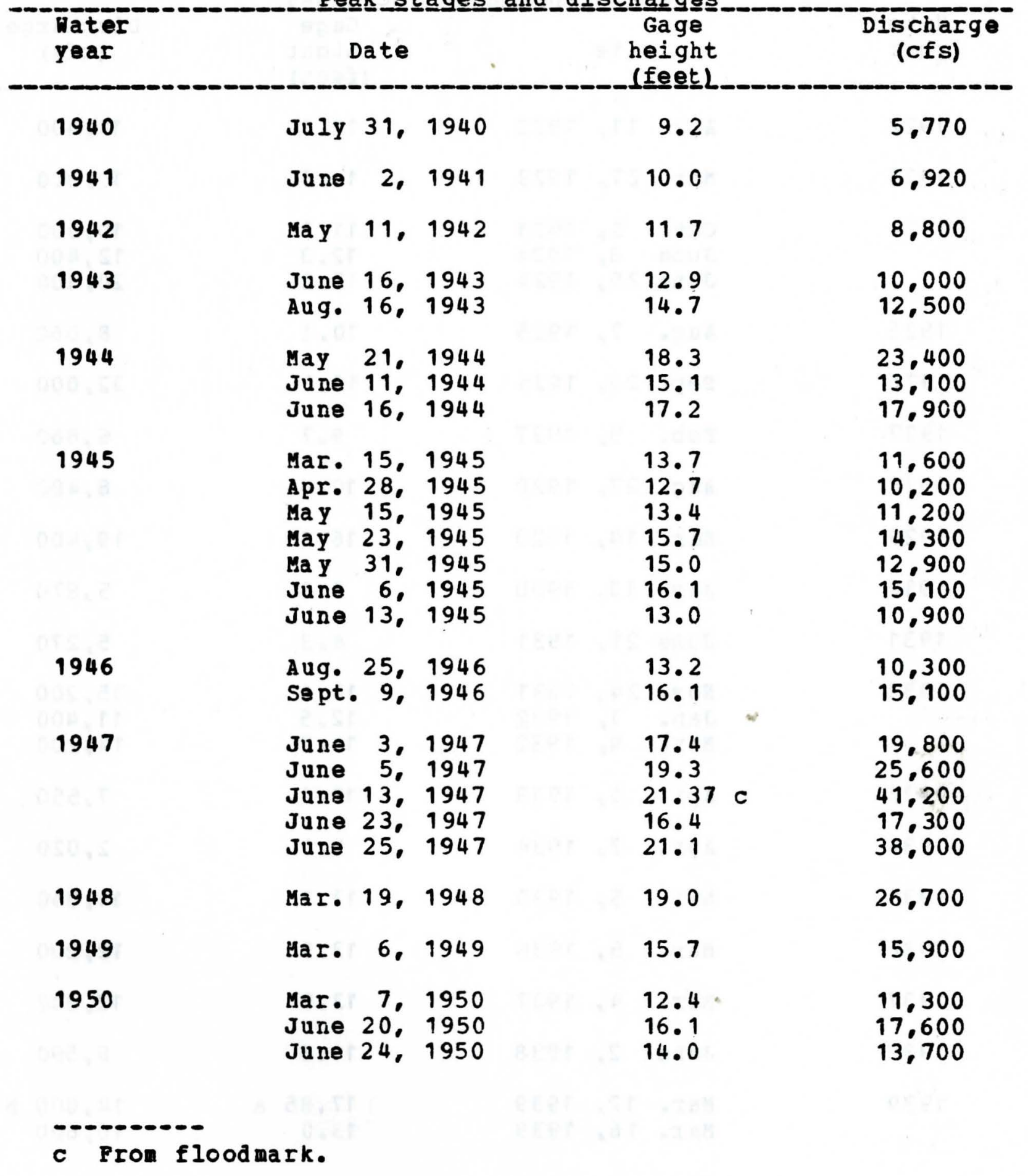


05-4845.00 Raccoor River at Van Meter, Iowa--(Continued)

Peak

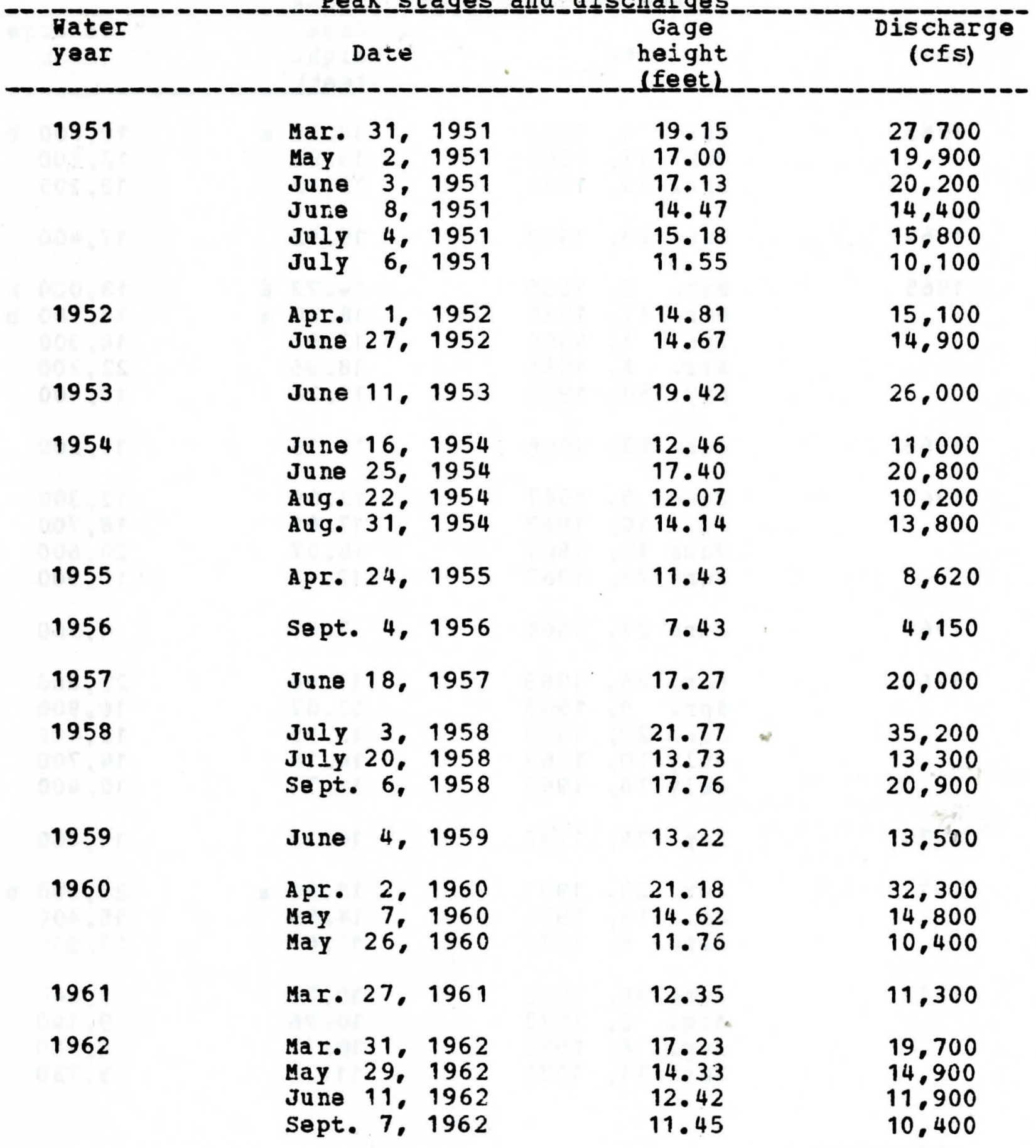


05-4845.00 Raccoor River at Van Meter, Iowa--(Continued)

Peak__stages_and_di

\begin{tabular}{|c|c|c|c|c|c|c|}
\hline $\begin{array}{l}\text { water } \\
\text { year }\end{array}$ & & Date & , & $\begin{array}{l}\text { Gage } \\
\text { height }\end{array}$ & & $\begin{array}{c}\text { Discharge } \\
\text { (cfs) }\end{array}$ \\
\hline 1963 & $\begin{array}{l}\text { Mar. } \\
\text { Mar. } \\
\text { Apr. }\end{array}$ & $\begin{array}{l}4 . \\
11 \% \\
29 .\end{array}$ & $\begin{array}{l}1963 \\
1963 \\
1963\end{array}$ & $\begin{array}{l}14.38 \\
13.85 \\
12.62\end{array}$ & $a$ & $\begin{array}{l}10,000 \\
12,200 \\
12.200\end{array}$ \\
\hline 1964 & June & 23 & 1964 & $15 \cdot 92$ & & 17.400 \\
\hline 1965 & $\begin{array}{l}\text { Mar. } \\
\text { Mar. } \\
\text { Apr. } \\
\text { Apr. } \\
\text { May }\end{array}$ & $\begin{array}{r}2 \% \\
17 \% \\
1 \% \\
6 \%\end{array}$ & $\begin{array}{l}1965 \\
1965 \\
1965 \\
1965 \\
1965\end{array}$ & $\begin{array}{l}14.73 \\
18.20 \\
13.93 \\
18.35 \\
11.20\end{array}$ & $\begin{array}{l}a \\
a\end{array}$ & $\begin{array}{l}13,000 \mathrm{~b} \\
20.100 \mathrm{~b} \\
14,300 \\
22,300 \\
10,400\end{array}$ \\
\hline 1966 & June & 13 & 1966 & $15 \cdot 15$ & & 16,200 \\
\hline 1967 & $\begin{array}{l}\text { June } \\
\text { June } \\
\text { June } \\
\text { June }\end{array}$ & $\begin{array}{l}8, \\
10 \\
12, \\
26\end{array}$ & $\begin{array}{l}1967 \\
1967 \\
1967 \\
1967\end{array}$ & $\begin{array}{l}13.09 \\
17.04 \\
18.07 \\
12.11\end{array}$ & & $\begin{array}{l}12,300 \\
18,700 \\
20,600 \\
10,900\end{array}$ \\
\hline 1968 & June & 27 & 1968 & 7.05 & , & 4.360 \\
\hline 1969 & $\begin{array}{l}\text { Mar. } \\
\text { Apr. } \\
\text { June } \\
\text { July } \\
\text { July }\end{array}$ & $\begin{array}{r}25 \\
9 \\
29 \\
10 \\
18\end{array}$ & $\begin{array}{l}1969 \\
1969 \\
1969 \\
1969 \\
1969\end{array}$ & $\begin{array}{l}17.60 \\
12.07 \\
12.95 \\
14.18 \\
11.74\end{array}$ & $*$ & $\begin{array}{l}22,800 \\
10,900 \\
12,400 \\
14,700 \\
10,400\end{array}$ \\
\hline 1970 & May & 14. & 1970 & 14.23 & & 14,800 \\
\hline 1971 & $\begin{array}{l}\text { Fab. } \\
\text { Mar. } \\
\text { June }\end{array}$ & $\begin{array}{r}20 \\
14 \\
6\end{array}$ & $\begin{array}{l}1971 \\
1971 \\
1971\end{array}$ & $\begin{array}{l}18.85 \\
14.55 \\
13.44\end{array}$ & $a$ & $\begin{array}{l}23.000 \mathrm{~b} \\
15.400 \\
13.300\end{array}$ \\
\hline 1972 & $\begin{array}{l}\text { June } \\
\text { Aug. } \\
\text { Aug. } \\
\text { Se pt. }\end{array}$ & $\begin{array}{r}18, \\
2 \% \\
6 \% \\
11 \%\end{array}$ & $\begin{array}{l}1972 \\
1972 \\
1972 \\
1972\end{array}$ & $\begin{array}{l}10.74 \\
10.96 \\
10.71 \\
11.33\end{array}$ & & $\begin{array}{l}8.840 \\
9.140 \\
8.790 \\
9.730\end{array}$ \\
\hline
\end{tabular}

a Affected by ice.

b about. 
05-4845.00 Raccoon River at Van Meter. Iowa--(Continued)

Peak stages and dischaIges

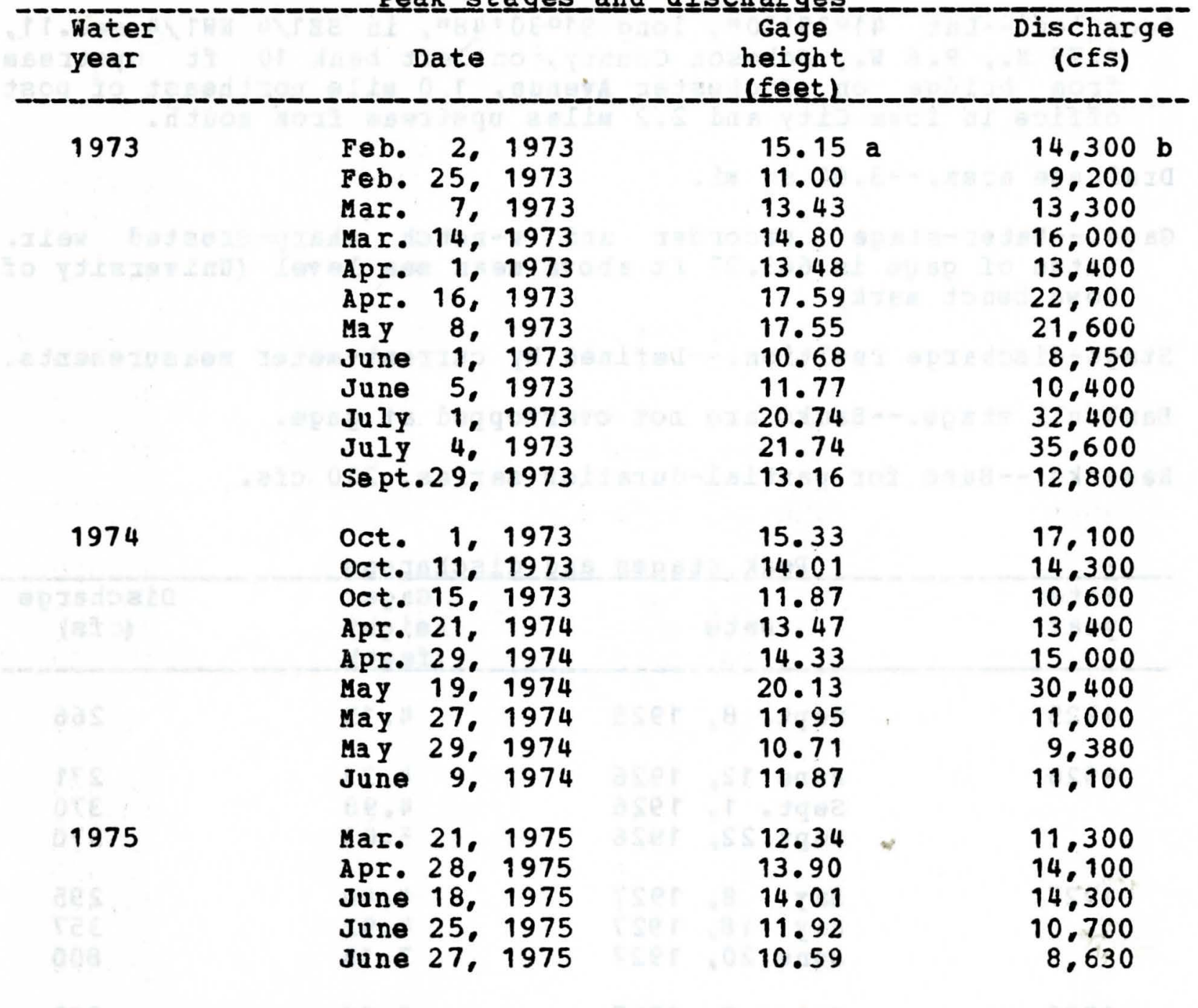

a Afected by ice.

b About. 
Location.--Iat $41039 \cdot 50 "$, long $91030 \cdot 48 "$, in SE1/4 NW1/4 sec.11. T.79 N., R.6 W.. Johnson County, on left bank 10 ft upstream from bridge on Rochester Avenue, 1.0 mile northeast of post office in Iowa City and 2.2 miles upstream from mouth.

Drainage area.--3.01 sq mi.

Gage.--Water-stage recorder and v-notch sharp-crested weir. Datum of gage is 663.27 ft above mean sea level (University of Iowa bench mark).

Stage-discharge realtion.--Defined by current-meter measurements. Bankfull stage.--Banks are not overtopped at gage.

Remarks.--Base for partial-duration series, $200 \mathrm{cfs}$.

Peak s_tages_and_ di

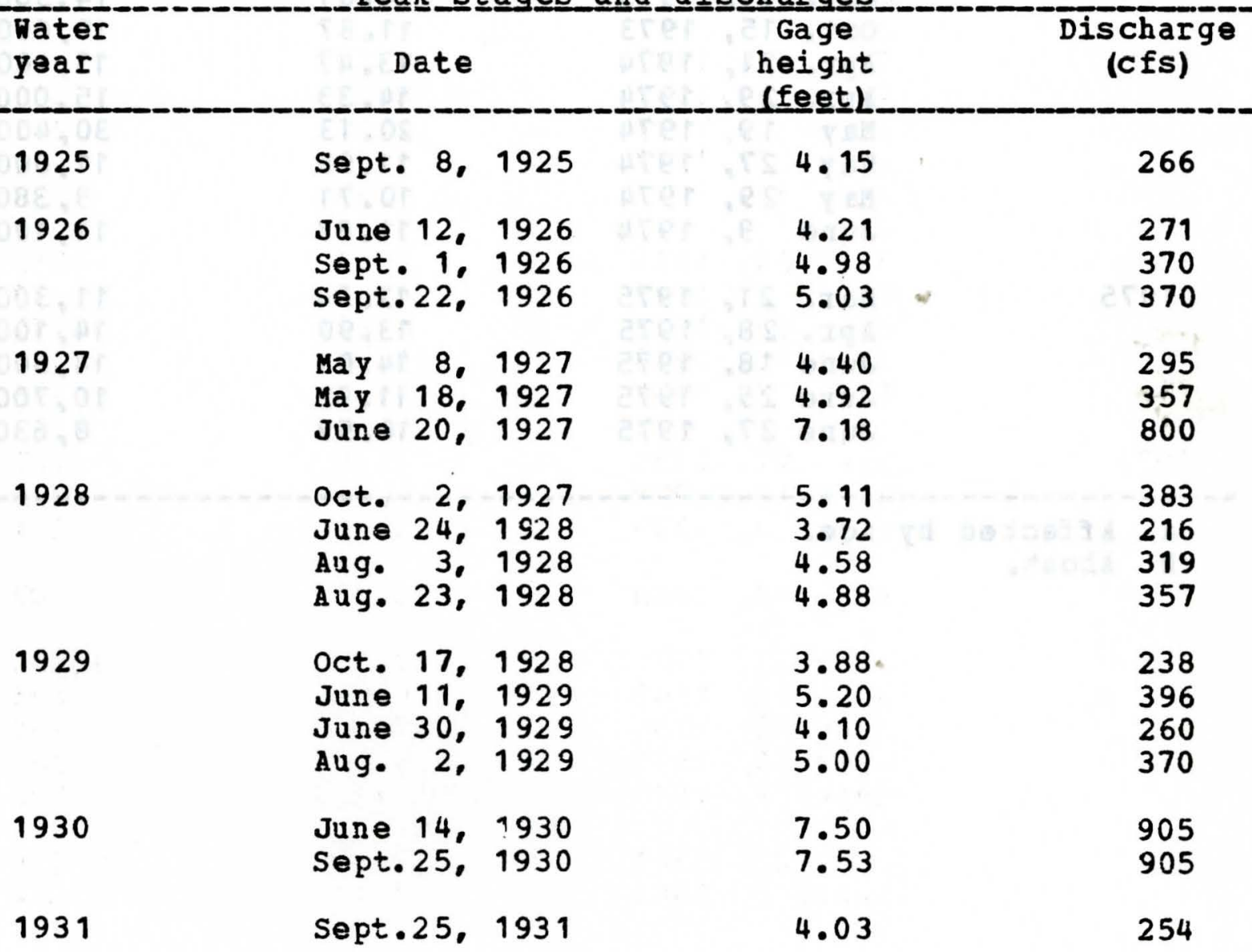


05-4550.00 Ralston Creek at Iowa City. Iowa--(Continued)

Peak stages and discharges

\begin{tabular}{|c|c|c|c|c|c|c|}
\hline $\begin{array}{l}\text { Water } \\
\text { year }\end{array}$ & Date & & . & $\begin{array}{c}\text { Gage } \\
\text { height } \\
\text { ffeetl }\end{array}$ & & $\begin{array}{l}\text { Discharge } \\
\text { (cfs) }\end{array}$ \\
\hline 1932 & $\begin{array}{ll}\text { No v. } & 23, \\
\text { June } & 17, \\
\text { July } 10, \\
\text { Aug. } 1 .\end{array}$ & $\begin{array}{l}1931 \\
1932 \\
1932 \\
1932\end{array}$ & & $\begin{array}{l}4.75 \\
4.77 \\
4.19 \\
8.18\end{array}$ & & $\begin{array}{r}344 \\
344 \\
271 \\
1.200\end{array}$ \\
\hline 1933 & Dec. 24 , & 1932 & & 3.30 & & 174 \\
\hline 1934 & JuIy 12 , & 1934 & & 4.00 & & 249 \\
\hline 1935 & $\begin{array}{l}\text { June } 1, \\
\text { June } 15, \\
\text { June } 26, \\
\text { Aug. } 20\end{array}$ & $\begin{array}{l}1935 \\
1935 \\
1935 \\
1935\end{array}$ & & $\begin{array}{l}4.11 \\
4.22 \\
6.37 \\
5.00\end{array}$ & & $\begin{array}{l}260 \\
271 \\
570 \\
370\end{array}$ \\
\hline 1936 & Sept. 1. & 1936 & & 3.59 & & 1.93 \\
\hline 1937 & $\begin{array}{lr}\text { Jan. } & 30, \\
\text { Feb. } 20, \\
\text { MaI. } & 2, \\
\text { May } 26, \\
\text { July } 14,\end{array}$ & $\begin{array}{l}1937 \\
1937 \\
1937 \\
1937 \\
1937\end{array}$ & & $\begin{array}{l}4.25 \\
6.28 \\
4.22 \\
3.93 \\
4.45\end{array}$ & & $\begin{array}{l}266 \\
533 \\
262 \\
230 \\
290\end{array}$ \\
\hline 1938 & $\begin{array}{lr}\text { Jan. } & 24, \\
\text { Feb. } & 5, \\
\text { May } & 17, \\
\text { July } & 6, \\
\text { Aug. } & 5,\end{array}$ & $\begin{array}{l}1938 \\
1938 \\
1938 \\
1938 \\
1938\end{array}$ & & $\begin{array}{l}4.61 \\
4.16 \\
4.30 \\
5.81 \\
4.51\end{array}$ & $\approx$ & $\begin{array}{l}310 \\
257 \\
274 \\
466 \\
265\end{array}$ \\
\hline 1939 & $\begin{array}{l}\text { MaI. } 12, \\
\text { JuIy } 16, \\
\text { Aug. }\end{array}$ & $\begin{array}{l}1939 \\
1939 \\
1939\end{array}$ & & $\begin{array}{l}4.71 \\
4.34 \\
3.96\end{array}$ & & $\begin{array}{l}322 \\
275 \\
231\end{array}$ \\
\hline 1940 & Aug. 13. & 1940 & & 3.00 & & 87 \\
\hline 1941 & $\begin{array}{l}\text { June } 27, \\
\text { June } 28, \\
\text { June } 30, \\
\text { July } 29, \\
\text { Sept. } 8,\end{array}$ & $\begin{array}{l}1941 \\
1941 \\
1941 \\
1941 \\
1941\end{array}$ & & $\begin{array}{c}8.25 \\
6.65 \\
7.14 \\
5.04 \\
--\end{array}$ & & $\begin{array}{r}1.230 \\
615 \\
736 \\
260 \\
220\end{array}$ \\
\hline 1942 & $\begin{array}{l}\text { oct. } 22, \\
\text { sept. } 8,\end{array}$ & $\begin{array}{l}1941 \\
1942\end{array}$ & & $\begin{array}{l}7.39 \\
7.41\end{array}$ & & $\begin{array}{l}816 \\
824\end{array}$ \\
\hline
\end{tabular}


05-4550.00 Ralston Creek at Iowa City. Iowa--(Continued)

Peak stages and di scharges

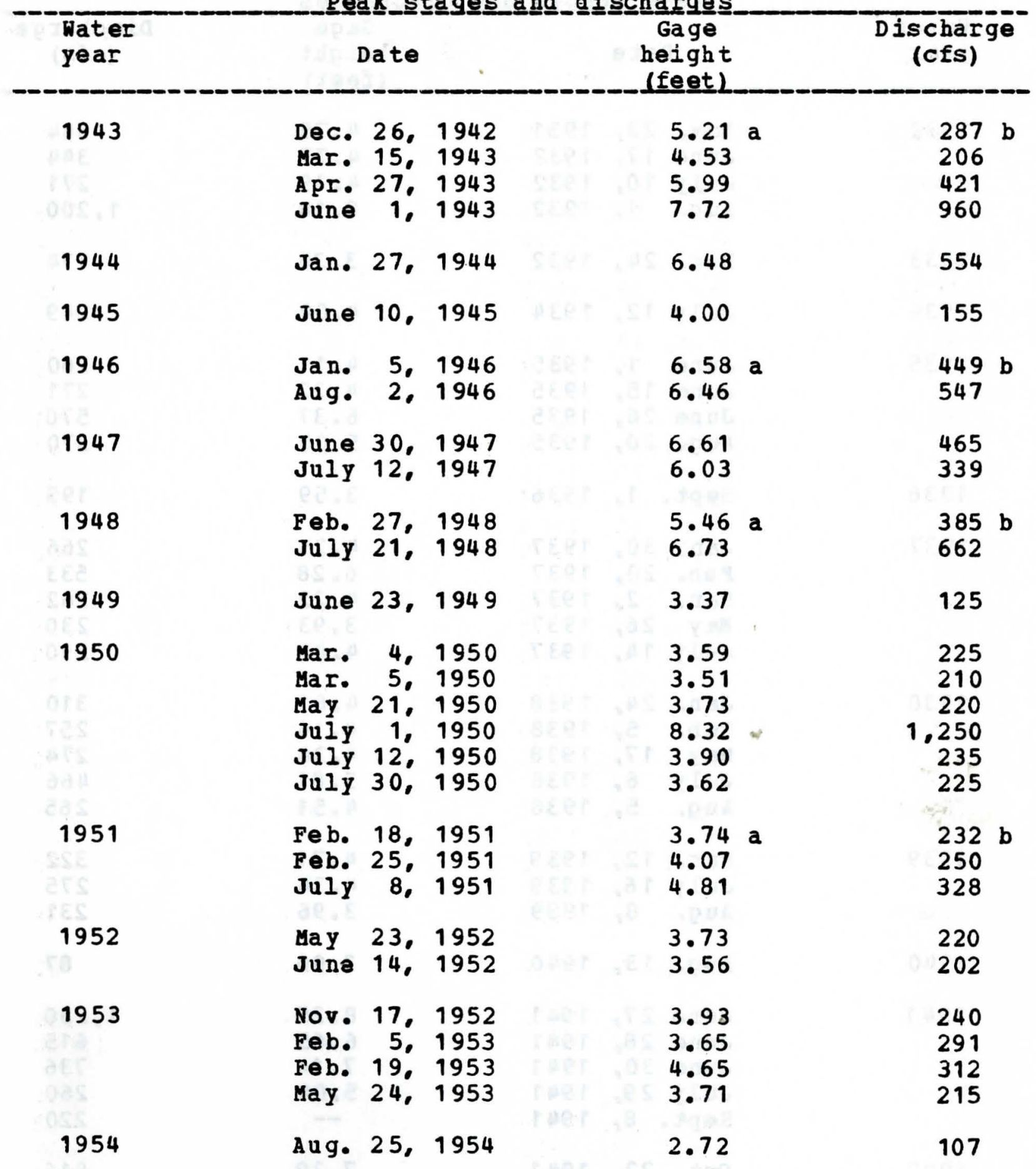

a Affected by ice.

b about. 
05-4550.00 Ralston Creek at Iowa City, Iowa--(Continued)

Peakㅡ_stag ge $\underline{\text { s and }}$ d_di

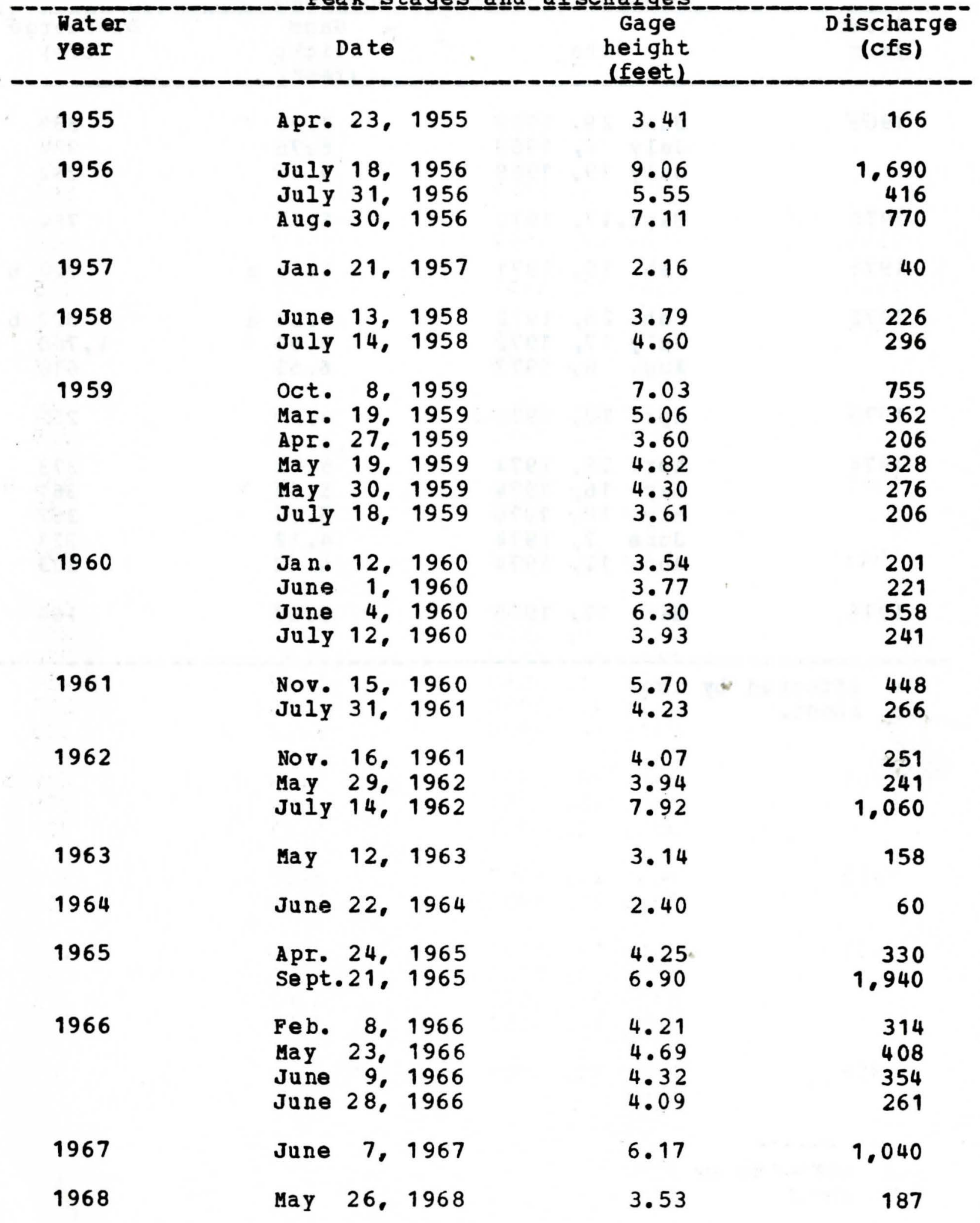


05-4550.00 Ralston Creek at Iowa City, Iowa--(Continued)

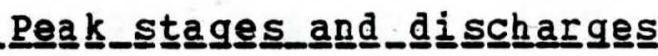

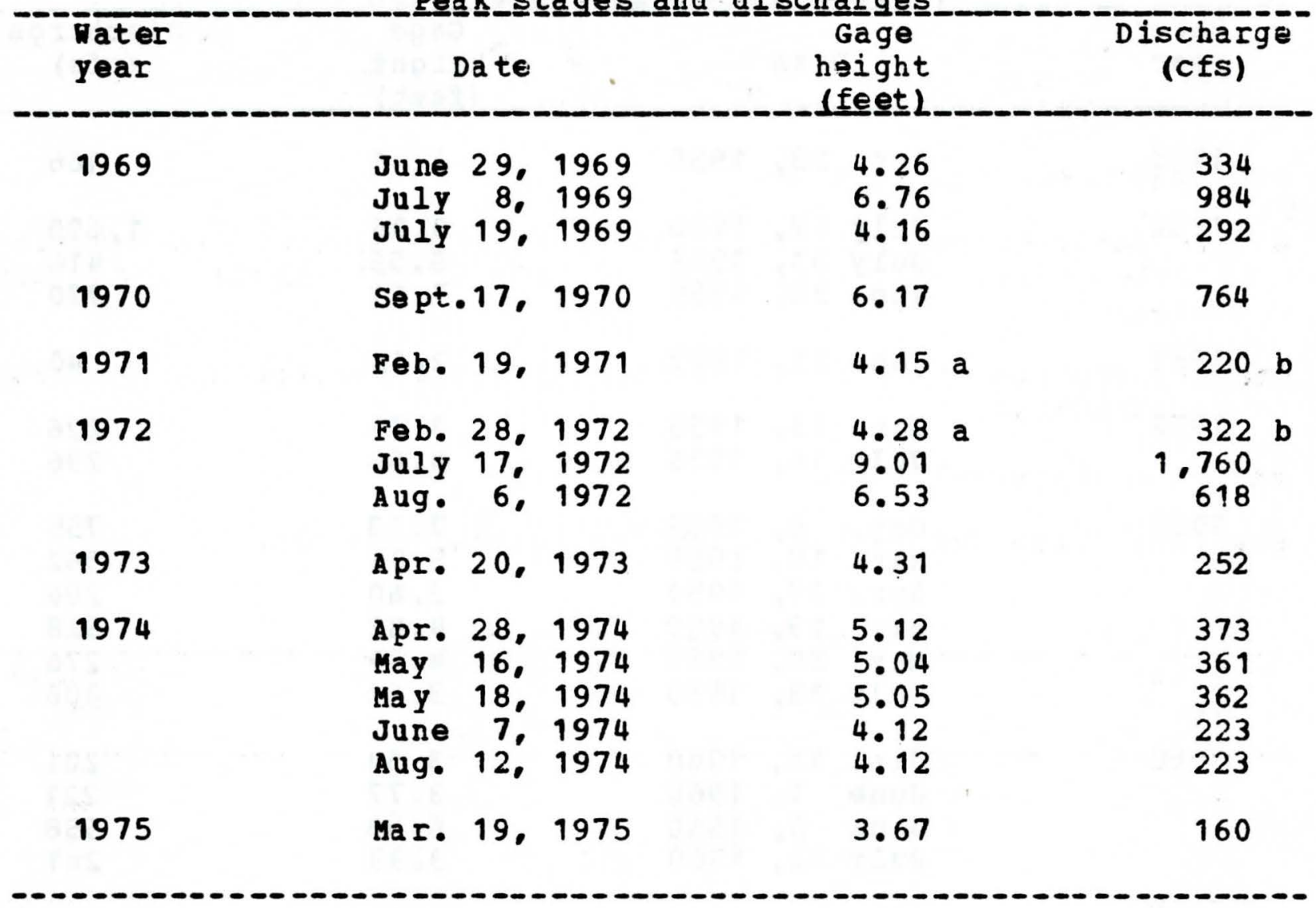

a Affected by ice.

b a bout. 
Location.--Lat 41041'19", long $91^{\circ} 29 \cdot 15^{\prime \prime}$, in NE1/4 NE1/4 sec.36, T. 80 N., R. 6 W., Johnson County, on left bank 80 ft upstream from bridge on State Highway $1,3.5$ miles northeast of Iowa city, and 4.7 miles upstream from mouth.

Drainage area. $--25.3 \mathrm{sq} \mathrm{mi}$.

Gage.--Water-stage recorder and concrete control with sharpcrested weir. Datum of gage is 673.72 ft above mean sea level.

Stage-discharge relatior.--Defined by current-meter and indirect measurements.

Bankfull stage.--9 feet.

Remarks.--Base for partial-duration series, 600 cfs.

Peakㅡ_s

\begin{tabular}{|c|c|c|c|}
\hline $\begin{array}{l}\text { Water } \\
\text { year }\end{array}$ & Date & $\begin{array}{l}\text { Gage } \\
\text { height } \\
\text { (feett. }\end{array}$ & $\begin{array}{c}\text { Dis charge } \\
\text { (cfs) }\end{array}$ \\
\hline 1938 & 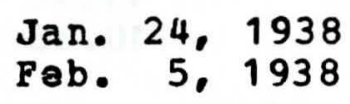 & $\begin{array}{l}10 \cdot 30 \\
10 \cdot 20\end{array}$ & $\begin{array}{l}868 \\
831\end{array}$ \\
\hline 1939 & $\begin{array}{lr}\text { Mar. } 12,1939 \\
\text { Aug. } 8,1939\end{array}$ & $\begin{array}{r}12.05 \mathrm{a} \\
9.56\end{array}$ & $\begin{array}{r}1.800 \mathrm{~b} \\
623 \mathrm{~b}\end{array}$ \\
\hline 1940 & Mar. 17, 1940 & 8.52 & 372 \\
\hline 1941 & $\begin{array}{l}\text { June 27, } 1941 \\
\text { June } 30,1941 \\
\text { Sept. } 8,1941\end{array}$ & $\begin{array}{l}12 \cdot 54 \\
11 \cdot 28 \\
10.53\end{array}$ & $\begin{array}{l}3.710 \\
1.980 \\
1.210\end{array}$ \\
\hline 1942 & $\begin{array}{l}\text { Oct. 22, } 1941 \\
\text { Oct. 31, } 1941 \\
\text { June 11, } 1942 \\
\text { Sept. 8, } 1942\end{array}$ & $\begin{array}{r}11 \cdot 32 \\
9 \cdot 78 \\
10 \cdot 15 \\
10 \cdot 15\end{array}$ & $\begin{array}{r}2.090 \\
697 \\
930 \\
850\end{array}$ \\
\hline 1943 & $\begin{array}{l}\text { Apr. 27, } 1943 \\
\text { Apr. 29, } 1943 \\
\text { June 1, } 1943\end{array}$ & $\begin{array}{r}11.00 \\
9.75 \\
11.48\end{array}$ & $\begin{array}{r}1.670 \\
780 \\
2.200\end{array}$ \\
\hline
\end{tabular}

a Affected by ice.

b About. 
05-4540.00 Rapid Creek near Iowa City. Iowa--(Continued)

Pea

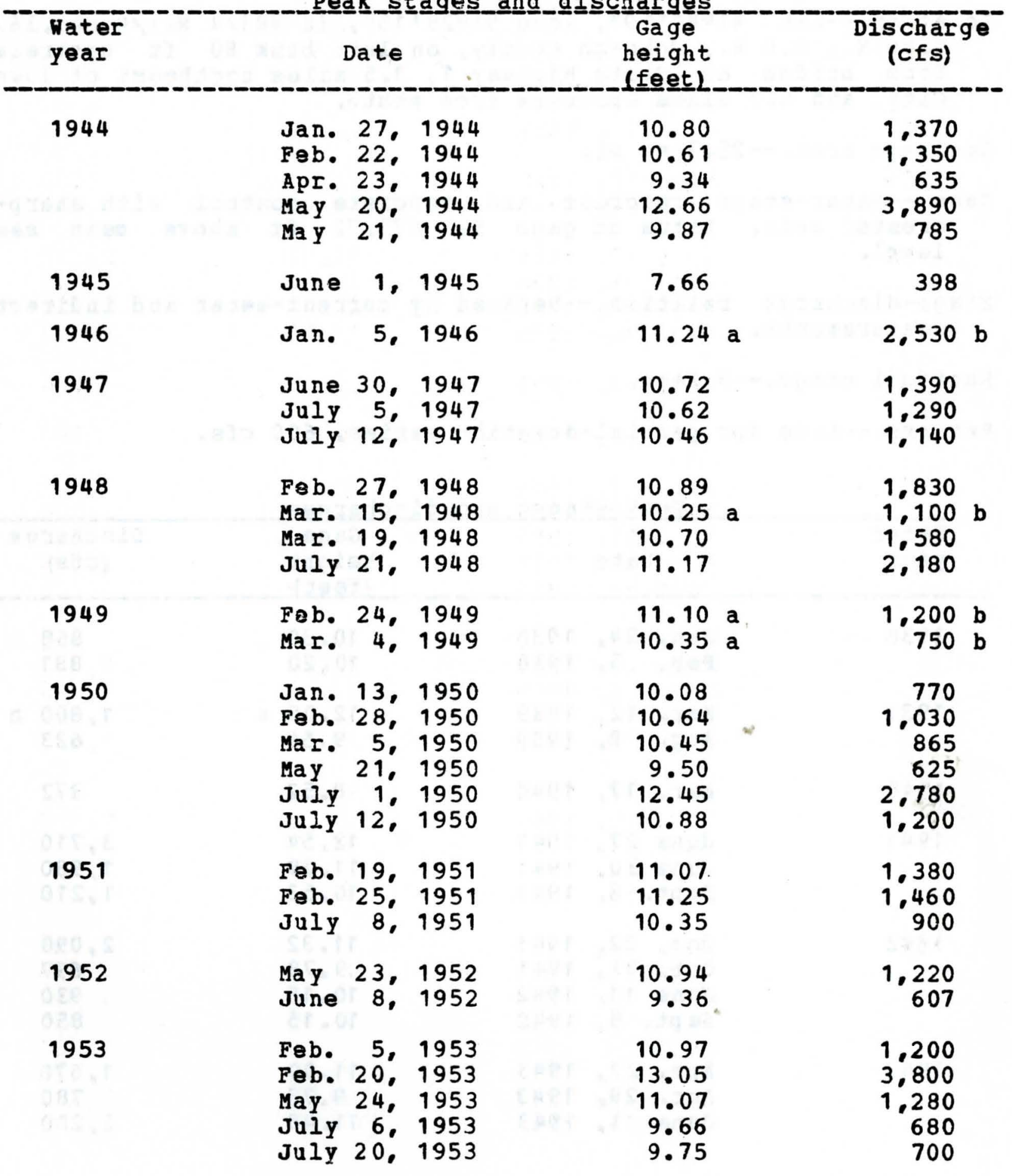

a Affected by ice.

b About. 
05-4540.00 Rapid Creek rear Iowa City, Iowa-- (Continued)

Peaㅡㄴㅡ_stage

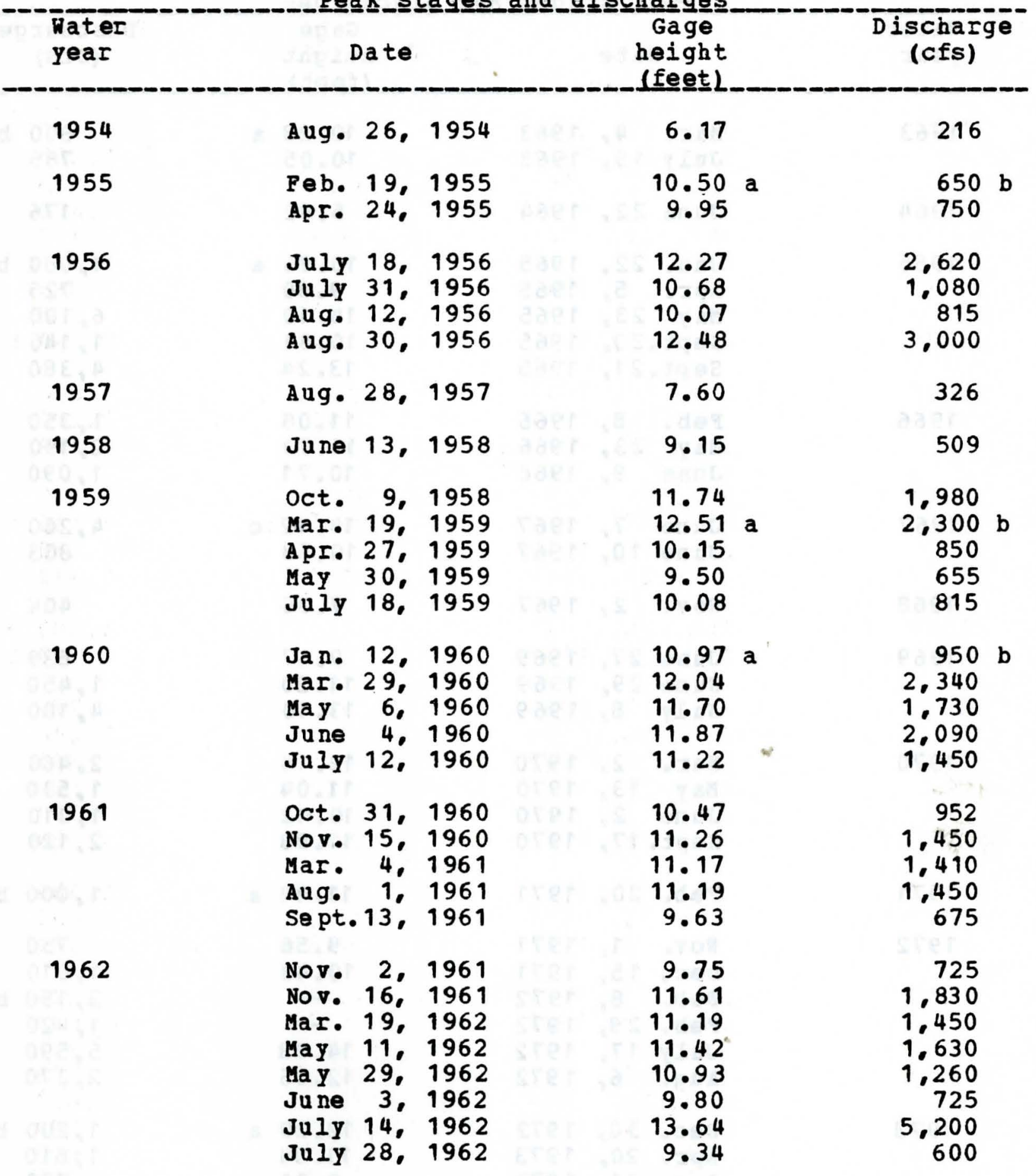

a Affected by ice.
b about. 
05-4540.00 Rapid Creek near Iowa City. Iowa--(Continued)

Peak stages and_discharges

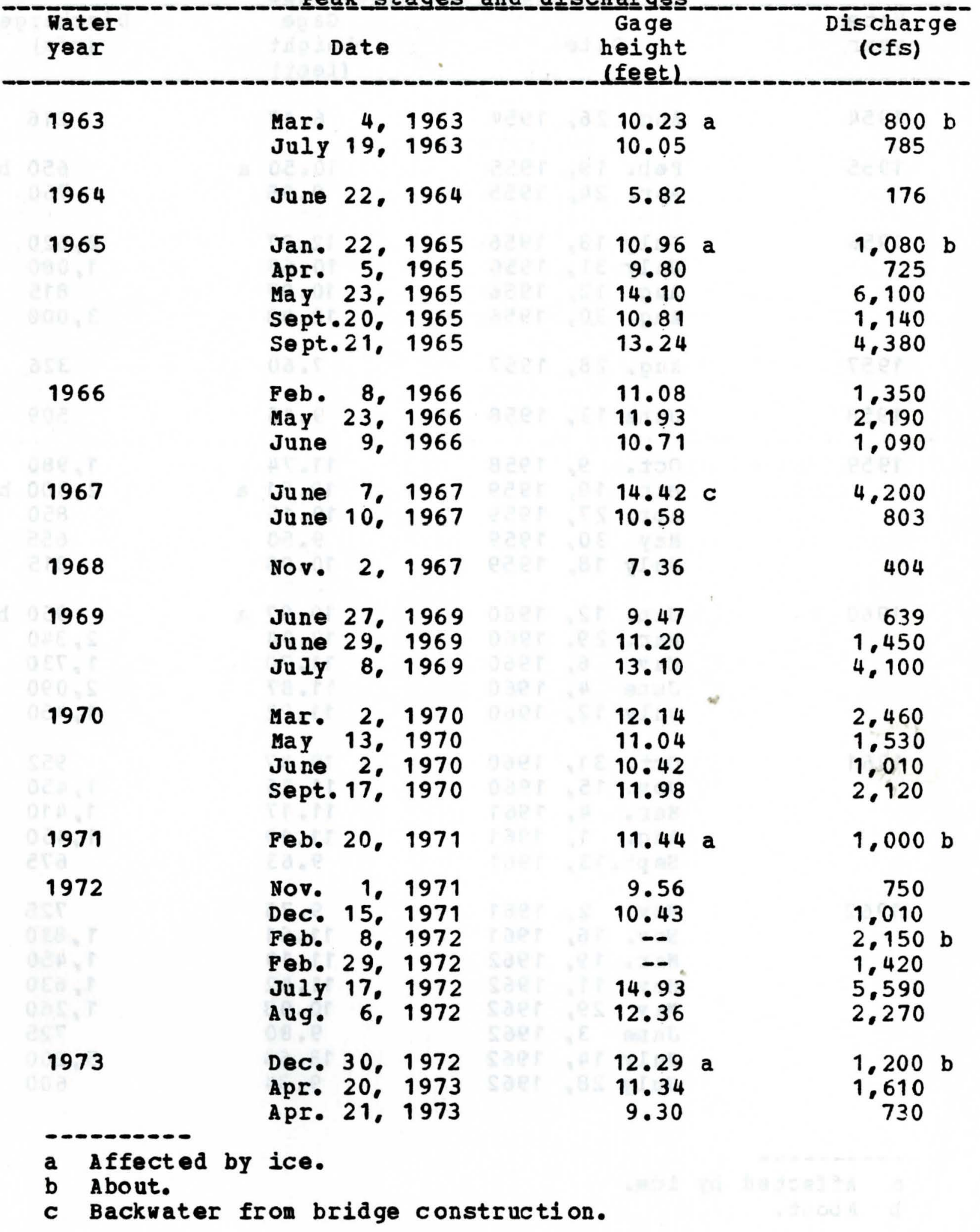


05-4540.00 Rapid Creek near Iowa City, Iowa--(Continued)

Peak__stages and_di

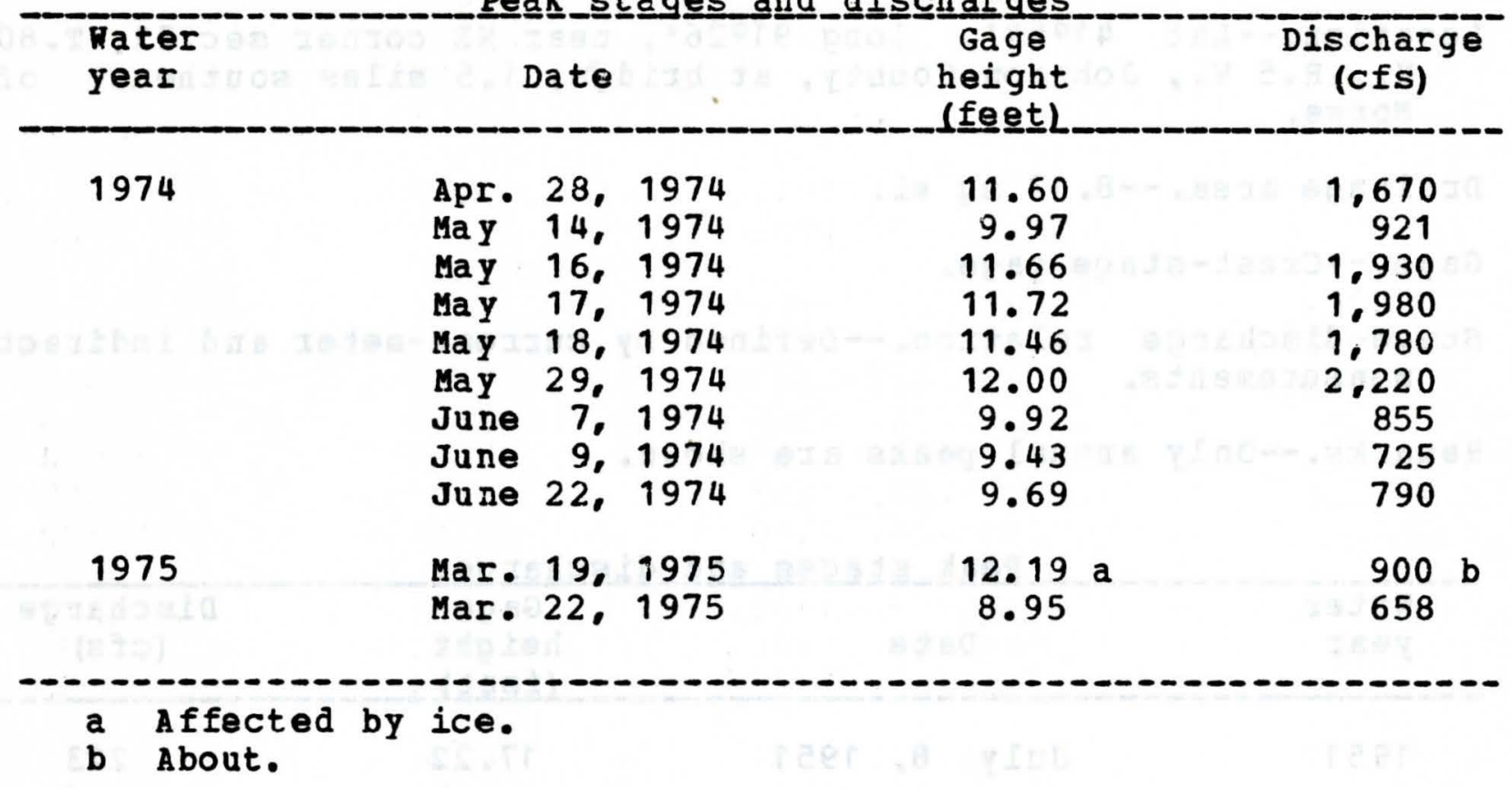


Location.--Iat $41044^{\circ}$, long $91026^{\circ}$, near NE corner sec.21, T.80 N.. R.5 W.. Johnson County, at bridge, 1.5 miles southeast of Morse.

Drainage area.--8. $12 \mathrm{sq} \mathrm{mi}$

Gage.--Crest-stage gage.

Stage-discharge relation.--Defined by current-meter and indirect measurements.

Remarks.--only annual peaks are shown.

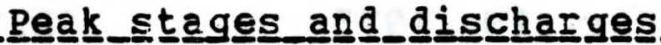

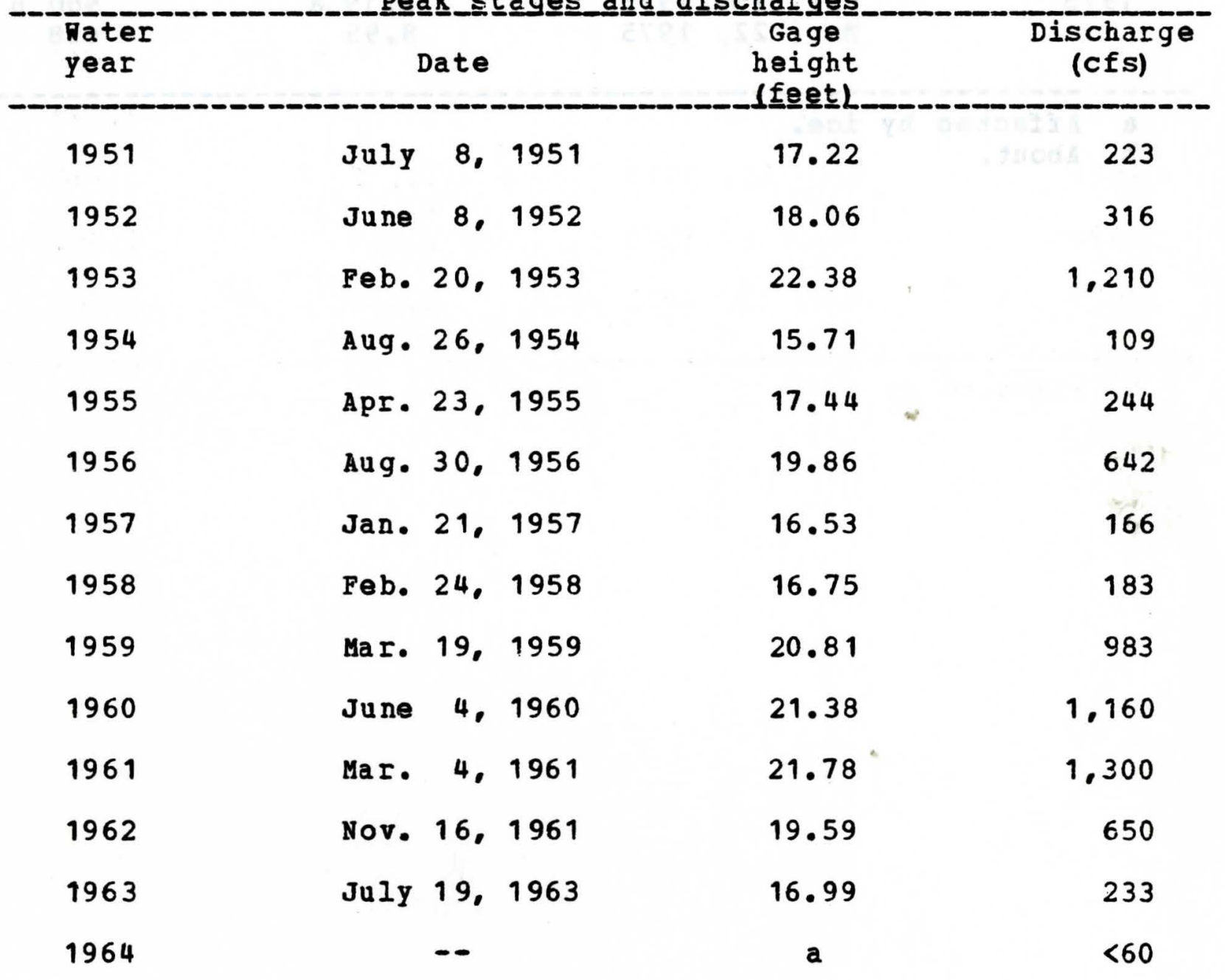

a Peak stage did not reach bottom of gage. 
05-4536.00 Rapid Creek below Morse. Iowa-- (Continued)

Peak__stages_and_dischharges

\begin{tabular}{|c|c|c|c|c|}
\hline $\begin{array}{l}\text { Water } \\
\text { year }\end{array}$ & Date & & $\begin{array}{c}\text { Gage } \\
\text { height } \\
\text { (fee }{ }_{\text {fet }}\end{array}$ & $\begin{array}{c}\text { Dis charge } \\
\text { (cfs) }\end{array}$ \\
\hline 1965 & 23 & 1965 & 25.48 & 2,750 \\
\hline 1966 & $\operatorname{May} 23$, & 1966 & $20 \cdot 32$ & 844 \\
\hline 1967 & June 7. & 1967 & 22.29 & 1.190 \\
\hline 1968 & June 24 . & 1968 & 16.02 & 132 \\
\hline 1969 & July 8, & 1969 & $21 \cdot 30$ & 946 \\
\hline 1970 & Sept. 17. & 1970 & 17.96 & 360 \\
\hline 1971 & $\mathrm{Fab} .19$, & 1971 & $21.29 \mathrm{~b}$ & 490 \\
\hline 1972 & JuIy 17 . & 1972 & 25.66 & 2.800 \\
\hline 1973 & Apr. 20 & 1973 & 20.33 & 640 \\
\hline 1974 & May 16 & 1974 & 22.74 & 1.400 \\
\hline 1975 & Mar. 19, & 1975 & 22.12 & 1,300 \\
\hline
\end{tabular}




\section{5-4537.50 Rapid Creek southwest of Morse, Iowa}

Location.--Lat $41043^{\prime}$, long 91026 , in W1/2 sec.21, T. 80 N.. R.5

W. Johnson County, at bridge, 2 miles southwest of Morse.

Drainage area.--15.2 sq mi.

Gage.--Crest-stage gage.

Stage-discharge relation.--Defined by current-meter and indirect measurements.

Remarks.--only annual peaks are shown.

Peakㅡ_stages_and

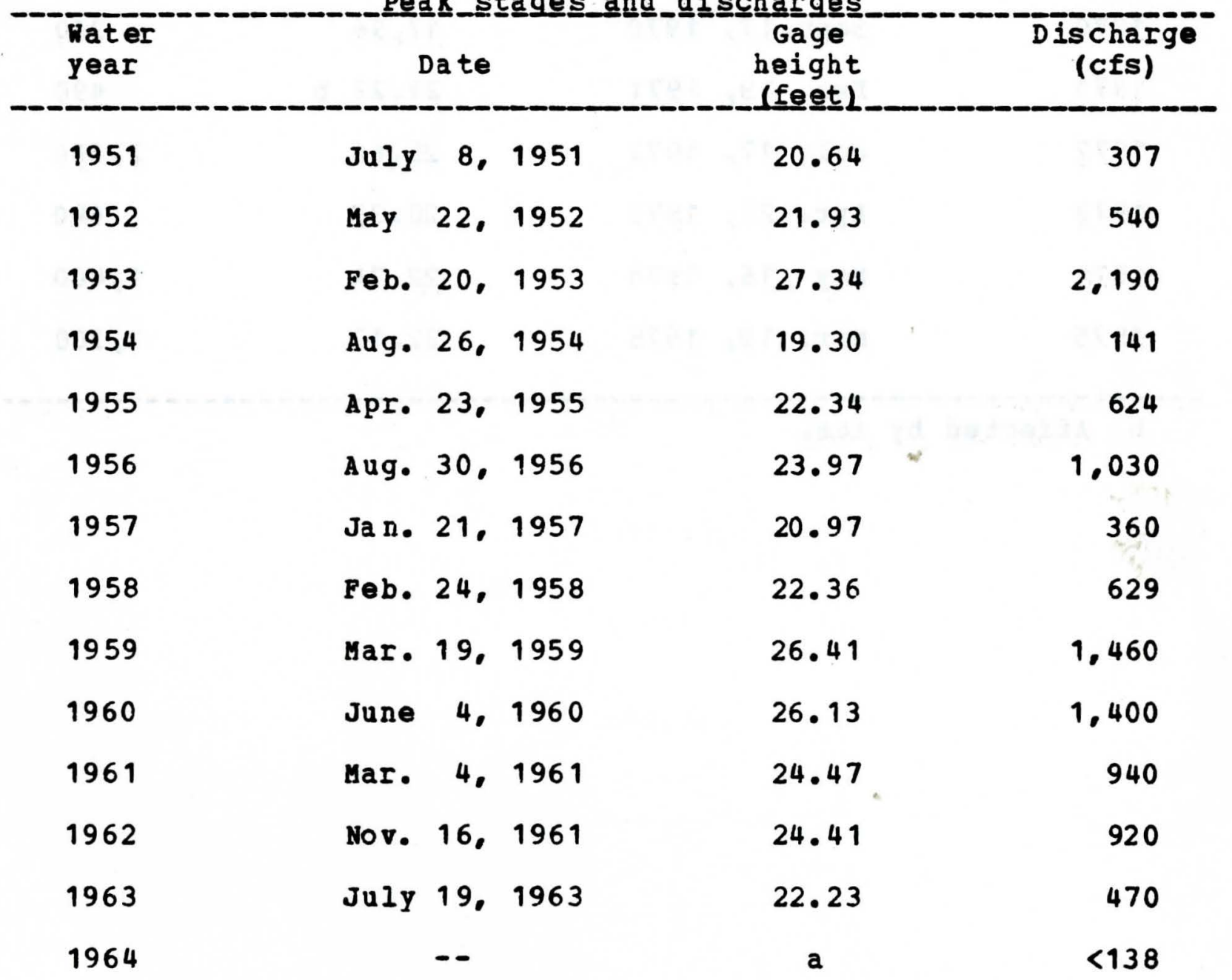

a Peak stage did not reach bottom of gage. 
05-4537.50 Rapid Creek southwest of Morse, Iowa--(Continued)

Peak﹎stages and di

\begin{tabular}{|c|c|c|c|c|c|}
\hline $\begin{array}{l}\text { Hater } \\
\text { year }\end{array}$ & & Date & . & $\begin{array}{l}\text { Gage } \\
\text { height } \\
\text { feet) }\end{array}$ & $\begin{array}{c}\text { Discharge } \\
\text { (cfs) }\end{array}$ \\
\hline 1965 & May & 23. & 1965 & 29.42 & 4.260 \\
\hline 1966 & $\operatorname{May}$ & 23. & 1966 & 26.92 & 1.640 \\
\hline 1967 & June & 7. & 1967 & 27.49 & 2.900 \\
\hline 1968 & Mar. & 26 & 1968 & 21.85 & 405 \\
\hline 1969 & JuIY & 8. & 1969 & 27.59 & 2.220 \\
\hline 1970 & June & 7. & 1970 & 25.45 & 1.470 \\
\hline 1971 & Feb. & 19. & 1971 & $25.15 \mathrm{~b}$ & 780 \\
\hline 1972 & Ju Iy & 17. & 1972 & 29.74 & 4.300 \\
\hline 1973 & Apr. & 20 & 1973 & $25 \cdot 11$ & 1.350 \\
\hline 1974 & May & 29. & 1974 & $27 \cdot 32$ & 2.200 \\
\hline 1975 & Mar. & 19. & 1975 & 23.90 & 970 \\
\hline
\end{tabular}

b Affected by ice. 
Location.--Lat 41042 , long $910^{\circ} 28^{\prime}$, in NW1/4 sec.31, T. 80 N.. R.5

w. Johnson County, at bridge, 4 miles northeast of Icwa City. Drainage area.--3.43 sq mi.

Gage.--Crest-stage gage.

Stage-discharge relation.--Defined by current-meter and indirect measurements.

Remarks.--only annual peaks are shown.

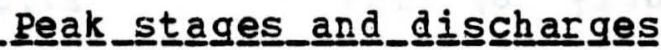

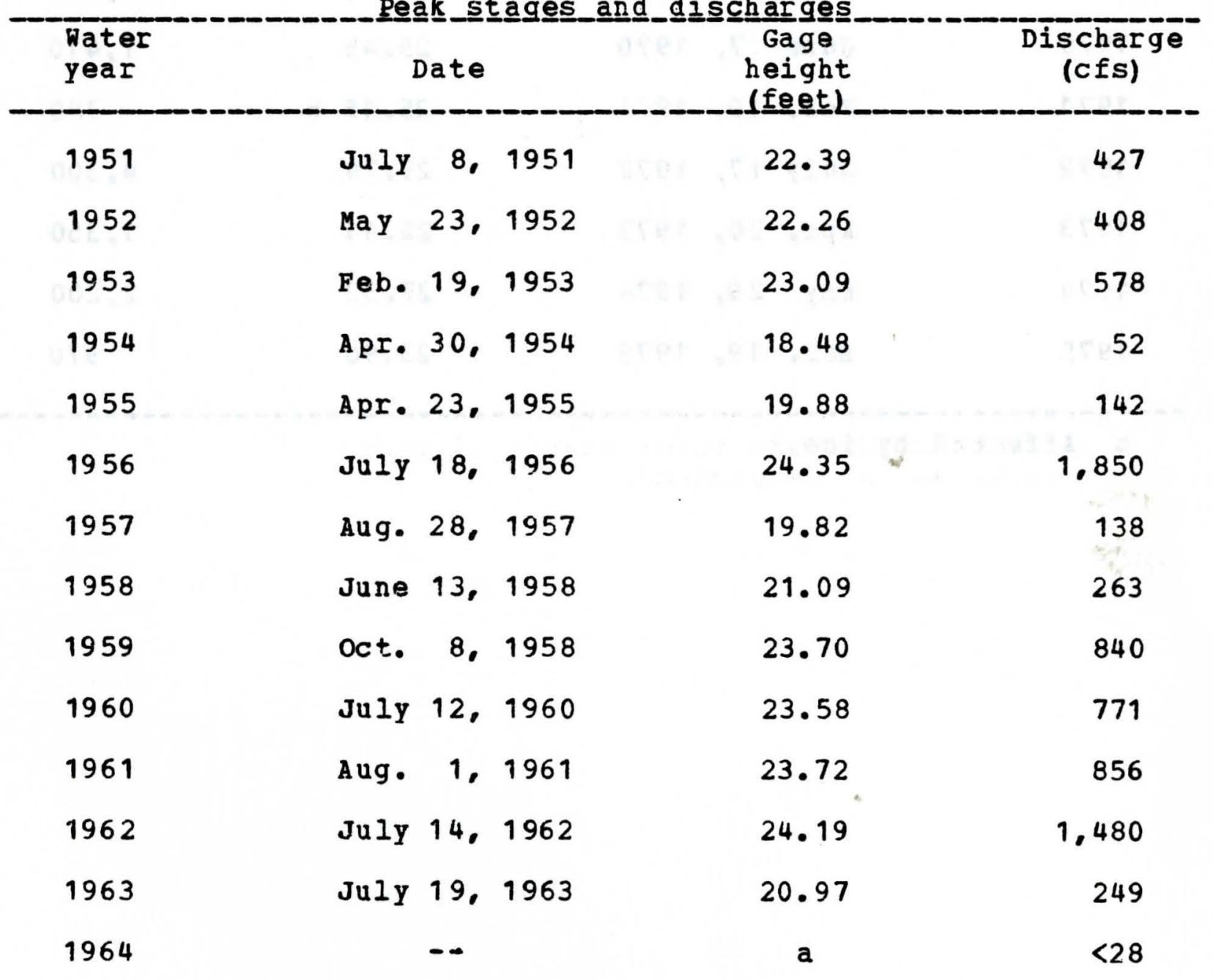

a Peak stage did not reach bottom of gage. 
05-4539.50 Rapid Creek tributary near Iowa City, Iowa--(Continued)

Peak__stageges_and_di

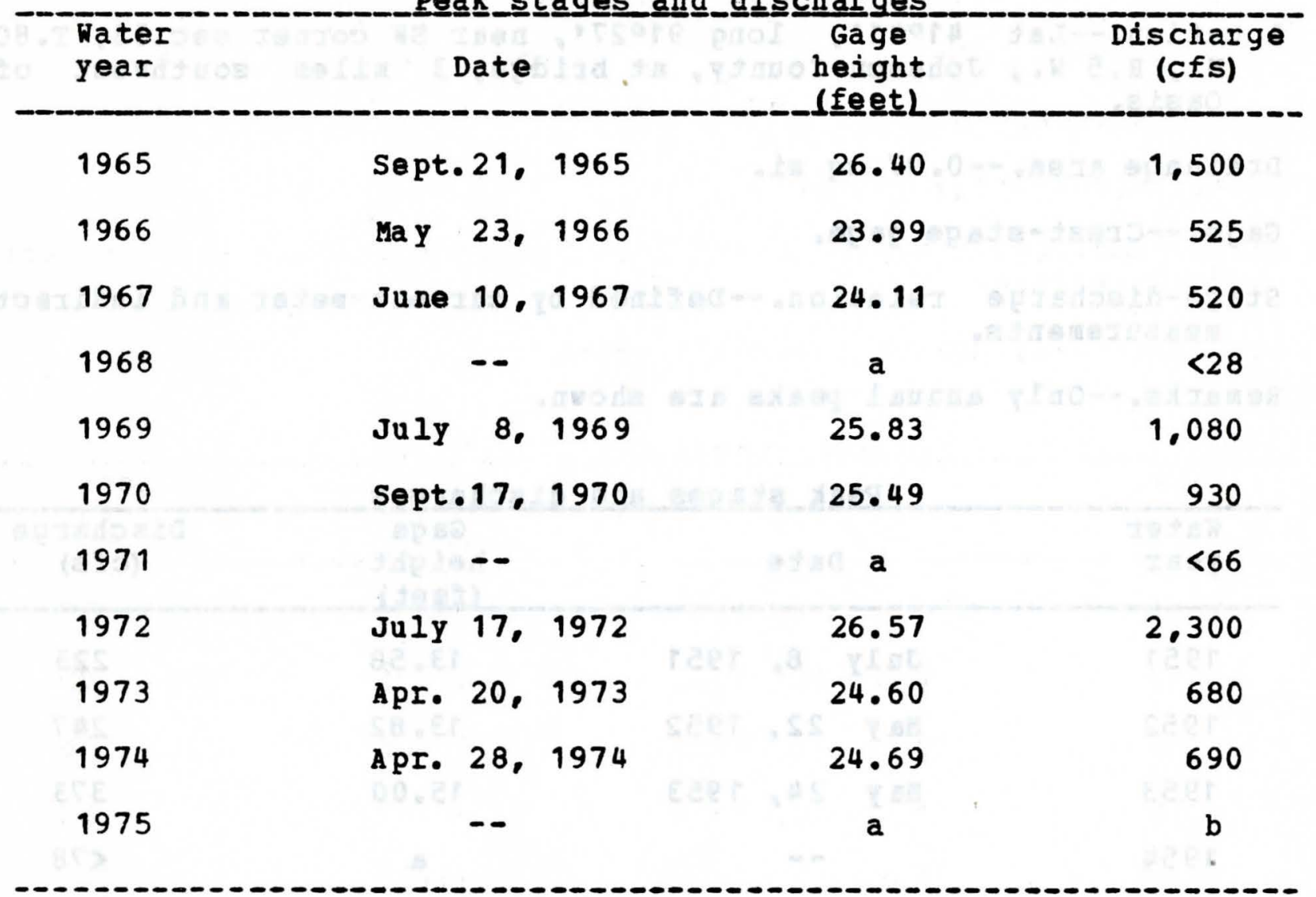

a Peak stage did not reach bottom of gage.

b Discharge not determined. 


\section{5-4539.00 Rapid Creek tributary near Oasis. Iowa}

Location.--Iat 41041', long 91027', near SH corner sec.33, T.80 N.. R.5 H.. Johnson County, at bridge, 3 miles southwest of Oasis.

Drainage area.--0.97 sq ai.

Gage.--Crest-stage gage.

Stage-discharge relation.--Defined by current-meter and indirect measurements.

Remarks.--only annual peaks are shown.

Peak_stages and_discharges

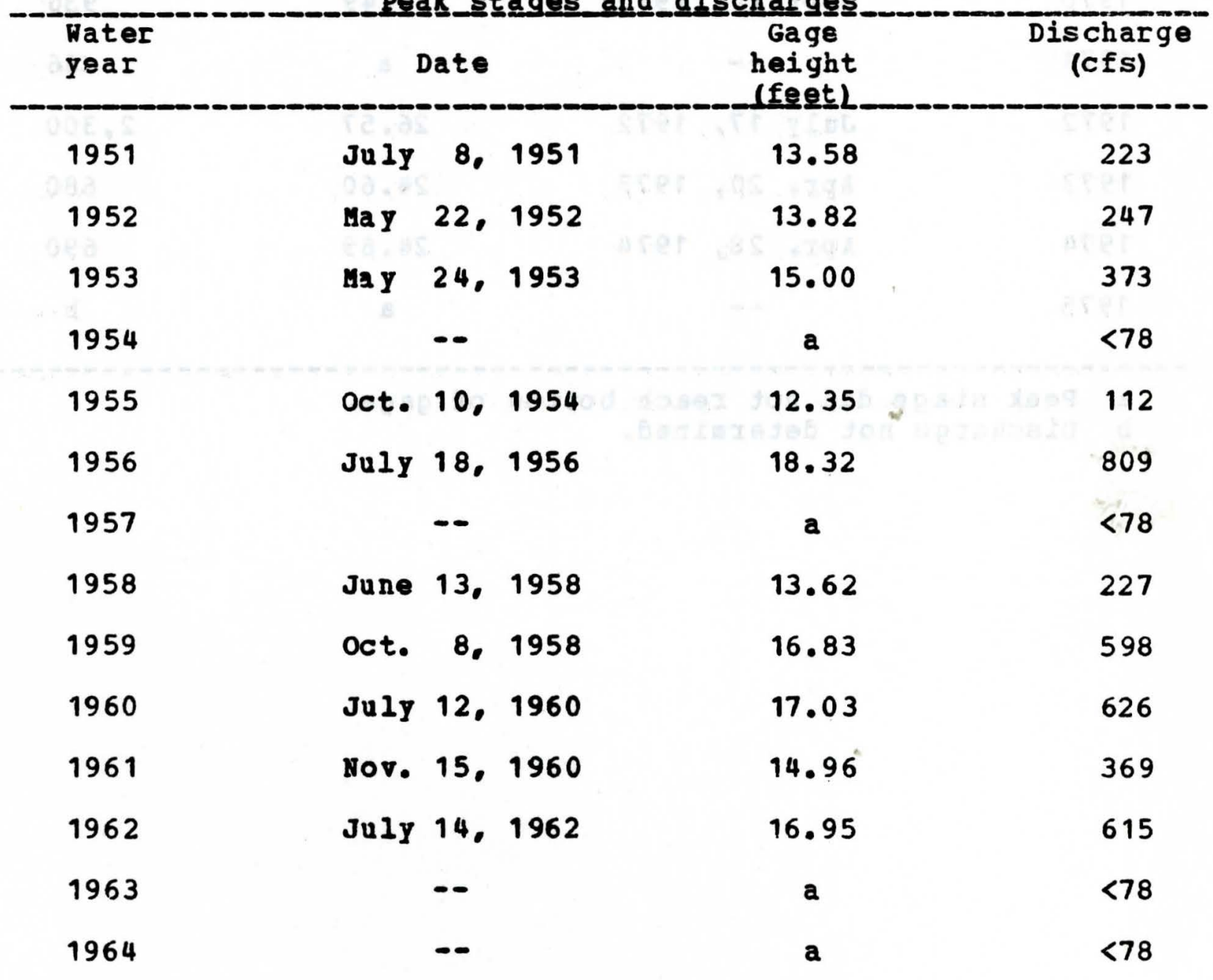

a Peak stage did not reach botton of gage. 
05-4539.00 Rapid Creek tributary near Oasis, Iowa--(Continued)

Peak_stages_and di

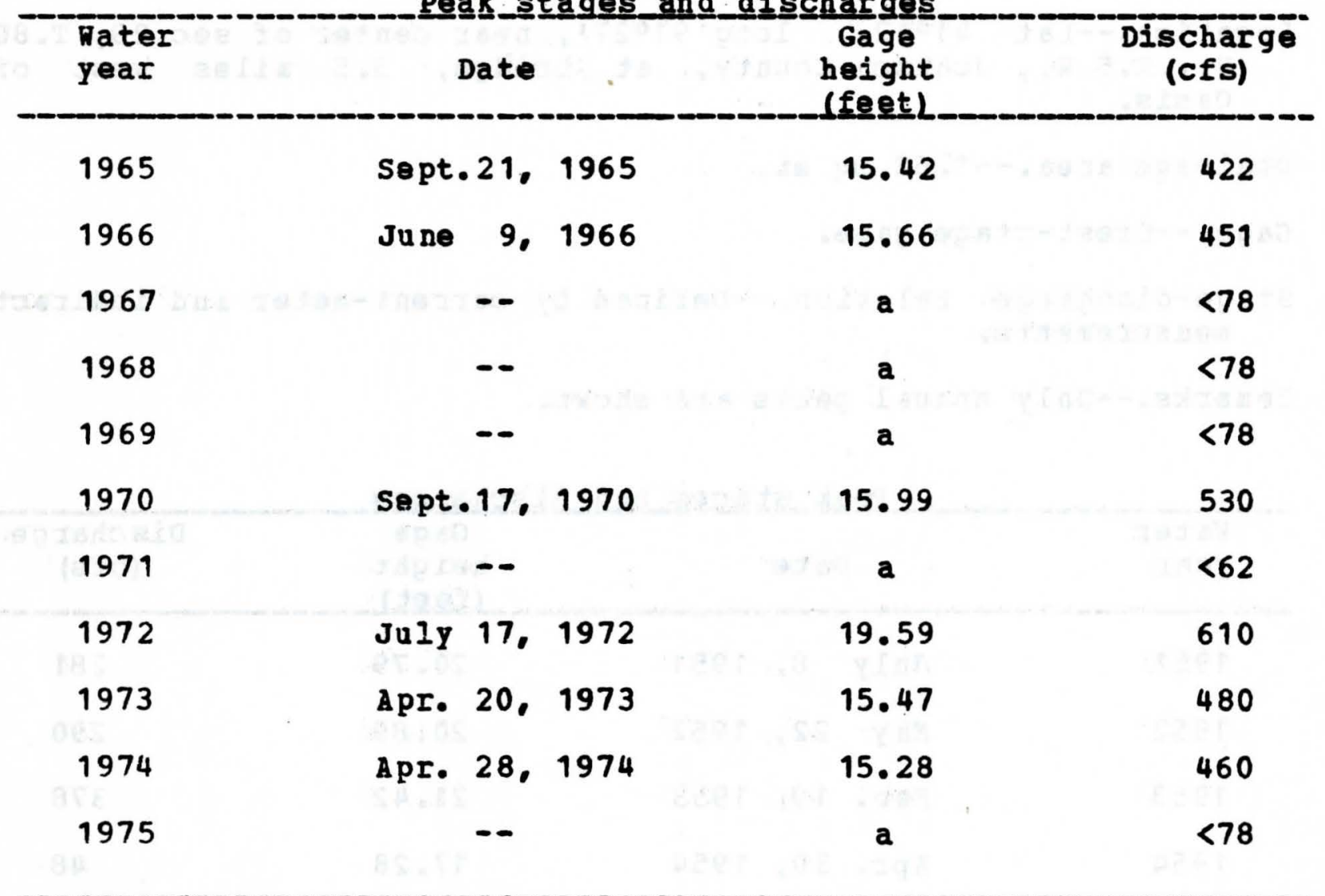

a Peak stage did not reach botton of gage. 
05-4538.50 Rapid Creek tributary No. 3 near Oasis. Iowa

Location.--Lat 41042;, long 91027\%, near center of sec.29, T.80 N., R.5 W.. Johnson County, at bridge, 3.5 miles west of Oasis.

Drainage area.--1.62 sq $\mathrm{mi}$.

Gage.--Crest-stage gage.

Stage-discharge relation.--Defined by current-meter and indirect measurements.

Remarks.--Only annual peaks are shown.

Peak

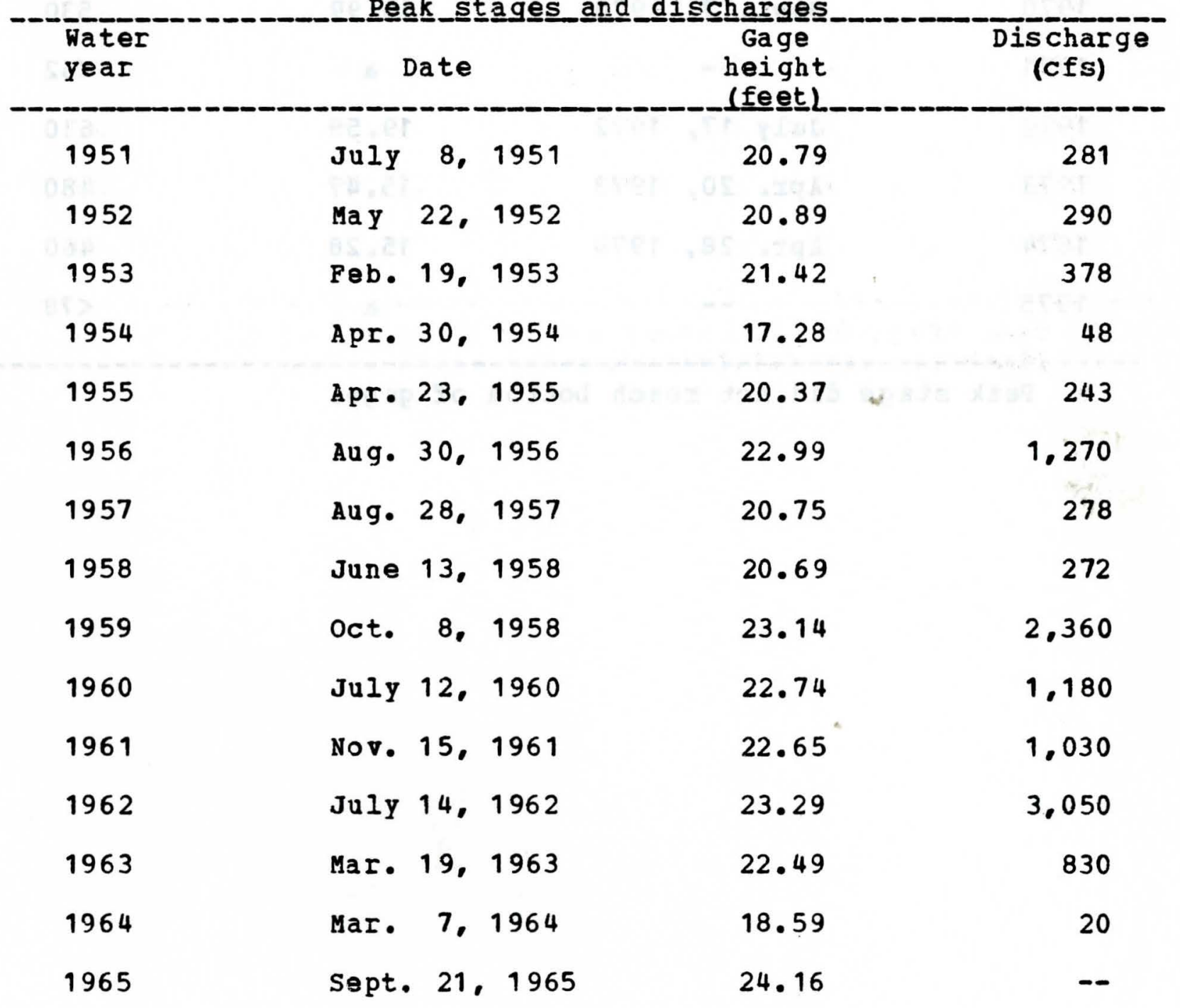


05-4538.50 Rapid Creek tributary No. 3 near Oasis, Iowa-- (Continued)

Peak﹎.stagges_and_d_i

\begin{tabular}{|c|c|c|c|}
\hline $\begin{array}{l}\text { Hater } \\
\text { year }\end{array}$ & Date & $\begin{array}{l}\text { Gage } \\
\text { height } \\
\text { dfeetl }\end{array}$ & $\begin{array}{l}\text { Dischargo } \\
\text { (cfs) }\end{array}$ \\
\hline 1966 & May 23,1966 & 23.52 & 1,300 \\
\hline 1967 & June 10,1967 & 20.09 & 213 \\
\hline 1968 & June 24,1968 & 19.34 & 152 \\
\hline 1969 & July 8,1969 & 23.83 & 1,600 \\
\hline 1970 & Sept. 17, 1970 & 22.68 & 470 \\
\hline 1971 & June 1, 1971 & 20.64 & 225 \\
\hline 1972 & July 17. 1972 & 24.11 & 950 \\
\hline 1973 & Apr. 20,1973 & 20.63 & 225 \\
\hline 1974 & Apr. 28,1974 & 22.05 & 370 \\
\hline 1975 & -- & a & b \\
\hline
\end{tabular}

a Peak stage did not reach bottoll of gage.

b Discharge not determined. 
05-4537.00 Rapid Creek tributary No. 4 near Oasis, Iowa

Location.--Iat $41043^{\prime}$, long $91^{\circ} 25^{\circ}$, near $51 / 4$ corner sec.22, T. 80 N.. R.5 W.. Johnson County, at culvert, 2 miles northwest of Oasis.

Drainage area. $--1.95 \mathrm{sq}$ mi.

Gage.--Crest-stage gage.

Stage-discharge relation.--Defined by current-meter and indirect measurements.

Remarks.--Only annual peaks are shown.

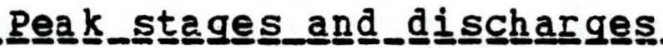

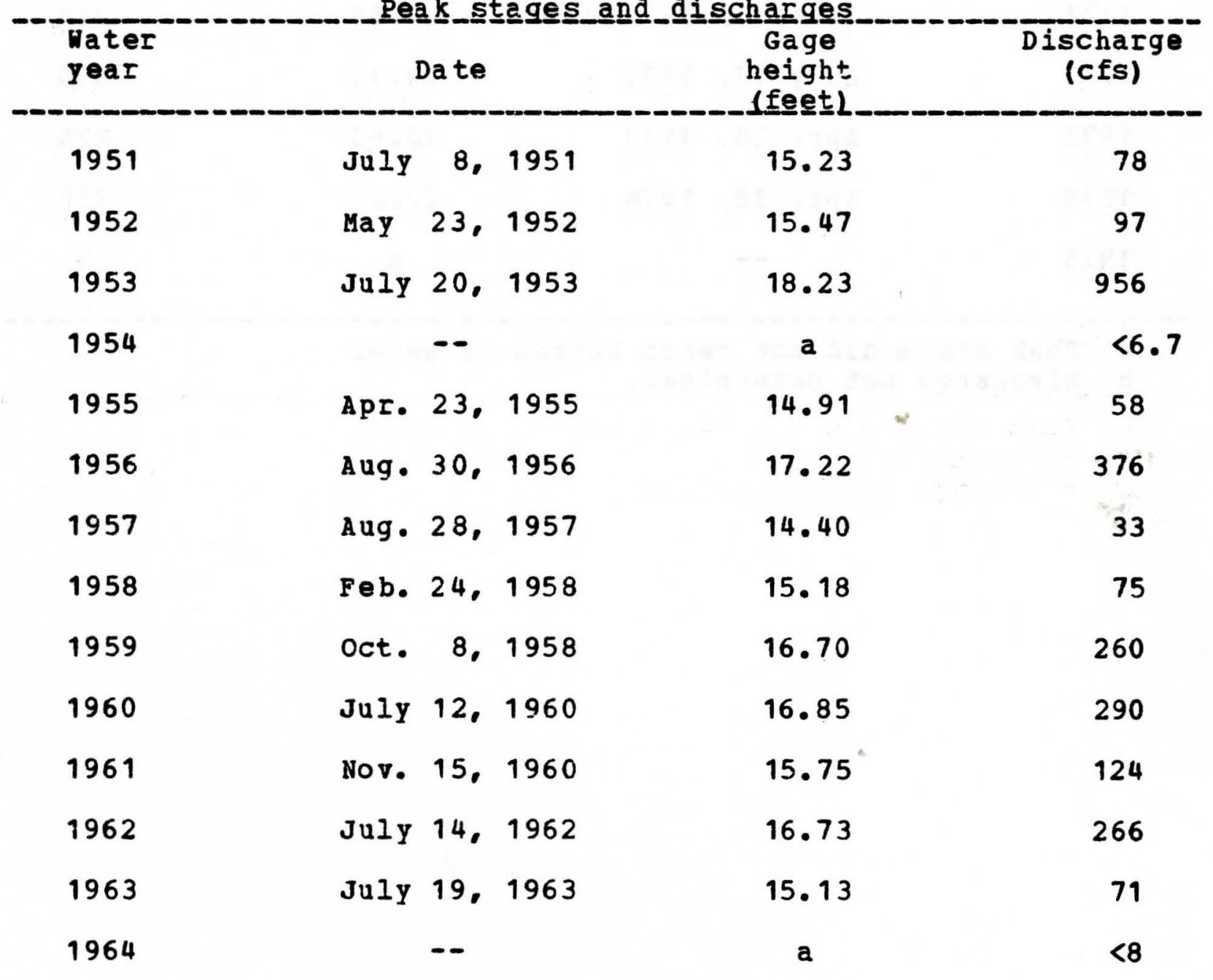

a Peak stage did not reach bottom of gage. 
05-4537.00 Rapid Creek tributary No. 4 near Oasis, Iowa-- (Continued)

Peak﹎.sta ges

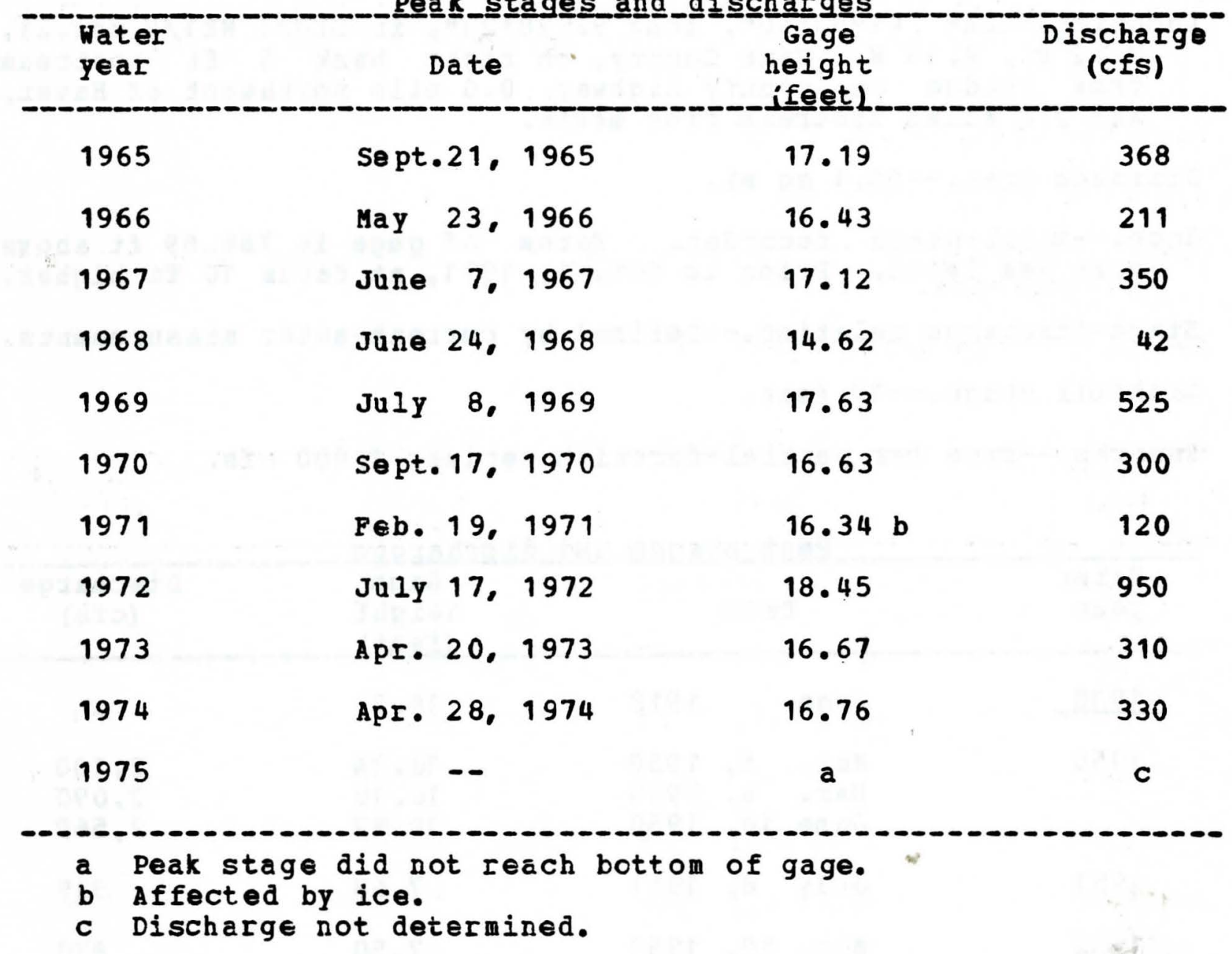


Location,--Lat $41053 \cdot 58 "$, long $920^{\circ} 28 \cdot 27 "$, in SE1/4 NE1/4 sec.21, T.82 N.. R. 14 W.. Tama County, on right bank 5 ft upstream from bridge on county highway, 0.6 mile northeast of Haven, and 2.8 miles upstrea m from mcuth.

Drainage area.--56.1 sq mi.

Gage.--Water-stage recorder. Datum of gage is $788.69 \mathrm{ft}$ above mean sea level. Prior to oct. 1, 1971, at datum $10 \mathrm{ft}$ higher. Stage-discharge relation.--Defined by current-meter measurements. Bankfull stage.--19 feet.

Remarks.--Base for partial-duration series, 1,000 cfs.

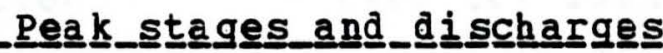

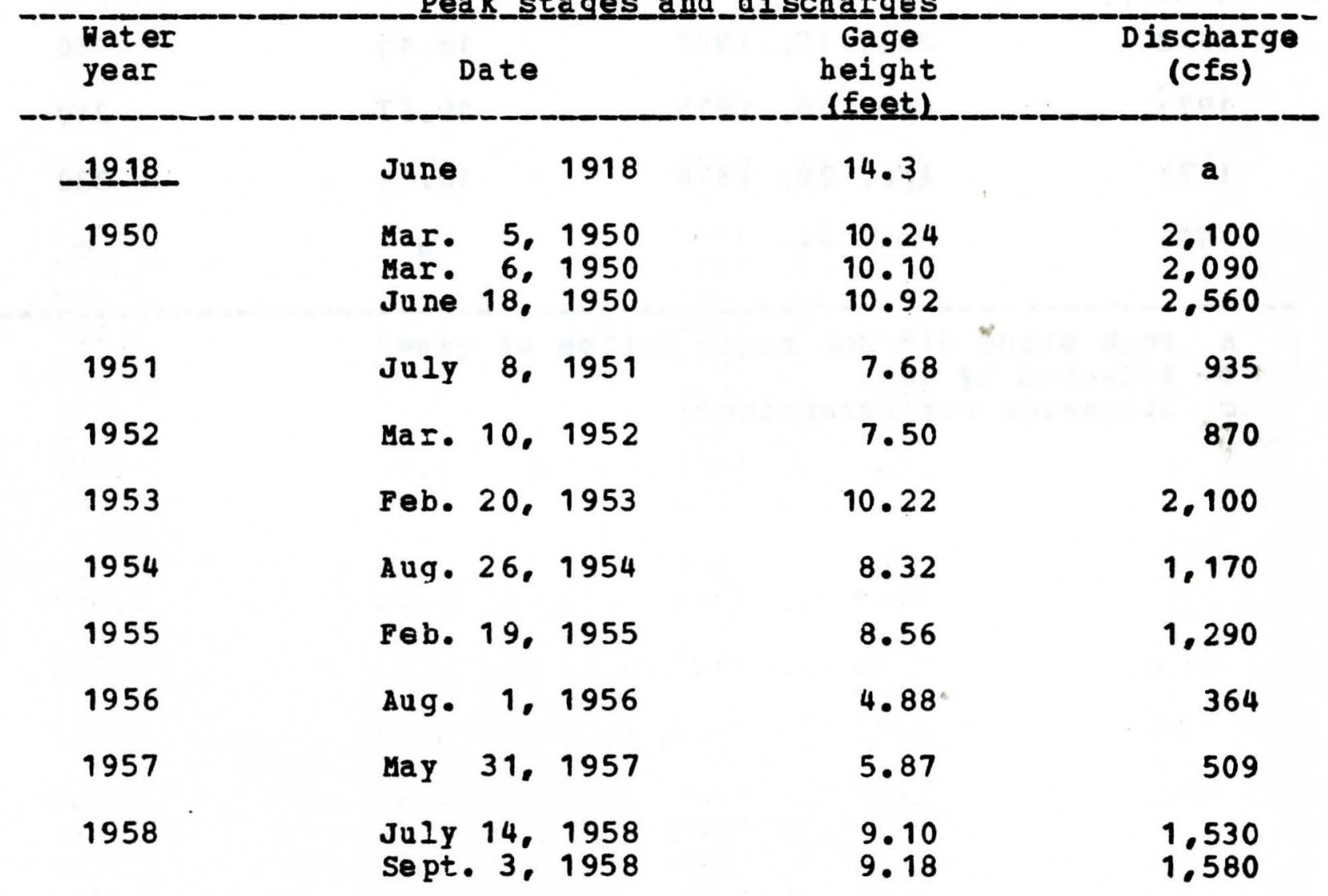

a Discharge not determined. 
05-4519.00 Richland Creek near Haven, Iowa--(Continued)

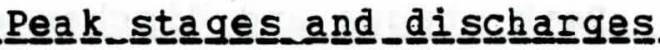

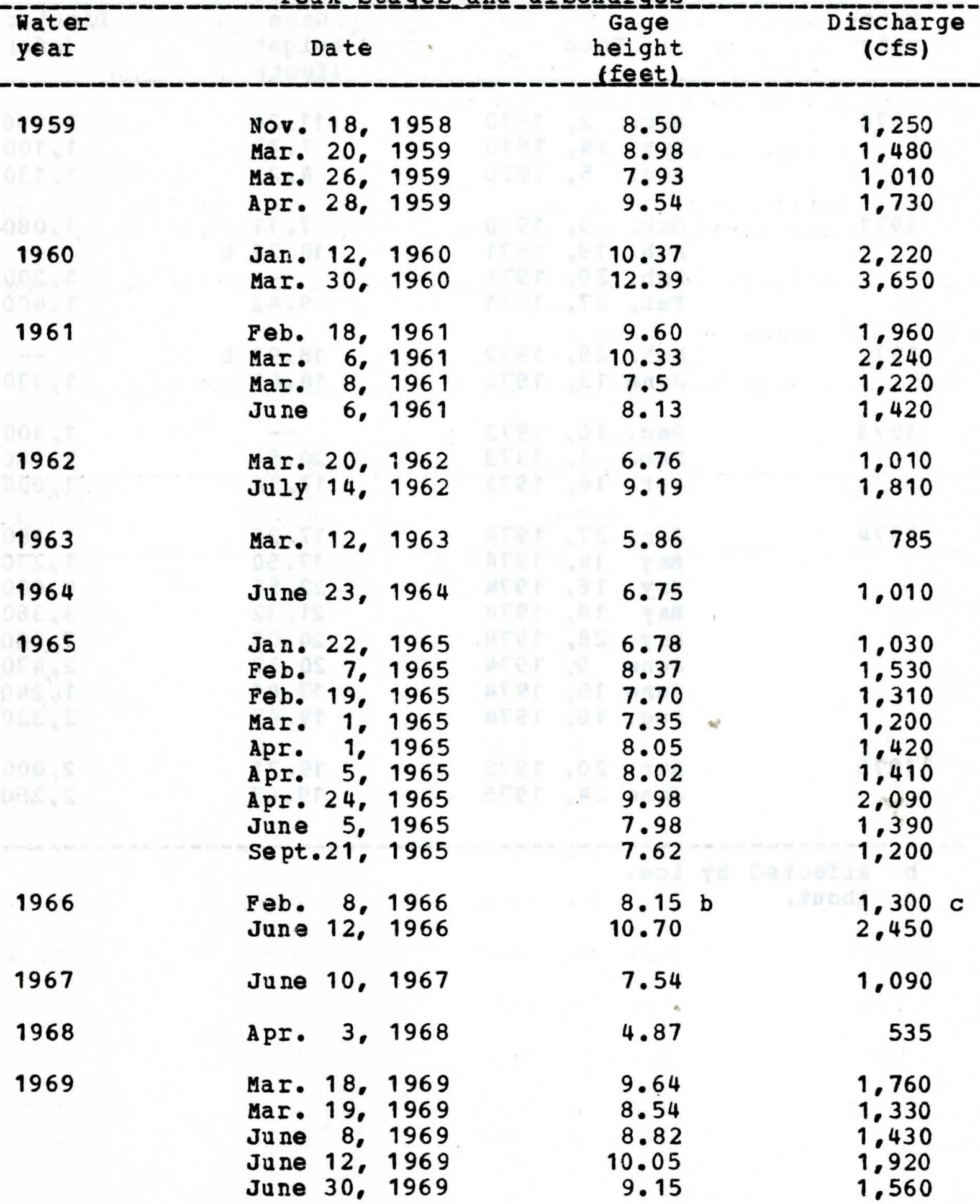

b Affectéd by ice.

c bout. 
05-4519.00 Richland Creek near Haven, Iowa--(Continued)

Peak stages and discharges

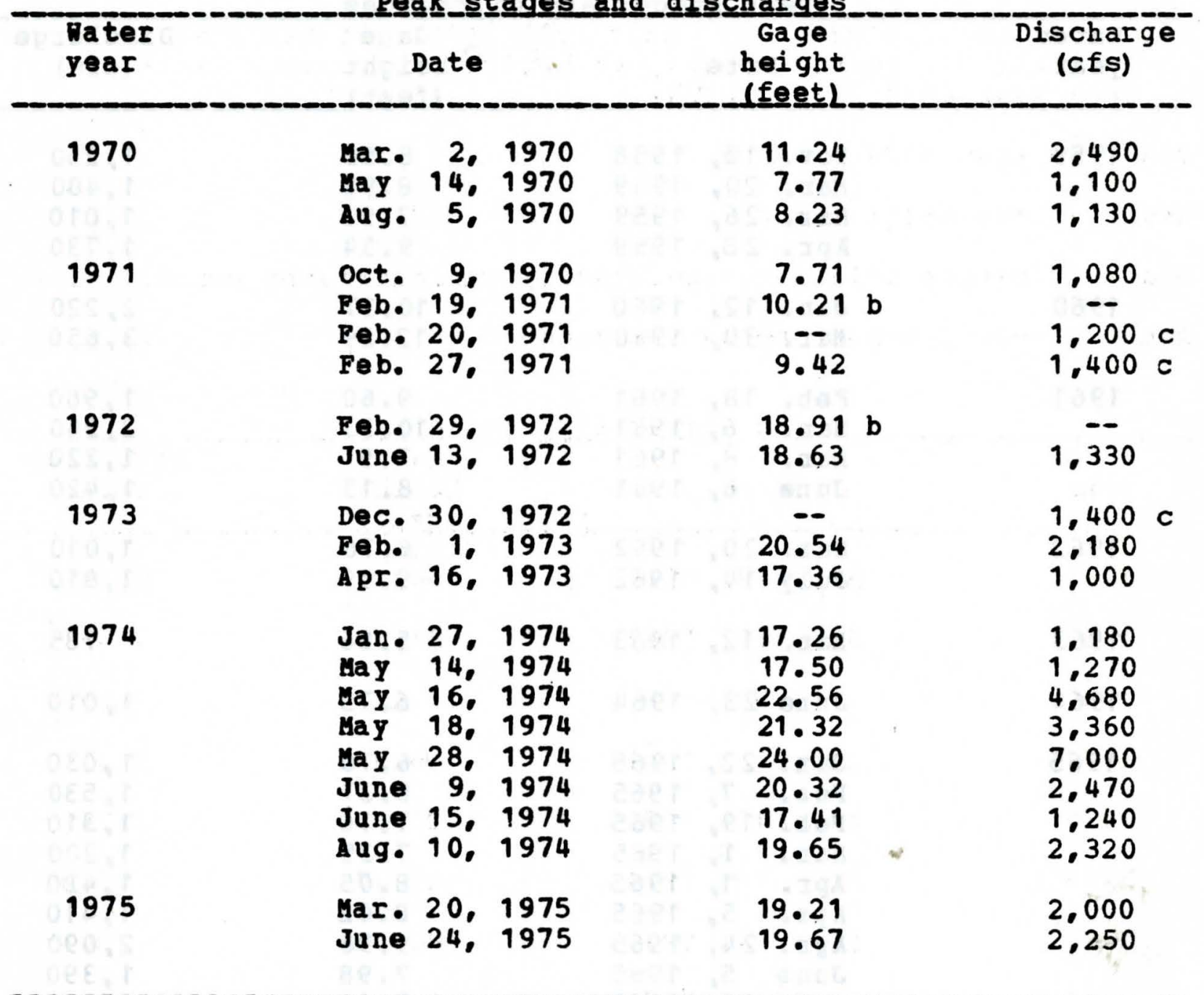

b affected by ice.

c about. 
Location.--Lat 41020112", long 92013020', in NE1/4 sEC.3, T.75 N.. R.12 N.. Keokuk County. at bridge on state Highway 92. near west edge of Sigourney.

Drainage area.--26.3 sq $\mathbf{m i}$.

Gage.--Crest-stage gage.

Stage-discharge relation.--Defined by current-neter measurements. Remarks.--Only annual peaks are shown.

Peak﹎.stages_and_didscharges

\begin{tabular}{|c|c|c|c|c|c|c|}
\hline $\begin{array}{l}\text { Water } \\
y \in a r\end{array}$ & & Date & & $\begin{array}{c}\text { Gage } \\
\text { height } \\
\text { (feet) }\end{array}$ & & $\begin{array}{c}\text { Discharge } \\
\text { (cfs) }\end{array}$ \\
\hline 1966 & May & 17. 1966 & & 90.14 & & 2,100 \\
\hline 1967 & June & 10,1967 & & 87.96 & & 900 \\
\hline 1968 & & -- & & a & & $<106$ \\
\hline 1969 & July & 18,1969 & & 90.38 & & 2,300 \\
\hline 1970 & sept. & . 17. 1970 & & 91.29 & & 3,300 \\
\hline 1971 & May & 19, 1971 & & 88.47 & 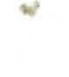 & 660 \\
\hline 1972 & May & 7. 1972 & & 88.91 & & 840 \\
\hline 1973 & May & 27. 1973 & & 89.59 & & 1.600 \\
\hline 1974 & Apr. & 28,1974 & & 90.03 & & 2.000 \\
\hline 1975 & Apr. & 28,1975 & & 88.13 & & 500 \\
\hline
\end{tabular}

a Peak stage did not reach botton of gage. 
Location.--Lat 43026'13", long $96009 \cdot 58^{\prime \prime}$, in NE1/4 SW1/4 sec. 33 , T. 100 N. . R. 45 W.. Iy on county, on right bank at dam on north side of city park in Rock Rapids, 0.3 mile upstraam from Tom Creek, 0.5 mile northeast of junction of U.S. Highways 75 and 9. and at mile 42.8 .

Drainage area.--788 sq mi.

Gage.--Water-stage recorder. Datum of gage is 1,331.55 ft above mean sea level.

Stage-discharge relation.--Defined by current-meter measurements. Flood stage. --6 feet.

Remarks.--Base for partial-duration series, 2,000 cfs.

Peakㅡ_stages and discharges

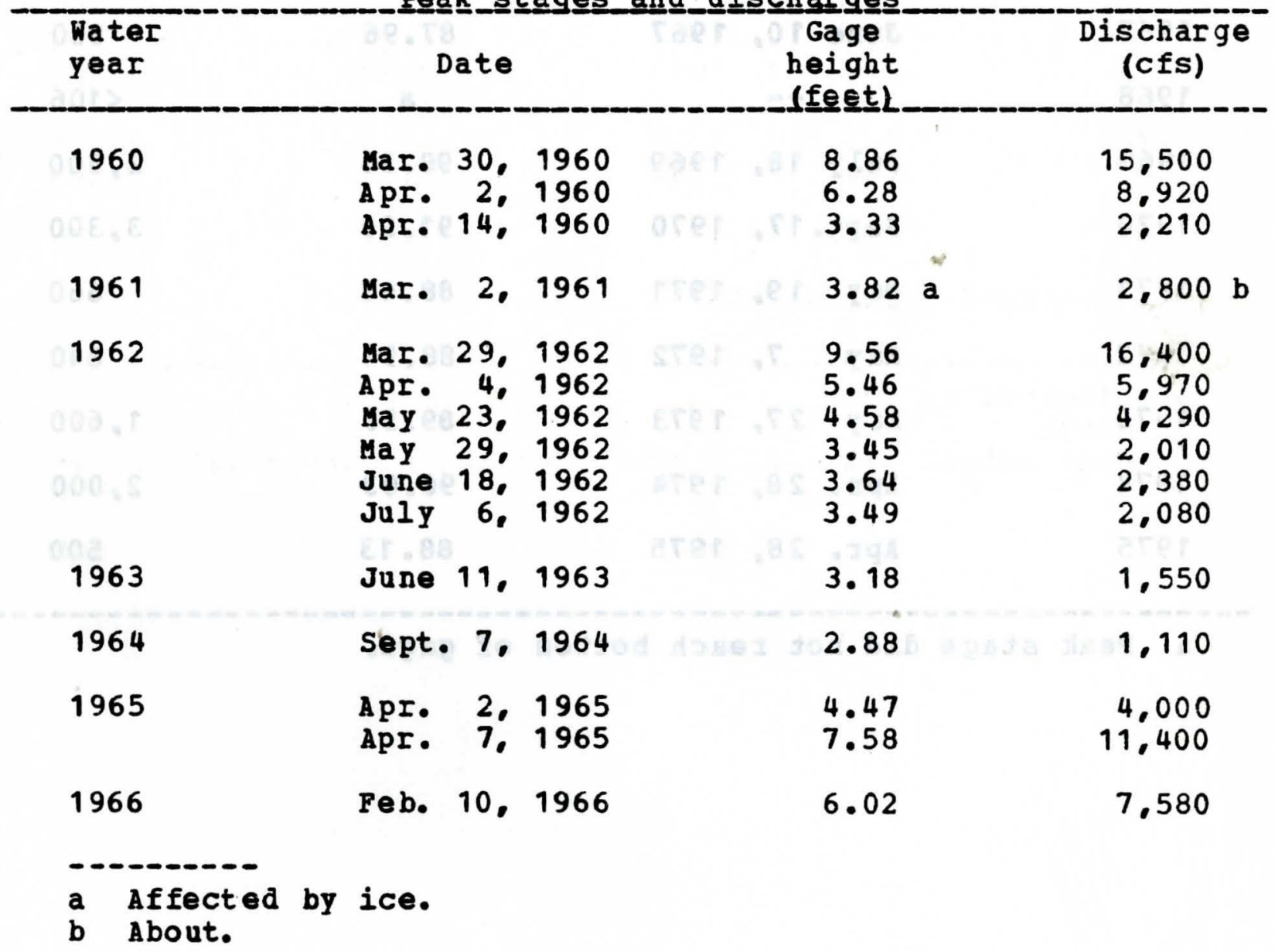


06-4832.70 Rock River at Rock Rapids, Iowa--(Continued)

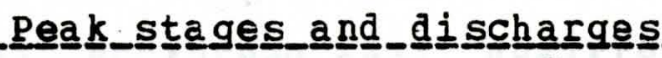

\begin{tabular}{|c|c|c|c|}
\hline $\begin{array}{l}\text { Water } \\
\text { year }\end{array}$ & Date & $\begin{array}{l}\text { Gage } \\
\text { height } \\
\text { (feet) }\end{array}$ & $\begin{array}{l}\text { Discharge } \\
\text { (cfs) }\end{array}$ \\
\hline 1967 & Apr. 3, 1967 & 3.72 & 2,470 \\
\hline 1968 & Sept.25, 1968 & 2.02 & 191 \\
\hline 1969 & 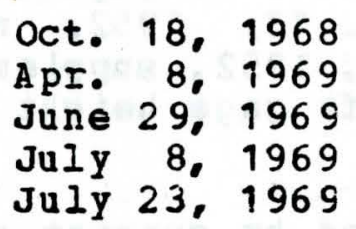 & $\begin{array}{r}3.61 \\
10.23 \\
9.42 \\
3.90 \\
3.90\end{array}$ & $\begin{array}{r}2,230 \\
29,000 \\
18,900 \\
3,090 \\
3,090\end{array}$ \\
\hline 1970 & $\begin{array}{ll}\text { Apr. } & 7,1970 \\
\text { MaY } & 28,1970\end{array}$ & $\begin{array}{l}3.63 \\
4.08\end{array}$ & $\begin{array}{l}2,530 \\
3.450\end{array}$ \\
\hline 1971 & $\begin{array}{l}\text { Feb. 19, } 1971 \\
\text { June 10, } 1971\end{array}$ & $\begin{array}{l}5.30 \\
3.59\end{array}$ & $\begin{array}{l}6.250 \\
2.450\end{array}$ \\
\hline 1972 & $\begin{array}{l}\text { Mar. } 15,1973 \\
\text { May }\end{array}$ & $\begin{array}{l}5.55 a \\
3.88\end{array}$ & $\begin{array}{l}4,200 \mathrm{~b} \\
3.030\end{array}$ \\
\hline 1973 & $\begin{array}{l}\text { Mar. 4, } 1973 \\
\text { Mar. 12, } 1973\end{array}$ & 3.53 & $\begin{array}{l}4,000 \\
2.300\end{array}$ \\
\hline $\begin{array}{l}1974 \\
\text { Discon }\end{array}$ & $\begin{array}{l}\text { Mar. } 5,1974 \\
\text { ptember } 1974\end{array}$ & 2.57 & 830 \\
\hline
\end{tabular}

a Affected by ice.

b About.

c Gage height unknown, occurred during snowmelt and ice breakup. 
Location.--Iat $43011 \cdot 58$ ", long $960200^{\circ} 22^{\prime \prime}$, in NW1/4 NE1/4 sec.25. T. 97 N.. R. 47 H.. Sioux County, on downstream side of bridge on U.S. Highway 18, 1.8 miles west of Rock Valley, and at mile 15.9.

Drainage area.--1,600 sq mi.

Gage.--Water-stage recorder. Datum of gage is 1.211.81 ft above mean sea level. Prior to Aug. 13, 1952, nonrecording gage. June 4, 1949, to Aug. 12, 1952, supplementary water-stage recorder operating above 6.2 ft gage height at same site and datum.

Stage-discharge relation.--Defined by current-meter measurements. Flood stage.--11 feet.

Remarks.--Base for partial-duration series, 3,000 cfs.

Peak_stag ges_and_ di

\begin{tabular}{|c|c|c|c|c|}
\hline $\begin{array}{l}\text { Water } \\
\text { year }\end{array}$ & Date & & $\begin{array}{l}\text { Gage } \\
\text { height } \\
\text { (feet) }\end{array}$ & $\begin{array}{c}\text { Dis charge } \\
\text { (cfs) }\end{array}$ \\
\hline 1897 & - & & 17.0 a & b \\
\hline 1948 & July 23. & 1948 & 10.9 & $4.090 \mathrm{c}$ \\
\hline 1949 & $\begin{array}{lr}\text { Mar. } & 6, \\
\text { Mar. } 29, \\
\text { Apr. } 8 .\end{array}$ & $\begin{array}{l}1949 \\
1949 \\
1949\end{array}$ & $\begin{array}{l}12.30 \\
11.75 \\
12.10\end{array}$ & $\begin{array}{l}5.790 \\
5.160 \\
5.530\end{array}$ \\
\hline 1950 & $\begin{array}{l}\text { Mar. } 5, \\
\text { Mar. } 25, \\
\text { Mar. } 28,\end{array}$ & $\begin{array}{l}1950 \\
1950 \\
1950\end{array}$ & $\begin{array}{l}11.60 \\
11.48 \\
11.33\end{array}$ & $\begin{array}{l}4.560 \\
4.320\end{array}$ \\
\hline 1951 & $\begin{array}{l}\text { Mar. } 30, \\
\text { Apr. } 5, \\
\text { June } 30\end{array}$ & $\begin{array}{l}1951 \\
1951 \\
1951\end{array}$ & $\begin{array}{l}11.37 \\
14.77 \\
11.08\end{array}$ & $\begin{array}{r}5,170 \\
14.300 \\
4,740\end{array}$ \\
\hline 1952 & $\begin{array}{l}\text { Mar. } 20, \\
\text { Mar. } 31 .\end{array}$ & $\begin{array}{l}1952 \\
1952\end{array}$ & $\begin{array}{l}12 \cdot 55 \\
15 \cdot 30\end{array}$ & $\begin{array}{r}6.100 \\
17.300\end{array}$ \\
\hline
\end{tabular}

a From information by State Highway Commission.

b Discharge not determined.

c Maximum for period June through september.

d Afected by ice. 
06-4835.00 Rock River near Rock Valley. Iowa--(Continued)

Peak

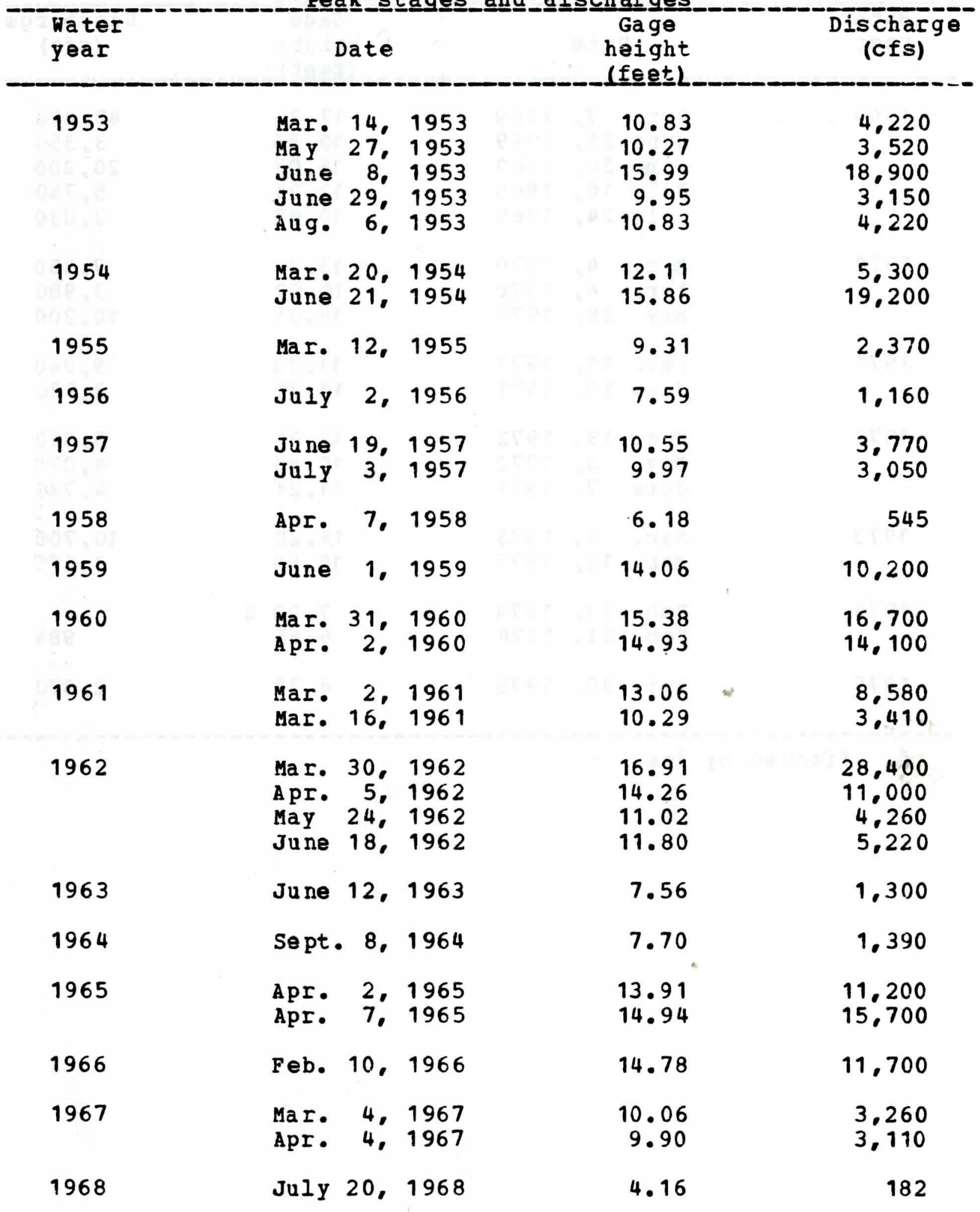


06-4835.00 Rock River near Rock Valley, Iowa--(Continued)

Peak_stagges_and_di

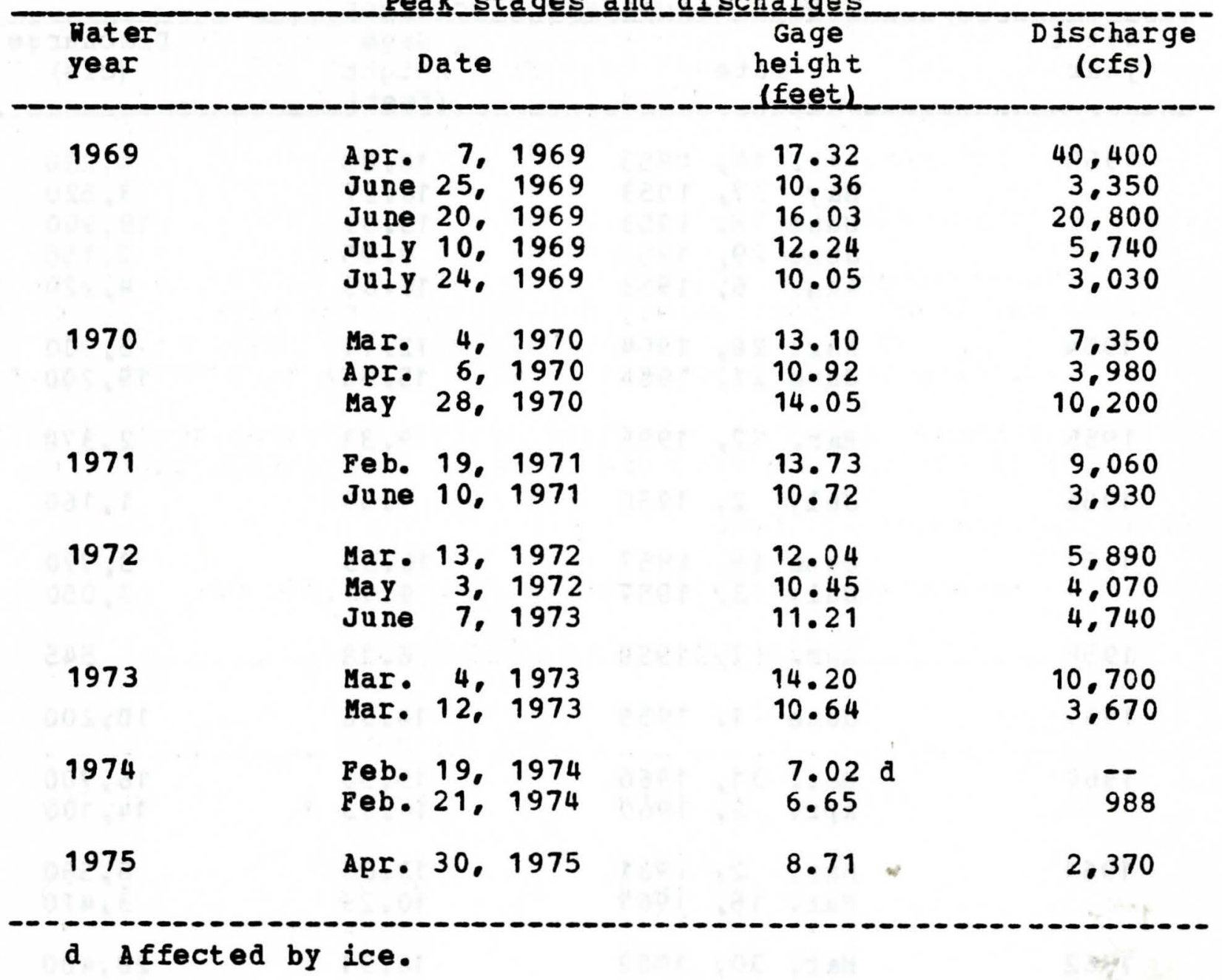




\section{5-4520.00 Salt Creek near Elberon, Iowa}

Location.--Lat 41057'51", long 92018147", in NW1/4 NW1/4 sec. 36 . T. 83 N., R.13 W., Tama County, near center of span on downstream side of bridge on U.S. Highway $30,2.0$ miles upstream from Hog Run, 3.0 miles south of Elberon, and 9.0 miles upstream from mouth.

Drainage area.--201 sq $\mathrm{mi}$.

Gage.--Water-stage recorder. Datum of gage is $781.58 \mathrm{ft}$ above mean sea level (I owa Highway Commission bench mark). Prior to oct. 15, 1945, and June 14, 1947, to Feb. 10, 1949, nonrecording gage on upstream side of bridge at present datum.

Stage-discharge relation.--Defined by current-meter measurements below $17,000 \mathrm{cfs}$ and extended above by logarithmic plctting.

Bankfull stage. --9.5 feet.

Remarks.--Basic for partial-duration series, 1,500 cfs.

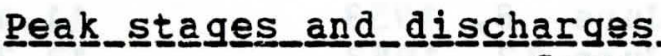

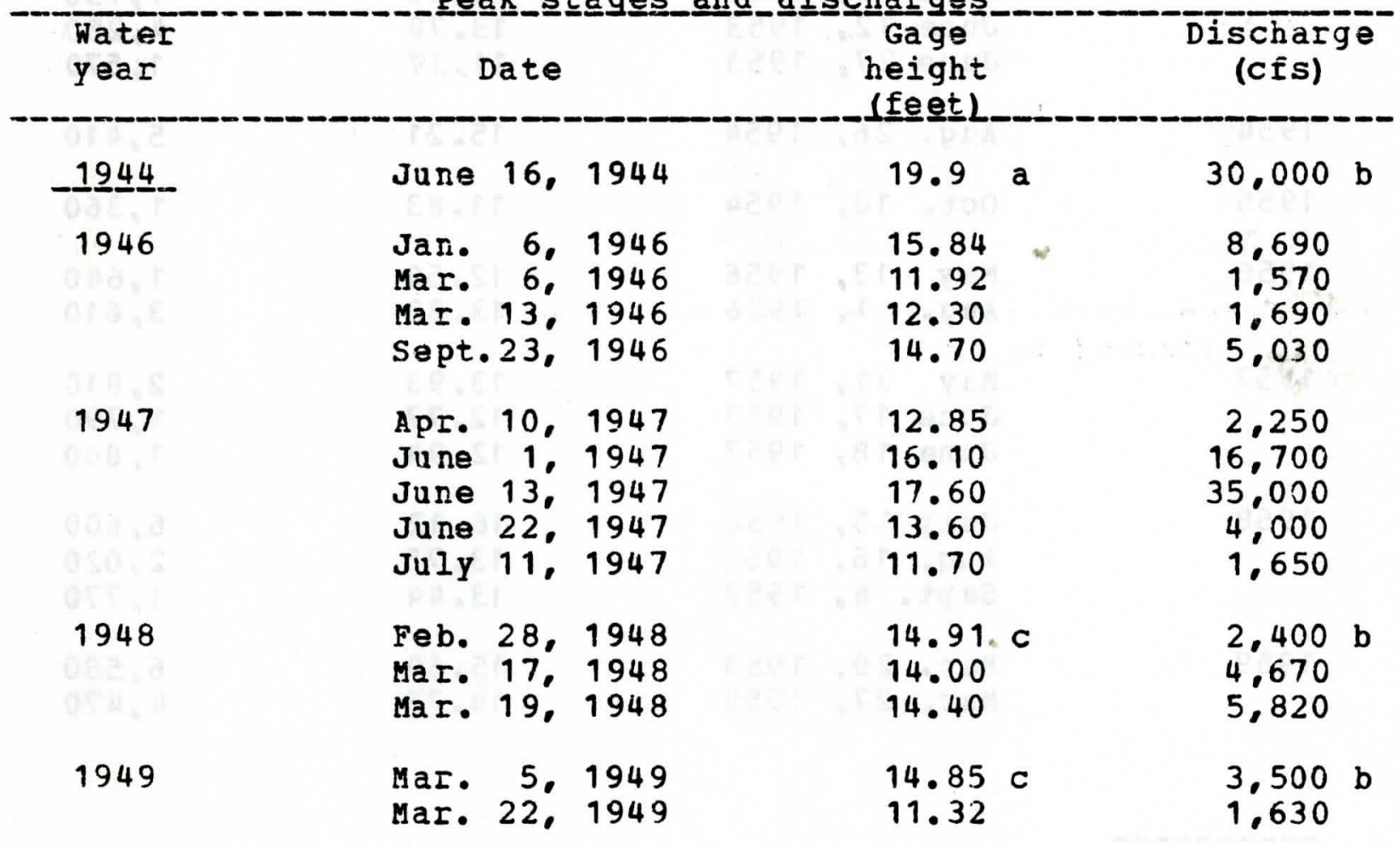

a From floodmark at downstream side of bridge.

b About.

c Affected by ice. 
05-4520.00 Salt Creek near Elberon, Iowa-- (Continued)

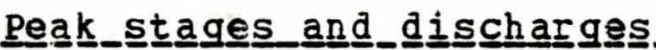

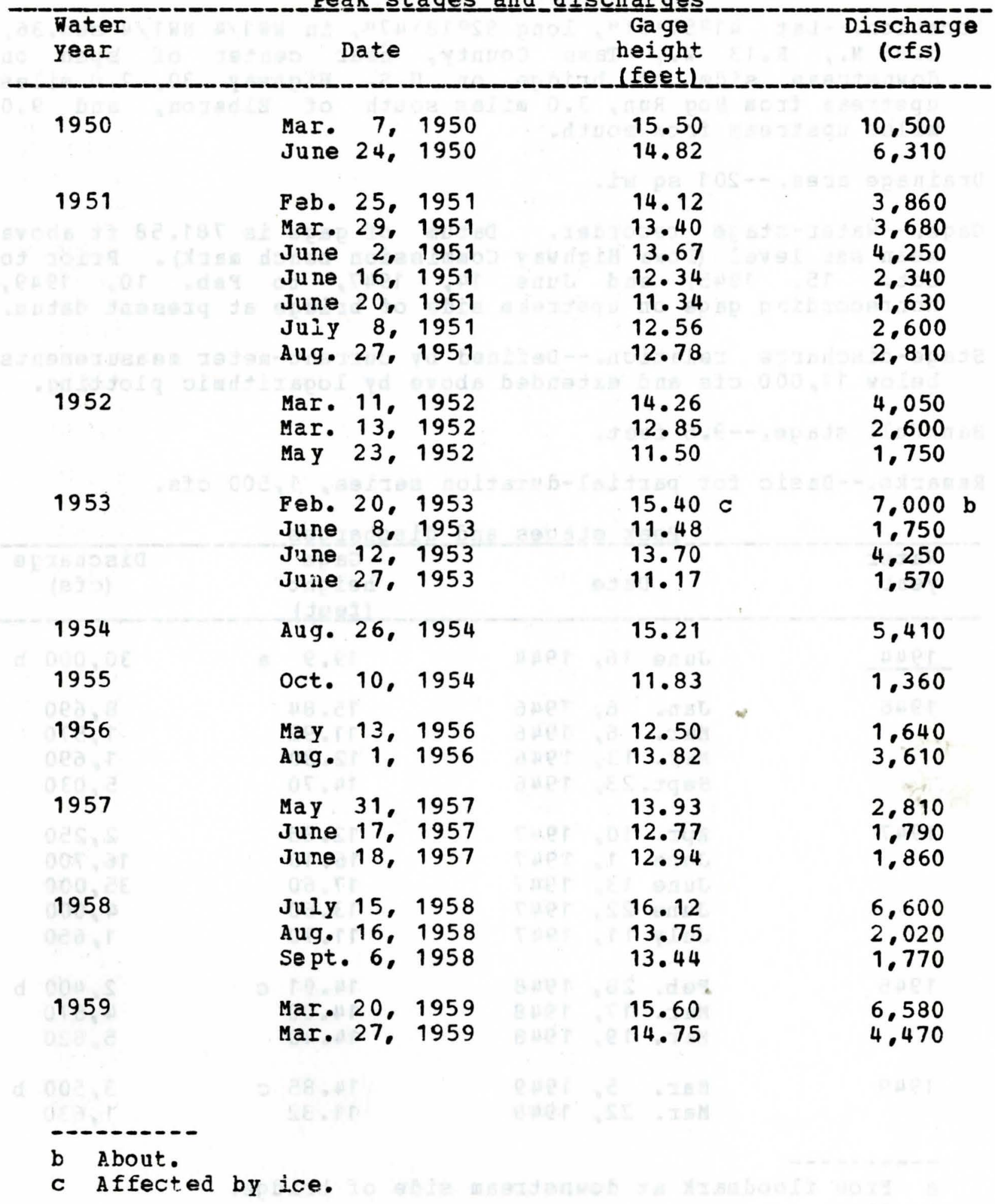


05-4520.00 Salt Creek near Elberon. Iowa-- (Continued)

Peak stages and discharges

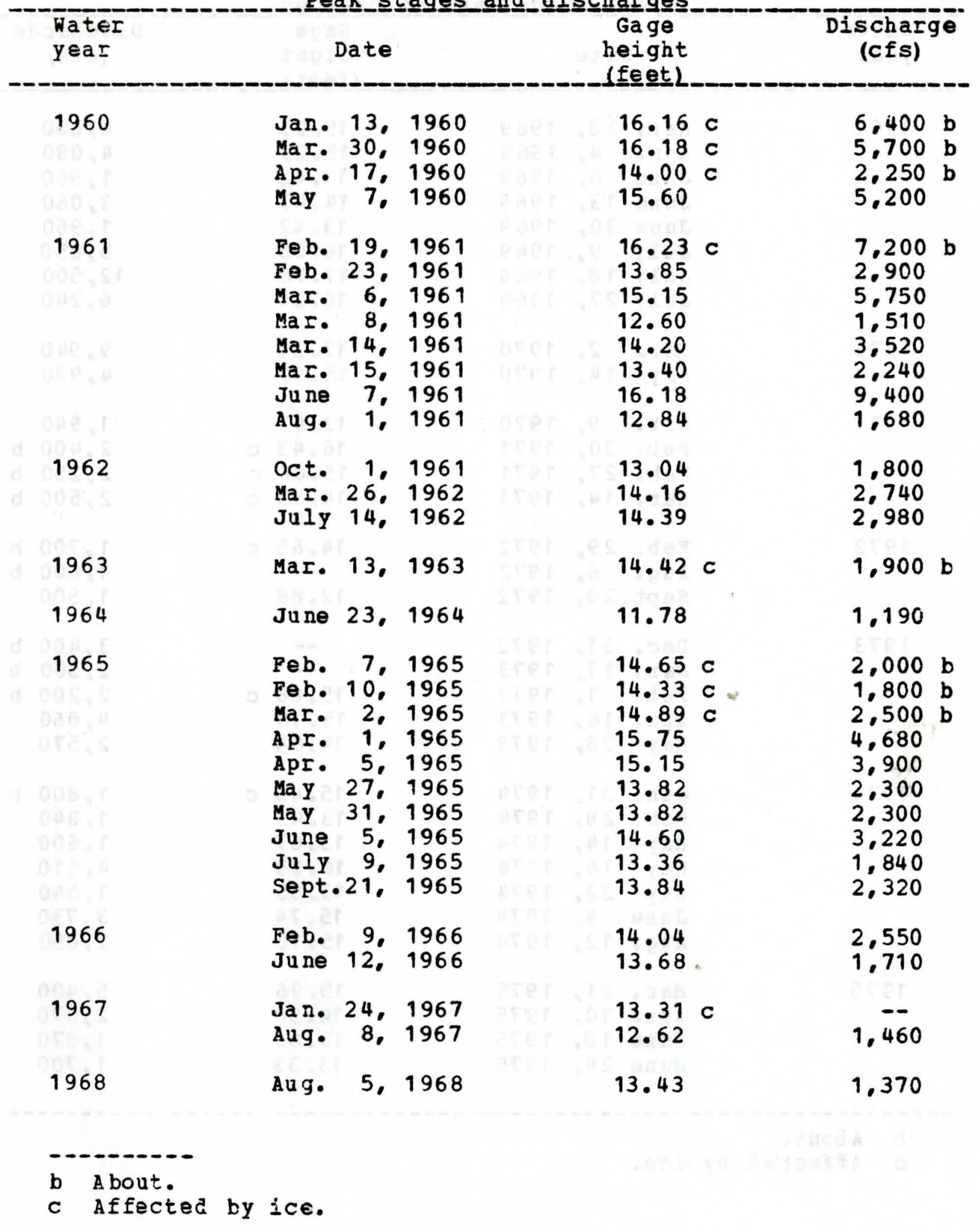


05-4520.00 Salt Creek near Elberon, Iowa-- (Continued)

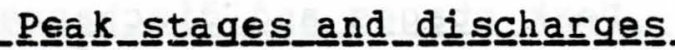

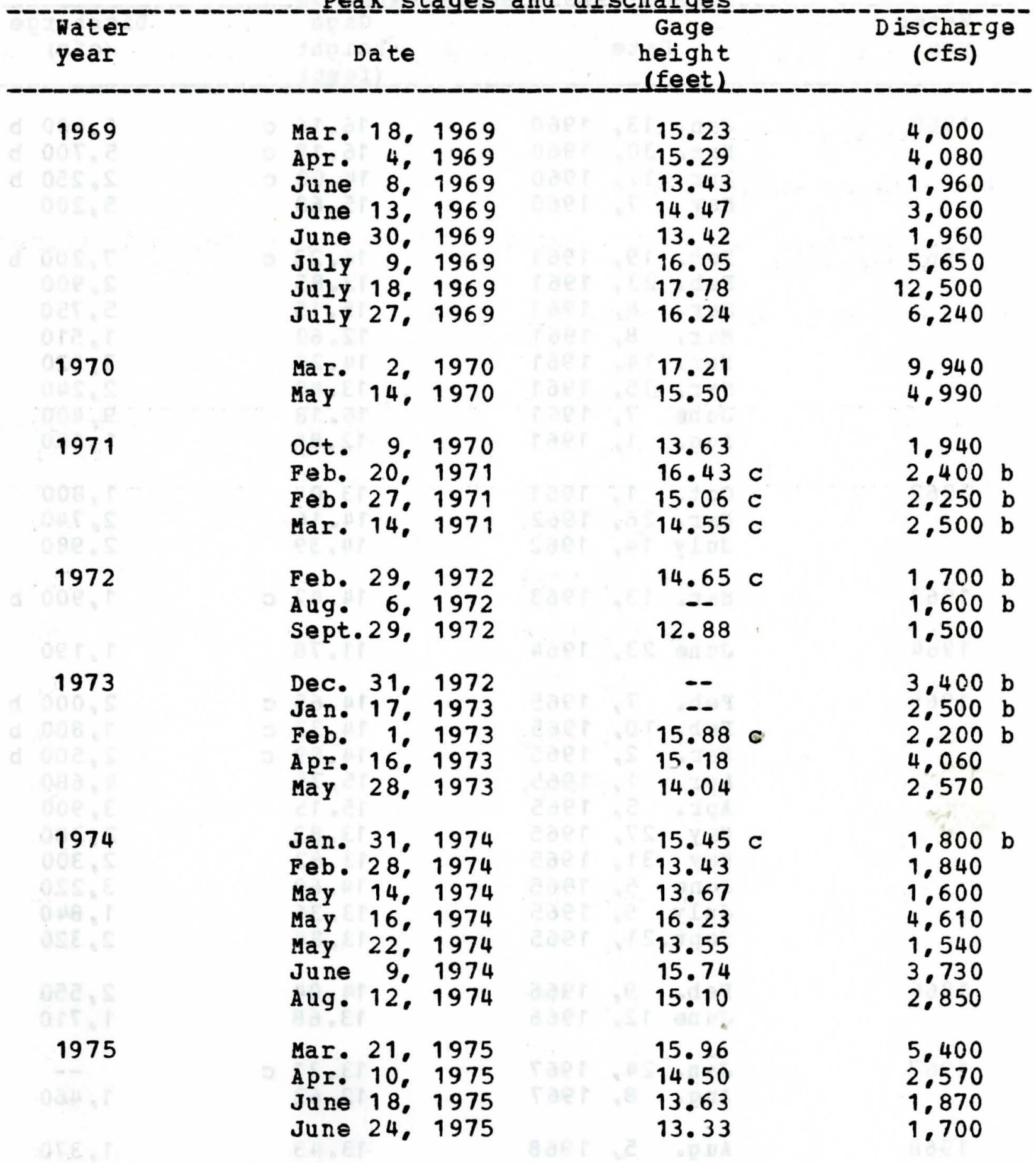

b A bout.

c Affecteả by ice. 


\section{6-4834.20 Schutte Creek near Sibley, Iowa}

Location.--Iat 43028', long 95047', near NW corner sec.23, T.100 N.. R.42 W., Osceola County, at culvert, 6 miles northwest of Sibley.

Drainage area.-- $-1.43 \mathrm{sq}$ mi.

Gage.--Crest-stage gage.

Stage-discharge relation.--Defined by current-meter and indirect measurem ents.

Remarks.--only annual peaks are shown.

Peakk_staqes_and__di

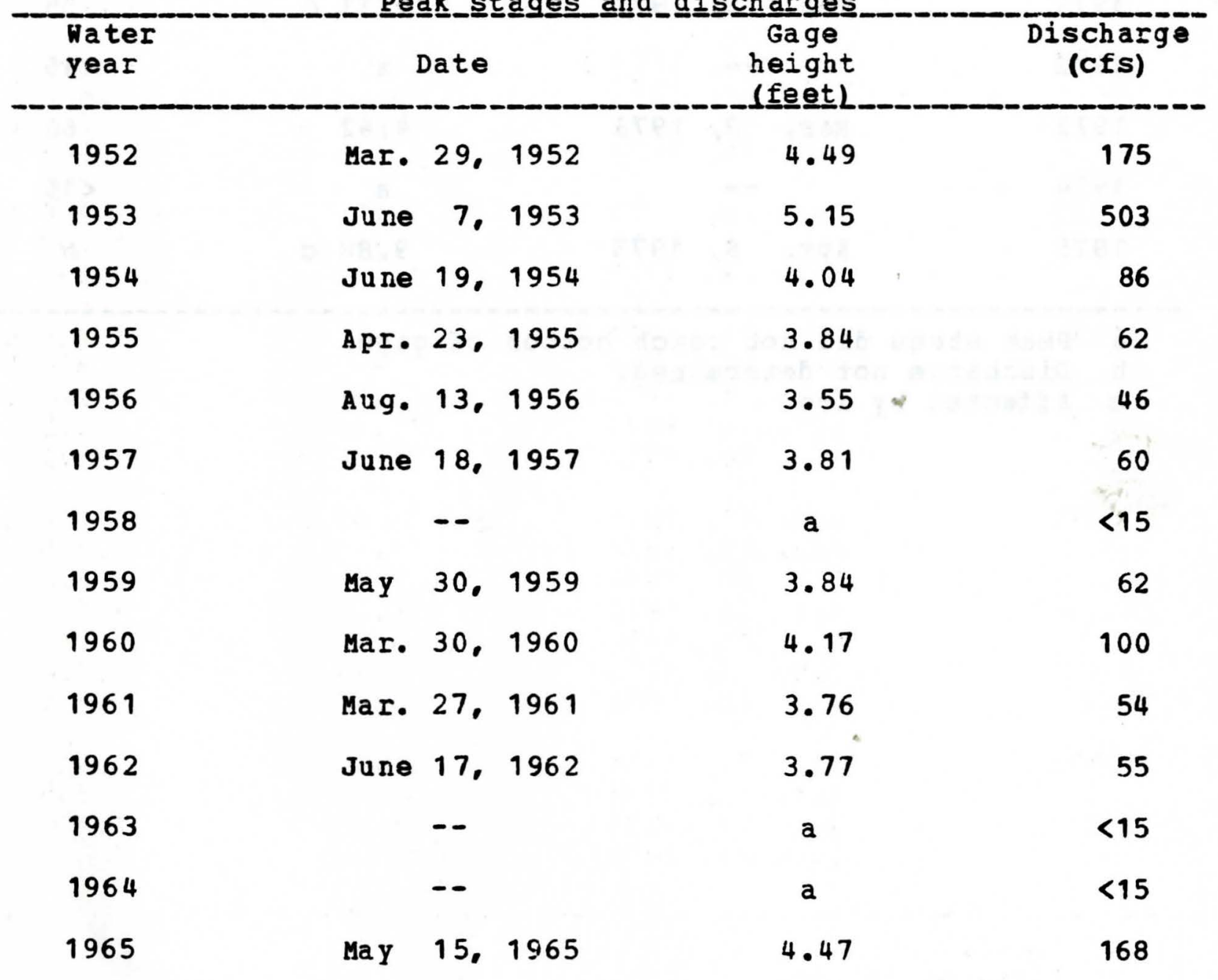

a Peak stage did not reach bottom of gage. 
06-4834.20 Schutte Creek near Sibley. Iowa--(Continuad)

Peak_s tag ges and_discharges

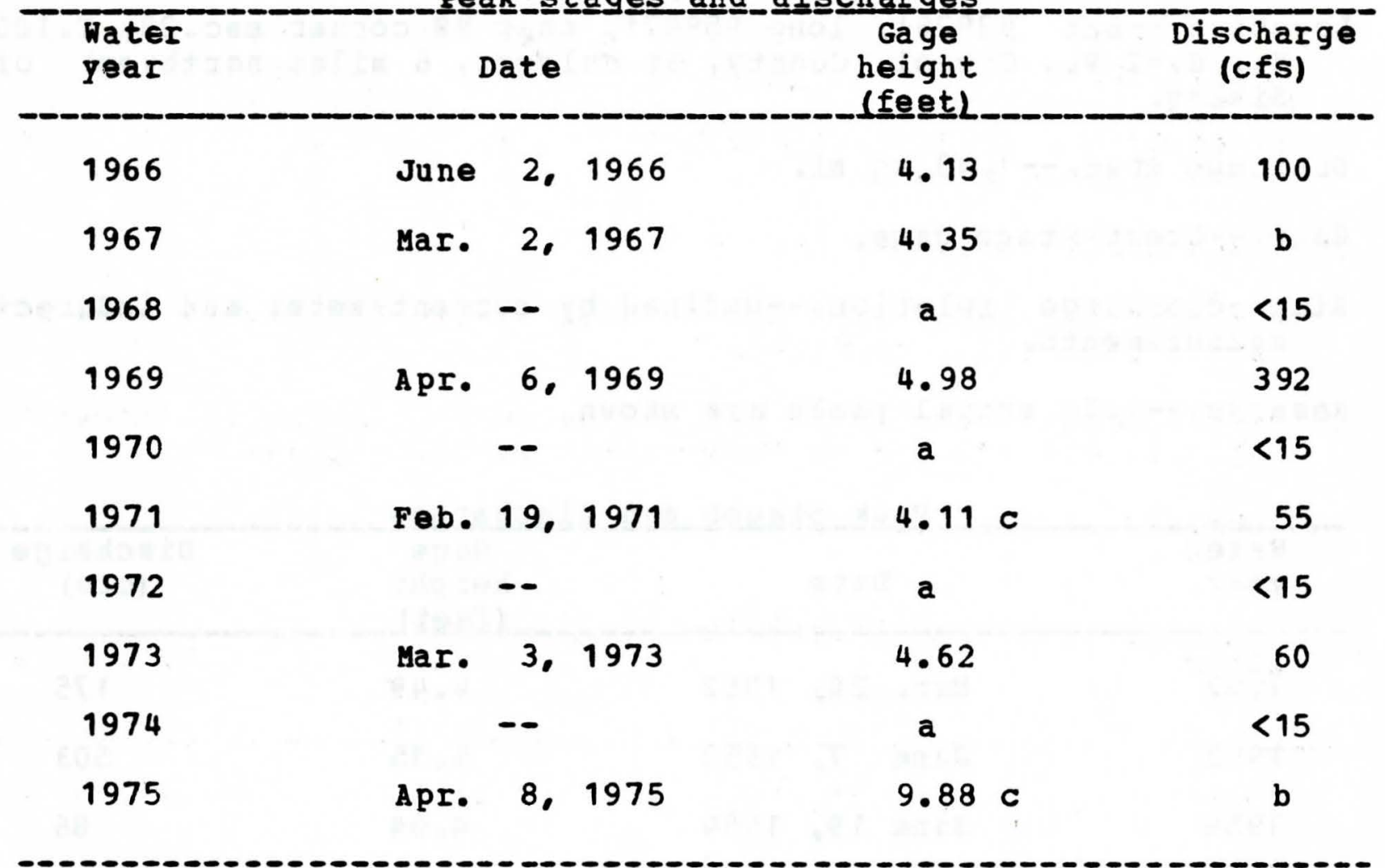

a Peak stage did not reach bottom of gage.

b Discharge not determined.

c Affected by ice. 


\section{5-4615.00 Shell Rock River near Clarksville. Iowa (Discontinued September 1934)}

Location.--Lat 42047'25". long $92041 \cdot 15^{\prime \prime}$, on line between sec. 12 and 13. T.92 N., R. 16 W.. Butler County, at highway bridge 1.25 miles northwest of clarksville, 5.4 miles downstream from Flood Creek, 20.9 miles above mouth, and at mile 226.8 above mouth of Iowa River.

Drainage area.--1,626 sq mi.

Gage.--Nonrecording. Altitude of gage is 916 feet above mean sea level. from river profiles.

Stage-discharge relation.--Defined by current-meter measurements below 10,000 cfs and by logarithmic plotting above.

Remarks.--Base for partial-duration series, 3,500 cfs.

Pea $\underline{\text { k }}$ st

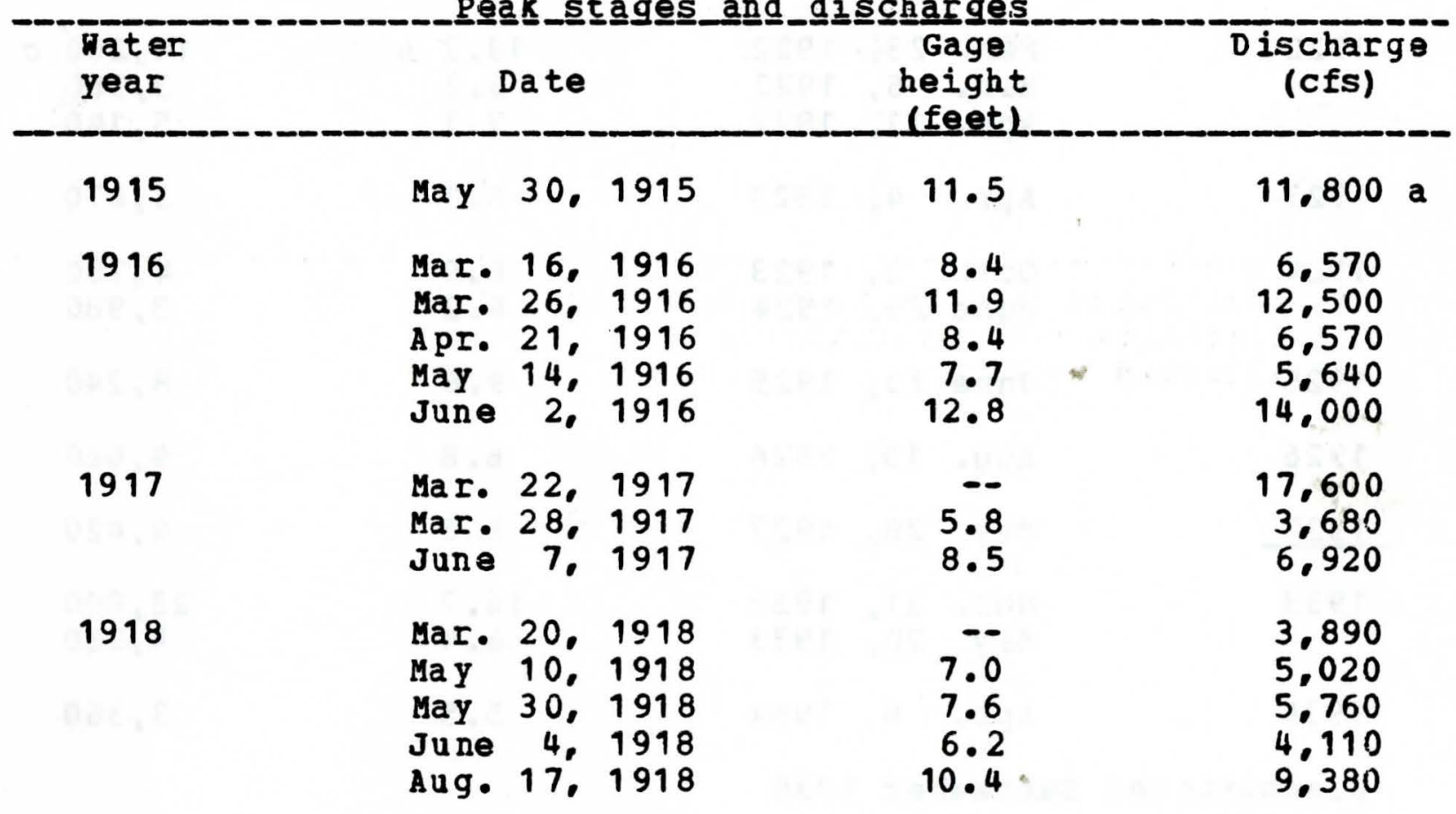

a Maximum for period May to September 1915. 
05-4615.00 Shell Rock River near Clarksville, Iowa--(Continued)

Peak stages and di scharges

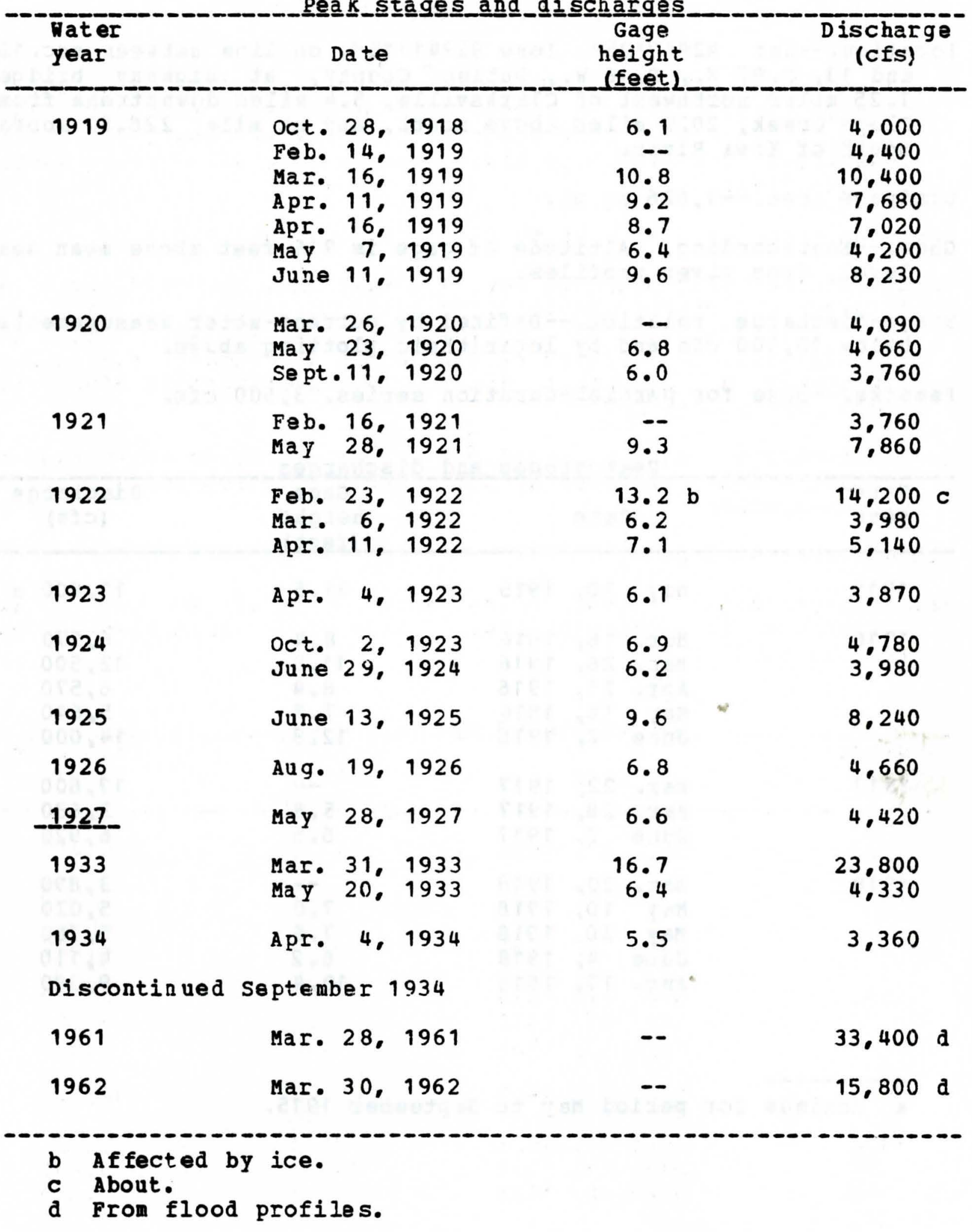




\section{5-4605.00 Shell Rock River at Marble Rock. Iowa \\ (Published as "at Greene", 1933-42) \\ (Discontinued september 1953)}

Location.--Lat 42058'00", long $92052 \cdot 15^{\prime \prime}$, in SE1/4 SE1/4 sec.8, T. 94 N., R. 17 W.. Floyd County, on left bank 20 ft above dam at Marble Rock, 1.1 mile upstream from Ackley Creek, 9.5 miles downstream from Winnebago River, and at mile 247.1 abcve mouth of Iowa River.

Drainage area.--1,318 sq $\mathrm{mi}$ at site used 1933-42:1,357 sq mi.

Gage.--Nonrecording prior to oct. 1, 1942; Mar. 13, 1945, to Jung 5. 1946; and since June 20, 1950. Recording Oct. 1, 1942, to Mar. 12, 1945, and June 6, 1946, to June 19, 1950. Prior to oct. 1, 1942, in tailrace of fowerplant at Greene, 5.7 miles downstream at different datum. Datum of gage is $960.39 \mathrm{ft}$ above mean sea level.

Stage-discharge relation.--Defined by current-meter measurements at Marble Rock: extended by logarithmic plotting above 23,000 cfs at Greene.

Flood stage. -4 feet.

Remarks.--Records at two sites not corrected for 29 sq mi difference in drainage area. Base for partial-duration series, $4,000 \mathrm{cfs}$.

Peak﹎stages and di

\begin{tabular}{|c|c|c|c|c|}
\hline $\begin{array}{l}\text { Water } \\
\text { year }\end{array}$ & Date & & $\begin{array}{l}\text { Gage } \\
\text { height } \\
\text { (feet). }\end{array}$ & $\begin{array}{c}\text { Discharge } \\
\text { (Cfs) }\end{array}$ \\
\hline 1933 & MaI. 27, & 1933 & 107.6 & 36.400 \\
\hline 1934 & Apr. 4. & 1934 & 94.2 & 3.760 \\
\hline 1935 & Mar. & 1935 & 97.5 & 6,910 \\
\hline 1936 & $\begin{array}{l}\text { MaI. } 12 . \\
\text { MaI. } 17 . \\
\text { Sept. } 15^{\circ}\end{array}$ & $\begin{array}{l}1936 \\
1936 \\
1936\end{array}$ & $\begin{array}{l}97.1 \\
97.2 \\
96.0\end{array}$ & $\begin{array}{l}6.470 \\
6.580 \\
5.340\end{array}$ \\
\hline 1937 & MaI. & 1937 & 105.9 & 10,000 \\
\hline 1938 & $\begin{array}{l}\text { June } 1 . \\
\text { June } 25, \\
\text { Sept. } 15 .\end{array}$ & $\begin{array}{l}1938 \\
1938 \\
1938\end{array}$ & $\begin{array}{r}95.2 \\
101.7 \\
97.7\end{array}$ & $\begin{array}{r}4.590 \\
13.400 \\
7.130\end{array}$ \\
\hline
\end{tabular}


05-4605.00 Shell Rock River at Marble Rock, Iowa--(Continued)

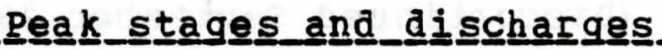

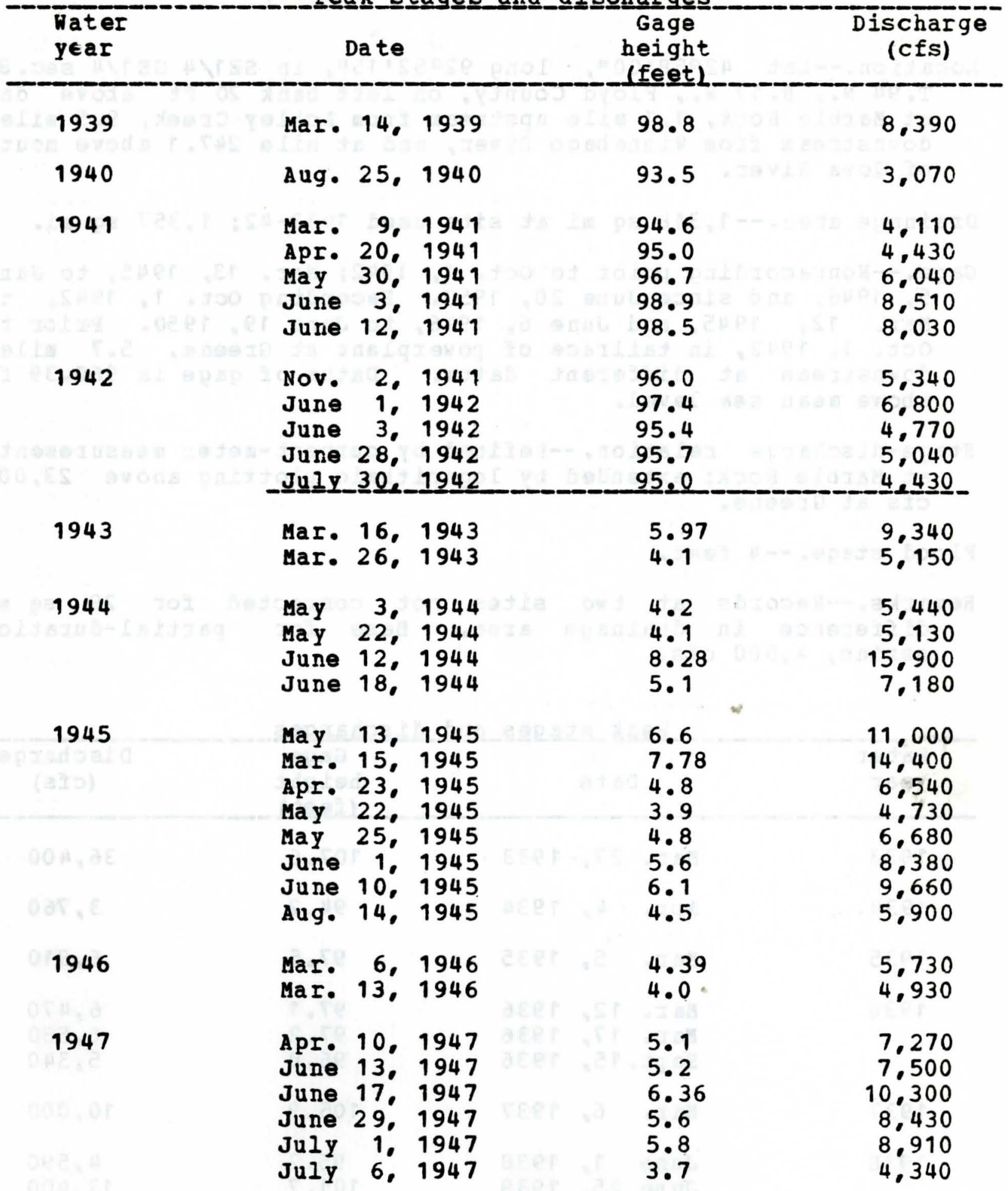


05-4605.00 Shell Rock River at Marble Rock, Iowa-- (Continued)

Peak_stages and dischharges

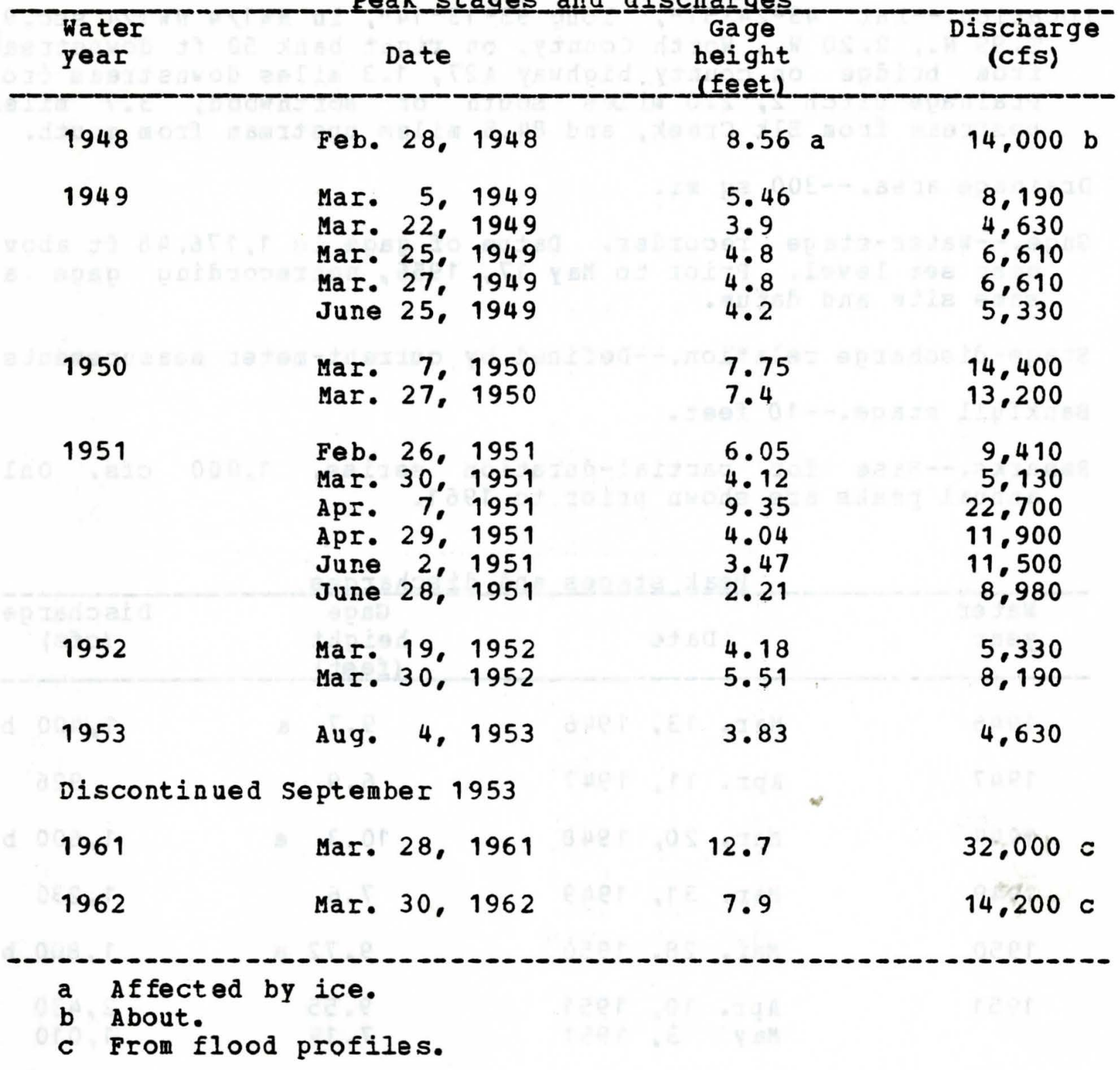


Location.--Lat 43024'51", long 93013'14", in NW1/4 Nw1/4 sec.9, T. 99 N., R. 20 W.. Worth County. on right bank 50 ft downstream from bridge on county highway A27, 1.3 miles downstream from Drainage ditch 2, 2.0 miles south of Northwood, 3.7 miles upstream from Elk Creek, and 84.5 miles upstream from mouth.

Drainage area. $--300 \mathrm{sq} \mathrm{mi}$

Gage.--Water-stage recorder. Datum of gage is $1,176.48 \mathrm{ft}$ abova mean sea level. Prior to May 17, 1956, nonrecording gage at same site and datum.

Stage-discharge relation.--Defined by current-meter measurements. Bankfull stage.--10 feet.

Remarks.--Base for partial-duration series, 1,000 cfs. only annual peaks are shown prior to 1961.

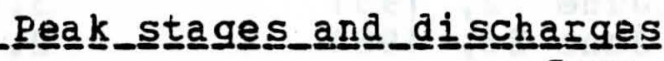

Water

year

Date
Gage height (feet)
Discharge

(cfs)
1946

1947

1948

1949

1950

1951

1952

1953

1954

1955
MaI. 13, 1946

Apr. 11, 1947

Mar. 20, 1948

MaI. 31, 1949

MaI. 28, 1950

Apr. 10, 1951

May 3, 1951

ApI. 2, 1952

Aug. 4, 1953

June 22, 1954

June 4, 1955
$9.7 \quad a$

6.9

$10.3 a$

7.6

$9.72 \mathrm{a}$

9.55

7.19

8.26

7.54

7.96

6.00
$1.400 \mathrm{~b}$

926

$1,600 \mathrm{~b}$

1,230

$1.800 \mathrm{~b}$

2,430

1.010

1.470

1.060

1,360

502

a Affected by ice.

b about. 
05-4590.00 Shell Rock River near Northwood, Iowa-- (Continued)

Pea $\underline{k}$ stanges_and di

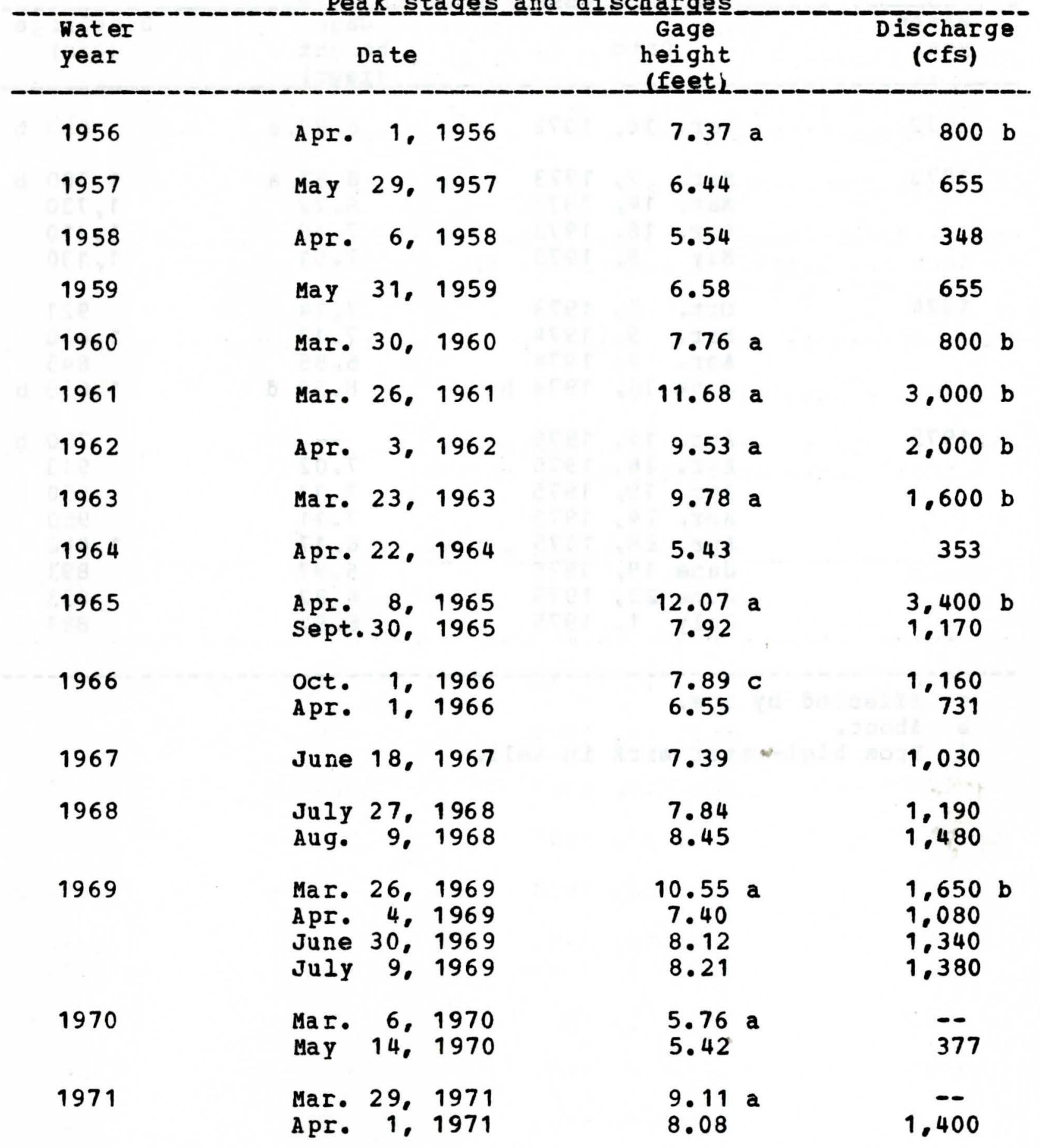

\footnotetext{
a Affected by ice.

b A bout.

c Stage falling.
} 
05-4590.00 Shell Rock River near Northwood, Iowa-- (Continued)

Peak _s stages_and

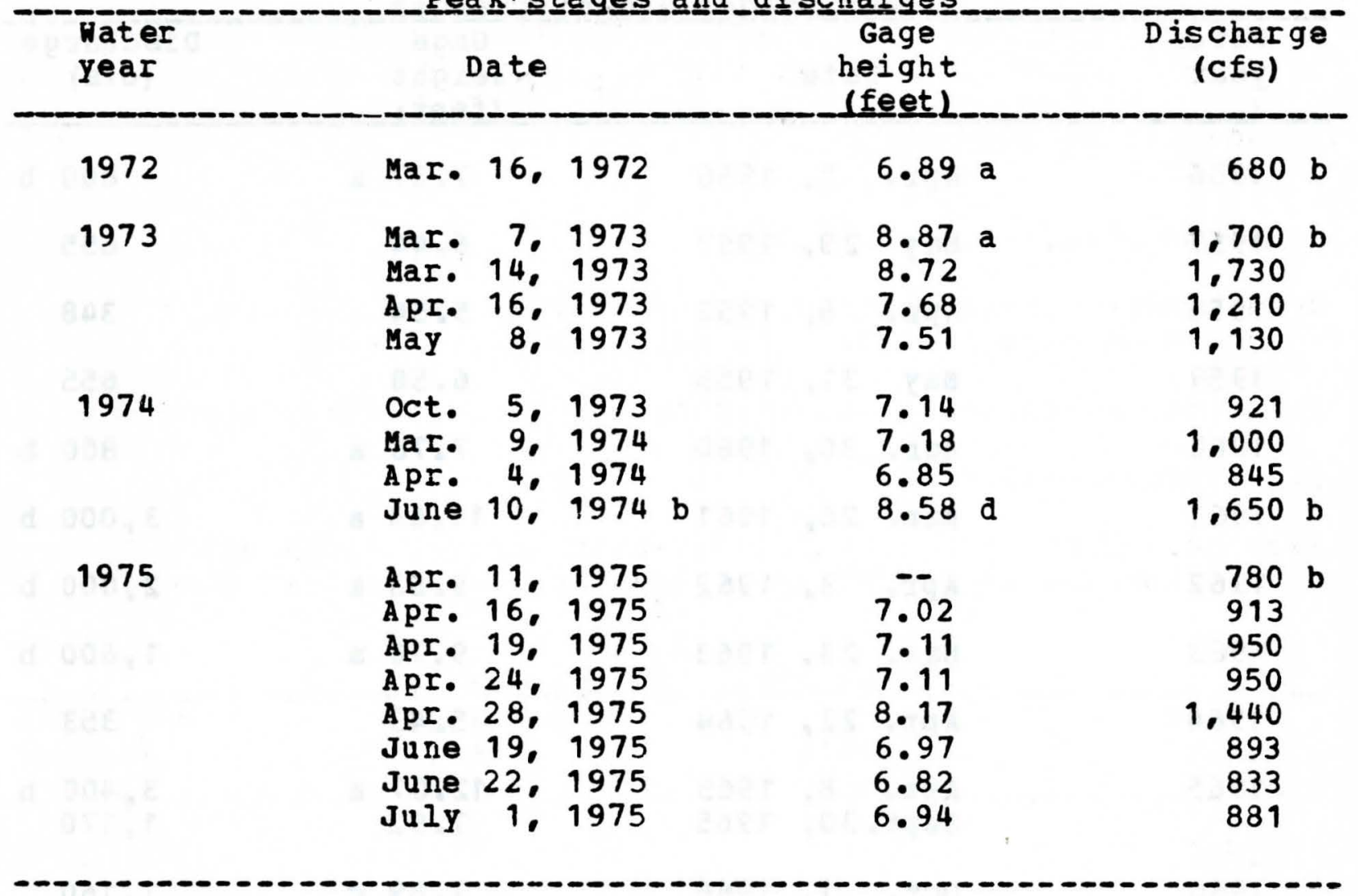

a Affected by ice.

b About.

d From high-water mark in well. 
Location.--Lat 42039110", long 92035'46", in NE $1 / 4 \mathrm{NW1/4}$ sec.11, T. 91 N.. R. 15 H.. Butler County, on right bank 400 ft upstream from bridge on county highway C45 in shell Rock, 2.2 miles downstream from Curry Creek, and 10.4 miles upstream from mouth.

Drainage area.--1,746 sq mi.

Gage.--Water-stage recorder. Rockfill dam since Oct. 19, 1957. Datum of gage is 885.34 ft above mean sea level.

Stage-discharge relation.--Defined by current-meter measurements. Flood stage.--12 feet.

Remarks.--Base for partial-duration series, 4,000 cfs. Diurnal fluctuation at low stages caused by powerplant at Greene.

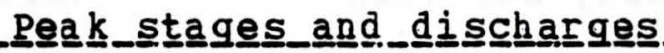

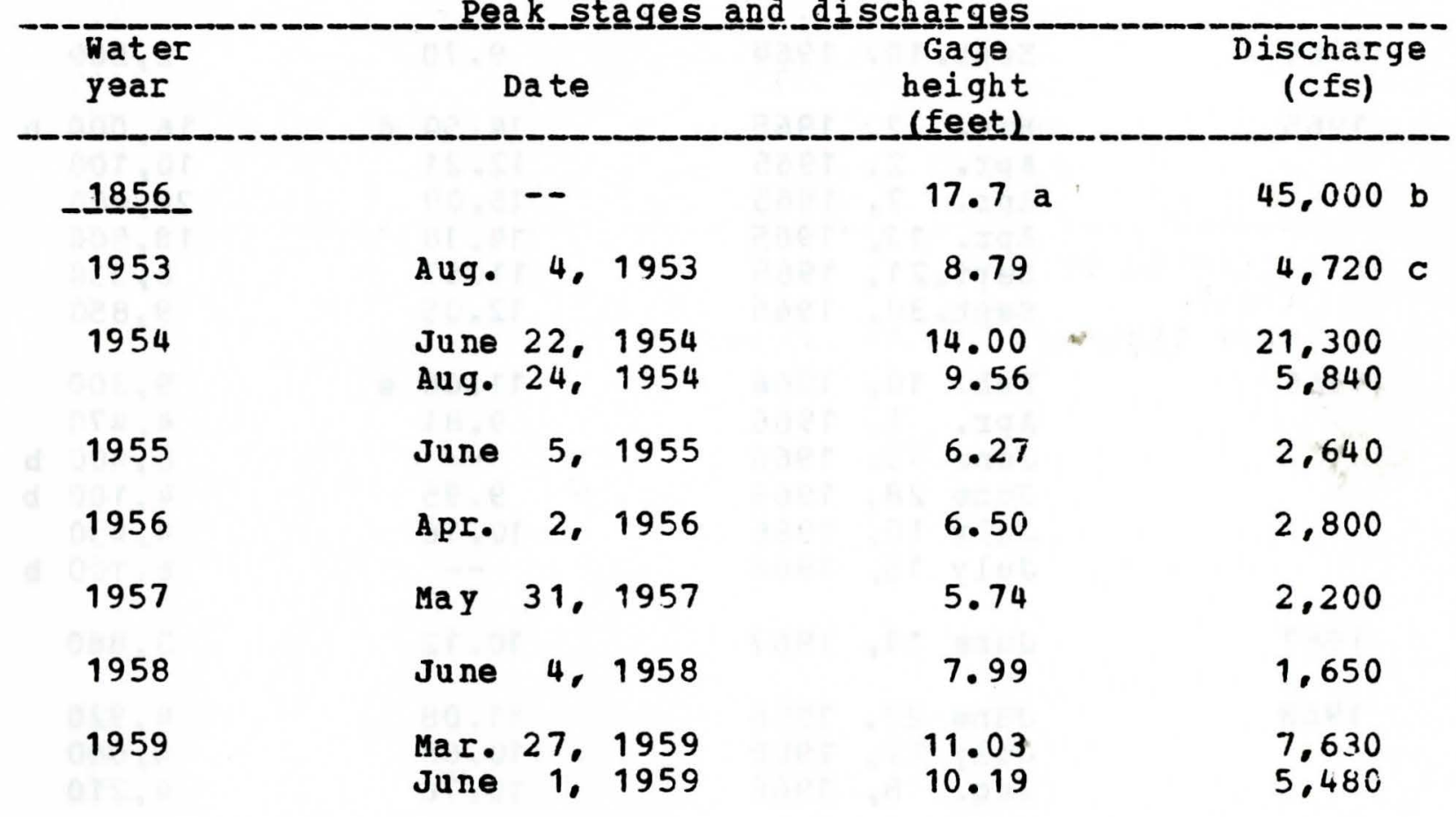

\footnotetext{
a At bridge 400 feet downstream; from information furnished by Corps of Engineers.

b A bout.

c Maximum for period June to September 1953.
} 
05-4620.00 Shell Rock River at Shell Rock, Iowa--(Continued)

Peak_s_stages_and_di $i$ schharges

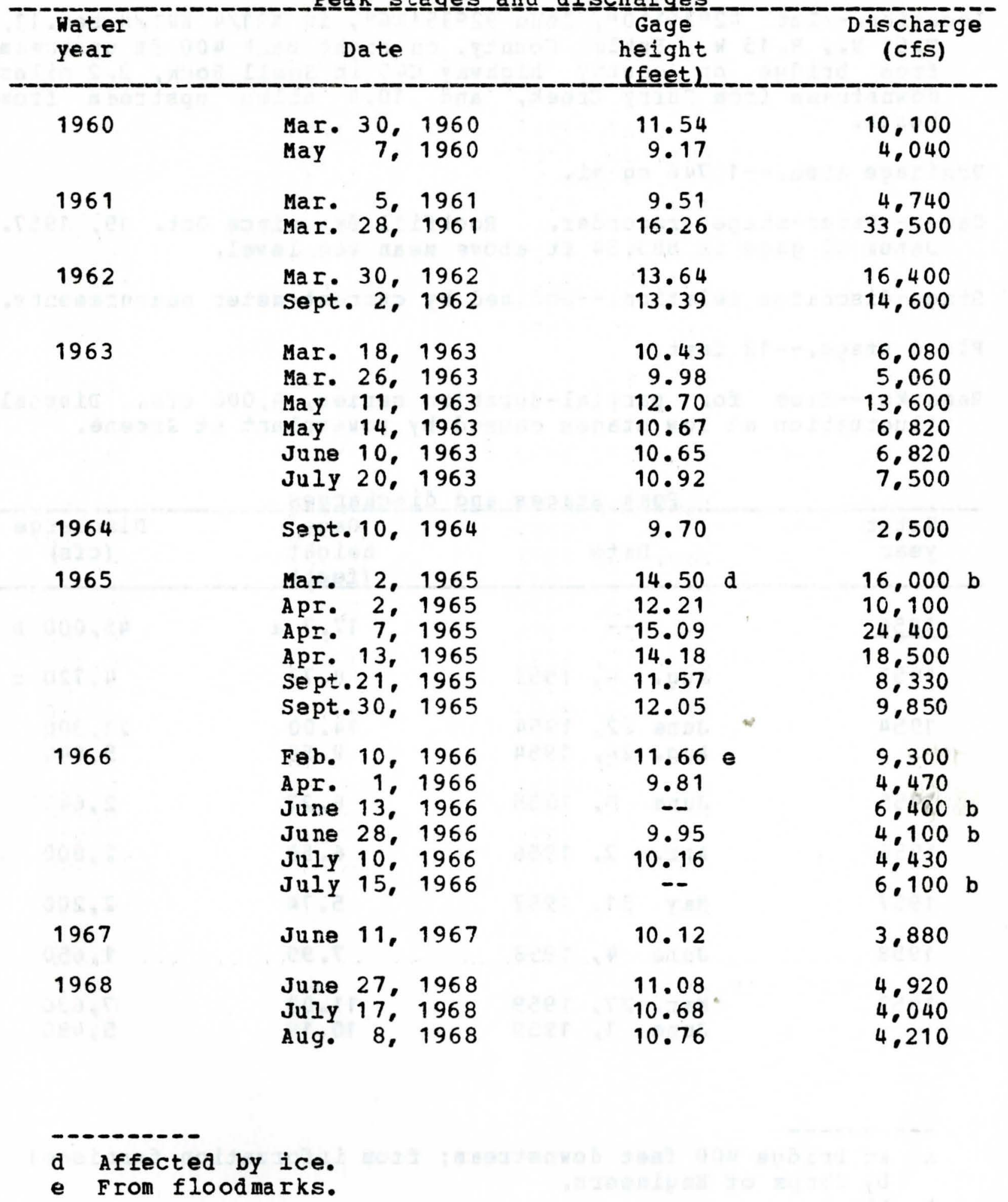


05-4620.00 She11 Rock River at Shell Rock, Iowa--(Continueâ)

Peak

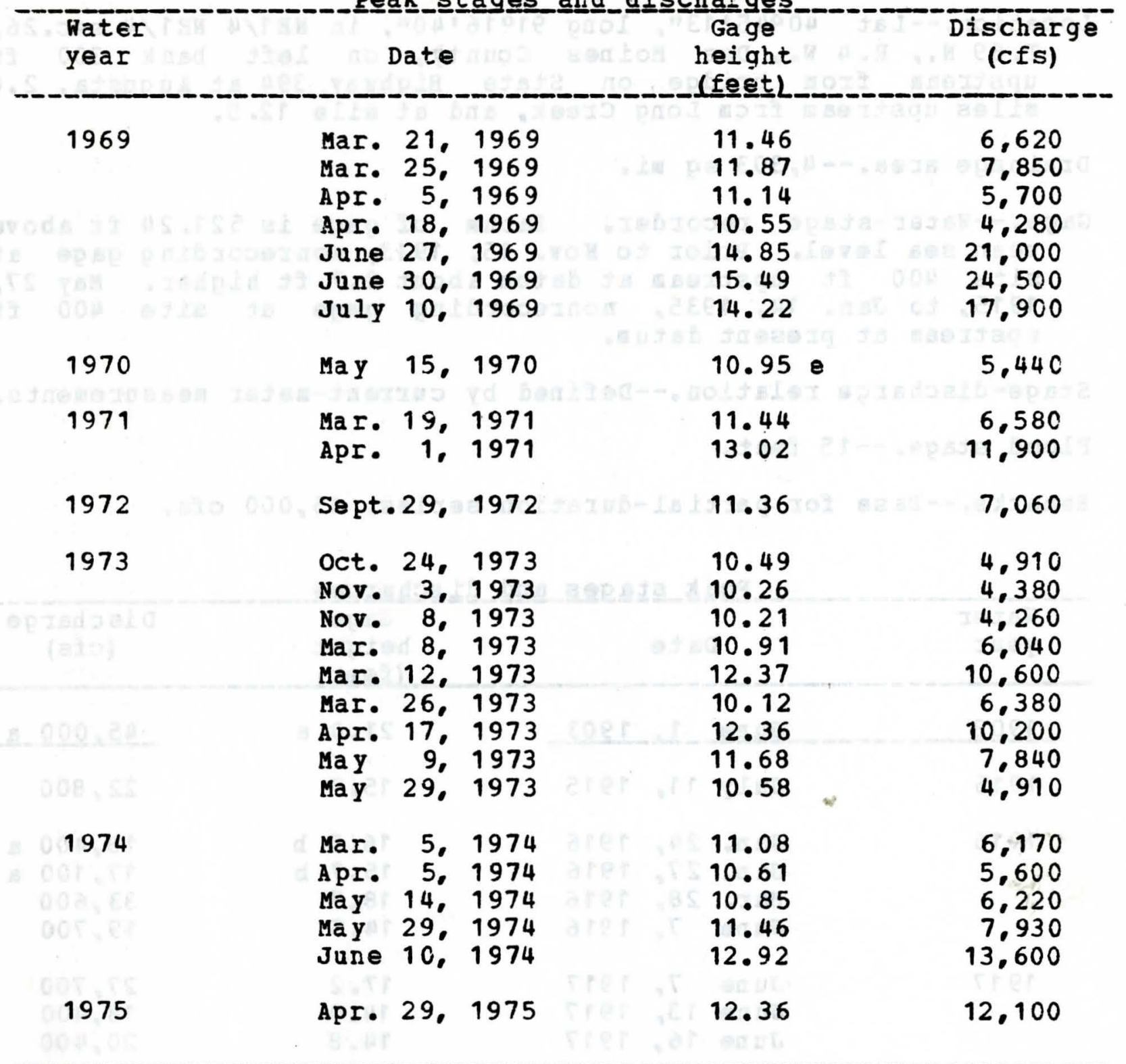

e From floodmarks. 
Location.--Iat $40045 \cdot 13^{\prime \prime}$, long $91016 \cdot 40^{\prime \prime}$, in NE1/4 NE1/4 sec.26, T.69 N.. R.4 N.. Des Moines County, on left bank $300 \mathrm{ft}$ upstream from bridge on state Highway 394 at Augusta, 2.0 miles upstream frcm long Creek, and at mile 12.5.

Drainage area.-- $4,303 \mathrm{sq} \mathrm{mi}$.

Gage.--Hater-stage recorder. Datum of gage is 521.24 ft above mean sea level. Prior to Nov. 15, 1913, nonrecording gage at site 400 ft upstream at datum about 0.7 ft higher. May 27. 1915, to Jan. 14, 1935, nonrecording gage at site $400 \mathrm{ft}$ upstream at present datum.

Stage-discharge relation.--Defined by current-meter measurements. Flood stage. -15 feet.

Remarks.--Base for partial-duration series, 15,000 cfs.

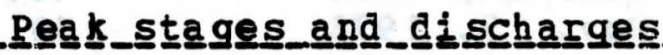

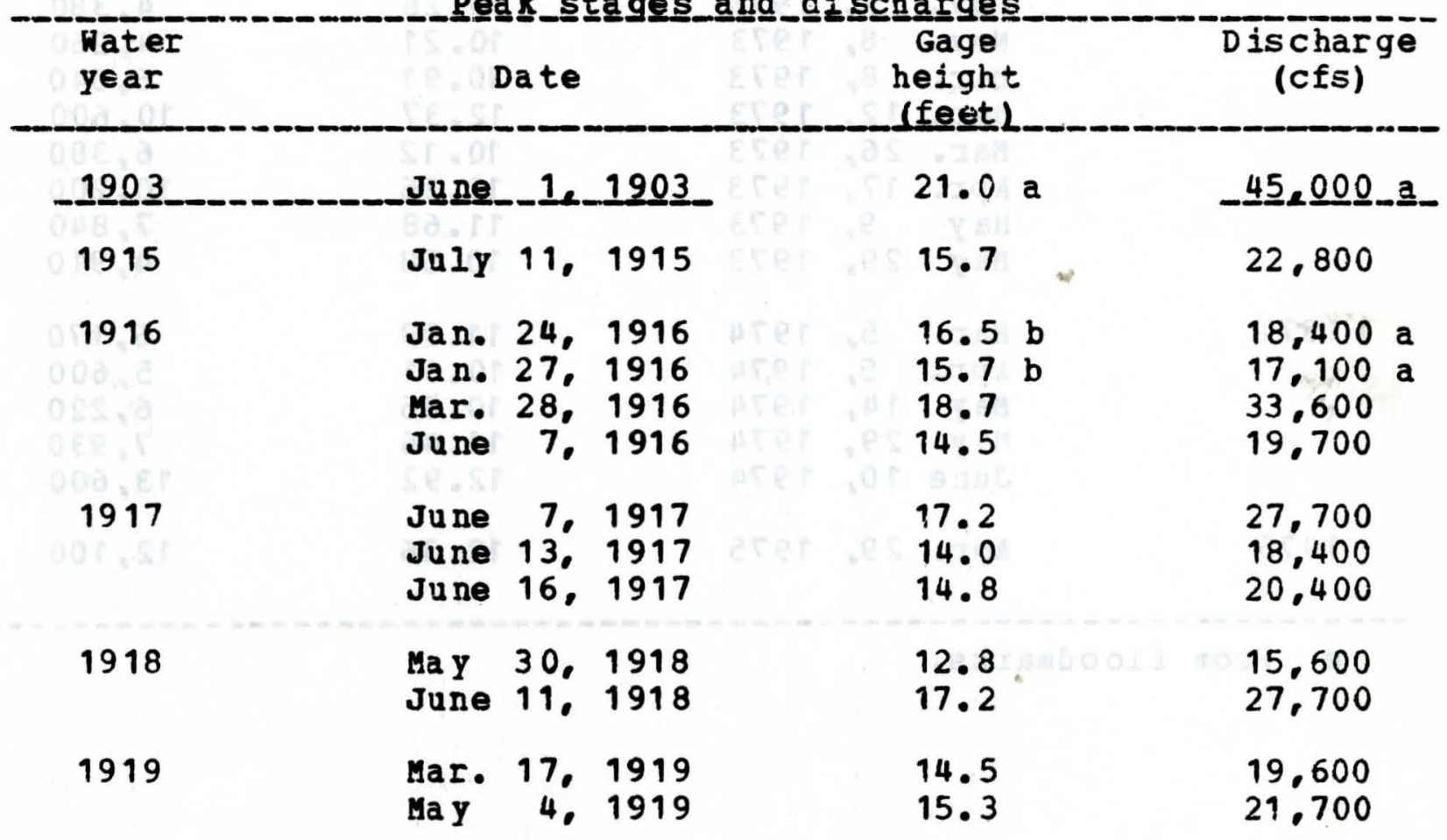

a About.

b Affected by ice. 
05-4740.00 Skunk River at Augusta, Iowa--(Continued)

Peak_stages_and_discharges

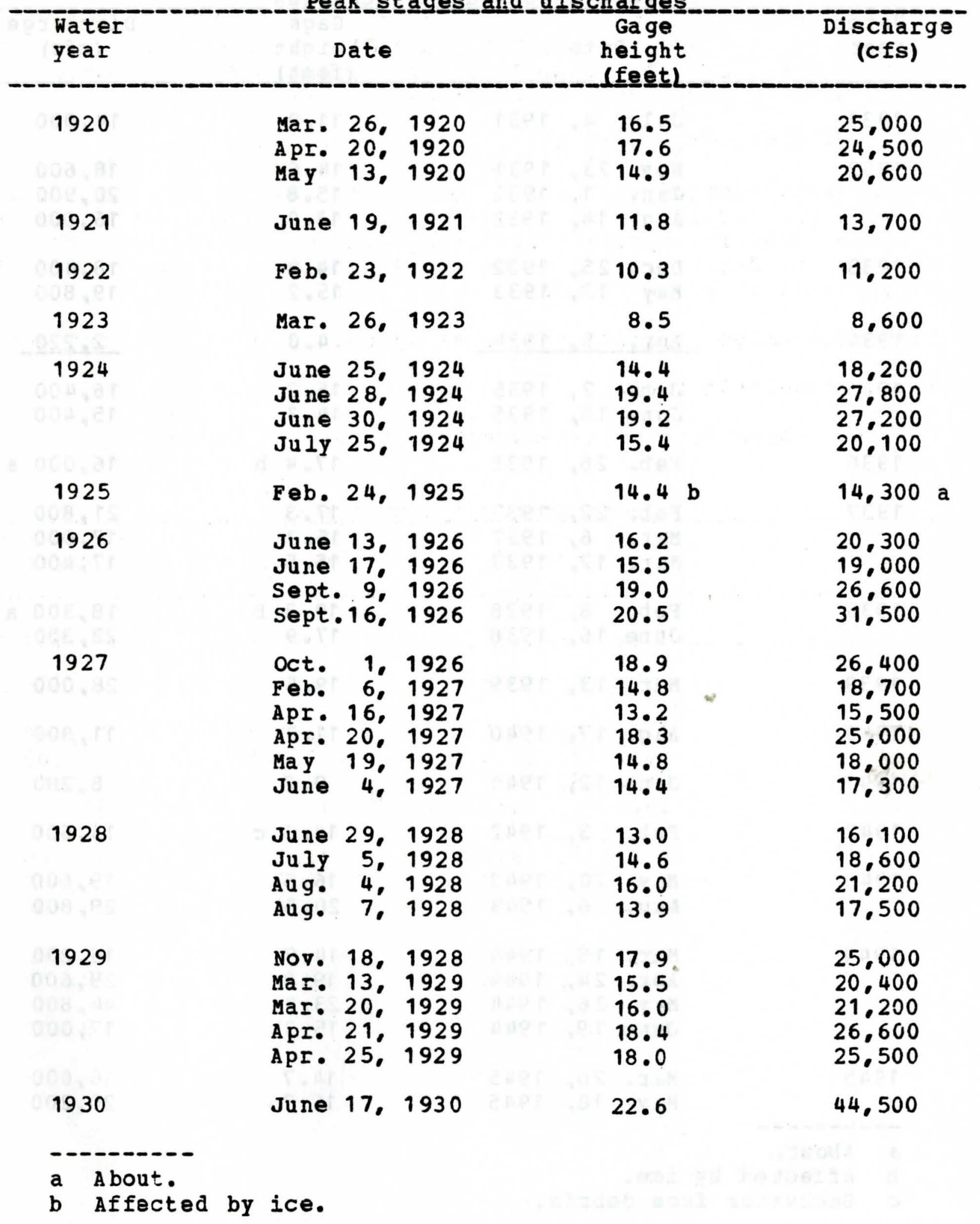


05-4740.00 Skunk River at Augusta, Iowa--(Continued)

Peak﹎.stagges_and__di

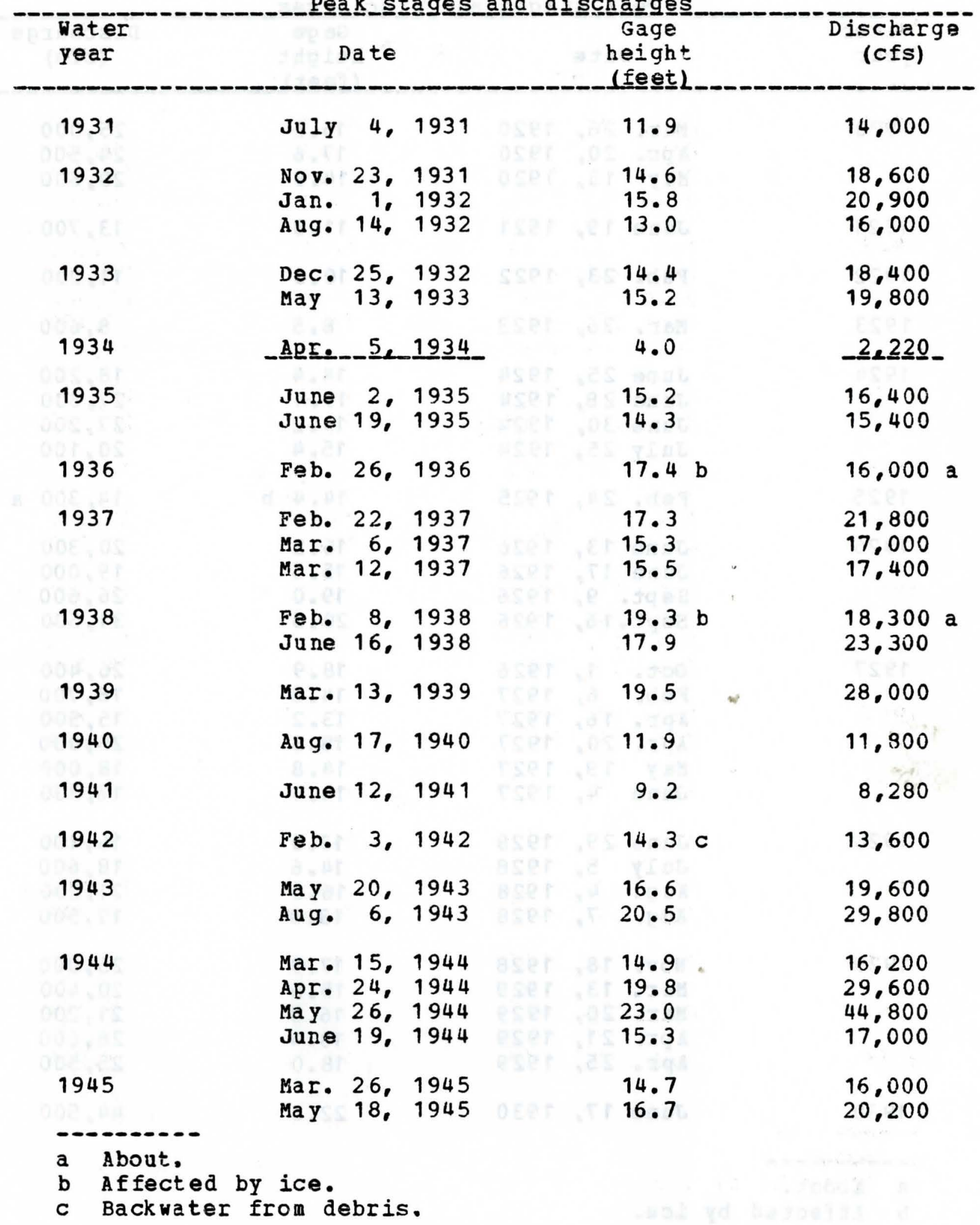


05-4740.00 Skunk River at Augusta, Iowa--(Continued)

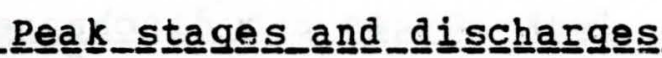

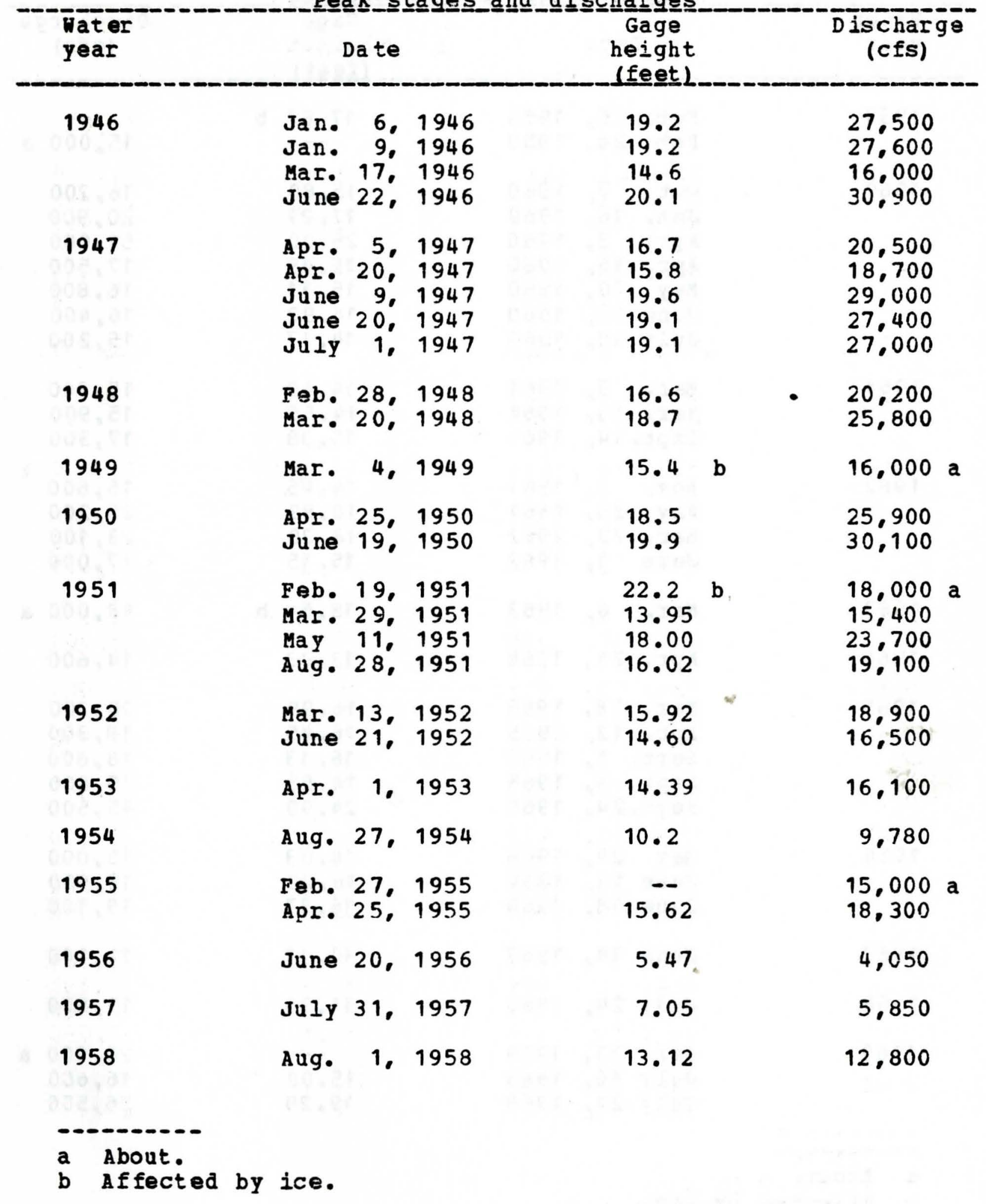


05-4740.00 Skunk River at Augusta, Iowa--(Continued)

Peak_stages and_discharges

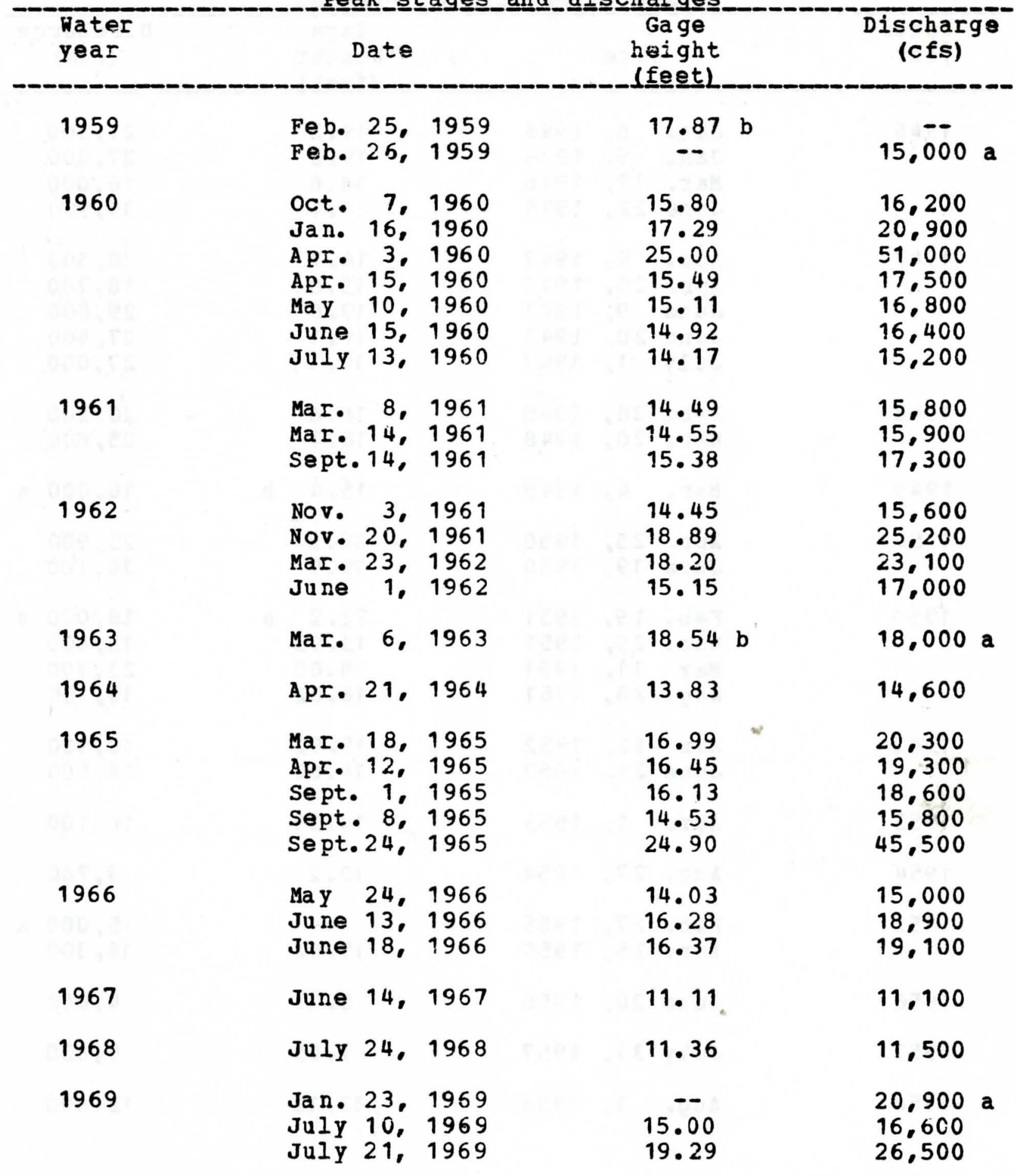

a About.

b affected by ice. 
05-4740.00 Skunk River at Augusta, Iowa--(Continued)

Pea k﹎staages_and_dis

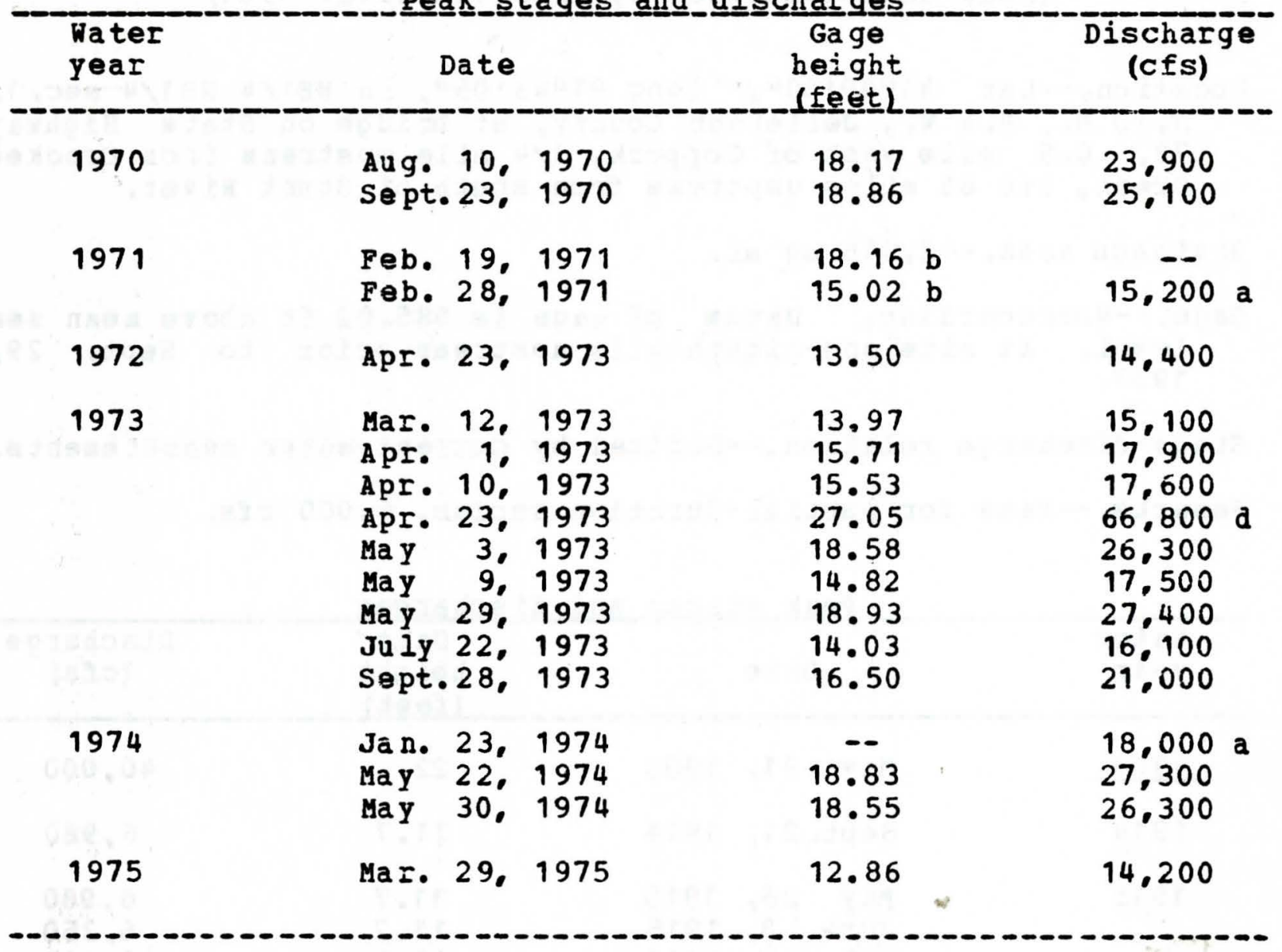

a About.

b Affected by ice.

d Stage and discharge for April 1973 flood believed to be greatest known since 1851 . 
05-4730.00 Skunk River at Coppock. Iowa

(Station operation discontinued sept. 30,1944 )

(Peak data collected by observer until 1951)

Location.--Lat $41009 \cdot 50^{\prime \prime}$, long $91043105 "$, in NE1/4 NE 1/4 sec. 1.

T. 73 N.. R. 8 W.. Jefferson County, at bridge on State Highway

78, 0.5 mile west of Coppock, $3 / 4$ mile upstream from Crooked

Creek, and 66 miles usptream from mouth of skunk River.

Drainage area.--2,916 sq ini.

Gage.--Nonrecording. Datum of gage is $585.02 \mathrm{ft}$ above mean sea

level. At site one-eighth mile upstream prior to sept.. 29. 1937.

Stage-discharge relation.--Defined by current-meter measurements. Remarks.--Base for partial-duration series, 6,000 cfs.

Peak﹎.sta $\underline{\text { ges }}$ and_dischharges

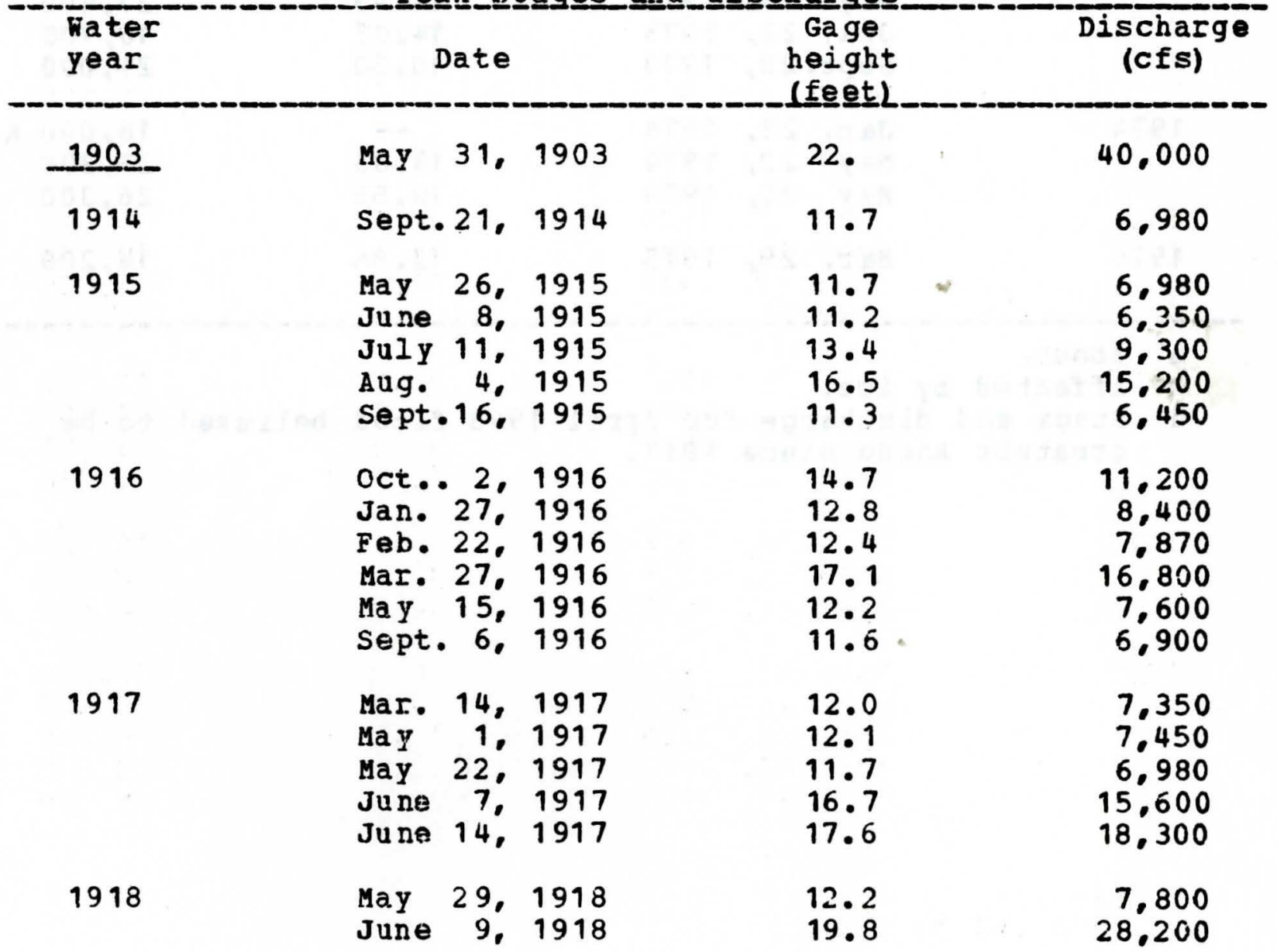


05-4730.00 Skunk River at Coppock, Iowa--(Continued)

Pea $\underline{k}$ stagges and_di

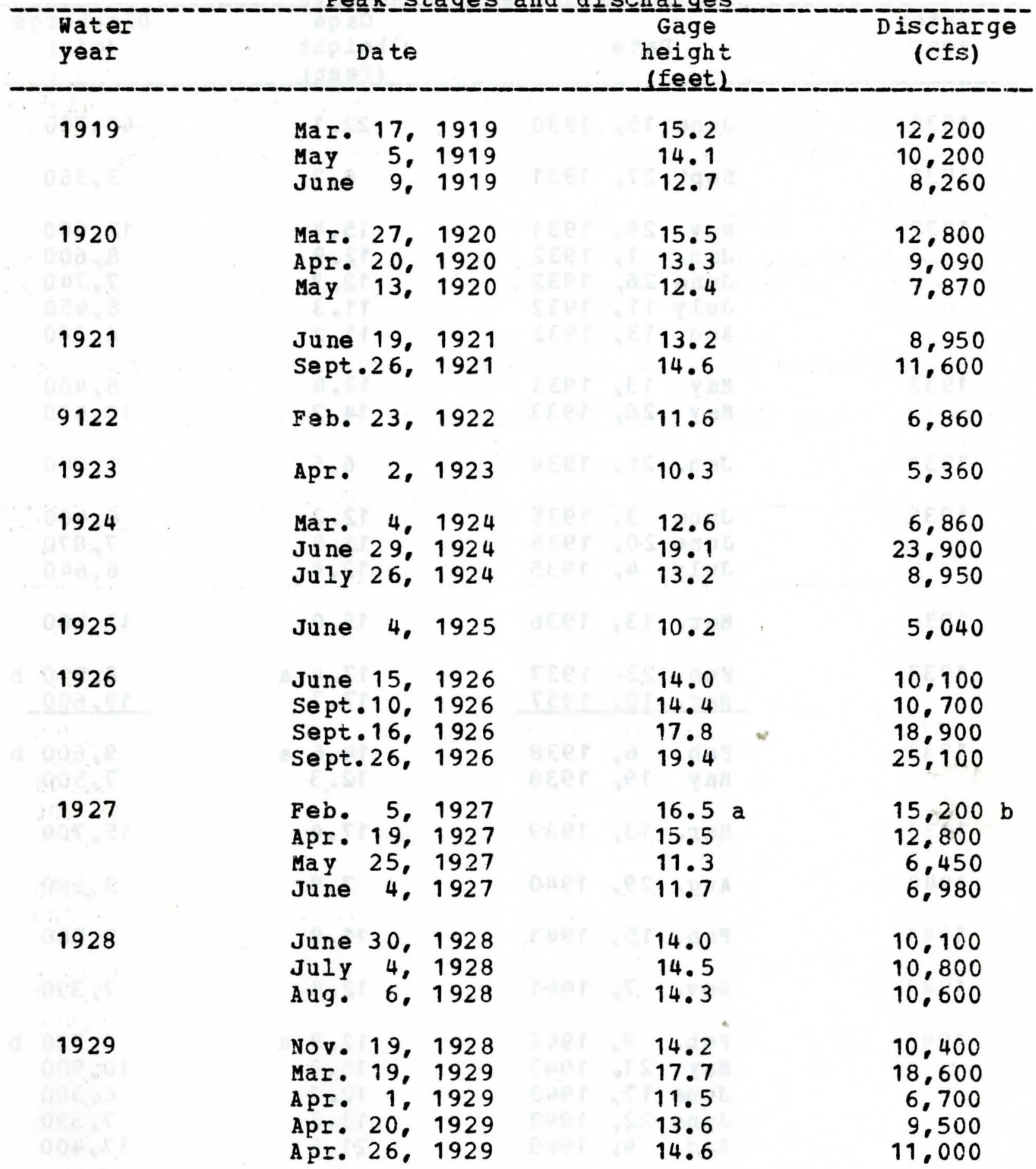

a Affected by ice.

b About. 
05-4730.00 Skunk River at Coppock, Iowa--(Continued)

Peak__stages_and_discharges

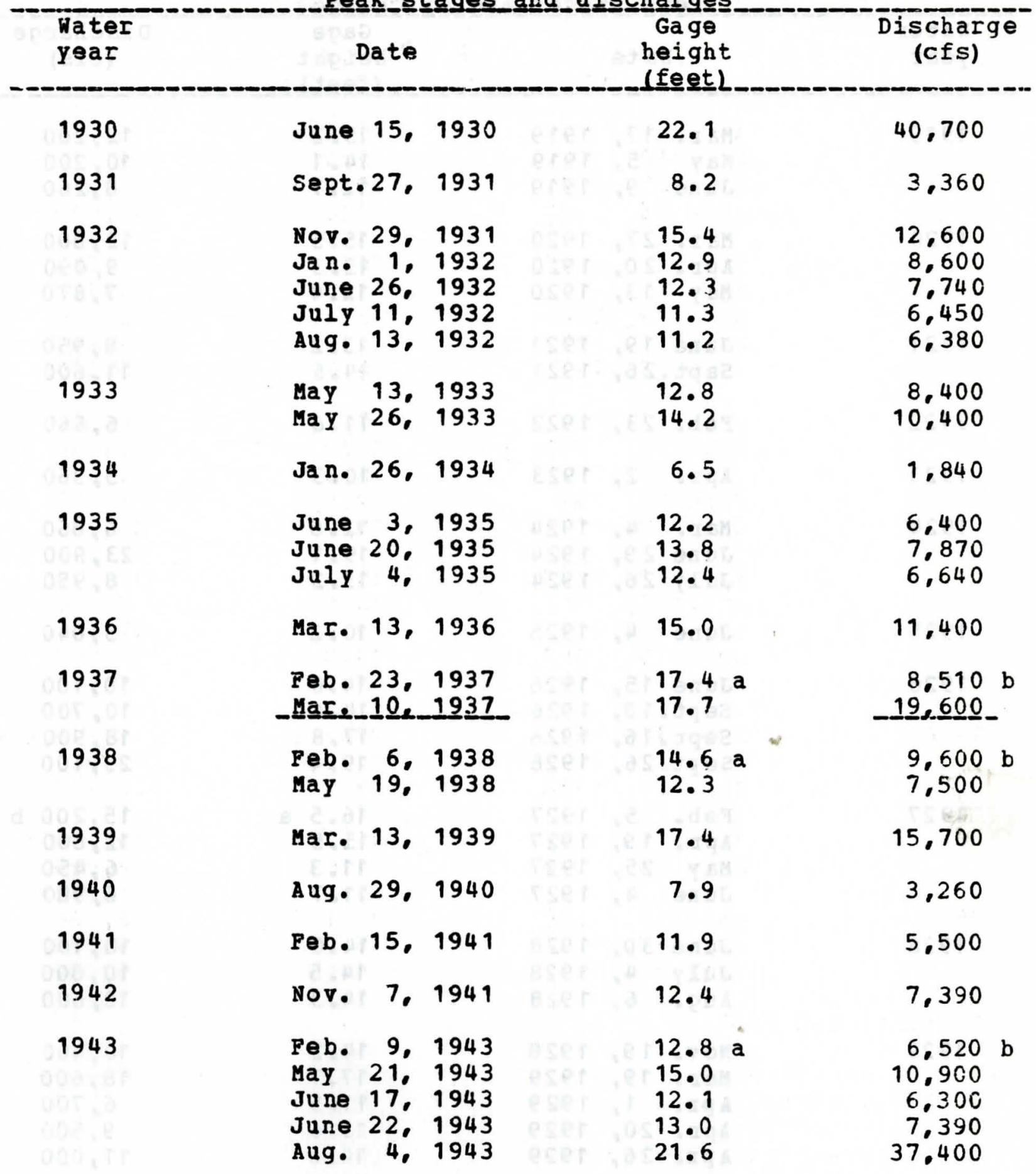

a Affected by $\doteq c e$.
b about. 
05-4730.00 Skunk River at Coppock. Iowa--(Continued)

Peak_stages_and_discharges

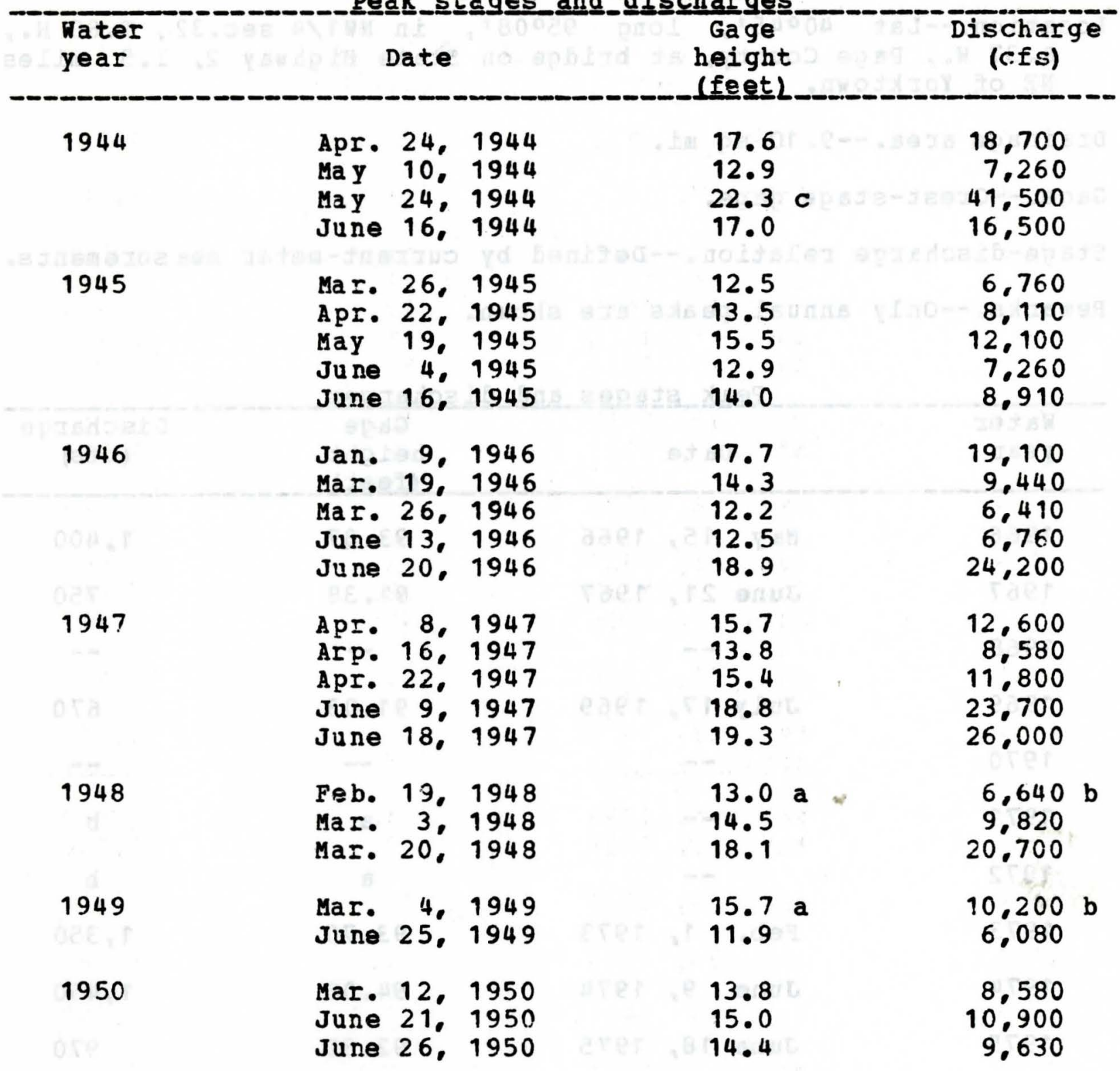

Discontinued 1951

\footnotetext{
a Affected by ice.

b About.

c Maximum stage known since 1881.
} 
Location.--Lat $40045^{\prime}$, long $95008^{\prime}$, in NW1/4 sec.32, T.69 N., R. 37 W. , Page County, at bridge on state Highway 2, 1.5 miles $N E$ of Yorktown.

Drainage area. $--9.10 \mathrm{sq} \mathrm{mi}$.

Gage.--Crest-stage gage.

Stage-discharge relation.--Defined by current-meter measurements. Remarks.--only annual peaks are shown.

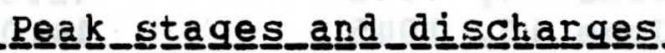

\begin{tabular}{|c|c|c|c|c|c|}
\hline $\begin{array}{l}\text { Water } \\
\text { year }\end{array}$ & & Date & $3 x$ & $\begin{array}{c}\text { Gage } \\
\text { height } \\
\text { (feett) }\end{array}$ & $\begin{array}{c}\text { Discharge } \\
\text { (cfs) }\end{array}$ \\
\hline 1966 & May & 15,1966 & & 93.87 & 1.400 \\
\hline 1967 & June & 21,1967 & & 91.38 & 750 \\
\hline 1968 & & -- & & - & -- \\
\hline 1969 & July & 17,1969 & & 91.03 & 670 \\
\hline 1970 & & -- & & -- & -- \\
\hline 1971 & & -- & & a & b \\
\hline 1972 & & -- & & a & b \\
\hline 1973 & Fab. & 1. 1973 & & 93.70 & 1,350 \\
\hline 1974 & June & 9, 1974 & & 94.00 & 1,450 \\
\hline 1975 & June & 18,1975 & & 92.32 & 970 \\
\hline
\end{tabular}

a Peak stage did not reach bottom of gage.

b Discharge not determined. 
Location.--Lat 41049'52", long 95055'50", in NW1/4 NE1/4 sec.14, T. 81 N.. R. 44 \%.. Harrison County, on left bank on downstream side of bridge on county highway F20, at west edge of Pisgah, 0.4 mile downstream from $\mathrm{Cobb}$ Creek, 0.5 mile upstream from Mogger Ditch, and 13.1 miles upstream from mouth.

Drainage area. $--407 \mathrm{sq} \mathrm{mi.}$

Gage.--Water-stage recorder. Datum of gage is 1,036.53 ft above mean sea level. Prior to oct. 11, 1954, nonrecording gage at same site and datum with supplementary water-stage recorder operating above 8.2 ft gage height Mar. 2. 1946, to Sept. 24, 1953.

Stage-discharge relation.--Defined by current-meter measurements. Flood stage.--28 feet.

Remarks.--Base for partial-duration series, 5,000 cfs.

Peakㅡ_s_tagess_and

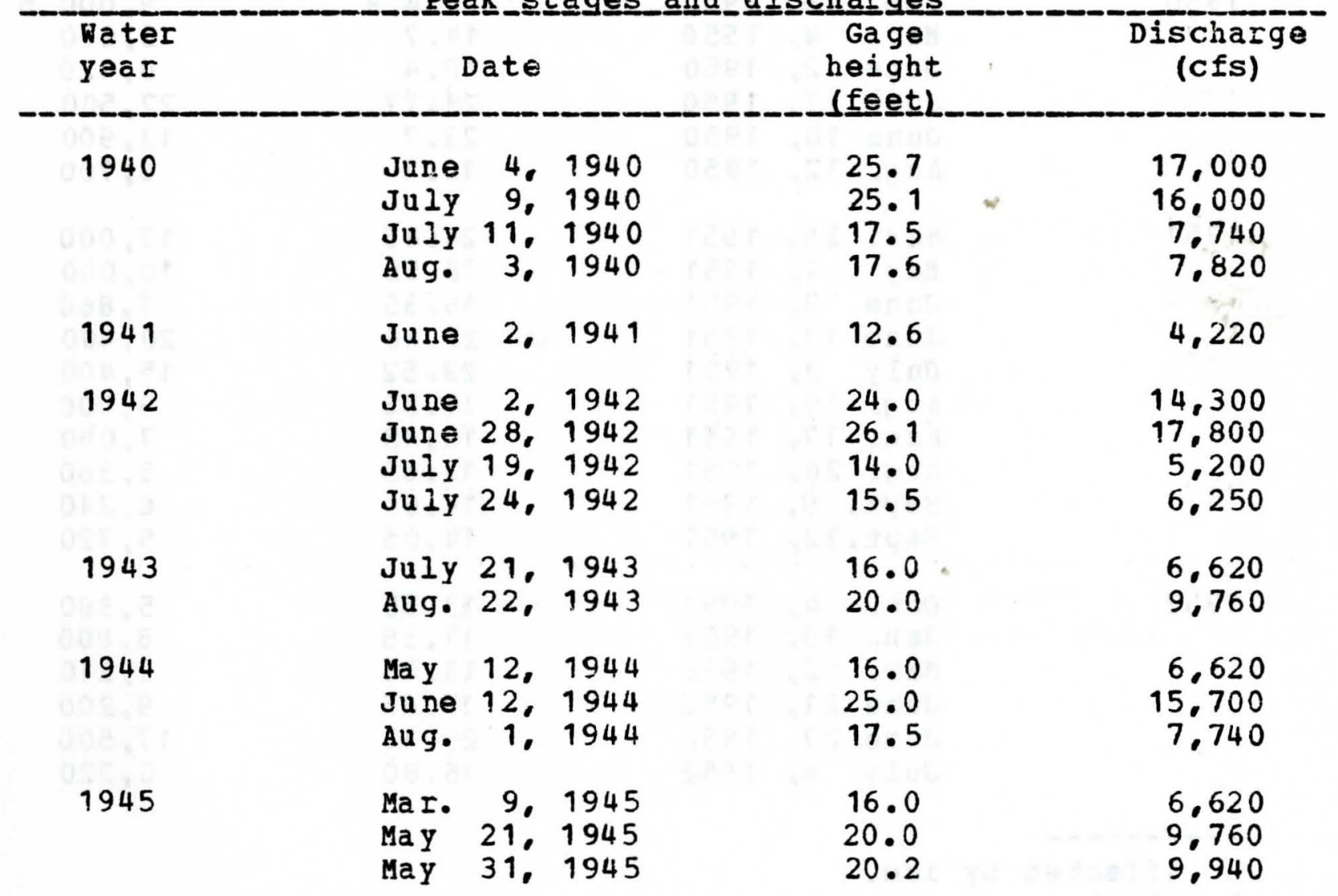


06-6085.00 Soldier River at Pisgah, Iowa-- (Continued)

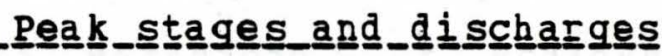

\begin{tabular}{|c|c|c|c|}
\hline $\begin{array}{l}\text { Water } \\
\text { year }\end{array}$ & Date & $\begin{array}{l}\text { Gage } \\
\text { height } \\
\text { (feet) }\end{array}$ & $\begin{array}{l}\text { Discharge } \\
\text { (cfs) }\end{array}$ \\
\hline 1946 & $\begin{array}{l}\text { Feb. } 5,1946 \\
\text { May } 24,1946 \\
\text { June 28, } 1946 \\
\text { June } 30,1946 \\
\text { Sept. 4, } 1946 \\
\text { Sept. } 7,1946\end{array}$ & $\begin{array}{l}17 \cdot 0 \text { a } \\
15.6 \\
20.1 \\
16.8 \\
22.6 \\
15.2\end{array}$ & $\begin{array}{r}5.830 \quad \mathrm{~b} \\
6,320 \\
9,850 \\
7.220 \\
12,400 \\
6,040\end{array}$ \\
\hline 1947 & June 22,1947 & 14.1 & 5,270 \\
\hline 1948 & 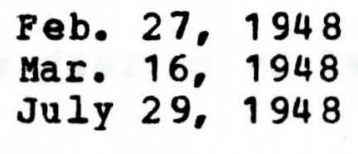 & $\begin{array}{l}22.1 \\
16.3 \\
15.0\end{array}$ & $\begin{array}{r}11.800 \\
6.790 \\
5.860\end{array}$ \\
\hline 1949 & $\begin{array}{lr}\text { Mar. } & 4,1949 \\
\text { June } 21, & 1949 \\
\text { Aug. } 12, & 1949\end{array}$ & $\begin{array}{l}22.0 \text { a } \\
15.9 \\
15.9\end{array}$ & $\begin{array}{l}9,500 \quad b \\
6,470 \\
6,540\end{array}$ \\
\hline 1950 & $\begin{array}{lr}\text { Feb. } 28,1950 \\
\text { Mar. } 4,1950 \\
\text { June } 2,1950 \\
\text { June 12, } 1950 \\
\text { June 18, } 1950 \\
\text { Aug. 12, } 1950\end{array}$ & $\begin{array}{l}20.4 \text { a } \\
14.7 \\
18.4 \\
28 \cdot 17 \\
23.7 \\
16.1\end{array}$ & $\begin{array}{r}9.000 \quad b \\
5.690 \\
8.420 \\
22.500 \\
13.900 \\
6.700\end{array}$ \\
\hline 1951 & $\begin{array}{lr}\text { Mar. } 26, & 1951 \\
\text { May } 1, & 1951 \\
\text { June } 2, & 1951 \\
\text { June } 17, & 1951 \\
\text { July 3, } & 1951 \\
\text { Aug. 14, } 1951 \\
\text { Aug. 17, } 1951 \\
\text { Aug. 20, } 1951 \\
\text { Sapt. 9, } 1951 \\
\text { Sept.12, } 1951\end{array}$ & $\begin{array}{l}24.85 \\
18.55 \\
16.35 \\
27.46 \\
23.52 \\
17.56 \\
15.48 \\
13.65 \\
14.60 \\
14.05\end{array}$ & $\begin{array}{r}17.000 \\
10,000 \\
7,860 \\
20,400 \\
15,400 \\
9,000 \\
7,050 \\
5,380 \\
6,240 \\
5,720\end{array}$ \\
\hline 1952 & $\begin{array}{lr}\text { Oct. } & 4,1951 \\
\text { Jan. } & 19,1952 \\
\text { Mar. } 12,1952 \\
\text { Juns } & 21,1952 \\
\text { June } & 27,1952 \\
\text { July } & 6,1952\end{array}$ & $\begin{array}{l}13.55 \\
17.35 \\
13.45 \\
17.85 \\
25.18 \\
16.80\end{array}$ & $\begin{array}{r}5,380 \\
8,800 \\
5,210 \\
9,200 \\
17,500 \\
8,220\end{array}$ \\
\hline
\end{tabular}

a Affected by ice.

b about. 
06-6085.00 Soldier Rivar at Pisgah, Iowa--(Continued)

Peakㅡ_stages and di

\begin{tabular}{|c|c|c|c|c|c|}
\hline $\begin{array}{l}\text { Water } \\
\text { year }\end{array}$ & & Date & $\begin{array}{l}\text { Gage } \\
\text { height } \\
\text { (feet) }\end{array}$ & & $\begin{array}{c}\text { Discharge } \\
\text { (cfs) }\end{array}$ \\
\hline 1953 & $\begin{array}{l}\text { June } \\
\text { Aug. } \\
\text { Aug. }\end{array}$ & $\begin{array}{r}25,1953 \\
3,1953 \\
6,1953\end{array}$ & $\begin{array}{l}16.40 \\
16.24 \\
13.80\end{array}$ & & $\begin{array}{l}7,860 \\
7,680 \\
5,550\end{array}$ \\
\hline 1954 & $\begin{array}{l}\text { Apr. } \\
\text { May } \\
\text { June } \\
\text { June }\end{array}$ & $\begin{array}{ll}21, & 1954 \\
27, & 1954 \\
19, & 1954 \\
21, & 1954\end{array}$ & $\begin{array}{l}17.6 \\
17.68 \\
23.35 \\
20.0\end{array}$ & & $\begin{array}{r}9.000 \\
9.100 \\
15.200 \\
11.400\end{array}$ \\
\hline 1955 & Mar. & 8,1955 & 11.79 & & 3,890 \\
\hline 1956 & July & 11,1956 & 10.68 & & 2,880 \\
\hline 1957 & June & 16,1957 & 17.64 & & 9,000 \\
\hline 1958 & July & 2,1958 & 13.7 & & 5,260 \\
\hline 1959 & $\begin{array}{l}\text { May } \\
\text { May }\end{array}$ & $\begin{array}{ll}28, & 1959 \\
31, & 1959\end{array}$ & $\begin{array}{l}14.60 \\
16.87\end{array}$ & & $\begin{array}{l}6,010 \\
8,060\end{array}$ \\
\hline 1960 & June & 16,1960 & 14.00 & & 5,580 \\
\hline 1961 & Mar. & 15,1961 & 11.47 & & 3,480 \\
\hline 1962 & $\begin{array}{l}\text { Mar. } \\
\text { Ma y } \\
\text { June } \\
\text { Aug. }\end{array}$ & $\begin{array}{ll}23, & 1962 \\
28, & 1962 \\
10, & 1962 \\
30, & 1962\end{array}$ & $\begin{array}{l}14.70 \\
12.96 \\
13.25 \\
22.40\end{array}$ & 8 & $\begin{array}{r}8.100 \\
5.800 \\
6.100 \\
15.500\end{array}$ \\
\hline 1963 & $\begin{array}{l}\text { June } \\
\text { Aug. }\end{array}$ & $\begin{array}{l}\text { 5, } 1963 \\
6,1963\end{array}$ & $\begin{array}{l}19.14 \\
16.89\end{array}$ & & $\begin{array}{r}12, .000 \\
9.800\end{array}$ \\
\hline 1964 & $\begin{array}{l}\text { May } \\
\text { May }\end{array}$ & $\begin{array}{l}24,1964 \\
26,1964\end{array}$ & $\begin{array}{l}20.50 \\
22.21\end{array}$ & & $\begin{array}{l}13,400 \\
15,300\end{array}$ \\
\hline 1965 & $\begin{array}{l}\text { Feb. } \\
\text { Mar. } \\
\text { Mar. } \\
\text { Apr. } \\
\text { May }\end{array}$ & $\begin{array}{rr}28, & 1965 \\
17, & 1965 \\
31, & 1965 \\
3, & 1965 \\
25, & 1965\end{array}$ & $\begin{array}{l}19.23 \\
13.90 \\
19.13 \\
13.98 \\
14.70\end{array}$ & a & $\begin{array}{r}--\overline{0} \\
12,800 \\
6,800 \\
7,600\end{array}$ \\
\hline 1966 & $\mathrm{Feb}$ & 9. 1966 & 11.00 & & 3,900 \\
\hline
\end{tabular}

a Affected by ice. 
06-6085.00 Soldier River at Pisgah, Iowa--(Continued)

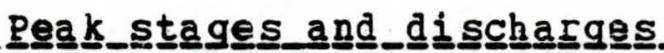

\begin{tabular}{|c|c|c|c|c|c|c|}
\hline $\begin{array}{l}\text { Vater } \\
\text { year }\end{array}$ & & ate & & $\begin{array}{l}\text { Gage } \\
\text { height } \\
\text { (feet). }\end{array}$ & & $\begin{array}{c}\text { Discharge } \\
\text { (cfs) }\end{array}$ \\
\hline 1967 & $\begin{array}{l}\text { June } \\
\text { June } \\
\text { June } \\
\text { June }\end{array}$ & $\begin{array}{r}7 . \\
9 . \\
14 . \\
19 .\end{array}$ & $\begin{array}{l}1967 \\
1967 \\
1967 \\
1967\end{array}$ & $\begin{array}{l}14.3 \\
19.2 \\
19.3 \\
12.70\end{array}$ & C & $\begin{array}{r}7,200 \\
12,100 \\
12,200 \\
5,600\end{array}$ \\
\hline 1968 & June & 25. & 1968 & 18.03 & & 10,600 \\
\hline 1969 & Mar. & 18. & 1969 & 14.08 & & 6,980 \\
\hline 1970 & May & 14. & 1970 & 9.68 & & 2,710 \\
\hline 1971 & $\begin{array}{l}\text { Feb. } \\
\text { Mar. }\end{array}$ & $\begin{array}{l}19 . \\
13 .\end{array}$ & $\begin{array}{l}1971 \\
1971\end{array}$ & $\begin{array}{l}23.70 \\
14.50\end{array}$ & & $\begin{array}{r}17.000 \\
7.400\end{array}$ \\
\hline 1972 & $\begin{array}{l}\text { July } \\
\text { Sept. }\end{array}$ & $\begin{array}{l}11 . \\
12 .\end{array}$ & $\begin{array}{l}1972 \\
1972\end{array}$ & $\begin{array}{l}21.87 \\
12.52\end{array}$ & & $\begin{array}{r}15.000 \\
5.420\end{array}$ \\
\hline 1973 & $\begin{array}{l}\text { Jan. } \\
\text { MaI. }\end{array}$ & 17. & $\begin{array}{l}1973 \\
1973\end{array}$ & $\begin{array}{l}11.04 \\
10.71\end{array}$ & $\mathbf{a}$ & 3.640 \\
\hline 1974 & May & 19. & 1974 & 12.71 & & 5,610 \\
\hline 1975 & Apr. & 28 & 1975 & 11.05 & & 3.950 \\
\hline
\end{tabular}

a Affected by ice.

c From floodmark. 


\section{5-4893.50 South Avery Creek near Blakesburg. I owa}

Location.--Iat $41001 \%$, long $92037^{\circ}$, in SE1/4 sec.19, T.72 N.,

R. 15 W., Wapello county, at bridge on U.S. Highway 34.3 .5 miles north of Blakesburg.

Drainage area.--33.1 sq $\mathrm{mi}$.

Gage.--Crest-stage gage.

Stage-discharge relation.--Defined by current-meter and indirect measurements.

Remarks.--only annual peaks are shown.

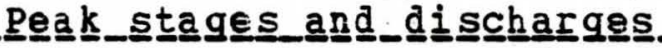

\begin{tabular}{|c|c|c|c|}
\hline $\begin{array}{l}\text { wateI } \\
\text { year }\end{array}$ & Date & $\begin{array}{l}\text { Gage } \\
\text { height } \\
\text { (feet) }\end{array}$ & $\begin{array}{l}\text { Discharge } \\
\text { (Cfs) }\end{array}$ \\
\hline 1965 & Sept.21, 1965 & 87.60 & 10.300 \\
\hline 1966 & May 11,1965 & 81.94 & 2.700 \\
\hline 1967 & June 9, 1967 & 88.95 & 15.000 \\
\hline 1968 & oct. 15, 1967 & 82.59 & 3.200 \\
\hline 1969 & June 8,1969 & 80.37 & 1.750 \\
\hline 1970 & Sept.17, 1970 & 82.19 & 2,900 \\
\hline 1971 & -- & a & $\mathbf{b}$ \\
\hline 1972 & May 8,1972 & 85.03 & 5.600 \\
\hline 1973 & Sept.27, 1973 & 83.91 & 4,300 \\
\hline 1974 & May 19,1974 & 85.39 & 6,200 \\
\hline 1975 & -- & a & $\mathbf{b}$ \\
\hline
\end{tabular}

a Peak stage did not reach bottom of gage.

b Discharge not determined. 
05-4550.10 South Branch Ralston Creek at Iowa City. Iowa

Location.--Lat $41039 \cdot 05 "$, lorg $92030 \cdot 27 "$ " in SW1/4 NE1/4 sec. 14,

T.79 N.. R.6 W.. Johnson County, on right bank $60 \mathrm{ft}$ downstream from bridge on Muscatine avenue in Iowa City, and 1.2 miles upstream from mouth.

Drainage area.--2.94 sq mi.

Gage.--Water-stage recorder and v-notch sharp-crested weir. Datum of gage is 678.03 ft above mean sea level.

Stage-discharge relation.--Defined by current-meter measurements below 220 cfs and by flow-through-culvert measurement at 780 cfs.

Remarks.--Base for partial-duration series, 200 cfs.

Peak﹎.stagges_and__di

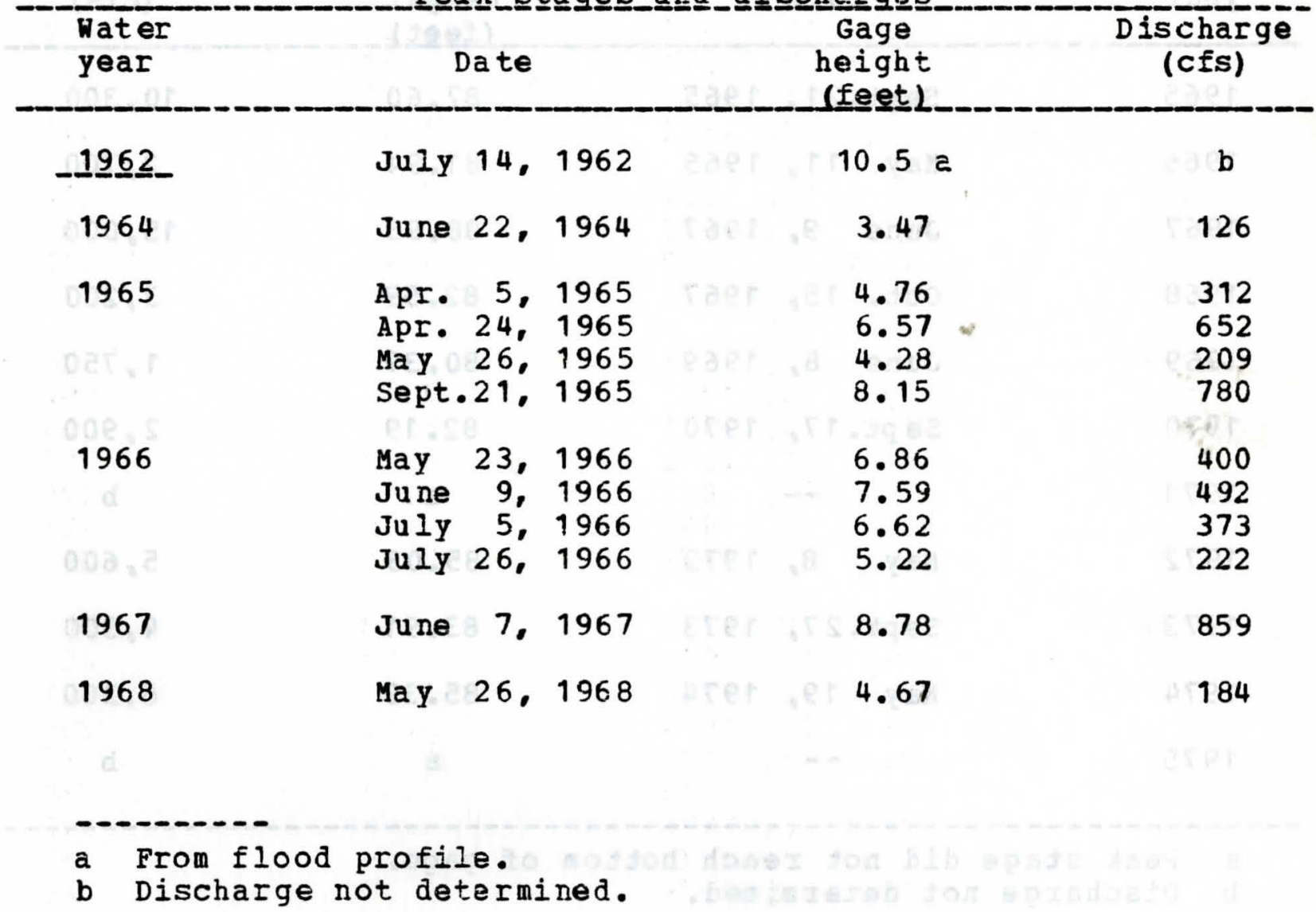


05-4550.10 South Branch Ralston Creek at Iowa City, Iowa--(Continued)

Peak stages and discharges

\begin{tabular}{|c|c|c|c|c|}
\hline $\begin{array}{l}\text { Water } \\
\text { year }\end{array}$ & D & Date & $\begin{array}{l}\text { Gage } \\
\text { height } \\
\text { feet }\end{array}$ & $\begin{array}{l}\text { Discharge } \\
\text { (cfs) }\end{array}$ \\
\hline 1969 & $\begin{array}{l}\text { June } \\
\text { June } \\
\text { June } \\
\text { JuIy } \\
\text { July } \\
\text { JuIy } \\
\text { July }\end{array}$ & $\begin{array}{rr}7, & 1969 \\
8, & 1969 \\
29, & 1969 \\
7, & 1969 \\
8, & 1969 \\
18, & 1969 \\
19, & 1969\end{array}$ & $\begin{array}{l}4.92 \\
5.06 \\
6.79 \\
5.68 \\
8.52 \\
5.15 \\
5.97\end{array}$ & $\begin{array}{l}203 \\
213 \\
341 \\
255 \\
677 \\
216 \\
272\end{array}$ \\
\hline 1970 & $\begin{array}{l}\text { Mar. } \\
\text { May } \\
\text { June } \\
\text { July } \\
\text { Sept. }\end{array}$ & $\begin{array}{r}2,1970 \\
29,1970 \\
20,1970 \\
3,1970 \\
17,1970\end{array}$ & $\begin{array}{l}5.99 \\
5.99 \\
5.55 \\
5.50 \\
7.40\end{array}$ & $\begin{array}{l}276 \\
276 \\
246 \\
242 \\
510\end{array}$ \\
\hline 1971 & $\begin{array}{l}\text { July } \\
\text { July } \\
\text { July } \\
\text { Sept. }\end{array}$ & 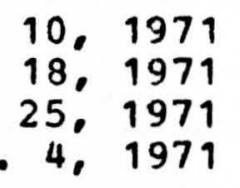 & $\begin{array}{l}6.20 \\
5.69 \\
5.15 \\
5.48\end{array}$ & $\begin{array}{l}292 \\
255 \\
218 \\
241\end{array}$ \\
\hline 1972 & $\begin{array}{l}\text { Dec. } \\
\text { May } \\
\text { JuIy } \\
\text { Aug. }\end{array}$ & $\begin{array}{rr}15, & 1972 \\
29, & 1972 \\
17, & 1972 \\
6, & 1972\end{array}$ & $\begin{array}{l}5.43 \\
5.30 \\
9.47 \\
7.71\end{array}$ & $\begin{array}{r}224 \\
236 \\
1.070 \\
578\end{array}$ \\
\hline 1973 & $\begin{array}{l}\text { Dec. } \\
\text { Apr. } \\
\text { Apr. } \\
\text { May } \\
\text { May } \\
\text { June } \\
\text { Sept. }\end{array}$ & $\begin{array}{r}30,1973 \\
20,1973 \\
30,1973 \\
1,1973 \\
27,1963 \\
4,1973 \\
21,1973\end{array}$ & $\begin{array}{l}-- \\
7.65 \\
5.16 \\
5.73 \\
5.62 \\
5.16 \\
5.60\end{array}$ & $\begin{array}{l}220 \text { c } \\
564 \\
226 \\
281 \\
270 \\
226 \\
268\end{array}$ \\
\hline 1974 & $\begin{array}{l}\text { Apr. } \\
\text { May } \\
\text { May } \\
\text { May } \\
\text { June } \\
\text { June } \\
\text { July } \\
\text { Aug. } \\
\text { Aug. } \\
\text { Aug. }\end{array}$ & $\begin{array}{rr}28, & 1974 \\
13, & 1974 \\
16, & 1974 \\
29, & 1974 \\
7, & 1974 \\
22, & 1974 \\
22, & 1974 \\
12, & 1974 \\
16, & 1974 \\
21, & 1974\end{array}$ & $\begin{array}{l}7.58 \\
5.83 \\
6.29 \\
5.95 \\
6.33 \\
6.18 \\
6.91 \\
6.40 \\
5.79 \\
5.66\end{array}$ & $\begin{array}{l}548 \\
298 \\
373 \\
306 \\
355 \\
336 \\
442 \\
368 \\
286 \\
270\end{array}$ \\
\hline
\end{tabular}


05-4550.10 South Branch Ralston Creek at Iowa Cicy, Iowa--(Continued)

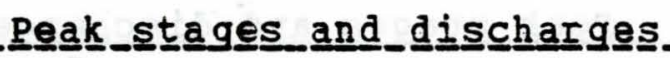

\begin{tabular}{l}
$\begin{array}{l}\text { Water } \\
\text { year }\end{array}$ \\
\hline 1975
\end{tabular}


05-4553.00 South English River near Barnes City. Iowa (Prior to 1967 published as "South Fork English River")

Locatior.--Lat $41031 \%$ long 920281 , near NW corner sec.34, T.78 N. R.14 W. Poweshiek County, at bridge, 1 mile north of Barnes City.

Drainage area.--11.5 sq mi.

Gage.--Crest-stage gage.

Stage-discharge relation.--Defined by current-meter and indirect measurements.

Remarks.--only annual peaks are shown.

Peak﹎.stages_and_di

\begin{tabular}{|c|c|c|c|c|c|}
\hline $\begin{array}{l}\text { Water } \\
\text { year }\end{array}$ & & Date & & $\begin{array}{l}\text { Ga g9 } \\
\text { həight } \\
\text { (feet) }\end{array}$ & $\begin{array}{l}\text { Discharge } \\
\text { (cfs) }\end{array}$ \\
\hline 1953 & June & 28 & 1953 & 11.40 & 478 \\
\hline 1954 & Aug. & 26 & 1954 & 10.88 & 352 \\
\hline 1955 & Apr. & 24. & 1955 & 9.20 & 157 \\
\hline 1956 & Aug. & 12 & 1956 & 8.43 & 121 \\
\hline 1957 & July & 3. & 1957 & 9.50 & 172 \\
\hline 1958 & JuIy & 31. & 1958 & 10.87 & 318 \\
\hline 1959 & July & 18 & 1959 & 11.73 & 611 \\
\hline 1960 & JuIy & 12 & 1960 & 12.14 & 865 \\
\hline 1961 & JuIy & 27 & 1961 & 13.43 & 1.790 \\
\hline 1962 & MaI. & 19. & 1962 & 11.49 & 666 \\
\hline 1963 & Mar. & 4. & 1963 & 10.80 & 298 \\
\hline 1964 & June & 22 & 1964 & 11.42 & 484 \\
\hline 1965 & July & 9, & 1965 & 12.07 & 812 \\
\hline 1966 & June & 12. & 1966 & 12.25 & 1.130 \\
\hline 1967 & Apr. & 13 & 1967 & 11.62 & 650 \\
\hline
\end{tabular}


05-4553.00 South English River near Barnes City, Iowa--(Continued)

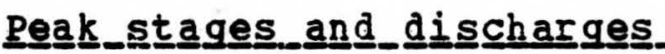

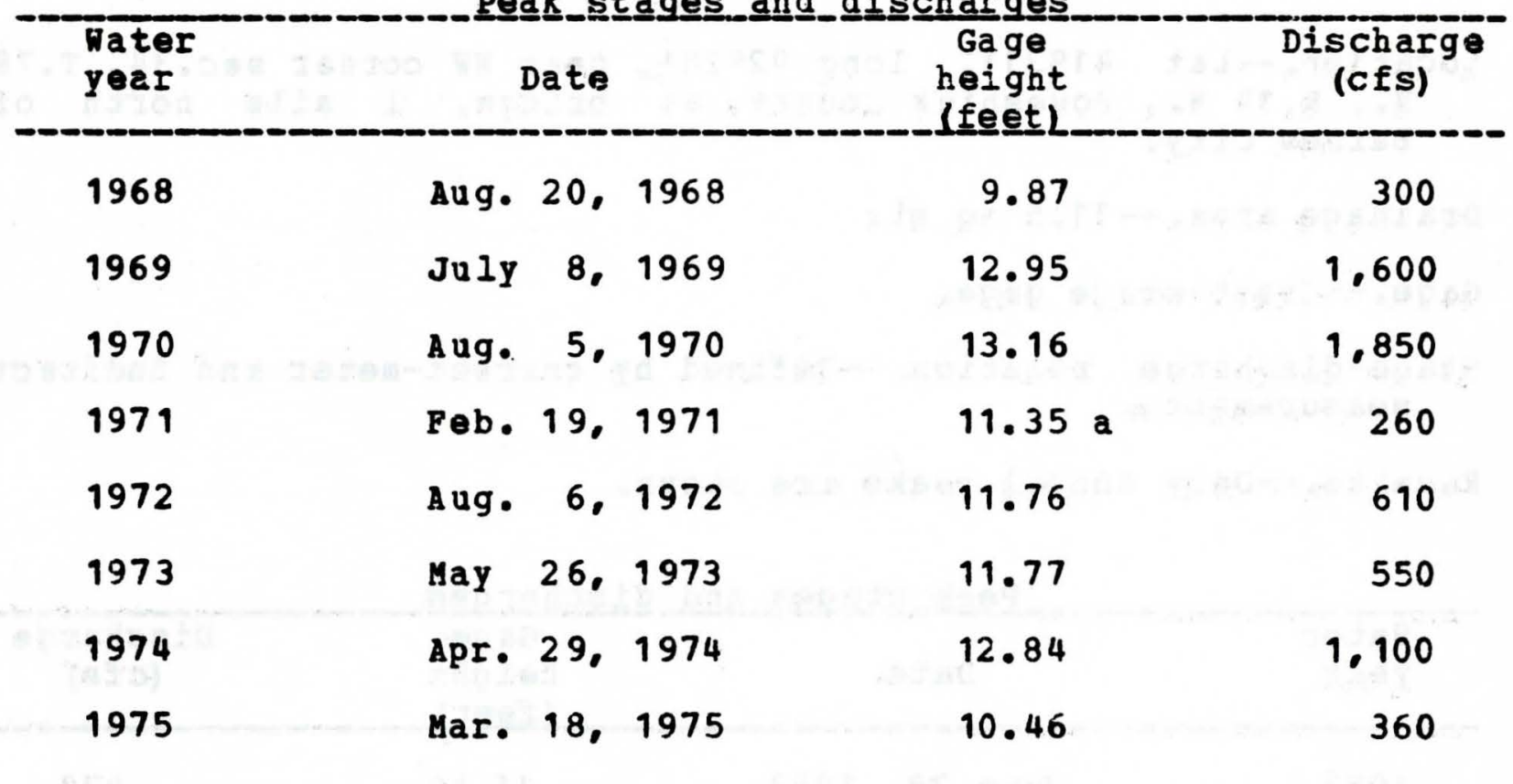

a Afected by ice. 
05-4552.80 South English River tributary near Barnes City, Iowa (Prior to 1967 published as "South Fork English River")

Location.-- Lat $41033^{\prime}$, long $92038^{\prime}$, near NE corner sec.21, T.78 N. . R.14. N., Poweshiek County, at bridge, 3 miles north of Barnes City.

Drainage area.--2.51 sq $\mathrm{mi}$.

Gage.--Crest-stage gage.

Stage-discharge relation.--Defired by current-meter and indirect measurements.

Remarks.--only annual peaks are shown.

Peak__stages_and__dis

\begin{tabular}{llcl}
\hline $\begin{array}{c}\text { Water } \\
\text { Year }\end{array}$ & \multicolumn{1}{c}{ Date } & $\begin{array}{c}\text { Gage } \\
\text { height } \\
\text { (feetL }\end{array}$ & $\begin{array}{c}\text { Discharge } \\
\text { (cfs) }\end{array}$ \\
\hline 1953 & June 28,1953 & 7.38 & 400 \\
1954 & Aug. 26,1954 & 8.21 & 650 \\
1955 & oct. 10,1954 & 6.19 & 170 \\
1956 & Aug. 12,1956 & 6.77 & 263 \\
1957 & July 3,1957 & 7.38 & 400 \\
1958 & Aug. 15,1958 & 6.72 & 255 \\
1959 & July 18,1959 & 8.55 & 793 \\
1960 & June 19,1960 & 8.57 & 690 \\
1961 & July 27,1961 & 8.81 & 784 \\
1962 & Nov. 16,1961 & 4.85 & 123 \\
1963 & Mar. 4,1963 & 5.21 & 145 \\
1964 & June 22, 1964 & 5.34 & 152 \\
1965 & July 9,1965 & 8.56 & 686 \\
1966 & June 12, 1966 & 8.33 & 606 \\
1967 & Apr. 13,1967 & 7.93 & 480
\end{tabular}



05-4552.80 South English River tributary near Barnes City. Iowa
-- (Continued)

Peak_staqes and_discharges

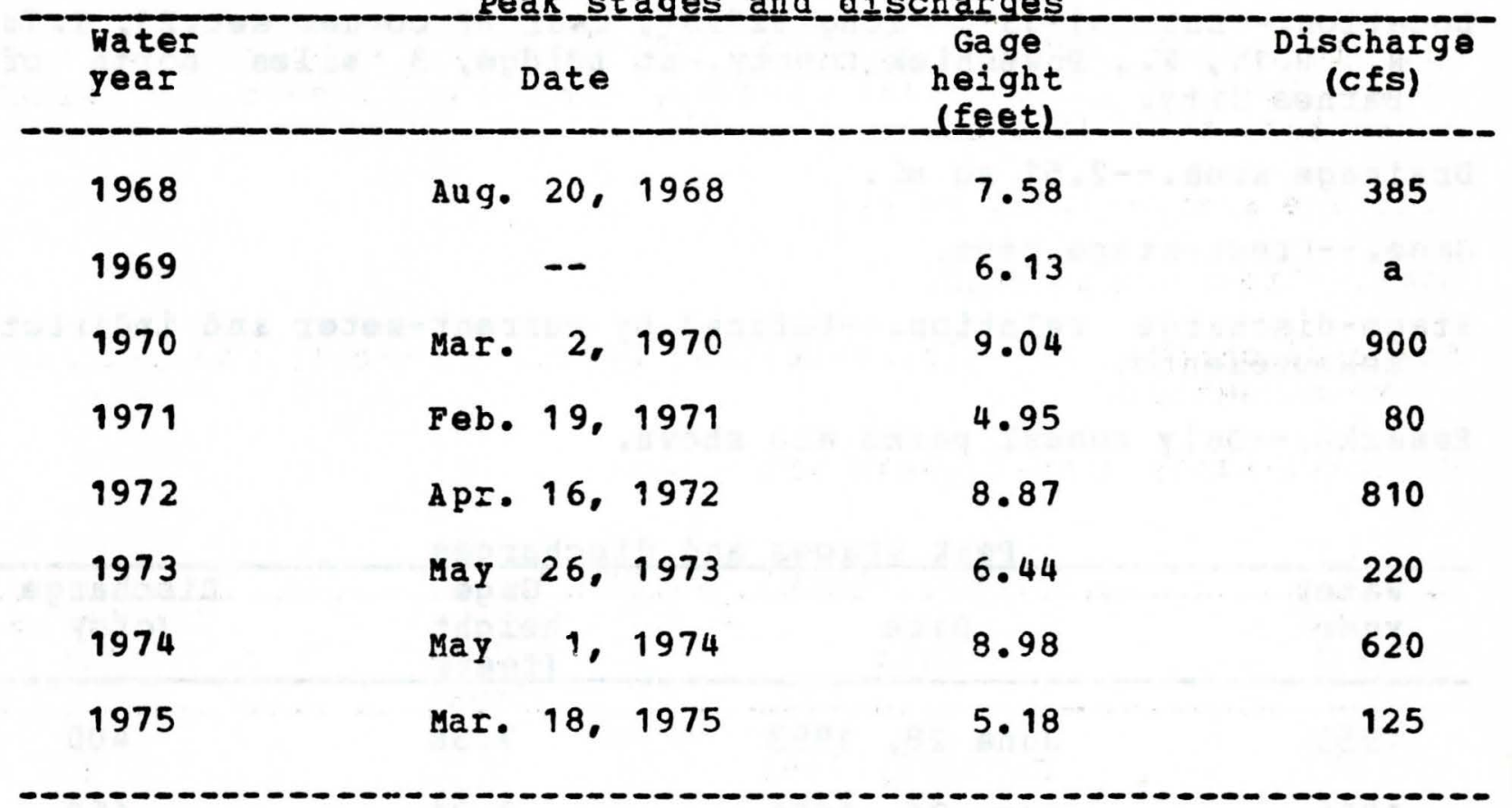

a Discharge not determined. 
05-4553.50 South EngIish River tributary No. 2 near Montezuma, Iowa (Prior to 1967 published as South Fork English River tributary No. 2 near Montezuma, Iowa)

Location.--Lat $41034^{\prime}$, iong $92027 \%$, near SW corner sec.11, t.78 N.. R.14 W.. Poweshiek County, at box culvert, 4 miles southeast of Montezuma.

Drainage area. $-0.523 \mathrm{sq} \mathrm{mi}$

Gage.--Crest-stage gage.

Stage-discharge relation.--Defined by current-meter and indirect mea surements.

Remarks.--Oniy annual peaks are shown.

Peak_stagges_and_dis

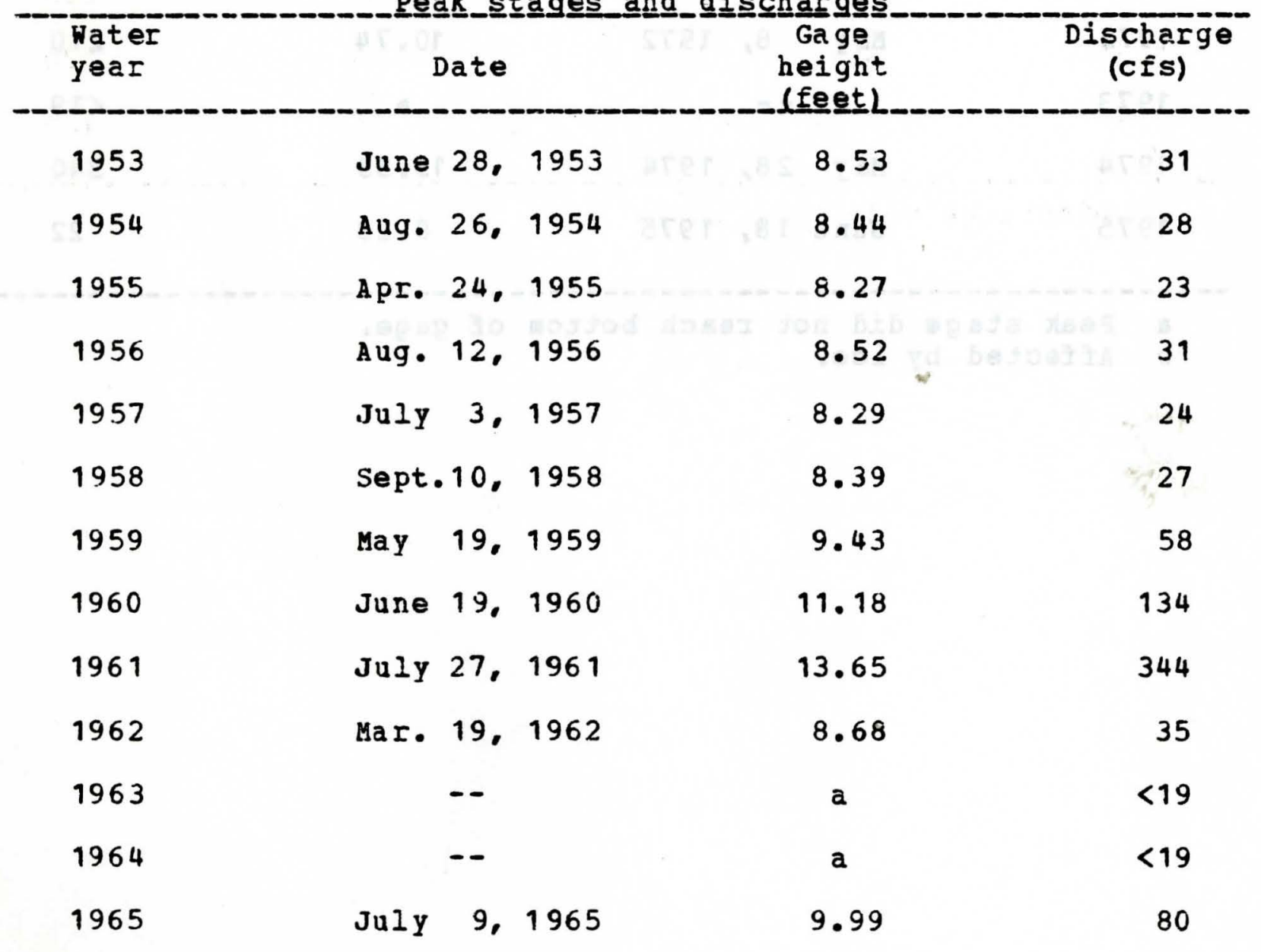

a Peak stage did not reach bottom of gage. 
05-4553.50 South English River tributary No. 2 near Montezuma, Io wa-- (Continued)

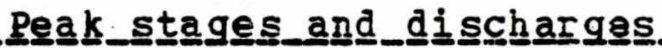

\begin{tabular}{|c|c|c|c|c|}
\hline $\begin{array}{l}\text { Water } \\
y \in a r\end{array}$ & & Date & $\begin{array}{r}\text { Gage } \\
\text { height } \\
\text { (feet) }\end{array}$ & $\begin{array}{c}\text { Discharge } \\
\text { (cfs) }\end{array}$ \\
\hline 1966 & June & 12,1966 & 9.87 & 75 \\
\hline 1967 & & -- & a & $<19$ \\
\hline 1968 & & -- & a & $<19$ \\
\hline 1969 & & -- & a & $<19$ \\
\hline 1970 & May & 20,1970 & 9.98 & 77 \\
\hline 1971 & Feb. & 19, 1971 & $8.37 \mathrm{~b}$ & 20 \\
\hline 1972 & $\operatorname{May}$ & 8. 1972 & 10.74 & 210 \\
\hline 1973 & & -- & a & $<19$ \\
\hline 1974 & May & 28,1974 & 13.53 & 340 \\
\hline 1975 & June & 18,1975 & 8.23 & 22 \\
\hline
\end{tabular}

a Peak stage did not reach bottol of gage.

b Affected by ice. 
Location.--Iat $40048 \cdot 02 \%$, long $93011 \cdot 32 "$, in Sw1/4 Sw1/4 sec.5. T. 69 N., R. 20 N.. Wayne County, on right bank 20 ft downstream from bridge on county highway $550,1.3$ miles downstream from Jordan zreek and 4.3 miles northwest of promise City.

Drainage area.--168 sq miles.

Gage.-Water-stage recorder. Datum of gage is 913.70 ft above mean sea level (Corps of Engineers bench mark).

Stage-discharge relation.--Defined by current-meter measurements. Flood stage.--18 feet.

Remarks.--Base for partial-duration series, 2,000 cfs.

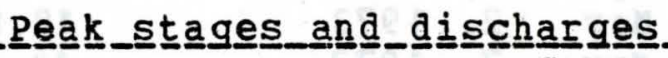

Whater

year.

Date

Sept.21, 1965

Apr. 20,1968

Apr. 23, 1968

1969

1970

1971
Jan. 16, 1969

API. 27, 1969

July 13,1969

Apr. 18, 1970

May 14, 1970

Aug. 8, 1970

Sept.17, 1970

sept.22, 1970

sept.24, 1970

oct. 9, 1970

Feb. 18, 1971

Feb. 26, 1971

MaI. 11. 1971
Gage

height

(feet)

25.5

14.60

20.96

$15.05 \mathrm{C}$

14.29

13.81

13.69

19.12

21.32

20.44

18.61

14.53

20.98

$18.93 \mathrm{C}$

$14.90 \mathrm{C}$

12.38
Discharge

(cfs)

2,710

6,940

$1,900 d$

2.600

2,290

2.250

4,280

7,660

6,160

4.420

2.690

6,970

$3.300 \mathrm{~d}$

$2,300 \mathrm{~d}$

2.010

\footnotetext{
a From floodmark.

b Discharge not determined.

c Affected by ice.

d a bout.
} 
06-9037.00 South Fork Chariton River near Promise City. Iowa-(Continued)

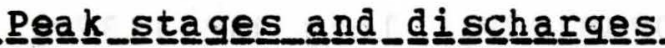

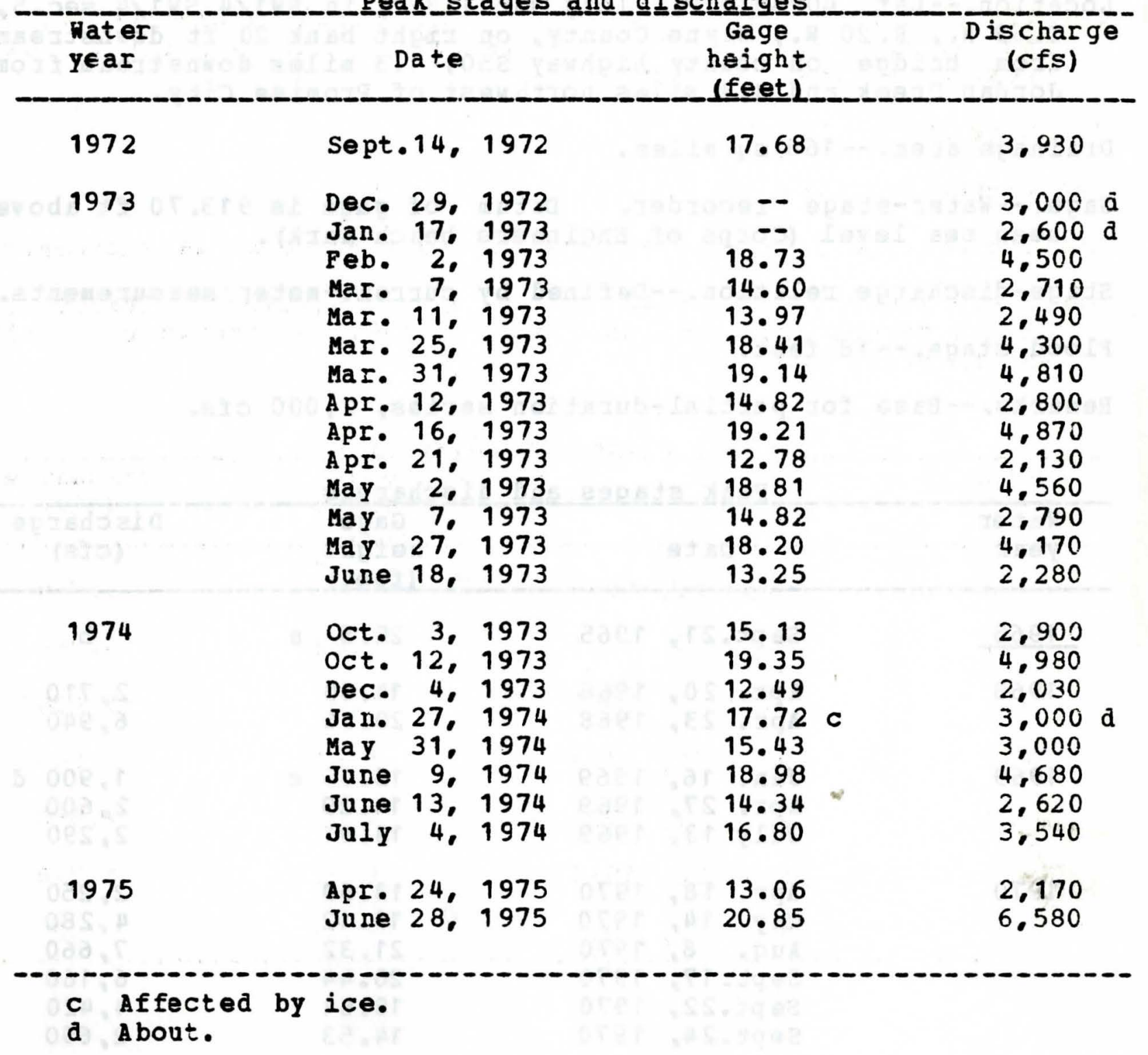


05-4512.00 South Fork Iowa River near New Providence, Iowa

Location.--Lat $42^{\circ} 19^{\prime}$, long $93010^{\circ}$, near north quarter corner of sec. 27, T.87 N.. R.20 W., Hardin County, 3 miles north of New Providence, Iowa.

Drainage area. $--233 \mathrm{sq} \mathrm{mi}$.

Gage.--Nonrecording.

Stage-discharge relation.--Defined by current-meter measurements. Remarks.--Records collected by Corps of Engineers. Station is inflow forecasting station for Coralville Reservoir. Only annual peaks are shown.

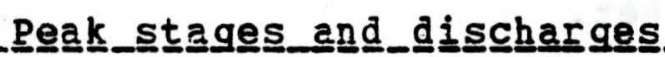

\begin{tabular}{|c|c|c|c|}
\hline $\begin{array}{l}\text { Water } \\
\text { year }\end{array}$ & Date & $\begin{array}{l}\text { Gage } \\
\text { height } \\
\text { - feetl }\end{array}$ & $\begin{array}{l}\text { Discharge } \\
\text { (cfs) }\end{array}$ \\
\hline 1950 & sept.20, 1950 & -- & 3,750 \\
\hline 1951 & Mar. 29, 1951 & 8.64 & 3,380 \\
\hline 1952 & July 9, 1952 & 6.27 & 1,400 \\
\hline 1953 & Mar. 11, 1953 & 5.60 & 1.060 \\
\hline 1954 & Aug. 27, 1954 & 7.75 & 2,550 \\
\hline 1955 & Feb. 20, 1955 & 6.06 & 1.310 \\
\hline 1956 & sept. 5, 1956 & 4.02 & 406 \\
\hline
\end{tabular}


Location.--Lat 41034'48", long 94010'58", in Sw1/4 Sw14/ sec.3. T.78 N.. R.29 H... Dallas County, on left bank $10 \mathrm{ft}$ downstream from bridge on county highway at Redfield, 0.8 mile dcwnstream from bridge on $0 . S$. Highway $6,1.0$ mile downstream from Middle Raccoon River, and 15.6 miles upstream from mouth.

Drainage area.--988 sq $\mathrm{mi}$.

Gage.--Water-stage recorder. Datum of gage is $896.43 \mathrm{ft}$ above mean sea level. Prior to June 12, 1946, nonrecording gage, and June 12, 1946, to sept. 30, 1966, water-stage recorder at site 20 ft upstream at same datum.

Stage-discharge relation.--Defined by current-meter measurements. Flood stage. -14 feet.

Remarks.--Base for partial-duration series, 5,000 cfs.

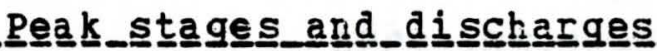

\begin{tabular}{|c|c|c|c|c|c|}
\hline $\begin{array}{l}\text { Water } \\
\text { year }\end{array}$ & & Date & $\begin{array}{l}\text { Gage } \\
\text { height } \\
\text { fefet. }\end{array}$ & & $\begin{array}{c}\text { Discharge } \\
\text { (cfs) }\end{array}$ \\
\hline 1940 & July & 31,1940 & $13 \cdot 3$ & & 6.100 \\
\hline 1941 & June & 28,1941 & $10 \cdot 5$ & $\approx$ & 3.550 \\
\hline 1942 & $\begin{array}{l}\text { May } \\
\text { Aug. }\end{array}$ & $\begin{array}{ll}11, & 1942 \\
28, & 1942\end{array}$ & $\begin{array}{l}13.0 \\
13.4\end{array}$ & & $\begin{array}{l}5.740 \\
6.380\end{array}$ \\
\hline 1943 & Aug. & 25,1943 & 14.1 & & 6,610 \\
\hline 1944 & $\begin{array}{l}\text { May } \\
\text { May } \\
\text { May } \\
\text { June }\end{array}$ & 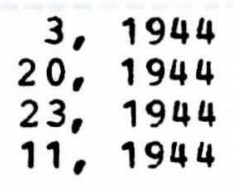 & $\begin{array}{l}13.2 \\
23.8 \\
16.9 \\
13.7\end{array}$ & & $\begin{array}{r}5.930 \\
20,000 \\
9.750 \\
6.430\end{array}$ \\
\hline 1945 & $\begin{array}{l}\text { May } \\
\text { May } \\
\text { May } \\
\text { June }\end{array}$ & $\begin{array}{r}14,1945 \\
22,1945 \\
30,1945 \\
6,1945\end{array}$ & $\begin{array}{l}15.0 \\
17.2 \\
15.0 \\
13.1\end{array}$ & * & $\begin{array}{r}7.730 \\
10.100 \\
7.730 \\
5.830\end{array}$ \\
\hline 1946 & $\begin{array}{l}\text { Aug. } \\
\text { Se pt. }\end{array}$ & $\begin{array}{r}24,1946 \\
8,1946\end{array}$ & $\begin{array}{l}18.9 \\
21.4\end{array}$ & & $\begin{array}{l}12,000 \\
15,200\end{array}$ \\
\hline
\end{tabular}


05-4840.00 South Raccoon River at Redfield, Iowa--(Continued)

Peak_t_t_agges and

\begin{tabular}{|c|c|c|c|}
\hline $\begin{array}{l}\text { Water } \\
\text { year }\end{array}$ & Date & $\begin{array}{l}\text { Gage } \\
\text { height } \\
\text { - fieetL. }\end{array}$ & $\begin{array}{l}\text { Discharge } \\
\text { (cfs) }\end{array}$ \\
\hline 1947 & $\begin{array}{l}\text { June } 2,1947 \\
\text { June } 5,1947 \\
\text { June } 12,1947 \\
\text { June } 24,1947\end{array}$ & $\begin{array}{l}19.9 \\
22.7 \\
24.3 \\
16.7\end{array}$ & $\begin{array}{l}15,000 \\
20,500 \\
23,800 \\
10,500\end{array}$ \\
\hline 1948 & Mar. 19,1948 & 21.3 & 17,600 \\
\hline 1949 & Mar. 6,1949 & 14.2 & 7,530 \\
\hline 1950 & $\begin{array}{lrr}\text { May } & 5, & 1950 \\
\text { June } & 19, & 1950 \\
\text { June } & 23, & 1950\end{array}$ & $\begin{array}{l}14.7 \\
17.9 \\
13.8\end{array}$ & $\begin{array}{r}7,990 \\
11,600 \\
7,080\end{array}$ \\
\hline 1951 & $\begin{array}{lrr}\text { Mar. } & 29, & 1951 \\
\text { May } & 2, & 1951 \\
\text { June } & 2, & 1951 \\
\text { June } & 7, & 1951 \\
\text { JuIY } & 3, & 1951\end{array}$ & $\begin{array}{l}20.10 \\
17 \cdot 70 \\
18.14 \\
12.19 \\
16.26\end{array}$ & $\begin{array}{r}15,400 \\
11,700 \\
12,200 \\
5,680 \\
10,100\end{array}$ \\
\hline 1952 & $\begin{array}{l}\text { Mar. 13, } 1952 \\
\text { Mar. 31, } 1952 \\
\text { June 21, } 1952 \\
\text { June 27, } 1952\end{array}$ & $\begin{array}{l}11.53 \\
14.39 \\
12.12 \\
16.06\end{array}$ & $\begin{array}{l}5,160 \\
7,840 \\
5,680 \\
9,740\end{array}$ \\
\hline 1953 & $\begin{array}{l}\text { May } 24,1953 \\
\text { June } 10,1953\end{array}$ & $\begin{array}{l}12.23 \\
23.08\end{array}$ & $\begin{array}{r}5,680 \\
21,300\end{array}$ \\
\hline 1954 & Aug. 22,1954 & 13.84 & 7,200 \\
\hline 1955 & Apr. 24, 1955 & 12.86 & 6,310 \\
\hline 1956 & Sept. 4, 1956 & 9.80 & 3,840 \\
\hline 1957 & June 17, 1957 & 17.80 & 12,700 \\
\hline 1958 & $\begin{array}{lrl}\text { July } & 2, & 1958 \\
\text { July } & 4, & 1958 \\
\text { July } & 19, & 1958 \\
\text { Sept. } & 6, & 1958\end{array}$ & $\begin{array}{l}29.04 a \\
19.28 \\
15.80 \\
25.12\end{array}$ & $\begin{array}{r}35,000 \\
14.200 \\
9.580 \\
25,500\end{array}$ \\
\hline 1959 & May 30,1959 & 10.95 & 5,420 \\
\hline
\end{tabular}


05-4840.00 South Râccoon River at kedfield, Iowa--(Continued)

Peak stages and discharges

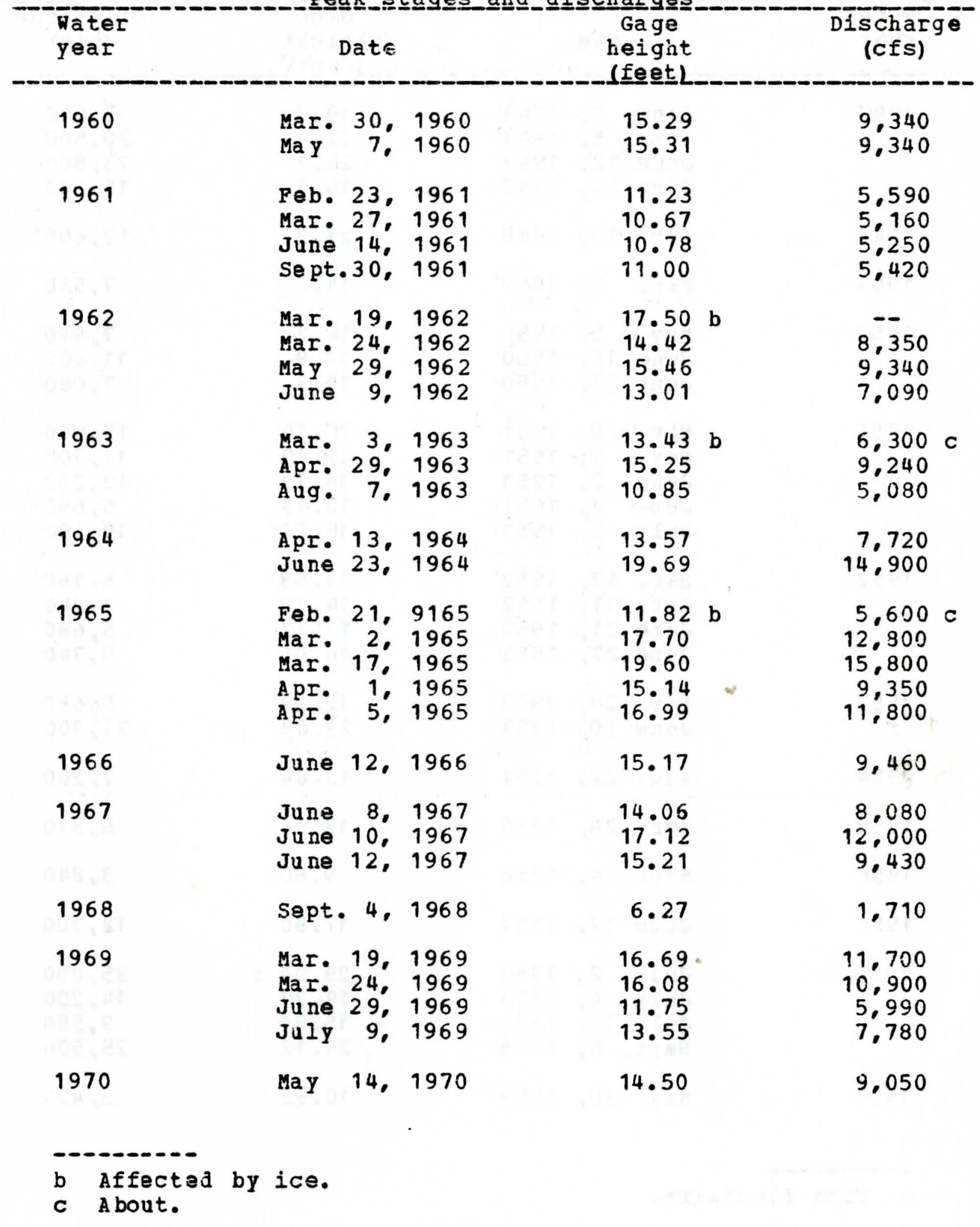


05-4840.00 South Raccoon River at Redfield, Iowa--(Continued)

Peak__stages and

\begin{tabular}{|c|c|c|c|c|}
\hline $\begin{array}{l}\text { Water } \\
\text { year }\end{array}$ & Date & & $\begin{array}{l}\text { Gage } \\
\text { height } \\
\text { (feet) }\end{array}$ & $\begin{array}{l}\text { Discharge } \\
\text { (cfs) }\end{array}$ \\
\hline 1971 & $\begin{array}{l}\text { Feb. } 19, \\
\text { Mar. } 14, \\
\text { June } 6,\end{array}$ & $\begin{array}{l}1971 \\
1971 \\
1971\end{array}$ & $\begin{array}{l}20.82 \\
14.61 \\
17.25\end{array}$ & $\begin{array}{r}17.800 \\
9.200 \\
12.500\end{array}$ \\
\hline 1972 & $\begin{array}{l}\text { Aug. } 2, \\
\text { Sept. 11. }\end{array}$ & $\begin{array}{l}1972 \\
1972\end{array}$ & $\begin{array}{r}12.82 \\
13.95\end{array}$ & $\begin{array}{l}7.220 \\
8,410\end{array}$ \\
\hline 1973 & $\begin{array}{l}\text { Mar. } 14, \\
\text { Apr. 1\% } \\
\text { Apr. 16, } \\
\text { May } 8, \\
\text { June 5, } \\
\text { July } 4, \\
\text { July } 30 \\
\text { Sept. } 26,\end{array}$ & $\begin{array}{l}1973 \\
1973 \\
1973 \\
1973 \\
1973 \\
1973 \\
1973 \\
1973\end{array}$ & $\begin{array}{l}10.33 \\
10.95 \\
14.77 \\
17.63 \\
10.74 \\
19.97 \\
10.96 \\
14.74\end{array}$ & $\begin{array}{r}5,010 \\
5,650 \\
9,650 \\
13,000 \\
5,260 \\
16,500 \\
5,450 \\
9,310\end{array}$ \\
\hline 1974 & $\begin{array}{ll}\text { Oct. } & 11, \\
\text { Apr. } 21, \\
\text { Apr. } 28, \\
\text { May } 16, \\
\text { May } 19, \\
\text { May } 21, \\
\text { May } 26,\end{array}$ & $\begin{array}{l}1973 \\
1974 \\
1974 \\
1974 \\
1974 \\
1974 \\
1974\end{array}$ & $\begin{array}{l}11.96 \\
15.58 \\
12.93 \\
10.64 \\
21.85 \\
13.42 \\
11.52\end{array}$ & $\begin{array}{r}6,380 \\
10,300 \\
7,380 \\
5,210 \\
20,000 \\
8,300 \\
6,150\end{array}$ \\
\hline 1975 & $\begin{array}{l}\text { Apr. } 28, \\
\text { June } 18, \\
\text { June } 25\end{array}$ & $\begin{array}{l}1975 \\
1975 \\
1975\end{array}$ & $\begin{array}{l}15.45 \\
14.28 \\
12.40\end{array}$ & $\begin{array}{r}10.200 \\
8.680 \\
6.720\end{array}$ \\
\hline
\end{tabular}


05-4874.70 South River neaI Ackworth, Iowa

Location.--Lat $410^{\circ} 20144^{\prime \prime}$, long $93029110^{\prime \prime}$, in SE1/4 SE1/4 sec. 34 , T.76 N.. R. 23 W.. Warren county, on right bank $15 \mathrm{ft}$ downstream from bridge on county highway, $0.5 \mathrm{mile}$ downstream from otter Creek, and 2.2 miles southwest of Ackworth.

Drainage area. $--460 \mathrm{sg}$ mi.

Gage.--Water-stage recorder. Datum of gage is $769.97 \mathrm{ft}$ abova mean sea level (levels by Corps of Engineers). Prior to June 12. 1946, nonrecording gage. June 13, 1946, to Apr. 13, 1960, water-stage recorder, and Apr. 14, 1960, to sept. 30, 1961. nonrecording gage, ail at site 4.0 miles downstream at datum $8.06 \mathrm{ft}$ lower.

Stage-discharge relation.--Defined by current-meter measurements. Flood stage.-- 19 feet.

Remarks.--Base for partial-duration series, 5.000 cfs.

Peak__stagges_and dis $\underline{\text { charghas }}$

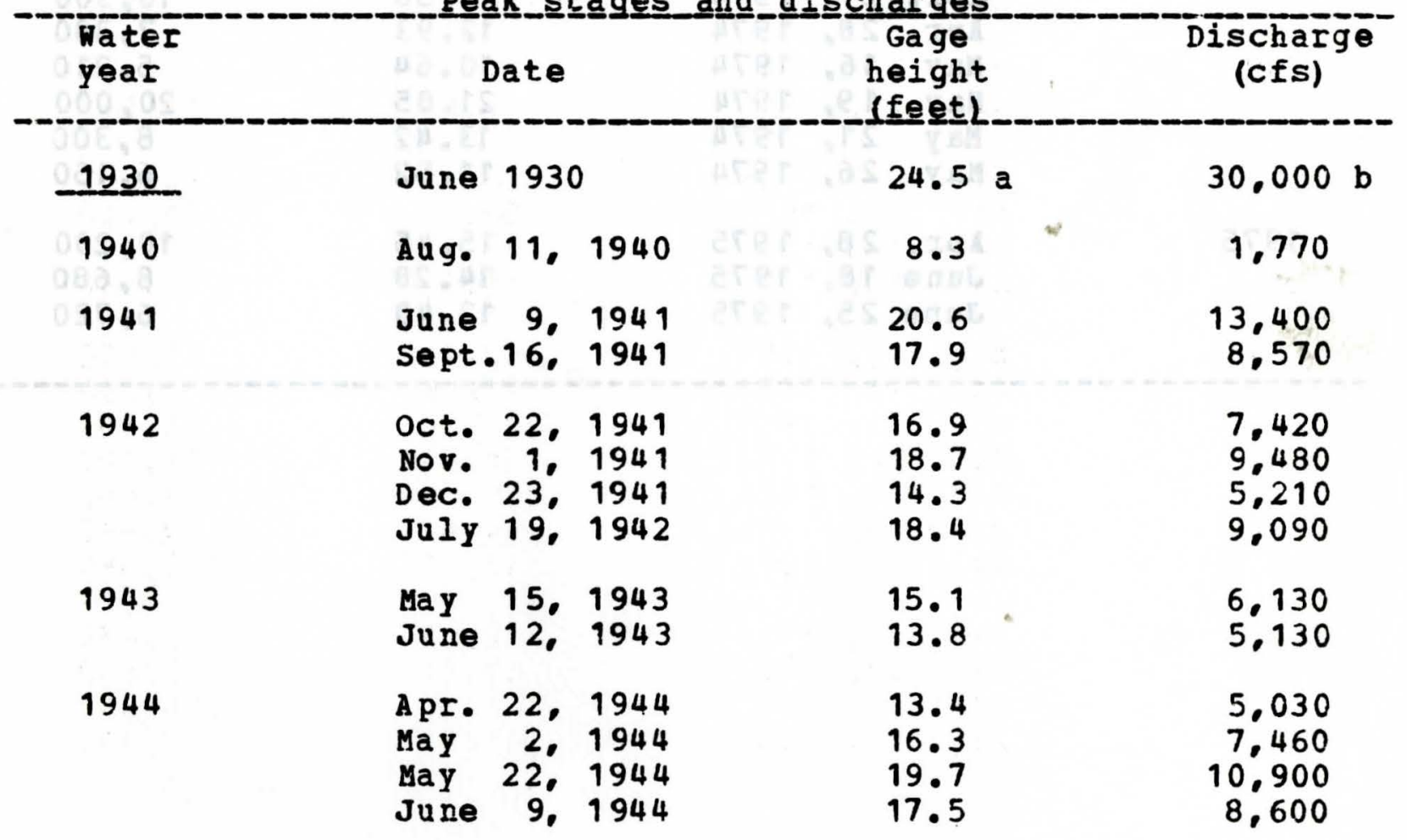

a From information by local residents.

b about. 
Peak﹎.stagges_and_di scharges

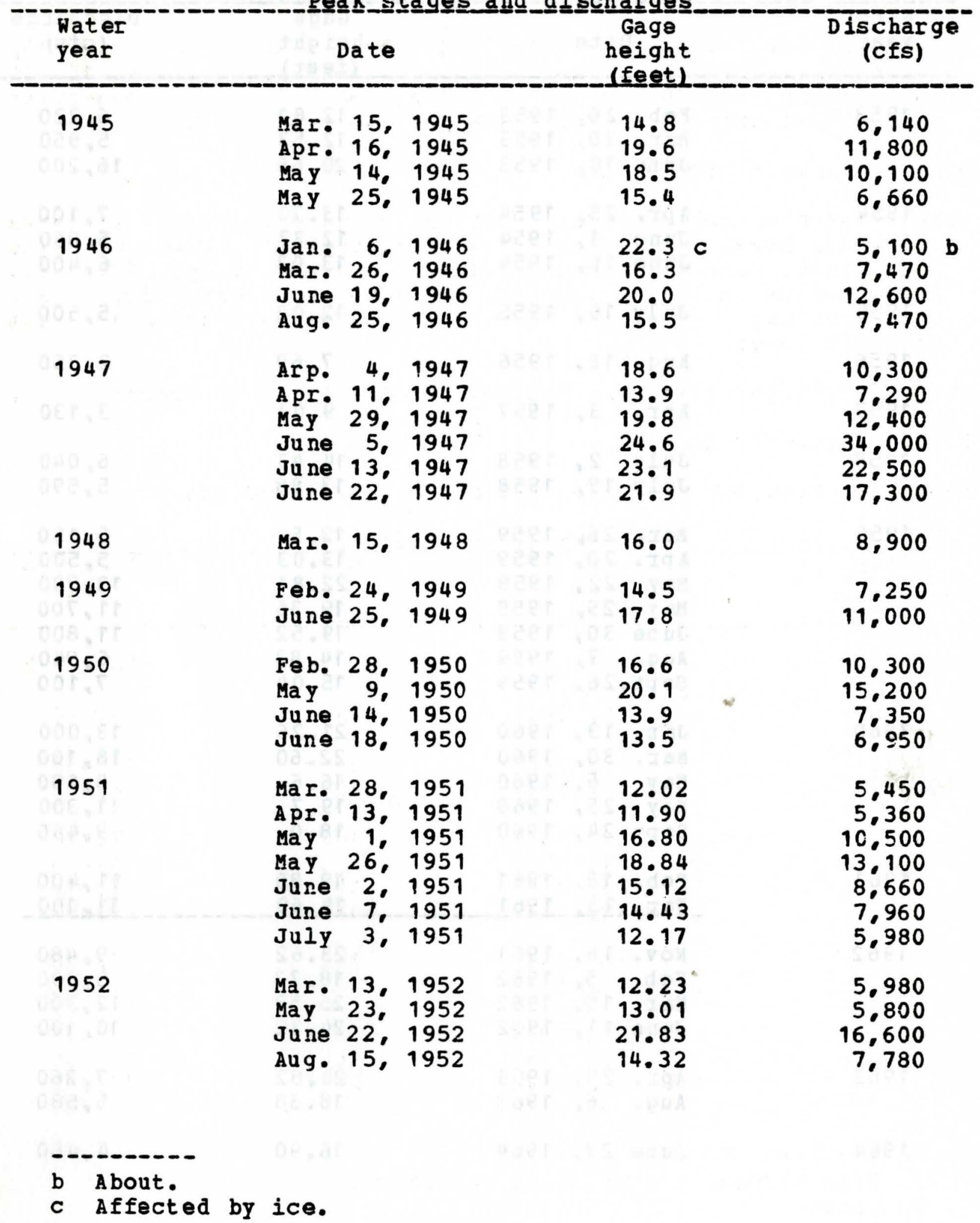


05-4874.70 South River near Ackworth, Iowa--(Continued)

Pea $k$ stages and di discharges

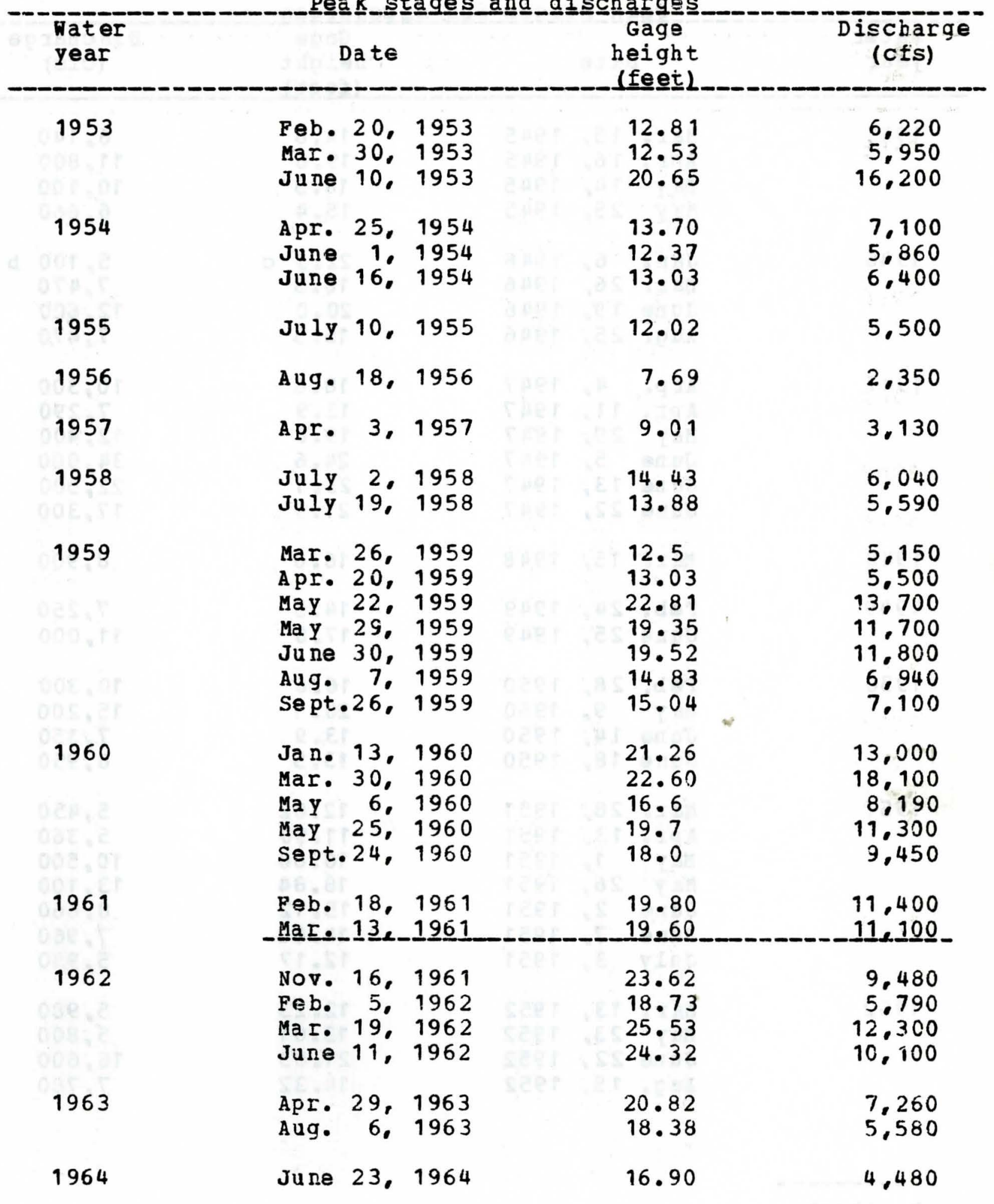


05-4874.70 South River near Ackworth, Iowa-- (Continued)

Peak_stagaes_and_di

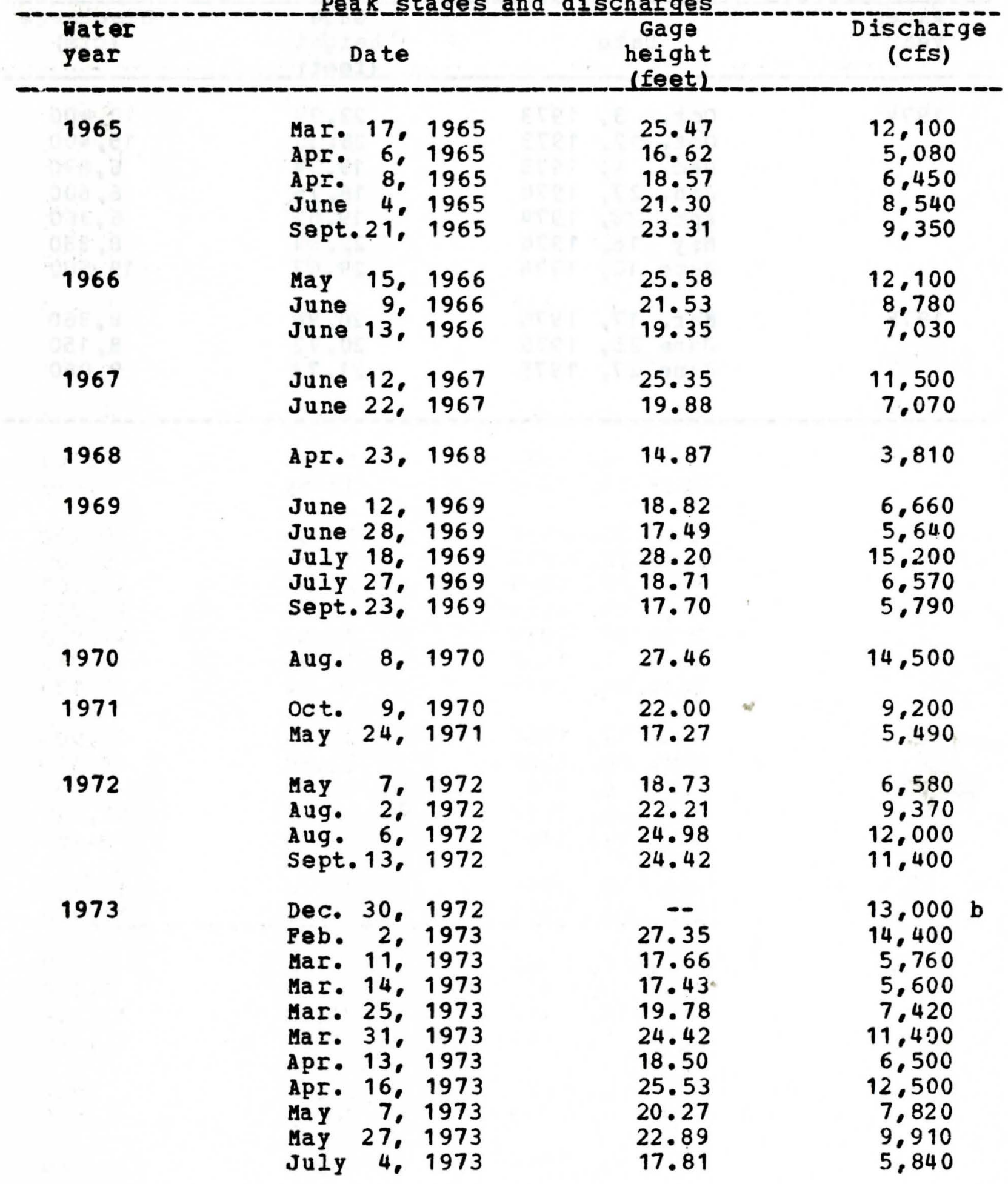

b About. 
05-4874.70 South River near Ackworth, Iowa--(Continued)

Peak﹎.stagges_and_di

\begin{tabular}{|c|c|c|c|}
\hline $\begin{array}{l}\text { Water } \\
\text { year }\end{array}$ & Date & $\begin{array}{l}\text { Gage } \\
\text { height } \\
\text { (feet). }\end{array}$ & $\begin{array}{c}\text { Discharge } \\
\text { (cfs) }\end{array}$ \\
\hline 1974 & $\begin{array}{l}\text { Oct. } 3,1973 \\
\text { Oct. } 12,1973 \\
\text { Dec. } 4,1973 \\
\text { Jan. } 27,1974 \\
\text { Apr. } 28,1974 \\
\text { May } 18,1974 \\
\text { June 10, } 1974\end{array}$ & $\begin{array}{l}23.39 \\
28.30 \\
19.34 \\
18.75 \\
19.05 \\
22.54 \\
29.07\end{array}$ & $\begin{array}{r}10.400 \\
15,400 \\
6.830 \\
6.600 \\
6.360 \\
8.880 \\
19.500\end{array}$ \\
\hline 1975 & $\begin{array}{l}\text { Mar. } 17,1975 \\
\text { June } 25,1975 \\
\text { June } 27,1975\end{array}$ & $\begin{array}{l}20.96 \\
20.72 \\
21.73\end{array}$ & $\begin{array}{l}8.360 \\
8.150 \\
9.060\end{array}$ \\
\hline
\end{tabular}


Location.--Lat $42004 \cdot 05^{\prime \prime}$, long $93037 \cdot 02^{\prime \prime}$, in NW1/4 $\mathrm{sH1} / 4$ sec. 23 , T. 84 N.. R. 24 W.. Story County, on left bank 2.5 miles north of Ames, 3.5 miles downstream from Keigley Branch, 5.2 miles upstream from squaw Creek, and at mile 228.1 upstream from mouth of Skunk River.

Drainage area.--315 sq mi.

Gage.-- Water-stage recorder. Concreta control since July 21. 1934. Datum of gage is $998.61 \mathrm{ft}$ above mean sea level (Iowa Highway Commission bench mark). Prior to Aug. 25, 1921, nonrecording gage at same site and datum.

stage-discharge relation.--Defined by current-meter measurements. Plood stage.-- 10 feet.

Remarks.--Base for partial-duration series, 1,500 cfs. Several diversions for irrigation above station.

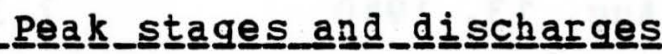

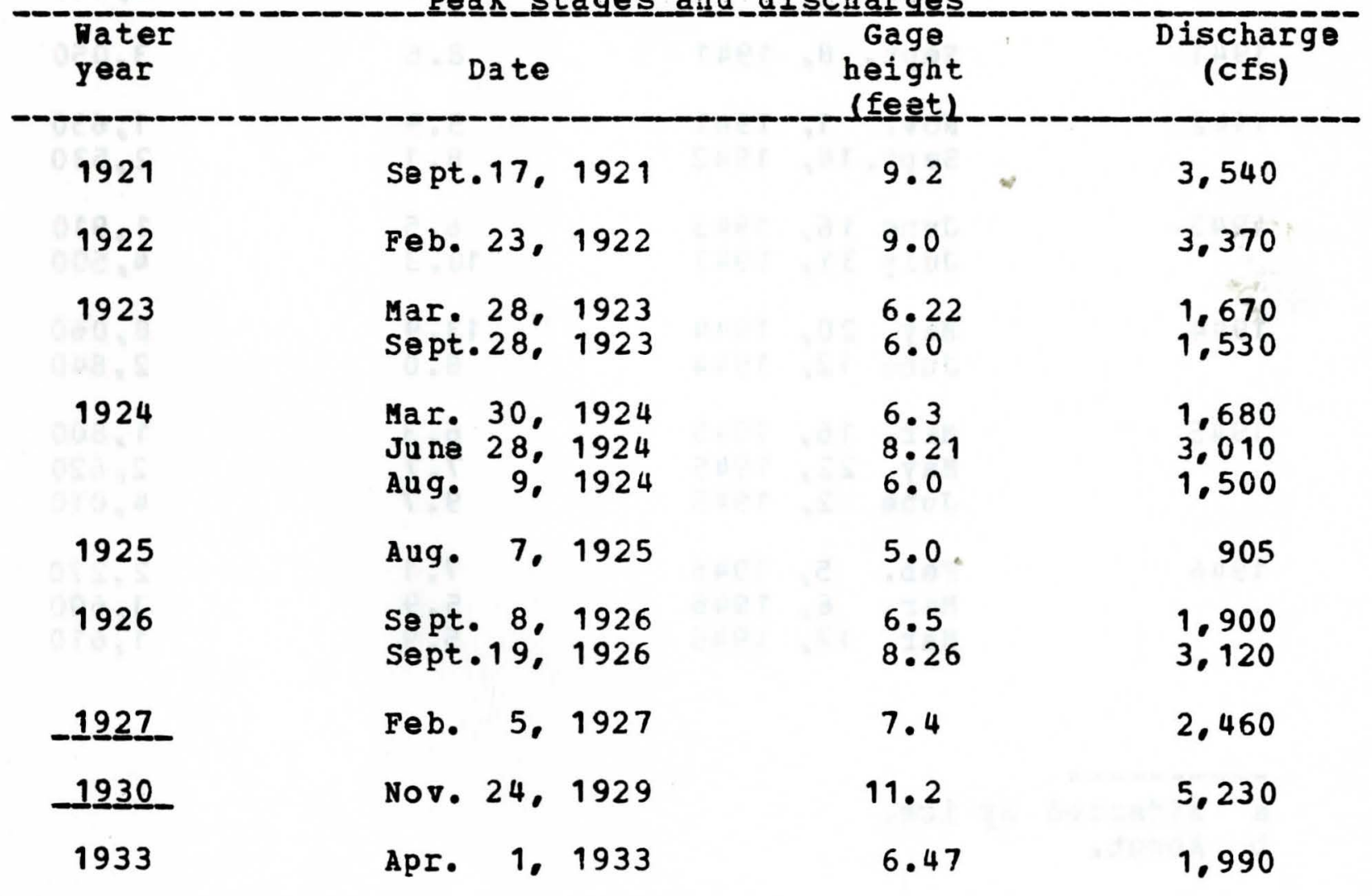


05-4700.00 South Skunk River near Ames, Iowa--(Continued)

Peak stages and di scharges

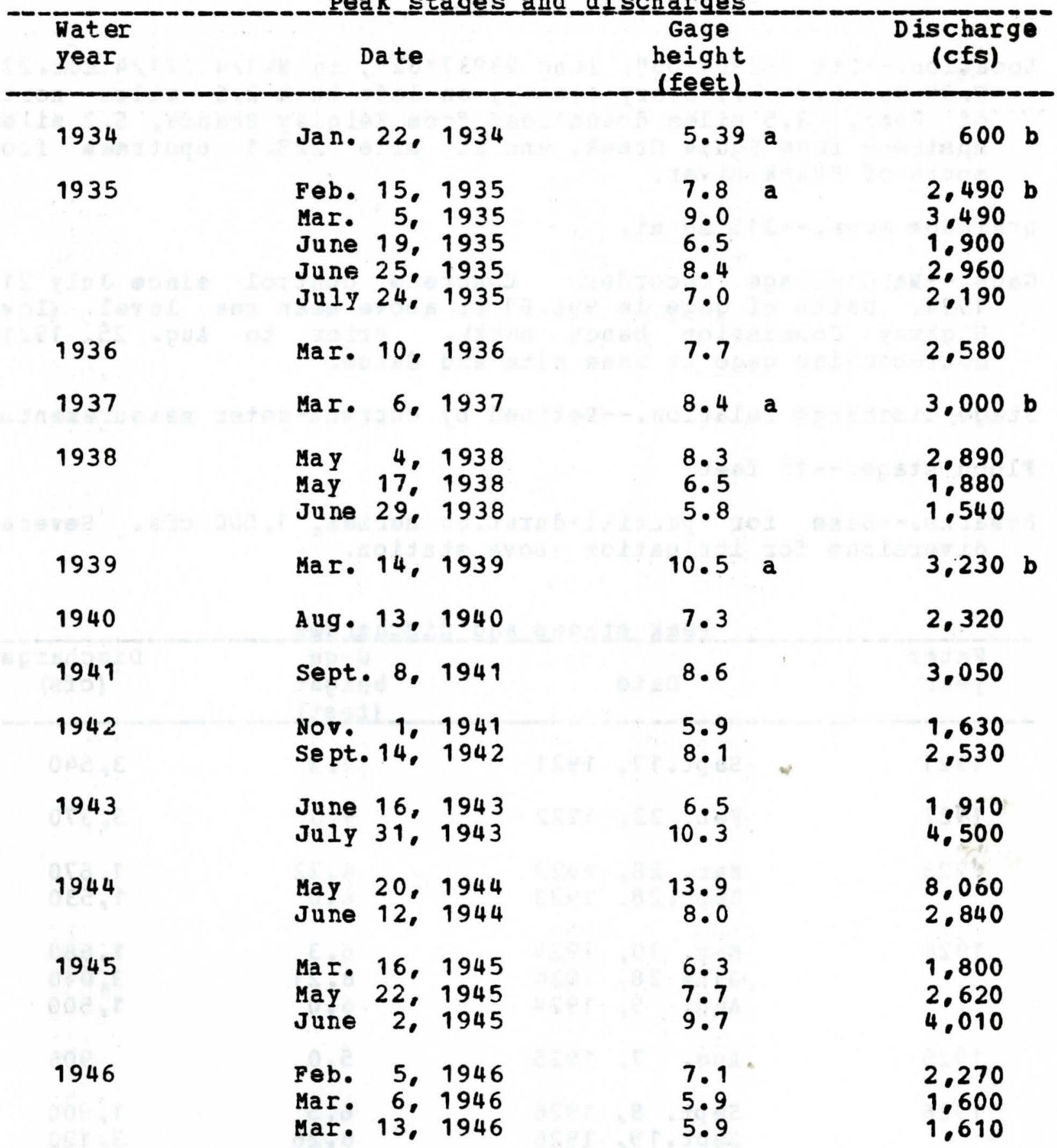

a Affected by ice.

b About. 
05-4700.00 South Skunk River near Ames, Iowa--(Continued)

Peak__staages_and

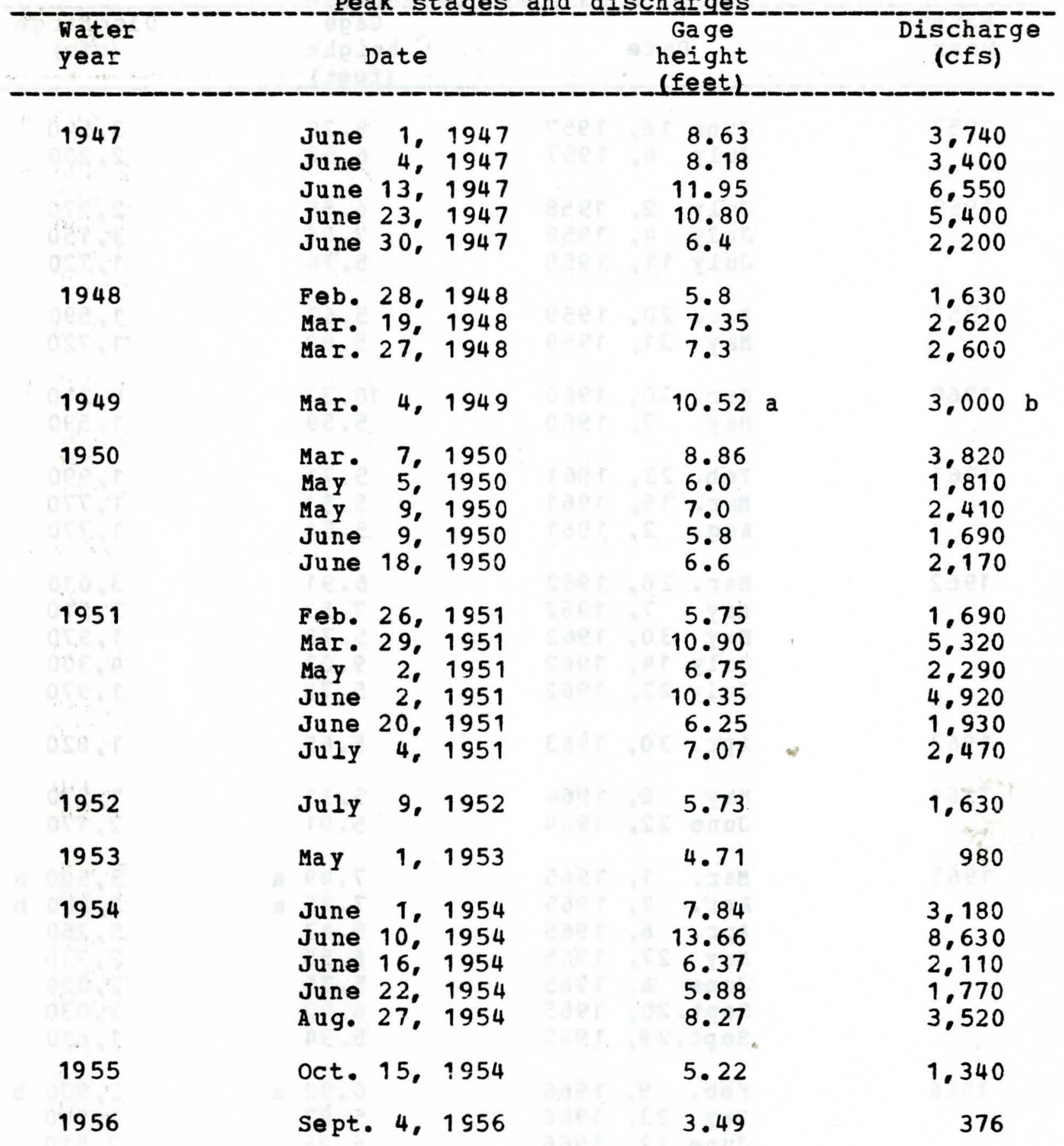

a Affected by ice.

b About. 
05-4700.00 South Skunk River near Ames, Iowa--(Continued)

Peak_sttages and di schharges

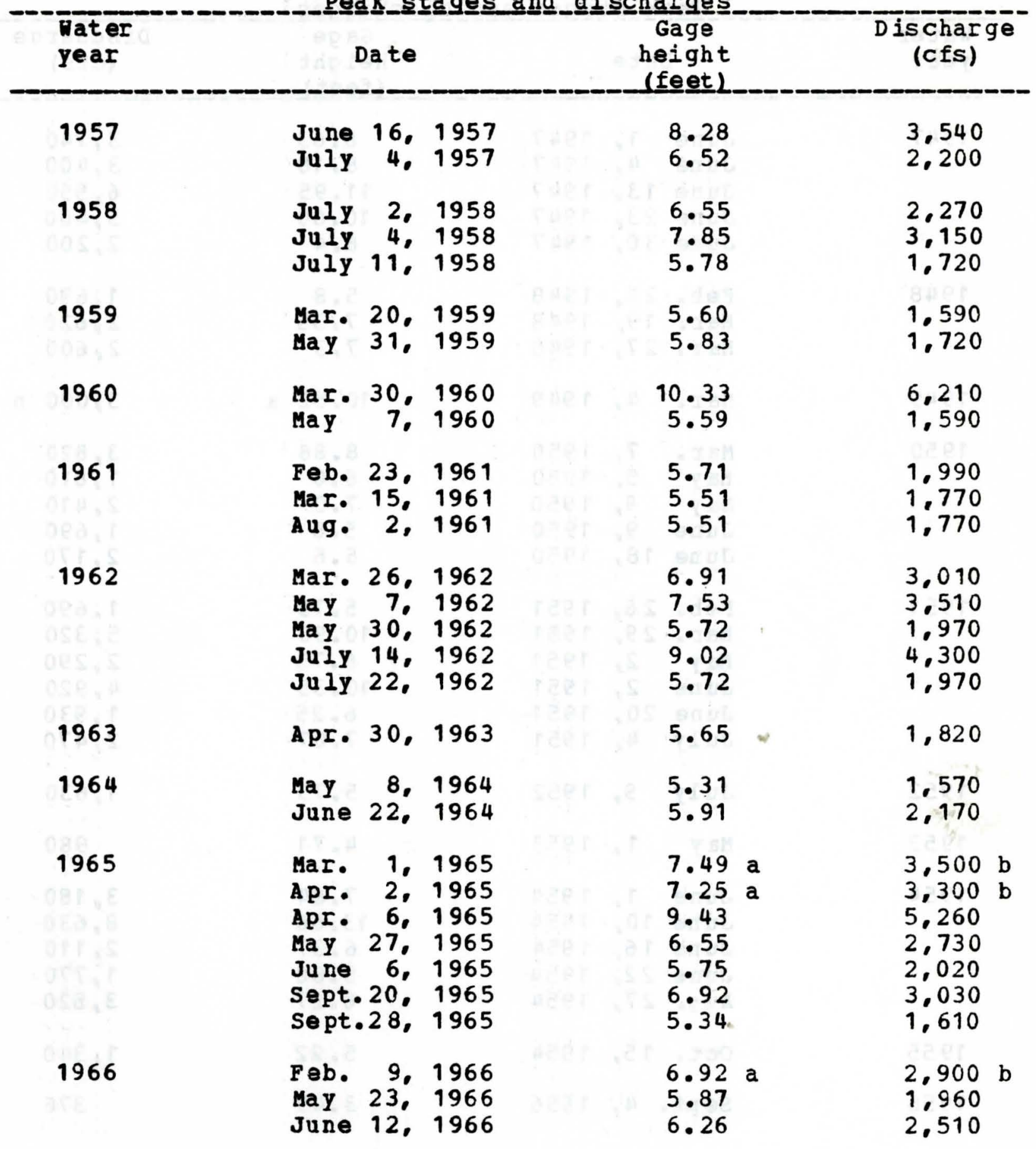

a Affected by ice.

b About. 
05-4700.00 South Skunk River near Ames, Iowa--(Continued)

Peak_stages_and_discharges

\begin{tabular}{|c|c|c|c|c|c|c|c|}
\hline $\begin{array}{l}\text { Water } \\
\text { year }\end{array}$ & I & bate & & & $\begin{array}{c}\text { Gage } \\
\text { height } \\
\text { lfeet }\end{array}$ & & $\begin{array}{l}\text { Discharge } \\
\text { (Cfs) }\end{array}$ \\
\hline 1967 & $\begin{array}{l}\text { June } \\
\text { June } \\
\text { June }\end{array}$ & $\begin{array}{l}8, \\
13 \% \\
18,\end{array}$ & $\begin{array}{l}1967 \\
1967 \\
1967\end{array}$ & & $\begin{array}{l}6.63 \\
5.87 \\
6.06\end{array}$ & & $\begin{array}{l}2.790 \\
2.140 \\
2.320\end{array}$ \\
\hline 1968 & June & 25 & 1968 & & 8.74 & & 4,890 \\
\hline 1969 & $\begin{array}{l}\text { Mar. } \\
\text { Mar. } \\
\text { June } \\
\text { June } \\
\text { June } \\
\text { July } \\
\text { July } \\
\text { July }\end{array}$ & $\begin{array}{l}20, \\
25, \\
73 \\
30, \\
10, \\
18, \\
28,\end{array}$ & $\begin{array}{l}1969 \\
1969 \\
1969 \\
1969 \\
1969 \\
1969 \\
1969 \\
1969\end{array}$ & & $\begin{array}{l}7.97 \\
6.27 \\
6.19 \\
5.28 \\
6.88 \\
8.49 \\
6.13 \\
7.32\end{array}$ & & $\begin{array}{l}3.910 \\
2.510 \\
2.440 \\
1.550 \\
2.910 \\
4.380 \\
2.390 \\
3.360\end{array}$ \\
\hline 1970 & May & 13. & 1970 & & 5.10 & & 1.330 \\
\hline 1971 & $\begin{array}{l}\text { Feb. } \\
\text { Feb. } \\
\text { Mar. }\end{array}$ & $\begin{array}{l}19 . \\
20 . \\
13 .\end{array}$ & $\begin{array}{l}1971 \\
1971 \\
1971\end{array}$ & & $\begin{array}{l}9.10 \\
7.67 \\
6.03\end{array}$ & a & $\begin{array}{l}3.660 \\
2.300\end{array}$ \\
\hline 1972 & $\begin{array}{l}\text { Mar. } \\
\text { June } \\
\text { Aug. } \\
\text { Aug. }\end{array}$ & $\begin{array}{l}7 . \\
6 . \\
3 . \\
7 .\end{array}$ & $\begin{array}{l}1972 \\
1972 \\
1972 \\
1972\end{array}$ & & $\begin{array}{l}8.93 \\
5.34 \\
5.40 \\
6.92\end{array}$ & a & $\begin{array}{l}1.610 \\
1.670 \\
3.030\end{array}$ \\
\hline 1973 & $\begin{array}{l}\text { Oct. } \\
\text { Nov. } \\
\text { Nov. } \\
\text { Dec. } \\
\text { Jan. } \\
\text { Fab. } \\
\text { Mar. } \\
\text { Mar. } \\
\text { Mar. } \\
\text { Apr. } \\
\text { May } \\
\text { May } \\
\text { Sept. }\end{array}$ & $\begin{array}{r}24, \\
2, \\
8, \\
30 \\
18, \\
2 \% \\
1 \% \\
11, \\
14 \\
16 \\
8, \\
28 \\
27\end{array}$ & $\begin{array}{l}1972 \\
1972 \\
1972 \\
1972 \\
1973 \\
1973 \\
1973 \\
1973 \\
1973 \\
1973 \\
1973 \\
1973 \\
1973\end{array}$ & & $\begin{array}{l}5.66 \\
5.33 \\
5.67 \\
7.13 \\
6.19 \\
7.94 \\
5.29 \\
5.77 \\
5.53 \\
7.30 \\
6.12 \\
5.38 \\
5.83\end{array}$ & $\begin{array}{l}a \\
a \\
a\end{array}$ & $\begin{array}{l}1,930 \\
1,600 \\
1,940 \\
2,790 \mathrm{~b} \\
2,210 \mathrm{~b} \\
2,470 \mathrm{~b} \\
1,560 \\
2,040 \\
1,800 \\
3,340 \\
2,380 \\
1,650 \\
2,100\end{array}$ \\
\hline
\end{tabular}

a Affected by ice.

b About. 
05-4700.00 South Skunk River near Ames, Iowa--(Continued)

Peakk_stagges and di

\begin{tabular}{|c|c|c|c|c|c|}
\hline $\begin{array}{l}\text { Water } \\
\text { year }\end{array}$ & & Date & & $\begin{array}{r}\text { Gage } \\
\text { height } \\
\text { (feet) }\end{array}$ & $\begin{array}{c}\text { Discharge } \\
\text { (cfs) }\end{array}$ \\
\hline 1974 & $\begin{array}{l}\text { Oct. } \\
\text { Apr. } \\
\text { May } \\
\text { May } \\
\text { May } \\
\text { May } \\
\text { June } \\
\text { June } \\
\text { June } \\
\text { June }\end{array}$ & $\begin{array}{l}12, \\
22, \\
14, \\
16, \\
19, \\
22, \\
9, \\
19, \\
20, \\
23,\end{array}$ & $\begin{array}{l}1973 \\
1974 \\
1974 \\
1974 \\
1974 \\
1974 \\
1974 \\
1974 \\
1974 \\
1974\end{array}$ & $\begin{array}{r}6.70 \\
5.10 \\
5.17 \\
5.37 \\
5.50 \\
5.37 \\
6.35 \\
8.90 \\
6.69 \\
9.61\end{array}$ & $\begin{array}{l}2,850 \\
1,730 \\
1.800 \\
2.000 \\
2.130 \\
2.000 \\
2.860 \\
5,100 \\
3,130 \\
5,780\end{array}$ \\
\hline 1975 & $\begin{array}{l}\text { Mar. } \\
\text { June } \\
\text { June } \\
\text { June } \\
\text { June }\end{array}$ & $\begin{array}{l}20, \\
19, \\
22, \\
25, \\
28,\end{array}$ & $\begin{array}{l}1975 \\
1975 \\
1975 \\
1975 \\
1975\end{array}$ & $\begin{array}{r}5.94 \\
5.09 \\
6.12 \\
6.19 \\
9.98\end{array}$ & $\begin{array}{l}2.170 \\
1.570 \\
2.290 \\
2.340 \\
5.230\end{array}$ \\
\hline
\end{tabular}


05-4710.00 South Skunk River below Squaw Creek near Ames, Iowa (Prior to October 1966, published as

skunk River below Squaw Creek near Ames)

Location.--Iai 42000131", long 93035'37", in NE1/4 NW1/4 sec.13, T. 83 N., R. 24 W.. Story County, on right bank 15 ft downstream from bridge on county highway, 0.2 mi downstream from squaw Creek, 0.2 mi upstream from bridge on U.S. Highway 30,2 mi southeast of Ames, and at mile 222.6 upstream from mouth of Skunk River.

Drainage area.--556 sq mi.

Gage.--Water-stage recorder and concrete controi. Datum of gage is 867.10 ft above mean sea level.

Stage-discharge relation.--Defined by current-meter measurements. Flood stage.-- 20 feet.

Remarks.--Base for partial-duration series, 2,500 cfs.

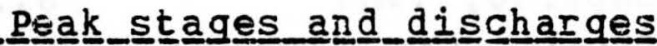

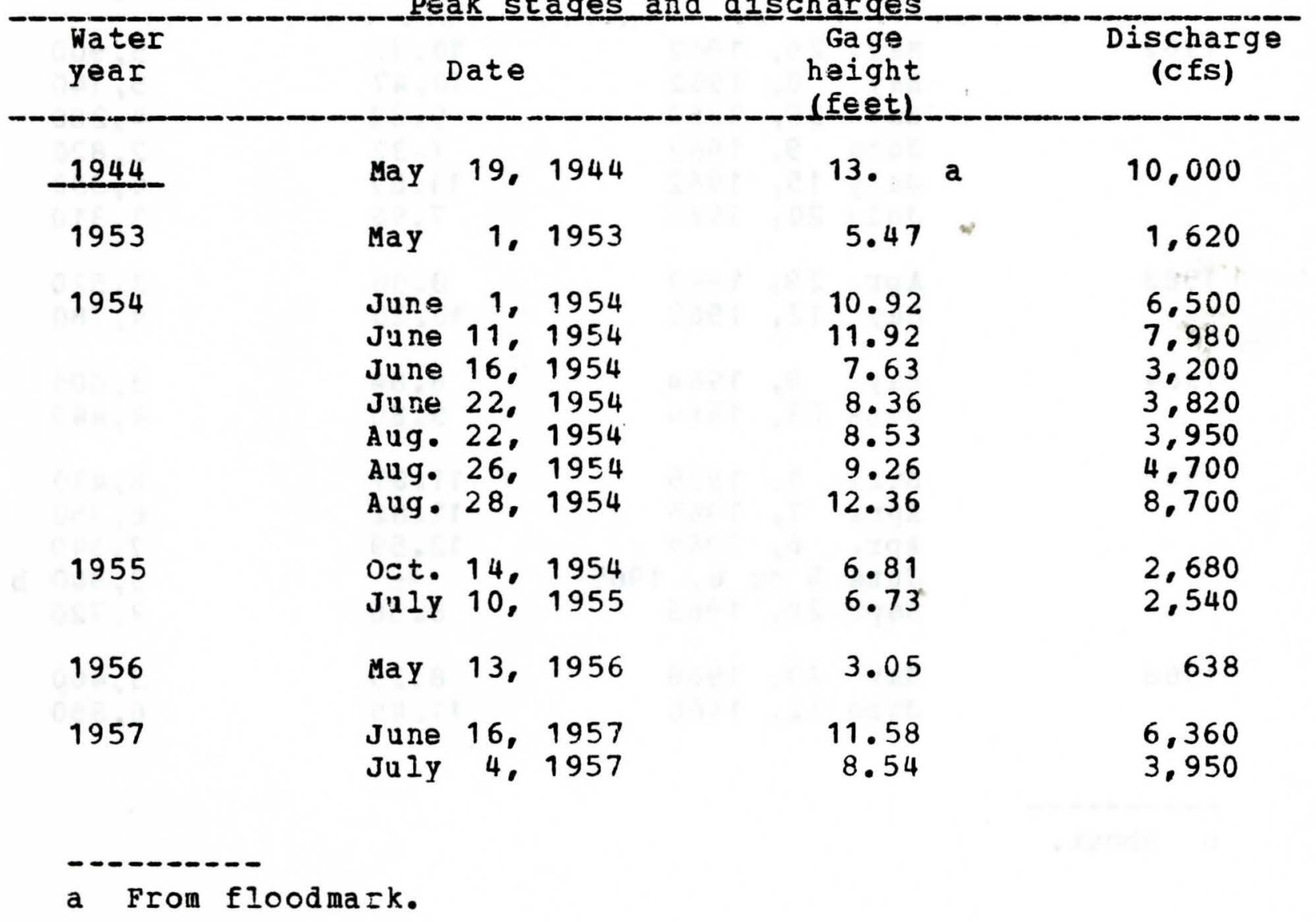


05-4710.00 South Skunk River below Squaw Creek near Ames, Iowa-(Continued)

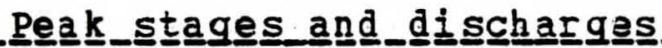

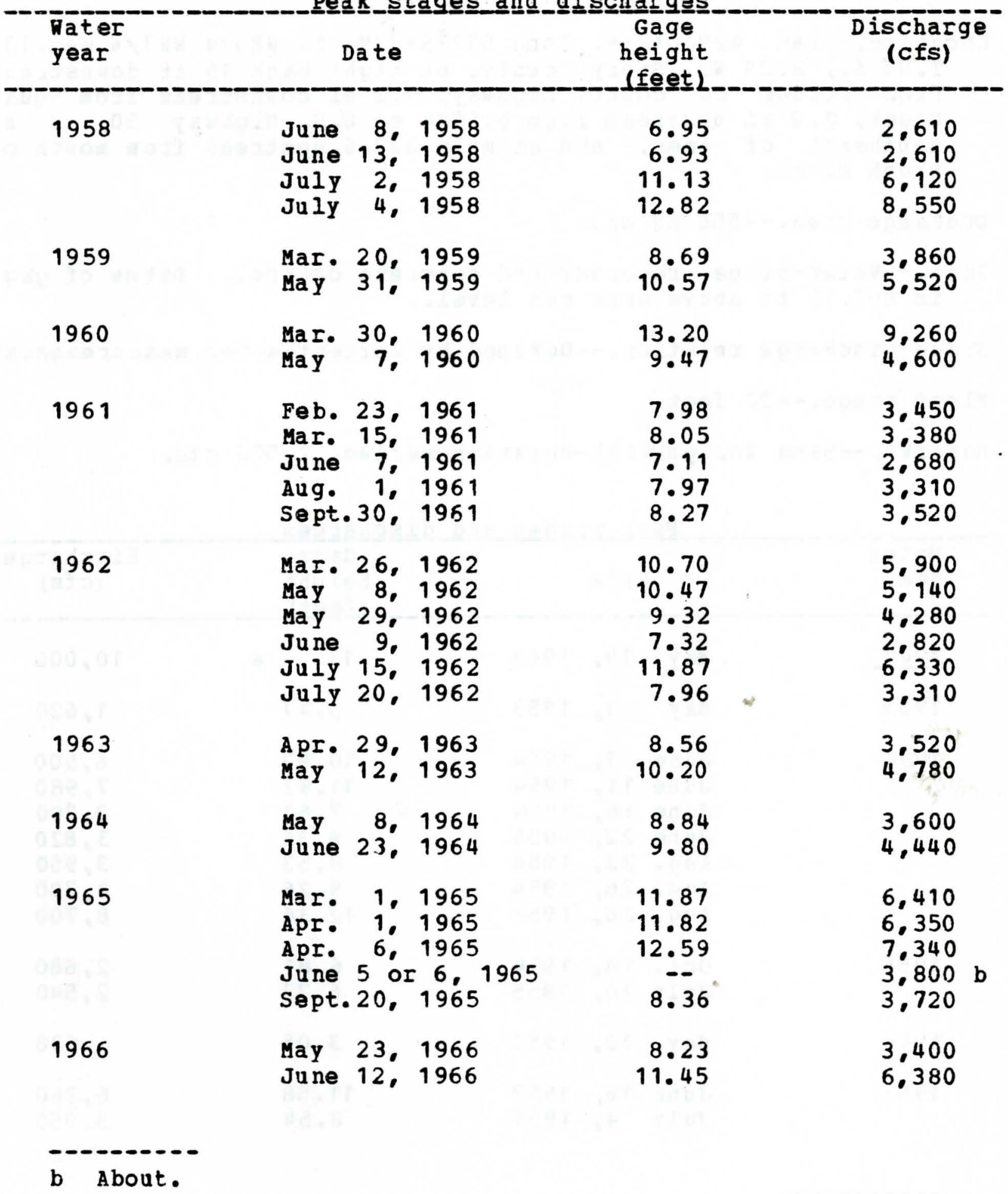


05-4710.00 South Skunk River below Squaw Creek near Ames, Iowa-(C ontinued)

Peak_stages and discharges

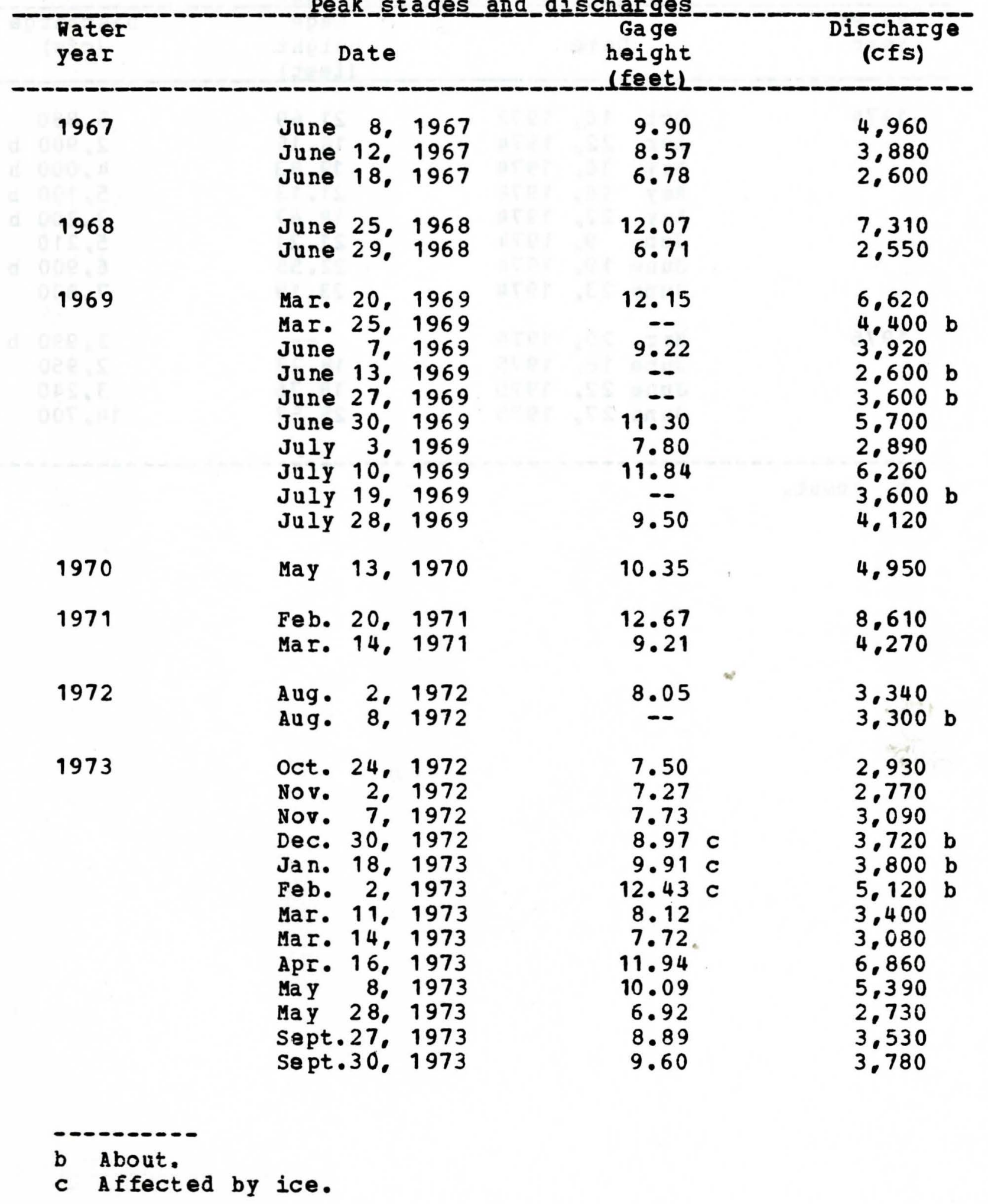


05-4710.00 South Skunk River below Squaw Creak near Ames, Iowa-(Continued)

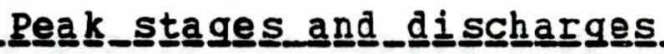

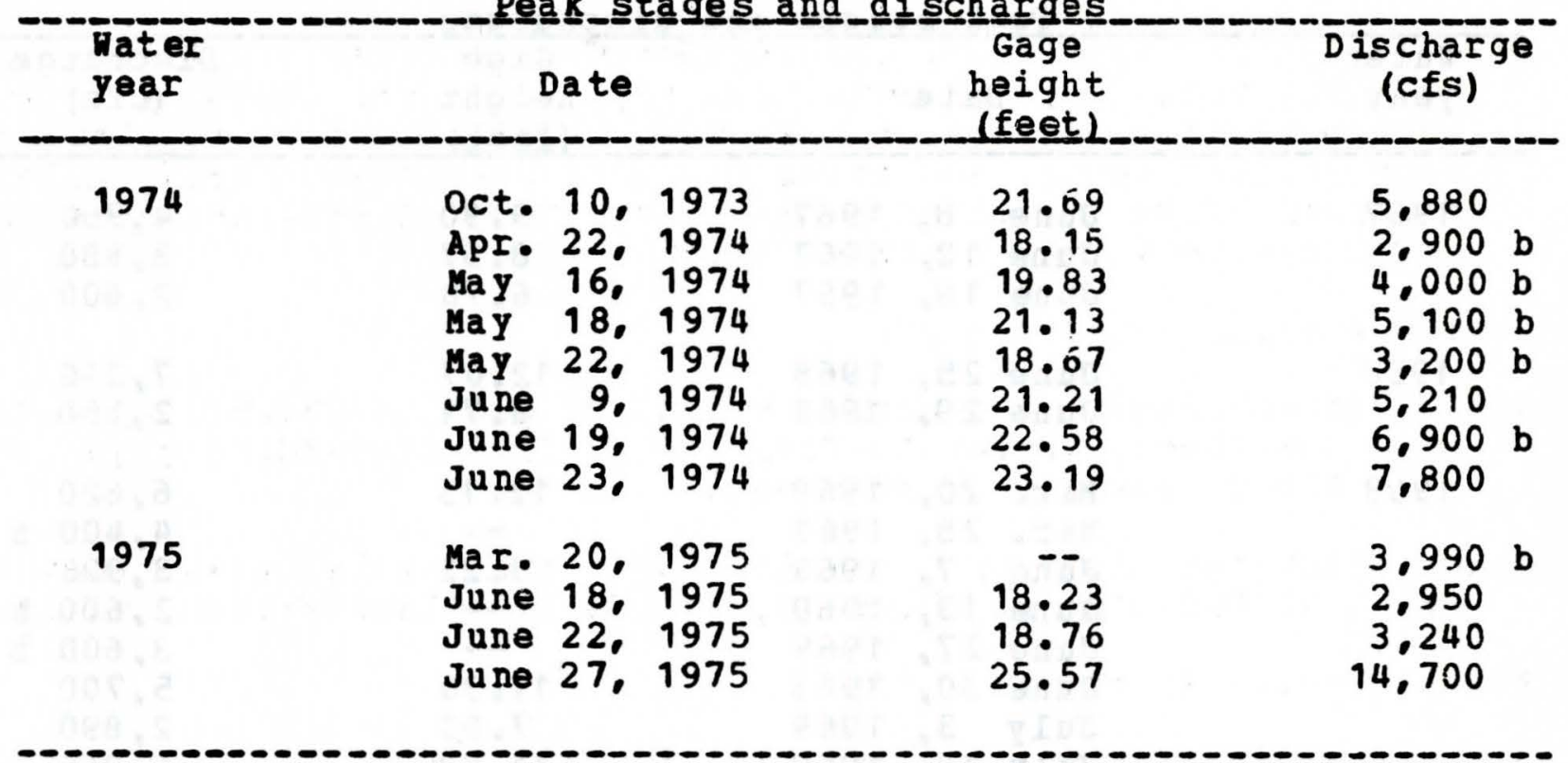

b about. 
05-4715.00 South Skunk River near 0skaloo:

(Prior to october 1966 published as "Skunk River natz ostaloosa")

Location.-- Lat $41021 \cdot 19 "$, long $92039131 "$, in NW1/4 SW $/ 4$ sec. 25 , T.76 N., R. 16 W.. Mahaska County, on right bank 400 ft upstream from bridge on 0.5 . Highway $63,0.3 \mathrm{mile}$ downstream from Painter Creek, 4.0 miles north of 0skaloosa. 53.7 miles upstream from confluence with North Skunk River, and at mile 147.3 upstream from mouth of Skunk River.

Drainage area. $--1,635$ sq mi.

Gage.--Water-stage recorder. Datum of gage is $685.50 \mathrm{ft}$ above mean sea level. Prior to Nov. 21, 1947, nonrecording gage at site $400 \mathrm{ft}$ downstream at same datum.

Stage-discharge relation.--Defined by current-meter measurements below 18,000 cfs and above 18,000 cfs on velocity-area study.

Flood stage.--15 feet.

Remarks.--Base for partial-duration series, 6,600 .

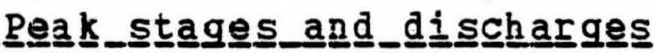

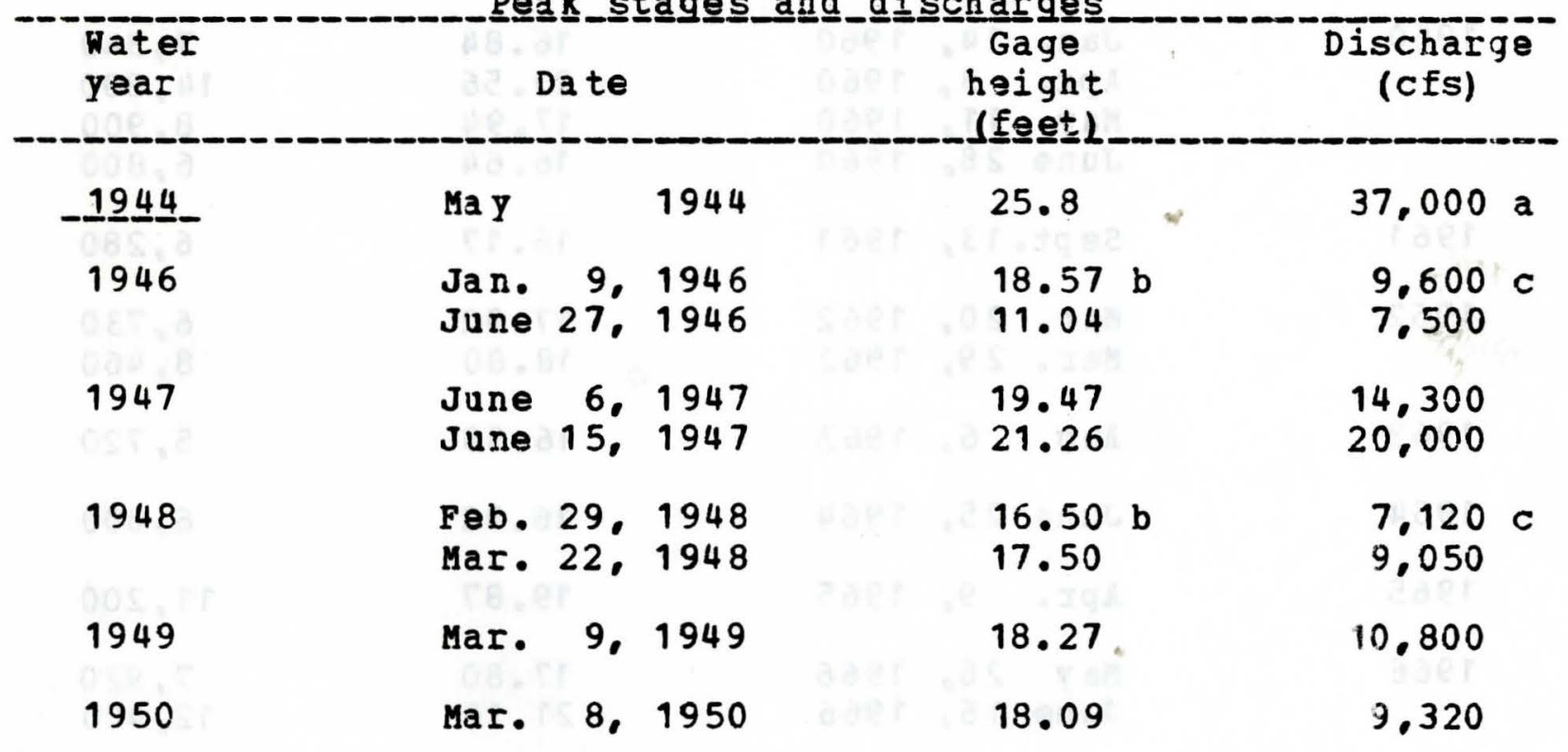

a From rating curve extended above 18.000 cfs on bis of velocity-area study.

b Affected by ice.

c About. 
05-4715.00 South Skunk River near Oskaloosa, Iowa--(Continued)

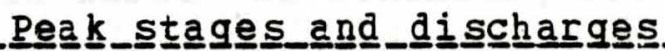

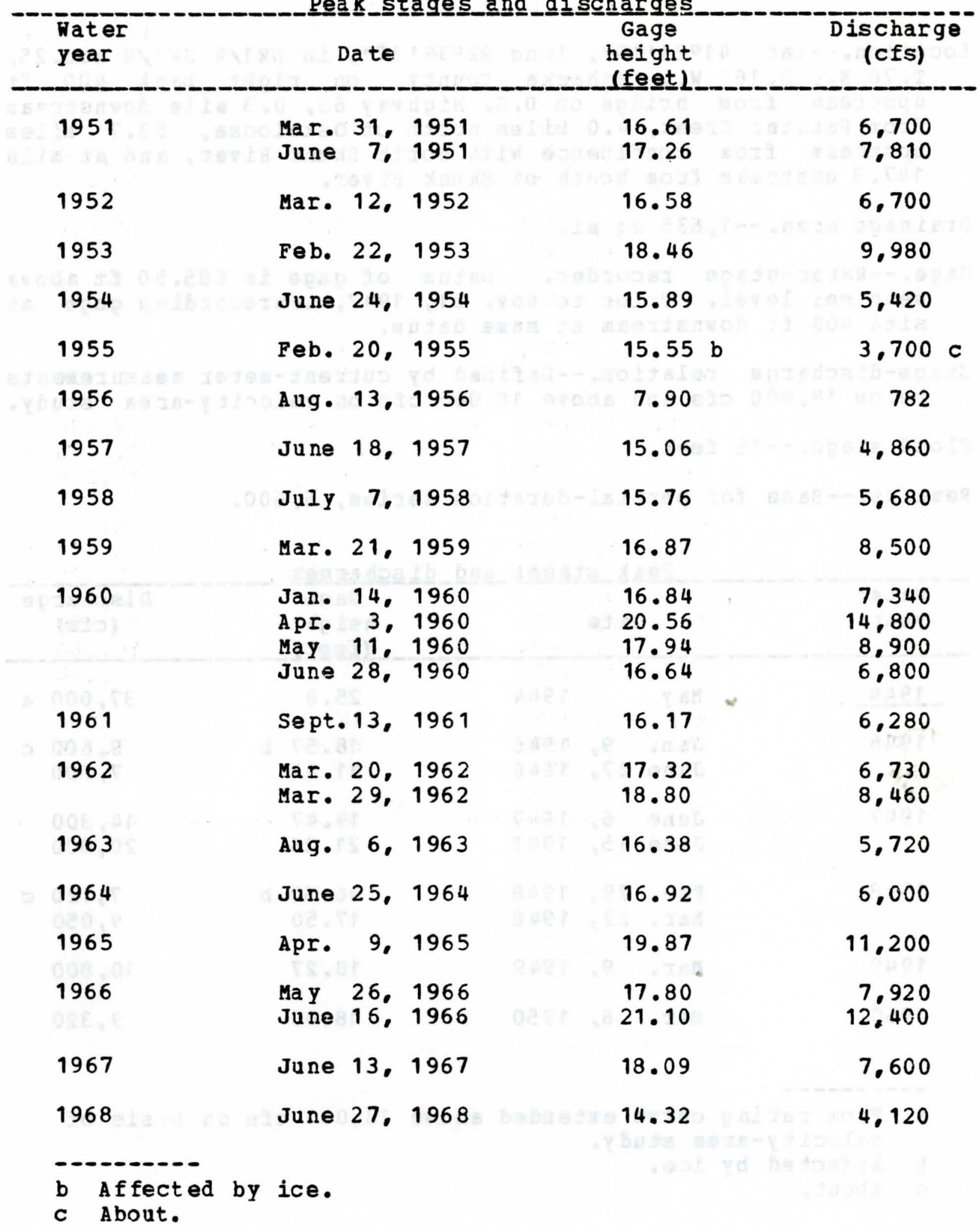


05-4715.00 South Skunk River near Oskaloosa, Iowa--(Continued)

Peak﹎.stagges_and_di

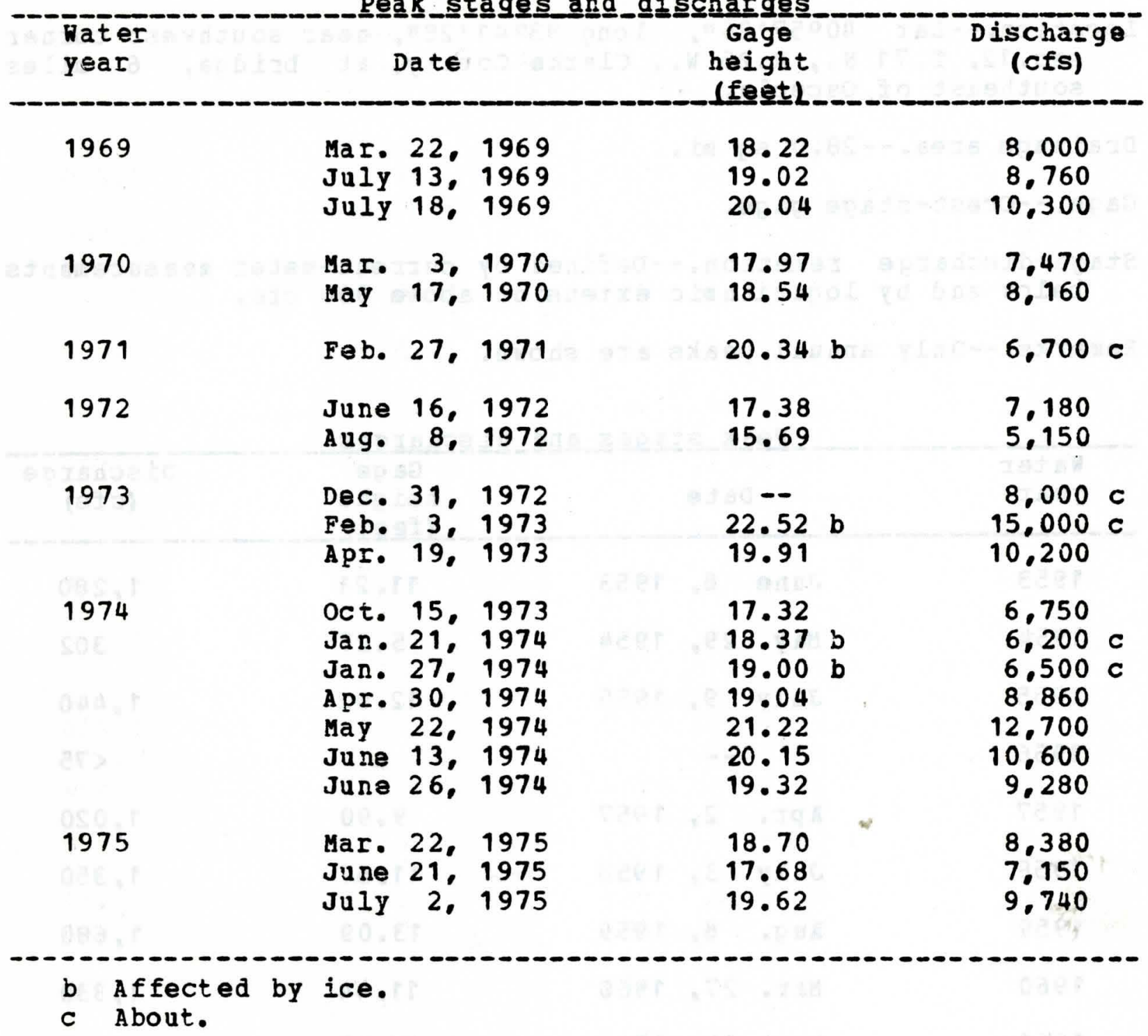


05-4876.00 South white Breast Creek near Osceola, Iowa

Location.--Lat 40057'36", long 93041'28", near southwest corner sec.12, T.71 N., R.25 W., Clarke County, at bridge, 6 miles southeast of Osceola.

Drainage area.--28.0 sq mi.

Gage.--Crest-stage gage.

Stage-discharge relation.--Defined by current-meter measurements below and by logarithmic extension above 900 cfs.

Remarks.--only annual peaks are shown.

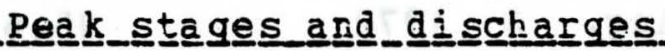

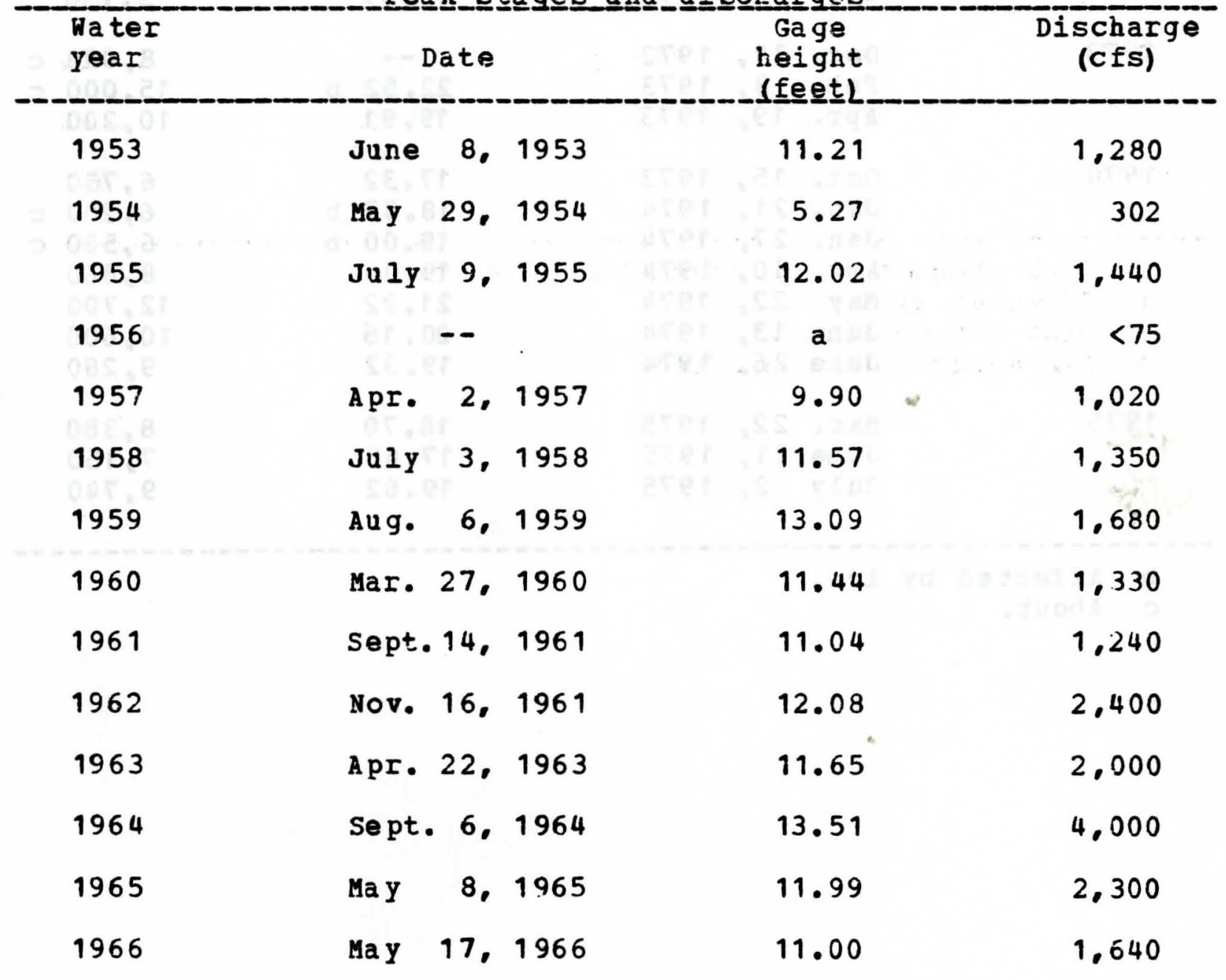

a Prak stage did not reach bottom of gage. 
05-4876.00 South White Breast Creek near Osceola, Iowa--(Continued)

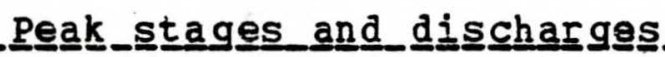

\begin{tabular}{|c|c|c|c|c|}
\hline $\begin{array}{l}\text { Water } \\
\text { year }\end{array}$ & & Date & $\begin{array}{l}\text { Gage } \\
\text { height } \\
\text { (feet). }\end{array}$ & $\begin{array}{l}\text { Discharge } \\
\text { (cfs) }\end{array}$ \\
\hline 1967 & June & 21,1967 & 13.05 & 3,500 \\
\hline 1968 & Apr. & 23,1968 & $10 \cdot 16$ & 1.150 \\
\hline 1969 & July & 17,1969 & 12.89 & 3.200 \\
\hline 1970 & Ma y & 13,1970 & 12.87 & 3,200 \\
\hline 1971 & $\mathrm{~F} \otimes \mathrm{b}$ & 19,1971 & $10.59 \mathrm{~b}$ & 500 \\
\hline 1972 & & $\cdots$ & C & $\mathbf{a}$ \\
\hline 1973 & Apr. & 15. 1973 & 12.05 & 2.400 \\
\hline 1974 & oct. & 11. 1973 & 13.51 & 3.400 \\
\hline 1975 & & -- & $\mathbf{a}$ & d \\
\hline
\end{tabular}

a Peak stage did not reach bottom of gage.

b Affected by ice.

c Peak not obtained.

d Discharge not determined. 
05-4956.00 South Wyaconda River near West Grove, Iowa

Location.--Lat $40043^{\circ}$. long 92030', near northwest corner sec.5, T. 68 N.. R. 14 W.. Davis County, at bridge, 2.5 miles east of West Grove.

Drainage area.- $-4.69 \mathrm{sq}$ miles.

Gage.--Crest-stage gage.

Stage-discharge relation.--Defined by current-meter and indirect measurements.

Renarks.--only annual peaks are shown.

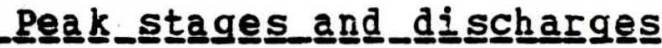

\begin{tabular}{|c|c|c|c|}
\hline $\begin{array}{l}\text { Water } \\
\text { year }\end{array}$ & Date & $\begin{array}{r}\text { Gage } \\
\text { height } \\
\text { (feet) }\end{array}$ & $\begin{array}{c}\text { Discharge } \\
\text { (cfs) }\end{array}$ \\
\hline 1953 & Mar. 30,1953 & 8.18 & 530 \\
\hline 1954 & Apr. 6,1954 & 8.09 & 485 \\
\hline 1955 & oct. 10,1954 & 9.15 & 1,250 \\
\hline 1956 & -- & a & $<35$ \\
\hline 1957 & June 11,1957 & 6.98 & 142 \\
\hline 1958 & July 31, 1958 & 9.21 & 1.310 \\
\hline 1959 & Aug. 5,1959 & 9.64 & 1.970 \\
\hline 1960 & oct. 6, 1959 & 9.39 & 1,490 \\
\hline 1961 & Mar. 27, 1961 & 7.34 & 215 \\
\hline 1962 & Nov. 16,1961 & 7.96 & 424 \\
\hline 1963 & Mar. 4, 1963 & 8.95 & 1.080 \\
\hline 1964 & June 15,1964 & 7.45 & 242 \\
\hline 1965 & Apr. $\quad 8,1965$ & 9.22 & 1,320 \\
\hline 1966 & May 11, 1966 & 6.49 & 86 \\
\hline
\end{tabular}

a Peak stage did not reach bottom of gage. 
05-4956.00 South Wyaconda River near West Grove, Iowa--(Continued)

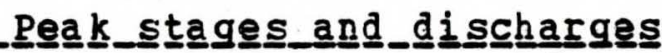

\begin{tabular}{|c|c|c|c|c|}
\hline $\begin{array}{l}\text { Water } \\
\text { year }\end{array}$ & Date & & $\begin{array}{l}\text { Gage } \\
\text { height } \\
\text { (feet) }\end{array}$ & $\begin{array}{c}\text { Discharge } \\
\text { (cfs) }\end{array}$ \\
\hline 1967 & June 13 & 1967 & 7.51 & 258 \\
\hline 1968 & Apr. 4. & 1968 & 7.90 & 400 \\
\hline 1969 & July 5 . & 1969 & 8.75 & 920 \\
\hline 1970 & sept.15. & 1970 & 10.11 & 3.100 \\
\hline 1971 & Mar. 11. & 1971 & 7.38 & 200 \\
\hline 1972 & - & & $\mathbf{a}$ & $\mathbf{b}$ \\
\hline 1973 & Apr. 22 & 1973 & 9.68 & 2.000 \\
\hline 1974 & -- & & a & b \\
\hline 1975 & $-\infty$ & & $a$ & $\mathbf{b}$ \\
\hline
\end{tabular}

a Peak stage did not reach bottom of gage.

b Discharge not determined. 
Location.--Lat $43012 \cdot 48 "$, long $93012 \cdot 38 "$, in ST1/4 sec.16, T.97 N.. R. 20 H. . Cerro Gordo County, at bridge on U.S. Highway 65. about 4 miles north of Mason City.

Drainage area. $--29.3 \mathrm{sq}$ miles.

Gage.--Crest-stage gage.

Stage-discharge relation.--Defined by current-meter measurements. Remarks.--only annual peaks are shown.

Peak__sta ges_and_dis

\begin{tabular}{|c|c|c|c|c|c|}
\hline $\begin{array}{l}\text { Water } \\
\text { year }\end{array}$ & & Date & & $\begin{array}{c}\text { Ga ge } \\
\text { height } \\
\text { (fegt) }\end{array}$ & $\begin{array}{l}\text { Discharge } \\
\text { (cfs) }\end{array}$ \\
\hline 1966 & JuIY & 14. & 1966 & 85.59 & 720 \\
\hline 1967 & & - & & a & b \\
\hline 1968 & & - & & a & b \\
\hline 1969 & JuIy & 8. & 1969 & 88.41 & b \\
\hline 1970 & May & 29 & 1970 & 86.66 & 1.280 \\
\hline 1971 & Mar. & 31. & 1971 & 84.89 & 495 \\
\hline 1972 & & - & & a & b \\
\hline 1973 & oct. & 23, & 1972 & 85.44 & 705 \\
\hline 1974 & & - & & a & b \\
\hline 1975 & Apr. & 28 & 1975 & 88.19 & 2.820 \\
\hline
\end{tabular}

a Peak stage did not reach bottom of gage.

b Discharge not determined. 


\section{5-8082.00 spring Valley Creek near Tabor, Iowa (Discontinued Sept. 30, 1964)}

Location.--Iat 40054'35", long 95036'00", in SW1/4 NE1/4 sec.31, T.71 N., R.41 W.., Mills county, on left bank 20 ft downstream from highway briage, 1.5 miles upstream from mouth and 4.0 miles northeast of Tabor.

Drainage area.--7.65 sq miles.

Gage.--Recording gage and concrete control. Altitude of gage is $975 \mathrm{ft}$ (fIom topographic map).

Stage-discharge relation.--Defined by current-meter measurements below 210 cfs and extended above on basis of a sloperarea measurement of peak flow.

Remarks.--Base for partial-duration series, 250 cfs.

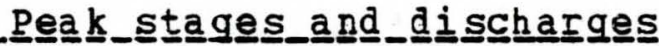

\begin{tabular}{|c|c|c|c|c|c|}
\hline $\begin{array}{l}\text { WateI } \\
y \in a I\end{array}$ & Date & & $\begin{array}{l}\text { Gage } \\
\text { height } \\
\text { (feet) }\end{array}$ & & $\begin{array}{c}\text { ischarge } \\
\text { (cfs) }\end{array}$ \\
\hline 1956 & $\begin{array}{ll}\text { June } & 11, \\
\text { July } & 15, \\
\text { Aug. } & 18\end{array}$ & $\begin{array}{l}8956 \\
1956 \\
1956\end{array}$ & $\begin{array}{r}8.59 \\
13.50 \\
8.78\end{array}$ & & $\begin{array}{r}317 \\
2.310 \\
359\end{array}$ \\
\hline 1957 & $\begin{array}{lr}\text { May } & 29, \\
\text { June } & 7, \\
\text { June } & 17, \\
\text { July } & 1 .\end{array}$ & $\begin{array}{l}1957 \\
1957 \\
1957 \\
1957\end{array}$ & $\begin{array}{r}12.07 \\
10.58 \\
8.90 \\
10.33\end{array}$ & 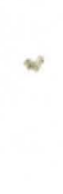 & $\begin{array}{r}1.480 \\
865 \\
380 \\
778\end{array}$ \\
\hline 1958 & $\begin{array}{ll}\text { July } & 19, \\
\text { July } & 30 .\end{array}$ & $\begin{array}{l}1958 \\
1958\end{array}$ & $\begin{array}{l}10.85 \\
15.48\end{array}$ & & $\begin{array}{r}935 \\
4.150\end{array}$ \\
\hline 1959 & $\begin{array}{lr}\text { May } & 18, \\
\text { May } & 29, \\
\text { Aug. } & 5 \\
\text { Se pt. } 18\end{array}$ & $\begin{array}{l}1959 \\
1959 \\
1959 \\
1959\end{array}$ & $\begin{array}{l}12.57 \\
10.0 \\
8.40 \\
8.51\end{array}$ & a & $\begin{array}{r}1.730 \\
670 \\
279 \\
298\end{array}$ \\
\hline 1960 & $\begin{array}{l}\text { Aug. } 17, \\
\text { Aug. } 28, \\
\text { Se pt. } 24,\end{array}$ & $\begin{array}{l}1960 \\
1960 \\
1960\end{array}$ & $\begin{array}{r}9.30 \\
12.28 \\
8.63\end{array}$ & & $\begin{array}{r}473 \\
1.570 \\
328\end{array}$ \\
\hline 1961 & June 27 & 1961 & 12.13 & & 1.480 \\
\hline
\end{tabular}

a About. 
06-8082.00 Spring Valley Creek near Tabor, Iowa--(Cont inued)

Peak﹎.sta ges and_di

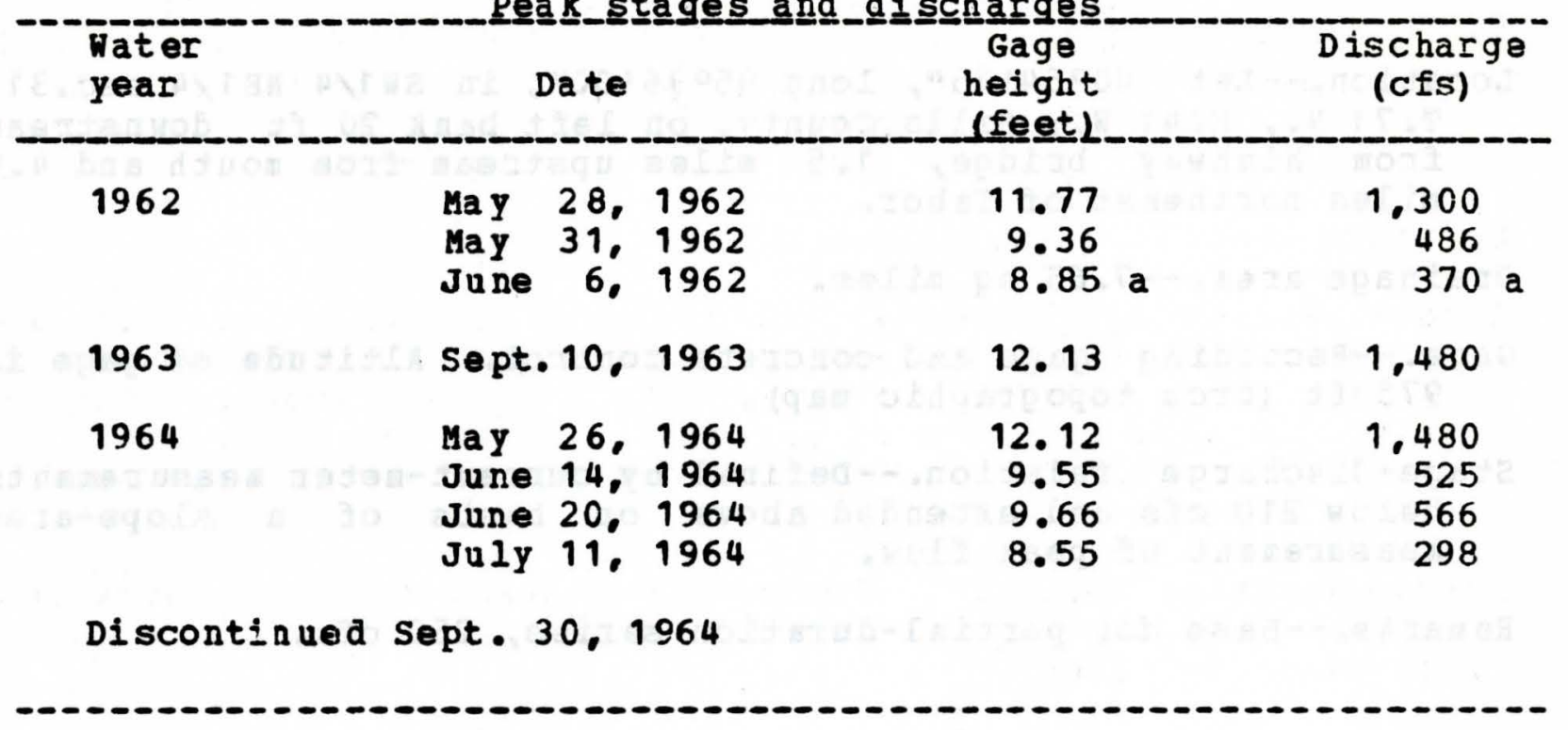

a A bout. 
Location.--Iat 42001'21", long 93037.45", in NE $1 / 4$ NW 1/4 sec.10, T. 83 N. R. 24 W.. Story County, on left bank 65 ft downstream from Lincoln Way Bridge in Ames, 0.1 mile downstream from College creek, and 1.8 miles upstream from mouth.

Drainage area.--204 sq miles.

Gage.--Water-stage recorder and concrete control. Datum of gage is $881.00 \mathrm{ft}$ above mean sea level (levels by Iowa state University). Prior to Mar. 11, 1925, nonrecording gage at site 0.6 mile upstream at different datum. Mar. 11, 1925, to Apr. 30. 1927, nonrecording gage at site 65 ft upstream at datum about $4 \mathrm{ft}$ higher.

Stage-discharge relation.--Defined by current-meter measurements. Flood stage. -7 feet.

Remarks.--Base for partial-duration series 1.000 cfs. Prior to 1965 only annual peaks are shown.

Peak_s_tages

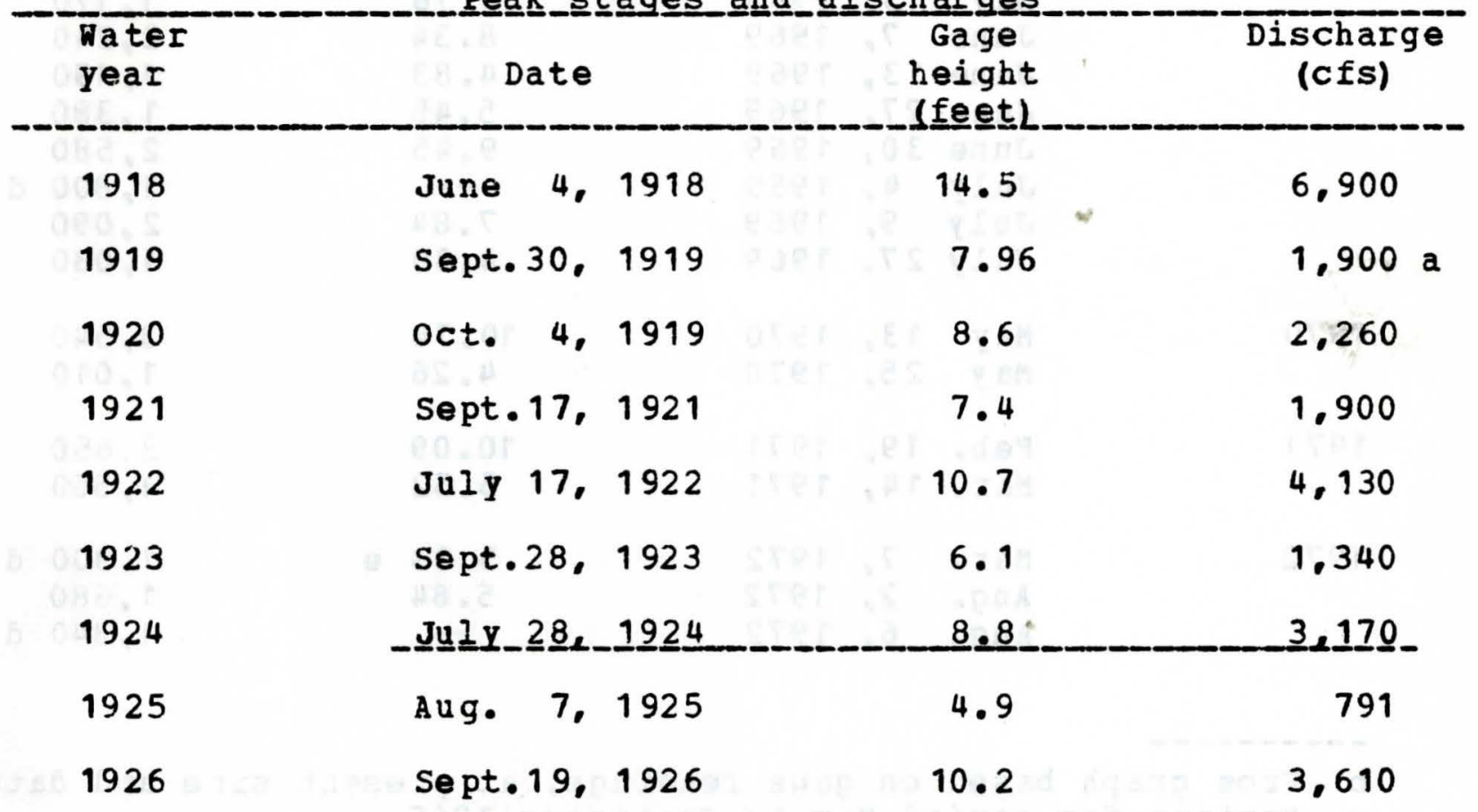

a Maximum for period May tc September 1919. 
05-4705.00 Sq̣uaw Creek at Ames, Iowa--(Continued)

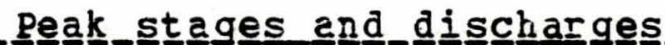

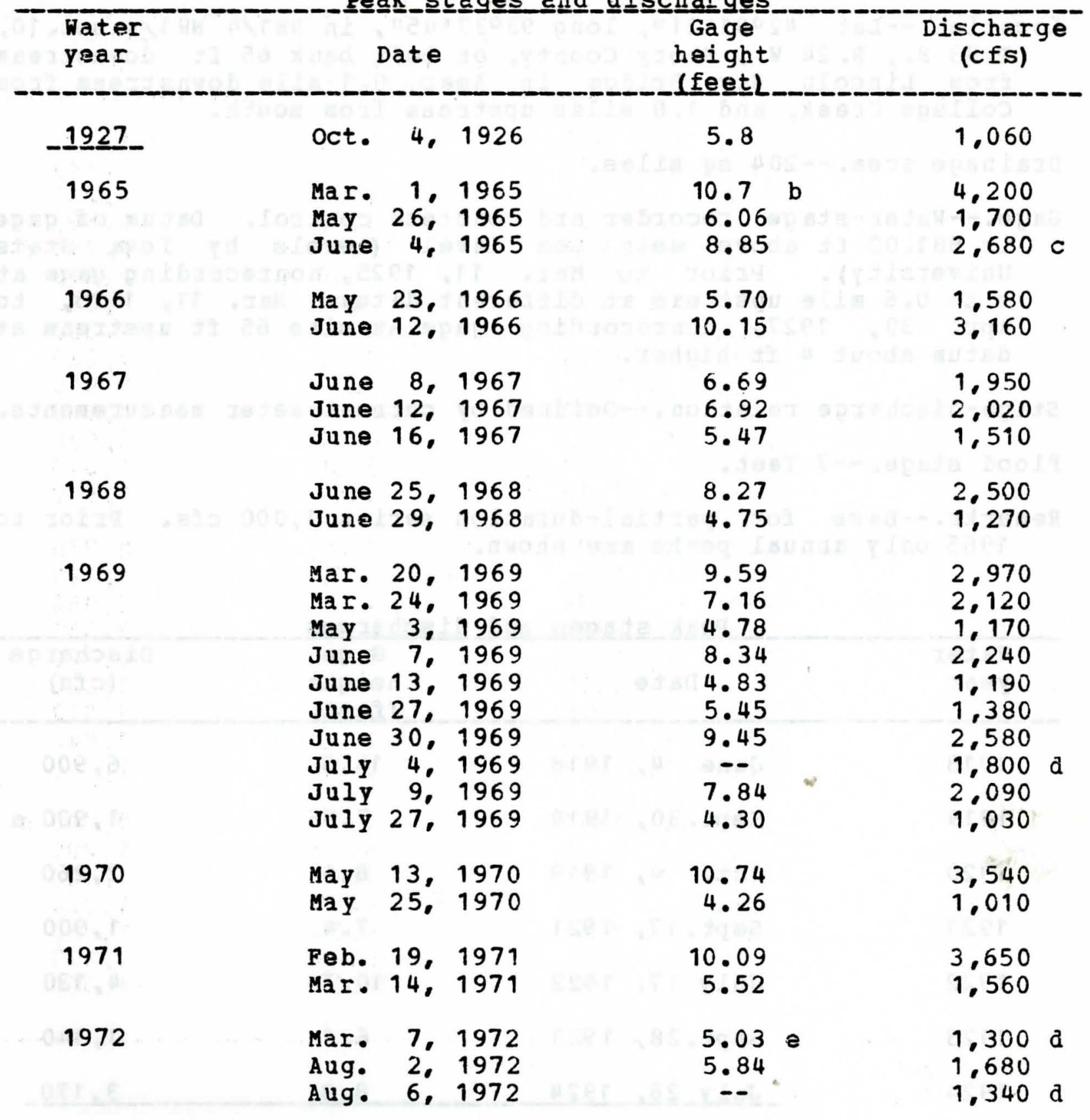

b From graph based on gâge readings, at present site and datum.

c Maximum for period May to Septemb 1965.

d A bout.

e Affectad by ice. 
05-4705.00 Squaw Creek at Ames, Iowa--(Continued)

Peak﹎.stages_and_disgharges

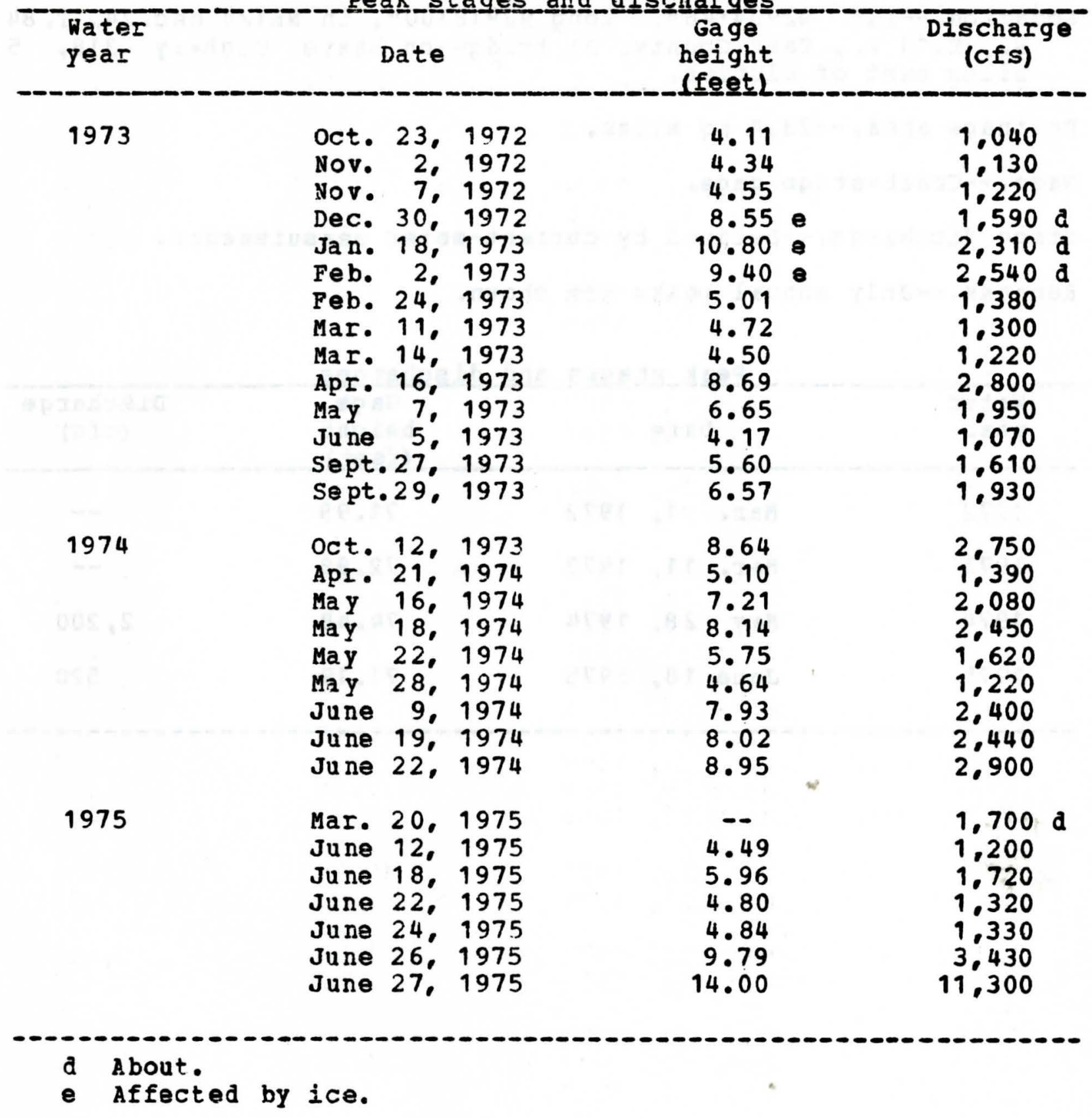




$$
\text { 05-4519.55 Stein Creek near Clutier, Iowa }
$$

Location.--Lat $42004 \cdot 46 "$ " long $92018 \cdot 00 "$, in NE1/4 sec. 24, T. 84 N. R.13 W., Tama County, at bridge on State Highway 318,5 miles east of clutier.

Drainage area.- $-23.4 \mathrm{sg}$ miles.

Gage.--Crest-stage gage.

Stage discharge.--Defined by current-meter measurements.

Remarks.--only annual peaks are shown.

Peak

\begin{tabular}{|c|c|c|c|}
\hline $\begin{array}{l}\text { Water } \\
\text { year }\end{array}$ & Date & $\begin{array}{c}\text { Gage } \\
\text { height } \\
\text { (feet) }\end{array}$ & $\begin{array}{c}\text { Discharge } \\
\text { (cfs) }\end{array}$ \\
\hline 1972 & Mar. 1. 1972 & 71.99 & -- \\
\hline 1973 & Ma I. 11, 1973 & 72.98 & -- \\
\hline 1974 & May 28, 1974 & 74.48 & 2.200 \\
\hline 1975 & June 18,1975 & 71.19 & 520 \\
\hline
\end{tabular}




\section{5-4910.00 Sugar Creek near Keokuk, Iowa}

(Discontinued September 1973)

Location.--Iat $40026 \cdot 33$ ", long $91028 \cdot 24 "$, in Nw1/4 SE $1 / 4$ seC.7, T. 65 N.. R. 5 W.. Lee County, on left bank 13 ft downstream from bridge on county highway $62,2.8$ miles downstream from Barlean Creek, 4.6 miles upstream from mouth, and 6.0 miles north west of post office in Keokuk.

Drainage area.--105 sq miles.

Gage.-- Hater-stage recorder. Datum of gage is $510.20 \mathrm{ft}$ above mean sea level. Prior to June 25, 1923, and Nov. 28, 1928, to Sept. 30, 1931, nonrecording gage: June 25, 1923, to Oct. B, 1928, and Aug. 29, 1958, to Oct. 1, 1967 , water-stage recorder at site of former bridge on old channel 0.6 mile downstream at same datum. Oct. 6, 1967, to Mar. 11, 1968, nonrecording gage at present site and datum.

Stage-discharge IElation.--Defined by current-meter measurements.

Bankfull stage.--11 feet.

Remarks.--Base for partial-duration series, 2,000 cfs. Records for period 1922 through 1924 furnished by Union Electric Corp. formerly Mississippi Power Company. only annual reaks are shown prior to 1959.

Peak﹎stagges and di discharges

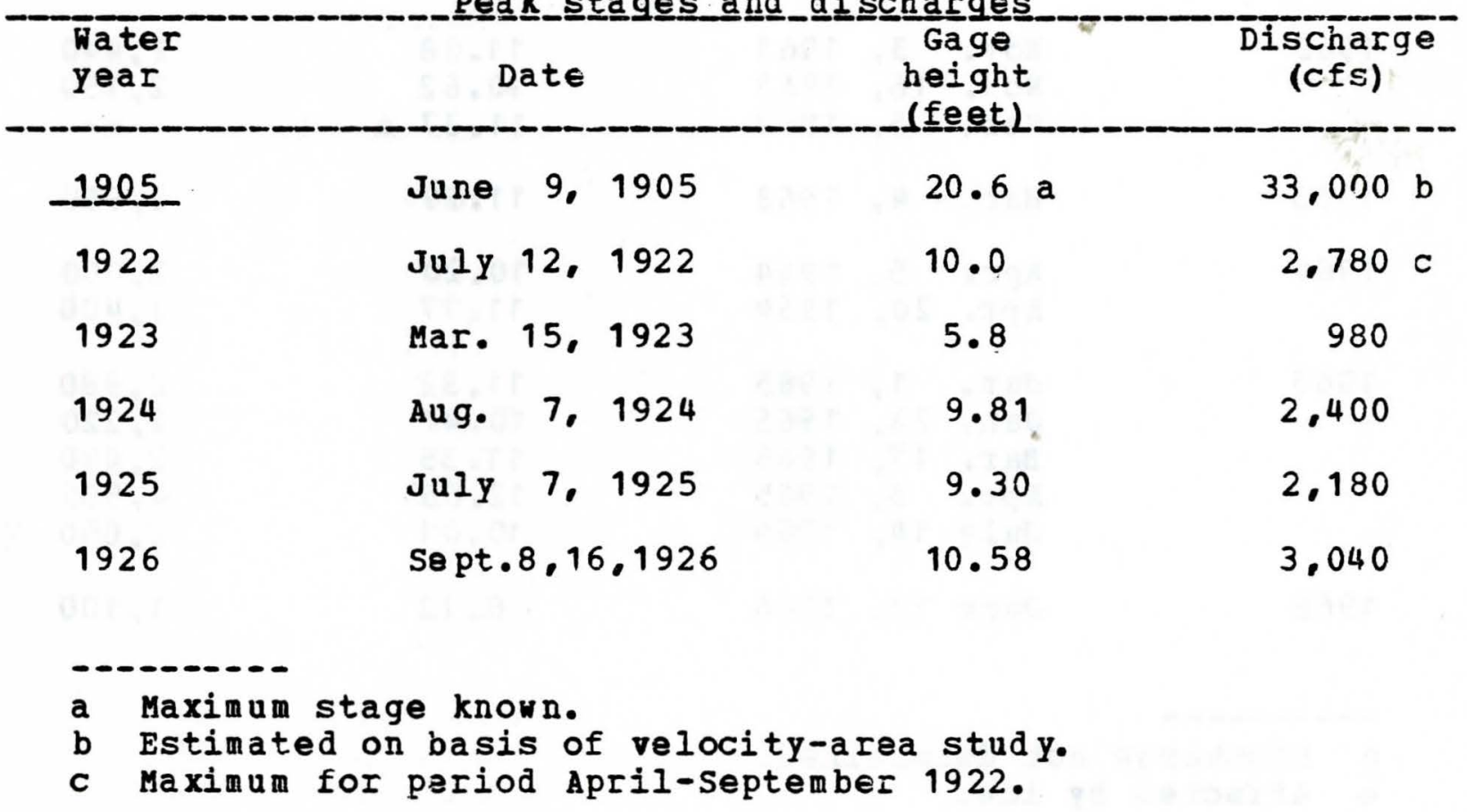


05-4910.00 Sugar Creek near Keokuk, Iowa--(Continued)

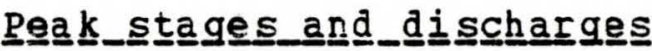

\begin{tabular}{|c|c|c|c|c|}
\hline $\begin{array}{l}\text { Water } \\
\text { year }\end{array}$ & Date & & $\begin{array}{l}\text { Gage } \\
\text { height } \\
\text { lfeet }\end{array}$ & $\begin{array}{c}D \text { ischarge } \\
\text { (cfs) }\end{array}$ \\
\hline 1927 & June 11 . & 1927 & 13.5 & 6.170 \\
\hline 1928 & oct. 1. & 1927 & 13.85 & 6,620 \\
\hline 1929 & Nov. 17 , & 1928 & -- & $\mathrm{d}$ \\
\hline 1930 & June 15 & 1930 & 9.0 & 1.970 \\
\hline $19 \underline{3} 1$ & June 6 & 1931 & 10.0 & 2.560 \\
\hline 1959 & $\begin{array}{l}\text { Apr. } 19, \\
\text { Aug. } 6, \\
\text { Sept. } 27, \\
\text { Sept. } 28 .\end{array}$ & $\begin{array}{l}1959 \\
1959 \\
1959 \\
1959\end{array}$ & $\begin{array}{l}10.56 \\
10.88 \\
10.92 \\
12.22\end{array}$ & $\begin{array}{l}2,320 \\
2,270 \\
2,460 \\
4,300\end{array}$ \\
\hline 1960 & $\begin{array}{l}\text { Oct. } 6, \\
\text { Mar. } 30, \\
\text { Apr. } 17, \\
\text { June } 23, \\
\text { JuIy } 1, \\
\text { July } 12,\end{array}$ & $\begin{array}{l}1959 \\
1960 \\
1960 \\
1960 \\
1960 \\
1960\end{array}$ & $\begin{array}{l}11.72 \\
11.40 \\
11.17 \\
11.54 \\
10.73 \\
12.87\end{array}$ & $\begin{array}{l}3.500 \\
2.900 \\
2.500 \\
3.200 \\
2.100 \\
6.120\end{array}$ \\
\hline 1961 & Sept.14. & 1961 & $12 \cdot 32$ & 4.750 \\
\hline 1962 & $\begin{array}{l}\text { Nov. } 3, \\
\text { Nov. } 16, \\
\text { Feb. } \quad 5,\end{array}$ & $\begin{array}{l}1961 \\
1961 \\
1962\end{array}$ & $\begin{array}{l}11.08 \\
10.62 \\
11.37\end{array}$ & $\begin{array}{c}2,440 \\
2.150 \\
--\end{array}$ \\
\hline 1963 & $\operatorname{Mar} .4$. & 1963 & 11.29 & 2.950 \\
\hline 1964 & $\begin{array}{l}\text { Apr. } \\
\text { Apr. }\end{array}$ & $\begin{array}{l}1964 \\
1964\end{array}$ & $\begin{array}{l}10.20 \\
11.77\end{array}$ & $\begin{array}{l}2,000 \\
3,400\end{array}$ \\
\hline 1965 & $\begin{array}{lr}\text { Jan. } & 1, \\
\text { Jan. } & 23, \\
\text { MaI. } & 17, \\
\text { A pr. } & 6, \\
\text { JuIy } 14,\end{array}$ & $\begin{array}{l}1965 \\
1965 \\
1965 \\
1965 \\
1965\end{array}$ & $\begin{array}{l}11.32 \\
10.47 \\
11.35 \\
12.65 \\
10.01\end{array}$ & $\begin{array}{l}2.980 \\
2.220 \\
2.440 \\
4.580 \\
2.050\end{array}$ \\
\hline 1966 & June 13 & 1966 & 8.12 & 1,100 \\
\hline
\end{tabular}

d Discharge not determined.

e Affected by ice. 
05-4910.00 Sugar Creek near Keokuk, Iowa--(Continued)

Peak_s_tages and_dis charges

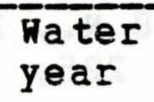

Hater

year

Date
Gage height

(feetet)

12.09

11.12

12.13

11.57

12.08

12.96

11.4

9.98

12.21

12.79

13.27

12.26

12.90

12.30

11.87

15.80

Sept.22, 1970

1971

1972

1973
Dec. 11, 1970

Feb. 18, 1971

Dec. 21, 1971

June 15, 1971

$\begin{array}{lr}\text { Mar. } 7, & 1973 \\ \text { Apr. } & 91973 \\ \text { Apr. } 22, & 1973 \\ \text { May } & 2,1973\end{array}$
9.73

12.04

12. 10

10.53

11.76

12.70

16.30

12.45
Discharge

(cfs)

3.100

2.250

3.140

2.560

3.090

-4.26으.

1.500

2.260

2.500

3.170

2.310

2.900

2. 380

2.140

6.400

1.250

-.

2.260

1.520

2.060

2.440

5.700

2.480

Discontinued september 1973

e Affected by ice. 
Location.--Lat $41^{\circ} 034^{\prime}$, long $92044^{\circ}$, in SE1/4 sec.7, T.78 N.. R.16 W. Poweshiek County, at bridge on State Highway $225,1.8$ miles west of searsboro.

Drainage area.--52.7 sq miles.

Gage.--Crest-stage gage.

Stage-discharge relation.--Defined by current-metar measurements. Remarks.--only annual peaks a re shown.

P으므_stagges_and_discharges

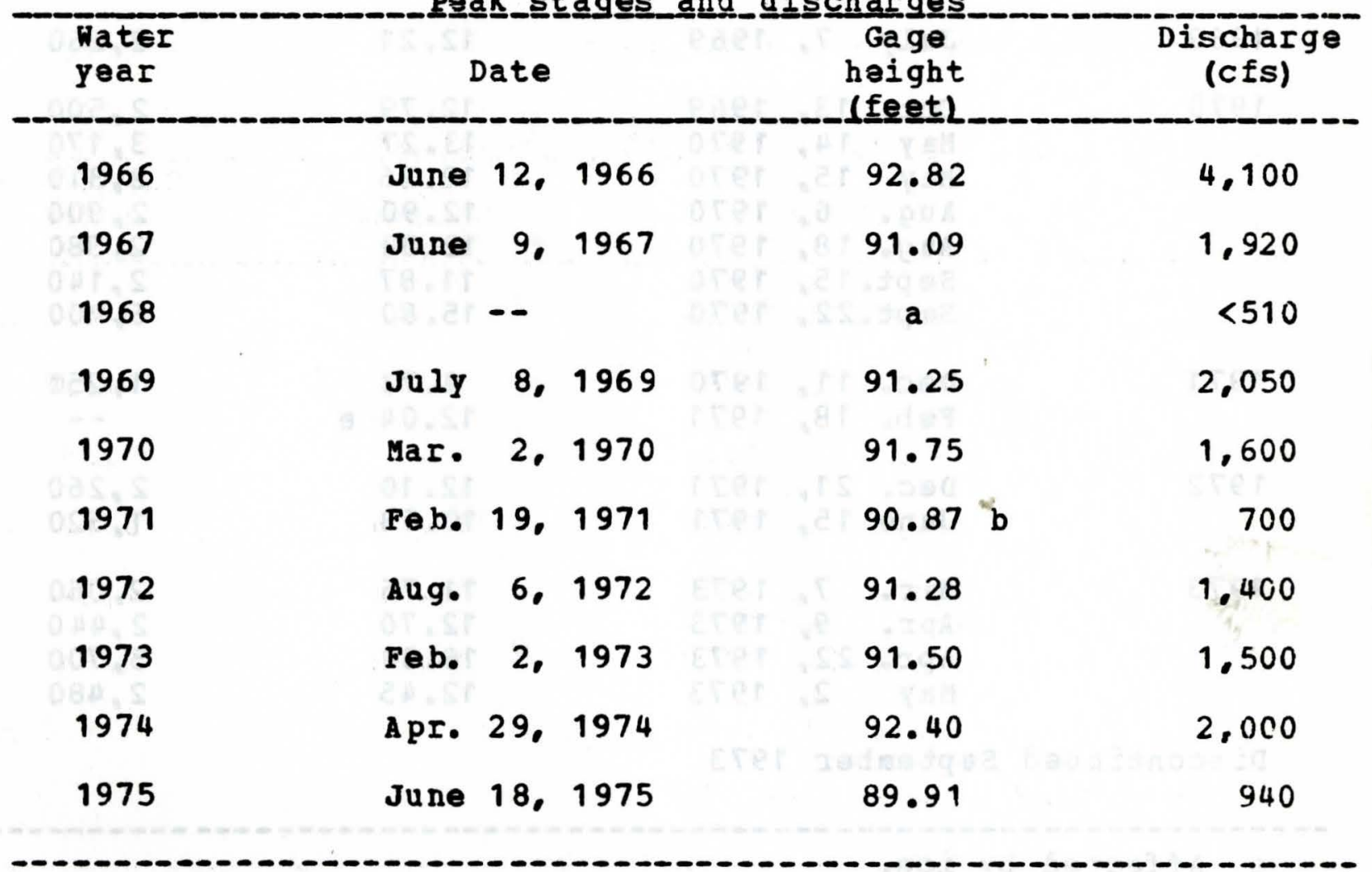

a Peak stage did not reach hottom of gage.

b Affected by ice. 
Location.--Lat 40035140", long 95013.25", on line between SE1/4 sec. 20 and NE1/4 sec. 29, T.67 N.. R. 38 W. . Page County, at bridge on State Highway 333,1 mile north of Blanchard and 8.2 miles downstream from snake creek.

Drainage area.--200 sq miles, approximately.

Gage.--Recording. Datum of gage is 940.32 feet above mean sea level. Prior to Mar. 5, 1940, at $5.00 \mathrm{ft}$ higher datum.

Stage-discharge relation.--Defined by current-meter measurements below 3,200 cfs and by slope-area measurement at 9,980 cfs.

Remarks.--only arnual peaks are shown.

Peak﹎.stagege_and__di

\begin{tabular}{llcr}
$\begin{array}{c}\text { Water } \\
\text { year }\end{array}$ & Date & $\begin{array}{c}\text { Gage } \\
\text { height } \\
\text { (feetL }\end{array}$ & $\begin{array}{c}\text { Discharge } \\
\text { (Cfs) }\end{array}$ \\
\hline 1934 & Sept.26, 1934 & - & 182 a \\
1935 & May 31,1935 & 9.10 & 1.920 \\
1936 & Apr. 28,1936 & 12.7 & 4,330 \\
1937 & May 21,1937 & 12.16 & 5.620 \\
1938 & Aug. 20,1938 & 10.12 & 4,240 \\
1939 & Mar. 12,1939 & 18.12 & 9,980 \\
1940 & Apr. 29,1940 &.- & 168 b \\
Discontinued June 30,1940 & &
\end{tabular}

a Maximum for period Mar. 13 to sept. $30,1934$.

b Maximum for period oct. 1, 1939, to June 30, 1940. 
Location.--Lat 41006', long 95006', near NE corner sec.28, T.73 N.. R.37 W.. Montgomery County, at bridge, 4.5 miles southeast of Elliot.

Drainage area.--10.7 sq miles.

Gage.--Crest-stage gage.

Stage-discharge relation.--Defined by current-meter and indirect measuzements.

Remarks.--only annual peaks are shown.

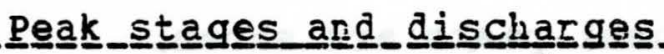

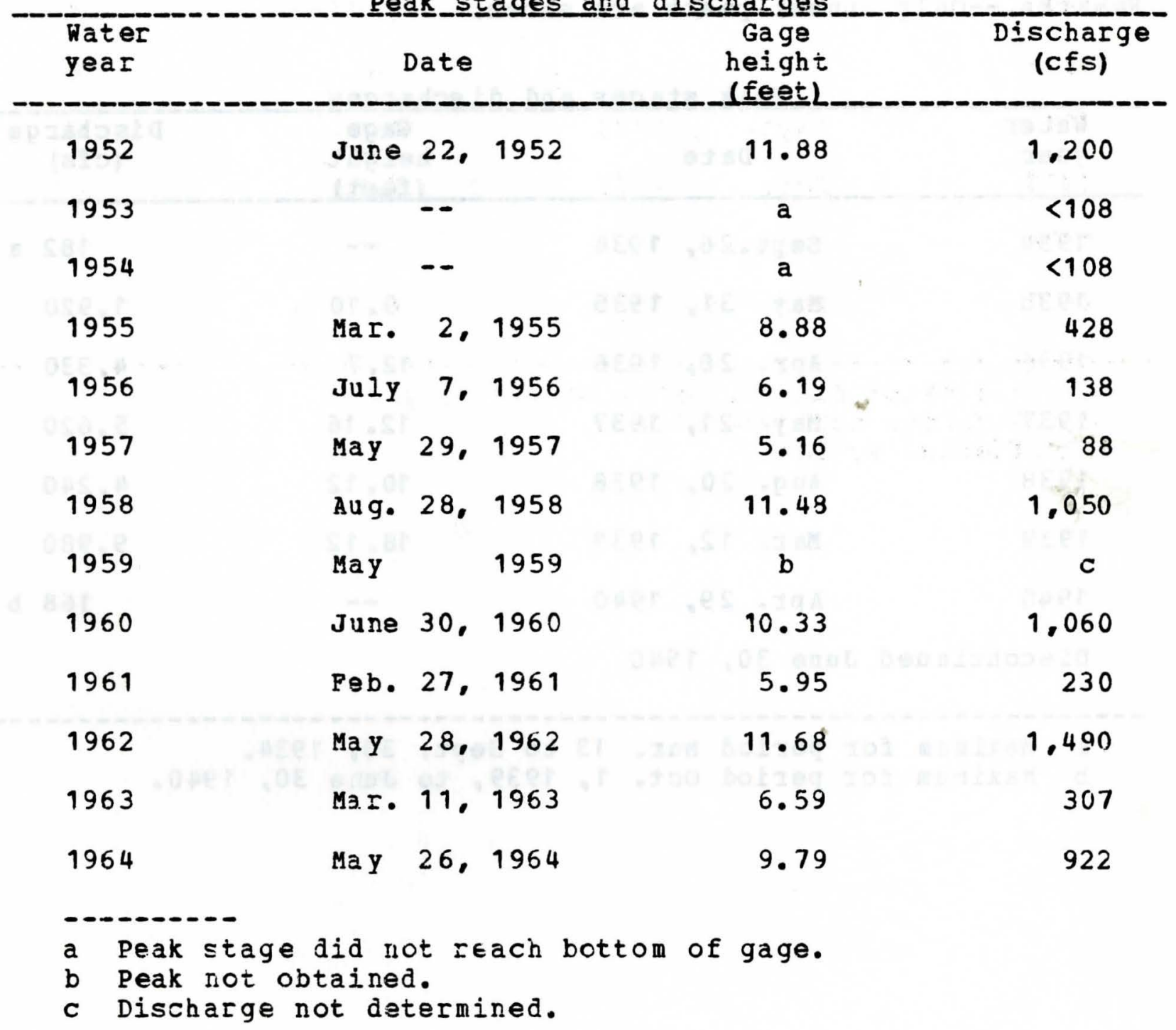


06-8117.60 Tarkio River near Elliot, Iowa--(Continued)

Peak__stages_and_ di

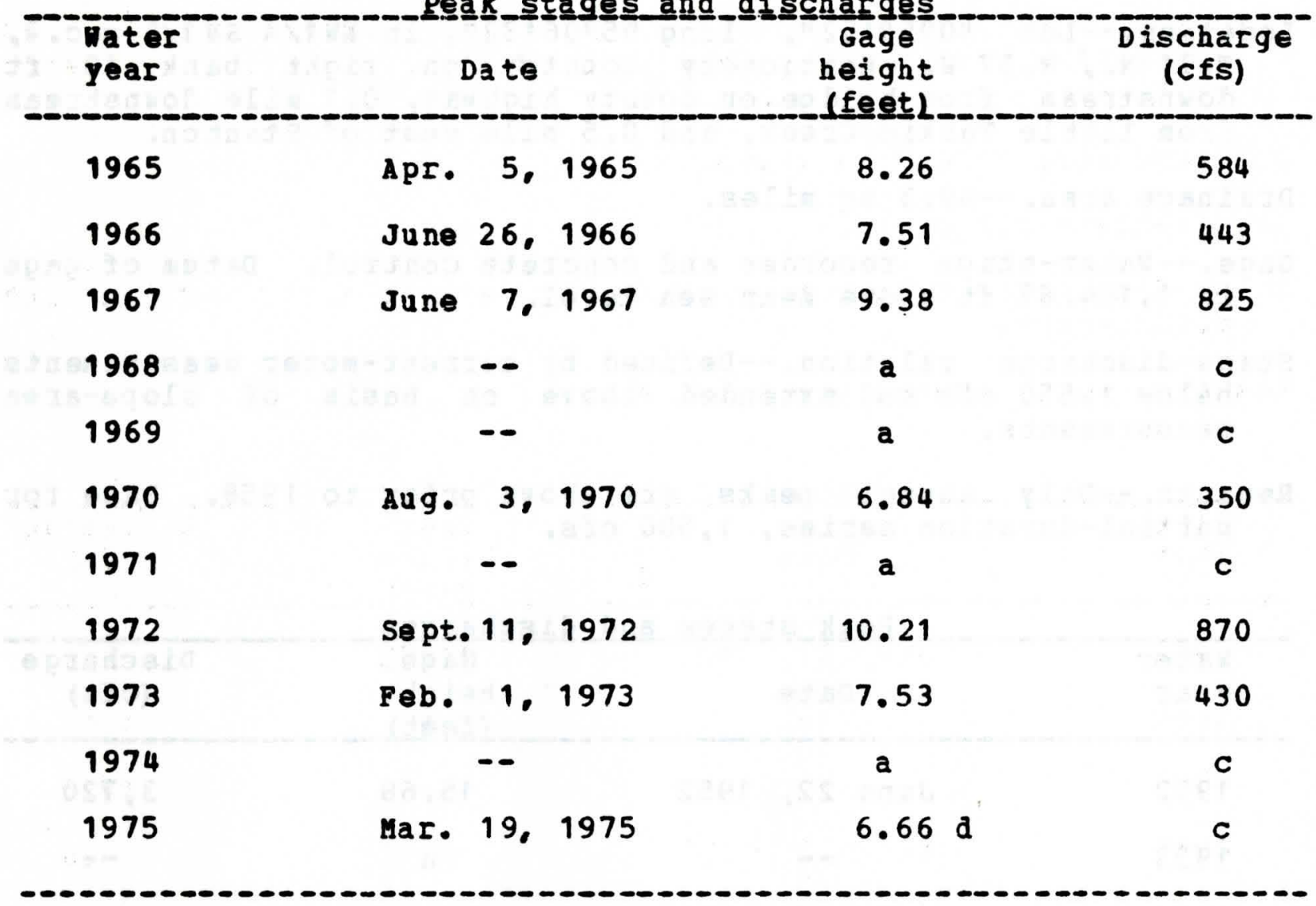

a Peak stage did not reach bcttom of gage.

c Discharge not determined.

d Iffected by ice. 
Location.--Iat 40058152", long 95006'32", in NW1/4 SW1/4 sec.4, T. 71 N.. R. 37 \%.. Montgomery County, on right bank $10 \mathrm{ft}$ downstream from bridge on county highway, 0.1 mile downstream from little Tarkio Creek, and 0.5 mile west of stanton.

Drainage area.--49.3 sq miles.

Gage.--hater-stage recorder and concrete control. Datum of gage is $1,104.67 \mathrm{ft}$ above mean sea level.

Stage-discharge ralation.--Defined by current-meter measurements below $1,550 \mathrm{cfs}$ and extended above on basis of slope-area measurements.

Remarks.--only annual peaks are shown prior to 1958 . Base for partial-duration series, 1,500 cfs.

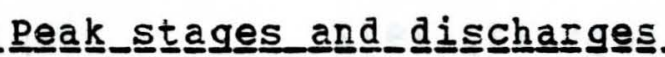

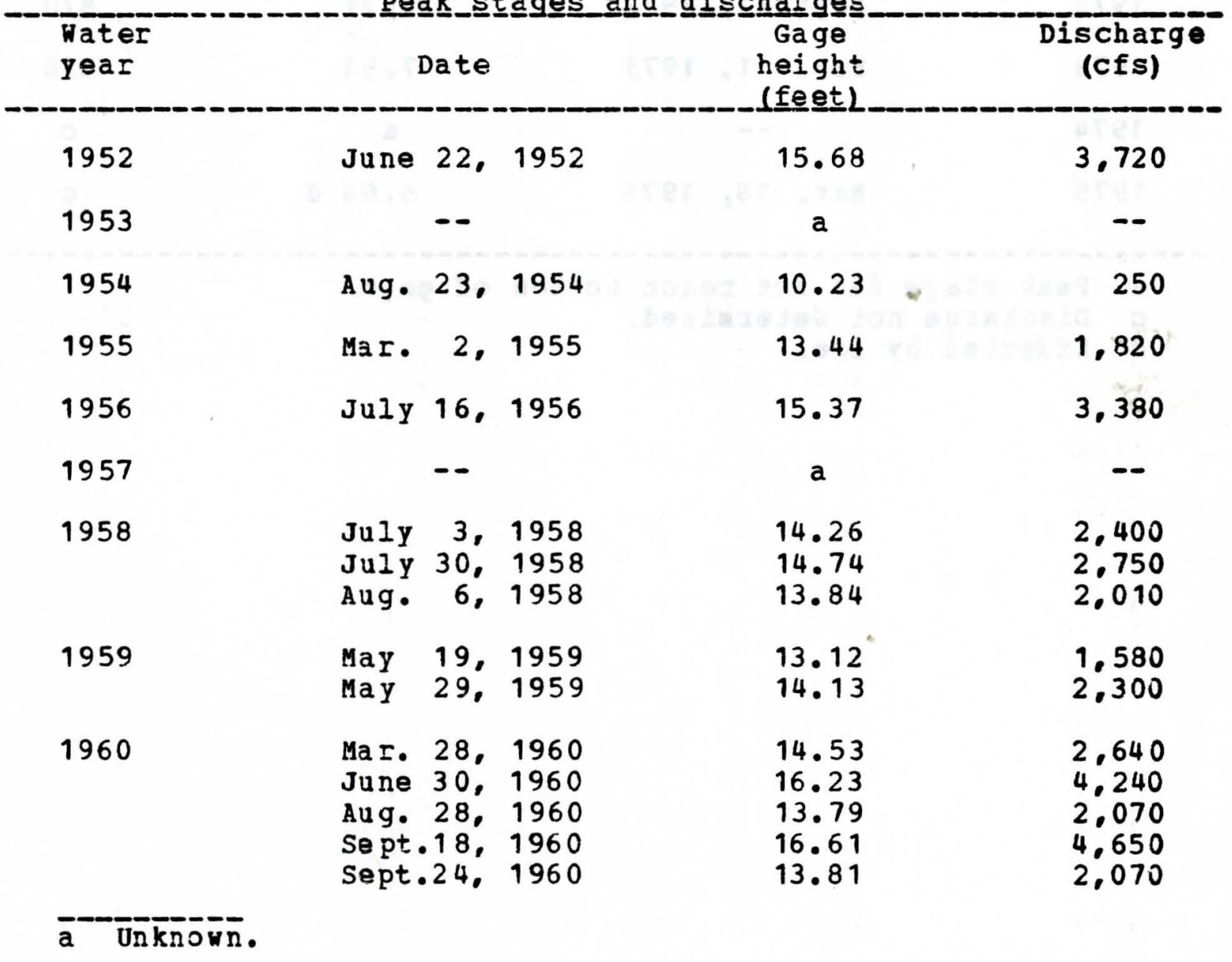


06-8118.40 Tarkio River at Stanton, Iowa-- (Continued)

Peák_stáges and_di $\mathbf{s}$ chargarges

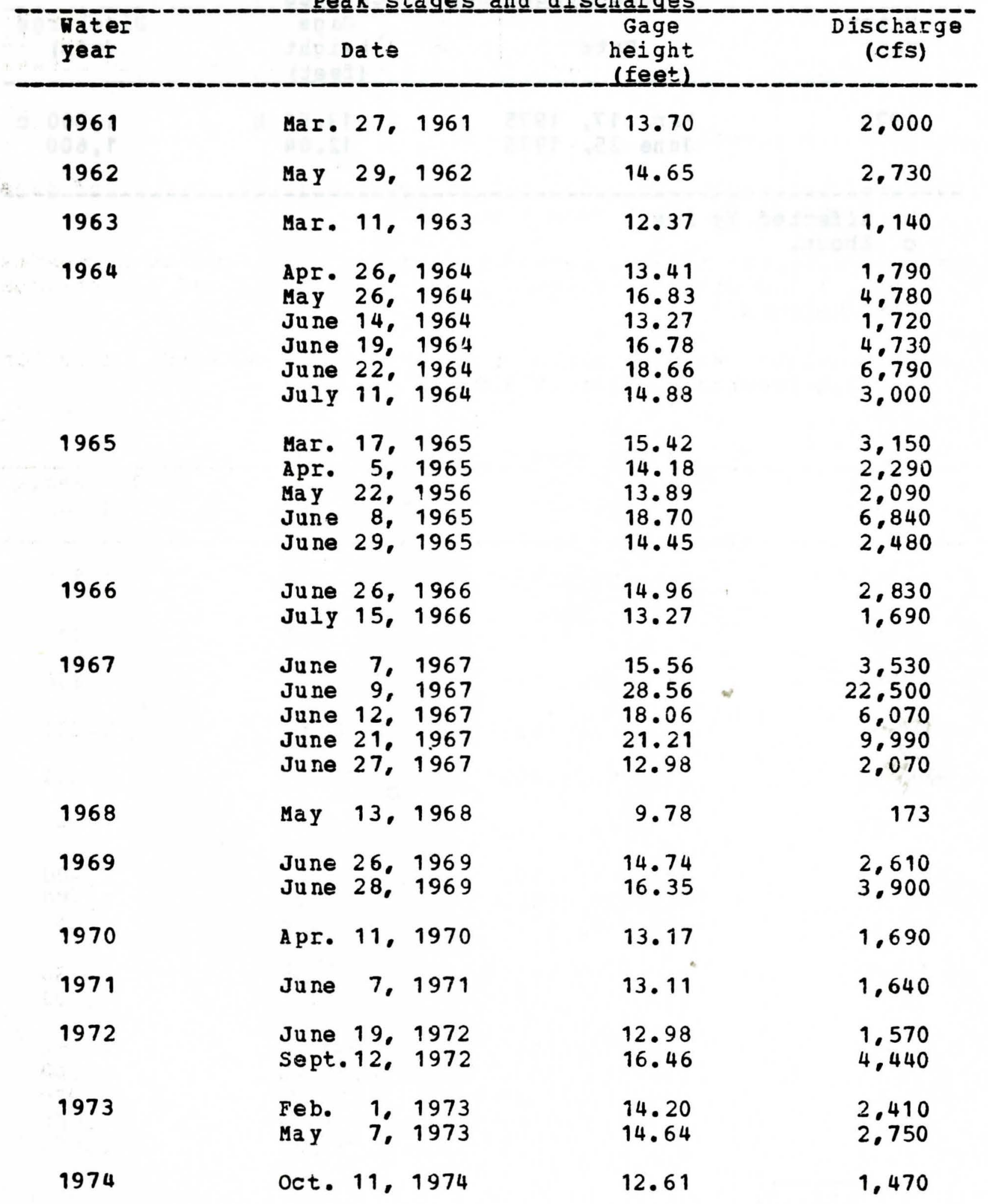


06-8118.40 Tarkio River at Stanton. Iowa-- (Continued)

Peak_stages_and_discharges.

\begin{tabular}{|c|c|c|c|}
\hline $\begin{array}{l}\text { Water } \\
\text { year }\end{array}$ & Date & $\begin{array}{l}\text { Gage } \\
\text { height } \\
\text { (feet) }\end{array}$ & $\begin{array}{c}\text { Discharge } \\
\text { (cfs) }\end{array}$ \\
\hline 1975 & $\begin{array}{l}\text { Mar. } 17,1975 \\
\text { June } 25,1975\end{array}$ & $\begin{array}{l}13.56 \mathrm{~b} \\
12.84\end{array}$ & $\begin{array}{l}1.500 \mathrm{c} \\
1.600\end{array}$ \\
\hline
\end{tabular}

b Affected by ice.

c About. 
Location.--Lat $41003^{\prime}$. Iong $95^{\circ} 06^{\prime}$, near northeast corner sec.16, T.72 N.. R. 37 F.. Montgomery County, at box culvert, 4 miles north of Stanton.

Drainage area. $-0.67 \mathrm{sq}$ miles.

Gage.--Crest-stage gage.

Stage-discharge relation.--Defined by step-backwater computations and by indirect measurements.

Remarks.--only annual peaks are shown.

Peaㅡㄴ_s_tages_and_didischarges

\begin{tabular}{llcc}
$\begin{array}{c}\text { Water } \\
\text { Year }\end{array}$ & Date & $\begin{array}{c}\text { Gage } \\
\text { height } \\
\text { (feetL }\end{array}$ & $\begin{array}{c}\text { Discharge } \\
\text { (cfs) }\end{array}$ \\
\hline 1952 & June 2,1952 & 4.51 & 248 \\
1953 & - & $a$ & $<97$ \\
1954 & June 21,1954 & 3.35 & 128 \\
1955 & Mar. 2,1955 & 3.82 & 166 \\
1956 & July 15,1956 & 4.88 & 318 \\
1957 & May 15,1957 & 3.54 & 142 \\
1958 & Aug. 28,1958 & 4.86 & 313 \\
1959 & May 28,1959 & 3.97 & 179 \\
1960 & Jure 30,1960 & 4.62 & 266 \\
1961 & Mar. 12,1961 & 3.40 & 132 \\
1962 & May 28,1962 & 3.73 & 158 \\
1963 & Mar. 4,1963 & 2.90 & 99 \\
1964 & May 24,1964 & 3.99 & 181 \\
1965 & June 8,1965 & 3.28 & 124 \\
\hline & & &
\end{tabular}

a Peak stage did not reach bottom of gage. 
06-8118.20 Tarkio River tributary near stanton. Iowa--(Continued)

Peak﹎.stagges_and_di $\underline{\text { sch }}$ arges

\begin{tabular}{|c|c|c|c|c|}
\hline $\begin{array}{l}\text { Water } \\
\text { year }\end{array}$ & Date & & $\begin{array}{l}\text { Gage } \\
\text { height } \\
\text { feetl }\end{array}$ & $\begin{array}{c}\text { Discharge } \\
\text { (cfs) }\end{array}$ \\
\hline 1966 & June 26 & 1966 & a & $<60$ \\
\hline 1967 & June 9. & 1967 & 5.18 & 835 \\
\hline 1968 & - & & a & $<60$ \\
\hline 1969 & -- & & $a$ & $<60$ \\
\hline 1970 & -- & & $a$ & $<60$ \\
\hline 1971 & $-\infty$ & & a & $<60$ \\
\hline 1972 & Sept. 11. & 1972 & 2.64 & 84 \\
\hline 1973 & Feb. & 1973 & 2.36 & 71 \\
\hline 1974 & - & & a & $<60$ \\
\hline 1975 & Mar. 14, & 1975 & $2.50 \mathrm{~b}$ & c \\
\hline
\end{tabular}

a Peak stage did not reach bottom of gage.

b Affected by ice.

c Discharge not determined. 
06-8980.00 Thompson River at Davis City. Iowa

(Published as "Grand River" prior to 1918)

Location.--Lat $40038 \cdot 25^{\prime \prime}$, long $93048129 "$, in SE1/4 SE1/4 sec. 35 , T.68 N.. R. 26 W.. Decatur County, on right bank 15 feet downstream from bridge on U.S. Highway 69 at Davis City, 2.6 miles upstream from Dickersons Branch, and 5.2 miles upstream from Iowa-Missouri State line.

Drainage area.--701 sq miles.

Gage.--Hater-stage Iecorder. Datum of gage is 874.04 feet above mean sea level. May 14, 1918, to July 2, 1925, July 14, 1941. to Feb, 24, 1942, ronrecording gage, and Feb. 25, 1942, to Feb. 8, 1967, water-stage recorder at same site at datum 2.00 ft higher.

Stage-discharge relation.--Defined by current-meter measurements below 15,000 cfs and extended above on basis of velocity-area study.

Flood stage. - 11 feet.

Remarks.--Base for partial-duration series, 4,500 cfs.

Pea

\begin{tabular}{|c|c|c|c|c|c|c|}
\hline $\begin{array}{l}\text { Water } \\
\text { year }\end{array}$ & Date & & & $\begin{array}{l}\text { Gage } \\
\text { height } \\
\text { (feet) }\end{array}$ & : & $\begin{array}{c}\text { Discharge } \\
\text { (cfs) }\end{array}$ \\
\hline-188 & Aug. 8 , & 1885 & & 22.8 a & $\approx$ & 30.000 \\
\hline 1897 & Apr. 24. & 1897 & & 21.7 & & -- \\
\hline$-19 \underline{0} 3$ & $\mathrm{Aug} \cdot 27$ & 1903 & & 21.0 & & -- \\
\hline 1909 & July 6 , & 1909 & & $20 \cdot 3$ & & -- \\
\hline 1914 & Aug. 16, & 1914 & & 20.2 & & - \\
\hline 1915 & Mar. 28, & 1915 & & 19.6 & & -- \\
\hline 1918 & June 6 , & 1918 & & 14.7 & & 5.660 \\
\hline 1919 & $\begin{array}{l}\text { Mar. } 16, \\
\text { Apr. 22, } \\
\text { May } 4, \\
\text { June } 4, \\
\text { Sept. } 30,\end{array}$ & $\begin{array}{l}1919 \\
1919 \\
1919 \\
1919 \\
1919\end{array}$ & & $\begin{array}{l}17.8 \\
14.6 \\
17.8 \\
18.8 \\
14.2\end{array}$ & & $\begin{array}{r}10,100 \\
5,580 \\
10,100 \\
12,500 \\
5,260\end{array}$ \\
\hline
\end{tabular}

a From floodmark. 
06-8980.00 Thompson River at Davis City. Iowa-- (Continued)

Peak_stages and discharges

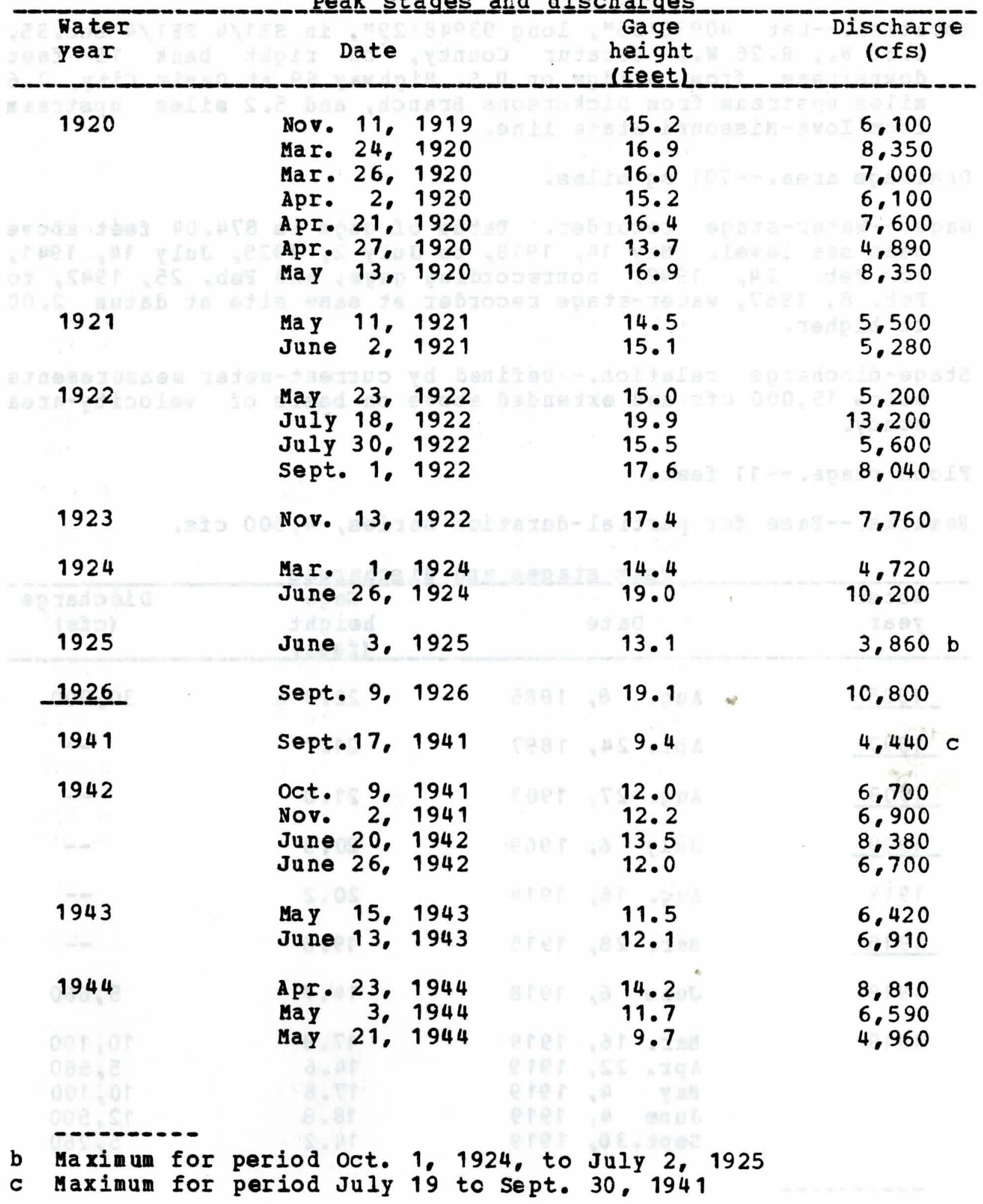


06-8980.00 Thompson River at Davis City. Iowa--(Continued)

Peak﹎.stąges_and

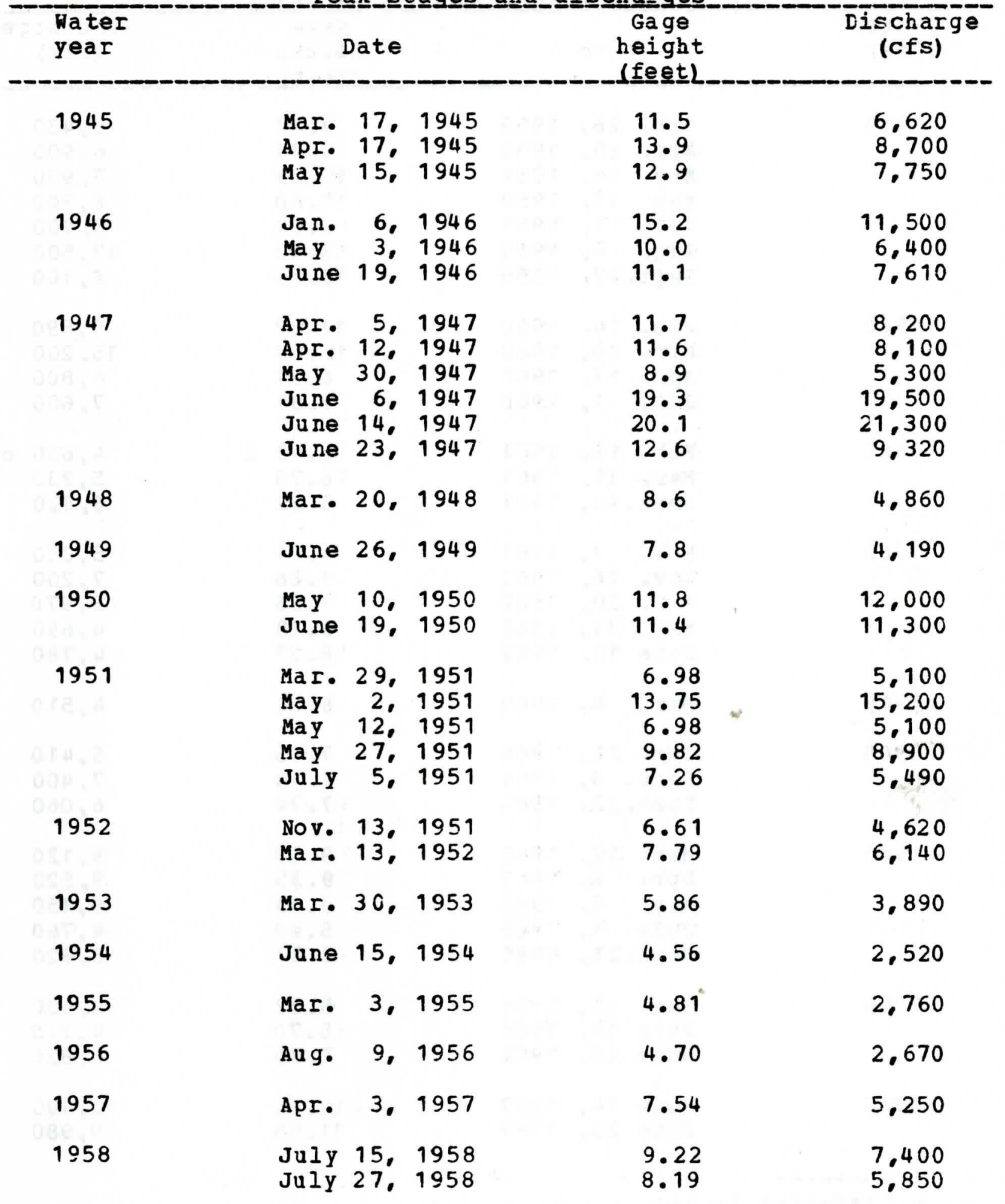


06-8980.00 Thompson River at Davis City, Iowa--(Continued)

Peak

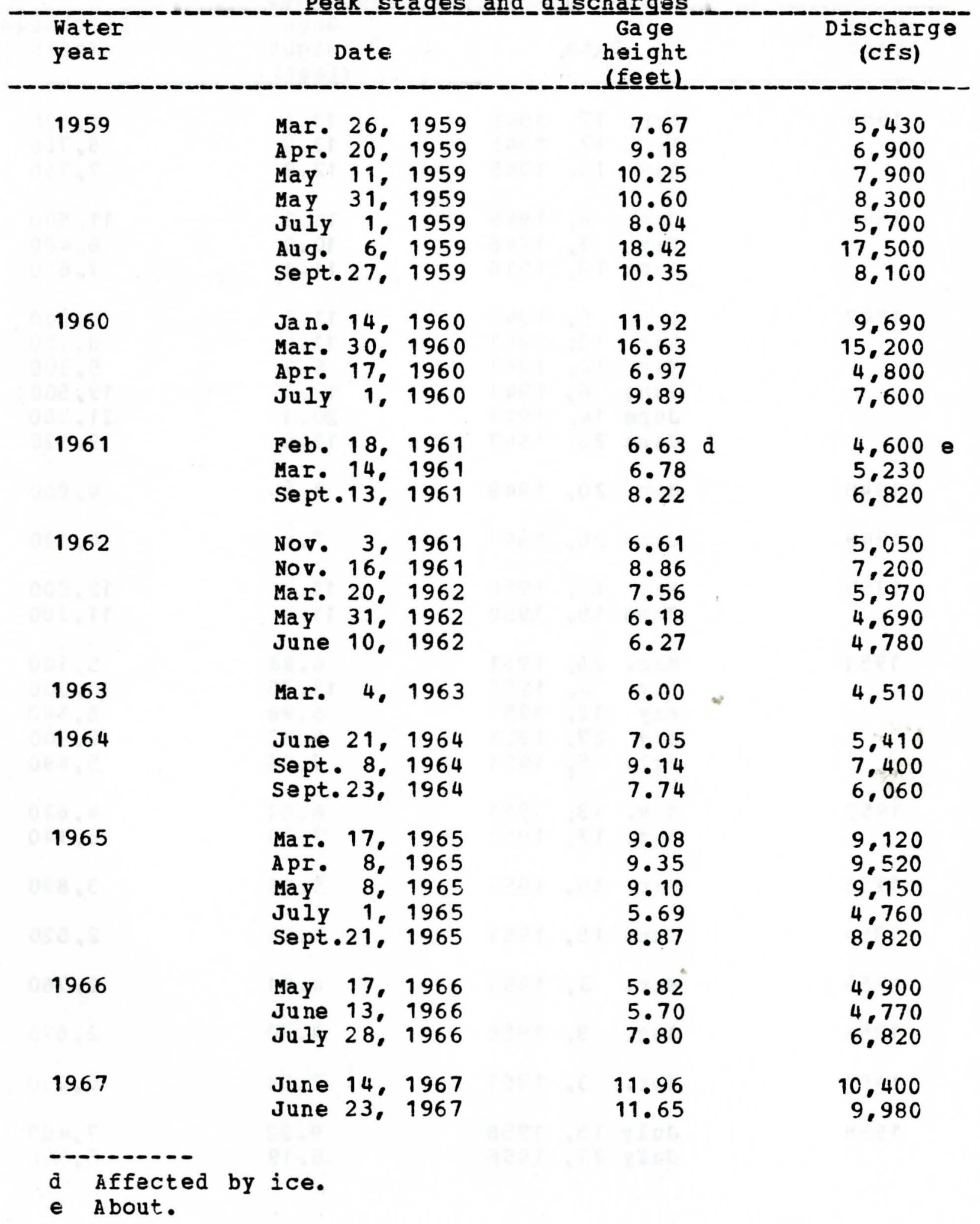


06-8980.00 Thompson River at Davis City, Iowa--(Continued)

Peak﹎stages_and_discharges

\begin{tabular}{|c|c|c|c|c|c|}
\hline $\begin{array}{l}\text { Water } \\
\text { year }\end{array}$ & Date & & $\begin{array}{c}\text { Gage } \\
\text { height } \\
\text { lfeetL }\end{array}$ & & $\begin{array}{c}\text { Discharge } \\
\text { (cfs) }\end{array}$ \\
\hline 1968 & Apr. 23. & 1968 & 8.58 & & $5.65 c$ \\
\hline 1969 & $\begin{array}{lr}\text { Apr. } & 28, \\
\text { May } & 9, \\
\text { June } & 13, \\
\text { July } & 9 \\
\text { July } & 19,\end{array}$ & $\begin{array}{l}1969 \\
1969 \\
1969 \\
1969 \\
1969\end{array}$ & $\begin{array}{r}7.87 \\
7.71 \\
9.69 \\
12.01 \\
11.39\end{array}$ & & $\begin{array}{r}4.830 \\
4.700 \\
7.190 \\
10.500 \\
9.460\end{array}$ \\
\hline 1970 & May 14, & 1970 & 7.99 & & 4.940 \\
\hline 1971 & $\mathrm{Feb} .20$ & 1971 & 8.40 & $\mathrm{~d}$ & $5.200 €$ \\
\hline 1972 & $\begin{array}{l}\text { May } 7, \\
\text { Sept. 12, } \\
\text { Sept. 16, }\end{array}$ & $\begin{array}{l}1972 \\
1972 \\
1972\end{array}$ & $\begin{array}{r}9.63 \\
10.82 \\
12.45\end{array}$ & & $\begin{array}{r}7.960 \\
8.470 \\
10.600\end{array}$ \\
\hline 1973 & $\begin{array}{l}\text { Dec. } 30, \\
\text { Feb. } 3, \\
\text { Mar. } 11, \\
\text { Mar. } 14, \\
\text { Mar. } 25, \\
\text { Mar. } 31 . \\
\text { Apr. 16, } \\
\text { May } 2, \\
\text { May } 8, \\
\text { Sept. } 26,\end{array}$ & $\begin{array}{l}1972 \\
1973 \\
1973 \\
1973 \\
1973 \\
1973 \\
1973 \\
1973 \\
1973 \\
1973\end{array}$ & $\begin{array}{r}10.15 \\
11.28 \\
8.29 \\
8.89 \\
9.05 \\
11.27 \\
10.71 \\
8.10 \\
8.36 \\
9.21\end{array}$ & $w$ & $\begin{array}{l}7.850 \\
9.420 \\
5.510 \\
6.230 \\
6.420 \\
9.400 \\
8.590 \\
5.280 \\
5.590 \\
6.610\end{array}$ \\
\hline 1974 & $\begin{array}{l}\text { Oct. } 11, \\
\text { Apr. } 21, \\
\text { May } 30, \\
\text { June } 10 .\end{array}$ & $\begin{array}{l}1973 \\
1974 \\
1974 \\
1974\end{array}$ & $\begin{array}{r}14.21 \\
8.27 \\
8.49 \\
19.43\end{array}$ & & $\begin{array}{r}14,200 \\
5,530 \\
5,750 \\
24,300\end{array}$ \\
\hline 1975 & Mar. 18. & 1975 & 7.38 & & 4.420 \\
\hline
\end{tabular}


Location.--Iat 42000'25", long 92051'15", in SE1/4 SW1/4 sec.8, T. 83 H.. R. 17 W.. Marshall County, on left bank 20 feet downstrean from bridge on U.S. Highway $30,3.5$ miles upstream from mouth, and 4.1 miles southeast of court house in Marshalltown.

Drainage area.--118 sq miles.

Gage.- Water-stage recorder. Datum of gage is $849.44 \mathrm{ft}$ above mean sea level.

stage-discharge relation.--Defined by current-meter measurements. Bankfull stage.--12 feet.

Remarks.--Base for partial-duration series, 1,000 cfs.

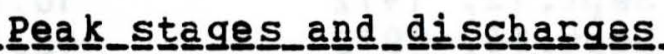

\begin{tabular}{|c|c|c|c|c|}
\hline $\begin{array}{l}\text { Water } \\
\text { yoar }\end{array}$ & & Date & $\begin{array}{l}\text { Gage } \\
\text { height } \\
\text { J feeet }{ }^{2}\end{array}$ & $\begin{array}{c}\text { Discharge } \\
\text { (cfs) }\end{array}$ \\
\hline-1947 & June & 1947 & 16.8 & 5,700 \\
\hline 1950 & $\begin{array}{l}\text { Fab. } \\
\text { Feb. } \\
\text { Mar. } \\
\text { June }\end{array}$ & $\begin{array}{rr}9, & 1950 \\
10, & 1950 \\
5, & 1950 \\
18, & 1950\end{array}$ & $\begin{array}{l}11.92 \\
12.30 \\
15.10 \\
15.77\end{array}$ & $\begin{array}{l}1.520 \\
1.690 \\
4.030 \\
4.940\end{array}$ \\
\hline 1951 & $\begin{array}{l}\text { Mar. } \\
\text { June }\end{array}$ & $\begin{array}{r}28,1951 \\
1,1951\end{array}$ & $\begin{array}{l}10.70 \\
11.52\end{array}$ & $\begin{array}{l}1,160 \\
1,390\end{array}$ \\
\hline 1952 & MaI. & 10. 1952 & 13.87 & 2,770 \\
\hline 1953 & $\mathrm{Feb}$. & 20,1953 & 15.09 & 4,030 \\
\hline 1954 & June & 10,1954 & 13.47 & 2.450 \\
\hline 1955 & Feb. & 19,1955 & 13.45 & 1,500 \\
\hline 1956 & May & 13,1956 & 4.35 & 150 \\
\hline 1957 & $\begin{array}{l}\text { June } \\
\text { July }\end{array}$ & $\begin{array}{r}18,1957 \\
3,1957\end{array}$ & $\begin{array}{l}14.23 \\
15.38\end{array}$ & $\begin{array}{l}3.030 \\
4.42 .0\end{array}$ \\
\hline
\end{tabular}


05-4517.00 Timber Creek near Marshalltown. Iowa--(Continued)

Peak

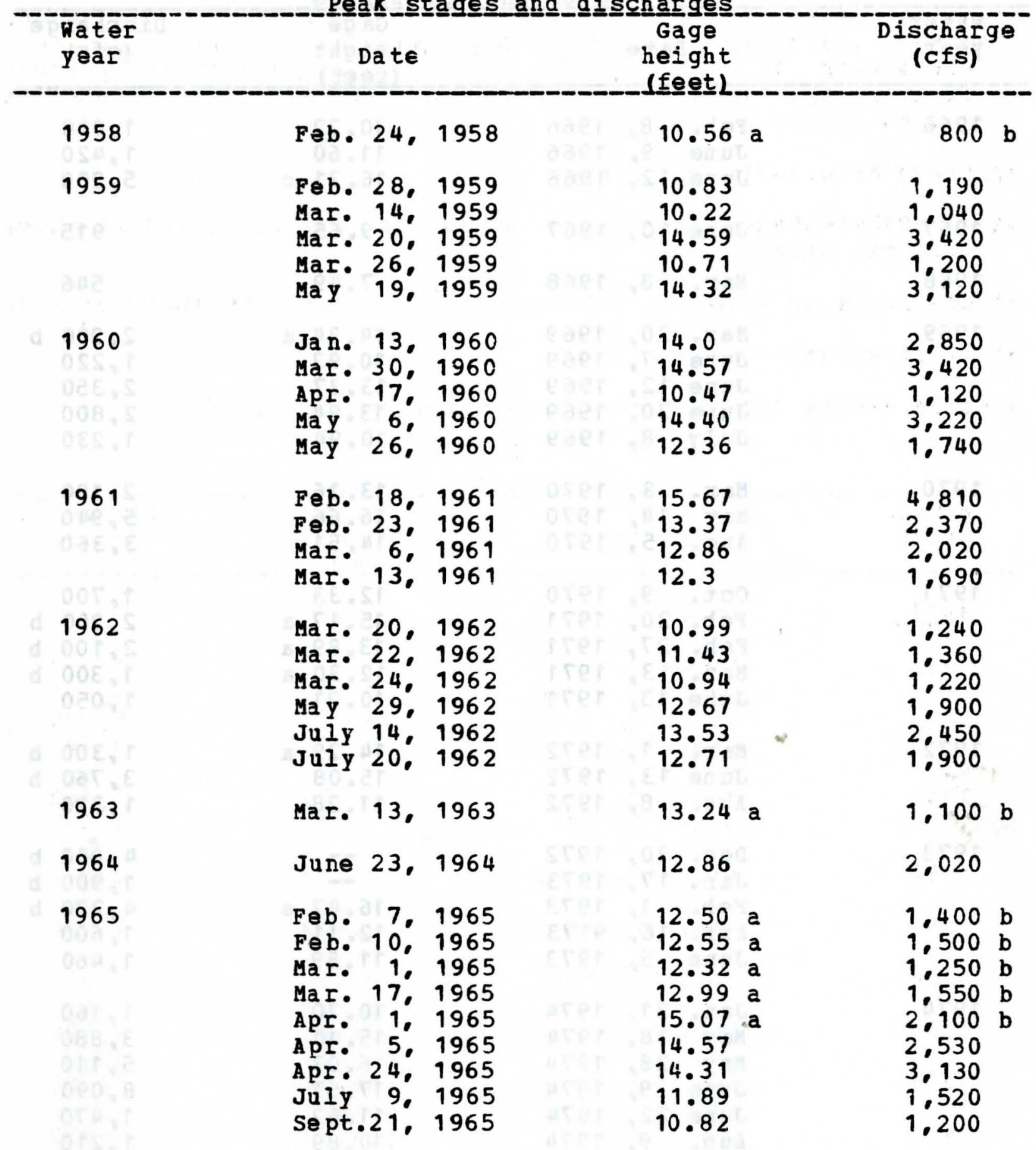

a Affected by ice.

b About. 
Peak__stages_and_di

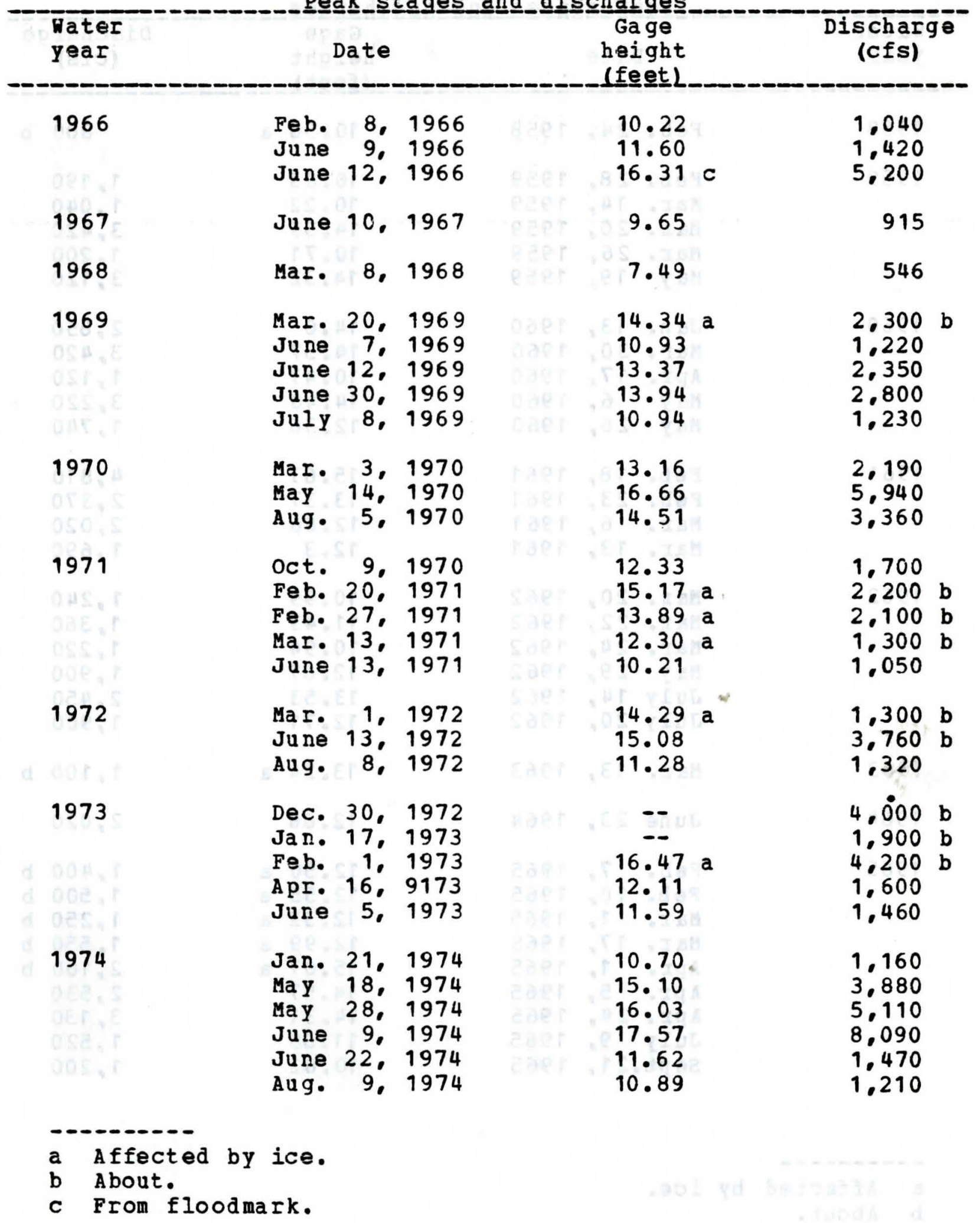


05-4517.00 Timber Creek near Marshalltown, Iowa--(Continued)

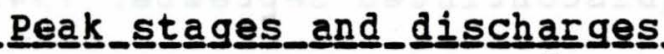

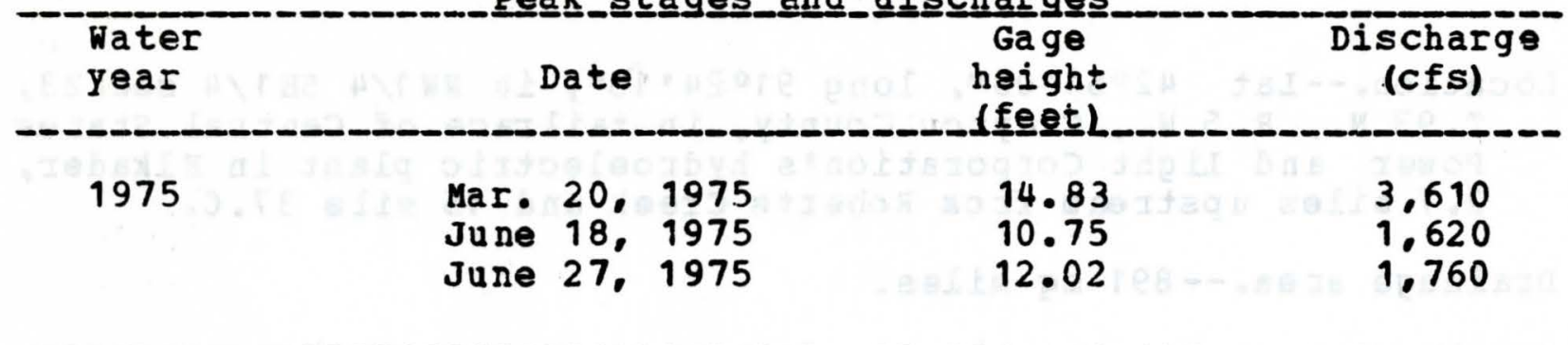




\section{5-4120.00 Turkey River at Elkadar, Iowa}

(Discontinued september 1942)

Location.--Lat 42051'05", long 91024'15", in NW1/4 SE1/4 sec.23,

T. 93 N.. R. 5 W., Clayton County, in tailrace of Central states Power and Light Corporation's hydroelectric plant in Elkader, 2.7 miles upstream from Roberts Creek and 15 mile 37.0.

Drainage area.-- 891 sq miles.

Gage.-Nonrecording. Datum of gage is $701.61 \mathrm{ft}$ above mean sea level.

Stage-discharge relation.--Defined by current-meter measurements. Remarks.--only annual peaks are shown.

\begin{tabular}{|c|c|c|c|c|}
\hline $\begin{array}{l}\text { Water } \\
\text { year }\end{array}$ & & Date & $\begin{array}{l}\text { Gage } \\
\text { height } \\
\text { lfeetl. }\end{array}$ & $\begin{array}{c}\text { Discharge } \\
\text { (cfs) }\end{array}$ \\
\hline 1916 & June & 1. 1916 & 34.3 & $30,000 a$ \\
\hline 1929 & Mar. & 16,1929 & - & $25.200 \mathrm{~b}$ \\
\hline 1933 & Apr. & 1,1933 & - & $23.800 \mathrm{~b}$ \\
\hline 1934 & Jan. & 22,1934 & 12.8 & 6.860 \\
\hline 1935 & Mar. & 6.1935 & 14.0 & 11.400 \\
\hline 1936 & Mar. & 11,1936 & 26.4 & 9.000 \\
\hline 1937 & Mar. & 7. 1937 & 27.5 & 12.300 \\
\hline 1938 & Feb. & 5, 1938 & 14.50 & 13.000 \\
\hline 1939 & MaI. & 14,1939 & 11.50 & 4.970 \\
\hline 1940 & July & 27.1940 & 29.1. & 19.000 \\
\hline 1941 & May & 31,1941 & 29.1 & 19.300 \\
\hline 1942 & June & 30,1942 & 13.0 & 9.200 \\
\hline
\end{tabular}

a A bout.

b Daily mean discharge, from records by Central states Power and light corpcration. 
Location.--Iat $42044 \cdot 24 "$, long $91015 \cdot 42 "$, in SE1/4 NW $1 / 4$ sec.36, T. 92 N.. R. 4 W.. Clayton county, on left bank 10 feet downstream from bridge on courty highway C43,800 ft upstream from Wayman Creek, $1,000 \mathrm{ft}$ southeast of Garber, 2,000 ft downstream from Elk Creek, 1 mile downstream from Volga River. and 19.8 miles upstream from mouth.

Drainage area.--1,545 sq miles.

Gage.--Water-stage recorder. Datum of gage is $634.46 \mathrm{ft}$ above mean sea level. Prior to Feb. 7, 1935, nonrecording gage at same site and datum.

Stage-discharge relation.--Defined by current-meter measurements. Flood stage.-- 17 feet.

Remarks.--Base for partial-duration series, 8,000 cfs. Prior to 1974 . peak base was 10,000 .

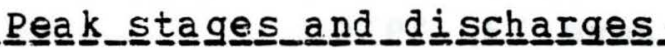

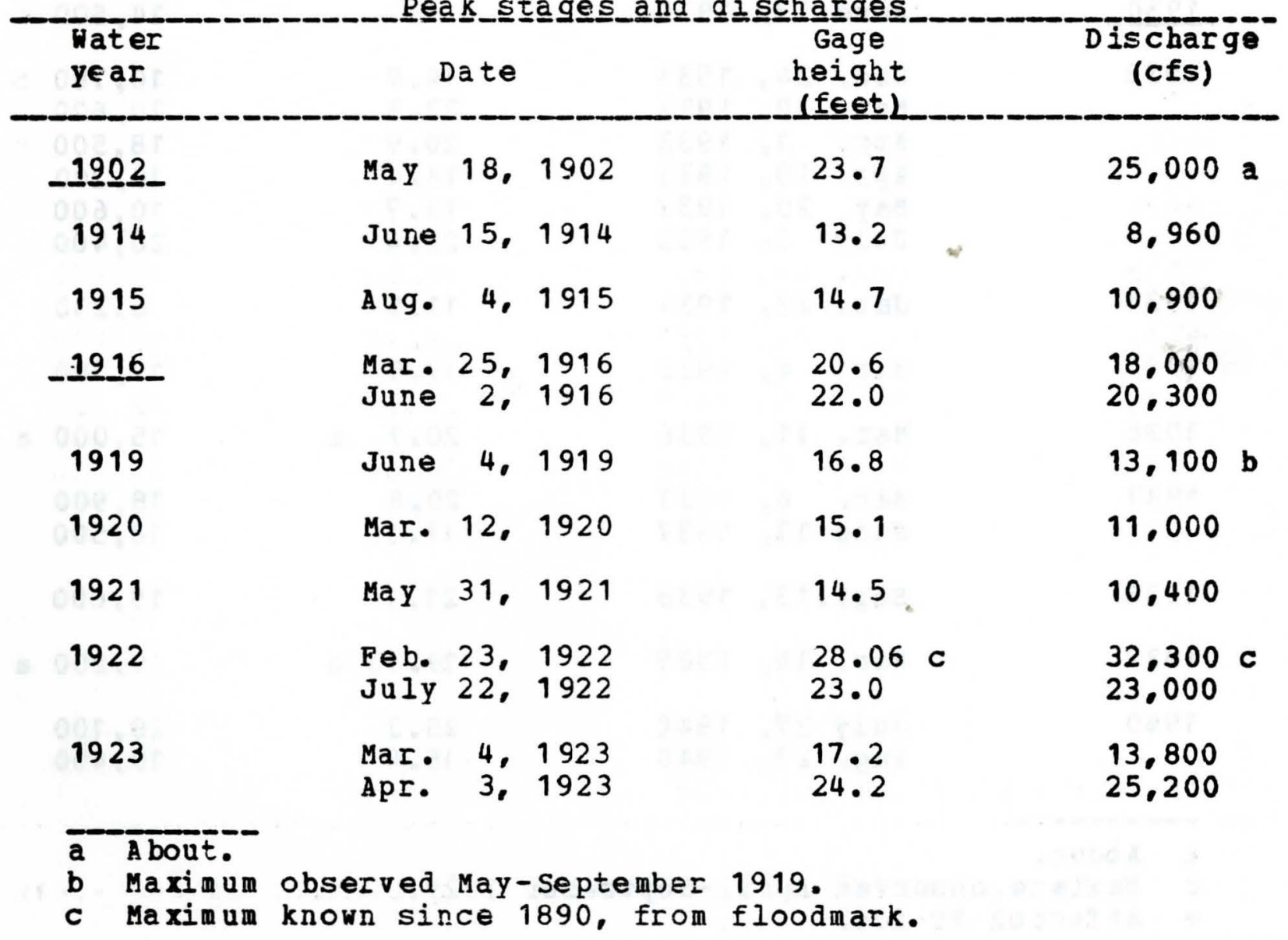


05-4125.00 Turkey River at Garber, Iowa--(Continued)

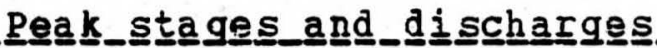

\begin{tabular}{|c|c|c|c|c|}
\hline $\begin{array}{l}\text { Water } \\
\text { year }\end{array}$ & Date & $\begin{array}{l}\text { Gage } \\
\text { height } \\
\text { lfeetl. }\end{array}$ & & $\begin{array}{l}\text { Discharge } \\
\text { (cfs) }\end{array}$ \\
\hline 1924 & $\begin{array}{l}\text { Mar. } 4,1924 \\
\text { July } 21,1924 \\
\text { Aug. 19, } 1924\end{array}$ & $\begin{array}{l}15.0 \\
17.4 \\
15.5\end{array}$ & & $\begin{array}{l}11.000 \\
14.600 \\
11.700\end{array}$ \\
\hline 1925 & $\begin{array}{l}\text { June } 15,1925 \\
\text { June } 17,1925 \\
\text { June } 24,1925\end{array}$ & $\begin{array}{l}24.7 \\
15.5 \\
15.5\end{array}$ & & $\begin{array}{l}26,200 \\
11,700 \\
11,700\end{array}$ \\
\hline 1926 & aug. 20,1926 & 12.0 & & 7.130 \\
\hline-1927 & $\begin{array}{lr}\text { Oct. } & 3,1926 \\
\text { May } & 24, \\
\text { May } & 28,1927 \\
\end{array}$ & $\begin{array}{l}16.8 \\
15.0 \\
14.6\end{array}$ & & $\begin{array}{l}13,700 \\
10,800 \\
10,300\end{array}$ \\
\hline 1929 & July 13, 1929 & -- & & $7,630 \mathrm{~d}$ \\
\hline$-19 \underline{3} \underline{0}$ & June 13,1930 & -- & & 14,500 \\
\hline 1933 & $\begin{array}{l}\text { Dac. } 24,1933 \\
\text { Mar. 30, } 1933 \\
\text { Apr. 1, } 1933 \\
\text { Apr. 10, } 1933 \\
\text { May 20, } 1933 \\
\text { July 2, } 1933\end{array}$ & $\begin{array}{l}14.9 \\
22.5 \\
20.9 \\
14.4 \\
14.7 \\
22.4\end{array}$ & $\sim$ & $\begin{array}{l}10,700 \\
20,600 \\
18,500 \\
10,200 \\
10,600 \\
20,400\end{array}$ \\
\hline 1934 & Jan. 22,1934 & 11.5 & & 6.230 \\
\hline 1935 & Mar. 4, 1935 & 19.9 & & 17.100 \\
\hline 1936 & Mar. 11, 1936 & 20.7 & 8 & $15.000 \mathrm{a}$ \\
\hline 1937 & $\begin{array}{l}\text { Mar. } 6,1937 \\
\text { June } 13,1937\end{array}$ & $\begin{array}{l}20.8 \\
17.1\end{array}$ & & $\begin{array}{l}18,900 \\
13,500\end{array}$ \\
\hline 1938 & Sept.13, 1938 & 21.1 & & 19,600 \\
\hline 1939 & Mar. 14, 1939 & 19.13 & e & $9.200 \mathrm{a}$ \\
\hline 1940 & $\begin{array}{l}\text { July } 27,1940 \\
\text { Aug. } 27,1940\end{array}$ & $\begin{array}{l}25.3 \\
16.4\end{array}$ & & $\begin{array}{l}26,100 \\
10.400\end{array}$ \\
\hline
\end{tabular}


05-4125.00 Turkey River at Garber, Iowa--(Continued)

Peak stages and discharges

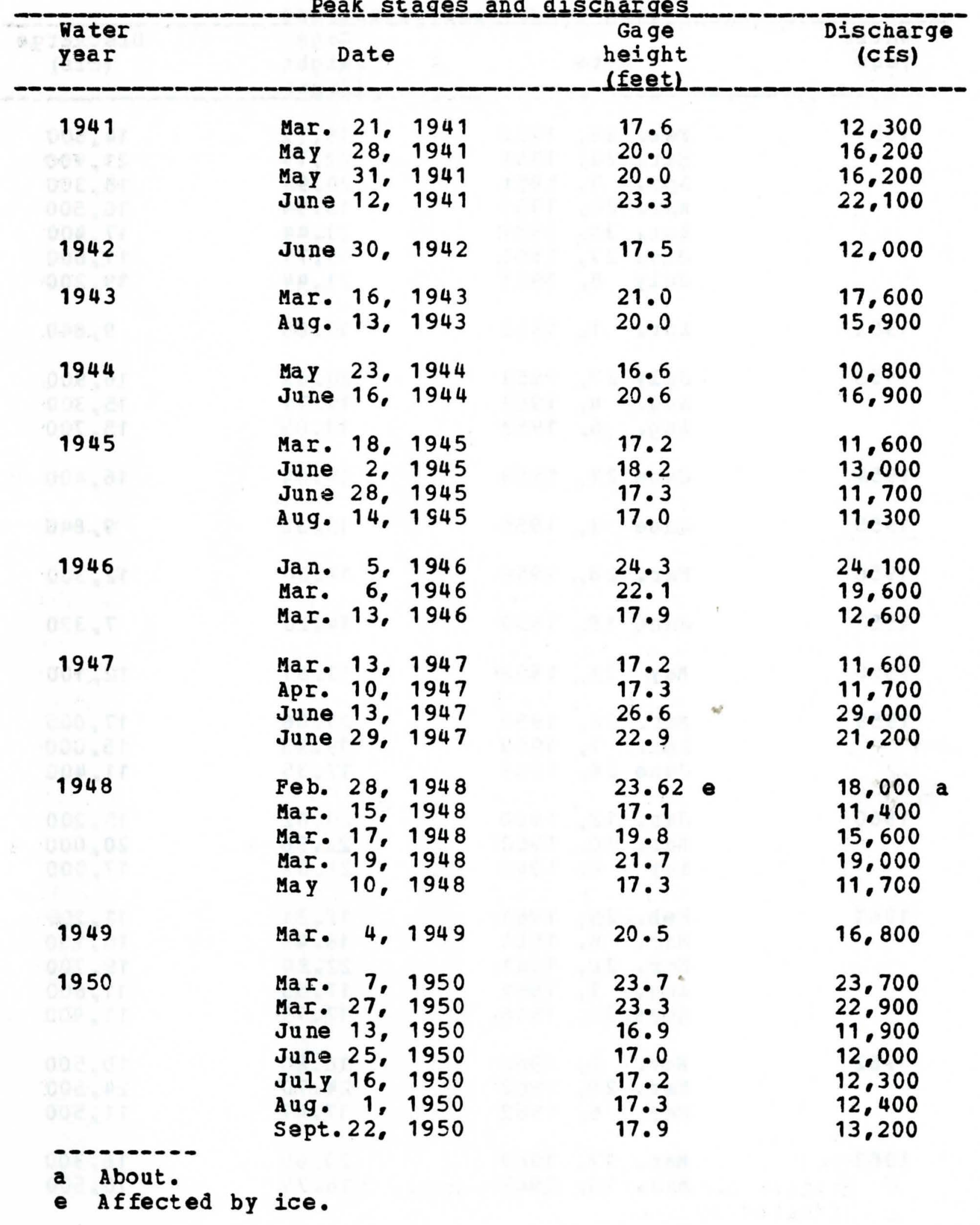


05-4125.00 Turkey River at Garber, Iowa--(Continued)

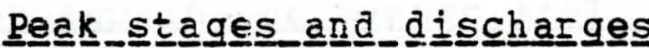

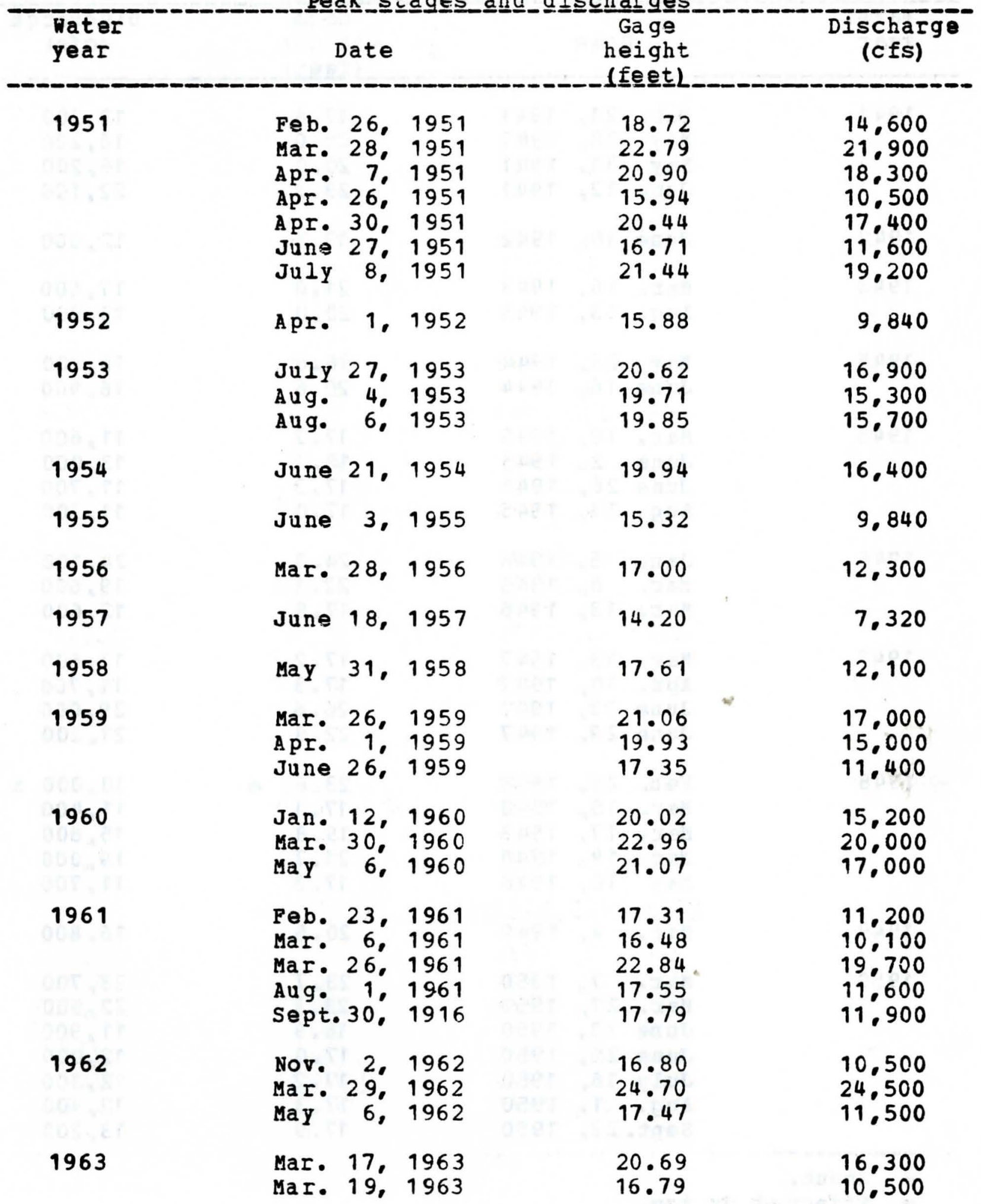


05-4125.00 Turkey River at Garber, Iowa--(Continued)

Peak_s stages_and_dís $\underline{\text { charges }}$

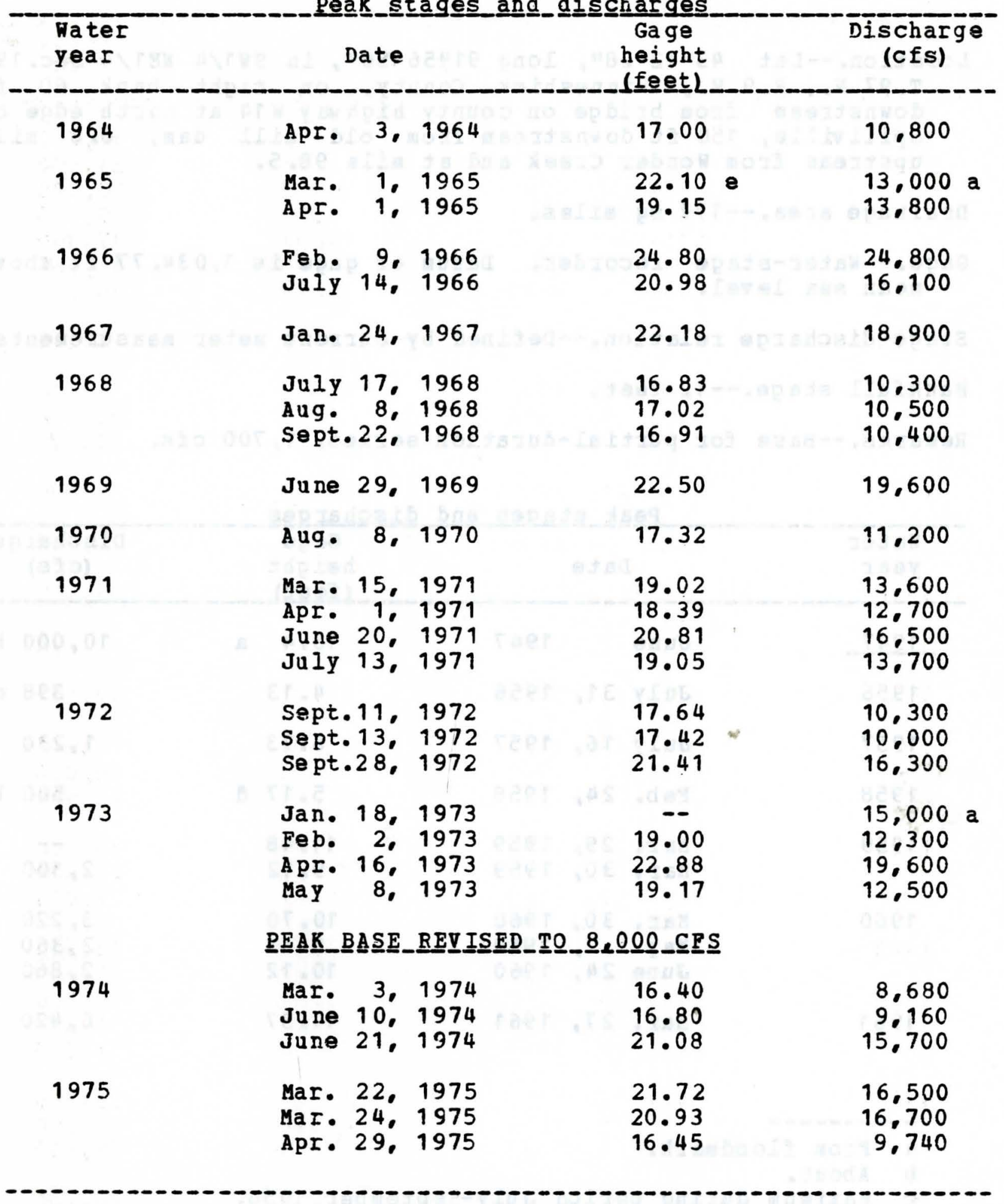

a A bout.

e Affected by ice. 


\section{5-4116.00 Turkey River at Spillville, Iowa}

(Discontinued September 1973)

Location.--Lat $43012 \cdot 28^{\prime \prime}$, long $91056 \cdot 56 "$, in SW1/4 NE1/4 sec.19, T.97 N.. R.9 W.. Ninneshiek County, on right bank 60 ft downstream from bridge on county highway 14 at north edge of Spillville, $150 \mathrm{ft}$ downstream from old mill dam, 0.6 mile upstream from Wonder creek and at mile 98.5.

Drainage area.--177 sq miles.

Gage.-Water-stage recorder. Datum of gage is 1,034.77 ft above mean sea level.

Stage-discharge relation.--Defined by current meter measurements. Bankfull stage.--12 feet.

Remarks.--Base for partial-duration series, 1,700 cfs.

Peak_stages_and_dis $\underline{\text { ch }}$ harges

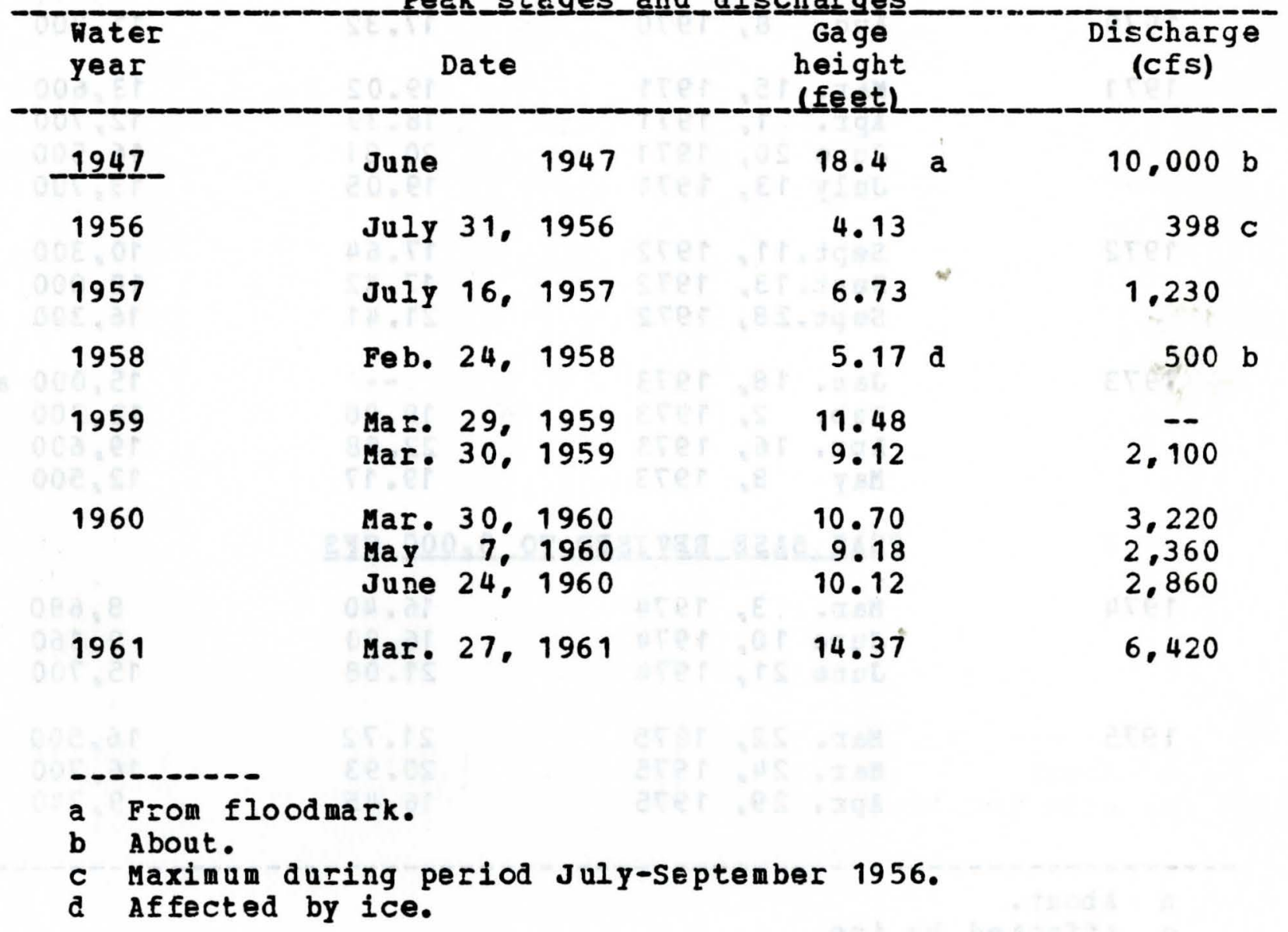


05-4116.00 Turkey River at spillville, Iowa--(Continued)

Peak﹎_stages

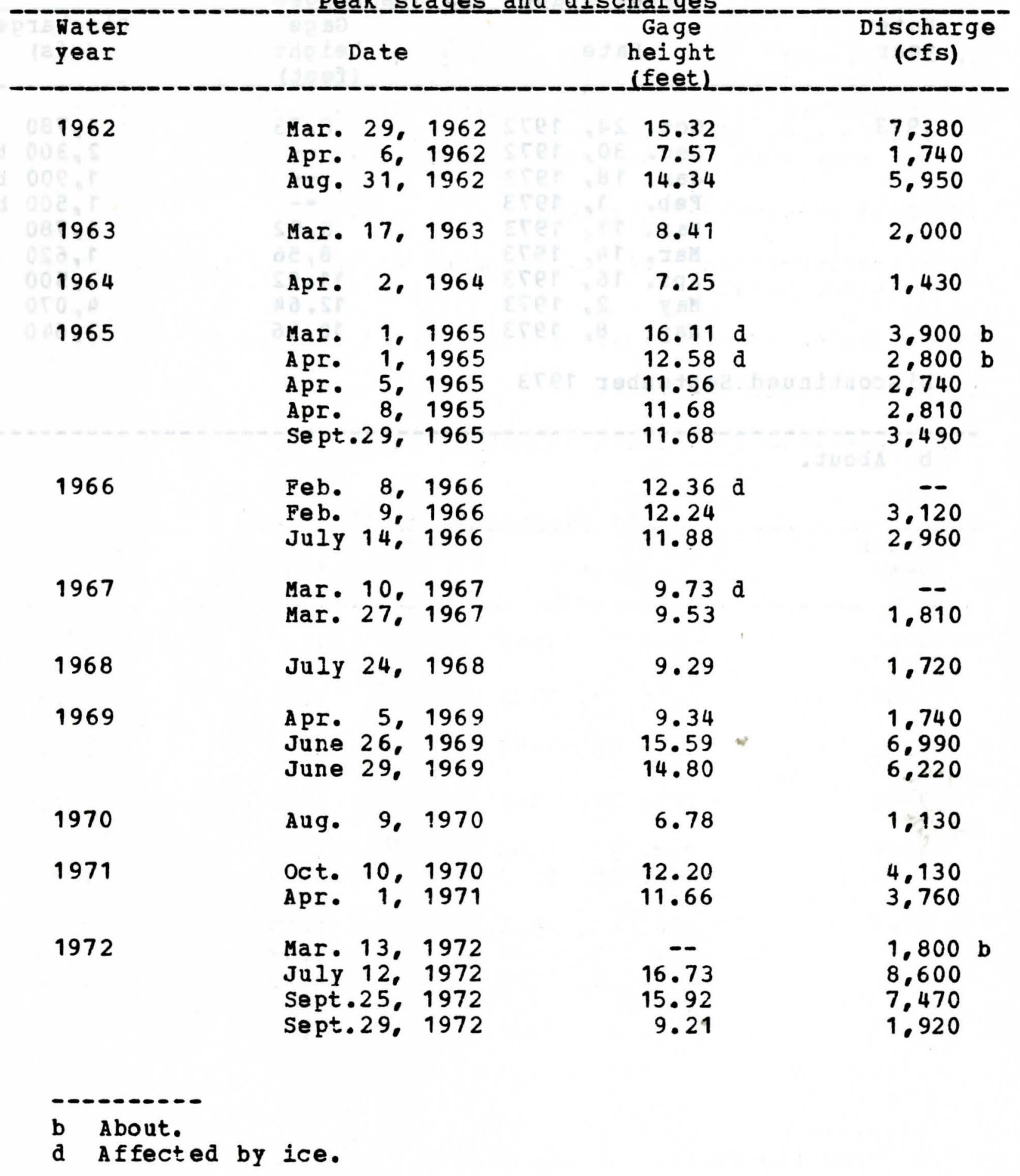


05-4116.00 Turkey River at Spillville, Iowa--(Continued)

Peak﹎.sta

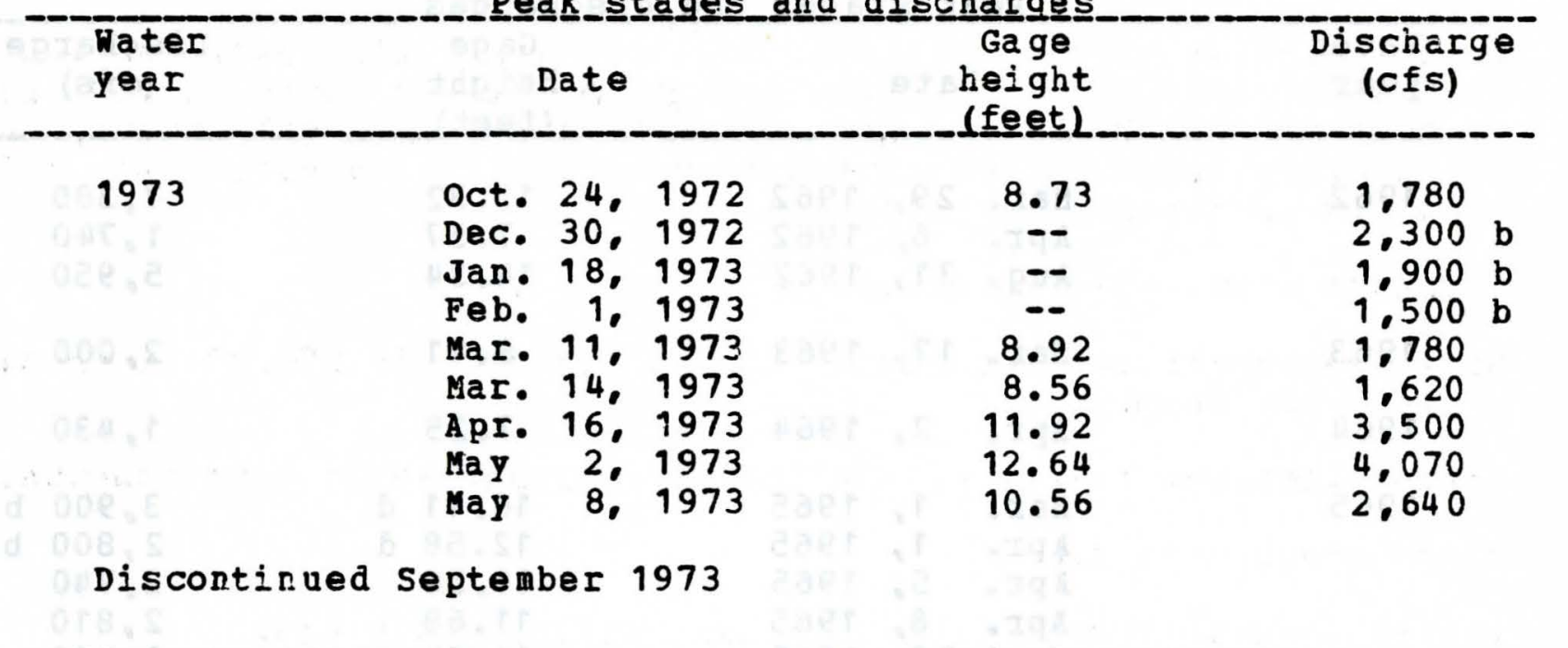

b About. 
Location.--Lat 4301819", long, $91047 \cdot 48 "$, in NE1/4 SW1/4 sec.16, T. 98 N.. R. 8 W.. Winneshiek County, on right bank 1.200 ft upstream from bridge on U.S. Highway 52 (city route) in Decorah, 1,500 ft downstream from Dry Run cutoff, and 3.0 miles upstream from Trout Run.

Drainage area.--511 sq miles.

Gage.-Water-stage recorder. Latum of gage is $850.00 \mathrm{ft}$ above mean sea level.

Stage-discharge relation.--Defined by current-meter masurements. Flood stage.--12 feet.

Remarks.--Base for partial-duration series, 4.000 cfs.

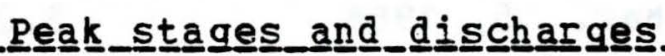

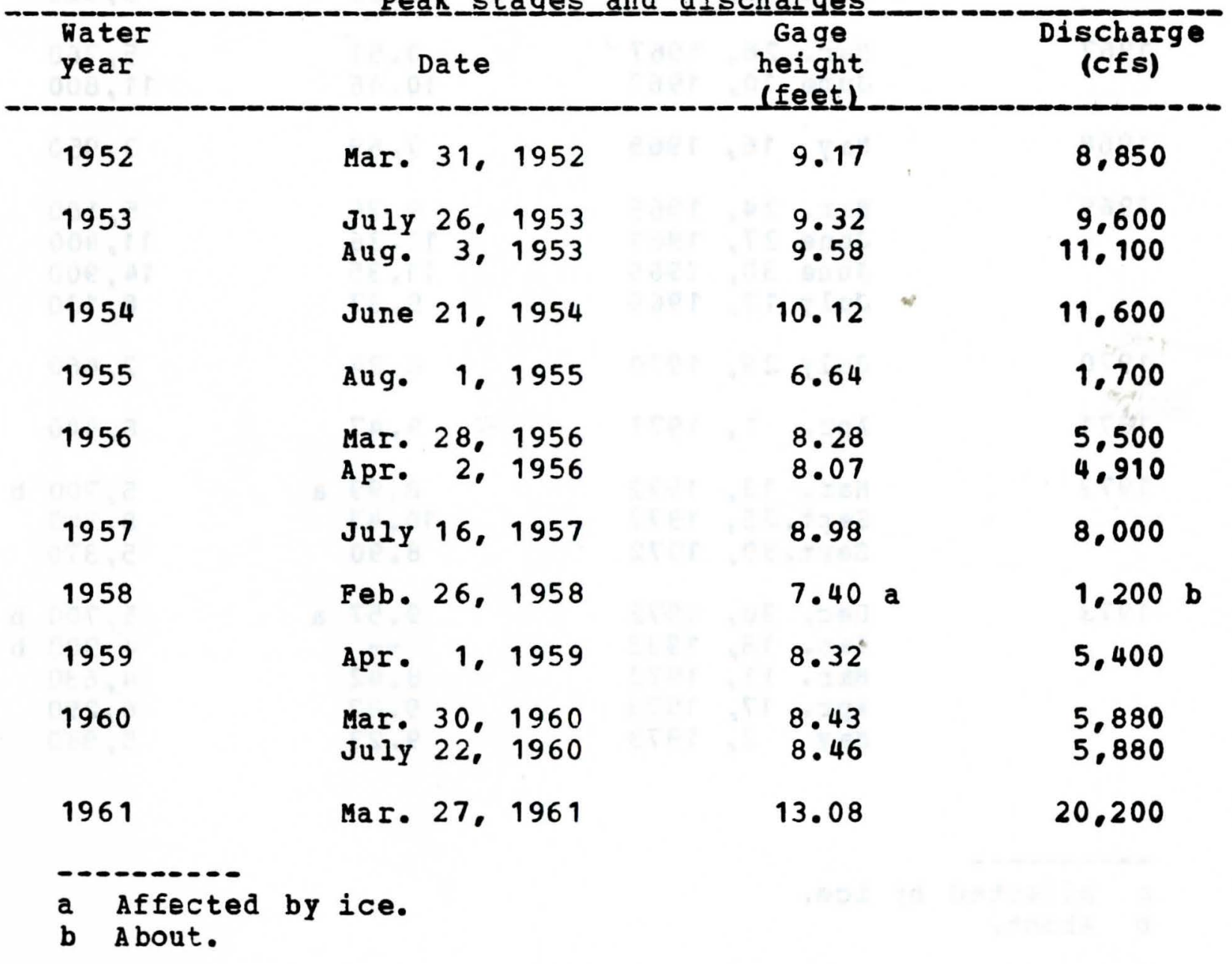


05-3875.00 Opper Iowa River at Decorah, Iowa--(Continued)

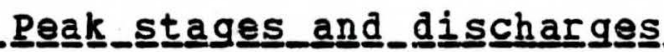

\begin{tabular}{|c|c|c|c|c|c|}
\hline $\begin{array}{l}\text { Hater } \\
\text { year }\end{array}$ & Date & & $\begin{array}{l}\text { Gage } \\
\text { height } \\
\text { (fee elt }\end{array}$ & & $\begin{array}{c}\text { Discharg } \\
\text { (cfs) }\end{array}$ \\
\hline 1962 & $\begin{array}{lr}\text { Mar. } & 30, \\
\text { JuIy } & 2, \\
\text { Aug. } & 31 .\end{array}$ & $\begin{array}{l}1962 \\
1962 \\
1962\end{array}$ & $\begin{array}{r}11.32 \\
8.68 \\
10.18\end{array}$ & & $\begin{array}{r}14.800 \\
5.320 \\
10.300\end{array}$ \\
\hline 1963 & Mar. 17. & 1963 & 8.68 & $a$ & 3,600 \\
\hline 1964 & Apr. 3. & 1964 & 7.97 & & 3.870 \\
\hline 1965 & $\begin{array}{l}\text { Mar. 2, } \\
\text { Apr. } 8, \\
\text { Sept.21, } \\
\text { Sept. } 30,\end{array}$ & $\begin{array}{l}1965 \\
1965 \\
1965 \\
1965\end{array}$ & $\begin{array}{l}9.89 \\
9.68 \\
8.41 \\
9.98\end{array}$ & & $\begin{array}{r}9.800 \\
9.100 \\
5.500 \\
10.100\end{array}$ \\
\hline 1966 & $\begin{array}{l}\text { Feb. } \\
\text { Mar. }\end{array}$ & $\begin{array}{l}1966 \\
1966\end{array}$ & $\begin{array}{l}9.65 \\
8.23\end{array}$ & & $\begin{array}{l}9,330 \\
5,320\end{array}$ \\
\hline 1967 & $\begin{array}{l}\text { Mar. } 26, \\
\text { June } 10,\end{array}$ & $\begin{array}{l}1967 \\
1967\end{array}$ & $\begin{array}{r}8.51 \\
10.46\end{array}$ & & $\begin{array}{r}5.760 \\
11.800\end{array}$ \\
\hline 1968 & May 16. & 1968 & 7.69 & & 3.950 \\
\hline 1969 & $\begin{array}{l}\text { Mar. } 24, \\
\text { June } 27, \\
\text { June } 30, \\
\text { July } 17 .\end{array}$ & $\begin{array}{l}1969 \\
1969 \\
1969 \\
1969\end{array}$ & $\begin{array}{r}8.26 \\
10.36 \\
11.35 \\
9.37\end{array}$ & $w$ & $\begin{array}{r}5,180 \\
11,400 \\
14,900 \\
8,130\end{array}$ \\
\hline 1970 & July 29 . & 1970 & 6.84 & & 2,460 \\
\hline 1971 & Apr. 1. & 1971 & 9.47 & & 8.440 \\
\hline 1972 & $\begin{array}{l}\text { Mar. } 13, \\
\text { Sept. } 25, \\
\text { Sept.30, }\end{array}$ & $\begin{array}{l}1972 \\
1972 \\
1972\end{array}$ & $\begin{array}{r}8.99 \\
10.47 \\
8.90\end{array}$ & $a$ & $\begin{array}{l}5,700 \\
8,340 \\
5,370\end{array}$ \\
\hline 1973 & $\begin{array}{l}\text { Dec. } 30, \\
\text { Jan. } 18^{\circ} \\
\text { Mar. } 11 . \\
\text { Apr. } 17^{\circ} \\
\text { May }\end{array}$ & $\begin{array}{l}1972 \\
1973 \\
1973 \\
1973 \\
1973\end{array}$ & $\begin{array}{c}9.57 \\
=- \\
8.42 \\
9.42 \\
9.23\end{array}$ & $a$ & $\begin{array}{l}5,700 \\
4,900 \\
4,630 \\
6.290 \\
5,940\end{array}$ \\
\hline
\end{tabular}

a Affected by ice.

b About. 
05-3875.00 Upper Iowa River at Decorah, Iowa--(Continued)

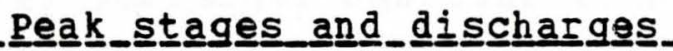

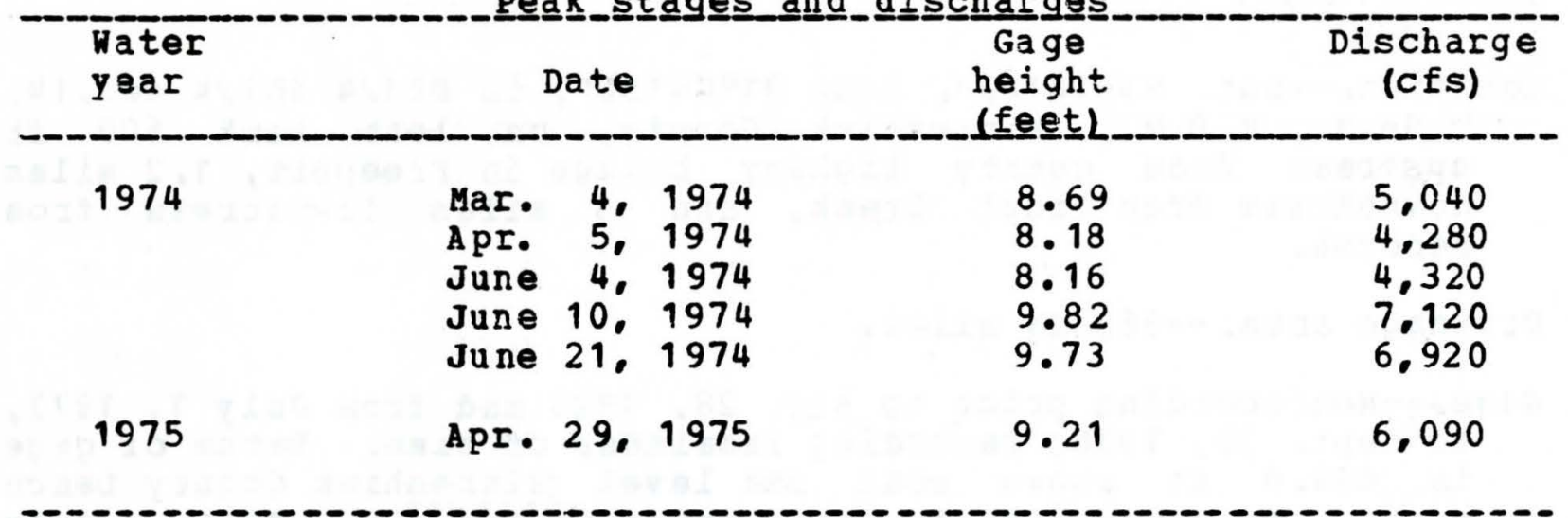




\section{5-3880.00 Upper Iowa River near Decorah. Iowa (Discontinued september 1951)}

Location.--Iat 43018'20", long 91044'50", in NE 1/4 SE1/4 sec.14, T.98 N., R. 8 W.. Winneshiek County, on left bank 500 ft upstream from county highway bridge in Freeport, 1.2 miles downstream from trout creek, and 3 miles downstream from Decorah.

Drainage area. --568 sq miles.

Gage.--Nonrecording prior to Aug. 28, 1920 and from July 1, 1933, to sept. 30, 1936; recording remainder of time. Datum of gage is 829.8 ft above mean sea level (Winneshiek County bench mark). At datum 3.96 ft lower prior to Aug. 28, 1920. July 1. 1933, to sept. 30, 1936, at site 4 miles downstream at different datum.

Stage-discharge relation.--Defined by currant-meter and slopearea measurements.

Flood stage.--12 feet.

Remarks.--Prior to May 24, 1920, gage heights are computed to be equivalent to those for presert gage. Base for partialduration series, 4,500 cfs. Records for period July 1, 1933 , to Sept. 30, 1936, furnished by Interstate Power Company.

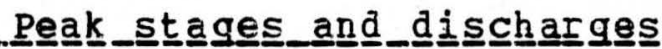

\begin{tabular}{|c|c|c|c|c|}
\hline $\begin{array}{l}\text { water } \\
\text { year }\end{array}$ & $\mathrm{Da}$ te & & $\begin{array}{l}\text { Gage } \\
\text { height } \\
\text { (feet) }\end{array}$ & $\begin{array}{c}\text { Discharge } \\
\text { (cfs) }\end{array}$ \\
\hline-1914 & $\operatorname{May} 24$, & 1914 & 11.6 & 7.100 \\
\hline 1919 & Se pt. 10 & 1919 & 11.05 & 6.220 \\
\hline 1920 & $\operatorname{May} 22$ & 1920 & $10 \underline{0} \cdot \underline{0}$ & 4,970 \\
\hline 1921 & $\begin{array}{l}\text { May } 27 \\
\text { May } 30 \\
\text { June } 20 \\
\text { Sept. } 17\end{array}$ & $\begin{array}{l}1921 \\
1921 \\
1921 \\
1921\end{array}$ & $\begin{array}{c}10.21 \\
9.2 \\
9.0 \\
7.8\end{array}$ & $\begin{array}{l}9.860 \\
8.000 \\
7.600 \\
5.680\end{array}$ \\
\hline 1922 & $\begin{array}{l}\mathrm{Fab} . \\
\operatorname{Mar} .\end{array}$ & $\begin{array}{l}1922 \\
1922\end{array}$ & $\begin{array}{c}10.42 \\
7.9\end{array}$ & $\begin{array}{r}10.500 \\
5.840\end{array}$ \\
\hline 1923 & Apr. & 1923 & 9.0 & 7.140 \\
\hline
\end{tabular}


05-3880.00 Opper Iowa River near Decorah, Iowa--(Continued)

Peakㅡ_stagges_and_di

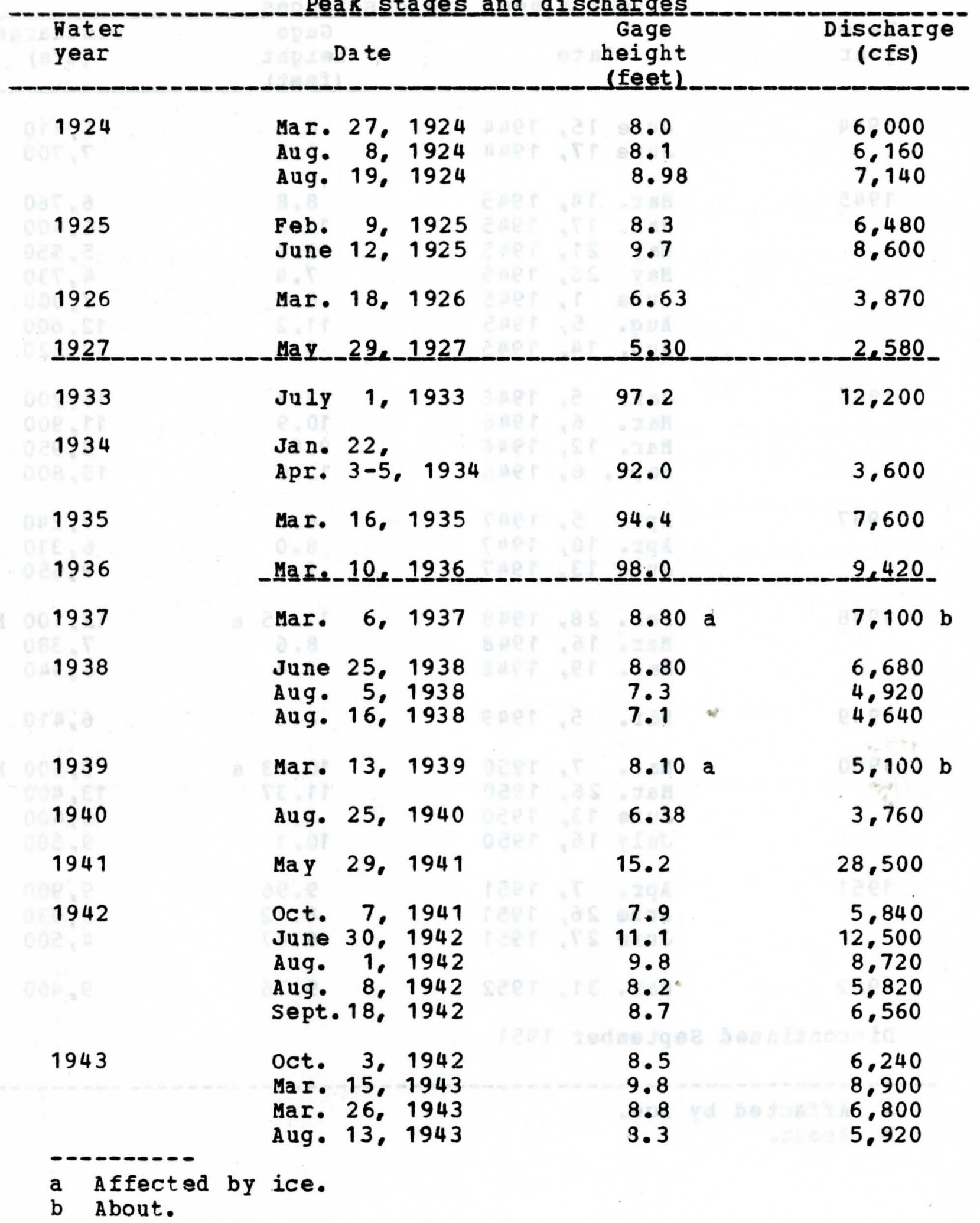


05-3880.00 Opper Iowa River near Decorah, Iowa--(Continued)

Pea $\underline{k}$ statages and d dis $\underline{\text { chargarges }}$

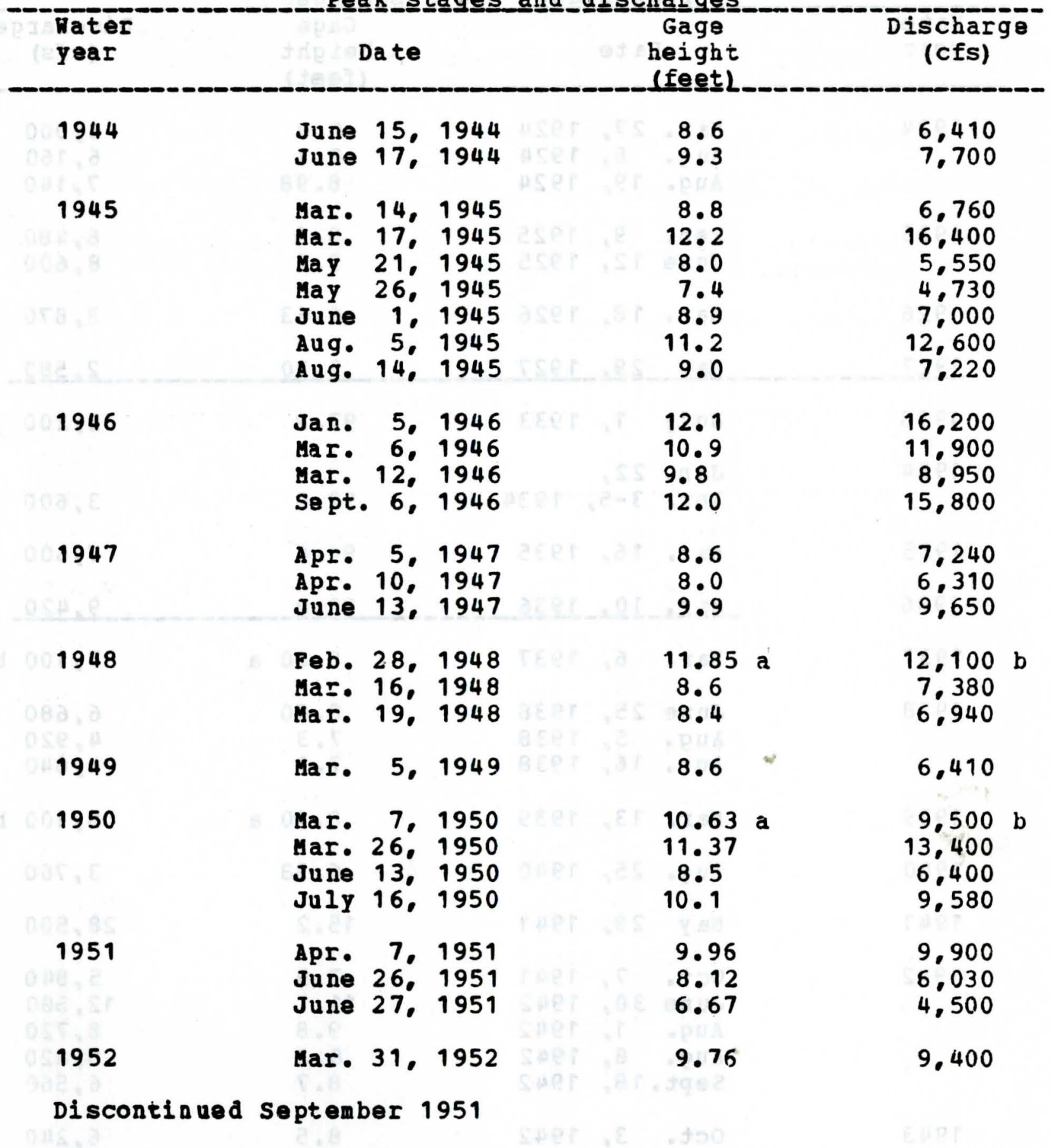

a Affected by ice.

b About. 


\section{6-4834.50 Wagner Creek near Ashton. Iowa}

Location.--Lat $43021 \%$ long $95046^{\circ}$, on south line sec.35, T.99 N.. R.42 W., Osceola County, at bridge, 3 miles northeast of Ashton.

Drainage area.--7.09 sq mi.

Gage.--Crest-stage gage.

Stage-discharge relation,--Defined by current-meter and indirect mea surements.

Remarks.--Only annual peaks are shown.

Peak﹎_stagges_and__di schharges

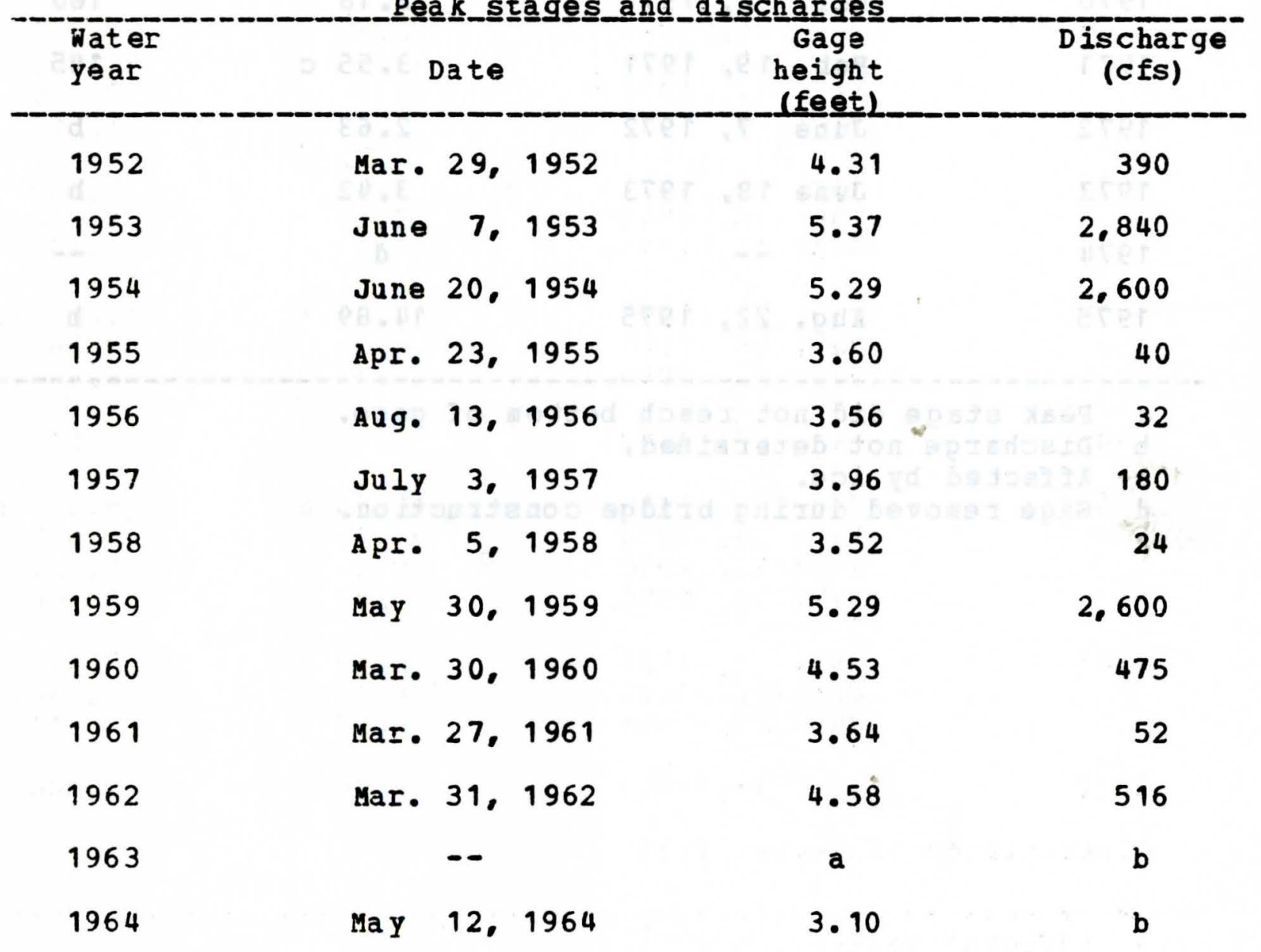

a Peak stage did not reach bottom of gage.

b Discharge not determined. 
06-4834.50 Wagner Creek near Ashton, Iowa--(Contiaued)

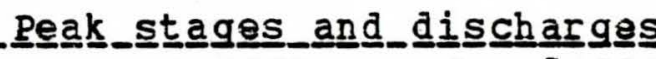

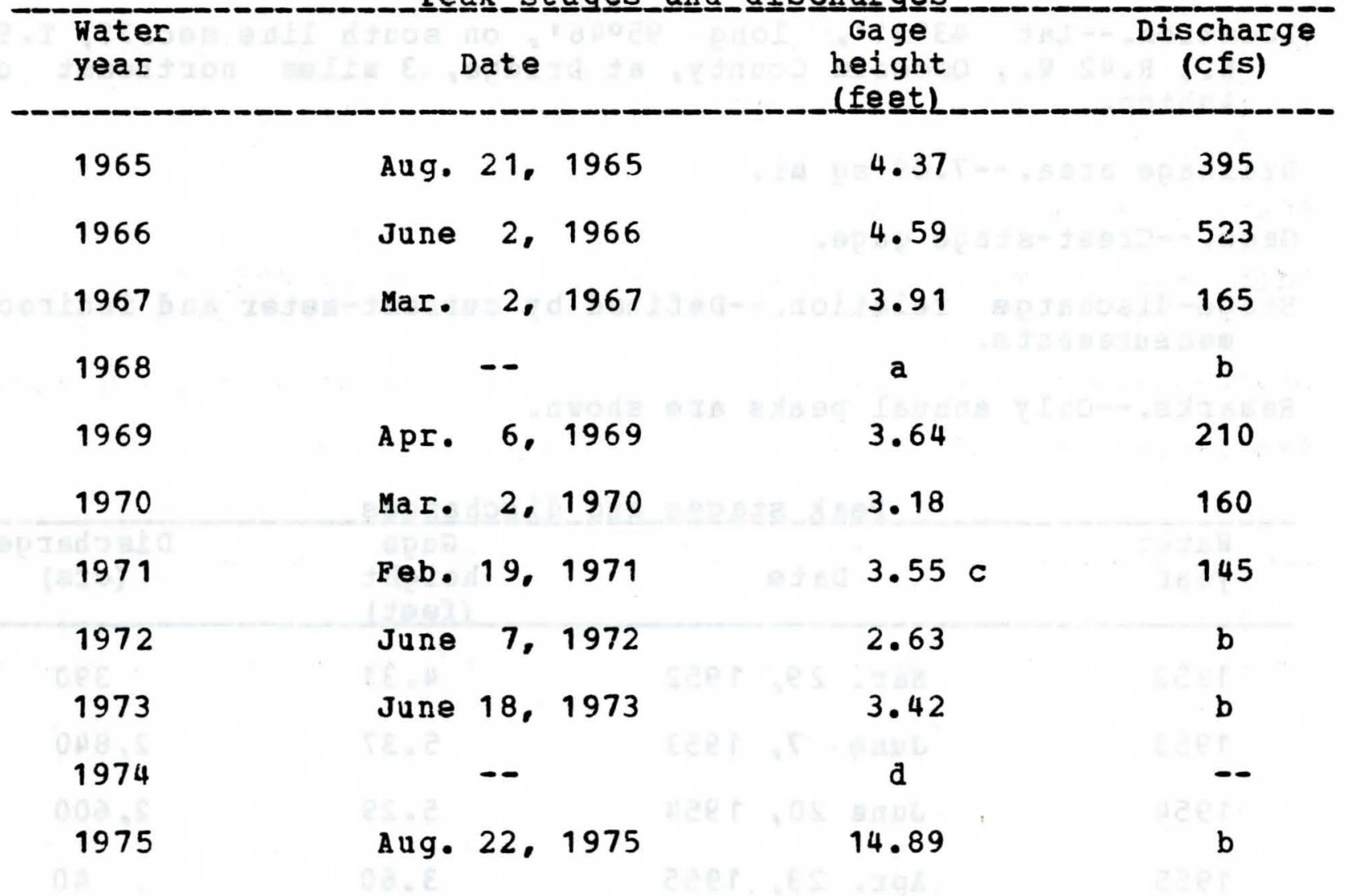

a Peak stage did not reach bottom of gage.

b Discharge not determined.

c Affected by ice.

d Gage removed during bridge construction. 
Location.--Iat 41035'14", long 93042'11", in SW1/4 SE1/4 sec.2. T.78 N., R. 25 W. Polk county, on left bank, 25 ft dcwnstream from bridge on 63rd street in Des Moines, and $2.2 \mathrm{mi}$ upstream from Raccoon River.

Drainage area. $--80.9 \mathrm{sq} \mathrm{mi}$.

Gage.-Nater-stage recorder. Datum of gage is $801.04 \mathrm{ft}$ above mean sea level (levels by Iowa Natural Resources Council).

Stage-discharge relation.--Defined by current-meter measurements. Remarks.--Base for partial-duration series, 600 cfs.

Peak stages and discharges

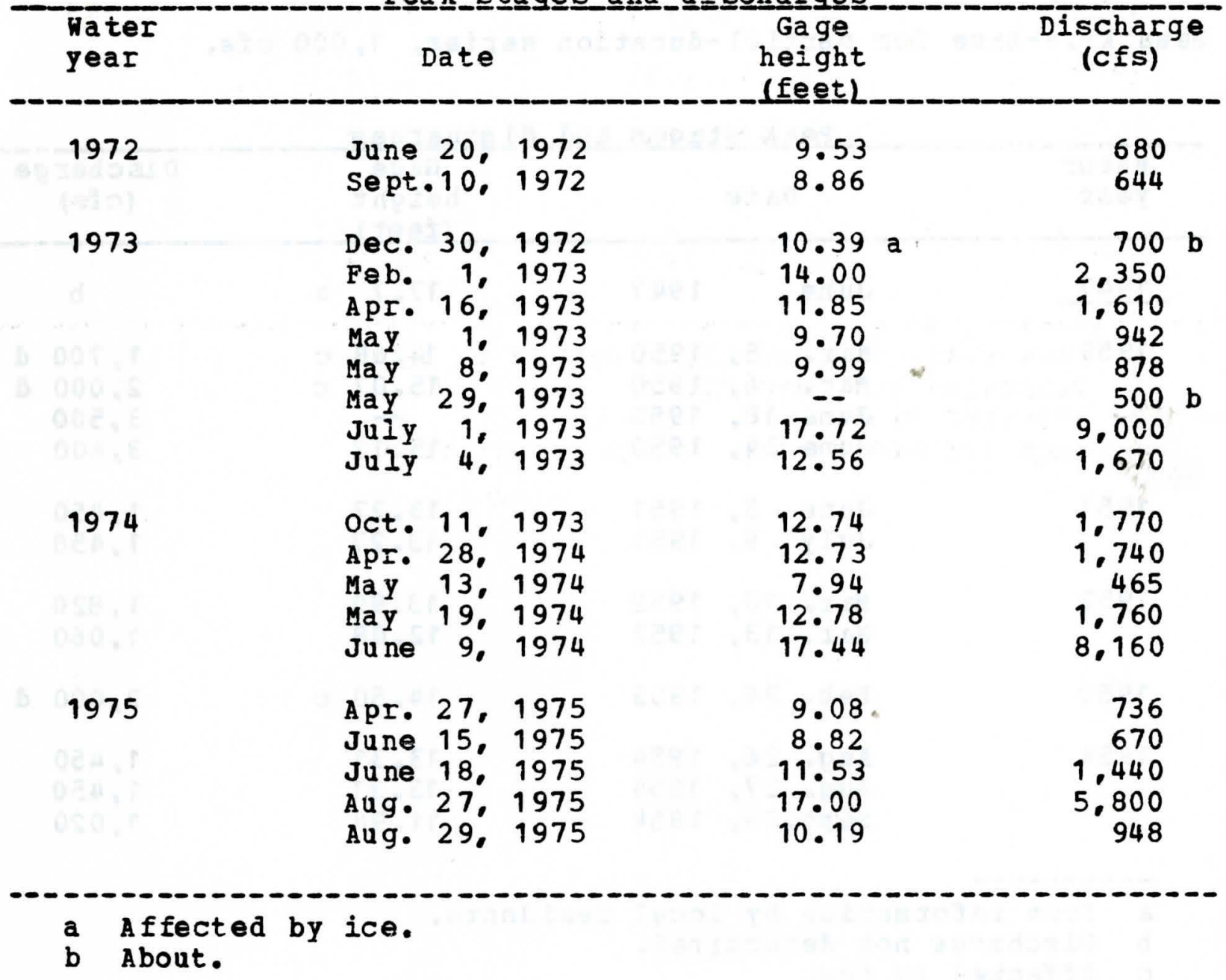


Location.--Lat $41050 \cdot 06 "$, long $92023 \cdot 10 "$, in SE1/4 SW1/4 sec.8, T. 81 N.. R. 13 W.. Poweshiek County, on left bank 5 ft upstrean from bridge on county highway v21, 1.2 miles downstream from North Walnut Creek, 4.0 miles northwest of Hartwick, and 6.5 miles upstream from mouth.

Drainage area.--70.9 sq miles.

Gage.--Water-stage recorder. Datum of gage is $786.59 \mathrm{ft}$ abore mean sea level.

Stage-discharge relation.--Defined by current-meter measurements below 2,600 cfs and extended above on basis of contracted opening and flow over-embankment measurement at peak flow.

Bankfull stage. --12 feet.

Remarks.--Base for partial-duration series, 1,000 cfs.

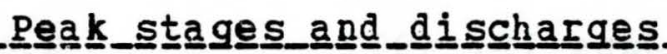

\begin{tabular}{|c|c|c|c|c|c|c|}
\hline $\begin{array}{l}\text { Water } \\
\text { year }\end{array}$ & & Da te & & $\begin{array}{l}\text { Gage } \\
\text { height } \\
\text { (feet) }\end{array}$ & & $\begin{array}{c}\text { Discharg } \\
\text { (cfs) }\end{array}$ \\
\hline-1947 & June & & 1947 & 17.7 & $a$ & b \\
\hline 1950 & $\begin{array}{l}\text { Mar. } \\
\text { Mar. } \\
\text { June } \\
\text { June }\end{array}$ & $\begin{array}{r}5 \\
6 \\
18 \\
24\end{array}$ & $\begin{array}{l}1950 \\
1950 \\
1950 \\
1950\end{array}$ & $\begin{array}{c}14.68 \\
15.07 \\
-- \\
15.12\end{array}$ & c & $\begin{array}{l}1.700 \\
2.000 \\
3.500 \\
3.600\end{array}$ \\
\hline 1951 & $\begin{array}{l}\text { June } \\
\text { JuIy }\end{array}$ & $\begin{array}{l}3 . \\
9 .\end{array}$ & $\begin{array}{l}1951 \\
1951\end{array}$ & $\begin{array}{l}13.27 \\
13.27\end{array}$ & & $\begin{array}{l}1.450 \\
1.450\end{array}$ \\
\hline 1952 & $\begin{array}{l}\text { Mar. } \\
\text { Mar. }\end{array}$ & $\begin{array}{l}10 \\
13\end{array}$ & $\begin{array}{l}1952 \\
1952\end{array}$ & $\begin{array}{l}13.90 \\
12.08\end{array}$ & & $\begin{array}{l}1.820 \\
1.060\end{array}$ \\
\hline 1953 & $\mathrm{Feb}$ & 20 & 1953 & 14.50 & $c$ & 2,000 \\
\hline 1954 & $\begin{array}{l}\text { Aug. } \\
\text { Aug. } \\
\text { Se pt. }\end{array}$ & $\begin{array}{l}26 . \\
27 \\
29\end{array}$ & $\begin{array}{l}1954 \\
1954 \\
1954\end{array}$ & $\begin{array}{r}13.31 \\
13.31 \\
11.94\end{array}$ & & $\begin{array}{l}1.450 \\
1.450 \\
1.020\end{array}$ \\
\hline
\end{tabular}

\footnotetext{
a From information by local residents.

b Discharge not determined.

c Affected by ice.

d About.
} 
05-4522.00 Walnut Creek near Hartwick, Iowa-- (Continued)

Peak

\begin{tabular}{|c|c|c|c|}
\hline $\begin{array}{l}\text { Water } \\
\text { year }\end{array}$ & Date & $\begin{array}{l}\text { Gage } \\
\text { height } \\
\text { lfeet }\end{array}$ & $\begin{array}{l}\text { Discharge } \\
\text { (cfs) }\end{array}$ \\
\hline 1955 & Apr. 23, 1955 & 11.57 & 952 \\
\hline 1956 & July 31, 1956 & 12.27 & 895 \\
\hline 1957 & May 31, 1957 & 10.97 & 694 \\
\hline 1958 & $\begin{array}{l}\text { July 14, } 1958 \\
\text { Sept. 3, } 1958 \\
\text { Sept. 6, } 1958\end{array}$ & $\begin{array}{l}13.45 \\
15.67 \\
13.41\end{array}$ & $\begin{array}{l}1.290 \\
4.930 \\
1.270\end{array}$ \\
\hline 1959 & $\begin{array}{l}\text { Mar. 20, } 1959 \\
\text { Mar. 26, } 1959 \\
\text { Apr. 1, } 1959 \\
\text { Apr. 27, } 1959 \\
\text { May 21, } 1959 \\
\text { June 30, } 1959\end{array}$ & $\begin{array}{l}14.88 \\
12.27 \\
11.91 \\
14.07 \\
13.74 \\
14.24\end{array}$ & $\begin{array}{l}3,230 \\
1,120 \\
1.020 \\
1,950 \\
1,680 \\
2,180\end{array}$ \\
\hline 1960 & $\begin{array}{l}\text { Nov. } 4,1959 \\
\text { Jan. } 12,1960 \\
\text { Jan. 14, } 1960 \\
\text { Mar. 29, } 1960 \\
\text { Mar. 31, } 1960 \\
\text { May } 6,1960\end{array}$ & $\begin{array}{l}13.21 \\
15.04 \\
13.01 \\
15.44 \quad c \\
12.73 \\
14.56\end{array}$ & $\begin{array}{l}1.410 \\
3,500 \\
1.450 \\
3,000 \mathrm{~d} \\
1.360 \\
2.640\end{array}$ \\
\hline 1961 & $\begin{array}{l}\text { Feb. 18, } 1961 \\
\text { Mar. } 6,1961 \\
\text { Mar. } 8,1961 \\
\text { Mar. 13, } 1961\end{array}$ & $\begin{array}{l}14.75 \\
15.17 \\
14.80 \\
12.10\end{array}$ & $\begin{array}{l}2.980 \\
3.700 \\
3.060 \\
1.350\end{array}$ \\
\hline 1962 & $\begin{array}{l}\text { Mar. 19, } 1962 \\
\text { Mar. } 23,1962 \\
\text { July } 14,1962 \\
\text { July } 19,1962\end{array}$ & $\begin{array}{l}13.85 \\
11.57 \\
14.30 \\
13.24\end{array}$ & $\begin{array}{l}1.780 \\
1.050 \\
2,250 \\
1.530\end{array}$ \\
\hline 1963 & $\begin{array}{l}\text { Mar. 4, } 1963 \\
\text { Mar. 12, } 1963\end{array}$ & $\begin{array}{l}13.34 \mathrm{c} \\
11.57 \mathrm{c}\end{array}$ & $\overline{850} \mathrm{~d}$ \\
\hline 1964 & June 23,1964 & 14.19 & 2,120 \\
\hline
\end{tabular}

c Affected by ice.

d About. 
05-4522.00 Walnut Creek near Hartwick, Iowa--(Continued)

Peak_stagges_and di

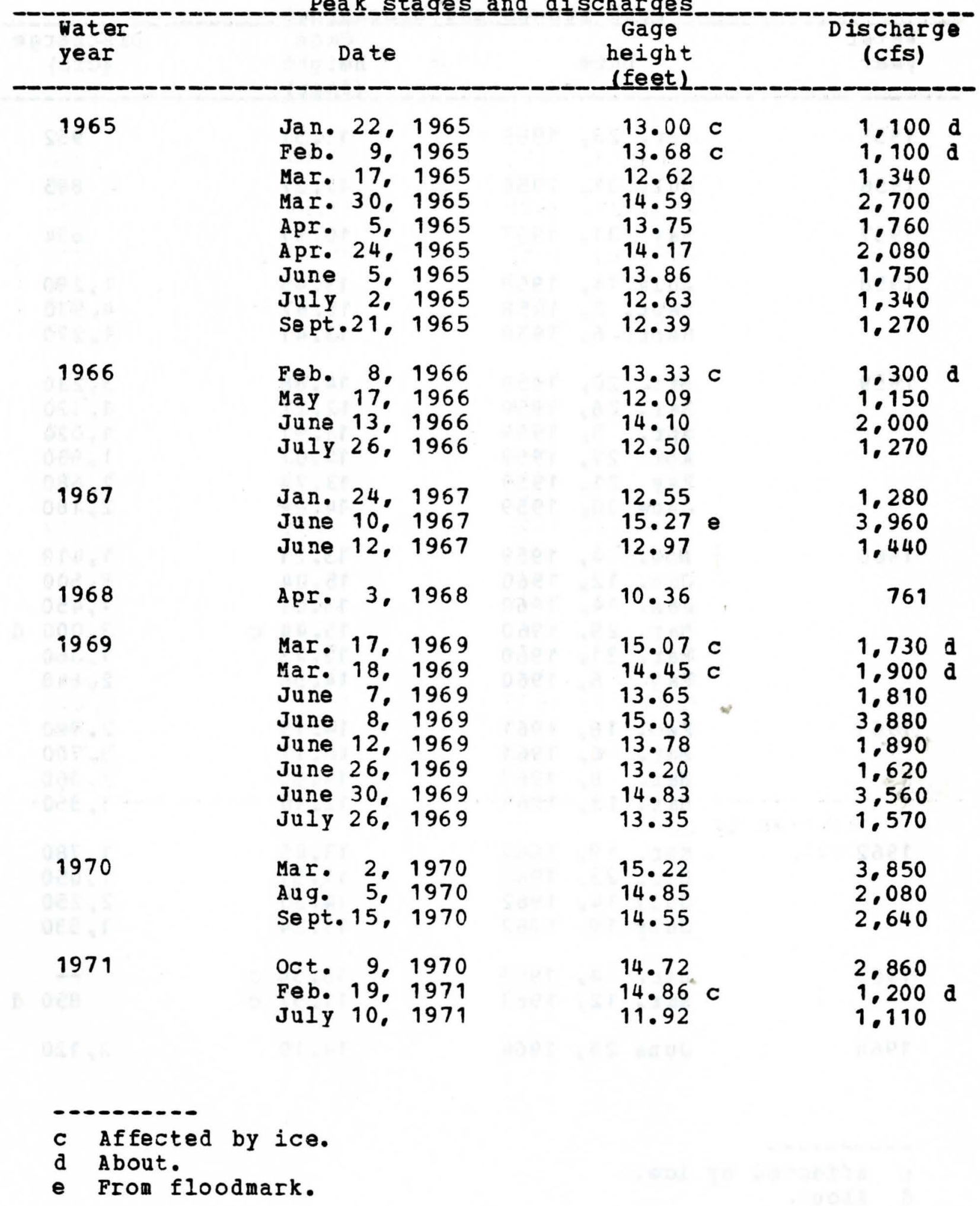


05-4522.00 Walnut Creek near Hartwick, Iowa--(Continued)

Peak﹎.stagqes_and_di

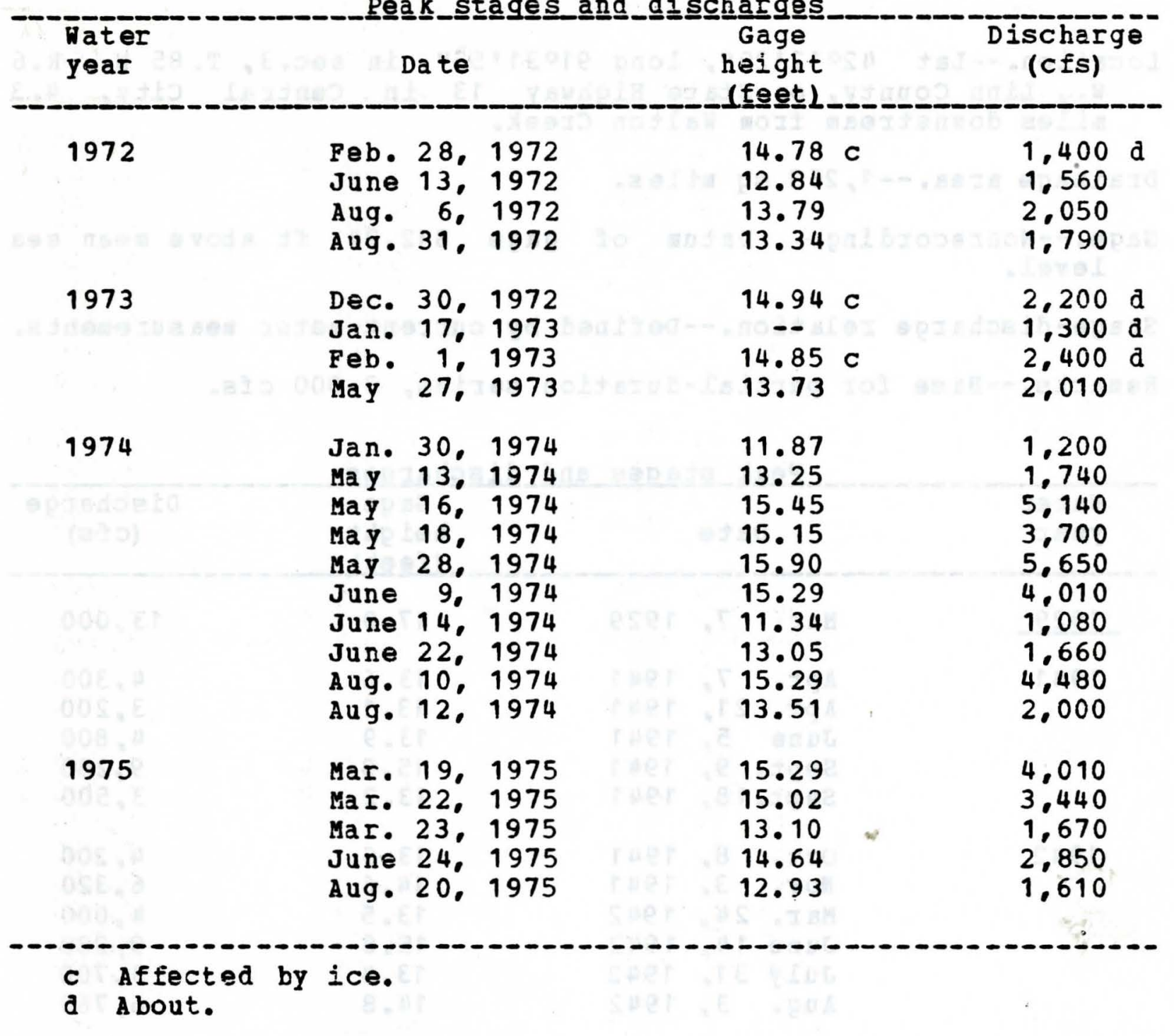


05-4214.00 Wapsipinicon River at Central City. Iowa (Discontinued Aug. 31, 1950)

Location,--Lat $42012 \cdot 20$ ", long $91031 \cdot 55^{\prime \prime}$, in sec.3, T. 85 N., R.6

W. Linn County, on state Highway 13 in Central City. 4.3 miles downstream from Walton Creak.

Drainage area.--1,263 sq miles.

Gage.--Nonzecording. Datum of gage 812.24 ft above mean sea level.

Stage-discharge relation.--Defined by current-meter measurements. Remarks.--Base for partial-duration series, 3,000 cfs.

Peak_stages_and_di

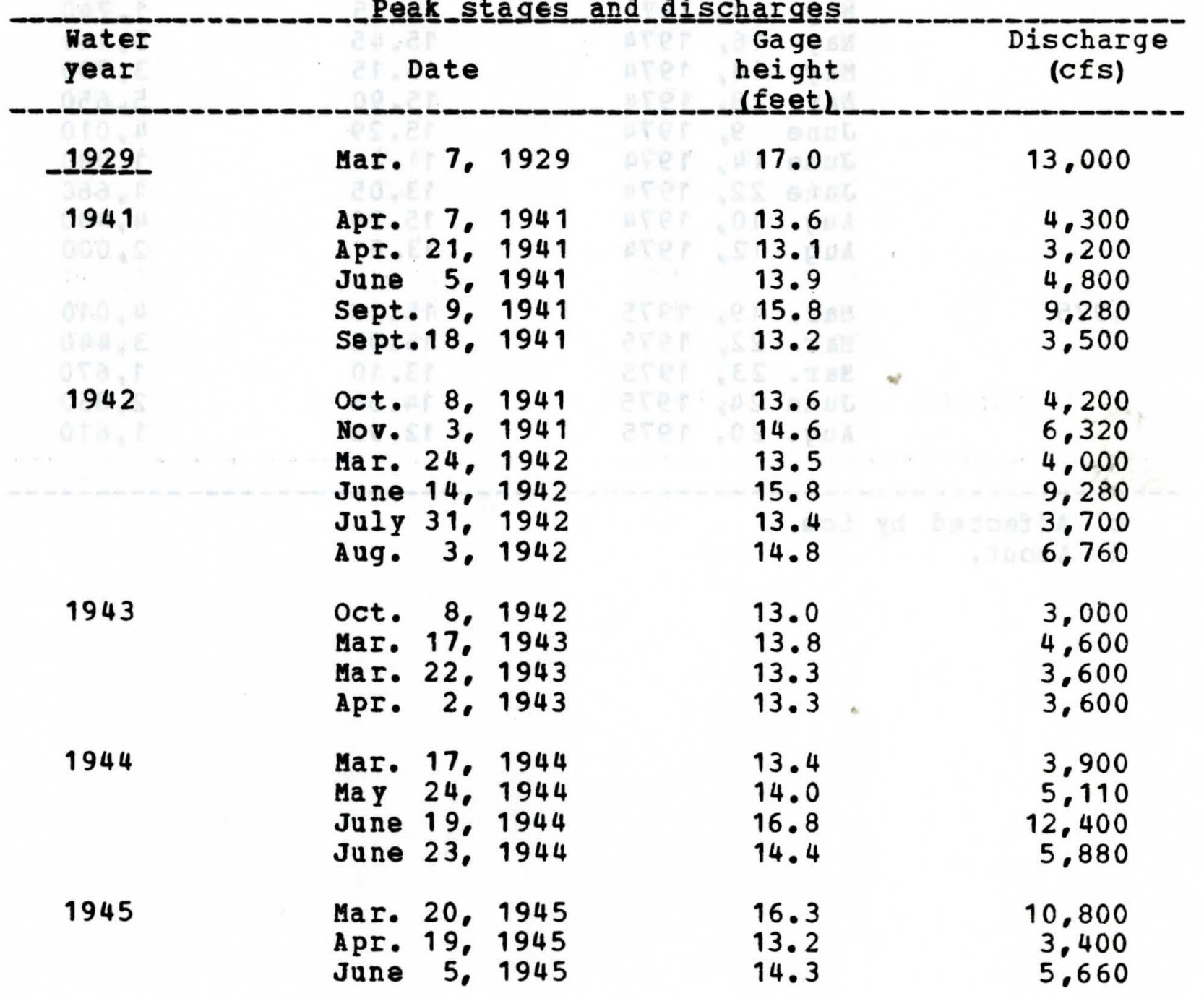


05-4214.00 Wapsipinicon River at Central City, Iowa--(Continued)

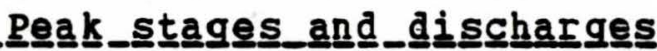

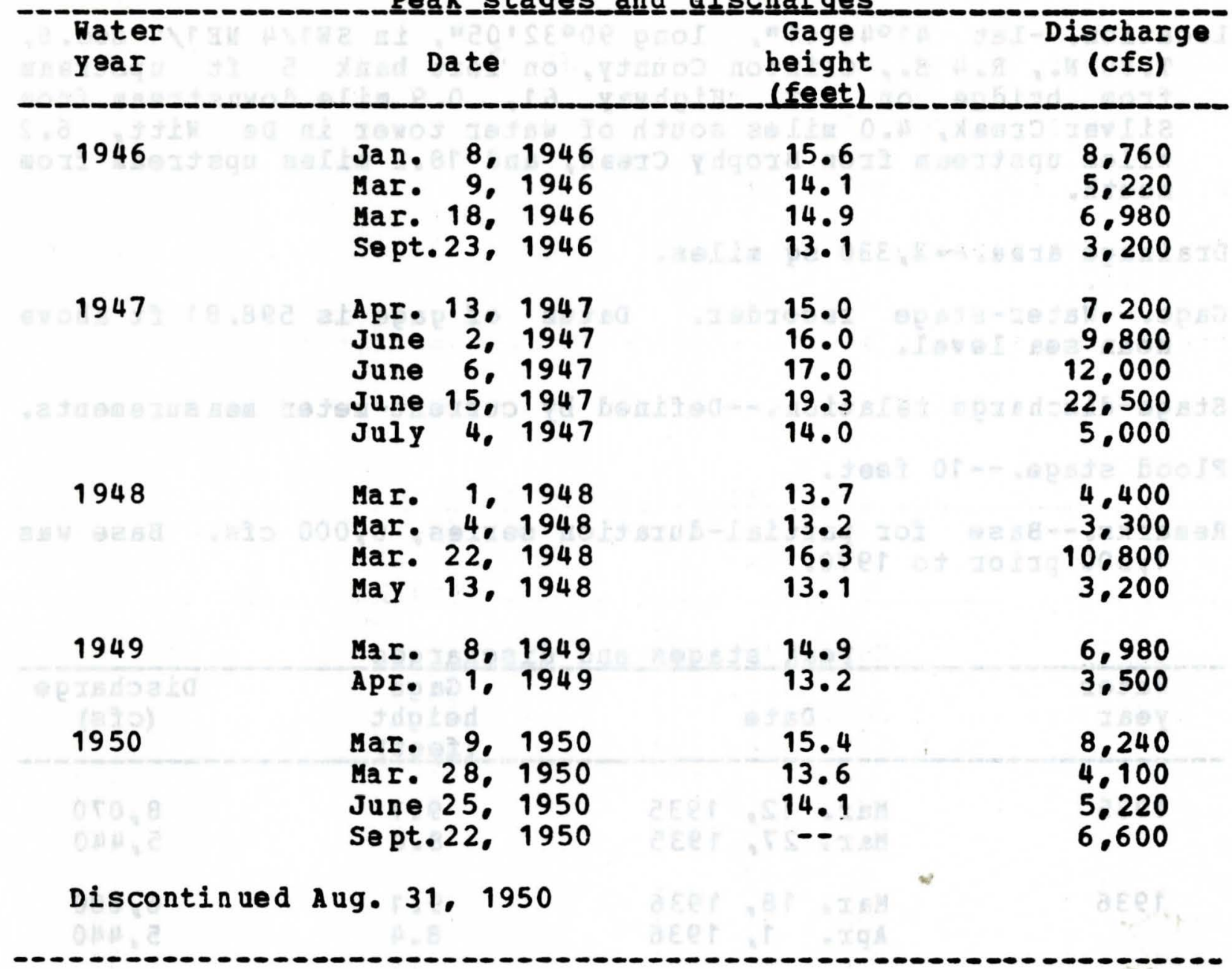


05-4220.00 Wapsipinicon River near DeWitt, Iowa

Location.--Iat 41046'01", long $90032 \cdot 05^{\prime \prime}$, in SW1/4 NE1/4 sec.6. T. 80 N.. R. 4 E.. Clinton County, on left bank 5 ft upstream from bridge on $0 . S$. Highway 61 , 0.9 mile downstream from Silver Creek, 4.0 miles south of water tower in De Witt, 6.2 miles upstream from Brophy Creek, and 18.2 miles upstream from mouth.

Drainage area.--2,330 sq miles.

Gage.--Water-stage recorder. Datum of gage is $598.81 \mathrm{ft}$ above mean sea level.

Stage-discharge relation.--Defined by current-meter measurements. Flood stage. -10 feet.

Remarks.--Base for partial-duration series, 6,000 cfs. Base was 4,500 prior to 1970 .

Peak_stages_and_dischharges

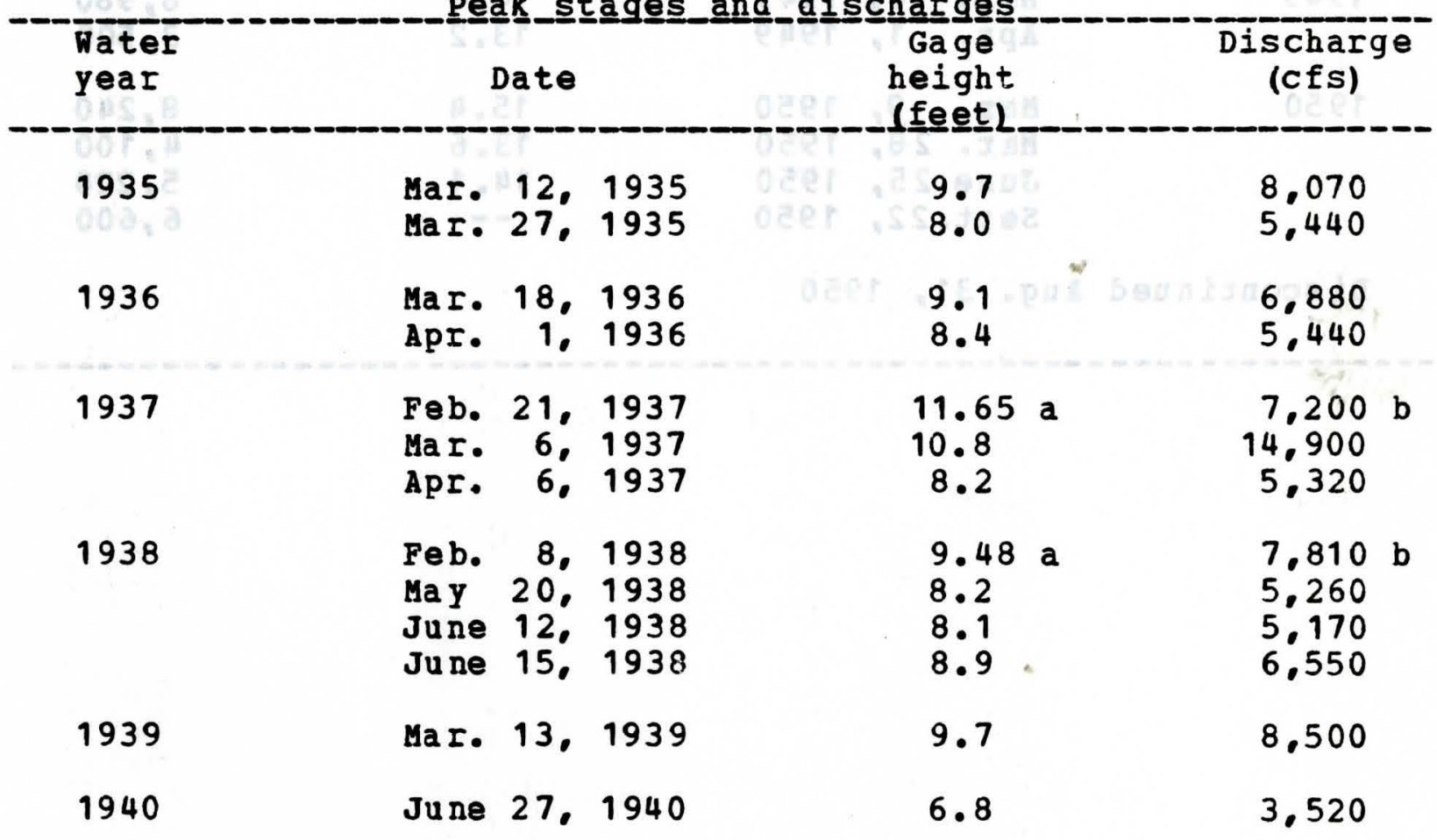

a Affected by ice.

b About. 
05-4220.00 Wapsipinicon River near DeWitt, Iowa--(Continued)

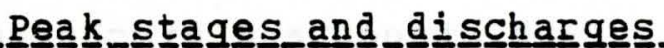

\begin{tabular}{|c|c|c|c|c|c|}
\hline $\begin{array}{l}\text { Water } \\
\text { year }\end{array}$ & Date & & $\begin{array}{l}\text { Gage } \\
\text { height } \\
\text { (feet). }\end{array}$ & & $\begin{array}{l}\text { Discharge } \\
\text { (cfs) }\end{array}$ \\
\hline 1941 & $\begin{array}{l}\text { Mar. } 23, \\
\text { Apr. 10, } \\
\text { Apr. } 21, \\
\text { June 1., } \\
\text { June 15, } \\
\text { Sept. } 14 .\end{array}$ & $\begin{array}{l}1941 \\
1941 \\
1941 \\
1941 \\
1941 \\
1941\end{array}$ & $\begin{array}{r}8.1 \\
8.3 \\
8.3 \\
8.6 \\
7.9 \\
10.2\end{array}$ & & $\begin{array}{l}4.840 \\
5.280 \\
5.160 \\
5.590 \\
4.650 \\
8.130\end{array}$ \\
\hline 1942 & $\begin{array}{l}\text { oct. } 13, \\
\text { Oct. } 23, \\
\text { Nov. } 8, \\
\text { June } 19, \\
\text { Aug. } 8,\end{array}$ & $\begin{array}{l}1941 \\
1941 \\
1941 \\
1942 \\
1942\end{array}$ & $\begin{array}{r}8.4 \\
8.6 \\
9.6 \\
10.3 \\
9.6\end{array}$ & & $\begin{array}{l}4.760 \\
5.000 \\
6.800 \\
8.390 \\
7.280\end{array}$ \\
\hline 1943 & $\begin{array}{l}\text { Dec. } 28, \\
\text { Feb. } 23, \\
\text { Mar. 19, } \\
\text { Mar. } 26,\end{array}$ & $\begin{array}{l}1942 \\
1943 \\
1943 \\
1943\end{array}$ & $\begin{array}{c}10.26 \\
8.7 \\
9.4 \\
8.5\end{array}$ & $a$ & $\begin{array}{l}5,500 \quad b \\
5,220 \\
6,610 \\
4.870\end{array}$ \\
\hline 1944 & $\begin{array}{l}\text { Mar. } 16, \\
\text { Apr. } 24, \\
\text { May } 21 . \\
\text { June } 24 . \\
\text { June } 27 .\end{array}$ & $\begin{array}{l}1944 \\
1944 \\
1944 \\
1944 \\
1944\end{array}$ & $\begin{array}{c}9.3 \\
9.4 \\
10.5 \\
10.3 \\
12.07\end{array}$ & & $\begin{array}{r}6,520 \\
6.550 \\
10.400 \\
9.440 \\
26.000\end{array}$ \\
\hline 1945 & $\begin{array}{l}\text { Mar. } 25, \\
\text { Apr. } 22, \\
\text { May } 18, \\
\text { June } 11, \\
\text { June } 30,\end{array}$ & $\begin{array}{l}1945 \\
1945 \\
1945 \\
1945 \\
1945\end{array}$ & $\begin{array}{r}10.2 \\
8.2 \\
8.4 \\
8.8 \\
8.4\end{array}$ & $*$ & $\begin{array}{l}9.000 \\
4.580 \\
4.970 \\
5.490 \\
4.900\end{array}$ \\
\hline 1946 & $\begin{array}{l}\text { Jan. } 6, \\
\text { Jan. } 10, \\
\text { Mar. } 21, \\
\text { Sept. } 6,\end{array}$ & $\begin{array}{l}1946 \\
1946 \\
1946 \\
1946\end{array}$ & $\begin{array}{r}11.1 \\
10.7 \\
10.0 \\
8.7\end{array}$ & & $\begin{array}{r}14.600 \\
11.600 \\
8.240 \\
5.320\end{array}$ \\
\hline 1947 & $\begin{array}{lr}\text { Apr. } & 6, \\
\text { Apr. } & 21, \\
\text { June } & 9, \\
\text { June } & 19, \\
\text { July } & 7, \\
\text { July } & 13,\end{array}$ & $\begin{array}{l}1947 \\
1947 \\
1947 \\
1947 \\
1947 \\
1947\end{array}$ & $\begin{array}{r}9.3 \\
10.3 \\
11.3 \\
11.8 \\
9.8 \\
8.5\end{array}$ & & $\begin{array}{r}6.420 \\
9.440 \\
16.600 \\
21.600 \\
7.610 \\
5.000\end{array}$ \\
\hline
\end{tabular}

a Affected by ice.

b a bout. 
05-4220.00 Wapsipinicon River near DeWitt, Iowa--(Continued)

Peak_stsages_and_discharges

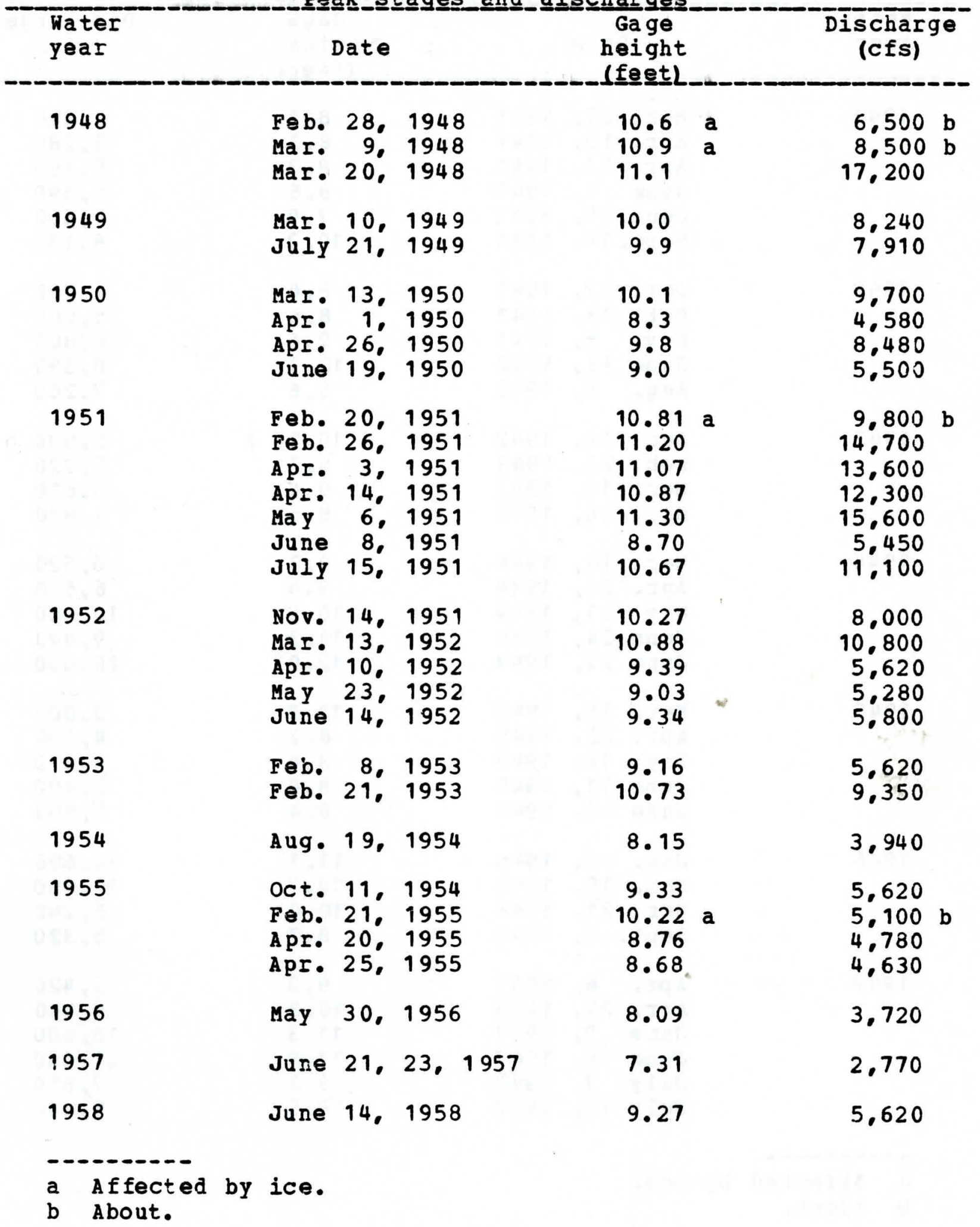




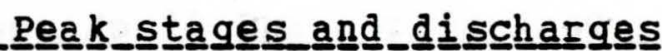

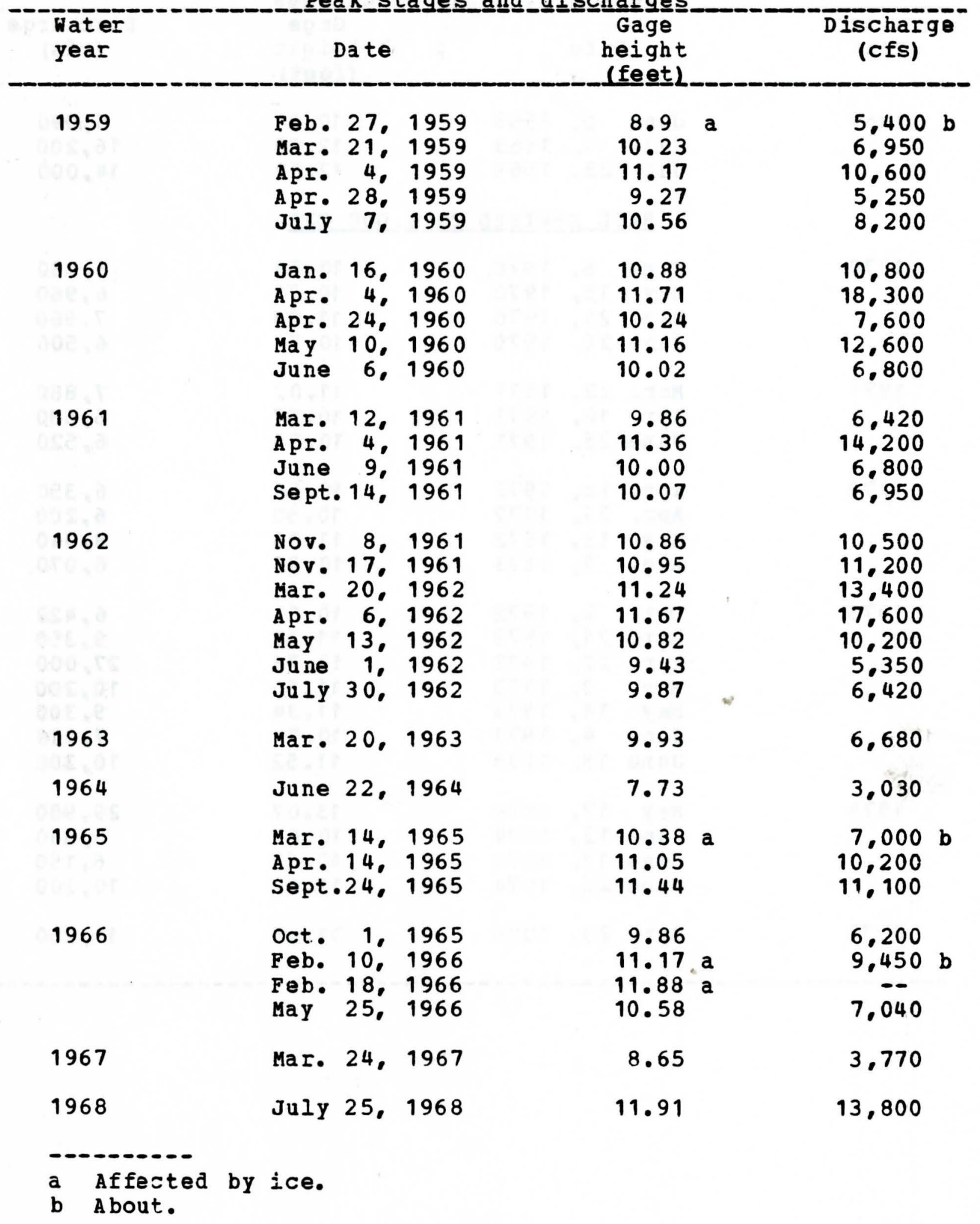


05-4220.00 Wapsipinicon River near Dewitt, Iowa--(Continued)

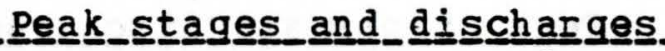

\begin{tabular}{|c|c|c|c|c|}
\hline $\begin{array}{l}\text { Water } \\
\text { year }\end{array}$ & & Date & $\begin{array}{c}\text { Gage } \\
\text { height } \\
\text { (feet) }\end{array}$ & $\begin{array}{l}\text { Discharge } \\
\text { (cfs) }\end{array}$ \\
\hline 1969 & $\begin{array}{l}\text { June } \\
\text { July } \\
\text { July }\end{array}$ & $\begin{array}{rr}9, & 1969 \\
9, & 1969 \\
23, & 1969\end{array}$ & $\begin{array}{l}10.37 \\
12.30 \\
12.02\end{array}$ & $\begin{array}{r}6,090 \\
16,200 \\
14,000\end{array}$ \\
\hline \multicolumn{5}{|c|}{ 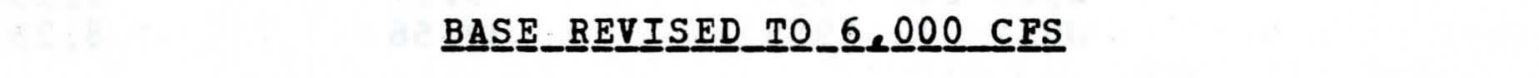 } \\
\hline 1970 & $\begin{array}{l}\text { Mar. } \\
\text { May } \\
\text { May } \\
\text { June }\end{array}$ & $\begin{array}{rr}6, & 1970 \\
15, & 1970 \\
25, & 1970 \\
20, & 1970\end{array}$ & $\begin{array}{l}10.53 \\
10.72 \\
11.04 \\
10.54\end{array}$ & $\begin{array}{l}6,480 \\
6,960 \\
7,960 \\
6,500\end{array}$ \\
\hline 1971 & $\begin{array}{l}\text { Mar. } \\
\text { Apr. } \\
\text { June }\end{array}$ & $\begin{array}{ll}22, & 1971 \\
10, & 1971 \\
25, & 1971\end{array}$ & $\begin{array}{l}11.02 \\
10.57 \\
10.55\end{array}$ & $\begin{array}{l}7,880 \\
6,580 \\
6,520\end{array}$ \\
\hline 1972 & $\begin{array}{l}\text { Apr. } \\
\text { Apr. } \\
\text { May } \\
\text { Aug. }\end{array}$ & $\begin{aligned} 18, & 1972 \\
23, & 1972 \\
13, & 1972 \\
7, & 1973\end{aligned}$ & $\begin{array}{l}10.56 \\
10.50 \\
11.06 \\
10.36\end{array}$ & $\begin{array}{l}6,350 \\
6.200 \\
8.040 \\
6.070\end{array}$ \\
\hline 1973 & $\begin{array}{l}\text { Oct. } \\
\text { Mar. } \\
\text { Apr. } \\
\text { May } \\
\text { May } \\
\text { June } \\
\text { June }\end{array}$ & $\begin{array}{r}8,1972 \\
21,1973 \\
22,1973 \\
3,1973 \\
14,1973 \\
4,1973 \\
18,1973\end{array}$ & $\begin{array}{l}10.51 \\
11.35 \\
12.76 \\
11.50 \\
11.34 \\
10.74 \\
11.52\end{array}$ & $\begin{array}{r}6,420 \\
9,350 \\
27,000 \\
10,200 \\
9,300 \\
7, .020 \\
10,300\end{array}$ \\
\hline 1974 & $\begin{array}{l}\text { May } \\
\text { June } \\
\text { June } \\
\text { June }\end{array}$ & $\begin{array}{ll}17, & 1974 \\
12, & 1974 \\
17, & 1974 \\
23, & 1974\end{array}$ & $\begin{array}{l}13.07 \\
10.61 \\
10.52 \\
11.62\end{array}$ & $\begin{array}{r}29,900 \\
6.380 \\
6.150 \\
10.200\end{array}$ \\
\hline 1975 & Mar. & 23,1975 & 11.65 & 11,200 \\
\hline
\end{tabular}




\section{5-4205.60 Wapsipinicon River near Elma, Iowa}

Location,--Iat $43014 \cdot 34$ ", long $92031 \cdot 48$ ", in Nw1/4 NW1/4 sec.8, T.97 N.. R.14 W.. Howard County, on right bank $10 \mathrm{ft}$ downstream from bridge on county highway B17, C.2 mile downstream from small left-bank tributary, $4.8 \mathrm{miles}$ west of Elma, and at mile 217.9.

Drainage area.--95.2 sq miles.

Gage.-- Nater-stage recorder. Datum of gage is 1,130.05 ft above mean sea level (revised).

Stage-discharge relation.--Defined by current-meter measurements. Remarks.--Base for partial-duration series, 600 cfs.

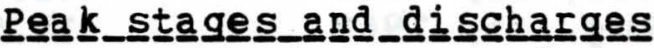

\begin{tabular}{|c|c|c|c|c|c|c|}
\hline $\begin{array}{l}\text { Water } \\
\text { year }\end{array}$ & & Date & & $\begin{array}{l}\text { Gage } \\
\text { height } \\
\text { (feet) }\end{array}$ & & $\begin{array}{c}\text { D is charge } \\
\text { (cfs) }\end{array}$ \\
\hline 1959 & $\begin{array}{l}\text { Mar. } \\
\text { Mar. }\end{array}$ & $\begin{array}{l}26, \\
30,\end{array}$ & $\begin{array}{l}1959 \\
1959\end{array}$ & $\begin{array}{l}11.58 \\
11.54\end{array}$ & a & $-\overline{902}$ \\
\hline 1960 & June & 24. & 1960 & 13.44 & & 2.980 \\
\hline 1961 & $\begin{array}{l}\text { Mar. } \\
\text { Aug. }\end{array}$ & $\begin{array}{r}27 . \\
1 .\end{array}$ & $\begin{array}{l}1961 \\
1961\end{array}$ & $\begin{array}{l}14.19 \\
12.92\end{array}$ & $\omega$ & $\begin{array}{l}4.970 \\
1.560\end{array}$ \\
\hline 1962 & $\begin{array}{l}\text { Mar. } \\
\text { Apr. } \\
\text { Aug. }\end{array}$ & $\begin{array}{r}29, \\
6 \% \\
31 .\end{array}$ & $\begin{array}{l}1962 \\
1962 \\
1962\end{array}$ & $\begin{array}{r}14.84 \\
11.74 \\
14.72\end{array}$ & a & $\begin{array}{r}5.700 \mathrm{~b} \\
940 \\
5,500\end{array}$ \\
\hline 1963 & $\begin{array}{l}\text { oct. } \\
\text { Mar. } \\
\text { Mar. }\end{array}$ & $\begin{array}{l}9 . \\
18, \\
26 .\end{array}$ & $\begin{array}{l}1962 \\
1963 \\
1963\end{array}$ & $\begin{array}{l}11.61 \\
12.29 \\
10.39\end{array}$ & $a$ & $\begin{array}{l}960 \\
650 \quad b \\
620\end{array}$ \\
\hline 1964 & May & 24. & 1964 & 9.90 & & 540 \\
\hline 1965 & $\begin{array}{l}\text { Mar. } \\
\text { Apr. } \\
\text { Apr. } \\
\text { Apr. } \\
\text { July } \\
\text { Sept } \\
\text { Sept }\end{array}$ & $\begin{array}{l}1 . \\
6, \\
8, \\
11 . \\
10, \\
20 . \\
29\end{array}$ & $\begin{array}{l}1965 \\
1965 \\
1965 \\
1965 \\
1965 \\
1965 \\
1965\end{array}$ & $\begin{array}{l}-- \\
13.66 \\
13.19 \\
12.54 \\
11.53 \\
13.16 \\
14.26\end{array}$ & a & $\begin{array}{r}740 \mathrm{~b} \\
2.300 \mathrm{~b} \\
2.430 \\
1.460 \\
844 \\
2.100 \\
4.730\end{array}$ \\
\hline
\end{tabular}

a Áfécted by ice.

b A bout. 
05-4205.60 Wapsipinicon River near Elma, Iowa--(Continued)

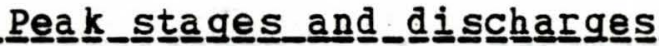

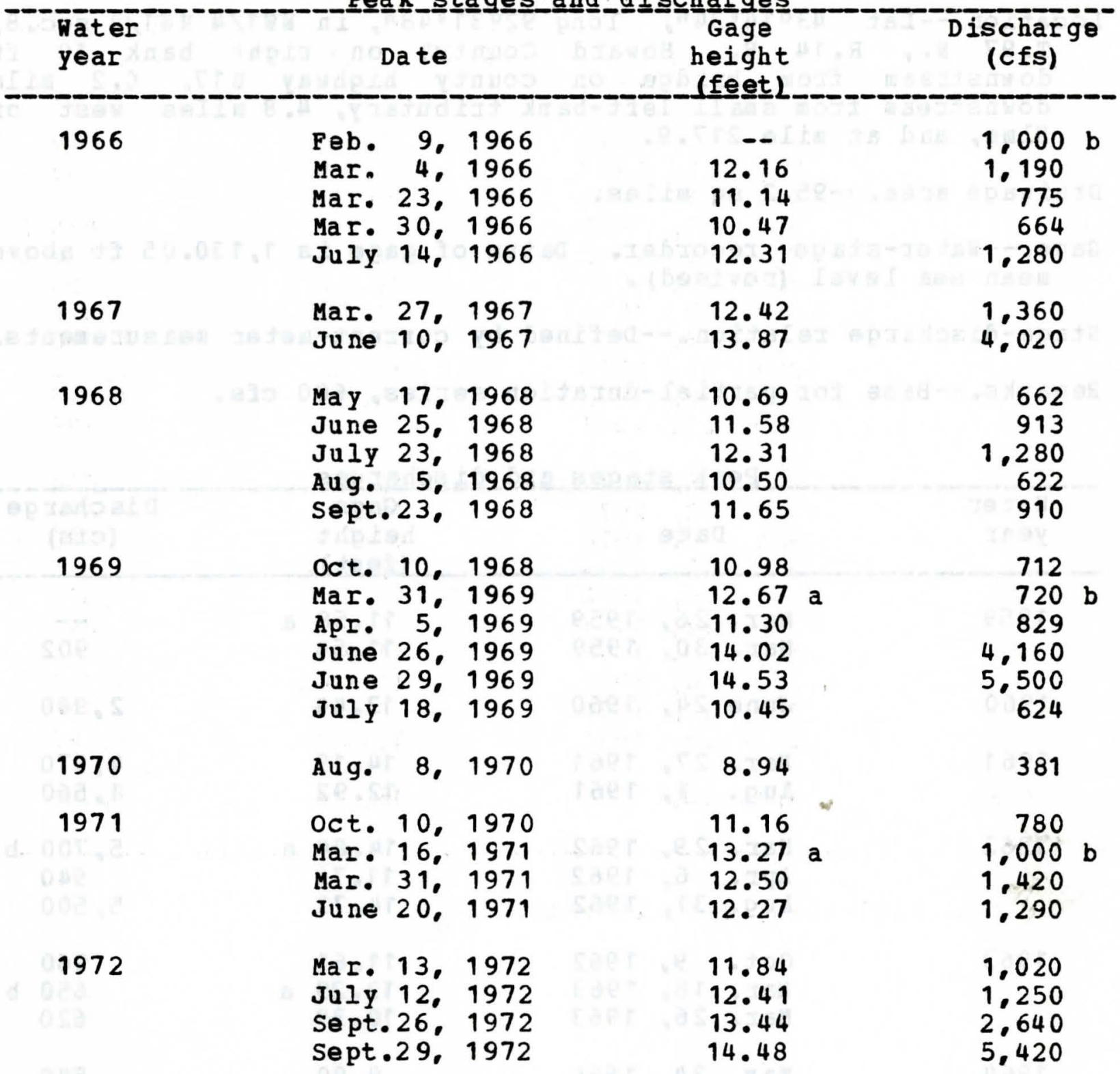

a Affected by ice.

b About. 
05-4205.60 Wapsipinicon River near Elma. Iowa--(Continued)

Peak_s_tages_and_discharges

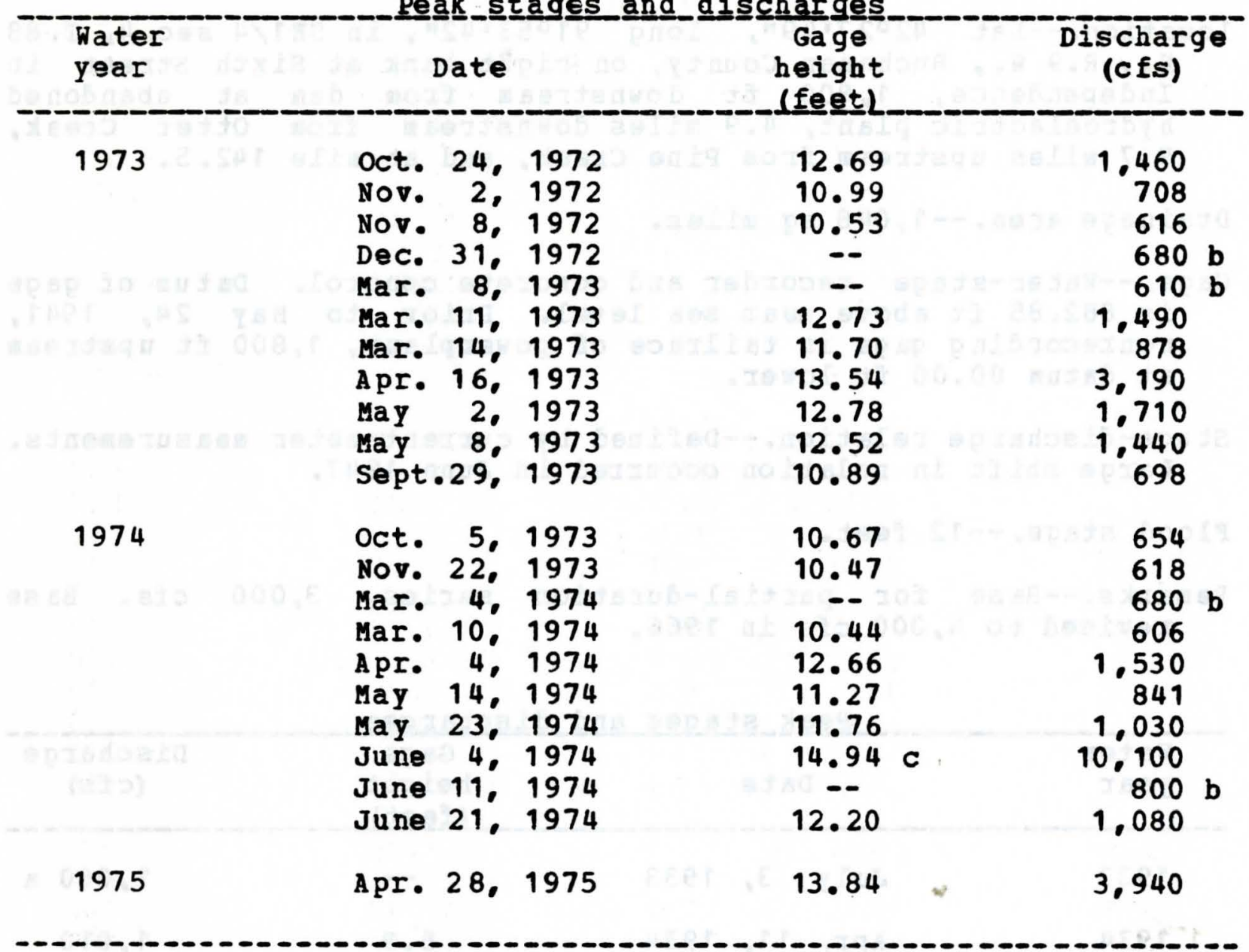

b About.

c From high-water mark in well. 
Location.--Lat $42027 \cdot 49 "$, long $91053 \cdot 42^{\prime \prime}$, in SE1/4 sec.4, T. 88 N.. R.9 W.. Buchanan County, on right bank at Sixth street in Independence, $\quad 1,800$ ft downstream from dam at abandoned hydroelectric plant. 4.9 miles downstream from otter Creek, 9.7 miles upstream from Pine Creek, and at mile 142.5.

Drainage area.--1,048 sq miles.

Gage.-Hater-stage recorder and concrete control. Datum of gage is 882.85 ft above mean sea level. Prior to May 24, 1941, nonrecording gage in tailrace of powerplant. 1,800 ft upstream at datum $80.00 \mathrm{ft}$ lower.

Stage-discharge relation.--Defined by current-meter measurements. Large shift in relation occurred in June 1947.

Flood stage. -12 feet.

Remarks.--Base for partial-duration series, 3,000 cfs. Base revised to $4,000 \mathrm{cfs}$ in 1966.

Peak

\begin{tabular}{|c|c|c|c|}
\hline $\begin{array}{l}\text { Water } \\
\text { year }\end{array}$ & Date & $\begin{array}{c}\text { Gage } \\
\text { height } \\
\text { lfeetl. }\end{array}$ & $\begin{array}{l}\text { Discharge } \\
\text { (cfs) }\end{array}$ \\
\hline 1933 & JuIY 3, 1933 & -- & $1.080 \mathrm{a}$ \\
\hline 1934 & Apr. 11, 1934 & 5.9 & 1.010 \\
\hline 1935 & $\begin{array}{l}\text { Mar. } 5,6,1935 \\
\text { Mar. } 24,1935 \\
\text { May } 5,1935\end{array}$ & $\begin{array}{r}11.4 \\
8.4 \\
7.5\end{array}$ & $\begin{array}{l}7.220 \\
4.040 \\
3.000\end{array}$ \\
\hline 1936 & $\begin{array}{l}\text { Mar. 12, } 1936 \\
\text { Mar. 26, } 1936\end{array}$ & $\begin{array}{r}11.1 \\
9.7\end{array}$ & $\begin{array}{l}6,900 \\
5,170\end{array}$ \\
\hline 1937 & $\begin{array}{l}\text { Feb. } 20,1937 \\
\text { Mar. } 8,1937 \\
\text { June 15, } 1937 \\
\text { June 21, } 1937\end{array}$ & $\begin{array}{r}7.9 \\
12.0 \\
7.6 \\
8.0\end{array}$ & $\begin{array}{l}3.480 \\
7.900 \\
3.180 \\
3.600\end{array}$ \\
\hline 1938 & $\begin{array}{l}\text { Feb. 1, } 1938 \\
\text { Sept.19, } 1938\end{array}$ & $\begin{array}{l}7.7 \\
8.4\end{array}$ & $\begin{array}{l}3.240 \\
3.990\end{array}$ \\
\hline
\end{tabular}

a Maximum for period July to September 1933. 
Peakㅡ_-sta

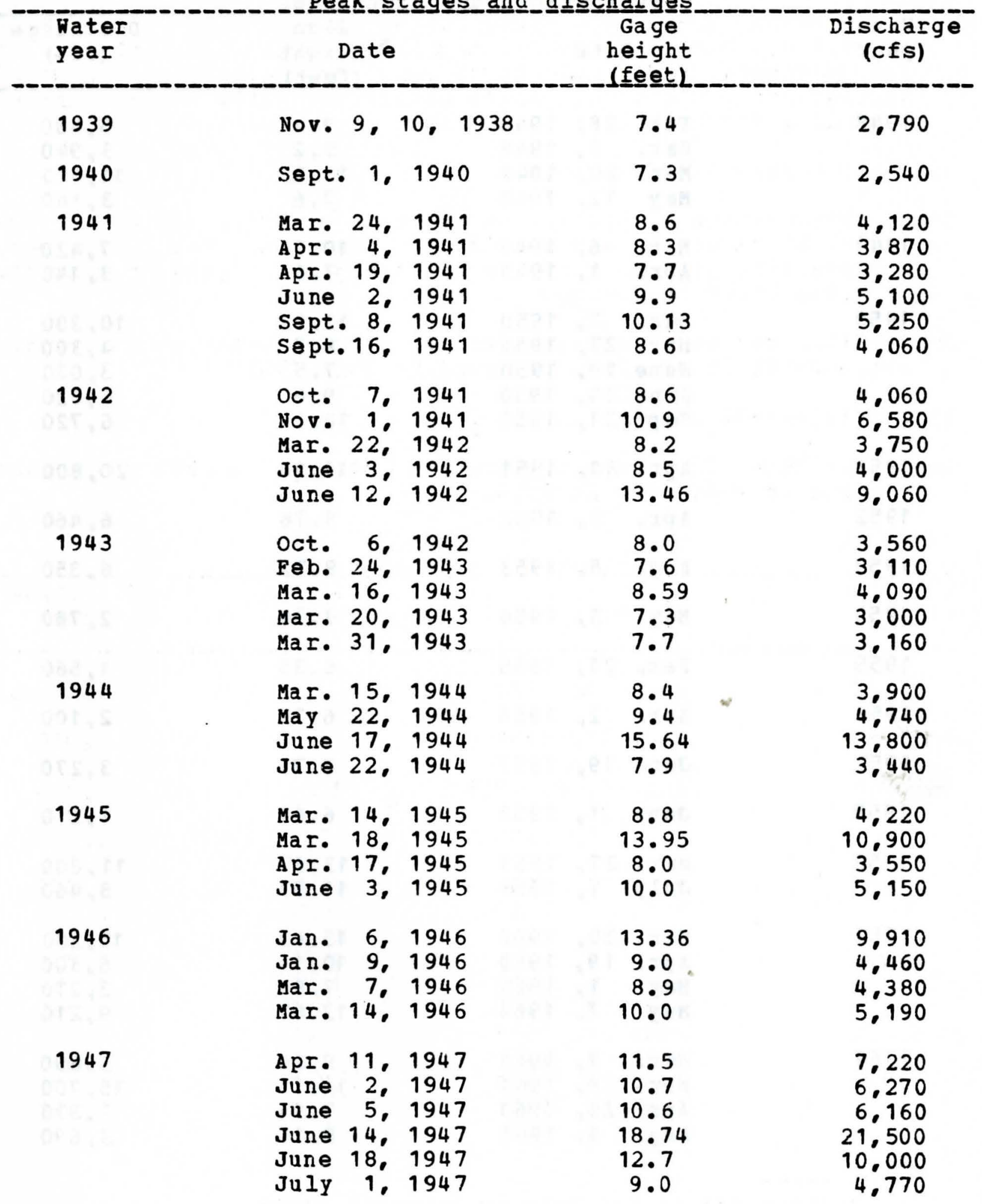


05-4210.00 Mapsipinicon River at Independence, Iowa--(Continued)

Peak_stagges and_di

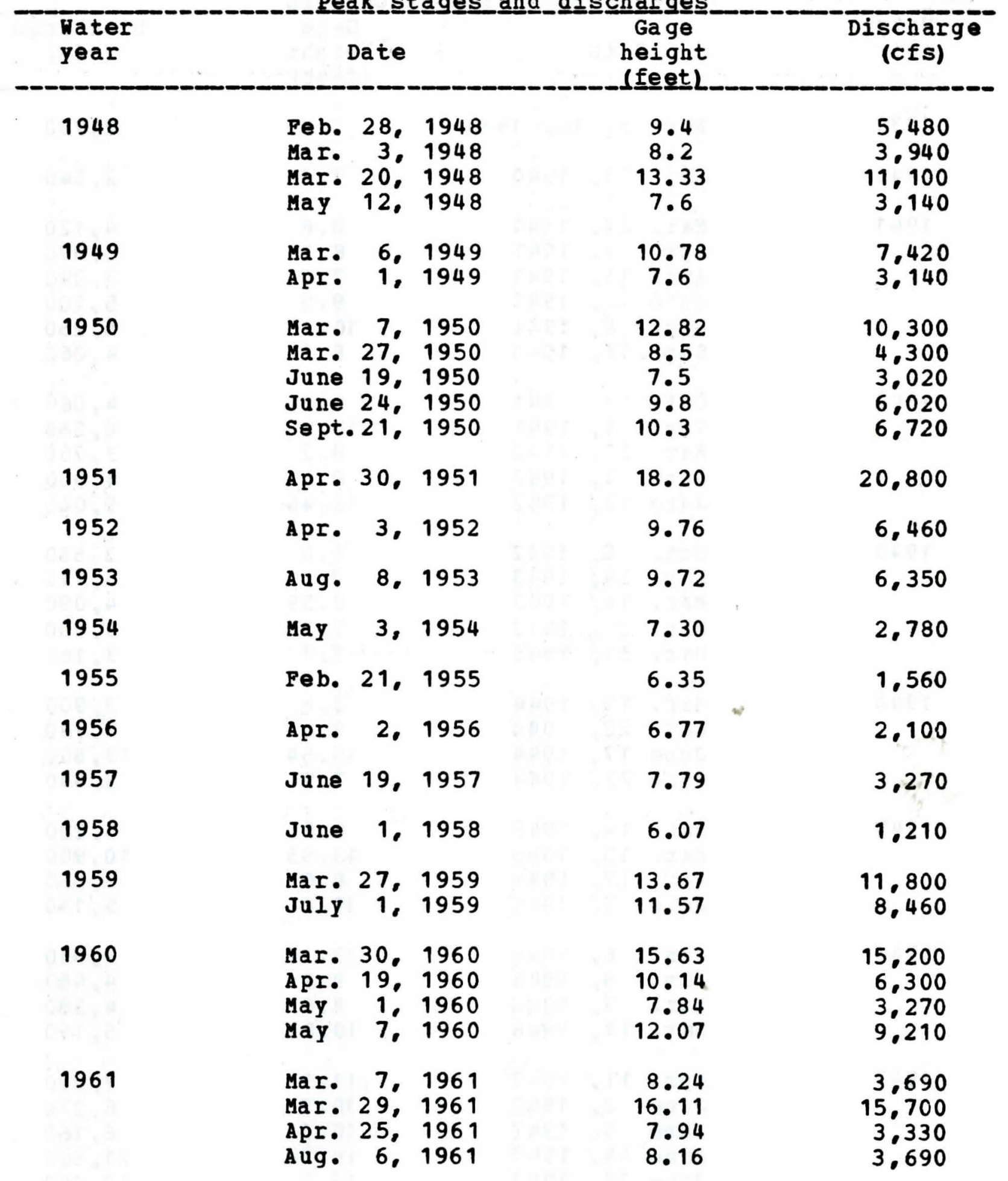


05-4210.00 Wapsipinicon River at Independence, Iowa--(Continued)

Pea

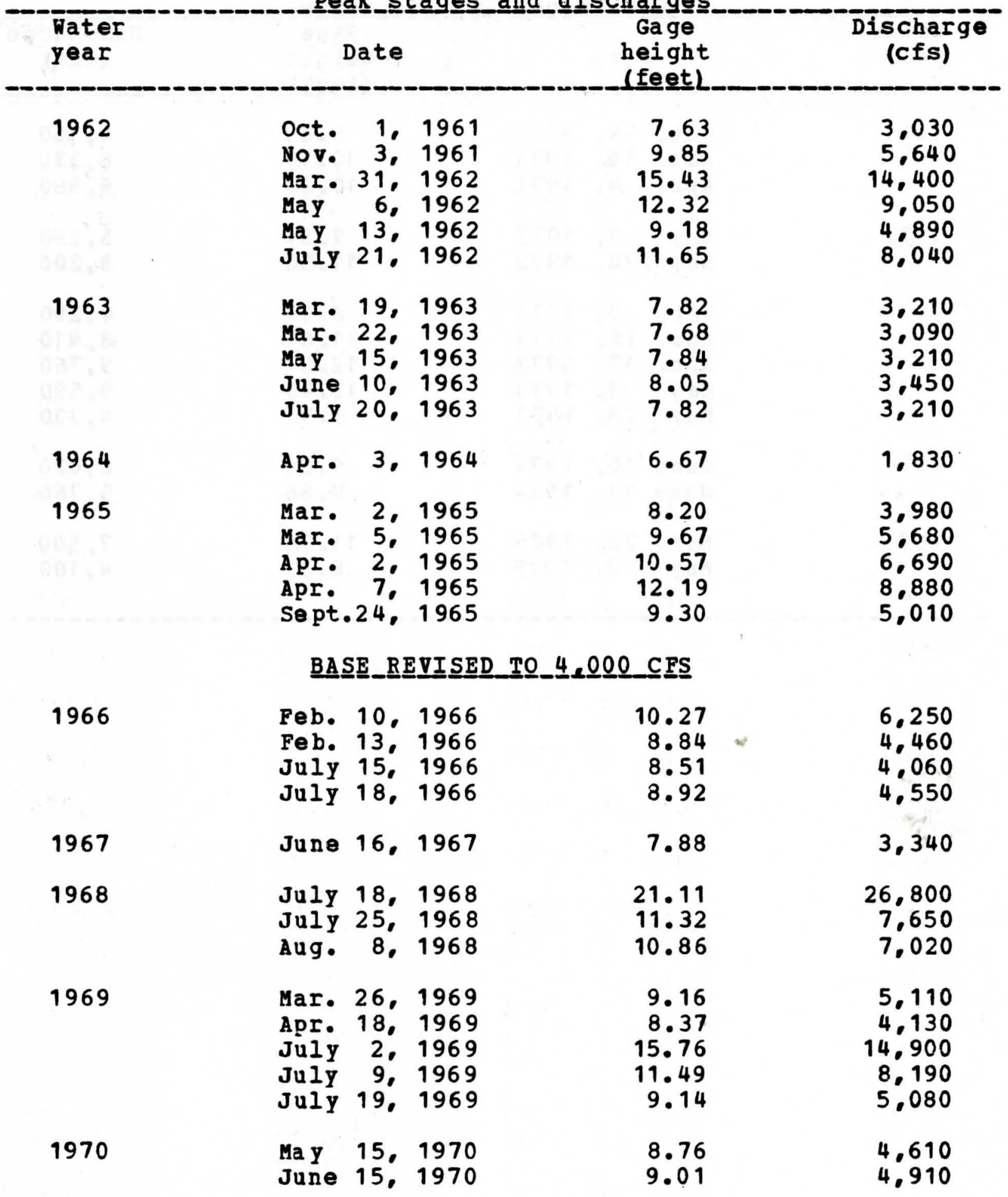


05-4210.00 Wapsipinicon River at Independence, Iowa--(Continued)

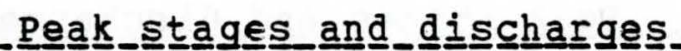

\begin{tabular}{|c|c|c|c|}
\hline $\begin{array}{l}\text { Water } \\
\text { year }\end{array}$ & Date & $\begin{array}{l}\text { Gage } \\
\text { height } \\
\text { (feet }\end{array}$ & $\begin{array}{c}\text { Discharge } \\
\text { (cfs) }\end{array}$ \\
\hline 1971 & $\begin{array}{l}\text { oct. 14, } 1970 \\
\text { Mar. } 16,1971 \\
\text { Apr. } 4,1971\end{array}$ & $\begin{array}{r}8 \cdot 39 \\
10 \cdot 10 \\
10.29\end{array}$ & $\begin{array}{l}4.160 \\
6.330 \\
6.580\end{array}$ \\
\hline 1972 & $\begin{array}{lr}\text { May } 7, & 1972 \\
\text { Sept. 30, } 1972\end{array}$ & $\begin{array}{r}9.31 \\
11.50\end{array}$ & $\begin{array}{l}5.280 \\
8.200\end{array}$ \\
\hline 1973 & $\begin{array}{lr}\text { Feb. } & 2,1973 \\
\text { Mar. } 15,1973 \\
\text { Apr. } 17,1973 \\
\text { May } & 8,1973 \\
\text { May } 28,1973\end{array}$ & $\begin{array}{r}8.49 \\
11.65 \\
12.57 \\
12.46 \\
8.50\end{array}$ & $\begin{array}{l}4.290 \\
8.410 \\
9.760 \\
9.590 \\
4.300\end{array}$ \\
\hline 1974 & $\begin{array}{l}\text { June } 10,1974 \\
\text { June } 14,1974\end{array}$ & $\begin{array}{l}9.86 \\
9.66\end{array}$ & $\begin{array}{l}6.020 \\
5.760\end{array}$ \\
\hline 1975 & $\begin{array}{lr}\text { Mar. 22, } 1975 \\
\text { May } & 3,1975\end{array}$ & $\begin{array}{r}11.06 \\
8.35\end{array}$ & $\begin{array}{l}7.580 \\
4.100\end{array}$ \\
\hline
\end{tabular}




$$
\begin{aligned}
& \text { 05-4215.00 Wapsipinicon River at Stone City. Iowa } \\
& \text { (Discontinued Sept. 30, 1914) }
\end{aligned}
$$

Location.--Lat 42007'00", long 91021110 ", in Sw1/4 NE1/4 sec.6, T. 84 N., R. 4 W., Jones County, at highway bridge at stone City about 180 ft usptream from Chicago, Milwaukee, St. Paul \& Pacific Railroad bridge 3.1 miles upstream from Buffalo Creek and at mile 92.5 .

Drainage area.-- 1,324 sq miles.

Gage.-Nonrecording. Datum of gage is about $776.7 \mathrm{ft}$ above mean sea level.

Stage-discharge relation.--Defined by current-meter measurements. Remarks.--Base for partial-duration series, 1,900 cfs.

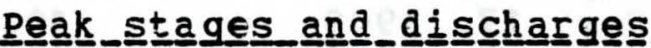

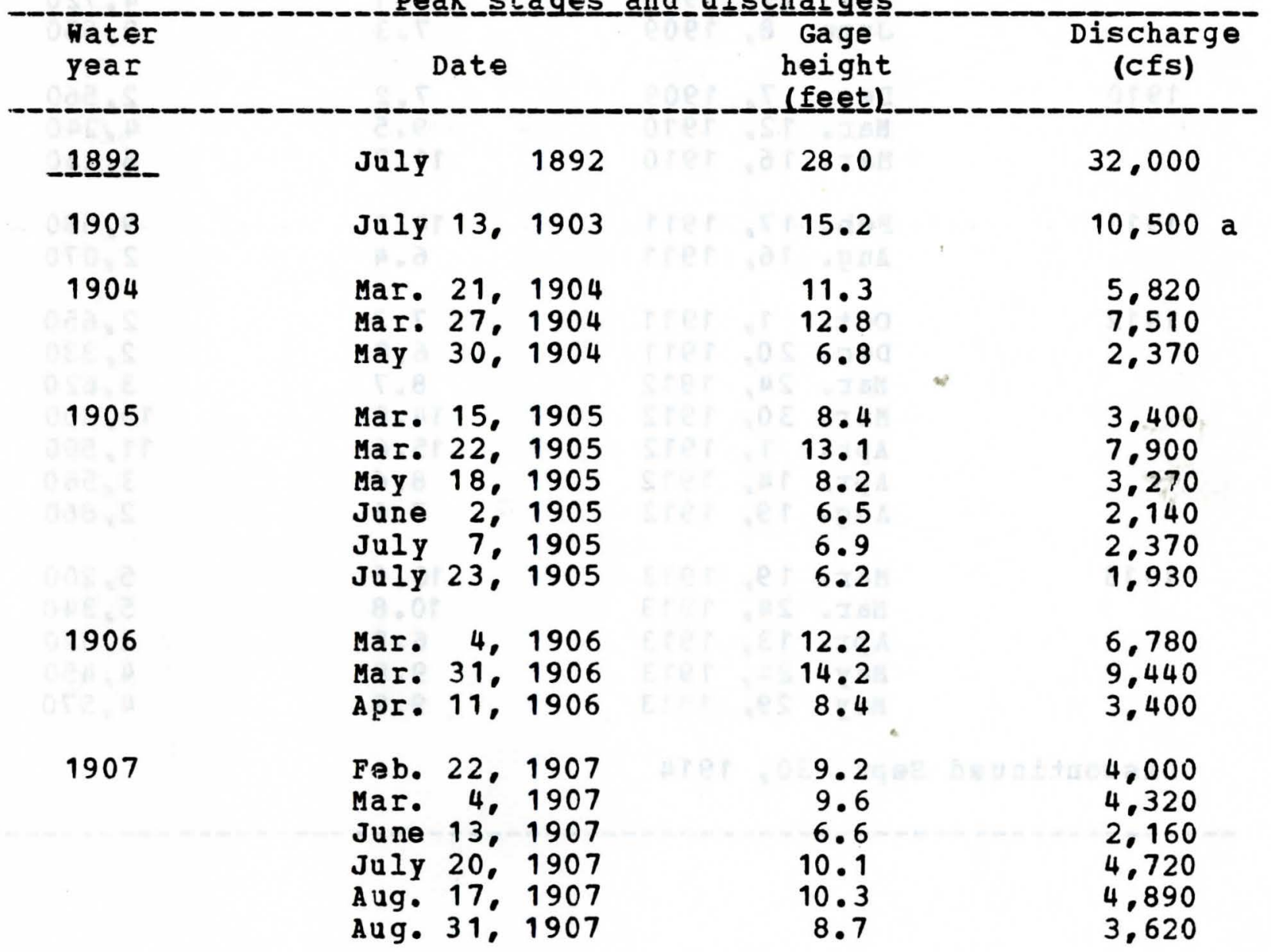

a Result of discharge measurement. 
05-4215.00 Dapsipinicon River at Stone City. Iowa--(Contirued)

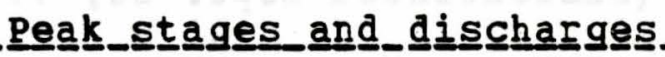

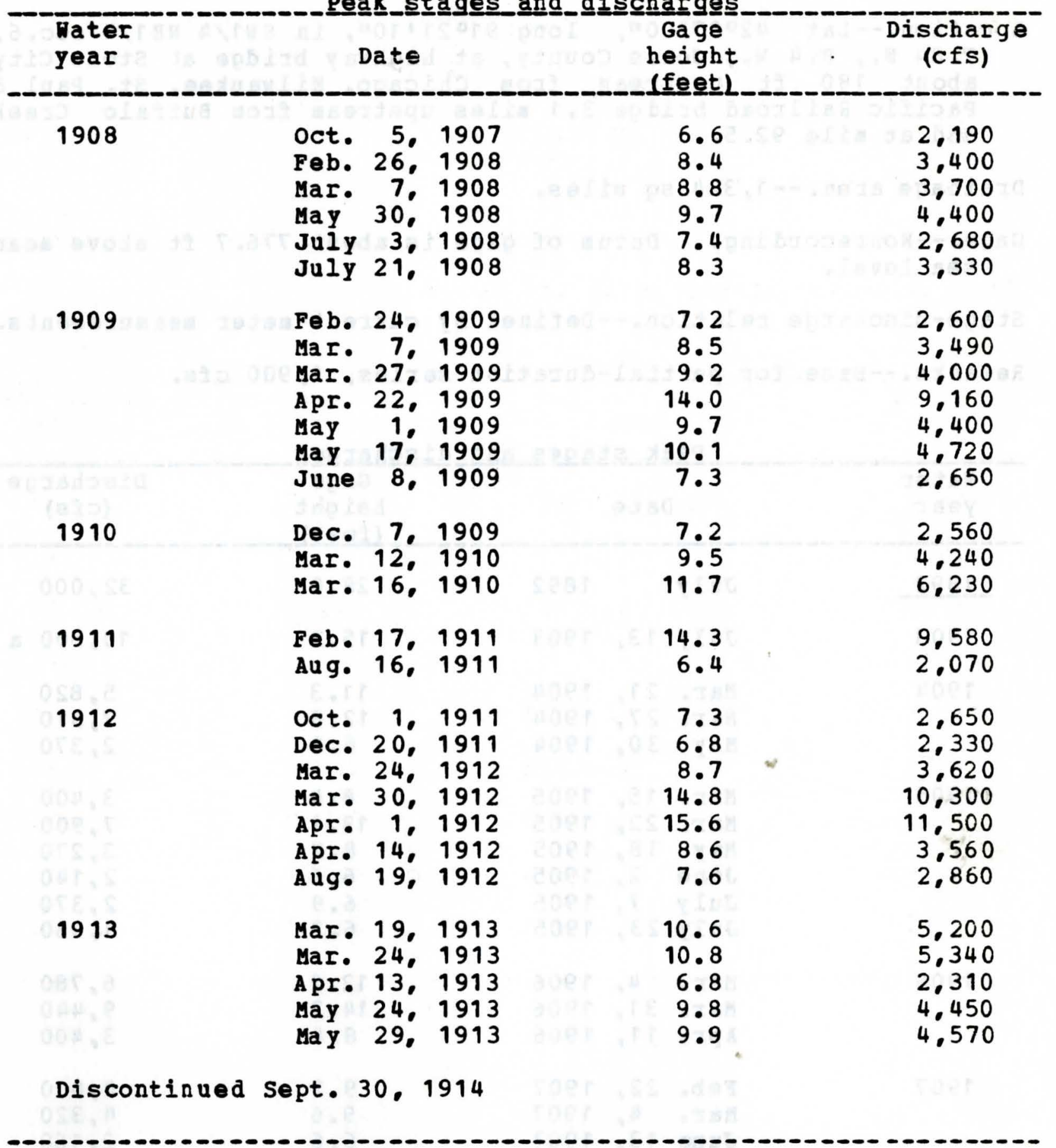


Location.--Lat 43011.06", long 95030143", in NE1/4 sec.36, T.97 N.. R.40 N., O Brien County, at bridge on U.S. Highway 18, 1.8 miles west of Hartley.

Drainage area.--28.7 sq miles.

Gage.--Crest-stage gage.

Stage-discharge realtion.--Defined by current-meter measurements. Remarks.--only annual peaks are shown.

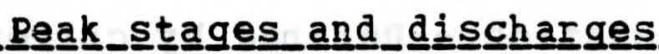

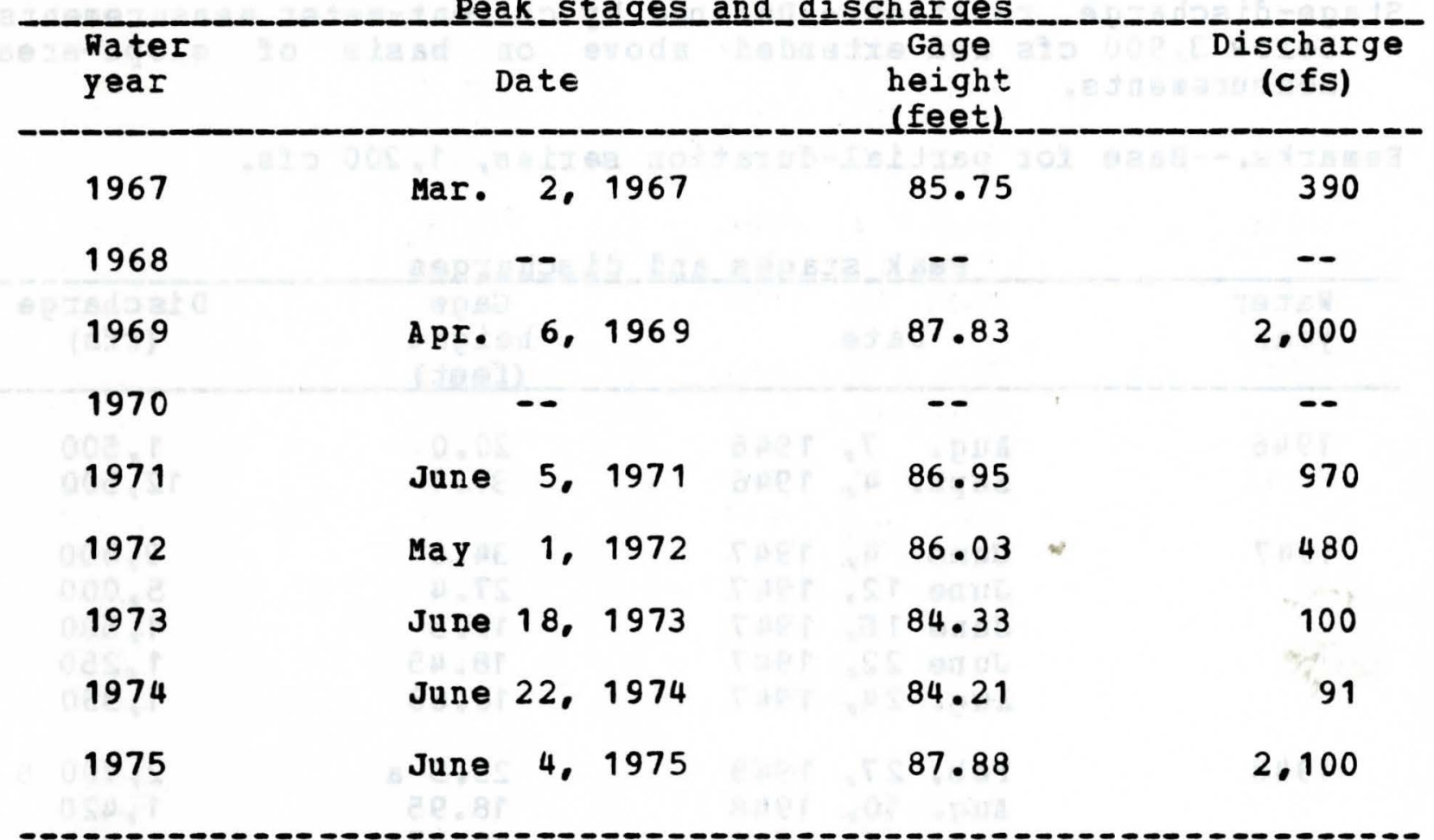




\section{6-8060.00 Waubonsie Creek near Bartlett. Iowa (Discontinued Sept. 30, 1969)}

Location.--Lat 40053104 ", long $95^{\circ} 44^{\prime} 47^{\prime \prime}$, in NE1/4 NE1/4 sec.11, T.70 N., R. 43 W.. Fremont County, on left pier on downstream side of highway bridge, 2.5 miles east of Bartlett and 3.5 miles west of Tabor, and 3.6 miles upstream from mouth.

Drainage area.-- $30.4 \mathrm{sq}$ miles.

Gage.--Recording. Datum of gage is $936.96 \mathrm{ft}$ above mean sea level. PIi or to June 16, 1951, nonrecording gage and Jan. 10 , 1946, to May 8, 1950, supplementary high-stage recording gage at same site and datum.

Stage-discharge relation.--Defined by current-meter measurements below 3,900 cfs and extended above on basis of slope-area measurements.

Remarks.--Base for partial-duration series, 1,200 cfs.

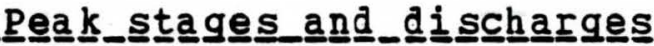

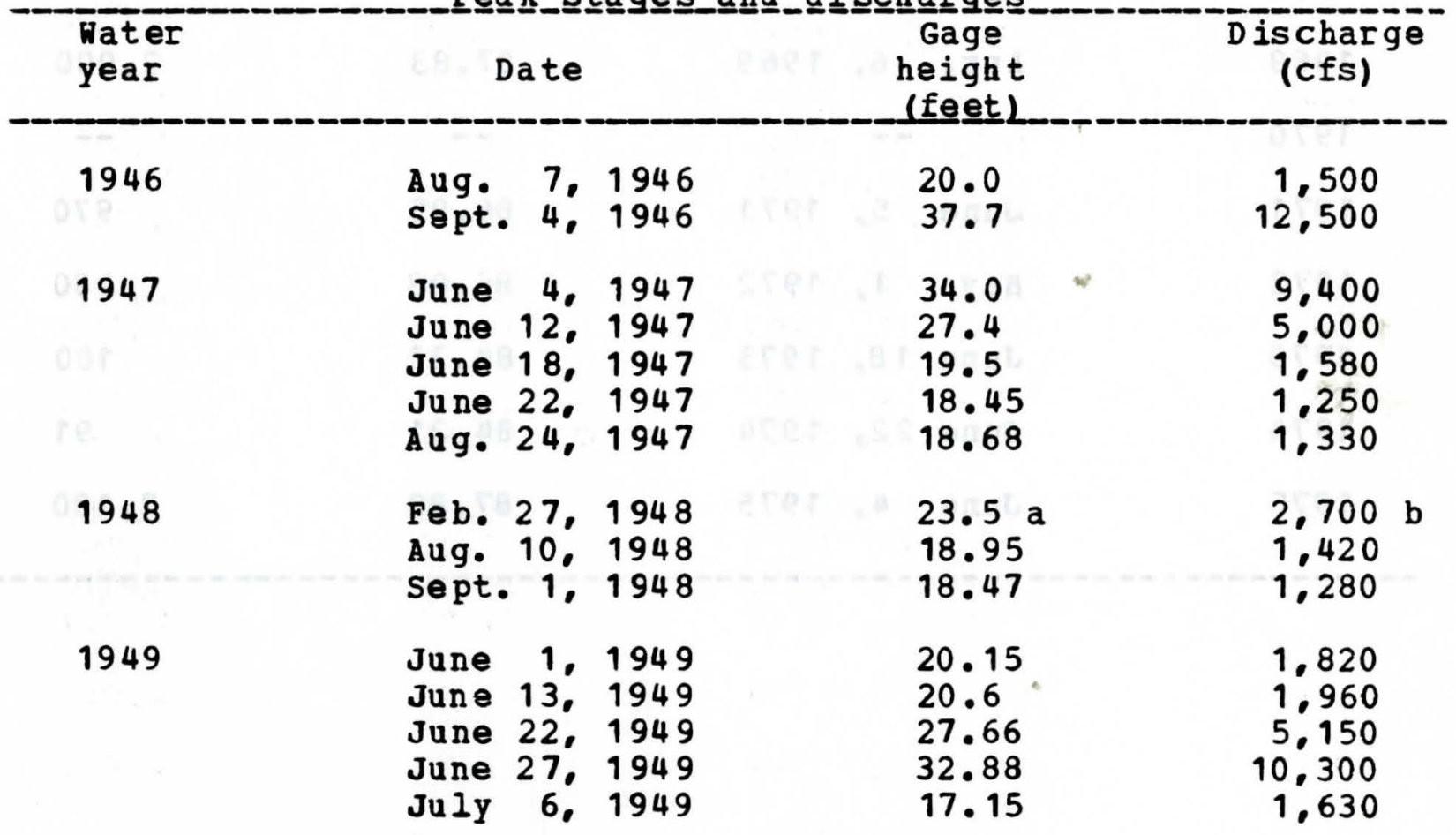

a Affected by ice.

b A bout. 
06-8060.00 Naubonsie Creek near Bartlett, Iowa--(Continued)

Peak_stages and discharges

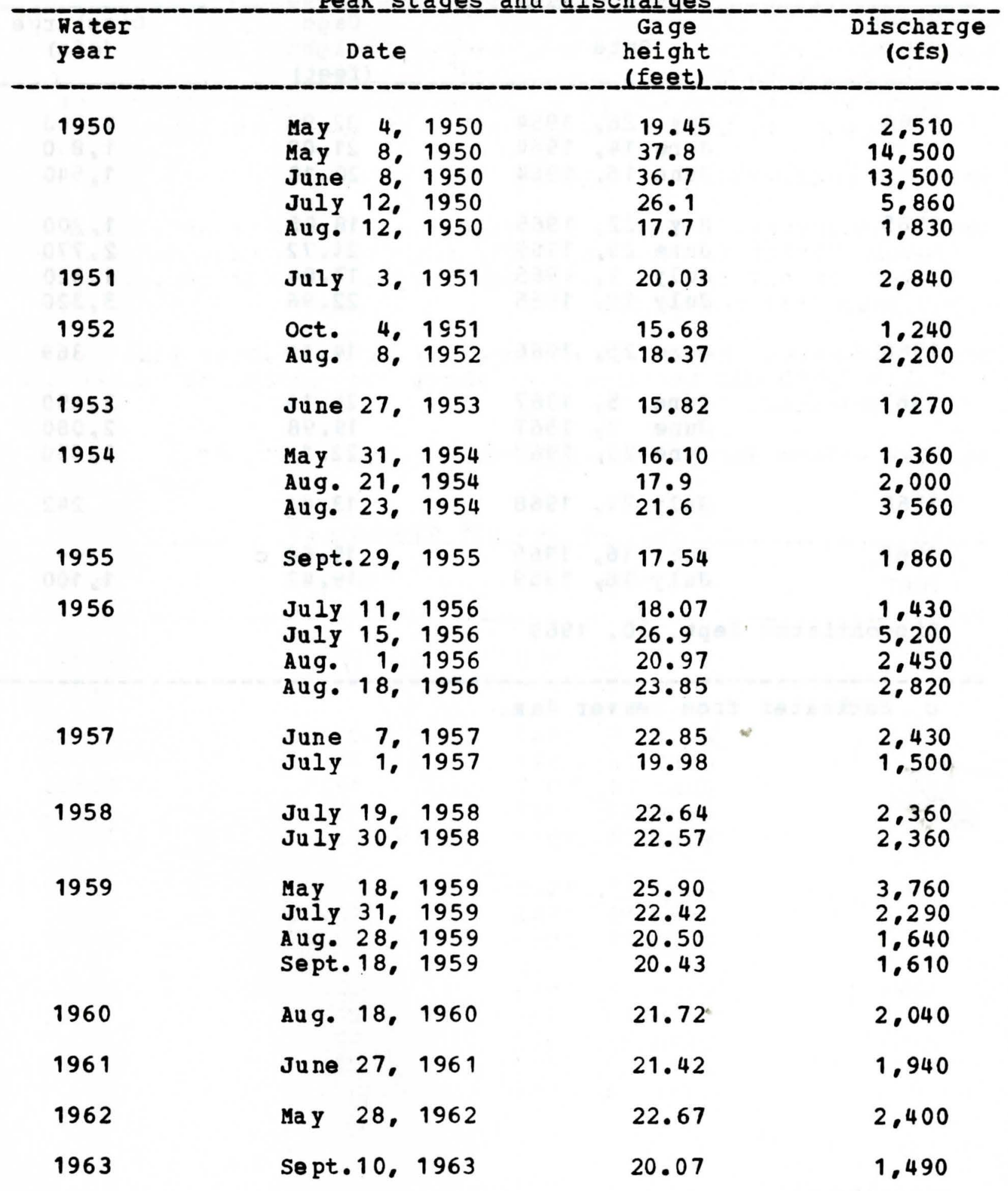


06-8060.00 Haubonsie Creek near Bartlett, Iowa--(Continued)

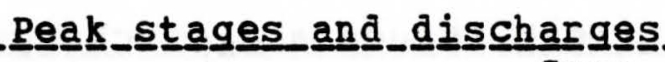

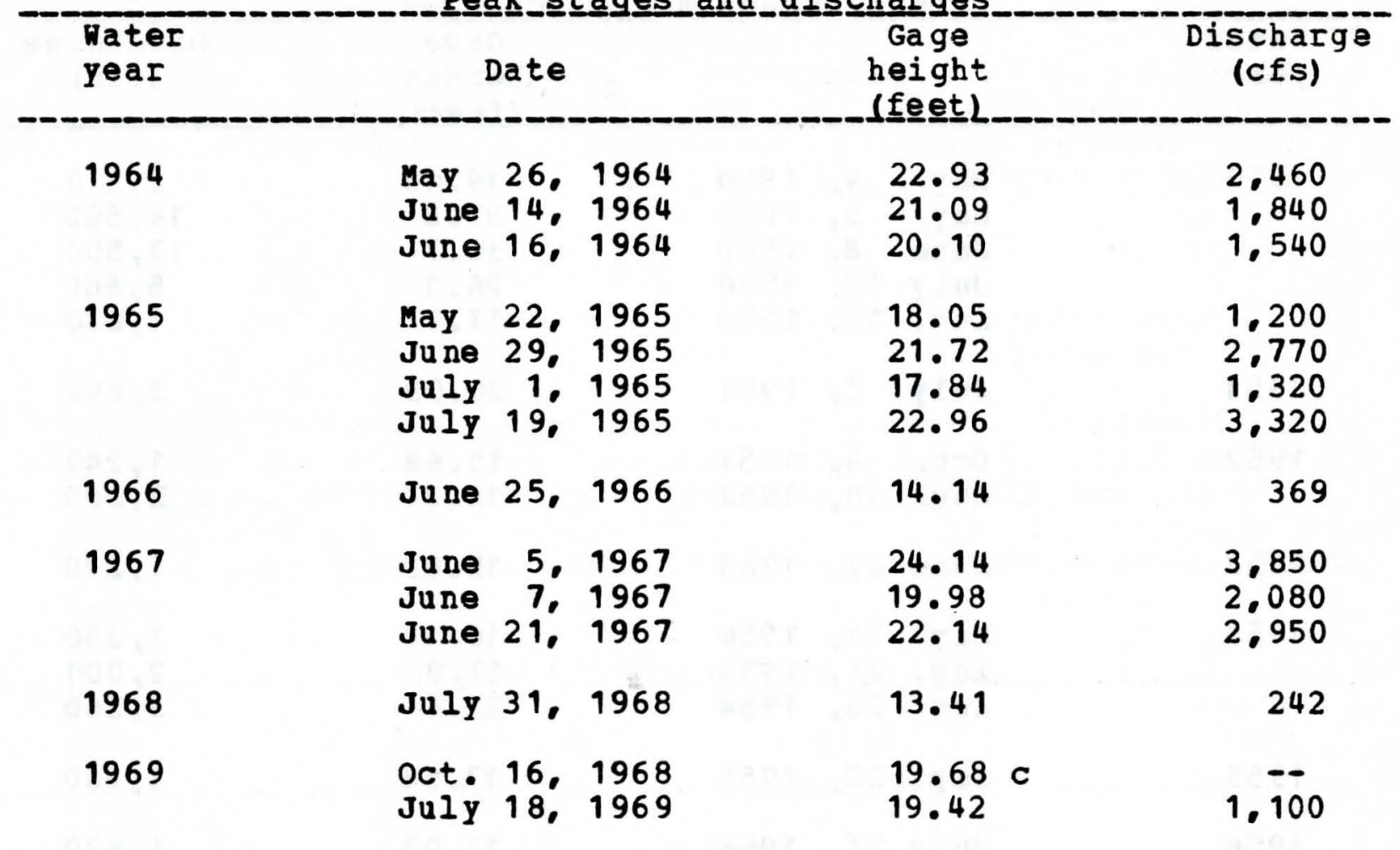

Discontinued sept. 30,1969

c Backwater from beaver dam. 
Location.--Lat $40041 \cdot 45^{\prime \prime}$, long $93038107 "$, in NE1/4 NE1/4 sec.17, T.68 N., R. 24 W., Decatur County, on left bank 10 ft downstream from bridge on county highway A, 200 ft upstream from unamed creek, 1.3 miles downstream from Brush creek, and 6.5 miles southeast of post cffice at leon.

Drainage area.--104 sq miles.

Gage.--Hater-stage recorder, Datum of gage is $906.26 \mathrm{ft}$ above mean sea level.

Stage-discharge relation.--Defined by current-meter measurements below 5,600 cfs and extended above on basis of contractedopening and flow-over-embankment measurement of peak flow.

Remarks,--Base for partial-duration series, 4,500 cfs.

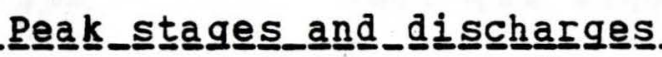

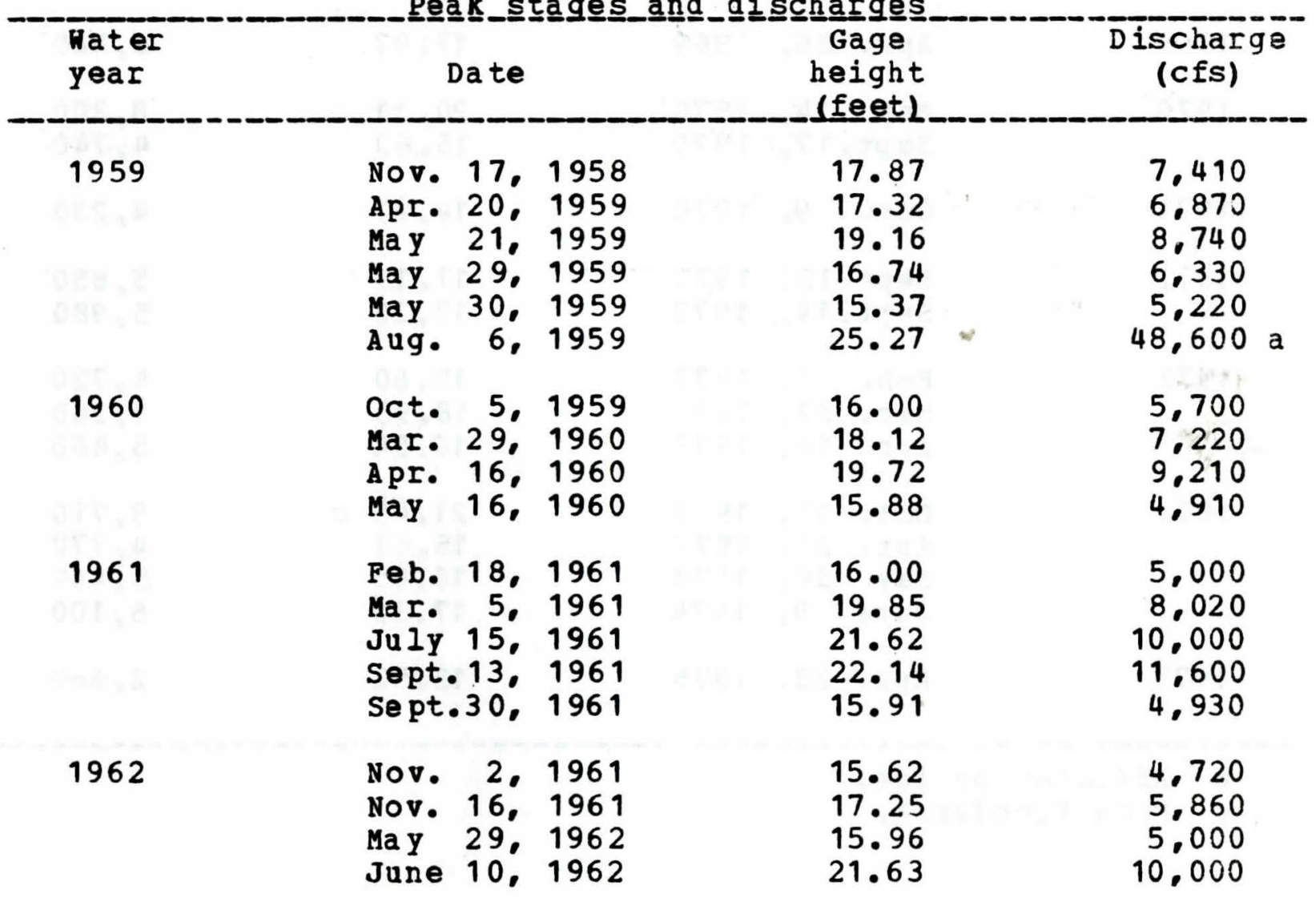

a Greatest flood since 1919. 
06-8984.00 Weldon River near Leon, Iowa--(Continued)

Peak_stagges and discharges

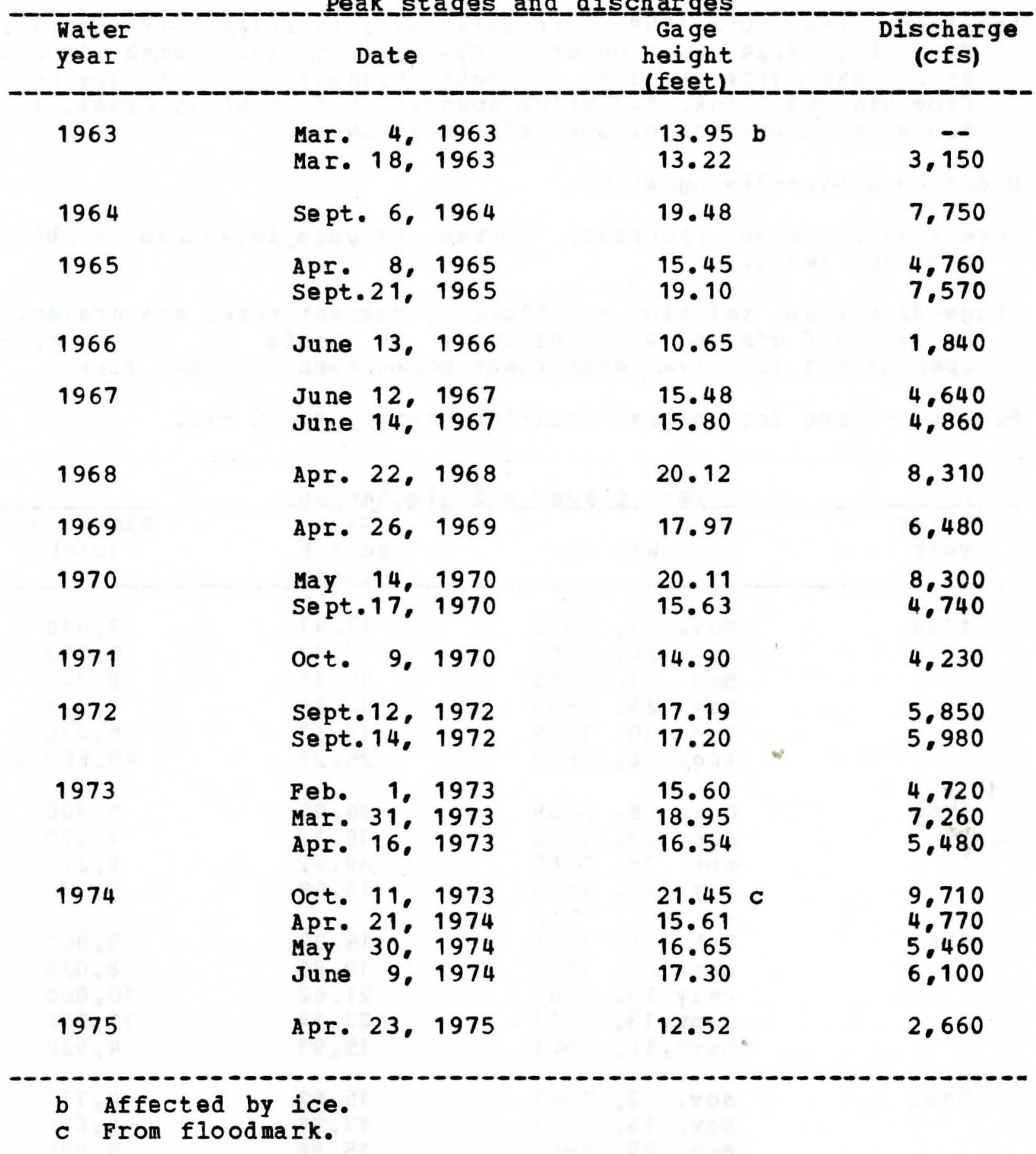


Location.--Lat $42002^{\prime}$, long $94013^{\prime}$, in NE1/4 sec.3, T. 83 N.. R.29 W. Greene county, at bridge on 0.5 . Highway 30 , near east edge of Grand Junction.

Drainage area.--12.6 sq miles.

Gage.--Crest-stage gage.

Stage-discharge relation.--Defined by current-meter measurements. Remarks.--only annual peaks are shown.

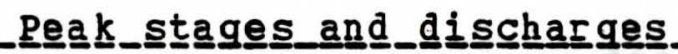

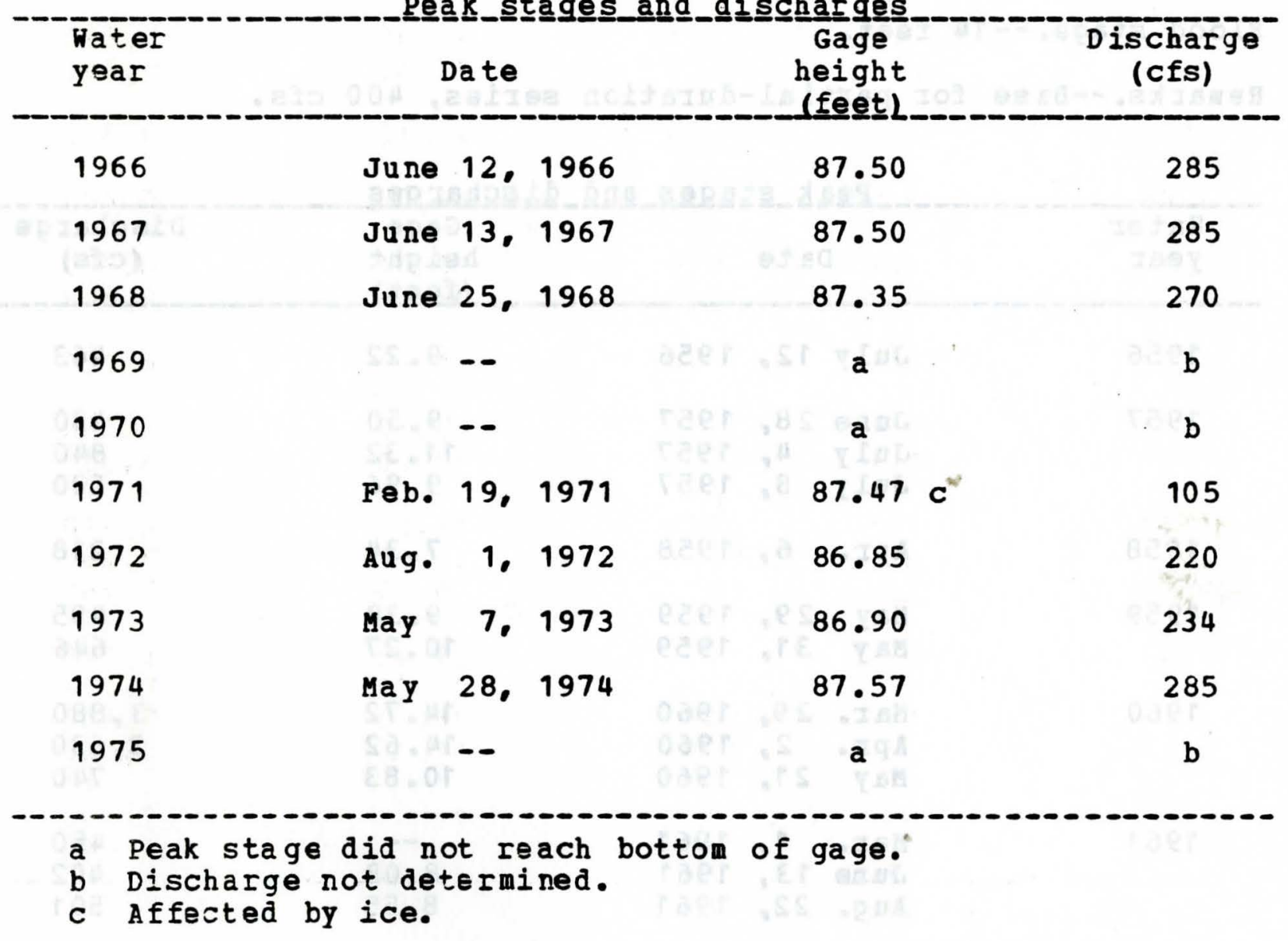


Location.--Lat 42055'15". long 96010'30", in NE1/4 NE1/4 sec. 32 . T. 94 N., R. 45 H.. Sioux County, or right bank at downstream side of bridge on county highway B62, 0.2 mile west of U.S. Highway 75, $0.8 \mathrm{mile}$ downstream from Orange City slough. 2.2 miles northeast of struble. 14 miles upstream from floyd River, and at mile 39.3.

Drainage area.--181 sq miles.

Gage.-Water-stage recorder. Datum of gage is 1,239.40 ft above mean sez level (State Highway Commission bench mark).

Stage-dischirge relation.--Defined by current-mater measurements. Flood stage.-- 14 feet.

Remarks.--Base for partial-duration series, 400 cfs.

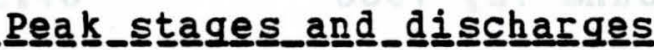

\begin{tabular}{|c|c|c|c|c|c|c|c|}
\hline $\begin{array}{l}\text { Water } \\
\text { year }\end{array}$ & I & Date & & $7 x$ & $\begin{array}{c}\text { Gage } \\
\text { height } \\
\text { (fegt) }\end{array}$ & & $\begin{array}{l}\text { Discharge } \\
\text { (cfs) }\end{array}$ \\
\hline 1956 & July & 12. & 1956 & & 9.22 & & 463 \\
\hline 1957 & $\begin{array}{l}\text { June } \\
\text { July } \\
\text { July }\end{array}$ & $\begin{array}{r}28 . \\
4, \\
8 .\end{array}$ & $\begin{array}{l}1957 \\
1957 \\
1957\end{array}$ & & $\begin{array}{r}9.50 \\
11.32 \\
9.96\end{array}$ & $*$ & $\begin{array}{l}430 \\
840 \\
500\end{array}$ \\
\hline 1958 & Apr. & 6. & 1958 & & 7.34 & & 218 \\
\hline 1959 & $\begin{array}{l}\text { May } \\
\text { May }\end{array}$ & $\begin{array}{l}29 . \\
31 .\end{array}$ & $\begin{array}{l}1959 \\
1959\end{array}$ & & $\begin{array}{r}9.38 \\
10.27\end{array}$ & & $\begin{array}{l}495 \\
646\end{array}$ \\
\hline 1960 & $\begin{array}{l}\text { Mar. } \\
\text { Apr. } \\
\text { May }\end{array}$ & $\begin{array}{r}29 . \\
2 \% \\
21 .\end{array}$ & $\begin{array}{l}1960 \\
1960 \\
1960\end{array}$ & & $\begin{array}{l}14.72 \\
14.62 \\
10.83\end{array}$ & & $\begin{array}{r}3.880 \\
3.630 \\
740\end{array}$ \\
\hline 1961 & $\begin{array}{l}\text { Mar. } \\
\text { June } \\
\text { Aug. }\end{array}$ & $\begin{array}{l}1, \\
132 \\
22 .\end{array}$ & $\begin{array}{l}1961 \\
1961 \\
1961\end{array}$ & & $\begin{array}{l}-- \\
8.08 \\
8.55\end{array}$ & 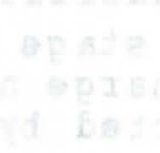 & $\begin{array}{l}450 \\
402 \\
501\end{array}$ \\
\hline 1962 & $\begin{array}{l}\text { Mar. } \\
\text { Apr. } \\
\text { May } \\
\text { June } \\
\text { June } \\
\text { June }\end{array}$ & $\begin{array}{r}28, \\
3 . \\
22, \\
5 . \\
8 .\end{array}$ & $\begin{array}{l}1962 \\
1962 \\
1962 \\
1962 \\
1962 \\
1962\end{array}$ & & $\begin{array}{r}15.63 \\
10.64 \\
9.94 \\
8.00 \\
7.62 \\
11.28\end{array}$ & & $\begin{array}{r}8.060 \\
1.110 \\
892 \\
480 \\
400 \\
1.320\end{array}$ \\
\hline
\end{tabular}


06-6003.00 West Branch Floyd River near Struble, Iowa--(Continued)

Peakㅡ_stages_and_di

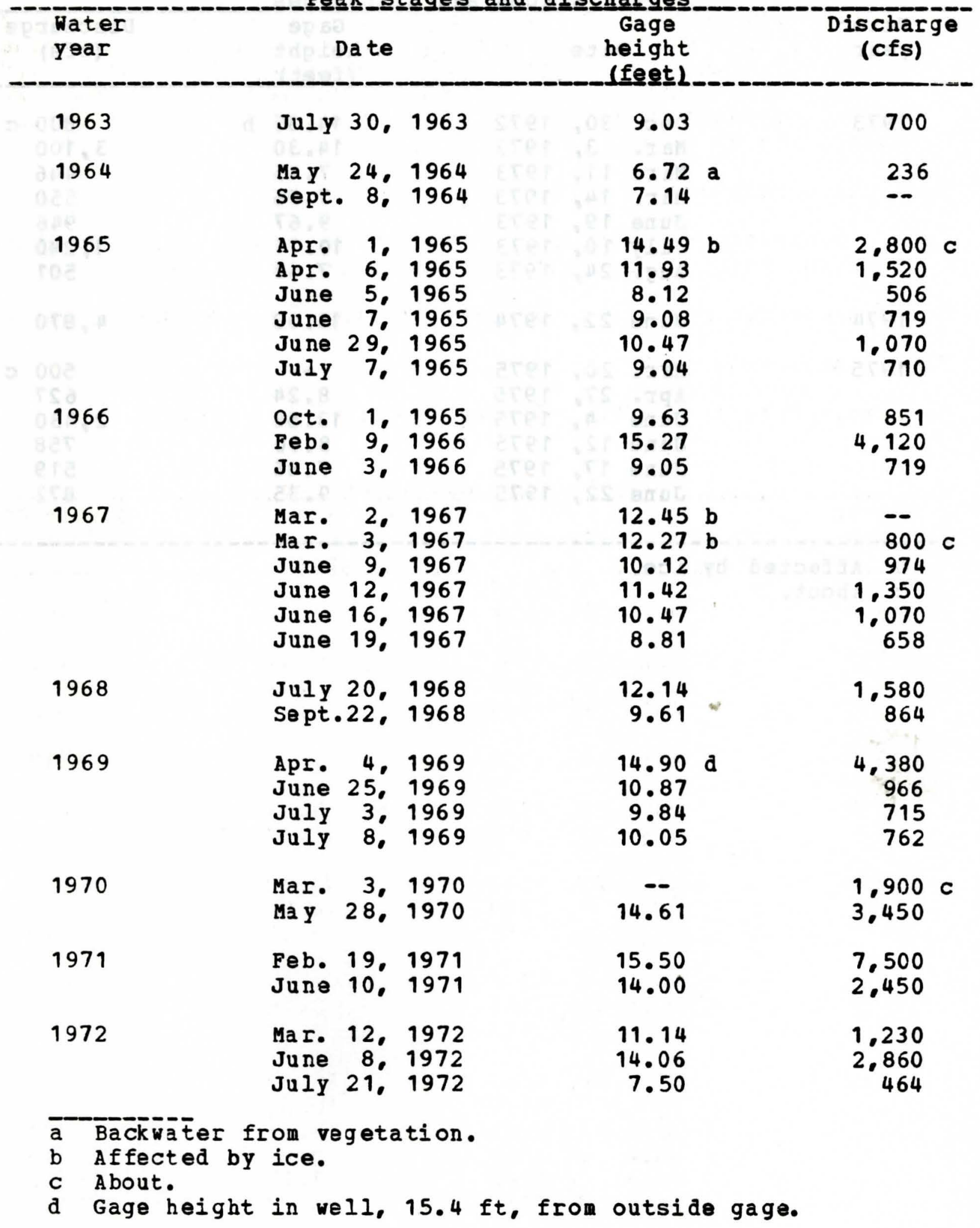


06-6003.00 West Branch Floyd River near Struble, Iowa--(Continued)

Peak stages and discharges

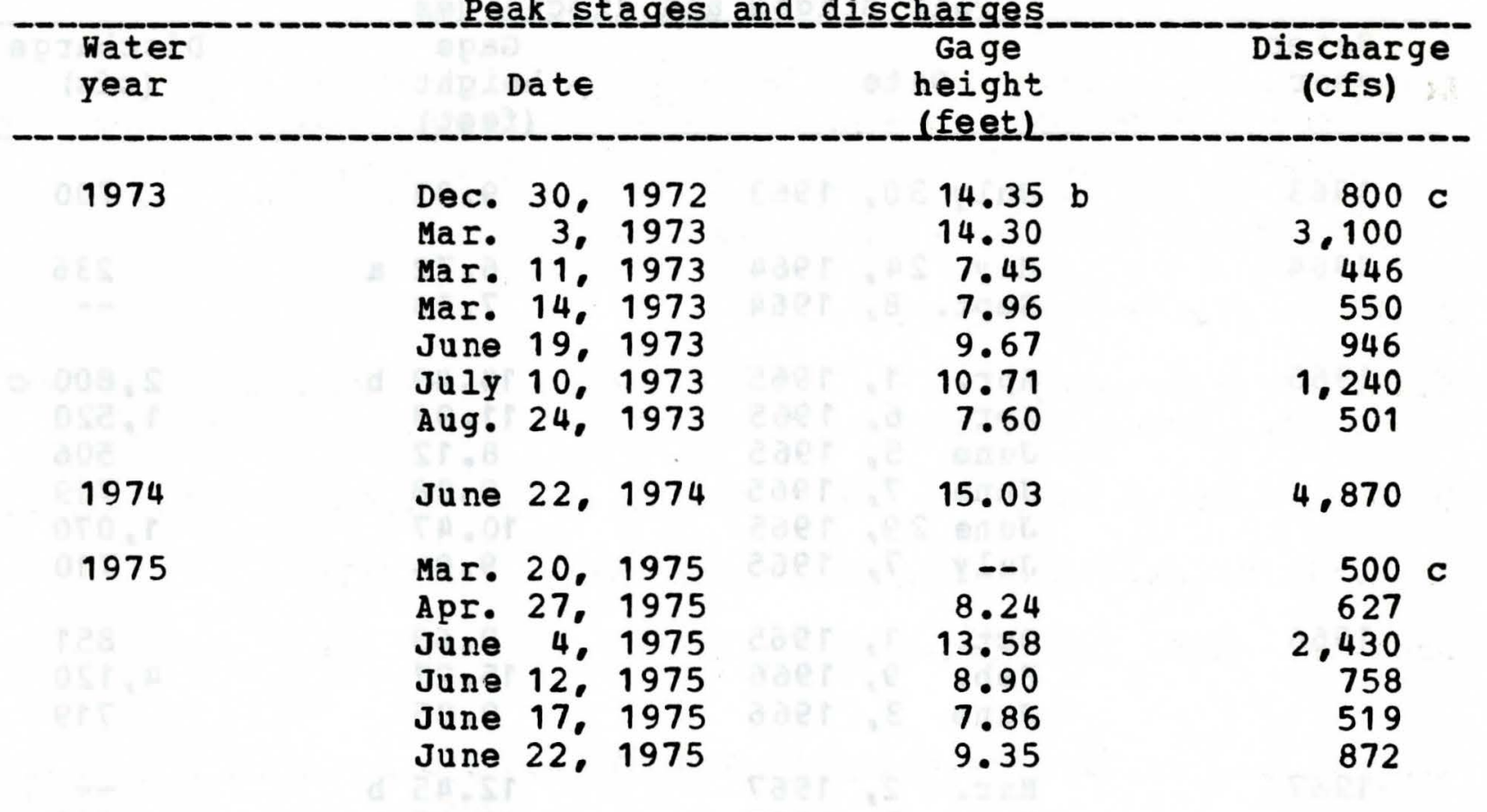

b Affected by ice.

c About. 
05-4485.00 West Branch Iowa River near Klemme. Iowa (Discontinued Sept. 30, 1958)

Location.--Lat $42057 \cdot 50 "$ " long $93042 \cdot 20^{\prime \prime}$, in NE1/4 NW1/4 sec.17, T. 94 N.. R. 24 W.. Hancock County, on downstream side of highway bridge 6 miles southwest of Klemme and 12.4 miles upstream from confluence with East Branch Iowa River, and at mile 338.9 above mouth of Iowa River.

Drainage area.--112 sq miles.

Gage.--Nonrecording. Datum of gage is $1,180.83 \mathrm{ft}$ above mean sea level. Prior to July 13. 1948, at datum 1.0 ft higher.

Stage-discharge relation.--Defined by current-meter measurements. Bankfull stage.--High banks; not subject to overflow.

Remarks.--Base for partial-duration series, 500 cfs.

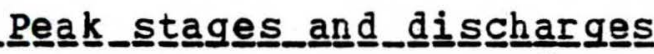

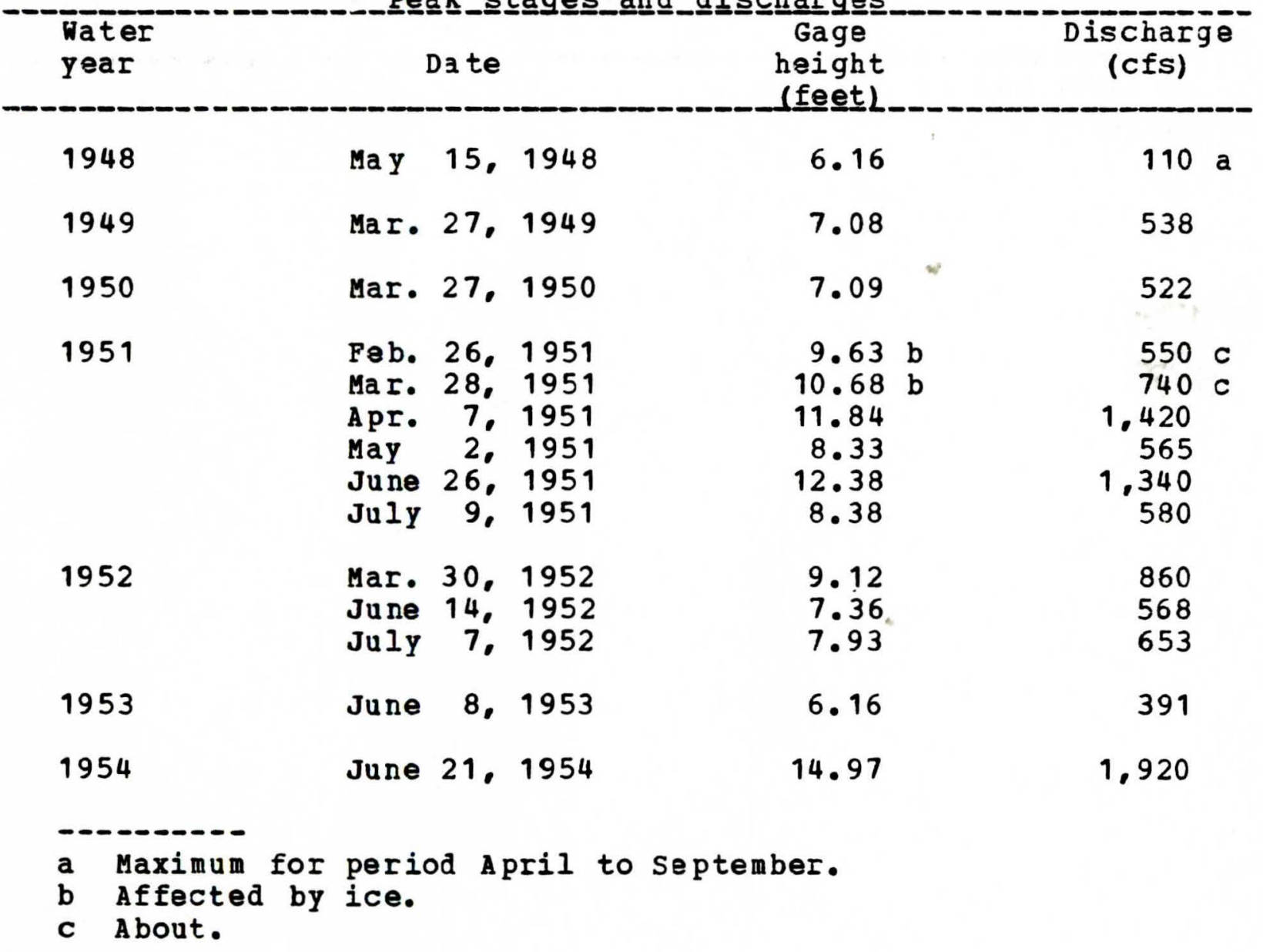


05-4485.00 West Branch Iowa River near Klemme, Iowa--(Continued) Pea

\begin{tabular}{|c|c|c|c|}
\hline $\begin{array}{l}\text { Hater } \\
\text { year }\end{array}$ & Date & $\begin{array}{c}\text { Gage } \\
\text { height } \\
\text { ffeet }\end{array}$ & $\begin{array}{l}\text { Discharge } \\
\text { (cfs) }\end{array}$ \\
\hline 1955 & July 6, 1955 & 5.9 & 349 \\
\hline 1956 & Mar. 27. 1956 & $4.40 \mathrm{~b}$ & $130 \mathrm{c}$ \\
\hline 1957 & May 30, 1957 & 5.15 & 272 \\
\hline 1958 & June 4, 1958 & 5.35 & 256 \\
\hline Disco & pt. 30,1958 & & \\
\hline
\end{tabular}


05-4589.00 West Fork Cedar River at Finchford. Iowa

Location.--Iat $420370^{\prime \prime \prime}$ long $92032 \cdot 24 "$ ", in sw1/4 SE1/4 sec. 6 , T. 90 N.. R. 14 W.. Black Hawk County, on left bank $100 \mathrm{ft}$ downstream from bridge on county highway C55 at Finchford, 3.2 miles upstream from $S$ hell Rock River, and 5.0 miles upstream from mouth.

Drainage area.--846 sq miles.

Gage.-Water-stage recorder. Datum of gage is $867.54 \mathrm{ft}$ above mean sea level (revised). prior to June 10, 1955, nonrecording gage at same site and datum.

Stage-discharge relation.--Defined by current-meter measurements.

Flood stage.--12 feet.

Remarks.--Base for partial-duration series, 2,500 cfs. An athorized diversion is made into Big Marsh. 16 miles upstream from gage, of about 2,100 acre-ft each year between sept. 1 and Nov. 15. Net effect on daily flows at gage is unknown.

Pea k__stages_and_di

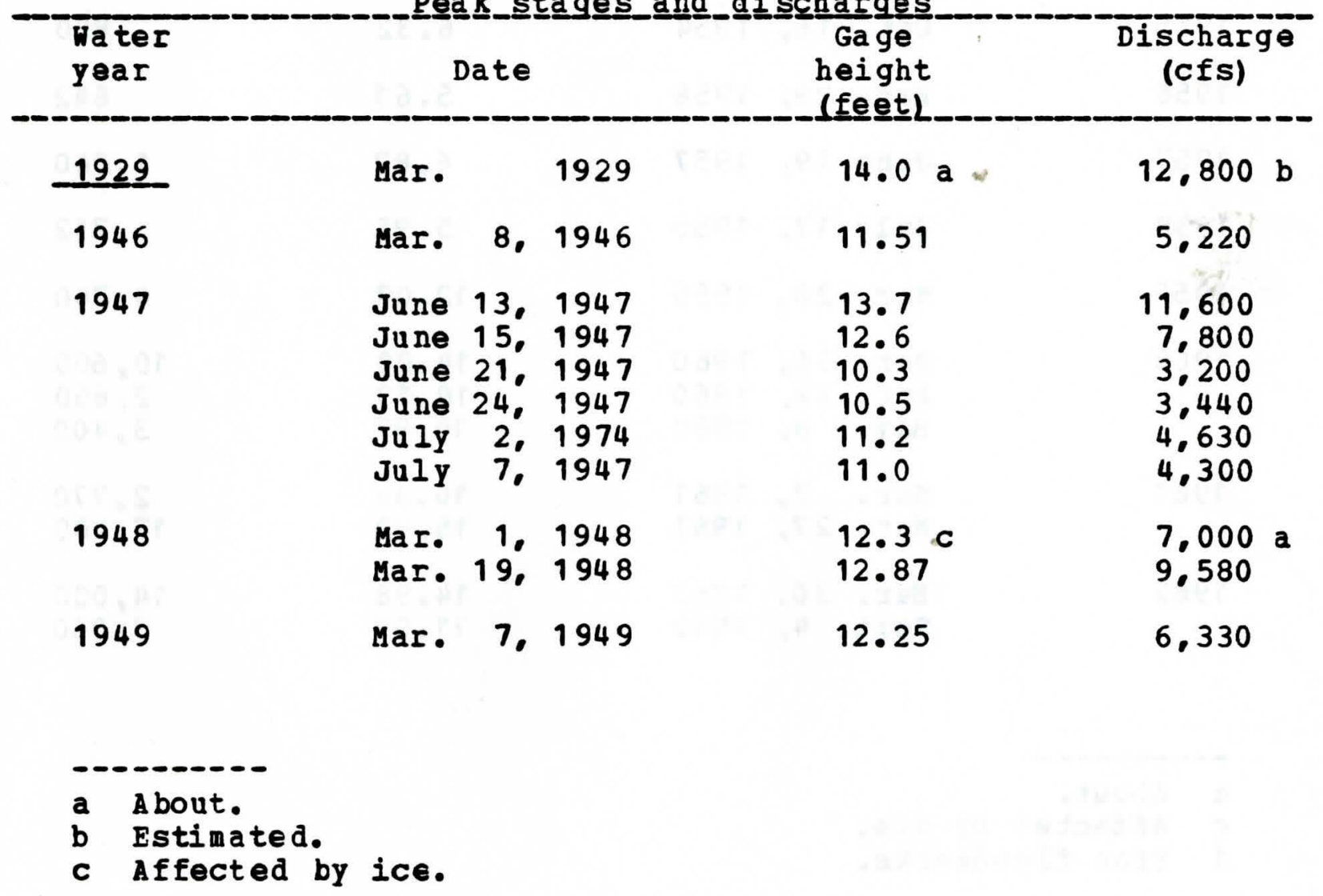


05-4589.00 West Fork Cedar River at Finchford. Iowa-- (Continued)

Peak

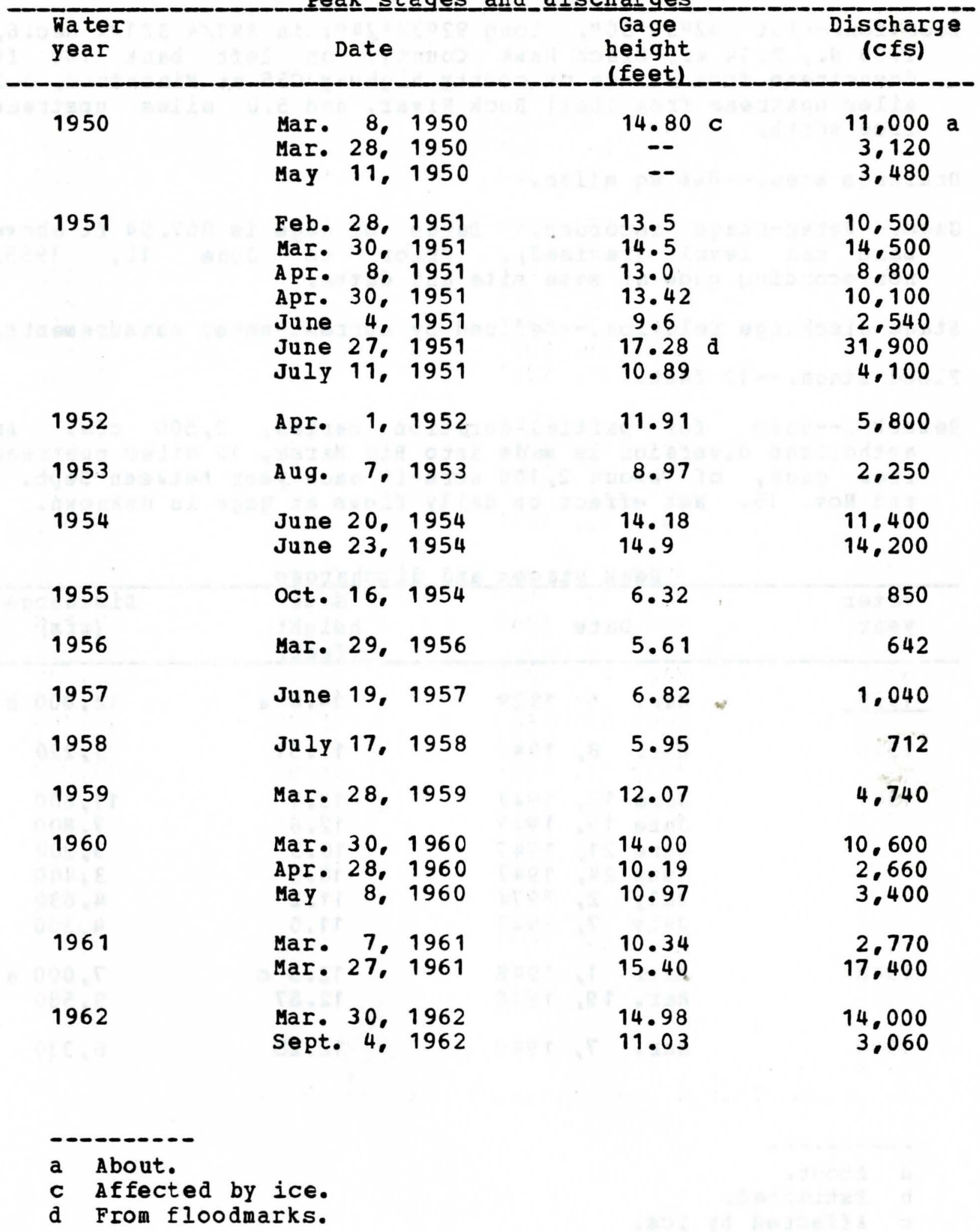


05-4589.00 West Fork Cedar River at Finchford, Iowa--(Continued)

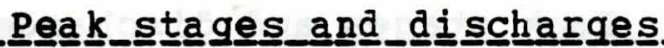

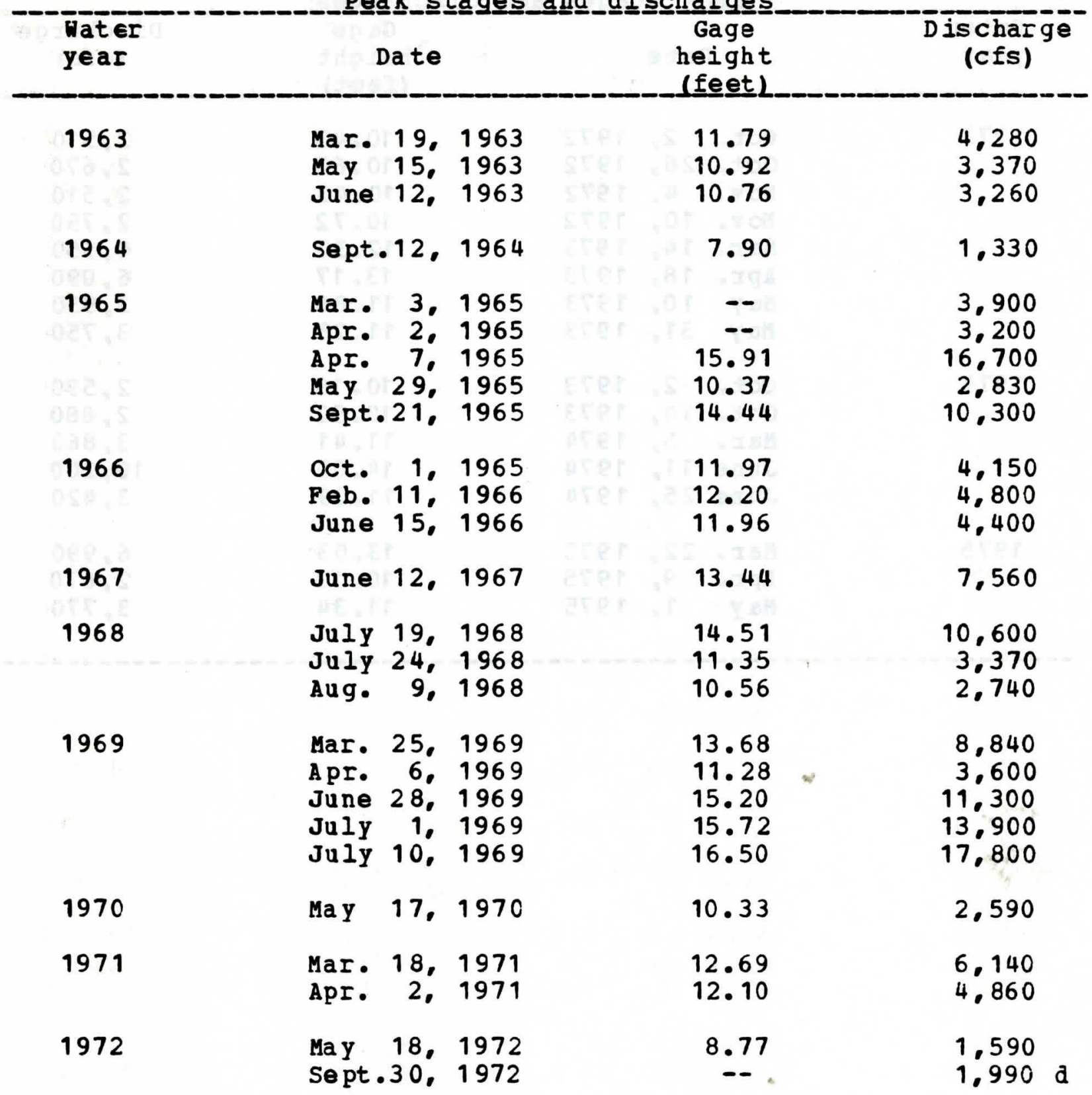

d Stage rising, peak occurred oct. 2, 1972. 
05-4589.00 West Fork Cedar River at Finchford, Iowa--(Continued)

Peak﹎_stagaes_and_dis

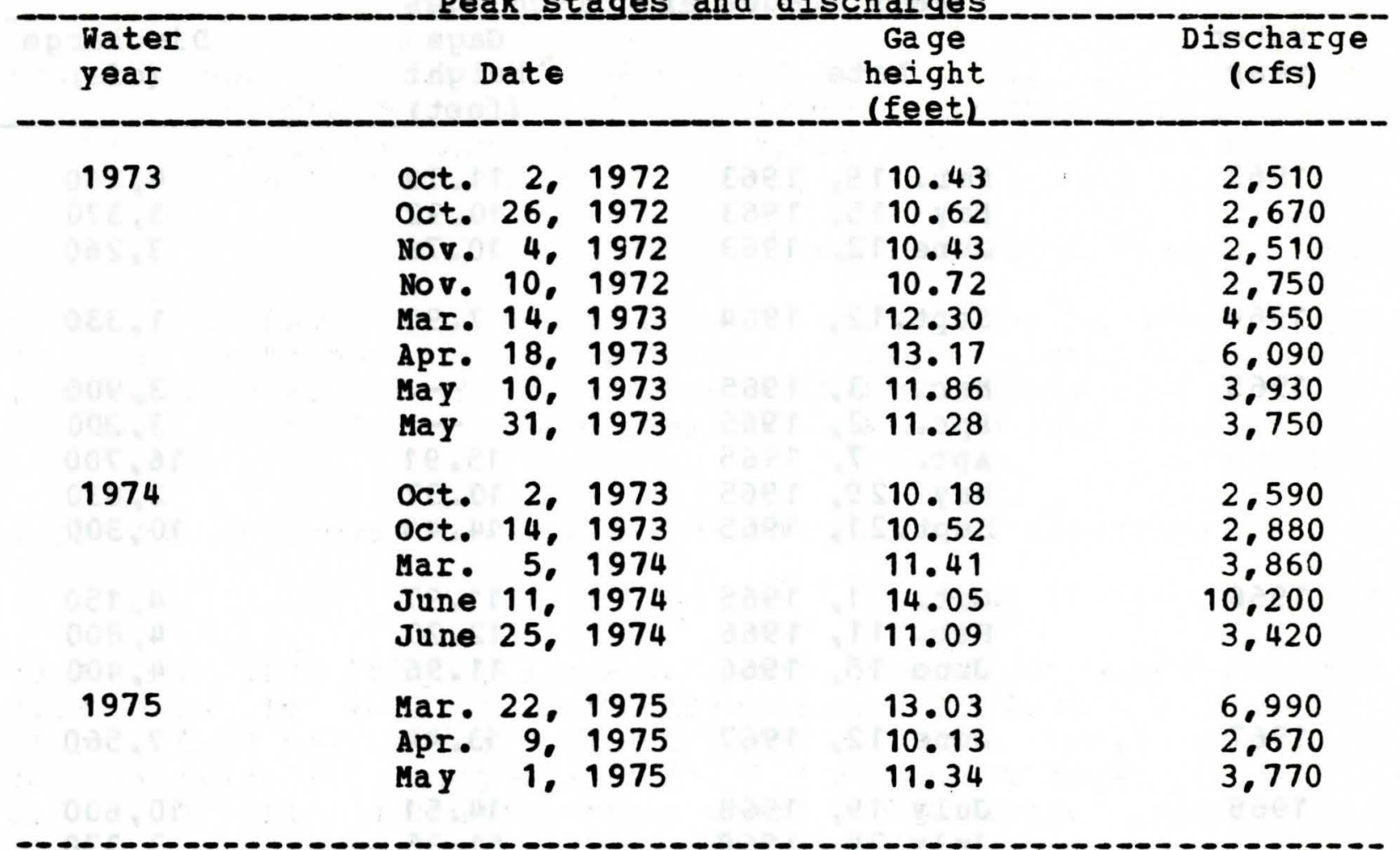


Location.--Lat $42013 \cdot 37 "$, Iong $96004 \cdot 40 "$, in Sw1/4 sec.27. T. 86 N.. R.45 W.. Woodbury County, on left bank at upstream side of State Highway 141 bridge, 1.0 mi east of Hornick, $9.2 \mathrm{mi}$ upstream from Wolf Creek, and $13.5 \mathrm{mi}$ north of Onawa.

Drainage area.--403 sq miles.

Gage.--Water-stage recorder. Datum of gage is 1,045.82 ft above mean sea level. Prior to June 16, 1959, nonrecording gage at site 3.0 miles upstream and June 16, 1959 to sept. 30, 1969. recording gage at site 2.2 miles upstream at datum 7.0 ft higher.

Stage-discharge relation.--Defined by current-meter measurements. Flood stage. -18 feet.

Remarks.--Base for partial-duratior. series, 1,800 cfs. West Fork ditch is a dredged channel which diverts flow of west Fork Little sioux River at Holly springs and carries it 5.5 miles south, thence southeast 6.5 miles to a point 1.2 miles west of Kennebec, where wolf Creek enters from the left. From this point, ditch roughly parallels little sioux River and becomes known as Monona-Harrison ditch.

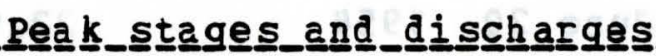

Water

year

Date

Gage height

Discharge

(feet)

(Cfs)

15.0

1.320

1939

Aug. 3, 1939

19.8

3.360

1940

June 4, 1940

19.0

2.580

1942

Sept.15, 1941

13.7

878

1943

June 30,1942

18.0

2.480

1944

JuIy 19, 1943

July 8, 1944

19.7

Aug. 1. 1944

19.0

3.590

1945

21.4

22.4
3.050

5.250

6.600 
06-6020.00 West Fork ditch at Hornick, Iowa-- (Continued)

Pea

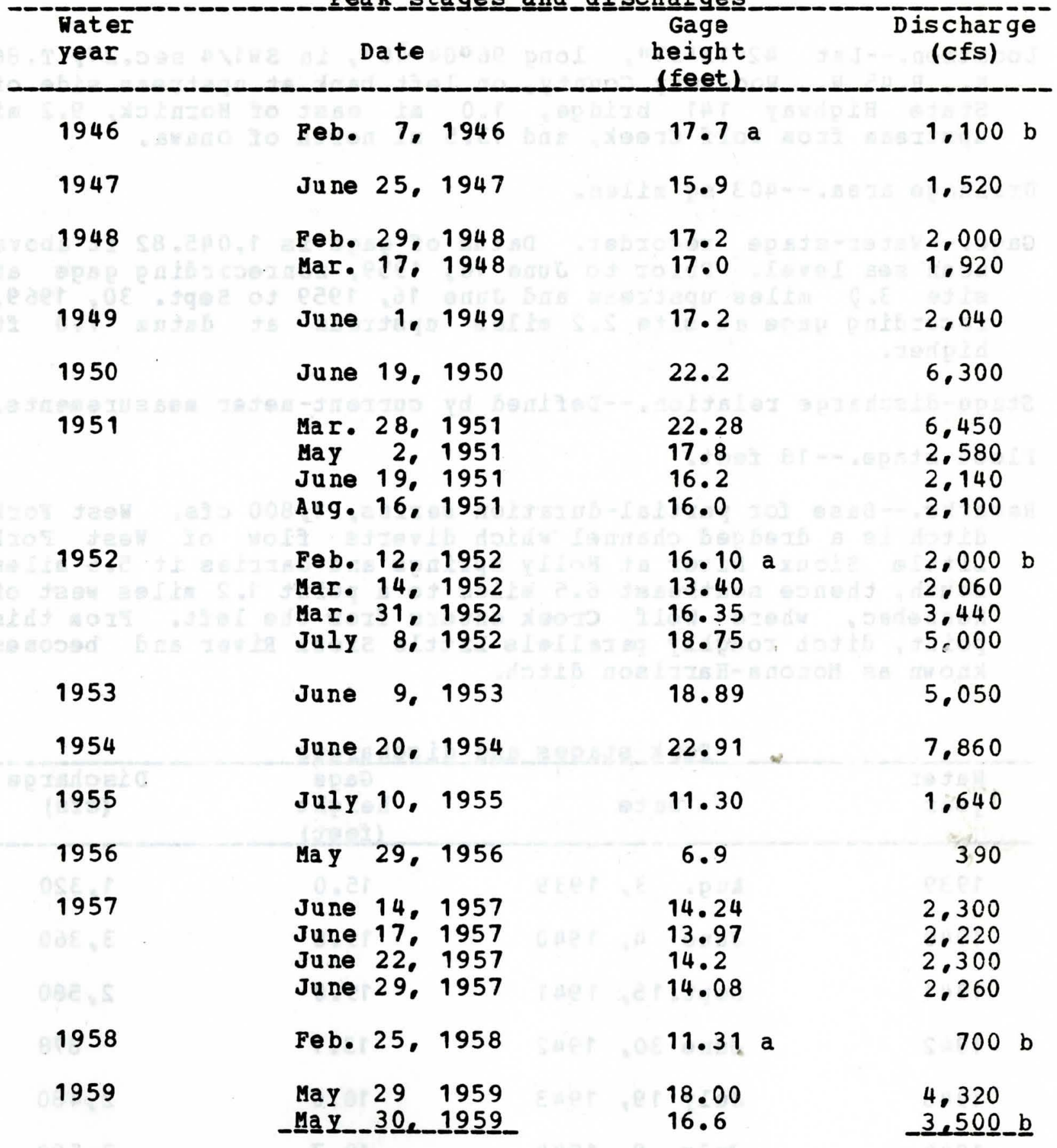

a Affected by ice.

b About. 
06-6020.00 West Fork ditch at Hornick, Iowa--(Continued)

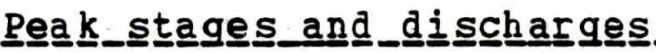

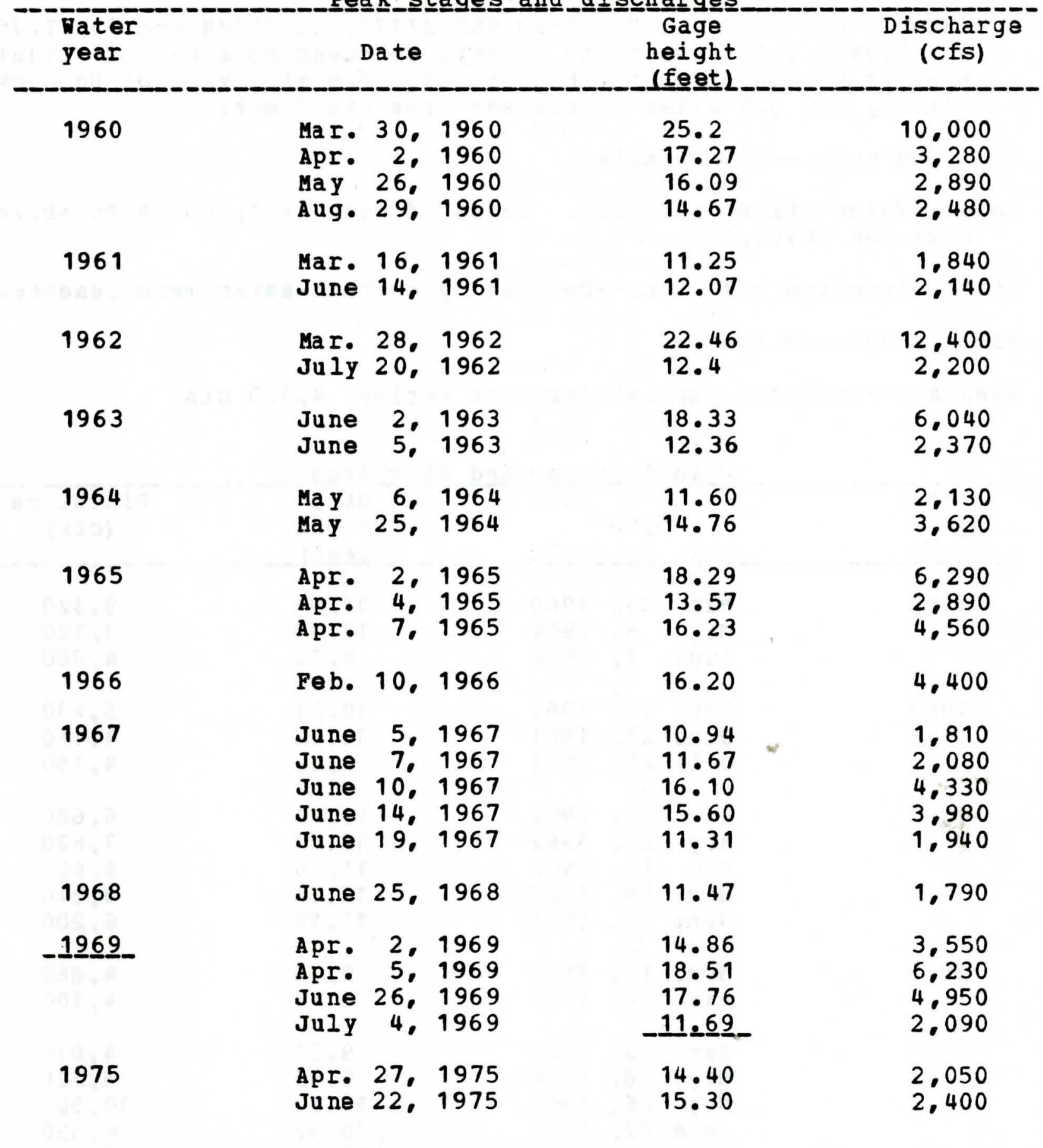


Location.--Iat $41023 \cdot 24 "$ " long $95022 \cdot 17 "$, in NE1/4 sec.18, T. 76 N. R.39 W. Pottawattamie county, on downstream end cf right pier of bridge on county highway G30, 0.6 mile west of Hancock school, and 3.0 miles downstream from Jim Creek.

Drainage area.--609 sq miles.

Gage.--Water-stage recorder. Datum of gage is $1,085.94 \mathrm{ft}$ above mean sea level.

Stage-discharge relation.--Defined by current-meter measurements. Flood stage. -8 feet.

Remarks.--Base for partial-duration series, 4,000 cfs.

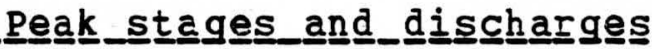

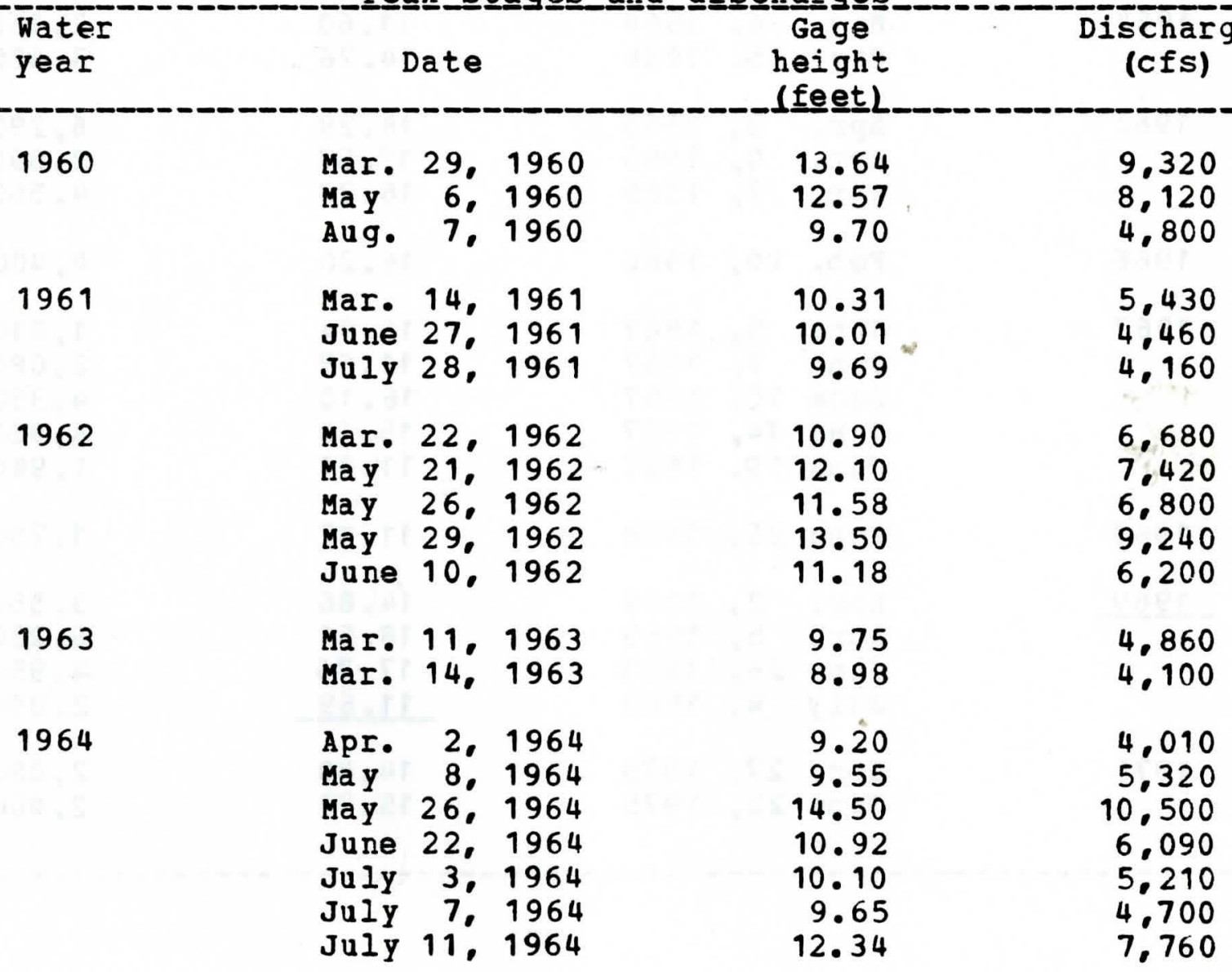


06-8074.10 West Nishnabotna River at Hancock, Iowa--(Continued)

Peak stages and discharges

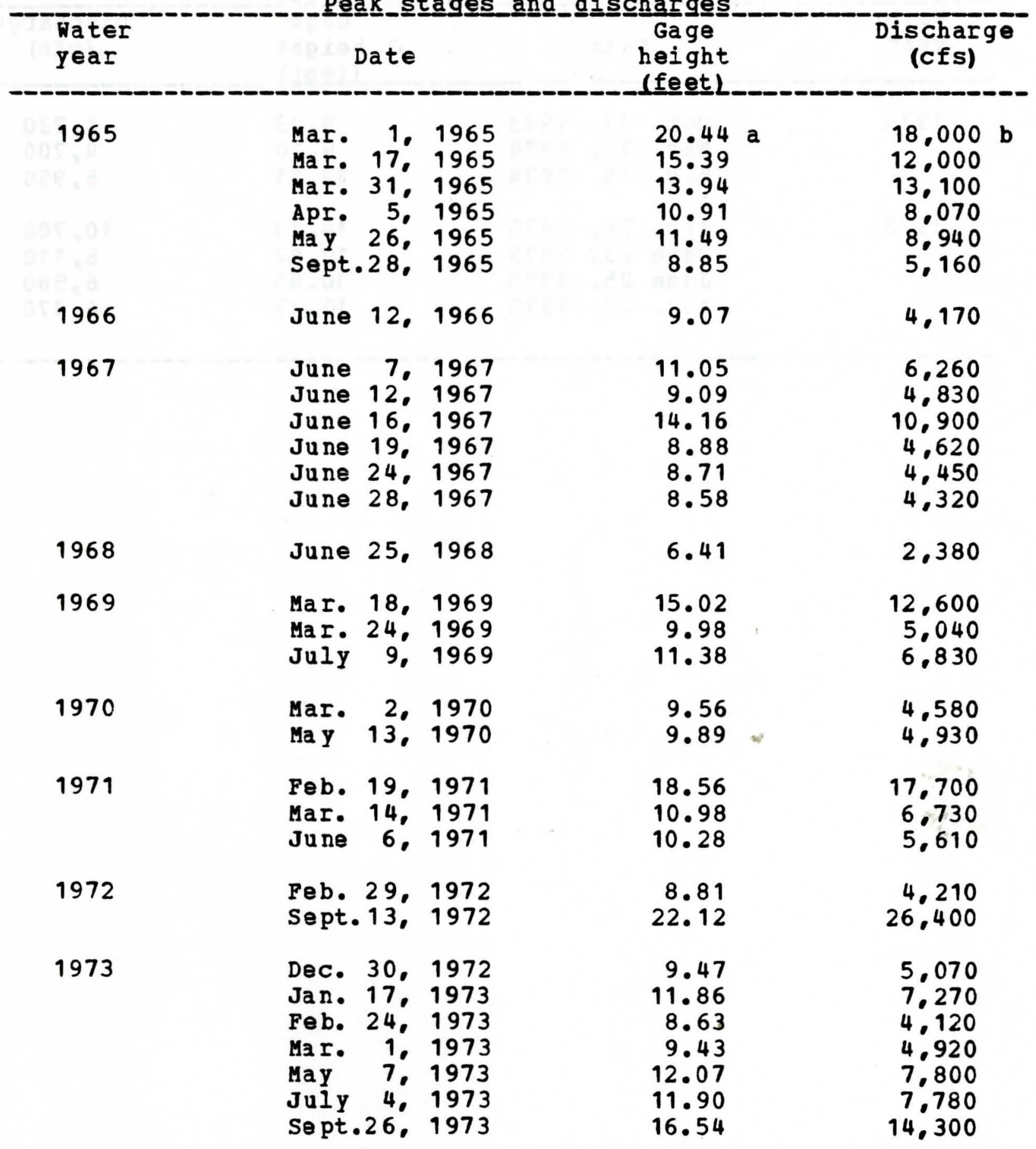

a Affected by ice.

b About. 
06-8074. 10 West Nishnabotna River at Hancock, Iowa--(Continued)

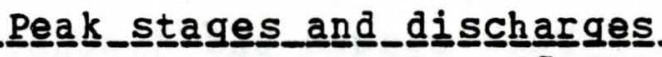

\begin{tabular}{|c|c|c|c|}
\hline $\begin{array}{l}\text { Water } \\
\text { year }\end{array}$ & Date & $\begin{array}{l}\text { Gage } \\
\text { height } \\
\text { (feestl. }\end{array}$ & $\begin{array}{l}\text { Discharge } \\
\text { (cfs) }\end{array}$ \\
\hline 1974 & 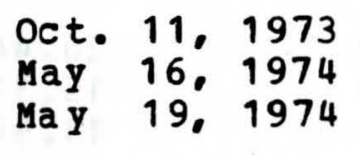 & $\begin{array}{r}9.13 \\
9.10 \\
12.81\end{array}$ & $\begin{array}{l}4,730 \\
4,700 \\
8,950\end{array}$ \\
\hline 1975 & $\begin{array}{l}\text { Apr. 28, } 1975 \\
\text { June 23, } 1975 \\
\text { June 25, } 1975 \\
\text { Aug. } 29,1975\end{array}$ & $\begin{array}{l}14 \cdot 13 \\
10.42 \\
10.85 \\
10.47\end{array}$ & $\begin{array}{r}10.700 \\
6.110 \\
6.580 \\
6.170\end{array}$ \\
\hline
\end{tabular}


Location.--Lat $40052 \cdot 23$ ", long $95034 \cdot 48 "$, in NE1/4 NE1/4 seC.17, T. 70 N., R. 41 W.. Fremont County, on right bank on downstream side of bridge on state Highway $184,0.3$ mile downstream from Deer Creek, $0.5 \mathrm{mile}$ west of Randolph, and 16.2 miles upstream from confluence with East Nishnabotna River.

Drainage area.--1,326 sq miles.

Gage.-Water-stage recorder. Datum of gage is $932.99 \mathrm{ft}$ above mean sea level, unadjusted. Prior to Aug. $26,1955$. nonrecording gage and June 30 , 1949, to Aug. 25, 1955, supplementary water-stage recorder, operating above gage height $8.4 \mathrm{ft}$ at same site and datum.

Stage-discharge relation.--Defined by current-meter measurements. Flood stage.--19 feet.

Remarks.--Base for partial-duration series, $6.500 \mathrm{cfs}$.

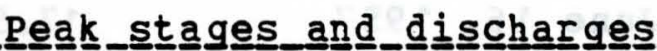

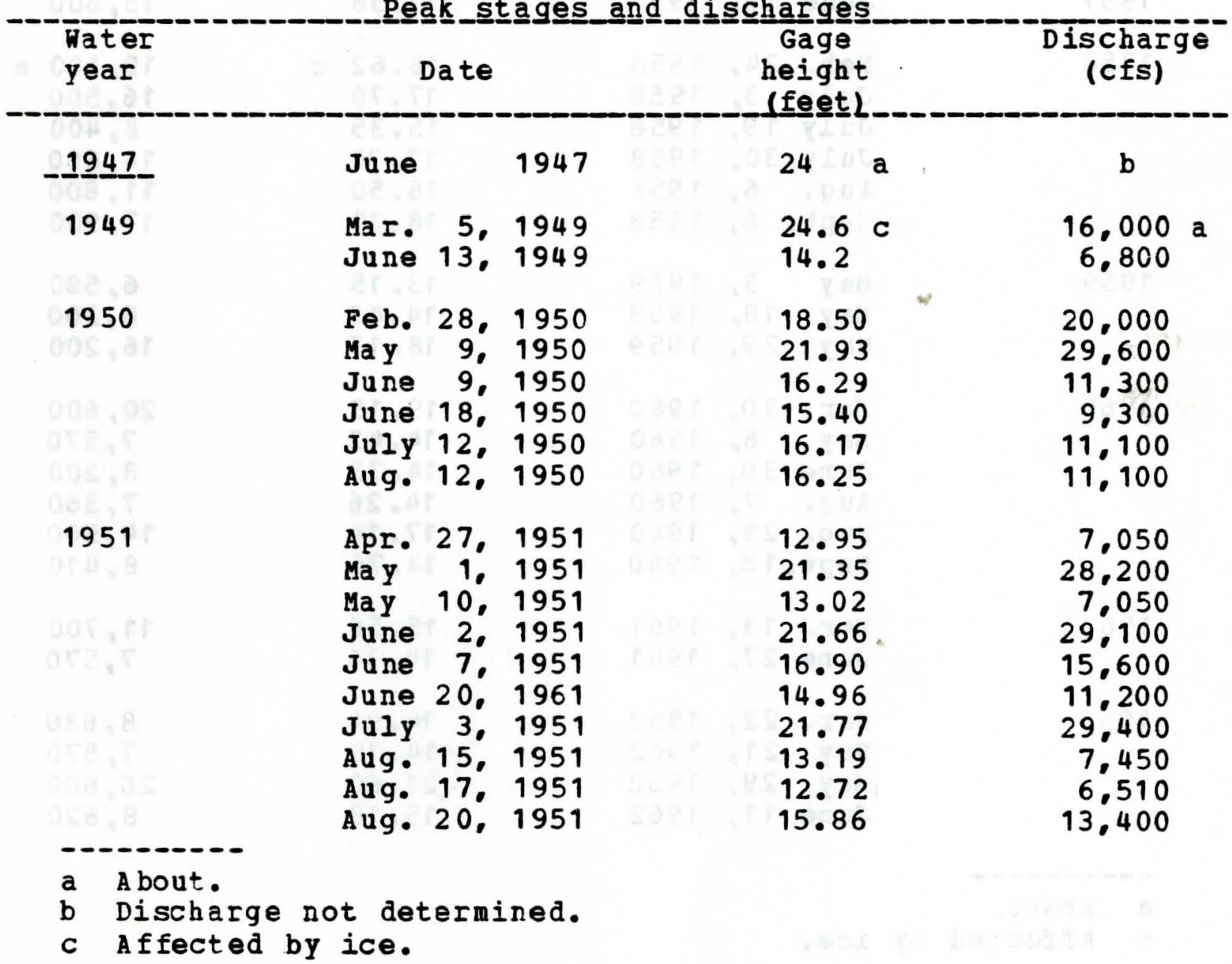


06-8085.00 West Nishnabotna River at Randolph. Iowa--(Continued)

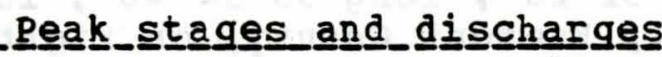

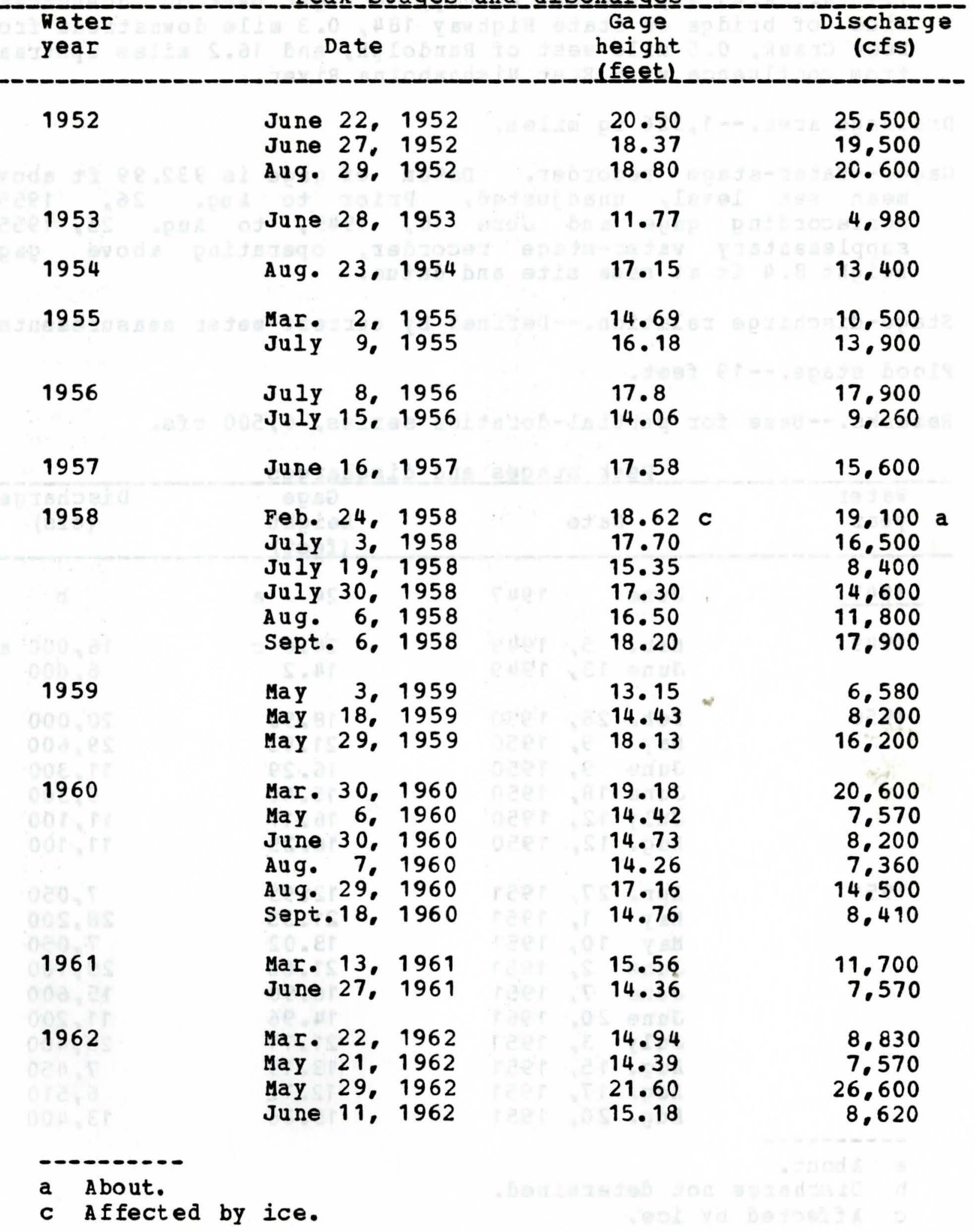


06-8085.00 West $\mathrm{N}$ ishnabot na River at Randolph, Iowa--(Continued)

Pea

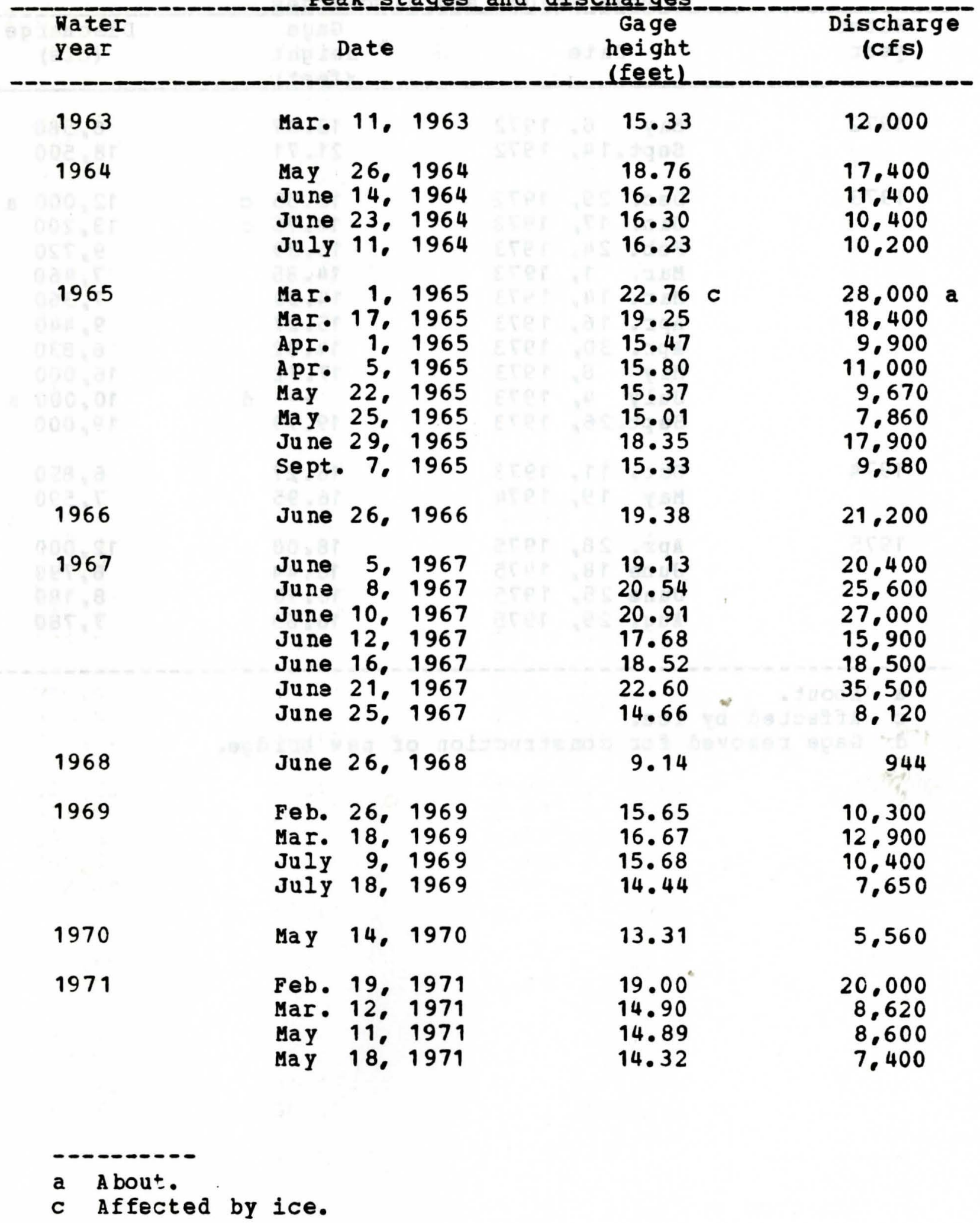


06-8085.00 West Nishnabotna River at Randolph, Iowa--(Continued)

Peaㅡㄴㅡ_stagges_annd di

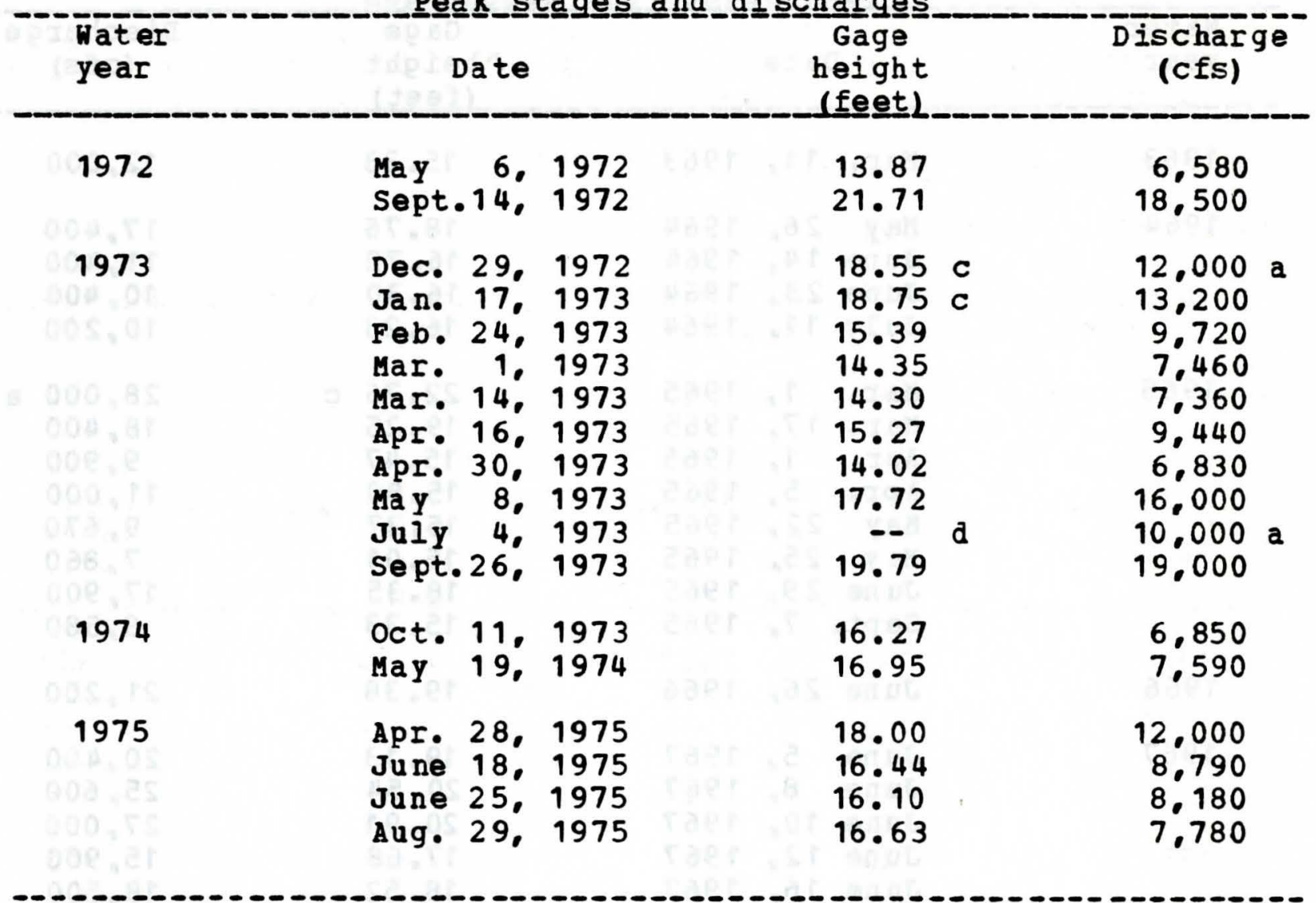

a About.

c Affected by ice.

d Gage removed for construction of new bridge. 


\section{5-3884.00 Wexford Creek near Harpers Ferry. Iowa}

Loction.--Lat $43^{\circ} 16^{\prime}$, long $91^{\circ} 08^{\prime}$, in SE1/4 sec. 25, T. 98 N.. R.3 W. Allamakee County, at bridge, 5 miles north of Harpers Ferry.

Drainage area. $--11.9 \mathrm{sq}$ miles.

Gage.--Crest-stage gage.

Stage-discharge relation.--Defined by current-meter measurements and step-backwater computations.

Remarks.--only annual peaks are shown.

Peak_s_tages_and

\begin{tabular}{|c|c|c|c|}
\hline $\begin{array}{l}\text { Water } \\
\text { year }\end{array}$ & Date & $\begin{array}{l}\text { Gage } \\
\text { height } \\
\text { (feet) }\end{array}$ & $\begin{array}{c}\text { Discharge } \\
\text { (cfs) }\end{array}$ \\
\hline 1953 & July 26,1953 & 4.91 & 659 \\
\hline 1954 & June 20,1954 & 4.90 & 655 \\
\hline 1955 & July 8,1955 & 6.29 & 1.490 \\
\hline 1956 & May 6,1956 & 5.00 & 695 \\
\hline 1957 & June 17, 1957 & 5.11 & 740 \\
\hline 1958 & -- & a & $<450$ \\
\hline 1959 & May 31, 1959 & 4.50 & 525 \\
\hline 1960 & Mar. 27,1960 & 6.40 & 1,590 \\
\hline 1961 & Se pt.30, 1961 & 6.82 & 2,030 \\
\hline 1962 & July 2, 1962 & 7.03 & 2.290 \\
\hline 1963 & -- & $\mathrm{a}$ & $<450$ \\
\hline 1964 & -- & a & $<450$ \\
\hline 1965 & Sept. 7, 1965 & 5.88 & 1,170 \\
\hline 1966 & Feb. 9. 1966 & 6.10 & 1,330 \\
\hline
\end{tabular}

a Peak stage did not reach bottom of gage. 
05-3884.00 Wexford Creek near Harpers Ferry. Iowa--(Continued)

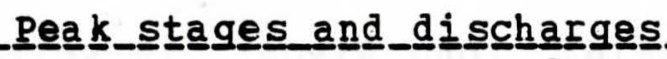

\begin{tabular}{|c|c|c|c|c|}
\hline $\begin{array}{l}\text { Water } \\
\text { year }\end{array}$ & Date & & $\begin{array}{r}\text { Gage } \\
\text { height } \\
\text { (feet) }\end{array}$ & $\begin{array}{c}\text { Discharge } \\
\text { (cfs) }\end{array}$ \\
\hline 1967 & -- & & a & $<450$ \\
\hline 1968 & June 25. & 1968 & 7.88 & 3.700 \\
\hline 1969 & - & & a & b \\
\hline 1970 & July 29. & 1970 & 6.61 & 1.350 \\
\hline 1971 & -- & & a & b \\
\hline 1972 & Mar. 14. & 1972 & 5.09 & b \\
\hline 1973 & Sept. 2. & 1973 & 6.96 & 1.680 \\
\hline 1974 & -- & & a & $\mathbf{b}$ \\
\hline 1975 & $-\infty$ & & $a$ & b \\
\hline
\end{tabular}

a Peak stage did not reach bottom of gage.

b Discharge not determined. 
Location.-- Lat $41014 \cdot 41$ ", long $93016 \cdot 08 "$, in NW1/4 NW1/4 sec.3. T.74 N.. R. 21 H... Marion County, on left bank $15 \mathrm{ft}$ downstream from bridge on county highway. 0.5 mile downstream from Kirk Branch, and 1.7 miles northwest of Dallas.

Drainage area.--342 sq miles.

Gage.-- Water-stage recorder. Datum of gage is $759.12 \mathrm{ft}$ above mean sea level. (Corps of Engineers bench mark).

stage-discharge relation.--Defined by current-meter measurements. Remarks.--Base for partial-duration series, 3,000 cfs.

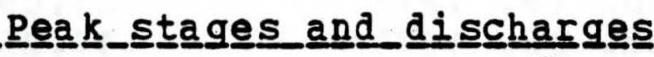

\begin{tabular}{|c|c|c|c|c|c|c|}
\hline $\begin{array}{l}\text { Water } \\
\text { year }\end{array}$ & & Date & & $\begin{array}{l}\text { Gage } \\
\text { height } \\
\text { feet }\end{array}$ & & $\begin{array}{c}\text { Discharge } \\
\text { (cfs) }\end{array}$ \\
\hline 1962 & June & 11. & 1962 & 28.87 & a & $12.000 \mathrm{~b}$ \\
\hline 1963 & $\begin{array}{l}\text { Mar. } \\
\text { Mar. }\end{array}$ & 19. & $\begin{array}{l}1963 \\
1963\end{array}$ & $\begin{array}{l}18.95 \\
21.40\end{array}$ & & $\begin{array}{l}3.500 \\
5.550\end{array}$ \\
\hline 1964 & $\begin{array}{l}\text { May } \\
\text { June } \\
\text { June }\end{array}$ & $\begin{array}{r}8 . \\
15 . \\
22\end{array}$ & $\begin{array}{l}1964 \\
1964 \\
1964\end{array}$ & $\begin{array}{l}17.24 \\
18.40 \\
19.74\end{array}$ & & $\begin{array}{l}3.490 \\
3.580 \\
4.200\end{array}$ \\
\hline 1965 & $\begin{array}{l}\text { Mar. } \\
\text { Apr. } \\
\text { Apr. } \\
\text { Apr. } \\
\text { Apr. } \\
\text { Se pt }\end{array}$ & $\begin{array}{r}17 . \\
5 . \\
8 . \\
11 . \\
25 . \\
21 .\end{array}$ & $\begin{array}{l}1965 \\
1965 \\
1965 \\
1965 \\
1965 \\
1965\end{array}$ & $\begin{array}{c}22.49 \\
19.44 \\
16.43 \\
16.18 \\
16.15 \\
20.57\end{array}$ & & $\begin{array}{l}6.640 \\
4.870 \\
3.360 \\
3.240 \\
3.400 \\
5.490\end{array}$ \\
\hline 1966 & $\begin{array}{l}\text { Apr. } \\
\text { May } \\
\text { May } \\
\text { May }\end{array}$ & $\begin{array}{l}18 . \\
15 . \\
17 . \\
24\end{array}$ & $\begin{array}{l}1966 \\
1966 \\
1966 \\
1966\end{array}$ & $\begin{array}{l}17.29 \\
20.32 \\
21.24 \\
16.61\end{array}$ & & $\begin{array}{l}3,860 \\
5,350 \\
5,890 \\
3,530\end{array}$ \\
\hline 1967 & $\begin{array}{l}\text { June } \\
\text { June } \\
\text { June }\end{array}$ & $\begin{array}{l}12 . \\
16 . \\
23\end{array}$ & $\begin{array}{l}1967 \\
1967 \\
1967\end{array}$ & $\begin{array}{l}20.95 \\
17.74 \\
18.81\end{array}$ & & $\begin{array}{l}5.720 \\
4.020 \\
4.560\end{array}$ \\
\hline
\end{tabular}

a From floodmark. Flood of Jure 6, 1947 may have been slightly higher.

b About. 
05-4879.80 White Breast Creek near Dallas, Iowa--(Continued)

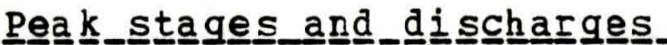

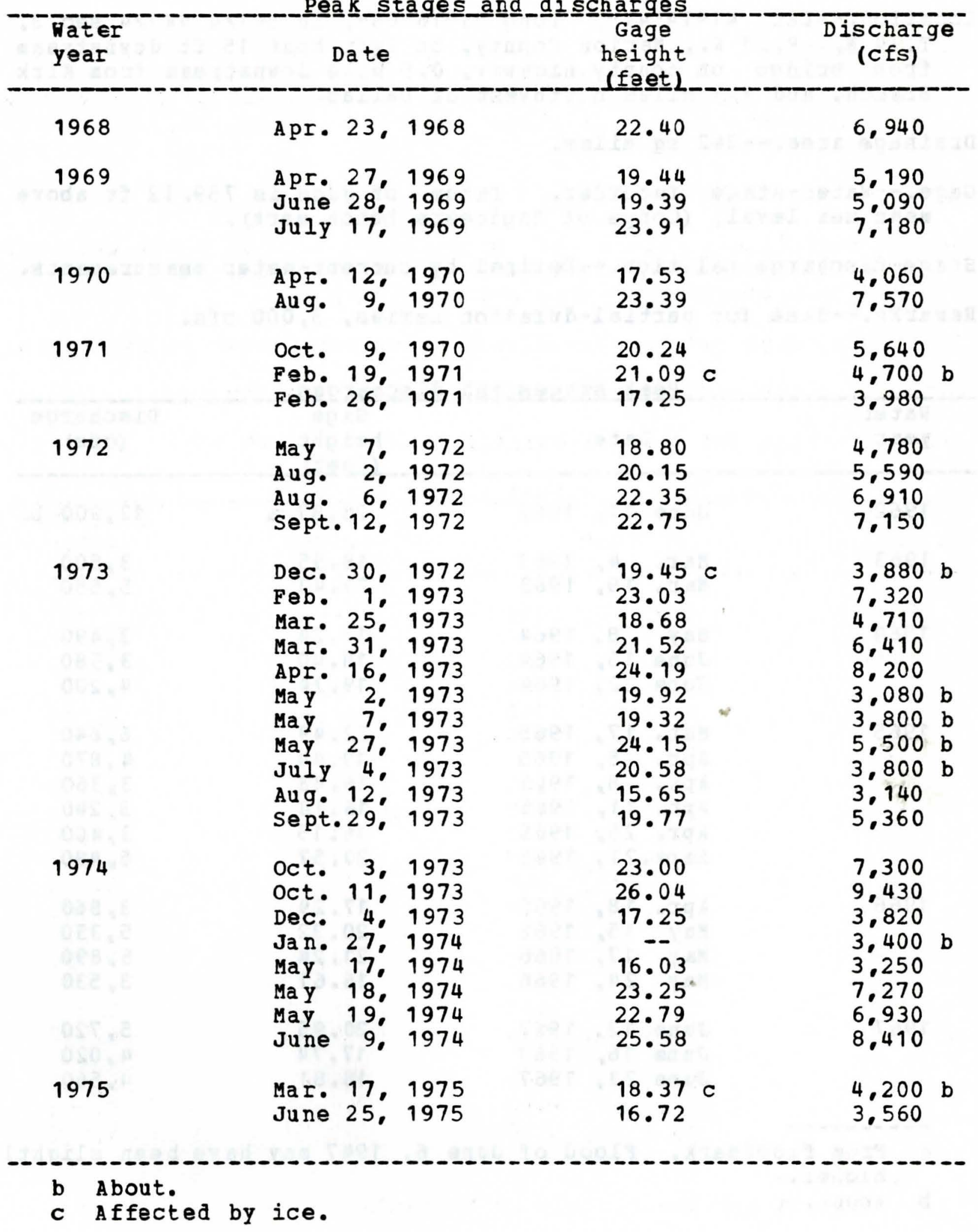




\section{5-4880.00 White Breast Creek near Knoxville, Iowa}

(Discontinued Sept. 30, 1962)

Location.--Lat $42019 \cdot 25^{\prime \prime}$, long $93^{\circ} 08155^{\prime \prime}$, in NE1/4 Sw1/4 sec.3, T.75 N., R.20 W.. Marian County, on right bank $10 \mathrm{ft}$ downstream from bridge on State Highway $92,1.1$ miles upstraam from Butcher Creek, 2.2 miles west of knoxville, and 11.1 miles upstream from mouth.

Drain ge area.--380 sq miles.

Gage.--Recording. Datum of gage is $734.73 \mathrm{ft}$ above mean sea level (Corps of Engineers bench mark). Prior to Feb. 16, 1949. nonrecording at same site and datum.

Stage-discharge relation.--Defined by current-meter measurements. Bankfull stage.--High banks are not subject to overflow.

Remarks.--Base for partial-duration series, 3,000 cfs.

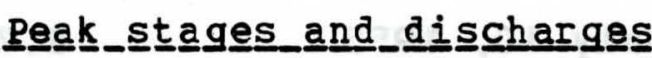

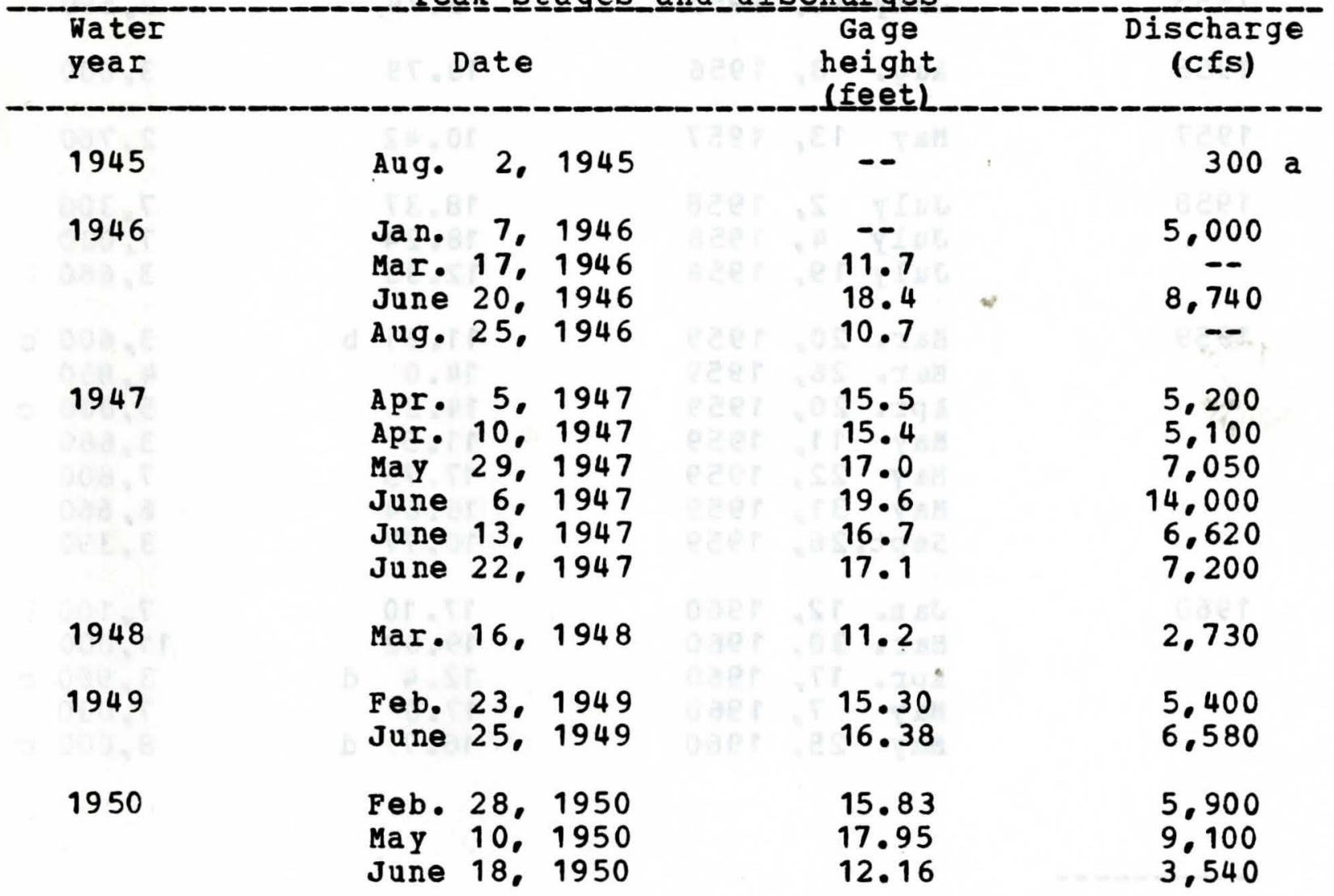

a Maximum for period July to September 1945. 
05-4880.00 White Breast Creek near Knoxville, Iowa--(Continued)

Pea $\underline{k}$ stagges_and_di

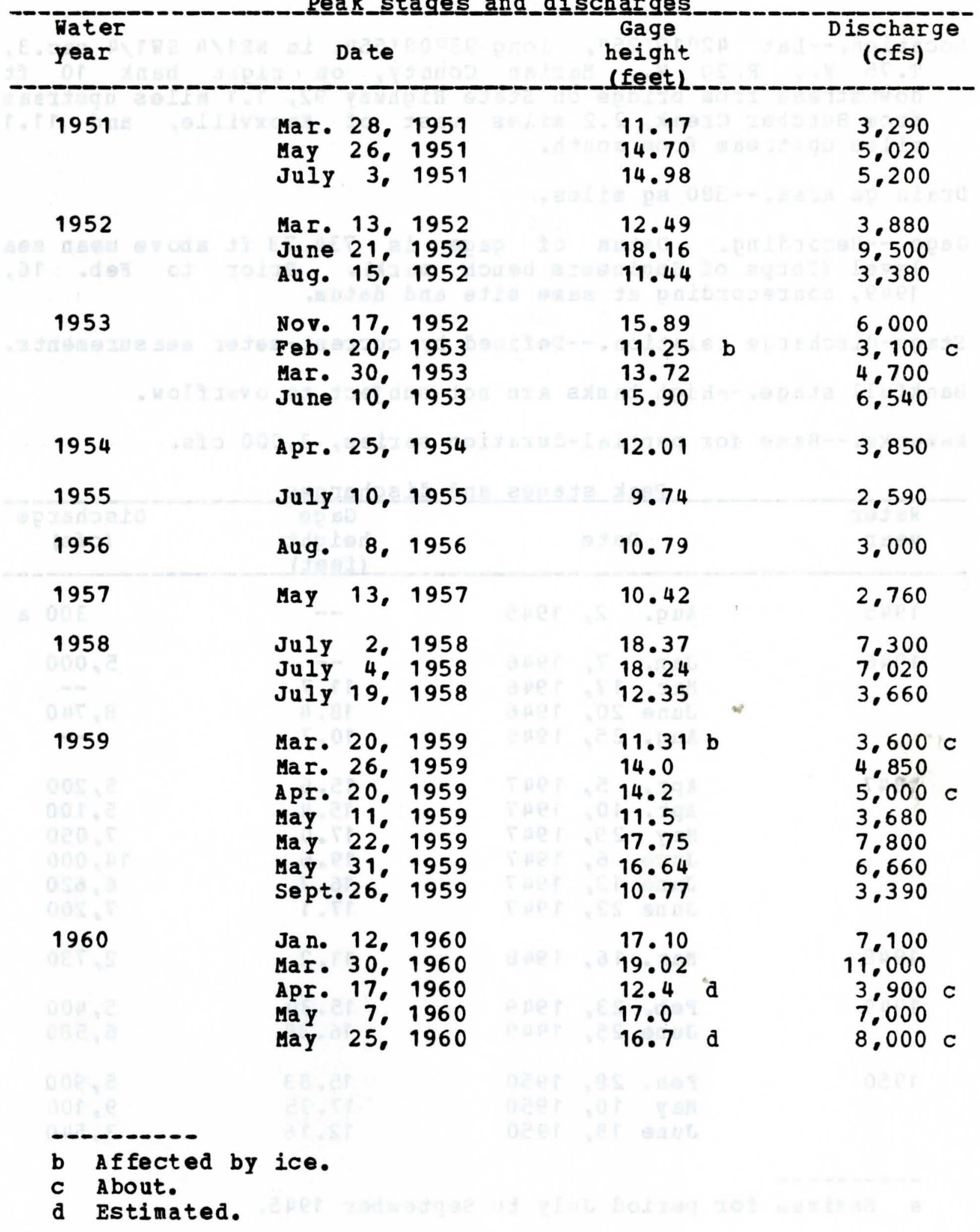


05-4880.00 White Breast Creek near Knoxville, Iowa--(Continued)

Peak﹎.stages and

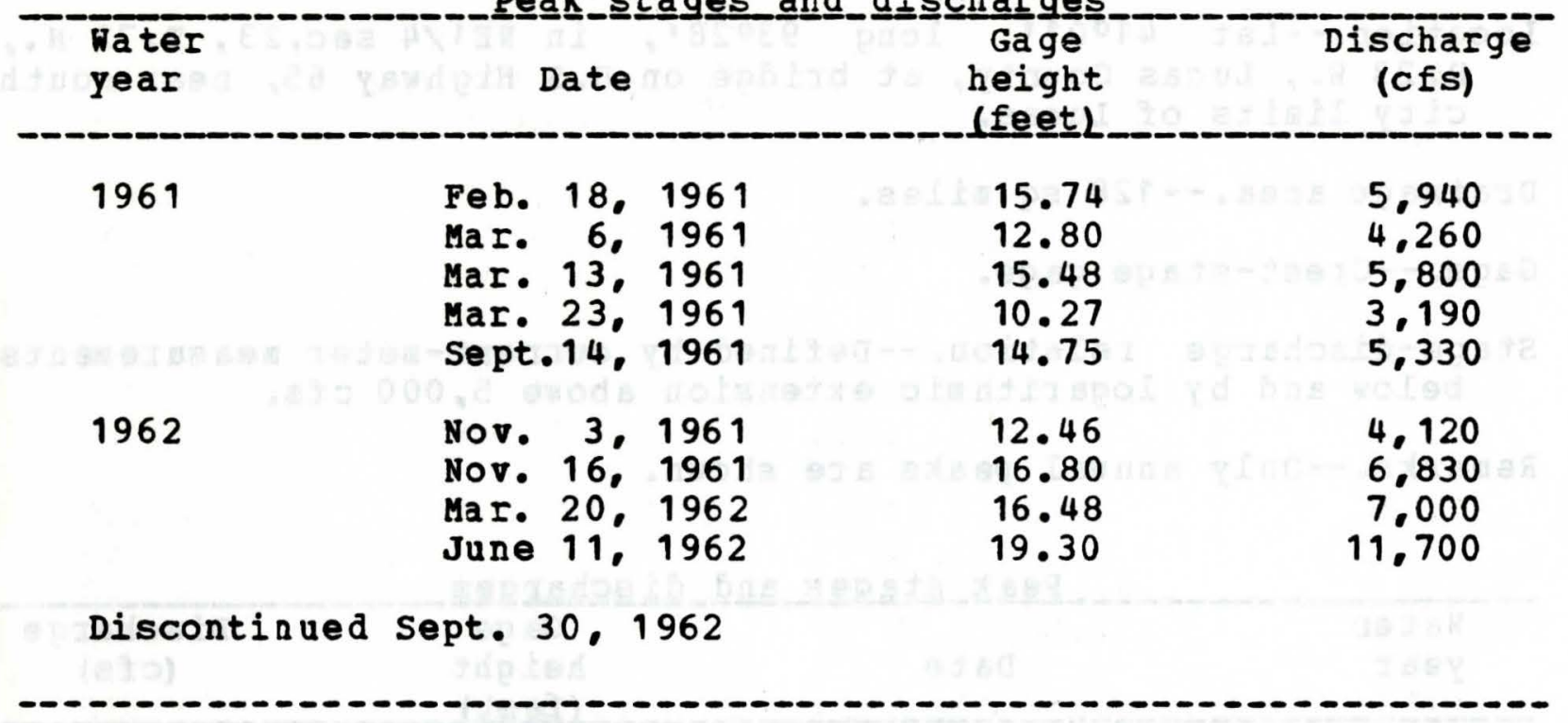


Location.--Lat $41001 \%$, long 930281 , in NE1/4 sec.23, T.72 N., R. $23 \%$. Lucas County, at bridge on 0.5 Highway 65 , near south city limits of Lucas.

Drainage area.--128 sq miles.

Gage.--Crest-stage gage.

Stage-discharge relation.--Defined by current-meter measurements below and by logarithmic extension above 5,000 cfs.

Remarks.--only annual peaks are shown.

Peㅡㅌㅡ_stages_s_and

\begin{tabular}{|c|c|c|c|}
\hline $\begin{array}{l}\text { Water } \\
\text { year }\end{array}$ & Date & $\begin{array}{l}\text { Ga ge } \\
\text { height } \\
\text { lfeet } \text { f }\end{array}$ & $\begin{array}{l}\text { Discharge } \\
\text { (cfs) }\end{array}$ \\
\hline 1953 & June 8,1953 & 15.15 & 3,420 \\
\hline 1954 & May 29, 1954 & 8.52 & 583 \\
\hline 1955 & July 8,1955 & 14.95 & 2.960 \\
\hline 1956 & -- & a & $<110$ \\
\hline 1957 & Apr. 4.1957 & 12.85 & 1,460 \\
\hline 1958 & July 30,1958 & 13.59 & 1.760 \\
\hline 1959 & May 22. 1959 & 16.98 & 11,900 \\
\hline 1960 & Mar. 29, 1960 & 15.80 & 5,600 \\
\hline 1961 & Sept.14. 1961 & 14.41 & 2.570 \\
\hline 1962 & Nov. 16, 1961 & 15.20 & 3.700 \\
\hline 1963 & Apr. 22, 1963 & $14 \cdot 10$ & 2,310 \\
\hline 1964 & June 20,1964 & 12.95 & 1.620 \\
\hline 1965 & May 8,1965 & 14.67 & 2,820 \\
\hline 1966 & Apr. 19, 1966 & 13.26 & 1.770 \\
\hline
\end{tabular}

a Peak stage did not reach bottom of gage. 
05-4878.00 White Breast Creek at Lucas, Iowa--(Continued)

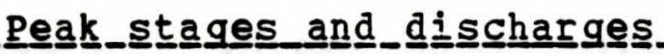

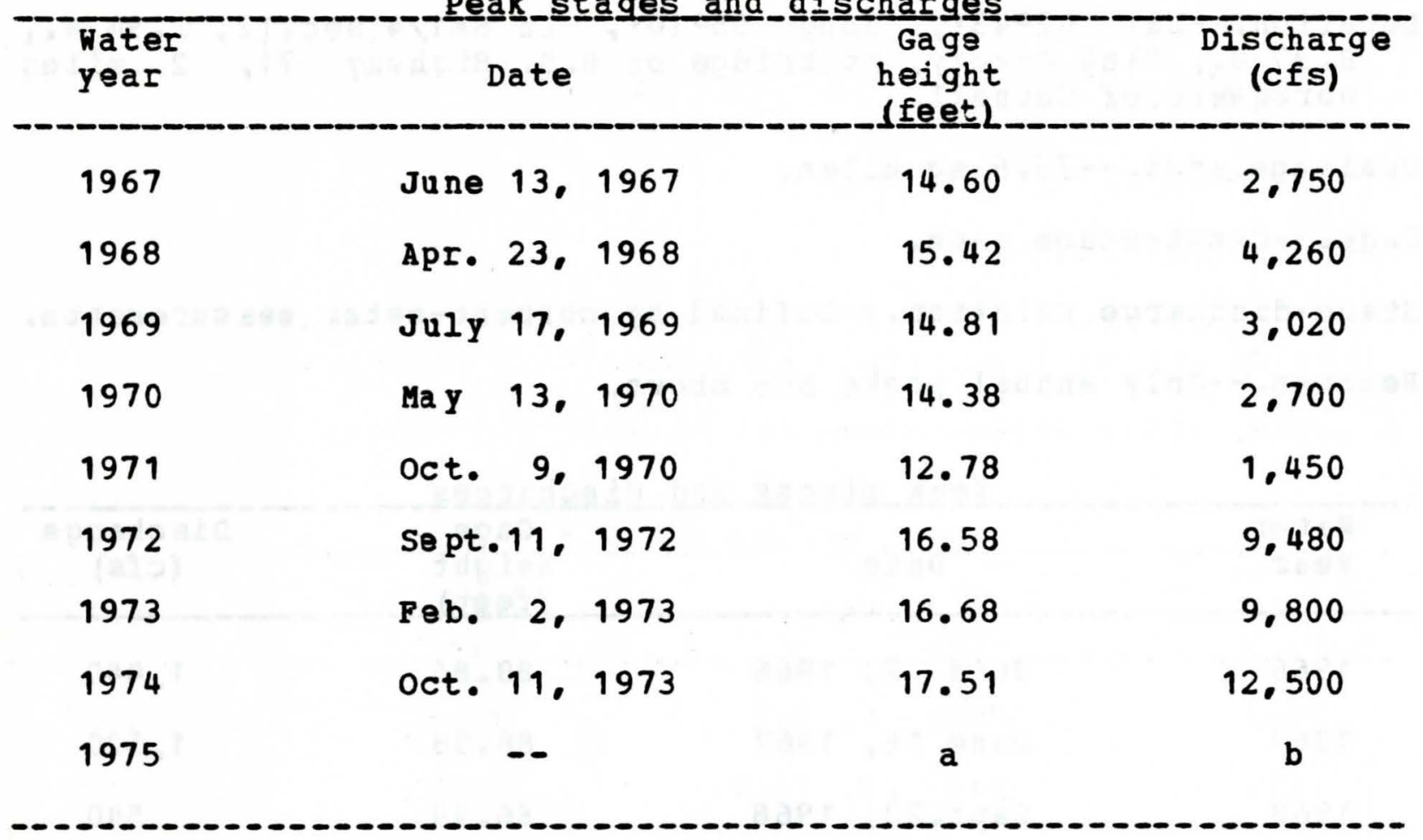

a Peak stage did not reach bottom of gage.

b Discharge not determined. 


\section{6-6057.50 Willow Creek near cornell, I owa}

Location.--lat 420431 , long $95010 \%$ in SE1/4 sec.12, T.94 N., R. 37 H.. Clay County, at bridge on 0.S. Highway 71, 2 miles northwest of Cornell.

Drainage area.--78.6 sq miles.

Gage.--Crest-stage gage.

Stage-discharge relation.--Defined by current-meter measurements. Remarks.--only annual peaks are shown.

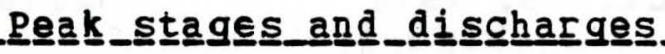

\begin{tabular}{|c|c|c|c|c|c|c|}
\hline $\begin{array}{l}\text { Water } \\
\text { year }\end{array}$ & & Date & & $\begin{array}{l}\text { Gage } \\
\text { height } \\
\text { (feet) }\end{array}$ & & $\begin{array}{c}\text { Discharge } \\
\text { (cfs) }\end{array}$ \\
\hline 1966 & June & 2. & 1.966 & 88.86 & & 1.440 \\
\hline 1967 & June & 16. & 1967 & 88.98 & & 1,520 \\
\hline 1968 & sept. & 23 & 1968 & 86.99 & & 540 \\
\hline 1969 & June & 25 & 1969 & 91.35 & & 3.700 \\
\hline 1970 & & - & & a & & $<203$ \\
\hline 1971 & June & 6. & 1971 & 89.57 & $\omega$ & 1.950 \\
\hline 1972 & June & 27 & 1972 & 87.08 & & 590 \\
\hline 1973 & Aug. & 23. & 1973 & 88.54 & & 1.360 \\
\hline 1974 & Ma y & 15. & 1974 & 87.48 & & 800 \\
\hline 1975 & Apr. & 28 & 1975 & 89.45 & & 1.650 \\
\hline
\end{tabular}

a Peak stage did not reach bottom of gage. 


\section{6-6096.00 Willow Creek near Logan. Iowa (Discontinued September 1975)}

Location.--Lat $41037 \cdot 54 "$ " long $95053127 "$, in NW 1/4 NE1/4 sec. 30 , T.79 N.. R. 43 H.. Harrison County, on right bank on downstraam side of bridge on county highway F50, 5.5 miles west of Logan, and 7.5 miles upstream from mouth.

Drainage area.--129 sq miles.

Gage.--Water-stage reocrder. Datum of gage is $1,005.40 \mathrm{ft}$ above mean sea level (levels by Corps of Engineers).

Stage-discharge relation.--Defined by current-meter measurements. Remarks.--Base for partial-duration series, 500 cfs.

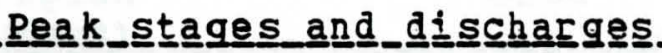

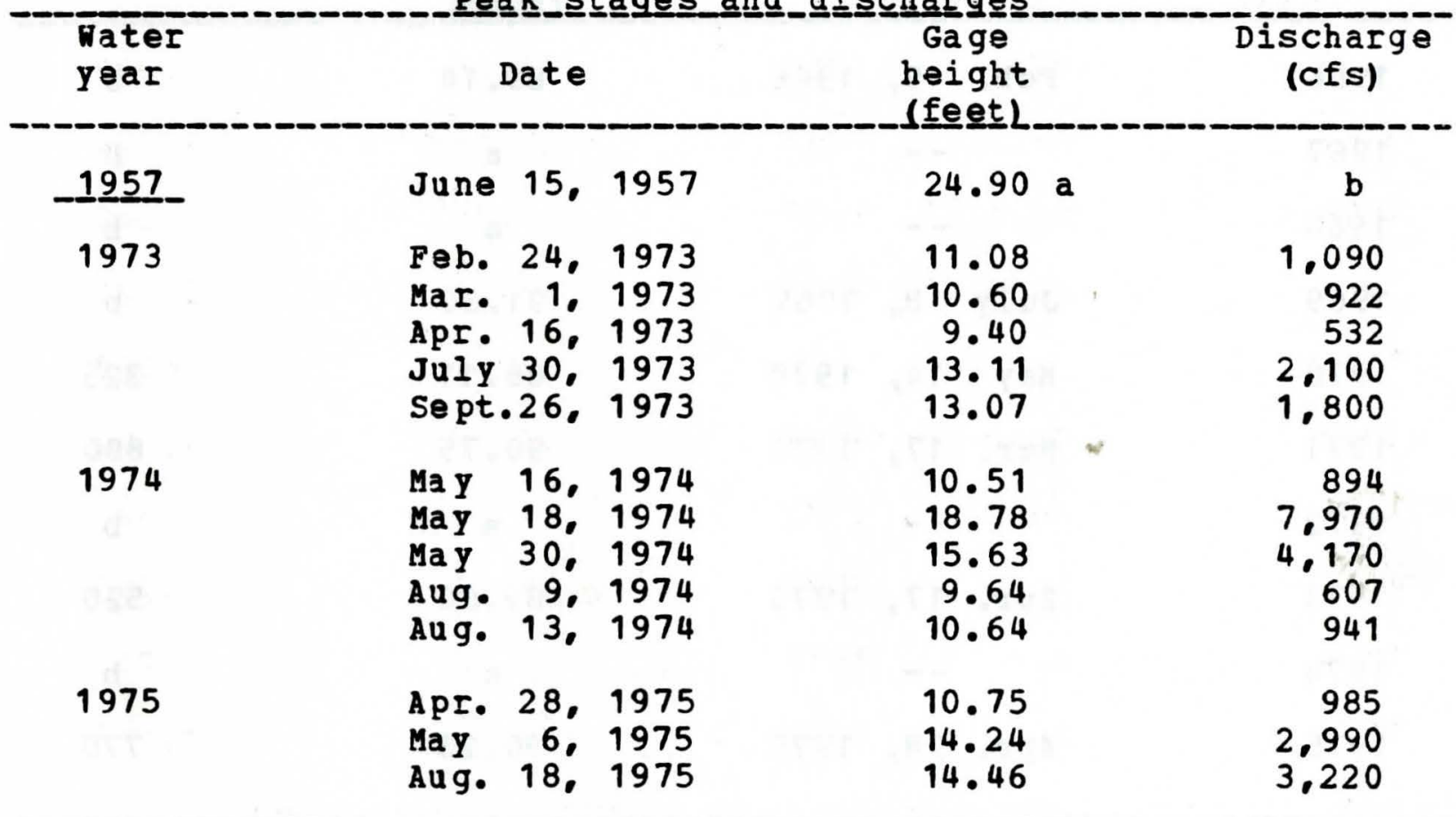

Discontinued September 1975

a From information by Corps of Engineers.

b Discharge not determined. 
Location.--Lat $43^{\circ} 09^{\prime}$, long $93^{\circ} 16^{\circ}$, in NE1/4 sec.12, T.96 N.. R. 21 H. . Cerro Gordo County, at bridge on U.S. Highway 18 , about 3.5 miles west of Mason City.

Drain ge area.--78.6 sq miles.

Gage.--Crest-stage gage.

Stage-discharge relation.--Defined by current-meter measurements. Remarks.--only annual peaks are shown.

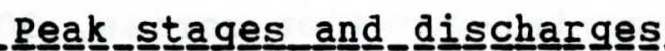

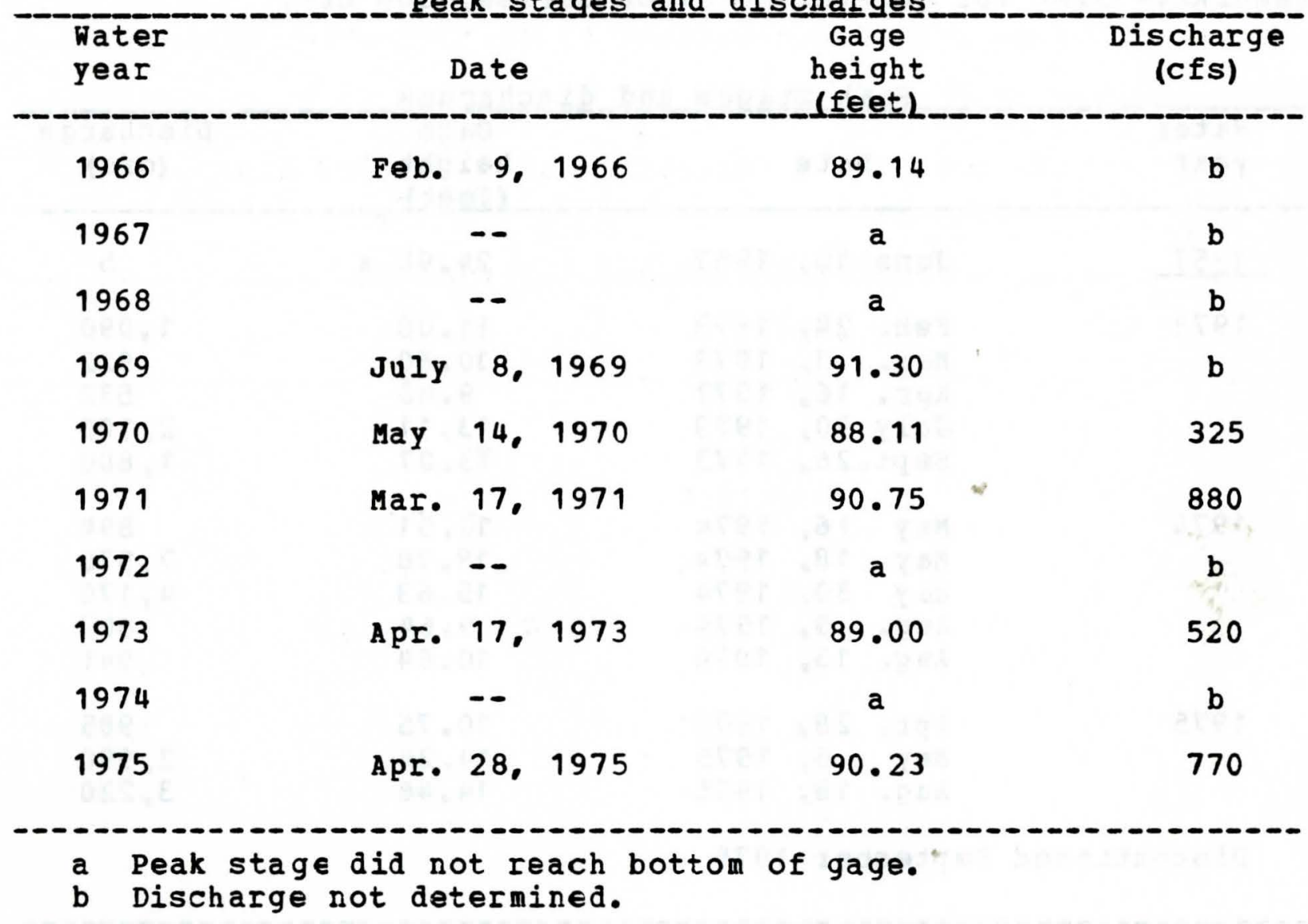


Location.--Lat $430094^{\prime \prime}$, long $93011 \cdot 33^{\prime \prime}$, in NE1/4 NW1/4 sec.3. T. 96 N.. R. 20 W.. Cerro Gordo County, on right bank 650 ft upstream from Thirteenth street Bridge in Mason City, 0.1 mile downstream from Calmus Creek, and 1.0 mile upstream from Willow zreek.

Drainage area.--526 sq miles.

Gage.--Water-stage recorder and concrete control. Datum of gage is 1.069.59 ft above mean sea level. Prior to oct. 15. 1934. non recording gage at datum $6.47 \mathrm{ft} l o w e r$ Oct. 15 to Nov. 6, 1934, nonrecording gage at different datum, and Nov. 7, 1934, to Mar. 22, 1935, nonrecording gage at present datum.

Stage-discharge relation.--Defined by current-meter measurements. Flood stage. --7 feet.

Remarks.--Base for partial-duration series, 2,000 cfs.

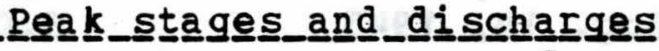

\begin{tabular}{|c|c|c|c|c|}
\hline $\begin{array}{l}\text { Water } \\
\text { year }\end{array}$ & Date & $x^{2}$ & $\begin{array}{c}\text { Gage } \\
\text { height } \\
\text { (feetl }\end{array}$ & $\begin{array}{l}\text { Discharge } \\
\text { (cfs) }\end{array}$ \\
\hline 1933 & Mar. 30,1933 & & 15.그므- & 10.800 \\
\hline 1934 & Apr. 3,1934 & & 4.1 & 1,470 \\
\hline 1935 & Mar. 5, 1935 & & 5.80 & 2,340 \\
\hline 1936 & $\begin{array}{l}\text { Mar. } 16,1936 \\
\text { Mar. } 17,1936\end{array}$ & & $\begin{array}{l}6.10 \mathrm{ab} \\
5.97 \mathrm{a}\end{array}$ & $\begin{array}{l}2,520 \\
2,440\end{array}$ \\
\hline 1937 & Mar. 5, 1937 & & 9.68 & 5.260 \\
\hline 1938 & $\begin{array}{l}\text { June } 23,1938 \\
\text { June 25, } 1938 \\
\text { Sept.15, } 1938\end{array}$ & & $\begin{array}{c}8.7 \\
10.29 \\
8.2\end{array}$ & $\begin{array}{l}4,340 \\
5,850 \\
3,970\end{array}$ \\
\hline 1939 & $\begin{array}{l}\text { Mar. 13, } 1939 \\
\text { Mar. 22, } 1939\end{array}$ & & $\begin{array}{l}7.9 \\
5.8\end{array}$ & $\begin{array}{l}3.730 \\
2.360\end{array}$ \\
\hline 1940 & Mar. 29, 1940 & & 3.4 & 980 \\
\hline $\begin{array}{ll} & \text { Pr } \\
\mathrm{b} & \mathrm{Af}\end{array}$ & $\begin{array}{l}\text { m. } \\
\text { ice. }\end{array}$ & & & \\
\hline
\end{tabular}


05-4595.00 Winnebago River at Mason City. Iowa--(Continued)

Peakk_stagges_and_dis

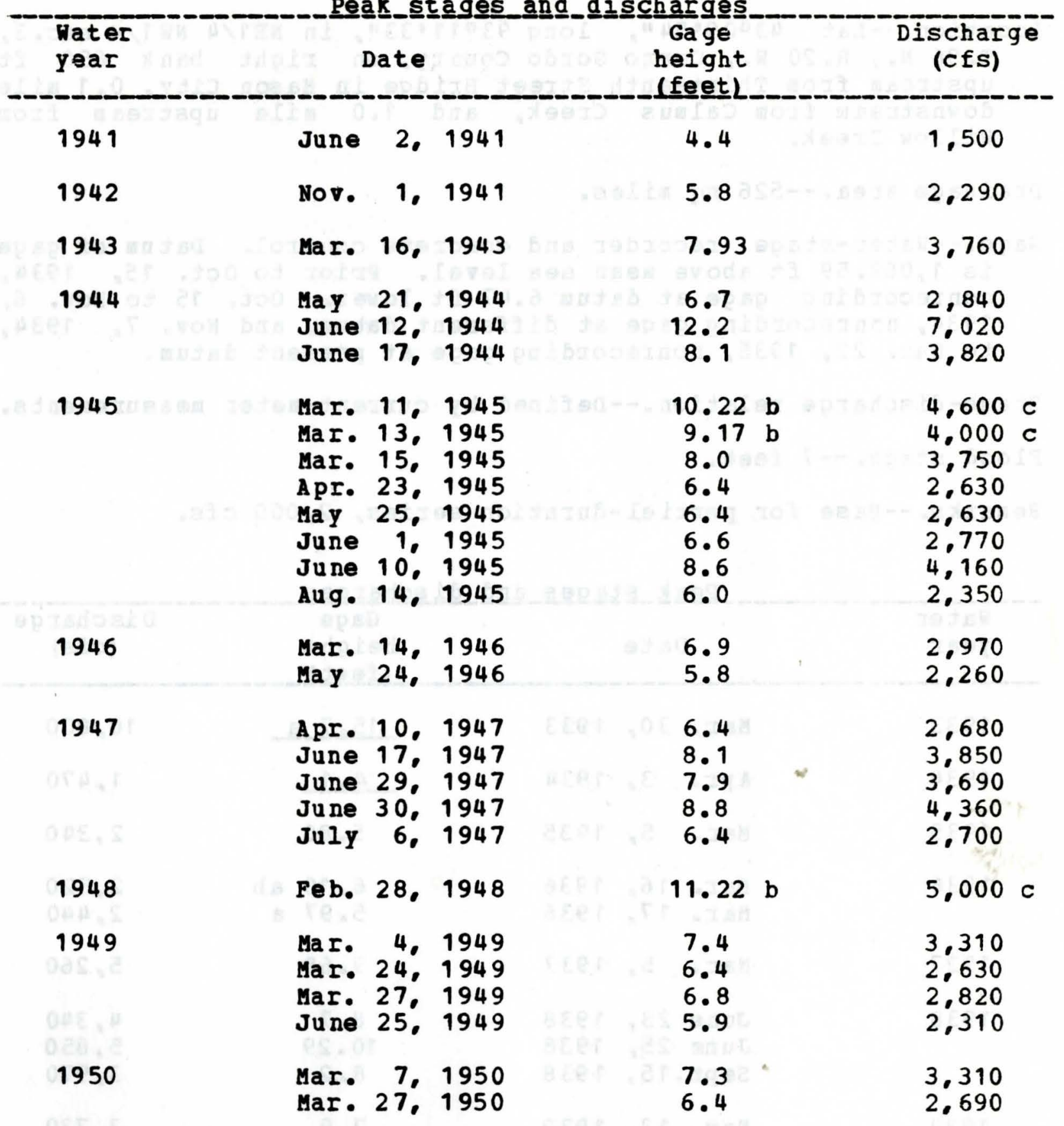

b Affected by ice.

c About. 
05-4595.00 Winnebago River at Mason City. Iowa--(Continued)

Peak﹎_stagges_and

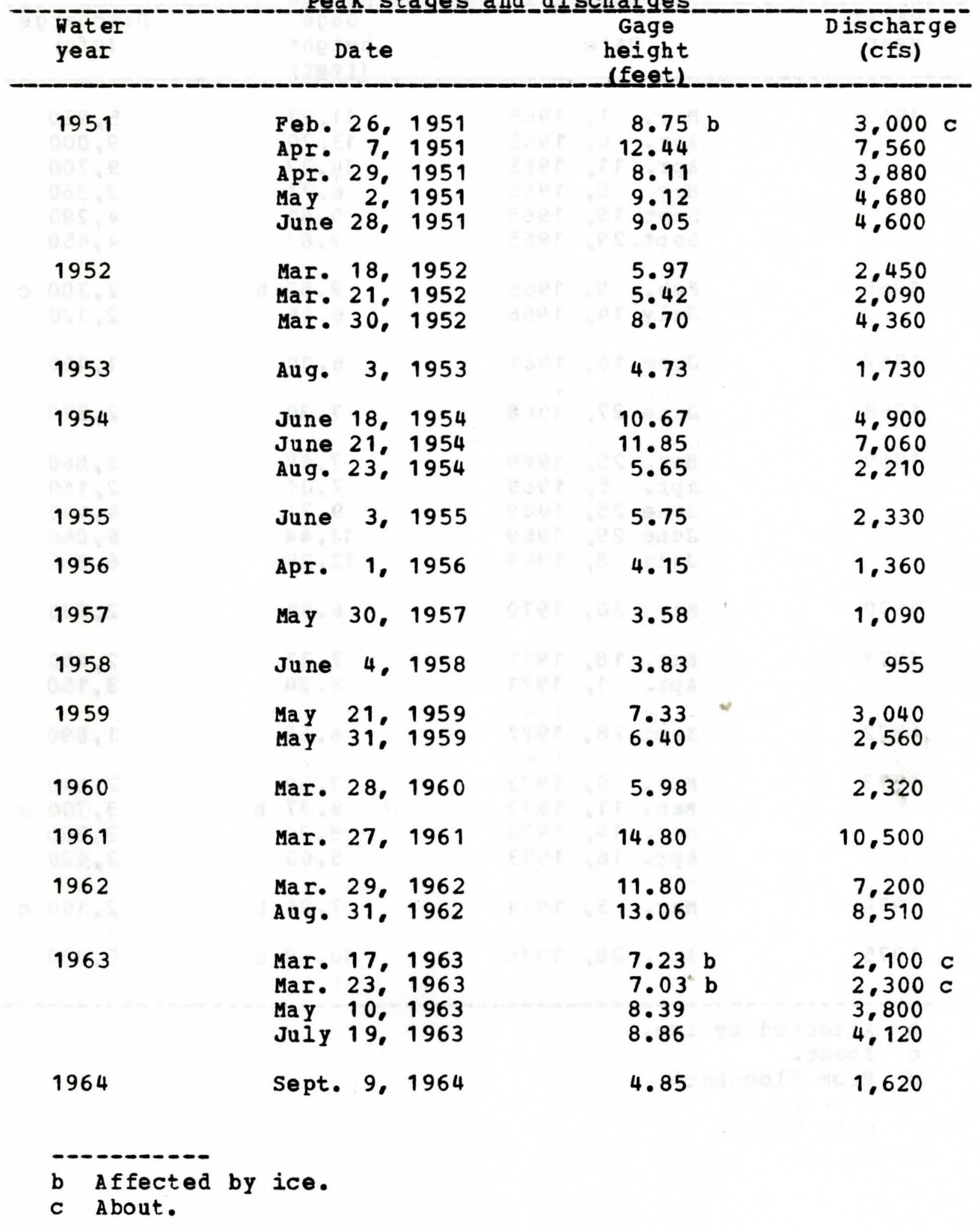




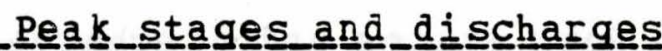

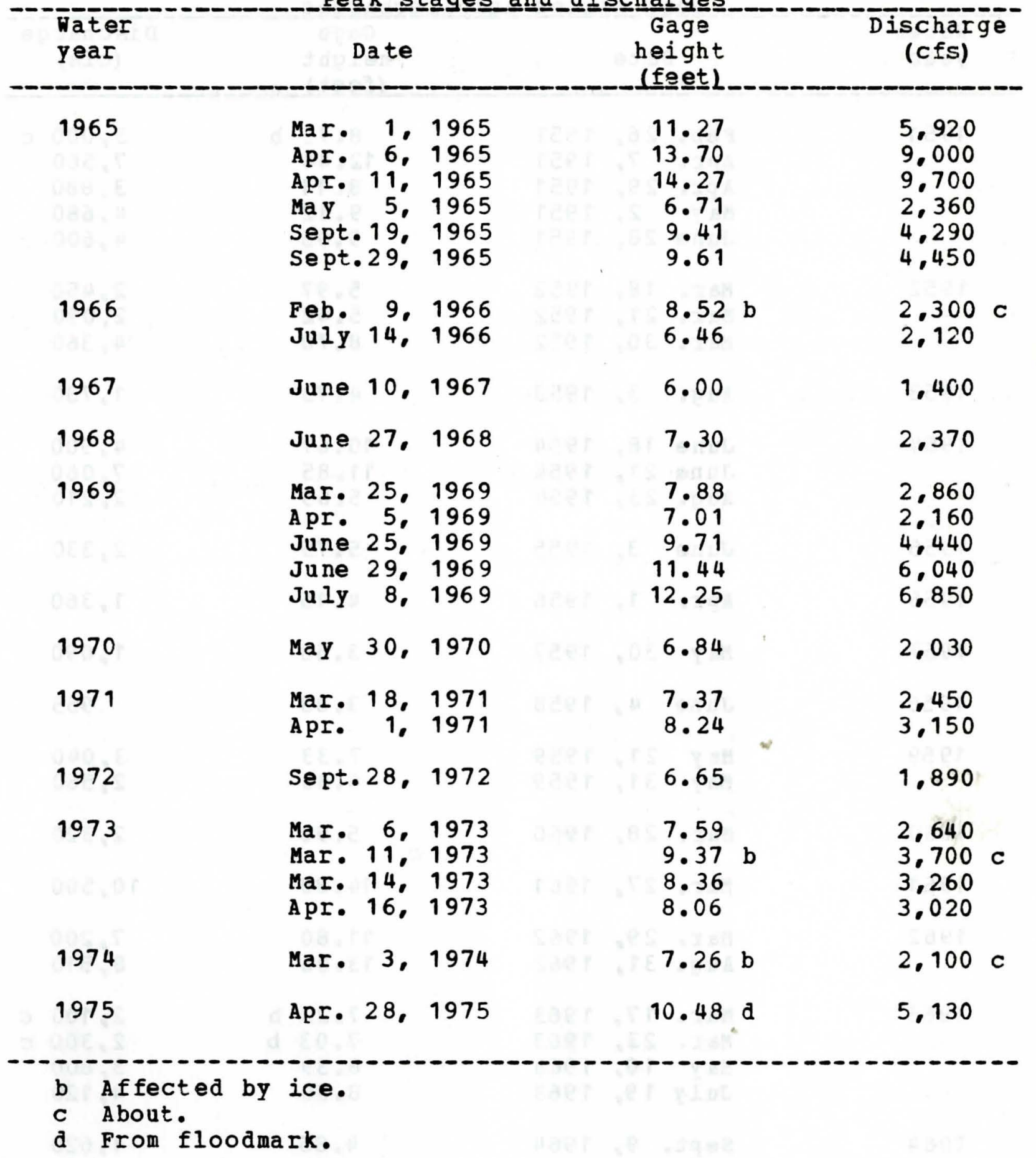




\section{5-3890.00 Yellow River at Ion, Iowa \\ (Discontinued sept. 30, 1951)}

Location.--Iat 43006'35", long $91015 \cdot 45^{\prime \prime}$, in SE1/4 SW1/4 sec.24, T. 96 N., R. 4 W.. Allamakee County, on downstream side of county highway bridge at Ion, 7.5 miles northwest of McGregor, and 8 miles upstream from mouth.

Drainage area.--221 sq miles.

Gage.--Nonrecording. Datum of gage is 664.65 ft above mean sea level.

Stage-discharge relation.--Defined by current-meter and indirect measurements and the relation is subject to large shifts.

Remarks.--Base for partial-duration series, $3,000 \mathrm{cfs}$.

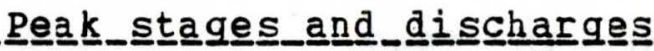

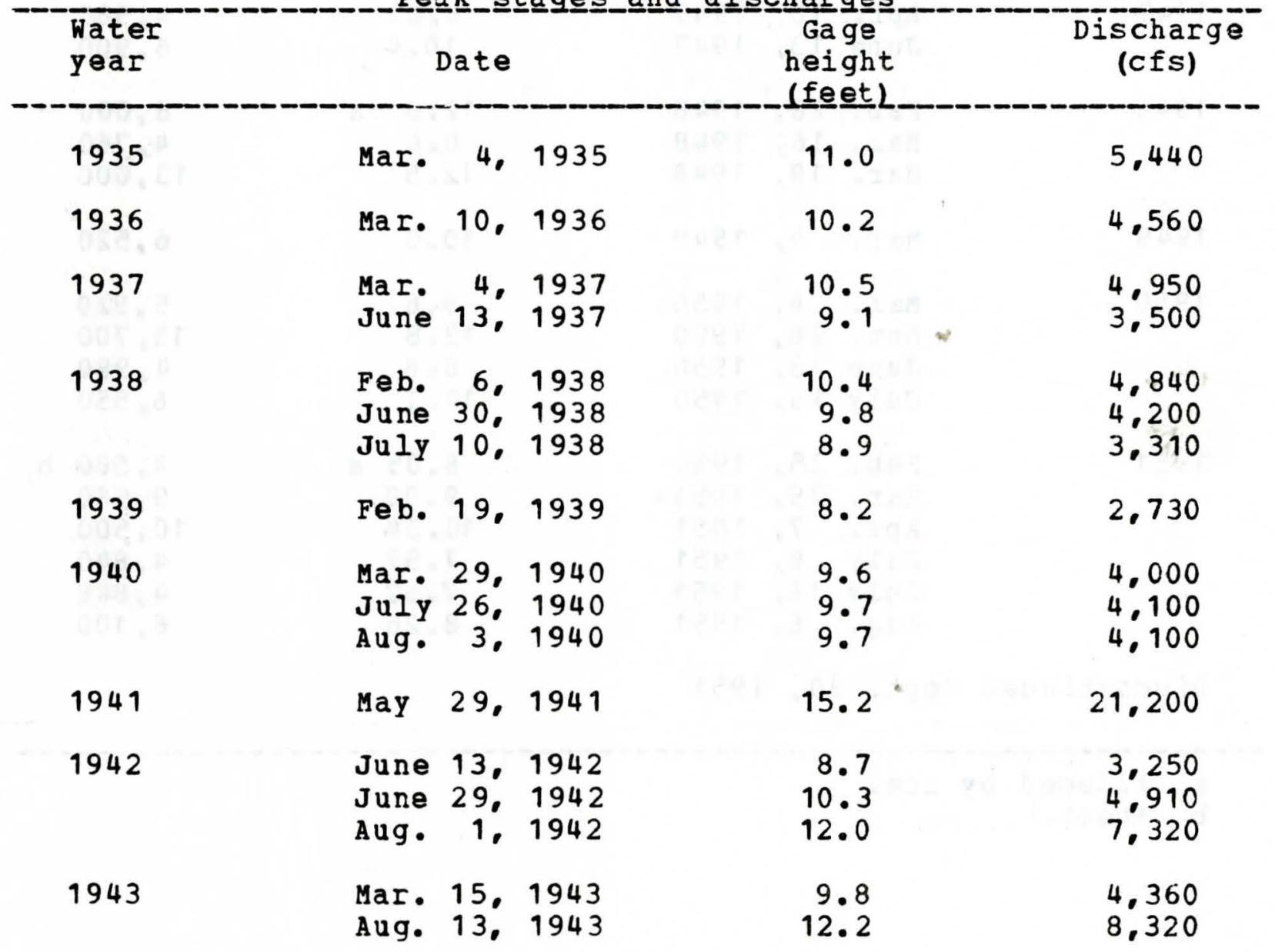


05-3890.00 Yellow River at Ion. Iowa--(Continued)

Peakㅗsaages_annd_di

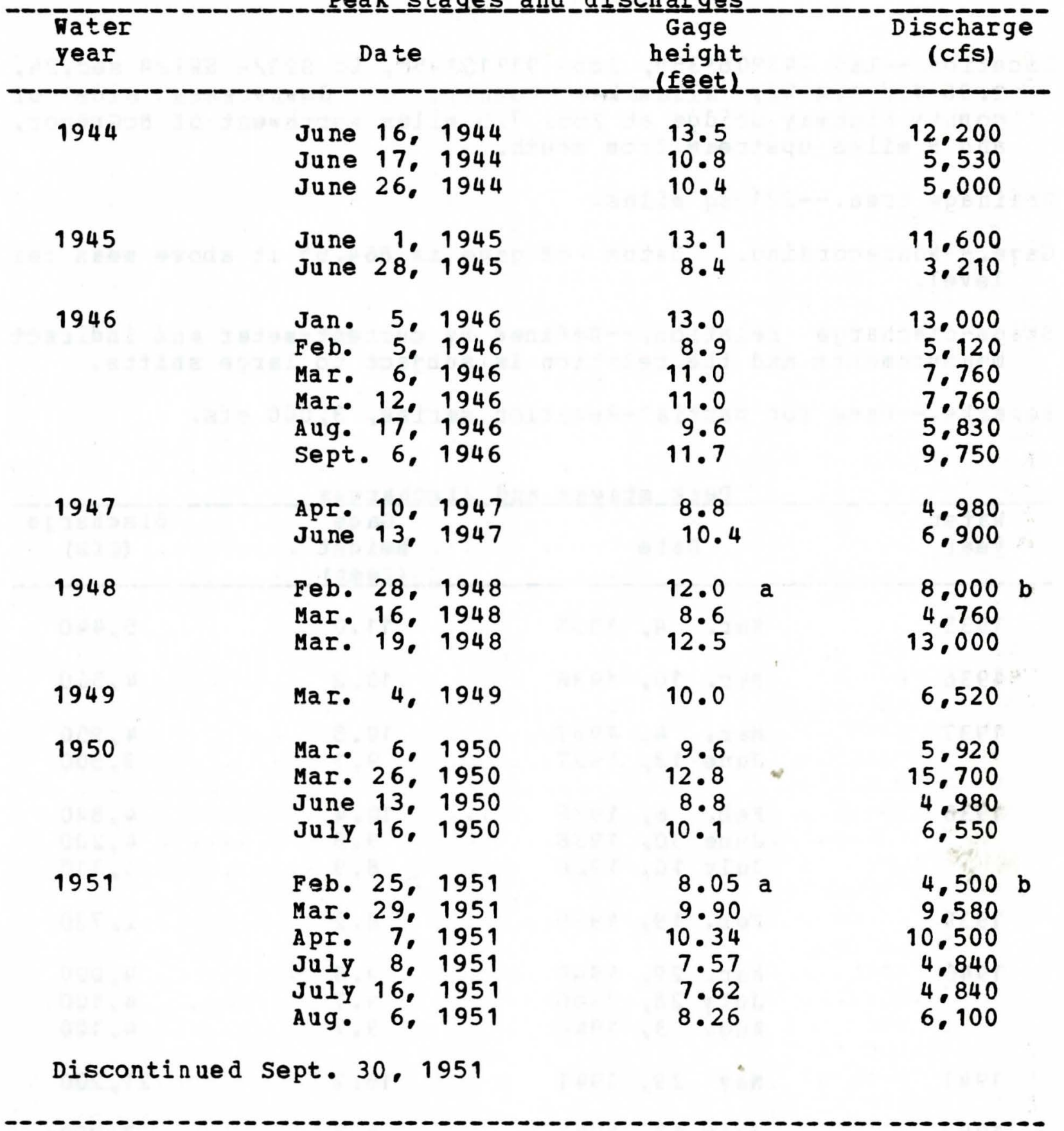

a Affeced by ice.

b About. 
Page

Bear Creek nr Monmouth.............................. 9

Bear Creek at ottumwa............................... 12

Beaver Creek at Beaver................................ 14

nI Eldora................................... 15

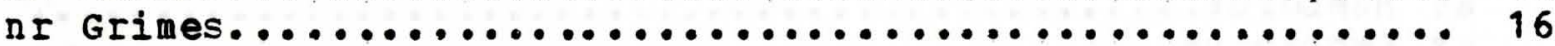

Beaver Creek at New Hartford........................... 18

tributary nI Aplington........................... 13

Beaverdan Creek nI sheffield.......................... 22

Big Bear Creek at Ladora............................ 23

Big Cedar Creek nr Varina............................. 28

Big Creek nI Mount Pleasant........................... 30

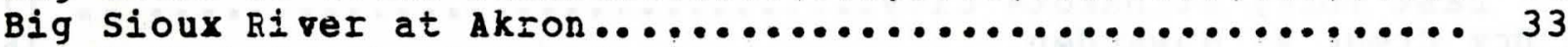

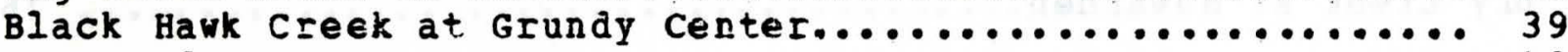

at Hudson...................................... 40

Bluff Creek at Pilot Mound.......................... 43

Boone River $n=$ Webster City.......................... 44

Boyer River at Logan................................. 49

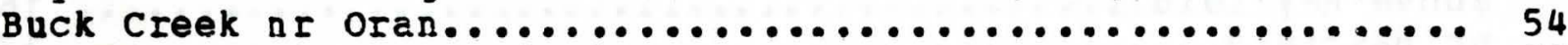

Buffalo Creek above finthrop....................... 55

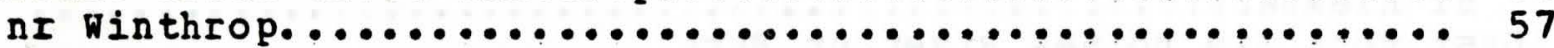

Bulgers Run $n I$ Riverside........................... 58

Cedar Creek nr Batavia............................. 59

Cedar Creek nI Bussey............................... 60

Cedar River at Cedar Rapids..........................6 63

at Charles City................................ 69

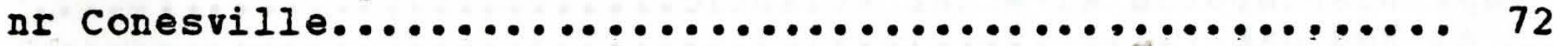

at Janesville.................................. 77

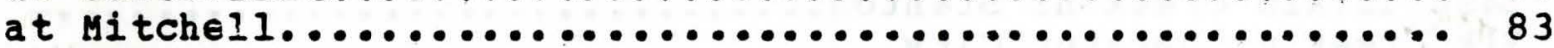

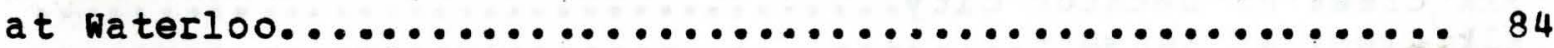

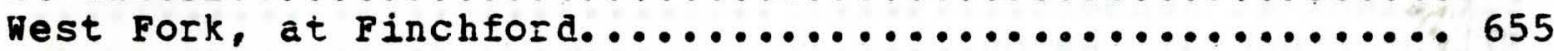

Chariton River nr Centervilie....................... 88

nr Chariton.................................... 91

at Coal city..................................... 93

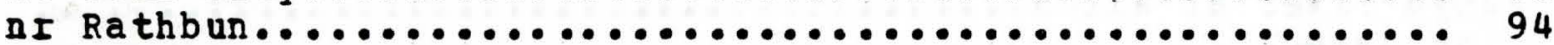

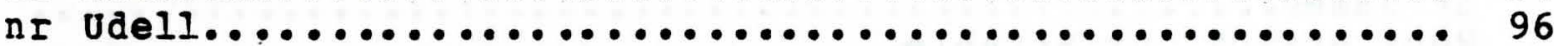

South Fork, nI Promise City....................... 547

clear Creek nr Coralville............................ 97

Cooper Creek at Centerville...........................100

Crane Creek nI Lourdes..............................101

tributary nr saratoga...........................103

Davids Creek nI Hamlin............................. 105

Dawson Creek nI sibley.............................. 108

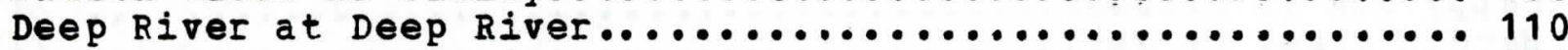

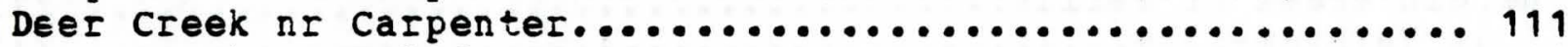

Deer Creek at Toledo................................112 
Page

DEs Moines River at Des Moines.......................113

below Raccoon River at Des Moines.....................118

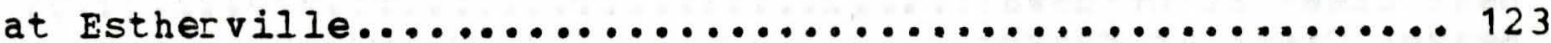

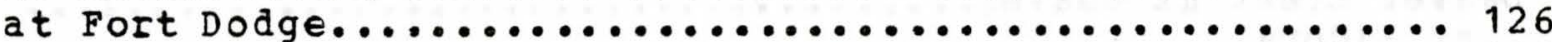

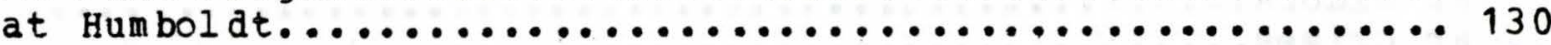

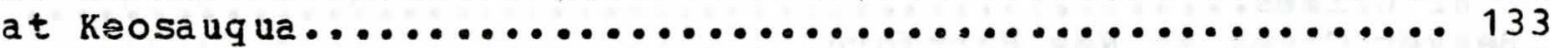

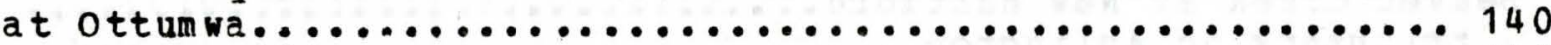

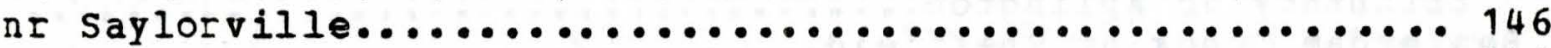

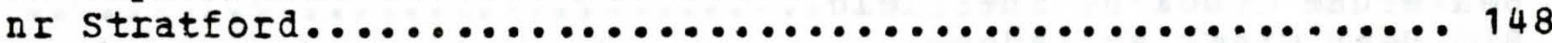

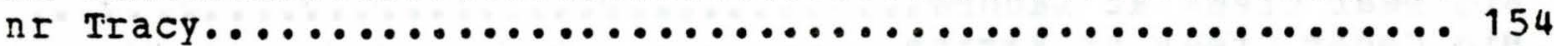

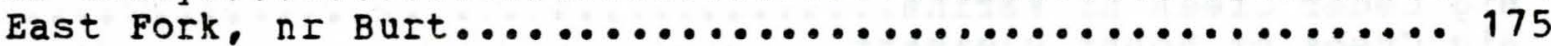

East Fork, at Dakota City........................178

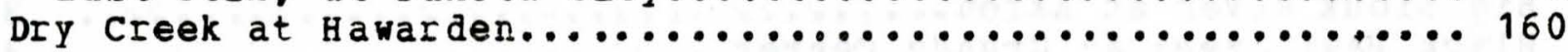

East Blue creek at center point........................163

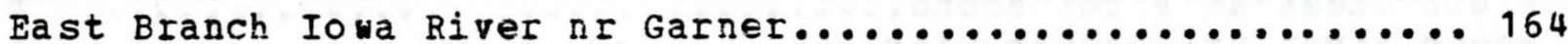

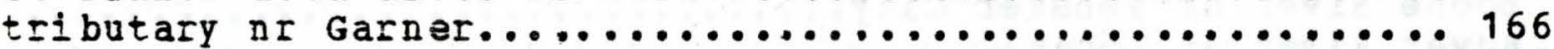

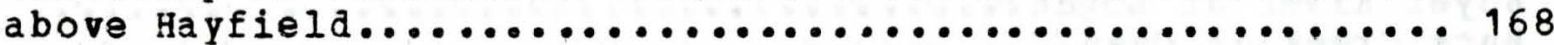

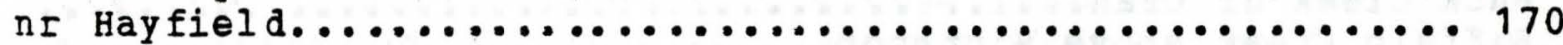

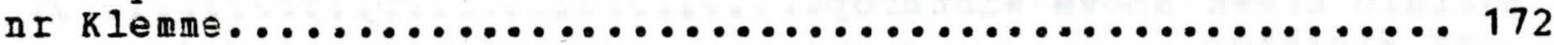

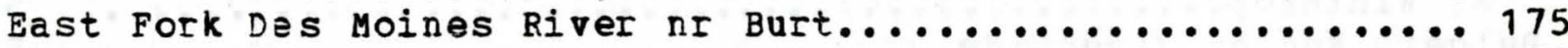

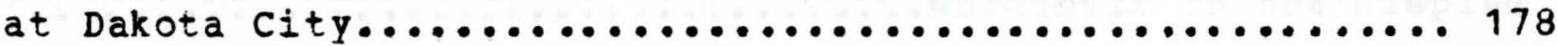

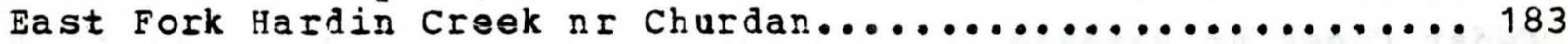

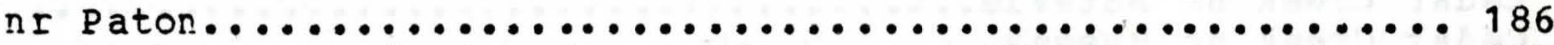

East Fork one Hundred and Two River nI Bedford............187

East Fork Wapsipinicon River nr New Hampton...............190

East Nishnabotna River nI Atlantic......................191

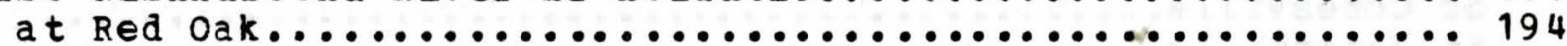

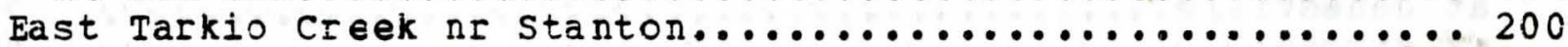

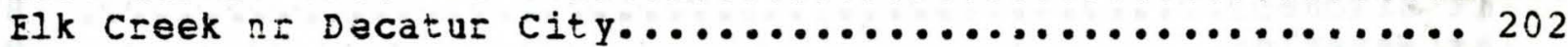

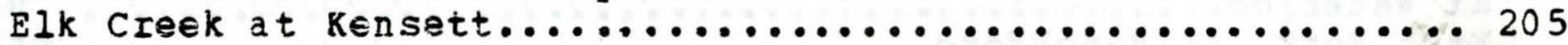

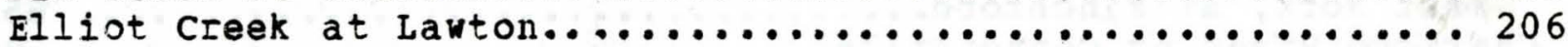

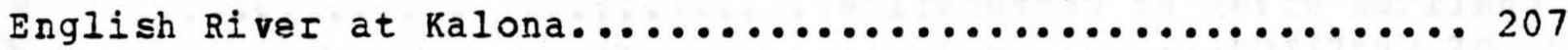

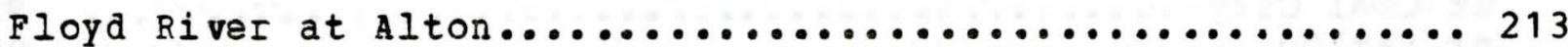

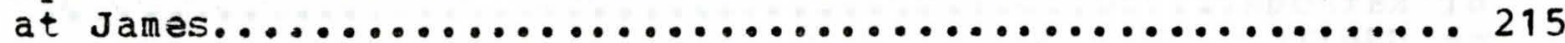

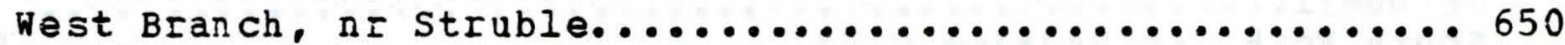

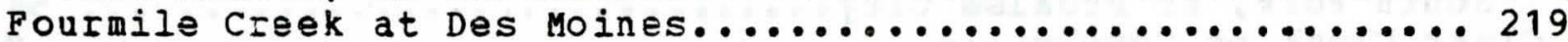

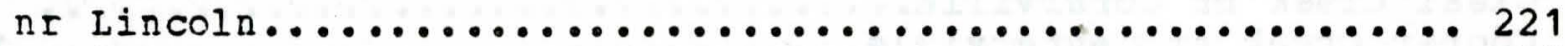

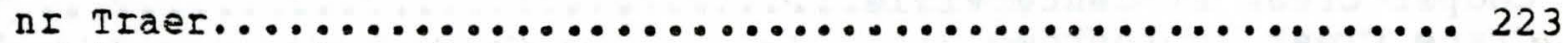

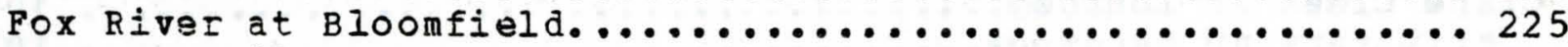

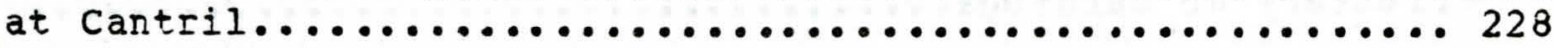

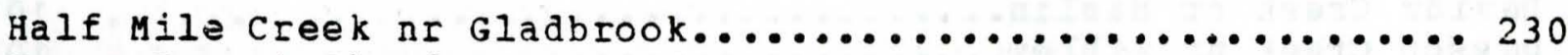

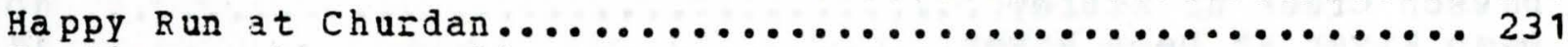

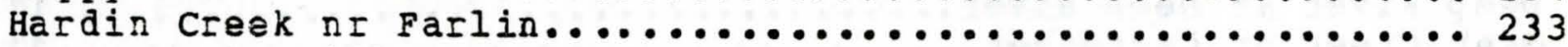

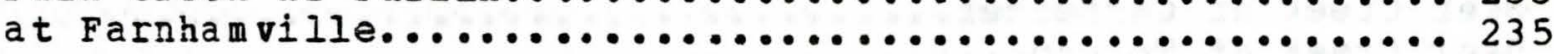

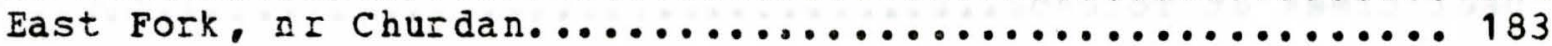

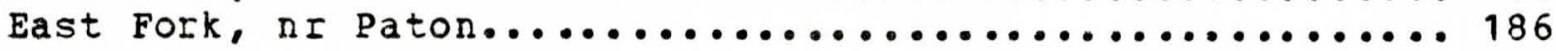


Harter Creek nI Independence........................ 237 Honey creek at Bangor.............................. 238 Honey Creek nI Russell............................ 239

Indian Creek at Council Bluffs....................... 241

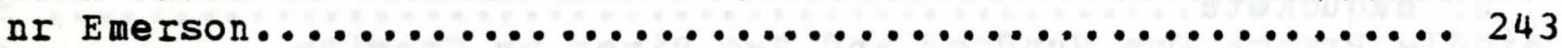

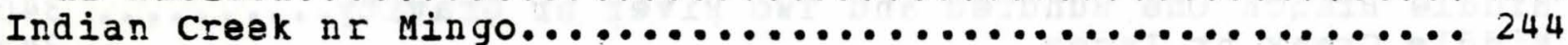

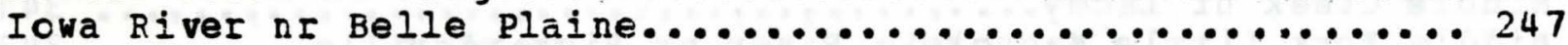

at Iowa city................................. 250

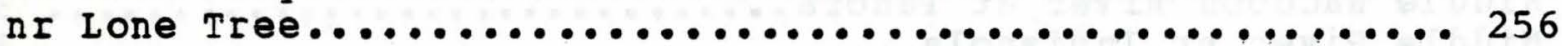

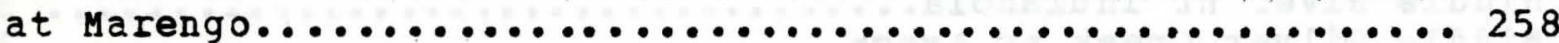

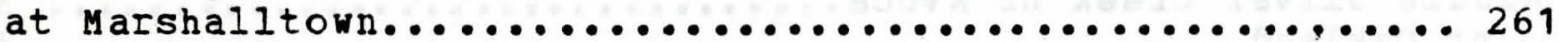

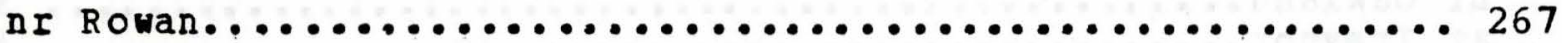

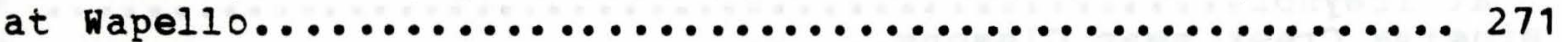

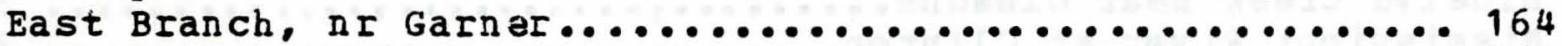

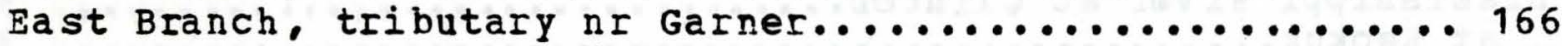

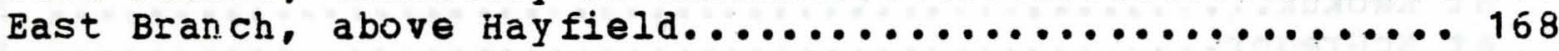

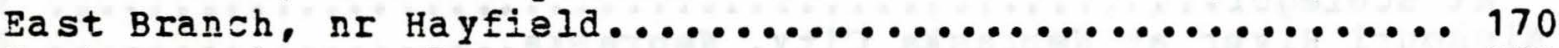

East Branch, nr klemme...........................172

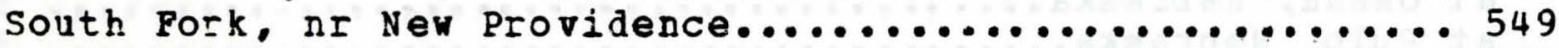

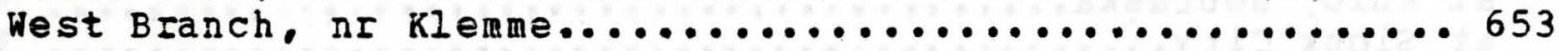

Keigley Branch nr story city...................... 277 Kitty Craek nI Iangworthy......................... 278

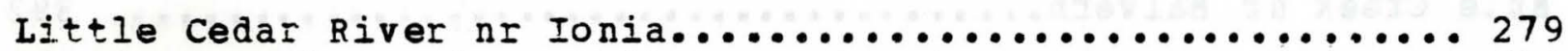

Little Maquoketa River tributary at Dubuque.............283

nI Durango................................... 285

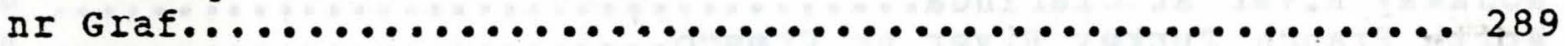

Middle Fork, nI Rickardsville..................... 342

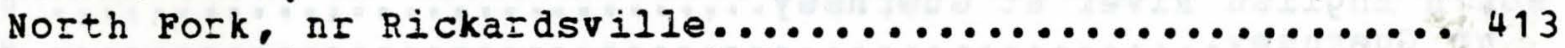

Little Muchakinock Creek at oskaloosa................... 291

Little paint creek tributary nI Watervilla............... 292

Little Sioux River at Correctionville..................294

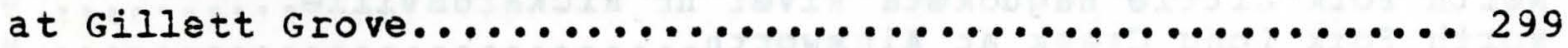

nI Kennebec................................... 301

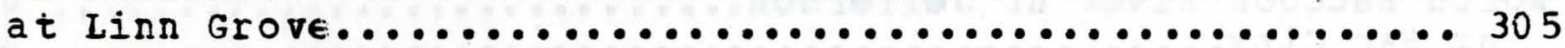

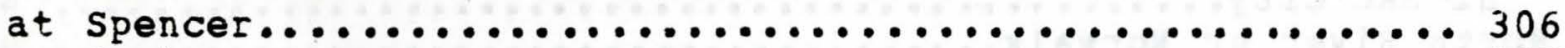

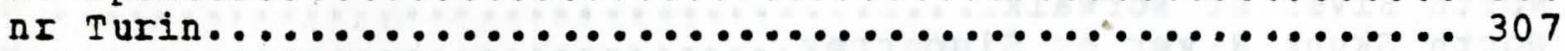

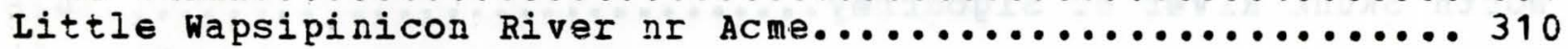

at Elma................................... 312

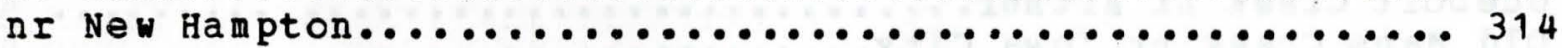

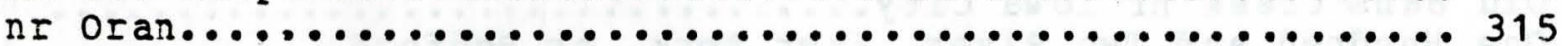

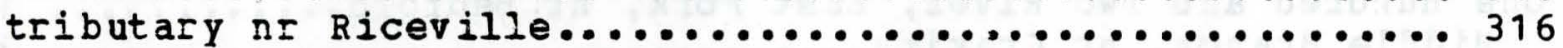

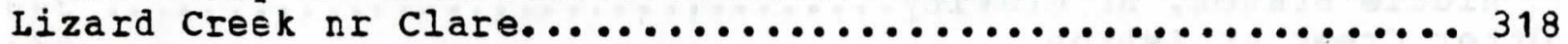

Loon Creek nI orleans.............................. 322 
Ma ple Creak nr Alta............................... 323

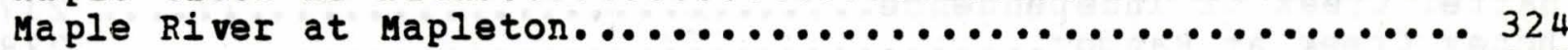

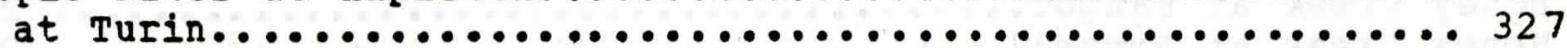

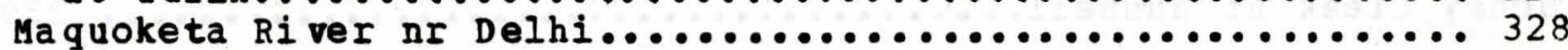

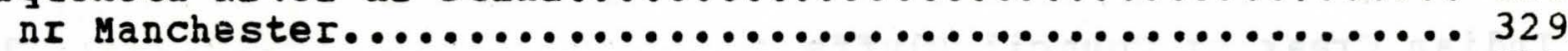

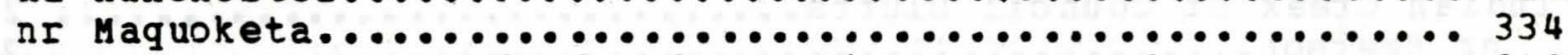

Middle Branch one Hundred and Two River nI Gravity......... 340

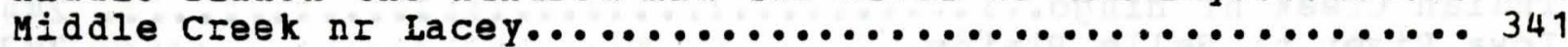

Middle Fork Little Maquoketa River nI Rickardsvilie....... 342

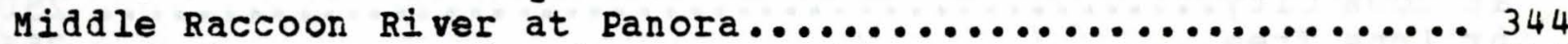

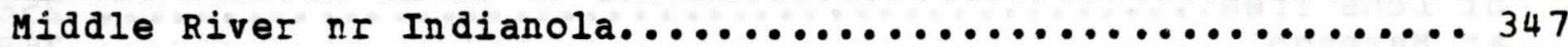

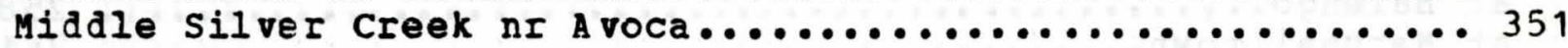

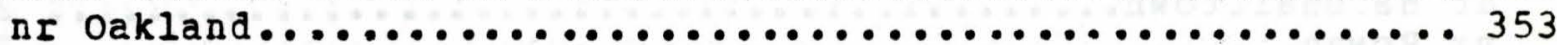

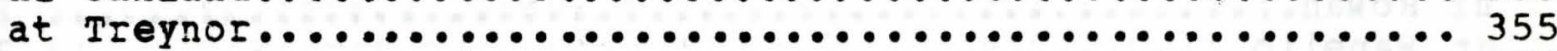

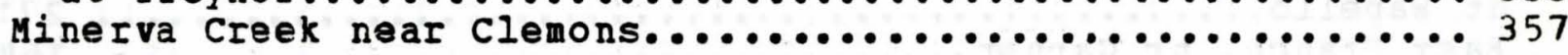

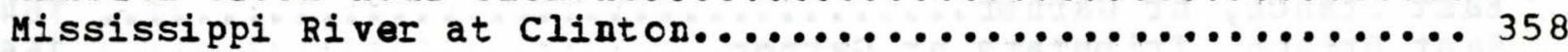

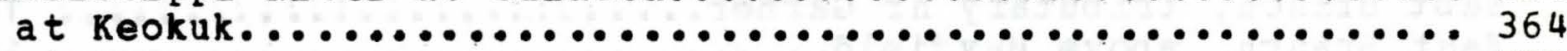

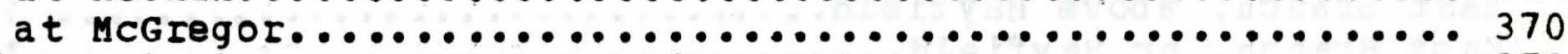

Missouri River at Nebraska City, Nebraska............... 373

at Omaha, Nebraska............................... 377

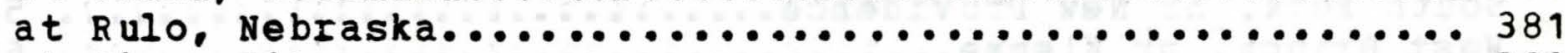

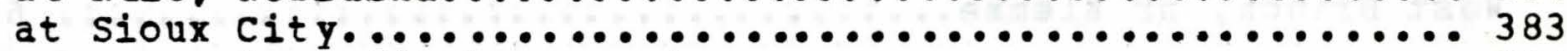

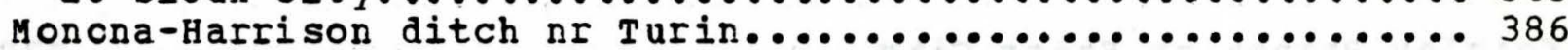

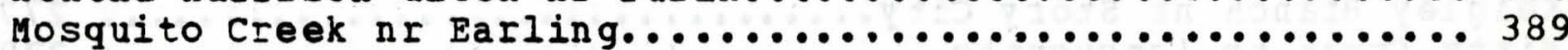

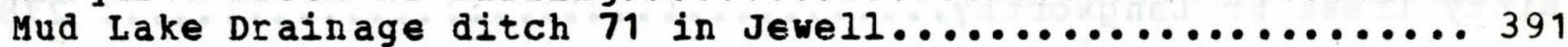

Mule Creek nr Malvern............................... 392

Nishnabotna River above Hamburg....................... 394

Nodaway River at Clarinda.......................... 400

North Branch Turkey River nI Cresco.................... 406

North English River at Guernsey.....................4 407

nI Guernsey.................................... 408

nI Montezuma..................................... 410

nI Montezuma..................................... 411

North Fork Little Maquoketa River nr Rickardsvilie........413

North Fork Long Creek at Ainsworth.................. 415

North Raccoon River nr Jefferson....................... 416

nI Sac city.................................... 420

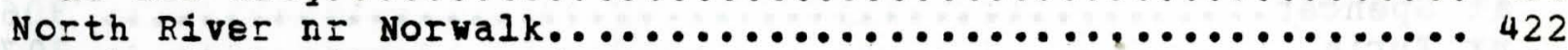

North skunk River nI Sigourney....................... 426

odebolt Creek nr arthur............................. 429

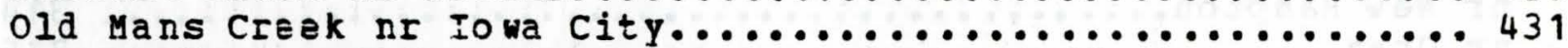

One Hurdred and Two River, East Fork, nr Bedford.......... 187

Middle Branch, nr Gravity........................ 340

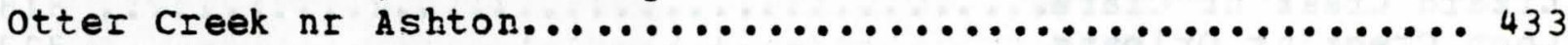

at sibley....................................445

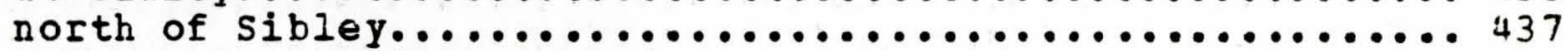

otter creek at Wilton Junction....................... 439 
Page

Paint Creek at Waterville.........................440

Paint Creek nI Waterville...........................443

Perry creek nr Hinton............................. 445

nI Merrill..................................... 447

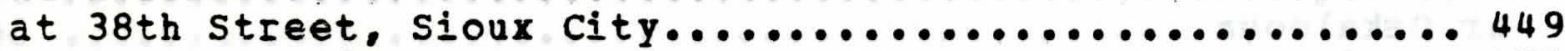

Pine Creek nr winthrop............................453

tributary nI Winthrop........................... 455

tributary No. 2 at Winthrop...................... 457

Platte River nI Diagonal...........................459

nI stringtown................................... 461

Plum Creek at Earlvilie.............................4462

Prairie Creek at Blairstown..........................4463

at Fairfax..................................... 464

Prairie Creek nI spencer............................466

Price Creek at Amana..............................4 467

Raccoon River at Van Meter.........................468

Ralston Creek at Iowa City...........................474

South Branch, at Iowa city...................... 538

Rapid Creek nI Iowa City..........................479

below Morse................................... 484

southwest of Morse.............................4 486

tributary nr Iosa City........................... 488

tributary nr oasis............................. 490

tributary No. $3 \mathrm{nr}$ Oasis........................... 492

tributary No. 4 nr Oasis............................ 494

Richland Creek nr Haven.............................496

Rock Creek at Sigourney........................... 500

Rock River at Rock Rapids......................... 500

nr Rock valley................................ 502

Salt creek nI EIberon............................. 505

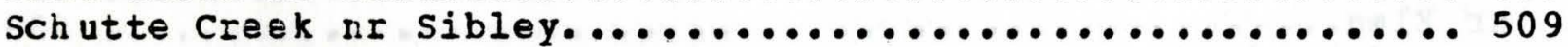

She 11 Rock River nI clarksville....................... 511

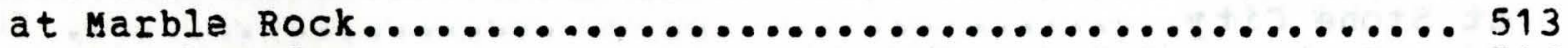

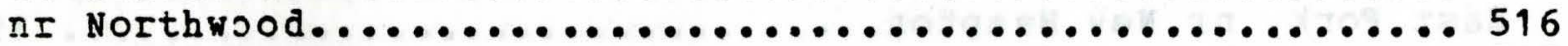

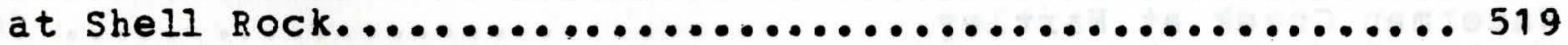

Skunk River at Augusta.......................... 522

at Coppock................................... 528

Snake Creek nI Yorktown............................ 532

Soldier River at Pisgah.......................... 533

South Avery Creek nI Blakesburg...................... 537

South Branch Ralston Creek at Iowa City................ 538

South English River nI Barnes City................... 541

tributary nr Barnes City......................... 543

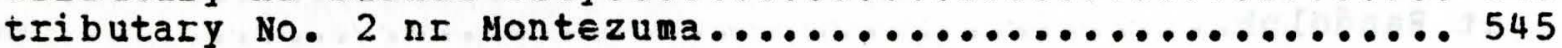

South Fork Chariton River nI Promise City............... 547

South Fork Iowa River near New Providence............... 549 
Page

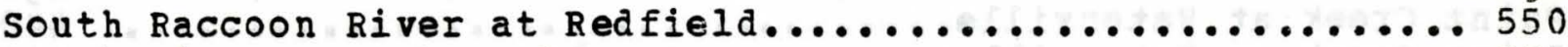

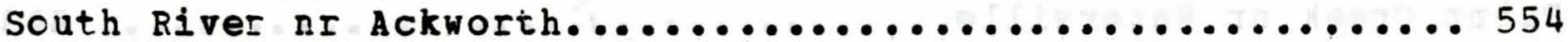

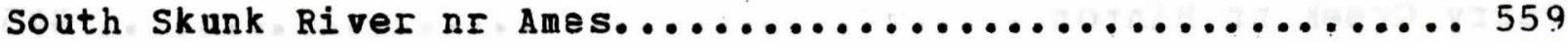

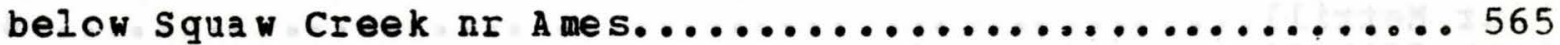

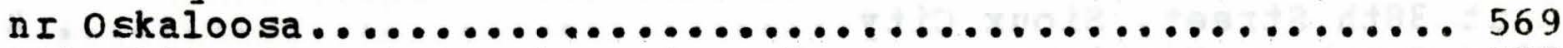

South White Breast Creek nr osceola.................. 572

South Wyaconda River nr West Grove.................. 574

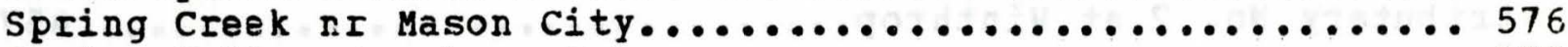

spring valley Creek nr Tabor....................... 577

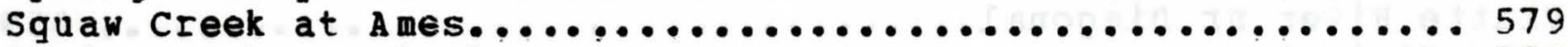

stein creek nr clutier.............................. 582

sugar Creek nr Keokuk.............................. 583

sugar creek nr searsboro.......................... 586

Tarkio River at Bianchard.......................... 587

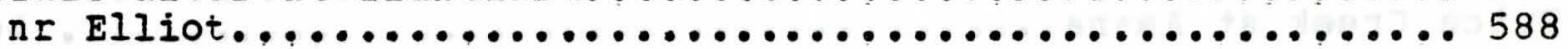

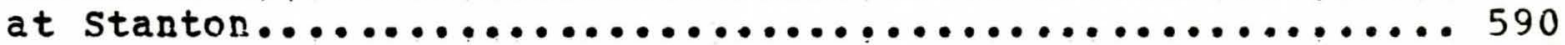

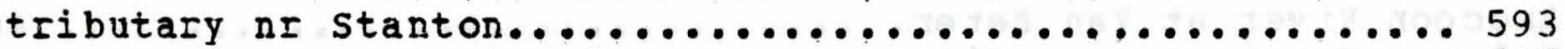

Thompson River at Davis City....................... 595

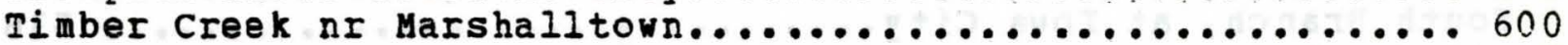

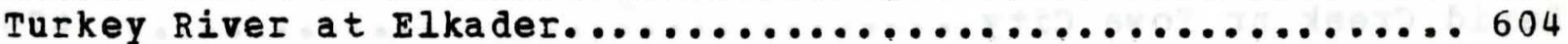

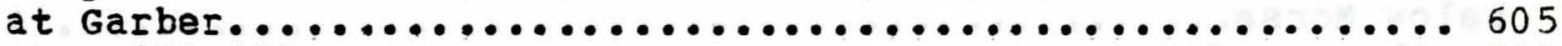

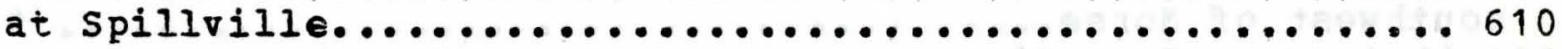

North Branch, nr Cresco.........................406

Upper Iowa River at Decorah......................... 613

nr Decorah................................... 616

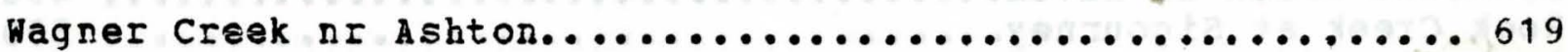

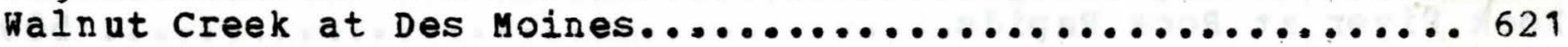

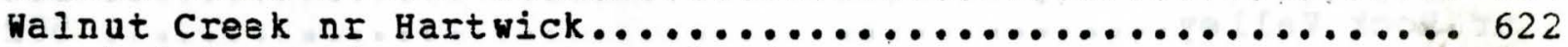

Wapsipinicon River at Central City....................6626

nr Dewitt.................................. 628

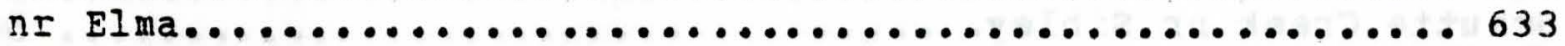

at Independence................................636

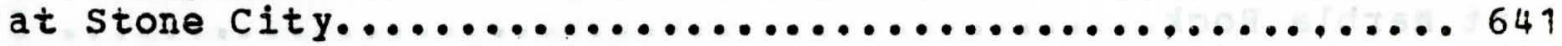

East Fork, nI New Hampton.......................... 190

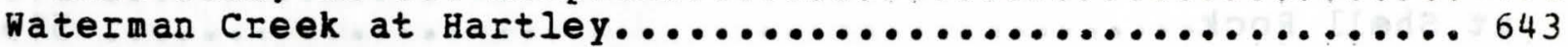

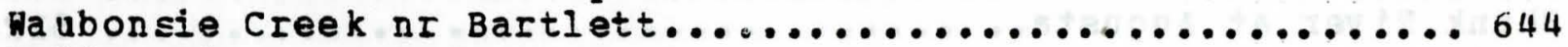

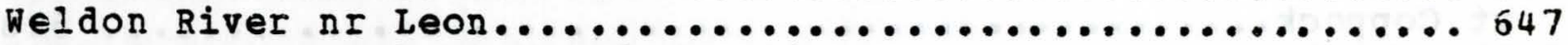

West Beaver Creek at Grand Junction....................649

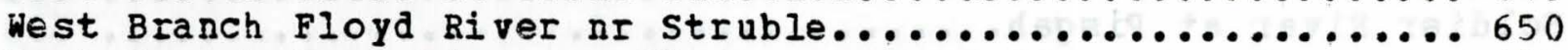

West Branch Iowa River nI Klemme..................... 653

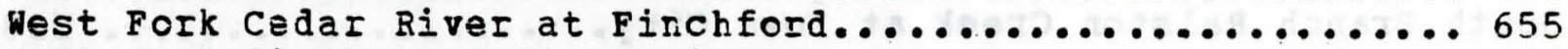

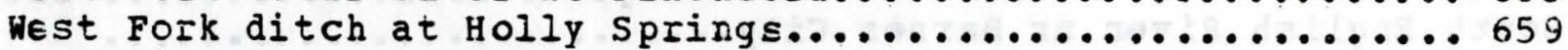

West Nishnabotna River at Hancock..................... 662

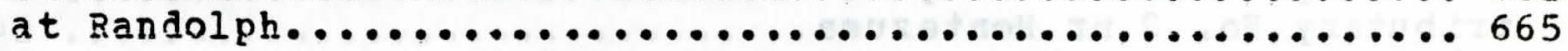




\section{INDEX}

Wexford Creek nI Harpers Ferry.......................669

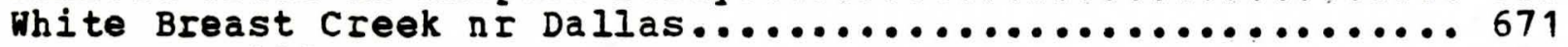

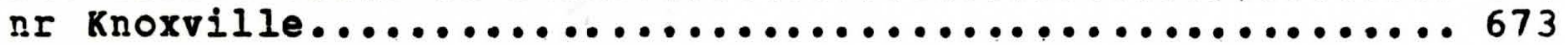

at Iucas...................................6 676

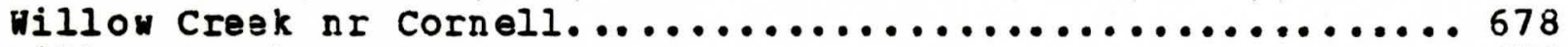

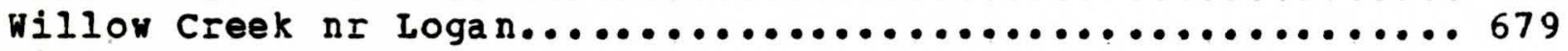

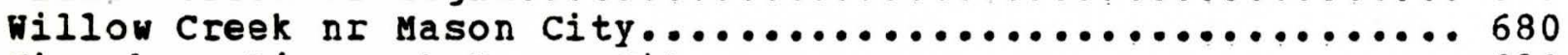

Winnebago River at Mason City.......................661

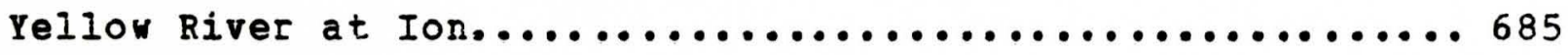

\&U. S. GOVERNMENT PRINTING OFFICE: 1976--766164/19 REGION NO. 6 
O

0 